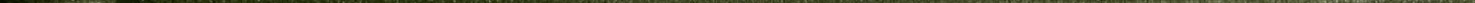




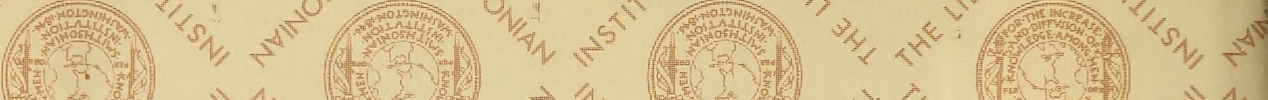

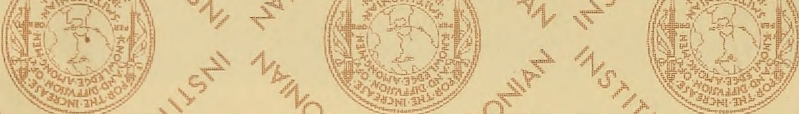
/s,

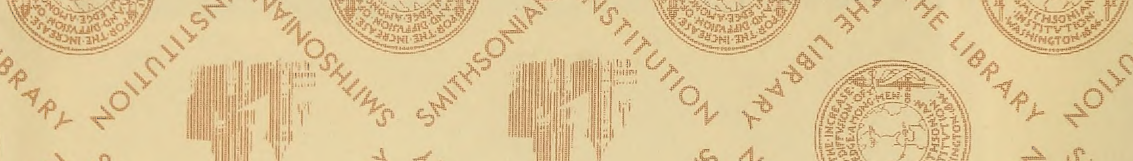

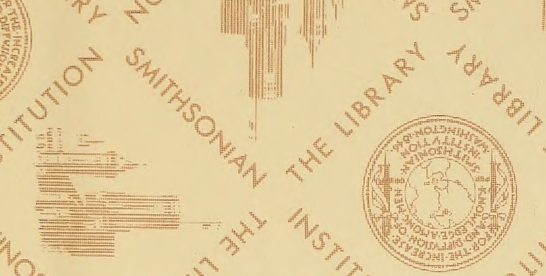

$\mathrm{O}_{\mathrm{S} / \mathrm{S}}$

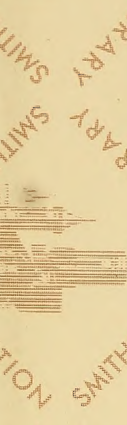
$e^{e^{4}}$

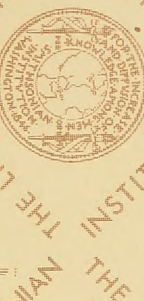

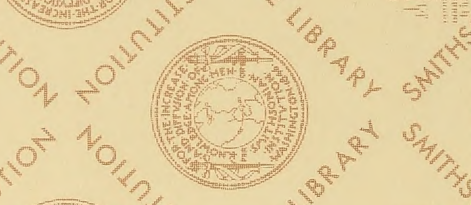

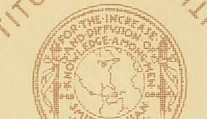
$\mathrm{s}^{5} \mathrm{r}$

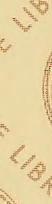
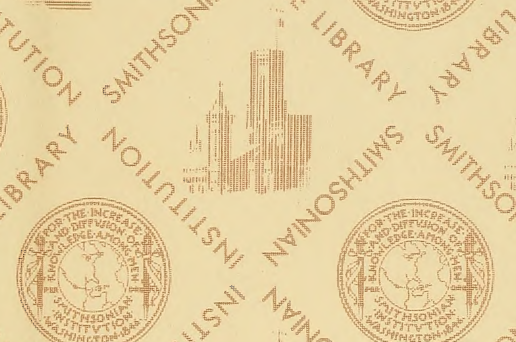
s.

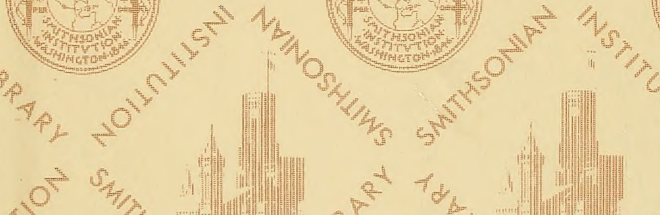

$\int_{0}+0^{\circ}$

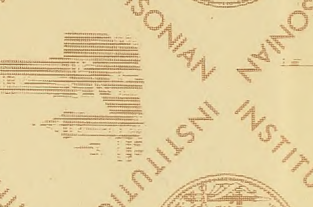

$$
v^{5} t^{1 / d_{b}}
$$

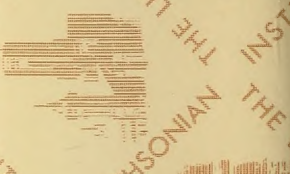
$\mathrm{C}^{2} \mathrm{~s}^{5}$

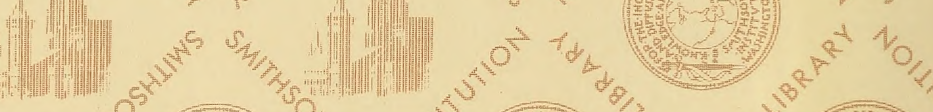

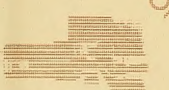
1) $\theta^{p^{2}} d^{4}$
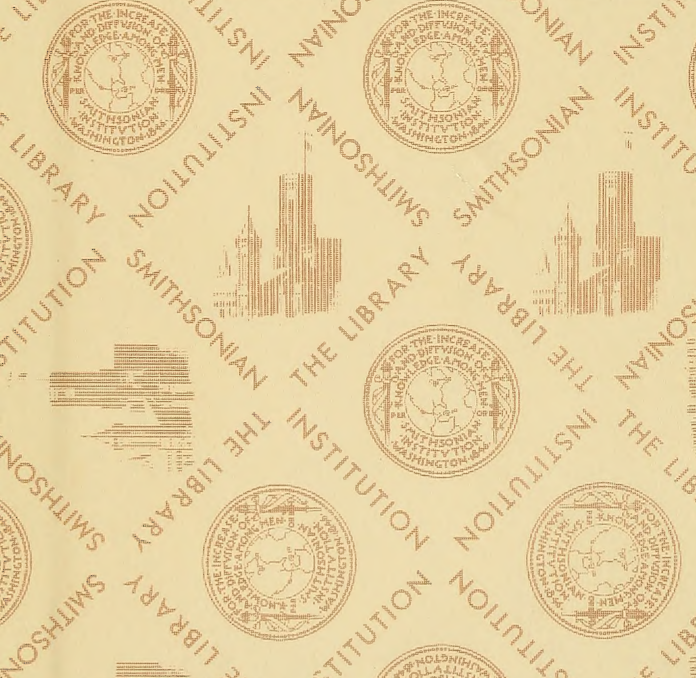

40

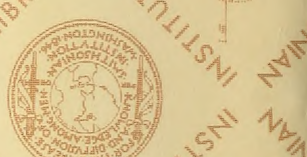

10

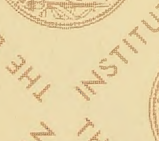

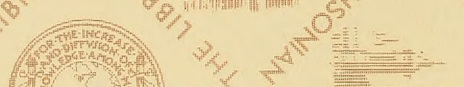

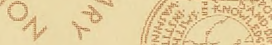

$\hat{s}_{p} v^{2}$ (1)

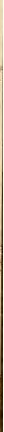




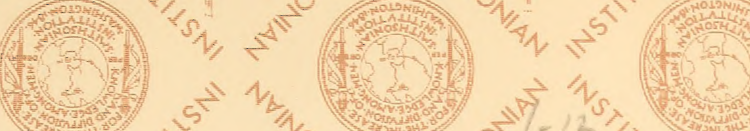
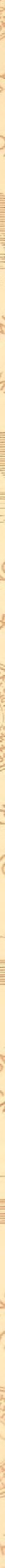



QE
26
$1937 x$
$1868 \quad$ ELEMENTS

OE

G E O L O G Y;

OR,

THE ANCIENT CHANGES OF THE EARTH AND ITS INHABITANTS AS ILLUSTRATED BY GEOLOGICAL MONUMENTS.

By SIR CHARLES LYELL, BART., F.R.S., ACZHOR OF "PRINCIPLES OF GEOLOGY,"

" reological EVIDENCES OF THE ANTiquity of MaN," etc.
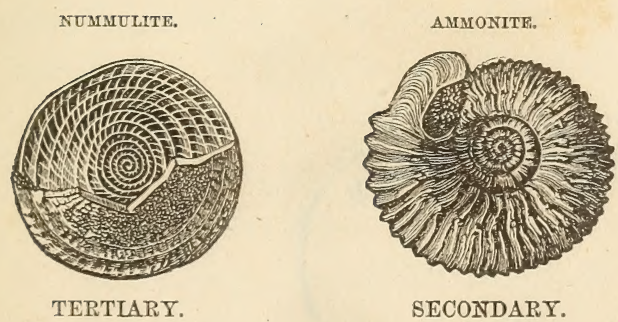

TRILOBITE.

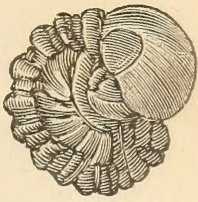

PRIMARY

SIXTH EDITION,

Grieatly Fonlarged, and Illustrated with 770 rdoodeuts.

NEW YORK:

D. APPLETON AND COMPANY, 90, 92 \& 94 GRAND STREET.

1868. 

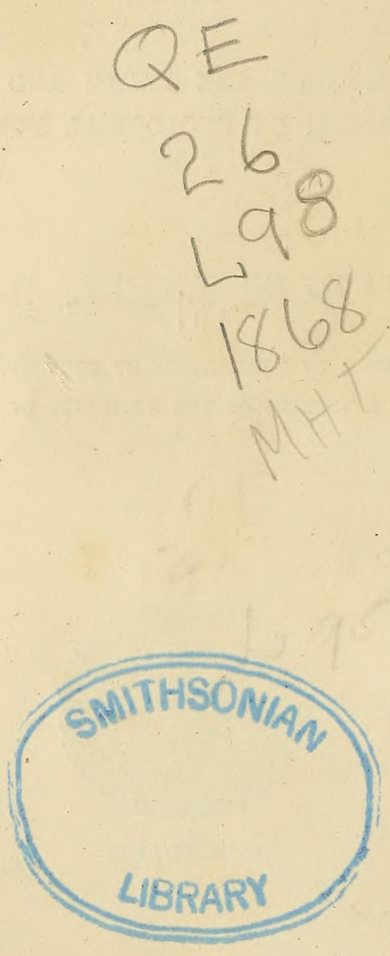


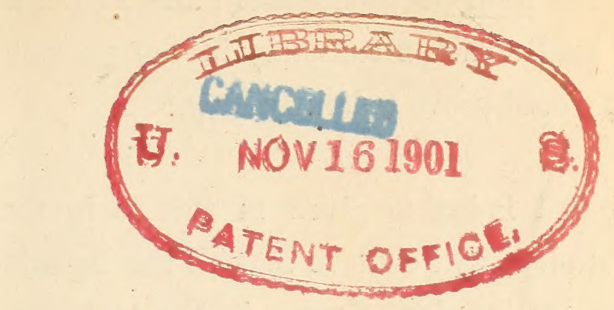

PREFACE.

THE last, or fifth edition of this work, was puolished in February, 1855, so that nearly ten years have since elapsed. I have allowed it to remain several years out of print, having been much occupied in travelling through various parts of Europe, and latterly in writing my "Geological Evidences of the Antiquity of Man," as well as the appendices to the second and third editions of that treatise. In the interval since 1855 I have published several supplements to the "Elements," the contents of which are now incorporated in this work. This and other new matter, illustrated by more than 50 new woodcuts, has added 130 pages to the volume, which has thus outgrown the dimensions usually assigned to a Manual. I have, therefore, restored to the book its original title of "The Elements of Geology," under which name it first appeared in 1838, when it consisted of an expansion of the fourth book of my "Principles of Geology," which had at that time reached a fifth edition.

The "Elements" were successively reëdited, and in each case to a great extent recast, in the years $1842,1851,1852$, and 1855. On former occasions I have given a list of the principal corrections and additions in which each new edition 
differed from its predecessor; but I shall not attempt to offer the reader such a summary in the present case, fearing that that would prove tediously long.*

A full index is given in this as in former editions, and the student will observe that all the organic remains of which there are woodcut figures in the text are printed in italics in the index.

\section{CHARLES LYELL.}

53 Harley Street, London, December 20, 1864.

* As it is impossible to enable the reader to recognize rocks and mmerals at sight by aid of verbal descriptions or figures, he will do well to obtain a wellarranged collection of specimens, such as may be procured from Mr. Tennant (149 Strand), teacher of Mineralogy at King's College, London. 


\section{CONTENTS.}

\section{Chapter I.-On the Different Classes of Rocks.}

Geology defined-Successive formation of the earth's crust-Classification of rocks according to their origin and age-Aqueous rocks-Their stratification and im bedded fossils-Volcanic rocks, with and without cones and craters-Plutonic rocks, and their relation to the volcanic-Metamorphic rocks, and their probable origin-The term "Primitive," why erroneously applied to the crystalline forma-

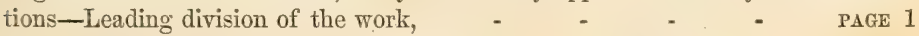

Chapter II.-Aqueous Rocks-Their Composition and Forms of Stratification.

Sineral composition of strata-Arenaceous rocks-Argillaceous-Calcareous-Gypsum-Forms of stratification-Original horizontality-Thinning out-Diagonal arrangement-Ripple mark,

CHAPTER III.-Arrangement of Fossits in Strata-Freshwater and Marine.

Successive deposition indicated by fossils-Limestones formed of corals and shells - Proofs of gradual increase of strata derived from fossils-Serpula attached to spatangus-Wood bored by teredina-Tripoli and semi-opal formed of infusoria -Chalk derived principally from organic bodies-Distinction of freshwater from marine formations-Genera of freshwater and land shells-Rules for recognizing marine testacea-Gyrogonite and chara-Freshwater fishes-Alternation of ma-

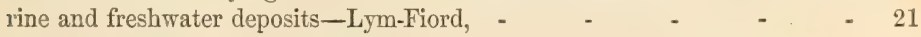

\section{Chapter IV.-Consolidation of Strata and Petrifaction of Fossils.}

Chemical and mechanical deposits-Cementing together of particles-Hardening by exposure to air-Concretionary nodules-Consolidating effects of pressure-Mineralization of organic remains-Impressions and casts how formed-Fossil wood - Göppert's experiments-Precipitation of stony matter most rapid where putrefaction is going on-Source of lime in solution-Silex derived from decomposition of felspar-Proofs of the lapidification of some fossils soon after burial, of others when much decayed,

Chapter V.-Elevation of Strata above the Sea-Horizontal and Inclined Stratification.

Why the position of marine strata, above the level of the sea, should be referred to the rising up of the land, not to the going down of the sea-Upheaval of extensive masses of horizontal strata-Inclined and vertical stratification-Anticlinal and synclinal lines-Bent strata in east of Scotland-Theory of folding by lateral movement-Creeps-Dip and strike-Structure of the Jura-Various 
forms of outcrop-Rocks broken by flexure-Inverted position of disturbed strata-Unconformable stratification-Hutton and Playfair on the same-Fractures of strata-Polished surfaces-Faults-Appearance of repeated alternations produced by them-Origin of great faults, - _ . . - PAGE 44

\section{Chapter VI.-Denudation.}

Denudation defined-Its amount equal to the entire mass of stratified deposits in the earth's crust-Horizontal sandstone denuded in Ross-shire-Levelled surface of countries in which great faults occur-Coalbrook Dale-Denuding power of the ocean during the emergence of land-Origin of valleys-Obliteration of seacliffs-Inland sea-cliffs and terraces in the Morea and Sicily-Limestone pillars at St. Mihiel, in France-in Canada-in the Bermudas,

66

\section{CHAPTER VII.-Alluvium.}

Alluvium described-Due to complicated causes-Of various ages, as shown in Auvergne-How distinguished from rocks in situ-Sandpipes in Chalk-Alluvial terraces caused by oscillation in the level of land, . _ _ _.. _ . . 79

\section{Chapter VIII - Chronological Classification of Rocks.}

Aqueous, plutonic, volcanic, and metamorphic rocks, considered chronologicallyLehman's division into primitive and secondary-Werner's addition of a transition class-Neptunian theory-Hutton on igneous origin of granite-How the name of primary was still retained for granite-The term "transition," why faulty - The adherence to the old chronological nomenclature retarded the progress of geology-New hypothesis intended to reconcile the igneous origin of granite to the notion of its high antiquity-Explanation of the chronological nomenclature adopted in this work, so far as regards primary, secondary, and

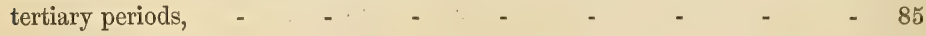

\section{Chapter IX.-On the Different Ages of the Aqueous Rocks.}

On the three principal tests of relative age--Superposition, mineral character, and fossils-Change of mineral character and fossils in the same continuous formation-Proofs that distinct species of animals and plants have lived at successive periods-Distinct provinces of indigenous species-Great extent of single provinces-Similar laws prevailed at successive geological periods-Relative importance of mineral and palæontological characters-Tests of age by included fragments-Frequent absence of strata of intervening periods-Principal groups of strata in western Europe-Tabular views of fossiliferous strata, - $\quad-92$

\section{Chapter X.-Recent and Post-Pliocene Periods.}

Recent and Post-pliocene periods-Terms defined-Formations of the Recent period-Modern littoral deposits containing works of art near Naples-Danish peat and shell mounds-Swiss lake-dwellings-Periods of stone, bronze, and iron-Form of human skulls of the Recent period-Post-pliocene formationsCoexistence of man with extinct mammalia-Higher and Lower-level Valleygravels-Loess or inundation mud of the Nile, Rhine, \&c.-Antiquity of Postpliocene Lake-terraces in Switzerland-Upraised marine strata in SardiniaOrigin of caverns-Remains of man and extinct quadrupeds in cavern deposits -Cave of Kirkdale-Reindeer period of south of France-Australian cavebreccias-Geographical relationship of the provinces of living vertebrata and those of extinct Post-pliocene species-Extinct struthious birds of New Zealand 
-Fluctuations of climate in Post-glacial period-Comparative longevity of species in the mammalia and testacea-Teeth of recent and Post-pliocene mam. malia,

PAGE 107

Chapter XI.-Post-pliocene Period, continued-Glacial Epoch.

Geographical distribution, form, and characters of glacial drift-Fundamental rocks, polished, grooved, and scratched-Abrading and striating action of glaciersMoraines, erratic blocks, and "Roches Moutonnées"-Alpine blocks on the Jura -Colossal size of ancient Swiss glaciers-Continental ice of Greenland-Ancient centres of the dispersion of erratics-Transportation of drift by floating icebergs-Bed of the sea furrowed and polished by the running aground of floating ice-islands-How to distinguish glacial drift of submarine from that of terrestrial origin,

GaAPTER XII.-Post-pliocene Period, continued-Glacial Epoch, concluded.

Glaciation of Scandinavia and Russia-Glaciation of Scotland-Marine shells in Scotch glacial drift-Their Arctic character-Rarity of organic remains in glacial deposits-Contorted strata in drift-Glaciation of Wales, England, and Ireland-Narine shells of Moel Tryfaen-Norfolk drift-Glacial formations of North America-How far of submarine origin-Many species of testacea and quadrupeds survived the glacial cold-Connection of the predominance of lakes with glacial action-Morainic lakes-Objections to the hypothesis of the erosion of large lake-basins by ice-Conversion of valleys of denudation into lakes by upward and downward movements-Action of ice in preventing the silting-up of lake-basins-How the bed of a sea where icebergs have abounded may, on emergence, afford lake-basins-General causes of change of climate-Submergence of the Sahara in the Post-pliocene period a cause of Alpine cold-Meteorites in drift,

\section{CHAPTER XIII.-Classification of Tertiary Formations.-Pliocene Period.}

Order of succession of sedimentary formations-Imperfection of the record-Defectireness and obscurity of the monuments greater in proportion to their antiquity -Reasons for studying the newer groups first-General principles of classification of tertiary strata-Detached formations scattered over Europe-Strata of Paris and London-More modern groups-Peculiar difficulties in determining the chronology of tertiary formations-Increasing proportion of living species of shells in strata of newer origin-Eocene, Miocene, and Pliocene terms explained -Formations of the Newer Pliocene period-Island of Ischia-Eastern base of Mount Etna-Newer Pliocene strata of great height and extent in Sicily-Formations of same age in the Upper Val d'Arno-Norwich Crag-Chillesford beds-Bridlington beds-Older Pliocene strata-Red Crag of Suffolk-White or coralline Crag-Successive refrigeration of climate proved by the pliocene shells of Suffolk and Norfolk-Antwerp Crag-Subapennine strata-Aralo-Caspian formations,

\section{CETAPTER XIV.-Miocene Period.}

Upper Miocene strata of France-Faluns of Touraine-Depth of sea and littoral character of fauna-Tropical climate implied by the testacea-Proportion of recent species of shells-Faluns more ancient than the Suffolk Crag-Varieties of Voluta Lamberti peculiar to Faluns and to Suffolk Crag-The same species are common to more than one geological Period-Lower Miocene strata of France-Remarks on classification, and where to draw the line of sepration 
between Miocene and Eocene strata-Relations of the Grès de Fontainebleau to the Faluns and to the Calcaire Grossier-Lower Miocene strata of Central France-Lacustrine strata of Auvergne-Indusial limestone-Fossil mammalia of the Limagne d'Auvergne-Freshwater strata of the Cantal-Its resemblance in some places to white chalk with flints-Proofs of gradual deposition-Miocene strata of Bordeaux and South of France-Upper Miocene strata of GersDryopithecus-Belgian and British Miocene formations-Edeghem beds near Antwerp-Diest sands of Belgium and contemporaneous iron-sands of North Downs-Upper Miocene beds of Belgium-Bolderberg-Lower Miocene strata of Kleyn Spawen-Hempstead beds, Isle of Wight-Bovey Tracey Lignites in Devonshire-Isle of Mull Leaf-beds-Miocene formations of GermanyMayence basin-Upper Miocene beds of Vienna basin-Lower Miocene of Croatia-Fossil Lepidoptera-Oligocene strata of Professor Beyrich-Miocene strata of Italy, - $\quad$ - $\quad \ldots \quad$ - $\quad$ - $\quad$ - $\quad$ - PAGE 212

ChAPTER XV.-Miocene F'ormations, continued.

Miocene Strata of Switzerland-Upper Miocene beds of CEningen-Importance of Fossil Plants-Heer's work on the Swiss Miocene flora-Plants and insects of Eningen imbedded in different seasons-Fossil fruits and flowers, as well as leaves-Middle or Marine Molasse of Switzerland-Lower Molasse, or Lower Miocene-Dense conglomerates and proofs of subsidence-Fossil plants of Lower Miocene period more tropical-Preponderance of arborescent speciesSupposed discordance in relative numbers of living species of plants and shells in Upper Miocene formations-Theory of a Miocene Atlantis-Whether the American plants abounding in the Miocene of Europe migrated by a westerly or an easterly ronte-Objections derived from depth and width of the AtlanticArguments in favor of a Trans-Asiatic migration-Miocene fossils of OregonAgreement of Miocene corals of the West Indies and Europe opposed to the theory of an Atlantic Continent-Upper Miocene formations of India-SubHimalayan or Siwâlik Hills-Older Pliocene and Miocene formations in the United States of America, -

\section{Chapter XVI.-Eocene Formations.}

Upper Eocene strata of England-Fluvio-marine series in the Isle of Wight and Hampshire-Successive groups of Eocene mammalia-Boundary-line between Lower Miocene and Eocene-Fossils of Barton Clay-British Middle EoceneShells, nummulites, fishes, and reptiles of the Bagshot and Bracklesham bedsVegetation of Middle Eocene period-Lower Eocene strata of England-Fossil plants and shells of the London Clay proper-Strata of Kyson in Suffolk-Plastic clays and sands-Thanet sands-Eocene formations of France-Gypseous series of Montmartre and extinct quadrupeds-Fossil footprints-Calcaire grossier-Miliolites-Lower Eocene in France-Nummulitic formations of Europe, Africa, and Asia - Their wide extent--Referable to the Middle Eocene periodEocene strata in the United States-Section at Claiborne, Alabama-Colossal cetacean--Orbitoidal limestone-Burr stone,

$-280$

\section{ChaPTER XVII.-Cretaceous Group.}

Lapse of time between the Cretaceous and Eocene periods-Whether certain formations in Belgium and France are of intermediate age-Pisolitic limestone-Divisions of the Cretaceous series in North-Western Europe-Maestricht beds-Chalk of Faxoe-White chalk-Its geographical extent and origin-Formed in an open and deep sea-How far derived from shells and corals-A similar rock now in progress in the depths of the Atlantic made up of Globigerinæ-Origin of Flint 
in Chalk-Siliceous Diatomaceæ of the Atlantic-By what intermittent action the alternate layers of white chalk and flint may have been caused-Potstones of Horstead-Isolated pebbles of quartz and foreign rocks in chalkFossils of the Upper Cretaceous rocks-Echinoderms, Mollusca, Bryozoa, Sponges-Upper Greensand and Gault-Blackdown beds-Flora of the Upper Cretaceous period-Fossil plants of Aix-la-Chapelle-Large proportion of Dicotyledonous Angiosperms-Their coexistence with large extinct genera of reptiles -Chalk of South of Europe-Hippurite limestone-Cretaceous rocks of the United States,

\section{ChAPTER XVIII.-Lower Cretaceous and Wealden Formations.}

Lower Greensand-Term "Neocomian"-Atherfield section, Isle of Wight-Fossils of Lower Greensand-Palæontological relations of the Upper and Lower Cretaceous strata-Wealden Formation-Freshwater strata intercalated between two marine groups-Weald Clay and Hastings Sand-Tunbriäge rocks-Fossil shells, fish, and plants of Wealden-Their relation to the Cretaceous type-Geographical extent of Wealden-Movements in the earth's crust to which the Wealden

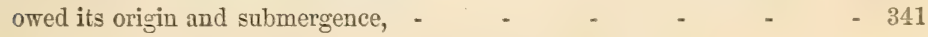

\section{ChaPTER XIX.-Denudation of the Chalk and Wealden.}

Physical geography of certain districts composed of Cretaceous and Wealden strata -Lines of inland chalk-cliffs on the Seine in Normandy-Outstanding pillars and needles of chalk-Denudation of the chalk and Wealden in Surrey, Kent, and Sussex-Chalk once continuous from the North to the South Downs-Anticlinal axis and parallel ridges-Longitudinal and transverse valleys-Chalk escarpments-Rise and denudation of the strata gradual-Ridges formed by harder, valleys by softer beds-At what periods the Weald Valley was denuded-Why no alluvium, or wreck of the chalk, in the central district of the Weald-Successive periods of marine denudation-The latest of these posterior to the Upper Miocene era-Elephant-bed, Brighton-Sangatte Cliff-The great escarpments and transverse valleys of the chalk mainly due to the waves and tides of the seaParoxysmal causes unnecessary for explaining the external configuration of the Wealden,

\section{CHAPTER XX.-Jurassic Group-Purbeck Beds and Oolite.}

The Purbeck beds a member of the Jurassic group-Subdivisions of that groupPhysical geography of the Oolite in England and France-Upper Oolite-Purbeck beds-New genera of fossil mammalia in the Middle Purbeck of DorsetshireDirt-bed or ancient soil-Fossils of the Purbeck beds-Portland stone and fossils - Lithographic stone of Solenhofen-Archæopteryx-Middle Oolite-Coral ragZoophytes-Nerinæan limestone-Diceras limestone-Oxford clay, Ammonites, and Belemnites-Kelloway Rock-Lower Oolite, Crinoideans-Great Oolite and Bradford clay-Stonesfield slate-Fossil mammalia-Resemblance to an Australian fauna-Northamptonshire slates-Yorkshire Oolitic coal-field-Brora coalFuller's earth-Inferior Oolite and fossils-Palæontological relations of the several subdivisions of the Oolitic group,

- 377

\section{CHAPTER XXI.-Jurassic Group, continued-Lias.}

Mineral character of Lias-Numerous successive Zones in the Lias, marked by distinct fossils, without unconformity in the stratification, or change in the mineral character of the deposits-Name of Gryphite limestone-Fossil shells and fishRadiata-Ichthyodorulites-Reptiles of the Lias-Ichthyosaur and Plesiosaur- 
Marine Reptile of the Galapagos Islands-Sudden destruction and burial of fossil animals in Lias-Fluvio-marine beds in Gloucestershire, and insect limestone -Fossil plants-Origin of the Oolite and Lias, and of alternating calcareous and

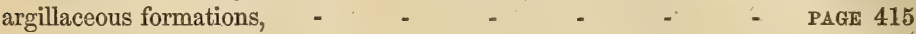

\section{Chapter XXII.-Trias or New Red Sandstone Group.}

Distinction between New and Old Red Sandstone-Between Upper and Lower New Red-The Trias and its three divisions-Most largely developed in GermanyRecognition of a Marine equivalent of the Upper-Trias in the Austrian AlpsTrue position of the St. Cassian and Hallstadt Beds-800 new species of triassic Mollusca and Radiata-Links thus supplied for connecting the Palæozoic and Neozoic faunas-Keuper and its fossils-Muschelkalk and fossils-Fossil plants of the Bunter-Triassic group in England-Bone-bed of Axmouth and AustRed Sandstone of Warwickshire and Cheshire-Footsteps of Cheirotherium in England and Germany-0steology of the Labyrinthodon-Whether this Batrachian was identical with Cheirotherium-Dolomitic Conglomerate of BristolOrigin of Red Sandstone and Rock-salt-Hypothesis of saline volcanic exhalations-Theory of the precipitation of salt from inland lakes or lagoons-Saliness of the Red Sea-Triassic coal-field of Eastern Virginia, near Richmond-New Red Sandstone in the United States-Fossil footprints of birds and reptiles in the valley of the Connecticut-Antiquity of the Red Sandstone containing themTriassic mammifer of North Carolina,

\section{ChaPTER XXIII.-Permian or Magnesian Limestone Group.}

Fossils of Magnesian Limestone and Lower New Red distinct from the TriassicTerm "Permian"-English and German equivalents-Marine shells and corals of English Magnesian Limestone-Palæoniscus and other fish of the marl-slateZechstein and Rothliegendes of Thuringia-Permian Flora-Its generic affinity to the Carboniferous-Psaronites or tree-ferns, - $\quad-\quad-\quad-\quad-458$

\section{Chapter XXIV.-The Coal, or Carboniferous Group.}

Carboniferous strata in the southwest of England-Superposition of Coal-measures to Mountain Limestone-Departure from this type in North of England and Scotland-Carboniferous series in Ireland-Section in South Wales-Under-clays with Stigmaria-Carboniferous Flora-Ferns, Lepidodendra, Equisetaceæ, Calamites, Asterophyllites, Sigillariæ, Stigmariæ-Coniferæ-Sternbergia-Trigonocarpon-Grade of Coniferæ in the Vegetable Kingdom-Absence of Angiosperms -Coal, how formed-Erect fossil trees-Parkfield Colliery-St. Etienne Coalfield-Oblique trees or snags-Fossil forests in Nova Scotia-Rain-prints-Purity of the Coal explained-Time required for the accumulation of the Coal-measures -Brackish-water and marine strata-Crustaceans of the Coal-Origin of Clay

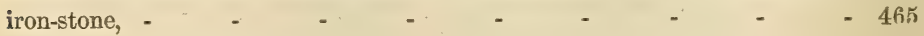

Chapter XXV.-Carboniferous Group, continued.

Coal-fields of the United States-Section of the country between the Atlantic and Mississippi-Position of land in the carboniferous period eastward of the Alle ghanies-Mechanically formed rocks thinning out westward, and limestones thickening-Uniting of many coal-seams into one thick bed-Horizontal coal at Brownsville, Pennsylvania-Vast extent and continuity of single seams of coal-Ancient river-channel in Forest of Dean coal-field-Climate of carboniferous period-Insects in coal-Rarity of air-breathing animals-Great number of fossil fish-First discovery of the skeletons of fossil reptiles-Foot- 
prints of reptilians-First land-shell found-Rarity of air-breathers, whether vertebrate or invertebrate, in Coal-measures-Mountain limestone-Its corals and marine shells,

\section{ChaPTER XXVI.-Old Red Sandstone, or Devonian Group.}

Old Red Sandstone of the Borders of Wales-Of Scotland and the South of Treland-Fossil Devonian plants at Kilkenny-Holoptychius of the Middle and Cephataspis of the Lower Old Red of Forfarshire-Pterygotus and supposed eggs of Crustaceans-Northern type of Old Red in Scotland-Classification of the Ichthyolites of the Old Red, and their relation to living types-Distinct lithological type of Old Red in Devon and Cornwall-Term "Devonian"-Organic remains of intermediate character between those of the Carboniferous and Silurian systems-Deronian series of England and the Continent-Upper Devonian rocks and fossils-Middle-Lower-Old Red Sandstone of Russia-Preponderance of Brachiopoda-Devonian strata of the United States and CanadaCoral reefs at the falls of the Ohio-Gaspé Sandstone-Vegetation of the Devonian period, -

\section{Chapter XXVII.-Silurian and Cambrian Groups.}

Silurian strata formerly called Transition-Term "Grauwacke"-Subdivisions of Upper, Middle, and Lower Silurians-Ludlow formation and fossils-Oldest known remains of fossil fish-Wenlock formation, corals, cystideans, trilobitesMiddle Silurian or Llandovery Beds-Lower Silurian rocks-Caradoc and Bala Beds-Upper and Lower Llandeilo formations-Cystideæ-Trilobites-Graptolites-Vast thickness of Lower Silurian strata, sedimentary and volcanic, in Wales-Foreign Silurian equivalents in Europe-Silurian strata of the United States-Amount of specific agreement of fossils with those of Europe-Canadian equivalents-Whether Silurian strata of deep-sea origin-Cambrian rocksClassification and nomenclature-Barrande's primordial fauna-Upper Cambrian of Wales-Tremadoc' slates-Lingula flags-Lower Cambrian-Longmynd group-Oldest organic remains known in Europe-Foreign equivalents of the Cambrian group-Primordial zone of Bohemia-Characteristic trilobitesMetamorphosis of trilobites-Alum schists of Sweden and Norway-Potsdam sandstone of United States and Canada-Footprints near Montreal-Quebec strata and Huronian rocks-Minnesota trilobites-Rocks older than the Cambrian-Laurentian group, Upper and Lower-Oldest known fossil, Eozoon Canadense-No remains of vertebrate animals known in strata below the Upper Silurian-Progressive discovery of vertebrata in older rocks-Theoretical inferences from the rarity or absence of vertebrata in the most ancient fossiliferous formations, -

- 549

\section{CHAPTER XXVIII.-Volcanic Rocks.}

Trap Rocks-Name, whence derived-Their igneous origin at first doubted-Their general appearance and character-Volcanic cones and craters, how formedMineral composition and texture of volcanic rocks-Varieties of felsparHornblende and augite-Isomorphism-Rocks, how to be studied-Basalt, trachyte, greenstone, porphyry, scoria, amygdaloid, lava, tuff-AgglomerateLaterite-Alphabetical list, and explanation of names and synouyms, of volcanic rocks-Table of the analyses of minerals most abundant in the volcanic and hypogene rocks

ChaPter XXIX.-Volcanic Rocks, continued.

Trap dikes-sometimes project-sometimes leave fissures vacant by decomposition-Branches and veins of trap-Dikes more crystalline in the centre- 
Strata altered at or near the contact-Obliteration of organic remains-Conversion of chalk into marble-Trap interposed between strata-Columnar and globular structure-Relation of trappean rocks to the products of active volcanoes-Form, external structure, and origin of volcanic mountains-Craters and Calderas-Sandwich Islands-Lava flowing underground-Truncation of cones-Javanese calderas-Canary Islauds-Structure and origin of the Caldera of Palma-Older and newer volcanic rocks in, unconformable-Aqueous conglomerate in Palma-Hypothesis of upheaval considered-Slope on which stony lavas may form-Extent and nature of aqueous erosion in Palma-Island of St. Paul in the Indian Ocean-Peak of Teneriffe, and ruins of older coneMadeira-Its volcanic rocks, partly of marine, and partly of subaërial originCentral axis of eruptions-Varying dip of solid lavas near the axis, and further from it-Leaf-bed, and fossil land-plants-Central valleys of Madeira not craters, or calderas, -

\section{ChAPTER XXX.-On the different Ages of the Volcanic Rocks.}

Tests of relative age of volcanic rocks-Tests by superposition and intrusionTest by alteration of rocks in contact-Test by organic remains-Test of age by mineral character-Test by included fragments-Volcanic rocks of the Post Pliocene period-Basalt of the Bay of Trezza in Sicily-Post-Pliocene volcanic rocks near Naples-Dikes of Somma, - _ - - _ $\quad-655$

\section{Chapter XXXI.—On the different Ages of the Volcanic Rocks, continued.}

Volcanic rocks of the Newer Pliocene period-Val di Noto-Sicilian dikes-Region of Olot in Catalonia-Volcanic rocks of the Older Pliocene period-TuscanyRome-Voleanic region of Olot in Catalonia-Cones and lava-currents-Ravines and ancient gravel-beds-Jets of air called Bufadors-Age of the Catalonian voleanoes-Upper Miocene period-Volcanic archipelagoes of Madeira, the Canaries, and the Azores-Lower Miocene period-Brown-coal of the Eifel and contemporaneous trachytic breccias-Age of the brown-coal-Peculiar characters of the voleanoes of the upper and lower Eifel-Lake Craters-Trass-Hungarian rolcanoes, .

Chapter XXXII.-On, the different Ages of the Volcanic Rocks, continued.

Volcanic rocks of the Tertiary period, continued-Extinct voleanoes of Auvergne-Mont Dor-Breccias and alluviums of Mont Perrier, with bones of quadrupedsRiver dammed up by lava-current-Range of minor cones from Auvergne to the Vivarais-Monts Dôme-Puy de Côme-Puy de Pariou-Cones not denuded by general flood-Lower Miocene volcanic rocks near Clermont-Hill of GergoviaEocene volcanic rocks of Monte Bolca-Trap of Cretaceous periqad-Oolitic period-New Red Sandstone period-Carboniferous period-" Rock and Spindle" near St. Andrew's-Old Red Sandstone period-Silurian period-Cambrian pe-

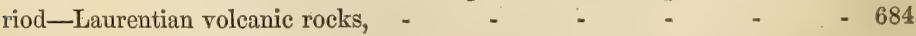

\section{Chapter XXXIII.-Plutonic Rocks-Granite.}

General aspect of granite-Decomposing into spherical masses-Rude columnar structure-Analogy and difference of volcanic and plutonic formations-Minerals in granite, and their arrangement-Graphic and porphyritic granite-Mutual penetration of crystals of quartz and felspar-Occasional minerals-SyeniteSyenitic, talcose, and schorly granites-Eurite-Passage of granite into trapExamples near Christiania and in Aberdeenshire-Analogy in composition of 
trachyte and granite-Granite reins in Glen Tilt, Cornmall, the Talorsine, and other countries-Different composition of veins from main body of graniteMetalliferous reins in strata near their junction with granite-Apparent isolation of nodules of granite-Quartz veins-Whether plutonic rocks are erer overlying -Their exposure at the surface due to denudation,

PAGE 702

\section{Chupter XXXIV.-On the different Ages of the:Plutonic Rocks.}

Difficulty in ascertaining the precise age of a plutonic rock-Test of age by relative position-Test by intrusion and alteration-Test by mineral composition-Test by included fragments-Recent and Pliocene plutonic rocks, why invisible-Tertiary plutonic rocks in the Andes-Granite altering Cretaceous rocks-Granite altering Lias in the Alps and in Skye-Granite of Dartmoor altering Carboniferous strata-Granite of the Old Red Sandstone period-Syenite altering Silurian strata in Norway-Blending of the same with gneiss-Most ancient plutonic rocks-Granite protruded in a solid form-On the probable age of the granites

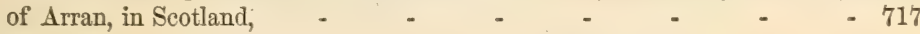

\section{CHAPTER XXXV.-Metamorphic Rocks.}

General character of metamorphic rocks-Gneiss-Hornblende-schist-Mica-schistClay-slate-Quartzite-Chlorite-schist-Metamorphic limestone-Alphabetical list and explanation of the more abundant rocks of this family-Origin of the metamorphic strata-Their stratification-Fossiliferous strata near intrusive masses of granite converted into rocks identical with different members of the metamorphic series-Arguments hence derired as to the nature of plutonic action-Time may enable this action to perrade denser masses-From what kinds of sedimentary rock each variety of the metamorphic class may be derived-Certain objections to the metamorphic theory considered-Partial conversion of Eocene

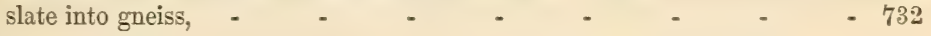

\section{ChAPTER XXXVI.-Metamorphic Rocks, continued.}

Definition of joints, slaty clearage, and foliation-Supposed causes of these structures-Mechanical theory of cleavage-Condensation and elongation of slate rocks by lateral pressure-Supposed combination of crystalline and mechanical forces-Lamination of some volcanic rocks due to motion-Whether the foliation of the crsstalline schists be usually parallel with the original planes of stratification-Examples in Norway and Scotland-Foliation in homogeneous rocks may coincide with planes of clearage, and in uncleared rocks with those of stratification-Causes of irregularity in the planes of foliation, - $\quad-746$

\section{CHAPTER XXXVII.-On the different Ages of the Metamorphic Rocks.}

Age of each set of metamorphic strata trofold-Test of age by fossils and mineral character not arailable-Test by superposition ambiguous-Conversion of dense masses of fossiliferous strata into metamorphic rocks-Limestone and shale of Carrara-Metamorphic strata of older date than the Cambrian rocks-Others of Lower Silurian origin-Others of the Jurassic and Eocene periods in the Alps of Switzerland and Saroy-Why scarcely any of the risible crystalline strata are very modern-Order of succession in metamorphic rocks-Cniformity of mineral character- Why the metamorphic strata are less calcareous than the fossiliferous, 


\section{Chapter XXXVIII.-Mineral Veins.}

Werner's doctrine that mineral veins were fissures filled from above-Veins of segregation-Ordinary metalliferous veins or lodes-Their frequent coincidence with faults-Proofs that they originated in fissures in solid rock-Veins shifting other veins-Polishing of their walls or "slicken-sides"-Shells and pebbles in lodes-Evidence of the successive enlargement and reopening of veins-Fournet's observations in Auvergne-Dimensions of veins-Why some alternately swell out and contract-Filling of lodes by sublimation from below-Chemical and electrical action-Relative age of the precious metals-Copper and lead veins in Ireland older than Cornish tin-Lead vein in lias, GlamorganshireGold in Russia, California, and Australia-Connection of hot springs and mineral veịns-Concluding remarks, - - - - - - PAGE 767 


\title{
ELEMENTS OF GEOLOGY
}

\author{
CHAPTER I. : \\ ON THE DIFFERENT CLASSES OF ROCKS.
}

Geology defined-Successive formation of the earth's crust-Classification of rocks according to their origin and age-Aqueous rocks-Their stratification and imbedded fossils-Volcanic rocks, with and without cones and cratersPlutonic rocks, and their relation to the volcanic-Metamorphic rocks and their probable origin-The term primitive, why erroneously applied to the crystalline formations-Leading division of the work.

OF what materials is the earth composed, and in what manner are these materials arranged? These are the first inquiries with which Geology is occupied, a science which derires its name from the Greek $\gamma \tilde{\eta}$, ge, the earth, and $\lambda_{0}$ os, logos, a discourse. Previously to experience, we might hare imagined that investigations of this kind would relate exclusively to the mineral kingdom, and to the various rocks, soils, and metals, which occur upon the surface of the earth, or at various depths beneath it. But, in pursuing such researches, we soon find ourselves led on to consider the successire changes which hare taken place in the former state of the earth's surface and interior, and the causes which have given rise to these changes ; and, what is still more singular and unexpecterl, we soon become engaget in researches into the history of the animate creation, or of the various tribes of animals and plants which have, at different perions of the past, inhabited the globe.

All are aware that the solid parts of the earth consist of distinct substances, such as clay, chalk, sand, limestone, coal, slate, granite, and the like; but previously to observation it is commonly imagined that all these had remained from the first in the state in which we now see them,- - that they were created in their present form, and in their present position. The greologist soon comes to a different conclusion, discovering proofs that the external parts of the earth were not all produced in the beginning of things, in the state in which we now behold them, nor in an instant of time. On the contrary, he can show that they have acruired their actual configuration and condition gradualls, under a great rariety 
of circumstances, and at successive periods, during each of which distinct races of living beings have flourished on the land and in the waters, the remains of these creatures still lying buried in the crust of the earth.

By the "earth's crust," is meant that small portion of the exterior of our planet which is accessible to human observation, or on which we are €nabled tc reason by observations made at or near the surface. These reasonings may extend to a depth of several miles, perhaps ten miles; and even then it may be said, that such a thickness is no more than $\frac{1}{400}$ part of the distance from the surface to the centre. The remark is just; but although the dimensions of such a crust are, in truth, insignificant when compared to the entire globe, yet they are vast, and of magnificent extent in relation to man, and to the organic being's which people our globe. Referring to this standard of magnitude, the geologist may admire the ample limits of his domain, and admit, at the same time, that not only the exterior of the planet, but the entire earth, is but an atom in the midst of the countless worlds surveyed by the astronomer.

The materials of this crust are not thrown together confusedly; but distinct mineral masses, called rocks, are found to occupy definite spaces, and to exhibit a certain order of arrangement. The term rock is applied indifferently by geolngists to all these substances, whether they be soft or stony, for clay and sand are included in the term, and some have even brought peat under this denomination. Our older writers endeavored to avoid offering such violence to our language, by speaking of the component materials of the earth as consisting of rocks and soils. But there is often so insensible a passage from a soft and incoherent state to that of stone, that geologists of all countries have found it indispensable to have one technical term to include both, and in this sense we find roche applied in French, rocca in Italian, and felsart in German. The beginner, however, must constantly bear in mind, that the term rock by no means implies that a mineral mass is in an indurated or stony condition.

The most natural and convenient mode of classifying the various rocks which compose the earth's crust, is to refer, in the first place, to their origin, and in the second to their relative age. I shall therefore begin by endeavoring briefly to explain to the student how all rocks may be divided into four great classes by reference to their different origin, or, in other words, by reference to the different circumstances and causes by which they have been produced.

The first two divisions, which will at once be understood as natural, are the aqueous and volcanic, or the products of watery and those of igneous action at or near the surface.

Aqueous rocks.-The aqueous rocks, sometimes called the sedimentary, or fossiliferous, cover a larger part of the earth's surface than any others. These rocks are stratified, or divided into distinct layers, or strata. The term stratum means simply a bed, or any thing spread out or strewed over a given surface; and we infer that these strata have been generally spread out by the action of water, from what we daily see taking place near the mouths of rivers, or on the land during temporary inundations. 
For, whenever a running stream charged with mud or sand, has its velocity checked, as when it enters a lake or sea, or overflows a plain, the sediment, previously held in suspension by the motion of the water sinks, by its own gravity, to the bottom. In this manner layers of mud and sand are thrown down one upon another.

If we drain a lake which has been fed by a small stream, we frequently find at the bottom a series of depusits, disposed with considerable regularity, one above the other ; the uppermost, perhaps, may be a stratum of peat, next below a more dense and solid variety of the same material ; still lower a bed of shell-marl, alternating with peat or sand, and then other będs of marl, divided by layers of clay. Now, if a second pit be sunk through the same continuous lacustrine formation, at some distance from the first, nearly the same series of beds is commonly met with, yet with slight variations; some, for example, of the layers of sand, clay, or marl, may be wanting, one or more of them having thinned out and given place to others, or sometimes one of the masses first examined is observed to increase in thickness to the exclusion of other beds.

The term "formation," which I have used in the above explanation, expresses in gुeology any assemblage of rocks which have some character in common, whether of origin, age, or composition. Thus we speak of stratified and unstratified, freshwater and marine, aqueous and volcanic, ancient and modern, metalliferous and non-metalliferous formations.

In the estuaries of large rivers, such as the Ganges and the Mississippi, we may observe, at low water, phenomena analogous to those of the drained lakes above mentioned, but on a grander scale, and extending over areas several hundred miles in length and breadth. When the periodical inundations subside, the river hollows out a channel to the depth of many yards through horizontal beds of clay and sand, the ends of which are scen exposed in perpendicular cliffs. These beds vary in their mineral composition, or color, or in the fineness or coarseness of their particles, and some of them are occasionally characterized by containing drift-rrood. At the junction of the river and the sea, especially in litgoons nearly separated by sand-bars from the ocean, deposits are often formed in which brackish-water and salt-water shells are included.

In Egrpt, where the Nile is almays adding to its delta by filling up part of the Mediterranean with mud, the newly-deposited sediment is stratified, the thin layer thromn down in one season differing slightly in color from that of a prerious year, and being separable from it, as has been observed in excavations at Cairo, and other places.*

When beds of sand, clay, and marl, containing shells and vegetable matter, are found arranged in a similar manner in the interior of the earth, we ascribe to them a similar origin; and the more we examine their characters in minute detail, the more exact do we find the resernblance. Thus, for example, at various heights and depths in the earth, nud often far from seas, lakes, and rivers, we meet with layers of rounded

* See Principles of Geology, by the Author, Index, "Nile," "Rivers," \& c. 
pebbles composed of flint, limestone, granite, or other rocks, resembling the shingles of a sea-beach or the gravel in a torrent's bed. Such layers of pebbles frequently alternate with others formed of sand or fine sediment, just as we may see in the channel of a river descending from hills bordering a coast, where the current sweeps down at one season coarse sand and gravel, while at another, when the waters are low and less rapid, fine mud and sand alone are carried seaward.*

If a stratified arrangement, and the rounded form of pebbles, are alone sufficient to lead us to the conclusion that certain rocks originated under water, this opinion is farther confirmed by the distinct and independent evidence of fossits, so abundantly included in the earth's crust. By a fossil is meant any body, or the traces of the existence of any body, whether animal or vegetable, which has been buried in the earth by natural causes. Now the remains of animals, especially of aquatic species, are found almost everywhere imbedded in stratified rocks, and sometimes, in the case of limestone, they are in such abundance as to constitute the entire mass of the rock itself. Shells and corals are the most frequent, and with them are often associated the bones and teeth of fishes, fragments of rood, impressions of leaves, and other organic substances. Fossil shells, of forms such as now abound in the sea, are met with far inland, both near the surface, and at great depths below it. They occur at all heights above the level of the ocean, having been obserred at elevations of more than 8000 feet in the Pyrenees, 10,000 in the Alps, 13,000 in the Andes, and above 18,000 feet in the Himalaya. $\dagger$

These shells belong mostly to marine testacea, but in some places exclusively to forms characteristic of lakes and rivers. Hence it is concluded that some ancient strata were deposited at the bottom of the sea, and others in lakes and estuaries. ...

When geology was first cultivated, it was a general belief, that these marine shells and other fossils were the effects and proofs of the deluge of Noah; but all who hare carefuily inrestigated the phenomena have long rejected this doctrine. A transient flood might be supposed to leave behind it, here and there upon the surface, scattered heaps of mud, sand, and shingle, with shells confusedly intermixed; but the strata containing fossils are not superficial deposits, and do not simply cover the earth, but constitute the entire mass of mountains. Nor are the fossils mingled without reference to the original habits and natures of the creatures of which they are the memorials; those, for example, being found associated together which lived in deep or in shallow water, near the shore or far from it, in brackish or in salt water.

It has, moreover, been a favorite notion of some modern writers, who were aware that fossil bodies could not all be referred to the deluge, that they, and the strata in which they are entombed, might have been deposited in the bed of the ocean during the period which intervened

* See p. 18, fig. 7 .

f Capt. R. J. Strachey found oolitic fossils 18,400 feet high in the Himalaya 
between the creation of man and the deluge. They have.iniagined that the antediluvian bed of the ocean, after having been the receptacle of many stratified deposits, became converted, at the time of the flood, into the lands which we inhabit, and that the ancient continents were at the same time submerged, and became the bed of the present seas. This hypothesis, although preferable to the diluvial theory before alluded to, since it admits that all fossiliferous strata were successively thrown down from water, is yet wholly inadequate to explain the repeated revolutions which the earth has undergone, and the signs which the existing continents exhibit, in most regions, of having emerged from the ocean at an era far more remote than four thousand years from the present time. Ample proofs of these reiterated revolutions will be given in the sequel, and it will be seen that many distinct sets of salimentary strata, hundreds and sometimes thousands of feet thick, are piled one upon the other in the earth's crust, each containing peculiar fossil animals and plants of species distinguishable for the most part from all those now living. The mass of some of these strata consists almost entirely of corals; others are made up of shells, others of plants turned into coal, while some are without fossils. In one set of strata the species of fossils are marine; in another, lying immediately above or below, they as clearly prove that the deposit was formed in a lake or brackish estuary. When the student has more fully examined into these appearances, he will become convinced that the time required for the origin of the rocks composing the actual continents must have been far greater than that which is conceded by the theory above alluded to; and likewise that no one universal and sudden conversion of sea into land will account for geological appearances.

We have now pointed out one great class of rocks, which, however they may vary in mineral composition, color, grain, or other characters, external and internal, may nerertheless be grouped together as having a common origin. They have all been formed under water, in the same manner as modern accumulations of sand, mud, shingle, banks of shells, reefs of coral, and the like, ancl-are all characterized by stratification or fossils, or by both.

Volcanic rocks.-The division of rocks which we may next consider are the volcanic, or those which have been produced at or near the surface whether in ancient or modern times, not by water, but by the action of fire or subterranean heat. These rocks are for the most part unstratified, and are devoid of fossils. They are more partially distributed than aqueous formations, at least in respect to horizontal extension. Among those parts of Europe where they exhilit characters not to be mistaken, I may mention not only Sicily and the country round Naples, but $\Lambda u$ vergne, Velay, and Vivarais, now the departments of Puy de Dome, Haute Loire, and Arlêclee, towards the centre and south of France, in which are several hundred conical hills having the forms of modern rolcanoes, with craters more or less perfect on many of their summits. These cones are composed moreover of lava, sand, and ashes, similar to those 
of active volcanoes. : Streams of lava may sometimes be traced from the cones into the adjoining valleys, where they have choked up the ancient channels of rivers with solid rock, in the same manner as some modern flows of lava in Iceland have been known to do, the rivers either flowing beneath or cutting out a narrow passage on one side of the lava. Although none of these French volcanoes have been in activity within the period of history or tradition, their forms are often very perfect. Some, however, have been compared to the mere skeletons of volcanoes, the rains and torrents having washed their sides, and removed all the loose sand and scoriæ, leaving only the harder and more solid materials. By this erosion, and by earthquakes, their internal structure has occasionally been laid open to view, in fissures and ravines ; and we then behold not only many successive beds and masses of porous lava, sand, and scorire, but also perpendicular walls, or dikes, as they are called, of volcanic rock, which have burst through the other materials. Such dikes are also observed in the structure of Vesuvius, Etna, and other active volcanoes. They have been formed by the pouring of melted matter, whether from above or below, into open fissures, and they commonly traverse deposits of volcanic tuff, a substance produced by the showering down from the air, or incumbent waters, of sand and cinders, first shot up from the interior of the earth by the explosions of volcanic -gases.

Besides the parts of France above alluded to, there are other countries, as the north of Spain, the south of Sicily, the Tuscan territory of Italy, the lower Rhenish provinces, and Hungary, where spent volcanoes may be seen, still preserving in many cases a conical form, and having craters and often lava-streams connected with them.

There are also other rocks in England, Scotland, Ireland, and almost every country in Europe, which we infer to be of igneous origin, although they do not form hills with cones and craters. Thus, for example, we feel assured that the rock of Staffa, and that of the Giants' Causeway, called basalt, is volcanic, because it agrees in its columnar structure and mineral composition with streams of lava which we know to have flowed from the craters of volcanoes. We find also similar basaltic and other igneous rocks associated with beds of tuff in various parts of the British Isles, and forming dikes, such as have been spoken of; and some of the strata through which these dikes cut are occasionally altered at the point of contact, as if they had been exposed to the intense heat of melted matter.

The absence of cones and craters, and long narrow streams of superficial lava, in England and many other countries, is principally to be attributed to the eruptions having been submarine, just as a considerabie proportion of volcanoes in our own times burst out beneath the sea. But this question must be enlarged upon more fully in the chapters on Igneous Rocks, in which it will also be shown, that as different sedimentary formations, containing each their characteristic fossils, have beer deposited at successive periods, so also volcanic sand and scoriæ 
have been thrown out, and lavas have flowed over the land or bed of the sea, at many different epochs, or have been injected into fissures; so that the igneous as well as the aqueous rocks may be classed as a chronological series of monuments, throwing light on a succession of events in the history of the earth.

Plutonic rocks (Granite, \&c.).-We have now pointed out the existence of two distinct orders of mineral masses, the aqueous and the volcanic: but if we examine a large portion of a continent, especially if it contain within it a lofty mountain range, we rarely fail to discover two other classes of rocks, very distinct from either of those above alluded to, and which we can neither assimilate to deposits such as are now accumulated in lakes or seas, nor to those generated by ordinary volcanic action. The members of both these divisions of rocks agree in being highly crystalline and destitute of organic remains. The rocks of one division have been called plutonic, comprehending all the granites and certain porphyries, which are nearly allied in some of their characters to volcanic formations. The members of the other class are stratified and often slaty, and have been called by some the crystalline schists, in which group are included gneiss, micaceous-schist (or mica-slate), hornblende-schist, statuary marble, the finer kinds of roofing slate, and other rocks afterwards to be described.

As it is admitted that nothing strictly analogous to these crystalline productions can now be seen in the progress of formation on the earth's surface, it will naturally be asked, on what data we can find a place for them in a system of classification founded on the origin of rocks. I cannot, in reply to this question, pretend to give the student, in a few words, an intelligible account of the long chain of facts and reasonings by which geologists have been led to infer the analogy of the rocks in question to others now in progress at the surface. The result, however, may be briefly stated. All the various kinds of granite, which constitute the plutonic family, are supposed to be of igneous origin, but to have been formed under great pressure, at a considerable depth in the earth, or sometimes, perhaps, under a certain weight of incumbent water. Like the lava of volcanoes, they have been melted, and have afterwards cooled and crystallized, but with extreme slowness, and under conditions very different from those of bodies cooling in the open air. Hence they differ from the volcanic rocks, not only by their more crystalline texture, but also by the absence of tuffs and breccias, which are the products of eruptions at the earth's surface, or beneath seas of inconsiderable depth. They differ also by the absence of pores or cellular cavities, to which the expansion of the entangled gases gives rise in ordinary lava.

Although granite lias often piercerl through other strata, it has rarely, if ever, been observed to rest upon them, as if it had overflowed. But as this is continually the case with the volcanic rocks, they have been styled, from this peculiarity, "overlying" by Dr. MacCulloch: 
and Mr. Necker has proposed the term "underlying" for the granites, to designate the opposite mode in which they almost invariably present themselves.

Metamorphic, or stratified crystalline rocks.-The fourth and last great division of rocks are the crystalline strata and slates, or schists, called gneiss, mica-schist, clay-slate, chlorite-schist, marble, and the like, the origin of which is more doubtful than that of the other three classes. They contain no pebbles, or sand, or scoriæ, or angular pieces of imbedded stone, and no traces of organic bodies, and they are often as crystalline as granite, yet are divided into beds, corresponding in form and arrangement to those of sedimentary formations, and are therefore said to be stratified. The beds sometimes consist of an alternation of substances varying in color, composition, and thickness, precisely as we see in stratified fossiliferous deposits. According to the Huttonian theory, which I adopt as the most probable, and which will be afterwards more fully explained, the materials of these strata were originally deposited from water in the usual form of sediment, but they were subsequently so altered by subterranean heat, as to assume a new texture. It is demonstrable, in some cases at least, that such a complete conversion has actually taken place, fossiliferous strata laving exchanged an earthy for a highly crystalline texture for a distance of a quarter of a mile from their contact with granite. In some cases, dark limestones replete with shells anc. corals, have been turned into white statuary marble, and hard clays, containing vegetable or other remains, into slates called mica-schist or hornblendeschist, every vestige of the organic bodies having been obliterated.

Although we are in a great degree ignorant of the precise nature of the influence exerted in these cases, yet it evidently bears some analogy to that which volcanic heat and gases are known to produce; and the action may be conveniently called plutonic, because it appears to have been developed in those regions where plutonic rocks are generated, and under similar circumstances of pressure and depth in the earth. Whether hot water or steam permeating stratified masses, or electricity, or any other causes have coöperated to produce the crystalline texture, may be matter of speculation, but it is clear that the plutonic influence has sometımes pervaded entire mountain masses of strata.

In accordance with the hypothesis above alluded to, I proposed in the first edition of the Principles of Geology (1833), the term "Metamorphic" for the altered strata, a term derived from $\mu \varepsilon \tau \alpha$, meta, trans, and $\mu_{0} \rho \varphi$, murphe, forma.

Hence there are four great classes of rocks considered in reference to their origin, - the aqueous, the volcanic, the plutonic, and the metamorphic. In the course of this work it will be shown, that portions of each of these four distinct classes have originated at many successive periods. They have all been produced contemporaneously, and may even now be in the progress of formation on a large scale. It is not true, as was formerly supposed, that all granites, together with the crystalline or metamorphic strata, were first formed, and therefore entitled to be called "primitive," and 
that the aqueous and roleanic rocks were afterwards superimposed, and should, therefore, rank as secondary in the order of time. This idea was adopted in the infancy of the science, when all formations, whether stratified or unstratified, earthy or crystalline, with or without fossils, were alike regarded as of aqueous origin. At that period it was naturally argued, that the foundation must be older than the superstructure; but it was afterwards discovered, that this opinion was by no means in every instance a legitimate deduction from facts ; for the inferior parts of the earth's crust have often been modified, and even entirely changed, by the influence of volcanic and other subterranean causes, while superimposed formations have not been in the slightest degree altered. In other words, the destroying and renovating processes have given birth to new rocks below, while those above, whether crystalline or fossiliferous, have remained in their ancient condition. Even in cities, such as Venice and Amsterdam, it cannot be laid down as universally true, that the upper parts of each edifice, whether of brick or marble, are more modern than the foundations on which they rest, for these often consist of wooden piles, which may have rotted and been replaced one after the other, without the least injury to the buildings above; meanwhile, these may have required scarcely any repair, and may have been constantly inhabited. So it is with the habitable surface of our globe, in its relation to large masses of rock immediately below : it may continue the same for ages, while subjacent materials, at a great depth, are passing from a solid to a fluid state, and then reconsolidating; so as to acquire a new texture.

As all the crystalline rocks may, in some respects, be viewed as belonging to one great family, whether they be stratified or unstratified, plutonic or metamorphic, it will often be conrenient to speak of them by one common name. It being now ascertained, as above stated, that they are of very different ages, sometimes newer than the strata called secondary, the terms primitive and primary, which were formerly used for the whole, must be abandoned, as they rould imply a manifest contradiction. It is indispensable, therefore, to find a new name, one which must nọt be of chronological import, and must express, on the one hand, some peculiarity equally attributable to granite and gneiss (to the plutonic as well as the altered rocks), and, on the other, must hare reference to characters in which those rocks differ, both from the rolcanic and from the unaltered sedimentary strata. I proposed in the Principles of Geology (first edition, rol. iii.), the term "hypogene" for this purpose, derived from ino, under, and rwoucs, to be, or to be born; a word implying the theory that granite, gneiss, aud the other crystalline formations are alike nether-formed rocks, or rocks which have not assumed their present form and structure at the surfäce. They occupy the lowest place in the order of superposition. Even in regions such as the Alps, where some masses of granite and gneiss can be shomn to be of comparatively modern date, belonging, for example, to the period hereafter to be described as tertiary, they are still underlying rocks. Ther nerer repose 
on the volcanic or trappean formations, nor on strata containing organic remains. They are hypogene, as "being under" all the rest.

From what has now been said, the reader will understand that each. of the four great classes of rocks may be studied under two distinct points of view ; first, they may be studied simply as mineral masses de. riving their origin from particular causes, and having a certain composition, form, and position in the earth's crust, or other characters both positive and negative, such as the presence or absence of organic remains. In the second place, the rocks of each class may be viewed as a grand chronological series of monuments, attesting a succession of events in the former history of the globe and its living inhabitants.

I shall accordingly proceed to treat of each family of rocks; first, in reference to those characters which are not chronological, and then in particular relation to the several periods when they were formed

CHAPTER II.

AQUEOUS ROCKS-THEIR COMPOSITION AND FORMS OF STRATIFI-

CATION.

Mineral composition of strata-Arenaceous rocks-Argillaceous-CalcareousGypsum-Forms of stratification-Original horizontality-Thinning out-Diagonal arrangement-Ripple mark.

Is pursuance of the arrangement explained in the last chapter, we shall begin by examining the aqueous or sedimentary rocks, which are for the most part distinctly stratified, and contain fossils. We may first study them with reference to their mineral composition, external appearance, position, mode of origin, organic contents, and other characters which belong to them as aqueous formations, independently of their age, and we may afterwards consider them chronologically or with reference to the successive geological periods when they originated.

I have already given an outline of the data which led to the belief that the stratified and fossiliferous rocks rere originally deposited under water ; but, before entering into a more detailed investigation, it will be desirable to say something of the ordinary materials of which such strata are composed. These may be said to belong principally to three divisions, the arenaceous, the argillaceous, and the calcareous, which are formed respectively of sand, clay, and carbonate of lime. Of these, the arenaceous, or sandy masses, are chiefly made up of siliceous or flinty grains; the argillaceous, or clayey, of a mixture of siliceous matter: with a certain proportion, about a fourth in weight, of aluminous earth : 
and, lastly, the calcareous rocks or limestones consist of carbonic acid and lime.

Arenaceous or siliceous rocks.-To speak first of the sandy division : beds of loose sand are frequently met with, of which the grains consist entirely of silex, which term comprehends all purely siliceous minerals, as quartz and common fiint. Quartz is silex in its purest form; flint usually contains some admixture of alumine and oxide of iron. The siliceous grains in sand are usually rounded, as if by the action of running water. Sandstone is an aggregate of such grains, which often cohere tog'ether without any visible cement, but more commonly are bound together by a slight quantity of siliceous or calcareous matter, or by iron or clay.

Pure siliceous rocks may be known by not effervescing when a drop of nitric, sulphurie, or other acid is applied to them, or by the grains not being readily scratched or broken by ordinary pressure. In nature there is every intermediate gradation, from perfectly loose sand, to the hardest sandstone. In micaceous sandstones miea is very abundant; and the thin silvery plates into which that mineral divides, are often arranged in layers parallel to the planes of stratification, giving a slaty or laminated texture to the rock.

When sandstone is coarse-grained, it is usually called grit. If the grains are rounded, and large enough to be called pebbles, it becomes a conglomerate, or pudding-stone, which may consist of pieces of one or of many different kinds of rock. A conglomerate, therefore, is simply gravel bound together by a cement.

Argillaceous rocks.-Clay, strictly speaking, is a mixture of silex or flint with a large proportion, usually about one-fourth, of alumine, or argil; but, in common language, any earth which possesses sufficient ductility, when kneaded up with water, to be fashioned like paste by the hand, or by the potter's lathe, is called a clay; and such clays vary greatly in their composition, and are, in general, nothing more than mud derived from the decomposition or wearing down of rocks. The purest clay found in nature is porcelain clay, or kaolin, which results from the decomposition of a rock composed of felspar and quartz, and it is almost always mixed with quartz.* Shale has also the property, like clay, of becoming plastic in water : it is a more solid form of clay, or argillaceous matter, condensed by pressure. It usually divides into laminæ, more or less regular.

One general character of all argillaceous rocks is to give out a peculiar, earthy odor when breathed upon, which is a test of the presence of alumine, although it does not belong to pure alumine, but, apparently, to the combination of that substance with oxide of iron. $\downarrow$

* The kaolin of China consists of 71.15 parts of silex, 15.86 of alumine, 1.92 of lime, and 6.73 of water (W. Phillips, Mineralogy, p. 33); but other porcelain clays differ materially, that of Cornwall being composed, according to Boase, of nearly equal parts of silica and alumine, with 1 per cent. of magnesia. ' (Phil. Mag. vol. x. 1837.)

† See W. Phillips's Mineralogy, "Alumine." 
Calcareous rocks. - This division comprehends those rocks which, like chalk, are composed chiefly of lime and carbonic acid. Shells and corals are also formed of the same elements, with the addition of animal matter. To obtain pure lime it is necessary to calcine these calcareous substances, that is to say, to expose them to heat of sufficient intensity to drive off the carbonic acid, and other volatile matter. White chalk is sometimes pure carbonate of lime; and this rock, although usually in a soft and earthy state, is occasionally sufficiently solid to be used for building; and even passes into a compact stone, or a stone of which the separate parts are so minute as not to be distinguishable from each other by the naked eye.

Many limestones are made up entirely of minute fragments of shells and coral, or of calcareous sand cemented together. These last might be called "calcareous sandstones ;" but that term is more properly applied to a rock in which the grains are partly calcareous and partly siliceous, or to quartzose sandstones, having a cement of carbonate of lime.

The variety of limestone called "oolite" is composed of numerous small egg-like grains, resembling the roe of a fish, each of which has usually a small fragment of sand as a nucleus, around which concentric layers of calcareous matter have accumulated.

Any limestone which is sufficiently hard to take a fine polish is called marble. Many of these are fossiliferous ; but statuary marble, which is also called saccharine limestone, as having a texture resembling that of loaf-sugar, is devoid of fossils, and is in many cases a member of the metamorphic series.

Siliceous limestone is an intimate mixture of carbonate of lime and flint, and is harder in proportion as the flinty matter predominates.

The presence of carbonate of lime in a rock may be ascertained by applying to the surface a small drop of diluted sulphuric, nitric, or muriatic acids, or strong vinegar; for the lime, having a greater chemical affinity for any one of these acids than for the carbonic, unites immediately with them to form new compounds, thereby becoming a suiphate, nitrate, or muriate of lime. The carbonic acid, when thus liberated from its union with the lime, escapes in a gaseous form, and froths up or effervesces as it makes its way in small bubbles through the drop of liquid. This effervescence is brisk or feeble in proportion as the limestone is pure or impure, or, in other words, according to the quantity of foreign matter mixed with the carbonate of lime. Without the aid of this test, the most experienced eye cannot always detect the presence of . carbonate of lime in rocks.

The above-mentioned three classes of rocks, the siliceous, argillaceous, and calcareous, pass continually into each other, and rarely occur in a perfectly separate and pure form. Thus it is an exception to the general rule to meet with a limestone as pure as ordinary white chalk, or witk. clay as aluminous as that used in Cornwall for porcelain, or with sand so entirely composed of siliceous grains as the white sand of Alum Bay in the Isle of Wight, or sandstone so pure as the grit of Fontaine 
bleau, used for parement in France. More commonly we find sand and clay, or clay and marl, intermixed in tne same mass. When the sand and clay are each in considerable quantity, the mixture is called loam. If there is much calcareous matter in clay it is called marl; but this term has unfortunately been used so vaguely, as often to be very ambiguous. It has been applied to substances in which there is no lime; as, to that red loam usually called red marl in certain parts of England. Agriculturists were in the habit of ealling any soil a marl, which, like true marl, fell to pieces reaaily on exposure to the air. Hence arose the confusion of using this name for soils which, consisting of loam, were easily worked with the plough, though devoid of lime.

Marl slate bears the same relation to marl which shale bears to clay, being a calcareous shale. It is very abundant in some countries, as in the Swiss Alps. Argillaceous or marly limestone is also of common occurrence.

There are few other kinds of rock which enter so largely into the composition of sedimentary strata as to make it necessary to dwell here on their characters. I may, however, mention two others,-magnesian limestone or dolomite, and gypsum. Magnesian limestone is composed of earbonate of lime and carbonate of magnesia ; the proportion of the latter amounting in some cases to nearly one-half. It effervesces much more slowly and feebly with acids than common limestone. In England this rock is generally of a yellowish color; but it varies greatly in mineralogical character, passing from an earthy state to a white compact stone of great hardness. Dolomite, so common in many parts of Germany and France, is also a variety of magnesian limestone, usually of a granular texture.

Gypsum.-Gypsum is a rock composed of sulphuric acid, lime, and water. It is usually a soft whitish-yellow rock, with a texture resembling that of loaf-sugar, but sometimes it is entirely composed of lenticular crystals. It is insoluble in acids, and does not effervesce like chalk and dolomite, because it does not contain carbonic acid gas, or fixed air, the lime being already combined with sulphuric acid, for which it has a stronger affinity than for any other. Anhydrous gypsum is a rare variety, into which water does not enter as a component part. Gypseous marl is a mixture of gypsum and marl. Alabaster is a granular and compact rariety of grpsum found in masses large enough to be used in sculpture and architecture. It is sometimes a pure snow-white substance, as that of Volterra in Tuscany, well known as being carved for works of art in Florence and Leghorn. It is a softer stone than marble, and more easily wrought.

Forms of stratification.-A series of strata sometimes consists of one of the above rocks, sometimes of two or more in alternating beds. Thus, in the coal districts of England, for example, we often pass through several beds of sandstone, some of finer, others of coarser grain, some white, others of a dark color, and below these, layers of shale and sandstone or beds of shale, dirisible into leaf-like laminæ, and containing 
beautiful impressions of plants. Then again we mect with beds of pure and impure coal, alternating with shales and sandstones, and underneath the whole, perhaps, are calcareous strata, or beds of limestone, filled with corals and marine shells, each bed distinguishable from another by cer. tain fossils, or by the abundance of particular species of shells or zoophytes.

This alternation of different kinds of rock produces the most distinct stratification; and we often find beds of limestone and marl, conglomerate and sandstone, sand and clay, recurring again and again, in nearly regular order, throughout a series of many hundred strata. The causes which may produce these phenomena are various, and have been fully discussed in my treatise on the modern changes of the earth's surface.* It is there seen that rivers flowing into lakes and seas are charged with sediment, varying in quantity, composition, color, and grain, according to the seasons; the waters are sometimes flooded and rapid, at other periods low and feeble; different tributaries, also, draining peculiar countries and soils, and therefore charged with peculiar sediment, are swollen at distinct periods. It was also shown that the waves of the sea and currents undermine the cliffs during wintry storms, and sweep away the materials into the deep, after which a season of tranquillity succeeds, when nothing but the finest mud is spread by the movements of the ocean over the same submarine area.

It is not the object of the present work to give a description of these operations, repeated as they are, year after year, and century after century; but I may suggest an explanation of the manner in which some micaceous sandstones have originated, namely, those in which we see innumerable thin layers of mica dividing layers of fine quartzose sand. I observed the same arrangement of materials in recent mud deposited in the estuary or La Roche St. Bernard in Brittany, at the mouth of the Loire. The surrounding rocks are of gneiss, which, by its waste, supplies the mud: when this dries at low water, it is found to consist of brown laminated clay, divided by thin seams of mica. The separation of the mica in this case, or in that of micaceous sandstones, may be thus understood. If we take a handful of quartzose sand, mixed with mica, and throw it into a clear running stream, we see the materials immediately sorted by the water, the grains of quartz falling almost directly to the bottom, while the plates of mica take a much longer time to reach the bottom, and are carried farther down the stream. At the first instant the water is turbid, but immediately after the flat surfaces of the plates of mica are seen all alone reflecting a silvery light, as they descend slowly, to form a distinct micaceous lamina. The mica is the heavier mineral of the two; but it remains a longer time suspended in the fluid, owing to its greater extent of surface. It is easy, therefore, to perceive that where such mud is acted upon by a river or tidal current, the thin plates of mica will be carried

* Consult Index to Principles of Geology, "Stratification," "Currents," "Deltas," "Water," \&c. 
farther, and not deposited in the same places as the grains of quartz; and since the force and velocity of the stream varies from time to time, layers of mica or of sand will be thrown down successively on the same area.

Original horizontality.-It is said generally that the upper and under surfaces of strata, or the planes of stratification, are parallel. Although this is not strictly true, they make an approach to paralIelism, for the same reason that sediment is usually deposited at first in nearly horizontal layers. The reason of this arrangement can by no means be attributed to an original evenness or horizontality in the bed of the sea; for it is ascertained that in those places where no matter has been recently deposited, the bottom of the ocean is often as uneven as that of the dry land, having in like manner its hills, valleys, and ravines. Yet if the sea should sink, or the water be removed near the mouth of a large river where a delta has been forming, we should see extensive plains of mud and sand laid dry, which, to the eye, would appear perfectly level, although, in realit;, they would slope gently from the land towards the sea.

This tendency in newly-formed strata to assume a horizontal position arises principally from the motion of the water, which forces along particles of sand ur mud at the bottom, and causes them to settle in hollows or depressions, where they are less exposed to the force of a current than when they are resting on elevated points. The velocity of the current and the motion of the superficial waves diminish from the surface downwards, and are least in those depressions where the water is deepest.

A good illustration of the principle here alluded to may be sometimes seen in the neighborhood of a volcano, when a section, whether natural or artificial, has laid open to view a succession of various-colored layers of sand and ashes, which have fallen in showers upon uneven ground. Thus let A B (fig. 1) be two ridges with an intervening valley. These original inequalities of the surface have been gradually effaced by beds of sand and ashes $c, d, e$, the surface at $e$ being quite level. It will be seen that although the materials of the first laycrs have accommodated

Fig. 1.

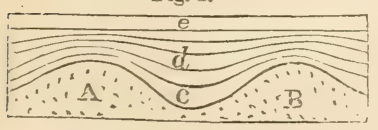
themselves in a great degree to the shape of the ground A B, yet each bed is thickest at the bottom. At first a great many particles would be carried by their own gravity down the steep sides of $A$ and $B$, and others would afterwards be blown by the wind as they fell off the ridges, and would settle in the hollow, which would thus become more and more effaced as the strata accumulated from $c$ to $e$. This levelling operation may perhaps be rendered more clear to the student by supposing a number of parallel trenches to be dug in a plain of moving sand, like the African desert, in which case the wind would soon cause all signs of these trenches to disappear, and the surface would be as uniform as before. Now, water in motion can exert this levelling power on similar materials more easily than air, for almost all stones lose in 
water more than a third of the weight which they have in air, the specific gravity of rocks being in general as $2 \frac{1}{2}$ when compared to that of water, which is estimated at 1. But the buoyancy of sand or mud would be still greater in the sea, as the density of salt water exceeds that of fresh.

Yet, however uniform and horizontal may be the surface of new deposits in general, there are still many disturbing causes, such as eddies in the water, and currents moving first in one and then in another direction, which frequently cause irregularities. We may sometimes follow a bed of limestone, shale, or sandstone, for a distance of many hundred yards continuously; but we generally find at length that each individual stratum thins out, and allows the beds which were previously above and below it to meet. If the materials are coarse, as in grits and conglomerates, the same beds can rarely be traced many yards without varying in size, and often coming to an end abruptly. (See fig. 2.)

Fig. 2.

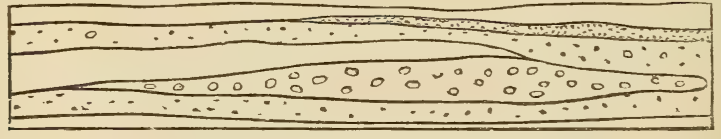

Section of strata of sandstone, grit, and conglomerate.

Diagonal or Cross Stratification.--There is also another phenomenon of frequent occurrence. We find a series of larger strata, each of which is composed of a number of minor layers placed obliquely to the general

Fig. 3.

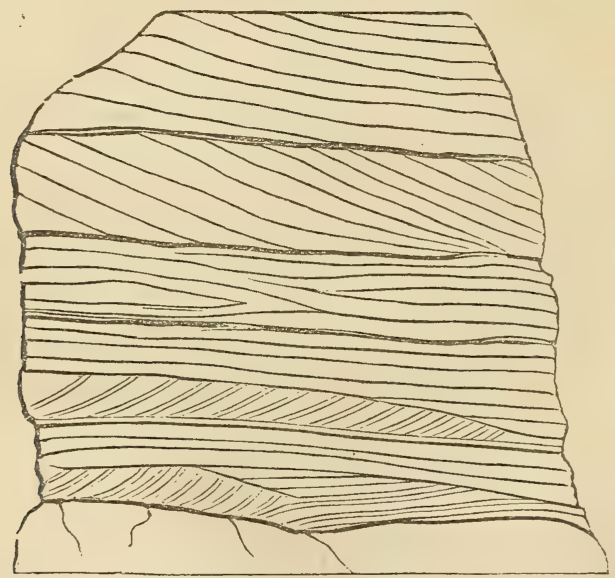

Section of sand at Sandy Hill, near Biggleswade, Bedfordshire. Height 20 fcet. (Green-sand formation.)

planes of stratification. To this diagonal arrangement the name of "false or cross stratification" has been given. Thus in the annexed section (fig. 3) we see seven or eight large beds of loose sand, yellow and 
brown, and the lines $a, b, c$, mark some of the principal planes of stratification, which are nearly horizontal. But the greater part of the subordinate laminæ do not conform to these planes, but have often a steep slope, the inclination being sometimes towards opposite points of the compass. When the sand is loose and incoherent, as in the case here represented, the deviation from parallelism of the slanting laminæ cannot possibly be accounted for by any rearrangernent of the particles acquired during the consolidation of the rock. In what manner then can such irregularities be due to original deposition? We must suppose that at the bottom of the sea, as well as in the beds of rivers, the motions of wares, currents, and eddies often cause mud, sand, and gravel to be thrown down in heaps on particular spots, instead of being spread out uniformly over a wide area. Sometimes, when banks are thus formed, currents may cut passages through them, just as a river forms its bed. Suppose the bank A (fig. 4) to be thus formed with a steep

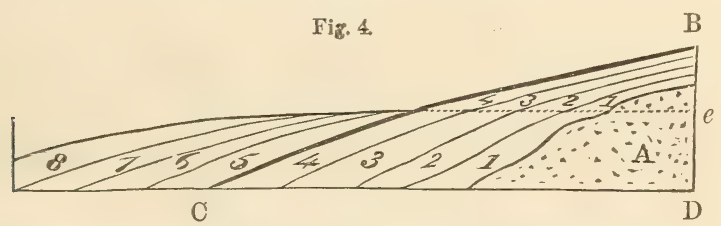

sloping side, and the water being in a tranquil state, the layer of sediment No. 1 is thrown down upon it, conforming nearly to its surface. Afterwards the other layers, 2, 3, 4, may be deposited in succession, so that the bank B C D is formed. If the current then increases in velocity, it may cut away the upper portion of this mass down to the dotted line $e$ (fig. 4), and deposit the materials thus remored farther on, so as to form the layers $5,6,7,8$. We have now the bank B C D E (fig. 5), of which the surface is almost levr!, and on which the nearly

Fig. 5.

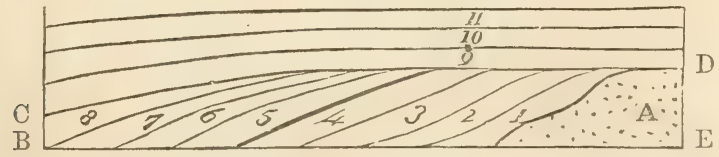

horizontal layers, 9, 10, 11, may then accumulate. It was sliown in fig. 3 that the diagonal layers of successire strati may sometimes have an opposite slope. This is well seen in some cliffs of loose sand on the

Fig. 6.

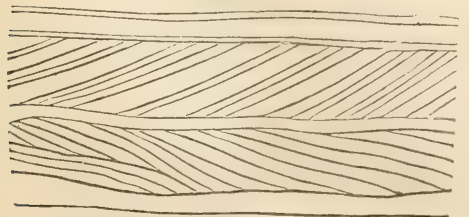

Clife between Mismer and Dunwich.
Suffolk coast. A portion of one of these is represented in fig. 6 , where the lavers, of which there are about six in the thickness of an inch, are composed of quartzose grains. This arrangement may have been due to the altered direction of the tides and currents in the same place. 
The description above given of the slanting position of the minor layers constituting a single stratum is in certain cases applicable on a much grander scale to masses several hundred feet thick, and many miles in extent. A fine example may be seen at the base of the Maritime Alps near Nice. The mountains here terminate abruptly in the sea, so that a depth of many hundred fathoms is often found within a stone's throw of the beach, and sometimes a depth of 3000 feet within half a mile. But at certain points, strata of sand, marl, or conglomerate, intervene between the shore and the mountains, as in the annexed fig. (7), where a vast succession of slanting beds of gravel and sand may be

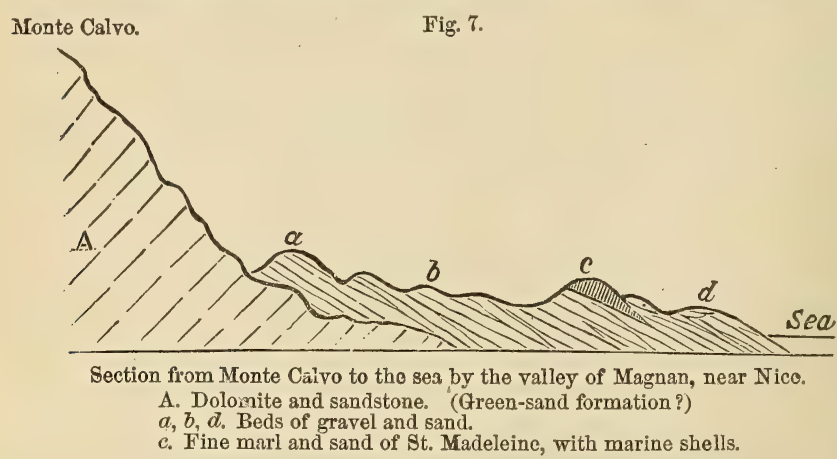

traced from the sea to Monte Calvo, a distance of no less than 9 miles in a straight line. The dip of these beds is remarkably uniform, being always southward or towards the Mediterranean, at an angle of about 25. They are exposed to view in nearly vertical precipices, varying from 200 to 600 feet in height, which bound the valley through which the river Magnan flows.' Although in a general view, the strata appear to be parallel and uniform, they are nevertheless found, when examined closely, to be wedge-shaped, and to thin out when followed for a few hundred feet or yards, so that we may suppose them to have been thrown down originally upon the side of a steep bank, where a river or alpine torrent discharged itself into a deep and tranquil sea, and formed a delta, which advanced gradually from the base of Monte Calvo to a distance of 9 miles from the original shore. If subsequently this part of the Alps and bed of the sea were raised 700 feet, the coast would acquire its present configuration, the delta would emerge, and a deep channel might then be cut through it by a river.

It is well known that the torrents and streams, which now descend from the alpine declivities to the shore, bring down annually, when the snow melts, vast quantities of shingle and sand, and then, as they subside, fine mud, while in summer they are nearly or entirely dry; so that it may be safely assumed, that deposits like those of the valley of the Magnan, consisting of coarse gravel alternating with fine sediment, are still in progress at many points, as, for instance, at the mouth of the Var. They must advance upon the Mediterranean in the form of great shoals terminating in a steep talus; such being the original mode of ac- 
cumulation of all coarse materials conveyed into deep water, especially where they are composed in great part of pebbles, which cannot be transported to indefinite distances by currents of moderate velocity. By inattention to facts and inferences of this kind, a very exaggerated estimate has sometimes been made of the supposed depth of the ancient ocean. There can be no doubt, for example, that the strata $\alpha$, fig. 7, or those nearest to Monte Calvo, are older than those indicated by $b$, and these again were formed before $c$; but the vertical depth of gravel and sand in any one place cannot be proved to amount even to 1000 feet, although it may perhaps be much greater, yet probably never exceeding at any point 3000 or 4000 feet. But were we to assume that all the strata were once horizontal, and that their present dip or inclination was due to subsequent movements, we should then be forced to conclude, that a sea 9 miles deep had been filled up with alternate layers of mud and pebbles thrown down one upon another.

In the locality now under consideration, situated a few miles to the west of Nice, there are many geological data, the details of which cannot be given in this place, all leading to the opinion, that when the deposit of the Magnan was formed, the shape and outline of the alpine declivities and the shore greatly resembled what we now behold at many points in the neighborhood. That the beds, $a, b, c, d$, are of comparatively modern date is proved by this fact, that in seams of loamy marl intervening between the pebbly beds are fossil shells, half of which belong to species now living in the Mediterranean.

Ripp?e mark.-The ripple mark, so common on the surface of sandstones of all ages (see fig. 8), and which is so often seen on the sea-shore

Fig. S.

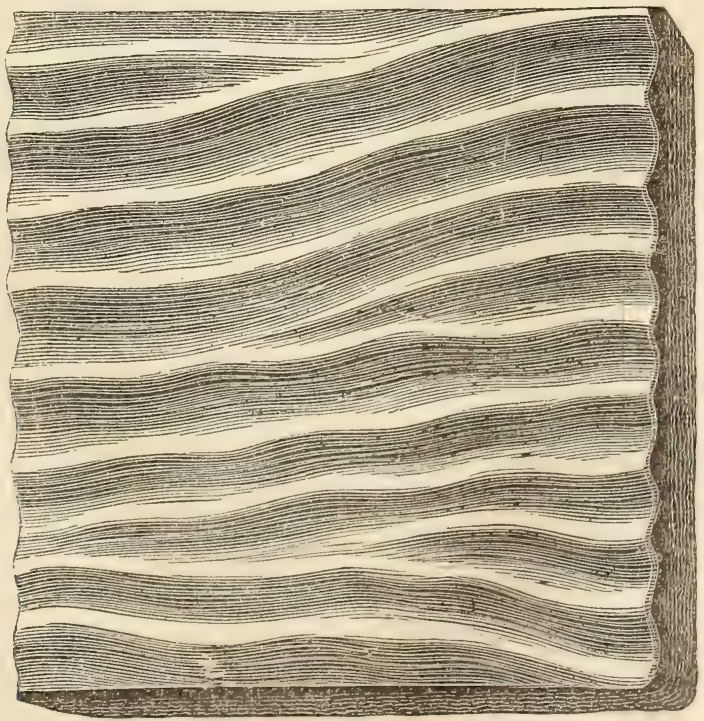

Slab of ripple-marked (new red) sandstone from Cheshire. 
at low tide, seems to originate in the drifting of materials along the bottom of the water, in a manner very similar to that which may explain the inclined layers above described. This ripple is not entirely confined to the beach between high and low water mark, but is also produced on sands which are constantly covered by water. 'Similar undulating ridges and furrows may also be sometimes seen on the surface of drift snow and blown sand. The following is the manner in which I once observed the motion of the air to produce this effect on a large extent of level beach, exposed at low tide near Calais. Clouds of fine white sand were blown from the neighboring dunes, so as to cover the shore, and whiten a dark level surface of sandy mud, and this fresh covering of sand was beautifully rippled. On levelling all the small ridges and furrows of this ripple sver an area of several yards square, I saw them perfectly restored in about ten minutes, the general direction of the ridges being always at right angles to that of the wind. The restoration began by the appearance here and there of small detached heaps of sand, which soon lengthened and joined together, so as to form long sinuous ridges with intervening furrows. Each ridge had one side slightly inclined, and the other steep ; the lee-side being always steep, as $b, c,-d, e$; the windwardside a gentle slope, as $a, b,-c, d$, fig. 9 . When a gust of wind blew

Fig. 9.

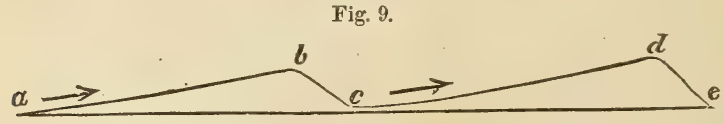

with sufficient force to drive along a eloud of sand, all the ridges were seen to be in motion at once, each encroaching on the furrow before it, and, in the course of a few minutes, filling the place which the furrows had occupied. The mode of advance was by the continual drifting of grains of cand up the slopes $a b$ and $c d$, many of which grains, when they arrived at $b$ and $d$, fell over the scarps $b c$ and $d e$, and were under shelter from the wind; so that they remained stationary, resting, according to their shape and momentum, on different parts of the descent, and a few only rolling to the bottom. In this manner each ridge was distinctly seen to move slowly on as often as the force of the wind augmented. Occasionally part of a ridge, advancing more rapidly than the rest, overtook the ridge immediately before it, and became confounded with it, thus causing those bifurcations and branches which are so com mon, and two of which are seen in the slab, fig. 8. We may observe this configuration in sandstones of all ages, and in them also, as now on the sea-coast, we may often detect two systems of ripples interfering with each other; one more ancient and half-effaced, and a newer one, in which the grooves and ridges are more distinct, and in a different direction. This crossing of two sets of ripples arises from a change of wind, and the new direction in which the waves are thrown on the shore.

The ripple mark is usually an indication of a sea-beach, or of water from 6 to 10 feet deep, for the agitation caused by waves even during 
storms extends to a very slight depth. To this rule, however, there are some exceptions, and recent ripple-marks have been observed at the depth of 60 or 70 feet. It has also been ascertained that currents or large bodies of water in motion may disturb mud and sand at the depth of 300 or even 450 feet.* Beach ripple, however, may usually be distinguished from current ripple by frequent changes in its direction. In a slab of sandstone, not more than an inch thick, the furrows or ridges of an ancient ripple may often be seen in several successive laminæ to run towards different points of the compass.

\section{CHAPTER III.}

ARRANGEMENT OF FOSSILS IN STRATA-FRESHWATER AND MARINE。

Successive deposition indicated by fossils-Limestones formed of corals and shells - Proofs of gradual increase of strata derived from fossils-Serpula attached to spatangus-Wood bored by teredina-Tripoli and semi-opal formed of infusoria-Chalk derived principally from organic bodies-Distinction of freshwater from marine formations-Genera of freshwater and land shells-Rules for recognizing marine testacea-Gyrogonite and chara-Freshwater fishesAlternation of marine and freshwater deposits--Lym-Fiord.

HAVING in the last chapter considered the forms of stratification so far as they are determined by the arrangement of inorganic matter, we may now turn our attention to the manner in which organic remains are distributed through stratified deposits. We should often be unable to detect any signs of stratification or of successive deposition, if particular kinds of fossils did not occur here and there at certain depths in the mass. At one level, for example, univalve shells of some one or more species predominate; at another, bivalve shells; and at a third, corals; while in some formations we find layers of regetable matter, commonly deriver from land plants, separating strata.

It may appear inconceivable to a beginner how mountains, several thousand feet thick, can hare become filled with fossils from top to bottom; but the difficulty is removed, when he reflects on the origin of stratification, as explained in the last chapter, and allows sufficient time for the accumulation of sediment. He must never lose sight of the fact that, during the process of deposition, each separate larer was once the uppermost, and corered immediately by the water in which aquatic animals lived. Each stratum in fact, howerer far it may now lie beneath the surface, was once in the state of shingle, or loose sand or soft mud at the bottom of the sea, in which shells and other bodies easily became enveloped.

By attending to the nature of these remains, we are often enabled to determine whether the deposition was slow or rapid, whether it took place in a deep or shallow sea, near the shore or far from land, and whether the water was salt, brackish, or fresh. Some limestones consist

* Edin. New Phil. Journ. vol. xxxi, and Darwin, Volc. Islands, p. 134. 
almost exclusively of corals, and in many cases it is evident that the present position of each fossil zoophyte has been determined by the manner in which it grew originally. The axis of the coral, for example, if its natural growth is erect, still remains at right angles to the plane of stratification. If the stratum be now horizontal, the round spherical heads of certain species continue uppermost, and their points of attachment are directed downwards. This arrangement is sometimes repeated throughout a great succession of strata. From what we know of the growth of similar zoophytes in modern reefs, we infer that the rate of increase was extremely slow, and some of the fossils must have flourished for ages like forest trees before they attained so large a size. During these ages, the water remained clear and transparent, for such corals cannot live in turbid water.

In like manner, when we see thousands of full-grown shells dispersed everywhere throughout a long series of strata, we cannot doubt that time was required for the multiplication of successive generations; and the evidence of slow accumulation is rendered more striking from the proofs, so often discovered, of fossil bodies having lain for a time on the floor of the ocean after death before they were imbedded in sediment. Nothing, for example, is more common than to see fossil oysters in clay, with serpulæ, or barnacles (acorn-shells), or corals, and other creatures, attached to the inside of the valves, so that the mollusk was certainly not buried in argillaceous mud the moment it died. There must have been an interval during which it was still surrounded with clear water, when the creatures whose remains now adhere to it, grew from an embryo to a mature state. Attached shells which are merely external, like some of the serpulæ $(\alpha)$ in the annexed figure (fig. 10), may often have grown upon

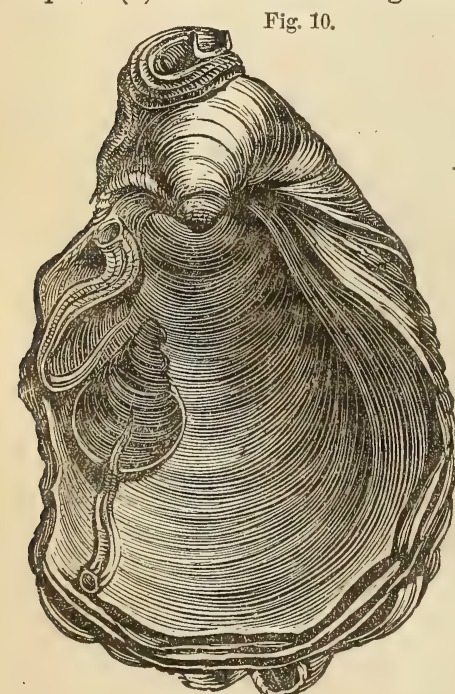

Fossil Gryphcea, covered both on the outside and inside with fossil serpulæ. an oyster or other shell while the animal within was still living; but if they are found on the inside, it could only happen after the death of the inhabitant of the shell which affords the support. Thus, in fig. 10, it will be seen that two serpulæ have grown on the interior, one of them exactly on the place where the adductor muscle of the Gryphoea (a kind of oyster) was fixed.

Some fossil shells, even if simply attached to the outside of others, bear full testimony to the conclusion above alluded to, namely, that an interval elapsed between the death of the creature to whose shell they adhere, and the burial of the same in mud or sand. The sea-urchins or Echini, so abundant in white chalk, afford a good 
illustration. It is well known that these animals, when living, are invariably covered with numerous suckers, or gelatinous tubes, called "ambulacral," because they serve as organs of motion. They are also armed witt: spines supported by rows of tubercles. These last are only seen after the death of the sea-urchin, when the spines have dropped off. In fig. 12 a living species of Spatangus, common on our coast, is represented with

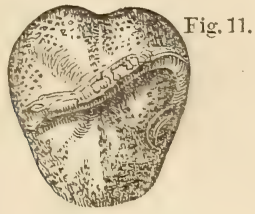

Serpula attached to a fossil Spatangus from the chalk.

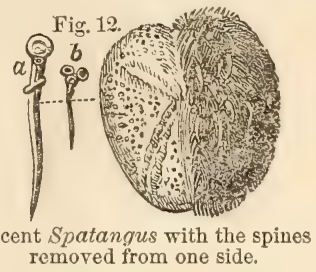

๖. Spine and tubercles, nat. size. a. The same magnified.

one-half of its shell stripped of the spines. In fig. 11 a fossil of the same genus from the white chalk of England shows the naked surface which the individuals of this family exhibit when denuded of their bristles. The full-grown Serpula, therefore, which now adheres externally, could not have begun to grow till the Spatangus had died, and the spines were detached.

Now the series of events here attested by a single fossil may be carried a step farther. Thus, for example, we often meet with a sea-urchin in the chalk (see fig. 13), which has fixed to it the lower valve of a Crania,

Fig. 13.

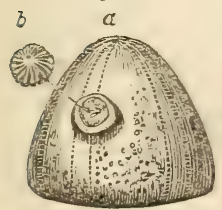

a. Echinus from the chalk, with lower attached.

i. Upper valve of ths Crania detached. a genus of bivalve mollusea. The upper valve ( $b$, fig 13) is almost invariably wanting, though occasionally found in a perfect state of preservation in white chalk at some distance. In this case, we see clearly that the sea-urchin first lived from youth to age, then died and lost its spines, which were carried away. Then the young Crania adhered to the bared shell, grew and perished in its turn; after which the upper valve was separated from the lower before the Echinus became enveloped in chalky mud.

It may be well to mention one more illustration of the manner in which single fossils may sometimes throw light on a former state of things, both in the bed of the ocean and on some adjoining land. IVe meet with many fragments of wood bored by ship-worms, at various depths in the clay on which London is built. Entire.branches and stems of trees, sereral feet in length, are sometimes dug out, drilled all over by the holes of these borers, the tubes and shells of the mollusk still remaining in the cylindrical hollows. In fig. $15 e$, a representation is given of a piece of recent wood pierced by the Teredo navalis, or common ship-worm, which destroys wooden piles and ships. When the cylindrical tube $d$ has been extracted from the wood, a shell is seen at tha larger extremity, composed of two pieces, as shown at $c$. In like 
manner, a piece of fossil wood ( $\alpha$, fig. 14) has been perforated by an animal of a kindred but extinct genus, called Teredina by Lamarck. The calcareous tube of this mollusk was united and as it were soldered

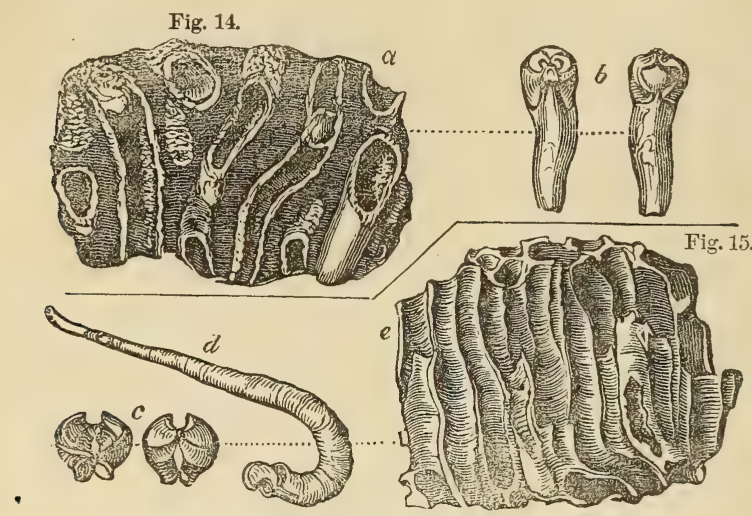

Fossil and recent wood drilled by perforating Mollusca.

Fig. 14. $a$. Fossil wood from London clay, bored by Teredina.

$b$. Shell and tube of Teredina personata, the right-hand figure the ventral, the left the dorsal view.

Fig. 15. e. Recent wood bored by Teredo.

d. Shell and tube of Teredo navatis, from the same.

$c$. Anterior and posterior view of the valves of same detached from the tube.

on to the valves of the shell $(b)$, which therefore cannot be detached from the tube, like the valves of the recent Teredo. The wood in this fossil specimen is now converted into a stony mass, a mixture of clay and lime; but it must once have been buoyant and floating in the sea, when the Teredino lived upon it, perforating it in all directions. Again, before the infant colony settled upon the drift-wood, the branch of a tree must have been floated down to the sea by a river, uprooted, perhaps, by a flood, or torn off and cast into the waves by the wind: and thus our thoughts are carried back to a prior period, when the tree grew for years on dry land, enjoying a fit soil and climate.

It has been already remarked that there are rocks in the interior of continents, at various depths in the earth, and at great heights above the sea, almost entirely made up of the remains of zoophytes and testacea. Such masses may be compared to modern oyster-beds and coral reefs; and, like them, the rate of increase must have been extremely gradual. But there are a variety of stony deposits in the earth's crust, now proved to have been derived from plants and animals, of which the organic origin was not suspected until of late years, even by naturalists. Great surprise was therefore created by the recent discovery of Professor Ehrenberg of Berlin, that a certain kind of siliceous stone, called tripoli, was entirely composed of millions of the remains of organic beings, which the Prussian naturalist refers to microscopic Infusoria, but which most others now believe to be plants. They abound in freshwater lakes and ponds in England and other countries, and are termed Diatomaceæ by those naturalists who believe in their vegetable origin. The substance 
alluded to has long been well known in the arts, being used in the form of powder for polishing stones and metals. It has been procured, among other places, from Bilin, in Bohemia, where a single stratum, extending over a wide area, is no less than 14 feet thick. This stone, when examined with a powerful microscope, is found to consist of the siliceous plates or frustules of the above-mentioned Diatomacer, united together

Fig. 16.

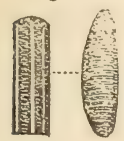

Bacillaria vulgaris?
Fig. 17.

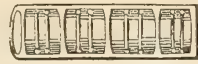

Gallonella
Fig. 1S.

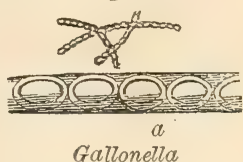

These figures are magnified nearly 300 times, except the lower figure of $G$. ferruginea (fig. $18 \alpha$ ), which is magnified 2000 times.

without any visible cement. It is difficult to convey an idea of their extreme minuteness; but Ehrenberg estimates that in the Bilin tripoli there are 41,000 millions of individuals of the Gaillonella distans (see fig. 17) in every cubic inch, which weighs about 220 grains, or about 187 millions in a single grain. At every stroke, therefore, that we make with this polishing powder, several millions, perhaps tens of millions, of perfect fossils are crushed to atoms.

The remains of these Diatomacer are of pure silex, and their forms :ire various, but rery marked and constant in particular genera and spe-

Fig. 20.

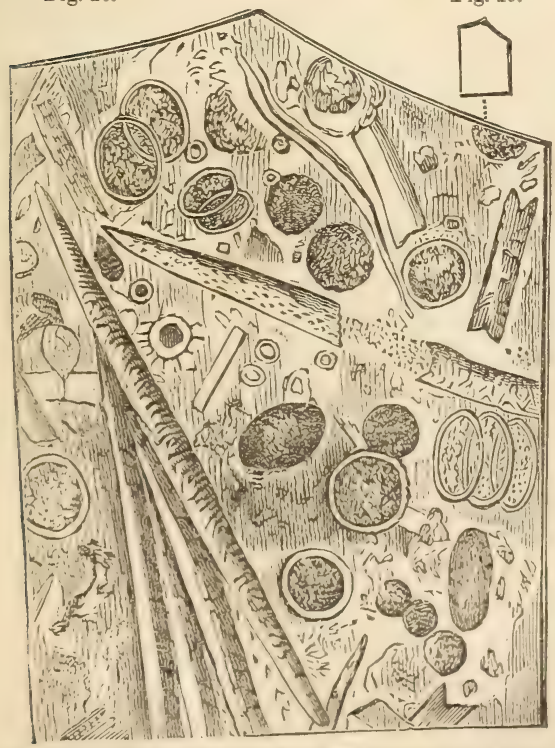

Fragment of semi-opal from the great bed of tripoli, Bilin. Fic. 19. Natural size.

Fig. 20. The same masnified. sbrwing cirenlar articulations of a species of Gallonella, and spiculæ of Spongilla. cies. Thus, in the family $B a-$ cillaria (see fig. 16), the fossils preserved in tripoli are seen to exhibit the same divisions and transverse lines which characterize the living species of kindred form. With these, also, the siliceous spiculæ or internal supports of the freshwater sponge, or Spongilla of Lamarck, are sometimes intermingled (see the needle-shaped bodies in fig. 20). These flinty cases and spicule, although hard, are very fragile, breaking like glass, and are therefore admirably adapted, when rubbed, for wearing down into a fine powcler fit for polishing the surface of metals.

Besides the tripoli, formed exclusively of the fossils above described, there occurs in the 
upper part of the great stratum at Bilin another heavier and more compact stone, a kind of semi-opal, in which innumerable parts of Diatomacea: and spiculæ of the Spongilla are filled with, and cemented together by, siliceous matter. It is supposed that the siliceous remains of the most delicate Diatomaceæ have been dissolved by water, and have thus giver rise to this opal in which the more durable fossils are preserved like insects in amber. This opinion is confirmed by the fact that the organic bodies decrease in number and sharpness of outline in proportion as the opaline cement increases in quantity.

In the Bohemian tripoli above described, as in that of Planitz in Saxony, the species of Diatomacer (or Infusoria, as termed by Ehrenberg) are freshwater; but in other countries, as in the tripoli of the Isle of France, they are of marine species, and they all belong to formations of the tertiary period, which will be spoken of hereafter.

A well-known substance, called bog-iron ore, often met with in peatmosses, has also been shown by Ehrenberg to consist of innumerable articulated threads, of a yellow ochre color, composed partly of flint and partly of oxide of iron. These threads are the cases of a minute microscopic body, called Gaillonella ferruginea (fig. 18).

It is clear that much time must have been required for the accumulation of strata to which countless generations of Diatomaceæ have contributed their remains; and these discoveries lead us naturally to suspect that other deposits, of which the materials have usually been supposed to be inorganic, may in reality have been derived from microscopic organic bodies. That this is the case with the white chalk, has often been imagined, this rock having been observed to abound in a variety of marine fossils, such as echini, testacea, bryozoa, corals, sponges, crustacea, and fishes. Mr. Lonsdale, on examining, Oct., 1835, in the museum of the Geological Society of London, portions of white chalk from different parts of England, found, on carefully pulverizing them in water, that what appear to the eye simply as white grains were, in fact, well preserved fossils. He obtained above a thousand of these from each pound weight of chalk, some being fragments of minute bryozoa and corallines, others entire Foraminifera and Cytheridx. The annexed drawings will give an idea of the beautiful forms of many of these bodies. The figures $a$ a represent their natural size, but, minute as they seem, the smallest of them, such as $\alpha$, fig. 24,

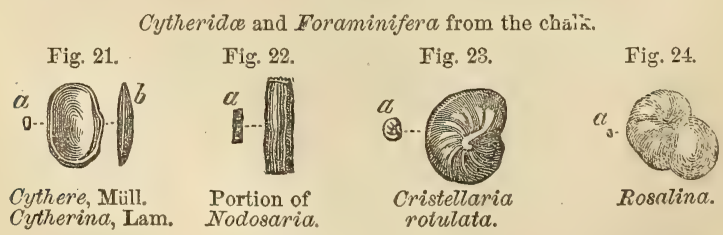

are gigantic in comparison with the cases of Diatomaceæ before mentioned. It has, moreover, been lately discovered that the chambers into which these Foraminifera are divided are actually often filled with thou- 
sands of well-preserved organic bodies, which abound in every minute grain of chalk, and are especially apparent in the white coating of flints, often accompanied by innumerable needle-shaped spiculæ of sponges. After reflecting on these discoveries, we are naturally led on to conjecture that, as the formless cement in the semi-opal of Bilin has been derived from the decomposition of animal and regetable remains, so also many chalk flints in which no organic structure can be recognized may nevertheless have constituted a part of microscopic animalcules.

"The dust we tread upon was once alive!"-Brrov.

How faint an idea does this exclamation of the poet convey of the real wonders of nature! for here we discover proofs that the calcareous and siliceous dust of which hills are composed has not only been once alive, but almost every particle, albeit invisible to the naked eye, still retains the organic structure which, at periods of time incalculably remote, was impressed upon it by the powers of life.

Freshwater and marine fossils.-Strata, whether deposited in salt or fresh water, have the same forms; but the imbedded fossils are very different in the two cases, because the aquatic animals which frequent lakes and rivers are distinct from those inhabiting the sea. In the northern part of the Isle of Wight formations of marl and limestone, more than 50 feet thick, occur, in which the shells are principally, if not all, of extinct species. Yet we recognize their freshwater origin, because they are of the same genera as those now abounding in ponds and lakes, either in our own country or in warmer latitudes.

In many parts of France, as in Auvergne, for example, strata of limestone, marl, and sandstone are found, hundreds of feet thick, which contain exclusively freshwater and land shells, together with the remains of terrestrial quadrupeds. The number of land shells scattered through some of these freshwater deposits is exceedingly great; and there are districts in Germany where the rocks scarcely contain any other fossils except snail-shells (helices) ; as, for instance, the limestone on the left bank of the Rhine, between Mayence and Worms, at Oppenheim, Findheim, Budenheim, and other places. In order to account for this phenomenon, the geologist has only to examine the small deltas of torrents which enter the Swiss lakes when the waters are low, such as the newlyformerl plain where the Kander enters the Lake of Thun. He there sees sand and mud strewed orer with innumerable dead land shells, which have been brought down from vallers in the Alps in the preceding spring, during the melting of the snows. Again, if we search the sands on the borders of the Rhine, in the lower part of its course, we find countless land shells mixed with others of species belonging to lakes, stagnant pools, and marshes. These indiriduals have been washed away from the alluvial plains of the great river and its tributaries, some from mountainous regions, others from the low country. 
Although freshwater formations are often of great thickness, yet they are usually very limited in area when compared to marine deposits, just as lakes and estuaries are of small dimensions in comparison with seas.

We may distinguish a "freshwater formation, first, by the absence of many fossils almost invariably met with in marine strata. For example, there are no sea-urchins, no corals, and scarcely any zoophytes; no chambered shells, such as the nautilus, nor microscopic Foraminifera. But it is chiefly by attending to the forms of the mollusca that we are guided in determining the point in question. In a freshwater deposit, the number of individual shells is often as great, if not greater, than in a marine stratum ; but there is a smaller variety of species and genera. This might be anticipated from the fact that the genera and species of recent freshwater and land shells are few when contrasted with the marine. Thus, the genera of true mollusca according to Woodward's system, excluding those altogether extinct and those without shells, amount to 446 in number, of which the terrestrial and freshwater genera scarcely form more than a fifth.*

Almost all bivalve shells, or those of acephalous mollusca, are marine,

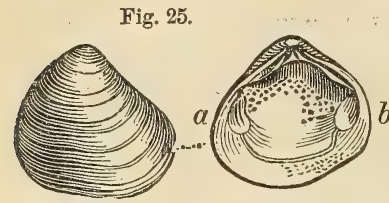

Cyclas obovata; fossil. Hants.
Fig. 26.

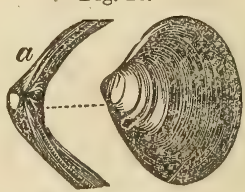

Cyrena consobrina; fossil. Grays, Hssex.

about ten only out of ninety genera being freshwater. Among these last, the four most common forms, both recent and fossil, are Cyclas, $C v$

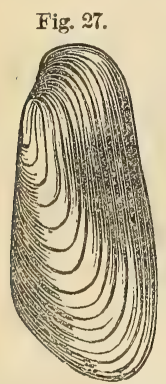

Anodonta Cordierii; fossil. Paris.

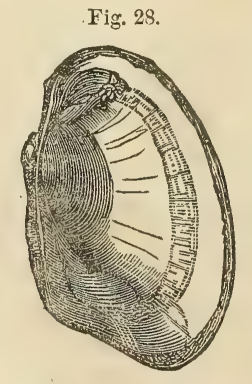

Anodonta latimarginatus; recent. Bahia.

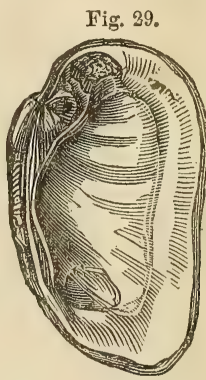

Unio littoralis; recent. Auvergne.

rena, Unio, and Anodonta (see figures); the two first and two last of which are so nearly allied as to pass into each other. 
Lamarck divided the bivalve mollusea into the Dimyary, or those having two large muscular impressions in each valve, as $a b$ in the Cyclas, fig. 25, and the Monomyary, such as the oyster and scallop, in which there is only one of these impressions, as is seen in fig. 30 . Now, as none of these last, or the unimuscular bivalves, are freshwater,* we may at once presume a deposit in which we find any of them to be marine.

The univalve shells most characteristic of aryphaca incurva, Sow. (G. fresh-water deposits are, Planorbis, Limnoca, and Paludina. (See figures.) But to these are occasionally added

Fig. 31.

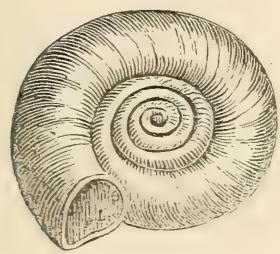

Planorbis euomphalus: fossil. Isle of Wight.
Fig. 32.

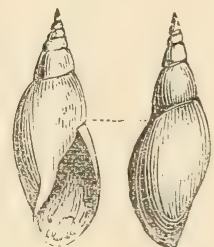

Limncea longiscata fossil. Hants.
Fig. 30.

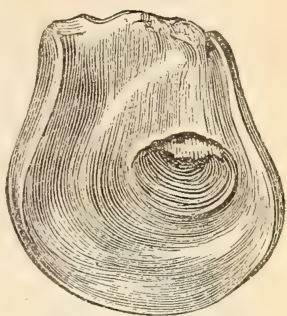

Physa, Succinea, Ancylus, Valvata, Melanopsis, Melania, Potamides, and Neritina. (See figures.)

Fig. 34 .

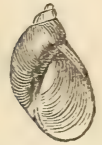

Succinea amphibia : fossil. Loess, Rhine.

Fig. 38.

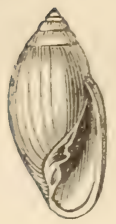

Auricula ; recent. Ava.
Fig. 35.

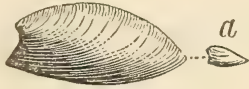

Ancylus elegans; fossil. Hants.

Fig. 39.

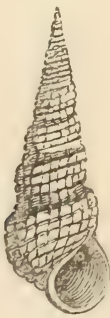

Melania inquinata. Paris basin.
Fig. 36.

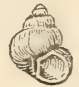

Talvaia; Physahypnom, fossil. recent. Grays, Essex.

\section{Paludina Zenta ;}

Fig. 37.

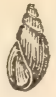

Fig. 41. fossil. Hants.

Fig. 33.

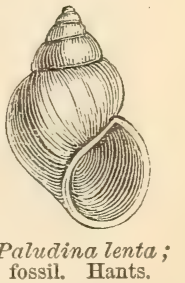

Fig. 40 .

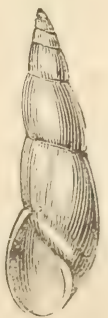

Physa columnaris. Paris basin.

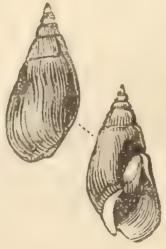

Melanopsis buccinoidea; recent. Asia.

* The freshwater Mulleria, which has two muscular impressions when young, has only one in the adult state, thus forming a single exception to the rule. 
Some naturalists include Neritina (fig. 42) and the marine Nerita (fig. 43) in the same genus, it being scarcely possible to distinguish

Fig. 42.

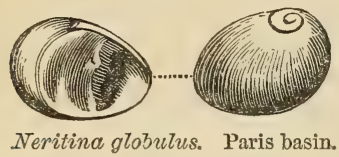

Fig. 43.

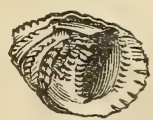

Nerita granulosa. Paris basin.
Fig. 44.

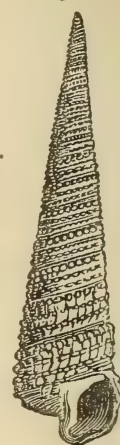

Potamides cinctus, Sow Paris basin.

the two by good generic characters. But, as a general rule, the fluviatile species are smaller, smoother, and more globular than the marine; and they have never, like the Neritce, the inner margin of the outer lip toothed or crenulated. (See fig. 43.)

The Potamides inhabit the mouths of rivers in warm latitudes, and are distinguished from the marine cerithia by their orbicular and multispiral opercula. The genus auricula (fig. 38) is amphibious, frequenting swamps and marshes within the influence of the tide.

The terrestrial shells are all univalves. The most abundant genera among these, both in a recent and fossil state, are Helix (fig. 45), $C y$ nlostoma (fig. 46), Pupja (fig. 47), Clausilia (fig. 48), Bulimus (fig. 49),

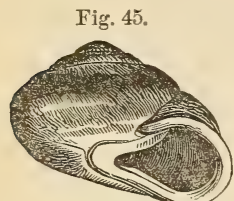

Hevix Turonensis. Faluns, Touraine.

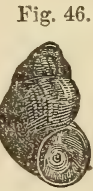

Cyclostoma Loess.
Fig, 47. Fig. 49.

Fig. 49 .
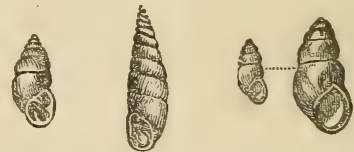

Buitimus lubricus. Loess, Rhine.

nnd Achatina; which two last are nearly allied and pass into each other.

The Ampullaria (fig. 50) is another genus of shells, inhabiting rivers

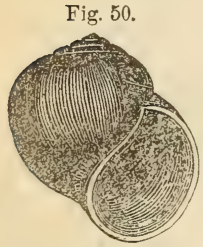

Ampullaria glauca, from the Jumna. and ponds in hot countries. Many fossil species have been referred to this genus, but they have been found chiefly in marine formations, and are suspected by some conchologists to belong to Natica and other marine genera.

All univalve shells of land and freshwater species, with the exception of Melanopsis (fig. 41), and Achatina, which, has a slight indentation, have entire mouths; and this circumstance may often serve as a convenient rule for distinguishing freshwater from marine strata; since, if any univalres occur of which the mouths are not entire, we may presume that the formation is marine. The aperture is said to be entire in such shells as the Ampullaria and the land shells (figs. 45$49)$, when its outline is not interrupted by an indentation or notch. 
such as that seen at $b$ in Ancillaria (fig. 52); or is not prolonged into a canal, as that seen at $\alpha$ in Pleurotoma (fig. 51).

The mouths of a large proportion of the marine univalves have these notches or canals, and almost all such species are carnivorous; whereas
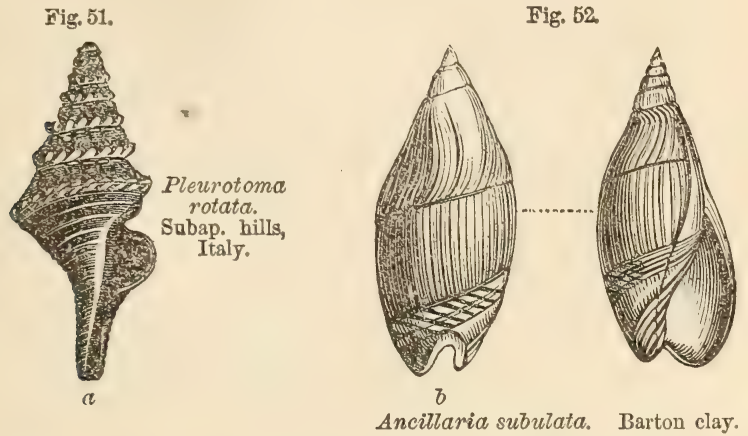

nearly all testacea having entire mouths, are plant-eaters; whether the species be marine, freshwater, or terrestrial.

There is, howerer, one genus which affords an occasional exception to one of the abore rules. The Cerithium (fig: 44), although provided with a short canal, comprises some species which inhabit salt, others brackish, and others fresh water, and they are said to be all plant-eaters.

Among the fossils very common in freshwater deposits are the shells of Cypris, a minute crustaceous animal, having a shell much resembling that of the bivalve mollusca.* Many minute living species of this genus swarm in lakes and stagnant pools in Great Britain; but their shells are not, if considered separately, conclusive as to the freshwater origin of a deposit, because the majority of species in another kindred genus of the same order, the Cytherina of Lamarck (see above, fig. 21, p. 26), inhabit salt water; and, although the animal differs slightly, the shell is scarcely distinguishable from that of the Cypris.

The seed-ressels and stems of Chara, a genus of aquatic plants, are rery frequent in freshwater strata. These seed-ressels were called, before their true nature was known, gyrogonites, and were supposed to be foraminiferous shells. (See fig. 53 a.)

The Charce inhabit the bottom of lakes and ponds, and flourish mostly where the water is charged with carbonate of lime. Their seedressels are corered with a very tough integ'ument, capable of resisting decomposition; to which circumstance we may attribute their abundanct in a fossil state. The annexed figure (fig. 54) represents a branch of one of many new species found by Professor Amici in the lakes of northern Italy. The seed-ressel in this plant is more globular than in the British Charce, and therefore more nearly rescmbles in form the extinct fossil species found in England, France, and other countries. The

* For figures of fossil species of Purbeck, see below, ch. $\mathbf{x x}$. 
stems, as well as the seed-ressels, of these plants occur both in modern shell marl and in ancient freshwater formations. They are generally

Fig. 53.

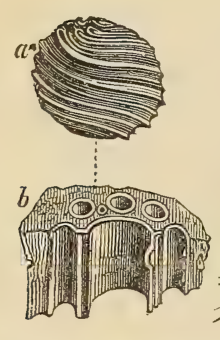

Chara medicaginula; fossil. Upper Eocene, Isle of Wight. a. Seed-vessel, magnified 20 diameters.

b. Stem, magnified.
Fig. 54.

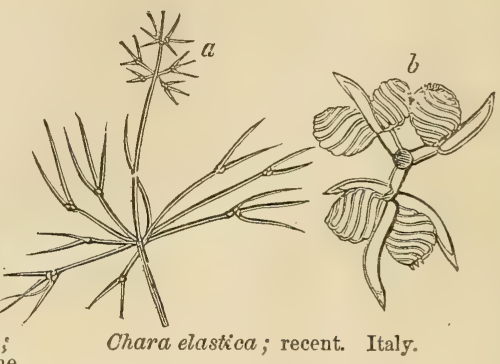

$a$. Sessile seed-vessel between the divisions of the leaves of the female plant.

b. Magnified transverse section of a branch, with five seed-vessels, seen from below npwards.

composed of a large tube surrounded by smaller tubes; the whole stem being divided at certain intervals by transverse partitions or joints. (See b, fig. 53.)

It is not uncommon to meet with layers of vegetable matter, impressions of leaves, and branches of trees, in strata containing freshwater shells; and we also find occasionally the teeth and bones of land quadrupeds, of species now unknown. The manner in which such remains are occasionally carried by rivers into lakes, especially during floods, has been fully treated of in the "Principles of Geology."

The remains of fish are occasionally useful in determining the freshwater origin of strata. Certain genera, such as carp, perch, pike, and loach (Cyprinus, Perca, Esox, and Cobitis), as also Lebias, being peculiar to freshwater. Other genera contain some freshwater and some marine species, as Cottus, Mugil, and Anguilla, or eel. The rest are either common to rivers and the sea, as the salmon; or are exclusively characteristic of salt water. The above observations respecting fossil fishes are applicable only to the more modern or tertiary deposits; for in the more ancient rocks the forms depart so widely from those of existing fishes, that it is very difficult, at least in the present state of science, to derive any positive information from icthyolites respecting the element in which strata were deposited.

The alternation of marine and freshwater formations, both on a small and large scale, are facts well ascertained in geology. When it occurs on a small scale, it may have arisen from the alternate occupation of certain spaces by river water and the sea; for in the flood season the river forces back the ocean and freshens it over a large area, depositing at the same time its sediment; after which the salt water again returns, and, on resuming its former place, brings with it sand, mud, and marine shells.

* See Index of Principles, "Fossilization." 
There are also lagoons at the mouths of many rivers, as the Nile and Mississippi, which are divided off by bars of sand from the sea, and which are filled with sait and fresh water by turns. They often communicate exclusively with the river for months, years, or even centuries; and then a breach being made in the bar of sand, they are for long periods filled with salt water.

The Lrm-Fiord in Jutland offers an excellent illustration of analogous changes; for, in the course of the last thousand years, the western extremity of this long frith, which is 120 miles in length, including its windings, has been four times fresh and four times salt, a bar of sand between it and the ocean having been 'as often formed and removed. The last irruption of salt water happened in 1824, when the North Sea entered, killing all the freshwater shells, fish, and plants ; and from that time to the present, the sea-reed Fucus vesiculosus, together with oysters and other marine mollusca, have succeeded the Cyclas, Lymnea, Paludina, and Charce.*

But changes like these in the Lym-Fiord, and those before mentioned as occurring at the mouths of great rivers, will only account for some cases of marine deposits of partial extent resting on freshwater strata. When we find, as in the southeast of England, a great series of freshwater beds, 1000 feet in thickness, resting upon marine formations and again covered by other rocks, such as the cretaceous, more than 1000 feet thick, and of deep-sea origin, we shall find it necessary to seek for a different explanation of the phenomena. $\dagger$

\section{CHAPTER IV.}

CONSOLIDATION OF STRATA AND PETRIFACTION OF FOSSILS.

Chemical and mechanical deposits-Cementing together of particles-Hardening by exposure to air-Concretionary nodules-Consolidating effects of pressureMineralization of organic remains-Impressions and casts how formed-Fossil Trood-Göppert's experiments-Precipitation of stony matter most rapid where putrefaction is going on-Source of lime in solution-Silex derived from de. composition of felspar-Proofs of the lapidification of some fossils soon after burial, of others when much decayed.

HAvivg spoken in the preceding chapters of the characters of sedimentary formations, both as dependent on the deposition of inorganic matter and the distribution of fosil; I mar next treat of the consolidation of stratified rocks, and the petrinction of imbedded organic remains.

Chemical and mechanical depinsils.-A distinction has been made bv

* See Principles, Index, "Lym-Fiord."

† See below, Chap. XVIII., on the Wealden. 
geologists between deposits of a chemical, and those of a mechanical. origin. By the latter name are designated beds of mud, sand, or pebbles produced by the action of running water, also accumulations of stones and scoriæ thrown out by a volcano, which have fallen into their present place by the force of gravitation. But the matter which forms a chemical deposit has not been mechanically suspended in water, but in a state of solution until separated by chemical action. In this manner carbonate of lime is often precipitated upon the bottom of lakes and seas in a solid form, as may be well seen in many parts of Italy, where mineral springs abound, and where the calcareous stone, called travertin, is deposited. In these springs the lime is usually held in solution by an excess of carbonic acid, or by heat if it be a hot spring, until the water, on issuing from the earth, cools or loses part of its acid. The calcareous matter then falls down in a solid, state, incrusting shells, fragments of wood and leaves, and binding them together.*

In coral reefs, large masses of limestone are formed by the stony skeletons of zoophytes; and these, together with shells, become cemented together by carbonate of lime, part of which is probably furnished to the sea-water by the decomposition of dead corals. Even shells of which the animals are still living, on these reefs, are very commonly found to be incrusted over with a hard coating of limestone. $\dagger$

If sand and pebbles are carried by a river into the sea, and these are bound together immediately by carbonate of lime, the deposit may be described as of a mixed origin, partly chemical, and partly mechanical.

Now, the remarks already made in Chapter II. on the original horizontality of strata are strictly applicable to mechanical deposits, and only partially to those of a mixed nature. Such as are purely chemical may be formed on a very steep slope, or may even incrust the vertical walls of a fissure, and be of equal thickness throughout; but such deposits are of small extent, and for the most part confined to vein-stones.

Cementing of particles.-It is chiefly in the case of calcareous rocks that solidification takes place at the time of deposition. But there are many deposits in which a cementing process comes into operation long afterwards. We may sometimes observe, where the water of ferruginous or calcareous springs has flowed through a bed of sand or gravel, that iron or carbonate of lime has been deposited in the interstices between the grains or pebbles, so that in certain places the whole has been bound together into a stone, the same set of strata remaining in other parts loose and incoherent.

Proofs of a similar cementing action are seen in a rock at Kelloway in Wiltshire. A peculiar band of sandy strata, belonging to the group called Oolite by geologists, may be traced through several counties, the sand being for the most part loose and unconsolidated, but becoming

* See Principles, Index, "Calcareous Springs," \&c.

† Ibid. "Travertin," "Coral Reefs," \&c. 
stony near Keiloway. In this district there are numerous fossil shells which have decomposed, having for the most part left only their casts. The calcareous matter hence derived has evidently served, at some former period, as a cement to the siliceous grains of sand, and thus a solid sandstone has been produced. If we take fragments of many other argillaceous grits, retaining the casts of shells, and plunge them imto dilute muriatic or other acid, we see them immediately changed into common sand and mud; the cement of lime derived from the shells, having been dissolved by the acid.

Traces of impressions and casts are often extremely faint. In some loose sands of recent date we meet with shells in so advanced a stage of decomposition as to crumble into powder when touched. It is clear that water percolating such strata may soon remove the calcareous matter of the shell ; and, unless circumstances cause the carbonate of lime to be again deposited, the grains of sand will not be cemented together; in which case no memorial of the fossil will remain. The absence of organic remains from many aqueous rocks may be thus explained; but we may presume that in many of them no fossils were ever imbedded, as there are extensive tracts on the bottoms of existing seas even of moderate depth on which no fragment of shell, coral, or other living creature can be detected by dredging. On the other hand, there are parts of the Mediterranean (the Egean sea for example), where, according to Prof. E. Forbes, the zero of animal life has been reached, at the depth of 230 fathoms; a deposit of yellowish mud of very uniform character, and devoid of organic remains, being there in progress.* Later experiments, however, have proved that organic being's inhabit other parts of the same sea at considerably greater depths.

In what manner silex and carbonate of lime may become widely diffused in small quantities through the waters which permeate the earth's crust will be spoken of presently, when the petrifaction of fossil bodies is considered; but I may remark here that such waters are always passing in the case of thermal springs from hotter to colder parts of the interior of the earth; and as often as the temperature of the solvent is lowered, mineral matter has a tendency to separate from it and solidify. Thus a stony cement is often supplied to sand, pebbles, or any fragmentary mixture. In some conglomerates, like the pudding-stone of Hertfordshire (a Lower Eocene deposit), pebbles of flint and grains of sand are united by a siliceous cement so firmly, that if a block be fractured the rent passes as readily through the pebbles as through the cement.

It is probable that many strata became solid at the time when they emerged from the waters in which they were deposited, and when they first formed a part of the dry land. A well-known fact seems to confirm this idea: by far the greater number of the stones used for building and road-making are much softer when first taken from the quarry than after they have been long exposed to the air ; and these, when once

* Report Brit. Ass. 1843, p. 178. 
dried, may afterwards be immersed for any length of time in water without becoming soft again. Hence it is found desirable to shape the stones which are to be used in architecture while they are yet soft and wet, and while they contain their " quarry-water," as it is called; also to break up stone intended for roads when soft, and then leave it to dry in the air for months that it may harden. Such induration may perhaps be accounted for by supposing the water, which penetrates the minutest pores of rocks, to deposit, on evaporation, carbonate of lime, iron, silex, and other minerals previously held in solution, and thereby to fill up the pores partially. These particles, on crystallizing, would not only be themselves deprived of freedom of motion, but would also bind together other portions of the rock which before were loosely aggregated. On the same principle wet sand and mud become as hard as stone when frozen; because one ingredient of the mass, namely, the water, has crystallized, so as to hold firmly together all the separate particles of which the loose mud and sand were composed.

Dr. MacCulloch mentions a sandstone in Skye, which may be moulded like dough when first found; and some simple minerals, which are rigid and as hard as glass in our cabinets, are often flexible and soft in their native beds; this is the case with asbestos, sahlite, tremolite, and chalcedony, and it is reported also to happen in the case of the beryl.*

The marl recently deposited at the bottom of Lake Superior, in North America, is soft, and often filled with freshwater shells; but if a piecc be taken up and dried, it becomes so hard that it can only be broken by a smart blow of the hammer. If the lake therefore was drained, such a deposit would be found to consist of strata of marlstone, like that observed in many ancient European formations, and like them containing freshwater shells.

It is probable that some of the heterogeneous materials which rivers transport to the sea may at once set under water, like the artificial mixture called pozzolana, which consists of fine volcanic sand charged with about 20 per cent. of oxide of iron, and the addition of a small quantity of lime. This substance hardens, and becomes a solid stone in water, and was used by the Romans in constructing the foundations of buildings in the sea.

Consolidation in these cases is brought about by the action of chemical affinity on finely comminuted matter previously suspended in water. After deposition similar particles seem to exert a mutual attraction on each other, and congregate together in particular spots, forming lumps, nodules, and concretions. Thus in many argillaceous deposits there are calcareous balls, or spherical concretions, ranged in layers parallel to the general stratification; an arrangement which took place after the shale nr marl had been thrown down in successive laminæ; for these laminæ

* Dr. MacCulloch, Syst. of Geol. vol. i. p. 123. 
are often traced in the concretions, remaining parallel to those of the surrounding unconsolidated rock. (See fig. 55.) Such nodules of lime-

Fig. 55.

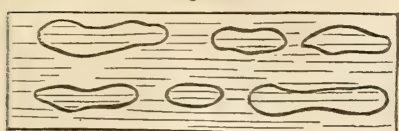

Calcareous nodules in Lias. stone have often a shell or other foreign body in the centre.*

Among the most remarkable exam. ples of concretionary structure are those described by Professor Sedgwick as abounding in the magnesian limestone of the north of England. The spherical balls are of various sizes, from that of a pea to a diameter of several feet, and they have both a concentric and radiated structure, while at the same time the laminæ of original deposition pass uninterruptedly through them. In some cliffs this limestone resembles a great irregular pile of cannon balls. Some of the globular masses have their centre in one stratum, while a portion of their exterior passes through to the stratum abore or belcw. Thus the larger spheroid in the annexed section (fig. 56) passes from the

Fig. 5̌.

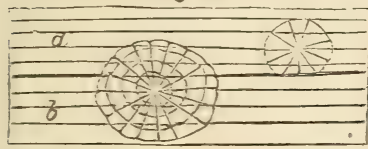

Spheroidal concretions in magnesian limestone. stratum $b$ upwards into $a$. In this instance we must suppose the deposition of a series of minor layers, first forming the stratum $b$, and afterwards the incumbent stratum $a$; then a movement of the particles took place, and the carbonates of lime and magnesia separated from the more impure and mixed matter, forming the still uneonsolidated parts of the stratum. Crrstallization, beginning at the centre, must hare gone on forming concentric coats, around the original nucleus without interfering with the laminated structure of the rock.

When the particles of rocks have been thus rearranged by chemical forces, it is sometimes difficult or impossible to ascertain whether certain lines of dirision are due to original deposition or to the subsequent aggregation of similar particles. Thus suppose three strata of grit, A, B,

Fig. 57.

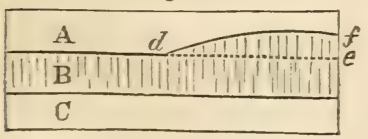

$\mathrm{C}$, are charged unequally with calcareous matter, and that $\mathrm{B}$ is the most calcareous. If consolidation takes place in $\mathrm{B}$, the concretionary action may spread upwards into a part of $\mathrm{A}$, where the carbonate of lime is more abundant than in the rest ; so that a mass $d, e, f$, forming a portion of the superior stratum, becomes united with $\mathrm{B}$ into one solid mass of stone. The original line of dirision $d, e$, being thus effaced, the line $d, f$, would generally be considered as the surface of the bed B, though not strictly a true plane of stratification.

Pressure and heat.- When sand and mud sink to the bottom of it deep sea, the particles are not pressed down by the enormous weight of the incumbent ocean; for the water, which becomes mingled with the sand and mud, resists pressure with a force equal to that of the column

* De la Beche, Geol Researches, p. 95, and Geol. Obserrer (1851), p. 686. 
of fluid above. The same happens in regard to organic remains which are filled with water under great pressure as they sink, otherwise they would be immediately crushed to pieces and flattened. Nevertheless, it the materials of a stratum remain in a yielding state, and do not set or solidify, they will be gradually squeezed down by the weight of other materials successively heaped upon them, just as soft clay or loose sand on which a house is built may give way: By such downward pressure particles of clay, sand, and marl, may become packed into a smaller space, and be made to cohere together permanently.

Analogous effects of condensation may arise when the solid parts of the earth's crust are forced in various directions by those mechanical movements afterwards to be described, by which strata have been bent, broken, and raised above the level of the sea. Rocks of more yielding materials must often have been forced against others previously consolidated, and, thus compressed, may have acquired a new structure. A recent discovery may help us to comprehend how fine sediment derived from the detritus of rocks may be solidified by mere pressure. The graphite or "black lead" of commerce having become very scarce, $\mathrm{Mr}$. Brockedon contrived a method by which the dust of the purer portions of the mineral fourd in Borrowdale might be recomposed into a mass as dense and compact as native graphite. The powder of graphite is first carefully prepared and freed from air, and placed under a powerful press on a strong steel die, with air-tight fittings. It is then struck several blows, each of a power of 1000 tons ; after which operation the powder is so perfectly solidified that it can be cut for pencils, and exhibits when broken the same texture as native graphite.

But the action of heat at various depths in the earth is probably the most powerful of all causes in hardening sedimentary strata. To thie subject I shall refer again when treating of the metamorphic rocks, and of the slaty and jointed structure.

Mineralization of organic remains.-The changes which fossil organic bodies have undergone since they were first imbedded in rocks, throw much light on the consolidation of strata. Fossil shells in some modern deposits have been scarcely altered in the course of centuries, having simply lost a part of their animal matter. But in other cases the shell has disappeared, and left an impression only of its exterior, or a cast of its interior form, or thirdly, a cast of the shell itself, the original matter of which has been removed. These different forms of fossilization may easily be understood if we examine the mud recently thrown out from a pond or canal in which there are shells. If the mud be argillaceous, it acquires consistency on drying, and on breaking open a portion of it we find that each shell has left impressions of its external form. If we then remove the shell itself, we find within a solid nucleus of clay, having the form of the-interior of the shell. This form is often very different from that of the outer shell. Thus a cast such as $\alpha$, fig. 58, commonly called a fossil screw, would never be suspected by an inexperienced conchologist to be the internal shape of the fossil univalve, $b$, fig. 58 . Nor should 
we have imagined at first sight that the shell $a$ and the cast $b$, fig. 59 , were different parts of the same fossil. The reader will observe, in the

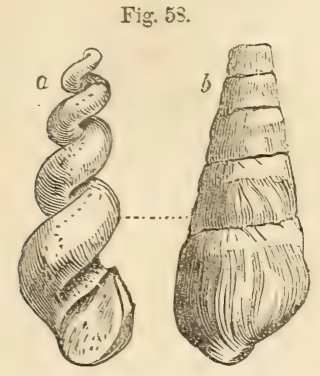

Phasianella Heddingtonensis, and cast of the same. Coral Rag.

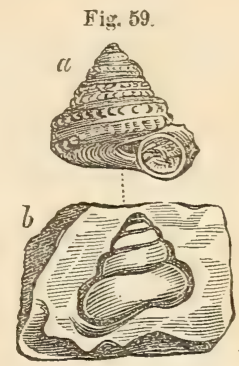

Pleurotomaria Anglica and cast. Lias.

last-mentioned figure ( $b$, fig:. 59), that an empty space shaded dark, which the shell itself once occupied, now intervenes between the enveloping stone and the cast of the smooth interior of the whorls. In such cases the shell has been dissolved and the component particles removed by water percolating the rock. If the nucleus were taken out a hollow mould would remain, on which the external form of the shell with its tubercles and stria, as seen in a, fig. 59, would be seen embossed. Now if the space alluded to between the nucleus and the impression, instead of being left empty, has been filled up with calcareous spar, flint, pyrites, or other mineral, we then obtain from the mould an exact cast both of the external and internal form of the original shell. In this manner silicified casts of shells have been formed; and if the mud or sand of the nucleus happen to be incoherent, or soluble in acid, we can then procure in flint an empty shell, which in shape is the exact counterpart of the original. This cast may be compared to a bronze statue, representing; merely the superficial form, and not the internal organization; but there is another description of petrifaction by no means uncommon, and of a much more wonderful kind, which may be compared to certain anatomical models in wax, where not only the outward forms and features, but the nerres, blood-ressels, and other internal organs are also shown. Thus we find corals, originally calcareous, in which not only the general shape, but also the minute and complicated internal organization are retained in flint.

Such a process of petrifaction is still more remarkably exhibited in fossil wood, in which we often perceive not only the rings of annual growth, but all the minute ressels and medullary rays. Many of the minute cells and fibres of plants, and eren those spiral ressels which in the living regetable can only be discorered by the microscope, are preserved. Among many instances, I may mention a fossil tree, 72 feet in length, found at Gosforth near Newcastle, in sandstone strata associated with coal. By cutting a transrerse slice so thin as to transmit light, and magnifying it about fifty-five times, the texture seen in fig. 60 is ex- 
hibited. A texture equally minute and complicated has been observed

Fig 60.

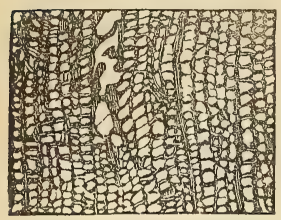

Texture of a tree from the coal strata, magnified. (Witham.) Transverse section. in the wood of large trunks of fossil trees found in the Craigleith quarry near Edinburgh, where the stone was not in the slightest degree siliceous, but consisted chiefly of carbonate of lime, with oxide of iron, alumina, and carbon. The parallel rows of vessels here seen are the rings of annual growth, but in one part they are imperfectly preserved, the wood having probably decayed before the mineralizing matter had penetrated to that portion of the tree.

In attempting to explain the process of petrifaction in such cases, we may first assume that strata are very generally permeated by water charged with minute portions of calcareous, siliceous, and other earths in solution. In what manner they become so impregnated will be afterwards considered. If an organic substance is exposed in the open air to the action of the sun and rain, it will in time putrefy, or be dissolved into its component elements, which consist chiefly of oxygen, hydrogen, and carbon. These will readily be absorbed by the atmosphere or be washed away by rain, so that all vestiges of the dead animal or plant disappear. But if the same substances be submerged in water, they decompose more gradually; and if buried in earth, still more slowly, as in the familiar example of wooden piles or other buried timber. Now, if as fast as each particle is set free by putrefaction in a fluid or gaseous state, a particle equally minute of carbonate of lime, flint, or other mineral, is at hand and ready to be precipitated, we may imagine this inorganic matter to take the place just before left unoccupied by the organic molecule. In this manner a cast of the interior of certain vessels may first be taken, and afterwards the more solid walls of the same may decay and suffer a like transmutation. Yet when the whole is lapidified, it may not form one homogeneous mass of stone or metal. Some of the original ligneous, osseous, or other organic elements may remain mingled in certain parts, or the lapidifying substance itself may be differently colored at different times, or so crystallized as to reflect light differently, and thus the texture of the original body may be faithfully exhibited.

The student may perhaps ask whether, on chemical principles, we have any ground to expect that mineral matter will be thrown down precisely in those spots where organic decomposition is in progress? The following curious experiments may serve to illustrate this point. Professor Göppert of Breslau attempted recently to imitate the natural process of petrifaction. For this purpose he steeped a variety of animal and vegetable substances in waters, some holding siliceous, others calcareous, others metallic matter in solution. He found that in the period of a few weeks, or even days, the organic bodies thus immersed were mineralized to a certain extent. Thus, for example, thin vertical slices of deal, taken from the Scotch fir (Pinus sylvestris), were immersed in a moderately 
strong solution of sulphate of iron. When they had been thorvughly soaked in the liquid for several days they were dried and exposed to a red-heat until the vegetable matter was burnt up and nothing remained but an oxide of iron, which was found to have taken the form of the deal so exactly that casts even of the dotted vessels peculiar to this family of plants were distinctly visible under the microseope.

Another accidental experiment has been recorded by Mr. Pepys in the Geological Transactions.* An earthen pitcher containing several quarts of sulphate of iron had remained undisturbed and unnoticed for about a twelvemonth in the laboratory. At the end of this time when the liquor was examined an oily appearance was observed on the surface, and a yellowish powder, which proved to be sulphur, together with a quantity of șmall hairs. At the bottom were discovered the bones of several mice in a sediment consisting of small grains of pyrites, others of sulphur, others of crystallized green sulphate of iron, and a black muddy oxide of iron. It was evident that some mice had accidentally been drowned in the fluid, and by the mutual action of the animal matter and the sulphate of iron on each other, the metallic sulphate had been deprived of its oxygen; hence the pyrites and the other compounds were thrown down. Although the mice were not mineralized, or turned into pyrites, the phenomenon shows how mineral waters, charged with sulphate of iron, may be deoxydated on coming in contact with animal matter undergoing putrefaction, so that atom after atom of pyrites may be precipitated, and ready, under favorable circumstances, to replace the oxygen, hydrogen, and carbon into which the original body would be resolved.

The late Dr. Turner observes, that when mineral matter is in a "nascent state," that is to say, just liberated from a previous state of chemical combination, it is most ready to unite with other matter, and form a new chemical compound. Probably the particles or atoms just set free are of extreme minuteness, and therefore move more freely, and are more ready to obey any impulse of chemical affinity. Whatever be the cause, it clearly follows, as before stated, that where organic matter newly imbedded in sediment is decomposing, there will chemical changes take place most actively.

An analysis was lately made of the water which was flowing off from the rich mud deposited by the Hooghly river in the Delta of the Ganges after the annual inundation. This water was found to be highly charged with carbonic acid gas holding lime in solution. $\nmid$ Now if newlydeposited mud is thus proved to be permeated by mineral matter in a state of solution, it is not difficult to perceive that decomposing organic bodies, naturally imbedded in sedinent, may as readily become petrified as the substances artificially immersed by Professor Göppert in various fluid mixtures.

It is well known that the water of springs, or that which is continually

* Vol. i. p. 399, first series.

$\uparrow$ Piddington, Asiat. Research. vol, xviii. p. 226. 
percolating the earth's crust, is rarely free from a slight admixture either of iron, carbonate of lime, sulphur, silica, potash, or some other earthy, alkaline, or metallic ingredient. Hot springs in particular are copiously charged with one or more of these elements; and it is only in their waters that silex is found in abundance. In certain cases, therefore, especially in volcanic regions, we may imagine the flint of silicified wood and corals to have been supplied by the waters of thermal springs. In other instances, as in tripoli, it may have been derived in great part, if not wholly, from the decomposition of diatomacer, sponges, and other bodies. But even if this be granted, we have still to inquire whence a lake or the ocean can be constantly replenished with the calcareous and siliceous matter so abundantly withdrawn from it by the secretions of living beings.

In regard to carbonate of lime there is no difficulty, because not only are calcareous springs very numerous, but even rain-water, when it falls on ground where vegetable matter is decomposing, may become so charged with carbonic acid as to acquire a power of dissolving a minute portion of the calcareous rocks over which it flows. Hence marine corals and mollusea may be provided by rivers with the materials of their shells and solid supports. But pure silex, even when reduced to the finest powder and boiled, is insoluble in water, except at very high temperatures. Nevertheless Dr. Turner has well explained, in an essay on the chemistry of geology, * how the decomposition of felspar may be a source of silex in solution. He has remarked that the siliceous earth, which constitutes more than half the bulk of felspar, is intimately combined with alumine, potash, and some other elements. The alkaline matter of the felspar has a chemical affinity for water, as also for the carbonic acid which is more or less contained in the waters of most springs. The water therefore carries away alkaline matter, and leaves behind a clay consisting of alumine and silica. But this residue of the decomposed mineral, which in its purest state is called porcelain clay, is found to contain a part only of the silica which existed in the original felspar. The other part, therefore, must have been dissolved and removed; and this can be accounted for in two ways ; first, because silica when combined with an alkali is soluble in water; secondly, because silica in what is technically called its nascent state is also soluble in water. Hence an endless supply of silica is afforded to rivers and the waters of the sea. For the felspathic rocks are universally distributed, constituting, as they do, so large a proportion of the volcanic, plutonic, and metamorphic formations. Even where they chance to be absent in mass, they rarely fail to occur in the superficial gravel or alluvial deposits of the basin of every large river.

The disintegration of mica also, another mineral which enters largely into the composition of granite and various sandstones, may yield silica which may be dissolved in water, for nearly half of this mineral consists of silica, combined with alumine, potash, and about a tenth part of iron. The oxidation of this iron in the air is the principal cause of the waste of mica.

* Jam. Ed. New Phil. Journ. No. 30, p. 246. 
We have still, however, much to learn before the conversion of fossil bodies into stone is fully understood. Some phenomena seem to imply that the mineralization must proceed with considerable rapidity, for stems of a soft and succulent character, and of a most perishable nature, are preserved in flint; and there are instances of the complete silicification of the young leaves of a palm-tree when just about to shoot forth, and in that state which in the West Indies is called the cabbage of the palm.* It may, however, be questioned whether in such cases there may not have been some antiseptic quality in the water which retarded putrefaction, so that the soft parts of the buried substance may have remained for a long time without disintegration, like the flesh of bodies imbedded in peat.

Mr. Stokes has pointed out examples of petrifactions in which the more perishable, and others where the more durable portions of wood are preserved. These variations, he suggests, must doubtless have depended on the time when the lapidifying mineral was introduced. Thus, in certain silicified stems of palm-trees, the cellular tissue, that most destructible part, is in good condition, while all signs of the hard woody fibre have disappeared, the spaces once occupied by it being hollow or filled with agate. Here, petrifaction must have commenced soon after the wood was exposed to the action of moisture, and the supply of mineral matter must then have failed, or the water must have become too much diluted before the woody fibre decayed. But when this fibre is alone discoverable, we must suppose that an interval of time elapsed before the commencement of lapidification, during which the cellular tissue was obliterated. When both structures, namely, the cellular and the woody fibre, are preserved, the process must have commenced at an early period, and continued wichout interruption till it was completed throughout. ${ }^{-}$

* Stokes, Geol. Trans. vol. v. p. 212, second series. + Ibid. 


\section{CHAPTER V.}

\section{ELEVATION OF STRATA ABOVE THE SEA-HORIZONTAL AND INCLINED} STRATIFICATION,

Why the position of marine strata, above the level of the sea, should be referred to the rising up of the land, not to the going down of the sea-Upheaval of extensive masses of horizontal strata-Inclined and vertical stratification-Anticlinal and synclinal lines-Bent strata in east of Scotiand-Theory of folding by lateral movement-Creeps-Dip and strike-Structure of the Jura-Various forms of outcrop-Rocks broken by flexure-Inverted position of disturbed strata-Unconformable stratification-Hutton and Playfair on the same-Fractures of strata--Polished surfaces-Faults-Appearance of repeated alternations produced by them-Origin of great faults.

$L_{A N D}$ has been raised, not the sea lowered.-It has been already stated that the aqueous rocks containing marine fossils extend over wide continental tracts, and are seen in mountain chains rising to great heights above the level of the sea (p. 4). Hence it follows, that what is now dry land was once under water. But if we admit this conclusion, we must imagine, either that there has been a general lowering of the waters of the ocean, or that the solid rocks, once covered by water, have been raised up bodily out of the sea, and have thus become dry land. The earlier geologists, finding themselves reduced to this alternative, embraced the former opinion, assuming that the ocean was originally universal, and had gradually sunk down to its actual level, so that the present islands and continents were left dry. It seemed to them far easier to conceive that the water had gone down, than that solid land had risen upwards into its present position. It was, however, impossible to invent any satisfactory hypothesis to explain the disappearance of so enormous a body of water throughout the globe, it being necessary to infer that the ocean had once stood at whatever height marine shells might be detected. It moreover appeared clear, as the science of Geology advanced, that certain spaces on the globe had been alternately sea, then land, then estuary, then sea again, and, lastly, once more habitable land, having remained in each of these states for considerable periods. In order to account for such phenomena, without admitting any movement of the land itself, we are required to imagine several retreats and returns of the ocean; and even then our theory applies merely to cases where the marine strata composing the dry land are horizontal, leaving unexplained those more 3ommon instances where strata are inclined, curved, or placed on their edges, and evidently not in the position in which they were first deposited.

Geologists, therefore, were at last compelled to have recourse to the other alternative, namely, the doctrine that the solid land has been repeatedly moved upwards or hownwards, so as permanently to change its 
position relatively to the sea. There are several distinct grounds for preferring this conclusion. First, it will account equally for the position of those elevated masses of marine origin in which the stratification remains horizontal, and for those in which the strata are disturbed, broken, inclined, or rertical. Secondly, it is consistent with human experience that land should rise gradually in some places and be depressed in others. Such changes hare actually occurred in our own days, and are now in progress, haring been accompanied in some cases by violent conrulsions, while in others they have proceeded so insensibly, as to have been ascertainable only by the most careful scientific observations, made at considerable intervals of time. On the other hand, there is no evidence from human experience of a lowering of the sea's level in any region, and the ocean cannot sink in one place without its level being depressed all over the globe.

These preliminary remarks will prepare the reader to understand the great theoretical interest attached to all facts connected with the position of strata, whether horizontal or inclined, curved or vertical.

Now the first and most simple appearance is where strata of marine origin occur abore the lerel of the sea in horizontal position. Such are the strata which we meet with in the south of Sicily, filled with shells for the most part of the same species as those now liring in the Mediterranean. Some of these rocks rise to the height of more than 2000 feet abore the sea. Other mountain masses might be mentioned, composed of horizontal strata of high antiquits, which contain fossil remains of animals wholly dissimilar from any now known to exist. In the south of Srreden, for example, near Lake Wener, the beds of one of the oldest of the fossiliferous deposits, namel $\Gamma$, that formerly called Transition, and now Silurian, by geologists, occur in as level a position as if they had recently formed part of the delta of a great river, and been left dry on the retiring of the annual floods. Aqueous rocks of about the same age extend for hundreds of miles orer the lake-district of North America, and exhibit in like manner a stratification nearly undisturbed. The Table Mountain at the Cape of Good Hope is another example of highly elerated ret perfectly horizontal strata, no less than 3500 feet in thickness, and consisting of sandstone of very ancient date.

Instead of imagining that such fossiliferous rocks were alwars at their present level, and that the sea was once high enough to corer them, we suppose them to have constituted the ancient bed of the ocean, and that ther were gradually uplifted to their present height. This idea, howwre startling it may at first appear, is quite in accordance, as before statel, with the analogy of changes now going on in certain regions of the globe. Thus, in parts of Sweden, and the shores and islands of the Gulf of Bothnia, proofs have been oltained that the land is experiencing. and has experienced for centuries, a slow uphearing morement. Playfair argued in faror of this opinion in 1802 ; and in 180 7 , Ton Buch, after his trarels in Scandinaria, announced his conviction that a rising of the land was in progress. Celsius and other Swedish writers had. 
a century before, declared their belief that a gradual change had, for ages, been taking place in the relative level of land and sea. They attributed the change to a fall of the waters both of the ocean and the Baltic. This theory, however, has now been refuted by abundant evidence; for the alteration of relative level has neither been universal nor everywhere uniform in quantity, but has amounted, in some regions, to several feet in a century, in others to a few inches; while in the southernmost part of Sweden, or the province of Scania, there has been actually a loss instead of a gain of land, buildings having gradually sunk below the level of the sea.*

It appears, from the observations of Mr. Darwin and others, that very extensive regions of the continent of South America have been undergoing slow and gradual upheaval, by which the level plains of Patagonia, covered with recent marine shells, and the Pampas of Buenos Ayres, have been raised above the level of the sea. $f$ On the other hand, the gradual sinking of the west coast of Greenland, for the space of more than 600 miles from north to south, during the last four centuries, has been established by the observations of a Danish naturalist, Dr. Pingel. And while these proofs of continental elevation and subsidence, by slow and insensible movements, have been recently brought to light, the evidence has been daily strengthened of continued changes of level effected by violent convulsions in countries where earthquakes are frequent. There the rocks are rent from time to time, and heaved up or thrown down several feet at once, and disturbed in such a manner, that the original position of strata may, in the course of centuries, be modified to any amount.

It has also been shown by Mr. Darwin, that, in those seas where circular coral islands and barrier reefs abound, there is a slow and continued sinking of the submarine mountains on which the masses of coral are based; while there are other areas of the South Sea, where the land is on the rise, and where coral has been upheaved far above the sea-level.

It would require a volume to explain to the reader the various facts which establish the reality of these movements of land, whether of elevation or depression, whether accompanied by earthquakes or accomplished slowly and without local disturbance. Having treated fully of these subjects in the Principles of Geology, $\$$ I shall assume, in the present work, that such changes are part of the actual course of nature; and when admitted, they will be found to afford a key to the interpretation of a variety of geological appearances, such as the elevation of horizontal, inclined, or disturbed marine strata, and the superposition of fresh-

* In the first three editions of my Principles of Geology, I expressed many doubts as to the validity of the alleged proofs of a gradual rise of land in Sweden; but after visiting that country, in 1834, I retracted these objections, and published a detailed statement of the observations which led me to alter my opinion in the Phil. Trans. 1835, Part I. See also the Principles, 4th and subsequent editions.

† See his Journal of a Naturalist in Voyage of the Beagle, and his work on Coral Reefs.

‡ See chapters xxvii, to xxxii. inclusive, and chap. 1. 
water to marine deposits, afterwards to be described. It will also appear, in the sequel, how much light the doctrine of a continued subsidence of land may throw on the manner in which a series of strata, formed in shallow water, may have accumulated to a great thickness. The excavation of valleys also, and other effects of denudation, of which I shal! presently treat, can alone be understood when we duly appreciate the proofs, now on record, of the prolonged rising and sinking of land, throughout wide areas.

To conclude this subject, I may remind the reader, that were we to embrace the doctrine which ascribes the elevated position of marine formations, and the depression of certain freshwater strata, to oscillations in the level of the waters instead of the land, we should be compelled to admit that the ocean has been sometimes everywhere much shallower than at present, and at others more than three miles deeper.

Inclined stratification.-The most unequivocal evidence of a change in the original position of strata is afforded by their standing up perpendicularly on their edges, which is by no means a rare phenomenon, especially in mountainous countries. Thus we find in Scotland, on the southern skirts of the Grampians, beds of pudding-stone alternating with thin layers of fine sand, all placed vertically to the horizon. When Saussure first observed certain conglomerates in a similar position in the Swiss Alps, he remarked that the pebbles, being for the most part of an oval shape, had their longer axes parallel to the planes of stratification (see fig. 61). From this he inferred, that such strata must, at first, have been horizontal, each oval pebble having originally settled at the bottom of the Vertical conglomerate and sandstonc. water, with its flatter side parallel to the horizon, for the same reason that an egg will not stand on either end if unsupported. Some few, indeed, of the rounded stones in a conglomerate occasionally afford an exception to the above rule, for the same reason that we see on a shingle beach some oval or flat-sided pebbles resting on their ends or edges; these having been forced along the bottom and against each other by a wave or current so as, to settle in this position.

Vertical strata, when they can be traced continuously upwards or downwards for some depth, are almost invariably seen to be parts of great curves, which may have a diameter of a few yards, or of several miles. I shall first describe two curves of considerable regularity, which occur in Forfarshire, extending over a country twenty miles in breadth, from the foot of the Grampians to the sea near Arbroath.

The mass of strata here shown may be nearly 2000 feet in thickness, consisting of red and white sandstone, and various colored shales, the beds being distinguishable into four principal groups, namely, No. 1, red marl or shale; No. 2, red sandstone, used for building; No. 3, conglomerate; and No. 4, gray paving-stone, and tile-stone, with green and red- 


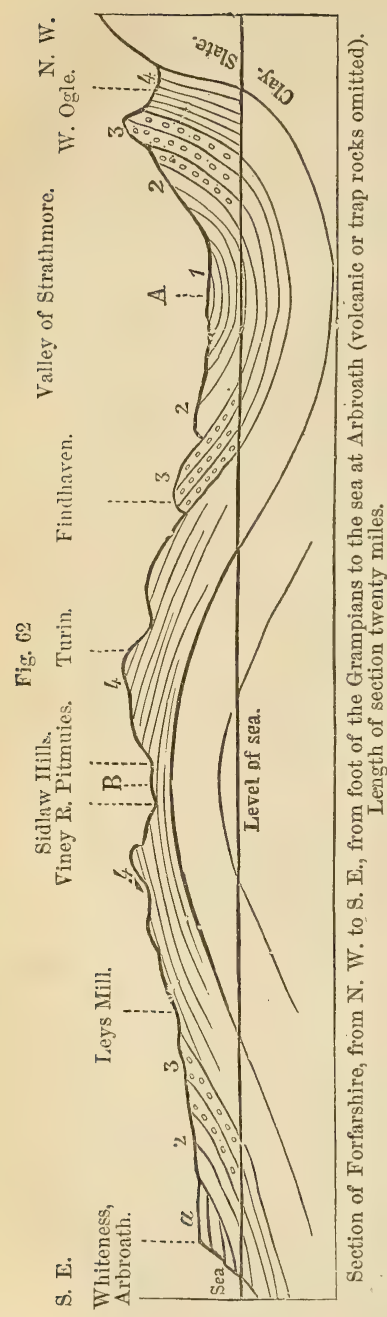

dish shale, containing peculiar organic remains. A glance at the section will show that each of the formations $2,3,4$, are repeated thrice at the surface, twice with a southerly, and once with a northerly inclication or dip, and the beds in No. 1, which are nearly horizontal, are still brought up twice by a slight curvature to the surface, once on each side of A. Beginning at the northwest extremity, the tile-stones and conglomerates No. 4 and No. 3 are vertical, and they generally form a ridge parallel to the southern skirts of the Grampians. The superior strata Nos. 2 and 1 become less and less inclined on descending to the valley of Strathmore, where the strata, having a concave Dend, are said by geologists to lie in a "trough" or "basin." Through the centre of this valley runs an imaginary line A, called technically a "synclinal line," where the beds, which are tilted in opposite directions, may be supposed to meet. It is most important for the observer to mark such lines, for he will perceive by the diagram, that in travelling from the north to the centre of the basin, he is always passing from older to newer beds; whereas, after crossing the line A, and pursuing his course in the same southerly direction, he is continually leaving the newer, and advancing upon older strata. All the deposits which he had before examined begin then to recur in reversed order, until he arrives at the central axis of the Sidlaw hills, where the strata are seen to form an arch or saddle, having an anticlinal line B, in the centre. On passing this line, and continuing towards the S. E., the formations 4, 3, and 2, are again repeated, in the same relative order of superposition, but with a southerly dip. At Whiteness (see diagram) it will be seen that the inclined strata are covered by a newer deposit, $a$, in horizontal beds. These are composed of red conglomerate and sand, and are newer than any of the groups, 1, 2, 3, 4, before described, and rest unconformably upon strata of the sandstone group, No. 2.

An example of curved strata, in which the bends or convolutions of the rock are sharper and far more numerous within an equal space, has been well described by Sir James Hall.* It occurs near St. Abb's Head.

$$
\text { * Edin. Trans. vol. vii. pl. } 3 .
$$


on the east coast of Scotland, where the rocks consist principally of a bluish slate, having frequently a ripple-marked surface. The undulations oi the beds reach from the top to the bottom of cliffs from 200 to 300

Fig. 63.

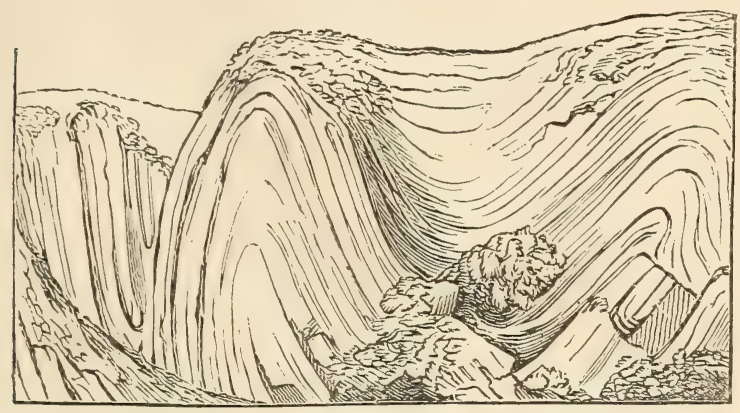

Curved strata of slate near St. Abb's Head, Berwickshire. (Sir J. Hall.)

feet in height, and there are sixteen distinct bendings in the course of about six miles, the curvatures being alternately concave and convex upwards.

An experiment was made by Sir James Hall, with a view of illustrating the manner in which such strata, assuming them to have been originally horizontal, may have been forced into their present position. A set of layers of clay were placed under a weight, and their opposite ends pressed towards each other with such force as to cause them to approach more nearly together. On the removal of the weight, the layers of clay were found to be curved and folded, so as to bear a miniature resemblance to the strata in the cliffs. We must, however, bear in mind, that in the natural section or sea-cliff we only see the foldings imperfectly, one part being invisible beneath the sea, and the other, or upper portion, being supposed to have been carried away by denudation, or that action of

Fig. 64.

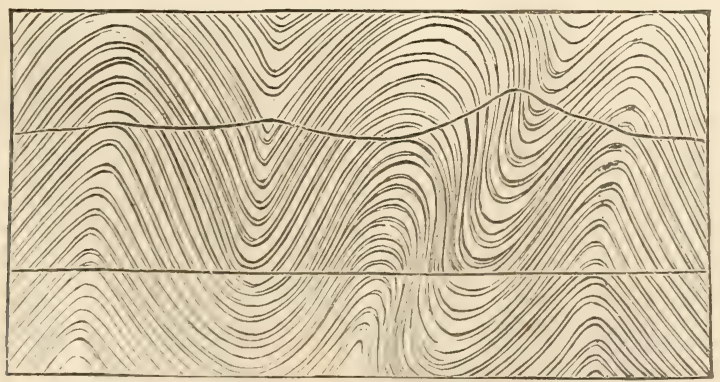

water which will be explained in the next chapter. The dark lines sn the accompanying plan (fig. 64) represent what is actually seen of the strata in part of the line of cliff alluded to; the fainter lines, that por- 
tion which is concealed beneath the sea-level, as also that which is supposed to have once existed above the present surface.

We may still more easily illustrate the effects which a lateral thrust might produce on flexible strata, by placing several pieces of differently colored cloths upon a table, and when they are spread out horizontally,

Fig. 65.

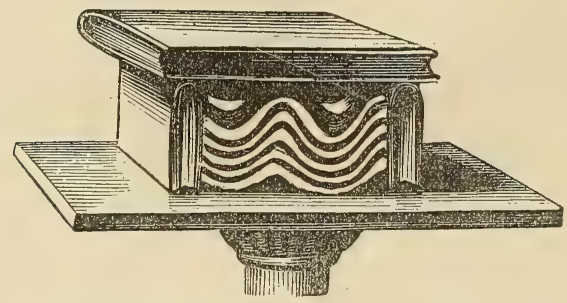

cover them with a book. Then apply other books to each end, and force them towards each other. The folding of the cloths will exactly imitate those of the bent strata. (See fig. 65.)

Whether the analogous flexures in stratified rocks have really been due to similar sideway movements is a question of considerable difficulty. It will appear when the volcanic and granitic rocks are described, that some of them have, when melted, been injected forcibly into fissures, while others, already in a solid state, have been protruded upwards through the incumbent crust of the earth, by which a great displacement of flexible strata must have been caused.

But we also know by the study of regions liable to earthquakes, that there are causes at work in the interior of the earth capable of producing a sinking in of the ground, sometimes very local, but sometimes extending over a wide area. The frequent repetition, or continuance throughout long periods, of such downward movements seems to imply the formation and renewal of cavities at a certain depth below the surface, whether by the removal of matter by volcanoes and hot springs, or by the contraction of argillaceous rocks by heat and pressure, or any other combination of circumstances. Whatever conjectures we may indulge respecting the causes, it is certain that pliable beds may, in consequence of unequal degrees of subsidence, become folded to any amount, and have all the appearance of having been compressed suddenly by a lateral thrust.

The "Creeps," as they are called in coal-mines, afford an excellent il. lustration of this fact.-First, it may be stated generally, that the excavation of coal at a considerable depth causes the mass of overlying strata to sink down bodily, even when props are left to support the roof of the mine. "In Yorkshire," says Mr. Buddle, "three distinct subsidences were perceptible at the surface, after the clearing out of three seams of coal below, and innumerable vertical cracks were caused in the incumbent mass of sandstone and shale, which thus settled down."

* Proceedings of Geol. Soc. vol. iii. p. 148. 
act amount of depression in these cases can only be accurately measured where water accumulates on the surface, or a railway traverses a coal-field.

When a bed of coal is worked out, pillars or rectangular masses of coal are left at intervals as props to support the roof and protect the colliers. Thus in fig. 66, representing a section at Wallsend, Newcastle,

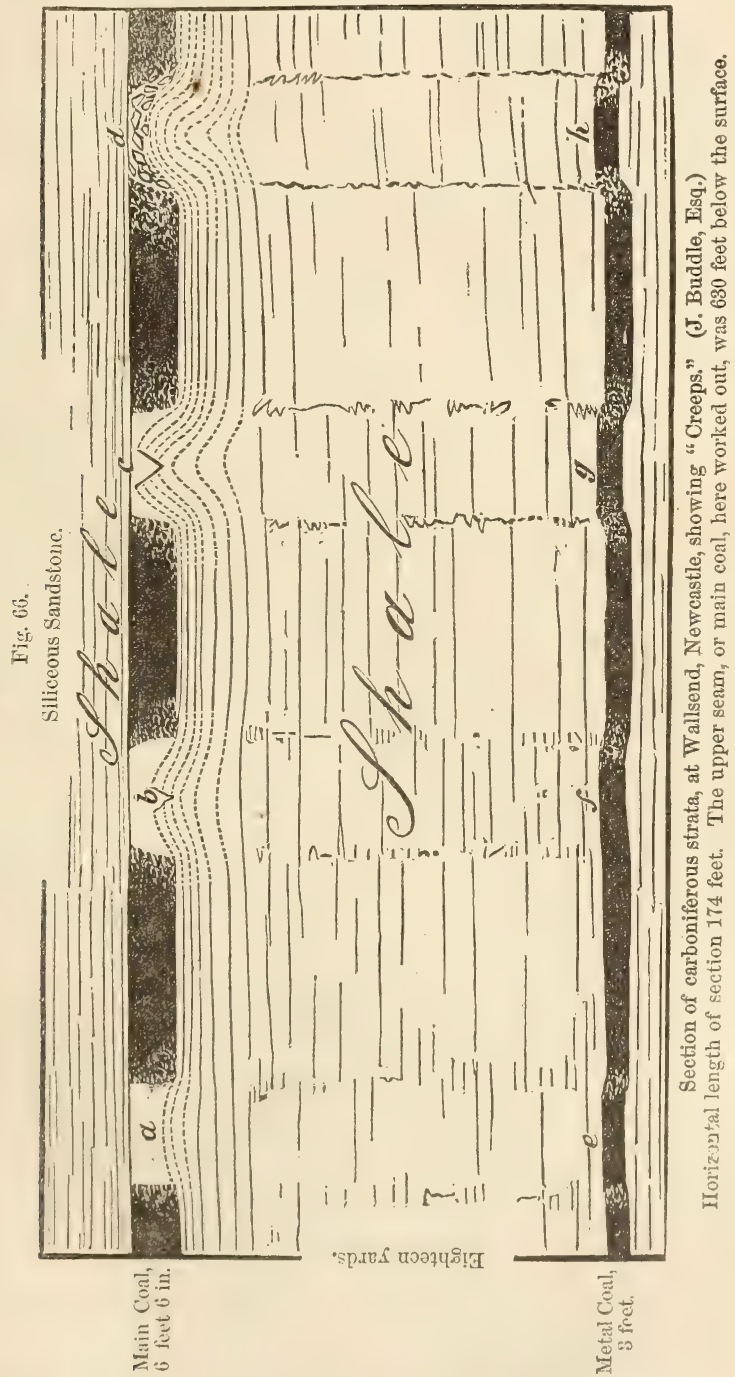

the galleries which have been excavated are represented by the white spaces $a b$, while the adjoining dark portions are parts of the original coal-seam left as props, beds of sandy clay or shale constituting the floor of the mine. When the props have been reduced in size, ther are pressed 
down by the weight of overlying rocks (no less than 630 feet thick) upon the shale below, which is thereby squeezed and forced up into the open spaces.

Now it might have been expected, that instead of the floor rising up, the ceiling would sink down, and this effect, called a "Thrust," does, in fact, take place where the pavement is more solid than the roof. But it usually happens, in coal-mines, that the roof is composed of hard shale, or occasionally of sandstone, more unyielding than the foundation, which often consists of clay. Even where the argillaceous substrata are hard at first, they soon become softened and reduced to a plastic state when exposed to the contact of air and water in the floor of a mine.

The first symptom of a "creep," says Mr. Buddle, is a slight curvature at the bottom of each gallery, as at $a$, fig. 66 : then the pavement continuing to rise, begins to open with a longitudinal crack, as at $b$ : then the points of the fractured ridge reach the roof, as at $c$; and, lastly, the upraised beds close up the whole gallery, and the broken portions of the ridge are reunited and flattened at the top, exhibiting the flexure seen at $d$. Meanwhile the coal in the props has become crushed and cracked by pressure. It is also found, that below the creeps $a, b, c, d$, an inferior stratum, called the "metal coal," which is 3 feet thick, has been fractured at the points $e, f, g, h$, and has risen, so as to prove that the upward movement, caused by the working out of the "main coal," has been propagated through a thickness of 54 feet of argillaceous beds, which intervene between the two coal seams. This same displacement has also been traced downwards more than 150 feet below the metal coal, but it grows continually less and less until it becomes imperceptible.

No part of the process above described is more deserving of our notice than the slowness with which the change in the arrangement of the beds is brought about. Days, months, or even years, will sometimes elapse between the first bending of the pavement and the time of its reaching the roof. Where the movement has been most rapid, the curvature of the beds is most regular, and the reunion of the fractured ends most complete; whereas the signs of displacement or violence are greatest in those creeps which have required months or years for their entire accomplishment. Hence we may conclude that similar changes may have been wrought on a larger scale in the earth's crust by partial and gradual subsidences, especially where the ground has been undermined throughout long periods of time; and we must be on our guard against inferring sudden violence, simply because the distortion of the beds is excessive.

Between the layers of shale, accompanying coal, we sometimes see the leaves of fossil ferns spread out as regularly as dried plants between sheets of paper in the herbarium of a botanist. These fern-leaves, or fronds, must have rested horizontally on soft mud, when first deposited. If, therefore, they and the layers of shale are now inclined, or standing on end, it is obviously the effect of subsequent derangement. The proof becomes, if possible, still more striking when these strata, including 
vegetable remains, are curved again and again, and even folded into the form of the letter $\mathrm{Z}$, so that the same continuous layer of coal is cut through several times in the same perpendicular shaft. Thus, in the coal-field near Mons, in Belgium, these zigzag bendings are repeated four

Fig. 67.

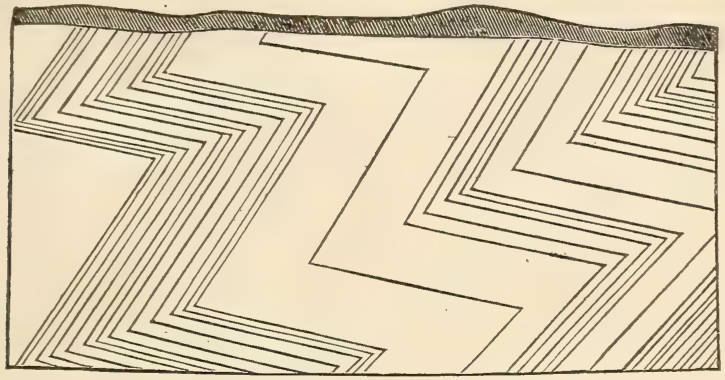

Zigzag flexures of coal near Mons.

or five times, in the manner represented in fig. 67 , the black lines representing seams of coal.*

Dip and strike.-In the above remarks, several technical terms have been used, such as dip, the unconformable position of strata, and the antictinal and synclinal lines, which, as well as the strike of the beds, I shall now explain. If a stratum or bed of rock, instead of being quite level, be inclined to one side, it is said to dip; the point of the compass to which it is inclined is called the point of dip, and the degree of deviation from a level or horizontal line is called the amount of dip, or the

Fig. 68 .

s N

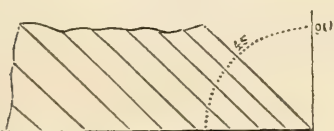
angle of dip. Thus, in the annexed diagram (fig. 68), a series of strata are inclined, and they dip to the north at an angle of forty-five degrees. The strike, or line of bearing, is the prolongation or extension of the strata in a direction at right angles to the dip; and hence it is sometimes called the direction of the strata. Thus, in the above instance of strata dipping to the north, their strike must necessarily be east and west. We have borrowed the word from the German geologists, streichen signifying to extend, to have a certain direction. Dip and strike may be aptly illustrated by a row of houses running east and west, the long ridge of the roof representing the strike of the stratum of slates, which dip on one side to the north, and on the other to the south.

A stratum which is horizontal, or quite level in all directions, has neither dip nor strike.

It is always important for the geologist, who is endeavoring to comprehend the structure of a country, to learn how the beds dip in every part of the district; but it requires some practice to avoid being occasionally deceived, both as to the point of dip and the amount of it.

* See plan by M. Chevalier, Burat's D'Aubuisson, tom. ii. p. 334. 
If the upper surface of a hard stony stratum be uncovered, whether artificially in a quarry, or by the waves at the foot of a cliff, it is easy to determine towards what point of the compass the slope is steepest, or in what direction water would flow, if poured upon it. This is the true dip. But the edges of highly inclined strata may give rise to perfectly horizontal lines in the face of a vertical cliff, if the observer see the strata in the line of their strike, the dip being inwards from the face of the cliff. If, however, we come to a break in the cliff, which exhibits a section exactly at right angles to the line of the strike, we are then able to ascertain the true dip. In the annexed drawing (fig: 69), we may suppose a headland, one side of which faces to the north, where the

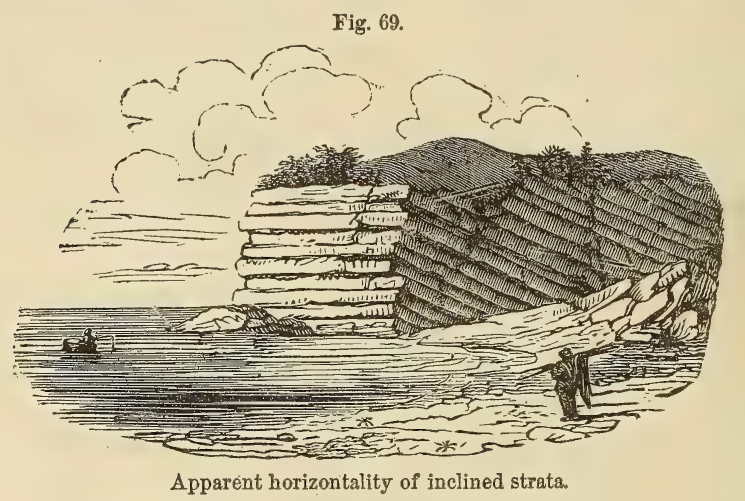

beds would appear perfectly horizontal to a person in the boat; while in the other side facing the west, the true dip would be seen by the person on shore to be at an angle of $40^{\circ}$. If, therefore, our observations are confined to a vertical precipice facing in one direction, we must endeavor to find a ledge or portion of the plane of one of the beds projecting beyond the others, in order to ascertain the true dip.

It is rarely important to determine the angle of inclination with such minuteness as to require the aid of the instrument called a clinometer. We may measure the angle within a few degrees by standing exactly

Fig. 70.

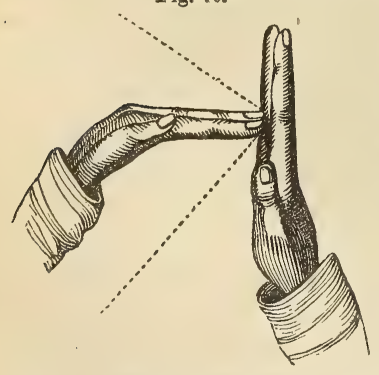
opposite to a cliff where the true dip is exhibited, holding the hands immediately before the eyes, and placing the fingers of one in a perpendicular, and of the other in a horizontal position, as in fig. 70. It is thus easy to discover whether the lines of the inclined beds bisect the angle of $90^{\circ}$, formed by the meeting of the hands, so as to give an angle of $45^{\circ}$, or whether it would divide the space into two equal or unequal portions. The upper dotted line

may express a stratum dipping to the north; but should the beds dip precisely to the opposite point of the compass as in the lower dotted 
line, it will be seen that the amount of inclination may still be measured by the hands with equal facility.

It has been already seen, in describing the curved strata on the east coast of Scotland, in Forfarshire and Berwickshire, that a series of concare and convex bendings are occasionally repeated several times. These usually form part of a scries of parallel waves of strata, which are prolonged in the same direction throughout a considerable extent of country. Thus, for example, in the Swiss Jura, that lofty chain of mountains has been proved to consist of many parallel ridges, with intervening longitudinal valleys, as in fig. 71, the ridges being formed by curved fossiliferous strata, of which the nature and dip are occasionally displayed in deep transverse gorges, called "cluses," caused by fractures at right angles to the direction of the chain.* Now let us suppose these ridges and parallel valleys to run north and south, we should then say that the strike of the beds is north and south, and the dip east and west. Lines drawn along the summits of the ridges, A, B, would be anticlinal lines, and one following the bottom of the adjoining valleys a synclinal line.

Fig. 71.

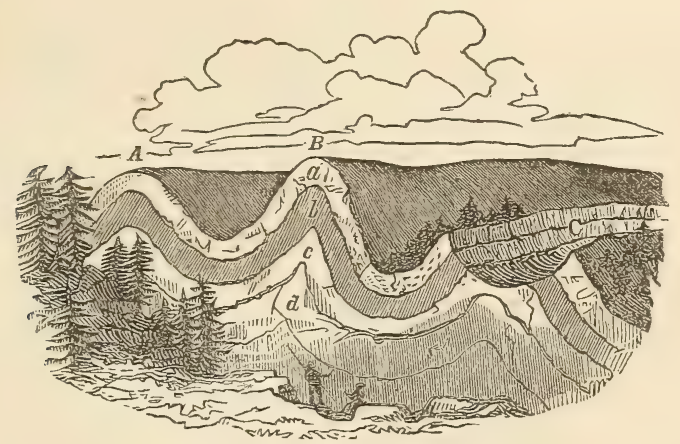

Section illustrating the structure of the Swiss Jura.

It will be observed that some of these ridges, A, B, are unbroken on the summit, whereas one of them, C, has been fractured along the line of strike, and a portio 2 of it carried away by denudation, so that the ridges of the beds in the formations $a, b, c$, come out to the day, or, as the

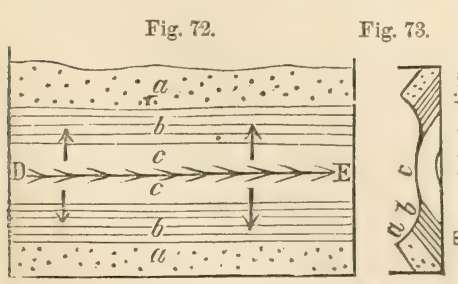

Ground plan of the denuded ridge C, fig. 71 . miners say, crop out, on the sides of a valley. The ground plan of of such a denuded ridge as $\mathrm{C}$, as given in a geological map, may be expressed by the diagram fig. 72, and the cross section of the same by fig. 73. The line D E, fig. 72, is the anticlinal line, on each side of which the dip is in opposite direc-

* See M. Thurmann's work, "Essai sur les Soulèvemens Jurassiques du Porrentruy, Paris, 1832," with whom I examined part of these mountains in 1835. 
tions, as expressed by the arrows. The emergence of strata at the surface is called by miners their outcrop or basset.

If, instead of being folded into parallel ridges, the beds form a boss or dome-shaped protuberance, and if we suppose the summit, of the dome carried off, the ground plan would exhibit the edges of the strata forming a succession of circles, or ellipses, round a common centre. These circles are the lines of strike, and the dip being always at right angles is inclined in the course of the circuit to every point of the compass, constituting what is termed a qua-quaversal dip-that is, turning each way.

There are endless variations in the figures described by the bassetedges of the strata, according to the different inclination of the beds, and the mode in which they happen to have been denuded. One of the simplest rules with which every geologist should be acquainted, relates to the $\mathrm{V}$-like form of the beds as they crop out in an ordinary valley. First, if the strata be horizontal, the V-like form will be also on a level, and the newest strata will appear at the greatest heights.

Secondly, if the beds be inclined and intersected by a valley sloping in the same direction, and the dip of the beds be less steep than the slope of the valley, then the V's, as they are often termed by miners, will point upwards (see fig. 74), those formed by the newer beds appear-

Fig. 74.

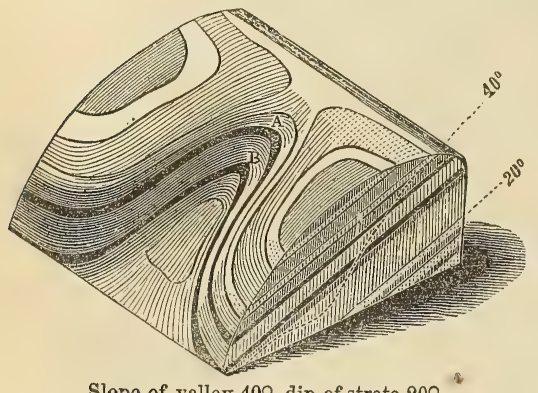

Slope of valley 400 , dip of strata $200^{*}$

Fig. 75.

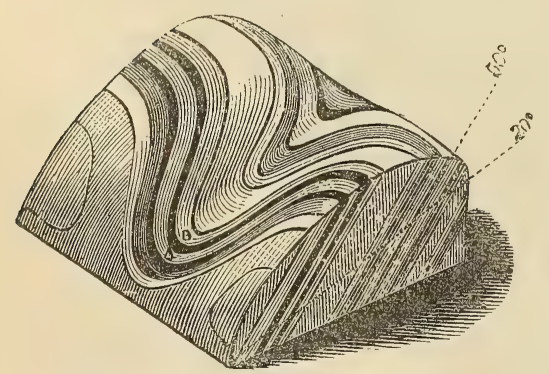

Slope of valley $20^{\circ}$, dip of strata 500 . ing in a superior position, and extending highest up the valley, as $A$ is seen above $\mathrm{B}$.

Thirdly, if the dip of the beds be steeper than the slope of the valley, then the V's will point downwards (see fig. 75), and those formed of the older beds will now appear uppermost, as $\mathrm{B}$ appears above A.

Fourthly, in every case where the strata dip in a contrary direction to the slope of the valley, whatever be the angle of inclination, the newer beds will appear the highest, as in the first and second cases. This is shown by the drawing (fig. 76), which exhibits strata ristrig at an angle of $20^{\circ}$, and crossed $b v$ 


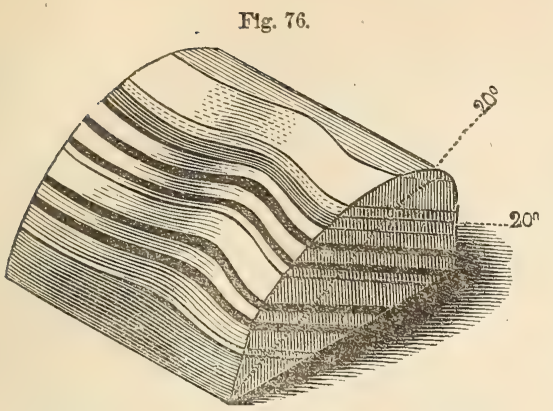

Slope of valley $20^{\circ}$, dip of strata $20^{\circ}$, in opposite

a valley, which declines in an opposite direction at $20^{\circ}$.*

These rules may often be of great practical utility; for the different degrees of dip occurring in the two cases represented in figures 74 and 75 , may occasionally be encountered in following the same line of flexure at points a few miles distant from each other. A miner unacquainted with the rule, who had first explored the valley (fig. 74), may have sunk a vertical shaft below the coal-seam $\mathrm{A}$, until he reached the inferior bed $\mathrm{B}$. He might then pass to the valley fig. 75 , and discovering there also the outcrop of two coal-seams, might begin his workings in the uppermost in the expectation of coming down to the other bed A, which would be observed cropping out lower down the valley. But a glance at the section will demonstrate the futility of such hopes.

In the majority of cases, an anticlinal axis forms a ridge, and a synclinal axis a valley, as in A, B, fig. 62, p. 48 ; but there are exceptions

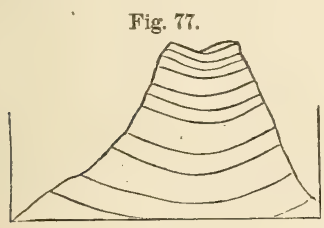
to this rule, the beds sometimes sloping inwards from either side of a mountain, as in fig. 77 .

On following one of the anticlinal ridges of the Jura, before mentioned, A, B, C, fig. 71 , we often discover longitudinal cracks and sometimes large fissures along the line where the flexure was greatest. Some of these, as above stated, have been enlarged by denudation into valleys of considerable width, as at C, fig. 71, which follow the line of strike, and which we may suppose to have been hollowed out at the time when these rocks were still beneath the level of the sea, or perhaps at the period of their gradual emergence from beneath the waters. The existence of such cracks at the point of the sharpest bending of solid strata of limestone is precisely what we should have expected; but the occasional want of all similar signs of fracture, even where the strain has been greatest, as at $\alpha$, fig. 71 , is not always easy to explain. We must imagine that many strata of limestone, chert, and other rocks which are now brittle, were pliant when bent into their present position. They may have owed their flexibility in part to the

* I am indebted to the kindness of T. Sopwith, Esq., for three models which I have copied in the above diagrams; but the beginner may find it by no means easy to understand such copies, although, if he were to examine and handle the originals, turning them about in different ways, he would at once comprehend their meaning, as well as the import of others far more complicated, which the same engineer has constructed to illustrate faults. 
fluid matter which they contained in their minute pores, as before described (p. 35), and in part to the permeation of sea-water while they were yet submerged.

At the western extremity of the Pyrenees, great curvatures of the strata are seen in the sea cliffs, where the rocks consist of marl, grit, and chert. At certain points, as at $a$, fig. 78 , some of the bendings of the

Fig. 78.

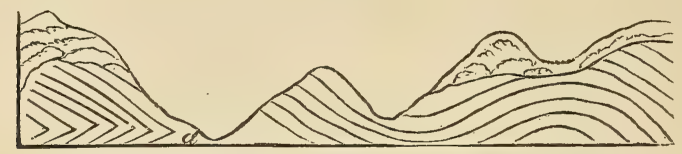

Strata of chert, grit, and marl, near St. Jean de Luz.

flinty chert are so sharp, that specimens might be broken off; well fitted to serve as ridge-tiles on the roof of a house. Although this chert could not have been brittle as now, when first folded into this shape, it presents, nevertheless, here and there at the points of greatest flexure small cracks, which show that it was solid, and not wholly incapable of breaking at the period of its displacement. The numerous rents alluded to are not empty, but filled with chalcedony and quartz.

Between San Caterina and Castrogiovanni, in Sicily, bent and undulating gypseous marls occur, with here and there thin beds of solid

Fig. 79.

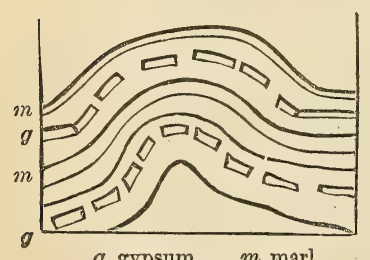

g. gypsum. m. marl, gypsum interstratified. Sometimes these solid layers have been broken into detached fragments, still preserving their sharp edges ( $g$ g, fig. 79), while the continuity of the more pliable and ductile marls, $m m$, has not been interrupted.

I shall conclude my remarks on bent strata by stating, that, in mountainous regions like the Alps, it is often difficult for an experienced geologist to determine correctly the relative age of beds by superposition, so often have the strata been folded back upon themselves, the upper parts of the curve having been removed by denudation. Thus, if we met with the strata seen in the section fig. 80 , we should

Fig. 80.

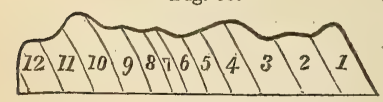
naturally suppose that there were twelve distinct beds, or sets of beds, No. 1 being the newest, and No. 12 the oldest of the series. But this section may, perhaps, exhibit merely six beds, which have been folded in the manner seen in fig. 81 , so that each of them is twice repeated, the position of one-half being reversed, and part of No. 1, originally the uppermost, having now become the lowest of the series. These phenomena are often observable on a magnificent scale in certain regions in Switzerland in precipices from 2000 to 3000 feet in perpendicular height. In the Iselten Alp, in the valley of the Lutschine, between 
Fig. 81.

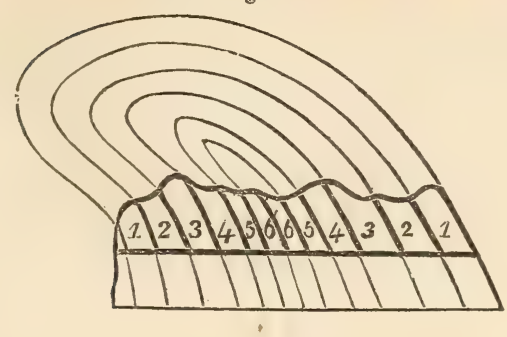

Unterseen and Grindelwald, curves of calcareous shale are seen from 1000 to 1500 feet in height, in which the beds sometimes plunge down vertically for a depth of 1000 feet and more, before they bend round

Fig. 82.

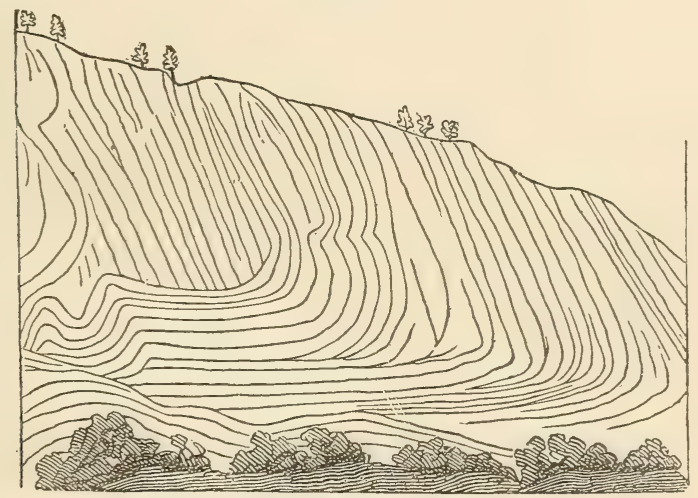

Curved strata of the Iselten Alp.

again. There are many flexures not inferior in dimensions in the Pyrenees, as those near Gavarnie, at the base of Mount Perdu.

Unconformable stratification.-Strata are said to be unconformable, when one series is so placed over another, that the planes of the superior repose on the edges of the inferior (see fig. 83). In this case it is evi-

Fig. 83.

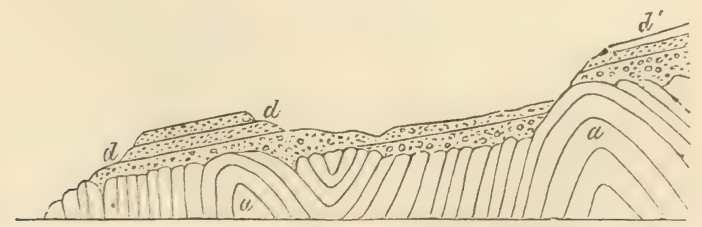

Unconformable junction of old red sandstone and Silurian schist at the Siccar Point, near St. Abb's Head, Berwickshire. See also Frontispiece.

dent that a period had elapsed between the production of the two sets of strata, and that, during this interval, the older series had been tilted 
and disturbed. Afterwards the upper series was thrown down in horizontal strata upon it. If these superior beds, as $d, d$, fig. 83 , are alsc inclined, it is plain that the lower strata, $\alpha, \alpha$, have been twice displaced; first; before the deposition of the newer beds, $d, d$, and a second time when these same strata were thrown out of the horizontal position.

Playfair has remarked* that this kind of junction, which we now call unconformable, had been described before the time of Hutton, but that he was the first geologist who appreciated its importance, as illustrating the high antiquity and great revolutions of the globe. He had observed that where such contacts occur, the lowest beds of the newer series very generally consist of a breccia or conglomerate consisting of angular and rounded fragments, derived from the breaking up of the more ancient rocks. On one occasion the Scotch geologist took his two distinguished pupils, Playfair and Sir James Hall, to the cliffs on the east coast of Scotland, near the village of Eyemouth, not far from St. Abb's Head, where the schists of the Lammermuir range are undermined and dissected by the sea. Here the curved and vertical strata, now known to be of Silurian age, and which often exhibit a ripple-marked surface, are well exposed at the headland called the Siccar Point, penetrating with their edges into the incumbent beds of slightly inclined sandstone, in which large pieces of the schist, some round and others angular, are united by an arenaceous cement. "What clearer evidence," exclaims Playfair, "could we have had of the different formation of these rocks, and of the long interval which separated their formation, had we actually seen them emerging from the bosom of the deep? We felt ourselves necessarily carried back to the time when the schistus on which we stood was yet at the bottom of the sea, and when the sandstone before us was only beginning to be deposited in the shape of sand or mud, from the waters of a superincumbent ocean. An epoch 'still more remote presented itself, when even the most ancient of these rocks, instead of standing upright in vertical beds, lay in horizontal planes at the bottom of the sea, and was not yet disturbed by that immeasurable force which has burst asunder the solid pavement of the globe. Revolutions still more remote appeared in the distance of this extraordinary perspective. The mind seemed to grow giddy by looking so far into the abyss of time; and while we listened with earnestness and admiration to the philosopher who was now unfolding to us the order and series of these wonderful events, we became sensible how much farther reason may sometimes go than imagination can venture to follow." $\dagger$

In the frontispiece of this volume the reader will see a view of this classical spot, reduced from a large picture, faithfully drawn and colored from nature by the youngest son of the late Sir James Hall. It was impossible, however, to do justice to the original sketch, in an engraving, as the contrast of the red sandstone and the light fawn-colored vertical schists

* Biographical account of Dr. Hutton.

+ Playfair, ibid. ; see his Works, Edin. 1822, vol. iv. p. 81. 
could not be expressed. From the point of view here selected, the underlying beds of the perpendicular schist, $a$, are visible at $b$ through a small opening in the fractured beds of the covering of red sandstone, $d d$, while on the vertical face of the old schist at $a^{\prime} a^{\prime \prime}$ a conspicuous ripple-mark is displayed.

It often happens that in the interval between the deposition of two sets of unconformable strata, the inferior rock has not only been denuded, but drilled by perforating shells. Thus, for example, at Autreppe and Gusigny, near Mous, beds of an ancient (primary or paleozoic) limestone, highiy

Fig. 84 .

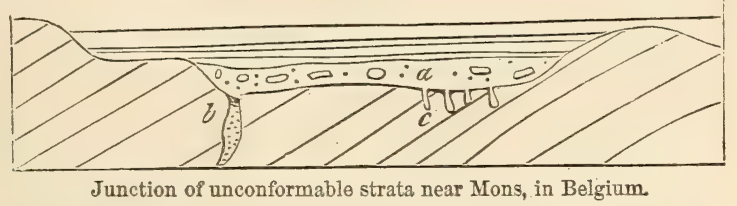

inclined, and often bent, are corered with horizontal strata of greenish and whitish marls of the Cretaceous formation. The lowest and therefore the oldest bed of the horizontal series is usually the sand and conglomerate, $\alpha$, in which are rounded fragments of stone, from an inch to two feet in diameter. These fragment, have often adhering shells attached to them, and have been bored by perforating mollusca. The solid surface of the inferior limestone has also been bored, so as to exhibit cylindrical and pear-shaped carities, as at $c$, the work of saxicavous mollusca; and many rents, as at $b$, which descend sereral feet or yards into the limestone, hare been filled with sand and shells, similar to those in the stratum $\alpha$.

Fractures of the strata and faults.-Numerous rents may often be seen in rocks which appear to have lsen simply broken, the separated parts remaining in the same places; but we often find a fissure, several inches or yards wide, interrening jetween the disunited portions. These fissures are usually filled with fine earth and sand, or with angular fragments of stone, evidently derived from the fracture of the contiguour rocks.

It is not uncommon to find the mass of rock, on one side of a fissure, thrown up above or down below the mass with which it was once in contact on the other side. This mode of displacement is called a shift, slip, or fault. "The miner," says Plarfair, describing a fault, "is often perplexed, in his subterraneous journey, by a derangement in the strata, which changes at once all those lines and bearings which had hitherto directed his course. When lis mine reaches a certain plane, which is sometimes perpendicular, as in A B, fig. 8.5, sometimes oblique to the horizon (as in C D, ibid.), he finds the beds of rock broken asunder. those on the one side of the plane having changed their place, by sliding in a particular direction along the face of the others. In this motion they have sometimes preserved their parallelism, as in fig. 85, so that 
Fig. 85.

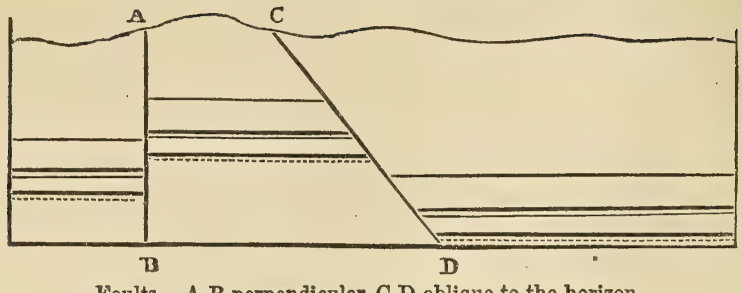

Faults. A B perpendicular, C D oblique to the horizon.

the strata on each side of the faults $\mathrm{AB}, \mathrm{CD}$, continue parallel to one another; in other cases, the strata on each side are inclined, as in $a, b, c, d$

Fig. 86.

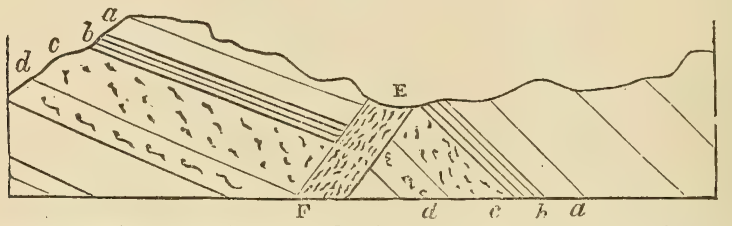

E F, fault or fissure flled with rubbish, on each side of which the shifted strata are not parallel.

(fig. 86), though their identity is still to be recognized by their possessing the same thickness, and the same internal characters."

In Coalbrook Dale, says Mr. Prestwich, $\nmid$ deposits of sandstone, shale, and coal, several thousand feet thick, and occupying an area of many miles, have been shivered into fragments, and the broken remnants have been placed in very discordant positions, often at levels differing several hundred feet from each other. The sides of the faults, when perpendicular, are commonly separated several yards, but are sometimes as much as 50 yards asunder, the interval being filled with broken débris of the strata. In following the course of the same fault, it is sometimes found to produce in different places very unequal changes of level, the amount of shift being in one place 300 , and in another 700 feet, which arises, in some cases, from the union of two or more faults. In other words, the disjointed strata have in certain districts been subjected to renewed movements, which they have not suffered elsewhere.

We may occasionally see exact counterparts of these slips, on a small scale, in pits of loose sand and gravel, many of which have doubtless been caused by the drying and shrinking of argillaceous and other beds, slight subsidences having taken place from failure of support. Sometimes, however, even these small slips may have been produced during earthquakes; for land has been moved, and its level, relatively to the sea, considerably altered, within the period when much of the alluvial sand and gravel now covering the surface of continents was deposited.

* Playfair, Illust. of Hutt. Theory, § 42.

f Geol. Trans. second series, vol. v. p. 452. 
I hare already stated that a geologist must be on his guard, in a region of disturbed strata, against inferring repeated alternations of rocks, when, in fact, the same strata, once continuous, have been bent round so as to recur in the same section, and with the same dip. A similar mistake has often been occasioned by a series of faults.

If, for example, the dark line $\mathrm{A} H$ (fig. 87) represent the surface of a country on which the strata $a b c$ frequently crop out, an observer, who

Fig. 87

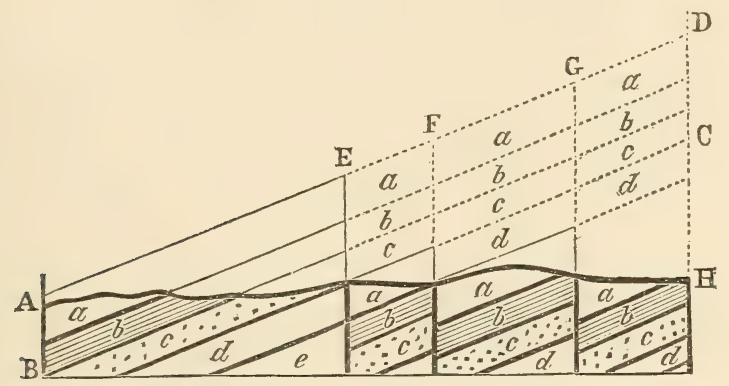

Apparent alternations of strata caused by vertical faults.

is proceeding from $\mathrm{H}$ to $\mathrm{A}$, might at first imagine that at erery step he was approaching new strata, whereas the repetition of the same beds has been caused by vertical faults, or downthrows. Thus, suppose the original mass, A, B, C, D, to have been a set of uniformly inclined strata, and that the different masses under E F, F G, and G D, sank down successirely, so as to leave vacant the spaces marked in the diagram by dotted lines, and to occupy those marked by the continuous lines; then let denudation take place along the line $\mathrm{A} \mathrm{H}$, so that the protruding masses indicated by the fainter lines are swept away, - a miner, who has not discorered the faults, finding the mass $a$, which we will suppose to be a bed of coal four times repeated, might hope to find four beds, workable to an indefinite depth, but first on arriving at the fault $G$ he is stopped suddenly in his workings, upon reaching the strata of sandstone $c$, or on arriring at the line of fault $\mathrm{F}$, he comes partly upon the shale $b$, and partly on the sandstone $c$, and on reaching $\mathrm{E}$ he is again stopped by a wall composed of the rock $d$.

The rery different levels at which the separated parts of the same strata are found on the different sides of the fissure, in some faults, is truly astonishing. One of the most celebrated in England is that called the " ninety-fathom dike," in the coal-field of Newcastle. This name has been given to it, because the same beds are ninety fathoms lower on the northern than they are on the southern side. The fissure has been filled by a body of sand, which is now in the state of sandstone, and is called the dike, which is sometimes rery narrow, but in other places more than twenty yards wide.* The walls of the fissure are scored by grooves, such

* Cnnybeare and Phillips, Outlines, \&c. p. 376. 
as would have been produced if the broken ends of the rock had been rubbed along the plane of the fault.* In the Tynedale and Craven faults, in the north of England, the vertical displacement is still greater, and the fracture has extended in a horizontal direction for a distance of thirty miles or more. Some geologists consider it necessary to imagine that the upward or downward movement in these cases was accomplished at a single stroke, and not by a series of sudden but interrupted movements. This idea appears to have been derived from a notion that the grooved walls have merely been rubbed in one direction. But this is so far from being a constant phenomenon in faults, that it has often been objected to the received theory respecting those polished surfaces called "slickensides," that the striæ are not always parallel, but often curved and irregular. It has, moreover, been remarked, that not only the walls of the fissure or fault, but its earthy contents, sometimes present the same polished and striated faces. Now these facts seem to indicate partial changes in the direction of the movement, and some slidings subsequent to the first filling up of the fissure. Suppose the mass of rock A, B, C, to overlie an extensive chasm $d e$, formed at the depth of seveial miles,

Fig. 88.

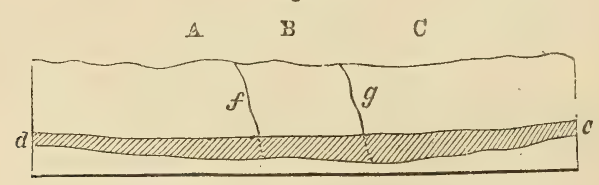

whether by the gradual contraction in bulk of a melted mass passing into a solid or crystalline state, or the shrinking of argillaceous strata, baked by a moderate heat, or by the subtraction of matter by volcanic action, or any other cause. Now, if this region be convulsed by earthquakes, the fissures $f g$, and others at right angles to them, may sever the mass $\mathrm{B}$ from $\mathrm{A}$ and from $\mathrm{C}$, so that it may move freely, and begin to sink into the chasm. A fracture may be conceived so clean and perfect as to allow it to subside at once to the bottom of the subterranean cavity; but it is far more probable that the sinking will be effected at successive periods during different earthquakes, the mass always continuing to slide in the same direction along the planes of the fissures $f g$, and the edges of the falling mass being continually more broken and triturated at each convulsion. If, as is not improbable, the circumstances which have caused the failure of support continue in operation, it may happen that when the mass $B$ has filled the cavity first formed, its foundations will again give way under it, so that it will fall again in the same direction. But, if the direction should change, the fact could not be discovered by observing the slickensides, because the last scoring would efface the lines of previous friction. In the present state of our ignorance of the causes of subsidence, an hypothesis which can explain the great amount of displacement in

* Phillips, Geology, Lardner's Cyclop. p. 41. 
some faults, on sound mechanical principles, by a succession of movements, is far preferable to any theory which assumes each fault to have been accomplished by a single upcast or downthrow of several thousand feet. For we know that there are operations now in progress, at great depths in the interior of the earth, by which both large and small tracts of ground are made to rise above and sink below their former level, some slowly and insensibly, others suddenly and by starts, a few feet or yards at a time; whereas there are no grounds for believing that, during the last 3000 years at least, any regions have been either upheaved or depressed, at a single stroke, to the amount of several hundred, much less several thousand feet. When some of the ancient marine formations are described in the sequel, it will appear that their structure and organic contents point to the conclusion, that the floor of the ocean was slowly sinking at the time of their origin. The downward movement was very gradual, and in Wales and the contiguous parts of England a maximum thickness of 32,000 feet (more than six miles) of Carboniferous, Devonian, and Silurian rock was formed, whilst the bed of the sea was all the time continuously and tranquilly subsiding:* Whatever may have been the changes which the solid foundation underwent, whether accompanied by the melting, consolidation, crystallization, or desiccation of subjacent mineral matter, it is clear from the fact of the sea having remained shallow all the while that the bottom never sank down suddenly to the depth of many hundred feet at once.

It is by assuming such reiterated variations of level, each separately of small rertical amount, but multiplied by time till they acquire importance in the aggregate, that we are able to explain the phenomena of denudation, which will be treated of in the next chapter. By such movements every portion of the surface of the land becomes in its turn a line of coast, and is exposed to the action of the waves ard tides. A country which is undergoing such movement is never allowed to settle into a state of equilibrium, therefore the force of rivers and tcrrents to remove or excavate soil and rocky masses is sustained in undiminished energy.

* See the results of the "Geological Survey of Great Britain;" Memoirs, voly. i. and ii. by Sir H. de la Beche, Mr. A. C. Ramsay, and Mr. John Phillips. 


\title{
CHAPTER VI.
}

\author{
DEN UDATION.
}

Denudation defined-Its amount equal to the entire mass of stratified deposits in the earth's crust-Horizontal sandstone denuded in Ross-shire-Levelled surface of countries in which great faults occur-Coalbrook Dale-Denuding power of the ocean during the emergence of land-Origin of Valleys-Obliteration of sea-cliffs-Inland sea-cliffs and terraces in the Morea and Sicily-Limestone pillars at St. Mihiel, in France-In Canada-In the Bermudas.

Denudation, which has been occasionally spoken of in the preceding chapters, is the removal of solid matter by water in motion, whether of rivers or of the waves and currents of the sea, and the consequent laying bare of some inferior rock. Geologists have perhaps been seldom in the habit of reflecting that this operation has exerted an influence on the structure of the earth's crust as universal and important as sedimentary deposition itself; for denudation is the inseparable accompaniment of the production of all new strata of mechanical origin. The formation of every new deposit by the transport of sediment and pebbles necessarily implies that there has been; somewhere else, a grinding down of rock into rounded fragments, sand, or mud, equal in quantity to the new strata. All deposition, therefore, except in the case of a shower of volcanic ashes, is the sign of superficial waste going on contemporaneously, and to an equal amount elsewhere. The gain at one point is no more than sufficient to balance the loss at some other. Here a lake has grown shallower, there a ravine has been deepened. The bed of the sea has in one region been raised by the accumulation of new matter, in another its depth has been augmented by the abstraction of an equal quantity.

When we see a stone building, we know that somewhere, far or near, a quarry has been opened. The courses of stone in the building may be compared to successive strata, the quarry to a ravine or valley which has suffered denudation. As the strata, like the courses of hewn stone, have been laid one upon another gradually, so the excavation both of the valley and quarry have been gradual. To pursue the comparison still farther, the superficial heaps of mud, sand, and gravel, usually called alluvium, may be likened to the rubbish of a quarry which has been rejected as useless by the workmen, or has fallen upon the road between the quarry and the building, so as to lie scattered at random over the ground. 
If, then, the entire mass of stratified deposits in the earth's crust is at once the monument and measure of the denudation which has taken place, on how stupendous a scale ought we to find the signs of this removal of transported materials in past ages! Accordingly, there are different classes of phenomena, which attest in a most striking manner the vast spaces left vacant by the erosive power of water. I may allude, first, to those valleys on both sides of which the same strata are seen following each other in the same order, and having the same mineral composition and fossil contents. We may observe, for example, several

Fig. 89.

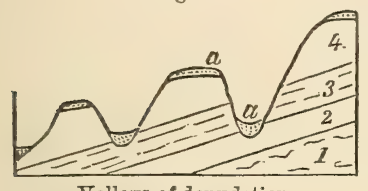

Valleys of denudation. a. alluvium. formations, as Nos. 1, 2, 3, 4, in the accompanying diagram (fig. 89); No. 1 conglomerate, No. 2 clay, No. 3 grit, and No. 4 limestone, each repeated in a series of hills separated by valleys varying in depth. When we examine the subordinate parts of these four formations, we find, in like manner; distinct beds in each, corresponding, on the opposite sides of the valleys, both in composition and order of position. No one can doubt that the strata were originally continuous, and that some cause has swept away the portions which once connected the whole series. A torrent on the side of a mountain produces similar interruptions; and when we make artificial cuts in lowering roads, we expose, in like manner, corresponding beds on either side. But in nature, these appearances occur in mountains several thousand feet high, and separated by intervals of many miles or leagues in extent, of which a grand exemplification is described by Dr. MacCulloch, on the northwestern coast of Rossshire, in Scotland.*

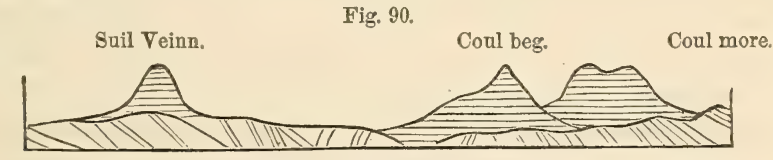

Denudation of red sandstone on northwest coast of Ross-shire. (MacCulloch.)

The fundamental rock of that country is gneiss, in disturbed strata, on which beds of nearly horizontal red sandstone rest unconformably. The latter are often very thin, forming mere flags, with their surfaces distinctly ripple-marked. They end abruptly on the declivities of many insulated mountains, which rise up at once to the height of about 2000 feet abore the gneiss of the surrounding plain or table-land, and to an average eleration of about 3000 feet above the sea, which all their summits generally attain. The base of gneiss varies in height, so that the lower portions of the sandstone occupy different levels, and the thickness of the mass is rarious, sometimes exceeding 3000 feet. It is impossible to compare these scattered and detached portions without imagining that the whole country has once been covered with a great body of sand. stone, and that masses from 1000 to more than 3000 feet in thickness havet been removed.

* Western Islands, vol. ii. p. 93, pl. 31, fig. 4. 
In the "Survey of Great Britain" (vol. i.), Professor Ramsay has shown that the missing beds, removed from the summit of the Mendips, must have been nearly a mile in thickness; and he has pointed out considerable areas in South Wales and some of the adjacent counties of England, where a series of primary (or palæozoic) strata, not less than 11,000 feet in thickness, have been stripped off. All these materials have of course been transported to new regions, and have entered into the composition of more modern formations. On the other hand, it is shown by observations in the same "Survey," that the palæozoic strata are from 20,000 to 30,000 feet thick. It is clear that such rocks, formed of mud and sand, now for the most part consolidated, are the monuments of denuding operations, which took place on a grand scale at a very remote period in the earth's history. For, whatever has been given to one area must always have been borrowed from another; a truth which, obvious as it may seem when thus stated, must be repeatedly impressed on the student's mind, because in many geological speculations it is taken for granted that the external crust of the earth has been always growing thicker, in consequence of the accumulation, period after period, of sedimentary matter, as if the new strata were not always produced at the expense of pre-existing rocks, stratified or unstratified. By duly reflecting on the fact, that all deposits of mechanical origin imply the transportation from some other region, whether contiguous or remote, of an equal amount of solid matter, we perceive that the stony exterior of the planet must always have grown thinner in one place whenever, by accessions of new strata, it was acquiring density in another. No doubt the vacant space left by the missing rocks, after extensive denudation, is less imposing to the imagination than a vast thickness of conglomerate or sandstone, or the bodily presence as it were of a mountain-chain, with all its inclined and curved strata. But the denuded tracts speak a clear and emphatic language to our reason, and, like repeated layers of fossil nummulites, corals or shells, or like numerous seams of coal, each based on its under clay full of the roots of trees, still remaining in their natural position, demand an indefinite lapse of time for their elaboration.

No one will maintain that the fossils entombed in these rocks did not belong to many successive generations of plants and animals. In like manner, each sedimentary deposit attests a slow and gradual action, and the strata not only serve as a measure of the amount of denudation simultaneously effected elsewhere, but are also a correct indication of the rate at which the denuding operation was carried on.

Perhaps the most convincing evidence of denudation on a magnificent scale is derived from the levelled surfaces of districts where large faults occur. I have shown, in fig. 87, p. 63, and in fig. 91, how angular and protruding masses of rock might naturally have been looked for on the surface immediately above great faults, although in fact they rarely exist. This phenomenon may be well studied in those districts where coal has been extensively worked, for there the former relation of the beds which have shifted their position may be determined with great ac- 
curacy. Thus in the coal field of Ashby de la Zouch, in Leicestershire (see fig. 91), a fault occurs, on one side of which the coal beds $a b c d$

Fig. 91 .

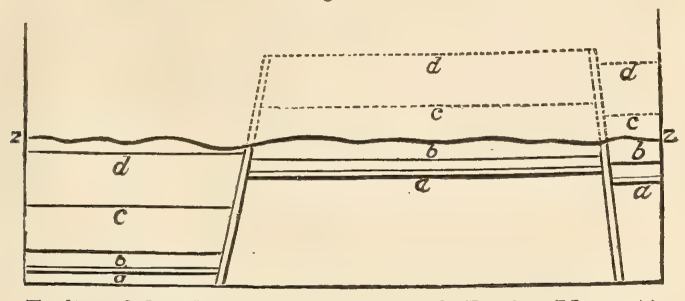

Faults and denuded coal strata, Ashby de lo Zouch. (Mammat.)

rise to the height of 500 feet above the corresponding beds on the other side. But the uplifted strata do not stand up $\mathbf{5 0 0}$ feet above the general surface; on the contrary, the outline of the country, as expressed by the line $z z$, is uniformly undulating without any break, and the mass indicated by the dotted outline must have been washed away.* There are proofs of this kind in some level countries, where dense masses of strata have been cleared away from areas several hundred square miles in extent.

In the Newcastle coal district it is ascertained that faults occur in which the upward or downward movement could not have been less than 140 fathoms, which, had they affected the configuration of the surface to an equal amount, would produce mountains with precipitous escarpments nearly 1000 feet high, or chasms of the like depth; yet is the actual level of the country absolutely uniform, affording no trace whatever of subterranean movements. $\dagger$

The ground from which these materials have been removed is usually overspread with heaps of sand and gravel, formed out of the ruins of the very rocks which have disappeared. Thus, in the districts above referred to, they consist of rounded and angular fragments of hard sandstone, limestone, and ironstone, with a small quantity of the more destructible shale, and even rounded pieces of coal.

Allusion has been already made to the shattered state and discordant position of the carboniferous strata in Coalbrook Dale (p. 62). The collier cannot proceed three or four yards without meeting with small slips, and from-time to time he encounters faults of considerable magnitude, which have thrown the rocks up or down several hundred feet. Yet the superficial inequalities to which these dislocated masses originally gave rise are no longer discernible, and the comparative flatness of the existing surface can only be explained, as Mr. Prestwich has observed, by supposing the fractured portions to have been removed by water. It is also clear that strata of red sandstone, more than 1000 feet thick, which once covered the coal, in the same region, have been carried away

* See Mammat's Geological Facts, \&c., p. 90, and plate.

† Conybeare's Report to Brit. Assoc. 1842, p. 381. 
from large areas. That water has, in this case, been the denuding agent, we may infer from the fact that the rocks have yielded according to their different degrees of hardness; the hard trap of the Wrekin, for example, and other hills, having resisted more than the softer shale and sandstone, so as now to stand out in bold relief.*

Origin of valleys.-Many of the earlier geologists, and Dr. Hutton among them, taught that "rivers have in general hollowed out their valleys." This is no doubt true of rivulets and torrents which are the feeders of the larger streams, and which, descending over rapid slopes, are most subject to temporary increase and diminution in the volume of their waters. It must also be admitted that the quantity of mud, sand, and pebbles constituting many a modern delta is so considerable, as to prove that a very large part of the inequalities now existing on the earth's surface are due to fluviatile action; but the principal valleys in almost every great hydrographical basin in the world, are of a shape and magnitude which imply that they have been due to other causes besides the mere excavating power of rivers.

Some geologists have imagined that a deluge, or succession of deluges, may have been the chief denuding agency, and they have speculated on a series of enormous waves raised by the instantaneous upthrow of continents or mountain chains out of the sea. But even were we disposed to grant such sudden upheavals of the floor of the ocean, and to assume that great waves would be the consequence of each convulsion, it is not easy to explain the observed phenomena by the aid of so gratuitous an hypothesis.

On the other hand, a machinery of a totally different kind seems capable of giving rise to effects of the required magnitude. It has now been ascertained that the rising and sinking of extensive portions of the earth's crust, whether insensibly or by a repetition of sudden shocks, is part of the actual course of nature, and we may easily comprehend how the land may have been exposed during these movements to abrasion by the waves of the sea. In the same manner as a mountain mass may, in the course of ages, be formed by sedimentary deposition, layer after layer, so masses equally voluminous may in time waste away by inches; as, for example, if beds of incoherent materials are raised slowly in an open sea where a strong current prevails. It is well known that some of these oceanic currents have a breadth of 200 miles, and that they sometimes run for a thousand miles or more in one direction, retaining a considerable velocity even at the depth of several hundred feet. Under these circumstances, the flowing waters may have power to clear away each stratum of incoherent materials as it rises and approaches the surface, where the waves exert the greatest force; and in this manner a voluminous deposit may be entirely swept away, so that, in the absence of faults, no evidence may remain of the denuding operation. It may indeed be affirmed that the signs of waste will usually be least obvious where the destruction has been most complete; for the annihilation

*. Prestwich, Geol. Trans. second series, vol. v. pp. 452, 473. 
may have proceeded so far, that no ruins are left of the dilapidated rocks.

Although denudation has had a levelling influence on some countries of shattered and disturbed strata (see fig. 87, p. 63, and fig. 91, p. 69), it has more commonly been the cause of superficial inequalities, especially in regions of horizontal stratification. The general outline of these regions is that of flat and level platforms, interrupted by valleys often of considerable depth, and ramifying in various directions. These hollows may once have formed bays and chanrels between islands, and the steepest slope on the sides of each valley may have been a sea-cliff, which was undermined for ages, as the land emerged gradually from the deep. We may suppose the position and course of each valley to have been originally determined by differences in the hardness of the rocks, and by rents and joints which ustally occur even in horizontal strata. In mountain chains, such as the Jura before described (see fig. 71, p. 55), we perceive at once that the principal valleys have not been due to aqueous excavation, but to those mechanical movements which have bent the rocks into their present form. Yet even in the Jura there are many valleys, such as C (fig. 71), which have been hollowed out by water ; and it may be stated that in every part of the globe the unevenness of the surface of the land has been due to the combined influence of subterranean movements and denudation.

I may now recapitulate a few of the conclusions to which we have arrived : first, all the mechanical strata have been accumulated gradually, and the concomitant denudation has been no less gradual: secondly, the dry land consists in great part of strata formed originally at the bottom of the sea, and has been made to emerge and attain its present height by a force acting from beneath : thirdly, no combination of causes has yet been conceived so capable of producing extensive and gradual denudation, as the action of the waves and currents of the ocean upon land slowly rising out of the deep.

Now, if we adopt these conclusions, we shall naturally be led to look everywhere for marks of the former residence of the sea upon the land, especially near the coasts from which the last retreat of the waters took place, and it will be found that such signs are not wanting.

I shall have occasion to speak of ancient sea-cliffs, now far inland, in the southeast of England, when treating in Chapter XIX. of the denudation of the chalk in Surrey, Kent, and Sussex. Lines of upraised sea-beaches of more modern date are traced, at various levels from 20 to 100 feet and upwards above the present sea-level, for great distances on the east and west coasts of Scotland, as well as in Devonshire, and other counties in England. These ancient beach-lines often form terraces of sand and gravel, including littoral shells, some broken, others entire, and corresponding with species now living on the adjoining coast. But it would be unreasonable to expect to meet everywhere with the signs of ancient shores, since no geologist can have failed to observe how soon all recent marks of the kind above alluded to are obscured or entirely ef- 
faced, wherever, in consequence of the altered state of the tides and currents, the sea has receded for a few centuries. We see the cliffs crumble down in a few years if composed of sand or clay, and soon reduced to a gentle slope. If there were shells on the beach they decompose, and their materials are washed away, after which the sand and shingle may resemble any other alluviums scattered over the interior.

The features of an ancient shore may sometimes be concealed by the growth of trees and shrubs, or by a covering of blown sand, a good example of which occurs a few miles west from Dax, near Bourdeaux, in the south of France. About twelve miles inland, a steep bank may be traced running in a direction nearly northeast and southwest, or parallel to the contiguous coast. This sudden fall of about 50 feet conducts us from the higher platform of the Landes to a lower plain which extends

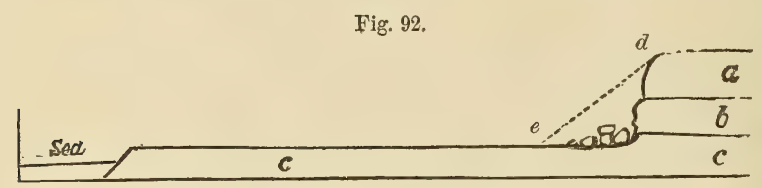

Section of inland cliff at Abesse, near Dax.
$\begin{array}{lll}\text { a. Sand of the Landes. } & \text { b. Limestone. } & c . \text { Clay. }\end{array}$

to the sea. The outline of the ground suggested to me, as it would do to every geologist, the opinion that the bank in question was once a seacliff, when the whole country stood at a lower level. But this is no longer matter of conjecture, for, in making excavations in 1830 for the foundation of a building at Abesse, a quantity of loose sand, which formed the slope $d e$, was removed; and a perpendicular cliff, about 50 feet in height, which had hitherto been protected from the agency of the elements, was exposed. At the bottom appeared the limestone $b$, containing tertiary shells and corals, immediately below it the clay $c$, and above it the usual tertiary sand $a$, of the department of the Landes. At the base of the precipice were seen large partially rounded masses of rock, evidently detached from the stratum $b$. The face of the limestone was hollowed out and weathered into such forms as are seen in the calcareous cliffs of the adjoining coast, especially at Biaritz, near Bayonne. It is evident that, when this country stood at a somewhat lower level, the sea advanced along the surface of the argillaceous stratum $c$, which, from its yielding nature, favored the waste by allowing the more solid superincumbent stone $b$ to be readily undermined. Afterwards, when the country had been elevated, part of the sand, $\alpha$, fell down, or was drifted by the winds, so as to form the talus, $d e$, which masked the inland clifi until it was artificially laid open to view.

When we are considering the various causes which, in the course of ages, may efface the characters of an ancient sea-coast, earthquakes must not be forgotten. During violent shocks, steep and overhanging cliffs are often thrown down and become a heap of ruins. Sometimes unequal movements of upheaval or depression entirely destroy that horizon- 
tality of the base-line which constitutes the chief peculiarity of an ancient sea-cliff.

It is, however, in countries where hard limestone rocks abound, that inland cliffs retain faithfully the characters which they acquired when they constituted the boundary of land and sea. Thus, in the Morea, no less than three, or even four, ranges of what were once sea-cliffs are well preserved. These have been described, by MM. Boblaye and Virlet, as rising one above the other at different distances from the actual shore, the summit of the highest and oldest occasionally exceeding 1000 feet in elevation. At the base of each there is usually a terrace, which is in some places a few yards, in others above 300 yards wide, so that we are conducted from the high land of the interior to the sea by a succession of great steps. These inland cliffs are most perfect, and most exactly resemble those now washed by the waves of the Mediterranean, where they are formed of calcareous rock, especially if the rock be a hard crystalline marble. The following are the points of correspondence observed between the ancient coast lines and the borders of the present sea:-1. A range of vertical precipices, with a terrace at their base. 2. A weathered state of the surface of the naked rock, such as the spray of the sea produces. 3. A line of littoral caverns at the foot of the cliffs. 4. A consolidated beach or breccia with occasional marine shells, found at the base of the cliffs, or in the caves. 5. Lithodomous perforations.

In regard to the first of these, it would be superfluous to dwell on the evidence afforded of the undermining power of waves and currents by perpendicular precipices. The littoral caves, also, will be familiar to those who have had opportunities of observing the manner in which the waves of the sea, when they beat against rocks, have power to scoop out caverns. As to the breccia, it is composed of pieces of limestone and rolled fragments of thick solid shell, such as Strombus and Spondylus, all bound together by a crystalline calcareous cement. Similar aggregations are now forming on the modern beaches of Greece, and in carerns on the sea-side; and the $y$ are only distinguishable in character from those of more ancient date, by including many pieces of pottery. In regard to the lithodomi above alluded to, these bivalve mollusks are well known to hare the power of excavating holes in the hardest limestones, the size of the carity keeping pace with the growth of the shell. When liring they require to be always covered by salt water, but similar pearshaped hollows, containing the dead shells of these creatures, are found at different heights on the face of the inland cliffs abore mentioned. Thus, for example, they have been observed near Modon and Navarino on cliffs in the interior 125 feet high abore the Mediterranean. As to the reathered surface of the calcareous rocks, all limestones are known to suffer chemical decomposition when moistened by the spray of the salt water, and are corroded still more deeply at points lower down where they are just reached by the breakers. By this action the stone acquires a wrinkled and furrowed outline, and very near the sea it becomes rough and branching; as if corered with corals. Such effects are traced rot 
only on the present shore, but at the base of the ancient cliffs far in the interior. Lastly, it remains only to speak of the terraces, which extend with a gentle slope from the base of almost all the inland cliffs, and are for the most part narrow where the rock is hard, but sometimes half a mile or more in breadth where it is soft. They are the effects of the encroachment of the ancient sea upon the shore at those levels at which the land remained for a long time stationary. The justness of this view is apparent on examining the shape of the modern shore wherever the sea is advancing upon the land, and removing annually small portions of undermined rock. By this agency a submarine platform is produced on which we may walk for some distance from the beach in shallow water, the increase of depth being very gradual, until we reach a point where the bottom plunges down suddenly. This platform is widened with more or less rapidity according to the hardness of the rocks, and when upraised it constitutes an inland terrace.

But the four principal lines of cliff observed in the Morea do not imply, as some have imagined, four great eras of sudden upheaval; they simply indicate the intermittance of the upheaving force. Had the rise of the land been continuous and uninterrupted, there would have been no one prominent line of cliff ; for every portion of the surface having been, in its turn, and for an equal period of time, a sea-shore, would have presented a nearly similar aspect. But if pauses occur in the pro. cess of upheaval, the waves and currents have time to sap, throw down, and clear away considerable masses of rock, and to shape out at several sinccessive levels lofty ranges of cliffs with broad terraces at their base.

There are some levelled spaces, however, both ancient and modern, in the Morea, which are not due to denudation, although resembling in outline the terraces above described. They may be called Terraces of Deposition, since they have resulted from the gain of land. upon the sea where rivers and torrents have produced deltas. If the sedimentary matter has filled up a bay or gulf surrounded by steep mountains, a flat plain is formed skirting the inland precipices; and if these deposits are upraised, they form a feature in the landscape very similar to the areas of denudation before described.

I have seen on the northern coast of Sicily one of these terraces of deposition in the environs of Palermo, where, as in Greece, a line of limestone cliffs with caverns at their base bounds a seawardsloping plain. Proceeding from the shore inland, we find the platform, $c$, fig. 93, a mile wide, composed of marine calcareous strata, the majority of the embedded shells and corals being of living species. We next arrive at a precipitous cliff of hippurite limestone, $a$, in which the well-known. cave of San Ciro, $b$, occurs, 130 feet long, 50 high, and 30 wide. Its entrance is now 180 feet above the sea; but the salt water must at one time have entered it, for the walls are drilled for a height of several yards by perforating molluses, and the bottom of the cave is strewed over with a thin layer of sand, in which more than forty species of sea-shells, nearly all of species now living 
In the Mediterranean have been found. Since the sea retired a considerable thickness of breccia has accumulated over the sand, so as to conceal from riew the lithodomous perforations, except in places

Fig. 93 ,

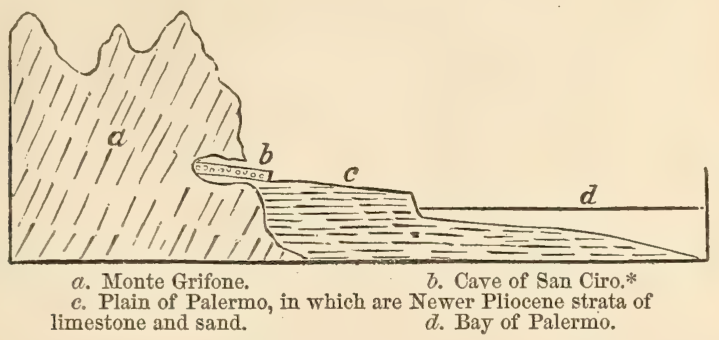

where these have been exposed to view by artificial excavations. The breccia is composed of pieces of limestone, quartz, and schist in a matrix of brown marl through which land shells are dispersed together with bones of two species, as we learn from Dr. Falconer, of extinct hippopotamus, in such numbers that they must have belonged to several hundred individuals. With these are associated the remains of Elephas antiquus (as determined by the same osteologist), and the osseous remains of Bos, Cervus, Sus, Ursus, Canis, and a large Felis. Some of these bones have been rolled as if partially subjected to the action of water, and the whole seem to have been introduced (perhaps by engulfed streams) both in this and some neighboring caverns through rents in the hippurite limestone, which must once have been connected with the surface of the country above, at a time when the physical geography of the region was extremely different from what it now is, and when rivers frequented by the hippopotamus existed where now no running water is to be found.

Besides terraces of deposition such as $c$, fig. 93, above alluded to, there are also in Sicily others of denudation. One of these occurs on the east coast to the north of Syracuse, and the same is resumed to the south beyond the town of Noto, where it may be traced forming a continuous and lofty precipice, $a b$, fig. 94, facing toward the sea, and constituting the abrupt termination of a calcareous formation, which extends in horizontal strata far inland. This precipice raries in height from 500 to 700 feet, and between its base and the sea is an inferior platform, $c b$, consisting of similar white limestone. All the beds dip toward the sea, but are usually inclined at a rery slight angle: they are seen to extend uninterruptedly from the base of the escarpment into the platform, showing distinctly that the lofty cliff was not produced by a fault or vertical shift of the beds, but by the removal of a considerable mass of rock. Hence we may conclude that the sea, which is now undermining the cliffs of the Sicilian coast, reached at some former period the base of the precipice $a b$, at which time the sur-

* Dr. Christie, Edin. New Phil. Jour. 
face of the terrace $c b$ must have been covered by the Mediterranean. There was a pause, therefore, in the upward movement, when the waves

Fig. 94.

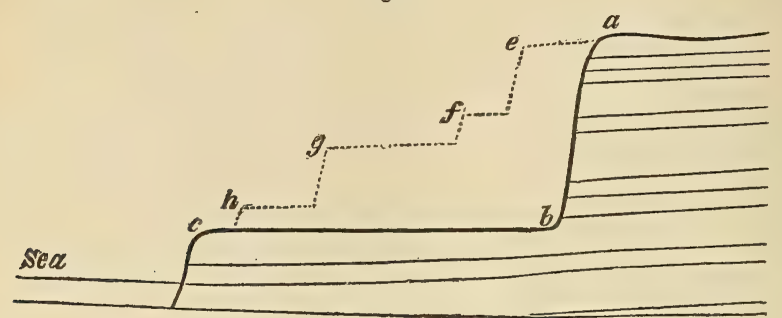

of the sea had time to carve out the platform $c b$; but there may have been many other stationary periods of minor duration. Suppose, for example, that a series of escarpments $e, f, g, h$, once existed, and that the sea, during a long interval free from subterranean movements, advances along the line $c b$, all preceding cliffs must have been swept away one after the other, and reduced to the single precipice $a b$.

That such a series of smaller cliffs, as those represented at $e, f, g, h$, fig. 94, did really once exist at intermediate heights in place of the single precipice $a b$, is rendered highly probable by the fact, that in certain bays and inland valleys opening towards the east coast of Sicily, and not far from the section given in fig. 94, the solid limestone is shaped out into a great succession of ledges, separated from each other by small vertical cliffs. These are sometimes so numerous, one above the other,

Fig. 95.

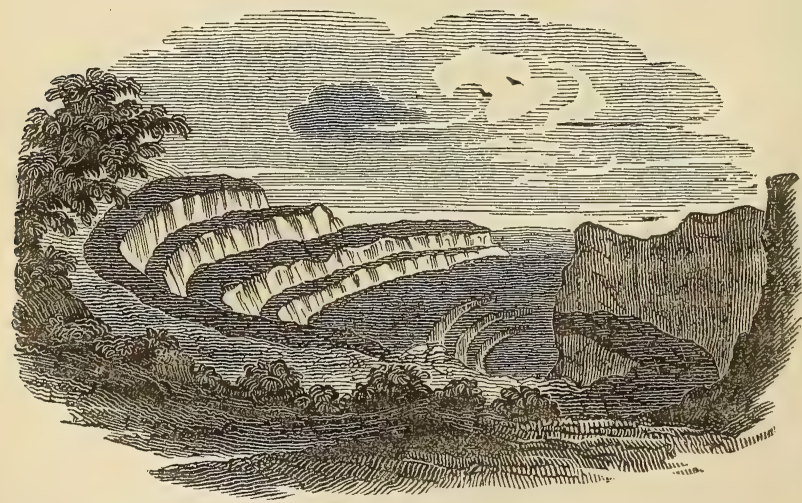

Valley called Gozzo degli Martiri, below Melilli, Val di Noto.

that where there is a bend at the head of a valley, they produce an effect singularly resembling the seats of a Roman amphitheatre. A good 
example of this configuration occurs near the town of Melilli, as seen in the annexed view (fig. 95). In the south of the island, near Spaccaforno, Scicli, and Modica, precipitous rocks of white limestone, ascending to the height of 500 feet, have been carved out into similar forms.

This appearance of a range of marble seats circling round the head of a valley, or of great flights of steps descending from the top to the botlom, on the opposite sides of a gorge, may be accounted for, as already hinted, by supposing the sea to have stood successively at many different levels, as at $a a, b b, c c$, in the accompanying fig. 96. But the causes of the gradual contraction of the valley from above downwards may

Fig. 96.

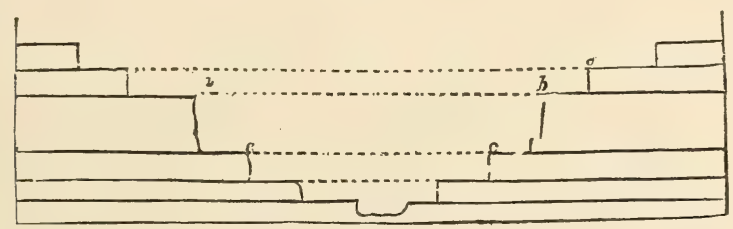

still be matter of speculation. Such contraction may be due to the greater force exerted by the waves when the land at its first emergence was smaller in quantity, and more exposed to denudation in an open sea; whereas the wear and tear of the rocks might diminish in propor. tion as this action became confined within bays or channels closed in on two or three sides. Or, secondly, the separate movements of elevation may have followed each other more rapidly as the land continued to rise, so that the times of those pauses, during which the greatest denudation was accomplished at certain levels, were always growing shorter. It should be remarked, that the cliffs and small terraces are rarely found on the opposite sides of the Sicilian valleys at heights so precisely answering to each other as those given in fig. 96, and this might have been expected, to whichever of the two hypotheses above explained we incline; for, according to the direction of the prevailing winds and currents, the waves may beat with unequal force on different parts of the shore, so that while no impression is made on one side of a bay, the sea may encroach so far on the other as to unite several smaller cliffs into one.

Before quitting the subject of ancient sea-cliffs, carved out of limestone, I shall mention the range of precipitous rocks, composed of a white marble of the Oolitic period, which I have seen near the northern gate of St. Mihiel in France. They are situated on the right bank of the Meuse, at a distance of 200 miles from the nearest sea, and they present on the precipice facing the river three or four horizontal grooves, one above the other, precisely resembling those which are scooped out by the undermining waves. The summits of several of these masses are detached from the adjoining hill, in which case the grooves pass all 
round them, facing towards all points of the compass, as if they had once formed rocky islets near the shore.*

Captain Bayfield, in his survey of the Gulf of St. Lawrence, discovered in several places, especially in the Mingan islands, a counterpart of the inland cliffs of St. Mihiel, and traced a succession of shingle beaches, one above the other, which agreed in their level with some of the principal grooves scooped out of the limestone pillars. These beaches consisted of calcareous shingle, with shells of recent species, the farthest from the shore being 60 feet above the level of the highest tides. In addition to the drawings of the pillars called the flower-pots, which he has published, $\uparrow$ I have been favored with other views of rocks on the same coast, drawn by Lieut. A. Bowen, R. N. (See fig. 97.)

Fig. 97.

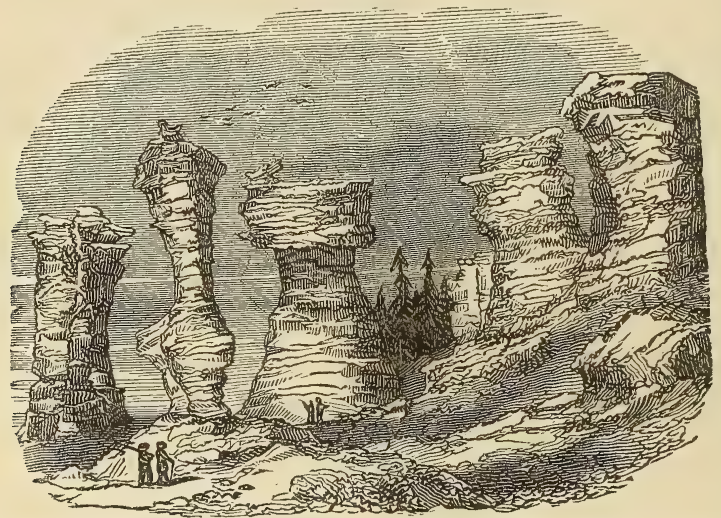

Limestone columns in Niapisca Island, in the Gulf of St. Lawrence. Height of the second column on the left, 60 feet.

In the North-American beaches above mentioned rounded fragments of limestone have been found perforated by lithodomi; and holes drilled by the same mollusks have been detected in the columnar rocks or "flower-pots," showing that there has been no great amount of atmospheric decomposition on the surface, or the cavities alluded to would have disappeared.

Fig. 98.

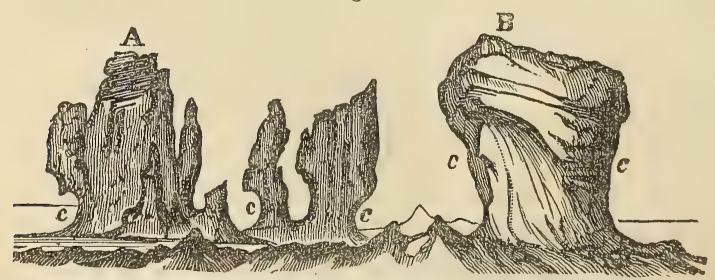

The North Rocks, Bermuda, lying outside the great coral recf.

$\begin{array}{ll}\text { A. } 16 \text { feet high, and B. } 12 \text { feet. } & \text { c. c. Hollows worn by the sea. }\end{array}$

* I was directed by M. Deshayes to this spot, which I visited in June, 1833.

† See Trans. of Geol. Soc. second series, vol. v. plate v. 
We have an opportunity of seeing in the Bermuda islands the manner in which the waves of the Atlantic have worn, and are now wearing out, deep smooth hollows on every side of projecting masses of hard limestone. In the annexed drawing, communicated to me by Capt Nelson, R. E., the excarations $c, c, c$, have been scooped out by the waves in a stone of very modern date, which, although extremely hard, is full of recent corals and shells, some of which retain their color.

When the forms of these horizontal grooves, of which the surface is sometimes smooth and almost polished, and the roofs of which often overhang to the extent of 5 feet or more, have been carefully studied by geologists, they will serve to testify the former action of the waves at innumerable points far in the interior of the continents. But we must learn to distinguish the indentations due to the original action of the sea, and those caused by subsequent chemical decomposition of calcareous rocks, to which they are liable in the atmosphere.

I shall conclude with a warning to beginners not to feel surprise if they san detect no evidence of the former sojourn of the sea on lands which we are nevertheless sure have been submerged at periods comparatively modern; for notwithstanding the enduring nature of the marks left by littoral action on calcareous rocks, we can by no means detect sea-beaches and inland cliffs everywhere, even in Sicily and the Morea. On the con trary, they are, upon the whole, extremely partial, and are often entirely wanting in districts composed of argillaceous and sandy formations, which must, nevertheless, have been upheaved at the same time, and by the same intermittent movements, as the adjoining calcareous rocks.

\section{CHAPTER VII.}

\section{ALLUVIUM.}

Alluvium described-Due to complicated causes-Of various ages, as shown in Aurergne-How distinguished from rocks in situ-Sand-pipes in chalk-Alluvial terraces caused by oscillations in the level of land.

BETWEEx the superficial covering of vegetable mould and the subjacent rock there usually intervenes in every district a deposit of loose gravel, sand, and mud, to which the name of alluvium has heen applied. The term is derived from alluvio, an inundation, or alluo, to wash, because the pebbles and sand commonly resemble those of a river's bed or the mud and gravel washed over low lands by a flood.

A partial corering of such alluvium is found alike in all climates, from the equatorial to the polar regions; but in the higher latitudes of Europe and North America it assumes a distinct character, being rery frequently deroid of stratification, and containing huge fragments of rocir, some angular and others rounded, which have been transported to great distances from their parent mountains. When it presents itself in this form, it has been called "diluvium," "drift," or the "boulder formation," and its prob- 
able connection with the agency of floating ice and glaciers will be treated of more particularly in the eleventh and twelfth chapters.

The student will be prepared, by what I have said in the last chapter on denudation, to hear that loose gravel and sand are often met with, not only on the low grounds bordering rivers, but also at various points on the sides or even summits of mountains. For, in the course of those changes in physical geography which may take place during the gradual emergence of the bottom of the sea and its conversion into dry land, any spot may either have been a sunken reef, or a bay, or estuary, or sea-shore, or the bed of a river. The drainage, moreover, may have been deranged again and again by earthquakes, during which temporary lakes are caused by landslips, and partial deluges occasioned by the bursting of the barriers of such lakes. For this reason it would be unreasonable to hope that we should ever be able to account for all the alluvial phenomena of each particular country, seeing that the causes of their origin are so various. Besides, the last operations of water have a tendency to disturb and confound together all pre-existing alluviums. Hence we are always in danger of regarding as the work of a single era, and the effect of one cause, what has in reality been the result of a variety of distinct agents, during a long succession of geological epochs. Much useful instruction may therefore be gained from the exploration of a country like Auvergne, where the superficial gravel of very different eras happens to have been preserved by sheets of lava, which were poured out one after the other at periods when the denudation, and probably the upheaval, of rocks were in progress. That region had already acquired in some degree its present configuration before any volcanoes were in activity, and before any igneous matter was superimposed upon the granitic and fossiliferous formations. The pebbles therefore in the older gravels are exclusively constituted of granite and other aboriginal rocks; and afterwards, when volcanic vents burst forth into eruption,

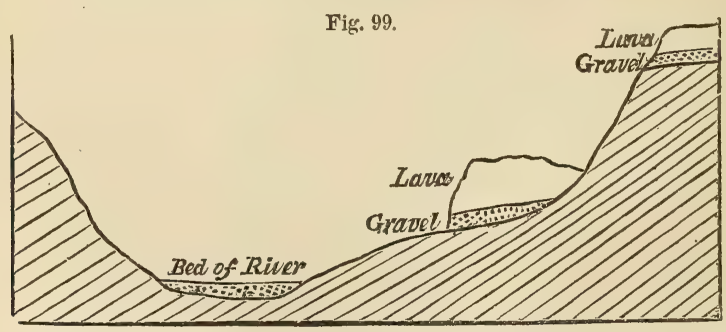

Lavas of Auvergne resting on alluviums of different ages.

those earlier alluviums were covered by streams of lava, which protected them from intermixture with gravel of subsequent date. In the course of ages, a new system of valleys was excavated, so that the rivers ran at lower levels than those at which the first alluviums and sheets of lava were formed. When, therefore, fresh eruptions gave rise to new lava, the melted matter was poured out over lower grounds; and the gravel 
of these plains differed from the first or upland alluvium, by containing in it rounded fragments of various volcanic rocks, and often bones belonging to distinet groups of land animals which flourished in the country in succession.

The annexed drawing will explain the different heights at which beds of lara and gravel, each distinct from the other in composition and age, are observed, some on the flat tops of hills, 700 or 800 feet high, others on the slope of the same hills, and the newest of all in the channel of the existing river where there is usually gravel alone, but in some cases a narrow stripe of solid lava sharing the bottom of the valley with the river. In all these accumulations of transported matter of different ages, the bones of extinct mammalia have been fornd belonging to assemblages of land quadrupeds which flourished in the country in succession, and whicl vary specifically, the one set from the other, in a greater or less degree. in proportion as the time which separated their entombment has been more or less protracted. The streams in the same district are still undermining their banks and grinding down into pebbles or sand, columns of basalt and fragments of granite and gneiss; but portions of the older alluriums, with the fossil remains belonging to them, are prevented from being mingled with the gravel of recent date by the cappings of lava before mentioned. But for the accidental interference, therefore, of this peculiar cause, all the alluviums might have passed so insensibly the one into the other, that those formed at the remotest era might have appeared of the same date as the newest, and the whole formation might hare been regarded by some geologists as the result of one sudden and violent catastrophe.

In almost every country, the alluvium consists in its upper part of transported materials, but it often passes downwards into a mass of broken and angular fragments derired from the subjacent rock. To this mass the provincial name of "rubble," or "brash," is given in many parts of England. It may be referred to the weathering" or disintegration of stone on the spot, the effects of air and water, sun and frost, and chemical decomposition.

The inferior surface of alluvial deposits is often very irregular, conforming to all the inequalities of the fundamental rocks (fig. 100). Oc-

Fig. 100.

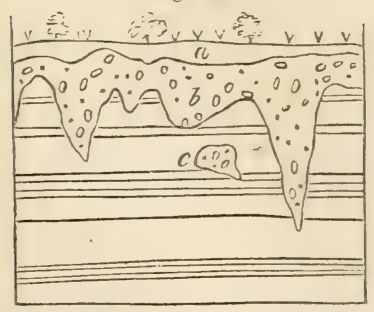

a. Vegetable soil.

c. Mass of same, apparently detached. casionally, a small mass, as at $c$, appears detached, and as if included in the subjacent formation. Such isolated portions are usually sections of winding subterranean hollows filled up with alluvium. They may have been the courses of springs or subterranean streamlets, which have flowed through and enlarged natural rents; or, when on a small scale and in soft strata, they may be spaces which the roots of large trees have once occupied, gravel and sand having been introduced after their decay. 
But there are other deep hollows of a cylindrical form found in England, France, and elsewhere, penetrating the white chalk, and filled witl sand and gravel, which are not so readily explained. They are sometimes called "sand-pipes," or "sand-galls," and "puits naturels," in France. Those represented in the annexed cut were observed by me in

Fig. 101.

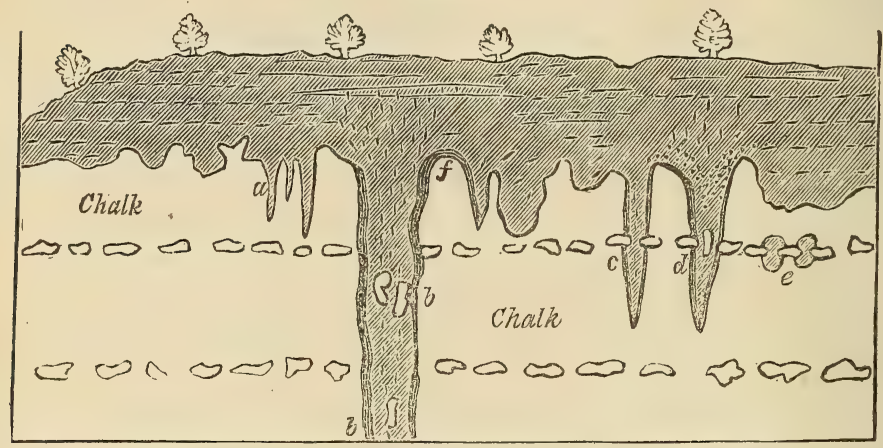

Sand-pipes in the chalk at Eaton, ncar Norwich.

1839, laid open in a large chalk-pit near Norwich. They were of very symmetrical form, the largest more than 12 feet in diameter, and some of them had been traced, by boring, to the depth of more than 60 feet. The smaller ones varied from a few inches to a foot in diameter, and seldom descended more than 12 feet below the surface. Even where three of them occurred, as at $\alpha$, fig. 101, very close together, the parting walls of soft white chalk were not broken through. They all taper downwards and end in a point. As a general rule, sand and pebbles occupy the central parts of each pipe, while the sides and bottom are lined with clay.

Mr. Trimmer, in speaking of appearances of the same kind in the Kentish chalk, attributes the origin of such "sand-galls" to the action of the sea on a beach or shoal, where the waves, charged with shingle and sand, not only wear out longitudinal furrows, such as may be observed on the surface of the above-mentioned chalk near Norwich when the incumbent gravel is removed, but also drill deep circular hollows by the rotatory motion imparted to sand and pebbles. Such furrows, as well as vertical cavities, are now formed, he observes, on the coast where the shores are composed of chalk.*

That the commencement of many of the tubular cavities now under consideration has been due to the cause here assigned, I have little doubt. But such mechanical action could not have hollowed out the whole of the sand-pipes $c$ and $d$, fig. 101, because several large chalk-fints seen protruding from the walls of the pipes have not been eroded, while sand and gravel have penetrated many feet below them. In other eases, as

* Trimmer, Proceedings of Geol. Soc. vol, iv. p. 7, 1842. 
at $b \quad b$, similar unrounded nodules of flint, still preserving their irregular form and white coating, are found at various depths in the midst of the lcose materials filling the pipe. These have evidently been detached from regular layers of flints occurring above. It is also to be remarked that the course of the same sand-pipe, $b \quad b$, is traceable above the level of the chalk for some distance upwards, through the incumbent gravel and sand, by the obliteration of all signs of stratification. Occasionally, also, as in the pipe $d$, the overlying beds of gravel bend downwards into the mouth of the pipe, so as to become in part vertical, as would happen if horizontal layers had sunk gradually in consequence of a failure of support. All these phenomena may be accounted for by attributing the enlargement and deepening of the sand-pipes to the chemical action of water charged with carbonic acid, derived from the vegetable soil and the decaying roots of trees. Such acid might corrode the chalk, and deepen indefinitely any previously existing hollow, but could not dissolve, the flints. The water, after it had become saturated with carbonate of lime, might freely percolate the surrounding porous walls of chalk, and escape through them and from the bottom of the tube, so as to carry away in the course of time large masses of dissolved calcareous rock, * and leave behind it on the edges of each tubular hollow a coating of fine clay, which the white chalk contains.

I have seen tubes precisely similar and from 1 to 5 feet in diameter traversing vertically the upper half of the soft calcareous building-stone, or chalk without flints, constituting St. Peter's Mount, Maestricht. These hollows are filled with pebbles and clay, derived from overlying beds of gravel, and all terminate downwards like those of Norfolk. I was informed that, 6 miles from Maestricht, one of these pipes, 2 feet in diameter, was traced downwards to a bed of flattened flints, forming an almost continuous layer in the chalk. Here it terminated abruptly, but a few small root-like prolongations of it were detected immediately below, probably where the dissolving substance had penetrated at some points through openings in the siliceous mass.

It is not so easy as may at first appear to draw a clear line of distinction between the fixed rocks, or regular strata (rocks in situ or in place), and alluvium. If the bed of a torrent or river be dried up, we call the gravel, sand, and mud left in their channels, or whatever, during floods, they may have scattered over the neighboring plains, alluvium. The very same materials carried into a lake, where they become sorted by water and arranged in more distinct layers, especially if they inclose the remains of plants, shells, or other fossils, are termed regular strata.

In like manner we may sometimes compare the gravel, sand, and broken shells, strewed along the path of a rapid marine current, with a deposit formed contemporaneously by the discharge of similar materials, year after year, into a deeper and more tranquil part of the sea. In such cases, when we detect marine shells or other organic remains en-

* See Lyell on Sand-pipes, \&c. Phil. Mag. third series, vol. xv. p. 257, Oct. 1839. 
tombed in the strata, which enable us to determine their age and mode of origin, we regard them as part of the regular series of fossiliferous formations, whereas, if there are no fossils, we have frequently no power of separating them from the general mass of superficial alluvium.

The usual rarity of organic remains in beds of loose gravel is partly owing to the friction which originally ground down rocks into pebbles or sand, and organic bodies into small fragments, and it is partly owing to the porous nature of alluvium when it has emerged, which allows the free percolation through it of rain-water, and promotes the decomposition and solution of fossil remains:

It has long been a matter of common observation that most rivers are now cutting their channels through alluvial deposits of greater depth and extent than could ever have been formed by the present streams. From this fact a rash inference has sometimes been drawn, that rivers in general have grown smaller, or become less liable to be flooded than formerly. But such phenomena would be a natural result of considerable oscillations in the level of the land experienced since the existing valleys originated.

Suppose part of à continent, comprising within it a large hydrographical basin like that of the Mississippi, to subside several inches or feet in a century, as the west coast of Greenland, extending 600 miles north and south, has been sinking for three or four centuries, between the latitudes $60^{\circ}$ and $69^{\circ} \mathrm{N}$.* It will rarely happen that the rate of subsidence will be everywhere equal, and in many cases the amount of depression in the interior will regularly exceed that of the region nearer the sea. Whenever this happens, the fall of the waters flowing from the upland country will be diminished, and each tributary stream will have less power to carry its sand and sediment into the main river, and the main river less power to convey its annual burden of transported matter to the sea. All the rivers, therefore, will proceed to fill up partially their ancient channels, and, during frequent inundations, will raise their alluvial plains by new deposits. If then the same area of land be again upheaved to its former height, the fall, and consequently the velocity, of every river would begin to augment. Each of them would be less given to overflow its alluvial plain; and their power of carrying earthy matter seaward, and of scouring out and deepening their channels, will be sustained till, after a lapse of many thousand years, each of them has eroded a new channel or valley through a fluviatile formation of comparatively modern date. The surface of what was once the river-plain at the period of greatest depression, will then remain fringing the valley sides in the form of a terrace apparently flat, but in reality sloping down with the general inclination of the river. Everywhere this terrace will present cliffs of gravel and sand, facing the river. That such a series of movements has actually taken place in the main valley of the Mississippi and in its tributary valleys during

* Principles of Geology, 7th ed. p. 506, 8th ed. p. 509. 
oscillations of level, I have endeavored to show in my description of that country; * and the freshwater shells of existing species and bones of land quadrupeds, partly of extinct races, preserved in the terraces of fluviatile origin, attest the exclusion of the sea during the whole process of filling up and partial re-excavation.

Such terraces are the converse of those mentioned at p. 80, fig. 99, where the uppermost of the series is formed of alluvium of oldest date, which originated long before the valley had attained its actual width and depth.

\section{CHAPTER VIII.}

\section{CHRONOLOGICAL CLASSIFICATION OF ROCKS.}

Aqueous, plutonic, volcanic, and metamorphic rocks, considered chronologicallyLehman's division into primitive and secondary-Werner's addition of a transition class-Neptunian theory-Hutton on igneous origin of granite-How the name of primary was still retained for granite-The term "transition," why faulty - The adherence to the old chronological nomenclature retarded the progress of geology-New hypothesis intended to reconcile the igneous origin of granite to the notion of its high antiquity-Explanation of the chronological nomenclature adopted in this work, so far as regards primary, secondary, and̃ tertiary periods.

In the first chapter it was stated that the four great classes of rocks, the aqueous, the volcanic, the plutonic, and the metamorphic, would each be considered not only in reference to their mineral characters, and mode of origin, but also to their relative age. In regard to the aqueous rocks, we have already seen that they are stratified, that some are calcareous, others argillaceous or siliceous, some made up of sand, others of pebbles; that some contain freshwater, others marine fossils, and so forth; but the student has still to learn which rocks, exhibiting some or all of these characters, have originated at one period of the earth's history, and which at another.

To determine this point in reference to the fossiliferous formations is more easy than in any other class, and it is therefore the most conrenient and natural method to begin by establishing a chronology for these strata, and then to refer as far as possible to the same divisions the sereral groups of plutonic, volcanic, and metamorphic rocks. Such a system of classification is not only recommended by its greater clearness and facility of application, but is also best fitted to strike the imagination by bringing into one view the contemporaneous revolutions of the inorganic and organic creations of former times. For the sedimentary formations are most readily distinguished by the different species of fossil animals and plants which

* Second Visit to the U. S., vol. ii., chap. 34. 
they inclose, and of which one assemblage after another has flourished and then disappeared from the earth in succession.

But before entering specially on the subdivisions of the aqueous rocks arranged according to the order of time, it will be desirable to say a few words on the chronology of rocks in general, although in doing so we shall be unavoidably led to allude to some classes of phenomena which the beginner must not yet expect fully to comprehend.

It was for many years a received opinion, that the formation of entire families of rocks, such as the plutonic and those crystalline schists spoken of in the first chapter as metamorphic, began and ended before any members of the aqueous and volcanic orders were produced; and although this idea has long been modified, and is nearly exploded, it will be necessary to give some account of the ancient doctrine, in order that beginners may understand whence many prevailing opinions, and some part of the nomenclature of geology, still partially in use, was derived.

About the middle of the last century, Lehman, a German miner, proposed to divide rocks into three classes, the first and oldest to be called primitive, comprising the hypogene, or plutonic and metamorphic rocks; the next to be termed secondary, comprehending the aqueous or fossilif-. érous strata; and the remainder, or third class, corresponding to our alluvium, ancient and modern, which he referred to "local floods, and the deluge of Noah." In the primitive class, he said, such as granite and gneiss, there are no organic remains, nor any signs of materials derived from the ruins of pre-existing rocks. Their origin, therefore, may have been purely chemical, antecedent to the creation of living beings, and probably coeval with the birth of the world itself. The secondary formations, on the contrary, which often contain sand, pebbles, and organic remains, must have been mechanical deposits, produced after the planet had become the habitation of animals and plants. This bold generalization, although anticipated in some measure by Steno, a century before, in Italy, formed at the time an important step in the progress of geology, and sketched out correctly some of the leading divisions into which rocks may be separated. About half a century later, Werner, so justly celebrated for his improved methods of discriminating the mineralogical characters of rocks, attempted to improve Lehman's classification, and with this view intercalated a class, called by him "the transition formations," between the primitive and secondary. Between these last he had discovered, in northern Germany, a series of strata, which in their mineral peculiarities were of an intermediate character, partaking in some degree of the crystalline nature of micaceous schist and clay-slate, and yet exhibiting here and there signs of a mechanical origin and organic remains. For this group, therefore, forming a passage between Lehman's primitive and secondary rocks, the name of übergang or transition was proposed. They consisted principally of clay-slate and an argillaceous sandstone, called grauwacke, and partly of calcareous beds. It happened in the district which Werner first investigated, that both the primitive and transition strata were highly inclined, while the beds of 
the newer fossiliferous rocks, the secondary of Lehman, were horizontal. To these latter therefore, he gave the name of flötz, or " a level floor ;" and every deposit more modern than the chalk, which was classed as the uppermost of the flötz series, was designated "the overflowed land," an expression which may be regarded as equivalent to alluvium, although ander this appellation were confounded all the strata afterwards called tertiary, of which Werner had scarcely any knowledge. As the followers of Werner soon discovered that the inslined position of the "transition beds," and the horizontality of the flötz, or newer fossiliferous strata, were mere local accidents, they soon abandoned the term flötz; and the four divisions of the Wernerian school were then named primitive, transition, secondary, and alluvial.

As to the trappean rocks, although their igneous origin had been already demonstrated by Arduino, Fortis, Faujas, and others, and especially by Desmarest, they were all regarded by Werner as aqueous, and as mere subordinate members of the secondary series.*

The theory of Werner's was called the "Neptunian," and for many years enjoyed much popularity. It assumed that the globe had been at first invested by a universal chaotic ocean, holding the materials of all rocks in solution. From the waters of this ocean, granite, gneiss, and other crystalline formations, were first precipitated; and afterwards, when the waters were purged of these ingredients, and more nearly resembled those of our actual seas, the transition strata were deposited. These were of a mixed character, not purely chemical, because the wares and currents had already begun to wear down solid land, and to give rise to pebbles, sand, and mud; nor entirely without fossils, because a ferw of the first marine animals had begun to exist. After this period, the secondary formations were accumulated in waters resembling those of the present ocean except at certain intervals, when, from causes wholly unexplained, a partial recurrence of the "chaotic fluid" took place, during which various trap rocks, some highly erystalline, were formed. This arbitrary hypothesis rejected all intervention of igneous agency, volcanoes being regardecl as modern, partial, and superficial accidents, of trifling account among the great causes which have modified the external structure of the globe.

Neanwhile Hutton, a contemporary of Werner, began to teach, in Scotland, that granite as well as trap was of igneous origin, and had at various periods intruded itself in a fluid state into different parts of the earth's crust. He recognized and faithfully described many of the phenomena of granitic veins, and the alterations produced by them on the invaded strata, which will be treated of in the thirty-third chapter. He, moreover, advanced the opinion, that the crystalline strata called primitive had not been precipitated from a primæval ocean, but were sedimentary strata altered by heat. In his writings, therefore, and in those of his illustrator, Playfair, we find the germ of that metamorphic theory which has been already hinted at in the first chapter, and which will be more fully expounded in the thirty-fourth and thirty-fifth charters.

* See Principles of Geology, vol. i. chap. IV. 
At length, after much controversy, the doctrine of the igneous origin of trap and granite made its way into general favor; but although it was, in consequence, admitted that both granite and trap had been produced at many successive periods, the term primitive or primary still continued to be applied to the crystalline formations in general, whether stratified, like gneiss, or unstratified, like granite. The pupil was told that granite was a primary rock, but that some granites were newer than certain secondary formations; and in conformity with the spirit of the ancient language, to which the teacher was still determined to adhere, a desire was naturally engendered of extenuating the importance of those more modern granites, the true dates of which new observations were continually bringing to light.

A no less decided inclination was shown to persist in the use of the term "transition," after it had been proved to be almost as faulty in its original application as that of flötz. The name of transition, as already stated, was first given by Werner, to designate a mineral character, inter mediate between the highly crystalline or metamorphic state and that of an ordinary fossiliferous rock. But the term acquired also from the first a chronological import, because it had been appropriated to sedimentary formations, which, in the Hartz and other parts of Germany, were more ancient than the oldest of the secondary series, and were characterized by peculiar fossil zoophytes and shells. When, therefore, geologists found in other districts stratified rocks occupying the same position, and inclosing similar fossils, they gave to them also the name of transition, according' to rules which will be explained in the next chapter ; yet, in many cases, such rocks were found not to exhibit the same mineral texture which Werner had called transition. On the contrary, many of them were not more crystalline than different members of the secondary class; while, on the other hand, these last were sometimes found to assume a semicrystalline and almost metamorphic aspect, and thus, on lithological giounds, to deserve equally the name of transition. So remarkably was this the case in the Swiss Alps, that certain rocks, which had for years been regarded by some of the most skilful disciples of Werner to be transition, were at last acknowledged, when their relative position and fossils were better understood, to belong to the newest of the secondary groups; nay, some of them have actually been discovered to be members of the lower tertiary series! If, under such circumstances, the name of transition was retained, it is clear that it ought to have been applied without reference to the age of strata, and simply as expressive of a mineral peculiarity. The continued appropriation of the term to formations of a given date, induced geologists to go on believing that the ancient strata so designated bore a less resemblance to the secondary than is really the case, and to imagine that these last never pass, as they frequently do, into metamorphic rocks.

The poet Waller, when lamenting over the antiquated style of Chaucer, complains that- 
But the reverse is true in geology ; for here it is our work which continually outgrows the language. The tide of observation advances with such speed that improvements in theory outrun the changes of nomenclature; and the attempt to inculcate new truths by words invented to express a different or opposite opinion, tends constantly, by the force of association to perpetuate error; so that dogmas renounced by the reason still retain a strong hold upon the imagination.

In order to reconcile the old chronological views with the new doctrine of the igneous origin of granite, the following hypothesis was substituted for that of the Neptunists. Instead of beginning with an aqueous menstruum or chaotic fluid, the materials of the present crust of the earth were supposed to have been at first in a state of igneous fusion, until part of the heat having been diffused into surrounding space, the surface of the fluid consolidated, and formed a crust of granite. This covering of crystalline stone, which afterwards grew thicker and thicker as it cooled, was so hot, at first, that no water could exist upon it; but as the refrigeration proceeded, the aqueous vapor in the atmosphere was condensed, and, falling in rain, gave rise to the first thermal ocean. So high was the temperature of this boiling sea, that no aquatic beings could inhabit its waters, and its deposits were not only devoid of fossils, but, like those of some hot springs, were highly crystalline. Hence the origin of the primary or crystalline strata, - gneiss, mica-schist, and the rest.

Afterwards, when the granitic crust had been partially broken up, land and mountains began to rise above the waters, and rains and torrents to grind down rock, so that sediment was spread over the bottom of the seas. Yet the heat still remaining in the solid supporting substances was sufficient to increase the chemical action exerted by the water, although not so intense as to prevent the introduction and increase of some living beings. During this state of things some of the residuary mineral ingredients of the primæval ocean were precipitated, and formed deposits (the transition strata of Werner), half chemical and half mechanical, and containing a few fossils.

By this new theory, which was in part a revival of the doctrine of Leibnitz, published in 1680, on the igneous origin of the planet, the old ideas respecting the priority of all crystalline rocks to the creation of organic beings, were still preserved; and the mistaken notion that all the semi-crystalline and partially fossiliferous ricks belonged to one period, while all the earthy and uncrystalline formations originated at a subsequent epoch, was also perpetuated.

It may or may not be true, as the great Leibnitz imagined, that the whole planet was once in a state of liquefaction by heat; but there are certainly no greological proofs that the granite which constitutes the foundation of so much of the earth's crust was ever at once in a state of universal fusion. On the contrary, all our evidence tends to show that the formation of granite, like the deposition of the stratified rocks, has been successive, and that different portions of granite have been in a melted state at distinct and often distant periods. One mass was solid, and had been frac- 
tured, before another body of granitic matter was injected into it, or through it, in the form of veins. Some granites are more ancient than any known fossiliferous rocks; others are of secondary; and some, such as that of Mont Blanc and part of the central axis of the Alps, of tertiary origin. In short, the universal fluidity of the crystalline foundations of the earth's crust, can only be understood in the same sense as the universality of the ancient ocean. All the land has been under water, but not all at one time; so all the subterranean unstratified rocks to which man can obtain access have been melted, but not simultaneously.

In the present work the four great classes of rocks, the aqueous, plutonic, volcanic, and metamorphic, will form four parallel, or nearly parallel, columns in one chronological table. They will be considered as four sets of monuments relating to four contemporaneous, or nearly contemporaneous, series of events. I shall endeavor, in a subsequent chapter on the plutonic rocks, to explain the manner in which certain masses belonging to each of the four classes of rocks may have originated simultaneously at every geological period, and how the earth's crust may have been continually modelled, above and below, by aqueous and igneous causes, from times indefinitely remote. In the same manner as aqueous and fossiliferous strata are now formed in certain seas or lakes, while in other places volcanic rocks break out at the surface, and are connected with reservoirs of nelted matter at vast depths in the bowels of the earth,-so, at every era of the past, fossiliferous deposits and superficial igneous rocks were in progress contemporaneously with others of subterranean and plutonic origin, and some sedimentary strata were exposed to heat and made to assume a crystalline or metamorphic structure.

It can by no means be taken for granted, that during all these change: the solid crust of the earth has been increasing in thickness. It has been shown, that so far as aqueous action is concerned, the gain by fresh deposits, and the loss by denudation, must at each period have been equal (see above, p. 68) : and in like manner, in the inferior portion of the earth's crust, the acquisition of new crystalline rocks, at each successive era, may merely have counterbalanced the loss sustained by the melting of materials previously consolidated. As to the relative antiquity of the crystalline foundations of the earth's crust, when compared to the fossiliferous and volcanic rocks which they support, I have already stated, in the first chapter, that to pronounce an opinion on this matter is as difficult as at once to decide which of the two, whether the foundations or superstructure of an ancient city built on wooden piles, may be the oldest. We have seen that, to answer this question, we must first be prepared to say whether the work of decay and restoration had gone on most rapidly above or below, whether the average duration of the piles has exceeded that of the stone buildings, or the contrary. So also in regard to the relative age of the superior and inferior portions of the earth's crust; we cannot hazard even a conjecture on this point, until we know whether, upon an average, the power of water above, or that of heat below; is most efficacious in giving new forms to solid matter.

After the observations which have now been made, the reader will per- 
ceive that the term primary must either be entirely renounced, or, if retained, must be differently defined, and not made to designate a set of crystalline rocks, some of which are already ascertained to be newer than all the secondary formations. In this work I shall follow most nearly the method proposed by Mr. Boué, who has called all fossiliferous rocks older than the secondary by the name of primary. To prevent confusion, I shall sometimes speak of these last as the primary fossiliferous formations, because the word primary has hitherto been most generally connected with the idea of a non-fossiliferous rock. Some geologists, to aroid misapprehension, hare introduced the term Paleozoic for primary,

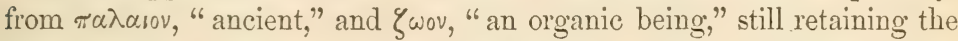
terms secondary and tertiary; Mr. Phillips, for the sake of uniformity, has proposed Mesozoic, for secondary, from $\mu \varepsilon \sigma 0 s$, "middle," \&c.; and Cainozoic, for tertiary, from xavvos, "recent," \&c.; but the terms primary, secondary, and tertiary are synonymous, and have the claim of priority in their favor.

If we can prove any plutonic, volcanic, or metamorphic rocks to be older than the secondary formations, such rocks will also be primary, according to this system. Mr. Boué, having with propriety excluded the metamorphic rocks, as a class, from the primary formations, proposed to call them all " crystalline schists."

As there are secondary fossiliferous strata, so we shall find that there are plutonic, rolcanic, and metamorphic rocks of contemporaneous origin, which I shall also term secondary.

In the next chapter it will be shown that the strata above the challz have been called tertiary. If, therefore, we discover any volcanic, plutonic, or metamorphic rocks, which have originated since the deposition of the chalk, these also will rank as tertiary formations.

It may perhaps be sug'ested that some metamorphic strata, and some granites, may be anterior in date to the oldest of the primary fossiliferous rocks. This opinion is doubtless true, and will be discussed in future chapters; but I may here observe, that when we arrange the four classes of rocks in four parallel columns in one table of chronology, it is by no means assumed that these columns are all of equal length; one may begin at an earlier period than the rest, and another may come down to a later point of time. In the small part of the globe hitherto examined, it is hardly to be expected that we should have discorered either the oldest or the newest members of each of the four classes of rocks. Thus, if there be primary, secondary, and tertiary rocks of the aqueous or fossiliferous class, and in like manner primary, secondary, and tertiary hypogene formations, we may not be yet acquainted with the most ancient of the primary fossiliferous beds, or with the newest of the hypogene. 


\section{CHAPTER IX.}

\section{ON THE DIFFERENT AGES OF THE AQUEOUS ROCKS.}

On the three principal tests of relative age-Superposition, mineral character, and fossils-Change of mineral character and fossils in the same continuous formation-Proofs that distinct species of animals and plants have lived at successive periods-Distinct provinces of indigenous species-Great extent of single provinces-Similar laws prevailed at successive geological periodsRelative importance of mineral and palæontological characters-Test of age by included fragments-Frequent absence of strata of intervening periods--Principal groups of strata in western Europe.

IN the last chapter I spoke generally of the chronological relations of tne four great classes of rocks, and I shall now treat of the aqueous rocks in particular, or of the successive periods at which the different fossiliferous formations have been deposited.

There are three principal tests by which we determine the age of a given set of strata; first, superposition; secondly, mineral character; and, thirdly, organic remains. Some aid can occasionally be derived from a fourth kind of proof, namely, the fact of one deposit including in it fragments of a pre-existing rock, by which the relative ages of the two may, even in the absence of all other evidence, be determined.

Superposition.-The first and principal test of the age of one aqueous deposit, as compared to another, is relative position. It has been already stated, that where strata are horizontal, the bed which lies uppermost is the newest of the whole, and that which lies at the bottom the most ancient. So, of a series of sedimentary formations, they are like volumes of history, in which each writer has recorded the annals of his own times, and then laid down the book, with the last written page uppermost, upon the volume in which the events of the era immediately preceding were commemorated. In this manner a lofty pile of chronicles is at length accumulated; and they are so arranged as to indicate, by 
their position alone, the order in which the events recorded in them have occurred.

In regard to the crust of the earth, however, there are some regions where, as the student has already been informed, the beds have been disturbed, and sometimes extensively thrown over and turned upside down. (See pp. 58,59.) But an experienced geologist can rarely be deceived by these exceptional cases. When he finds that the strata are fractured, curved, inclined, or vertical, he knows that the criginal order of superposition must be doubtful, and he then endeavors to find sections in some neighboring district where the strata are horizontal, or only slightly inclined. Here the true order of sequence of the entire series of deposits being ascertained, a key is furnished for settling the chronology of those strata where the displacement is extreme.

Mineral character.-The same rocks may often be observed to retain for miles, or even hundreds of miles, the same mineral peculiarities, if we follow the planes of stratification, or trace the beds, if they be undisturbed, in a horizontal direction. But if we pursue them vertically, or in any direction transverse to the planes of stratification, this uniformity ceases almost immediately. In that case we can scarcely ever penetrate a stratified mass for a few hundred yards without beholding a succession of extremely dissimilar rocks, some of fine, others of coarse grain, some of mechanical, others of chemical origin; some calcareous, others argillaceous, and others siliceous. These phenomena lead to the conclusion, that rivers and currents have dispersed the same sediment over wide areas at one period, but at successire periods have been charged, in the same region, with very different kinds of matter. The first observers were so astonished at the vast spaces orer which they were able to follow the same homogeneous rocks in a horizontal direction, that they came hastily to the opinion, that the whole globe had teen environed by a succession of distinct aqueous formations, disposed round the nucleus of the planet, like the concentric coats of an onion. But although, in fact, some formations may be continuous over districts as large as half of Europe, or even more, yet most of them either terminate wholly within narrower limits, or soon change their lithological character. Sometimes they thin out gradually, as if the supply of sediment had failed in that direction, or they come abruptly to an end, as if we had arrived at the borders of the ancient sea or lake which served as their receptacle. It no less frequently happens that they vary in mineral aspect and composition, as we pursue them horizontally. For example, we trace a limestone for a hundred miles, until it becomes more arenaceous, and finally passes into sand, or sandstone. We may then follow this sandstone, already proved by its continuity to be of the same age, through out another district a hundred miles or more in length.

Organic remains.-This character must be used as a criterion of the age of a formation, or of the contemporaneous origin of two deposits in distant places, under very much the same restrictions as the test of mineral composition.

First, the same fossils may be traced over wide regions, if we examine 
strata in the direction of their planes, although by no means for indefinite distances.

Secondly, while the same fossils prevail in a particular set of strata for hundreds of miles in a horizontal direction, we seldom meet with the same remains for many fathoms, and very rarely for several hundred yards, in a vertical line, or a line transverse to the strata. This fact has now been verified in almost all parts of the globe, and has led to a conviction, that at successive periods of the past, the same area of land and water has been inhabited by species of animals and plants even more distinct than those which now people the antipodes, or which now coexist in the arctic, temperate, and tropical zones. It appears, that from the remotest periods there has been ever a coming in of new organic forms, and an extinction of those which pre-existed on the earth; some species having endured for a longer, others for a shorter, time; while none have ever reappeared after once dying out. The law which has governed the creation and extinction of species seems to be expressed in the verse of the poet,-

Natura il fece, e poi ruppe la stampa. Ariosto.

Nature made him, and then broke the die.

And this circumstance it is which confers on fossils their highest value as chronological tests, giving to each of them, in the eyes of the geologist, that authority which belongs to contemporary medals in history.

The same cannot be said of each peculiar variety of rock; for some of these, as red marl and red sandstone, for example, may occur at once at the top, bottom, and middle of the entire sedimentary series; exhibiting in each position so perfect an iajentity of mineral aspect as to be undistinguishable. Such exact repetitions, however, of the same mixtures of sediment have not often been produced, at distant periods, in precisely the same parts of the globe; and even where this has happened, we are seldom in any danger of confounding together the monuments of remote eras, when we have studied their imbedded fossils and their relative position.

It was remarked that the same species of organic remains cannot be traced horizontally, or in the direction of the planes of stratification for indefinite distances. This might have been expected from analogy; for when we inquire into the present distribution of living beings, we find that the habitable surface of the sea and land may be divided into a considerable number of distinct provinces, each peopled by a peculiar assemblage of animals and plants. In the Principles of Geology, I have sndeavored to point out the extent and probable origin of these separate divisions; and it was shown that climate is only one of many causes on which they depend, and that difference of longitude as well as latitude is generally accompanied by a dissimilarity of indigenous species.

As different seas, therefore, and lakes are inhabited at the same period, by different aquatic animals and plants, and as the lands adjoining these 
may be peopled by distinct terrestrial species, it follows that distinct fossils will be imbedded in contemporaneous deposits. If it were otherwise-if the same species abounded in every climate, or in every part of the globe where, so far as we can discover, a corresponding temperature and other conditions favorable to their existence are found-the identification of mineral masses of the same age, by means of their included organic contents, would be a matter of still greater certainty.

Nevertheless, the extent of some single zoological provinces, especially those of marine animals, is very great; and our geological researches have proved that the same laws prevailed at remote periods; for the fossils are often identical throughout wide spaces, and in detached deposits, consisting of rocks varying entirely in their mineral nature.

The doctrine here laid down will be more readily understood, if we reflect on what is now going on in the Mediterranean. That entire sea may be considered as one zoological province; for, although certain species of testacea and zoophytes may be very local, and each region has probably some species peculiar to it, still a considerable number are common to the whole Mediterranean. If, therefore, at some future period, the bed of this inland sea should be converted into land, the geologist might be enabled, by reference to organic remains, to prove the contemporaneous origin of various mineral masses scattered over a space equal in area to half of Europe.

Deposits, for example, are well known to be now in progress in this sea in the deltas of the Po, Rhone, Nile, and other rivers, which differ as greatly from each other in the nature of their sediment as does the composition of the mountains which they drain. There are also other quarters of the Mediterranean, as off the coast of Campania, or near the base of Etna, in Sicily, or in the Grecian Archipelago, where another class of rocks is now forming; where showers of volcanic ashes oecasionally fall into the sea, and streams of lava overflow its bottom; and where, in the intervals between volcanic eruptions, beds of sand and clay are frequently derived from the waste of cliffs, or the turbid waters of rivers. Limestones, moreover, such as the Italian travertins, are here and there precipitated from the waters of mineral springs, some of which rise up from the bottom of the sea. In all these detached formations, so dirersified in their lithological characters, the remains of the same shells, corals, crustacea, and fish are becoming inclosed; or, at least, a sufficient number must be common to the different localities to enable the zoologist to refer them all to one contemporaneous assemblage of species.

There are, however, certain corabinations of geographical circumstances which cause distinct provinces of animals and plants to be separated from each other by rery narrow limits; and hence it must happen. that strata will be sometimes formed in contiguous regions, differing widely both in mineral contents and organic remains. Thus, for example, the testacea, zoophytes, and fish of the Red Sea are, as a group, ex- 
tremely distinct from those inhabiting the adjoining parts of the Mediterranean, although the two seas are separated only by the narrow isthmus of Suez. Of the bivalve shells, according to Philippi, not more than a fifth are common to the Red Sea and the sea around Sicily, while the proportion of univalves (or Gasteropoda) is still smaller, not exceeding eighteen in a hundred. Calcareous formations have accumulated on a great scale in the Red Sea in modern times, and fossil shells of existing species are well preserved therein; and we know that at the mouth of the Nile large deposits of mud are amassed, including the remains of Mediterranean species. It follows, therefore, that if at some future period the bed of the Red Sea should be laid dry, the geologist might experience great difficulties in endeavoring to ascertain the relative age of these formations, which, although dissimilar both in organic and mineral characters, were of synchronous origin.

But, on the other hand, we must not forget that the northwestern shores of the Arabian Gulf, the plains of Egypt, and the isthmus of Suez, are all parts of one province of terrestrial species. Small streams, therefore, occasional land-floods, and those winds which drift clouds of sand along the deserts, might carry down into the Red Sea the same shells of fluviatile and land testacea which the Nile is sweeping into its delta, together with some remains of terrestrial plants and the bones of quadrupeds, whereby the groups of strata, before alluded to, might, notwithstanding the discrepancy of their mineral composition and marine organic fossils, be shown to have belonged to the same epoch.

Yet while rivers may thus, carry down the same fluviatile and terrestrial spoils into two or more seas inhabited by different marine species, it will much more frequently happen, that the coexistence of terrestrial species of distinct zoological and botanical provinces will be proved by the identity of the marine beings which inhabited the intervening space. Thus, for example, the land quadrupeds and shells of the south of Europe, north of Africa, and northwest of Asia, differ considerably, yet their remains are all washed down by rivers flowing from these three countries into the Mediterranean.

In some parts of the globe, at the present period, the line of demarcation between distinct provinces of animals and plants is not very strongly marked, especially where the change is determined by temperature, as it is in seas extending from the temperate to the tropical zone, or from the temperate to the arctic regions. Here a gradual passage takes place from one set of species to another. In like manner the geologist, in studying particular formations of remote periods, has sometimes been able to trace the gradation from one ancient province to another, by observing carefully the fossils of all the intermediate places. His success in thus acquiring a knowledge of the zoological or botanical geography of very distant eras has been mainly owing to this circumstance, that the mineral character has no tendency to be affected by climate. A large river may convey yellow or red mud into some part of the ocean, where it may be dispersed by a current over an area several hundred 
leagues in length, so as to pass from the tropics into the temperate zone. If the bottom of the sea be afterwards upraised, the organic remains imbedded in such yellow or red strata may indicate the different animals or plants which once inhabited at the same time the temperate and equatorial regions.

It may be true, as a general rule, that groups of the same species of animals and plants may extend over wider areas than deposits of homogeneous composition; and if so, palæontological characters will be of more importance in geological classification than the test of mineral composition; but it is idle to discuss the relative ralue of these tests, as the aid of both is indispensable, and it fortunate happens, that where the one criterion fails, we can often avail ourselves of the other.

Test by included fragments of older rocks.-It was stated, that independent proof may sometimes be obtained of the relative date of two formations, by fragments of an older rock being included in a newer one. This evidence may sometimes be of great use, where a geologist is at a loss to determine the relative age of two formations from want of clear sections exhibiting their true order of position, or because the strata of each group are vertical. In such cases we sometimes discover that the more modern rock has been in part derived from the degradation of the older. Thus, for example, we may find chalk with flints in one part of a country; and, in another, a distinct formation, consisting of alternations of clay, sand, and pebbles. If some of these pebbles consist of similar flint, including fossil shells, sponges, and foraminiferæ, of the same species as those in the chalk, we may confidently infer that the chalk is the oldest of the two formations.

Chronological groups.-The number of groups into which the fossiliferous strata may be separated are more or less numerous, according to the views of classification which different geologists entertain; but when we have adopted a certain system of arrangement, we immediately find that a few only of the entire series of groups occur one upon the other in any single section or district.

The thinning out of individual strata was before described (p. 16).

Fig. 102.

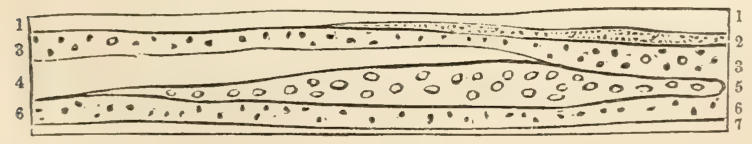

But let the aunexed diagram represent seven fossiliferous groups, instead of as many strata. It will then be seen that in the middle all the superimposed formations are present; but in consequence of some of them thinning out, No. 2 and No. 5 are absent at one extremity of the section, and No. 4 at the other.

In the annexed diagram, fig. 103, a real section of the geological formations in the neighborhood of Bristol and the Mendip Hills, is pre- 
sented to the reader, as laid down on a true scale by Prof. Ramsay, where the newer groups $1,2,3,4$, rest uncomformably on the formations

Fig. 103.

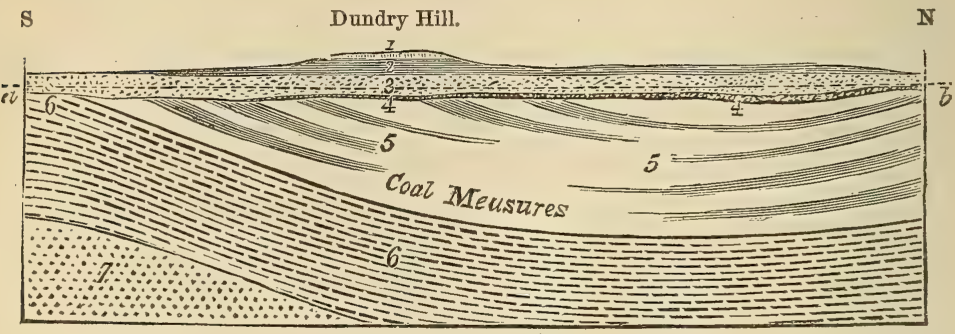

Section South of Bristol.

A. C. Ramsay.

Length of section, 4 miles.

$a, b$. Level of the sea.
1. Inferior oolite.
2. Lias.
3. New red sandstone.
4. Magnesian conglomerate

5. Coal measures.
6. Carboniferous limestone.
7. Old red sandstone.

5 and 6 . Here at the southern end of the line of section we meet with the beds No. 3 (the New Red Sandstone) resting immediately on No. 6, while farther north, as at Dundry Hill, we behold six groups superimposed one upon the other, comprising all the strata from the inferior oolite to the coal and carboniferous limestone. The limited extension of the groups 1 and 2 is owing to denudation, as these formations end abruptly, and have left outlying patches to attest the fact of their having originally covered a much wider area.

In many instances, however, the entire absence of one or more formations of intervening periods between two groups, such as 3 and 5 in the same section, arises, not from the destruction of what once existed, but because no strata of an intermediate age were ever deposited on the inferior rock. They were not formed at that place, either because the region was dry land during the interval, or because it was part of a sea or lake to which no sediment was carried.

In order, therefore, to establish a chronological succession of fossiliferous groups, a geologist must begin with a single section, in which several sets of strata lie one upon the other. He must then trace these formations, by attention to their mineral character and fossils, continuously, as far as possible, from the starting point. As often as he meets with new groups, he must ascertain by superposition their age relatively to those first examined, and thus learn how, to jntercalate them in a tabular arrangement of the whole.

By this means the German, French, and English geologists have determined the succession of strata throughout a great part of Europe, and have adopted pretty generally the following groups, almost all of which have their representatives in the British Islands. 
Groups of Fossiliferous Strata observed in Western Europe, arranged in what is termed a descending Series, or beginning' with the newest. (See a more detailed Tabular view, pp. 101-106.)

1. Post-Tertiary, including Recent and Post-Pliocene.

2. Pliocene.

3. Miocene.

4. Eocene.

5. Chalk.

6. Greensand and Wealden.

7. Upper Oolite, including the Purbeck.

8. Middle Oolite.

9. Lower Oolite.

10. Lias,

11. Trias.

12. Permian.

13. Coal.

14. Old Red Sandstone, or Devonian.

15. Upper Silurian.

16. Lower Silurian.

17. Cambrian and older fossiliferous strata.

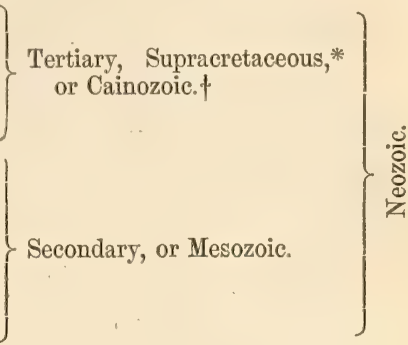

Primary.

It is not pretended that the three principal sections in the above table, called primary, secondary, and tertiary, are of equivalent importance, or that the eighteen subordinate groups comprise monuments relating to equal portions of past time, or of the earth's history. But we can assert that they each relate to successive periods, during which certain animals and plants, for the most part peculiar to their respective eras, have flourished, and during which different kinds of sediment were deposited in the space now occupied by Europe.

If we were disposed, on palæontological grounds, to divide the entire fossiliferous series into a few groups less numerous than those in the above table, and more nearly co-ordinate in value than the sections called primary, secondary, and tertiary, we might, perhaps, adopt the six groups or periods given in the next table.

At the same time, I may observe, that, in the present state of the science, when we have not yet compared the evidence derivable from all classes of fossils, not even those most generally distributed, such as shells, corals, and fish, such generalizations are premature, and can only be regarded as conjectural or provisional schemes for the founding of large natural groups.

* For tertiary, Sir H. De la Beche has used the term "supracretaceous," a name implying that the strata so called are superior in position to the chalk.

† For an explanation of Cainozoic, see p. 95.

$\ddagger$ Palæontology is the science which treats of fossil remains, both animal and

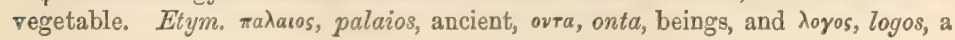
discourse. 
Fossiliferous Strata of Western Europe divided into Eight Groups.

1. Post-Tertiary and Ter- $\{$ from the Recent to the Eocene inclusive.
tiary -

2. Cretaceous - - $\left\{\begin{array}{l}\text { from the Maestricht Chalk to the Wealden inclu- } \\ \text { sive }\end{array}\right.$

3. Oolitic - - - $\quad$ from the Purbeck to the Lias inclusive.

4. Triassic - - - $\quad$ including the Keuper, Muschelkalk, and Bunter-

Parmistein of the Germans.

5. Permian and Carboni- including Magnesian Limestone, Coal Measures, ferous - - - $\{$ and Mountain Limestone.

6. Devonian or Old Red $\}$ from the Yellow Sandstone of Fife to the ForfarSandstone - - $\left\{\begin{array}{l}\text { shire paving stones with cephalaspis. } \\ \text { - }\end{array}\right.$

7. Silurian - - - $\{$ from the Upper Ludlow to the Bala Limestone,

8. Cambrian - $\quad\left\{\begin{array}{l}\text { and Graptolite Schists. } \\ \text { from the Lingula flags or primordial zone of Bar- } \\ \text { rande to the lowest known fossiliferous rocks. }\end{array}\right.$

But the following more detailed list of fossiliferous strata, divided into a greater number of sections, will be found useful by the reader when he is studying our descriptions of the sedimentary formations given in the next 18 chapters. 


\section{ABRIDGED GENERAL TABLE OF FOSSILIFEROUS STRATA.}

1. RECENT.

2. POST-PLIOCENE.

\} POST-TERTIARY.

3. NEWER PLIOCENE.

4. OLDER PLIOCENE.

5. UPPER MIOCENE.

6. LOWER MIOCENE.

7. UPPER EOCENE.

8. MIDDLE EOCENE.

9. LOWER EOCENE.

\} PLIOCENE.

\} MIOCENE.

EOCENE.

10. MAESTRICHT BEDS.

11. WHITE CHALK.

12. UPPER GREENSAND.

13. GAULT.

14. LOWER GREENSAND

15. WEALDEN.

16. PURBECK BEDS.

17. PORTLAND STONE.

18. KIMMERIDGE CLAY.

19. CORAL RAG.

20. OXFORD CLAY.

21. GREAT OR BATH OOLITE.

22. INFERIOR OOLITE.

23. LIAS.

24. UPPER TRIAS.

25. MIDDLE TRIAS.

26. LOWER TRIAS.

27. PERMIAN.

28. COAL MEASURES.

29. CARBONIFEROUS LIMESTONE,

30. UPPER

31. MIDDLE $>$ DEVONIAN.

32. LOWER

33. UPPER

34. MIDDLE SILURIAN.

35. LOWER

36. UPPER

37. LOWER CAMBRIAN.

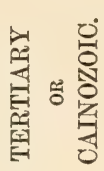

0
0
0
0
0
2
2

38. UPPER

39 LOWER LAURENTIAN.

LAURENTIAN.
CAMLBIAN.

JURASSIC.

TRIASSIC.

CARBONIFEROUS.

DEVONIAN.

SILURIAN.

PERIMIAN.

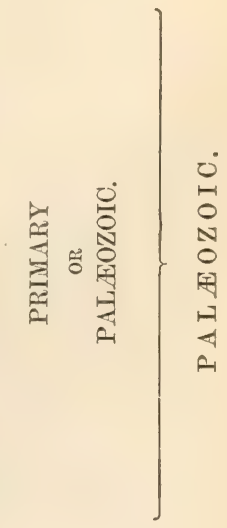




\section{TABULAR VIEW OF THE FOSSILIFEROUS STRATA,}

SHOWING THE ORDER OF SUPERPOSITION OR CHRONOLOGICAL SUCCESSION OF THE PRINCIPAL GROUPS, WITH REFERENCE TO THE PAGES WHERE THEY ARE DESCRIBED IN THIS WORK.

\section{POST-TERTIARY}

\section{(Terrains contemporains et quaternaires.)}

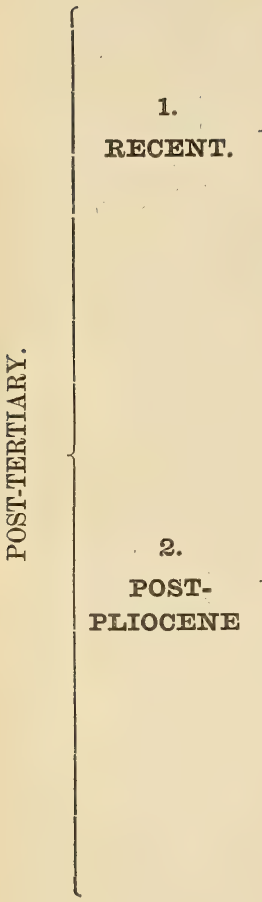

\section{EXAMPLES.}

British-Marine strata, with human remains on coast of Cornwall (p. 109).

Marine strata, with canoes, in the estuary of the Clyde (p. 109).

Foreign-Danish peat (kitehen-middens), with implements of bronze and stone (p. 109).

Shells and

Lacustrine mud, with remains of Swiss lakedwellings and implements of stone and metal (p. 110).

Marine strata inclosing Temple of Serapis, at Puzzuoli (p. 108).

Lacustrine strata of Cashmere (p. 108).

British-Loam of Brixham cave, with flint knives and bones of extinct and living quadrupeds (p. 124).

Valley gravels, or ancient alluvium of the Thames and Ouse; with stone implements (p. 115).

Glacial drift of Scotland, with marine shells (p. 153).

Boulder formation of Norfolk cliffs (p. 162).

Forest-bed of Norfolk cliffs, with bones of elephant, \&c. (p. 161).

Glacial drift of Wales with marine fossil shells nearly 1400 feet high, on Moel Tryfaen (p. 158).

Foreign-Ancient valley gravels of Amiens, with flint implements and bones of extinct mammalia (p. 116)

Loess of Rhine (pp. 119, 120).

Ancient Nile-mud forming river-terraces (p 118).

Marine strata of Sardinia, 300 feet above sealevel, with pottery and bones of extinct quadrupeds (p. 121).

Loam and breccia of Liege caverns, with human remains, and bones of extinct and re cent mammalia (p. 124).

Australian cave-breccias, with bones of extinct marsupials (p. 126).

Glacial drift of Northern Europe (pp. 142-151).

Post-glacial freshwater deposits of North America with remains of Mastodon (p. 166).

mammalia, al] of living

species.

Shells, recent mammalia

in part

extinct.

\section{TERTIARY.}

\section{(Terrains tertiaires.)}

British-Norwich crag, marine, with 11 per cent. of the shells of extinct species, bones of Mastodon arvrenensis, \&c. (p. 199).

Chillesford beds, with marine shells, 9 per cent. extinct, and those of living species chiefly Aretic (p. 199).

3. Bridlington beds, marine Arctic fauna, commencement of glacial epoch (p. 199).

NEWER

Cone of Monte Somma (p. 190).

Marine shells of which Eastern base of Mount Etna (p. 190). $\left\{\begin{array}{l}1 \text { to } 7 \text { per cent. } \\ \text { species extinct. }\end{array}\right.$

Calcareous and argillaceous strata and volcanic tuffs of Sicily, with shells from 10 to 30 per cent. of extinct species (p. 191).

Lacustrine strata of Upper Val d'Arno, with Mastodon arvernensis, \&c. (p. 196).

British-Red Crag of Suffolk, marine shells, some of northern forms, 40 per cent. of extinct species (pp. 200-205).

White or coralline crag of Suffolk, testacea less northern, 48 per cent. of extinct species (p. 202).

OLDER PLIOCENE.

Foreign-Upper and middle Antwerp crag, shells from 40 to 50 per cent. extinct, bones of cetacea numerous (p. 207).

Subapennine marls and sands (p. 208).

Aralo-Caspian brackish-water formations (p. 211). 
EXAMPLES.

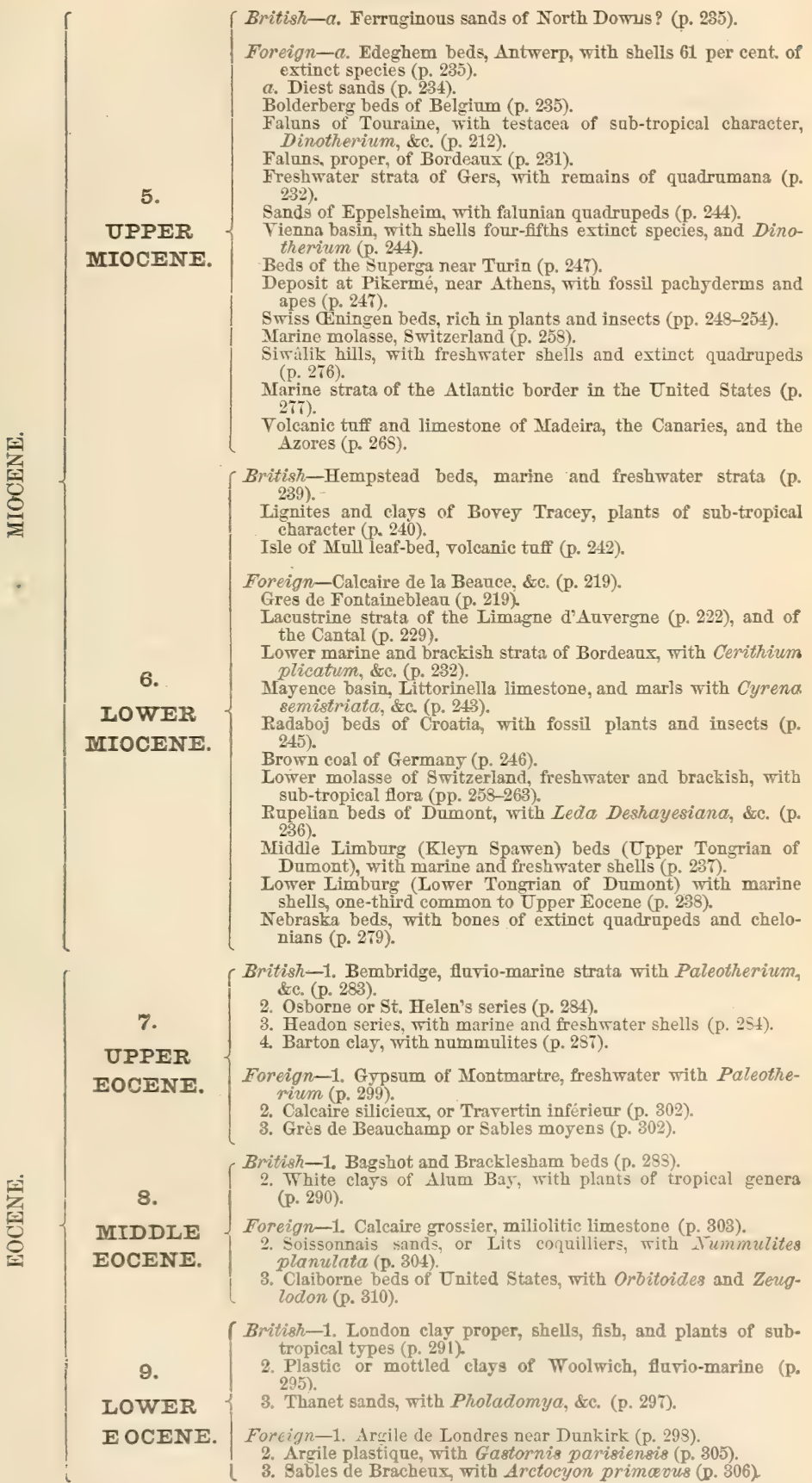




\section{SECONDARY.}

(T'errains secondqires.)

EXAMPLES.

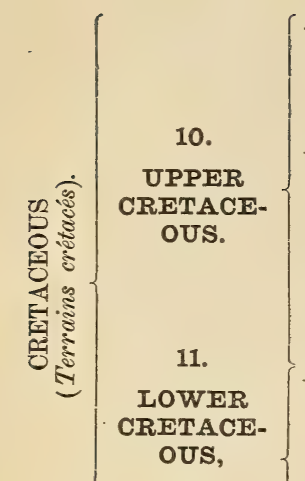

OR

NEOCO-

IMIAN.

12.

UPPER

OOLITE.

13.

IVIDDLE

OOLITE.

14.

LOWER

OOLITE.

15.

IIAS.

16.

UPPER

TRIAS.

17.

IIIDDLE

TRIAS.

18.

LOWER

TRIAS.

British-1. Wanting.

2. White chalk with flints, marine (p. 321).

3. Chalk marl, marine (p. 330).

4. Upper Greensand-fire-stone of Surrey, marine (p. 331).

5. Gault-dark blue marl of southeast of England (p. 331). Blackdown beds of littoral origin (p. 332).

Foreign-1. Maestricht beds, with Mosasaurus (p. 315). Faxoe chalk with Nautilus danicus, \&c. (p. 316).

2. White chalk of France, Sweden and Russia (p. 318).

3. Pläner-kalk of Saxony (p. 325)

2 and 3. Sands and clays of Aix-la-Chapelle, with preponderance of dicotyledonous angiosperms (p. 333).

4. Quader sandstein of Germany (p. 334)

5. Gault of the Loire (p. 332)

2 and 3. Hippurite limestone of South of France (p. 336).

2 to 5. New Jersey (U. S.) sands and marls (p. 338).

2 to 5. Siliceous limestone of Texas (p. 340).

British-1. Ferruginous and green sands (p. 341).

Kentish rag, or calcareous stone (p. 342).

Atherfield beds, marine, with Perna Mulleti (p. 342).

2. Weald clay of Surrey, Kent, and Sussex, freshwater, with Cypris (p. 346).

Hastings sands (Tunbridge and Ashburnham beds), fresh water, Iguanodon Mantelli (p. 348).

Foreign -1. Neocomian of Neufchatel (p. 341).

2. Wealden beds of Hanover (p. 351).

British-Upper Purbeck beds, freshwater, Purbeck Marble (p. 379).

Middle Purbeck fluvio-marine, with numerous marsupial quadrupeds, \&c. (p. 380).

Lower Purbeck freshwater, with intercalated dirt-bed (p. 389).

Portland stone and sand (p. 394)

Kimmeridge clay, bituminous shale, with marine shells, 24 per cent. common to middle oolite (p. 394).

Foreign-Marnes à gryphées virgules of Argonne (p. 395̃).

Lithographic stone of Solenhofen with Archoeopteryx (p. 395).

British-Coral-rag of Berkshire, Wilts, and Yorkshire (p. 398).

Oxford clay, with belemnites and amamonites (p. 399).

Kelloway rock of Wilts and Yorkshire, with shells, 21 per cent. common to lower oolite (p. 400).

Foreign-1. Nerinæan limestone of the Jura (p. 399)

Diceras limestone of the Alps (p. 399).

British-Cornbrash and forest marble of Wilts and Gloucestershire (p. 401).

Great oolite of Bradford, with encrinites, \&c. (p. 402).

Stonesfield slate with marsupials and Araucaric (p. 405).

Fuller's earth of Bath with Ostrea acuminata (p.412).

Inferior oolite, with 24 per cent. of shells common to great oolite (p. 412).

Upper lias, argillaceous, with Ammonites striatulus, Spirifer, and Leptcena (p. 417).

Shale and limestone, with Ammonites bifrons (p. 418).

Marlstone series, or middle lias divisible into three zones with characteristic Ammonites (p. 416).

Lower lias, divisible into siz zones, Ammonites Bucklandi in the lowest but one, and $A$. planorbis in the lowest zone ( $p$. 419).

British-Penarth, or Avicula contorta beds-White lias, with fish of the genera Hybodus, \&c. (p. 441).

Dolomitic conglomerate of Bristol, with Thecodontosaumus, \&c. (p. 447)

Red clay, with thick beds of salt, at Northwich, in Cheshire (p. 448).

Foreign-Keuper beds of Germany, with Microlestes and fish of the genera Hybodus, \&c. (p. 432).

St. Cassian or Hallstadt beds, with rich marine fauna (p. 434).

Coalfield of Richmond, Virginia, with Estheria ovata and plants resembling those of European Keuper (p. 451).

Chatham coalfield, North Carolina, with Dromatherium (p. 457).

British-Wanting.

Foreign-Muschelkalk of Germany, with Encrinus liliiformis and Placodus gigas (p. 438).

British-New red sandstone of Lancashire and Cheshire, with Labyrinthodon and footpriuts of Cheirotherium (p. 443).

Foreign-Bunter-sandstein of Germany, with footsteps of Labyrinthodon (p. 440).

Red sandstone of Connecticut Valley, with footprints of birda and reptiles (p. 452). 
PRIMARY.

(Terrains paléozoïques.)

EXAMPLES.

British-1. Concretionary magnesian limestone of Durham and Yorkshire (p. 459).

2. Brecciated magnesian limestone of Tynemouth Cliff, \&c. (p. 459).

3. Fossiliferous magnesian limestone, with Fenestella retiformis (p. 460)

4. Compact magnesian limestone (p. 461).

5. Marl-slate of Durham, with heterocercal fish (461).

6. Inferior sandstones, with plants resembling those of the coal, but differing in species (p. 462).

Foreign-1. Stinkstein of Thuringia (p. 458).

2. Rauchwacke, $i b i d$. (p. 458)

8. Dolomite or Upper Zechstein (p. 463).

4. Zechstein or Lower Zechstein (p. 463).

5. Mergel-schiefer or Kupfer-schiefer, with Protorosaumus (p. 463).

6. Roth-liegendes of Thuringia, with Psaronius (p. 463).

Magnesian limestones, \&c., of Russia (j. 463).

British-Coal measures of South Wales, with underclays enclos: ing Stigmaria (p. 466).

20.

UPPER

CARBONIFEROUS.

Millstone grit (p. 466)

Carboniferous rocks of Ireland (p. 466).

Foreign-St. Etienne coalfield, with erect fossil trees (p. 482)

Coalfield of Saarbrück with Archegosaurus (p. 506).

Carboniferous strata of Nova Scotia, with fossil forests, and land-shell Pupa vetusta (p. 511).

Appalachian coalfield, 720 miles long and 180 miles wide, with footprints of Cheirotherium (p. 509).

British-Mountain limestone of Wales and South of England, with marine fossils, chiefly corals and crinoids (p. 514).

21.

Same in Somersetshire and Ireland, with fish-beds (p. 521).

LOWER

CARBOINIFEROUS. ing sandstones (p. 466).

Foreign-Mountain limestone of Belgium (p. 521).

Kiesel-schiefer and Jungere Grauwacke of Germany, with Posidonomya Becheri (p. 522).

Gypseous beds and Encrinital limestone, Nova Scotia (p. 522).

British-Yellow sandstone of Dura Den, with Glyptolcemus (p. 524, 533); and of Kilkenny with fossil fish (p. 524).

22.

Pilton group of North Devon, with Spirifer disjunctus (p. $536)$.

Petherwyn group of Cornwall, with Clymenia and Cypridina (p. 537).

UPPER

DEVO-

NIAN.

Foreign-Clymenien kalk and Cypridinen-schiefer of Germany (p. 537).

Limestones of the Fichtelgebirge, with trilobites of the genera Brontes, \&c. (p. 538).

Catskill and Chemung group of New York, U. S. (p. 544).

British-Sandstones of Forfarshire and Perthshire, with Holoptychius, \&c. (p. 526).

23.

MIDDLE

DEVO-

NIAN.

24. fish (p. 531).

Unfossiliferous series of North Devon (p. 538)

Ilfracombe beds with mauy trilobites and corals, and with cephalopoda distinct from Upper Devonian (p. 535).

Foreign-Eifel limestone with underlying schists containing Calceola (p. 540).

Corniferous formation of Western Canada and New York (p. 546).

Devonian strata of Russia (p. 542).

British-Arbroath paving-stones with Cephalaspis, Pterygotus, and Parka (p. 526).

Lower sandstones of Caithness with Pterygotus (p. 531).

Sandstones and slates of the Foreland and Linton (p. 541)

LOWER

DEVO-

IIAN.

Sandstones of Torquay with broad-winged spirifers (p. 541)

Foreign-South African Devonian strata with Homalonotus, \&c. (p. 546).

Oriskany sandstone of Westeru Canada and New York (p. 516). 


\section{EXAMPLES.}

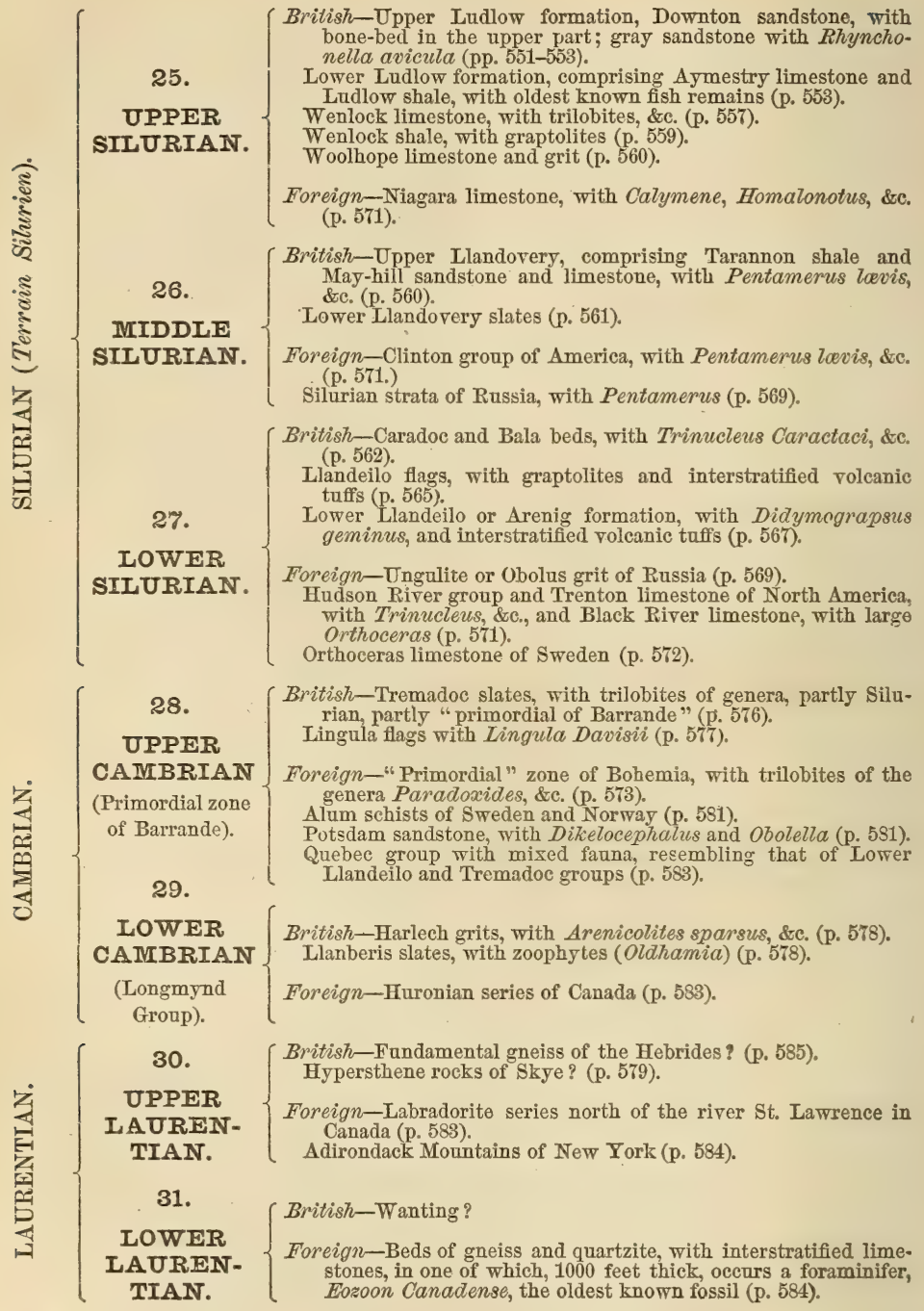




\title{
CHAPTER X.
}

\author{
RECENT AND POST-PLIOCENE PERIODS.
}

Recent and Post-pliocene periods-Terms defined-Formations of the Recent period-Modern littoral deposits containing works of art near Taples-Danish peat and shell mounds-Swiss lake-dwellings-Periods of stone, bronze, and iron-Form of human skulls of the Recent period-Post-pliocene formationsCoexistence of man with extinct mammalia-Higher and Lower-level Valleygravels-Loess or inundation mud of the Nile, Rhine, \&c.-Antiquity of Postpliocene Lake-terraces in Switzerland-Upraised marine strata in SardiniaOrigin of carerns-Remains of man and extinct quadrupeds in carern deposits -Cave of Kirkdale-Reindeer period of south of France-Australian cavebreccias-Geographical relationship of the provinces of living vertebrata and those of extinct Post-pliocene species-Extinct struthious birds of Tem Zealand -Fluctuations of climate in Post-glacial period-Comparative longerity of species in the mammalia and testacea-Teeth of recent and Post-pliocene mammalia.

Frow the general tables, given at the end of the last chapter, the reader will hare learned that the uppermost or newest strata are called Post-tertiary, as being more modern than the Tertiarr. It will also be obserred that the Post-tertiar formations are dirided into two subordinate groups: the Recent, and Post-pliocene. In the former, or the Recent, the mammalia as well as the shells are identical with species now liring; whereas in the Post-pliocene a part, and often a considerable part, of the mammalia belong to extinct species. To this nomenclature it mar be objected that the term Postpliocene should in strictness include all geological monuments posterior in date to the Pliocene; but when I hare occasion to speak of the whole collectirels, I shall call them Post-tertiary, and reserte the term Post-pliocene for the older Post-tertiars formations, while the Upper or newer ones will be called "Recent."

Cases will occur where it may be scarcely possible to draw the boundary line betreen the Recent and Post-pliocene deposits; and we must expect these difficulties to increase rather than diminish with every adrance in our knowledge, and in proportion as gaps are filled up in the series of records.

In 1839 I proposed the term Pleistocene as an abbreriation for Tewer Pliocene, and it soon became popular, having been adopted by the late Edward Forbes in his admirable essay on "The Geological Relations of the existing Fauna and Flora of the British Isles;" but he applied the term almost precisely in the sense in which I shall use Post-pliocene in this rolume, and not as short for Newer Pliocene. In order to prerent confusion, I think it hest entirely to abstain from 
the use of Pleistocene in this work, for I find that the introduction of such a fourth name (unless restricted solely to the older Posttertiary formations) must render the use of Pliocene, in its original extended sense, impossible, and it is often almost indispensable to have a single term to comprehend both divisions of the Pliocene period.*

\section{RECENT PERIOD.}

It was stated in the sixth chapter, when I treated of denudation, that the dry land, or that part of the earth's surface which is not covered by the waters of lakes or seas, is generally wasting away by the incessant action of rain and rivers, and in some cases by the undermining and removing power of waves and tides on the sea coast. But the rate of waste is very unequal, since the level and gently sloping lands, where they are protected by a continuous covering of vegetation, escape nearly all wear and tear, so that they may remain for ages in a stationary condition, while the removal of matter is constantly widening and deepening the intervening ravines and valleys.

The materials, both fine and coarse, carried down annually by rivers from the higher regions to the lower, and deposited in successive strata in the basins of seas and lakes, must be of enormous volume. We are always liable to underrate their magnitude, because the accumulation of strata is going on out of sight.

There are, however, causes at work which, in the course of centuries, tend to render visible these modern formations, whether of marine or lacustrine origin. For a large portion of the earth's crust is always undergoing a change of level, some areas rising and othors sinking at the rate of a few inches, or a few feet, perhaps sometimes yards, in a century, so that spaces which were once subaqueous are gradually converted into land, and others which were high and dry become submerged. In consequence of such movements we find in certain regions, as in Cashmere for example, where the mountains are often shaken by earthquakes, deposits which were formed in lakes in the historical period, but through which rivers have now cut deep and wide channels. In lacustrine strata thus intersected, works of art and freshwater shells are seen. In other districts on the borders of the sea, usually at very moderate elevations above its level, raised beaches occur, or marine littoral deposits, such as those in which, on the borders of the Bay of Baiæ, near Naples, the well-known temple of Serapis was embedded. In that case the date of the monuments buried in the marine strata is ascertainable, but in many other in-

* If geologists still think it convenient to retain the term Pleistocene, I would recommend them to use it not in the sense originally proposed by me, nor in the somewhat vague manner in which it was applied by Edward Forbes, but in place of Post-pliocene as this term is defined in the present work. 
stances, the exact age of the remains of human workmanship is uncertain, as in the estuary of the Clyde at Glasgow, where many canoes hare been exhumed, with other works of art, all assignable to some part of the recent period.

On the coast of Cornwall, at Pentuan, near St. Austell; and at Carnon in the same countr, at the depth of 53 feet, human skulls hare been met with beneath marine strata, in which the bones of whales, and of sereral land quadrupeds, all of living species, were embedded.

Danish peat and shell mounds, or kitchen-middens.-Sometimes we obtain evidence, without the aid of a change of level, of erents which took place in pre-historic times. The combined labors, for example, of the antiquary, zoologist, and botanist have brought to light many monuments of the early inhabitants buried in peatmosses in Denmark. Their geological age is determined by the fact that, not only the contemporaneous freshwater and land shells, but all the quadrupeds, found in the peat, agree specifically with those now inhabiting the same districts, or which are known to have been indigenous in Denmark within the memory of man. In the lorrer beds of peat (a deposit rayring from 20 to 30 feet in thickness), weapons of stone accompany trunks of the Scotch fir, Pinus sylvestris, while in the higher portions of the same bogs, bronze implements are associated with trunks and acorns of the common oak. It appears that the pine has nerer been a native of Denmark in historical times, and it seems to have given place to the oak about the time when articles and instruments of bronze superseded those of stone. It also appears that, at a still later period, the oak itself became scarce, and was nearly supplanted by the beech, a tree which now flourishes luxuriantly in Denmark. Again, at the still later epoch when the beech tree abounded, tools of iron were introduced, and were gradually substituted for those of bronze.

On the coasts of the Danish islands in the Baltic, certain mounds, called in those countries "Kjökken-mödding," or "kitchen-iniddens," occur, consisting chiefly of the castaway shells of the oyster, cockle, periminkle, and other eatable kinds of mollusks. These mounds are from 3 to 10 feet high, and from 100 to 1000 feet in their longest diameter. They greatly resemble heaps of shells formed by the Red Indians of North America along the eastern shores of the United States. In the old refuse-heaps, recently studied by the Danish antiquaries and naturalists with great skill and diligence, no implements of metal hare erer been detected. All the knires, hatchets, and other tools, are of stone, horm, bone, or wood. With them are often intermixed fragments of rude pottery, charcoal and cinders, and the bones of quadrupeds on which the rude people fed. These bones belong to wild species still liring in Europe, though some of them, like the bearer, hare long been extirpated in Denmark. The only animal which they seem to have domesticated was the dog. 
As there is an entire absence of metallic tools, these refuse-heaps are referred to what is called the age of stone, which immediaiely preceded in Denmark the age of bronze-a race more advanced in civilization, armed with weapons of that mixed metal, having apparently invaded Scandinavia, and ousted the aborigines.*

Lacustrine habitations of Switzerland.-In Switzerland a different class of monuments, illustrating the successive ages of stone, bronze, and iron, has been of late years investigated with great success, and especially since 1854, in which year Dr. F. Keller explored near the shore at Meilen, in the bottom of the lake of Zurich, the ruins of an old village, originally built on numerous wooden piles, driven, at some unknown period, into the muddy bed of the lake. Since then a great many other localities, more than a hundred and fifty in all, have been detected of similar pile-dwellings, situated near the borders of the Swiss lakes, at points were the depth of water does not exceed 15 feet. $\uparrow$ The superficial mud in such cases is filled with various articles, many hundreds of them being often dredged up from a very limited area. Thousands of piles, decayed at their upper extremities, are often met with still firmly fixed in the mud.

Herodotus relates that in the time of Darius (about 520 B.c.) there existed a similar settlement in the middle of Lake Prasias (probably now Lake Takinos), in Pœonia, or in the modern Turkish province of Roumelia. "The houses," he says, "were built on a platform of wood supported by wooden stakes, and a narrow bridge, which could be withdrawn at pleasure, communicated with the shore." $\ddagger$ "When man," says Morlot, $\S$ "thus stationed his dwellings on piles, all the refuse of his industry and of his food were naturally thrown into the lake, and were often well preserved in the mud at the bottom. If occasionally such establishments were burnt, whether intentionally by the enemy, or by accident, a vast quantity and variety of articles, including some of great value, would sink to the botton of the waters. Such aquatic sites were probably selected as places of safety, since, when the bridge was removed, they could only be approached by boats, and the water would serve for protection alike against wild animals and human foes."

As the ages of stone, bronze, and iron merely indicate successive stages of civilization, they may all have coexisted at once in different parts of the globe, and even in contiguous regions, among nations having little intercourse with each other. To make out, therefore, a distinct chronological series of monuments is only possible when our

* See the works of Nilsson, Thomsen, Warsäae, Steenstrup aud others.

$\uparrow$ See the works of MM. Troyon and Keller, and M. Morlot's sketch of these researches. Bulletin de la Société Vaudoise des Sci. Nat., t. vi., Lausanne, 1860; and Antiquity of Man, by the Author, ch. ii.

$\ddagger$ Herod., v. 16.

$\S$ General Views of Archæology, by Morlot, Memoirs of Smithsonian Institution, 1861. 
observations are confined to a limited district, such as Switzerland; and the distinctness of date becomes more striking when a settlement like that of Moosseedorf, near Berne, belonging exclusively to the age of stone, is surrounded by a great many others all referable to the period of bronze. The number of objects found at Moosseedorf exceeds two thousand, among which no metallic ones were observed. At Wangen, on the Lake of Constance, more than 1300 articles of stone, bone, and pottery were collected, without the intermixture of a single utensil, instrument, or ornament of bronze. In other lakes, as in those of Bienne and Geneva, there are settlements were the number of bronze articles is equally numerous, with a very slight admixture of weapons of stone.

The relative antiquity of the pile-dwellings, which belong respectively to the ages of stone and bronze, is also clearly illustrated by the association of the tools with certain groups of animal remains. Where the tools are of stone, the castaway bones which served for the food of the ancient people are those of deer, the wild boar, and wild ox, which abounded when society was in the hunter state. But the bones of the latter or bronze epoch were chiefly those of the domestic ox, goat, and pig, indicating progress in civilization. Some villages of the stone age are of later date than others, and exhibit signs of an inproved state of the arts. Among their relics are discovered carbonized grains of wheat and barley, and pieces of bread, proving that the cultivation of cereals had begun. In the same settlements, also, cloth made of woven flax and straw, has been detected.

To the Swiss pile-buildings of the bronze age belong manufactured objects which display a very decided superiority in beauty of form, and ornamentation, when contrasted with those of the antecedent age of stone. In one village at Nidau, on the lake of Bienne, a great number of axes, lances, sickles, fish-hooks, and bracelets, altogether nearly two thousand articles, have been obtained, and with them some few implements of stone. These last, dredged up from the same site, may perhaps have been used simultaneously; or possibly the same village, founded in the age of stone, may have continued to flourish in the succeeding period of bronze.* The pottery of the bronze age in Switzerland is of a finer texture, and more elegant in form, than that of the age of stone. At Nidau, articles of iron have also been discovered, so that this settlement was evidently not abandoned till that metal had come into use.

At La Thène, in the northern angle of the lake of Neufchâtel, a great many articles of iron have been obtained, which in form and ornamentation are entirely different both from those of the bronze period and from those used by the Romans. Gaulish and Celtic coins have also been found there by MIN. Schwab and Desor. They agree in character with remains, including many iron swords, which have

* Mr. J. Lubbock's Lecture, Royal Institution, Feb. 27th, 1863. 
been found at Tiefenau, near Berne, in ground supposed to have been a battle-field; and their date appears to have been anterior to the great Roman invasion of Northern Europe, though perhaps not long before that event.*

The period of bronze must have been one of foreign commerce, as tin, which enters into this metallic mixture in the proportion of about ten per cent. to the copper, was obtained by the ancients chiefly from Cornwall. From that country it is supposed to have been supplied at one time by the Phœnicians to the Greeks, as well as to all the inhabitants of the eastern shores of the Mediterranean. Even the tin said to have come from Iberia, or Spain, is imagined by many antiquaries to have been first shipped from the Cassiterides, or Cornwall, to Cadiz. $\uparrow$ At a later period we learn from Diodorus that ingots of tin were shipped from Iktis, or St. Michael's Mount, in Cornwall, and conveyed over the channel to the opposite coast, and thence on the backs of horses across Gaul, in about thirty days, to Massilia or Marseilles, from whence the Romans obtained it.+

The Greeks are described by Homer in the Iliad as arned with

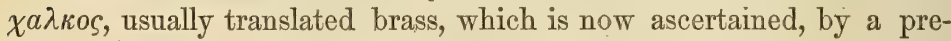
cise analysis of ancient Greek armor and coins, to have consisted not of copper and zinc, but of copper and tin, or what we now call bronze. Contemporaneously with bronze, iron was also in use among the ancients, even from very remote times; but so long as the art of making steel by blending iron in certain chemical proportions with carbon was unknown, or still in its infancy, bronze seems to have competed successfully with iron in the construction of all cutting implements. The best definition, perhaps, of the age of iron yet proposed, is that which describes it as the period when this metal had, for the most part, superseded bronze in all instruments requiring a sharp cutting edge. It is remarkable that in Herculaneum and Pompeii, which was buried under the ashes of Vesuvius in the year 79, nearly a thousand years after Homer's time, the prevailing metal of which the agricultural, culinary, and even the surgical instruments are made was bronze; although articles of iron are by no means wanting among the relics found in those ancient cities. In Transylvania and Hungary, according to Keller, an age of copper instruments intervened between that of stone and bronze.

In estimating the degree in which iron and bronze prevailed in prehistoric ages, we are in some danger of being misled by the great durability of the one metal, and the facility with which the other, or the iron, is decomposed. But if iron be corroded in large quantities by oxidation, it would usually betray itself to the geologist by acting as a cement, and binding together the particles of sand, gravel, mud, and

* Mr. J. Lubbock's Lecture, Royal Institution, Feb. 27th, 1863.

+ Sir G. Cornwall Lewis, Astronomy of the Ancients, ch. viii.

‡ Diodorus, v. 21, 22, and Sir H. James, Note on Block of Tin dredged up in Ealmouth Harbor. Royal Institution of Cornwall, 1863. 
shells in which it lay. A cylindrical coating of such materials has sometimes been found encircling cannon and gun-barrels, the further corrosion of which seems to have been arrested by such an envelope.*

Human remains of the recent period.-Very few human bones of the bronze period have been met with in the Danish peat, or in the Swiss lake-dwellings, and this scarcity in generally attributed by archæologists to the custom of burning the dead, which prevailed in the age of bronze. In the antecedent era of stone, the primitive population of the North are said to have buried their dead in sepulchral vaults, carefully constructed of large undressed blocks of stone. From such burial-places many skulls have been obtained by Scandinavian ethnologists, which show that the ancient race had small heads, remarkably rounded in every direction, but with a facial angle tolerably large, and a well-developed forehead. (See figure 104.) Similar skulls have, according to Retzius, been discovered in France, Ireland, and Scotland, and they are so like those of the modern Laplanders, as to have suggested the idea that the latter were the last survivors of the stone period in the north of Europe. The Laplanders have usually been considered as an extreme branch of the Mongolian race.

The cranial type of the bronze age is not yet well known, but with the introduction of iron, the custom of burying the dead was resumed, and with it a new form of skulls appears, resembling that now-a-days

Fig. 104

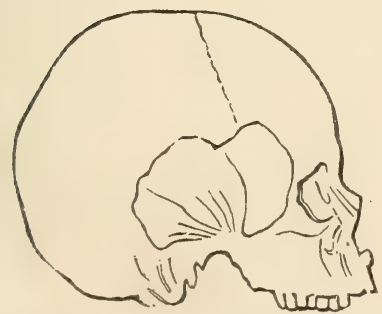

Brachycephalous type of the age of stone of the recent period in Denmark.
Fig. 105.

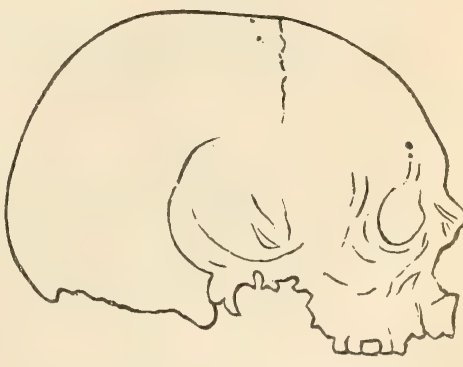

Dolichocephalous type of the beginnin? of the age of iron in Denmark.

most common in Europe. As seen in fig. 105, it is elongated fore and aft, has a forehead somewhat retreating, and corresponds with what is often called the Celtic type.

\section{POST-PLIOCENE PERIOD.}

From the foregoing observations we may infer that the ages of iron and bronze in Northern and Central Europe were preceded by a stone

* See Lyell's Principles of Geology, 9th ed., p. 760.

+ Morlot, ibid. 
age, referable to the recent division of the post-tertiary epoch as determined by the organic remains which accompany the stone implements. But memorials have of late been brought to light of a still older age of stone, when man was contemporary in Europe with the elcphant and rhinoceros, and various other animals, of which many of the most conspicuous have long since died out. The alluvial and marine deposits of this remoter age, the earliest to which any vestiges of man have yet been traced back, belong to a time when the physical geography of Europe differed in a more marked degree from that now prevailing than during the latter part of the post-tertiary period, when the valleys and rivers coincided almost entirely with those by which the present drainage of the land is carried on, and when the peat-mosses were the same as those now growing. So, also, the situation of the shell-mounds and lake-dwellings above alluded to is such as to imply that the topography of each district where they are observed has not subsequently undergone any material alteration. In some exceptional cases, it is true, a marked change has been brought about by the rising or sinking of the earth's crust in the neighborhood

Fig. 106.

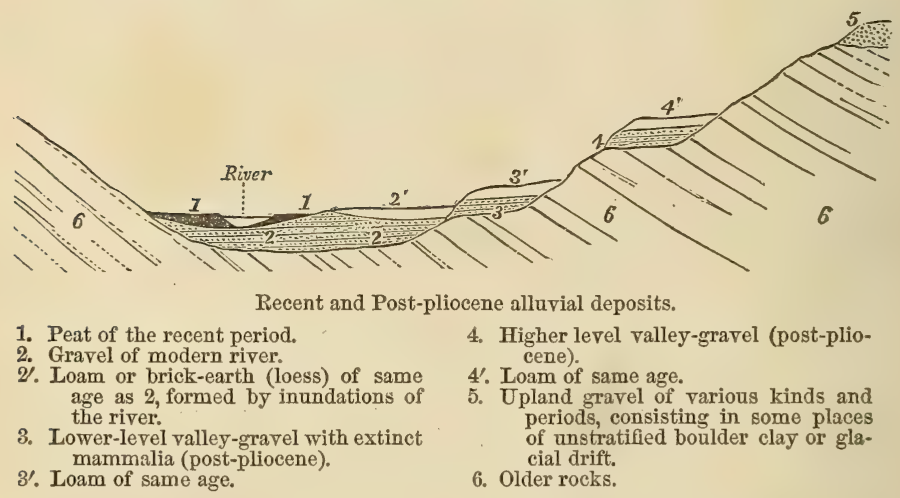

of the sea, so that raised beaches occur at moderate heights rarely exceeding twenty-five feet above high-water mark; or in other places submerged forests are seen at low water, skirting the coasts; and we may take for granted that similar or even greater movements have been experienced far inland within the same era, although we cannot recognize them, or appreciate their magnitude, for want of a standard of measurement such as that which the contiguity of the ocean affords. These movements, whether upward or downward, have affected somewhat uniformly very wide areas, so as not greatly to derange the local features of such an extent of country as the eye can embrace at one view. But we no sooner examine the post-pliocene formations in which the remains of so many extinct mammalia are found, than we at once perceive a more decided discrepancy between the former and 
present outline of the surface. Since those deposits originated, changes of considerable magnitude have been effected in the depth and width of many valleys, also in the direction of the superficial and subterranean drainage, and, as is manifest near the sea-coast, in the relative position of land and water. In the annexed diagram (fig. 106), an ideal section is given, illustrating the different position which the recent and post-pliocene alluvial deposits occupy in many European valleys.

The peat No. 1 has been found in a low part of the modern alluvial plain, in parts of which gravel No. 2 of the recent period is seen. Over this gravel the loam or fine sediment $2^{\prime}$ has in many places been deposited by the river during floods which covered nearly the whole alluvial plain.

No. 3 represents an older alluvium, composed of sand and gravel, formed before the valley had been excavated to its present depth. It contains the remains of fluviatile shells of living species associated with the bones of mammalia, in part of recent and in part of extinct species. Among the latter, the mammoth (E. primigenius) and Siberian rhinoceros ( $R$. tichorhinus) are the most common in Europe. No. $3^{\prime}$ is a remnant of the loam or brick earth by which No. 3 was overspread. Fo. 4 is a still older and more elevated terrace, similar in its composition and organic remains to No. 3 , and covered in like manner with its inundation mud, $4^{\prime}$. Often there is only one of these valley gravels of older date, and occasionally there are more than two, marking as many successive stages, in the excavation of the valley. They usually occur at heights varying from 10 to 100 feet, sometimes on the right and sometimes on the left side of the existing river-plain, but rarely in great strength on exactly opposite sides of the valley.

Among the genera of extinct quadrupeds most frequently met with in England, France, Germany, and other parts of Europe, are Elephas, Rhinoceros, Hippopotamus, Equns, Megaceros, Ursus, Felis, and Hycena. In the peat No. 1 (fig. 106) and in the more modern gravel and silt (No. 2), works of art of the ages of iron and bronze, and of what we may call the "later stone period," already described, are met with. In the more ancient gravels, 3 and 4 (fig. 106), there have been found of late years in several valleys in France and England, as, for example, in those of the Seine and Somme, and of the Thames, and Ouse, near Bedford, stone implements of a rude type, showing that man coexisted in those districts with the elephant and other extinct quadrupeds of the genera above enumerated.

Sereral geologists had come to the conclusion, about the close of the last and beginning of the present century, that certain human remains embedded in the mud and breccia of cares were as old as the extinct mammalia with which they were associated. But the evidence of such high antiquity was not generally received as satisfactory, seeing that so many caves had been inhabited by a succession of tenants, 
and selected by man as places both of domicile and of sepulture, while suites of caverns have also served as the channels through which underground rivers have flowed; so that the remains of living beings which peopled the district at more than one era may, at a later date, have been mingled and confounded together in one and the same deposit. But in 1847, M. Boucher de Perthes observed in an ancient alluvium at Abbeville, in Picardy, the bones of extinct mammalia associated in such a manner with flint implements of a rude type as to lead him to infer that both the organic remains and the works of art were referable to one and the same period. This inference, though questioned for a time, was soon confirmed by fresh observations made by Dr. Rigollot, at Amiens, and all doubts were finally cleared up in 1859, by Mr. Prestwich, who found a flint tool in situ in the same stratum at Amiens, that contained the remains of extinct mammalia. Geologists were, moreover, better prepared to accept such proofs of the coexistence of man with the ancient fauna in consequence of the more exact data obtained from the exploration of the Brixham cave in 1860 , to be mentioned in the sequel.

The flint implements found at Abbeville and Amiens are most of them considered to be hatchets and spear-heads, and are different from those commonly called "Celts." These celts, so ofted found in the recent formations, have a more regular oblong shape, the result of grinding, by which also a sharp edge has been given to them. The Abbeville tools found in gravel at different levels, as in Nos. 3 and 4, fig. 106, in which the bones of the elephant, rhinoceros, and other extinct mammalia occur, are always unground, having evidently been brought into their present form simply by the chipping off of fragments of flint by repeated blows, such as could be given by a stone hammer.

Some of them are oval, others of a spear-headed form, no two exactly alike, and yet the greater number of each kind are obviously fashioned after the same general pattern. Their outer surface is often white, the original black flint having been discolored and bleached by exposure to the air, or by the action of acids, as they lay in the gravel. They are most commonly stained of the same ochreous color as the flints of the gravel in which they are embedded. Occasionally their antiquity is indicated not only by their color but by superficial incrustations of carbonate of lime, or by dendrites formed of oxide of iron and manganese. The edges also of most of them are worn, either by having been used as tools, or by having been rolled in the river's bed. They are usually found at depths of from 15 to 25 feet from the surface, in gravel, covered by loam, and most of them near the bottom of the gravel, and not far from its contact with the subjacent chalk. They are met with not only in the lower-level gravels, as in No. 3, fig. 106, but also in No. 4 , or the higher gravels, as at St. Acheul, in the suburbs of Amiens, where the old alluvium lies at an elevation of about 100 feet above the level of the river Somme. At 
both levels fluviatile and land-shells are met with in the loam as well as in the gravel, but there are no marine shells associated, except at Abbeville, in the lowest part of the gravel, near the sea, and a fow feet only above the present high-water mark. Here with fossil shells of living species are mingled the bones of Elephas primigenius and E. antiquus, Rhinoceros tichorhinus, Hippopotamus, Felis speloca, Hycena spelcea, reindeer, and many others, the bones accompanying the flint implements in such a manner as to show that both were buried in the old alluvium at the same period.

Nearly the entire skeleton of a rhinoceros was found at one point, namely, in the Menchecourt drift at Abbeville, the bones being in such juxtaposition as to show that the cartilage must have held them together at the time of their inhumation.

The general absence here and elsewhere of human bones from gravel and sand in which flint tools are discovered, may in some degree be due to the present limited extent of our researches. But it may also be presumed that when a hunter population, always scanty in numbers, ranged over this region, they were too wary to allow themselves to be overtaken by the floods which swept away many herbivorous animals from the low river-plains where they may have been pasturing or sleeping. Beasts of prey prowling about the same alluvial flats in search of food may also have been surprised more readily than the human tenant of the same region, to whom the signs of a coming tempest were better known.

In the very few instances in which we have good evidence in Europe of the occurrence of human remains in post-pliocene deposits, exclusive of those in caves, the fossil relics have been found at or near the line of junction of the superficial loam $\left(3^{\prime}, 4^{\prime}\right.$, fig. 106) with the underlying gravel. Thus M. Ami Boué, an experienced observer, disinterred with his own hands, in the valley of the Rhine in 1853, parts of a human skeleton from the lower portion of a deposit of loam or loess 80 feet thick. This discovery was made at Lahr, a small town in the Grand Duchy of Baden, nearly opposite Strasburg, on the right side of the valley of the Rhine. They were shown at the time to Cuvier, and recognized by him as human." One of them, a femur, first attracted notice as it projected from a perpendicular cliff of loess, forming the lowest of a succession of terraces, which had been excavated in the loam by the denuding power of the Schutter, a small tributary which at Lahr joins the great alluvial plain of the Rhine. The loam in which the bones were embedded is similar in mineral character to that of the great adjoining plain, and so continuous as to imply that the Rhine once flowed up into the valley of its tributary, and filled it to a considerable height with its muddy sediment, at the time when the skeleton was enveloped in it.

Inundation-mud of rivers._Brick-earth._Fluviatile loam, or loess.

* Lyell, Antiquity of Man. Appendix $2 \mathrm{~d}$ and $3 \mathrm{~d}$ ed. 
-As a general rule, the fluviatile alluvia of different ages (Nos. 2, 3, 4, fig. 106) are severally made up of coarse materials in their lower portions, and of fine silt or loam in their upper parts. For rivers are constantly shifting their position in the valley-plain, encroaching gradually on one bank, near which there is deep water, and deserting the other or opposite side, where the channel is growing shallower, being destined eventually to be converted into land. Where the current runs strongest, coarse gravel is swept along, and where its velocity is slackened, first sand, and then only the finest mud, is thrown down. A thin film of this fine sediment is spread, during floods, over a wide area, on one, or sometimes on both sides, of the main stream, often reaching as far as the base of the bluffs or higher grounds which bound the valley. Of such a description are the well-known annual deposits of the Nile, to which Egypt owes its fertility. So thin are they, that the aggregate amount accumulated in a century is said rarely to exceed five inches, although in the course of thousands of years it has attained a vast thickness, the bottom not having been reached by borings extending to a depth of 60 feet towards the central parts of the valley. Everywhere it consists of the same homogeneous mud, destitute of stratification-the only signs of successive accumulation being where the Nile has silted up its channel, or where the blown sands of the Libyan desert have invaded the plain, and given rise to alternate layers of sand and mud.

The general absence of lamination in the loam of the Egyptian river-plain is probably owing to the thinness of the layer thrown down in a single year, and to its being exposed for eight months to drying winds, or the rays of a hot sun. Parts of it are often swept in the form of dust from one region to another, and almost everywhere the soil is pierced by worms, insects, and the roots of plants. Many geologists have been disposed to refer the absence of stratification in such formations to the sudden and tumultuous action of floods, by which dense masses of mud were thrown down rapidly and uninterruptedly; but I believe that the absence of divisional planes or marks of successive deposition has arisen, not from the want of intermittent action, but because the amount of annual deposit has been so slight, and because it has taken place on ground not permanently submerged. There may be found in deposits of this class examples of every gradation, from a stratified to an unstratified condition.

In European river-loams we occasionally observe isolated pebbles and angular pieces of stone which have been floated by ice to the places where they now occur; but no such coarse materials are met with in the plains of Egypt. Above and below the first cataract, ancient river terraces composed of fluviatile deposits have been observed by Dr. Adams and others at various elevations above the present alluvial plain of the Nile. In these old river-formations-some of which are 30 , others 100 , and others several hundred feet above the river- 
fossil shells, identical with species now living in the Nile, have been found. The probable causes of such alterations in the level of the river, and the successive filling up and re-excavation of the same hydrographical basin at different periods, will be presently spoken of. Ther are changes of a kind that cannot fail to result from great continental morements of subsidence and upheaval, such as we may safely assume that Egypt has undergone in the post-tertiary epoch, because the eastern shore of the Red Sea on one side, and the great desert of the Sahara on the other, hare been conrerted from sea into land since the commencement of the Post-pliocene period.

In some parts of the valley of the Rhine the accumulation of similar loam, called in Germany " loess," has taken place on an enormous scale. Its color is yellowish-gray, and very homogeneous; and Professor Bischoff has ascertained, by analysis, that it agrees in composition with the mud of the Nile. Although for the most part unstratified, it betrays in some places marks of stratification, especially where it contains calcareous concretions, or in its lower part where it rests on subjacent gravel and sand which alternate with each other near the junction. About a sixth part of the whole mass is composed of carbonate of lime, and there is usually an intermixture of fine quartzose and micaceous sand.

Although this loam of the Rhine is unsolidified, it usually terminates where it has been undermined by running water in a rertical cliff, from the face of which shells of terrestrial, freshwater and amphibious mollusks project in relief. These shells do not imply the permanent sojourn of a body of fresh water on the spot, for the most aquatic of them, the Succinea, inhabits marshes and wet grassy meadows. The Succinea elongata, (or S. oblonga, fig. 107, is very characteristic both of the loess of the Rhine and of some other European riverloams.

Among the land-shells of the Rhenish loess, Helix plebeia and Pupa muscorum are very common.

Fig. 107.

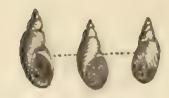

Succinea elongata.
Fig. 108,

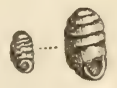

Pupa muscorum.
Fig. 109.

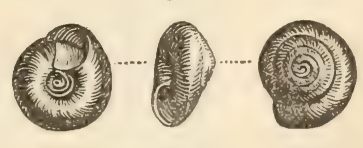

Helix plebeia.

Both the terrestrial and aquatic shells are of most fragile and delizate structure, and yet they are almost invariably perfect and uninjured. They must have been broken to pieces had they been swept along by a violent inundation. Even the color of some of the land-shells, as that of Helix nemoralis, is occasionally preserved.

I observed the three fossils abore figured in the upper fluviatile loam of the Saale, near Rudolstadt, in Thuringia, a river which falls into the Ilm, and belongs to the basin of the Elbe. I have also seen 
loam like that of the Phine at the Porta Westphalica, near Minden, at the height of 500 feet above the river-plain of the Weser, in which the same three shells were conspicuous.

If in some places mollusks of purely aquatic species of such genera as Lymnea, Planorbis, and Paludina, occur near the base of the loess, they probably indicate ancient ponds and lakes marking the course of old deserted river channels, which were afterwards silted up.

In parts of the valley of the Rhine, between Bingen and Basle, the fluviatile loam or loess now under consideration is several hundred feet thick, and contains here and there throughout that thickness land and amphibious shells. As it is seen in masses fringing both sides of the great plain, and as occasionally remnants of it occur in the centre of the valley, forming hills several hundred feet in height, it seems necessary to suppose, first, a time when it slowly accumulated; and secondly, a later period, when large portions of it were removed, or when the original valley, which had been partially filled up with it, was reexcavated.

Such changes may have been brought about by a great movement of oscillation, consisting first of a general depression of the land, and then of a gradual re-elevation of the same. The amount of continental depression which first took place in the interior, must be imagined to have exceeded that of the region near the sea, in which case the higher part of the great valley would have its alluvial plain gradually raised by an accumulation of sediment, which would only cease when the subsidence of the land was at an end. If the direction of the movement was then reversed, and, during the re-elevation of the continent, the inland region nearest the mountains should rise more rapidly than that near the coast, the river would acquire a denuding power sufficient to enable it to sweep away gradually nearly all the loam and gravel with which parts of its basin had been filled up. Terraces and hillocks of mud and sand would then alone remain to attest the various levels at which the river had thrown down and afterwards removed alluvial matter.

Post-pliocene lake-terraces in Switzerland.-In Switzerland terraces of drift are found at different levels above the present rivers and lakes, which correspond to the older gravels (Nos. 3 and 4, fig. 106), and they contain the remains of the mammoth, reindeer, and other mammalia, many of them extinct or no longer inhabitants of Europe; ogether with shells, all of them of species still living. Skirting the Lake of Geneva are the deltas of numerous torrents which bring down mud, sand, and pebbles to the lake, so as to make annual additions to the littoral accumulations. "If," says M. Morlot, "we follow up the course of any of these streams to the height of 150 feet above the lake, we encounter another and more ancient delta, about ten times as large, evidently the monument of a more protracted period, when the water stood for ages at that higher level, and when the physical geography of the country differed considerablv from that now established." 
One of the deltas of transported matter, or, as M. Morlot styles them, flattened cones, is seen at the mouth of the Tinière, a torrent which enters the lake on its south side, near Villeneuve. Its internal structure has been laid open by a railway cutting, which has exposed to riew three layers of regetable soil, each of which has once formed the surface of the delta. For that part of the cone which is above the lerel of the lake is for the most part covered with vegetation, as are generally the higher and unsubmerged parts of all river deltas. The uppermost of these old buried soils, about five feet deep from the present surface, contained Roman tiles and a coin; in the soil next below, six inches thick and ten feet from the surface, were found pottery and instruments of the bronze epoch; and in the third soil, which was half a foot thick and nineteen feet deep, pottery, pieces of charcoal, bones, and a human skeleton having a small, round, and very thick skull, of the brachycephalous type (fig. 104, p. 113) M. Morlot estimates the Roman relics as about seventeen centuries old, those of the bronze age between 3000 and 4000 years, and those of the stone period from 5000 to 7000 years. To the entire delta he ascribes an antiquity of about 10,000 years, while he conjectures that the higher cone or delta, which is ten timès as large, may have taken about 100,000 years for its formation. It contains, as above stated, the remains of the mammoth, and is probably contemporaneous, in the geological sense of the term, with the gravels of Amiens and Abberille, from which so many flint implements of an antique type have been extracted. The above calculation does not pretend to be more than a rude approximation to the truth. Ancient as are the upper terraces when compared to historical times, they are certainly postglacial, or more modern than the glacial period, which will be treated of in the next chapter. In other words, the Alpine glaciers had already shrunk nearly into their present contracted limits before even the higher deltas, containing the mammoth bones, were formed.

Upraised marine strata with pottery in Sardinia.-The most elevated marine strata of the post-pliocene period in Europe, in which articles of human workmanship have yet been noticed, are those observed on the south coast of Sardinia, near Cagliari, so well described by Count Albert de la Marmora. They consist of a breccia, containing fragments of limestone and numerous shells of living Mediterranean species, such as the eatable oyster and mussel, with both valres united. Among these shells, pieces of pottery of a very rude kind are dispersed. They are traceable to a height of 300 feet abore the sea. In the regetable soil corering such marine strata, fragments of a more modern or Roman pottery have been found. There are also in the rocks of the same district numerous fissures filled with breccia, containing the remains of terrestrial quadrupeds, some of them of extinct species. These breccias, although very ancient, as shown by mammalian bones, are more modern than the mnarine post-pliocene strata with pottery above mentioned, for some of the 
shells, the Mytilus edulis for example, washed out of the older formation, have been mingled in the fissures with bones of the extinct quadrupeds.*

There are examples in Europe of marine strata characterized in like manner by embedded shells of living species which reach elevations far exceeding those of Cagliari, but in which no human bones or works of art have yet been discovered.

\section{CAVERN DEPOSITS CONTAINING HUMAN REMAINS AND BONES OF EXTINCT ANIMALS.}

In England, and in almost all countries where limestone rocks abound caverns are found, usually consisting of cavities of large dimensions, connected together by low, narrow, and sometines tortuous galleries or tunnels. These subterranean vaults are usually filled in part with mud, pebbles, and breccia, in which bones occur belonging to the same assemblage of animals as those characterizing the post-pliocene alluvia above described. Some of these bones are referable to extinct and others to living species, and they are occasionally intermingled, as in the valley gravels, with implements of one or other of the great divisions of the stone age, and these are not unfrequently accompanied by human bones, which are much more common in cavern deposits than in valley alluvium.

Each suite of caverns, and the passages by which they communicate the one with the other, afford memorials to the geologists of at least three successive phases through which the physical geography of the country where they occur must have passed. First there was a period when limestone rocks were dissolved on a great scale, and when the carbonate of lime was carried out gradually by springs from the interior of the earth; secondly, an era when engulfed rivers or occasional floods swept organic and inorganic debris into the subterranean hollows previously formed; and thirdly, there were such changes in the configuration of the region as caused the engulfed rivers to be turned into new channels, and springs to be dried up, after which the cave-mud, breccia, gravel, and fossil bones would bear the same kind of relation to the existing drainage of the country as the older valley drifts with their extinct mammalian remains and works of art bear to the present rivers and alluvial plains.

In the first of the periods above supposed the operations are entirely subterranean. We know that in every limestone district the rain water is soft or free from earthy ingredients when it falls upon the soil, and when it enters the rocks below, whereas it is hard, or charged with carbonate of lime, when it issues again to the surface in springs, which, by failing after long droughts, and by in- 
creasing in volume after rainy seasons, betray their dependence for a supply of water on atmospheric sources. The rain derives some of its carbonic acid from the air, but much more from the decay of vegetable matter in the soil which it percolates, and by the excess of this acid, limestone is dissolved, an $\alpha$ tne water becomes charged with carbonate of lime. The mass of solid matter silently and unceasingly subtracted in this way from the rocks in every century is considerable, and must in the course of thousands of years be so vast that the space it once occupied may well be expressed by a long suite of caverns. The varying size and shape of these will be determined by innumerable local accidents, such as the direction of pre-existing rents and faults, or the unequal purity and consequent solubility of the limestone in different strata, or in different parts of the same stratum.

If there be a series of convulsions and movements of upheaval and depression, during which old valleys are gradually deepened and widened, or new ones formed, accompanied by the rending of rocks in many places, the surface drainage may in time be so altered that streams sweeping along angular and rounded stones may break into cavities once having no such connexion with the surface. Such streams may introduce fine mud, or angular and rounded pebbles and land-shells, with portions of skeletons of various quadrupeds, or of man, together with fragments of works of art, and fill up a large part of the underground rents, galleries, and chambers with heterogeneous materials. The whole of these may sometimes be united into solid breccias and conglomerates by stalactitic infiltrations.

In the descriptions given of violent earthquakes we read of the sudden appearance of new fissures several fect wide, often of great depth, and some of which remain permanently open. Wild animals chased by beasts of prey fall into such natural pit-falls; the pursued and the pursuer perishing together. Their bones, during the slow decay of the carcase, may be carried separately into subterranean vaults, or many of them still bound together by ligaments; even entire skeleton may sometimes be washed into cares and be there preserved.

The quarrying away of large masses of Carboniferous and Devonian limestone, near Liège, in Belgium, has afforded the geologist magnificent sections of some of these caverns, and the former communication of cavities in the interior of the rocks with the old surface of the country by means of vertical or oblique fissures, has been demonstrated in places where it would not otherwise have been suspected, so completely hare the upper extremities of these fissures been concealed by superficial drift, while their lower ends, which extencled into the roofs of the cares, are masked by stalactitic incrustations.

The origin of the stalactite is thus explained by the eminent chemist Liebig. On the surface of Franconia, where the limestone 
abounds in caverns, is a fertile soil, in which vegetable matter is continually decaying. This mould or humus, being acted on by moisture and air, evolves carbonic acid, which is dissolved by rain. The rain water, thus impregnated, permeates the porous limestone, dissolves a portion of it, and afterwards, when the excess of carbonic acid evaporates in the caverns, parts with the calcareous matter, and forms stalactite. Even while caverns are still liable to be occasionally flooded - such calcareous incrustations accumulate, but it is generally when they are no longer in the line of drainage that a solid floor of hard stalagmite is found on the bottom. On the whole, the circumstances under which an organic body is usually introduced into a cave are far more favourable to its preservation than those which accompany its envelopment in valley-alluvium; for where the mud or stones are connected together by carbonate of line, the free percolation of water, and consequent decay and removal of the bones or shells, are arrested.

The late Dr. Schmerling examined forty caves near Liège, and found in all of them the remains of the same fauna, comprising the mammoth tichorhine rhinoceros, cave-bear, cave-hyæna, cave-lion, and many others, some of extinct and some of living species, and in all of them flint implements. In four or five caves only parts of human skeletons were met with, comprising sometimes skulls with a few other bones, sometimes nearly every part of the skeleton except the skull. In one of the caves, that of Engihoul, where Schmerling had found the remains of at least three human individuals, they were mingled in such a manner with bones of extinct mammalia, as to leave no doubt on his mind of man having coexisted with them.

In 1860, Professor Malaise, of Liège, explored with me this same cave of Engihoul, and beneath a hard floor of stalagmite we found mud full of the bones of extinct and living animals, such as Schmerling had described, and my companion, persevering in his researches after I had returned to England, extracted from the same deposit two human lower jaw-bones retaining their teeth. The skulls from these Belgian caverns display no marked deviation from the normal European type of the present day. One of them, for example, obtained by Schmerling from the Engis care, situated on the left bank of the Meuse, is now preserved in the museum of the University of Liège, and agrees with the long-headed type (fig. 105, p. 113), and not with the short round form which seems, in Scandinavia at least, to have been the more ancient of the two.

The careful investigations carried on by Dr. Falconer, Mr. Pengelly, and others, in the Brixham cave near Torquay, in 1858, demonstrated that flint knives were there embedded in such a manner in loam underlying a floor of stalagmite as to prove that man had been an inhabitant of that region when the cave-bear and other members of the ancient post-pliocene fauna were also in existence.

The certainty of the data on which this conclusion was founded 
had no small influence in inducing many English and French geolo. gists to appreciate more justly the opinion at which M. Boucher de Perthes had arrived after his researches at Abbeville before mentioned, which were still regarded by the scientific public in general with skepticism and suspicion.

'The absence of gnawed bones had led Dr. Schmerling' to infer that none of the Belgian caves which he explored had served as the dens of wild beasts; but there are many cares in Germany and England which have certainly been so inhabited, especially by the extinct hyæna and bear.

A fine example of a hyæna's den was afforded by the cave of Kirkdale, so well described by the late Dr. Buckland in his Reliquice Diluviance. In that cave, about twenty-five miles N.N.E. of York, the remains of about 300 hyænas, belonging to individuals of every age, were detected. The species (Hycena spelcea) is extinct, and was larger than the fierce Hycena crocuta of South Africa, which it most resembled. Dr. Buckland, after carefully examining the spot, proved that the hyænas must have lived there; a fact attested by the quantity of their dung, which, as in the case of the living hyæna, is of nearly the same composition as bone, and almost as durable. In the care were found the remains of the ox, young elephant, hippopotamus, rhinoceros, horse, bear, wolf, hare, water-rat, and several birds. All the bones hare the appearance of having been broken and gnawed by the teeth of the hyænas; and they occur confusedly mixed in loam or mud, or dispersed through a crust of stalagmite which covers it. In these and many other cases it is supposed that portions of herbirorous quadrupeds have been dragged into caverns by beasts of prey, and have served as their food-an opinion quite consistent with the known habits of the living hyæna.

Reindeer period in South of France.-In the larger number of the caves of Europe, as for example in those of England, Belgium, Germany, and many parts of France, the animal remains agree specifically with the fauna of the oldest division of the age of stone, or that to which belongs the drift of Amiens and Abbeville already mentioned, containing flint implements of a very antique type. But there are some caves in the departments of Dordogne, Aude, and other parts of the south of France, which are believed by M. Lartet. to be of intermediate date between that ancient division of the stone age and the more modern one which is represented by the Swiss lake-dwellings. To this intermediate era M. Lartet gave, in 1863, the name of the "reindeer period," because rast quantities of the bones and horns of that deer have been met with in those French caverns. In some cases separate plates of molars of the mammoth, and several teeth of the great Irish deer, Cervus Megaceros, have been found mixed up with cut and carved bones of reindeer; but whether these extinct quadrupeds were really contemporaneous at the era in question with man and the reindeer, is not yet clearly made out. Al- 
though the mammalian fauna consists of living species, the presence of the reindeer, marmot, and some other northern animals, seems to imply a colder climate than that of the Swiss lake-dwellings, in which no remains of reindeer have as yet been discovered. The absence of these in the old lacustrine habitations of Switzerland is the more significant, because in a cave in the neighborhood of the Lake of Geneva, namely, that of Mont Salève, bones of the reindeer occur with flint implements similar to those of the caverns of Dordogne and Perigord.

The state of the arts, as exemplified by the instruments found in these caverns of the reindeer period, is somewhat more advanced than that which characterizes the tools of the Amiens drift, but is nevertheless more rude than that of the Swiss lake-dwellings. No metallic articles occur, and the stone hatchets are not ground after the fashion of celts; but some of the bones are artistically carved, so as to represent animals; and the needles of bone are shaped in a workmanlike style, having their eyes drilled with consummate skill.

Australian cave-breccias.-Ossiferous breccias are not confined to Europe, but occur in all parts of the globe; and those discovered in fissures and caverns in Australia correspond closely in character with what has been called the bony breccia of the Mediterranean, in which the fragments of bone and rock are firmly bound together by a red ochreous cement.

Some of these caves were examined by the late Sir T. Mitchell in the Wellington Valley, about 210 miles west of Sidney, on the river Bell, one of the principal sources of the Macquarie, and on the Macquarie itself. The caverns often branch off in different directions through the rock, widening and contracting their dimensions, and the roofs and floors are covered with stalactite. The bones are often broken, but do not seem to be water-worn. In some places they lie imbedded in loose earth, but they are usually included in a breccia.

The remains found most abundantly are those of the kangaroo, of which there are four species, besides which the genera Hypsiprymnus, Phalangista, Phascolomys, and Dasyurus, occur. There are also bones, formerly conjectured by some osteologists to belong to the hippopotamus, and by others to the dugong, but which are now referred by Mr. Owen to a marsupial genus, allied to the Wombat.

In the fossils above enumerated, several species are larger than the largest living ones of the same genera now known in Australia. The preceding figure of the right side of a lower jaw of a kangaroo (Macropus atlas, Owen) will at once be seen to exceed in magnitude the corresponding part of the largest living kangaroo, which is represented in fig. 111. In both these specimens part of the substance of the jaw has been broken open, so as to show the permanent false molar ( $a$, fig. 110) concealed in the socket. From the fact of this molar not having been cut, we learn that the individual was young, 
and had not shed its first teeth. In fig. 112 a front tooth of the same species of kangaroo is represented.

Fig. 110.

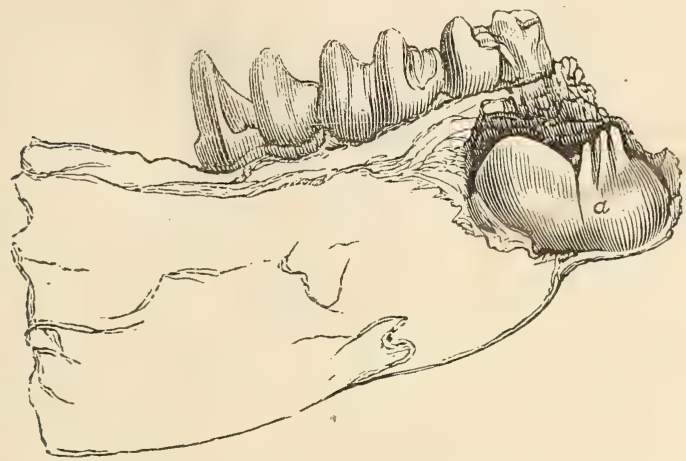

Part of lower jaw of Mucropus atlas. Owen. A young individual of an extinct species. a. Permanent false molar, in the alveolus.

Fig. 111.

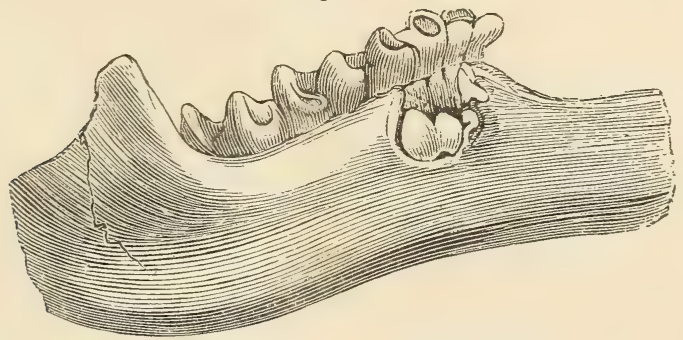

Lower jaw of largest living species of kangaroo.

(Macropus major.)

The reader will observe that these extinct quadrupeds of Australia belong to the marsupial family, or, in other words, that they are referable to the same peculiar type of organization which now distinguishes the Australian mammalia from those of other parts of the globe. This fact is one of many pointing to a general law deducible from the fossil vertebrate and invertebrate animals of times immediately antecedent to our own, namely, that the present geographical distribution of organic forms dates back to a period anterior to the origin of existing species; in other words, the limitation of particular genera or families of quadrupeds, mollusca, \&c., to certain existing provinces of land and sea, began before the larger part of the species now contemporary with man had been introduced into the earth.

Fig. 112.

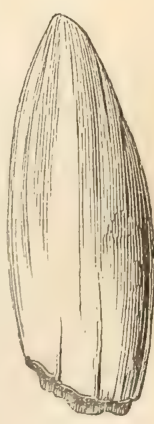

Incisor of Macropus.

Professor Owen, in his excellent "History of British Fossil Main- 
mals," has called attention to this law, remarking that the fossil quadrupeds of Europe and Asia differ from those of Australia or South America. We do not find, for example, in the EuropæoAsiatic province fossil kangaroos or armadillos, but the elephant, rhinoceros, horse, bear, hyæna, beaver, hare, mole, and others, which still characterize the same continent.

In like manner, in the Pampas of South America the skeletons of Megatherium, Megalonyx, Glyptodon, Mylodon, Toxodon, Macrauchenia, and other extinct forms, are analogous to the living sloth, armadillo, cavy, capybara, and llama. The fossil quadrumana, also associated with some of these forms in the Brazilian cares, belong to the Platyrrhine family of monkeys, now peculiar to South America. That the extinct fauna of Buenos Ayres and Brazil was very modern has been shown by its relation to deposits of marine shells, agreeing with those now inhabiting the Atlantic; and when in Georgia, in 1845, I ascertained that the Megatherium, Mylodon, Equus curvidens, and other quadrupeds a'lied to the Pampean type, collected by Mr. Hamilton Couper, were posterior in date to beds containing marine shells belonging to forty-five recent species of the neighboring sea.

There are indeed some cosmopolite genera, such as the Mastodon (a genus of the elephant family) and the horse, which were simultaneously represented by different fossil species in Europe, North America, and South America; but these few exceptions can by no means invalidate the rule which has been thus expressed by Professor Owen, that in "the highest organized class of animals the same forms were restricted to the same great provinces at the Pliocene periods (and we may add Post-pliocene) as they are at the present day."

However modern, in a geological point of view, we may consider the Newer Pliocene and Post-pliocene epochs, it is evident that causes more general and powerful than the intervention of man have occasioned the disappearance of the ancient fauna from so many extensive regions. Not a few of the species had a wide range; the same Megatherium, for instance, extended from Patagonia and the river Plata in South America, between latitudes $31^{\circ}$ and $39^{\circ}$ south, to corresponding latitudes in North America, the same animal being also an inhabitant of the intermediate country of Brazil, where its fossil remains have been met with in caves. The mammoth (Elephas primigenius) has been likewise found fossil in North America, and again in the eastern hemisphere from Siberia to the south of Europe. If it be objected that, notwithstanding the adaptation of such quadrupeds to a variety of climates and geographical conditions, their great size exposed them to extermination by the first hunter tribes, we may observe that the investigations of Lund and Clausen in the ossiferous limestone caves of Brazil have demonstrated that these large mammalia were associated with a great many smaller quadrupeds, some of them as diminutive as field-mice, which have all died out together, while the 
land-shells formerly their contemporaries still continue to exist in the same countries. As we may feel assured that these minute quadrupeds could never have been extirpated by man, especially in a country so thinly peopled as Brazil, so we may conclude that all the species, small and great, have been annihilated one after the other, in the course of indefinite ages, by those changes of circumstances in the organic and inorganic world which are always in progress, and are capable in the course of time of greatly modifying the physical geography, climate, and all other conditions on which the continuance upon the earth of any living being must depend.*

The law of geographical relationship above alluded to, between the living vertebrata of every great zoological providence and the fossils of the period immediately antecedent, even where the fossil species are extinct, is by no means confined to the mammalia. New Zealand, when first examined by Europeans, was found to contain no indigenous land quadrupeds, no kangaroos, or opossums, like Australia; but a wingless bird abounded there, the smallest living representative of the ostrich family, called the Kiwi by the natives (Apteryx). In the fossils of the Post-pliocene period in this same island, there is the like absence of kangaroos, opossums, wombats, and the rest; but in their place a prodigious number of $\pi$ ell-preserved specimens of gigantic birds of the struthious order, called by Owen Dinornis and Palapteryx, which are entombed in superficial deposits. These genera comprehended many species, some of which were four, some seven, others nine, and others eleven feet in height! It seems doubtful whether any contemporary mammalia shared the land with this population of gigantic feathered bipeds.

Mr. Darwin, when describing the recent and fossil mammalia of South America, has dwelt much on the wonderful relationship of the extinct to the living types in that part of the world, inferring from such geographical phenomena that the existing species are all related to the extinct ones which preceded them by a bond of common descent.

The late able naturalist, Edward Forbes, had declared in 1846 his conviction that, not only the great extinct deer, Cervus megaceros, but also the mammoth, and other lost pachyderms and carnivora, lived in Britain after the extreme cold of the glacial period had passed away. $\nmid$ More recent observations by Mr. Prestwich and Dr. Falconer, on the fossil contents of the drift and cave deposits of England, have confirmed this opinion, and have also proved that a larger number of the lost species than Forbes probably suspected were posterior in date to the submergence of central England beneath the waters of the glacial sea -an event which will be spoken of in the twelfth chapter. Mr. Prestwich has pointed out that there are some contortions of the 
strata in the higher level gravels of the Seine and Somme which indicate ice-action, such-as might be caused by the freezing over of the rivers in winter, as now happens in corresponding latitudes in Canada. As these higher-level gravels, which contain human implements mingled with remains of extinct mammalia, approach in age to the glacial period in proportion as they recede to a greater distance from our time, it is natural that we should discover in them some indications of a colderr climate. Accordingly, in addition to the disturbed stratification, a phenomenon to which I shall again allude in the sequel, p. 156, the large dimension of many angular fragments of rock buried in the higher gravel, and which have been transported from great distances in the same hydrographical basins, afford corroborative indications of ice-action.

If it be asked whether the character of the fluviatile and land-shells of the same post-pliocene drifts also implies a colder climate, it may be said that they are generally of the same species as those now inhabiting the same districts, but most of them have now so wide a northward range into Norway and Finland, that they may perhaps have flourished when the cold, especially in winter, was greater than now. But when we contemplate the whole of the evidence as to climate derived from a wide area in Europe, we find it to be very conflicting, owing possibly to post-glacial fluctuations in temperature, occasioning the migrations of quadrupeds from north to south and from south to north, during different seasons of the same year, or during successive stages of the same era. The reindeer and the musk-buffalo, Bubalus moschatus, are well known as living inăabitants of the Arctic regions, and they both occur fossil in the valley of the Thames, and in that of the Avon, near Batheaston, as well as in the drift of the valley of the Oise, a tributary of the Seine. The same buffalo has also been met with in the post-pliocene drift of North Germany, at the gates of Berlin, where, as in England, it accompanied the mammoth, Elephas primigenius, and the two-horned, or woolly rhinoceros, $R$. tichorhinus. The last-mentioned mammalia were both of them found by Pallas preserved with their flesh in the frozen gravel of Siberia, and they have also been met with in the drift of North Germany, near Quedlinburg, associated with the Norwegian lemming, Myodes lemmus, and another species of the same family, called by Pallas Myodes torquatus (by Hensel Misothermus torquatus), a still more Arctic quadruped, for it was observed by Parry in lat. $82^{\circ} \mathrm{N}$, and is said never to stray farther south than the northern borders of the woody region.

No instance has yet occurred in North Germany of the association of these lemmings, reindeer, and musk-buffalos, with the hippopotamus. When the latter genus occurs in England, it is usually accompanied by Elephas antiquus, and Rhinoceros hemitochos (Falc.), or sometimes with Rhinoceros leptorhinus.

At Gray's Thurrock, in Essex, on the left or north bank of the 
Thames, where the three pachyderms last enumerated are found together, a fossil shell, Cyrena fuminalis, is abundant, which no longer lires in any European rirer, but still inhahits the Nile and parts of Asia. With it, in the same sand and gravel, the Unio littoralis occurs, now extinct in Britain, but still living in the Seine and Loire in France: It may be contended that when the Cyrena fuminalis abounded in the Thames, the hippopotamus may have been suited to the same climate, just as the same mollusk and the living hippopotamus now coexist in the Nile. We may doubtless imagine that during the countless centuries which may have passed away since the glacial epoch, there have been oscillations of temperature, in the course of which certain members of a more southern fauna migrated northwards, and then retreated again when a succession of less genial seasons prevailed, while other migratinns in an opposite direction took place whenever there was a change from a warmer to a colder climate.

In the valley of the Somme the rude flint tools before mentioned, page 116, hare been found at Menchecourt, near Abberille, associated with the Cyrena fuminalis, and with the Hippopotamus major. These were met with in the lower level post-pliocene gravel, and may be referable, as Mr. Prestwich has suggested, to a period when the climate was somewhat warmer than that of the higher level drift of this same ralley. It is in that higher and older drift at St. Acheul, near Amiens, that flint implements hare been found in the greatest number, together with the bones of the elephant and other postpliocene quadrupeds, so that man, must hare existed through several successire phases of the geography and climate of that region in prehistoric times.

In 1863, sereral individuals of the Greenland lemming, and several of a new species of Spermophilus, an Arctic type allied to the marmot, were found by Dr. Blackmore in the ancient alluvium of the Wiley near Salisbury, in lower-lerel drift, rising about thirty feet abore the present water meadows. They were associated with the mammoth, tichorine rhinoceros, care hyæna, reindeer, and many other mammalia, probably suited, like them, to a cold climate. In the immediate ricinity occurs a higher level gravel, ninety feet abore the Wiler, from which flint implements, much rolled and resembling some of those at Amiens, have been obtained. After examining the spot, I agree with Dr. Blackmore, that these flint tools, and the gravel in which they are embedded, are older than the deposits containing the extinct mammalia, so that in this instance we cannot suppose, as in the case of Menchecourt abore alluded to, that the fossils of the more modern or lower-level deposit indicate a more genial climate.

Nearly all the known post-pliocene quadrupeds hare now been found either in ralley drifts or care deposits in England or on the Continent, accompanying flint knives or hatchets in such a way as to 
imply the co-existence of the same mammalia with man. The antiquity, therefore, of the human race may be inferred from the concurrent testimony of several independent classes of geological facts. In the first place, the disappearance of many wild animals from a large continent, even where man has been an active agent of extermination, must always require a considerable lapse of time for its accomplishment; indeed, before the invention of fire-arms, it is hard to say how many centuries it would take to bring about such utter extirpation. Yet there can be no doubt that many species became extinct after man was a denizen of the earth, and before the Danish shell-mounds were formed, or the oldest of the Swiss lake-dwellings constructed. Secondly, thousands of years must have been required to enable rivers to deepen and widen their valleys, and to grind down fragments of rock into mud, sand, and pebbles, on such a scale as to produce the old valley gravels, both higher and lower, containing flint implements and the bones of extinct mammalia. Thirdly, much time is also demanded to enable springs and engulfed rivers to change their courses, and for caves which once lay in the line of a great subterranean drainage to become dry, and to have their floors encrusted over with a hard covering of stalagmite. Lastly, ages must have been required to bring about such a change in the climate of a wide region as to cause the winters to be less severe, and the geographical distribution of certain species of mammalia and land and freshwater shells to vary. The length of the historical epoch, even if assumed to be 3000 or 4000 years, does not furnish us with any appreciable measure for calculating the number of centuries which would suffice for such a series of changes, which are by no means of a local character, but have already been traced from England and the North-west of France to Sardinia and Sicily.

Relative longevity of species in the mammalia and testacea.-I called attention, in $1830, *$ to the fact which had not at that time attracted notice, that the association in the post-pliocene deposits of shells, exclusively of living species, with many extinct quadrupeds, betokened a longevity of species in the testacea far exceeding that in the mammalia. Subsequent researches seem to show that this greater duration of the same specific forms in the class mollusea is dependent on a still more general law, namely, that the lower the grade of animals, or the greater the simplicity of their structure, the more persistent are they in general in their specific characters throughout vast periods of time. Not only have the invertebrata, as shown by geological data, altered at a less rapid rate than the vertebrata, but if we take one of the classes of the former, as for example the mollusca, we find those of more simple structure to have varied at a slower rate than those of a higher and more complex organization; the brachiopoda, for example, more slowly than the lamellibranchiate bivalves,

* Principles of Geology, 1st ed. vol. iii. p. 140. 
while the latter have been more persistent than the univalves, whether gasteropoda or cephalopoda. In like manner the specific identity of the characters of the foraminifera, which are among the lowest types of the invertebrata, has outlasted that of the mollusca in an equally decided manner.

Teeth of post-pliocene mammalia.-To those who have never studied
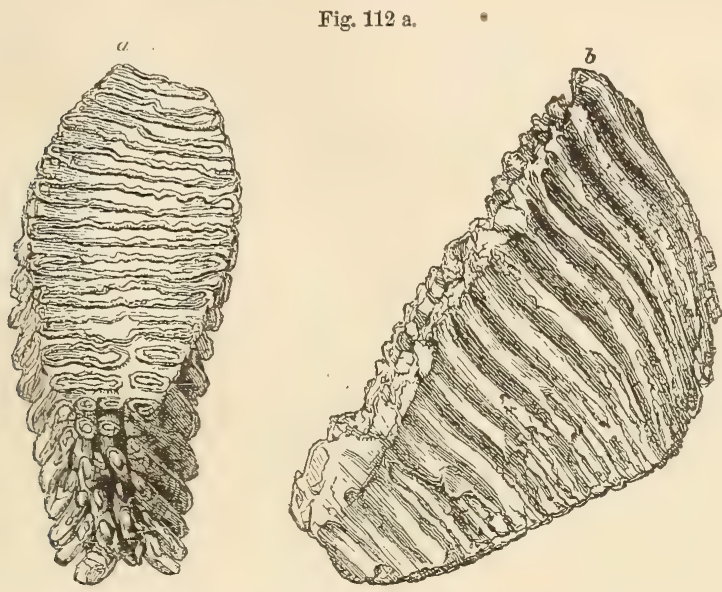

Elephas primigenius (or Mammotb); molar of upper jaw, right side; one third of nat. size. Post-pliocene.

a. Grinding surface.

b. Side view.

comparative anatomy, it may seem scarcely credible that a single bone taken from any part of the skeleton may enable a skilful osteologist to distinguish, in many cases, the genus, and sometimes the species, of quadruped to which it belonged. Although few geologists can aspire to such knowledge, which must be the result of long practice and study, they will nevertheless derive great advantage from learning, what is comparatively an easy task, to distinguish the principal divisions of the mammalia by the forms and characters of their ieeth.

The annexed figures represent the teeth of some of the more common species and genera found in alluvial and cavern deposits.

Fig. 113.

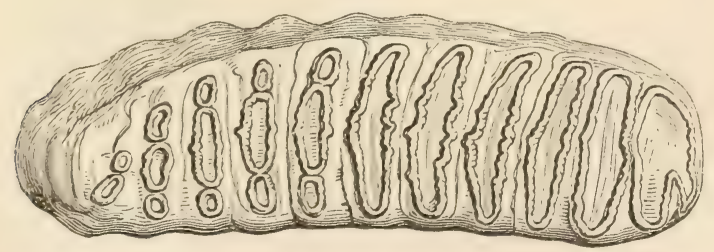

Elephas antiquus, Falconer. Penaltimate molar, one-third of nat. size. Post-pliocene and pliocene. 
Fig. 114.

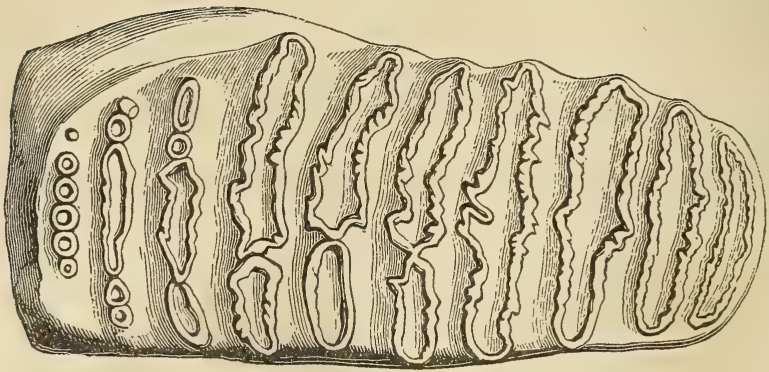

Elephas meridionalis, Nesti. Penultimate molar, one-third of nat. size. Post-pliocene and pliocene.

Fig. 115.

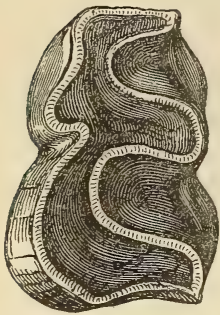

Rhinoceros leptorhinus, Cuvier = Rhin, megarhinus, Christol; fossil from freshwater beds of Grays, Essex (see p. 130); penultimate molar, lower jaw, left side two-thirds of nat. size. Postpliocene and Newer Pliocene.

Fig. 118.

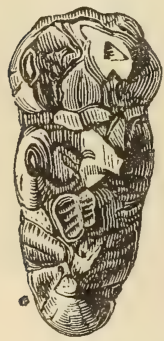

Pig.

Sus serofa, L. (common pig); from shell-marl. Forfarshire; posterior molar lower jaw, nat, size. Recent.
Fig. 116.

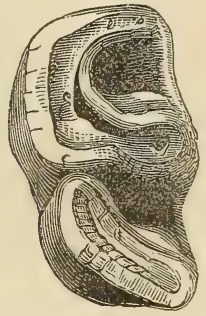

Rhinoceros tichorhinus; penultimate molar, lower jaw, left side; two-thirds of nat. size. Post-pliocene.
Fig. 117.

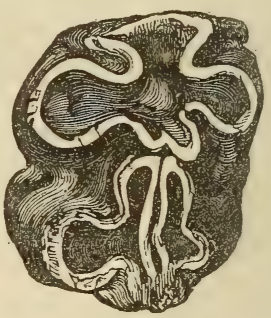

Hippopotamus ; from cave near Palermo; molar tooth two-thirds of nat. size. Postpliocene.

Fig. 119
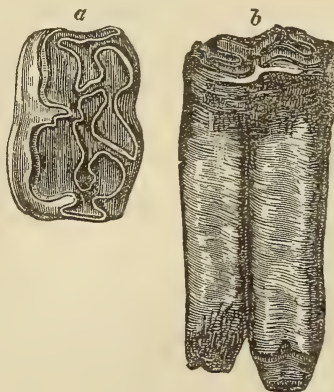

Horse.

Equns caballus, L. (common horse) from the shell-marl, Forfarshire; second molar, lower jaw. Recent.

a. Grinding surface, two-thirds nat. size.

$b$. Side view of same, half nat. size.

On comparing the grinding surfaces of the corresponding molars 
of the three species of elephants, figs. 112 a, 113, 114, it will be seen that the folds of enamel are most numerous in the mammoth, ferrer and wider, or more open, in $E$. antiquus, and most open and fewest in $E$. meridionalis. It will be also seen that the enamel in the molar of the rhinoceros tichorhinus (fig. 116) is much thicker than in that of the rhinoceros leptorhinus (fig. 115).

Fig. 120.

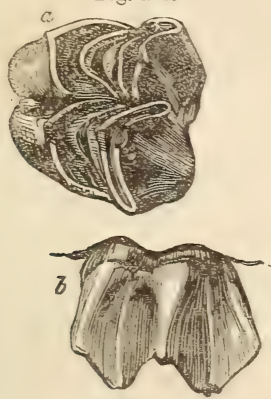

$a, b$. Deer.

Elk (Cervus alees, $\mathrm{L}_{\text {. }}$ ); re. cent; molar of upper jaw.

a. Grinding surface.

b. Side view; two-thirds of nat, size.

Fig. 122.

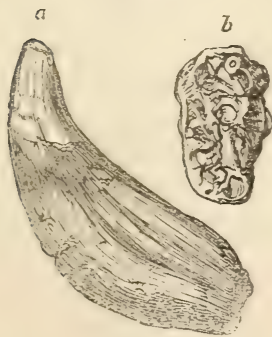

Bear.

a. Canine tooth or trisk of bear (Ursus spelceus) ; from cave near Liege.

b. Molar of left side, upper jaw; onethird of nat. size. Post-pliocene.
Fig. 121.

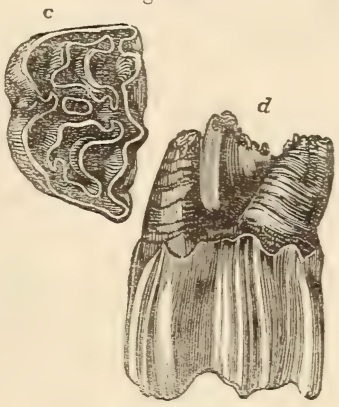

$c, d$. Ox.

Ox, common, from shell-marl, Forfarshire; true molar, upper jaw; twothirds nat. size. Recent.

c. Grinding surface

d. Side view; fangs uppermost.

Fig. 123.

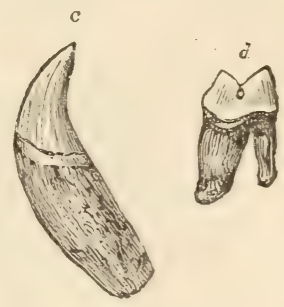

Tiger.

c. Canine tooth of tiger (Felis tigris); recent.

d. Outside view of posterior molar, lower jaw; one-third of nat. size; recent.

Fig. 124.

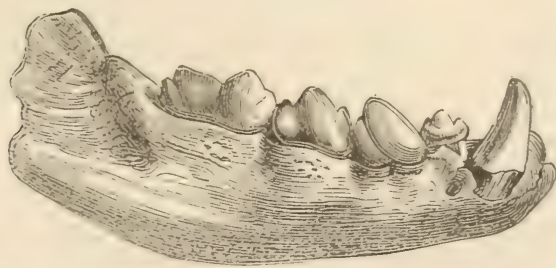

Hyana spelaca; lower jaw. Kent's Hole, Torquay, Devonshire. One-third nat. size. Post-pliocene. 
Fig. 125

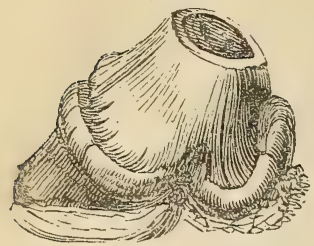

Hyóna speloea; second molar, left side, lower jaw; nat. size. Cave of Kirkdale. Post-pliocene.
Fig. 126.
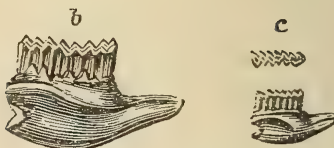

Teeth of a new species of Arvicola, field-mouse; from the Norwich Crag. Newer Pliocene.

$a$. Grinding surface. $b$. Side view of same. $c$. Nat, size of $a$ and $b$.

Fig. 127.

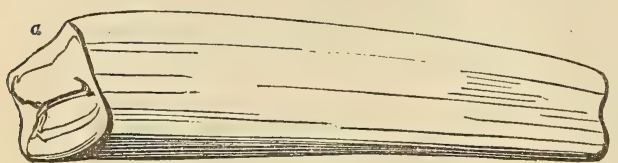

a. Fourth molar, right side, lower jaw. Megatherium; Georgia, U. S.; one-third nat. size. Post-pliocene.

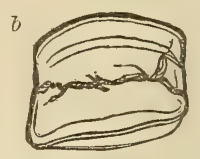

๖. Crown of same.

\section{CHAPTER XI.}

\section{POST-PLIOCENE PERIOD CONTINUED.-GLACIAL EPOCH.}

Geographical distribution, form, and characters of glacial drift-Fundamental rocks, polished, grooved, and scratched-Abrading and striating action of glaciersMoraines, erratic blocks, and "Roches Moutonnées"-Alpine blocks on the Jura -Colossal size of ancient Swiss glaciers-Continental ice of Greenland-Ancient centres of the dispersion of erratics-Transportation of drift by floating icebergs-Bed of the sea furrowed and polished by the running aground of floating ice-islands-How to distinguish glacial drift of submarine from that of terrestrial origin.

Among the different kinds of alluvium described in Chapter VII., a passing allusion was made (page 80 ) to the "boulder formation" and to its origin as probably connected with the agency of glaciers and floating ice. This formation, to which many names, such as "diluvium," "northern drift," "boulder clay," and "glacial deposits" have been given, is abundant in Europe north of the 50th, and in North America north of the 40th parallel of latitude. It is wanting in the warmer and equatorial regions, and reappears when we examine the lands which lie south of the 40th and 50th parallels in the Southern Hemisphere; as, for example, in Patagonia, Terra del Fuego, and New Zealand. It consists of sand and clay, sometimes stratified, but often wholly devoid of stratification for a depth of 50 , 100 , or even a greater number of feet. To this unstratified form of 
the deposit the name of till has long been applied in Scotland. It generally contains a mixture of angular and rounded fragments of rock, some of large size, having occasionally one or more of their sides flattened and smoothed, or eren highly polished. The smoothed surfaces usually exhibit many scratches parallel to each other, one set of which often crosses an older set. The till is almost everywhere wholly deroid of organic remains, except those washed into it from older formations, though in some places it contains marine shells of arctic species, many of them in a fragmentary state. The bulk of the till has usually been derived from the grinding down into mud of rocks in the immediate neighborhood, so that it is red in a region of Red Sandstone, as in Strathmore in Forfarshire; gray or black in a district of coal and coal-shale, as around Edinburgh; and white in a chalk country, as in parts of Norfolk and Denmark. The stony fragments dispersed irregularly through the till usually belong, especially in mountainous countries, to rocks found in some parts of the same hydrographical basin; but there are regions where the whole of the boulder clay has come from a distance, and huge blocks, or "erratics," as they have been called, many feet in diameter, have not unfrequently travelled hundreds of miles from their point of departure, or from the parent rocks from which they have evidently been detached. These are commonly angular, and have often one or more of their sides polished and furrowed.

The fundamental rock on which the boulder formation reposes, if it consists of granite, gneiss, marble, or other hard stone, capable of permanently retaining any superficial markings which may have been imprinted upon it, is usually smoothed or polished, like the erratics above described; and exhibits parallel striæ and furrows having a determinate direction. This direction, both in Europe and North America, agrees generally in a marked manner with the course taken by the erratic blocks in the same district.

The boulder clay, when it was first studied, seemed in many of its characters so singular and anomalous, that geologists despaired of ever being able to interpret the phenomena by reference to causes now in diurnal action. In those exceptional cases, where marine shells of the same date as the boulder clay were found, nearly all of them were recognised as living species-a fact conspiring with the superficial position of the drift to indicate a comparatively modern origin. The recentness of the date caused the enigma to appear only the more perplexing, and strengthened the belief that the phenomena were the results of forces distinct both in kind and energy from those now operating in the ordinary course of nature. Notions of this kind were calculated to retard the progress of science, by diverting attention from such every-day operations as were capable of producing analogous effects.

The term "diluvium" was for a time the most popular name of the boulder formation, because it was referred by many to the deluge of 
Noah, while others retained the name as expressive of their opinion that a series of diluvial waves raised by hurricanes and storms, or by earthquakes, or by the sudden upheaval of land from the bed of the sea, had swept over the continents, carrying with them vast masses of mud and heavy stones, and forcing these stores over rocky surfaces so as to polish and imprint upon them long furrows and striæ.

But geologists were not long in seeing that the boulder formation was characteristic of high latitudes, and that on the whole the size and number of erratic blocks increases as we travel toward the arctic regions. They could not fail to be struck with the contrast which the countries bordering the Baltic presented when compared with those surrounding the Mediterranean. The multitude of travelled blocks and striated rocks in the one region, and the absence of such appearances in the other, were too obvious to be overlooked. Even the great development of the boulder formation, with large erratics so far south as the Alps, offered an exception to the general rule favorable to the hypothesis that there was some intimate connection between it and accumulations of snow and ice.

Abrading, polishing, scouring and transporting power of glaciers.It is well known that those parts of the Alps which rise to heights exceeding 8500 feet above the level of the sea are covered with perpetual snow. This snow, as it receives annual additions, would increase indefinitely in altitude were not its accumulation checked by the constant descent of a large portion of it by gravitation. As it glides slowly down the principal valleys flanking the highest mountains, it becomes converted into solid ice, and forms what are termed glaciers, or rivers of ice, the lower extremities of which, when they descend into warmer regions, melt and give rise to torrents of water. On the borders of every glacier are seen on either side mounds, or taluses of rubbish, consisting of angular fragments of rock, with large heaps of sand and mud. At certain distances from each side, and often in the centre, ridges composed of similar debris from three to twelve feet in height, are observable. Each of these has originated, like the lateral mounds, in the form of a talus accumulated at the foot of a steep slope or precipice. Frost, rain, lightning, and avalanches of snow are constantly detaching fragments of rock and soil which fall or roll down to the bottom of such precipices. If the base of the heap of loose materials were washed by a river, it would soon be undermined and swept away, but when this fallen matter reaches the edge of a glacier, which is always moving onward night and day at the rate of several inches, or sometimes a foot or two in twenty-four hours, the whole talus becomes locomotive, and is changed into a long stream of blocks and earthy matter, fringing the glacier on both sides, and constituting what are called lateral moraines. As often as glaciers are conflu ent, the right lateral moraine of one blends with the left moraine of the other, and both are then carried down in the middle of the mass 
of ice produced by the union of the two glaciers, forming what is called a medial moraine. The number and position of these moraines will depend on the number and size of the tributary glaciers which join the main one. By such machinery, not only small stones and earth, but erratic blocks of the largest size, are carried down from the mountains to the lower valleys and plains, performing a journey of twenty or thirty miles in the course of several centuries, and usually retaining their edges sharp and unworn to the last.

When the glacier passes over uneven ground, it becomes rent, and traversed by broad and deep transverse fissures, into which portions of the lateral or medial moraines are precipitated. Rills of water also, derived from the liquefaction of the ice by the sun's rays in summer, run over the surface of the glacier until, arriving at one of these fissures, they cascade into it. From this source, as well as from springs, which must occasionally break out under the glacier, are derived torrents which flow under the ice in tunnels, where the angular stones which have fallen to the bottom through the fissures often become rounded, as in the ordinary bed of a river, Other blocks and pebbles, being fixed in the ice, and firmly frozen into it, are pushed along the bottom of the glacier, abrading, polishing, and grooving the rocky floor below, while each stone is reciprocally flattened, polished, and striated on its lower side. As the forces of downward pressure and onward propulsion are enormous, each small grain of sand, if it consists of quartz or some hard mineral, scratches and polishes the surface, whether of the underlying rock or of the boulder which impinges on it, as a diamond cuts glass or as emery powder polishes steel. The striæ which are made, and the deep grooves which are scooped out by this action, are rectilinear and parallel to an extent never seen in those produced on loose stones or rocks, where shingle is hurried along by a torrent, or by the waves on a sea-beach.

As water is always flowing under some parts of a glacier, and much melting and regelation are going on in different places, stones are liable to change their position, in which case a second set of striæ and furrows may be imprinted in a new direction, or another side of the stone becomes, in its turn, flattened, striated, and polished. In like manner the solid rock underneath the glacier may exhibit scratches and grooves in more than one direction. The furrows will, most of them, coincide with the general course of the ralley; but as the ice in different seasons varies in quantity, the direction of its motion at any giren point is not uniform, so that the groores and scratches will also vary, one set often intersecting another.

When a Swiss glacier, laden with mud and stones, descends so far as to reach a region about 3500 feet above the level of the sea, the warmth of the air is such that it melts rapidly in summer, and in spite of the downward movement of the mass, it can advance no farther. Its precise limits are variable from year to year, and still more so from century to century; one example being on record of a recession of 
half a mile in a single year. We also learn from M. Venetz, that whereas, between the eleventh and fifteenth centuries, all the Alpine glaciers were less advanced than now, they began in the seventeenth

Fig. 128

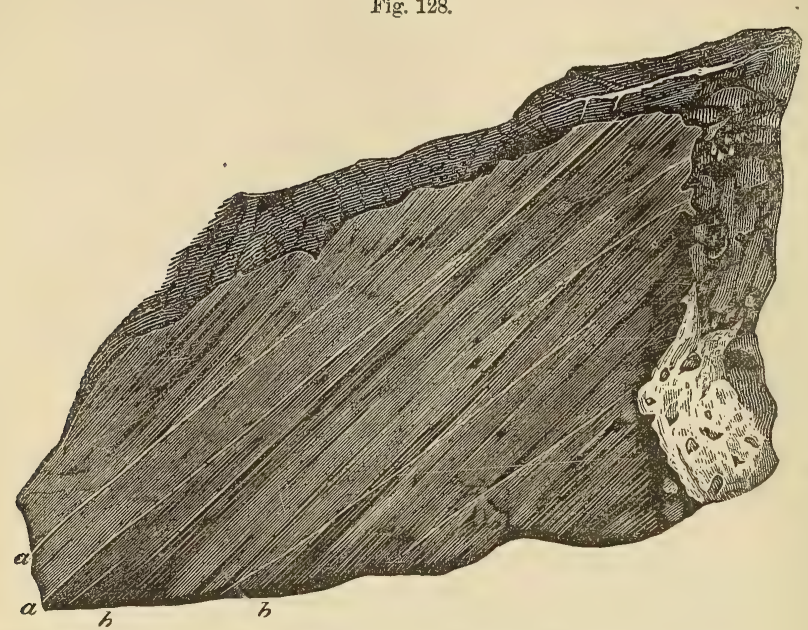

Limestone polished, furrowed, and scratched by the glacier of Rosenlaui, in Switzerland. (Agassiz.)

$a$ a. White streaks or scratches, caused by small grains of flint frozen into the ice.

$b$ b. Furrows.

and eighteenth centuries to push forward, so as to cover roads formerly open, and to overwhelm forests of ancient growth.

These oscillations enable the geologist to note the marks which a glacier leaves behind it as it retrogrades; and among these the most prominent is the terminal moraine, which is a confused heap of unstratified rubbish, like the till before described; all the mud, sand, and pieces of rock, with which the glacier was loaded, having been slowly deposited in the same spot where no running water interfered to sort them, by carrying the smaller and lighter particles and stones farther than the bigger and heavier ones. These terminal moraines often cross the valley in the form of transverse mounds, more or less divided into separate masses or hillocks by the action of the torrent which flows out from the end of the glacier. Such transverse barriers were formerly pointed out by Saussure, below the glacier of the Rhone, as proving how far it had once transgressed its present boundaries. On these moraines we see many large angular fragments, which, having been carried along on the surface of the ice, have not had their edges worn off by friction; there are also many boulders, of various sizes, which have been rounded; some, as before stated, by the power of water beneath the glacier, others by the mechanical force of the ice which has pushed them against each other, or against the rocks flanking the valley.

As the terminal moraines are the most prominent of all the monu- 
ments left by a receding glacier, so are they the most liable to obliteration; for violent floods or debacles are often occasioned in the Alps by the sudden bursting of what are called glacier-lakes. These temporary sheets of water are caused by the damming up of a river by a glacier which has increased during a succession of cold seasons, and descending from a tributary into the main valley, has crossed it from side to side. On the failure of this icy barrier, the accumulated waters are let loose, which sweep away and level many a transverse mound of gravel and loose boulders below, and spread their materials in confused and irregular beds over the river-plain.

In addition to the polished, striated, and grooved surfaces of rock already described, another mark of the former action of a glacier is, the "roche moutonnée." Projecting eminences of rock so called have been smoothed and worn into the shape of flattened domes by the glacier as it passed over them.

Although the surface of almost every kind of rock, when exposed in the open air, wastes away by decomposition, yet some retain for ages their polished and furrowed exterior; and, if they are well protected by a covering of clay or turf, these marks of abrasion seem capable of enduring for ever. They have been traced in the Alps to great heights above the present glaciers, and to great horizontal distances beyond them.

There are also found, on the sides of the Swiss valleys, rounc and deep holes with polished sides, such holes as waterfalls make in the solid rock, but in places remote from running waters, and where the form of the surface makes it difficult to suppose that any cascade could ever have existed. Similar cavities are common in hard rocks, such as gneiss in Sweden, where they are called giant caldrons, and are sometimes ten feet and more in depth; but in the Alps and Jura they often pass into spoon-shaped excavations and prolonged gutters. We learn from M. Agassiz that hollows of this form are now cut out by streams of water which, after flowing along the surface of a glacier, fall into open fissures in the ice and form a cascade. Here the fallen water, causing the gravel and sand at the bottom to rotate, cuts out a round eavity in the rock. But as the glacier moves on, the cascade becomes locomotive, and what would otherwise have been a circular hole is prolonged into a deep groove. The form of the rocky bottom of the ralley down which the glacier is moving causes the rents in the ice and these locomotive cascades to be formed again and again, year after year, in exactly the same spots.

Another effect of a glacier is to lodge a ring of stones round the summit of a conical peak, or a single block on a sharp ridge, which may happen to project through the ice. If the glacier is lowered greatly by melting, these blocks or circles of large angular fragments, which are called "perched blocks," are left in a singular situation at or near the top of a sharp pinnacle or ridge, the lower parts of which may be destitute of boulders. 
Alpine blocks on the Jura.-Some or all the marks above enumerated-the moraines, erratics, polished surfaces, domes, striæ, caldrons, and perched rocks-are observed in the Alps at great heights above the present glaciers, and far below their actual extremities; also in the great valley of Switzerland, fifty miles broad; and almost everywhere on the Jura, a chain which lies to the north of this valley. The average height of the Jura is about one-third that of the Alps, and it is now entirely destitute of glaciers; yet it presents almost everywhere simular moraines, and the same polished and grooved surfaces and water-worn cavities. The erratics, moreover, which cover it, presents a phenomenon which has astonished and perplexed the geologist for more than a half a century. No conclusion can be more incontestable than that these angular blocks of granite, gneiss, and other crystalline formations, came from the Alps, and that they have been brought for a distance of fifty miles and upward across one of the widest and deepest valleys in the world; so that they are now lodged on the hills and valleys of a chain composed of limestone and other formations, altogether distinct from those of the Alps. Their great size and angularity, after a journey of so many leagues, has justly excited wonder; for hundreds of them are as large as cottages; and one in particular, composed of gneiss, celebrated under the name of Pierre à Bot, rests on the side of a hill about 900 feet above the lake of Neufchatel, and is no less than 40 feet in diameter.

In the year 1821, M. Venetz first announced his opinion that the Alpine glaciers must formerly have extended far beyond their present limits, and the proofs appealed to by him in confirmation of this doctrine were afterward acknowledged by M. Charpentier, who strengthened them by new observations and arguments, and declared, in 1836, his conviction that the glaciers of the Alps must once have reached as far as the Jura, and have carried thither their moraines across the great valley of Switzerland. M. Agassiz, after several excursions in the Alps with M. Charpentier, and after devoting himself for some years to the study of glaciers, published, in 1840, an admirable description of them and of the marks which attest the former action of great masses of ice over the entire surface of the Alps and the surrounding country.*

M. Charpentier conceived that the Alps, at the time when the glaciers extended continuously from them to the Jura, and conveyed to them so many Alpine erratics, where 2000 or 3000 feet higher than now. Professor James D. Forbes, in his excellent work on the Alps, published in 1843 , came in like manner to the conclusion that the ancient glaciers were of colossal size, and had once stretched from the principal chain to the Jura. The original theory of Saussure, that the erratics were all whirled along to great distances by a rapid current of

* Agassiz, Études sur les Glaciers, and Système Glacière. 
muddy water rushing from the Alps, has long been exrloded; and the hypothesis of the submergence of Switzerland beneath the waters of the sea, and the transportation of moraines and erratic blocks on ice-rafts or floating icebergs from the Alps to the Jura, then an island - a view to which I myself formerly leaned-has been disproved by a careful study of the present distribution of the travelled masses. Their arrangement, both on the north and south of the great chain, whether in the Pays de Vaud and Jura or in the plains of the Po, is such as to imply that they were transported to their present sites by glaciers of enormous size descending by the existing valleys at a time when all the great lakes were filled with ice, or, in other words, formed parts of these same glaciers. The entire absence of marine shells from the old glacial drift of Switzerland, and of the Alps generally, is confirmatory of this theory, and against the doctrine of a marine submergence. The moraine-like arrangement of the boulders has also led the most experienced Swiss and Italian geologists, who have of late years devoted much time and talent to the study of this subject, to adopt the same hypothesis of land-glaciers. Among other writers I may mention MM. Studer, Guyot, Escher von der Linth, Morlot, Gastaldi, Gabriel de Mortillet, Omboni, and others.

It has been stated that the boulder formation and all the attendant phenomena of striated and dome-shaped rocks and far-transported erratics become more and more conspicuous in proportion as we extend our survey to higher latitudes. We find, for example, a characteristic display of them in Norway, Sweden, and Denmark, the southern borders of the Baltic or Northern Germany, European Russia, and Finland. They are also observable in the mountainous regions of Scotland, Wales, and of the British Isles generally. But, besides the appearances already noticed, there occur here and there in the countries just alluded to, deposits of marine fossil shells, strictly belonging to the glacial period, which exhibit so arctic a character that they must have led the geologist to infer the former prevalence of a much colder climate, even had he not encountered so many accompanying signs of ice-action. The same marine shells demonstrate the submergence of large areas in Scandinavia and the British Isles, and other regions, during parts of the glacial epoch.

A characteristic feature of the deposits under consideration in all these countries is the occurrence of large erratic blocks and sometimes of moraine matter, in situations remote from lofty mountains, and separated from the nearest points where the parent rocks appear at the surface by great intervening valleys, or arms of the sca. Such appearances require us to suppose important geographical changes of a date subsequent to the drift. But even where the land does not seem to have undergone much local alteration, such as would result from upheaval and subsidence, we often obscrve striæ and furrows, as in Norway, Sweden, and Scotland, which are not in strict accordance with the direction of any separate glaciers, which can be supposed to have 
once descended through existing valleys. Many of the markings referred to deviate from the direction which they ought to follow if they had been connected with the present line of drainage, and they, therefore, imply the prevalence of a very distinct condition of things at the time when the cold was most intense. The actual state of the Continent of North Greenland seems to afford the best explanation of such abnormal glacial markings.

Of that country a faithful description has been given to us by Rink, now governor of the Danish Settlements in Baffin's Bay, who has, more than any other scientific traveller, explored both the coast and the interior.* The land, he says, may be divided into two regionsthe inland and the outskirts. The inland is 800 miles from west to east, and of much greater length from north to south. It is a vast unexplored continent, buried under one continuous and colossal mass of ice that is always moving seaward,' a very small part of it in an easterly direction, and all the rest westward, or toward Baffin's Bay. All the minor ridges and valleys are levelled and concealed under a general covering of snow, but here and there some steep mountains protrude abruptly from the icy slope, and a few superficial lines of stones or moraines are visible at certain seasons, when no snow has fallen for many months, and when evaporation, promoted by the wind and sun, has caused much of the upper snow to disappear. After penetrating a great distance eastward in lat. $72^{\circ} \mathrm{N}$., Rink still saw lines of these stones in the extreme distance, indicating, he says, the existence of precipitous mountains, piercing through the snow still farther east. The height of this continent is unknown, but it must be very great, as the most elevated lands of the outskirts which are described as comparatively low, attain altitudes of 4000 and 6000 feet. The icy slope gradually lowers itself toward the outskirts, and then terminates abruptly in a mass about 2000 feet in thickness, the great discharge of ice taking place through certain large friths which, at their upper ends, are usually about four miles across. Down these friths the ice is protruded in huge masses, several miles wide, which continue their course - grating along the rocky bottom like ordinary glaciers long after they have reached the salt water. When at last they arrive at parts of Baffin's Bay deep enough to buoy up icebergs from 1000 to 1500 feet in vertical thickness, broken masses of them float off, carrying: with them on their surface not only fine mud and sand but large stones. These fragments of rock, as I am informed by Dr. Otto Torell, who has examined many of the bergs after they had run aground, are often polished and scored on one or more sides, and as the ice melts, they drop down to the bottom of the sea, where large quantities of mud are deposited, and this muddy bottom is inhabited by many mollusca.

* Rink, Journal of Royal Geograph. Soc., vol. xxiii. p. 145, and Lyell, Antiquity of Man, p. 235. 
The outskirts, where the Danish colonists are settled, comprise an area of 30,000 square miles in extent, including many islands and peninsulas, and some fiords from 50 to 100 miles long, down which the ice passes, either floating or sometimes, as already stated, in contact with the bottom. Rink counted twenty-two great ice-streams along the coast, which indicate the position of as many concealed valleys or straths, by which relief is given to the snow and ice annually accumulating in the interior. From the same points the principal glaciers or rivers would issue if, at some future period, there should be a milder climate. But although the direction of the ice-streams in Greenland may concide in the main with that which separate giaciers wonld take if there were no more ice than there is now in the Swiss Alps, yet the striation of the surface of the rocks on an ice-clad continent would, on the whole, vary considerably in its minor details from that which would be imprinted on rocks constituting a region of separate glaciers. For where there is a universal covering of ice there will be a general outward movement from the higher and more central regions toward the circumference and lower country, and this movement will be, to a certain extent, independent of the minor inequalities of hill and valley, when these are all reduced to one level by the snow. The moving ice may sometimes cross even at right angles deep narrow ravines, or the crests of buried ridges, on which last it may afterward seem strange to detect glacial striæ and polishing after the liquefaction of the snow and ice has taken place.

Rink mentions that, in North Greenland, powerful springs of clayey water escape in winter from under the ice, where it descends to " the outskirts," and where, as already stated, it is often 2000 feet thick-a fact showing. how much grinding action is going on upon the surface of the subjacent rocks. I also learn from Dr. Torell that there are large areas in the outskirts, now no longer covered with permanent snow or glaciers; which exhibit on their surface unmistakable signs of ancient ice-action, so that, vast as is the power now exerted by ice in Greenland, it must once have operated on a still grander scale. The land, though now very elevated, may perhaps have been formerly much bigher. This, indeed, is more than probable, as, ever since the country has been known to the Danes, or for the last four centuries, the whole coast, from latitude $60^{\circ}$ to about $70^{\circ}$ $\mathrm{N}$. has been sinking at the rate of several feet in a century. By this means a surface of reck, well scored and polished by ice, is now slowly subsiding beneath the sea, and is becoming strewed orer, as the icebergs melt, with impalpable mud and smoothed and scratched stones.

When we contemplate, therefore, the effects which are now in progress in North Greenland and on its shores, as well as in the bed of the adjoining sea, under the influence of the ice, both of glaciers and floating bergs, combined with a rertical morement of the continent 
and floor of the ocean, which is now one of subsidence, but which may at some future time be converted into one of upheaval, we are presented with a key to the interpretation of many distinct classes of glacial phenomena once regarded as most enigmatical.

An account was given so long ago as the year 1822, by Scoresby, of icebergs seen by him in the Arctic seas drifting along in latitudes $69^{\circ}$ and $70^{\circ} \mathrm{N}$., which rose above the surface from 100 to 200 feet, and some of which measured a mile in circumference. Many of them were loaded with beds of earth and rock, of such thickness that the weight was conjectured to be from 50,000 to 100,000 tons. A similar transportation of rocks is known to be in progress in the southern hemisphere, where boulders included in ice are far more frequent than in the north. One of these icebergs was encountered in 1839 , in mid-ocean, in the antarctic regions, many hundred miles from any known land, sailing northward, with a large erratic block firmly frozen into it. In order to understand in what manner long and straight grooves may be cut by such agency, we must ramember that these floating islands of ice have a singular steadiness of motion, in consequence of the larger portion of their bulk being sunk deep under water, so that they are not perceptibly moved by the winds and waves even in the strongest gales. Many had supposed that the magnitude commonly attributed to icebergs by unscientific navigators was exaggerated, but now it appears that the popular estimate of their dimensions has rather fallen within than beyond the truth. Many of them, carefully measured by the officers of the French exploring expedition of the Astrolabe, were between 100 and 225 feet high above water, and from two to five miles in length. Captain d'Urville ascertained one of them which he saw floating in the Southern Ocean to be 13 miles long and 100 feet high, with walls perfectly vertical. The submerged portions of such islands must, according to the weight of ice relatively to sea-water, be from six to eight times more considerable than the part which is visible, so that when they are once fairly set in motion, the mechanical force which they might exert against any obstacle standing in their way would be prodigious.* A considerable proportion of these floating masses of ice is supposed not to be derived from terrestrial glaciers, but to be formed at the foot of cliffs by the drifting of snow from the land over the frozen surface of the sea, the snow by repeated melting and regelation being in time converted into ice. But most of the bergs of the Southern Ocean are formed in the same way as the principal ones in Baffin's Bay ; for Dr. Hooker informs me that the ice of the Antarctic Continent, or Victoria Land, like that of Greenland, as described by Rink, is strewed over with rocky fragments, there being always some bare precipices and mountain peaks protruding from the great wilderness of snow from which moraines may be derived. These moraines are

* T. L. Hayes, Boston Journ. Nat. Hist., 1844. 
carried down to the coast and then floated northward on detached icebergs to great distances.

We learn, therefore, from a study both of the arctic and antarctic regions, that a great extent of land may be entirely covered throughout the whole year by snow and ice, from the summits of the loftiest mountains to the sea coast, and may yet send down angular erratics to the ocean. We may also conclude that such land will become in the course of ages almost everywhere scored and polished like the rocks which underlie a glacier. The discharge of ice into the surrounding sea will take place principally through the main valleys, although these are hidden from our sight. Erratic blocks and moraine matter will be dispersed somewhat irregularly after reaching the sea, for not only will prevailing winds and marine currents govern the distribution of the drift, but the shape of the submerged area will have its influence; inasmuch as floating ice, laden with stones, will pass freely through deep water while it will run aground where there are reefs and shallows. Some icebergs in Baffin's Bay have been seen stranded on a bottom 1000 or even 1500 feet deep. In the course of ages such a sea-bed may become densely covered with transported matter, from which some of the adjoining greater depths may be free. If, as in West Greenland, the land is slowly sinking, a large extent of the bottom of the ocean will consist of rock polished and striated by land-ice, and then overspread by mud and boulders detached from melting berg's. But other large areas of the bed of the sea will also be marked by the repeated friction of masses of floating ice, some of them several miles in diameter, which, when they strand on a gently shelving reef, must grate along the bottom for some distance before their course is arrested. The plasticity of ice, or its capability, by whatever theory explained, of moulding itself suddenly into new forms under great pressure, is so remarkable, that when enormous masses of it are floating, and moving at the rate of two or more miles an hour, they must, on arriving at a shelving floor of rock, adapt their forms to its surface, and often be forced with violence into any cavities which the uneven bottom may present. Before the momentum of so vast a volume of matter can be overcome, the ice, moving with what may be called great relocity, when contrasted with the insensible progress of a glacier, must give rise to no small trituration of rock. This will be the more sure to happen, because the largest bergs, by their uncqual rate of melting above and below water, are continually capsizing; the centre of gravity often shifting; and by such changes the supcrficial moraines, often firmly frozen into the ice, are carried down to form the base of the iceberg, and supply sand and stones for polishing and scouring the occan's floor. The submarine strix and groores may be as uniform in their direction, and as parallel as those scooped out by glaciers in an inland valley; for in the same tracts the floating ice-islands will annually take the same course at corresponding seasons of the jear, being carried by similar winds and currents 
in the same direction. Their vast size also must often tend to give an uniformity to their scoring action, over a space several miles in width. Could we imagine buildings such as St. Peter's or St. Paul's to be submerged, and an iceberg, several miles in diameter and two thousand feet in height, advancing with the velocity of two or three miles an hour to strike them, it is evident they must be thrown down as readily as were the stone walls of the peasants' chalets in the early part of the present century by the Görner glacier above Zermatt. We may, therefore, fairly presume that whenever a submerged area which had once been traversed by floating and occasionally stranding icebergs is converted into land by upheaval, it will display on its surface most of the characteristics which mark the former agency of glaciers on dry land. No sharp pinnacles of rocks can be left standing, since they will all have been worn down and reduced to domeshaped masses, while scratches and long grooves will everywhere be left on rocky surfaces. Even till, or unstratified matter, undistinguishable from ordinary moraines, will rarely be wanting.

Those who have had opportunities of inspecting, in the sea off the coast of Labrador, packs of icebergs which have run aground in water having sometimes a depth of many hundred feet, describe lagoon-like expanses of sea perfectly quiet, and free from all agitation of the waves of the Atlantic. These areas of still water are surrounded on all sides by icebergs from 100 to 300 feet high, frequently containing moraine matter on their surface, or frozen into them. Such icy masses may remain aground for weeks or months, until they are reduced by melting to a size which admits of their floating off and resuming their wanderings. The mud, sand, and boulders which they let fall in still water must be exactly like the moraines of terrestrial glaciers, devoid of stratification and organic remains. But occasionally, on the outer side of such packs of stranded bergs, the waves and currents may cause the detached earthy and stony materials to be sorted according to size and weight before they reach the bottom, and to acquire a stratified arrangement.

I have already alluded (p. 146) to the large quantity of ice, containing great blocks of stone, which are sometimes seen floating far from land, in the southern or Antarctic seas. It is evident that such glacial drift, wherever it may happen to alight on the floor of the ocean, will have no connection with the external shape, or internal composition, of the rocks on which it may chance to fall. After the emergence, therefore, of such a submarine area, the superficial detritus will have no necessary relation to the hills, valleys, and river-plains over which it will be scattered. Many a water-shed may intervene between the starting-point of each erratic or pebble and its final resting-place, and the only means of discovering the country from which it took its departure will consist in a careful comparison of its mineral or fossil contents with those of the parent rocks.

It will be seen in the next chapter that throughout large parts of 
Scotland, Scandinaria, and other countries, the till and boulders are so connected in mineral and lithological character with the struoture of the hills and valleys belonging to the hydrographical basins over which they are strown, that they must have been produced by landglaciers, although in the same regions drift of submarine origin is occasionally met with.

\section{CHAPTER XII.}

POST-PLIOCENE PERIOD, CONTINUED.-GLACIAI EPOCH, CONCLUDED.

Glaciation of Scandinavia and Russia-Glaciation of Scotland-Marine shells in Seotch glacial drift-Their Aretic character-Rarity of organic remains in glacial deposits-Contorted strata in drift-Glaciation of Wales, England, and Ireland-IIarine shells of Moel Tryfaen-Norfolk drift-Glacial formations of North America-How far of submarine origin-Many species of testacea and quadrupeds survived the glacial cold-Connection of the predominance of lakes with glacial action-Morainic lakes-Objections to the hypothesis of the erosion of large lake-basins by ice-Conversion of valleys of denudation into lakes by upward and downward movements-Action of ice in preventing the silting-up of lake-basins-How the bed of a sea where icebergs have abounded may, on emergence, afford lake-basins-General causes of change of climate-Submergence of the Sahara in the Post-pliocene period a cause of Alpine cold-Meteorites in drift.

HAVING in the last chapter described the permanent effects which continental ice, glaciers, and icebergs imprint on the surface, I shall now proceed to describe some of the geological monuments of iceaction of more ancient date, or of the Post-pliocene period, observble in Europe and North America.

Glaciation of Scandinavia and Russia.-In. large tracts of Norway and Sweden, where there have been no glaciers in historical times, the signs of ice-action have been traced as high as 6000 feet above the lerel of the sea. These signs consist chiefly of polished and furrowed rock surfaces, of moraines and erratic blocks. The direction of the erratics, like that of the furroms, has usually been conformable to the course of the principal valleys; but the lines of both sometimes radiate outward in all directions from the highest land, in a manner which is only explicable by the hypothesis of a general envelope of continental ice, like that of Greenland, noticed in the last chapter. Some of the far-transported blocks have been carried from the central parts of Scandinaria toward the Polar regions; others southward to Denmark; some southwestward, to the coast of Norfolk in England; others southeastward, to Germany, Poland, and Russia, and to these same countries small stones and finer matter 
have also been conveyed, evidently by the aid of floating ice. The southern and southeastern limits of this drift have been well marked out by Sir Roderick I. Murchison and his fellow-laborers, M. de Verneuil and Count Keyserling, in a map illustrating their great work on the geology of Russia; and they have pointed out how this drift "proceeded eccentrically from a common central region."

It appears from their observations that the blocks, scattered over large districts of Russia and Poland, agree precisely in mineral character with rocks of the mountains of Lapland and Finland; while the masses of gneiss, syenite, porphyry, and trap, strewed over the low sandy countries of Pomerania, Holstein, and Denmark, are identical in their composition with the mountains of Norway and Sweden.

It is found to be a general rule in Russia, that the smaller blocks are carried to greater distances from their point of departure than the larger; the distance being sometimes 800 , and even 1000 , miles from the nearest rocks from which they were broken off; the direction having been from N.W. to S.E., or from the Scandinavian mountains over the seas and low lands to the southeast. That its accumulation throughout this area took place in part during the Post-pliocene period, is proved by its superposition at several points to strata containing recent shells. Thus, for example, in European Russia, Sir R. Murchison and his associates found, in 1840, that the flat country between St. Petersburg and Archangel, for a distance of 600 miles, consisted of horizontal strata, full of shells similar to those now inhabiting the Aretic Sea, and on these rested the boulder formation, containing large erratics.

In Sweden, in the immediate neighborhood of Upsala, I had observed, in 1834, a ridge of stratified sand and gravel, in the midst of which occurs a layer of marl, evidently formed originally at the bottom of the Baltic, by the slow growth of the mussel, cockle, and other marine shells of living species, intermixed with some proper to fresh water. The marine shells are all of dwarfish size, like those now inhabiting the brackish waters of the Baltic; and the marl, in which myriads of them are imbedded, is now raised more than 100 feet above the level of the Gulf of Bothnia. Upon the top of this ridge repose several huge erratics, consisting of gneiss for the most part unrounded, from 9 to 16 feet in diameter, and which must have been brought into their present position since the time when the neighboring gulf was already characterized by its peculiar fauna." Here, therefore, we have proof that the transport of erratics continued to take place, not merely when the sea was inhabited by the existing testacea, but when the north of Europe had already assumed that remarkable feature of its physical geography, which separates the Baltic from the North Sea, and causes the Gulf of Bothnia to have only one-fourth of the saltness belonging to the ocean. In Den-

* See paper by the Author, Phil. Trans., 1835, p. 15. 
mark, also, recent shells have been found in stratified beds, closely associated with the boulder clay.

It was stated that in Russia the erratics diminished generally in size in proportion as they are traced farther from their source. The same observation holds true in regard to the average bulk of the Scandinavian boulders, when we pursue them southward, from the south of Norway and Sweden through Denmark and Westphalia. This phenomenon is in perfect harmony with the theory of ice-islands floating in a sea of variable depth; for the heavier erratics require iceberg's of a larger size to buoy them up; and, even when there are no stones frozen in, more than seven-eighths, and often nine-tenths, of a mass of drift-ice is under water. The greater, therefore, the volume of the iceberg, the sooner would it impinge on some shallower part of the sea; while the smaller and lighter floes, laden with finer mud and gravel, may pass freely over the same banks, and be carried to much greater distances. In those places, also, where in the course of centuries blocks have been carried southward by coast-ice, having been often stranded and again set afloat in the direction of a prerailing current, the blocks will diminish in size the farther they travel from their point of departure, for two reasons : first, because they will be repeatedly exposed to wear and tear by the action of the wares; secondly, because the largest blocks are seldom without divisional planes or "joints," which cause them to split when weathered. Hence, as often as they start on a fresh royage, becoming buoyant by coast-ice which has frozen on to them, one portion of the mass is detached from the rest. An examination which I made in 1852 of several trains of huge erratics in lat. $42^{\circ} 50^{\prime} \mathrm{N}$. in the United States, in Berkshire, on the western confines of Massachusetts, has convinced me that this cause has been rery influential both in reducing the size of erratics, and in restoring angularity to blocks which might otherwise be rounded in proportion to their distance from their original starting-point.

Glaciation of Scotland.-Professor Agassiz, after visiting Scotland in 1840, came to the opinion that the Grampians had been covered by a rast thickness of ice, and had once, like the Alps, been an independent centre, whence erratic blocks were dispersed in all directions. Mr. Robert Chambers, in 1848, maintained in like manner that Scotland had once been "moulded in ice," which had everywhere smoothed and scratched the rocks, and ground them down so as to enlarge and widen many ralleys. Mr. T. F. Jamieson, following up the same line of investigation in 1858 , adduced a great body of additional facts to prore that the Grampians once sent down glaciers from the central regions in all directions torard the sea. "The glacial grooves" he observed, "radiate outward from the central heights toward all points of the compass, although they do not always strictly conform to the actual shape and contour of the minor valleys and ridges."

In many parts of Scotland, and conspicuously in the basin of the 
Forth, there is a form of hill to which Sir James Hall gave the name of "Crag-and-Tail." Isolated ice-worn hills, or knolls, present polished faces to the west and northwest in the district alluded to, with rough declivities to the east and southeast, or where the tail occurs. It is a common error, says Mr. Geikie, to suppose that this "tail" consists merely of detritus, heaped up on the lee side of each hill, for often it is composed in great part, like the west side or "crag," of solid rock, but usually with a considerable corering of boulder clay.*

According to Mr. T. F. Jamieson, on extending our survey of Scotland we find many examples of such "crag," or natural escarpments, facing the inland country, or that from which we may suppose a mass of continental ice to have descended, whereas the "tail" or mound of sand, and boulders, occupies the seaward side. It has also been remarked in Scandinavia that abrupt protuberances and outstanding ridges of rock are often polished and furrowed on the side facing the region from which the erratics have come (usually on the north side in Norway); while on the other, or "lee side," such superficial markings are wanting. There is usually a collection on this lee side of boulders and gravel, or of large angular fragments. In explanation, we may imagine that the north side was exposed, when still submerged, to the action of icebergs, and afterwards, when the land was rising, of coast-ice, which ran aground upon shoals, so that there would be great wear and tear on that exposed side, whereas on the opposite or south slope, gravel and boulders might accumulate in a sheltered position.

The facts above alluded to, and other characteristics of the Scotch drift, led Mr. Jamieson to infer, first, that in the early part of the -glacial period Scotland stood much higher than at present, so that there was a general covering of snow and ice, which, as it slid down to lower levels, polished the subjacent rocks, and swept off from the surface most of the preëxisting alluvium, leaving in its place till and boulders in various parts. Secondly, that to this succeeded a period of depression and partial submergence, when the sea advanced and gradually covered the greater part of the country, when floating ice abounded, and when some marine drift with arctic shells was deposited. Thirdly, that the land reëmerged from the water, and, reaching a level somewhat above its present heights, became connected with the Continent of Europe, glaciers being formed once more in the higher regions, though the ice probably never regained its former extension. $\dagger$ After all these changes, there were some minor oscillations in the level of the land, on which, although they have had important geographical consequences, separating Ireland from England, for example, and England from the continent, we need not here enlarge.

* Glacial Drift of Scotland; Glasgow, 1863, p. 30.

† Quart. Geol. Journ., 1860, vol. xvi. p. 370 
Mr. Geikie has arrived at the same general conclusions as Mr. Jamieson, with respect to the principal movements of the land in Scotland. The great mass of till, of which in some of the lower rallers the thickness exceeds 150 feet, he attributes not to icebergs, but to ice action on land, for it consists of the debris of rocks, everywhere found in situ in the same hydrographical basin. The absence of marine shells is at once accounted for if we assume it to be of glacier origin. The rarity of angular stones, those in the till being. usually rounded or sub-angular, and the number of fragments polished and striated on one or several sides, may also be explained by supposing the till to have been shored along under a heary mass of ice, like that of Greenland, instead of forming parts of superficial moraines, carried down without trituration on the top of the ice. If, in accordance with the riews above set forth, we admit a second glacial period, when the land was reëlerated after the great submergence, the action of ice at this later date may well be supposed to have obliterated almost all signs of the sojourn of the sea upon the land in the highest regions, where the cold was most intense; but in the lower countrr, some patches of marine strata with arctic shells might more easily escape destruction.

The greatest height to which marine shells have yet been traced in Scotch drift is only 524 feet above the level of the sea, at which eleration they have been observed at Airdrie, fourteen miles southeast of Glasgow. At that spot they were found imbedded in stratified clays with till abore and below them. There appears no doubt that the overlying deposit was true glacial till, as some boulders of granite were observed in it, which must have come from distances of sixty miles at the least.*

Fig. 129.

Astarte borealis.

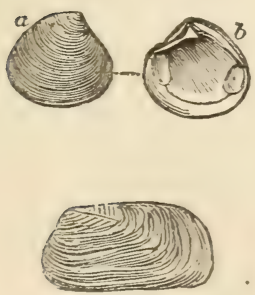

Fig. 131.

Saxicaiva rugosa.

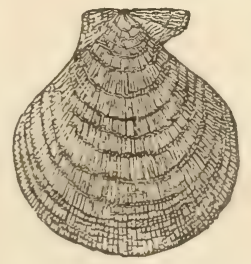

Fig. 132.
Fig. 130.

Leda oblonga.

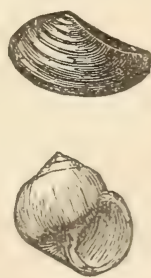

Fig. 133.

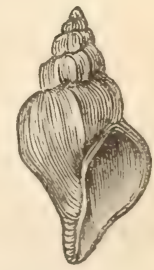

Fig. 134

Pecten islandicus. Natica clausa. Trophon clathratum. Northern shells common in the drift of the Clyde, in Scotland.

The shells here figured are only a few out of a large assemblage of living species, which, taken as a whole, bear testimony to conditions far more arctic than those now prevailing in the Scottish seas. But

* Smith, of Jordan Hill, Geol, Quart. Journ., vol, vi. p. 387. 1850. 
a group of marine shells, indicating' a still greater excess of cold, has been brought to light since 1860 by the Rev. Thomas Brown, from glacial drift or clay on the borders of the estuaries of the Forth and Tay. This clay occurs at Elie in Fife, and at Errol in Perthshire; and has already afforded about 35 shells, all of living species, and now inhabitants of arctic regions, such as Leda truncata, Tellina proxima (see figures below), Pecten Groenlandicus, Crenella lavigata, Gray, Crenella nigra, Gray, and others, some of them first brought by Captain Sir E. Parry from the coast of Melville Island, latitude $76^{\circ}$ N. These were all identified in 1863 by Dr. Torell, who had just returned from a survey of the seas around Spitzbergen, where he had collected no less than 150 species of mollusca, living chiefly on a bottom of fine mud derived from the moraines of melting glaciers which

Fig. 135 .

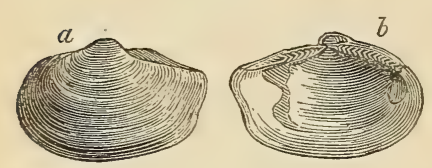

Leda truncata.

a. Exterior of left valve. b. Interior of same.
Fig. 136.

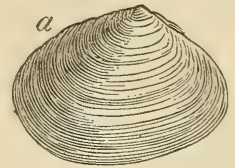

Tellina proxima.

a. Outside of left valve.

b. Interior of same.

there protrude into the sea. He informed me that the fossil fauna of this Scotch glacial deposit exhibits not only the species but also the peculiar varieties of mollusca now characteristic of very high latitudes. Their large size implies that they formerly enjoyed a colder, or what was to them a more genial climate, than that now prevailing: in the latitude where they occur. Marine shells have also been found in the glacial drift of Caithness and Aberdeenshire at heights of 250 feet, and in Banff of 350 feet, and stratified drift continmous with the above ascends to heights of 500 feet. There are, likewise, other deposits in Scotland very similar in character but devoid of shells more than 1000 feet high, resting on rocks groored and polished by ice-action. The want of marine shells in these last has naturally inclined some geologists to suspect that they may have been deposited in glacier lakes, and this opinion may be correct, although on this subject there is no small danger of drawing false conclusions from negative evidence, so partially do organic remains occur in glacial formations even in those of indubitably marine origin. When the gravel and sand are of a porous nature, we can easily account for the decomposition of the shells and their total disappearance in the course of thousands of years, but a large part of the Scotch till is so impervious to water that the absence of fossil testacea leads us rather to suspect that it was originally the moraine of a terrestrial glacier, and, therefore, from the first devoid of shells.

I formerly suggested that the absence of all signs of organic life in 
a great portion of this drift might be conmected with the severity of the cold, and also in some places with the depth of the sea during: the period of extreme submergence; but my faith in such an hypothesis has been shaken by modern investigations, an exuberance of life haring been obserred both in arctic and antarctic seas of great clepth, and where floating ice abounds. Thus, Dr. Hooker enumerates crustacea, mollusca, serpulæ, and other invertebrata, at depths of 200 and 400 fathoms off Victoria Land, between latitudes $71^{\circ}$ and $7 \mathrm{~S}^{\circ} \mathrm{S}$., and animal life was traced eren to a depth of 550 fathoms; whilst ML. Torell and Chydenius in 1861 obtained mollusca, between Spitzbergen and Norway, at the enormous depths of 1000 and 1500 fathoms, the temperature of the mud being between $32^{\circ}$ and $33^{\circ}$ Fahrenheit.

We have seen that the scoring and polishing of the rocks in Scotland, as in Sweden and elsewhere, is not confined to the land, but is seen to pass under the sea, the same furrows being so continuous as to imply that glaciers or continental ice once acted on a surface now submerged. Mr. Geikie observes that, on the rest coast of Scotland, these glacial markings are almost always fresher at and below the present sea-level than at higher levels. In some places, even where the ice-moulded rocks are washed by the wares of the sea, they retain their finer, striæ, and bosses of rock their rounded and smoothed surfaces. Yet, at an elevation of 20 feet and upward, the rounded outlines are broken, and all the exposed surfaces disintegrated by the water. In explanation of these peculiar appearances, he supposes, first, the sinking of land which had been polished and striated by continental ice in the manner before alluded to, p. 144; secondly, a rery recent date for the uphearal of the lowest 25 feet of the coast, a sug'estion confirmed by the occurrence of a raised beach in which the recent shells agree with those of the adjoining sea, and indicate a less glacial climate than those of an older beach found at a higher level, or about 40 feet above high-water mark. The upper of the two beaches has suffered more from atmospheric action than the lower, and has evidently been exposed for a much longer time.

Besides the proofs afforded by shells at the height of about 500 feet, there are also on the mountains of many parts of Scotland, as, for example, on the Grampians, and on the Sidlaw and Pentland Hills, erratic blocks, at heights from 1000 to 2000 feet and upward, so wholly unconnected with the mineral structure of the region where ther lis, that they seem to point to a former period of submergence and floating ice. There is also another curious phenomenon bearing on this sulject which the late Hugh Viller styled the striated "pavements" of the boulder clay. Where portions of the till have been remored by the sea on the shores of the Forth, or in the interior by railway cuttings, the boulders imbedded in what remains of the drift are seen to have been all subjected to a process of abrasion and striation, the striæ and furrows being parallel and persistent across them 
all, exactly as if a glacier or iceberg had passed over them and scored them in a manner similar to that which the solid rocks below the glacial drift have so often undergone. It is possible, as Mr. Geikie conjectures, that this second striation of the boulders may be referable to the second era of drift or floating ice.*

Contorted Strata in Drift.-In Scotland the till is often covered with stratified gravel, sand, and clay, the beds of which are sometimes horizontal and sometimes contorted for a thickness of several. feet. Such contortions are not uncommon in Forfarshire, where I observed them, among other places, in a vertical cutting made in 1840 near the left bank of the South Esk, east of the Bridge of Cortachie. The convolutions of the beds of fine and coarse sand, gravel, and loam, extend through a thickness of no less than 25 feet perpendicular, or from $b$ to $c$, fig. 137, the horizontal stratification being resumed very abruptly at a short distance, as beyond $f, g$. The overlying coarse gravel and sand $\alpha$, is in some places horizontal, in others

Fig. 137.

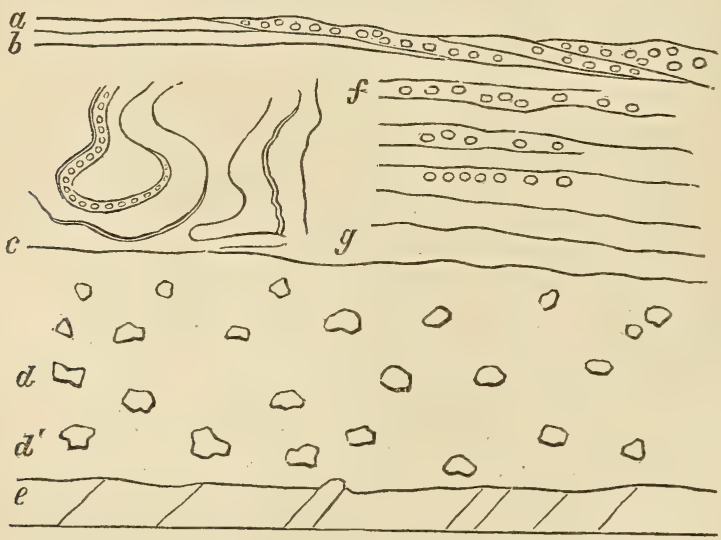

Section of contorted drift overlying till, seen on left bank of South Esk, near Cortachie, in 1810. Height of section seen, from $a$ to $d$, about 50 feet.

$a$. Superficial sand, with some beds of coarse gravel with cross bedding in parts -4 feet.

$b, c$. Contorted beds 25 feet in vertical height, by the side of which, in the same continuous section, are seen horizontal beds of stratified drift, some of them with coarse gravel and large boulders.

$c, d$. Unstratified red till, with large boulders of granite, gneiss, quartzite, \&c., 20 feet thick, the red loam being derived from triturated old red sandstone.

$d, d^{\prime}$. Similar till continued, thickness unknown.

e. Inclined strata of old red sandstone, not laid open in this place.

it exhibits cross bedding, and does not partake of the disturbances which the strata $b, c$ have undergone. The underlying till is exposed for a depth of about 20 feet; and we may infer from sections in the neighborhood that it is considerably thicker, and that it rests on the edges of highly inclined strata of old red sandstone, as represented in the section. 
In some cases I have seen fragments of stratified clays and sands, bent in like manner, in the middle of a great mass of till. Mr. Trimmer has suggested, in explanation of such phenomena, the intercalation in the glacial period of large irregular masses of snow or ice between layers of sand and gravel. Some of the cliffs near Behring's Straits, in which the remains of elephants occur, consist of ice mixed with mud and stones; and Middendorf describes the occurrence in Siberia of masses of ice, found at various depths from the surface after digging through drift. We are as yet unacquainted with the mode of operation by which such intermixtures of earthy matter and ice are commonly produced, but we may easily conceive their occurrence in Siberia, where the rivers flow from south to north, so that the thaw begins in the country where they take their rise, while in the lower regions which they overflow their channels are still choked up with ice and snow. In the arctic and antarctic regions, also, the frozen surface of the sea at the base of lofty cliffs is sometimes seen to be the receptacle first of mud and sand, washed down from the land when there is a thaw, and then, when the cold returns, of dense masses of snow drifted by the wind over the edge of the cliff. Icerafts, supporting such alternations of snow and of earthy and stony matter, have leen seen floating from place to place in polar latitudes. Whenerer the intercalation of snow and ice with drift, whether stratified or unstratified, has takei place, the melting of the ice will cause sich a failure of support as may give rise to flexures, and sometimes to the most complicated foldings.

But in many cases the strata may have been bent and deranged by the mechanical pressure of an advancing glacier, or by the sideway thrust of huge islands of ice running aground against sandbanks; in which case, the position of the beds forming the foundation of the banks may not be at all disturbed by the shock. Mr. Geikie has described examples, in the basin of the Clyde, of extremely contorted beds of sand and clay, which he attributes to porrerful pressure experienced under a glacier or mass of continental ice.

It should also be borne in mind that lateral pressure may be exerted simply by the weight of a heary mass of materials thrown down on some adjoining area, to which pliant beds of clay and sand may extend. When a railway embankment is thrown across a marsh or across the bed of a drained lake, we frequently find that the foundation, consisting of peat and shell-marl, or of quicksand and mud, gives way, and sinks as fast as the embankment is raised at the top. At the same time, there is often seen at the distance of many yards, in some neighboring part of the morass, a squeezing up of pliant strata, the amount of uphearal depending on the volume and weight of materials heaped upon the embankment. In 1852 I saw a remarka. ble instance of such a downward and lateral pressure, in the surburbs of Boston (U. S.), near the South Cove. With a view of converting 
part of an estuary overflowed at high tide into dry land, they had thrown into it a vast load of stones and sand, upwards of 900,000 cubic yards in volume. Under this weight the mud had sunk down many yards vertically. Meanwhile the adjoining bottom of the estuary, supporting a dense growth of salt-water plants, only visible at low tide, had been pushed gradually upward, in the course of many months, so as to project five or six feet above high-water mark. The upraised mass was bent into five or six anticlinal folds, and below the upper layer of turf, consisting of salt-marsh plants, mud was seen above the level of high tide, full of sea-shells, such as Mya arenaria, Modiola plicatula, Sanguinolaria fusca, Nassa obsoleta, Natica triseriata, and others. In some of these curved beds the layers of shells were quite vertical. The upraised area was 75 feet wide, and several hundred yards long. Were an equal load, melted out of icebergs or coast-ice, thrown down on the floor of a sea, consisting of soft mud and sand, similar disturbanices and contortions might result in some adjacent pliant strata, yet the underlying more solid rocks might remain undisturbed, and newer formations, perfectly horizontal, might be afterwards superimposed.

Glaciation of Woles, England, and Ireland.-The mountains of North Wales were recognized, in 1842 , by Dr. Buckland, as having been an independent centre of the dispersion of erratics,-great glaciers, long since extinct, having radiated from the Snowdonian heights in Carnarvonshire, through seven principal valleys toward as many points of the compass, carrying with them large stony fragments, and grooving the subjacent rocks in as many directions.

Besides this evidence of land glaciers, Mr. Trimmer had previously, in 1831, detected the signs of a great submergence in Wales in the Post-pliocene period. He had observed stratified drift, from which he obtained about a dozen species of marine shells, near the summit of Moel Tryfaen, a hill 1400 feet high, on the south side of the Menai Straits. Although his observations were afterwards confirmed by the late E. Forbes, and still later by Mr. Prestwich and Professor Ramsay, doubts as to the nature and age of the deposit still lingered in many minds. But on these subjects all doubt has at length been removed by aid of a long and deep cutting made through the drift in 1863 by the Alexandra Mining Company in search of slates. In this cutting a stratified mass of incoherent sand and gravel, 35 feet thick, was laid open near the summit of Moel Tryfaen, containing shells, some entire, but most of them in fragments. In the summer of 1863 I examined the newly-opened section in company with the Rev. W. S. Symonds, and we obtained 20 species of shells on the spot, and found in the lowest beds of the drift large heavy boulders of far-transported rocks, glacially polished and scratched on more than one side. Underneath the whole we saw the edges of vertical slates exposed to view, which here, like the rocks in other parts of Wales, some at greater and some at less elevations, exhibit, beneath the drift, unequi- 
rocal marks of prolonged glaciation. Mr. R. D. Darbishire, after a diligent search in 1863, formed a collection from this same drift of Moel Trrfacin of no less than 54 species of mollusca, besides three characteristic arctic rarieties-in all 57 forms. They belong without exception to species still living in British or more northern seas; eleven of them being exclusively aretic, four common to the aretic and British seas, and a large proportion of the remainder having a northward range, or, if found at all in the southern seas of Britain, being comparatively less abundant.

The whole deposit has much the appearance of an accumulation in shallow water or on a beach, and it probably acquired its thickness during the gradual subsidence of the coast-an hypothesis which would require us to ascribe to it a high antiquity, since we must allow time, first for its sinking, and then for its re-elevation. As the layers of shell-bearing sand and gravel are so porous, we may naturally feel surprise that they hare escaped decomposition. To account for this, Mr. Darbishire suggests that a bed of orerlying clay, nearly two feet thick, may, by its impermeable nature, hare prevented the fossils from being dissolved by the percolation of rain-water.

The eleration reached by these fossil shells on Moel Tryfaen is no less than 1360 feet-a most important fact when we consider that we have scarcely a well-authenticated case as yet on record beyond the limits of Wales, whether in Europe or North America, of marine shells having been found in glacial drift at half the height abore indicated.

Mr. Darwin, after studying the Welsh glacial drift previously shown by Mr. Trimmer to have been of submarine origin, came to the opinion that the land, when it was re-upheaved to its present height, was corered a second time, at least in the higher valleys, by glaciers which swept the surface clean of all the rubbish left by the sea.*

Professor Ramsay, also, in a "Memoir on the Welsh Glaciers," in $1851, \uparrow$ announced his conviction that there had been, first, an intensely cold period when the land was more elevated than now, then a submergence beneath the sea, and lastly, a re-elevation attended by a second period of glaciers. Although he had not been able to trace marine shells in the drift to a level exceeding 1300 feet above the sea, he estimated the probable amount of submergence during some part of the glacial period at about 2300 fect; for he was unable to distinguish the superficial sands and grarel which reached that high eleration from tho drift which, at Moel Tryfaen and at lower points, contains shells of living species.

The evidence of the marine origin of the highest drift is no doubt inconclusive in the absence of shells, so great is the resemblance of the 
gravel and sand of a sea beach and of a river's bed, when organic remains are wanting; but, on the other hand, when we consider the general rarity of shells in drift which we know to be of marine origin, we cannot suppose that, in the shelly sands of Moel Tryfaen, we have hit upon the exact uppermost limit of marine deposition, or, in other words, a precise measure of the submergence of the land beneath the sea during the glacial period.

We are gradually obtaining proofs of the larger part of England north of a line drawn from the mouth of the Thames to the Bristol Channel, having been under the sea and traversed by floating ice since the commencement of the glacial epoch. Among recent observations illustrative of this point, I may allude to the discovery, by Mr. J. F. Bateman, near Blackpool, fifty miles from the sea, and at the height of 568 feet above its level, of till containing rounded and angular stones and marine shells, such as Turritella communis, Purpura lapillus, Cardium edule, and others, among which Trophon clathratum (=Fusus Bamffius), though still surviving in North British seas, indicates a cold climate. Drift of similar character covers a large part of Ireland, although marine shells have not been detected in it at greater height than 600 feet, and very rarely higher than 500 ; but there can be no doubt that that island, like the greater part of England and Scotland, was for ages an archipelago traversed by floating ice. There was first a period when Ireland formed part of the continent of Europe, from whence it received the plants and animals now inhabiting it. In some part of this period its rocks were largely smoothed and striated by ice-action in the more mountainous regions. After this there was great subsidence, and the conversion of the island into an archipelago, followed by a re-elevation of land and a second continental period, and, after all these changes, a final separation from England and Wales.*

Norfolk Drift.-In England the monuments of the period of submergence can nowhere be so advantageously studied as in the cliffs of the Norfolk coast between Happisburgh and Cromer. Vertical sections, varying in height from 30 to 300 feet, are there exposed to view for a distance of about fifty miles, where the series of formations, beginning with the lowest, is as follows:-First, chalk, with flints in nearly horizontal strata; secondly, Norwich Crag, or a marine tertiary formation of the Newer Pliocene era, which extends from Weybourne seven miles to Cromer, and then thins out; thirdly, the forest bed, chiefly composed of vegetable matter, with scattered cones of the Scotch and spruce firs, and many other recent plants, and with bones of the elephant and of other extinct and living species of mammalia. In this forest bed the stumps of many trees stand erect with their roots in an ancient soil. Fourthly, a fluvio-marine series, with abundant lignite beds, and with alternations of freshwater and marine strata of sand

* See Antiquity of Man, by the Author, chap. xiv. 
and clar, the shells being all of recent species; fifthly, firmly laminated blue clay without fossils, on which rests the boulder clay of the glacial period, from 20 to 80 feet thick, with far-transported erratics, some of them polished and scratched; sixthly, contorted drift; seventhly, superficial gravel and sand.

In the Norwich Crag above mentioned, which will be described in chap. xiii., there is a small mixture (about 12 per cent.) of extinct species of shells, but in the overlying formations, beginning with the forest bed, the species are identical with those now living, and it is remarkable that, while the plants in the forest bed and lignite are such as now exist in Europe, and are nearly all of them indigenous in Great Britain, the mammalian fauna contains many conspicuous species which no longer survive in any part of the globe. Among these last, as appears from the rich collections of Messrs. Gunn and King, are no less than three species of elephant, namely, first, the mammoth, $E$. primigenius; secondly, the elephant first observed in the Val d'Arno, E. meridionalis, Nesti; and, thirdly, E. antiquus, in smaller numbers than the two former. These are accompanied by Rhinoceros etruscus (a species first obtained from beds of the same age near Florence), Hippopotamus major, the common pig, a species of horse and of bear, the common wolf, a bison, the large Irish deer, the reindeer, and other deer, the common beaver, besides a larger extinct species, also the walrus, narwhal, and some others. They amount in all to about 20 species, of which rather more than half are extinct.

It will be seen in the next chapter that the shells of some of the latest deposits of Norwich Crag show that great cold prevailed in the British seas before the close of the Newer Pliocene period; when we speak, therefore, of the regetation and quadrupeds of the Cromer forest being pre-glacial, we merely mean that they preceded the era of the general submergence of the British Isles beneath the waters of the glacial sea. That they were anterior to that submergence may be inferred from the superposition on the forest and lignite beds of the vast load of boulder-clay above alluded to, which contains fartransported blocks, some of Scandinavian origin, and probably floated from the north when Norway and Sweden were as much covered with ice as the modern continent of Greenland. Other portions of the till may have come from the northwest, as they comprise the wreck of the Cretaceous, Oolitic, and older British formations.

The fluvio-marine series affords distinct evidence of several alternations of fluviatile, marine, and terrestrial conditions. Besides the forest bed, for example, Professor Philips has obserred at one point a growth of land-plants in an erect position, at a higher level, and Mr. King has found intercalated beds in which bivalve shells, such as Mya truncata, are so placed erect in the loam with their siphuncular ends uppermost, as to show, as unmistakably as does the erect position of the trees with their roots still fixed in their original soil, that they lived on the spot where they are now entombed. It was 
stated that upon the fluvio-marine formation repose laminated clays without fossils, and these are followed by great masses of till or unstratified clay from 20 to 80 feet thick. Among the included fragments of rock are some of granite, the largest of which are from 6 to 8 feet in diameter; also syenite, of Scandinavian origin, and the wreck of the Norwich Crag, London Clay, chalk, oolite, and lias, with boulders of more ancient fossiliferous rocks.

The cliff-sections above described show that in various parts of Norfolk and Suffolk several of the extinct as well as the living species of mammalia lived after the accumulation of the glacial till and boulders, as well as before it. The Elephas primigenius affords an example of one of these extinct species, and in many British localities the Elephas antiquus and Hippopotamus major occur in the alluvium of valleys of later date than the marine boulder clay. Some of the valleys in question have been excavated through the glacial drift after the latter had been upraised from the bed of the sea.

At Mundesley, in the Norfolk cliffs, and at Hoxne, not only has such denudation taken place, but the hollows near Diss, in Suffoll, scooped out of the drift, have been again filled up with freshwater strata, in some of which the remains of the elephant have been discovered.*

One of the formations of the Norfolk cliffs, above mentioned as overlying the till, has been called contorted drift, so frequently are its beds of gravel, sand, and clay, bent and folded back upon themselves, in the same manner as parts of the Scotch drift, represented in fig. 137 , p. 156. In some cases these contortions extend for a height of 70 or 80 feet, and they are coiled round isolated masses of chalk, such as may have fallen in landslips from a perpendicular cliff on the surface of a frozen sea, or of an ice-island first driven by the winds and currents against a steep coast, and then carried away again by a change of the wind until it grounded in a sea of sufficient depth to allow of the deposition of its earthy and stony burthen on the spot where it melted on the bottom of the sea. The bent and disturbed beds often rest on strata of sand and clay, which are perfectly horizontal: In those places where the contortions are on the greatest scale, as at Sherringham for example, the chalk with flints at the base of the cliffs retains its horizontality, and has evidently not participated in the slightest degree in the violent movements to which the stratified drift and the huge masses of chalk, transported bodily from their original position, bear testimony. The probable causes of such partial derangement in the strata so peculiarly characteristic of the glacial period have already been spoken of (p. 157). The successive deposits seen in direct superposition on the Norfolk coast imply at first the prevalence over a wide area of the Newer Pliocene sea.

* For a fuller account of these Norfolk deposits, see Lyell, Antiquity of Man, chap. xii. 
Afterward the bed of this sea was converted into dry land, and underwent sereral oscillations of level, so as to be first land, supporting a forest, then an estuary, then again land, and finally a sea near the mouth of a river, till the downward movement became so great as to convert the whole area into a sea of considerable depth, in which much floating ice carrying mud, sand, and boulders melted and let fall its burthen to the bottom. Finally, over the till, with boulders, stratified drift was formed, aiter which, but not until the total subsidence had amounted to more than 400 feet, an upward movement began, which reëlevated the country, so that the lowest of the terrestrial formations, or the forest bed, was brought up to nearly its pristine level in such a manner as to be exposed at low tide. Both the descending and ascending movements seem to have been very gradual.

GLACIAL FORMATIONS IN NORTH AMERICA.

In the Western Hemisphere, both in Canada and as far south as the 40th and eren 38th parallel of latitude in the United States, we meet with a repetition of all the peculiarities which distinguish the European boulder formation. Fragments of rock hare travelled for great distances, especially from north to south: the surface of the subjacent rock is smoothed, striated, and fluted; unstratified mud or till containing boulders is associated with strata of loam, sand, and clay, usually devoid of fossils. Where shells are present, they are of species still living in northern seas, and half of them identical with those already enumerated as belonging to European drift. The fauna also of the glacial epoch in North America is less rich in species than that now inhabiting the adjacent sea, whether in the Gulf of St. Lawrence, or off the shores of Maine, or in the Bay of Massachusetts.

The extension on the American continent of the range of erratics during the Post-pliocene period to lower latitudes than they reached in Europe, agrees well with the present southward deflection of the isothermal lines, or rather the lines of equal winter temperature. It seems that formerly, as now, a more extreme climate and a more abundant supply of floating ice prevailed on the western side of the Atlantic.

Another resemblance between the distribution of the drift fossils in Europe and North America has jet to be pointed out. In Canada and the United States, as in Yorray, Sweden, Scotland, and Europe generally, the marine shells are confined to very moderate elevations above the sea (between 100 and 700 feet), while the erratic blocks and the groored and polished surfaces of rock extend to elevations of several thousand feet.

I described in 1839 the fossil shells collected by Captain Bayfield, from strata of drift at Beauport, near Quebec, in lat. $47^{\circ}$, and drew 
from them the inference that they indicated a more northern climate, the shells agreeing in great part with those of Uddevalla in Sweden.* The shelly beds attain at Beauport and the neighborhood a height of 200,300 , and sometimes 400 feet above the sea, and dispersed through some of them are large boulders of granite, which could not have been propelled by a violent current, because the accompanying fragile shells are almost all entire. They seem, therefore, said Captain Bayfield, writing in 1838, to have been dropped down from melting ice, like similar stones which are now annually deposited in the St. Lawrence.t I visited this locality in 1842 , and made the annexed section, fig. 138, which will give an idea of the general position of the drift in Canada and the United States. I imagine that the whole of

Fig. 138.

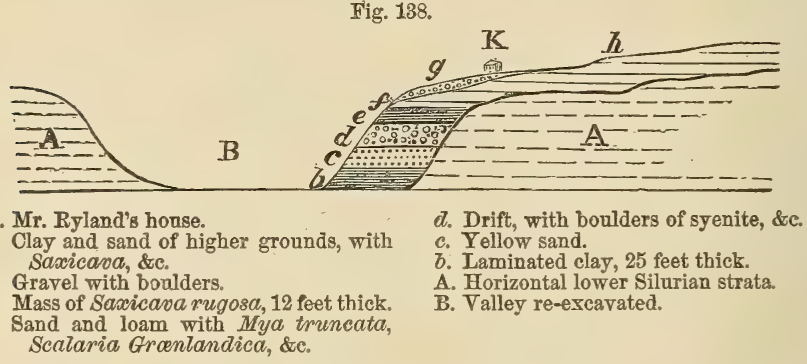

the valley, $\mathrm{B}$, was once filled up with the beds $b, c, d, e, f$, which were deposited during a period of subsidence, and that subsequently the higher country $(h)$ was submerged and overspread with drift. The partial reëxcavation of $\mathrm{B}$ took place when this region was again uplifted above the sea to its present height. Among the twenty-three species of fossil shells collected by me from these beds at Beauport, all were of recent northern species; the only supposed exception, Astarte Laurentiana, being now considered by good conchologists as a variety of the British $A$. compressa (see fig. 139). I also examined

Fig. 139.
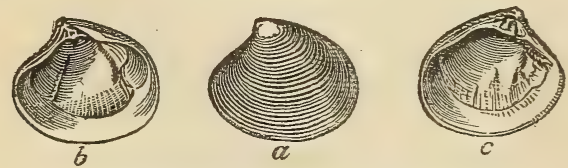

Astarte compressa, Flem. $=$ A. Laurentiana.

a. Outside.

b. Inside of right valve.

c. Left valve.

the same formation farther up the valley of the St. Lawrence, in the suburbs of Montreal, where some of the beds of loam are filled with

* Geol. Trans., 2 d series, vol. vi. p. 135. Mr. Smith of Jordan Hill had arrived at similar conclusions as to climate from the shells of the Scotch glacial drift.

† Proceedings of Geol. Soc., No. 63, p. 119. 
great numbers of the Mytilus edulis, or our common European mussel, retaining both its valves and its purple color. This shelly deposit, containing among other marine shells Saxicava rugosa, characteristic of the glacier drift of Sweden, also occurs at an elevated point on the mountain of Montreal, 450 feet above the level of the sea.*

In my account of Canada and the United States, published in 1845, I announced the conclusion to which I had then arrived, that to explain the position of erratics and the polished surfaces of rocks, and their striæ and flutings, we must assume first a gradual submergence of the land in North America, after it had acquired its present outline of hill and valley, cliff and ravine, and then its reëmergence from the ocean. In order to account for the universal glaciation of the surface of the solid rocks, on which the drift reposes in the neighborhood of the great lakes, and north and south of the St. Lawrence, it seemed necessary to assume the action of ice previous to all deposition of drift or transportation of erratics. The general direction of the furrows from north to south, for they rarely deviate more than $10^{\circ}$ or $20^{\circ}$ to the east or west of the meridian, seemed to favor the idea of their being for the most part due to the running aground of icebergs drifting from arctic latitudes. The absence in many regions, as in the Niagara district, of high mountain chains, and the extension of undiminished ice action as far south as the 40th parallel, made me unwilling to appeal, save in some exceptional cases, to land glaciers as the principal agents of this glaciation. I assumed, therefore, that while the land was slowly sinking, the sea which bordered it was covered with islands of floating ice coming from the north, which, as they grounded on the coast and on shoals, pushed along such loose materials of sand and pebbles as lay strewed over the bottom. By this force all angular and projecting points were broken off, and fragments of hard stone, frozen into the lower surface of the ice, scooped out grooves in the subjacent solid rock. The sloping beach, as well as the floor of the ocean, might be polished and scored by this machinery, producing such long, straight, and parallel furrows, as are everywhere visible in the Niagara district, and generally in the region north of the 40th parallel of latitude.

This hypothesis of a slow and gradual subsidence of the land enables us to imagine that the polishing and grooving action may have been going on simultaneously with the transportation of the erratics. During the successive depression of high land, varying originally in height from 1000 to 3000 feet above the sea-level, every portion of the surface would be brought down by turns to the level of the ocean, so as to be converted first into a coast-line, and then into a shoal; and at length, after being well scored by the stranding upon it

* Travels in N. America, vol. ii. p. 141

† Ibid., vol. ii. chap. xix. p. 99. 
year after year of large masses of coast-ice and occasional icebergs, might be sunk to a depth of several hundred fathoms. By the constant depression of land, the coast would recede farther and farther from the successively formed zones of polished and striated rock, each outer zone becoming in its turn so deep under water, as to be no longer grated upon by the heaviest icebergs. Such sunken areas would then simply serve as receptacles of mud, sand, and boulders dropped from melting ice, perhaps to a depth scarcely, if at all, inhabited by testacea and zoophytes. Meanwhile, during the formation of the unstratified and unfossiliferous mass in deep water, the smoothing and furrowing of shoals and beaches would still go on elsewhere upon and near the coast in full activity. If at length the subsidence should cease, and the direction of the movement of the earth's crust be reversed, the sunken area covered with drift would be slowly reconverted into land. The boulder deposit, before emerging, would then for a time be brought within the action of the waves, tides, and currents, so that its upper portion, being partially denuded, would have its materials rearranged and stratified. Streams also flowing from the land would in some places throw down layers of sediment upon the $t i l l$. In that case, the order of superposition will be, first and uppermost, sand, loam, and gravel occasionally fossiliferous; secondly, an unstratified and unfossiliferous mass called till, for the most part of much older date than the preceding, with angular erratics, or with boulders interspersed; and thirdly, beneath the whole, a surface of polished and furrowed rock.

If we reflect on the vast area over which the dispersion of marine glacial drift is now in progress, we shall at once see that it must equal, if it does not greatly exceed, the space over which glaciers and continental ice are moving. It would, therefore, have been in the highest degree perplexing if we had not met with proofs of submarine glaciation on a most extensive scale, including all the phenomena of polishing, scratching, furrowing, and rounding of rocky surfaces, and the transportation of erratics and finer materials; seeing that there is so much evidence everywhere in Europe and North America of the conversion of sea into land, as well as land into sea, since the commencement of the glacial epoch.

But although a large portion of the drift of North America has been due, like that of Europe, to floating ice and a period of submergence, that continent has also had its land-ice, and its centres of dispersion of erratic blocks. The White Mountains of New Hampshire, lat. $44^{\circ} \mathrm{N}$., the loftiest of which is more than 6000 feet high, may be cited as an example; and the late Professor Hitchcock inferred that some of the highest hills in Massachusetts once sent down their glaciers into the lower country. I have already mentioned that in Europe several quadrupeds of living, as well as extinct, species were common to pre-glacial and post-glacial times. In like manner there is reason to suppose that in North America much of the ancient 
mammalian fauna, together with nearly all the invertebrata, lived through the ages of intense cold.

That in the United States, the Mastodon giganteus was very abundant after the drift period is evident from the fact that entire skeletons of this animal are met with in bogs and lacustrine deposits occupying hollows in the drift. They sometimes occur in the bottom even of small ponds recently drained by the agriculturist for the sake of the shell marl. I examined one of these spots at Geneseo in the state of New York, from which the bones, skull, and tusk of a Mastodon had been procured in the marl below a layer of black peaty earth, and ascertained that all the associated freshwater and land shells were of a species now common in the same district. They consisted of several species of Lymnea, of Planorbis bicarinatus, Physa heterostropha, \&c.

In 1845 no less than six skeletons of the same species of Mastodon were found in Warren county, New Jersey, 6 feet below the surface, by a farmer who was digging out the rich mud from a small pond which he had drained. Five of these skeletons were lying together, and a large part of the bones crumbled to pieces as soon as they were exposed to the air. But nearly the whole of the other skeleton, which lay about 10 feet apart from the rest, was preserved entire, and proved the correctness of Cuvier's conjecture respecting this extinct animal, namely, that it had twenty ribs like the living elephant. From the clay in the interior within the ribs, just where the contents of the stomach might naturally have been lcoked for, seven bushels of vegetable matter were extracted. I submitted some of this matter to Mr. A. Henfrey, of London, for microscopic examination, and he informs me that it consists of pieces of small twig's of a coniferous tree of the Cypress family, probably the young shoots of the white cedar, Thuja occidentalis, still a native of North America, on which therefore we may conclude that this extinct Mastodon once fed.

Another specimen of the same quadruped, the most complete and probably the largest ever found, was exhumed in 1845 in the town of Nemburg, New York, the length of the skeleton being 25 feet, and its height 12 feet. The anchylosing' of the last two ribs on the right side afforded Dr. John C. Warren a true gauge for the space occupied by the intervertebrate substance, so as to enable him to form a correct estimate of the entire length. The tusks when discovered were 10 feet long, but a part only could be preserved. The large proportion of animal matter in the tusk, teeth, and bones of some of these fossil mammalia is truly astonishing. It amounts in some cases, as Dr. C. T. Jackson has ascertained by analysis, to 27 per 'cent., so that when all the earthy ingredients are remored by acids, the form of the bone remains as perfect, and the mass of animal matter is almost as firm, as in a recent bone subjected to similar treatment.

It would be rash, howerer to infer from such data that these quadrupeds were mired in modern times, unless we use that term strictly in a geological sense. I have shown that there is a fluviatile deposit in the 
valley of the Niagara, containing shells of the genera Melania, Lymnea, Planorbis, Valvata, Cyclas, Unio, Helix, \&c., all of recent species, from which the bones of the great Mastodon have been taken in a very perfect state. Yet the whole excavation of the ravine, for many miles below the Falls, has been slowly effected since that fluviatile deposit was thrown down.

Whether or not, in assigning a period of more than 30,000 years for the recession of the Falls from Queenstown to their present site, I have over or under estimated the time required for that operation, no one can doubt that a vast number of centuries must have elapsed before so great a series of geographical changes were brought about as have occurred since the entombment of this elephantine quadruped. The freshwater gravel which incloses it is decidedly of much more modern origin than the drift or boulder clay of the same region.*

Other extinct animals accompany the Mastodon giganteus in the postglacial deposits of the United States, among which the Castoroides ohioensis, Foster and Wyman, a huge rodent allied to the beaver, and the Capybara may be mentioned. But whether the "loess," and other freshwater and marine strata of the Southern States, in which sixeletons of the same Mastodon are mingled with the bones of the Megatherium, Mylodon, and Megalonyx, were contemporaneous with the drift, or were of subsequent date, is a chronological question still open to discussion. It appears clear, however, from what we know of the tertiary fossils of Europe-and I believe the same will hold true in North America-that many species of testacea and some mammalia, which existed prior to the glacial epoch, survived that era. As European examples among the warmblooded quadrupeds, the Elephas primigenius and Rhinoceros tichorinus may be mentioned. As to the shells, whether freshwater, terrestrial, or marine, they need not be enumerated here, as allusion will be made to them in the sequel, when the pliocene tertiary fossils of Suffolk are described. The fact is important, as refuting the hypothesis that the cold of the glacial period was so intense and universal as to annihilate all living creatures throughout the globe.

That the cold was greater for a time than it is now in certain parts of Siberia, Europe, and North America, will not be disputed; but, before we can infer the universality of a colder climate, we must ascertain what was the condition of other parts of the northern, and of the whole southern, hemisphere at the time when the Scandinavian, British, and Alpine erraties were transported into their present position. It must not be forgotten that a great deposit of drift and erratic blocks is now in full progress of formation in the southern hemisphere, in a zone corresponding in latitude to the Baltic, and to Northern Italy, Switzerland, France, and England. Should the uneven bed of the southern ncean be hereafter converted by upheaval into land, the hills and valleys will be strewed over with transported fragments, some derived from the antarctic conti-

* See Travels in N. America, vol. i. chap. ii,, and Principles of Geol. chap xiv. 
nent, others from islands corered with glaciers, like South Georgia, which must now be centres of the dispersion of drift, although situated in a latitude agreeing with that of the Cumberland mountains in England.

Not only are these operations going on between the 45 th and 60 th parallels of latitude south of the line, while the corresponding zone of Europe is free from ice; but, what is still more worthy of remark, we find in the southern hemisphere itself, only 900 miles distant from South Georgia, where the perpetual snow reaches to the sea-beach, lands covered with forest, as in Terra del Fuego. There is here no difference of latitude to account for the luxuriance of vegetation in one spot, and the absolute want of it in the other; but among other refrigerating causes in South Georgia may be enumerated the countless icebergs which float from the antarctic zone, and which chill, as they melt, the waters of the ocean, and the surrounding air, which they fill with dense fogs. The contrast of climate and glacial conditions in corresponding zones of the northern and southern hemispheres, and even in corresponding latitudes on the same side of the equator, makes it highly probable that the extreme of cold in the glacial period was not experienced simultaneously in North America and Europe.

Connection of the predominance of lakes with glacial action.-It has been truly remarked that lakes are very common in those countries where erratics, striated boulders, and rock surfaces, with other signs of glaciation abound; and that they are comparatively rare in tropical and subtropical regions. When travelling over some of the lower lands in Sweden, far from mountains, as well as over the coast region of Maine in the United States, and other districts in North America, I was much struck with the innumerable ponds and small lakes, of which counterparts are described as equally characteristic of Finland, Canada, and the Hudson's Bay Territories. I have never seen any similar form of the surface south of latitude $40^{\circ} \mathrm{N}$. in the western, and $50^{\circ} \mathrm{N}$. in the eastern hemisphere. The relation of a certain number of these sheets of water to the glacial period is obrious enough, for not a few of them are dammed up by barriers of unstratified drift, such as may have constituted the terminal and lateral moraines of glaciers, or may have been thrown down from melting icebergs when the country was still under water. To this class of lakes and ponds the term "morainic" has been applied. But I agree with Professor Ramsay, that the origin of many, eren of the moderate-sized depressions now filled with water, cannot be so explained, because many of them have their barriers formed of solid rock.

With reference to carities of large dimensions containing water in mountainous regions, they have been truly said to lie almost unirersally in the course of ralleys of erosion, being, like them, narrow in proportion to their length. If many of them run in the lines of great rents and faults, trarersing the older rocks, this is no more than may be 
said of most of the longitudinal and transverse valleys of every mountain chain. Mr. Jukes has well observed that lake-basins are by no means caused by rents gaping or widening in their higher extremities; and he adds that where fissures have been examined by miners in the interior of the earth, whether the rocks have been shifted or not, they are usually only a few feet wide, and even when traced for more than 1000 feet in a vertical direction, they preserve a remarkable uniformity in width. Nor are valleys and lake-basins the result of engulfment or the swallowing up in subterranean abysses of masses once at or near the surface. Had this been the case, we should not find, as we now do, the same strata often continuous from side to side, at the upper and lower ends of the lake. It is evident that the materials which once filled the basin have been gradually removed, so that older formations are now exposed to view on the bottom. It may be said of the particular masses of rock now constituting the sides of such cavities, as we may affirm of valleys in general, that they were never nearer each other than they are at present. The only question, then, to be discussed is, whether the denuding cause was ice or running water-a glacier or a river.

At the foot of every cataract we see that the water has formed a deep circular pool. In like manner it is suggested that ice, descending a precipice or steep slope, and rubbing off sand and stones from the surface of the same, may, when it reaches the bottom and presses on it with its whole weight, so grind down and wear away the rock, as to scoop out one of those cavities called tarns. But if we admit such a process as matter of speculation, we must at the same time suppose that after it has worked out a cavity it loses all power to extend the same, being wholly unable to cut a gorge through the barriei forming the lower margin of the tarn at the point where the discharge of ice formerly took place, and where a stream now issues. This diminished force of erosion wherever the ice has to ascend a slope, or to move horizontally, seems adverse to the hypothesis advanced by Professor Ramsay of the formation of lakes of considerable length and depth by glaciers. Yet the advocates of the origin of lakes by ice-action do not hesitate to appeal to the same causation to account for the largest Swiss and Italian lakes at the northern and southern foot of the Alps, such as those of Genera, Como, and Lago Maggiore, which vary from twenty to nearly fifty miles in length, and in depth from 500 to 2000 feet, and more.

In speculating on such a mode of origin, we feel greatly the want of positive data, which might enable us to test the actual power of a glacier to scoop cavities out of a floor of subjacent rock. It may, however, be remarked, that where opportunities are enjoyed of seeing part of a valley from which a glacier has retreated in historical times, no basin-shaped hollows are conspicuous. Domeshaped protuberances, the "roches moutonnées" before described, are frequent; but the converse of them, or cup and saucer-shaped cavities, are wanting. Everv- 
where we behold proofs that the glacier, by the aid of sand and pebbles, can grind dorn, polish, and plane the bottom; but it seems incapable of doing more, although the fundamental rocks must in dif ferent places, be of rery unequal hardness. It is also mell known that at certain points in the course of some of the principal glaciers of the Alps, transverse rents in the ice, or crevices, several feet wide and of great number and depth, occur, which are referred by geologists to inequalities in the ground below, over which the icy mass is pushed. In such instances, though the ice moves on and the old crevices close up, others of precisely the same form and dimensions are renewed every year, century after century, in the same place, implying that even where the declivity is very great, and the propelling force from behind enormous, the ice cannot saw through and get rid of the obstacles which impede the freedom of its onward march.

When we are endeavoring to form sound opinions as to the relation of the frequency of lake-basins to an antecedent glacial period, we must not forget that such basins, large and small, are met with in all latitudes, and that there are lacustrine deposits of all geological epochs, attesting the existence of lakes at times when no one is disposed to attribute them to the agency of ice. In Central France, for example, in the Miocene and Eocene periods, there were lakes of considerable dimensions when the climate, like that of the preceding Cretaceous era, was sub-tropical. It would, indeed, be the most perplexing of all enigmas if we did not find that lake-basins were now, and had been at all times, a normal feature in the physiognomy of the

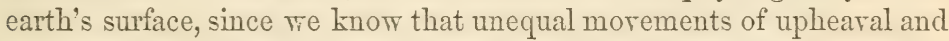
subsidence are now in progress, and were going. on at all former geological periods.

It needs but little reflection on this subject to discorer that, when such changes of lerel are in progress, some of the principal ralleys can hardly fail to be converted in some parts of their course into lakes of considerable magnitude. To escape such a result we should have to assume that the greatest eleratory morement always conforms to the central axis of every chain, or, what would be still more singular, that it concides in direction with every water-shed. Occasionally, no doubt, there would be such a coincidence, and if so, the upheaval, instead of interfering with the drainage and damming back the rirers, would, by increasing the fall of water, tend even to obliterate such lakes as preëxisted. But sometimes uphearal will be in excess in the lower part of the ralley, and at otlier times (which would equally produce lake-basins) there would be an excess of subsidence in the higher region, the allurial plains below sinking at a less rapid rate, or being; perhaps, stationary.

Then controrerting, in 1863 , in the first edition of my "Antiquity of Man" (p. 316), Professor Pamsay's hypothesis of the scooping out by ice of long and deep carities like those containing the Sriss and Ital. ian lakes, I proposed to substitute for his ice-agency the theor: of 
unequal movements of upheaval and subsidence. I assumed that the Alpine region had been exposed for countless ages to the action of rain and rivers from Older Pliocene if not from Upper Miocene times, and I therefore inferred that the larger valleys, throughout the greater part of their depth and width, were of pre-glacial origin. If they were not so, it seemed to me that we should be called upon to explain a more difficult enigma than the origin of the lake-basins, namely, why the rivers had been idle for a million years or more, leaving to glaciers the task of doing in comparatively modern times the whole work of excaration.

The Alps are from 80 to 100 miles across. Let us suppose a central depression in this chain at the rate of 5 feet in a century, while the intensity of the movement gradually diminishes as it approaches the outskirts of the chain, till at length it dies out in the surrounding lower region. After a long continuance of such a change of level, there will not only be a lessened fall of all the rivers, but the courses of many of them will, at rarious points, especially near the foot of the mountains, be converted into lakes. If, in the case of Wales, we can demonstrate an upward movement of 1400 feet during a part of the glacial epoch, we may well suppose still greater alterations of level in the Alps, and agree with Charpentier that those mountains which from a remote geological era have been the theatre of reiterated upward and downward movements may have been, at the time of the most intense cold, three thousand feet higher than they are now. They may also have been lowered again, as I have elsewhere suggested ("Antiquity of Man," p. 321,) before the close of the Glacial epoch, and oscillations of such magnitude may well have been accompanied by such inequalities of movement as would ineritably have turned some parts of the preëxisting valleys into the receptacles of vast bodies of ice, destined afterward to be converted into water. We know that in the earthquake in the northern island of New Zealand, in January, 1855 , there was a permanent rise of land on the northern shores of Cook's Strait to the extent of 9 feet vertically. On one side of Mukomuka Point, or immediately to the east, there was no movement, while on the other side, or to the westward, there was a gradual diminution of the upheaval from 9 feet to a few inches, until, at a distance of about 23 miles, no change of level was perceptible. Simultaneously with this eleration of land, there was a sinking of the low coast to the amount of 5 feet in the middle island south of Cook's Strait. The repetition of such unequal movements may, in a time geologically brief, turn parts of any valley into a lake. In Finmark an ancient water-level has been carefully measured along the borders of a fiord, rising gradually at the rate of 4 feet in a mile for 30 miles from south to north, until at one extremity it attains an elevation of 135 feet above the other end, and this movement is of post-pliocene date. Whenever the lower part of a fiord or valley is thus raised, or whenever in the upper portion, subsidence is in like manner in excess, a 
lake-basin may result as above stated. If there be no ice, the formation of a lake will depend on the relation of two forces: the rate at which the land is raised or sunk, and the rate at which the river can deposit sediment in the new depressions. Should the movement be very slow, the river may fill the incipient cavity with mud, sand, and pebbles, as fast as it is formed, and having levelled it up may afterward cut through the new stony barrier at the lower margin of the depressed area; but if the capacity of the new basin increases at too great a rate, the river will only be able to encroach partially upon it by forming a delta at its higher extremity. If the change takes place in a glacial period, the thickness of the ice will augment from century to century, not in consequence of erosion, but simply because the contour of the valley is becoming gradually more basin-shaped. The mere occupancy, therefore, of cavities by ice, by preventing fluviatile and lacustrine deposition, is one cause of the abundance of lakes which will come into existence whenever the climate changes and the ice melts.

In Switzerland there are lacustrine formations of the Post-pliocene period, which show that the Lake of Zurich, and some other Swiss lakes, were formed before the erosive power of ice had been exerted in that country ("Antiquity," p. 314). In Scotland, also, there is evidence that some of the main valleys by which the drainage now takes place were in existence before the Glacial epoch. But although most of the valleys of the Alps and some of the lakes were pre-glacial, there seems ground for suspecting that not a few of the valleys were converted into lake-basins during the long series of ages in which ice prevailed. In support of this view, many good observers affirm that below the present outlet of the great lakes in Switzerland and Italy, an ancient fluviatile alluvium rnay be seen, on which the moraines of the great glaciers which once traversed the lakes repose. The pebbles in these old alluviums comprise all those varieties of rocks which belong to the upper course of the valley above, or to tributary valleys in the same higher region. The phenomenon here alluded to would be in perfect accordance with the theory that the rivers were once continuous, or not intercepted by lake-basins destined to be filled and traversed by glaciers. It is unnecessary to resort to M. de Mortillet's hypothesis, that each basin was first filled up with alluvium sometimes abore 2000 feet thick, and that this was afterward cleared out by a glacier, for such removal would imply a capacity of erosion which we are not warranted to assume, and which, if granted, might have enabled the ancient glacier of the Rhone to excavate the basin of the Lake of Geneva out of the miocene molasse. Dr. Falconer, Mr. Ball, and other writers, have pointed out that the form of several of the great Italian lakes, such as Como, Naggiore, and Garda, is by no means in harmony with the hypothesis that they have been hollowed out by great glaciers which once passed through them.

From the analogy of flowing water, we have reason to suspect that 
ice would move slower and exert less friction on the botton in proportion to the depth of the cavity which it fills, for the motion of a glacier resembles that of a river-the upper strata moving faster than the lower; and if there be a depth of 2600 feet, as in Lago Maggiore, it is difficult to conceive, when the principal discharge of ice is almost entirely effected in the upper part of the mass, that the movement at the bottom would be sufficiently energetic to enable the ice to penetrate deeply into the rocks below. A still more serious objection to the ice-origin of lake-basins is deducible from absence of such basins of the first magnitude in the plains of the Po at certain points where the greatest of the extinct glaciers once came down from the Alps, leaving their gigantic moraines in the low country. Of this absence, the finest example occurs at Ivrea and south of it, where we observe a moraine more than 1500 feet high in its northern part, consisting of mud, stones, and large erratic blocks, evidently brought down from the two highest of the Alps, Mont Blanc and Monte Rosa. This old moraine, when it issues from the mountains and spreads over the plains of the Po, reposes on marine strata of the Pliocene age, so unconsolidated that the glacier might have scooped out of it a deep cavity had moving ice possessed such an excavating power.

Another example of the absence of a great lake where we ought to have found one, according to the glacier-erosion hypothesis, occurs in a contiguous region on the other side of Turin, bctween that city and Susa, where the moraine of the Dora Riparia extends far and wide.

If, in surveying a mountain-chain, lengthwise or transversely, we observe a capricious distribution of lake-basins, we have no reason to feel surprise, so long as we conceive the origin of the basins to be due to subterranean movements in the earth's crust, for these may be partial in their extent, or may vary in their direction in a manner which has no relation to the course of the valleys. But if, rejecting: the aid of changes of level, we invoke a superficial agency, like that of glaciers, we are then utterly at a loss to explain why they should scoop out a hollow in one valley and perform no similar feat in an adjoining one.

We have shown that rivers are doubly instrumental in preventing the formation of lake-basins ; first, by labouring incessantly to silt up an incipient cavity, and secondly, by deepening their channels, or cutting out new ones through the rocks, which may have been slowly raised up so as to interfere with the regular drainage. There is no analogous agency at work at the bottom of the sea except partially, where marine currents deriving sediment from wasting shores, or from rivers, deposit it at the bottom. With the exceptions of such areas of submarine deposition, every partial subsidence will cause a permanent depression, ready to become the receptacle of fresh water whenever the tract emerges or is turned into land. As to the extent of such lake-basins, we should have no right to wonder if they equal in size Lakes Erie and Ontario, or even Lake Superior itself, provided the 
lapse of geological time has been sufficiently protracted. But suppose the submerged area to have been continually traversed by huge iceberg's like Baffin's Bar, for thousands of years before it became part of the continent. In that case we should not only find on it a multi tude of morainic lakes of rarious sizes, but probably many shallow sancer-like carities worn in the bed of the sea, out of rocks in situ, by the reiterated impinging upon them of huge masses of ice, moving (as before described, p. 148) in their lowest parts with a velocity of as many miles as even the uppermost strata of a glacier move inches. The winds and currents might carry hundreds of such bergs during every century torrard the same tracts, and these might exert a great amount of friction on the floor of the ocean. The mud and sand formed by the abrasion of rock, or any stones which might be frozen into the bottom of the iceberg, or driven into it when the mass impinged with great force on the bed of the sea, may be remored as soon as the berg, by melting in its upper part, becomes lighter, and rising floats away. In this instance the conditions are more favorable, both for triturating a rocky floor and clearing out earth and stones from the new-formed cavitr, than are conceirable in the case of a glacier descending a ralley.

Causes of Change of Climate.-Submergence of the Sahara.-I endearored in 1830, in the "Principles of Geology," chapters vii. and riii., to point out the intimate connection of climate with the state of the physical geography of the globe existing at any giren period. If, for example, at certain periods of the past, the antaretic land was less elerated and less extensire than now, while that at the north pole was higher and more continuous, the conditions of the northern and southern hemispheres might have been to a great extent the reverse of what we now witness in regard to climate. But if in both of the polar regions a considerable area of elerated dry land existed, such a concurrence of refrigerating conditions in both hemispheres might have created for a time an intensity of cold never experienced since. Some geologists hare objected that the cold of the glacial period was so general throughout the polar and temperate regions on both sides of the equator, that mere local changes in the external configuration of our planet cannot be imagined to afford an adequate cause for a revolution in temperature of so modern a date. But the more we compare the state of the earth's surface in pliocene, post-pliocene, and recent times, the more evidence do we obtain of upward and downward morement on such a scale as to conrince us that in different parts of the periods in question a map of the world would no more resemble our present maps than Europe now resembles America or Africa. I careful study of the distribution of the living species of animals and plants in tertiary and recent times leads to similar conclusions as to the rastness of the changes which the physical geography of the globe has undergone, so that the theory in question cannot be impugned on the score of a want of unirersality in the morements of the earth's crust. 
The changes alluded to in the "Principles of Geology" as capable of affecting the climates of the globe at successive geological periods, consisted chiefly of the conversion of sea into land and land into sea, the increased or diminished height of mountain chains and continents, and the preponderance of land and water in high and low latitudes, together with the new direction given to the principal currents of the ocean, such as the Gulf-stream. But although I did not omit to mention the vast heat which is carried by the winds from the great desert of Africa to those parts of Europe which lie immediately north of it, I was not able to avail myself of a geographical fact since ascertained by geologists respecting the Sahara, namely, that this desert must have formed part of the sea when the cold of the glacial epoch was at its height. Ritter had suggested in 1817, that the African desert had been under water at a very modern period, and M. Escher von der Linth gave it as his opinion in 1852, that if this submergence were true, it would explain why the Alpine glaciers had attained in the Post-pliocene period those colossal dimensions which Venetz and Charpentier, reasoning on geological data, first assigned to them. Since this hint was thrown out by the distinguished Swiss geologists, Messrs. Laurent and Tristram, and in 1863 M. Escher himself, together with MM. Desor and Martins, have found marine shells, especially the common cockle, Cardium edule, scattered far and wide, from west to east, over the desert, while the shells of these and other living species have also been found in boring Artesian wells, at the depth of many feet below the surface.

The space now occupied by the Sahara, instead of forming a tract of parched and burning sand, from which the south wind or sirocco now derives its scorching heat and dryness, constituted formerly a wide marine area, stretching several hundred miles north and south and east and west. From this area the south wind must formerly have absorbed moisture, and must have been still farther cooled and saturated with aqueous vapor as it passed over the Mediterranean. When at length it reached the Alps, and, striking. them, was driven into the higher and more rarefied regions of the atmosphere, it would part with its watery burden in the form of snow, so that the same aërial current which under the name of the Föhn or Sirocco now plays a leading part with its hot and dry breath, sometimes even in the depth of winter, in melting the snow and checking the growth of glaciers, must, at the period alluded to, have been the principal feeder of Alpine snow and ice.

\section{METEORITES IN DRIFT.}

As my account of the glacial period has led me to speak at some length of post-pliocene drift, I may take this opportunity of referring to the discovery of a meteoric stone at a great depth in the alluvium of Northern Asia. 
Erman, in his Archives of Russia for 1841 (p. 314), cites a very circumstantial account drawn up by a Russian miner of the finding of a mass of meteoric iron in the auriferous alluvium of the Altai. Some sinall fragments of native iron were first met with in the gold-washing: of Petropawlowsker in the Mrassker Circle; but though they attracted attention, it was supposed that they must have been broken off from the tools of the workmen. At length, at the depth of 31 feet 5 inches from the surface, they dug out a piece of iron we:ghing $17 \frac{1}{2}$ pounds, of a steel-gray color, somewhat harder than ordinary iron, and, on analyzing it, found it to consist of native iron, with a small proportion of nickel, as: usual in meteoric stones. It was buried in the bottom of the deposit where the gravel rested on a flaggy limestone. Much brown iron ore, as well as gold, occurs in the same gravel, which appears to be part of that extensive auriferous formation in which the bones of the mammoth. the Rhinoceros tichorhinus, and other extinct quadrupeds abound. No sufficient data are supplied to enable us to determine whether it be of Post-Pliocene or Newer Pliocene date.

We ought not, I think, to feel surprise that we have not hitherto succeeded in detecting the signs of such aerrolites in older rocks, for, besides their rarity in our orm days, those which fell into the sea (and it is with marine strata that geologists have usually to deal), being chiefly composed of native iron, would rapidly enter into new chemical combinations, the water and mud being charged with chloride of sodium and other salts. We find that anchors, cannon, and other cast-iron implements which have been buried for a few hundred years off our English coast hare decomposed in part or entirely, turning the sand and grarel which inclosed them into a conglomerate, cemented together by oxide of iron. In like manner meteoric iron, although its rusting would be somewhat checked by the alloy of nickel, could scarcely erer fail to decompose in the course of thousands of years, becoming oxide, sulphuret, or carbonate of iron, and its origin being then no longer distinguishable. The greater the antiquity of rocks, - the oftener they have been heated and cooled, permeated by gases or by the waters of the sea, the atmosphere or mineral springs, - the smaller must be the chance of meeting with a mass of native iron unaltered; but the preservation of the ancient meteorite of the Altai, and the presence of nickel in these curious bodies. renders the recognition of them in deposits of remote periods less hopeless than we might have anticipated. 


\section{CHAPTER XIII.}

\section{CLASSIFICATION OF TERTIARY FORMATIONS.-PLIOCENE PERIOD.}

Order of succession of sedimentary formations-Imperfection of the record-Defectiveness and obscurity of the monuments greater in proportion to their antiquity -Reasons for studying the newer groups first-General principles of classification of tertiary strata-Detached formations scattered over Europe-Strata of Paris and London-More modern groups-Peculiar difficulties in determining the chronology of tertiary formations-Increasing proportion of living species of shells in strata of newer origin-Eocene, Miocene, and Pliocene terms explained -Formations of the Newer Pliocene period-Island of Ischia-Eastern base of Mount Etna-Newer Pliocene strata of great height and extent in Sicily-Formations of same age in the Upper Val d'Arno-Norwich Crag-Chillesford beds-Bridlington beds-Older Pliocene strata-Red Crag of Suffolk-White or coralline Crag-Successive refrigeration of climate proved by the pliocene shells of Suffolk and Norfolk-Antwerp Crag-Subapennine strata-Aralo-Caspian formations.

The post-tertiary formations, comprising the Post-pliocene and Recent, having been described in the last three chapters, I have now to give an account of the strata called tertiary and the several groups into which they have been subdivided.

The annexed diagram will show the order and superposition of the principal sets of fossiliferous deposits enumerated in the table, page

Fig. 140.

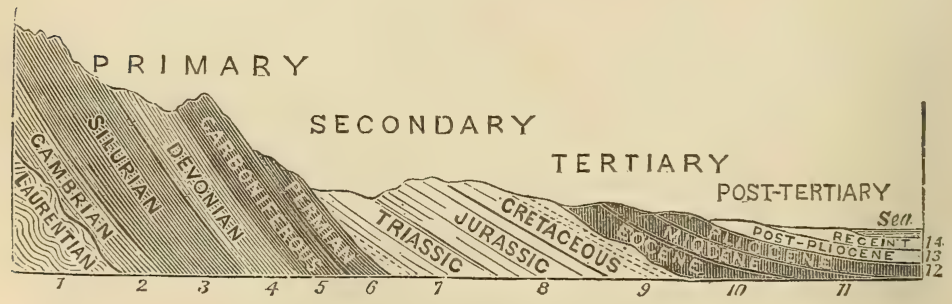

101, assuming them all to be visible in one continuous section. In nature, as before hinted, page 98 , we have never an opportunity of seeing the whole of them so displayed in a single region; first, because sedimentary deposition is confined, during any one geological period, to limited areas; and secondly, because strata, after they have been formed, are liable to be utteriy annihilated over wide areas by denudation. But wherever certain members of the series are present, they overlie one another in the order indicated in the diagram, 
though not always in the exact manner there represented, because some of them repose occasionally in unconformable stratification on others. This mode of superposition has been already explained at page 59. Where it occurs it is almost invariably accompanied by a great dissimilarity in the species of organic remains of the sets of strata next in succession, the discordance implying a considerable lapse of time which intervened between the two formations in juxtaposition. During the ages which elapsed, and of which no records have been handed down to us in the area in question, we may suppose a gradual change to have been going on in the state of the animal creation, and the same interval allowed time for a great amount of movement and dislocation to have been brought about in the earth's crust, so that the strata previously existing in the region alluded to had been much disturbed and their edges exposed to aqueous denudation before the more modern set were thrown down upon them.

Where the widest gaps appear in the sequence of organic remains, as between the Permian and Triassic rocks, or between the Cretaceous and Eocene, examples of such unconformability are very frequent. But they are also met with in some part or other of the world at the junction of almost all the other principal formations, and sometimes the subordinate divisions of any one of the leading groups may be found lying unconformably on another subordinate member of the same-the Upper, for example, on the Lower Silurian, or the superior division of the Old Red Sandistone on a lower mem$\mathrm{bc}_{2}$ of the same, and so forth. Instances of such irregularities in the mode of succession of the strata next in contact are the more intelligible the more we extend our survey of the fossiliferous formations, for we are continually bringing to light deposits of intermediate date, which have to be intercalated between those previously known, and which reveal to us a long series of events, of which antecedently to such discoveries we had no knowledge.

But while unconformability invariably bears testimony to a lapse of unicpresented time, the conformability of two sets of strata in contact by no means implies that the newer formation immediately succeeded the older one. It simply implies that the ancient rocks were subjected to no movements of such a nature as to tilt, bend, or break them before the more modern formation was superimposed. It does not show that the earth's crust was motionless in the region in question, for there may have been a gradual sinking or rising, extending, uniformly orer a large surface, and yet, during such movement, the stratified rocks may have retained their original horizontality of position. There may have been a conversion of a wide area from sea into land and from land into sea, and during these changes of level some strata may have been slowly remored by aqueous action, and after this new strata may be superimposed, differing perhaps in date by thousands of years or centuries, and yet resting con- 
formably on the older set. There may even be a blending of the materials constituting the older deposit with those of the newer, so as to give rise to a passage in the mineral character of the one rock into the other as if there had been no break or interruption in the depositing process.

Although by the frequent discovery of new sets of intermediate strata the transition from one type of organic remains to another is becoming less and less abrupt, yet the entire series of records appears to the geologists now living far more fragmentary and defective than it seemed to their predecessors half a century ago. The earlier enquirers, as often as they encountered a break in the regular sequence of formations, connected it theoretically with a sudden and violent catastrophe, which had put an end to the regular course of events that had been going on uninterruptedly for ages, annihilating at the same time all or nearly all the organic beings which had previously flourished, after which, order being reëstablished, a new series of events was initiated. In proportion as our faith in these views grows weaker, and the phenomena of the organic and inorganic world presented to us by geology seem explicable on the hypothesis of gradual and insensible changes, varied only by minor convulsions, such as have been witnessed in historical times; and in proportion as it is thought possible that former fluctuations in the organic world may be due to the indefinite modifiability of species without the necessity of assuming new and independent acts of creation, the number and magnitude of the gaps which still remain, or the extreme imperfection of the record, become more and more striking, and what we possess of the ancient annals of the earth's history appears as nothing when contrasted with that which has been lost.

When we examine a large area such as Europe, the average as well as the extreme height above the sea attained by the older formations is usually found to exceed that reached by the more modern ones, the primary or paleozoic rising higher than the secondary, and these in their turn than the tertiary, while in reference to the three divisions of the tertiary, the lowest or Eocene group attains a higher summit level than the Miocene, and these again a greater height than the Pliocene formations. Lastly, the post-tertiary deposits, such, at least, as are of marine origin, are most commonly restricted to much more moderate elevations above the sea level than the tertiary strata.

It is also observed that strata, in proportion as they are of newer date, bear the nearest resemblance in mineral character to those which are now in the progress of formation in seas or lakes, the newest of all consisting principally of soft mud or loose sand, in some places full of shells, corals, and other organic bodies, animal or vegetable, in others wholly devoid of such remains. The farther we recede from the present time, and the higher the antiquity of the formations which we examine, the greater are the changes which the sedimentarv de- 
posits have undergone. Masses, for example, which were originally soft and yielding have been condensed by pressure, others which were incoherent have been solidified by the infiltration of mineral matter which has cemented together their separate parts; others have been modified by heat, trarersed by shrinkage cracks, and partially crystallized, or the strata have been fractured during earthquakes, or bent and contorted by lateral pressure, or thrown into a rertical position, or eren orerturned so that the original order of superposition has been inverted, and the beds which were at first the lowest have become the uppermost.

The organic remains also have sometimes been obliterated entirely, or the mineral matter of which they were composed has been removed and replaced by other substances, as when calcareous fossils have been silicified.

We likewise observe that the older the rocks the more widely do their organic remains depart from the types of the living creation. First, we find in the newer tertiary rocks a few species which no longer exist, mixed with many living ones, and then, as we go farther back, many genera and families at present unknown make their appearance, until we come to strata in which the fossil relics of existing species are nowhere to be detected, except a few of the lowest forms of invertebrata, while some orders of animals and plants wholly unrepresented in the living world begin to be conspicuous.

When we study, therefore, the geological records of the earth and its inhabitants, we find, as in human history, the defectiveness and obscurity of the monuments always increasing the remoter the era to which we refer. The difficulty of determining the true chronological relations of rocks is also more and more enhanced, especially when we are comparing those which trere formed simultaneously in very distant regions of the globe. Hence we advance with securer steps when we begin with the study of the geological records of later times, proceeding from the newer to the older, or from the more to the less known.

In thus inferting what might at first seem to be the more natural order of historical research, we must bear in mind that each of the periods abore enumerated, even the shortest, such as the Post-tertiary, or the Pliocene, Miocene, or Eocene, embrace a succession of events of rast extent, so that to gire a satisfactory account of what we already know of any one of them would require many rolumes of the size of this treatise. Then, therefore, we approach one of the netrer groups before endearoring to decipher the monuments of au older one, it is like endearoring to master the history of our own country and that of some contemporary nations, before we enter upon Roman History, or like investigating the annals of Ancient Italy and Greece before we approach those of Egrpt and Assrria. That there are inconveniences in thus inrerting the order in which the successive erents are spoken of I fully admit, but there are also unquestionable advantages, and 
practically it will lead to no misapprehension as to the chronological sequence of formations.

The origin of the terms Primary and Secondary was explained in the eighth chapter, p. 92.

The Tertiary strata were so called because they were all posterior in date to the Secondary series, of which last the Chalk or Cretaceous, No. 9; fig. 140, constitutes the newest group. The whole of them were at first confounded, as before stated, p. 87, with the superficial alluviums of Europe; and it was long before their real extent and thickness, and the various ages to which they belong, were fully recognized. They were observed to occur in patches, some of freshwater, others of marine origin, their geographical area being usually small as compared to the secondary formations, and their position often suggesting the idea of their having been deposited in different bays, lakes, estuaries, or inland seas, after a large portion of the space now occupied by Europe had already been converted into dry land.

The first deposits of this class, of which the characters were accurately determined, were those occurring in the neighborhood of Paris, described in 1810 by MM. Cuvier and Brongniart. They were ascertained to consist of successive sets of strata, some of marine, others of freshwater origin, lying one upon the other. The fossil shells and corals were perceived to be almost all of unknown species, and to have in general a near affinity to those now inhabiting warmer seas. The bones and skeletons of land animals, some of them of large size, and belonging to more than forty distinct species, were examined by Cuvier, and declared by him not to agree specifically, nor even for the most part generically, with any hitherto observed in the living creation.

Strata were soon afterwards brought to light in the vicinity of London, and in Hampshire, which although dissimilar in mineral composition, were justly inferred by Mr. T. Webster to be of the same age as those of Paris, because the greater number of the fossil shells were specifically identical. For the same reason rocks found on the Gironde, in the South of France, and at certain points in the North of Italy, were suspected to be of contemporaneous origin.

A variety of deposits were afterwards found in other parts of Europe, all reposing immediately on rocks as old or older than the chalk, and which exhibited certain general characters of resemblance in their organic remains to those previously observed near Paris and London. An attempt was therefore made at first to refer the whole to one period; and when at length this seemed impracticable, it was contended that as in the Parisian series there were many subordinate formations of considerable thickness which must have accumulated one after the other, during a great lapse of time, so the various patches of tertiary strata scattered over Europe might correspond in age, some of them to the older, and others to the newer, subdivisions of the Parisian series. 
This error, though almost unavoidable on the part of those who made the first generalizations in this branch of Geology, retarded seriously for some years the progress of classification. A more scrupulous attention to specific distinctions, aided by a careful regard to the relative position of the strata containing them, led at length to the conviction that there were formations both marine and freshwater of various ages, and all newer than the strata of the neighborhood of Paris and London.

One of the first steps in this chronological reform was made in 1811 , by an English naturalist, Mr. Parkinson, who pointed out the fact that certain shelly strata, provincially termed "Crag" in Suffolk, lie decidedly over a deposit which was the continuation of the blue clay of London. At the same time he remarked that the fossil testacea in these newer beds were distinct from those of the blue clay, and that while some of them were of unknown species, others were identical with species now inhabiting the British seas.

Another important discovery was soon afterwards made by Brocchi in Italy, who investigated the argillaceous and sandy deposits replete with shells which form a low range of hills, flanking the Apennines on both sides, from the plains of the Po to Calabria. These lower hills were called by him the Subapennines, and were formed of strata chiefly marine, and newer than those of Paris and London.

Another tertiary group occurring in the neighborhood of Bourdeaux and Dax, in the south of France, was examined by M. de Basterot in 1825, who described and figured several hundred species of shells, which differed for the most part both from the Parisian series and those of the Subapennine hills. It was soon, therefore, suspected that this fauna might belong to a period intermediate between that of the Parisian and Subapennine strata, and it was not long before the evidence of superposition was brought to bear in support of this opinion; for other strata, contemporaneous with those of Bourdeaux, were observed in one district (the Valley of the Loire), to overlie the Parisian formation, and in another (in Piedmont) to underlie the Subapennine beds. The first example of these was pointed out in 1829 by M. Desnoyers, who ascertained that the sand and marl of marine origin called Faluns, near Tours, in the basin of the Loire, full of sea-shells and corals, rested upon a lacustrine formation, which constitutes the uppermost subdivision of the Parisian group, extending continuously throughout a great table-land interrening between the basin of the Seine and that of the Loire. The other example occurs in Italy, where strata, containing many fossils similar to those of Bourdeaux, were observed by Bonelli and others in the environs of Turin, suljacent to strata belonging to the Subapennine group of Brocchi.

Without pretending to give a complete sketch of the progress of discovery, I may refer to the facts above enumerated, as illustrating the course usually pursued by geologists when they attempt to found new chronological divisions. The method bears some analogy to that pur- 
sued by the naturalist in the construction of genera, when he selects a typical species, and then classes as congeners all other species of animals and plants which agree with this standard within certain limits. The genera $\mathrm{A}$ and $\mathrm{C}$ having been founded on these principles, a new species is afterwards met with, departing widely both from $\mathrm{A}$ and $\mathrm{C}$, but in many respects of an intermediate character. For this new type it becomes necessary to institute the new genus $\mathrm{B}$, in which are included all species afterwards brought to light, which agree more nearly with $\mathrm{B}$ than with the types of A or C. In like manner a new formation is met with in geology, and the characters of its fossil fauna and flora investigated. From that moment it is considered as a record of a certain period of the earth's history, and a standard to which other deposits may be compared. If any are found containing the same or nearly the same organic remains, and occupying the same relative position, they are regarded in the light of contemporary annals. All such monuments are said to relate to one period, during which certain events occurred, such as the formation of particular rocks by aqueous or volcanic agency, or the continued existence and fossilization of certain tribes of animals and plants. When several of these periods have had their true places assigned to them in a chronological series, others are discovered which it becomes necessary to intercalate between those first known; and the difficulty of assigning clear lines of separation must unavoidably increase in proportion as chasms in the past history of the globe are filled up.

Every zoologist and botanist is aware that it is a comparatively easy task to establish genera in departments which have been enriched with only a small number of species, and where there is as yet. no tendency in one set of characters to pass almost insensibly, by a multitude of connecting links, into another. They also know that the difficulty of classification augments, and that the artificial nature of their divisions becomes more apparent, in proportion to the increased number of objects brought to light. But in separating families and genera, they have ne other alternative than to avail themselves of such breaks as still remain, or of every hiatus in the chain of animated beings which is not yet filled up. So in geology, we may be eventually compelled to resort to sections of time as arbitrary, and as purely conventional, as those which divide the history of human events into centuries. But in the present state of our knowledge, it is more convenient to use the interruptions which still occur in the regular sequence of geological monuments, as boundary lines between our principal groups or periods, even though the groups thus established are of very unequal value.

The isolated position of distinct tertiary deposits in different parts of Europe has been already alluded to. In addition to the difficulty presented by this want of continuity when we endeavor to settle the chronological relations of these deposits, another arises from the frequent dissimilarity in mineral character of strata of contemporaneous date, such, for example, as those of London and Paris before mentioned. The identity or non-identity of species is also a criterion which often fails us. 
For this we might have been prepared, for we have already seen, that the Mediterranean and Fed Sea, although within 70 miles of each other, on each side of the Isthmus of Suez, have each their peculiar fauna; and a marked difference is found in the four groups of testacea now living in the Baltic, English Channel, Black Sea, and Mediterranean, although all these seas have many species in common. In like manner a considerable diversity in the fossils of different tertiary formations, which have been thrown down in distinct seas, estuaries, bays, and lakes, does not always imply a distinctness in the times when they were produced, but may have arisen from climate and conditions of physical greography wholly independent of time. On the other hand, it is now abundantly clear, as the result of geological investigation, that different sets of tertiary strata, immediately superimposed upon each other, contain distinct imbedded species of fossils, in consequence of fluctuations which have been going on in the animate creation, and by which in the course of ages one state of things in the organic world has been substituted for another wholly dissimilar. It has also been shown that in proportion as the age of a tertiary deposit is more modern, so is its fauna more analogous to that now in being in the neighboring seas. It is this law of a nearer agreement of the fossil testacea with the species now living, which may often furnish us with a clue for the chronological arrangement of scattered deposits, where $\pi$ re cannot arail ourselves of any one of the three ordinary chronological tests; namely, superposition, mineral character, and the specific identity of the fossils.

Thus, for example, on the African border of the Red Sea, at the height of 40 feet, and sometimes more, above its level, a white calcareous formation has been observed, containing sereral hundred species of shells differing from those found in the clay and volcanic tuff of the country round Naples, e.g. in the Bay of Bair. Another deposit has been found at Udderalla, in Sweden, in which the shells do not agree with those found near Naples. But although in these three cases there may be scarcely a single shell common to the three different deposits, we do not hesitate to refer them all to one period (the PostPliocene), because of the rery close agreement of the fossil species in every instance with those now living in the contiguous seas.

To take another example, where the fossil fauna recedes a few steps farther back from our own times. We may compare, first, certain beds at the eastern base of Etna near Trezza, hereafter to be mentioned; secondly, others of fluvio-marine origin near Torwich; and, lastly, a third set often rising to considerable heights in Sicily, and we liscorer that in every case more than three-fourths of the shells agree with species still living, while the remainder are extinct. Hence we may conciude that all these, greatly diversified as are their organic remains, belong to one and the same era, or to a period immediately antecedent to the Post-Pliocene, because there has been time in each of the areas alluded to for an equal or nearly equal amount of change in the marine testaceous fiauna. Contemporaneousness of origin is inferred in these 
cases, in spite of the most marked differences of mineral character or organic contents, from a similar degree of divergence in the shells from those now living in the adjoining seas. The advantage of such a test consists in supplying us with a common point of departure in all countries, however remote.

But the farther we recede from the present times, and the smaller the relative number of recent as compared with extinct species in the tertiary deposits, the less confidence can we place in the exact value of such a test, especially when comparing the strata of very distant regions; for we cannot presume that the rate of former alterations in the animate world, or the continual going out and coming in of species, has been everywhere exactly equal in equal quantities of time. The form of the land and sea, and the climate, may have changed more in one region than in another; and consequently there may have been a more rapid destruction and renovation of species in one part of the globe than elsewhere. Considerations of this kind should undoubtedly put us on our guard against relying too implicitly on the accuracy of this test; ye: it can never fail to throw great light on the chronological relations of tertiary groups with each other, and with the Post-Pliocene period.

We may derive a conviction of this truth not only from a study of geological monuments of all ages, but also by reflecting on the tendency which prevails in the present state of nature to a uniform rate of simultaneous fluctuation in the flora and fauna of the whole globe. The grounds of such a doctrine cannot be discussed here, and I have explained them at some length in the third Book of the Principles of Geology, where the causes of the successive extinction of species are considered. It will be there seen that each local change in climate and physical geography is attended with the immediate increase of certain species, and the limitation of the range of others. A revolution thus effected is rarely, if ever, confined to a limited space, or to one geographical province of animals or plants, but affects several other surrounding and contiguous provinces. In each of these, moreover, analogous alterations of the stations and habitations of species are simultaneously in progress, reacting in the manner already alluded to on the first province Hence, long before the geography of any particular district can be essen tially altered, the flora and fauna throughout the world will have been materially modified by countless disturbances in the mutual relation of the various members of the organic creation to each other. To assume that in one large area inhabited exclusively by a single assemblage of species any important revolution in physical geography can be brought about, while other areas remain stationary in regard to the position of land and sea, the height of mountains, and so forth, is a most improbable hypothesis, wholly opposed. to what we know of the laws now governing the aqueous and igneous causes. On the other hand, even were this conceivable, the communication of heat and cold between different parts of the atmosphere and ocean is so free and rapid, that the 
temperature of certain zones cannot be materially raised or lowered without others being immediately affected; and the elevation or diminution in height of an important chain of mountains or the submergence of a wide tract of land would modify the climate even of the antipodes.

It will be observed that in the foregoing allusions to organic remains, the testacea or the shell-bearing moliusca are selected as the most useful and conrenient class for the purposes of general classification. In the first place, they are more universally distributed through strata of every age than any other organic bodies. Those families of fossils which are of rare and casual occurrence are absolutely of no avail in establishing a chronological arrangement. If we have plants alone in one group of strata and the bones of mammalia in another, we can draw no conclusion respecting the affinity or discordance of the organic beings of the two epochs compared; and the same may be said if we have plants and vertebrated animals in one series and only shells in another. Althougb. corals are more abundant, in a fossil state, than plants, reptiles, or fish, they are still rare when contrasted with shells, especially in the European tertiary formations. The utility of the testacea is, moreover, enhanced by the circumstance that some forms are proper to the sea, others to the land, and others to freshwater. Rivers scarcely ever fail to carry down into their deltas some land shells, together with species which are at once fluviatile and lacustrine. By this means we learn what terrestrial, freshwater, and marine species coexisted at particular eras of the past; and having thus identified strata formed in seas with others which originated contemporaneously in inland lakes, we are then enabled to advance a step farther, and show that certain quadrupeds or aquatic plants, found fossil in lacustrine formations, inhabited the globe at the same period when certain fish, reptiles, and zoophytes lived in the ocean.

Among other characters of the molluscous animals, which render them extremely valuable in settling chronological questions in geology, may be mentioned, first, the wide geographical range of many species; and, secondly, what is probably a consequence of the former, the great duration of species in this class, for they appear to have surpassed in longerity the greater number of the mammalia and fish. Had each species inhabited a rery limited space, it could never, when imbedded in strata, have enabled the geologist to identify deposits at distant points; or had they each lasted but for a brief period, they could have thrown no light on the connection of rocks placed far from each other in the chronological, or, as it is often termed, vertical series.

Many authors have divided the European tertiary strata into three groups-lower, middle, and upper; the lower comprising the oldest formations of Paris and London before-mentioned; the middle those of Bourdeaux and Touraine; and the upper all those newer than the middle group.

When engaged in 1828 in preparing my work on the Principles of Geology, I conceived the idea of classing the whole series of tertiary strata in four groups, and endeavoring to find characters for each, ix- 
pressive of their different degrees of affinity to the living fauna. With this view, I obtained information respecting the specific identity of many tertiary and recent shells from several Italian naturalists, and among others from Professors Bonelli, Guidotti, and Costa. Having in 1829 become acquainted with M. Deshayes, of Paris, already well known by his conchological works, I learnt from him that he had arrived, by independent researches, and by the study of a larye collection of fossil and recent shells, at very similar views respecting the arrangement of tertiary formations. At my request he drew up, in a tabular form, lists of all the shells known to him to occur both in some tertiary formation and in a living state, for the express purpose of ascertaining the proportional number of fossil species identical with the recent which characterized successive groups; and this table, planned by us in common, was published by me in 1833.* The number of tertiary fossil shells examined by M. Deshayes was about 3000 ; and the recent species with which they had been compared about 5000. The result then arrived at was, that in the lower tertiary strata, or those of London and Paris, there were about $3 \frac{1}{2}$ per cent. of species identical with recent; in the middle tertiary of the Loire and Gironde about 17 per cent.; and in the upper tertiary or Subapennine beds, from 35 to 50 per cent. In formations still more modern, some of which I had particularly studied in Sicily, where they attain a vast thickness and elevation above the sea, the number of species identical with those now living was believed to be from 90 to 95 per cent. For the sake of clearness and brevity, I proposed to give short technical names to these four groups, or the periods to which they respectively belonged. I called the first or oldest of them Eocene, the second Miocene, the third Older Pliocene, and the last or fourth Newer Pliocene. The first of the above terms, Eocene, is derived from $\eta \omega s$, eos, dawn, and xavvos, cainos, recent, because the fossil shells of this period contain an extremely small proportion of living species, which may be looked upon as indicating the dawn of the existing state of the testaceous fauna, no recent species having been detected in the older or secondary rocks.

The term Miocene (from $\mu \varepsilon ı v$, meion, less, and xaıvos, cainos, recent) is intended to express a minor proportion of recent species (of testacea), the term Pliocene (from $\pi \lambda \varepsilon s 0 v$, pleion, more, and xavvos, cainos, recent) a comparative plurality of the same. It may assist the memory of students to remind them, that the Miocene contain a minor proportion, and Pliocene a comparative plurality of recent species; and that the greater number of recent species always implies the more modern origin of the strata.

It has sometimes been objected to this nomenclature that certain species of infusoria found in the chalk are still existing, and, on the other hand, the Miocene and Older Pliocene deposits often contain the remains of mammalia, reptiles, and fish, exclusively of extinct species. But the 
reader must bear in mind that the terms Eocene, Niocene, and Pliocene were originally invented with reference purely to conchological data, and in that sense have always been and are still used by me.

The distribution of the fossil species from which the results before mentioned were obtained in 1830 by M. Deshayes was as follows:-

In the formations of the Pliocene periods, older and newer, _ $\quad 777$

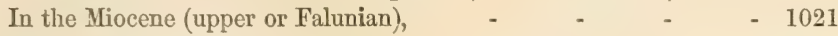

In the Eocene (including the Grès de Fontainebleau), - - 1238

3036

Since the year 1830, the number of new living species obtained from different parts of the globe has been exceedingly great, supplying fresh data for comparison, and enabling the paleontologist to correct many erroneous indentifications of fossil and recent forms. New species also have been collected in abundance from tertiary formations of every age, while newly discovered groups of strata have filled up gaps in the preriously known series. Hence modifications and reforms have been called for in the classinication first proposed. The Eocene, Miocene, and Pliocene periods have been made to comprehend certaii sets of strata of which the fossils do not always conform strictly in the proportion of recent to extinct species with the definitions first given by me, or which are implied in the etymology of those terms. Of these and other innorations I shall treat more fully in the fourteenth and fifteenth chapters.

Newer Pliocene-Ischia.-We have already seen, page 108, that in the neighborhood of Naples there are stratified tuffs containing a large number of fossil shells agreeing specifically with those now living in the Mediterranean. Of an age immediately antecedent to those Post-pliocene formations are the rolcanic tuffs of the neighboring island of Ischia, some of them rising in the summit of Santa Nicola or. Monte Epomeo to the height of 2605 feet abore the sca. I stated in the first editions of the "Principles of Geology" * that in 1828 I had procured many fossil shells from near the village of IIoropano, at an eleration of 2000 feet above the Mediterranean. I have since found, on rerisiting Ischia, that the spot is not more than 1600 fect high; but this crror is not of geological importance, as the beds are admitted to form a part of the same greenish and bluish marls which reach the top of Epomeo. The whole of the fossil species, 28 in number, which I first collected there, were examined by M. Deshayes nud recognized by him as all now living. I called them Newer Pliocene, considering them of much more modern date than the Subapenuine strata, $\uparrow$ to $\pi$ hich Signor Spada Lavini proposed, in 1853, to infor them. He seems to hare alopted this opinion, because among

* Principles of Geology, vol, iii. p. 126, 1833.

† See Principles, Table, vol. iii. pp. 16 and 126. 
a larger number of fossils obtained from these beds in Ischia, Buccinum semistriatum and Murex vaginatus (see fig. 141) had been found. Both of these shells were supposed to be extinct; but although this is true of the first, which is a common Subapennine shell, it is not so of the other, for the Murex still lives in the Mediterranean, though rare,* and recent specimens of it may be seen in Mr. Cuming's collection in London, from which the annexed figure is taken. Several Italian geologists, who had not examined Ischia, hastily adopted the classification of Signor Spada; but M. Puggaard, who was well acquainted with the island, immediately entered his protest against it; $\dagger$ and there can be no doubt, from the general character of the organic remains, that the mass of Epomeo was formed beneath the waters of the sea at the close of the Newer Pliocene period, and was raised to a height of 2600 feet above its original level in Post-pliocene times.

Vesuvius.-The old cone of Vesuvius, or Monte Somma, is, geologically speaking, so modern that the eruption by which it was formed burst through marine clays and tuffs of the same age as those of

Fig. 141.

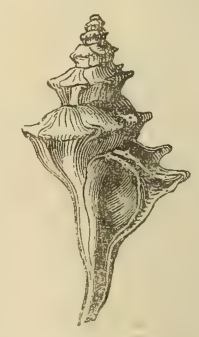

Murex vaginatus, Phil. Ischia above mentioned. Fragments of tuff and conglomerate found amongst the ancient ejectamenta, and constituting part of the strata laid open in the ravine called Fosso Grande and in the Rivo di Quaglia, the latter 972 feet high above the sea, have supplied Signor Guiscardi with 100 shells, among which one, and one only, namely, Buccinum semistriatum, before alluded to, is extinct. The oldest eruptions, therefore, of the Campi Phlegræi, or volcanic regions of Naples, took place precisely at the close of the Newer Pliocene period, when about one shell only in a hundred differed from those now living in the Mediterranean.

Sicily, Eastern base of Mount Etna.-At several points north of Catania, on the eastern seacoast of Sicily, as at Aci-Castello, for example, Trezza, and Nizzeti, marine strata, associated with volcanic tuffs and basaltic lavas, are seen, which belong to a period when the first igneous eruptions of Mount Etna were taking place in a shallow bay of the Mediterranean. During my first visit to Sicily in 1828, I collected sixty-five species of shells from these clays and sands, which may be said, together with the associated igneous products, to constitute the foundations of the great volcano. With the help of M. Deshayes, I was enabled to publish a list of their names, $\downarrow$ showing that nearly all of them agreed with species now inhabiting the adjoining sea.

* Lyell on Mount Etna, Phil. Trans., p. 778, 1858.

† Bulletin de la Soc. Géol. de France, tom. xi. 2 e sér., p. 72, and tom. xiii. p. 285, and Xv. p. 362.

$\ddagger$ Principles of Geology, vol. iii., Appendix, 1833. 
In 1857 and 1858, when I revisited Sicily, I obtained, through the kindness of Dr. Aradas, of Catania, a much larger number of species from the same localities, which confirmed the conclusions formerly arrived at as to the age of these deposits. Out of 142 shells, all but eleven proved to be identical with species now liring. Some few of these eleven shells may possibly still linger in the depths of the Mediterranean, like Murex vaginatus, fig. 141, p. 190. The last-mentioned shell had already become rare, when the sub-Etnean deposits were formed. On the whole, the modern character of the testaceous fauna under consideration is expressed not only by the small proportion of extinct species, but by the relative number of individuals by which most of the other species are represented, for the proportion agrees with that observed in the present fauna of tho Mediterranean. The only extinct shell which can be said to be common is Buccinum semistriatum; $B$. musivum comes next in abundance. The rarity of the other nine is such as to imply that they were already on the point of dying out, having flourished chiefly in the earlier Pliocene times when the Subapennine strata were in progress.

Yet since the accumulation of these Newer Pliocene sands and clays, the whole cone of Etna, 11,000 feet in height and about ninety miles in circumference at its base, has been slowly built up ; an operation requiring many tens of thousands of years for its accomplishment, and to estimate the magnitude of which it is necessary to study in detail the internal structure of the motintain, and to see the proofs of its double axis, or the evidence of the lavas of the present great centre of eruption having gradually overwhelmed and enveloped a more ancient cone, situated $3 \frac{1}{2}$ miles to the east of the present one. TVe ought also to satisfy ourselves, as we may easily do, that in breadth and thickness each of the older lavas did not exceed in their average volume the products of single outpourings of historical times. In speculating, moreorer, on the lapse of bygone ages, we must take into account the different dates and varying composition of the dikes up which the laras poured, whether belonging to the eastern or western axis, and the manner in which one set of dikes cuts through an older one; also, the vast denudation to which the Val del Bove, or deep valley, on the eastern flank of the mountain, bears testimony; and, lastly, the gradual upheaval above the level of the sea of some of the submarine rocks first formed, and the origin of many lundred minor cones, the result of lateral outbreaks during the most modern phase of eruption. These and other observations must be made, before the prodigious antiquity of the Newer Pliocene marine strata abore described can be fully appreciated.*

It appears that while Etna was increasing in bulk by a scries of cruptions, its whole mass, comprising the foundations of subaqueous

* See a Memoir on the Laras and Mode of Origin of Mount Etna, by the Author, Phil. Trans., 1858. 
origin above alluded to, was undergoing a slow upheaval, by which those marine strata were raised to the height of 1200 feet above the sea, as seen at Catera, and perhaps to greater heights, for we cannot trace their extension westward owing to the dense and continuous covering of modern lava under which they are buried. During the gradual rise of these Newer Pliocene formations (consisting of clays, sands, and basalts), other strata of Post-pliocene date, marine as well as fluviatile, accumulated round the base of the mountain, and these, in their turn, partook of the upward movement, so that several inland cliffs and terraces at low levels, due partly to the action of the sea and partly to the river Simeto, originated in succession.

Fossil remains of the elephant, and other extinct quadrupeds, have been found in these Post-pliocene strata, associated with recent shells.

Newer Pliocene strata of Sicily. - There is probably no part of Europe where the Newer Pliocene formations enter so largely into the structure of the earth's crust, or rise to such heights above the level of the sea, as Sicily. They cover nearly half the island, and near its centre, at Castrogiovanni, reach an elevation of 3000 feet. They consist principally of two divisions, the upper calcareous, and the lower argillaceous, both of which may be seen at Syracuse, Girgenti, and Castrogiovanni.

According to Philippi, to whom we are indebted for the best accoun of the tertiary shells of this island, thirty-five species out of one hundred and twenty-four obtained from the beds in central Sicily are extinct.

A geologist, accustomed to see nearly all the Newer Pliocene formations in the north of Europe occupying low grounds and very incoherent in texture, is naturally surprised to behold formations of the same age so solid and stony, of such thickness, and attaining so great an clevation above the level of the sea.

The upper or calcareous member of this group in Sicily consists in some places of a yellowish-white stone, like the Calcaire Grossier of Paris ; in others, of a rock nearly as compact as marble. Its aggregate thickness amounts sometimes to 700 or 800 feet. It usually occurs in regular horizontal beds, and is occasionally intersected by deep valleys such as those of Sortino and Pentalica, in which are numerous caverns. The fossils are in every stage of preservation, from shells retaining portions of their animal matter and color to others which are mere casts.

The limestone passes downward into a sandstone and conglomerate, below which is clay and blue marl, like that of the Subapennine hills, from which perfect shells and corals may be disengaged. The clay sometimes alternates with yellow sand.

South of the plain of Catania is a region in which the tertiary beds are intermixed with volcanic matter, which has been for the most part the product of submarine eruptions. It appears that, while the clay, sand, and yellow limestone before mentioned were in course of deposition at the bottom of the sea, volcanoes burst out beneath the waters, like-that of Graham Island, in 1831, and these explosions recurred again and again at distant intervals of time. Volcanic ashes and sand were showered 
down and spread by the wares and currents so as to form strata of tuff, which are found intercalated between beds of limestone and clay containing marine shells, the thickness of the whole mass exceeding 2000 feet. The fissures through which the lava rose may be seen in many places forming what are called dikes.

In part of the region above alluded to, as, for example, near Lentini, a conglomerate occurs in which I observed many pebbles of volcanic rocks corered by full grown serpulce. We may explain the origin of these by supposing that there were some small volcanic islands which may hare been destroyed from time to time by the waves, as Graham Island has been swept away since 1831. The rounded blocks and pebbles of solid volcanic matter, after being rolled for a time on the beach of such temporary islands, were carried at length into some tranquil part of the sea, where they lay for years, while the marine serpulce adhered to them, their shells growing and covering their surface, as they are seen adhering to the shell figured in p. 22. Finally, the bed of pebbles was itself covered with strata of shelly limestone. At Vizzini, a town not many miles distant to the S. W., I remarked another striking proof of the gradual manner in which these modern rocks were formed, and the long intervals of time which elapsed between the pouring out of distinct sheets of lava. A bed of oysters no less than 20 feet in thickness rests upon a current of basaltic lava. The oysters are perfectly identifiable with our common eatable species. Upon the oyster bed, again, is superimposed a second mass of lava, together with tuff or peperino. In the midst of the same alternating igneous and aqueous formations is seen near Galieri, not far from Vizzini, a horizontal bed, about a foot and a half in thickness, composed entirely of a common Mediterranean coral (Caryophyllia caspitosa, Lam.). These corals stand erect as they grew;

Fig. 142
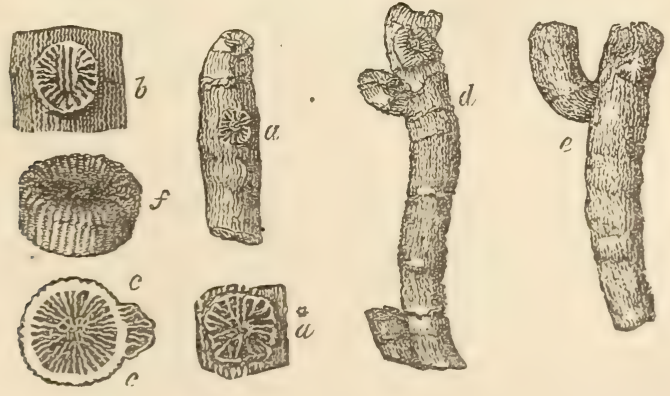

Caryophyllia caspitosa, Lam.

(Cludocora stellaria, Milne Edw. and Haime.)

$a$. Stem with young stem growing from its side.

$a *$. Young stem of same twice magnified.

v. Portion of branch, twice magnified, with the base of a lateral branch; the exterior ridges of the main branch appearing through the lamellæ of the lateral one.

c. Transverse section of same, proving by the integrity of the main branch, that the lateral one did not originate in a subdivision of the animal.

d. A branch, having at its base another laterally united to it, and two young corals at its upper part.

e. A main branch, with a full grown lateral one.

f. A perfect terminal star. 
and, after being traced for hundreds of yards, are again found at a cor. responding height on the opposite side of the valley.

The corals are usually branched, but not by the division of the animals as some have supposed, but by the attachment of young individuals to the sides of the older ones; and we must understand this mode of increase, in order to appreciate the time which was required for the building up of the whole bed of coral during the growth of many successive generations.*

Among the other fossil shells met with in these Sicilian strata, which still continue to abound in the Mediterranean, no shell is more conspicuous, from its size and frequent occurrence, than the great scallop, Pecten jacobceus (see fig. 143), now so common in the neighboring seas. We see this shell in the calcareous beds at Palermo in great numbers, in the limestone at Girgenti, and in that which alternates with volcanic rocks in the country between Syracuse and Vizzini, often at great heights above the sea.

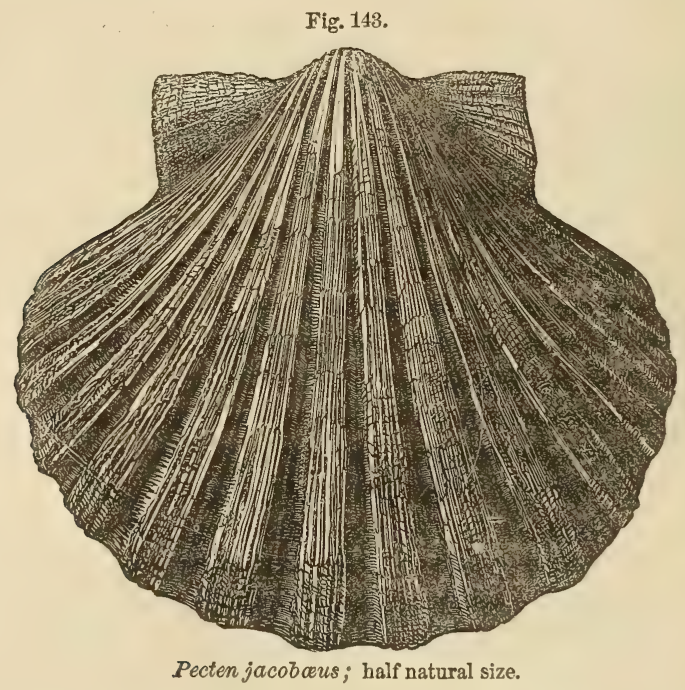

The more we reflect on the preponderating number of these recent shells, the more we are surprised at the great thickness, solidity, and height above the sea of the rocky masses in which they are entombed, and the vast amount of geographical change which has taken place since their origin. It must be remembered that, before they began to emerge, the uppermost strata of the whole must have been deposited under water. In order, therefore, to form a just conception of their antiquity, we must first examine singly the innumerable minute parts of which the whole is made up, the successive beds of shells, corals, volcanic ashes, conglomerates, and sheets of lava; and we must afterwards contemplate the time

* I am indebted to Mr. Lonsdale for the details above given respecting the structure of this coral. 
required for the gradual upheaval of the rocks, and the excavation of the valleys. The historical period seems scarcely to form an appreciable unit in this computation, for we find ancient Greek temples, like those of Girgenti (Agrigentum), built of the modern limestone of which we are speaking, and resting on a hill composed of the same; the site having remained to all appearance unaltered since the Greeks first colonized the island.

The modern geological date of the rocks in this region leads to another singular and unexpected conclusion, namely, that the fauna and flora of a large part of Sicily are of higher antiquity than the country itself, haring not only flourished before the lands were raised from the deep, but eren before their materials were brought together beneath the waters. The chain of reasoning which conducts us to this opinion may be stated in a few words. The larger part of the island has been conrerted from sea into land since the Mediterranean was peopled with nearly all the living species of testacea and zoophytes. We may therefore presume that, before this region emerged, the same land and river shells, and almost all the same animals and plants, were in existence which now people Sicily; for the terrestrial fauna and flora of this island are precisely the same as that of other lands surrounding the Mediterranean. There appear to be no peculiar or indigenous species, and those which are now established there must be supposed to have migrated from preexisting lands, just as the plants and animals of the Neapolitan territory hare colonized Monte Nuoro, since that rolcanic cone was thrown up in the sixteenth century.

Such conclusions throw a new light on the adaptation of the attributes and migratory habits of animals and plants to the changes which are unceasingly in progress in the physical geography of the globe. It is clear that the duration of species is so great, that they are destined to outlive many important rerolutions in the configuration of the earth's surface; and hence those innumerable contrivances for enabling the subjects of the animal and regetable creation to extend their range; the inhabitants of the land being often carried across the ocean, and the aquatic tribes over great continental spaces. It is obviously expedient that the terrestrial and fluriatile species should not only be fitted for the rivers, valleys, plains, and mountains which exist at the era of their creation, but for others that are destined to be formed before the species shall become extinct; and, in like manner, the marine species are not only made for the deep and shallow regions of the ocean existing at the time when they are called into being, but for tracts that may be submerged or variously altered in depth during the time that is allotted for their continuance on the globe.*

* The three last pages, on "The Newer Pliocene Strata of Sicily," are given rerbatim as they appeared thirty jears ago in the first edition of the Principles of Geology (vol. iii. p. 115, 1833). The last sentence, marked with inverted commas, was couched in language implying my adherence to the theory that each species was originally created such as it now exists, and was incapable of rarring so as 
Newer Pliocene strata of the Upper Val d'Arno.-When we ascend the Arno for about ten miles above Florence, we arrive at a deep narrow valley called the Upper Val d'Arno, which appears once to have been a lake at a time when the valley below Florence was an arm of the sea. The horizontal lacustrine strata of this upper basin are 12 miles long and 2 broad. The depression which they fill has been excavated out of Eocene and Cretaceous rocks, which form everywhere the sides of the valley in highly inclined stratification. The thickness of the more modern and unconformable beds is about 750 feet, of which the upper 200 feet consist of Newer Pliocene strata, while the lower are Older Pliocene. The newer series are made up of sands and a conglomerate called "sansino." Among the imbedded fossil mammalia are Mastodon arvernensis, Elephas meridionalis, Rhinoceros etruscus, Hippopotamus major, and remains of the genera bear, hyæna, and felis.

In the same upper strata are found, according to M. Gaudin, the leaves and cones of Glyptostrobus europceus, a plant closely allied to G. heterophyllus, now inhabiting the north of China and Japan. This conifer had a wide range in time, having been traced back to the Lower Miocene strata of Switzerland-and being common at Eningen in the Upper Miocene, as we shall see in the sequel, Chapter XV.

Newer Pliocene strata of England.-It is in the counties of Norfolk, Suffolk, and Essex, that we obtain our most valuable information respecting the British Pliocene strata, whether newer or older. They have obtained in those counties the provincial name of "Crag;" applied particularly to masses of shelly sand which have long been used in agriculture to fertilize soils deficient in calcareous matter.

In Suffolk the strata so named are divisible into the Lower, called the White, or Coralline, and the Upper, or the Red Crag; * but the inferior division occupies a very limited area, and the Red Crag usually reposes directly and without the intervention of the Coralline on older strata, as in Essex, for example, where the relative position of the Red Crag to the London Clay (an Eocene deposit) and to the

to pass into a new and distinct species. In my recent work on the Geological Evidences of the Antiquity of Man, I have shown (chaps. xxi. to xxiv.) that Mr. Darwin's theory of natural selection removes many of the principal difficulties which stood in the way of Lamarck's doctrine of transmutation; and had I inclined as much in 1833 toward embracing Mr. Darwin's views as I do now, I should have expressed myself somewhat differently. But I have thought it best not to recast a passage which has been so often cited, both by writers who opposed and approved of it. The main proposition which seemed so startling in 1833, namely, that species in general may be older than the lands and seas they inhabit, is now the creed of almost every geologist, whether he adopts or rejects the theory that species may be indefinitely modified in their organization under the influence of new conditions in the animate and inanimate world.

* See paper by E. Charleswortb, Esq.; London and Ed. Phil. Mag., No. xxxviii. p. 81, Aug. 1835 . 
Fig. 144 ,

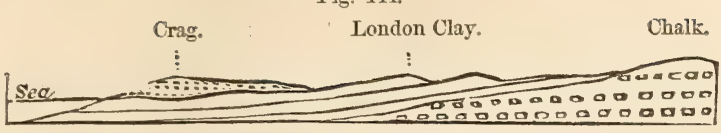

chalk is explained in the foregoing diagram. Both the White and the Red Crag, as we shall see in the sequel, belong to the Older Pliocene period, whereas a more modern deposit, occurring in the neighborhood of Norwich, is referable to the Newer Pliocene. It consists of beds of incoherent sand, loam, and gravel, which are exposed to view on both banks of the Yare near Norwich. As they contain a mixture of marine, land, and freshwater shells, with ichthyolites and bones of mammalia, it is clear that these beds have been accumulated at the bottom of a sea near the mouth of a river. They form patches varying from 2 to 20 feet in thickness, resting on white chalk, and are covered by a dense mass of stratified flint-gravel. The surface of the chalk is often perforated to the depth of several inches by the Pholas crispata, each fossil shell still remaining at the bottom of its cylindrical carity, now filled up with loose sand from the incumbent crag. This species of Pholas still exists, and drills the rocks between high and low water on the British coast. The most common shells of these strata, such as Fusus striatus, $F$. antiquus, Turritella communis, Cardium edule, and Cyprina islandica, are now abundant in the British seas; but with them are some extinct species, such as Nucula Cobboldice (fig. 145), and Tellina obliqua (fig. 146). Natica helicoides (fig: 147) is an example of a species formerly known only

Fig. 145.

Fig. 146 .

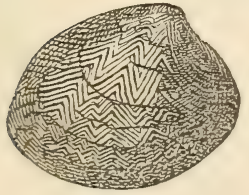

Nucula Cobboldice

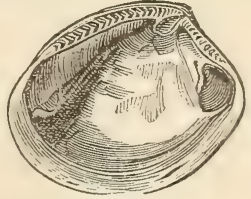

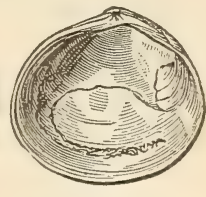

Tellina obliqua.
Fig. 147.

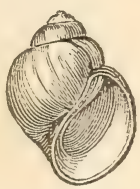

Natica helicoides, Johnston.

as fossil, but which has now been found living in our seas; and I have recently seen, in the British Museum, a living shell from Vancouver's Island, so closely allied to $N$. Cobboldice, that it would be considered by many as merely a marked variety of the same form.

The Norwich Crag is seen resting on chalk in the sea cliff between Weybourne and Cromer, and is found at many points to the westward in the interior. The only place where beds containing the peculiar shells of this formation have been found directly overlying the Red Crag is at Chillesford, near Orford in Suffolk; but we do not require the evidence of direct superposition to prove that the Norwich is a much newer deposit than the Red Crag, since the proportion of recent to extinct species is so much greater in the Norwich beds, amounting, 
according to the latest investigations, to 89 per cent., whereas in the Red Crag it does not exceed 60 per eent.

Among the accompanying remains of mammalia are those of a Mastodon, a portion of the upper jawbone with a tooth having been found by Mr. Wigham at Postwick, near Norwich. This species has also been found in the Red Crag, both at Sutton and at Felixstow, and was till lately regarded as an Upper Miocene or Falunian species; and under this persuasion, calling it $M$. angustidens, on the authority of Professor Owens, I suggested that its remains might have been washed out of older strata into the Crag, just as we sometimes observe London Clay and Chalk fossils introduced into the same deposit. But Dr. Falconer, who has devoted many years to the study of the fossil and recent Proboscideans, has shown that the fossil is a Pliocene species, first observed in Auvergne by MM. Croizet and Jobert, and named by them Mastodon arvernensis. Cuvier did not

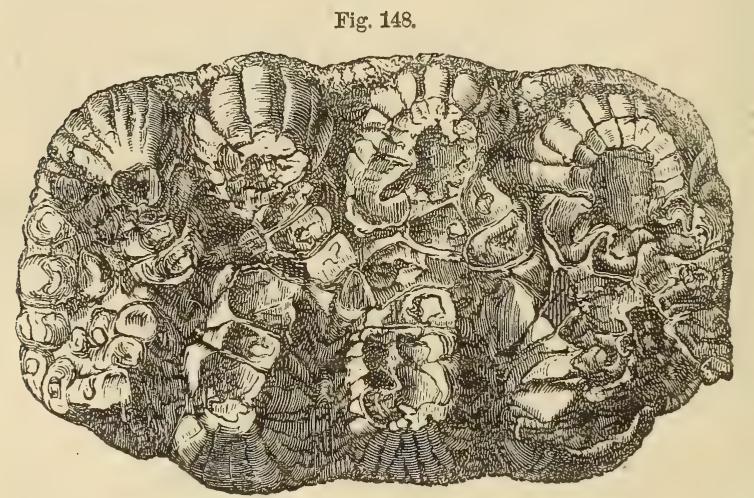

Mastodon arvernensis (Norwich Crag, Postwick, also found in Red Crag, see p. 202); third milk molar, left side, upper jaw; grinding surface, nat. size. Newer Pliocene.

adopt this name, for he had seen but a few specimens from Auvergne, and he confounded them with $M$. angustidens. The entire skeleton of both these Mastodons having now been obtained, they are found to be referable to two distinct sub-genera. The Crag' fossil belongs to the Tetralophodon of Falconer, a sub-genus of which five species are known, so called because there are four ridges in the penultimate true molar as well as in the two teeth which are placed immediately before it in both jaws. The Mastodon angustidens, on the other hand, belongs, with six other species, to the section called Tritophodon, in which the corresponding teeth have each three ridges; and is, according to MM. Lartet and Falconer, characteristic of the Faluns of Touraine, as well as of Sansan at the foot of the Pyrenees, and several other Miocene localities.

The Mastodon arvernensis, says Dr. Falconer, is the only one yet found in England. It abounds with the Hippopotamus major in the 
Pliocene strata of the Val d'Arno, as well as in strata of the same age in Piedmont and at Montpelier. It may be considered, therefore, as a characteristic Pliocene species in Italy, France, and Europe generally.

This Mastodon has never been found in the Cromer forest bed abore mentioned, p. 160, but sereral of the mammalia of that deposit, including the Elephas meridionalis, are common to the Norwich beds, and to the older or Red Crag. As to the Norwich Crag, it is now ascertained that it contains a larger proportion of living as compared to extinct shells than was formerly supposed; for many of the lost species once referred to this formation are worn specimens, few in number, and evidently washed out of the Red Crag into the newer strata. Others, which are really of contemporary date, and which were beliered to have died out, have been found living in the British seas, where they have become exceedingly rare. From the latest researches of Mr. S. P. Woodward, it seems probable that the extinet species do not exceed 11 in a hundred.

Chillesford beds.-It was stated that at Chillesford, near Woodbridge in Suffolk, the Norwich Crag has been found overlying the Red Crag. In this case the Newrer Pliocene beds are argillaceous, and about 20 feet thick. Messrs. Prestwich and Searles Wood obtained from them 23 species of shells, of which 2 only, Nucula Cobboldioe and Tellina obliqua, are extinct. Among the other, or liring species, a large proportion, such as Leda lanceolata, Cardium gronlandicum, Lucina borealis, Cyprina islandica, Panopeea norvegica, and Mya truncata, betray a northern and some of them an Arctic character. There is good reason to believe that the Chillesford beds are older than the forest bed of Cromer, before alluded to ; and when we consider that these fossils occur within eighty miles of London, in the $52 \mathrm{~d}$ parallel of latitude, we see in them a proof that the glacial epoch began before the end of the Post-pliocene period.*

Bridlington beds.-At Bridlington, on the coast of Yorkshire, near Flamborough Head, lat. $54^{\circ} \mathrm{N}$., another deposit occurs of about the same age as the Chillesford beds, and therefore older than the Cromer Forest, though somewhat newrer than the Norwich Crag before described, for it contains a still larger proportion of recent shells. The deposit is heterogeneous in composition, consisting of sand and clay, with pebbles of rarious rocks, chalk and flint being the most abundant. The prevailing color resembles that of London Clay. Mr. S. P. Woodward has lately been able to add 32 new species to the fossils of this formation br studring the collections of MLessrs. Bean and Leckenley at Scarborough, bringing up the total number to 64 , of which 4 only are extinct, $\uparrow$ namely, Natica occlusa, Cardita analis, Nucula Cobboldice, and Tellina obliqua, giving a proportion of only 6 
per cent. of extinct species instead of 11, as in the Norwich beds on the Yare. Of the whole 64 shells, 36 are common to the Norwich Crag proper, and 12 are peculiar to Bridlington, or were not previously known in any pliocene or glacial deposits in Great Britain. What is most remarkable is the fact, that of the 60 species which remain after abstracting the extinct forms, no less than 30 are inhabitants of the Arctic regions, none of them extending southward to the British seas. This is the more singular when we consider that Bridlington is situated in lat. $54^{\circ} \mathrm{N}$. It will be seen in the next chapter that the cold came on gradually, beginning when the White Crag was formed, and increasing in the period of the Red Crag, and still more in that of the Norwich formation, during which there may have been several oscillations of temperature. The refrigeration seems to have reached its maximum, and to have been developed most extensively in Europe in Post-pliocene times. It may, no doubt, be said that the shells of Moel Tryfaen above mentioned, found at a height of nearly 1400 feet above the sea, and in lat. $53^{\circ} \mathrm{N}$., or nearly the same as that of Bridlington, do not imply so great a cold as the latter, as they only contain 11 shells in 54 of exclusively Arctic character, or only one-fifth of the whole number of species, instead of nearly half, as in the case of Bridlington. But the fauna of Moel Tryfaen does not illustrate the extreme cold of the glacial period like the beds of Errol and Elie, on the borders of the Tay and Forth. (See p. 153.)

\section{OLDER PLIOCENE STRATA.}

Red Crag of Suffolk.-The Crag of Suffolk, as already mentioned, is divisible into the Upper or Red, and the Lower or White Crag.*

These deposits, according to the late E. Forbes, appear by their imbedded shells to have been formed in a sea of moderate depth, usually from 15 to 25 fathoms, but in some few spots perhaps deeper. Yet they cannot be called littoral, because the fauna is such as may have extended 40 or 50 miles from land. The Upper or Red Crag consists chiefly of quartzose sand, with an occasional intermixture of shells, for the most part rolled, and sometimes comminuted. It is distinguished by the deep ferruginous or ochreous color, both of its sands and shells, while the Older Crag, commonly called the Coralline, is white. Both formations are of moderate thickness; the Red Crag rarely exceeding 40 , and the Coralline seldom amounting to 20 feet. But their importance is not to be estimated by the density of the mass of strata or its geographical extent, but by the extraordinary richness of its organic remains, belonging to a very peculiar type, which seems to characterize the state of the living creation in the north of Europe during the Older Pliocene era.

* See paper by E. Charlesworth, Esq. ; London and Ed. Phil. Mag., No. xxxviii. p. 81 , Aug. 1835 . 
The relative position of the Red Crag in Essex and the subjacent London clay and chalk has been already pointed out (fig. 144). Whenever the two divisions are met with in the same district, the Red Crag lies uppermost; and in some cases, as in the section represented in fig. 149, which I had an opportunity of seeing exposed to

Fig. 149.

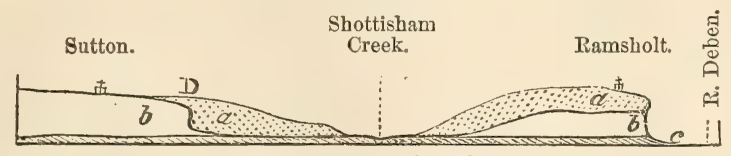

Section near Ipswich, in Suffolk.

$a$. Red Crag. $\quad$ b. Coralline Crag. c. London Clay.

riew in 1839 , it is clear that the older or Coralline mass $b$ had suffered denudation before the newer formation $a$ was thrown down upon it. At D there is not only a distinct cliff, 8 or 10 feet high, of Coralline Crag, running in a direction N.E. and S.W., against which the Red Crag abuts with its horizontal layers ; but this cliff occasionally overhangs. The rock composing it is drilled everywhere by. Pholades, the holes which they perforated having been afterwards filled with sand and covered over when the newer beds were thrown down. As the older formation is shown by its fossils to have accumulated in a deeper sea ( 15 , and sometimes 25 , fathoms deep or more), there must no doubt have been an upheaval of the sea-bottom before the cliff here alluded to was shaped out. We may also conclude that so great an amount of denudation could scarcely take place, in such incoherent materials, without many of the fossils of the inferior beds becoming mixed up with the overlying crag, so that considerable difficulty must be occasionally experienced by the palæontologists in deciding which species belong severally to each group.

The Red Crag being formed in a shallower sea, often resembles in structure a shifting sandbank, its layers being inclined diagonally, and the planes of stratification being sometimes directed in the same quarry to the four cardinal points of the compass, as at Butley. That in this and many other localities, such a structure is not deceptive or due to any subsequent concretionary rearrangement of particles, or to mere lines of color, is proved by each bed being made up of flat pieces of shell which lie parallel to the planes of the smaller strata.

Some fossils which are very abundant in the Red Crag, have never been found in the white or coralline division; as, for example, the Fusus contrarius (fig. 150), and several species of Murex and Buccinum (or $N$ assa) (see figs. 151, 152), which two genera seem wanting in the Lower Crag.

Mauy of these shells are found in a good state of preservation in the cliffs of Walton-on-Naze, in Essex; at Felixstow the cliffs afford fewer shells, and most of them are fragmentary. 
Fig. 150.

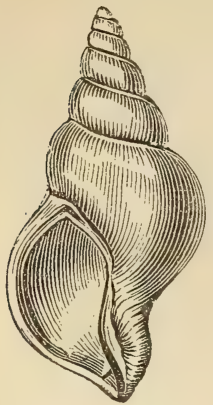

Fusus contrarius.

Fossils characteristic of the Red Crag.

Fig. 151.

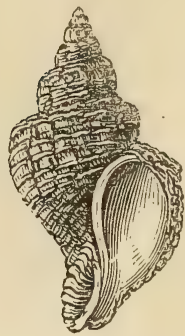

Purpura tetragona.
Fig. 152.

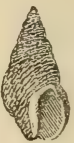

Nassa granulata.

Fig. 15̃3.

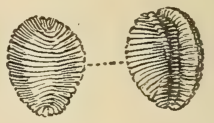

Cyproa europcea.

Fig. 150 half nat. size; the others nat, size.

Among the bones and teeth of fishes are those of large sharks (Carcharodon), and a gigantic skate of the extinct genus Myliobates, and many other forms, some common to our seas, and many foreign to them. It is questionable, however, whether all these can really be ascribed to the era of the Red Crag. Not a few of them may possibly have been derived from older strata, especially from those Lower Miocene formations to be described in the next chapter, which are largely developed in Belgium, and of which a fragment only (the Hempstead beds of Forbes) escaped denudation in England.

Many of the fossils found in the Red Crag have been washed out of older Tertiary strata, especially out of the Liondon Clay. This is particularly the case in one of the lower beds, which has of late been much used in agriculture for manure, as containing nodules of phosphate of lime. These nodules often include crabs and fishes like those of the London Clay, and thus clearly betray the date of their origin. With the nodules (in which there is nearly 60 per cent. of phosphate of lime), occur rolled flint pebbles, and others of sandstone, containing casts of crag-shells and many ear-bones of whales.

Fig. 154.

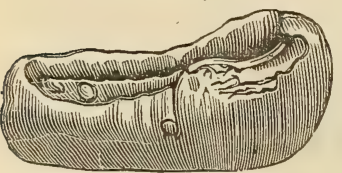

Tympanic bone of Balcena emarginata, Owen; Red Crag, Felixstow.

Some teeth of the Mastodon arvernensis, and of a rhinoceros and tapir, have also been found in the same bed, which has been worked near Felixstow among other places. As to the earbones of cetacea, Professor Henslow found those of two or three distinct species in this detrital bed at Felixstow. They belong, according to Professor Owen, to true whales of the family Balcenidoe (fig. 154). Mr. Wood is of opinion that they are of the age of the Red Crag, or if not, that they may be derived from the destruction of beds of Coralline Crag.

White or Coralline Crag.-The lower or Coralline Crag is of very limited extent, ranging over an area about 20 miles in length, and 3 
or 4 in breadth, betreen the rirers Alde and Stour. It is ggenerally calcareous and marly-a mass of shells, bryozoa," and small corals, passing occasionally into a soft building stone. At Sudbourn, near Orford, where it assumes this character, are large quarries, in which the bottom of it has not been reached at the depth of 50 feet. At some places in the neighborhood, the softer mass is dirided by thin flag's of hard limestone, and bryozoa placed in the upright position in which they grew.

From the abundance of these bryozoa or coralloid mollusca the lotrest or White Crag obtained its popular name; but true corals, as now defined, or zoantharia, are very rare in this formation.

The distinctness of the fossils of the Coralline from those of the Red Crag, arises in part from their higher antiquitr, and, in some degree, from a difference in the geographical conditions of the submarine bottom. The prolific gromth of echini, bryozoa, and a prodigious rarietr of testacea, implies a region of deeper and more tranquil water; whereas, the Red Crag may hare been formed afterward on the same spot, when the water mas shallower. In the mean time the climate became decidedly somemhat cooler, and some of the zoophrtes which flourished in the first period disappeared, so that the fauna of the Red Crag acquired a character more nearly resembling that of our northern seas, as is implied by the large development of certain sections of the genera Fusus, Buccinum, Purpura, and Trochus, proper to high latitudes, and which are manting or feebly represented in the inferior crag.

Some of the corals and bryozoa of the lower Crag of Suffolk belong to genera unknomn in the liring creation, and of a rery peculiar structure; as, for example, that represented in the figure (155) on the following page, which is one of sereral species haring a globular form. The great number and rariety of these zoophytes probably indicate an equable climate, free from intense cold in winter. On the other hand, that the heat was nerer excessire is confirmed by the preralence of northern forms among the testacea, such as the Glycimeris, Cyprina, and Astarte. Of the genus last mentioned (see fig. 156) there are about fourteen species, many of them being rich in individuals; and there is an absence of genera peculiar to hot climates, such as Conus, Oliva, Mitra, Fasciolaria, Crassatella, and others. The comries (Cypreca, fig. 153), also, are small, and belong to a section (Trivin) now inhabiting the colder regions. A large rolute,

* Ehrenberg proposed in 1831 the term Bryozoum, or "Moss-animal," for the molluscous or ascilian form of poltr, characterized by haring tro openings to the digestive sack, as in Escleara, Flustra, Retepora, and other zoophrtes popularly included in the corals, but now classed br naturalists as mollusca. The term Polyzoum, snnonrmous with Bryozoum, was, it seems, proposed in 1830 , or the rear before, br Ir. J. T. Thompson, but is less generally adopted. The animals of the Zoantharia of Milne Edwards and Haime, or the true corals, hare only one opening to the stomacb. 
called Voluta Lamberti (fig. 157), may seem an exception; but it differs in form from the volutes of the torrid zone, and may, like the living Voluta Magellanica, have been fitted for an extra-tropical climate:

The occurrence of a species of Lingula at Sutton (see fig. 160) is worthy of remark, as these Brachiopoda seem now confined to more iequatorial latitudes; and the same may be said still more decidedly

Fig. 155.
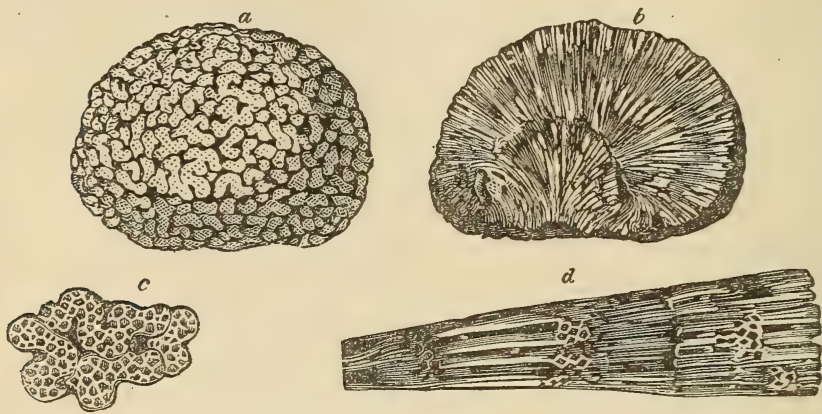

Fascicularia aurantium, Milne Edwards. Family, Tubuliporidce, of same author.

Bryozoan of extinct genus, from the inferior or Coralline Crag, Suffolk.

a. Exterior. $\quad$ b. Vertical section of interior.

c. Portion of exterior magnified.

$d$. Portion of interior magnified, showing that it is made up of long, thin, straight tubes united in conical bundles.

Fig. 156 .

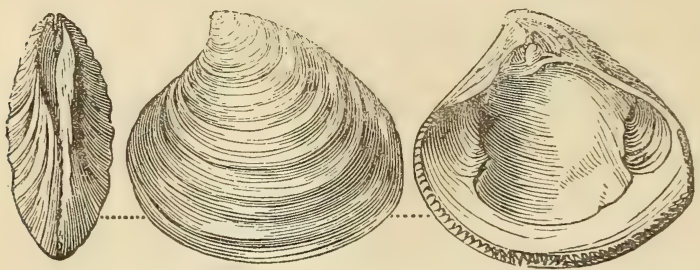

Astarte (Crassina, Lam.); species common to upper and lower crag.

1 starte Omalii, Lajonkaire; Syn. A. bipartita, Sow. Min. Con. T. 521, f. 3; a very rariable species, most characteristic of the Coralline Crag, Suffolk.

Fig. 157.

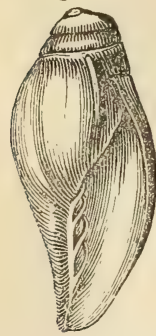

Voluta Lamberti, young individ., Cor, and Red Crag.
Fig. 153.

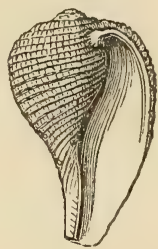

Pyrula reticulata, Lam.; Coralline Crag, Ramsholt.
Fig. 159.

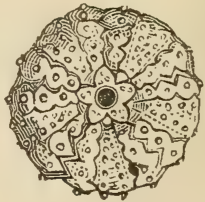

Temnechinus excavatus, Forbes; Temnopleurus excavatus, Wood; Cor. Crag, Ramsholt. 
of a species of Pyrula, supposed by Mr. Wood to be identical with P. reticulata (fig. 158), now living in the Indian Ocean. A genus also of echinoderms, called by Professor Forbes Temnec?inus (fig. 159), is peculiar to the Red and Coralline Crag of Suffolk. The only species now living occur in the Indian Ocean. .

One of the most interesting conclusions deduced from a careful comparison of the shells of these British Older Pliocene strata and the fauna of our present seas, has been pointed out by Professor E. Forbes. It appears that, during the glacial period, a period intermediate, as we have seen, between that of the crag and our own time, many shells, previously established in the temperate zone, retreated southward to aroid an uncongenial climate. The Professor has given a list of fifty shells which inhabited the British seas while the Coralline and Red Crag were forming, and which, though now living in our seas, are all wanting in the glacial deposits. They must therefore, after their migration to the south, which took place during the glacial period, have made their way northward again. In corroboration of these riews, it is stated that all these fifty species occur fossil in the Newer Pliocene strata of Sicily, Southern Italy, and the Grecian Archipelago, where they may have enjoyed, during the era of floating icebergs, a climate resembling that now prevailing in higher European latitudes.*

The following tables have been drawn up for me by Mr. Samuel P. Woodward, shoming the results of a comparison of the lists of Crag shells described by Mr. Searles Wood in his excellent monograph on the fossil testacea of the British Pliocene formations. The list of the Norwich Crag shells has been corrected and enlarged by Mr. Woodward himself. They exhibit clear evidence of a gradual refrigeration of climate, which went on in the area of England from the time of the older to that of the most modern Pliocene strata, a refrigeration which has already been inferred from an examination of the Crag shells in $\mathbf{1 8 4 6}$ by the late Edward Forbes.

Number of known Species of Marine Testacea in the three English Pliocene Deposits, called the Norwich, the Red, and the Coralline Crays.

$\begin{array}{llllll}\text { Brachiopoda, } & - & - & - & - & - \\ \text { Conchifera, } & - & - & - & - & -210 \\ \text { Gasteropoda, } & - & - & - & - & - \\ & & & \\ & & & \\ & & & \\ & & & \end{array}$

* E. Forbes, Mem. Geol. Survey Gt. Brit., vol. i. p. 386.

+ Mem. of Geol. Survey, London, 1846, p. 391.

$\ddagger$ The 25 shells peculiar to Bridlington (p. 199) are not included in the Norwich Crag shells of these tables. 


\section{Distribution of the above Marine Testacea.}

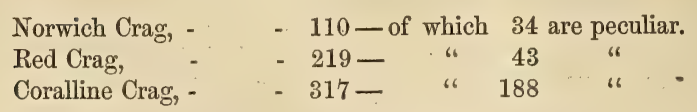

\section{Species common to the}

Norwich and Red Crag, and not in Coralline, Norwich and Coralline, and not in Red, Red and Coralline, and not in Norwich, - - 103

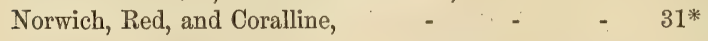

Proportion of Recent to Extinct Species.

\begin{tabular}{|c|c|c|c|c|}
\hline & & Recent. & Extinct. & $\begin{array}{l}\text { Per-centage of Recent. } \\
89\end{array}$ \\
\hline Norwich Crag, & - & $\begin{array}{l}-\quad 98 \\
-\quad 100\end{array}$ & & $\begin{array}{r}89 \\
60\end{array}$ \\
\hline Red Crag, & - & $\begin{array}{l}-132 \\
-165\end{array}$ & $\begin{array}{r}87 \\
152\end{array}$ & $\begin{array}{l}60 \\
52\end{array}$ \\
\hline
\end{tabular}

\section{Recent Species not living now in British Seas.}

\begin{tabular}{|c|c|c|c|c|c|}
\hline & & & & Northern. & Southern \\
\hline Norwich Crag, & - & - & - & 15 & 0 \\
\hline Red Crag, - & - & - & - & 11 & 19 \\
\hline Coralline Crag, & - & - & - & 1 & 28 \\
\hline
\end{tabular}

In the above list the shells of the Glacial beds, those, for example, of the Clyde, Errol, and Elie, and Moel Tryfaen (pp. 154 and 158), and other British deposits newer than the Norwich Crag, have not been included. The land and freshwater shells have also been purposely omitted, as well as some London Clay shells, and others suspected to be spurious.

By far the greater number of the recent marine species included in these tables are still inhabitants of the British seas; but even these differ considerably in their relative abundance, some of the commonest of the Crag shells being now extremely scarce; as, for example, Buccinum Dalei, and others rarely met with in a fossil state, being now very common, as Murex erinaceus and Cardium echinatum.

The last table throw's light on a marked alteration in the climate of the three successive periods. It will be seen that in the Coralline Crag there are 28 Southern shells, including 26 Mediterranean and 1 West Indian species (Erato Maugerice). Of these only 13 occur in the Red Crag, associated with 3 new Southern species, while the whole of them disappear from the Norwich beds. On the other hand, the Coralline Crag contains only 2 shells closely related to living Northern forms, namely, Admete and Limopsis; whereas, in the Red Crag, as

* These 31 species must be added to the numbers 42,3 , and 103, respectively, in order to obtain the full amount of common species in each of those cases. 
stated in the table, there are 11 Northern species all common to the Norwich Crag, in which last we have also 4 additional inhabitants of the Arctic regions; so that there is good evidence of a continual refrigeration of climate during the Pliocene period in Britain. The presence of these Northern shells cannot be explained away by supposing that they were inhabitants of the deep parts of the sea; for some of them, such as Tellina calcarea $(=T$. obliqua) and Astarte borealis, occur plentifully, and sometimes with the valves united by their ligament, in company with other littoral shells, such as Mya arenaria and Littorina rudis, and evidently not thrown up from deep water. Yet the Northern character of the Norwich Crag is not fully shown by simply saying that it contains 12 Northern species. It is the predominance of certain genera and species, such as Rhynchonclla psittacea, Tellina calcarec, Astarte borealis, Scalaria gronlandica and Fusus carinatus which satisfies the mind of a conchologist as to the Arctic character of the Norwich Crag. In like manner, it is the presence of such gonera as Pyrula, Columbella, Terebra, Cassidaria, Pholadomya, Lingula, Discina, and others, which give a southern aspect to the Coralline Crag shells.

The cold, which had gone on increasing from the time of the Coralline to that of the Norwich Crag, continued, though not perhaps without some oscillations of temperature, to become more and more severe after the accumulation of the latter, until it reached its maximum in what has been called the glacial epoch. The marine fauna of this last period contains, both in Ireland and Scotland, recent species of mollusea now living in Greenland and other seas far north of the areas where we find their remains in a fossil state.

Antwerp Crag.-Strata of the same age as the Red and Coralline Crag of Suffolk have been long known in the country round Antwerp and on the banks of the Scheidt, below that city. More than 200 species of testacea had been collected by MM. De Wael, Nyst, and others, when I risited Antwerp in 1851, of which two-thirds were indentified with Suffolk fossils by Mr. Wood. Among these he recognized Lingula Dumortieri of Nyst (fig. 160), which I found in. abundance in what was called by M. de Wael the Middle Crag. More than half of the shells of this Antwerp deposit agree with living species, and these belong in great part to the fauna of our Northern scas, though some Mediterranean species appear among them. I also met with numerous cetacean bones of the genera Balconoptera and Ziphius in the Upper Antwerp Crag. They are not rolled, as if washed out of older beds, and I infer that the Lingule Dumortieri, Nysto animals to which they belong once coexisted in the same sea with the associated fossil mollusca.* 
Three divisions of the Antwerp Crag have been recognized by the Belgian geologists : first, the Uppermost or Yellow Crag, in which 81 species of shells were known when I gave a list of them in 1852; secondly, the Middle Crag, from which 94 species were known; and thirdly, the lowest or Black Crag, from which 65 shells had been obtained. This bed derives its name from the dark color of most of the sand, which consists of green grains of glauconite.

There can be no doubt that the two first formations are referable to the Older Pliocene period, the Yellow Crag containing about 60 per cent. of recent species, while the Middle or Grey Crag contains about 50 per cent. Their close connection with the Red and Coralline Crag of Suffolk is equally clear, for in a list of 52 shells from the Upper or Yellow Crag, and of 94 from the Middle Crag, there are only 7 species which are not found in the British formations of corresponding age. As we might have expected, the Upper Antwerp Crag agrees more with the Red Crag of England, while the shells of the Middle Antwerp Crag correspond more with the Older or Coralline group of Suffolk.

But when we come to the Lowest or Black Crag we are beginning to pass beyond the limits of the Older Pliocene formations, and approaching the Miocene. Only two-thirds of the shells agree with those of the Coralline Crag, and somewhat less than half of the fossil species are identifiable with species still living. They seem to form the first links of a chain of passage by which we shall in time be conducted without a break to those older formations, the Upper Miocene of Belgium, to be treated of in the next chapter.

Normandy.-I observed in 1840 a small patch of shells corresponding to those of the Suffolk Crag, near Valognes, in Normandy; and - there is a deposit containing similar fossils at St. George Bohon, and several places a few leagues to the south of Carentan, in Normandy; but they have never been traced farther southward.

OLDER PLIOCENE FORMATIONS IN ITALY.

Subapennine Strata.-The Apennines, it is well known, are composed chiefly of secondary rocks, forming a chain which branches off from the Ligurian Alps and passes down the middle of the Italian peninsula. At the foot of these mountains, on the side both of the Adriatic and the Mediterranean, are found a series of tertiary strata, which form, for the most part, a line of low hills occupying the space between the older chain and the sea. Brocchi, as we have seen (p. 183), was the first Italian geologist who described this newer group in detail, giving it the name of the Subapennine; and he classed all the tertiary strata of Italy, from Piedmont to Calabria, as parts of the same system. Certain mineral characters, he observed, were common to the whole; for the strata consists generally of light brown or blue marl, covered by yellow calcareous sand and gravel. There are also, he 
added, some species of fossil shells which are found in these deposits throughout the whole of Italy.

We have now, however, satisfactory evidence that the Subapennine beds of Brocchi, although chiefly composed of Older Pliocene strata, belong nevertheless, in part, both to older and newer members of the tertiary series. The strata, for example, of the Superga, near Turin, are Niocene; those of Asti and Parma Older Pliocene, as is the blue marl of Sienna; while the shells of the incumbent yellow sand of the same territory approach more nearly to the recent fauna of the Mediterranean, and may be Newer Pliocene.

We have seen that most of the fossil shells of the Older Pliocene strata of Suffolk which are of recent species are identical with testacea now living in British seas, yet some of them belong to Mediterranean species, and a few even of the genera are those of warmer climates. We might therefore expect, in studying the fossils of corresponding age in countries bordering the Mediterranean, to find among them some species and genera of warmer latitudes. Accordingly, in the marls belonging to this period at Asti, Parma, Sienna, and parts of the Tuscan and Roman territories, we observe the genera Conus, Cyprcea, Strombus, Pyrula, Mitra, Fasciolaria, Sigaretus, Delphinula, Ancillaria, Oliva, Terebellum, Terebra, Perna, Plicatula, and Corbis, some characteristic of tropical seas, others represented by species more numerous or of larger size than those now proper to the Mediterranean.

The proportion borne by the recent to the extinct species varies in the same district, as Professor Ponzi pointed out to me, in 1857, in the neighborhood of Rome, according to the place in the series occupied by different sets of superimposed marls and sands.

The classification of these several members of the Pliocene period, and the separation of them from the Miocene, is a task the accomplishment of which will task the skill and industry of the Italian geologists for many years to come.

I have already alluded to the Newer Pliocene deposits of the Upper Val d'Arno above Florence, and stated that below those sands and conglomerates, containing the remains of the Elephas meridionalis and other associated quadrupeds, lie an older horizontal and conformable series of beds, which may be classed as Older Pliocene. They consist of blue clays with some subordinate layers of lignite, and exhibit a richer flora than the overlying Newer Pliocene beds, and one receding farther from the existing vegetation of Europe. They also comprise more species common to the antecedent $\lambda$ Hiocene period. Among the genera of flowering plants II. Gaudin enumerates Pinus, Glyptostrobus, Taxodium, Sequoia, Ilex, Quercus, Prunus, Platanus, Alnus, Ulmus, Ficus, Laurus, Persea, Oreodaphne (fig. 161), Cinnamomum, Cassia, Acer, Juglans, Betula, Rhamnus, Carya, Rhas, Smilax, Sassafras, Psoralea, and some others.

This-assemblage of plants indicates a warm climate, but not so 
subtropical a one as that of the Upper Miocene period, which will presently be considered.

M. Gaudin, jointly with the Marquis Strozzi, has thrown much light on the botany of beds of the same age in another part of Tuscany at a place called Montajone, between the rivers Elsa and Evola, where, among other plants, is found the Oreodaphne Heerii, Gaud. (see fig. 161), which is probably only a variety of Oreodaphne foetens,

Fig. 161.

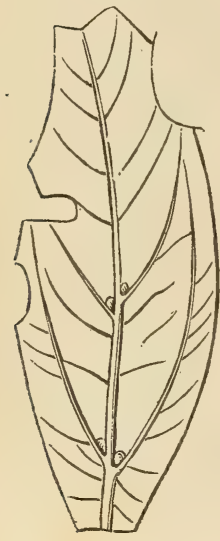

Oreodaphne Heerii. Leaf half nat. size.*
Fig. 162.

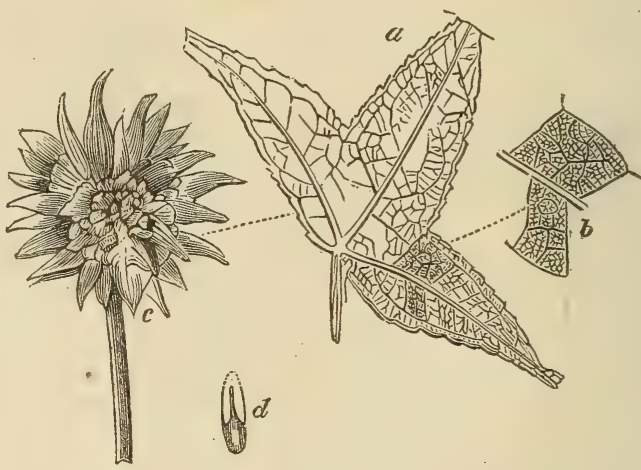

Liquidambar curopoвum var. trilobatum, A. Br.; (sometimes 4-lobed and more commonly 5-lobed).

$a$. Leaf, half nat. size. c. Fruit, nat. size.

b. Part of same, nat. size. $\quad d$. Seed, do. EEningen.

or the laurel called the Til in Madeira, where, as in the Canaries, it constitutes a large portion of the native woods, but cannot now endure the climate of Europe. In the fossil specimens the same glands or protuberances as those which are observed in the axils of the primary veins of the leaves in the recent Til are preserved. $\uparrow$

Another plant also indicating a warmer climate is the Liquidambar europceum, Brong. (see fig. 162), a species nearly allied to $L$. styracifluum, L., which flourishes in most places in the Southern States of North America, on the borders of the Gulf of Mexico.

As the leaves come nearer to this American form, while the fruit, according to Heer, is smaller and nearer to the Syrian Liquidambar orientale, the fossil may, according to the doctrine of transmutation, have been the original stock from which both have diverged. The Javanese Liquidambar is very distinct; the fossil, according to Heer, ranges from the Older Pliocene to the Newer Miocene, but the genus has now disappeared from Europe.

* Feuilles fossiles de la Toscane. Contributions à la Flore fossile Italienne. Gaudin and Strozzi. Plate 11, fig. 3.

† Gaudin, p. 22. 
The Tuscan blue marls of various localities, from which the abovementioned flora was obtained, have yielded 36 species of marine mollusca, in which 16, according to M. Karl Mayer, are recent.

Aralo-Caspian formations.-This name has been given by Sir R. Murchison and M. de Verneuil to the limestone and associated sandy beds of brackish-water origin, which have been traced over a very extensire area, surrounding the Caspian, Azof, and Aral Seas, and parts of the northern and western coasts of the Black Sea. The fossil shells are partly freshwater, as Paludina, Neritina, \&c., and partly marine, of the family Cardiacice and Mytili. The species are identical, in great part, with those now inhabiting the Caspian; and when not living, they are analogous to forms now found in the inland seas of Asia, rather than to oceanic types. The limestone rises occasionally to the height of several hundred feet above the sea, and is supposed to indicate the former existence of a rast inland sheet of brackish water as large as the Mediterranean, or larger.

The proportion of recent species agreeing with the fauna of the Caspian is so considerable, as to leave no doubt in the minds of the geologists abore cited that this rock, also called by them the "Steppe Limestone," belongs to the Pliocene period.*

* Geol. of Russia, p. 279. 


\title{
CHAPTER XIV.
}

\author{
MIOCENE PERIOD.
}

Upper Miocene strata of France-Faluns of Touraine-Depth of sea and littoral character of fauna-Tropical climate implied by the testacea-Proportion of recent species of shells-Faluns more ancient than the Suffolk Crag-Varieties of Voluta Lamberti peculiar to Faluns and to Suffolk Crag-The same species are common to more than one geological Period-Lower Miocene strata of France-Remarks on classification, and where to draw the line of separation between Miocene and Eocene strata-Relations of the Grès de Fontainebleau to the Faluns and to the Calcaire Grossier-Lower Miocene strata of Central France-Lacustrine strata of Auvergne-Indusial limestone-Fossil mammalia of the Limagne d'Auvergne-Freshwater strata of the Cantal-Its resemblance in some places to white chalk with flints-Proofs of gradual deposition-Miocene strata of Bordeaux and South of France-Upper Miocene strata of GersDryopithecus-Belgian and British Miocene formations-Edeghem beds near Antwerp-Diest sands of Belgium and contemporaneous iron-sands of North Downs-Upper Miocene beds of Belgium-Bolderberg-Lower Miocene strata of Kleyn Spawen-Hempstead beds, Isle of Wight-Bovey Tracey Lignites in Devonshire-Isle of Mull Leaf-beds-Miocene formations of GermanyMayence basin-Upper Miocene beds of Vienna basin-Lower Miocene of Croatia-Fossil Lepidoptera-Oligocene strata of Professor Beyrich-Miocene strata of Italy.

\section{MIOCENE STRATA OF FRANCE.-UPPER MIOCENE FALUNS OF} TOURAINE.-MIOCENE FORMATIONS.

THE strata which we meet with next in the descending order are those called by many geologists "Middle Tertiary," for which in 1833 I proposed the name of Miocene, selecting the "faluns" of the valley of the Loire in France as my example or type.

I shall now call these Falunian deposits Upper Miocene, to distinguish them from others to which the name of Lower Miocene will be given. The latter were classed by me in former editions of this work as Upper Eocene, and the reasons which have induced me to alter this classification will be fully explained to the reader in this and the following chapter. The term "faluns" is given provincially by French agriculturists to shelly sand and marl spread over the land in Touraine, just as the "crag" was formerly much used to fertilize the soil in Suffolk. Isolated masses of such faluns occur from near the mouth of the Loire, in the neighborhood of Nantes, to as far inland as a district south of Tours. They are also found at Pontlevoy, on the Cher, about 70 miles above the junction of that river with the Loire, and 30 miles S.E. of Tours. Deposits of the same age also appear under new mineral conditions near the 
towns of Dinan and Rennes, in Brittany. I have visited all the localities abore enumerated, and found the beds on the Loire to consist principally of sand and marl, in which are shells and corals, some entire, some rolled, and others in minute fragments. In certain districts, as at Doué, in the department of Maine and Loire, 10 miles S. W. of Saumur, they form a soft building-stone, chiefly composed of an aggregate of broken shells, bryozoa, corals, and echinoderms, united by a calcareous cement; the whole mass being very like the Coralline Crag near Aldborough and Sudbourn in Suffolk. The scattered patches of faluns are of slight thickness, rarely exceeding 50 feet; and between the district called Sologne and the sea they repose on a great variety of older rocks; being; seen to rest successively upon gneiss, clayslate, various secondary formations, including the chalk; and, lastly, upon the upper freshwate: limestone of the Parisian tertiary series, which, as before mentioned (p. 183), stretches continuously from the basin of the Seine to that of the Loire.

At some points, as at Louans, south of Tours, the shells are stained of a ferruginous color, not unlike that of the Red Crag of Suffolk. The species are, for the most part, marine, but a few of them belong to land and fluviatile genera. Among the former, Helix turonensis (fig. 45, p. 30) is the most abundant. Remains of terrestrial quadrupeds are here and there intermixed, belonging to the genera Deinotherium (fig. $162 \alpha$ ), Mastodon, Rhinoceros, Hippopotamus, Chæropotamus, Dichobune, Deer, and others, and these are accompanied by cetacea, such as the Lamantine, Morse, Sea-Calf, and Dolphin, all of extinct species.

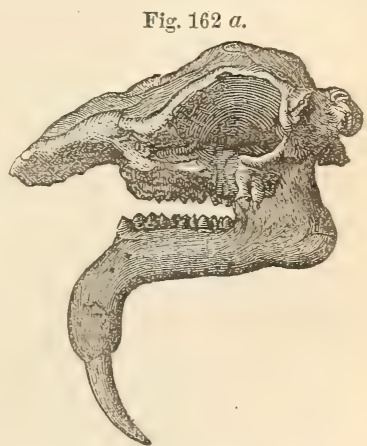

Deinotherium giganteum, Kaup.

Professor E. Forbes, after studying the fossil testacea which I obtained from these beds, informs me that he has no doubt they were formed partly on the shore itself at the level of low water, and partly at very moderate depths, not exceeding ten fathoms below that level. The molluscous fauna of the "faluns" is on the whole much more littoral than that of the Red and Coralline Crig of Suffolk, and implies a sballower sea. It is, moreover, contrasted with the Suffolk Crag by the indications it affords of an extra-European climate. Thus it contains seren species of Cypreca, some larger than any existing cowry of the Mediterranean, several species of Oliza, Ancillaria, Mitra, Terebra, Pyrula, Fasciolaria, and Conus. Of the cones there are no less than eight species, some very large, whereas the only European cone is of diminutive size. The genus Nerita, and many others, are also represented by individuals of a type now characteristic of equatorial seas, and wholly unlike any Mediterranean forms. These proofs of a more elerated temperature seem to imply the higher antiquity of the faluns as compared with the Suffolk Crag, and 
are in perfect accordance with the fact of the smaller proportion of testacea of recent species found in the faluns.

Out of 290 species of shells, collected by myself in 1840 at Pontlevoy, Louans, Bossée, and other villages twenty miles south of Tours; and at Savigné, about fifteen miles northwest of that place, seventy-two only could be identified with recent species, which is in the proportion of twenty-five per cent. A large number of the 290 species are common to all the localities, those peculiar to each not being more numerous than we might expect to find in different bays of the same sea.

The total number of testaceous mollusca from the faluns, in my possession, is 302 ; of which forty-five only were found by $\mathrm{Mr}$. Wood to be common to the Suffolk Crag. The number of corals, including bryozoa and zoantharia, obtained by me at Doué, and other localities before adverted to, amounts to forty-three, as determined by Mr. Lonsdale, of which seven (one of them a zoantharian) agree specifically with those of the Suffolk Crag. Only one has, as yet, been identified with a living species. But it is difficult, notwithstanding the advances recently made by MM. Dana, Milne Edwards, Haime, and Lonsdale, to institute a satisfactory comparison between recent and fossil zoantharia and bryozoa. Some of the genera occurring fossil in Touraine, as the Astrea, Dendrophyllia, Lunulites, have not been found in European seas north of the Mediterranean; nevertheless the zoantharia of the faluns do not seem to indicate on the whole so warm a climate as would be inferred from the shells.

It was stated that, on comparing about 300 species of Touraine shells with about 450 from the Suffolk Crag, forty-five only were found to be common to both, which is in the proportion of only fifteen per cent. The same small amount of agreement is found in the corals also. I formerly endeavored to reconcile this marked difference in species with the supposed coexistence of the two faunas, by imagining them to have severally belonged to distinct zoological provinces or two seas, the one opening to the north, and the other to the south, with a barrier of land between them, like the Isthmus of Suez, separating the Red Sea and the Mediterranean. But I now abandon that idea for several reasons; among others, because I succeeded in 1841 in tracing the Crag fauna southwards in Normandy to within seventy miles of the Falunian type, near Dinan, yet found that both assemblages of fossils retained their distinctive characters, showing no signs of any blending of species or transition of climate.

On a comparison of 280 Mediterranean shells with 600 British species, made for me by an experienced conchologist in 1841, 160 were found to be common to both collections, which is in the proportion of fifty-seven per cent., a fourfold greater specific resemblance than between the seas of the crag and the faluns, notwithstanding the greater geographical distance between England and the Mediterranean than between Suffolk and the Loire. The principal grounds, however, for referring the English crag to the Older Pliocene and the French faluns to the Miocene epochs, consist in the predominance of fossil shells in the British strata identifiable 
with species not only still living, but which are now inhabitants of neighboring seas, while the accompanying extinct species are of genera such as characterize Europe. In the faluns, on the contrary, the recent species are in a decided minority; and most of them are now inhabitants of the Mediterranean, the coast of Africa, and the Indian Ocean; in a word, less northern in character and pointing to the preralence of a warmer climate. They indicate a state of things receding farther from the present condition of central Europe in physical geography and climate, and doubtless, therefore, receding farther from our era in time.

Among the conspicuous shells which are common to the faluns of the Loire and the Suffolk Crag is the Voluta Lamberti, before mentioned, page 204. All the specimens of this shell which I have myself collected in Touraine or have seen in museums are thicker and heavier than British individuals of the same species, and shorter in proportion to their width, and have the folds on the columella less oblique, as represented in the annexed figures.

Fig. $162 b$.

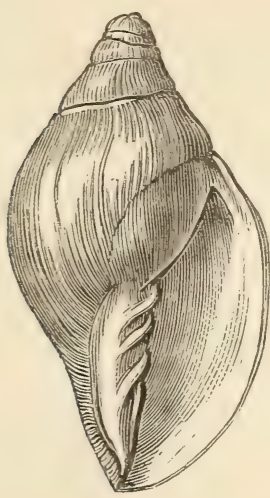

Voluta Lamberti.

Variety characteristic of Faluns of Touraine. Miocene.
Fig. 163.

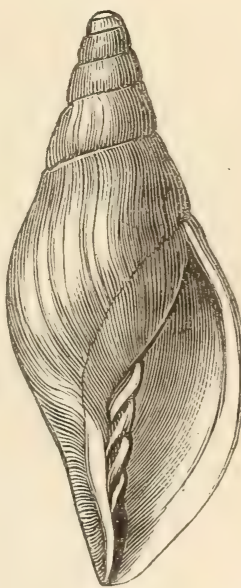

T. Lamberti.

Variety characteristic of Suffolk Crag. Pliocene.

Mr. Searles Wood has fully appreciated these constant differences, but has, I think, with propriety regarded the two forms as mere rarieties, or races of one and the same species. It is remarkable, howerer, that the late Alcide d'Orbigny, "who so often founded species on very fine distinctions, should have coincided in this view. It may, I think, be fairly assumed that be would not have done so had he not imagined the Suffolk Crag to be identical in age with the

* A. d’Orbignf, Cours Elémentaire de Paléontologie, rol. ii. pp. 793, 797, 1852. 
faluns of the Loire, not being aware that it differed in so many important respects, especially in its approach to the living fauna of the neighboring sea, from the French deposit. He was one of those naturalists who advocated the doctrine that there was a complete distinction between the fossil species of periods standing next to each other in chronological succession. Had he ranked the faluns as Miocene and the Crag of Suffolk as Pliocene, he would not have assimilated two forms so easily distinguishable. This we are entitled to infer from his refusal to admit the specific agreement of any falunian and living shells, and, what is still more remarkable, his refusing to allow the existence of more than 44 recent species out of 437 in his newer or Subapennine group. He divided the whole tertiary series into five stages, each supposed to mark an era of repose on the earth's surface, at the end of which all the living inhabitants were annihilated by a great catastrophe, the earth being afterward repeopled with a new set of forms. Even when he was forced to admit that one or two in a hundred of the fossils passed from one formation to another, he was inclined to attribute that small amount of agreement to the washing of dead shells from older into newer strata. This doctrine of the absolute distinction of species in formations next in the order of succession would scarcely be worth referring to now that it is so generally rejected by the most experienced geologists, were it not for the great ingenuity with which some of its advocates have defended their views. When the shells are confessedly undistinguishable, it has sometimes been suggested, that if the soft parts of the animals had been preserved, they would probably have been found to differ. On the other hand, it is not uninstructive to note how easily palæontologists of unquestionable merit can, if they are under the influence of a theory, such as that above alluded to, find specific distinctions wherever they are wanted, or, on the other hand, pronounce the same to have merely the value of a variety.

The points of difference expressed in the two figs. $162 b$. and 163 may be regarded by the same zoologist as mere races or geographical varieties so long as both are believed to belong to the same precise era, but they will take the rank of species if one be regarded as Miocene and the other as Pliocene. Specimens have occasionally been found of this volute in the Coralline Crag which help to connect the Touraine form with that of the Red Crag; but it often happens in analogous cases that no formation of intermediate age is extant, and then all intermediate gradations, all evidence of there having been a passage from one form to the other, and of both having had a common descent, may be lost. Zoologists, whether they adopt or reject the theory of the origin of species by natural selection, are still bound to be consistent with themselves in regard to the amount of deviation from certain types which shall be deemed sufficient to constitute a specific difference. It is sufficiently difficult to arrive at philosophical conclusions when the characters relied on are strictly those of the external forms and inter- 
nal peculiarities of individuals; but when once our specific determinations are biassed by geological or geographical considerations, there is an end of all reasonable hope of coming to consistent results.

\section{LOWER MIOCENE STRATA OF FRANCE.}

Remarks on classification, and where to draw the line of separation between Miocene and Eocene strata.-The marine faluns of the valley of the Loire have been already described as resting in some places on a freshwater tertiary limestone, fragments of which have been brokeu off and rolled on the shores and in the bed of the Miocene sea. Such pebbles are frequent at Pontlevoy on the Cher, with hollows drilled in them in which the perforating marine shells of the Falunian period still remain. Such a mode of superposition implies an interval of time between the origin of the freshwater limestone and its submergence beneath the waters of the Upper Miocene sea. The limestone in question forms a part of the formation called the Calcaire de la Beauce, which constitutes a large tableland between the basins of the Loire and the Seine. It is associated with marls and other deposits, such as may have been formed in marshes and shallow lakes in the newest part of a great delta. Beds of flint, continuous or in nodules, accumulated in these lakes, and aquatic plants called Charce, left their stems and seed-ressels embedded both in the marl and flint, together with freshwater and land shells. Some of the siliceous rocks of this formation are used extensively for millstones. The flat summits or platforms of the hills round Paris, and large areas in the forest of Fontainebleau, as well as the Plateau de la Beauce, already alluded to, are chiefly composed of these freshwater strata. Next to these in the descending order are marine sauds and sandstone, commonly called the Grès de Fontainebleau, from which a considerable number of shells, rery distinct from those of the faluns, have been obtained at Etampes, south of Paris, and at Montmartre and other hills in Paris itself, or in its suburbs. At the bottom of these sands a green clay occurs, containing a small oyster, Ostrea cyathula, Lam., which, although of slight thickness, is spread over a wide area. This clay rests immediately on the Paris gypsum, or that series of beds of gypsum and 2rpseous marl from which Cuvier first obtained sereral species of Paleotherium and other extinct mammalia.* At this point the majority of French geologists have always drawn the line between the Niddle and Lower Tertiary, or between the Miocene and Eocene formations, regarding the Fontainebleau sauds and the Ostrea cyathula clay as the base of the Miocene, and the gypsum with its mammalia as the top of the Eocene group. From that method of classification I formerly dissented, agreeing with M. Deshayes that the fossils of

* See below, Chapter XVI. 
the marine sands showed a much greater affinity to the subjacent Eocene formations than to the more modern faluns of Touraine. In his classical work on the fossil shells of the environs of Paris (1824-'37) he had described twenty-nine species from the Fontainebleau sands, of which some few could be identified with fossils belonging to the older Calcaire Grossier, whereas no one of them was common to the faluns of Touraine. He also insisted on the general aspect or facies of the fauna bearing a far greater resemblance to the testacea of the older or Eocene group than to that of the faluns.

A few years after the publication of my "Principles of Geology" (vol. iii.) in 1833, the directors of the Government Survey of France, MM. Dufrénoy and E. de Beaumont, referred the Paris gypsum in their geological map of the Eocene, and the overlying marine sands and Calcaire de la Beauce to the Níocene, the faluns of Touraine being regarded by them as constituting an upper division of the same Miocene series. M. d'Archiac, in 1839, adopted the same method; and M. Alcide d'Orbigny, in his Paleontology, in 1852, classed the Grès de Fontainebleau, or "Sables Supérieurs," as "Falunien A," and the faluns of the Loire as "Falunien B," thus giving in his adhesion to the same system of classification. That there should have been much difference of opinion on this subject was very natural, for; at the time when I first took part in the controversy, there seemed very little prospect of bridging over the wide gap between the two formations which it was thus proposed to link together in one group. In 1857, by aid of a railway cutting at Etampes, the number of marine shells derived from the Fontainebleau sands was suddenly raised from 29 to 90 species. The newly-discovered fossils furnished arguments both for and against the views of those who desired to refer the strata containing them to the Miocene rather than to the Eocene series. As bearing against those views, may be mentioned the fact that none of the 90 shells agreed with species proper to the faluns of the Loire, while some of them were identical with Calcaire Grossier species. This was the more worthy of note because Etampes is within seventy miles of Pontlevoy, near Blois, and not more than 100 miles from Savigné, near Tours, two localities where the falunian shells are very abundant. So striking a difference between the species of the valley of the Loire and those of the basin of the Seine, when we consider the contiguity of the spots above alluded to, could not be the result of geographical distribution at one and the same era, but must evidently have depended on a great difference in the age of the deposits. It marked the influence of Time, and not of Space.

On the other hand, in favor of grouping the Étampes or Fontainebleau sands with the newer Falunian rather than with the older Eocene formations, M. Hébert pointed out that a majority of the 90 Étampes and Grès de Fontainebleau fossils agreed specifically with shells which, in Belgium, Mayence, and other localities, had been shown by the labors of MM. Dumont, Nyst, De Koninck, and Bosquet to occupy a 
very distinct geological position above the typical Eocene series of the Paris basin, and of which the equivalents at Mayence had long been recognized as Miocene. Mr. Hébert also published, in 1855, a map descriptive of the areas of two tertiary seas, which succeeded each other in the Paris basin,- - the first that of the Calcaire Grossier, and the second that of the Fontainebleau Sands, - showing how marked is the want of coincidence betreen them; a fact which implies the occurrence of great geographical changes in the interval of time between the two eras compared. In the explanation of his map he gires his reasons for regarding the zone of Cerithium plicatum, or that of the Fontainebleau Sands, as the most convenient line of demarcation between Lower and Middle Tertiary, or between Eocene and Miocene.*

When I was hesitating as to the course which it would be most expedient to take in drawing the line between Eocene and Miocene, M. Lartet, the distinguished French zoologist, whose writings on fossil mammalia are of such acknowledged value, remarked to me that although the fossil testacea of the Fontainebleau Sands show a preponderance of affinities torrard an Eocene famna, and small connection with the faluns of Touraine, yet, on the other hand, the freshwater "Calcaire de la Beauce," immediately overlying the Fontainebleau Sands, and other lacustrine formations in Aurergne and Central France, as well as the fossiliferous strata of the Marence basin, cannot be included in the same Eocene system without doing riolence to paleontological principles. The grouping of the fossil mammalia, he obserred, becomes less natural by such an arrangement; for not only many genera, but even some species, are found on both sides of the arbitrary line of demarcation thus drawn between Eocene and Niocene. The genera Dorcatherium, Cainotherium, Anchitherium, and Titanomys, for example, and Rhinoceros incisivus and others, would thereby be made common to Eocene and Miocene.

Other arguments drawn from fossil botany in faror of uniting the Grès de Fontainebleau and faluns in one group will be more fully set forth in the next chapter, when I treat of the tertiary strata called "Molasse" in Switzerland, and of the German Brown Coal.

Mr unwillingness to include the Fontainebleau sands and other strata of the same age in the Miocene Epoch arose partly from the necossity thereby incurred of abandoning for such deposits the definition which I had alreadr giren of the term Miocene as implying that a marked proportion, though a minority, of the fossil shells belong: to liring species. I had felt mrself obliged, eren in 1833, to disregard this difficulty, when, in the first edition of the "Principles of Geologr," I classed the strata of the Marence basin as Miocene, conceiving that, although almost erery species of shell was extinct, they had more affinity with the Falunian than with the Eocene formations. 
From the first I had advocated the doctrine that there has been a continual coming in of new species, and dying out of old ones, and a gradual change in the physical geography and climate of the earth, and not such a recurrence of sudden revolutions in the animate and inanimate worlds, as was, in 1833, insisted upon by many English geologists of note, and is still maintained by some eminent continental writers. I therefore foretold that from time to time new sets of strata would come to light, and require to be intercalated between those already described, in which case the fossils of some of the newly-found beds would " deviate from the normal types first selected, and approximate more and more to the types of the antecedent or subsequent epochs." According to this view, it was obvious from the first that the oldest Miocene records, whenever they were detected, would not be easily distinguishable from the youngest members of the Eocene series, especially in the proportion of the living to the extinct species of fossil shells. The importance, indeed, of the latter test must diminish rapidly the more we recede from the Pliocene and approach the Miocene, and still more the Eocene formations, although it is never without its value, and often furnishes the only common standard of comparison between strata of very distant countries. To this subject of classification, or the line of demarcation between the Eocene and Miocene strata, I shall again refer in this and the sixteenth chapter.

Lower Miocene strata of Central France.-Lacustrine strata, belonging, for the most part, to the same Miocene system as the Calcaire de la Beauce, are again met with in Auvergne, Cantal, and Velay, the sites of which may be seen in the annexed map. They appear to be the monuments of ancient lakes, which, like some of those now existing in Switzerland, once occupied the depressions in a mountainous region, and have been each fed by one or more rivers and torrents. The country were they occur is almost entirely composed of granite and different varieties of granitic schist, with here and there a few patches of secondary strata, much dislocated, and which have probably suffered great denudation. There are also some vast piles of volcanic matter (see the map), the greater part of which is newer than the freshwater strata, and is sometimes seen to rest upon them, while a small part has evidently boen of contemporaneous origin. Of these igneous rocks I shall treat more particularly in another part of this work.

Before entering into any details, I may observe that the study of these regions possesses a peculiar interest, very distinct in kind from that derivable from the investigation either of the Parisian or English tertiary areas. For we are presented in Auvergne with the evidence of a series of events of astonishing magnitude and grandeur, by which the original form and features of the country have been greatly changed, yet never so far obliterated but that they may still, in part at least, be restored in imagination. Great lakes have disappeared-lofty mountains have been formed, by the reiterated emission of lava, preceded and. 
Fig. 164. *

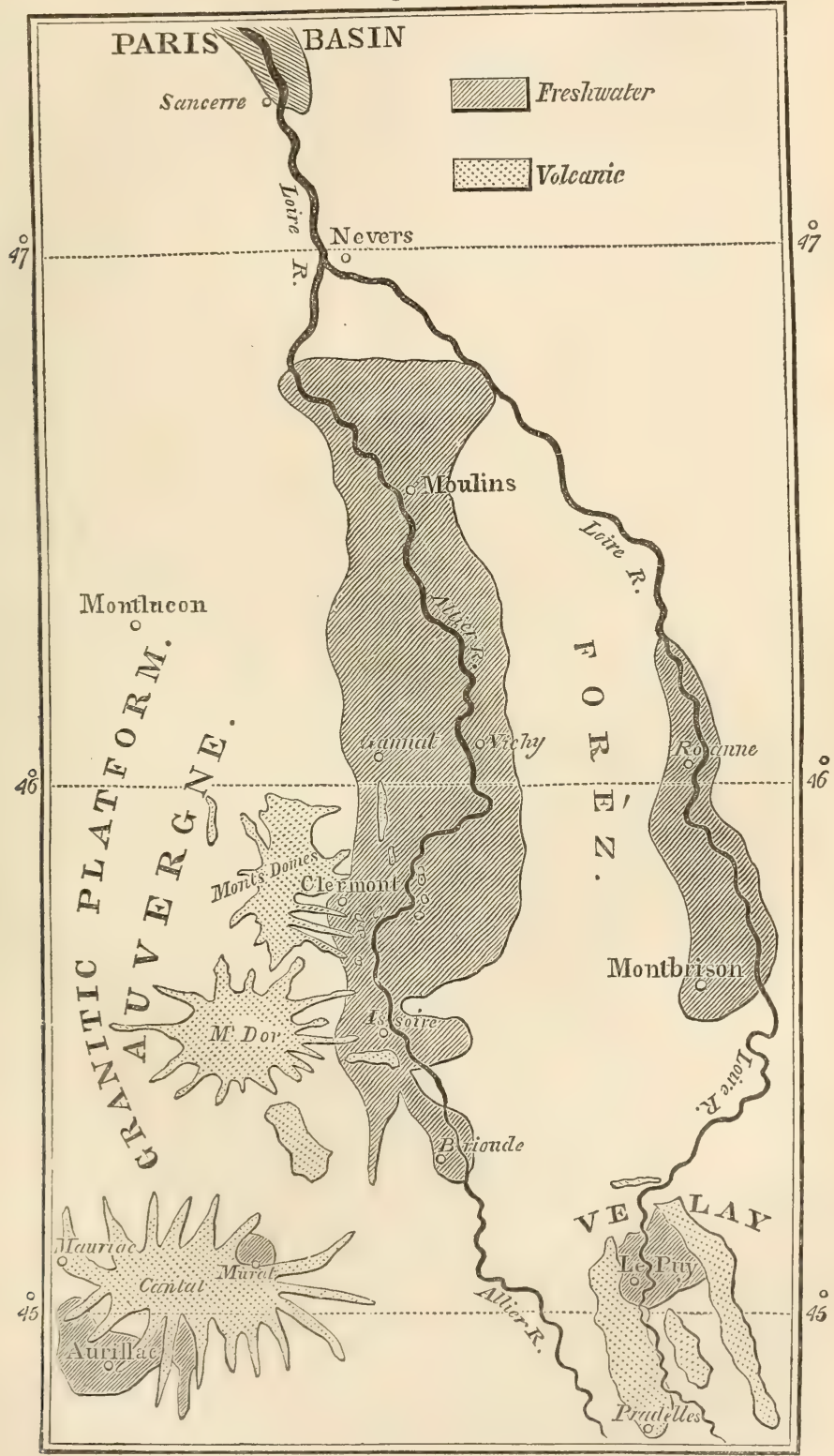


followed by showers of sand and scoriæ,- -deep valleys have been subsequently furrowed out through masses of lacustrine and volcanic origin, - at a still later date, new cones have been thrown up in these valleys, new lakes have been formed by the damming up of rivers,- and more than one creation of quadrupeds, birds, and plants, Eocene, Miocene, and Pliocene, have followed in succession; yet the region has preserved from first to last its geographical identity; and we can still recall to our thoughts its external condition and physical structure before these wonderful vicissitudes began, or while a part only of the whole had been completed. There was first a period when the spacious lakes, of which we still may trace the boundaries, lay at the foot of mountains of moderate elevation, unbroken by the bold peaks and precipices of Mont Dor, and unadorned by the picturesque outline of the Puy de Dome, or of the volcanic cones and craters now covering the granitic platform. During this earlier scene of repose deltas were slowly formed; beds of marl and sand, several hundred feet thick, deposited; siliceous and calcareous rocks precipitated from the waters of mineral springs; shells and insects imbedded, together with the remains of the crocodile and tortoise, the eggs and bones of water birds, and the skeletons of quadrupeds, some of them belonging to the same genera as those entombed in the Eocene gypsum of Paris. To this tranquil condition of the surface succeeded the era of volcanic eruptions, when the lakes were drained; and when the fertility of the mountainous district was probably enhanced by the igneous matter ejected from below, and poured down upon the more sterile granite. D During these eruptions, which appear to have taken place after the disappearance of the upper Eocene fauna, and partly in the Miocene epoch, the mastodon, rhinoceros, elephant, tapir, hippopotamus, together with the ox, various kinds of deer, the bear, hyæna, and many beasts of prey, ranged the forest, or pastured on the plain, and were occasionally overtaken by a fall of burning cinders, or buried in flows of mud, such as accompany volcanic eruptions. Lastly, these quadrupeds became extinct, and gave place in their turn to the species now existing. There are no signs, during the whole time required for this series of events, of the sea having intervened, nor of any denudation which may not have been accomplished by currents in the different lakes, or by rivers and floods accompanying repeated earthquakes, or subterranean movements, during which the levels of the district have in some places been materially modified, and perhaps the whole upraised relatively to the surrounding parts of France.

Awvergne.-The most northern of the freshwater groups is situated in the valley-plain of the Allier, lying in the department of the Puy de Dome, being the tract which went by the name of the Limagne d'Auvergne. It is enclosed by two parallel mountain ranges,- - that of the Forez, which divides the waters of the Loire and Allier on the east; and that of the Monts Domes, which separates the Allier from the Sioule on the west.* The average breadth of this tract is about twenty

* Scrope, Geology of Central France, p. 15. 
miles; and it is for the most part composed of nearly horizontal strata of sand, sandstone, calcareous marl, clay, and limestone, none of which observe a fixed and invariable order of superposition. The ancient borders of the lake, wherein the freshwater strata were accumulated, may generally be traced with precision, the granite and other ancient rocks rising up boldly from the level country. The actual junction, however, of the lacustrine and granitic beds is rarely seen, as a small valley usually interrenes betwreen them. The freshwater strata may sometimes be seen to retain their horizontality within a very slight distance of the borderrocks, while in some places they are inclined, and in few instances vertical. The principal divisions into which the lacustrine series may be separated are the following :-1st, Sandstone, grit, and conglomerate, including red marl and red sandstone. 2dly, Green and white foliated marls. 3dly, Limestone or travertin, often oolitic. 4thly, Gypseous marls.

1. a. Sandstone and conglomerate.-Strata of sand and gravel, sometimes bound together into a solid rock, are found in great abundance around the confines of the lacustrine basin, containing, in different places, pebbles of all the ancient rocks of the adjoining elevated country; namely, granite, gneiss, mica-schist, clay-slate, porphyry, and others, but without any intermixture of basaltic or other tertiary volcanic rocks. These strata do not form one continuous band around the margin of the basin, being rather disposed like the independent deltas which grow at the mouths of torrents along the borders of existing lakes.

At Chamalieres, near Clermont, we have an example of one of these deltas, or littoral deposits, of local extent, where the pebbly beds slope away from the granite, as if they had formed a talus beneath the waters of the lake near the steep shore. A section of about 50 feet in vertical height has been laid open by a torrent, and the pebbles are seen to consist throughout of rounded and angular fragments of granite, quartz, primary slate, and red sandstone. Partial layers of lignite and pieces of wood are found in these beds.

At some localities on the margin of the basin quartzose grits are found; and, where these rest on granite, they are sometimes formed of separate crystals of quartz, mica, and felspar, derived from the disintegrated granite, the crystals having been subsequently bound together by a siliceous cement. In these cases the granite seems regenerated in a new and more solid form; and so gradual a passage takes place between the rock of crystalline and that of mechanical origin, that we can scarcely distinguish where one ends and the other begins.

In the hills called the Puy de Jussat and La Roche, we have the advantage of seeing a section continuously exposed for about 700 feet in thickness. At the bottom are foliated marls, white and green, about 400 feet thick; and abore, resting on the marls, are the quartzose grits, cemented by calcareous matter, which is sometimes so abundant as to form imbedded nodules. These sometimes constitute spheroidal concretions 6 feet in diameter, and pass into beds of solid limestone, resembling the Italian travertins, or the deposits of mineral springs. 
1. b. Red marl and sandstone-But the most remarkable of the arenaceous groups is one of red sandstone and red marl, which are identical in all their mineral characters with the secondary New Red sandstone and marl of England. In these secondary rocks the red ground is sometimes variegated with light greenish spots, and the same may be seen in the tertiary formation of freshwater origin at Coudes, on the Allier. The marls are sometimes of a purplish-red color, as at Champheix, and are accompanied by a reddish limestone, like the well-known "cornstone," which is associated with the Old Red sandstone of English geologists. The red sandstone and marl of Auvergne have evidently been derived from the degradation of gneiss and mica-schist, which are seen in situ on the adjoining hills, decomposing into a soil very similar to the tertiary red sand and marl. We also find pebbles of gneiss, mica-schist, and quartz in the coarser sandstones of this group, clearly pointing to the parent rocks from which the sand and marl are derived. The red beds, although destitute themselves of organic remains, pass upwards into strata containing tertiary fossils, and are certainly an integral part of the lacustrine formation. From this example the student will learn how small is the value of mineral character alone, as a test of the relative age of rocks.

2. Green and white foliated marls.-The same primary rocks of Auvergne, which, by the partial degradation of their harder parts, gave rise to the quartzose grits and conglomerates before mentioned, would, by the reduction of the same materials into powder, and by the decomposition of their felspar, mica, and hornblende, produce aluminous clay, and, if a sufficient quantity of carbonate of lime was present, calcareous marl. This fine sediment would naturally be carried out to a greater distance frorn the shore, as are the various finer marls now deposited in Lake Superior. And as, in the American lake, shingle and sand are annually amassed near the northern shores, so in Auvergne the grits and conglomerates before mentioned were evidently formed near the borders.

The entire thickness of these marls is unknown; but it certainly exceeds, in some places, 700 feet. They are, for the most part, either lightgreen or white, and usually calcareous. They are thinly foliated,-a character which frequently arises from the innumerable thin shells, or carapace-valves, of that small crustacean called Cypris, which is provided with two small valves, not unlike those of a bivalve shell, and moults its integuments periodically, which the conchiferous mollusks do not. This circumstance may partly explain the countless myriads of the shells of Cypris which were shed in the ancient lakes of Auvergne, so as to give rise to divisions in the marl as thin as paper, and that, too, in stratified masses several hundred feet thick. A more convincing proof of the tranquillity and clearness of the waters, and of the slow and gradual process by which the lake was filled up with fine mud, cannot be desired. But we may easily suppose that, while this fine sediment was thrown down in the deep and central parts of the basin, gravel, sand, and rocky fragments were hurried into the lake, and deposited near the shore, forming the group described in the preceding section. 
Not far from Clermont, the green marls, containing the Cyprs in abundance, approach to within a few yards of the granite which forms the borders of the basin. The occurrence of these marls so near the ancient margin may be explained by considering that, at the bottom of the ancient lake, no coarse ingredients were deposited in spaces intermediate between the points where rivers and torrents entered, but finer

Fig. 165.

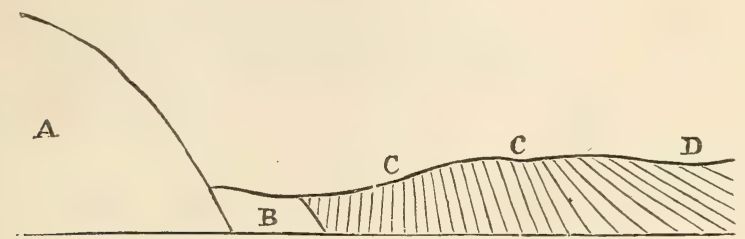

Vertical strata of marl, at Champradelle, near Clermont.
A. Granite.
B. Space of 60 feet, in which no section is seen.
C. Green marl, vertical and inclined.
D. White marl.

mud only was drifted there by currents. The verticality of some of the beds in the above section bears testimony to considerable local disturbance subsequent to the deposition of the marls; but such inclined and vertical strata are very rare.

3. Limestonc, travertin, oolite.-Both the preceding members of the lacustrine deposit, the marls and grits, pass occasionally into limestone. Sometimes only concretionary nodules abound in them; but these, where there is an increase in the quantity of calcareous matter, unite into regular beds.

On each side of the basin of the Limagne, both on the west at Gannat, and on the east at Vichy, a white oolitic limestone is quarried. At Vichy, the oolite resembles our Bath stone in appearance and beauty; and, like it, is soft when first taken from the quarry, but soon hardens on exposure to the air. At Gannat, the stone contains land-shells and bones of quadrupeds. At Chadrat, in the hill of La Serre, the limestone is pisolitic, the small spheroids combining both the radiated and concentric structure.

Indusial limestone.-There is another remarkable form of freshwater limestone in Auvergne, called "indusial," from the cases, or indusice, of caddis-worms (the larræ of Phryganea); great heaps of which have been incrusted, as they lay, by carbonate of lime, and formed into a hard travertin. The rock is sometimes purely calcareous, but there is occasionally an intermixture of siliceous matter. Several beds of it are frequently seen, either in continuous masses, or in concretionary nodules, one upon another, with layers of marl interposed. The annexed drawing (fig. 166) will show the manner in which one of these indusial beds $(a)$ is laid open at the surfice, between the marls $(b b)$, near the base of the hill of Gergoria; and affords, at the same time, an example of the extent to which the lacustrine strata, which must once have filled a hollow, have been denuded, and shaped out into hills and valleys, on the site of the nncient lakes. 
Fig. 166.

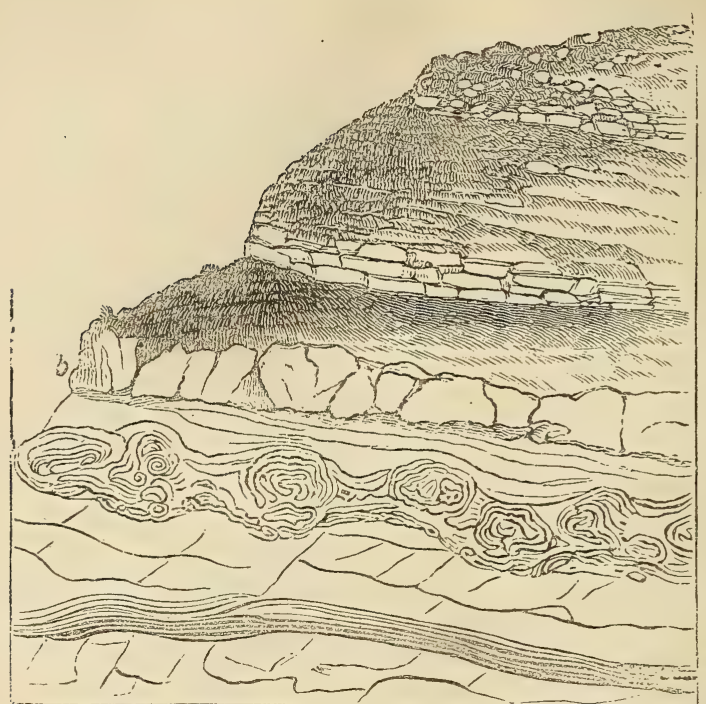

Bed of indusial limestone, interstratified with freshwater marl, near Clermont (Kleinschrod).

We may often observe in our ponds the Phryganea (or Caddis-fly), in its caterpillar state, covered with small freshwater shells, which they have the power of fixing to the outside of their tubular cases, in order, probably, to give them weight and strength. The individual figured in the annexed cut, which belongs to a species very abundant in England,

Fig. 167 .

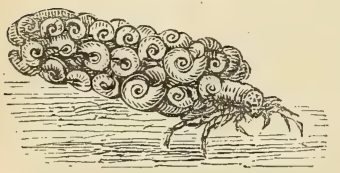

Larva of recent Phryganea.* has covered its case with shells of a small Planorbis. In the same manner a large species of caddis-worm which swarmed in the Eocene lakes of Auvergne was accustomed to attach to its dwelling the shells of a small spiral univalve of the genus Paludina. A hundred of these minute shells are sometimes seen arranged around one tube, part of the central cavity of which is often empty, the rest being filled up with thin concentric layers of travertin. The cases have been thrown together confusedly, and often lie, as in fig. 168, at right angles one to the other. When we consider Fig. 168.
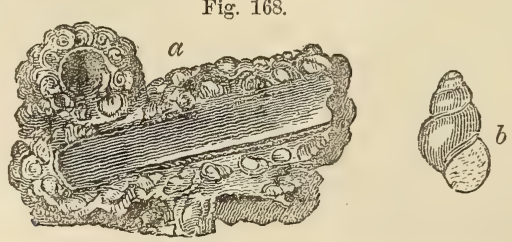

a. Indusial limestone of Auvergne.

๖. Fossil Pahudina magnified.

* I believe that the British specimen here figured is P. rhombica, Linn. 
that ten or twelve tubes are packed within the compass of a cubic inch and that some single strata of this limestone are 6 feet thick, and may be traced orer a considerable area, we may form some idea of the countless number of insects and mollusca which contributed their integuments and shells to compose this singularly constructed rock. It is unnecessary to suppose that the Phryganece lived on the spots where their cases are now found; they may have multiplied in the shallows near the margin of the lake, or in the streams by which it was fed, and their cases may have been drifted by a current far into the deep water.

In the summer of 1837 , when examining, in company with Dr. Beck, a small lake near Copenhagen, I had an opportunity of witnessing a beautiful exemplification of the manner in which the tubular cases of Auvergne were probably accumulated. This lake, called the Fuure-Soe, occurring in the interior of. Seeland, is about twenty English miles in circumference, and in some parts 200 feet in depth. Round the shallow borders an abundant crop of reeds and rushes may be observed, covered with the indusiæ of the Phryganea grandis and other species, to which shells are attached. The plants which support them are the bullrush, Scirpus lacustris, and common reed, Arundo phragmites, but chiefly the former. In summer, especially in the month of June, a violent gust of wind sometimes causes a current by which these plants are torn up by the roots, washed away, and floated off in long bands, more than a mile in length, into deep water. The Cypris swarms in the same lake; and calcareous springs alone are wanting to form extensive beds of indusial limestone, like those of Auvergne.

4. Gypseous marls.-More than 50 feet of thinly laminated gypseous marls, exactly resembling those in the hill of Montmartre, at Paris, are worked for gypsum at St. Romain, on the right bank of the Allier. They rest on a series of green cypridiferous marls which alternate with grit, the united thickness of this inferior group being seen, in a vertical section on the banks of the river, to exceed 250 feet.

General arrangement, origin, and age of the freshwater formations of Auvergne.-The relations of the different groups above described cannot be learnt by the study of any one section; and the geologist who sets out with the expectation of finding a fixed order of suecession may perhaps complain that the different parts of the basin give contradictory results. The arenaceous division, the marls, and the limestone, may all be seen in some places to alternate with each other; yet it can by no means be affirmed that there is no order of arrangement. The sands, sandstone, and conglomerate constitute in general a littoral group; the foliated white and green marls, a contemporaneous central deposit; and the limestone is for the most part subordinate to the newer portions of both. The uppermost marls and sands are more calcareous than the lower; and we never meet with calcreous rocks covered by a considerable thickness of quartzose sand or green marl. From the resemblance of the limestones to the Italian travertins, we may conclude that they were derived from the waters of mineral springs, - such springs as even 
now exist in Auvergne, and which may be seen rising up through the granite, and precipitating travertin. They are sometimes thermal, but this character is by no means constant.

It seems that, when the ancient lake of the Limagne first began to be filled with sediment, no volcanic action had yet produced lava and scoriæ on any part of the surface of Auvergne. No pebbles, therefore, of lava were transported into the lake,-no fragments of volcanic rocks imbedded in the conglomerate. But at a later period, when a considerable thickness of sandstone and marl had accumulated, eruptions broke out, and lava and tuff were deposited, at some spots, alternately with the lacustrine strata. It is not improbable that cold and thermal springs. holding different mineral ingredients in solution, became more numerous during the successive convulsions attending this development of volcanic agency, and thus deposits of carbonate and sulphate of lime, silex, and other minerals were produced. Hence these minerals predominate in the uppermost strata. The subterranean movements may then have continued, until they altered the relative levels of the country, and caused the waters of the lakes to be drained off, and the farther accumulation of regular freshwater strata to cease.

We may easily conceive a similar series of events to give rise to analogous results in any modern basin, such as that of Lake Superior, for example, where numerous rivers and torrents are carrying down the detritus of a chain of mountains into the lake. The transported materials must be arranged according to their size and weight, the coarser near the shore, the finer at a greater distance from land; but in the gravelly and sandy beds of Lake Superior no pebbles of modern volcanic rocks can be included, since there are none of these at present in the district. If igneous action should break out in that country, and produce lava, scoriæ, and thermal springs, the deposition of gravel, sand, and marl might still continue as before; but, in addition, there would then be an intermixture of volcanic gravel and tuff, and of rocks precipitated from the waters of mineral springs.

Although the freshwater strata of the Limagne approach generally to a horizontal position, the proofs of local disturbance are sufficiently numerous and violent to allow us to suppose great changes of level since the lacustrine period. We are unable to assign a northern barrier to the ancient lake, although we can still trace its limits to the east, west, and south, where they were formed of bold granite eminences. Nor need we be surprised at our inability to restore entirely the physical geography of the country after so great a series of volcanic eruptions; for it is by no means improbable that one part of it, the southern, for example, mav have been moved upwards bodily, while others remained at rest, or even suffered a movement of depression.

It is scarcely possible to determine the age of the oldest part of the freshwater series of the Limagne, large masses both of the sandy and marly strata being devoid of fossils. Some of the lowest beds may be of upper Eocene date, although, according to M. Pomel, only one bone 
of a Paleotherium has been discovered in Auvergne. But in Vélay, in strata containing some species of fossil mammalia common to the Limagne, no less than four species of Paleothere have been found by M. Aymard, and one of these is generally supposed to be identical with Paleotherium magnum, an undoubted Upper Eocene fossil, of the Paris gypsum, the other three being peculiar.

Not a few of the other mammalia of the Limagne made known to us by the labours of MIM. Bouillet, Bravard, Croizet, Jobert, Laizer, Robert, Aymard, and Pomel, belong undoubtedly to genera and species elsewhere proper to the Lower Miocene. Thus, for example, the Cainotherium of Brevard, a genus not far removed from the Anoplotherium, is represented by several species, one of which, as I learn from Mr. Waterhouse, agrees with Microtherium Renggeri of the Mayence basin. In like manner the Amphitragulus elegans of Pomel, an Auvergne fossil, is identified by Waterhouse with Dorcatherium nanum of Kaup, a Rhenish species from Weissenau, near Hayence. A small species also of rodent, of the genus Titanomys of H. von Meyer, is common to the Lower Miocene of Mayence and the Limagne d'Auvergne, and there are many other points of agreement which the discordance of nomenclature tends to conceal. A remarkable carnivorous genus, the Hyænodon of Laizer, is represented by more than one species. The same genus has also been found in the Upper Eocene marls of Hordwell Cliff, Hampshire, just below the level of the Bembridge Limestone, and therefore a formation older than the Gypsum of Paris. Several species of opossum (Didelphis) are met with in the same strata of the Limagne. The association of such genera as Dinotherium, Tapir, Anthracotherium, and Rhinoceros with those above mentioned, helps to connect the Auvergne fauna with the Upper Miocene, but the species are different from those of the neighboring faluns of the Loire, or those of Sansan, in the South of France. Nor do the Upper Miocene species appear, so far as we yet know, in the overlying volcanic formations of Auvergne, where the quadrupeds hitherto discovered belong either to the older or newer Pliocene periods.

The total number of mammalia enumerated by M. Pomel as appertaining to the Lower Miocene fauna of the Limagne and Vélay, falls little short of a hundred, and with them are associated some large crocodiles and tortoises, and some Ophidian and Batrachian reptiles.

Cantal.-A freshwater formation already alluded to, of about the same age and very analogous to that of Auvergne, is situated in the Department of Haute Loire, near the town of Le Puy, in Vélay; and another occurs near Aurillac, in Cantal. The leading feature of the formation last mentioned, as distinguished from those of Auvergne and Vélay, is the immense abundance of silex associated with calcareous marls and limestone.

The whole series may be separated into two divisions; the lower, composed of gravel, sand, and clay, such as might have been derived from 
the wearing down and decomposition of the granitic schists of the surrounding country ; the upper system, consisting of siliceous and calcareous marls, contains subordinately gypsum, silex, and limestone.

The resemblance of the freshwater limestone of the Cantal, and its accompanying flint, to the upper chalk of England, is very instructive, and well calculated to put the student upon his guard against relying too implicitly on mineral character alone as a safe criterion of relative age.

When we approach Aurillac from the west, we pass over great heathy plains, where the sterile mica-schist is barely covered with vegetation. Near Ytrac, and betwieen La-Capelle and Viscamp, the surface is strewed over with loose broken flints, some of them black in the interior, but with a white external coating; others stained with tints of yellow and red, and in appearance precisely like the flint gravel of our chalk districts. When heaps of this gravel have thus announced our approach to a new formation, we arrive at length at the escarpment of the lacustrine beds. At the bottom of the hill which rises before us, we see strata of clay and sand, resting on mica-schist; and above, in the quarries of Belbet, Leybros, and Bruel, a white limestone, in horizontal strata, the surface of which has been hollowed out into irregular furrows, since filled up with broken flint, marl, and dark vegetable mould. In these cavities we recognize an exact counterpart to those which are so numerous on the furrowed surface of our own white chalk. Advancing from these quarries along a road made of the white limestone, which reflects as glaring a light in the sun as do our roads composed of chalk, we reach, at length, in the neighborhood of Aurillac, hills of limestone and calcareous marl, in horizontal strata, separated in some places by regular layers of flint in nodules, the coating of each nodule being of an opaque white color, like the exterior of the flinty nodules of our chalk.

The abundant supply both of siliceous, calcareous, and gypseous matter, which the ancient lakes of France received, may have been connected with the subterranean volcanic agency of which those regions were so long the theatre, and which may have impregnated the springs with mineral matter, even before the great outbreak of lava. It is well known that the hot springs of Iceland, and many other countries, contain silex in solution; and it has been lately affirmed, that steam at a high temperature is capable of dissolving quartzose rocks without the aid of any alkaline or other flux.* Warm water charged with siliceous matter would immediately part with a portion of its silex, if its temperature was lowered by mixing with the cooler waters of a lake.

A hasty observation of the white limestone and flint of Aurillac might convey the idea that the rock was of the same age as the white chalk of Europe; but when we turn from the mineral aspect and composition to the organic remains, we find in the flints of the Cantal seed-vessels of the freshwater Chara, instead of the marine zoophytes so abundant in chalk

* See Proceedings of Royal Soc., No. 44, p. 233. 
llints; and in the limestone we meet with shells of Limnea, Planorbis, and other lacustrine genera.

Proofs of gradual deposition.- Some sections of the foliated marls in the valley of the Cer, near Aurillac, attest, in the most unequivocal manner, the extreme slowness with which the materials of the lacustrine series were amassed. In the hill of Barrat, for example, we find an assemblage of calcareous and siliceous marls; in which, for a depth of at least 60 feet, the layers are so thin, that thirty are sometimes contained in the thickness of an inch; and when they are separated, we see preserved in every one of them the flattened stems of Charce, or other plants, or sometimes myriads of small Paludince and other freshwater shells. These minute foliations of the marl resemble precisely some of the recent laminated beds of the Scotch marl lakes, and may be compared to the pages of a book, each containing a history of a certain period of the past. The different layers may be grouped together in beds from a foot to a foot and a half in thickness, which are distinguished by differences of composition and color, the tints being white, green, and brown. Occasionally there is a parting layer of pure flint, or of black carbonaceous vegetable matter, about an inch thick, or of white pulverulent marl. We find several hills in the neighborhood of Aurillac composed of such materials, for the height of more than 200 feet from their base, the whole sometimes covered by rocky currents of trachytic or basaltic lava.*

Thus wonderfully minute are the separate parts of which some of the most massive geological monuments are made up! When we desire to classify, it is necessary to contemplate entire groups of strata in the aggregate; but if we wish to understand the mode of their formation, and to explain their origin, we must think only of the minute subdivisions of which each mass is composed. We must bear in mind how many thin leaf-like seams of matter, each containing the remains of myriads of testacea and plants, frequently enter into the composition of a single stratum, and how vast a succession of these strata unite to form a single group! We must remember, also, that piles of volcanic matter, like the Plomb du Cantal, which rises in the immediate neighborhood of Aurillac, are themselves equally the result of successive accumulation, consisting of reiterated sheets of lava, showers of scoriæ, and ejected fragments of rock-Lastl 5 , we must not forget that continents and mountain-chains, colossal as are their dimensions, are nothing more than an assemblage of many such igneous and aqueous groups, formed in succession during an indefinite lapse of ages, and superimposed upon each other.

Miocene strata of Bordeaux and South of France.-A great extent of country between the Pyrenees and the Gironde is orerspread by tertiary deposits of rarious ages and chiefly of Miocene date. M. Tonmouer, in an able memoir on these formations, $\nmid$ has shown that

* Lyell and Murchison, Sur les Dépôts Lacustres Tertiaires du Cantal, \&c. Ann. des Sci. Nat., Oct. 1829.

† Bulletin Soc. Géol. de France, tome xviii., 1861-'2, p. 1035. 
there is a remarkable continuity in the succession of strata, the uppermost being somewhat newer than the faluns of Touraine and the lowest somewhat older than the Fontainebleau sandstone already alluded to. In the highest group, that of Salles, in which Voluta Lamberti and Cardita Jouanneti occur, there are many fossils common to the Pliocene or Subapennine strata. Next below these are the faluns proper of Bordeaux, which include the faluns of Saucats and Leognan and those of Dax in the adjoining basin of the Adour. These formations, which contain among other shells Pecten Burdigalensis and Ancillaria glandiformis, coincide in age with the faluns of Touraine; but so many of the species are peculiar to the south as to imply that there was a separation by a considerable tract of land between the basins of the Loire and Gironde.

Strata which may be referred to the Lower Miocene come next in the descending order, comprising those of Mérignac and Bazas, the first blackish and the latter of marine origin. In this fluvio-marine series, Cerithium plicatum (fig. 173, p. 240), C. margaritaceum, $C$. Brongniarti, \&c., and in the marine beds Pyrula Lainei occur. The greater part of this series is considered by $\mathbf{M}$. Tournouer to correspond in age with the freshwater limestone of La Beauce in the basins of the Loire and Seine.

Still lower is the Asterias limestone, which with its overlying marls is about 300 feet in thickness, in which Cerithium plicatum and $C$. margaritaceum are again met with, tngether with Natica crassatina and other shells characteristic of the Etampes and Fontainebleau sands before mentioned. In these lower strata are many species common to the Parisian Eocene system, to the Calcaire Grossier for example, and even beds still lower. There are also several species of nummulites in the Asterias limestone, and their presence marks a difference in the character of the Lower Miocene of the South of Europe, as contrasted with that of the North. These and other indications of a passage from an older to a newer group, is just what we might expect in proportion as our series of monuments begins to be more and more complete. According to M. Tournouer, the Lower Miocene shells identifiable with Eocene species are always varieties of the same-an important fact as bearing on theories of the origin of species Below the whole of these formations lies a true Eocene limestone called the Calcaire de Blaye, of the age of the Calcaire Grossier of the Paris basin. In order to explain the succession of beds in the basin of the Gironde, several oscillations of level are necessary. The same wide area was alternately converted into sea and land and into brackish-water lagoons, and finally into freshwater ponds and lakes.

Upper Miocene strata of Gers.-Among the freshwater strata last alluded to near the base of the Pyrenees, are many of Upper Miocene age, from which bones of the Dinotherium giganteum and entire skeletons of the Mastodon angustidens have been obtained by M. Lartet. 
In one of these deposits that eminent comparative anatomist discovered, in $\mathbf{1 8 3 7}$, the first remains of quadrumana which had been detected in Europe. They were associated with the quadrupeds above mentioned in beds of freshwater marl, limestone, and sand near Auch, in the Department of Gers, about forty miles west of Toulouse. They were referred by ML. Lartet and Blainville to a genus closely allied to the Gibbon, to which they gave the name of Pliopithecus. More recently (1856) M. Lartet described another species of the same family of longarmed apes (Hyiobates), which he obtained from strata of the same age at Saint-Gaudens, in the Haute Garonne. The fossil remains of this animal consists of a portion of a lower jaw with teeth and the shaft of a humerus. It is supposed to have been a tree-climbing frugivorous ape, equalling Man in stature. As the trunks of oaks are common in the lignite beds in which it lay, it has received the generic name of Dryopithecus. The angle formed by the ascending ramus of the jaw and the alveolar border is less open, and therefore more like the human subject than in the Chimpanzee, and, what is still more remarkable, the fossil, a young but adult individual, had all its milk teeth replaced by the second set, while its last true molar (or wisdom tooth) was still undeveloped, or only existed as a germ in the jaw-bone. In the mode, therefore, of the succession of its teeth (which, as in all the Old World apes, exactly agree in number with those in Man) it differed from the Gorilla and Chimpanzee and corresponded with the human species.

This peculiarity in its dentition, however, it shared, as M. Lartet reminds us, with one of the living Gibbons called the Siamang. It is only one of several characters, such as the more globular form of the cranium and the smaller size of the canine teeth of the lower jaw, in which the Gibbons approach Man in their structure more nearly than do any other of the tailless apes. There is an analogy between such points of agreement and the fact that man and the Orang (Pithecus) hare each twelve pair of ribs, whereas the Gorilla and Chimpanzee (Troglodytes), notwithstanding that in the aggregate of their characters they approach nearer to the human type than the Orang, have each thirteen pair. A still more curious analogy is afforded by some of the platyrrhine monkeys of South America, which, although they differ from all the Old World quadrumana and from Man in having four supernumerary molars, yet are not only less prognathous than the catarrhine monkers, but have the cerebellum more decidedly overlapped by the posterior lobe of the cerebrum than the Old World apes. Yet the brains of the latter are, on the whole, much more akin to the human in their anatomical structure.

BELGIAN AND BRITISH MIOCENE FORMATIONS.

Upper Miocene near Antwerp._Edeghem beds.-The black or Glauconiferous Crag of Antwerp was mentioned at page 208 as bearing a 
considerable affinity to that of Suffolk, about two-thirds of the 65 shells obtained from it being common to the Suffolk Coralline Crag, and somewhat less than half of the whole being of living species.

About the year 1862, an important discovery was made at Edeghem, in the environs of Antwerp, of another deposit somewhat older than the Black Crag. In excavating for brick earth, they came upon a bed of argillaceous sand, in which no less than 152 fossils were found, comprising 145 mollusca and echinoderms, and some zoophytes, especially a large species of Flabellum. All these have been examined and tabulated by M. Nyst, and carefully compared with the fossils of other Miocene and Pliocene deposits of Europe.* These Edeghem beds, which repose on Lower Miocene clay, the "Rupelian" of Dumont, are most nearly related by their fossils to the Black Crag above alluded to, but they betray many indications of greater antiquity. Fifty-eight of the species are new to the Belgian tertiaries, and of these 14 only, or about 25 per cent., are recent. Of the whole 145 Edeghem shells, 52 are considered by Nyst as living species, besides 5 others, which are probably identical with the living, making, if all are accepted, a proportion of 39 per cent., which is decidedly smaller than that observed in the Antwerp Black Crag (see above, p. 208). A still more signifcant indication of the connection of the Edeghem sands with an older or Miocene period is afforded, first, by the fact that no less than 83 of the 145 mollusca are falunian, as shown by M. Nyst's tables, or, in other words, a proportion of 56 per cent. are specifically identical with shells occuring in the Upper Miocene beds of North Germany, Touraine, the Vienna basin, the Bordeaux faluns, and other localities unquestionably of Upper Miocenc date ; secondly, what is perhaps even more in favor of their antiquity, there occur in them shells of the genera Conus, Ancillaria, and Oliva, all of which are not only wanting in the Red and Coralline Crag of Suffolk, and in the Upper and Middle Crags of Antwerp, but are also absent from the lowest or Black Crag of Antwerp. These same genera are also met with in the strata of the Bolderberg in Belgium, a true Upper Miocene formation, the fauna of which recedes still farther from that now existing in the proportion of its shells of living species.

Upper Miocene (?) of Belgium and England.-Diest Sands.-M. Nyst is of opinion that the formation called by Dumont the Diestian is of the same age as the sands of Edeghem-a conclusion which is probably well founded. These ferruginous sands and sandstones of Diest are well seen near the town of that name, about thirty miles north-east of Brussels. They abound in green grains, resembling in mineral character the ferruginous beds of the Lower Greensand in the south-east of England. The strata contain but a small number of fossils, the Terebratula grandis being one of the few which are well preserved. The Diest sands are conspicuous as forming the cappinge 
of hills stretching fiom Diest by Louvain and westward by Oudenarde to Cassel in French Flanders, whore they are seen at the summit of a hill 515 feet high. After having been thus traced for a hundred miles from east to west, they are again seen retaining the same mineral character for another hundred miles in a similar westward direction, first capping the Downs near Folkestone, and then appearing at various points, such as Paddlesworth, Lenham near Maidstone, and Vigo Hill near Otford in Kent.

The geological position of thesc iron sands in England was first made out by Mr. Prestwich, who, in a paper read to the Geological Society of London in 1857, described them as being possibly older than the Coralline Crag, and as occurring on the summit of the North Downs at various points between Folkestone and Dorking. He mentioned their resemblance to the sands at Diest in Belgium, and that they contained the Terebratula grandis, and casts of Astarte pyrula, Emarginula, and ot fossils, all common to the British Crag. After the publication of Mr. Prestwich's paper, I visited with him the principal localities in Kent to which he had called attention, and saw the ferruginous sands, twenty feet thick, resting on the chalk near the edge of the escarpment, about a mile N.E. of Folkestone, and again at Paddlesworth, on the summit of the Downs, four miles W.N.W. of Folkestone, where the sands are about forty feet thick, and where they occur at an elevation of about 500 feet above the sea. At Lenham, ten miles east of Maidstone, fragments of the more consolidated ferruginous layers, full of casts of marine shells and other fossils, are preserved in vertical sandpipes, which penetrate the white chalk. Here I saw organic remains, reminding me of those which I had seen in 1850, at Kesseloo, near Lourain, in the "Diest Sands," which there overlie the Limburg or Lower Miocene beds.* The evidence, both in Belgium and in Kent, being derived from casts, consists mainly in the correspondence of genera; but some of the species, such as the large Terebratula and a Turbinolia, seem identical.

We cannot determine at present, in consequence of the dearth of fossils in the Diest sands, their exact relation to the Edeghem beds, or whether they may be intermediate between the Edeghem and Bolderberg strata, but we may at least affirm that the only British strata at present known which can have any claim to be regarded as Upper Miocene are the ferruginous sands of the North Downs here alluded to.

Upper Miocene of the Bolderberg in Belgium.-In a small hill or ridge callecl the Bolderberg, which I visited in 1851, situated near Hasselt, about forty miles E.N.E. of Brussels, strata of sand and gravel occur, to which M. Dumont first called attention as appearirg to constitute a northern representative of the faluns of Touraine. On the whole they are very distinct in their fossils from the two upper divis-

* See a Memoir by V. Raulin, 1848: Bordeaux. 
ions of the Antwerp Crag before mentioned, and contain shells of the genera Oliva, Conus, Ancillaria, Pleuro-

Fig. 169.
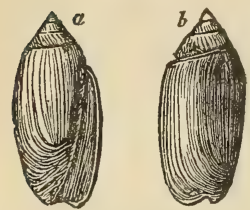

Oliva Dufresnii, Bast. Bolderberg, Belgium, nat. size. $a$. Front view; $b$, back view. toma, and Cancellaria in abundance. The most common shell is an Olive (see fig. 169), called by Nyst Oliva Dufresnii, Bast.; and constituting, as M, Bosquet observes, a smaller and shorter variety of the Bordeaux species.*

The Upper Miocene strata in the Bolderberg occur at the height of about 200 feet above the level of the sea. They are covered by the Diestian sands and iron sandstone already described, and they repose on Lower Miocene beds called Rupelian by Dumont. So

far as the shells are known, the proportion of recent species agrees with that in the faluns of Touraine, and the climate must have been warmer than that of the Coralline Crag of Engla d.

In none of the Belgium Lower Miocene strata could I find any nummulites; and M. d'Archiac had previously observed that these foraminifera characterize his "Lower Tertiary Series," as contrasted with the Middle, and may therefore serve as a good test of age in the North of Europe at least, between Eocene and Miocene. The same naturalist informs us that one nummulite only has ever yet been seen to penetrate upwards into the middle tertiary, viz., Nummulites intermedia, an Eocene species. It has been found in the hill of the Superga, near Turin, in Miocene beds, somewhat older than the falunian type (see above p. 107).

North Germany.-We learn from the able treatise published by M. Beyrich, in 1853, that the same fossil fauna, which is so meagrely exhibited in the Bolderberg, is rich in species in other localities in North Germany, as in Mecklenburg, Lüneburg, the Island Sylt, and at Bersenbrück, north of Osnabrück, in Westphalia, where it was first observed by F. Römer. $\dagger$

Lower Miocene, Belgium.-It was stated that the Bolderberg beds rests on the Rupelian of Dumont, a Lower Miocene formation best seen at the villages of Rupelmonde and Boom, ten miles south of Antwerp, on the banks of the Scheldt and near the junction with it of a small stream called the Rupel. A stiff clay abounding in fossils is extensively worked at the above localities for making tiles. It attains a thickness of about 100 feet, and, though very different in age, much resembles in mineral character the "London Clay," containing, like it, septaria or concretions of argillaceous limestone traversed by cracks in the interior, which are filled with calc-spar. The shells, referable to about forty species, have been described by MM. Nyst and De

* Lyell on Belgian Tertiaries, Quart. Geol. Journ., 1852, p. 295. Nyst's figrure seems to be copied from that given by Basterot of the Bordeaux fossil.

+ Beyrich, Die Conchylien der Norddeutschen Tertiärgebirge : Berlin, 1853. 
Koninck. Among them Leda (or Nucula) Deshayesiana (see fig: 170 ) is by far the most abundant; a fossil unknown as yet in the

Fig. 170 ,

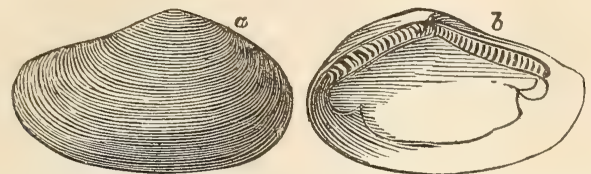

Leda Deshayesiana. Nyst. Syn. Nucula Deshayesiana.

English tertiary strata, but when young resembling Leda amygdaloides of the London clay proper (see fig. 256 p. 294). Among other characteristic shells are Pecten Hoeninghausii, and a species of Cassidaria, and several of the genus Pleurotoma. Not a few of these testacea agree with English Eocene species, such as Actcon simulatus, Sow., Cancellaria evulsa, Brander, Corbula, pisum (fig. 171), and Nautilus (Aturia) ziczac. They are accompanied by many teeth of sharks, as Lamna contortidens, Ag., Oxyrhina xiphodon, Ag., Charcharodon heterodon (see fig. 240), Ag., and other fish, some of them common to the Middle Eocene strata.

Rupelian Clay of Hermsdorf near Berlin.-Professor Beyrich has described a mass of clay, used for making tiles, within seren miles of the gates of Berlin, near the village of Hermsdorf, rising up from beneath the sands with which that country is chiefly overspread. This clay is more than forty feet thick, of a dark bluish-grey color, and, like that of Rupelmonde, contains septaria. Among other shells, the Leda Deshayesiana before mentioned (fig. 170) abounds, together with many species of Pleurotoma, Voluta, \&c., a certain proportion of the fossils being identical in species with those of Rupelmonde. The succession of the Lower Miocene strata of Belgium can be best studied in the environs of Kleyn Spawen, a village situated about seren miles west of Maestricht, in the old province of Limburg in Belgium. In that region, about 200 species of testacea, marine and freshwater, have been obtained, with many foraminifera and remains of fish.

The following table will show the position of these Belgian or Limburg beds :-

UPPER Miocene.

A. Bolderberg beds, see p. 235, seen near Hasselt.

LOWer Mtocene.

3. : Nucula Loam of Kleyn Spawen, same age as the clay of Rupelmonde Upper Limburg beds.-Rupelian of and Boom.

B. 2. Flurio-marine beds of Bergh, Lethen, I Middle Limburg beds.-Upper Tonand other places near Kleyn Spawen. $\int$ grian of Dumont. 
B. 3. Marine green sand of Bergh, Neerepen, \&c., and Tongres, near Kleyn Lower Limburg beds.-Lower TonSpawen.

grian of Dumont.

\section{UPPER EOCENE.}

C. Calcareous sandy beds of Laeken, near Brussels, with nummulites, \&c., of same age as the "Sables Moyens" of the Paris basin and the Barton clay of Hampshire.

The uppermost of the three subdivisions (B. 1) into which the Lower Miocene or Limburg series is separated in the above table, con. tains at Kleyn Spawen many of the same fossils as the clay, above mentioned, of Rupelmonde and Boom, places sixty miles N.W. of Kleyn Spawen.

The lower, or Tongrian divisions, B. 2 and B. 3, are much better developed at Kleyn Spawen than B. 1. The first of these, B. 2, consists of several alternations of sand and marls, in which a greater or less intermixture of fluviatile and marine shells occurs, implying the occasional entrance of a river near the spot, and possibly oscillations in the level of the bottom of the sea. Among the shells ar found Cyrena semistriata (fig. 172), Cerithium plicatum, Lam., (fig. 173) Rissoa Chastelii, Bosq. (fig. 175), and Corbula pisum (fig. 171), four shells all common to the Hempstead or British Lower Miocene beds of the Isle of Wight, to be mentioned in the sequel. With the above, Lucina Thierensii, and other marine forms of the genera Venus, Limopsis, Trochus, \&c., are met with.

In B. 3, or the Lower Tongrian, more than 100 marine shells hare been collected, among which the Ostrea ventilabrum is very conspicuous. Species common to the underlying Brussels sands, or the Upper Eocene, are numerous, constituting a third of the whole; but most of these are feebly represented in comparison with the more peculiar and characteristic shells, such as Ostrea ventilabrum Mytilus Nystii, Voluta suturalis, \&c.

Whether this Lower Tongrian should be classed as the lowest member of the Miocene series, or as the uppermost of the Eocene, or, in other words, as the marine equivalent of the freshwater gypsum of Paris, is a question not yet decided. I incline at present to the belief that it is somewhat newer than the Paris gypsum, but certainly near the boundary line which separates the two systems. Its relation to the Upper Eocene deposits of England or the Isle of Wight will be more fully discussed in the sixteenth chapter, p. 281.

In none of the Belgian Lower Miocene strata could I find any nummulites; and M. d'Archiac had previously observed that these foraminifera characterized his "Lower Tertiary Series," as contrasted with the Middle, and they therefore served as a good test of age between Eocene and Miocene, at least in Belgium and the North of France.*

* D'Archiac, Monogr., pp. 79, 100. 
Between the Bolderberg beds and the Rupelian clay there is a great chasm in Belgium, which seems, according to M. Beyrich, to be filled up in the North of Germany by what he calls the Sternberg beds, and which, had Dumont found them in Belgium, he might rrobably have termed Upper Rupelian.

\section{LOWER MIOCENE STRATA OF ENGLAND.}

Hempstead beds, Isle of Wight.-We have already seen that the Upper. Niocene period is meagrely and somewhat questionably represented in England by certain ferruginous sands on the North Downs, of the age of the Diestian beds of Belgium. The Lower Miocene period is more decidedly represented by certain strata in the Isle of Wight, the true age of which was not recognized until the year 1852, when the late Edward Forbes observed * that there was a series of tertiarr strata near Yarmouth newer than those of Binstead and Bembridge. These last are the undoubted equivalants of the Paris gypsum, boing characterized by the same species of Paleotherium Anoplotherium, \&c., as those described by Cuvier from Montmartre. The Lower Miocene deposits alluded to are 170 feet in thickness and rich in fossils, and hare been called the Hempstead series, from a hill of that name on the coast near Yarmouth. $\dagger$ The following is the succession of the strata :-

SCBDIVISIONS OF THE HEMPSTEAD SERIES.

1. The uppermost or Corbula beds, consisting of marine sands and clays, contain Voluta Rathieri, a characteristic Lower Miocene shell, Corbula pisum, fig. 171, a species common to the Upper Eocene clay of Barton; Cyrena semistriata, fig. 172, several Cerithia, and other shells peculiar to this series.

Fig. 171.

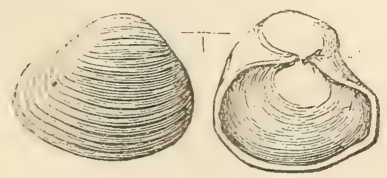

corbula pisum. Hempstead Beds, Isle of Wight.
Fig. 172 .

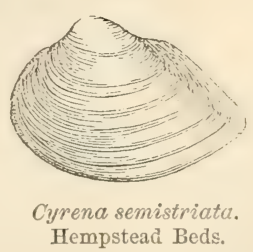

2. Next below are freshwater and estuary marls and carbonaceous clays, in the brackish-rrater portion of which are found abundantly Cerithium plicatum, Lam., fig. 173, C. elegans, fig. 174, and C. tricinctum; also Rissoa Chastelii, fig. 175, a very common Kleyn Spawen shell, and which occurs in each of the four subdivisions of the Hempstead series down to its base, where it passes into the Bembridge beds. In the freshwater portion of the same beds Paludina lenta,

* E. Forbes, Geol. Quart. Journ., 1853.

$\uparrow$ This hill must not be confounded with Hampstead Hill, near London, where the Lower Eocene or London Clay is capped by Middle Eocene sands. 
fig. 176, occurs a shell identified by some conchologists with a species now liv. ing, P. unicolor; also several species of Iymneus, Planorbis, and Unio.

3. The next series, or middle freshwater and estuary marls, are distinguished by the presence of Melania fasciata, Paludina lenta, and clays with Cypris; the lowest bed contains Cyrena semistriata, fig. 172, mingled with Cerithia and a Ponopcea.

4. The lower ireshwater and estuary marls contain Melania costata, Sow., Melanopsis, \&c. The bottom bed is carbonaceous, and called the "Black band," in which Rissoa Chastelii, fig. 175, before alluded to, is common. This bed contains a

Fig. 173.

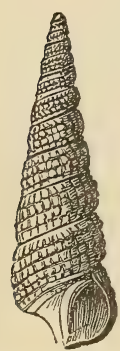

Cerithium plicatum, Lam. Hempstead.
Fig. 174

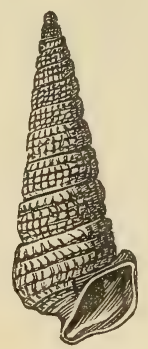

Cerithium elegans, Hempstead.
Fig. 175 .

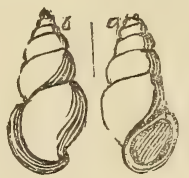

Rissoa Chastelii, Nyst, Sp. Hempstead, Isle
of Wight.
Fig. 176.

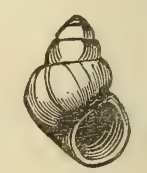

Paludina lenta. Hempstead Bede.

mixture of Hempstead shells with those of the underlying Upper Eocene or Bembridge scries. The mammalia, among which is Hyopotamus bovinus, differ, so far as they are known, from those of the Bembridge beds. Among the plants, Professor Heer has recognized four species common to the lignite of Bovey Tracey, a Lower Miocene formation presently to be described: namely, Sequoia Couttsice, Heer; Andromeda reticulata, Etting; Nymphoea Doris, Heer; and Carpolithes Websteri, Brong:* The seed-vessels of Chara medicaginula, Brong., and $C$. helecteres are characteristic of the Hempstead beds generally.

The Hyopotamus belongs to the hog tribe, or the same family as the Anthracotherium, of which seven species, varying in size from the hippopotamus to the wild boar, have been found in Italy and other parts of Europe associated with the lignites of the Lower Miocene period.

Lignites and Clays of Bovey Tracey, Devonshire.-Surrounded by the granite and other rocks of the Dartmoor hills in Devonshire, is a formation of clay, sand, and lignite, long known to geologists as the Bovey Coal formation, respecting the age of which, until the year 1861, opinions were very unsettled. This deposit is situated at Bovey Tracey, a village distant eleven miles from Exeter in a south-west, and about as far from Torquay in a north-west direction. The strata extend over a plain nine miles long, and they consist of the materials of decomposed and worn-down granite and vegetable matter, and have evidently filled up an ancient hollow or lake-like expansion of the valleys of the Borey and Teign.

* Pengelly, preface to The Lignite Formation of Bovey Tracey, p. xvii.: London, 1863. 
The lignite is of bad quality for economical purposes, as there is a great admixture in it of iron pyrites, and it emits a sulphurous odour, but it has been successfully applied to the baking of pottery, for which some of the fine clays are well adapted. Mr. Pengelly has confirmed Sir H. De la Beche's opinion that much of the upper portion of this old lacustrine formation has been removed by denudation.*

At the surface is a dense covering of clay and gravel with angular stones probably of the Post-pliocene period, for in the clay are three species of willow and the dwarf birch, Betula nana, indicating a climate colder than that of Devonshire at the present day.

Below this are Lower Miocene strata about 300 feet in thickness, in the upper part of which are twenty-six beds of lignite, clay, and sand, at their base a ferruginous quartzose sand, varying in thickness from two to twenty-seven feet. Below this sand are forty-five beds of alternating lignite and clay. No shells or bones of mammalia, and no insect with the exception of one fragment of a beetle (Buprestis); in a word, no organic remains except plants have as yet been found. These plants occur in fourteen of the beds, namely, in two of the clays, and the rest in the lignites. One of the beds is a perfect mat of the débris of a coniferous tree, called by Heer Sequoia Couttsice, intermixed with leaves of ferns. The same Sequoia is spread through all parts of the formation, its cones, and seeds, and branches of every age being preserved. It is a species supplying a link between S. Langsdorfii (see figs. 201, 202 p. 263) and S. Sternbergi, the widely-spread fossil representatives of the two living trees $S$. sempervirens and S. gigantea (or Wellingtonia), both confined in the living creation to California. Another bed is full of the large rhizomes of ferns, while two others are rich in dicotyledonous leaves. In all Professor Heer enumerates forty-nine species of plants, twenty of which are common to the Miocene bed of the Continent, a majority of them being characteristic of the Lower Miocene. The new species, also of Borey, are allied to plants of the older Miocene deposits of Switzerland, Germany, and other continental countries. The grape-stones of two species of rine occur in the clays, and the leaves of three species of fig, seeds also supposed to belong to three new species of Nyssa, or Tupelo tree, a genus now common in the swamps of South Carolina and Florida, two species of Annona, and a new water-lily. The oak and laurel have supplied many leaves. Of the triple-nerved laurels three or four are referred to Cinnamomum. There is a palm also, of which the genus is not determined. Among the Proteacer are mentioned Dryandrcides Hakecefolia (fig. 198), D. Banksiaefolia, and another. Among the ferns is the well-known continental fossil Las. trcea stiviaca (fig. 203, p. 264), displaying at Bovey as in Switzerland its fructification.

"* Phil. Trans., 1863. Paper by W. Pengelly, F.R.S., and Dr. Oswald Heer. 
The croziers of some of the young ferns are very perfect, and were at first mistaken by collectors for shells of the genus Planorbis. On the whole, the vegetation of Bovey implies the existence in Devonshire, in the Lower Miocene period, of a sub-tropical climate.

Scotland.-Isle of Mull.-In the sea-cliffs forming the headland of Ardtun on the west coast of Mull, in the Hebrides, several bands of tertiary strata containing leaves of dicotyledonous plants were discovered in 1851 by the Duke of Argyle.* From his description it appears that there are three leaf-beds, varying in thickness from $1 \frac{1}{2}$ to $2 \frac{1}{2}$ feet, which are interstratified with volcanic tuff and trap, the whole mass being about 130 feet in thickness. A sheet of basalt 40 feet thick covers the whole; and another columnar bed of the same rock, 10 feet thick, is exposed at the bottom of the cliff. One of the leafbeds consists of a compressed mass of leaves unaccompanied by any stems, as if they had been blown into a marsh where a species of Equisetum grew, of which the remains are plentifully embedded in clay.

It is supposed by the Duke of Argyle that this formation was accumulated in a shallow lake or marsh in the neighborhood of a volcano, which emitted showers of ashes and streams of lava. The tufaceous envelope of the fossils may have fallen into the lake from the air as volcanic dust, or have been washed down.into it as mud from the adjoining land. Even without the aid of organic remains we might have decided that the deposit was newer than the chalk, for chalk flints containing cretaceous fossils were detected by the Duke in the principal mass of volcanic ashes or tuff. $\downarrow$

The late Edward Forbes observed that some of the plants of this formation resembled those of Croatia, described by Unger, and his opinion has been confirmed by Professor Heer, who found that the conifer most prevalent was the Sequoia Langsdorfii (figs. 201, 202), also Corylus grosse-dentata, a Lower Miocene species of Switzerland and of Menat in Auvergne. There is likewise a plane tree, the leaves of which seem to agree with those of Platanus aceroides (fig. 187, p. 254), and a fern which is as yet peculiar to Mull, Filicites hebridica, Forbes.

These interesting discoveries in Mull naturally raise the question, whether the basalt of Antrim in Ireland, and of the celebrated Giant's Causeway, may not be of the same age. For in Antrim the basalt overlies the chalk, and the upper mass of it covers everywhere a bed of lignite and charcoal, in which wood, with the fibre well preserved, and evidently dicotyledonous, is enclosed. The general dearth of strata in the British Isles, intermediate in age between the formation of the Eocene and Pliocene periods, may arise, says Professor Forbes, from the extent of dry land which prevailed in that vast interval of time. If land predominated, the only monuments we are likely ever

* Quart. Geol. Journ., 1851, p. 89.

+ Ibid., p. 90 . 
to find of Miocene date are those of lacustrine and volcanic origin, such as the Borey Coal in Deronshire, the Ardtun beds in Mull, or the lignites and associated basalts in Antrim.

\section{MIOCENE FORMATIONS OF GERMANY.}

Mayence basin.-An elaborate description has been published by Dr. F. Sandberger of the Mayence tertiary area, which occupies a tract from fire to trelre miles in breadth, extending for a great distance along the left bank of the Rhine from Mayence to the neighborhood of Mauheim, and which is also found to the east, north, and south-Test of Frankfort. M. de Koninck, of Liége, first pointed out to me that the purely marine portion of the deposit contained many species of shells common to the Kleyn Spawen beds, and to the clay of Rupelmonde, near Antwerp. Among these he mentioned Cassidaria depressa, Tritonium argutum, Brander (T. Alandricum, De Koninck), Tornatella simulata, Aporrhais Sowerbyi, Leda Deshayesiana (fig. 170, p. 237), Corbula pisum (fig. 171), and Pectunculus terebratularis.

First, in the neighborhood of the above-mentioned strata of the Mayence basin are the sands of Eppelsheim, containing Dinotherium giganteum, and other Falunian or Upper Miocene quadrupeds. Next, the uppermost part of the Mayence series consists of what is called the Littorinella Limestone, which contains among other mammalia Hippotherium gracile, Acerotherium (or Rhinoceros) incisivum Paleomeryx, and Chalicomys, all indicating a Lower Miocene fauna.

The shell (fig. 177) from which the above-mentioned limestone is named much resembles the recent Littorinella (or Rissoa) ulva. Each shell is like a grain of rice in size, and they are often in such quantity as to form entire beds of marl and limestone, in stratified masses from fifteen to thirty feet in thickness, just as in the Baltic modern accumulations several feet thick of the Littorinella ulva are spread far and wide orer the bottom of the sea. In the same beds, sereral species of Dreissena abound, a form common to the

Fig. 177.

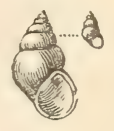

Paludina. Mayence. Headon or Cpper Eocene beds of the Isle of Wight, as well as to the existing seas.

Among the plants obtained by XI. Ludwig from argillaceous strata of the Littorinella limestone series, are many which have a wide range in the Mliocene period, but two of them, says Heer, riz., Dryandroides Banksicefolia and $D$. arguta, are characteristic of the Lower Miocene, or of beds below the faluns or Marine Molasse of Switzerland.

Next belor the marls containing Cyrena semistriata, Cerithium plicatum, C. mairgaritaceum, and C. Lamarckii.* These marls, with 
the underlying clays containing Leda Deshayesiana, are regarded as the Rupelian of Dumont, while the shell-bearing sands of Weinheim, near Alzey, are supposed to be somewhat older, and the equivalents of the Grès de Fontainebleau.

Upper Miocene beds of the Vienna basin.-In South Germany the general resemblance of the shells of the Vienna tertiary basin with those of the faluns of Touraine has long been acknowledged. In Dr. Hörnes' excellent work on the fossil mollusca of that formation we see accurate figures of many shells, clearly of the same species as those found in the falunian sands of Touraine.

According to Professor Suess, the most ancient and purely marine of the Miocene strata in this basin consist of sands, conglomerates, limestones, and clays, and they are inclined inwards or from the borders of the trough toward the centre; their outcropping edges rising much higher than the newer beds, whether Miocene or Pliocene, which overlie them, and which occupy a small area at an inferior elevation above the sea. M. Hörnes has described 500 species of gasteropods, of which he identifies one-fifth with living species of the Mediterranean, Indian, or African seas, but the proportion of existing species among the lamelli-branchiate bivalves, exceeds this average. Among many univalves agreeing with those of Africa on the eastern side of the Atlantic are Cyprecea sanguinolenia, Buccinum lyratum and Oliva flammulata. In the lowest marine beds of the Vieuna basin the remains of several mammalia have been found, and among them a species of Dinotherium, a Mastodon of the Trilophodon family, a Rhinoceros (allied to $R$. megarhinus, Christol), also Listriodon, Meyer (of the hog tribe), and a carnivorous animal of the canine family.

The Hetix turonensis (fig. 45, p. 30), the most common land-shell of the French faluns, accompanies the above. In a higher member of the Vienna Miocene series are found Dinotherium giganteum, Mastodon longirostris, Rhinoceros Schleiermacheri, Acerotherium incisivum and Hippotherium gracile, all of them equally characteristic of an Upper Miocene deposit occurring at Eppelsheim in Hesse Darmstadt, above alluded to. M. Alcide d'Orbigny has shown that the foraminifera of the Vienna basin differ alike from the Eocene and Pliocene species, and agree with those of the faluns, so far as the latter are known. Among the Vienna foraminifera, the genus Amphistegina (fig. 178) is

Fig. 178.
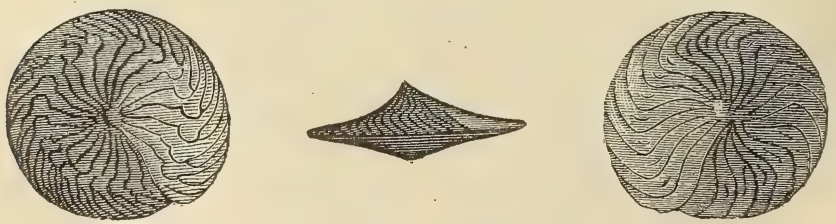

Amphistegina Hauerina, D'Orb. Upper Miocene strata, Vienna. 
very characteristic, and is supposed by D'Archiac to take the same place among the Rhizopods of the Upper Miocene era which the Nummulities occupy in the Eocene period.

The flora of the Vienna basin exhibits some species which have a general range through the whole Miocene period, such as Cinnamomum polymorphum (fig. 188), and another species, C. Scheuchzeri also Planera Richardi, Mich., (fig. 205), Liquidambar europaum (fig. 160), Juglans bilinica, Cassia ambigua, and C. lignitum. With these are also found one or two Older Miocene forms, together with some of the Upper Miocene plants of Eningen in Switzerland, such as Platanus aceroides (fig. 187), Myrica vindobonensis, Heer, \&c.

Lower Miocene beds of Croatia.-The Brown Coal of Radaboj, near Angram in Croatia, not far from the borders of Styria, is covered, says Von Buch, by beds containing the marine shells of the Vienna basin, or, in other words, by Upper Miocene or Falunian strata. They appear to correspond in age to the Mayence basin, or to the Rupelian strata of Belgium. They have yielded more than 200 species of fossil plants, of which Professor Unger has given an admirable description. They are well preserved in a hard marlstone, and contain several palms; among them the Sabal, fig. 197, p. 259, and another genus allied to the date-palm Phonicites spectabilis. Among the fossils of the same marls we also find a fern, which will be mentioned in the next chapter (fig. 195, p. 258), called Woodwardia Rössneriana. The only abundant plant among the Radaboj fossils which is characteristic of the Upper Miocene period is the Populus mutabilis, whereas no less than fifty of the Radaboj species are common to the more ancient flora of the Lower Molasse of Switzerland.

The insect fauna is very rich, and, like the plants, indicates a more tropical climate than do the fossils of Eningen presently to be mentioned. There are ten species of Termites, or white ants, some of gigantic size, and large dragon-flies with speckled wings, like those of the Southern States in North America; there are also grasshoppers of considerable size, and even the Lepidoptera are not unrepresented.

Fig. 179.

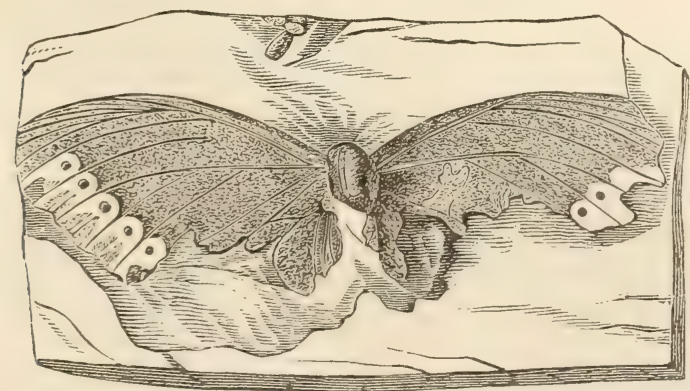

Vanessa Pluto; nat. size. Lower Miocene, Radaboj, Croatia. 
In one instance, the pattern of a butterfly's wing has escaped obliteration in the marlstone of Radaboj; and when we reflect on the remoteness of the time from which it has been faithfully transmitted to us, this fact may inspire the reader with some confidence as to the reliable nature of the characters which other insects of a more durable texture, such as the beetles, may afford for specific determination. The Vanessa above figured retains, says Heer, some of its colors, and corresponds with $V$. Hadena of India.

The lignites called Brown Coal in Germany belong, for the most part, to the Lower Miocene epoch. Among these may be mentioned those of the Siebengebirge, near Bonn, which are associated with volcanic rocks.

Professor Beyrich, in his important "Memoirs on the Tertiary Strata of the North of Germany," * has made known to us the existence of a long succession of marine strata which lead, by an almost gradual transition, from the Sternberg beds (see above, p. 239), approaching in age to the faluns of the Loire, to others agreeing in date with the Lower Tongrian of Dumont, already mentioned, p. 238, as the base of the Miocene. In conformity with the method which I formerly adopted, he has appropriated the term Miocene exclusively to the faluns of Touraine and strata of that age; but for all the formations below that level, as far down as the Uppermost Eocene, he has proposed the new term of Oligocene. The Sternberg beds are called Upper Oligocene; the next five groups, to which those of the Mayence bașin, amongst others, belong, as well as the Calcaire de la Beauce and Fontainebleau Sandstone, are named Middle Oligocene; while the Egeln beds and some. North German Brown Coals of the age of the Lower Tongrian of Dumont are called Lower Oligocene. The difficulty of drawing a boundary line between these last formations and the Eocene is precisely the same as that of separating the Lower Miocene and Eocene (as defined in the preceding chapters) in France and Belgium. After full consideration, it seems to me most convenient to accept the classification so long adopted by many writers, which places the gypsum of Montmartre as the uppermost of the Eocene subdivisions; and if it can be demonstrated that any part of the Tongrian of Dumont, or of the German strata classed by Beyrich as Lower Oligocene, is strictly contemporaneous with the Paris gypsum or the Bembridge strata of the Isle of Wight, I should then separate them from the Lower Miocene, and consider them as Upper Eocene. We are now arriving at that stage of progress when the line, wherever it be drawn, will be an arbitrary one, or one of mere convenience, as I shall have an opportunity of showing when the Upper Eocene formations in the Isle of Wight are described in the sixteenth chapter.

* Abhandlungen der Königl. Acad. der Wissen. zu Berlin, 1855, and ibid. 1858, p. 59. 
Miocene strata of Italy.-We are indebted to Signor Michelotti for a valuable work on the Miocene shells of Northern Italy. Those found in the hill called the Superga, near: Turin, have long been known to correspond in age with the faluns of Touraine, and they contain so many species common to the Upper Miocene strata of Bordeaux as to induce M. Tournouer to conclude that there was a free communication between the northern part of the Mediterranean and the Bay of Biscay in the Upper Miocene period. In the hills of which the Superga forms a part there is a great series of Tertiary strata which pass downward into the Lower Miocene. Even in the Superga itself there are some fossil plants which, according to Heer, have never been found in Switzerland so high as the Marine Molasse, such as Banksia longifolia, and Carpinus grandis.* In several parts of the Ligurian Apennines, as at Dégo and Carcare, the Lower Miocene appears, containing some nummulites, and at Cadibona, north of Savona, freshwater strata of the same age occur, with dense beds of lignite enclosing remains of the Anthracotherium magnum and A. minimum, besides other mammalia enumerated by Gastaldi. In these beds a great number of the Lower Miocene plants of Switzerland have been discovered.

Upper Miocene formations of Greece.-At Pikermé, near Athens, MM. Wagner and Roth have described a deposit in which they found the remains of the genera Mastodon, Dinotherium, Hipparion, Antelope, two Giraffes, and others, some living and others extinct. With them were also associated fossil bones of the Semnopithecus, showing: that here, as in the South of France, the quadrumana were characteristic of this period. The whole fauna attests the former extension of a vast expanse of grassy plains where we have now the broken and mountainous country of Greece-plains which were probably united with Asia Minor, spreading over the area where the deep Egean Sea and its numerous islands are now situated.

\footnotetext{
* Recherches sur le Climat et la Végétation du Pays Tertiaire, par Oswald Heer. 1851.
} 


\title{
CHAPTER XV.
}

\author{
MIOCENE FORMATIONS-continued.
}

\begin{abstract}
Miocene Strata of Switzerland-Upper Miocene beds of Eningen-Importance of Fossil Plants-Heer's work on the Swiss Miocene flora-Plants and insects of EEningen imbedded in different seasons-Fossil fruits and flowers, as well as leaves-Middle or Marine. Molasse of Switzerland-Lower Molasse, or Lower Miocene-Dense conglomerates and proofs of subsidence-Fossil plants of Lower Miocene period more tropical-Preponderance of arboreseent speciesSupposed discordance in relative numbers of living species of plants and shells in Upper Miocene formations-Theory of a Miocene Atlantis-Whether the American plants abounding in the Miocene of Europe migrated by a westerly or an easterly route-Objections derived from depth and width of the AtlanticArguments in favor of a Trans-Asiatic migration-Miocene fossils of OregonAgreement of Miocene corals of the West Indies and Europe opposed to the theory of an Atlantic Continent-Upper Miocene formations of India-SubHimalayan or Siwâlik Hills-Older Pliocene and Miocene formations in the United States of America.
\end{abstract}

MIOCENE STRATA OF SWITZERLAND.

Upper Miocene beds of Eningen.-The faluns of the Loire first served, as already stated (p. 212), as the type of the Miocene formations in Europe. They yielded a plentiful harvest of fossil shells and zoophytes, but were entirely barren of plants and insects. In Switzerland, on the other hand, deposits of the same age have been discovered, remarkable for their botanical and entomological treasures.

We are indebted to Professor Heer of Zurich for the description, restoration, and classification of more than 900 species of these fossil plants, the whole of which he has illustrated by excellent figures in his."Flora Tertiaria Helvetiæ." * In this great work he has achieved for the botany of the Tertiary formations what his distinguished predecessor, Adolphe Brongniart, had done for the fossil plants of the Primary and Secondary rocks. MM. Unger and Göppert, by their able descriptions of the plants of the Brown Coal of Germany, had already prepared the minds of geologists to expect that botany would one day play almost as important a part as conchology in enabling us to identify and classify the middle tertiary strata. But no

* This work, in three vols., cantaining 155 folio plates of fossil plants, was published at Winterthur in 1855-'9, and a French translation of those chapters which relate to the geology, botany, and climate of the Swiss Miocene strata appeared in 1862, edited by Prof. Heer and M. Charles-Th. Gaudin, entitled "Recherches sur le Climat et la Végétation du Pays Tertiaire." 
small skepticism had always prevailed among botanists of the highest attainments as to whether fossil remains of the regetable kingdom could ever afford sufficient data for determining the species, or eren the genera or families, of plants of which nothing but the leares are imbedded in the rocks. In truth, before such remains could be rendered available, a new science had to be created. It was necessary to study the outlines, nerration, and microscopic structure of the leaves with a degree of care which had never been called for in the classification of living plants, where the flower and fruit afforded characters so much more definite and satisfactory. As geologists, we cannot be too grateful to those who, instead of despairing when a task of such difficulty was presented to them, entered with full faith and enthusiasm into the new and unexplored field. That they should frequently have fallen into errors was unavoidable, but it is remarkable, especially if we inquire into the history of Professor Heer's researches, how often early conjectures as to the genus and family founded on leaves alone were afterwards confirmed when fuller information was obtained; as, for example, when the fruit, and in some instances both fruit and flower, were found attached to the same stem as the leaves which had been first described. Nor should we forget that when a skilful botanist has deroted his powers of discrimination to the classification of the leaves according to their forms, veining, and minute or microscopic structure, he may afford the most important palæontological assistance to the geologist, eren if he happen to make some erroneous guesses as to the generic or eren ordinal affinities of the plants in question. His power of recognizing the same identical fossil in two distinct places or two distinct formations may settle a disputed point in chronology, where there is no other evidence at hand, and the conclusions dramn from such data as to the relative age of the beds have often held good, even when it was afterwards proved that several species, or even genera, had been constructed out of the lcaves of the same plant, or that the fruit and leaves of one and the same tree had been referred to genera of distinct families.

The Miocene formations of Switzerland have been called Molasse, a term derived from the French mol, and applied to a soft, incoherent, greenish sandstone, occupying the country betreen the Alps and the Jura. This molasse comprises three divisions, of which the middle one is marine, and being closely related by its shells to the faluns of Touraine, may be classed as Upper Miocene. The two others are freshwater, the upper of which may be also grouped with the faluns, while the lower must be referred to the Lower Miocene, as defined in the last chapter.

The upper freshwater Molasse may first be considered. It is best seen at Eningen, in the valley of the Rhine, between Constance and Schaffhausen, a locality celebrated for haring produced in the year 1700 the supposed buman skeleton called by Scheuchzer "homo dilurii testis," a fossil afterwards demonstrated by Curier to be a 
reptile, or aquatic salamander, of larger dimensions than even its great living representative the salamander of Japan.

The Eningen strata consist of a series of marls and limestones, many of them thinly laminated, and which appear to have slowly accumulated in a lake probably fed by springs holding carbonate of lime in solution.

The elliptical area over which this freshwater formation has been traced extends, according to Sir Roderick Murchison, for a distance of ten miles east and west from Berlingen, on the right bank of the river to Wangen, and to Eningen, near Stein, on the left bank. The organic remains have been chiefly derived from two quarries, the lower of which is about 550 feet above the level of the Lake of Constance, while the upper quarry is $\mathbf{1 5 0}$ feet higher. In this last, a section thirty feet deep displays a great succession of beds, most of them splitting into slabs and some into very thin laminx. Twentyone beds are enumerated by Professor Heer, the uppermost a bluishgray marl seven feet thick, without organic remains, resting on a limestone with fossil plants, including leaves of poplar, cinnamon, and pond-weed (Potamogeton), together with some insects; while in the bed No. 4, below, is a bituminous rock, in which the Mastodon angustidens, a characteristic Upper Miocene quadruped, has been met with. The 5th bed, two or three inches thick, contains fossil fish, e.g. Leuciscus (roach), and the larvæ of dragon-flies, with plants such as the elm (Ulmus), and the aquatic Chara. Below this are other plantbeds; and then, in No. 9, the stone in which the great salamander (Andrias Scheuchzeri) and some fish were found. Below this, other strata occur with fish, tortoises, the great salamander before alluded to, freshwater mussels, and plants. In No. 16 the fossil fox of Eningen, Galecynus EEningensis, Owen, was obtained by Sir R. Murchison. To this succeed other beds with mammalia (Lagomys), reptiles (Emys), fish, and plants, such as walnut, maple, and poplar. In the 19 th bed are numerous fish, insects, and plants, below which are marls, of a blue indigo color.

In the lower quarry eleven beds are mentioned, in which, as in the upper, both land and freshwater plants and many insects occur. In the 6th, reckoning from the top, many plants have been obtained, such as Liquidambar, Daphnogene, Podogonium, and Elm, together with tortoises, besides the bones and teeth of a ruminant quadruped, named by H. V. Meyer Paleomeryoe eminens. No. 9 is called the insect bed, a laver only a few inches thick, which, when exposed to the frost, splits into leaves as thin as paper. In these thin laminæ plants such as Liquidambar, Daphnogene, and Glyptostrobus occur, with in numerable insects in a wonderful state of preservation, usually found singly. Below this is an indigo-blue marl, like that at the bottom of the higher quarry, resting on yellow marl ascertained to be at least thirty feet thick.

All the above fossil-bearing strata were evidently formed with 
extreme slowness. Although the fossiliferous beds are, in the aggregate, not more than a few yards in thickness, and have only been examined in the small arca comprised in the two quarries just alluded to, they gire us an insight into the state of animal and regetable life in part of the Upper Miocene period, such as no other region in the world has elsewhere supplied. In the year 1859, Professor Heer had already determined no less than 475 species of plants and 900 insects from these Eningen beds. He supposes that a river entering a lake floated into it some of the leares and land-insects, together with the carcasses of quadrupeds, such as the great Mastodon. Occasionally, during tempests, twigs and even boughs of trees with their leaves were torn off and carried for some distance so as to reach the lake. Springs, containing carbonate of lime, seem at some points to have supplied calcareous matter in solution, giving origin locally to a kind of travertin, in which organic bodies sinking to the bottom became hermetically sealed up. The laminæ, says Heer, which immediately succeed each other, were not all formed at the same season, for it can be shomn that, when some of them originated, certain plants were in flower, whereas, when the next of these layers was produced, the same plants had ripened their fruit. This inference is confirmed by independent proofs derived from insects. The principal insect-bed is rarely two inches thick, and is composed, says Heer, of about 250 leaflike laminæ, some of which were deposited in the spring; when the Cinnamomum polymorphum (p. 254) was in flower; others in summer, when winged ants were numerous, and when the poplar and willow had matured their seed; others, again, in autumn, when the

Fig. 180.

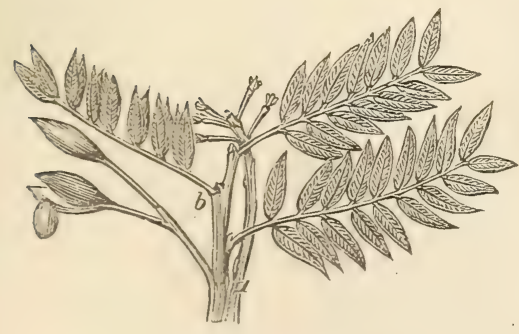

Fig. 181.

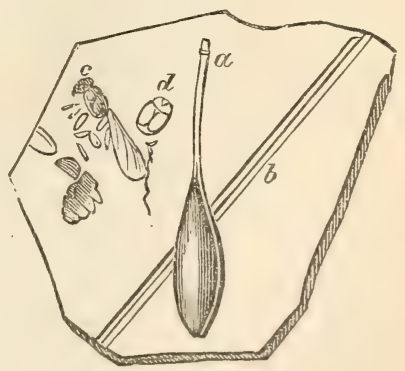

Podogonium Knorii. Upper Miocene of GEningen and many parts of Germany. Fig. 180. Restoration of the plant by Prof. Heer. Frontispiece, Flora Tert. Hel. $\frac{1}{3}$ nat. size. a. Branch bearing flowers before the leaves appear. b. Branch with leaves and ripe fruit.

Fig. 181. a. Pod of P. Knorii. Eningen, $\frac{1}{3}$ nat. size. b. Leaf of gramineous plant.

c. Formica lignitum. Heer, pl. 134, fig. 26.

d. Hister cojyolithorum.

same Cinnamomum polymorphum (fig. 188) was in fruit, as well as the liquidambar, oak, clematis, and many other plants.

The ancient lake seems to have had round its borders a belt of 
poplars and willows, countless leaves of which became imbedded in the mud. Together with them, at some points, a species of reed, Arundo, was very common.

One of the most characteristic shrubs is a papilionaceous and leguminous plant of an extinct genus, called by Heer Podogonium, of which two species are known. Entire twigs have been found ( $a$, fig. 180 ), with flowers, and always without leaves, the flowers having evidently come out, as in the poplar and willow tribe, before any leaves made their appearance. Other specimens have been obtained with ripe fruit accönpanied by leaves, as shown in the branch $b$, fig. 180 . In some specimens are seen the embryo and cotyledons, in others the calyx and young fruit. The leaves resemble those of the tamarind, but each pod contains only a single seed, whereas the pod of the tamarind, an allied genus, contains many seeds.

In fig. 181 we see a ripe seed-vessel of this plant, and on the same thin slab a winged ant, c, Formica lignitum, Heer. Another species of ant, also with wings, has been found associated with the same Podogonium in fructification, from which fact Professor Heer concludes that it ripened its seed in summer, at which season alone swarms of perfect male and female ants, having their wings fully developed, make their flights. Such, for example, is the habit of the living Formica herculeana, which comes very near to $F$. lignitum. In the same slab, at $d$, is a portion of a beetle of the genus Hister.

The Upper Miocene flora of OEningen is peculiarly important, in consequence of the number of genera of which not merely the leaves,

Fig. 182.

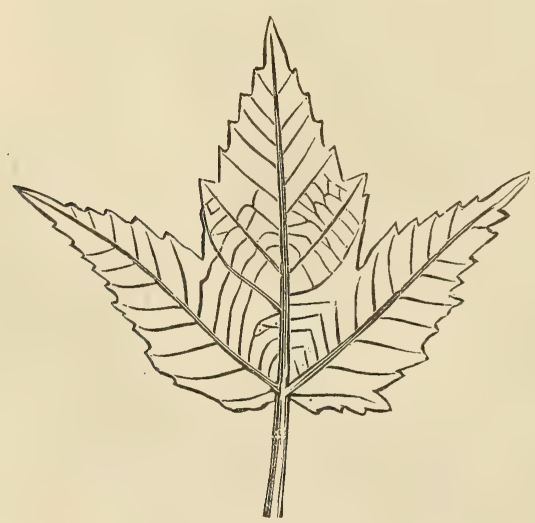

Acer tritobatum, normal form. Heer, Flora Tert. Helv., pl. 114, fig. 2. Size $\frac{1}{3}$ diam.

(Part only of the long stalk of the original fossil specimen is here given.)

Upper Miocene, CEningen; also found in Lower Miocene of Switzerland.

but, as in the case of the Podogonium just mentioned, the fruit also and even the flower are known. Thus there are nineteen species of 
maple, tein of which have already been found with fruit. Although in no one region of the globe do so many maples now flourish, we need not suspect Professor Heer of having made too many species in this genus when we consider the manner in which he has dealt with one of them, Acer trilobatum, figs. 182, 183, 185. Of this plant the number of marked varieties figured and named is very great, and no less than three of them had been considered as distinct species by

Fig. 183.

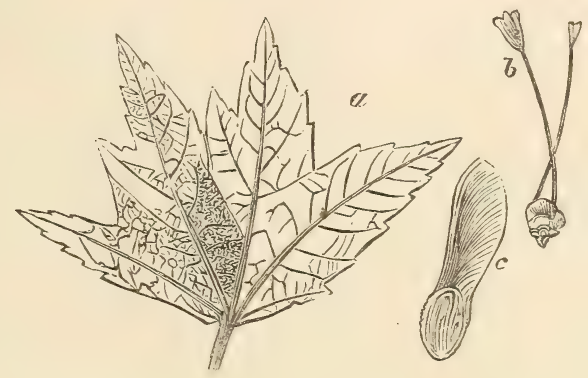

Acer trilobatum.

a. Abnormal variety of leaf. Heer, pl, 110, fig. 16 .

b. Flower and bracts, normal form. Heer, pl. 111, fig. 21.

c. Half a seed-vessel. Heer, pl. 111, fig. 5.

Fig. 181.

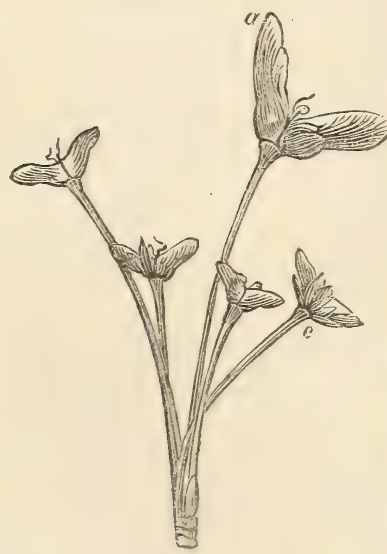

Fig. 184. Acer mubrum, $\mathrm{L}$.

Living in N. America.

Heer, pl. 111, fig. 22; natural size,

a. The carpels. c. Three petals of the corolla.

Fig. 185. Acer trilobatum. Fossil, EEningen.

Heer, pl. 155, fig. 9 ; natural size.

Fig. 186. Acer trilobatum.

§. The two carpels. Heer, pl. 111, fig. 18.

d. Calyx.
Fig. 185.

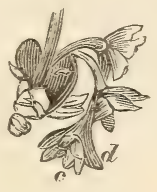

Fig. 136.

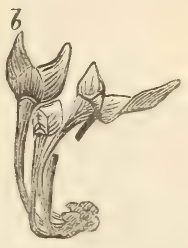

other botanists, while six of the others might have laid claim, with nearly equal propriety, to a like distinction. The common form, 
cailed Acer tritobatum, fig. 182, may be taken as a normal representative of the Eningen fossil, and fig. 183 as one of the most divergent varieties, having almost four lobes in the leaf instead of three.

We have a remarkable example in fig. 185 of the preservation of the female flower, enabling the botauist to recognize the resemblance between the petals of the Miocene species and those of -the living Acer rubrum, fig. 184.*

In like manner the fossil specimen, fig. $186 b$, shows how much more pointed were the winged appendages of the seed-vessels than are those of the most nearly allied living species, fig. $184 a$.

Among the genera which abounded in the Miocene period in Eu-

Fig. 187.

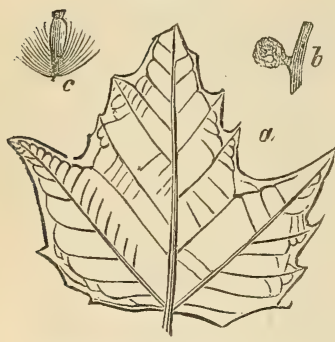

Platanus aceroides, Göpp

Heer, pl. 88, figs. 5-8.

Size $\frac{2}{3}$ diam. Upper Miocene,

a. Leaf. Eningen.

b. The core of a bundle of pericarps. c. Single fruit or pericarp, nat. size. formations of the same age in Germany, leaves of one of them, namely, the beech, have been detected. Many species of the laurel tribe characterize the fiora both of the Upper

Fig. 188.

Fig. 189.

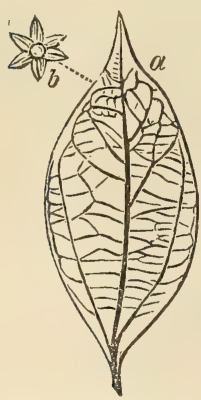

Cinnamomum polymorphum, Ad. Brong. a. Leaf.

b. Flower, nat. size. Heer, pl. 93, fig. 28. Upper and Lower Miocene. sil species being considered by Heer to come nearer to the American $P$. occidentalis than to $P$. orientalis of Greece and Asia Minor. In some of the fossil specimens the male flowers are preserved. Among other points of resemblance with the living plane-trees, as we see them in the parks and squares of London, fossil fragments of the trunk are met with, having pieces of their bark peeling off.

No leaves of the beech-tree or of the chestnut have yet been found in any Miocene strata of Switzerland, although in rope is the plane-tree, Platanus, the fos- 
and Lower Miocene strata in Switzerland and Germany, especially the cinnamon (see fig. 188). The leares of this genus are easily recognizable, and often serre as useful guides to the geologist. The fruit also and the flower are found at CEningen.

Professor Heer observes that the fruit in the fossil, fig. $189 a$, is more oval in shape than that of the recent Japanese plant, C. camphora, b, fig. 189, which comes nearest to it, and that the peduncle is not thickened at its upper end as in the living one.

The rine of Eningen, Vitis teutonica, Aḍ. Brong., is of a North American trpe, approncling nearest to Vitis vulpina, L.; both the leaves and seeds have been found at Eningen, and bunches of compressed grapes of the same species hare been met with in the Brown Coal of Wetteravia in Germany.

To less than eight species of smilax, a monocotyledonous genus, oseur at Eningen and in other Upper Miocene localities, the flowers of some of them, as well as the leares, being preserred, as in the case of the very common fossil S. sagitififera, fig. $190 a$.

Fig. 190.

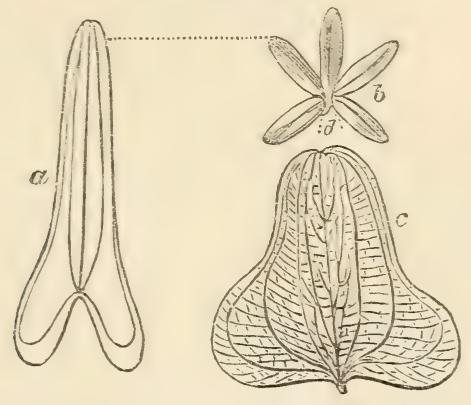

Smilaw sagittifera. Heer, pl. 30, lig. 7. Size $\frac{1}{2}$ diamecer.

$a$. Leaf. $b$. Flower magnified, one of the six petals wanting at.d. Upper Miocene, CEningen. c. Leaf of Smilax obtusifolia. Yeer, pl. 30, fig. 9: nat. size. Upper Miocene, EEningen.

Plants referable to no less than fire genera of the order Proteacere have been obtained partly from Eningen and partly from the lacus-

Fig. 191.
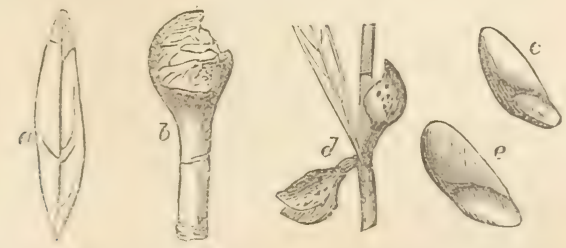

Fruit of the fossil and recent species of Hakea, a genus of Proteacer.

a. Leaf of fossil species, Hatiea salicina. Upper Miocene, CEningen; called Embothri:!n by Heer, pl. 97, fig. 29 . $\frac{1}{3}$ diam.

b. Fruit of same. $\frac{2}{3}$ diam.

c. Seed of same. Natural size.

d. Frait of living Australian species, Hakea saligna, R. Brown. $\frac{1}{y}$ diam.

e. Seed of same. Natural size. 
trine formation of the same age at Locle in the Jura. These five genera all of them, except the last, now living in Australia, are the following: Banksia, Grevillea, Hakea, Persoonia, and Dryandroides. Of Hakea both the seed-vessel and the seeds have been obtained, so that they can be compared with the recent; and the dimensions of the fossil fruit are similar in size, the difference in $d$ and $b$, fig. 191, arising from the different scale of reduction (see description of figure).

More will be said of the Proteaceæ when I treat of the plants of the Lower Miocene period, at which era that family was still more prevalent in Europe. In the same beds at Locle with the Proteaceæ there occurs a fan palm of the American type Sabal, a genus which ranges throughout the low country near the sea from the Carolinas to Florida and Louisiana.

Among the Coniferæo of Upper Miocene age is found a deciduous

Fig. 192.

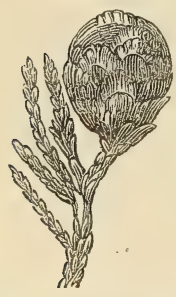

Glyytostrobus europaus. Branch with ripe fruit. Heer, pl. 20, fig. 1 a. Upper
Miocene, CEningen, cypress nearly allied to the Taxodium distichum of N. America, and a Glyptostrobus, fig. 192, very like the Japanese G. heterophyllus, now common in our shrubberies.

It was stated that in the upper quarry at CEningen the remains of the Mastodon angustidens occur. The association of so characteristic a falunian fossil with the flora above described is important, as helping to settle the true Upper Miocene date of these beds. M. Ziegler showed me in the museum at Winterthur in Switzerland, in 1857, two fine specimens of the skulls and jaws of the same species, one young and the other adult, determined by Dr. Falconer, which had been found at Veltheim in that neighborhood, in strata belonging, like the OEningen beds, to the upper freshwater molasse. This formation is there seen to overlie the marine falunian beds of Rorbas. In that same molasse the Podogonium Knorii, above described, and Populus latior, with other characteristic CEningen plants, have been met with.

Before the appearance of Heer's work on the Miocene flora of Switzerland, Unger and Göppert had already pointed out the large proportion of living North American genera which distinguished the vegetation of the Miocene period in Central Europe. Next in number, says Heer, to these American forms at Eningen the European genera preponderate, the Asiatic ranking in the third, the African in the fourth, and the Australian in the fifth degree. The American forms are more numerous than in the Italian Pliocene flora, and the whole vegetation indicates a warmer climate, though not so high a temperature, as that of the older or Lower Miocene period.

The conclusions drawn from the insects are for the most part in perfect harmony with those derived from the plants, but they have a somewhat less tropical and less American aspect, the South European types being more numerous. On the whole, the insect fauna is 
richer than that now inhabiting any part of Europe. No less than 844 species are reckoned by Heer from the Eningen beds alone, the number of specimens which he has examined being 5080 . The entire list of Swiss species from the Upper and Lower Miocene together amount to 1322. Almost all the living families of Coleoptera are represented, but, as we might have anticipated from the preponderance of arborescent and ligneous plants, the wood-eating beetles play the most conspicuous part, the Buprestidæ and other long-horned beetles being particularly abundant. There are also no less than thirty species of those beetles, of which the larvæ feed on the dung of mammalia, implying, says Heer, the existence of a great many more ruminants in the days of the CEningen Lake than the single one of that class known to us, namely, the Palceomeryx eminens of Meyer. There were also species of the carrion-feeding Silpha; also twentyfour species of water-beetles of the genera Dytiscus, Hydrophilus, \&c.

The patterns and some remains of the colors both of Coleopterca and Hemipter $\alpha$ are preserved at Eningen, as, for example, in the annexed figure of Harpactor, in which the antennæ, one of the eyes, and the legs and wings are retained. The characters, indeed, of many of the insects are so well defined as to incline us to believe that if this class of the invertebrata were not so rare and local, they might be more useful than even the plants and shells in settling chronological points in geology.*

Few of the genera of insects are extinct, but many of them imply a geographical distribution widely different from that now obtaining in the same part of the world. Thus, for example, in this Swiss fauna, there were many white ants or Termites, and dragon-flies. of a South African type called Agrion, besides several Indian and Americau forms referable to various orders.

Fig. 193.

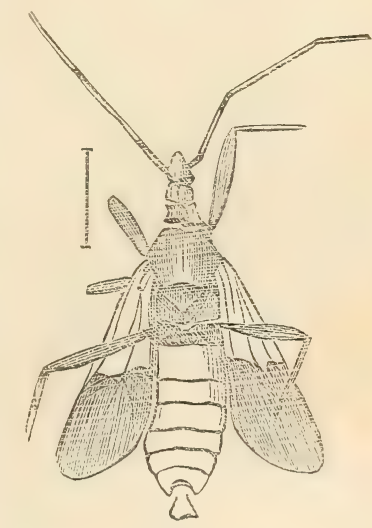

Harpactor maculipes, Heer. Upper Miocene, CEningen.

To account for the perfect state of the specimens, Heer supposes that the insects which sank to the bottom of the water may have been killed by mephitic gases which rose from the lake, and which were connected with the volcanic eruptions of which some of the products are seen at Hochgau, and which are believed by Swiss geologists to have taken place in the Upper Miocene period.

* See Heer's beautiful figures and descriptions of Eningen beetles, \&c., in the Haarlem Transactions. Naturkundige Verhandelingen van der Hollandsche Maat. schappij der Wetensch, \&c. Haarlem, 1862. 
Middle or Marine Molasse (Upper Miocene) of Switzerland.-It was before stated that the Miocene formation of Switzerland consisted of, 1st, the upper freshwater molasse, comprising the lacustrine marls of Eningen; 2 dly, the marine molasse, corresponding in age to the faluns of Touraine; and 3dly, the lower freshwater molasse. Some of the beds of the marine or middle series reach a height of 2470 feet above the sea. A large number of the shells are common to the faluns of Touraine, the Vienna basin, and other Upper Miocene localities. The terrestrial plants play a subordinate part in the fossiliferous beds, yet more than 90 of them are enumerated by Heer as belonging to this falunian division, and of these more than half are common to subjacent Lower Miocene beds, while a proportion of about 45 in a hundred are common to the overlying Eningen flora. Twenty-six of the 92 species are peculiar.

Lower Molasse (Lower Miocene) of Switzerland.-Next in descending order comes the Lower Molasse, almost entirely of freshwater origin, of which the Upper division contains 211 species of plants and the Lower no less than 336 species. The first of these two is called in Heer's work the "Mayencien," it being supposed to agres in age with the strata of the Mayence basin already described, while the lower division is called the "Aquitanien," as corresponding with some of the older Miocene beds of the South of France. But the fossil shells by which these comparisons have been made appear to me to be at present too few in number to enable us to place much reliance on such identifications. The superposition, however, of the Molasse called "Mayencien" to the lower beds called "Aquitanien," which last are well seen on the borders of the Lake of Geneva, is perfectly clear.

To the upper group belong the sandy marls of Eriz, in the Canton of Berne, in which there are 68 species of plants, half of them common to the Eningen strata. Among the North American forms in this locality the tulip tree may be mentioned, a species very closely allied to the Liriodendron tulipifera, $\mathrm{L}$.

Fig. 194.

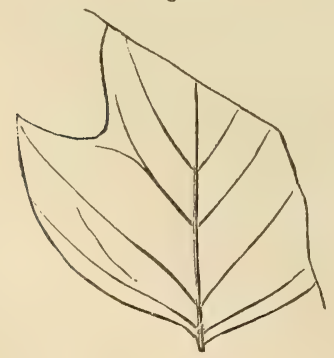

Iiriodenaron Procaccinii, Unger. IIeer, pl. 108, fig. 6. Eriz. Lower Miocene.
Fig. 195,

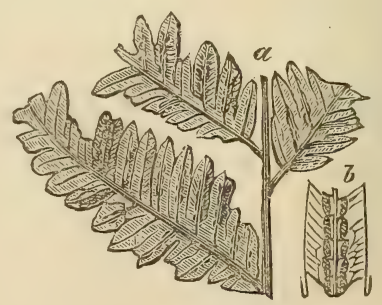

Woodroardia Rössneriana, Unger. Heer, pl. 5. Eriz. Lower Miocene. a. Part of a branch. $b$. Part of a leaf mas. nified, showing the position of the sori. 
The most abundant of the associated plants are two species of cinnamon, one of them already mentioned as frequent at Eningen, $C$. polymorphum, fig: 188. Next to these in number come species of the dogrrood, or Corinus, of the hornbeam, Carpinus, and of the buckthorn, Rhammus. Among the fir-tribe or coniferæ is a Taxodium nearly allied to the deciduous cypress, $T$. distichum, of N. America. Professor Göppert considers it the same, but Unger and Heer have pointed out differences, showing that it is at least a marked variety. Among the ferns is found a Woodwardia (see fig. 195), so like the living $W$. radicans, that in spite of the large size and some slight differences in the shape of the leaf (a part so often variable in ferns), it may, says Heer, be a question with some botanists whether the fossil does not agree specifically with the recent plant. Yet this fern ranges still lower, being also found at Monod, a locality to which I shall presently allude.

Before quitting the plants of this lower division of the molasse, I may mention that a fan-palm, Chamcerops Helvetica (fig. 196), occurs at Utznach, in the Canton of St. Gall, in Lower Miocene strata somewhat higher in the series than those of Eritz. This genus is now South European, Asiatic, and American.

Fig. 196.

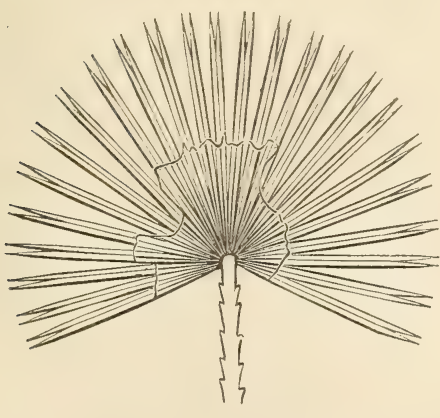

Chamerops Helvetica, Heer.

Utznach, St. Gall, Lower Miocene. (Heer, Flora Foss. Helvet., pl. 41.)
Fig. 197.

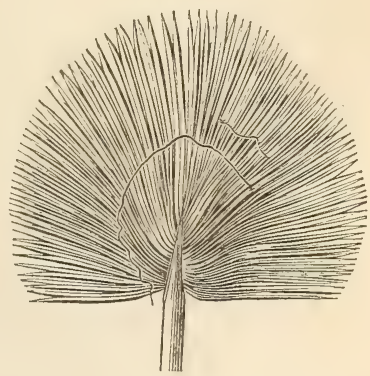

Sabal major, Unger sp. Vevay, Lower Miocene. (Heer, pl. 41.) Genus now proper to America.

The inferior subdivision of the Lower Molasse, called Aquitanian in Heer's work, is best seen on the northern coast of the Lake of Geneva. The beds consist of sandstone and conglomerate, and are nearly 2000 feet thick. The conglomerates are often rery unequal in thickness, in closely adjoining districts, as might be expected, since in a littoral formation accumulations of pebbles would swell out in certain places where rivers entered the sea, and would thin out to comparativcly small dimensions where no streams or only small ones came domn to the coast. These old shingle-beds attain in the Rigi, and in the mountain called Speer, near Lucerne, a thickness of 5000 and 7000 feet. 
Nearly the whole of this Lower Molasse is freshwater, yet some of the lowest beds contain a mixture of marine and fluviatile shells, the Cerithium margaritaceum, a well-known Lower Miocene fossil, being: one of the marine species. Notwithstanding, therefore, that some of these Lower Miocene strata reach an elevation of 6000 or even 7000 feet above the sea, the deposition of the whole series must have begun at or below that level. For ages, in spite of a gradual sinking of the coast and adjacent sea-bottom, the rivers continued to cover the sinking area with their deltas; but finally, the subsidence being in excess, the sea of the Middle Molasse gained upon the land, and marine beds were thrown down over the dense mass of freshwater and brackish-water deposit, called the Lower Molasse, which had previously accumulated.

The great change of level above alluded to must be borne in mind if we would account for a phenomenon by which geologists have been much puzzled; namely, the fact that in the "nagelflue," as the conglomerates are called by the Swiss, pebbles of gneiss, granite, and porphyry are common, and yet no such rocks now enter into the structure of the Alps. Along the original coast-line, when tho pebble-beds of the Lower Miocene were forming, there may have been hills of granite and gneiss more than a thousand feet high, but when the subsidence had continued for a long series of years, these would all be gradually submerged and covered over by fluviatile sediment; for the effect of a general depression going on at a faster rate than the accumulation of sediment is to cause the shore-line to retreat inland, the sea occupying successively old zones of coast. In the present period we see at the southern base of the Alps in Italy, hills of gneiss and porphyry of moderate height, although rocks of this class form at present no part of the chain itself, and these crystalline formations might be submerged and buried under deltas derived from the detritus of the higher Alps, if the level of the whole region were to be lowered by another great downward movement.

As I have already stated, the inferior portion of the Swiss Lower Miocene, called Aquitanian by Heer, may best be studied on the northern borders of the Lake of Geneva between Lausanne and Vevay, where the contiguous villages of Monod and Rivaz are situated. The strata there, which I have myself examined, consist of alternations of conglomerate sandstone and finely laminated marls with fossil plants. A small stream falls in a succession of cascades over the harder beds of puddingstone, which resist, while the sandstone and plant-bearing shales and marls give way. From the latter no less than 193 species of plants have been obtained by the exertions of MM. Heer and Gaudin, and they are considered to afford a true type of the vegetation of the inferior subdivision of the Lower Miocene formations of Switzerland-a vegetation departing farther in its character from that now flourishing in Europe than any of the higher members of the series before alluded to, and yet displaying so much 
affinity to the flora of Eningen as to make it natural for the botanist to refer the whole to one and the same Miocene period. There are, indeed, no less than 81 species of these Older Miocene plants which pass up into the flora of CEningen, and in this number, says Heer, are many of those which, by an abundance of individuals and by their arborescence, must have constituted a leacing feature in the forests of that era.

Nearly all the plants at Monod are contained in three layers of marl separated by two of soft sandstone. The thickness of the marls is ten feet, and regetable matter predominates so much in some layers as to form an imperfect lignite. One bed is filled with large leaves of a species of fig (Ficus populina), and of a hombeam (Carpinus grandis), the strength of the wind having probably been great when they were blown into the lake; whereas another contiguous layer contains almost exclusively smaller leaves, indicating, apparently, a diminished strength in the wind. Some of the upper beds at Monod abound in leares of Proteaceæ, Cypercaceæ, and ferns, while some of the lowrer ones, Sequoia, Cinnamomum, and Sparganium, are common. In one bed of sandstone the trunk of a large palm tree was found unaccompanied by other fossils, and near Vevay, in the same series of Lower Miocene strata, the leaves of a palm of the genus Sabal were obtained (see fig. 197, p. 259).

Among other genera of the same class is a Flabellaria occurring near Lausanne, and a magnificent Phœnicites allied to the date palm. When these plants flourished the climate must have been much hotter than now. The Alps were no doubt lower, and the palms now found fossil in strata elerated 2000 feet abore the sea grew nearly at the sea-level, as is demonstrated by the brackish-water character of some of the beds into which they were carried by winds or rivers from the adjoining coast.

In the same plant-bearing deposits of the Lower Molasse in Switzerland have been found no less than 20 species of Proteaceæ, an order already spoken of as being well represented in the Eningen beds, though by no means so plentifully as in these Lower Miocene strata, and which were still more strikingly predominant in the antecedent Eocene and in the still more ancient Cretaceous formations.

One of the following named plants, Dryandra Schrankii, comes very near to $D$. formosa, R. Brown, a living New Holland species, and is considered by IIcer as "homologous," but the leaf only of the fossil is known. This is one of the species which characterizes all stages of the Lower Miocene, and is not found in the Upper. It also occurs in Great Britain in the Miocene beds of the Island of Niull, in the Hebrides, and in the lignite of Bovey Tracey, in Devonshire.

The Proteas and other plants of this family now flourish at the Cape of Good Hope ; while the Banksias, and a set of genera distinct from those of Africa grow most luxuriantly in the southern and temperate parts of Australia. They were probably inhabitants, says 
Fig. 198.

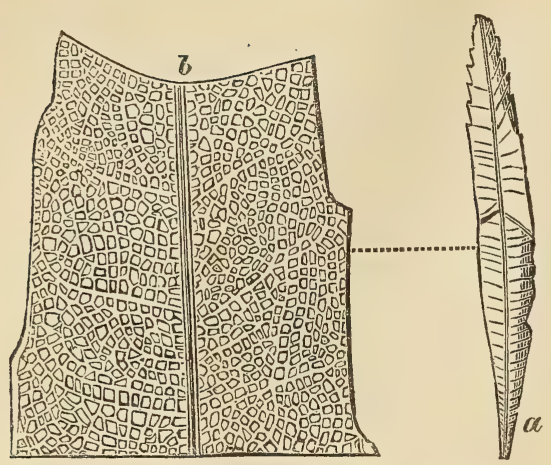

Fig. 199.

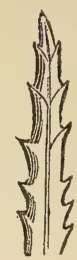

Fig. 200.

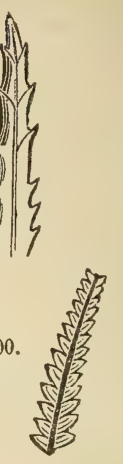

Fig. 198. a. Leaf of Dryandroides Hakeafolia. Lower Miocene. $\frac{1}{3}$ nat. size. Monod, near Lausanne. (Heer, pl, 98, fig. 6.)

b. Small portion of the same magnified. (Heer, pl. 98, fig. 13.)

Fig. 199. Hakea exulata. Hohen Rhonen, Switzerland. Lower Miocene. Nat. size. (Heer, pl. 98, fig. 19.)

Fig. 200. Dryandra Schrankii. Monod. Lower Miocene. $\frac{1}{3}$ nat. size. (Heer, pl. 98, fig. 20 b.)

Heer, of dry hilly ground, and the stiff leathery character of their leaves must have been favorable to their preservation, allowing them to float on a river for great distances without being injured and then to sink, when water-logged, to the bottom. It has been objected by some botanists that the fruit of the Proteacer is of so tough and enduring a texture that it ought to have been more commonly met with, instead of being restricted to a single example like that of the Hakea saligna before mentioned (fig. 191; p. 255); but the season of fructification in these plants may not have coincided with that of the most active sedimentary deposition, and there may be other reasons for the absence of the fruit of which we are at present ignorant. Some mistakes have certainly been made, and Count Saporta has shown that one plant formerly referred to Dryandroides, and of which he discovered the fruit, really belongs to the bog-myrtle, or sweet-gale tribe (Myrica). But there is no reason to question the general accuracy of the determination of the fossil Proteaceæ. Those of the cretaceous marls of Aix-la-Chapelle were formerly disputed, but fortunately the leaves in that case, notwithstanding their antiquity, are so much better preserved than any known Miocene plants, that their epidermis can be examined microscopically. A leaf from Aix which, from its form and nervation, had been referred to the genus Grevillea, was found, when submitted to this test, to have regular and polygonal cellules resembling in shape and thickness those of the living $G$. oleoides of Australia.

The eight or nine species of fig (Ficus) which are met with at Monod and Rivaz, have their nearest living analogues in the hotter parts of India, Africa, and America. Among the Coniferæ the Sequoia 
here figured is common at Rivaz, and Fig. 201. is one of the most universal plants in the Lowest Miocene of Switzerland, while it also characterizes the Miocene Brown Coals of Germany and certain beds of the Val d'Arno, which I have called Older Pliocene, p. 196.

It is an interesting fact that this tree should also have been discovered in the surturbrand or lignite of Iceland, and by Dr. Walker in Disco Island, in Greenland, in lat. $70^{\circ} \mathrm{N}$. It comes so near to the living $S$. sempervirens (Taxodium) of California,

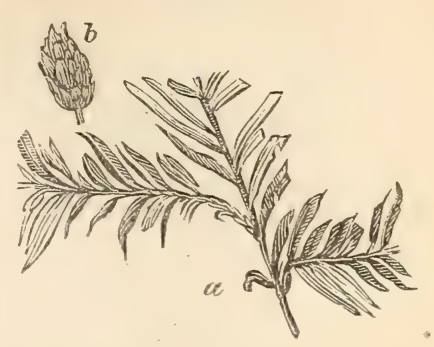
that some botanists entertain doubts whether they may not be varieties of the same species. As a fossil, its geographical range extends from Greenland, lat $70^{\circ} \mathrm{N}$., to Sinigaglia in Italy, lat. $44^{\circ} \mathrm{N}$., and in an east and west direction from the Hebrides (Isle of. Mull) to the Steppe of the Kirghis.

Sir John Richardson found this same fossil tree on the Mackenzie River, two miles north of its junction with Bear River, lat. $65^{\circ} \mathrm{N}$, or in about the same parallel as the north of Iceland.

I am indebted to Professor Heer for the annexed figure of this North American specimen taken from the original.

Fig. 202.

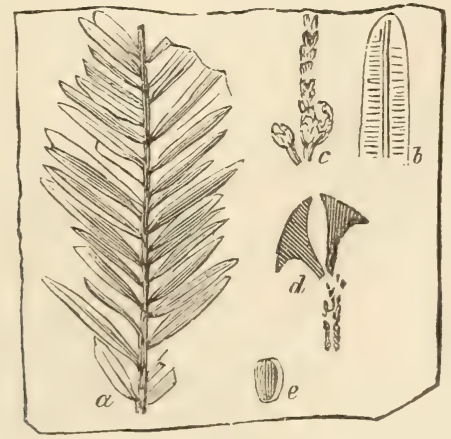

Sequoia Langsdorfi. Fossil, Mackenzie River, lat. $65^{\circ} \mathrm{N}$.

Sir G. Richardson, Voyage, 185̃1, vol. i. p. 186; vol. ii. p. 403.

a. Branch with leaves, one year's growth.

$b$. Under side of a leaf magnified, showing punctuations as in the living S. sempervirens.

c. Male flowers.

$d$. Carpels of the cone.

e. Seed.

Among the ferns met with in profusion at Monod is the Lastraca stiriaca, Unger, which has a wide range in the Niocene period from strata of the age of Eningen to the lowest part of the Swiss molasse. 
In some specimens, as shown in the annexed figure, the fructification is distinctly seen.

Fig. 203.
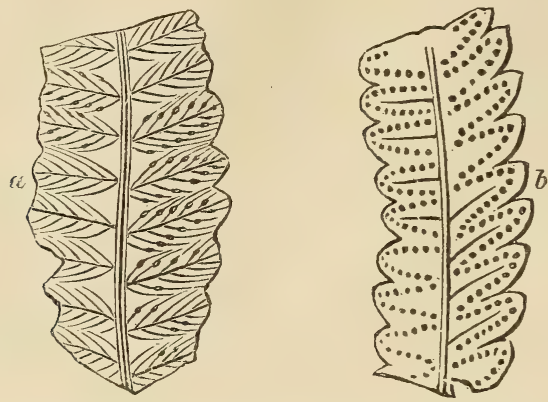

Lastrcea stiriaca, Ung. (Heer's Flora, pl, 143, fig. 8.)

Natural size. Lower and Upper Miocene. Switzerland.

a. Specimen from Monod, showing the position of the sori on the middle of the tertiary nerves.

b. More common appearance, where the sori remain and the nerves are obliterated.

In the Upper Miocene flora of Eningen already described the number of forest trees and evergreen shrubs is very great. Their predominance, however, in the period of the Lower Miocene was still more marked, and is characteristic of subtropical countries. No less than two-thirds of all the ligneous plants were evergreens.

Among other features which cause this flora to resemble that of

Fig. 204.

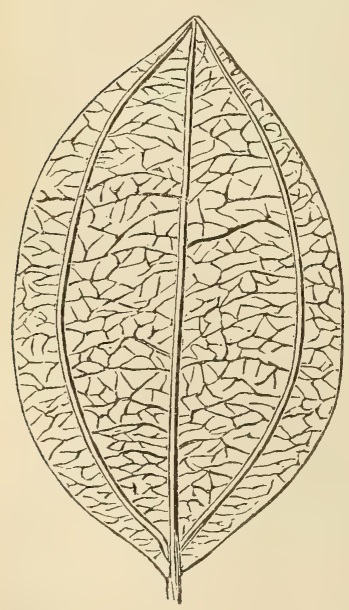

Jinnamomum Rossmässteri, Heer, Daphnogene cinnamomifolia, Unger. Upper and Lower Miocene, Switzerland and Germany.
North America is the great abundance of trees of the order Amentaceæ, such as the oak, poplar, alder, birch, willow, hornbeam, plane, \&c.

The papilionaceous plants, of which there are twenty-four genera, are the most abundantly represented of all families, both in the Lower and Upper Miocene. But the laurels, of which there are only five genera, have contributed most leaves to the Miocene strata. Among these several species of Cinnamomum, as before mentioned, are very conspicuous.

Besides C. polymorphum, before figured, p. 254, another species also ranges from the Lower to the Upper Molasse of Switzerland, and is very characteristic of different deposits of Brown Coal in Germany. It has been called Cinnamomum Rosmässleri by Heer (see fig. 204). 
This plant is nearly allied to a living North Indian species, C. eucalyptoides. The leares, as before mentioned, are easily recognized as having tro side reins, which run up uninterruptedly to their point.

The lowest of the Swiss Miocene beds, the sandstone of Ralligen, on the Lake of Thun, in which 32 plants have been found, contains no less than 6 species in common with Eningen-a proportion of 18 in a hundred. Among them we find Taxodium, closely allied to the deciduous crpress of the Mississippi, also a pine, an arundo, and one of the Proteaceæ, Dryandroides lignitum.

\section{Alleged difference in the degree of affinity of the Upper Miocene plants and shells to the living creation.}

Before concluding my remarks on the fossil Flora and Fauna of Switzerland, I may say a few words on the embarrassment which some geologists have felt in consequence of the alleged anomaly of the results derired from the study of the fossil shells as compared to the fossil plants and insects. Of the shells of the marine Molasse which underlies the freshwater deposit of Eningen, a fourth or more than a fourth have been declared by able conchologists to be of species still existing, whereas all the plants and insects have been said to differ from living ones. On looking more closely into the eridence, we shall perhaps find that this supposer inconsistency disappears.

Professor Heer, it is true, does not identify any Miocene plants with liring species, but he has enumerated 72 species which he terms "homologous," 40 of them known by their fruits as well as their leares; and although he is opposed to the doctrine of transmutation, he admits that these homologous species are so closely allied to the nearest forms now liring, that the latter may be their lineal descendants. He cannot, he says, decide "whether the variation has been brought about by some influence which has been exerted continuously for ages, or whether at some giren moment of past time the old types were struck with a new image."

Now the degree of relationship here implied would be at once accepted br most naturalists as constituting specific identity. Let us suppose that the sessile variety of the common oak, Quercus robur, had been only known to us as a fossil from Euingen and not as a living form, and that the other liring raricts, in which the flower and acorns are supported on a stalk, was the only form now existing. The first of these would, according to the method adopted in Professor Heer's work, rank as an extinct Miocene species; whereas the two forms now co-existing in European forests are generally regarded by botanists as mere varieties. That such a distinction would have been made by Heer we are entitled to infer from the manner in which he has dealt with the fossil specimens of a plant called by him Plancra Ungeri. To the leaves and fruit of this tree, which is allied to the 
elm, Unger had previously given the name of $P$. Richardi, identify ing it with a tree now living in the Caucasus and Crete; but Heer

Fig. 205.
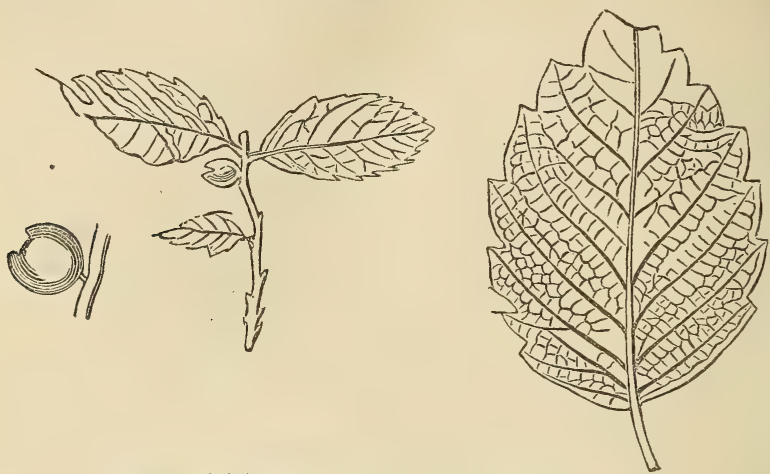

Planera Richardi, Unger. $P$. Ungeri, Heer.

Upper Miocene. (Heer, pl. 80, Flora Tert. Helvetiæ.)
a. A branch from CEningen.
b. Fruit magnified.
c. Leaf, CEningen.

had pointed out that in the fossil the size of the fruit was larger. When, however, in 1861, the Swiss Professor visited with me the rich herbarium of Kew, Dr. Hooker showed us a living variety of $P$. Richardi in which the fruit was fully as big as that of Eningen, so that this last must retain Unger's name, and this example, if there were no other, might suffice to warn us, in the present imperfect state of our knowledge, not to indulge in too positive a belief that all the Miocene species have become extinct.

Fig. 206.

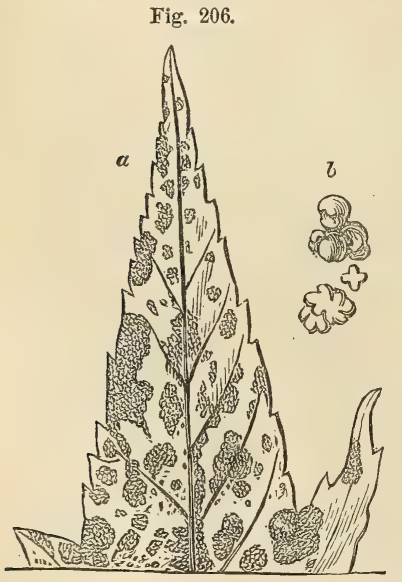

a. Part of a leaf of Acer trilobatum with numerous specimens of the fungus called Rhytisma induratum, Heer. 7. Magnified view of the fungus,

(Heer, pl. 112, fig. 7.) Upper Miocene,

Out of the 72 homologous speeies above mentioned, 67 are phænogamous and only 5 cryptogamous; but it may well be doubted whether among the 49 Miocene Cryptogamia described in Heer's Flora Tertiaria, a much greater number, perhaips more than half, might not with propriety have received (provisionally at least) the names of living plants. Heer admits that the majority come very near to existing species, and we know well how wide is the geographical range of the ferns, and still more of flowerless plants of lower grades, such as mosses, lichens, and fungi, many species of which are cosmopolitan, and therefore fitted, by their adaptability to varying conditions, for a long duration in time. 
On the leares of a fossil maple, Acer tritobatum, already mentioned, fig. 183, p. 253 , a small body is frequently seen resembling the living fungus which grows on maples, called by Fries Rhytisma acerinum. It is tuberculated and crenulated (see the magnified figure, $b$ ). The fossil has made so deep an indentation on the incumbent and subjacent layer of marl as to lead Professor Heer to infer that it was somewhat thicker than the living form. Instead, therefore, of treating it as a variety, he has called it $R$. induratum, under which title it helps to swell the list of extinct Miocene species.

In like manner there is a minute fungus, called by Heer Sphoria ceuthocarpoides, which spots the leaves of Populus ovalis at Eningen, rery closely resembling the living Sphoeria ceuthocarpa of Fries. Some botanists would think it very hazardous to assign even generic names to such objects, and still more rash to decide that the fossil differed specifically from its living analoguc.

Another of these fungi forming black spots on the fossil leaves of a poplar is proved in like manner to have been a real subtance, and not simply the effect of discoloration, for it has left indentations both on the under and overlying layers of marl. To decide that it is not a living species would require far ampler data. Some botanists are even uncertain whether as much can be said of the Populus latior itself of Eningen, on which the fungus grew, and of which seren varieties are described by Heer, some of them coming very near to the Populus monilifera of North America.

Similar comments might be made on the long list of homologous insects given by Heer from the Miocene strata of Switzerland. Their specific distinctness from their nearest representatives now living might appear to the zoologist in a very different light, according to the state of mind in which he may approach their study. If he is reflecting on the fact that all the Upper Miocene mammalia and a great majority of the testacea are extinct, and is then endeavoring to decide whether a fossil and a recent form, between which there is a close affinity, should be regarded as varieties or distinct species, it may scem the safest course to incline to the latter alternative; yet, by giving a new name to the fossil in doubtful cases, a serious responsibility is incurred, as the naturalist thereby commits himself to an absolute negation of specific identity between such Miocene and living insects and plants. If it be right to exercise extreme caution in identifying, it is equally important not to separate individuals which may really belong to the same species. In spite of the soundness and general accuracy of the conclusions arrived at by Professor Heer after such great and conscicntious labors, there appears to me an inconsistency in one of his results, which may have been owing to an unwillingness to identify Upper Miocene and living plants. When we consult his tabular list of the fossil plants of Switzerland, we find that a great number of species pass from the Aquitanian Flora to that of Eningen, which are as distinct from each other in age as are the Fon- 
tainebleau sands from the Faluns of the Loire. But scarcely one plant is admitted to have survived the shorter interval of time which separated the flora of Eningen from our own epoch. I say shorter interval, because, as we have seen, p. 217, all the shells of the Fontainebleau sands differ from those of the Faluns, whereas a fifth part, and in some cases a third, of the shells of falunian deposits are still living. If, therefore, the differential characters of the plants had been measured in the same scale, and without any bias, it appears to me that since many of them pass from a lower to one of the uppermost members of the Miocene group, so a still greater number should have been recognized as being common to the uppermost Miocene period and the living creation.

Theory of a Miocene Atlantis.-The Swiss plants of the Miocene period have been obtained from a country not exceeding one-fifth of Switzerland in area, yet the abundance of species in certain genera and families best adapted for preservation in a fossil state is so great as to demonstrate that the Miocene was richer than the modern flora, rich and varied as the latter is well known to be. The researches already made imply, according to Heer, that in the phænogamous class alone there must have been 3000 Miocene species, and, making due allowance and deductions on account of those which are limited to certain subordinate members of the Miocene group, and which may not all have existed at once, he comes to the conclusion that in no equal area in the South of Europe (in Lombardy, for example, or Sicily) is there now so luxuriant and diversịied a vegetation. It exceeded in variety the Southern States of America, such as Georgia and the Carolinas, and rivalled that of tropical countries, such as Jamaica and Bahia.

The majority of the fossil forms are allied to living species or genera, but there are certain extinct types, specific and generic, which have a wide range through successive tiers of strata from the lowest Molasse up to those of Eningen, and there is a certain unity of character stamped on the whole Miocene flora in spite of the contrast between that of the uppermost and lowest formations, The proofs of a warmer climate, and the preponderance of trees and shrubs over herbasceous plants, and the excess of evergreen over deciduous species, are characters common to the whole flora, but which are. intensified as we descend to the inferior deposits. 'On the other hand, the comparative number of American forms, though always conspicuous, is somewhat lessened in the lowest beds. The living American types, says Heer, are the most prominent; those of Europe are in the second rank; those of Asia in the third; Africa in the fourth; and New Holland in the fifth. In Europe it is the Mediterranean region which presents the greatest number of analogous species. In America, the Southern United States, such as Louisiana, Florida, Georgia, and the Carolinas; in Asia, Japan, and the countries of the Caucasus and Asia Minor; in Africa, the small islands in the Atlantic, such as the Canaries and Madeira. 
If we consider not simply a mere list of species but those plants which would constitute the mass of the vegetation, the European part of the fossil flora is thrown still more in the background, and the foreground is occupied by America with its numerous evergreen oaks, maples, poplars, planes, Liquidambar, Robinia, Sequoia, Taxodium, and ternate-leaved pines, and Japan with its many camphor trees and glyptostrobus, the Atlantic Islands with their laurels, and Asia Minor with its planera and Populus mutabilis.* During the Miocene period in Europe, there was a singular coexistence of generic types of plants which are now peculiar to America, or to Asia, or to Africa, or Australia; in a word, to paris of the globe extremely distant from each other. This fusion of the characters now belonging to distinct botanical provinces becomes more marked as we go back to the Lower Mioccne formations, and will be found to be still more strikingly exemplified in the antecedent Eocene and Cretaceous periods. In the Lower Miocene formations of Central Europe the climate seems to have been not only hotter but more uniform and humid, and this humidity would favor the formation of beds of lignite, such as constitute the Brown Coal of Germany.

The large number of American genera in the Miocene flora induced Unger to suggest that the present basin of the Atlantic was occupied by land, over which the Miocene plants could pass freely, and this hypothesis has been enlarged and advocated with great ability by Heer. It seems at the first glance to derive much support from the fact that it is the eastern or Atlantic side of North America, or that which is nearest to Europe, which presents the greatest number of vegetable forms analogous to the Miocene flora. But Dr. Asa Gray, following up a hint thrown out by Mr. Bentham, has argued with great force that it is far more probable that the plants, instead of reaching Europe by the shortest route over an imaginary Atlantis, migrated in an opposite direction, and took a course four times as long across America and the whole of Asia.

If the eridence in the botanical seale were equally balanced in favor of these two opposite theories, a geologist would not hesitate to prefer that of Dr. Asa Gray as demanding an incomparably smaller amount of change in physical geography since the close of the Miocene period. It is true that since the beginning of that era there have been vast alterations in the level of the Alps and contiguous regions, as we have seen, p. 260, and in the Mediterranean, especially the Egean Sea, p. 247. And there was perhaps, as the late Edward Forbes contended, an extension westward of European and North African land even in the Pliocene period. $\nmid$ If, instead of assigning an almost historical date to a continental condition of the area between Africa and the Southern States of North America, such as might

* Heer and Gaudin, p. 59

† See Map, vol. i. pl. 7. Memoirs of Geol. Survey, \&c., 1846. 
realize the story of the Atlantis spoken of by the Egyptian priests to Plato, we could look back through the whole interval which separates us from the Eocene or Cretaceous periods, we might then indeed freely grant, as geologists, any amount of change that may be required in the position of land and sea. All that is wanting is time for the gradual development of a long series of subterranean movements; that being conceded, there would be no exaggeration in the lines of the poet-

\footnotetext{
"Earthquakes have raised to heaven the humble vale,

And gulfs the mountain's mighty mass entombed,

And where the Atlantic rolls wide continents have bloomed."-Beattie.
}

It is the enormous depth and width of the Atlantic which makes us shrink from the hypothesis of a migration of plants, fitted for a subtropical climate in the Upper Miocene period, from America to Europe, by a direct course from west to east. Can we not escape from this difficulty by adopting the theory that the forms of regetation common to Recent America and Miocene Europe first extended from east to west across North America and passed thence by Behring's Straits and the Aleutian Islands to Kamtschatka, and thence by land, placed between the 40 th and 60th parallels of latitude where the Kurile Islands and Japan are now situated, and thence to China, from which they made their way across Asia to Europe.

If that be the case, the breaks in a once continuous province of plants, and the extinction as well as the diminished range of many species, might well have been caused by the mighty revolutions in physical geography which we know to have occurred in various parts of this area in Post-miocene times.

Professor Oliver, after making a careful analysis of Heer's work, above cited, on the "Tertiary Flora of Switzerland," has given us an able essay on the bearing of the valuable store of facts therein contained on the two rival theories above alluded to.* In the first place he has thought it safer to set aside all the cryptogamia, and to discard a certain number of the phrnogamous plants as having been doubtfully determined by their leaves alone; but after these deductions there remain about 800 plants referred to 196 genera in the Swiss Miocene flora. It is of course understood that some of these determinations are very doubtful in the absence of fruit or flowers, but the positive data which remain are amply sufficient for sound generalizations, and we need not fear that these will be materially shaken by future discoveries. The reasoning is the more to be relied on because in so great a number of genera only twenty-one are extinct, fifteen of these being monocotyledonous and six dicotyledonous.

It is admitted that there is an unquestionable analogy between the 
Miocene flora of Central Europe and the Recent flora of North America, and that the analogy is greater than betwecn the same fossil flora and that now existing in Europe. But in the first place it is remarked by Dr. Asa Gray that the Swiss Miocene plants are more like those of Japan than they are like those now living in Europe, which at once suggests the idea that the American plants may have taken a westerly instead of an easterly route. In the next place it is remarked that, if we travel from Europe to the east, the farther we go the more we find the living regetation putting on the characters of the Old Miocene flora. Thus in passing from the Mediterranean to the Levant, the Caucasus, and Persia, we meet, says Professor Oliver, Ivith Chamarops, Platanus, Liquidambar, Pterocarya, Juglans, \&c., \&c., then we trace along the Himalaya and through China other Miocene genera, the eastern part of the Asiatic continent forming with Japan one great botanical region. In the Southern American States eighty-cight of the Miocene genera are now represented; but Pro. fessor Oliver gives a table to show that if we take Europe, Asia, and Japan together, as before suggested, there are na less than 120 Recent genera which are common to the Swiss Miocene flora. Moreover there are some general features in which the living flora of Japan is more like the Old Miocene regetation of Europe than is the living flora of America. For example, the nine Tertiary orders which are numerically the largest are the following:-1. Gramineæ (grasses); 2. Compositæ; 3. Cyperaceæ (sedges); 4. Salicaceæ (willows); 5. Coniferæ (pines) ; 6. Leguminosæ; 7. Laurineæ (laurels); 8. Acerineæ (maples); and 9. Proteacer. The six first of these are included in the nine largest orders of Japan, and only four of them, namely, the three first and the sixth, in the largest orders of the Southern States of North America; and farther, the three last of the nine are much more developed in Japan than in the Southern States.

Heer estimates the proportion of ligneous species in the Swiss Hiocene as exceeding 60 per cent. of all the plants. Professor Oliver remarks on this subject that in Japan they constitute 40 per cent. of the whole flora, and only 22 per cent. in that of the Southern United States. There are seventy-seven genera common to the recent flora of Japan and to the European Miocene strata, and nearly the same number are common to the tertiary and the living flora of Europe; but the genera which are common in these two instances are by no means the same, and no less than twenty-six of the Japanese list are wanting in Europe, having become extinct there since the Miocene period. Not a few of these, such as Cinnamomum and Glyptostrobus, play a conspicuous part among the fossils.

In order to understand the disappearance of so many forms, we have only to call to mind the great geographical changes already alluded to, which are known to hare taken place in Eastern Europe and Western Asia since the Miocene era. It seems at first sight an anomaly that the plants on the castern side of North America should 
agree more closely with those of Japan than does the flora of the intervening countries, Oregon and California, west of the Rocky Mountains. It would naturally lead us to conjecture that many of the Miocene genera of Europe now found only on the Atlantic side of North America may once have ranged to the Pacific side. In favor of such an hypothesis, it may be mentioned that in 1859 Lesguereux discovered in a fossil state in Vancouver's Island and in Oregon many of the Miocene genera which are no longer represented in the flora now living on the west side of the Rocky Mountains. Among these there is a Cinnamomum resembling C. Rossmässleri, see fig. 204, a planer-tree, like Planera Richardi, a Glyptostrobus like G. Eningensis, Br., and a fan palm, besides willows and maples, the whole assemblage implying a warmer climate in Oregon in the Miocene period, and also pointing to the spread of a similar vegetation across the whole American continent in ancient times.

In support of the Atlantis theory, Heer has pointed out that certain American genera, such as Oreodaphne, closely related to $O$. foetens or the Til, also Clethra, Bystropogon, Cedronella, and others, are common to the Miocene of Europe, and to the flora of Madeira and Porto Santo, and to that of the Canaries and Azores. Had the number of genera proper to these islands, especially to the Azores, been very considerable, this argument would be entitled to have great weight, for such Atlantic islands would then appear to have been the last remnants of a lost continent over which a continuous vegetation once ranged from west to east. But Professor Oliver truly observes that the botanical types having the geological and geographical relations required by the hypothesis are extremely few in the Atlantic islands. Moreover two of those above cited, Clethra and Cedronella, are of little or no value, as species of both of them now grow in Japan, and some of the other plants may have reached the Atlantic islands at the time when these were united with Barbary, and Barbary with Europe, at which same period many European land-shells and plants now flourishing in Madeira and Porto Santo may have migrated thither.

The existence of a continuous land communication between Eastern America and Western Europe in the Pliocene period, by means of which many plants migrated, before the Glacial period, from one region to the other, was suggested by Mr. Darwin in his "Origin of Species" (chap. xi., 1859); and Dr. Leidy has observed that a like continuity of land from east to west is implied by the identity of some of the extinct Pliocene mammalia of the Niobrara Valley in Nebraska with those of a corresponding geological age in Europe. The ideal map given by Heer of the Atlantis represents a continent as large as Europe precisely in that portion of the Atlantic Ocean which is now the broadest and deepest.*. The depth has been lately shown to

* Heer and Gaudin, Flora Tertiaria Helvetiæ, vol. iii. pl. 156, fig. 9, aud Recher. ches sur le Climat, pl. 1, fig. 9. 
range in the central parts from two to three miles. To suppose that a continent, therefore, was so situated up to the close of the Miocene period, when the American types, as seen at CEningen, were most dominant, would imply a prodigious amount of subsidence in a comparatively brief period. In the lifetime of a single generation of men, plants, of which the seeds have been unintentionally transported to a distant coast, have made their way for many miles into the interior without human aid. A botanist, therefore, might form some rude estimate of the number of centuries which would be required for an assemblage of plants to spread over land several thousand miles in extent from east to west; but no geologist would venture to estimate the ages required to convert so many thousand miles of land into a shallow sea and then turn that vast shoal into a sea-bottom two or three miles deep.

Even if we were called upon to imagine that the Miocene flora originated in the Southern United States, in Georgia and the Carolinas for example, and that they made their way overland westward for a distance of 16,000 miles to Europe, we might conceive such a migration to be performed in a mere fraction of the period which it would take to convert Africa or North America into an ocean as deep as the Atlantic.

Behring's Straits do not exceed in depth and width the Straits of Dover, so that the former union of North America with Asia would demand only a slight change of level, and the present existence of such chains of islands as the Kurile and Aleutian makes it easy to imagine that there may have been a post-miocene connection between Kamtschatka, Japan, and China. Independently, therefore, of the botanical arguments in faror of a migration from east to west, this latter theory inrolres us in far less hazardous speculations as to geographical change than that of a Miocene Atlantis.

We are not, however, entitled to take for granted that some of the American types may not have crossed to Europe in high Northern latitudes, when Greenland, Iceland, and the Hebrides were united by a continuous land communication. And in support of this view it may be urged that a Miocene flora has been discovered in several parts of the Arctic lands, especially in Disco Island, in Greenland, lat. $70^{\circ} \mathrm{N}$, and in Iceland, and, as above mentioned, p. 242, in the Island of Mull in the Hebrides. But in the first place, in reference to these northern miocene deposits, it may be observed that palms and other tropical forms are wanting; and secondly, the depth of the ocean in the regions alluded to is very great. Sir. L. Mac. Clintock, when sounding for the proposed submarine telegraph, found? a depth of 4092 fect betreen Sicotland and Iceland, and again a depth of no less than 9432 feet between Iceland and Greenland. Possibly the number of fathoms might not be so great if a survey of the Arctic Seas were made in a still more north-westerly direction from Iccland to Greenland, but we have no data at present which favor this notion. 
Upon the whole, the theory which derives the American types from the east instead of the west seems by far the most natural, and it seems to acquire still more claims to our favor when we study the fossil shells and corals of that ancient period as well as the plants. In 1850, Mr. John Carrick Moore pointed out that certain tertiary shells of San Domingo exhibited affinities to the miocene shells of Europe,* and that although such of the San. Domingo species as agreed with the living were chiefly Atlantic forms, there were some so closely allied to the existing Pacific fauna as to lead him to infer that there had been a channel in Miocene times through what is now the Isthmus of Panama, by which the mollusca could have migrated from one ocean to the other. Such an hypothesis, he observes, will be the more readily accepted when we consider that the isthmus nowhere attains an elevation exceeding 1000 feet, which is not half the height to which the marine Miocene strata of San Domingo have been uplifted since their deposition.

Similar inferences have lately been drawn by Dr. Duncan, $\uparrow$ from the corals of San Domingo, Antigua, Jamaica, Barbadoes, and other West Indian islands. They are allied in a most unequivocal-manner to the corals of the Faluns of Vienna, Bordeaux, Dax, Saucats, and Turin, while at the same time the forms are those of the Pacific and not of the Caribbean Sea and Atlantic. Dr. Duncai concludes, therefore, not only that there was no isthmus of Panama, but also that there was no great barrier of land or Atlantic continent separating the Miocene seas of Europe from the contemporaneous seas of the West Indies. The bearing of these views is the more direct on the theory of an Atlantis before discussed, because the affinities of the marine shells and the corals belong precisely to that period (the Upper Miocene), when the flora of Europe was most American. There may have been, as Dr. Duncan supposes, numerous islands in the Atlantic, large and smail, as there are now in parts of the Pacific and Indian Oceans, where corals abound, but there could not have been that continuity of land which is represented in Heer's ideal map of the Atlantic already cited, p. 272, which would be indispensable in order to produce an affinity in so many genera and even species of plants as is observed between the Recent American and the Swiss Miocene flora.

It is right, however, before concluding this subject, that I should warn the reader that much of the reasoning employed by those who have taken part in discussing the probable existence of a Miocene Atlantis, whether as advocates or opponents of the hypothesis, has proceeded on the assumption that the geographical distribution of genera has been governed by laws strictly analogous to those which govern the distribution of species. When Professor Heer speaks of plants called by him homologous, and shows that about half of these

* Quart. Geol. Journ., 1850, vol. iv. p. 43.

† Ibid. vol. xir. p. 455. 
are common to Miocene Europe and to the living flora of America, and that this is more especially true of those closely-allied or homologous species which are known by their fruits as well as their leaves, the force of his argument will be fully appreciated by all who believe that each species has had a single birthplace, or has been formed in one limited geographical area from which it may have migrated to distant parts; for Heer supposes the homologous living species to be the hereditary descendants of their closely-allied Miocene progenitors. But when the reasoning is founded on plants which have only a generic connection, as in a great part of Heer's work, and everywhere throughout the essay of Professor Oliver, its force depends on the previous assumption that, not only the individuals of a species, but also the different species of a genus, have radiated from certain geographical areas which constituted the original starting-points of such genera. This is not the place to enter into a question so difficult and unsettled as that of the origin of species, but whether we adopt or reject the doctrine of transmutation, it is necessary to bear in mind, when we compare the recent and fossil flora and endeavor to ascertain whether the miocene plants came to Europe by a western or eastern route, that a single identical or very closely-allied species is of more value than a great many genera represented by species not closely allied. Thus, for example, Heer considers the walnut-tree of CEningen called Juglans bilinica to be homologous with the living American hickory, Juglans nigra, and that another Upper Miocene walnut of Europe, Juglans vetusta, is homologous with our common walnut, J. regia, which was first brought into Europe from Persia. When, therefore, the Swiss Professor founds on the one an argument in favor of a migration across an Atlantic continent for the Miocene walnuts of Switzerland, and Professor Oliver founds on the other an Asiatic route for the same, their reasoning is logical and its cogency is great in proportion to the identity or very near affinity of the fossil and recent plants which are compared. But several other Tertiary walnuts of Switzerland have a comparatively remote bearing on the question of a Miocene Atlantis, because Juglans, as a genus, flourished in Europe in the Eocene, and even, according to Göppert, in the antecedent Cretaceous period. Some, therefore, of the Niocene species of Juglans may hare come from indigenous European Eocene, or even Cretaceous ancestors; and the same remark applies to a great number of the genera of other orders and classes which are common to the Hiocene flora of Europe and to older tertiary rocks. Thus cight out of 232 fossil species of Monte Bolea, a locality where the rocks belong to the Nummulitic or Niddle Eocene period, pass up into the Miocene formations, according to Massalongo and Heer.*

The Proteaceæ also abounded in the Eocene strata of England, France, and Italy, and in the cretaceous rocks at Aix-la-Chapelle. To these 
countries, therefore, rather than to Australia and Africa, we ought to look for the origin of many of the species of that order which we find both in Upper and Lower Miocene formations.

But notwithstanding the caution which we must use in our speculatrons on the alleged affinity of the Miocene flora of Europe to the living plants of America and other countries, I consider the generalizations of Unger, Asa Gray, Heer, Oliver, and others on this subject, to be most important, and that their investigations cannot fail to throw great light on the past history of species and genera in the vegetable kngdom.

UPPER MIOCENE FORMATIONS, INDIA.

Sub-Himalayan or Siwalitk Hills.-The Siwâlik Hills lie at the southern foot of the Himalayan chain, rising. to the height of 2000 and 3000 feet. Between the Jumna and the Ganges they consist of inclined strata of sandstone, shingle, clay, and marl. We are indebted to the indefatigable researches of Dr. Falconer and Sir Proby Cautley, continued for fifteen years, and to the labors of other scientific officers in the Indian service, for the discovery in these marls and sandstones of a great variety of fossil mammalia and reptiles, together with many freshwater shells. Fifteen species of shells of the genera Paludina, Melania, Ampullaria, and Unio were shown by Falconer and Cautley in 1846 to the late Professor E. Forbes, who pronounced them to be all extinct or unknown species with the exception of four, which are still inhabitants of Indian rivers. Such a proportion of living to extinct mollusca agrees well with the usual character of an Upper Miocene or Falunian fauna, as observed in Touraine, or in the basin of Vienna and elsewhere.

The genera of mammalia point in the same direction. One of them, named originally Anoplotherium, was at first considered to supply a link between this Indian fauna and that of the Eocene period of Europe, but it is now recognized to belong to the genus Chalicotherium (or Anisodon of Lartet), a pachyderm intermediate between the Rhinoceros and Anoplothere, and characteristic of the Upper Miocene strata of Eppelsheim, and of Sansans in the Department of Gers in the South of France. With in occurs also an extinct form of Hippopotamus, called Hexaprotodon, and a species of Hippotherium and pig, also two species of Mastodon, two of elephant, and three other elephantine proboscidians; none of them agreeing with any fossil forms of Europe, and being intermediate between the genera Elephas and Mastodon, constituting the sub-genus Stegodon of Falconer. With these are associated a monkey, allied to the Semnopithecus entellus, now living in the Himalaya, and many ruminants. Amongst these last, besides the giraffe, camel, antelope, stag, and others, we . find a remarkable new type, the Sivatherium, like a gigantic fourhorned deer. There are also new forms of carnivora, both feline and 
canine, the Machairodus among the former, also hyænas, and a suburs . ine form called the Hyænarctos, and a genus allied to the otter (Enhydriodon), of formidable size.

The giraffe, camel, and a large ostrich may be cited as proofs that there were formerly extensive plains where now a steep chain of hills, with deep ravines, runs for many hundred miles east and west. Among the accompanying reptiles are several crocodiles, some of huge dimensions, and one not distinguishable, says Dr. Falconer, from a species now living in the Ganges ( $C$. Gangeticus), and there is still another saurian which the same anatomist has identified with a species now inhabiting India. There was also an extinct species of tortoise of gigantic proportions (Colossochelys Atlas), the curved shell of which was twelve feet three inches long and eight feet in diameter, the entire length of the animal being estimated at eighteen feet, and its probable height seven feet.

That some of the reptiles should, as well as many of the shells, have survived from the Upper Miocene to the human epoch, need scarcely excite surprise, for we have no reason to assume that the mean temperature of India in the Miocene period differed materially from that which now prevails; although the climate must have been greatly modified by the revolution which has since occurred in the physical geography of the district. The heat may be as great now, if not greater, than when the Sivatherium and Chalicotherium flourished.

Numerous fossils of the Siwâlik type have also been found in Perim Island, in the Gulf of Cambay, and among these a species of Dinotherium, a genus so characteristic of the Upper Miocene period in Europe.

Atlantic Islands.-Something will be said of the Upper Miocene formations of marine origin in Madeira, the Canary Islands, and the Azores, when I speak, in the thirty-first chapter, of the volcanic rocks of those countries.

Older Pliocene and Miocene formations in the United States.-Between the Alleghany Mountains, formed of older rocks, and the Atlantic, there intervenes, in the United States, a low region occupied principally by beds of marl, clay, and sand, consisting of the cretaceous and tertiary formations, and chiefly of the latter. The general elevation of this plain bordering the Atlantic does not exceed 100 feet, although it is sometimes several hundred feet high. Its width in the middle and southern States is very commonly from 100 to 150 miles. It consists, in the South, as in Georgia, Alabama, and South Carolina, almost exclusirely of Eocene deposits; but in North Carolina, Maryland, Virginia, Delaware, more modern strata predominate, which, after examining them in 1842, I supposed to be of the age of the English Crag and faluns of Touraine.* If, chronologically speaking,

* Proceed. of the Geol. Soc., rol. iv. Pt. 3, 1845, p. 547. 
they can be truly said to be the representatives of these two European formations, they may range in age from the Older Pliocene to the Miocene epoch, according to the classification of European strata adopted in this chapter.

The proportion of fossil shells agreeing with recent, out of 147 species collected by me, amounted to about 17 per cent., or one-sixth of the whole; but as the fossils so assimilated were almost always the same as species now living in the neighboring Atlantic, the number may hereafter be augmented, when the recent fauna of that ocean is better known. In different localities, also, the proportion of recent species varied considerably.

On the banks of the James River, in Virginia, about twenty miles below Richmond, in a cliff about 30 feet high, I observed yellow and white sands overlying an Eocene marl, just as the yellow sands of the crag lie on the blue London clay in Suffolk and Essex in England. In the Virginian sands, we find a profusion of an Astarte ( $A$. undulata, Conrad), which resembles closely, and may possibly be a variety of, one of the commonest fossils of the Suffolk Crag (A. bipartita); the other shells also, of the genera Natica, Fissurella, Artemis, Lucina,

Fig. 207.

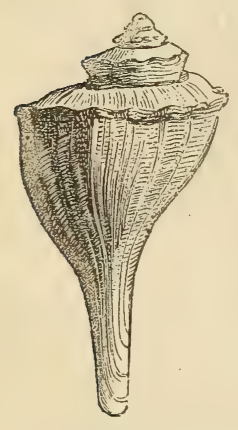

Fulgur canaliculatus. Maryland.
Fig. 208 .

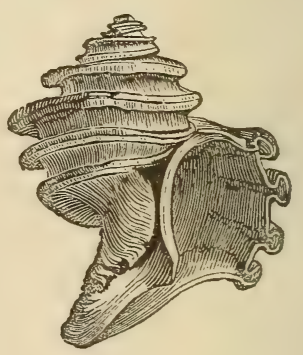

Fusus quadricostatus, Say. Maryland.

Chama, Pectunculus, and Pecten, are analogous to shells both of the English crag and French faluns, although the species are almost all distinct. Out of 147 of these American fossils I could" only find 13 species common to Europe, and these occur partly in the Suffolk Crag, and partly in the faluns of Touraine; but it is an important characteristic of the American group, that it not only contains many peculiar extinct forms, such as Fusus quadricostatus, Say (see fig. 208), and Venus tridacnoides, abundant in these same formations, but also some shells which, like Fulgur carica of Say and $F$. canaliculatus (see fig. 207), Calyptrcea costata, Venus mercenaria, Lam., Modiola olandula, Totten, and Pecten magellanicus, Lam., are recent species, yet of forms now confined to the western side of the Atlantic-a fact implying that some traces of the beginning of the present geographi- 
cal distribution of mollusca date back to a period as remote as that of the Miocene strata.

Of ten species of zoophytes which I procured on the banks of the James Rirer, one was formerly supposed by Mr. Lonsdale to be identical with a fossil from the faluns of Touraine, but this species (see fig. 209) proves on reëxamination to be different, and to agree generically with a Fig. 209. coral now living on the coast of the United States. With respect to climate, Mr. Lonsdale regards these corals as indicating: a temperature exceeding that of the Mediterranean, and the shells would lead to similar conclusions. Those occurring on the James River are in the 37th degree of N. latitude, while the French faluns are in the 4 t th; yet the forms of the American fossils would scarcely imply so warm a climate as must have prevailed in France when the Miocene strata of Touraine originated.

Among the remains of fish in these Post-eocene strata of the United States are sereral large teeth of the shark family, not distinguishable specifically from fossils of the faluns of Touraine.

\section{LOWER MIOCENE, UNITED STATES.}

Nebraska.-In the territory of Nebraska, on the Upper Missouri, near the Platte River, lat. $42^{\circ} \mathrm{N}$., a tertiary formation occurs, consisting of white limestone, marls, and siliceous clay, described by Dr. D. Dale Owen, * in which many bones of extinct quadrupeds, and of chelonians of land or freshwater forms, are met with. Among these, Dr. Leidy describes a gigantic quadruped, called by him Titanotherium, nearly allied to the Palceotherium, but larger than any of the species found in the Paris gypsum. With these are several species of the genus Oreodon, Leidy, uniting the characters of pachyderms and ruminants also; Eucrotaphus, another new genus of the same mixed character; two species of rhinocercas of the sub-genus Acerotherium, a Lowrer Aíiocene form of Europe before mentioned; two species of Archcootherium, a pachyderm allied to Choropotamus and Hyracotherium; also Pobrotherium, an extinct ruminant allied to Dorcatherium, Kaup; also Agriochcegnes of Leidy, a ruminant allied to Merycopotamus of Falconer and Cautley; and, lastly, a large carnivorous animal of the genus Machairodus, the most ancient example of which in Europe occurs in the Lowcr Miocene strata of Auvergne, but of which some species are found in Pliocene deposits. The tur-

* David Dale 0wen, Geol. Survey of Wisconsin, \&c. ; Philad. 1852. 
tles are referred to the genus Testudo, but have some affinity to Emys. On the whole, the Nebraska formation is probably newer than the Paris gypsum, and referable to the Lower Miocene period, as above defined.

\section{CHAPTER XVI.}

\section{EOCENE FORMATIONS.}

Upper Eocene strata of England-Fluvio-marine series in the Isle of Wight and Hampshire-Successive groups of Eocene mammalia-Boundary-line between Lower Miocene and Eocene-Fossils of Barton Clay-British Middle EoceneShells, nummulites, fishes, and reptiles of the Bagshot and Bracklesham bedsVegetation of Middle Eocene period-Lower Eocene strata of England-Fossil plants and shells of the London Clay proper-Strata of Kyson in Suffolk-Plastic clays and sands-Thanet sands-Eocene formations of France-Gypseous series of Montmartre and extinct quadrupeds-Fossil footprints-Calcaire grossier-Miliolites-Lower Eocene in France-Nummulitic formations of Europe, Africa, and Asia - Their wide extent--Referable to the Middle Eocene periodEocene strata in the United States-Section at Claiborne, Alabama-Colossal cetacean--Orbitoidal limestone-Burr stone.

THE strata next in order in the descending series are those which I term Upper Eocene. In the accompanying map, the position of several Eocene areas is pointed out, such as the basin of the Thames,

Fig. 210 .

Map of the principal tertiary basins of the Eocene period.

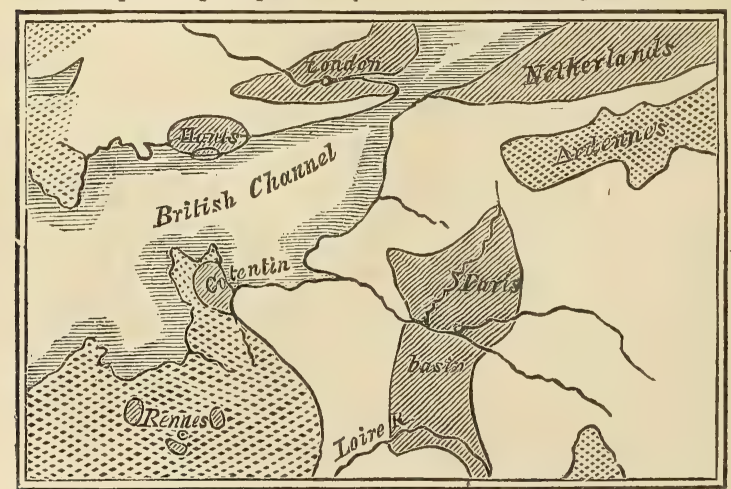

Hypogene rocks and strata WIII/ Eocene formations.

older than the Devonian or Old Red series.

N. B. The space left blank is occupied by secondary formations from the Devonian or old red sands tone to the chalk inclusive.

part, of Hampshire, part of the Netherlands, and the country round Paris. The three last-mentioned areas contain some marine and 
freshwater formations, which have been already spoken of as Lower Miocene, but their superficial extent is insignificant, except in the Paris basin between the Seine and the Loire.

\section{UPPER EOCENE FORMATIONS, ENGLAND.}

The following table will show the order of succession of the strata found in the Tertiary areas, commonly called the London and Hampshire basins. (See also Table, p. 103, et seq.)

LOWER MIOCENE.

Thickness.

Hempstead beds, Isle of Wight, see above, p. 239, - _ - 170 feet.

UPPER EOCENE.

A. 1. Bembridge Series--North coast of Isle of Wight, - $\quad$ - 120

A. 2. Osborne or St. Helen's Series-ibid., - _ _ _ - _ 100

A. 3. Headon Series-Isle of Wight, and Hordwell Cliff, Hants, $\quad$ - $\quad 170$

A. 4. Barton Clay, Isle of Wight, and Barton Cliff, Hants, - _ - 300

MIDDLE EOCENE.

B. Bagshot and Bracklesham Sands and Clays-London and Hants basins,

LOWER EOCENE.

C. 1. London Clay proper and Bognor beds--London and Hants basins, - $\quad$ - $\quad$ - $\quad$ - $\quad$ - $\quad$ - $\quad$ - 350 to 500

C. 2. Plastic and Mottled Clays and Sands-London and Hants basins, - $\quad$ - $\quad$ - $\quad$ - $\quad$ - $\quad$ - $\quad$ - 100

C. 3. Thanet Sands-Reculvers, Kent, and Eastern part of London

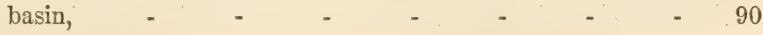

The true relative position of the Hempstead beds and of the Bembridge, A. 1, and the Osborne or St. Helen's series, A. 2, were not made out in a satisfactory manner till Professor Forbes studied them in detail in 1852. The true place of the Bagshot sands, B., and of the Thanet sands, C. 3, was first accurately ascertained by Mr. Prest wich in 1847 and 1852 .

UPPER EOCENE, ENGLAND.

Bembridge series, A. 1.-These beds are about 120 feet thick, and, as before stated (p. 239), are conformable with the Hempstead beds, near Yarmouth, in the Isle of Wight. They consist of marls, clays, and limestones of freshwater, brackish, and marine origin. Some of the most abundant shells, as Cyrena semisiriata var., and Paludina lenta, fig. 176, p. 240 , are common to this and to the overlying Hempstead series; but the majority of the species are distinct. The following are the subdivisions described by Professor Forbes:- 
a. Upper marls, distinguished by the abundance of Melania turritissima, Forbes (fig. 211).

b. Lower marl, characterized by Cerithium mutabile, Cyrena pulchra, \&c., and by the remains of Trionyx (see fig. 212).

Fig. 211.

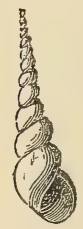

Melania turritissima, H'orbss. Bembridge,
Fig. 212.

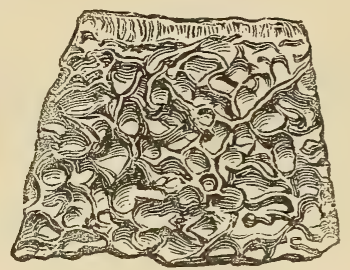

Fragment of Carapace of Trionyx. Bembridge Beds, Isle of Wight.

c. Green marls, often abounding in a peculiar species of oyster, and accompanjed by Cerithia, Mytili, an Arca, a Nucula, \&c.

Fig. 213.

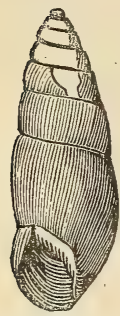

Butimus ellipticus, Sow. Bembridge Limestone. $\frac{1}{2}$ nat. size.
Fig. 214 .

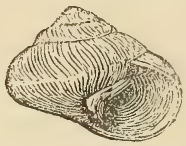

Helix occlusa, Edwards. Bembridge Limestcne, Isle of Wight.
Fig. 215.

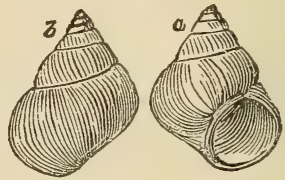

Paludina orbicularis. Bembridge.

$d$. Bembridge limestones, compact cream-colored limestones alternating with shales and marls, in all of which land-shells are common, especially at Sconce, near

Fig. 216.
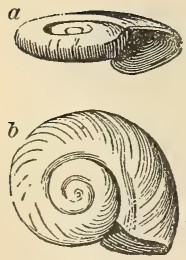

Planorbis discus, Edwards. Bembridge. $\frac{1}{2}$ diam.
Fig. 217.

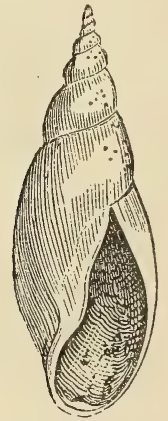

Lymnea longiscata, Brard. Nat. size.
Fig. 218.

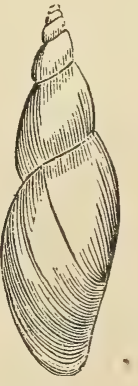

Chara tuberculata. Bembridge Limestone, I. of Wight. 
Yarmouth, as described by Mr. Edwards. The Bulimus ellipticus, fig. 213, and Helix occlusa, fig. 214, are among its best known land-shells. Paludina orbicularis, fig. 215, is also of frequent occurrence. One of the bands is filled with a little globular Paludina. Among the freshwater pulmonifera, Lymnea longiscata (fig. 217) and Planorbis discus (fig. 216) are the most generally distributed: the latter represents or takes the place of the Plaseorbis euomphalus (see fig. 221), of the more ancient Headon series. Chara tuberculata (fig. 218) is the characteristic Bembridge gyrogonite.

From this formation on the shores of Whitecliff Bay, Dr. Mantell obtained a fine specimen of a fan palm, Flabellaria Lamanonis, Brong., a plant first obtained from beàs of corresponding age in the suburbs of Paris. The well-known building-stone of Binstead, near Ryde, a limestone with numerous hollows caused by Cyrence which have disappeared and left the moulds of their shells, belong's to this subdirision of the Bembridge series. In the same Binstead stone Mr. Pratt and the Rev. Darwin Fox first discovered the remains of mammalia characteristic of the gypseous series of Paris, as Palcootherium magnum (fig. 220), $P$. medium, $P$. minus, $P$. mimimum, $P$. curtum, $P$. crassum; also Anoplotherium commune (fig. 219), A. secundarium, Dichobune cervinum, and Chceropotamus Cuvieri. The genus Paleothere, above alluded to, resembled the living tapir in the form of the head, and in having a short proboscis, but its molar teeth were more like those of the rhinoceros. Paleotherium magnum was of the

Fig. 219.

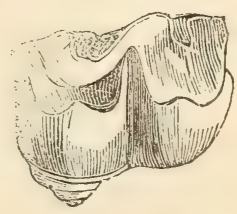

Lower molar tooth, nat. size.

Anoplotherium commune. Binstead, Isle of Wight. size of a horse, three or four feet high. The annexed woodcut, fig. 220 , is one of the restorations which Cuvier attempted of the outline

Fig. 220.

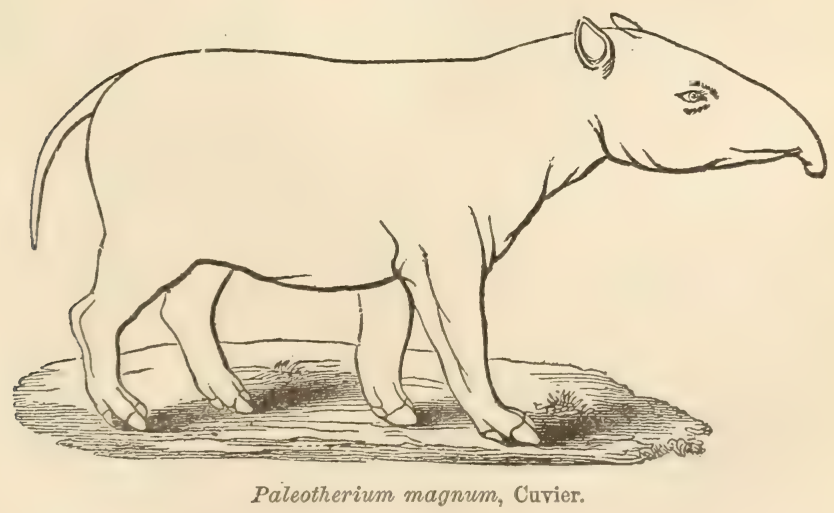

of the living animal, derived from the study of the entire skeleton. As the vertical range of particular species of quadrupeds, so far as 
our knowledge extends, is far more limited than that of the testacea, the occurrence of so many species at Binstead, agreeing with fossils of the Paris gypsum, strengthens the evidence derived from shells and plants of the synchronism of the two formations.

Osborne or St. Helen's series, A. 2.-This group is of fresh and brackish-water origin, and very variable in mineral character and thickness. Near Ryde, it supplies a freestone much used for building, and called by Professor Forbes the Nettlestone grit. In one part ripple-marked flagstones occur, and rocks with fucoidal markings. The Osborne beds are distinguished by peculiar species of Paludina, Melania, and Melanopsis, as also of Cypris and the seeds of Chara.

Headon series, A. 3.-These beds are seen both in Whitecliff Bay and in Headon Hill, or at the east and west extremities of the Isle of Wight. The upper and lower portions are freshwater, and the middle of mixed origin, sometimes brackish and marine. Everywhere Planorbis euomphalus, fig. 221, characterizes the freshwater deposits,

Fig. 221.

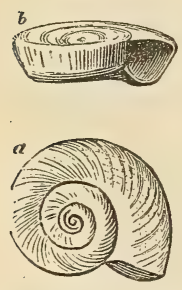

Planorbis euomphatus, Sow. Headon Hill. $\frac{1}{2}$ diam.
Fig. 222.

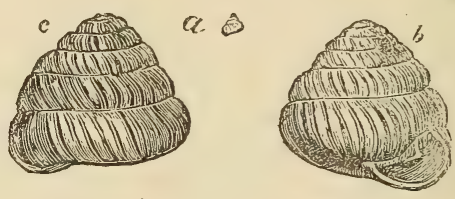

Helix labyrinthica, Say. Headon Hill, Isle of Wight; and Hordwell Cliff, Hants-also recent.

just as the allied form, $P$. discus, fig. 216, does the Bembridge limestone. The brackish-water beds contain Potamomya plana, Cerithium mutabile, and Potamides cinctus (fig. 44, p. 30), and the marine beds Venus (or Cytherea) incrassata, a species common to the Limburg

Fig. 223.
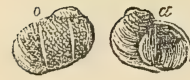

Neritina concava. Headon series.
Fig. 221 .

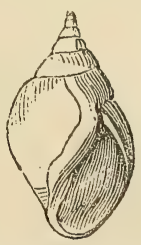

Lymnea caudata. Headon beds.
Fig. 225 .

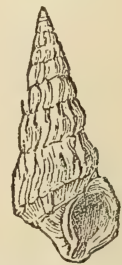

Cerithium concavum. Headon series.

beds and Grès de Fontannebleau, or the Lower Miocene series. The prevalence of salt-water remains is most conspicuous in some of the central parts of the formation. Mr. T. Webster, in his able memoirs 
on the Isle of Wight, first separated the whole into a lower freshwater, an upper marine, and an upper freshwater division.

Among the shells which are widely distributed through the Headon series are Neritina concava (i̊g. 223), Lymnea caudata (fig. 224), and Cerithium concavum (fig. 225). Helix labyrinthica, Say (fig. 222), a land-shell now inhabiting the United States, was discorered in this series by Mr. Wood in Hordwell Cliff. It is also met with in Headon Hill, in the same beds. At Sconce, in the Isle of Wight, it occur's in the Bembridge series, and affords a rare example of an Eocene fossil of a species still living, though, as usual in such cases, haring no local connection with the actual geographical range of the species.

The lower and middle portion of the Headon series is also met with in Hordwell Cliff (or Hordle, as it is often spelt), near Lymington, Hants, where the organic remains have been studied by Mr. Searles Wood, Dr. Wright, and the Marchioness of Hastings. To the latter we are indebted for a detailed section of the beds,* as well as for the discovery of a variety of new species of fossil mammalia, chelonians, and fish; also, for first calling attention to the important fact that these rertebrata differ specifically from those of the Bembridge beds. Imong the abundant shells of Hordwcll are Paludina lenta and various species of Lymnea, Planorbis, Melania, Cyclas, and Unio, Potamomya, Dreissena, \&c.

Among the chelonians we find a species of Emys, and no less than six species of Trionyx; among the saurians an alligator and a crocodile; among the ophidians two species of land-snakes (Paleriy Orren); and among the fish Sir P. Egerton and Mr. Wood hare found the jaws, teeth, and hard shining scales of the genus Lepidosteus, or bony pike of the American rirers. This same genus of freshwater ganoids has also been met with in the Hempstead beds in the Isle of Wight. The bones of several birds have been obtained from Hordwell, and the remains of quadrupeds. The latter belong to the genera Paloplotherium of Orren, Anoplotherium, Anthracotherium, Dichodon of Owen (a new genus discovered by Mr. A. H. Falconer), Dichobune, Spalacodon, and Hyoenodon. The latter offers, I believe, the oldest known example of a true carnivorous animal in the series of British fossils, although I attach very little theoretical importance to the fact, because herbivorous species are those most easily met with in a fossil state in all save cavern deposits. In another point of view, however, this fauna deserves notice. - Its geological position is considerably lower than that of the Bembridge or Montmartre beds, from which it differs almost as much in species as it does from the still more ancient fama of the Lower Eocene beds to be mentioned in the sequel. It therefore teaches us what a grand succession of distinct assemblages of mammalia flourished on the carth during the Eocene period. 
Many of the marine shells of the blackish-water beds of the above series, both in the Isle of Wight and Hordwell Cliff, are common to the underlying Barton Clay; and, pn the other hand, there are some freshwater shells, such as Cyrena obovata, which are common to the Bembridge beds, notwithstanding the intervention of the St. Helen's series. The white and green marls of the Headon series, and some of the accompanying limestones, often resemble the Eocene strata of France in mineral character and color in so striking a manner, as to suggest the idea that the sediment was derived from the same region, or produced contemporaneously under very similar geographical circumstances.

At Brockenhurst, near Lyndhurst, in the New Forest, marine strata have recently been found, containing fifty-nine shells, of which many have been described by Mr. Edwards. These beds rest on the Lower Headon, and are considered as the equivalent of the middle part of the Headon series, many of the shells being common to the brackishwater or Middle Headon beds of Colwell and Whitecliff Bays, such as Cancellaria muricata, Sow., Fusus labiatus, Sow., \&c. Baron von Könen * has pointed out that no less than forty-six out of the fifiy-nine Brockenhurst shells, or a proportion of 78 per cent., agree with species occurring in Dumont's Lower Tongrian formation in Belgium. This being the case, we might fairly expect that if we had a marine equivalent of the Bembridge series, or of the contemporaneous Paris gypsum, we should find it to contain a still greater number of shells common to the Tongrian beds of Belgium, but the exact" correlation of these freshwater groups of France, Belgium, and Britain, has not yet been fully made out. It is possible that the Tongrian of Dumont may be newer than the Bembridge series, and therefore referable to the Lower Miocene, according to the classification adopted by me in Chapter XIV. p. 217.

If ever the whole series should be complete, we must be prepared to find the marine equivalent of the Bembridge beds, or the uppermost Eocene, passing by imperceptible shades into the overlying lowest Miocene strata.

Among the fossils found in the Middle Headon are Cytherea incrassata and Cerithium plicatum, fig. 173, p. 240. These shells, especially the latter, are very characteristic of the Lower Miocene, and their occurrence in the Headon series has been cited as an objection to the line proposed to be drawn between Miocene and Eocene. But if we were to attach importance to such occasional passages, we should soon find that no lines of division could be drawn anywhere, for in the present state of our knowledge of the Tertiary series there will always be species common to beds above and below our boundarylines.

Both in Hordwell Cliff and the Isle of Wight, the Headon beds

* Quart. Geol. Journ., vol. xx. p. 97. 1864. 
rest on white sands, used for making glass, and constituting the upper member of the Barton series, A. 4, p. 281, nest to be mentioned.

White sands and Barton clay, A. 4 (Table, p. 281).-In one of the upper sandy beds of this formation, Dr. Wright found Chama squamosa in great plenty. The same sands contain impressions of many marine shells (especially in Whitecliff Bay) common to the upper Bagshot sands afterwards to be described. The underlying Barton clay has yielded about 252 marine shells, more than half of them, according to Mr. Prestwich, pecuFig. 226. liar; and only about one in twenty being common to the London clay proper, a much older Eocene group (see p. 291), with which the Barton clay was formerly confounded. About one-third of the Barton clay shells agree specifically with those of the calcaire grossier of the Paris basin.* It is nearly a century since Brander published, in 1766, an account of the Chama squamosa. organic remains collected from these Barton and Hord-

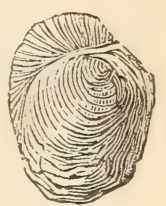
well Cliffs, and his excellent figures of the shells then deposited in the British Museum are justly admired by conchologists for their accuracy.

SHELLS OF THE BARTON CLAY, HANTS.

Certain foraminifera called Nummulities begin, when we study the tertiary formations in a descending order, to maks their first appear-

Fig. 227.

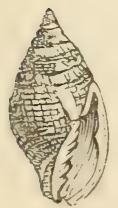

Mitra scabra.
Fig. 22S.

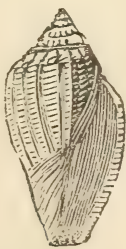

Toluta ambigue.

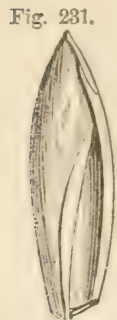

Terebellum fusiforme. Barton and Bracklesbam.

Terebellum 80 Lam.

Seraphs convo.
Fig. 229.

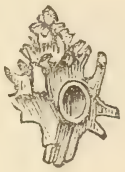

Typhis pungens.

Fig. 233.

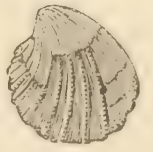

Cardita sulcata. pita, Brandner,

lutum, Montf.
Fig. 230.

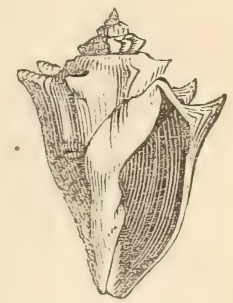

Totuta athleta. Barton and Bracklesham.

Fig. 234.

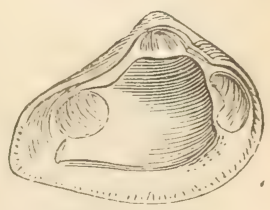

Crassatella suloata.

- Quart. Geol. Journ., vol, xiii. p. 134. London 1857. 
ance in these Barton beds. A small species called Nummulites variolaria is found both on the Hampshire coast and in beds of the same age in Whitecliff Bay, in the Isle of Wight. Several marine shells, such as Carbula pisum, are common to the Barton beds and the Hempstead or Lower Miocene series, and a still greater number, as before stated, are common to the Headon series.

\section{MIDDLE EOCENE, ENGLAND.}

Bagshot and Bracklesham beds, B.--The Bagshot beds, consisting chiefly of siliceous sand, occupy extensive tracts round Bagshot, in Surrey, and in the New Forest, Hampshire. They may be separated into three divisions, the upper, and lower consisting of light yellow sands, and the central of dark green sands and brown clays, the whole reposing on the London clay proper.* The uppermost division is probably very nearly related in age to the Barton series. Although the Bagshot beds are usually devoid of fossils, they contain marine shells in some places, among which Venericardia planicosta (see fig. 235 ) is abundant, with Turritella sulcifera and Nummulites loevigatce (see fig. 239, p. 289).

Fig. 235.
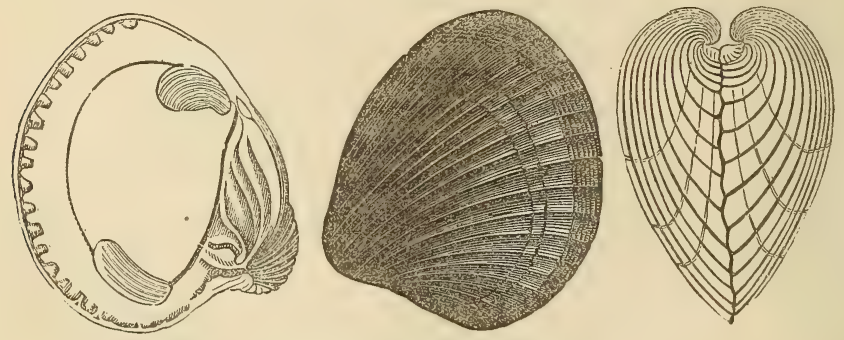

Venericardia planicosta, Lam. Cardita planicosta, Deshayes.

At Bracklesham Bay, near Chichester, in Sussex, the characteristic shells of this member of the Eocene series are best seen; among others, the huge Cerithium giganteum, so conspicuous in the calcaire grossier of Paris, where it is sometimes two feet in length. The volutes and cowries of this formation, as well as the lunulites and corals, seem to favor the idea of a warm climate having prevailed, which is borne out by the discovery of a serpent Palooophis typhoeis (see fig. 236), exceeding, according to Professor Owen, twenty feet in length, and allied in its osteology to the Boa, Python, Coluber, and Hydrus. The compressed form and diminutive size of certain

* Prestwich, Quart. Geol. Journ., vol. iii. p. 386. 
caudal vertebræ indicate so much anology with Hydrus as to induce Professor Owen to pronounce this extinct ophidian to have been marine.* He had previously combated with much success the evi-

Fig. 236.
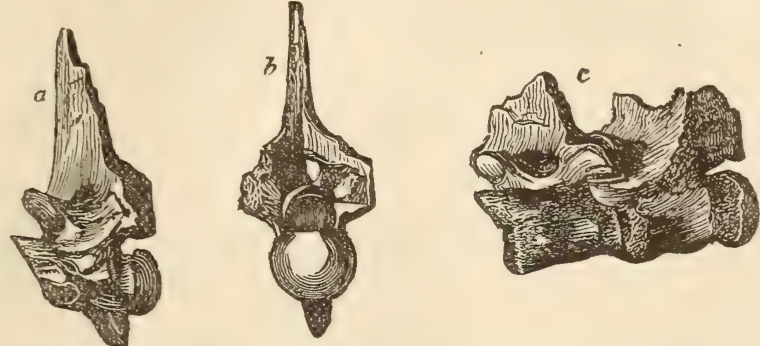

Palcoophis typhoeus, Owen; an Eocene sea-serpent. Bracklesham.

$a, b$. Vertebra, with long nearal spine preserved. c. Two vertebræ in natural articulation.

dence advanced to prove the existence in the Northern Ocean of huge sea-serpents in our own times, but he now contends for the former existence in the British Eocene seas of less gigantic serpents, when the climate was probably more genial; for amongst the companions of the sea-snake of Bracklesham was an extinct Gavial (Gavialis Dixoni, Owen), and a numerous fish, such as now frequent the seas of warm latitudes, as the ostraceont fish, of which a spine is figured (see fig. 237), and gigantic rays of the genus Myliobates (see fig. 238).

Fig. 237

Defensive spine of an Ostraceon, or fish of the family Batistida. Bracklesham. Dixon's Fossils of Sussex, pl, 11, fig. 26.

Fig. 238,

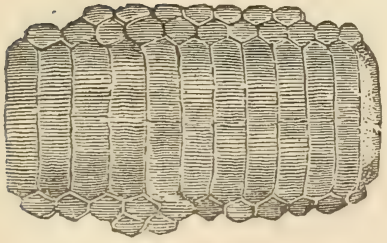

Dental plates of Myliobates Edroardsi. Bracklesham Bay. Tbid., pl. 8.
Fig. 239.
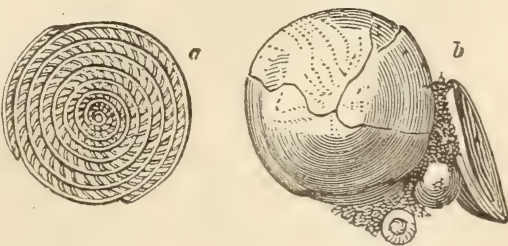

Nummulites (Nummularia) lovigata. Bracklesham. Tbid., pl. 8.

a. Section of the nummulite.

b. Group, with an individual showing the exterior of the shell.

The teeth of sharks also, of the genera Carcharodon, Otodus, Lamna, Galeocerdo, and others, are abundant. (See figs. 240, 241, 242, 243.) The Nummulites lcevigata (see fig. 239), so characteristic of

* Palæont. Sor. Monograph. Rept., Pt. ii. p. 61. 
the lower beds of the calcaire grossier in France, where it sometimes forms stony layers, as near Compiegne, is very common at Bracklesham, together with $N$. scabra and $N$. variolaria. Out of 193 species of testacea procured from the Bagshot and Bracklesham beds in England, 126 occur in the calcaire grossier in France. It was clearly, therefore, coeval with that part of the Parisian series more nearly than with any other.

Fig. 240.

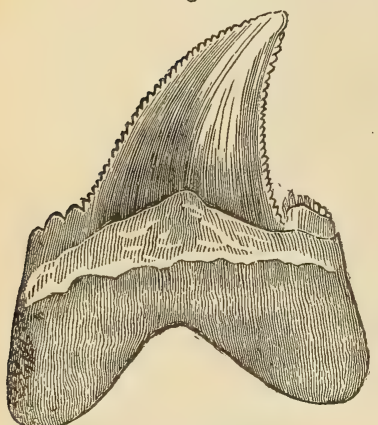

Carcharodon heterodon, Agass.
Fig. 241.

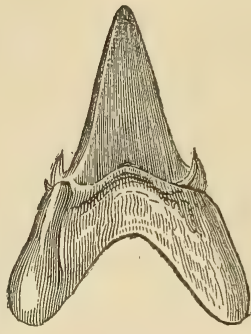

Otodus obtiquns, Agass.
Fig. 242.

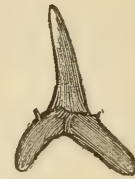

Lamna elegans, Agass.

Teeth of sharks from Bracklesham Bay.
Fig. 243.

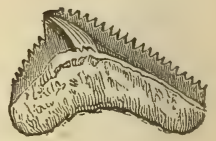

Galeocerdo latidene Agass.

Marine Shells of Bracklesham Beds.

Fig. 244 .

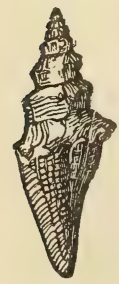

Plerurotoma attenu. ata, Sow.
Fig. 245.

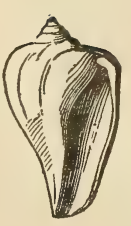

Voluta Selseïensis, Edwarde.
Fig. 246.

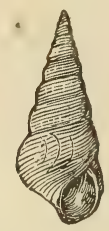

Turritella. multisulcata, Lam.
Fig. 247.

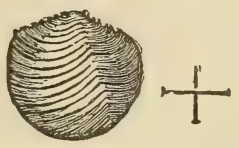

Lucina serrato, Dixon. Magnified.
Fig. 248.

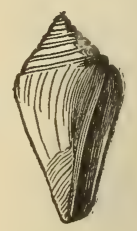

Conus deperditus.

\section{VEGETATION OF MIDDLE EOCENE PERIOD.}

The plants of Alum Bay in the Isle of Wight, and of Bournemouth, on the south coast of Hampshire, imbedded in white clays of the Middle Eocene series, bear a great resemblance generally to those of the Miocene period, as described in the last chapter; but the species are with very few exceptions quite distinct. Forty of these are mentioned by MM. de la Harpe and Gaudin, among which the Proteaceæ 
(Dryandia, drc.), and the fig tribe are abundant, as well as the cinnamon and sereral other laurineæ, with some papilionaceous plants. On the whole they remind the botanist of the types of tropical India and Australia.*

Heer has mentioned several species which are common to this Alum Bay flora and that of Monte Bolca, near Verone, so celebrated for its fossil fish, and where the strata contain nummulites and other Middle Eocene fossils. $\nmid$ He has particularly alluded to Aralia primigenia, De la Harpe; Daphnogene Veronensis, Massalongo sp.; and Ficus granadilla, Mass. sp., as among the species common to and characteristic of the Isle of Wight and Italian Eocene beds; and he observes that in the flora of this period those forms of a temperate climate which constitute a marked feature in the European Miocene formations, such as the willow, poplar, birch, alder, elm, hornbeam, oak, fir, and pine, are wanting. The American types are also absent, or much more feebly represented than in the Hiocene period. The number of exotic forms which are common to the Eocene and Miocene strata of Europe demonstrate the remoteness of the times in which the geographical distribution of living plants originated. A great majority of the Eocene genera have disappeared from our temperate climates, but not the whole of them; and they must all have exerted some influence on the assemblaye of species which succeeded them. Many of these are indeed so closely allied to the flora now surviring as to make it questionable, even in the opinion of naturalists opposed to the doctrine of transmutation, whether they are not genealogically related the one to the other.

\section{LOWER EOCENE FORMATIONS, ENGLAND.}

London Clay proper (C. 1, Table, p. 281).-This formation underlies the preceding; and consists of tenacious brown and bluish-gray clay, with layers of concretions called septaria, which abound chiefly in the brown clar, and are obtained in sufficient numbers from seacliffs near Harwich, and from shoals off the Essex coast, to be used for making Roman cement. The principal localities of fossils in the London Clay are Highgate Hill, near London, the island of Sheppey, and Bognor in Hampshire. Out of 133 fossil shells, Mr. Prestwich found only 20 to be common to the calcaire grossier (from which 600 species have been obtained), while 33 are common to the "Lits Coquilliers" (p. 304), in which 200 species are known in France. We may presume, therefore, that the London clay proper is older than the calcaire grossier. This may perhaps remore a difficulty which M. Adolphe Brongniart has experienced when comparing the Focene Flora of the neighborhoods of London and Paris. The fossil

* Heer, Climat et Végétation du Pays Tertiaire, p. 172.

+ For remarks on the Monte Bolca rocks, see below, Chap. XXXII. 
species of the Island of Sheppey, he observes, indicate a much more tropical climate than the Eocene Flora of France. Now the latter had deen derived principally from the Uppermost Eocene or gypseous

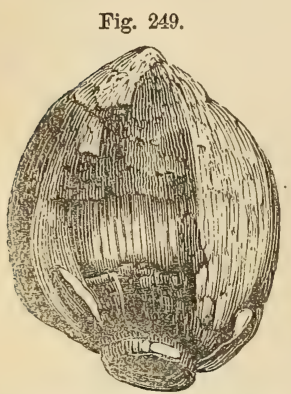

Nipadites ellipticus, Bow. series, and resembles the vegetation of the borders of the Mediterranean rather than that of an equatorial region; whereas the older flora of Sheppey belongs to an antecedent epoch, separated from the period of the Paris gypsum by all the Barton and Bagshot series-in short, by the equivalents of the great nummulitic series of continental writers.

Mr. Bowerbank, in a valuable publication on the fossil fruits and seeds of the island of Sheppey, near London, has described no Fossil fruit of palm, from Shep-less than thirteen fruits of palms of the pey. recent type Nipa, now only found in the Molucca and Philippine Islands and in Bengal (see fig. 249). In the delta of the Ganges, Dr. Hooker observed the large nuts of Nipa fruticans floating in such numbers in the various arms of that great river, as to obstruct the paddle-wheels of steamboats. These plants are allied to the cocoa-nut tribe on the one side, and on the other to the Pandanus, or screw-pine. The fruits of other palms besides those of the cocoa-nut tribe are also met with in the clay of Sheppey; also three species of Anona, or custard apple; and cucurbitaceous fruits (of the gourd and melon family) are in considerable abundance. Fruits of various species of Acacia are in profusion, and these, although less decidedly tropical, imply a warm climate.

The contiguity of land may be inferred not only from these vegetable productions, but also from the teeth and bones of crocodiles and turtles, since these creatures, as Dean Conybeare remarked, must bave resorted to some shore to lay their eggs. Of turtles there were numerous species reforred to extinct genera. These are, for the most part, not equal in size to the largest living tropical turtles. A seasnake, which must have been thirteen feet long, of the genus Palcophis before mentioned (p. 289), has also been described by Professor Owen from Sheppey, of a different species from that of Bracklesham. A true crocodile, also, Crocodilus toliapicus, and another saurian more nearly allied to the gavial, accompany the above fossils; also the relics of several birds and quadrupeds. One of these last belongs to the new genus Hyracotherium of Owen, of the hog tribe, allied to Chæropotamus; another is a Lophiodon; a third a pachyderm called Coryphodon eocenus by Owen, larger than any existing tapir. All these animals seem to have inhabited the banks of the great river which floated down the Sheppey fruits. They imply the existence of a mammiferous fauna antecedent to the period when nummulites flourshed in Europe and Asia, and therefore before the Alps, Pyrenees, 
and other mountain-chains now forming the backbones of great continents, were raised from the deep; nay, even before a part of the constituent rock masses now entering into the central ridges of these chains had been deposited in the sea.

The marine shells of the London clay confirm the inference derivable from the plants and reptiles in faror of a high temperature. Thus many species of Comus and Voluta occur, a large Cyproea, C. oviformis, a very large Rostellaria (fig. 252), a species of Cancellaria, six species of Nautilus (fig. 254), besides other Cephalopoda of extinct genera, one of the inost remarkable of which is the Belosepia* (fig. 255). Among many characteristic bivalve shells are Leda amygdaloides (fig. 256) and Cryptodon angulatum (fig. 257), and among the Radiata a star-fish called Astropecten (fig. 258).

\section{FOSSIL SHELLS OF THE LONDON CLAY.}

Fig. 250 .

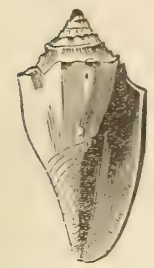

Toluta nodosa, Sow. Highgate.
Fig. 251.

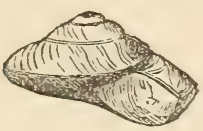

Phorus extensus, Sow. Highgate.

Fig. 253.

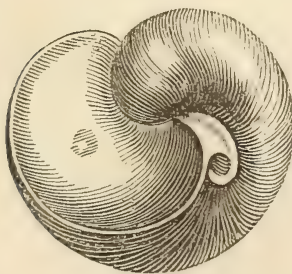

Nautitus centralis, Sow. Higbgate.

Fig. 254

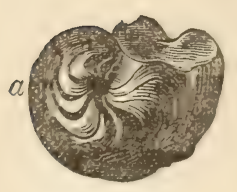

Aturia ziczac, Brown and Edwards. Syn. Nautilus ziczac, Sow. London clay. Sheppey.
Fig. 252.

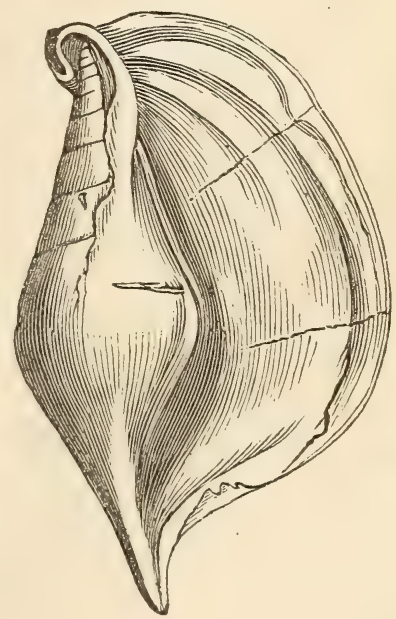

Rostellaria ampla, Brander. $\frac{1}{3}$ of nat. size; also found in the Barton clay.

Fig. 255.

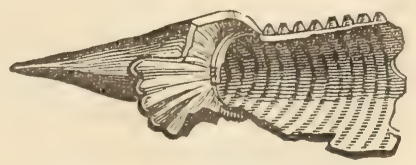

Belosepia sepioidea. De Blainv. London Clay. Sheppey.

* For description of Eocene Cephalopoda, see Monograph by F. E. Edwards, Palæontograph. Soc., 1849. 
Fig. 256.

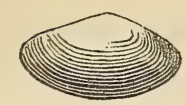

Leda amygdaloides. Highgate.
Fig. 257.

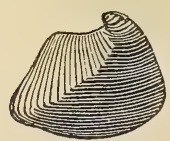

Cryptodon angulatum. London clay. Hornsea.
Fig. 258.

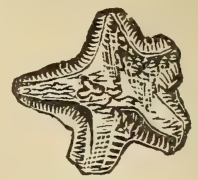

Astropecten crispatus.

E. Forbes. Sheppey.

These fossils are accompanied by a sword-fish (Tetrapterus priscus, Agassiz), about eight feet long, and a saw-fish (Pristis bisulcatus, Ag.), about ten feet in length; genera now foreign to the British seas. On the whole, no less than fifty species of fish have been described by M. Agassiz from these beds in Sheppey, and they indicate, in his opinion, a warm climate.

Strata of Kyson in Suffolk.-At Kyson, a few miles east of Woodbridge, a bed of Eocene clay, twelve feet thick, underlies the red crag. Beneath it is a deposit of yellow and white sand, of considerable interest, in consequence of many pecular fossils contained in it. Its geological position is probably the lowest part of the London clay proper. In this sand have been found remains of an opossum (Didelphys) (see fig. 259), and an insectivorous bat (fig. 260), together with many teeth of fishes of the shark family. Mr. Colchester, in 1840, obtained other mammalian relics from Kyson, among which Professor Owen has recognized several teeth of the genus Hyracotherium (fig. 261), and the vertebræ of a large serpent, probably a Palceophis.

Fig. 259.

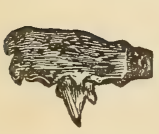

Fig. 260.

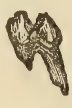

Molars of insectivorous bats, twice nat. size.

From Kyson, Suffolk.

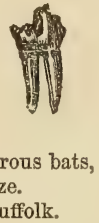

Fig. 261.

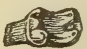

Molar of Hyracotherium.

As the remains both of the Hyracotherium and Palocophis were afterwards met with in the London clay, as before remarked, these fossils confirm the opinion previously entertained, that the Kyson sand belongs to the Lower Eocene period. A fossil lower jaw with teeth from the same bed was at first referred by Professor Owen, in 1840, to a monkey called Macacus eoccenus, and afterwards Eopithecus; but he has since (1862) retracted this opinion, and, on reëxamination, and with more ample materials at his command, has pronounced it to belong to a Hyracotherium. There is now, therefore, no Eocene monkey known to palæontologists unless M. Rütimeyer is right in referring to 
this family a small fragment of a jaw with three molar teeth, found in the Upper Eocene strata of the Swiss Jura.

Plastic or mottled clays and sands (C. 2, p. 281).- The clays called plastic, which lie immediately below the London clay, received their name originally in France from being often used in pottery. Beds of the same age (the Woolwich and Reading series of Prestwich) are used for the like purposes in England.*

No formations can be more dissimilar on the whole in mineral character than the Eocene deposits of England and Paris; those of our own island being almost exclusively of mechanical origin,-accumulations of mud, sand, and pebbles; while in the neighborhood of Paris we find a great succession of strata composed of limestones, some of them siliceous, and of crystalline gypsum and siliceous sandstone, and sometimes of pure flint used for millstones. Hence it is by no meaus an easy task to institute an exact comparison between the various members of the English and French series, and to settle their respective ages. It is clear that, on the sites both of Paris and London, a continual change was going on in the fauna and flora by the coming in of new species and the dying out of others; and contemporaneous changes of geographical conditions were also in progress in consequence of the rising and sinking of the land and bottom of the sea. A particular subdivision, therefore, of the time was occasionally represented in one area by land, in another by an estuary, in a third by the sea, and even where the conditions were in both areas of a marine character, there was often shallow water in one, and deep sea in another, producing the want of agreement in the state of animal life.

But in regard to that division of the Eocene series which we have now under consideration, we find an exception to the general rule, for, whether we study it in the basins of London, Hampshire, or Paris, we recognize everywhere the same mineral character. This uniformity of aspect must be seen in order to be fully appreciated, since the beds consist simply of mottled clays and sand, with lignite and well-rolled flint pebbles, derived from the chalk, and varying in size from that of a pea to an egg. These strata may be seen in the Isle of Wight in contact with the chalk, or in the London basin, at Reading, Blackheath, and Woolwich. In some of the lowest of them, banks of oysters are observed, consisting of Ostrea bellovacina, so common in France in the same relative position, and Ostrea edulina, scarcely distinguishable from the living eatable species. In the same beds at Bromley, Dr. Buckland found one large pebble to which five fullgrown oysters were affixed, in such a manner as to show that they had commenced their first growth upon it, and remained attached to it through life.

In several places, as at Woolwich on the Thames, at Newhaven in Sussex, and clsewhere, a mixture of marine and freshwater testacea

* Prestrich, Waterbearing Strata of London, 1851. 
distinguishes this member of the series. Among the latter, Melania inquinata (see fig. 263) and Cyrena cuneiformis (see fig. 262) are very

Fig. 262.
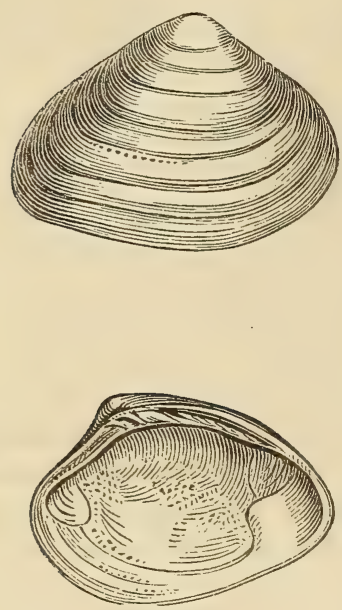

Cyrena cuneiformis, Min. Con. Natural size.
Fig. 263.

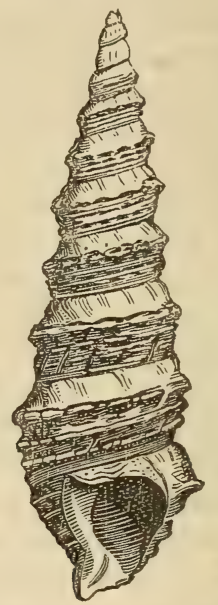

Melania inquinata, Des. Nat, size. Syn. Cerithium melanoides, Min Con.

common, as in beds of corresponding age in France. They clearly indicate points where rivers entered the Eocene sea. Usually there is a mixture of brackish freshwater, and marine shells, and sometimes, as at Woolwich, proofs of the river and the sea having successively prevailed on the same spot. At New Charlton, in the suburbs of Woolwich, M. de la Condamine discovered in 1849 , and pointed out to me, a layer of sand associated with well-rounded flint pebbles in which numerous individuals of the Cyrena tellinella were seen standing endwise with both their valves united, the posterior extremity of each shell being uppermost, as would happen if the mollusks had died in their natural position. I have described * a bank of sandy mud, in the delta of the Alabama River at Mobile, on the borders of the Gulf of Mexico, where in $1846 \mathrm{I}$ dug out at low tide specimens of living species of Cyrena and of a Gnathodon, which were similarly placed with their shells erect, or in a position which enables the animal to protrude its siphon upwards and draw in or reject water at pleasure. The water at Mobile is usually fresh, but sometimes brackish. At Woolwich a body of river-water must have flowed permanently into the sea where the Cyrence lived, and they may have been killed suddenly by an influx of pure salt water, which invaded the spot when the river was low, or when a subsidence of land took place. Traced in one direction, or eastward toward Herne Bay, the Woolwich beds 
assume more and more of a marine character ; while in an opposite, or south-western direction, they become, as near Chelsea and other places, more freshwater, and contain Unio, Paludina, and layers of lignite, so that the land drained by the ancient river seems clearly to have been to the south-west of the present site of the metropolis.

Before the minds of geologists had become familiar with the theory of the gradual sinking of the land, and its conversion into sea at different periods, and the consequent change from shallow to deep water, the freshwater and littoral character of this inferior group appeared strange and anomalous. After passing through hundreds of feet of London clay, proved by its fossils to have been deposited in deep salt water, we arrive at beds of fluviatile origin, and in the same underlying formation masses of shingle, attaining at Blackheath, near London, a thickness of 50 feet, indicate the proximity of land, where the flints of the chalk were rolled into sand and pebbles, and spread continuously over wide spaces. Such shingle always appears at the bottom of the series, whether in the Isle of Wight, or in the Hampshire or London basins. It may be asked why they did not constitute simple narrow littoral zones, such as we might look for on an ancient seashore. In reply Mr. Prestwich has suggested that such zones of shingle may have been slowly formed on a large scale at the period of the Thanet sands (C. 3, p. 281), and while the land was sinking the well-rolled pebbles may have been dispersed simultaneously over considerable areas, and exposed during gradual submergence to the action of the waves of the sea, aided occasionally by tidal currents and river floods.

Thanet sands (C. 3, p. 281).-The mottled or plastic clay of the Isle of Wight and Hampshire is often seen in actual contact with the chalk, constituting in such places the lowest member of the British Eocene series. But at other points another formation of marine origin, characterized by a somewhat different assemblage of organic remains, has been shown by Mr. Prestwich to intervene between the chall and the Woolwich series. For these beds he has proposed the name of "Thanet Sands," because they are well seen in the Isle of Thanet, in the northern part of Kent, and on the seacoast between Herne Bay and the Reculvers, where they consist of sands with a few concretionary masses of sandstone, and contain among other fossils Pholadomya cuneata, Cyprina Morrisii, Corbula longirostris, Scalaria Bowerbankii, \&c. The greatest thickness of these beds is about 90 feet.

GENERAL TABLE OF FRENCH EOCENE STRATA.

UPPER EOCENE.

French subdivisions.

A. 1. Gypseous series of Montmartre.

A. 2. Calcaire silicieux, or Travertin Inférieur.
English equivalents.

1. Bembridge series, p. 281.

2. Osborne and Headon series, p. 284. 
A. 3. Grès de Beauchamp, or Sables Moyens.
3. White sand and clay of Barton Cliff, Hants.

MIDDLE EOCENE.

B. 1. Calcaire Grossier.

B. 2. Soissonnais Sands, or Lits Coquilliers.
1. Bagshot and Bracklesham beds.

2. Wanting.

LOWER EOCENE.

C. 1. Argile de Londres at base of Hill of Cassel, near Dunkirk.

C. 2. Argile plastique and lignite.

C. 3. Sables de Bracheux.
1. London Clay.

2. Plastic clay and sand with lignite (Woolwich and Reading series).

3. Thanet sands.

The tertiary formations in the neighborhood of Paris consists of a series of marine and freshwater strata, alternating with each other, and filling up a depression in the chalk. The area which they occupy has been called the Paris basin, and is about 180 miles in its greatest length from north to south, and about 9.0 miles in breadth from east to west (see Map, p. 221). MM. Cuvier and Brongniart attempted, in 1810, to distinguish five different groups, comprising three freshwater and two marine, which were supposed to imply that the waters of the ocean, and of rivers and lakes, had been by turns admitted into and excluded from the same area. Investigations since made in the Hampshire and London basins have rather tended to confirm these views, at least so far as to show that since the commencement of the Eocene period there have been great movements of the bed of the sea, and of the adjoining lands, and that the superposition of deep sea to shallow water deposits (the London clay, for example, to the Woolwich beds) can only be explained by referring to such movements. Nevertheless, it appears, from the researches of M. Constant Prévost, that some of the minor alternations and intermixtures of freshwater and marine doposits, in the Paris basin, may be accounted for by imagining both to have been simultaneously in progress, in the same bay of the same sea, or a gulf into which many rivers entered.

Gypseous series of Montmartre.-To enlarge on the numerous subdivisions of the Parisian strata would lead me beyond my present limits; I shall therefore give some examples only of the most important formations enumerated in the foregoing Table.

Beneath the Grès de Fontainebleau, often called "Upper marine sands," and belonging to the Lower Miocene, as before stated, we find, in the neighborhood of Paris, a series of white and green marls, with subordinate beds of gypsum, A., Table, p. 297. These are most largely developed in the central parts of the Paris basin, and, among other places, in the hill of Montmartre, where its fossils were first studied by Cuvier.

The gypsum quarried there for the manufacture of plaster of Paris 
occurs as a granular crystalline rock, and together with the associated marls, contains land and fluviatile shells, together with the bones and skeletons of birds and quadrupeds. Several landplants are also met with, among which are fine specimens of the fan palm or palmetto tribe (Flabellaria). The remains also of freshwater fish, and of crocodiles and other reptiles, occur in the gypsum. The skeletons of mammalia are usually isolated, often entire, the most delicate extremities being preserved; as if the carcases, slothed with their flesh and skin, had been floated down soon after death, and while they were still swollen by the gases generated by their first decomposition. The few accompanying shells are of those light kinds which frequently float on the surface of rivers, together with wood.

M. Prévost has therefore suggested that a river may have swept away the bodies of animals, and the plants which lived on its borders, or in the lakes which it traversed, and may have carried them down into the centre of the gulf into which flowed the waters impregnated with sulphate of lime. We know that the Fiume Salso in Sicily enters the sea so charged with various salts that the thirsty cattle refise to drink of it. A stream of sulphureous water as white as milk, descends into the sea from the volcanic mountain of Idienne on the east of Java; and a great body of hot water, charged with sulphuric acid, rushed down from the same volcano on one occasion, and inundated a large tract of country, destroying, by its noxious properties, all the vegetation.* In like manner the Pusanibio, or "Vinegar River," of Columbia, which rises at the foot of Puracé, an extinct volcano, 7500 feet above the level of the sea, is strongly impregnated with sulphuric and hydrochloric acids and with oxide of iron. We may easily suppose the waters of such streams to have properties noxious to marine animals, and in this manner the entire absence of marine remains in the ossiferous gypsum may be explained. $\uparrow$ There are no pebbles or coarse sand in the gypsum; a circumstance which agrees well with the hypothesis that these beds were precipitated from water holding sulphate of lime in solution, and floating the remains of different animals.

In this formation the relics of about fifty species of quadrupeds, including the genera Paleotherium (see fig. 220), Anoplotherium (see fig. 219), and others, have been found, all extinct, and nearly fourfifths of them belonging to the Perissodactyle or odd-toed division of the order Pachydermata, which now contains only four living genera, namely, rhinoceros, tapir, horse, and hyrax. With them a few carnivorous animals are associated, among which are the Hyonodon dasyuroides, a species of dog, Canis Parisiensis, and a weasel, Cynodon Parisiensis. Of the Rodentia are found a squirrel; of the

* Leyde Magaz. voor Wetensch. Konst en Lett., partie v. cahier i. p. 71. Cited by Rozet, Journ. de Géologie, tom. i. p. 43.

† M. C. Prévost, Submersions Itératives, \&c. Note 23. 
Cheiroptera, a bat; while the Marsupialia (an order now confined to America, Australia, and some contiguous islands) are represented by an opposum.

Of birds, about ten species have been ascertained, the skeletons of some of which are entire. Nonc of them are referable to existing species.* The same remark applies to the fish, according to MM. Cuvier and Agassiz, as also to the reptiles. Among the last are crocodiles and tortoises of the genera Emys and Trionyx.

The tribe of land quadrupeds most abundant in this formation is such as now inhabits alluvial plains and marshes, and the banks of rivers and lakes, a class most exposed to suffer by river inundations. Among these were several species of Paleotherium, a genus before alluded to (p. 283). These were associated with the Anoplotherium, a tribe intermediate between pachyderms and ruminants. One of the three divisions of this family was called by Cuvier Xiphodon. Their forms were slender and elegant, and one, named Xiphodon gracile (fig. 264), was about the size of the chamois ; and Cuvier in-

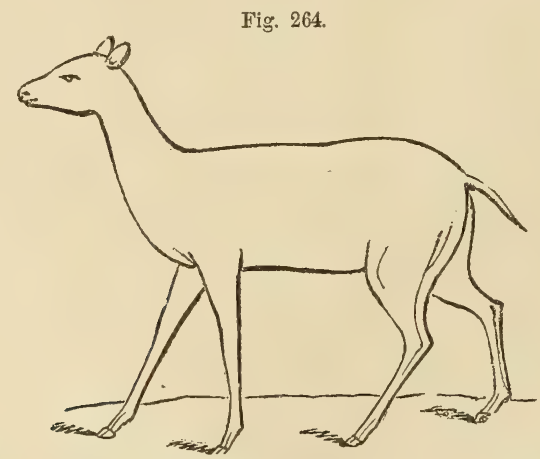

Xiphodon gracile, or Anoplotherium gracile, Cuvier. Restored outline.

ferred from the skeleton that it was as light, graceful, and agile as the gazelle.

When the French osteologist declared, in the early part of the present century, that all the fossil quadrupeds of the gypsum of Paris were extinct, the announcement of so startling a fact, on such high authority, created a powerful sensation, and from that time a new impulse was given throughout Europe to the progress of geological investigation. Eminent nuturalists, it is true, had long before maintained that the shells and zoophytes met with in many ancient European rocks had ceased to be inhabitants of the earth, but the majority even of the educated classes continued to believe that the species of animals and plants, now contemporary with man, were the same as those which been called into being when the planet itself was created.

* Cuvier, Oss. Foss., tom. iii. p. 255. 
It was easy to throw discredit upon the new doctrine by asking whether corals, shells, and other creatures previously unknown, were not annually discovered? and whether living forms corresponding with the fossils might not yet be dredged up from seas hitherto unexamined? But from the era of the publication of Cuvier's "Ossements Fossiles," and still more his popular Treatise called "A Theory of the Earth," sounder riews began to prevail. It was clearly demonstrated that most of the mammalia found in the gypsum of Montmartre differed eren generically from any now known to exist, and the extreme improbability that any of them, especially the larger ones, would ever be found surriring in continents yet unexplored, was made manifest. Moreover, the non-admixture of a single living species in the midst of so rich a fossil fauna was a striking proof that there had existed in that region a state of the earth's surface zoologically unconnected with the present.

Fossil footprints. - There are three superimposed masses of gypsum in the neighborhood of Paris, separated by intervening deposits of laminated marl. In the uppermost of the three in the valley of Montmorency M. Desnoyers discovered in 1859 many footprints of animals occurring at no less than six different levels.* The gypsum to which they belong raries from thirty to fifty feet in thickness, and is that which has yielded to the naturalist the largest number of bones and skeletons of mammalia, birds, and reptiles. I visited the quarries, soon after the discovery was made known, with M. Desnoyers, who also showed me large slabs in the Museum at Paris, where, on the upper planes of stratification, the indented footmarks were seen, while corresponding casts in relief appeared on the lower surfaces of the strata of gypsum which were immediately superimposed. A thin film of marl, which before it was dried and condensed by pressure must have represented a much thicker layer of soft mud, intervened between the beds of solid gypsum. On this mud the animals had trodden, and made impressions which had penetrated to the gypseous mass below, then evidently unconsolidated. Tracks of the Anoplotherium with its bisulcate hoof, and the trilobed footprints of Paleotherium, were seen of different sizes, corresponding to those of several species of these genera which Curier had reconstructed, while in the the same beds were footmarks of carnivorous mammalia. The tracks also of fluriatile, lacustrine, and terrestrial tortoises (Emys, Trionyx, \&c.), hare been discorered, also those of crocodiles, iguanas, geckos, and great batrachians, and the footprints of a huge bird, apparently a wader, of the size of the gastornis, to be mentioned in the sequel. There were likerrise impressions of the feet of other creatures, some of them clearly distinguishable from any of the fifty cxtinct types of mammalia, of which the bones have been found in the Paris gypsum.

* Sur des Empreintes de Pas d'Animaux, par M. J. Desnoyers. Compte Rendu de l'Institut, 1859. 
The whole assemblage, says Desnoyers, indicate the shores of a lake, or several small lakes communicating with each other, on the borders of which many species of Pachyderms wandered, and beasts of prey which occasionally devoured them. The toothmarks of these last had been detected by palæontologists lung before on the bones and skulls of Paleotheres entombed in the gypsum.

These footmarks have revealed to us new and unexpected proofs that the air-breathing fauna of the Upper Eocene period in Europe far surpassed in the number and variety of its species the largest estimate which had previously been formed of it. We may now feel sure that the mammalia, reptiles, and birds, which have left portions of their skeletons as memorials of their existence in the solid gypsum, constituted but a part of the then living creation. Similar inferences may be drawn from the study of the whole succession of geological records. In each district the monuments of periods embracing thousands, and probably in some instances millions of years, are totally wanting. Even in the volumes which are extant the greater number of the pages are missing in any given region, and where they are found they contain but few and casual entries of the physical events or living beings of the times to which they relate. It may also be remarked that the subordinate formations met with in two neighboring countries, such as France and England (the minor Tertiary groups above enumerated), commonly classed as equivalents and referred to corresponding periods, may nevertheless have been by no means strictly coincident in date. Though called contemporaneous, it is probable that they were often separated by intervals of hundreds of thousands of years. We may compare them to double stars, which appear single to the naked eye because seen from a vast distance in space, and which really belong to one and the same stellar system though occupying places in space extremely remote if estimated by our ordinary standard of terrestrial measurements.

Calcaire siliceux, or Travertin inférieur (A. 2, p. 297).-This compact siliceous limestone extends over a wide area. It resembles a precipitate from the waters of mineral springs, and is often traversed by small empty sinuous carities. It is, for the most part, devoid of organic remains, but in some places contains freshwater and land species, and never any marine fossils. The calcaire siliceux and the calcaire grossier usually occupy distinct parts of the Paris basin, the one attaining its fullest development in those places where the other is of slight thickness. They are described by some writers as alternating with each other toward the centre of the basin, as at Sergy and Osny.

The gypsum, with its associated marls before described, is in greatest force toward the centre of the basin, where the calcaire grossier and calcaire siliceux are less fully developed.

Grès de Beauchamp, or Sables moyens (A. 3, p. 298).-In some parts of the Paris basin, sands and marls, called the Grès de Beauchamn, or 
Sables moyens, divide the gypseous beds from the calcaire grossier proper. These sands, in which a small nummulite $(N$. variolaria $)$ is very abundant, contain more than 300 species of marine shells, many of them peculiar, but others common to the next division.

Calcaire grossier, upper and middle (B. 1, p. 298).-The upper division of this group consists in great part of beds of compact, fragile limestone, with some intercalated green marls. The shells in some parts are a mixture of Cerithium, Cyclostoma, and Corbula; in others Limnea, Cerithium, Paludina, \&c. In the latter, the bones of reptiles and mammalia, Paleotherium and Lophiodon, have been found. The middle division, or calcaire grossier proper, consists of a coarse limestone, often passing into sand. It contains the greater number of the fossil shells which characterize the Paris basin. No less than 400 distinct species have been procured from a single spot near Grignon, where they are embedded in a calcareous sand, chiefly formed of comminuted shells, in which, nevertheless, individuals in a perfect state of preservation, both of marine, terrestrial, and freshwater species, are mingled togethei. Some of the marine shells may have lived on the spot; but the Cyclostoma and Limnea must have been brought thither by rivers and currents, and the quantity of triturated shells implies considerable movement in the waters.

Nothing is more striking in this assemblage of fossil testacea than the great proportion of species referable to the genus Cerithium (see figures, p. 240). There occur no less than 137 species of this genus in the Paris basin, and almost all of them in the calcaire grossier. Most of the living Cerithia inhabit the sea near the mouths of rivers, where the waters are brackish; so that their abundance in the marine strata now under consideration is in harmony with the hypothesis that the Paris basin formed a gulf into which several rivers flowed.

In some parts of the calcaire grossier round Paris, certain beds occur of a stone used in building, and called by the French geologists

Fig. 265 .

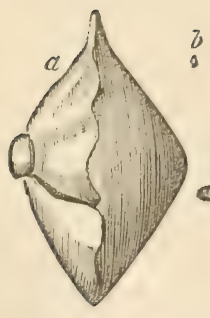

Calcarina rarispina, Desh. b. Natural size. $a, c$. Same magnified.
Fig. 266.

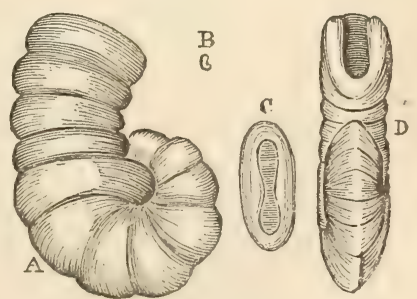

Spirolina stenostoma, Desh.

B. Natural eize. A, C, D. Same magnified. 
Fig. 267.
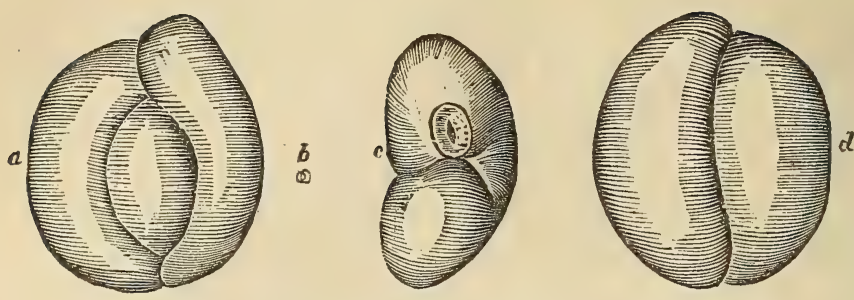

Triloculina inflata, Desh.

$b$. Natural size. $a, c, d$. Same magnified.

Fig. 268.
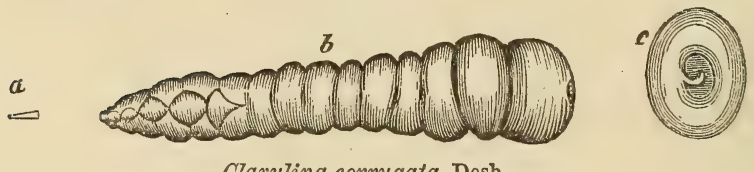

Clavulina corrugata, Desh.

a. Natural size. $b, c$. Same magnified.

"Miliolite limestone." It is almost entirely made up of millions of microscopic shells, of the size of minute grains of sand, which all belong to the class Foraminifera. Figures of some of these are given in the annexed woodcut. As this miliolitic stone never occurs in the Faluns, or Upper Miocene strata of Brittany and Touraine, it often furnishes the geologist with a useful criterion for distinguishing the detached Eocene and Miocene formations scattered over those and other adjoining provinces. The discovery of the remains of Paleotherium and other mammalia in some of the upper beds of the calcaire grossier shows that these land animals began to exist before the deposition of the overlying gypseous series had commenced.

Lower Calcaire grossier, or Glauconie grossière (B. 1, p. 298).-The lower part of the calcaire grossier, which often contains much green earth, is characterized at Auvers, near Pontoise, to the north of Paris, and still more in the environs of Compiegne, by the abundance of nummulites, consisting chiefly of $N$. lcevigata, $N$. scabra, and $N$. Lamarcki, which constitute a large proportion of some of the stony strata, though these same foraminifera are wanting in beds of similar age in the immediate environs of Paris.

Soissonnais sands, or Lits coquilliers (B. 2, p. 298).-Below the preceding formation, shelly sands are seen, of considerable thickness, especially at Cuisse-Lamotte, near Compiegne, and other localities in the Soissonnais, about fifty mles N. E. of Paris, from which about 300 species of shells have been obtained, many of them common to the calcaire grossier and the Bracklesham beds of England, and many peculiar. The Nummulites planulata is very abundant, and the most characteristic shell is the Nerita conoidea, Lam., a fossil which has a very wide geographical range; for, as M. d'Archiac remarks, 
Fig. 269.
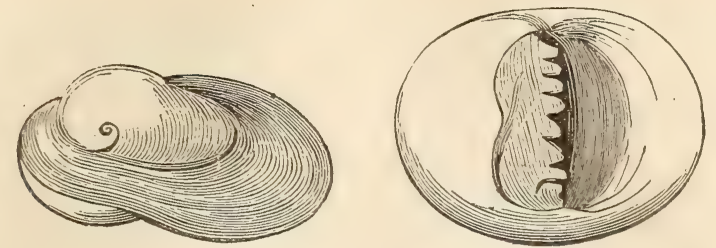

Nerita conoidea, Lam.

Syn. N. Schmidelliana, Chemnitz.

it accompanies the nummulitic formation from Europe to India, having been found in Cutch, near the mouths of the Indus, associated with Nummulites scabra. No less than 33 shells of this group are said to be identical with shells of the London clay proper, yet, after risiting Cuisse-Lamotte and other localities of the "Sables inférieurs" of Archiac, I agree with Mr. Prestwich, that the latter are probably newer than the London clay, and perhaps older than the Bracklesham beds of England. The London clay seems to be unrepresented in the Paris basin, unless partially so, by these sands.* One of the shells of the sandy beds of the Soissonnais is adduced by M. Deshayes as an example of the changes which certain species underwent in the successive stages of their existence. It seems that different varieties of the Cardium porulosum are characteristic of different formations.

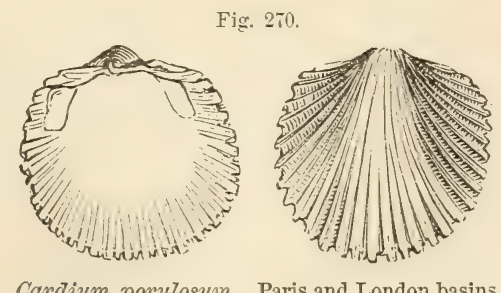

Cardium porulosum. Paris and London basins.

In the Soissonnais this shell acquires but a small volume, and has many peculiarities, which disappear in the lowest beds of the calcaire grossier. In these the shell attains its full size, with many distinctive characters, which are again modified in the uppermost beds of the calcaire grossier; and these last modifications of form are preserved throughout the "upper marine" (or Lower Miocene) series.

LOWER EOCENE FORMATIONS OF FRANCE.

Argile plastique (C. 2, p. 298).-At the base of the tertiary system in France are extensive deposits of sands, with occasional beds of clay

* D'Archiac, Bulletin, tom. x. ; and Prestwick, Geol. Quart. Journ., 1847, p. 377.

+ Coquilles caractéristiques des Terrains, 1831. 
used for pattery, and called "argile plastique." Fossil oysters (Ostrea bellovacina) abound in some places, and in others there is a mixture of fluviatile shells, such as Cyrena cuneiformis (fig. 262, p. 296), Melania inquinata (fig. 263), and others, frequently met with in beds occupying the same position in the valley of the Thames. Layers of lignite also accompany the inferior clays and sands.

Immediately upon the chalk at the bottom of all the tertiary strata in France there generally is a conglomerate or breccia of rolled and angular chalk-flints, cemented by cilicious sand. These beds appear to be of littoral origin, and imply the previous emergence of the chalk, and its waste by denudation. In the year 1855, the tibia and femur of a large bird equalling at least the ostrich in size were found at Meudon, near Paris, at the base of the Plastic clay. This bird, to which the name of Gastornis Parisiensis has been assigned, appears, from the Memoirs of MM. Hébert, Lartet, and Owen, to belong to an extinct genus. Professor Owen refers it to the class of wading land birds rather than to an aquatic species.*

That a formation so much explored for economical purposes as the Argile Plastique around Paris, and the clays and sands of corresponding age near London, should never have afforded any vestige of a feathered biped previously to the year 1855 , shows what diligent search and what skill in osteological interpretation are acquired before the existence of birds of remote ages can be proved by more decisive evidence than their footprints.

Sables de Bracheux (C. 3, p. 298).-The marine sands called the Sables de Bracheux (a place near Beauvais), are considered by M. Hébert to be older than the Lignites and Plastic clay, and to concide in age with the Thanet Sands of England. At La Fère, in the Department of the Aisne, in a deposit of this age, a fossil skull has been found of a quadruped called by Blainville Arctocyon primoevus, and supposed by him to be related both to the bear and to the Kinkajou (Cercoleptes). This creature appears to be the oldest known tertiary mammifer.

Nummulitic formation of Europe, Asia, \&c.-When I visited Belgium and French Flanders in 1851, with a view of comparing the tertiary strata of those countries with the English series, I found that all the beds between the Lower Miocene or Limburg formations and the Lower Eocene or London clay proper, might be conveniently divided into three sections, distinguished, among other palæontological characters, by three different species of nummulities, $N$. variolaria in upper beds, $N$. lcevigata in the middle, and $N$. planulata in the lower. After I had adopted this classification, I found, what I had overlooked or forgotten, that the superposition of these three species in the order here assigned to them had been previously recognized in the North of France, in 1842, by Viscount d'Archiac. The same author, in

* Quart. Geol. Journ., vol. xii. p. 204, 1856. 
the valuable monograph published by him in $1853, *$ has observed that a somewhat similar distribution of these and other species in time, prevails very widely in the South of France and in the Pyrenees, as well as in the Alps and Apennines, and in Istria-the lowest nummulitic beds being characterized by fewer and smaller species, the middle by a greater number and by those which individually attain the largest dimensions, and the uppermost beds again by small species.

In the treatise alluded to, M. d'Archiac describes no less than fiftytwo species of this genus, and considers that they are all of them characteristic of those tertiary strata which I have called Middle Eocene. In very few instances at least do certain species diverge from this narrow limit, whether into incumbent or subjacent tertiary formations, one or two species only, of which Nummulites intermedia, also a Middle Eocene form, is an example, ascend into the Lower Miocene, but it seems doubtful whether any of them descend to the level of the London clay. Certainly they have never been traced so low down as the marine beds, coeval with the Plastic clay or Lignite, in any country of which the geology has been well worked out. This conclusion is a very unexpected result of recent inquiry, since for many years it was a matter of controversy whether the nummulitic rocks of the Alps and Pyrenees ought not to be regarded as cretaceous rather than Eocene. The late M. Alex. Brongniart first declared the specific identity of many shells of the marine Eocene strata near Paris, and those of the nummulitic formation of Switzerland, although he obtained these last from the summit of the Diablerets, one of the loftiest of the Swiss Alps, which rises more than 10,000 feet above the level of the sea.

The nummulitic limestone of the Alps is often of great thickness, and is immediately covered by another series of strata of dark-colored slates, marls, and fucoidal sandstones, to the whole of which the provincial name of "flysch" has been given in parts of Switzerland. The researches of Sir Roderick Murchison in the Alps in 1847 have shown that all these tertiary strata enter into the disturbed and loftiest portion of the Alpine chain, to the upheaval of which they enable us therefore to assign a comparatively modern date.

The nummulitic formation, with its characteristic fossils, plays a far more conspicuous part than any other tertiary group in the solid framework of the earth's crust, whether in Europe, Asia, or Africa. It often attains a thickness of many thousand feet, and extends from the Alps to the Carpathians, and is in full force in the north of Africa, as, for example, in Algeria and Morocco. It has also been traced from Egypt, where it was largely quarried of old for the building of the Pyramids, into Asia Minor, and across Persia by Bagdad to the mouths of the Indus. It occurs not only in Cutch, but in the 
mountain ranges which separate Scinde from Persia, and which form the passes leading to Caboul; and it has been followed still farther eastward into India, as far as eastern Bengal and the frontiers of China.

Fig. 271.

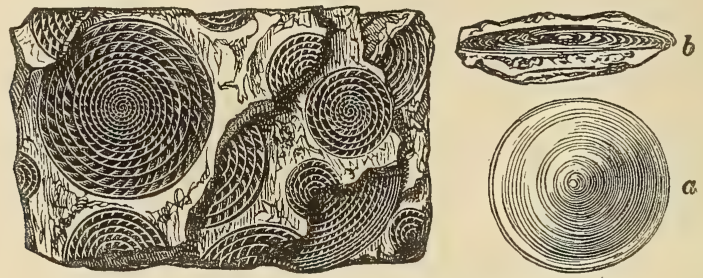

Nummulites Puschi, D'Archiac. Peyrehorade, Pyrenees.

a. External surface of one of the nummulites, of which longitudinal sections are seen in the limestone.

b. Transverse section of same.

Dr. T. Thompson found nummulites at an elevation of no less than 16,500 feet above the level of the sea, in Western Thibet.

One of the species, which I myself found very abundant on the

Fig. 272 .

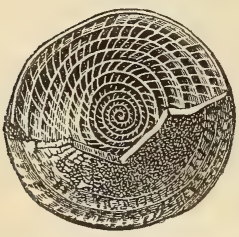

Nummutites exponens.

Sow. Europe and Asia. flanks of the Pyrenees, in a compact crystalline marble (fig. 271), is called by M. d'Archiac Nummulites Puschi. The same is also very common in rocks of the same age in the Carpathians.

Another large species (see fig. 272), Nummulites exponens, J. Sow., occurs not only in the South of France, near Dax, but in Germany, Italy, Asia Minor, and in Cutch ; also in the mountains of Sylhet, on the frontiers of China.

In many of the distant countries above alluded to, in Cutch, for example, some of the same shells, such as Nerita conoidea (fig. 269), accompany the nummulites, as in France.

The opinion of many observers, that the Nummulitic formation belongs partly to the cretaceous era, seems chiefly to have arisen from confounding an allied genus, Orbitoides, with the true Nummulite.

When we have once arrived at the conviction that the nummulitic formation occupies a middle place in the Eocene series, we are struck with the comparatively modern date to which some of the greatest revolutions in the physical geography of Europe, Asia, and Northern Africa must be referred. All the mountain chains, such as the Alps, Pyrenees, Carpathians, and Himalayas, into the composition of whose central and loftiest parts the nummulitic strata enter bodily, could have had no existence till after the Middle Eocene period. During that period the sea prevailed where these chains now rise, for num- 
mulites and their accompanying testacea were unquestionably inhabitants of salt water. Before these events, comprising the conversion of a wide area from a sea to a continent, England had been peopled, as I before pointed out (p. 294), by various quadrupeds, by herbivorous pachyderms, by insectivorous bats, and by opossums.

Almost all the extinct volcanoes which preserve any remains of their original form, or from the craters of which lava streams can be traced, are more modern than the Eocene fauna now under consideration; and besides these superficial monuments of the action of heat, Plutonic influences have worked vast ehanges in the texture of rocks within the same period. Some members of the nummulitic and overlying tertiary strata called flysch have actually been converted in the central Alps into crystalline rocks, and transformed into marble, quartz-rock, mica-schist, and gneiss.*

\section{EOCENE STRATA IN THE UNITED STATES.}

In North America the Eocene formations occupy a large area bordering the Atlantic, which increases in breadth and importance as it is traced southward from Delaware and Maryland to Georgia and Alabama. They also occur in Louisiana and other States both east and west of the valley of the Mississippi. At Claiborne in Alabama, no less than four hundred species of marine shells, with many echinoderms and teeth of fish, characterize one member of this system. Among the shells, the Cardita planicosta, before mentioned (fig. 235, p. 288), is in abundance; and this fossil and some others identical with European species, or very nearly allied to them, make it highly probable that the Claiborne beds agree in age with the central or Bracklesham group of England, and with the calcaire grossier of Paris. $\uparrow^{-}$

Higher in the series is a remarkable calcareous rock, formerly called "the nummulite limestone," from the great number of discoid bodies resembling nummulites which it contains, fossils now referred by A. d'Orbigny to the genus Orbitoides, which has been demonstrated by Dr. Carpenter to belong to the foraminifera. That naturalist, moreover, is of opinion that the Orbitoides alluded to $(O$. Mantelli) is of the same species as one found in Cutch in the Middle Eocene or nummulitic formation of India. The following section will enable the reader to understand the position of three subdivisions of the Eocene series, Nos. 1, 2, and 3, the relations of which I

\footnotetext{
* Murchison, Quart. Journ. of Geol. Soc., vol. v., and Lyell, vol. vi., 1850. Anniversary Address.

+ See paper by the Author, Quart. Journ. Geol. Soc., vol. iv. p. 12 ; and Second Visit to the U. S., vol. ii. p. 59.

$\ddagger$ Quart. Journ. Geol. Soc., vol. vi. p. 32.
} 
ascertained in Clarke County, between the rivers Alabama and Tombeckbee.

The lowest set of strata, No. 1, having a thickness of more than 100 feet, comprise marly beds, in which the Ostrea sellofformis occurs, a shell ranging from Alabama to Virginia, and being a representative form of the Ostrea flabellula of the Eocene group of Europe. In other beds of No. 1, two European shells, Cardita planicosta, before mentioned, and Solarium canaliculatum, are found with a great many other species peculiar to America. Numerous corals also, and the remains of placoid fish and of rays, occur, and the "swords" (fig. 237, p. 289), as they are called, of sword-fishes, all bearing a great generic likeness to those of the Eocene strata of England and France.

No. 2 (fig. 273) is a white limestone, sometimes soft and argilla

Fig. 273.

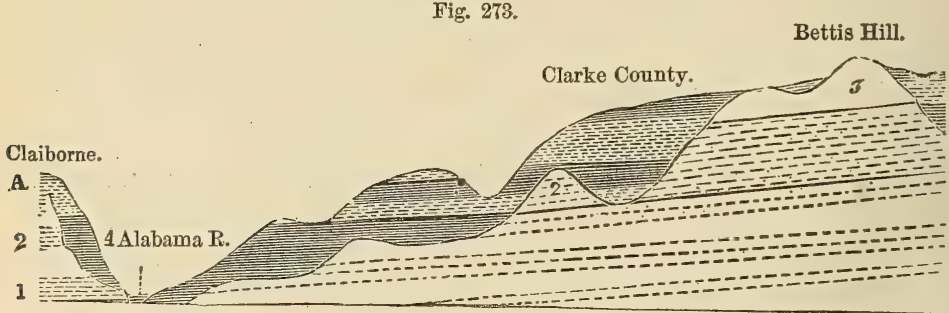

1. Sand, marl, \&c., with numerous fossils.

2. White or rotten limestone, with Zeuglodon. $\}$ Eocene.

3. Orbitoidal, or so-called nummulitic limestone.

4. Overlying formation of sand and clay without fossils. Age unknown.

ceous, but in parts very compact and calcareous. It contains several peculiar corals, and a large nautilus allied to $N$. ziczac; also in its upper bed a gigantic cetacean, called Zeuglodon by Owen.*

The colossal bones of this cetacean are so plentiful in the interior of Clarke County as to be characteristic of the formation. The vertebral column of one skeleton found by Dr. Buckley at a spot visited by me, extended to the length of nearly 70 feet, and not far off part of another backbone nearly 50 feet long was dug up. I obtained. evidence, during a short excursion, of so many localities of this fossil animal within a distance of 10 miles, as to lead me to conclude that they must have belonged to at least forty distinct individuals.

Professor Owen first pointed out that this huge animal was not reptilian, since each tooth was furnished with double roots (see fig. 274), implanted in corresponding double sockets; and his opinion of the cetacean nature of the fossil was'afterwards confirmed by Dr. Wyman and Dr. R. W. Gibbes. That it was an extinct mammal of the whale tribe has since been placed beyond all doubt by the discovery of the entire skull of another fossil species of the same family, having the

* See paper by R. W. Gibbes, Journ. of Acad. Nat. Sci. Philad., vol. i., 1847. 


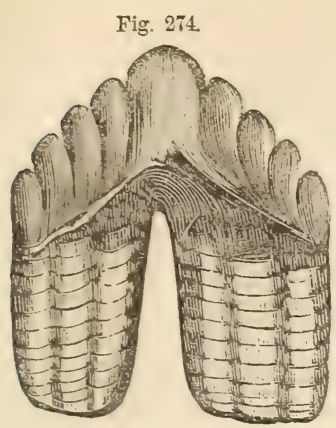

Fig. 275 .

\section{Zeuglodon cetoides, Owen.}

Basilosaurus, Harlan.

Fig. 274, Molar tooth, natural size.

Fig. 275. Vertebra, reduced.

double occipital condyles only met with in mammals, and the convoluted tympanic bones which are characteristic of cetaceans.

Near the junction of No. 2 and the incumbent limestone, No. 3, next to be mentioned, are strata characterized by the following shells: Spondylus dumosus (Plagiostoma dumosum, Morton), Pecten Poulsoni, Pecten perplanus, and Ostrea cretacea.

No. 3 (fig. 273 ) is a white limestone, for the most part made up of the Orbitoides of D'Orbigny before mentioned (p. 309), formerly supposed to be a nummulite, and called $N$. Mantelli, mixed with a few lunulites, some small corals, and shells.* The origin, therefore, of this cream-colored soft stone, like that of our white chalk, which it much resembles, is, I believe, due to the decomposition of these foraminifera. The surface of the country where it prevails is sometimes marked by the absence of wood, like our chalk downs, or is covered exclusicely by the Juniperus Virginiana, as certain chalk districts in England by the yew tree and juniper.

Some of the shells of this limestone are common to the Claiborne beds, but many of them are peculiar.

It will be seen in the section (fig. 273, p. 310) that the strata Nos. 1, 2, 3 are, for the most part, overlaid by a dense formation of sand or clay without fossils. In some points of the bluff or cliff of the Alabama Rirer, at Claiborne, the beds Nos. 1, 2 are exposed nearly from top to bottom, whereas at other points the newer formation, No. 4 , occupies the face of nearly the whole cliff. The age of this overlying mass has not yet besn determined, as it has hitherto proved destitute of organic remains.

The burr-stone strata of the Southern States contain so many fossils agreeing with those of Claiborne, that it doubtless belongs to the same part of the Eocene group, though I was not fortunate enough to see the relations of the two deposits in a continuous sec- 
tion. Mr. Tuomey considers it as the lower portion of the series. It may, perhaps, be a form of the Claiborne beds in places where lime was wanting, and where silex, derived from the decomposition of felspar, predominated. It consists chiefly of slaty clays, quartzose sands, and loam, of a brick-red color, with layers of cellular chert or burr-stone, used in some places for mill-stones.

\section{CHAPTER XVII.}

\section{R E T A C E O U G RO U P.}

Lapse of time between the Cretaceous and Eocene periods-Whether certain formations in Belgium and France are of intermediate age-Pisolitic limestone-Divisions of the Cretaceous series in North-Western Europe-Maestricht beds-Chalk of Faxoe-White chalk-Its geographical extent and origin-Formed in an open and deep sea-How far derived from shells and corals-A similar rock now in progress in the depths of the Atlantic made up of Globigerinæ-Origin of Flint in Chalk-Siliceous Diatomaceæ of the Atlantic-By what intermitteut action the alternate layers of white chalk and flint may have been caused-Potstones of Horstead-Isolated pebbles of quartz and foreign rocks in chalkFossils of the Upper Cretaceous rocks-Echinoderms, Mollusca, Bryozoa, Sponges-Upper Greensand and Gault-Blackdown beds-Flora of the Upper Cretaceous period-Fossil plants of Aix-la-Chapelle-Large proportion of Dicotyledonous Angiosperms-Their coexistence with large extinct genera of reptiles -Chalk of South of Europe-Hippurite limestone-Cretaceous rocks of the United States.

HAVING treated in the preceding chapters of the tertiary strata, we have next to speak of the uppermost of the secondary groups, commonly called the chalk or the cretaceous strata, from creta, the Latin name for that remarkable white earthy limestone, which constitutes an upper member of the group in those parts of Europe where it was first studied. The marked discordance in the fossils of the tertiary, as compared with the cretaceous formations, has long induced many geologists to suspect that an indefinite series of ages elapsed between the respective periods of their origin: Measured, indeed, by such a standard, that is to say, by the amount of change in the Fauna and Flora of the earth effected in the interval, the time between the Cretaceous and Eocene may have been as great as that between the Eocene and Recent periods, to the history of which the last seven chapters have been devoted. Several fragmentary deposits have been met with here and there, in the course of the last half century, of an age intermediate between the white chalk and the plastic clays and sands of the Paris and London districts, monuments which have the same kind of interest to a geologist which certain mediæval records excite when we study the history of nations. For both of them 
throw light on ages of darkness, preceded and followed by others of which the annals are comparatively well known to us. But these newly-discorered records do not fill up the wide gap, some of them being closely allied to the Eocene, and others to the Cretaceous type, while none appear as yet to possess so distinct and characteristic a fauna as may entitle them to hold an independent place in the great chronological series.

Among the formations alluded to, the Thanet Sands of Prestwich have been sufficiently described in the last chapter, and classed as Lower Eocene. To the same tertiary series belong the Belgian formations, called by Professor Dumont, Landenian and Heersian, although the latter may be of higher antiquity than the Thanet Sands. On the other hand, the Maestricht and Faxoe limestones are very closely connected with the chalk, to which also the Pisolitic limestone of France has been referred by high authorities.

The Lower Landenian beds of Belgium consist of marls and sands, often containing much green earth, called glauconite. They may be seen at Tournay, and at Angres, near Mons, and at Orp-le-Grand, Lincent, and Landen in the ancient province of Hesbaye, in Belgium, where they supply a durable building-stone, yet one so light as to be easily transported. Some few shells of the genus Pholadomya, Scalaria, and others, agree specifically with fossils of the Thanet Sands; but most of them, such as Astarte incequilatera, Nyst, are peculiar. In the building-stone of Orp-le-Grand, I found a Cardiaster, a genus which, according to Professor E. Forbes, was previously unknown in rocks newer than the cretaceous.

Still older than the Lower Landenian is the marl, or calcareous glauconite, of the village of Heers, near Waremme, in Belgium ; also seen at Marlinne in the same district, where I have examined it. It has been sometimes classed with the cretaceous series, although as yet it has yielded no forms of a decidedly cretaceous aspect, such as Ammonite, Baculite, Belemnite, Hippurite, \&c. The species of shells are for the most part new; but it contains, according to M. Hébert, Pholadomya cuneata, an Eocene fossil, and he assigns it with confidence to the tertiary series.

Pisolitic limestone of France.-Geologists have been still more at rariance respecting the chronological relations of this rock, which is met with in the neighborhood of Paris, and at places north, south, east, and west of that metropolis, as between Vertus and Laversines, Meudon, and Montereau. It is usually in the form of a coarse yellowish or whitish limestone, and the total thickness of the series of beds already known is about 100 feet. Its geographical range, according to M. Hébert, is not less than 45 leagues from east to west, and 35 from north to south. Within these limits it occurs in small patches only, resting unconformably on the white chalk. It was originally regarded as cretaceous by M. E. de Beaumont, on the ground of its having undergone, like the white chalk, extensive denu- 
dation previous to the Eocene period; but many able palæontologists, and among others MM. C. d'Orbigny, Deshayes, and d'Archiac, disputed this conclusion, and, after enumerating 54 species of fossils, declared that their appearance was more tertiary than cretaceous. More recently, M. Hébert, having found the Pecten quadricostatus, a cretaceous species, in this same pisolitic rock, at Montereau near Paris, and some few other fossils common to the Maestricht chalk, and to the Baculite limestone of the Cotentin, in Normandy, classed it as an upper member of the cretaceous group, an opinion since adopted by M. Alcide d'Orbigny, who has carefully examined the fossils. The Nautilus Danicus, fig. 278, and two or three other species found in this rock, are frequent in that of Faxoe in Denmark, but as yet no Ammonites, Hamites, Scaphites, Turrulites, Baculites, or Hippurites have been met with. The proportion of peculiar species, many of them of tertiary aspect, is confessedly large; and great aqueous erosion suffered by the white chalk, before the pisolitic limestone was formed, affords an additional indication of the two deposits being widely separated in time. The pisolitic formation, therefore, may eventually prove to be somewhat more intermediate in date between the secondary and tertiary epochs than the Maestricht rock.

It should, however, be observed, that all the above-mentioned strata, from the Thanet Sands to the Pisolitic limestone inclusive, and even the Maestricht rock, next to be described, exhibit marks of denudation experienced at various dates, subsequently to the consolidation of the white chall. This fact helps us in some degree to explain the remarkable break in the sequence of European rocks, between the secondary and tertiary eras, for many strata which once existed have doubtless been swept away.

\section{CLASSIFICATION OF THE CRETACEOUS ROCKS.}

The cretaceous group has generally been divided into an Upper and a Lower series, each of them comprising several subdivisions, distinguished by peculiar fossils, and sometimes retaining a uniform mineral character throughout wide areas. The Upper series is often called familiarly the chalk, and the-Lower the greensand, the lastmentioned name being derived from the green color imparted to certain strata by grains of chloritic matter. The following table comprises the names of the subdivisions most commonly adopted :-

\section{UPPER CRETACEOUS.}

A. 1. Maestricht beds and Faxoe limestones.

2. White chalk with flints.

3. Chalk marl, or gray chalk slightly argillaceous.

4. Upper Greensand, occasionally with beds of chert, and with chloritic marl (craie chloritée of French authors) in the upper portion.

5. Gault, including the Blackdown beds. 
LOWER CRETACEOUS (or Neocomian).

B. 1. Lower Greensand-green sand, iron sand, clay, and occasional beds of limestone (Kentish Rag).

2. Wealden beds or Weald clay and Hastings sands.*

Maestricht Beds.-On the banks of the Meuse, at Maestricht, reposing on ordinary white chalk with flints, we find an upper calcareous formation about 100 feet thick, the fossils of which are, on the whole, very peculiar, and all distinct from tertiary species. Some few are of species common to the inferior white chalk, among which may be mentioned Belemnites mucronatus (fig. 290, p. 325) and Pecten quadricostatus, a shell regarded by many as a mere variety of $P$. quinquecostatus (see fig. 305, p. 327). Besides the Belemnite there are other genera, such as Baculite and Hamite, never found in strata newer than the cretaceous, but frequently met with in these Maestricht beds. On the other hand, Voluta, Fasciolaria, and other genera of univalve shells, usually met with only in tertiary strata, occur.

The upper part of the rock, about 20 feet thick, as seen in St. Peter's Mount, in the suburbs of Maestricht, abounds in corals and Bryozoa, often atachable from the matrix; and these beds are succeeded by a soft yellowish limestone 50 feet thick, extensively quarried from time immemorial for building. The stone below is whiter, and contains occasional nodules of gray chert or chalcedony.

M. Bosquet, with whom I examined this formation (August, 1850), pointed out to me a layer of chalk from two to four inches thick, containing green earth and numerous encrinital stems, which forms the line of demarcation between the strata containing the fossils peculiar to Maestricht and the white chalk below. The latter is distinguished by regular layers of black flint in nodules, and by several shells, such as Terebratula carnea (see fig. 301), wholly wanting in beds higher than the green band. Some of the organic remains, how ever, for which St. Peter's Mount is celebrated, occur both above and below that parting layer, and, among other's, the great marine reptile called Mosasaurus (see fig. 276), a saurian supposed to have been 24 feet in length, of which the entire skull and a great part of the skeleton have been found. Such remains are chiefly met with in the soft

* M. Alcide d'Orbigny, in his valuable work entitled Paléontologie Française, has adopted new terms for the French subdivisions of the Cretaceous Series, which, so far as they can be made to tally with English equivalents, seem explicable thus :-

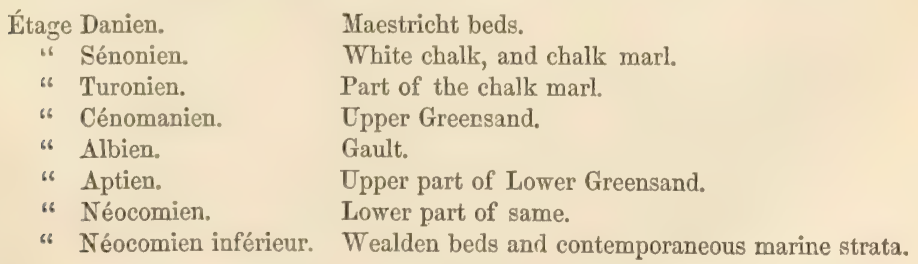


Fig. 276.

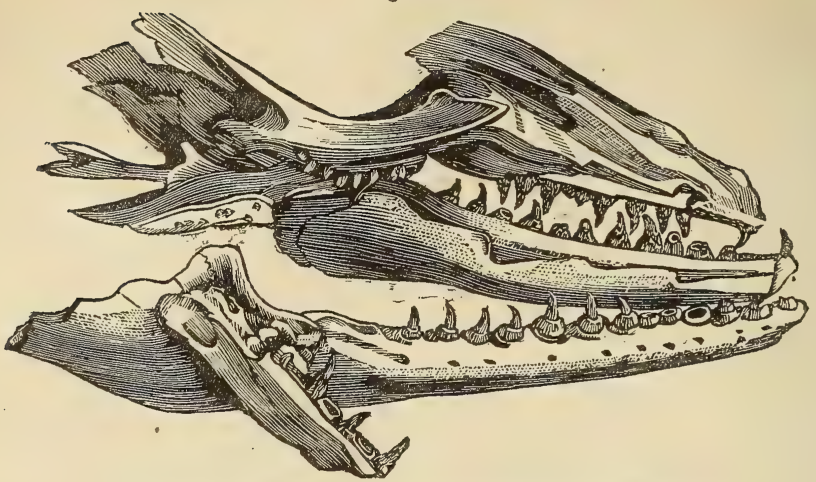

Mosasaurus Camperi. Original more than three feet long.

freestone, the principal member of the Maestricht beds. Among the fossils common to the Maestricht and white chalk may be instanced the echinoderm, fig. 277.

I saw proofs of the previous denudation of the white cialk ex-

Fig. 277.

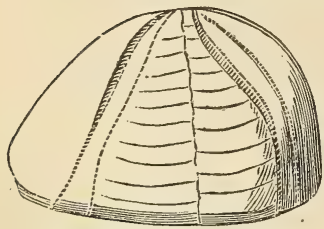

Hemipneustes radiatus, $\mathrm{Ag}$. Spatangus radiatus, Lam. Chaik of Maestricht and white chalk. hibited in the lower bed of the Maestricht formation in Belgium, about 30 miles S.W. of Maestricht, at the village of Jendrain, where the base of the newer deposit consisted chiefly of a layer of well-rolled, black, chalk-fint pebbles, in the midst of which perfect specimens of Thecidea radians and Belemnites mucronatus are imbedded.

Chalk of Faxoe.-In the island of Seeland, in Denmark, the newest member of the chalk series, seen in the sea-cliffs at Stevensklint resting on white chalk with flints, is a yellow limestone, a portion of which, at Faxoe, where it is used as a buildingstone, is composed of corals, even more conspicuously than is usually

Fig. 278.
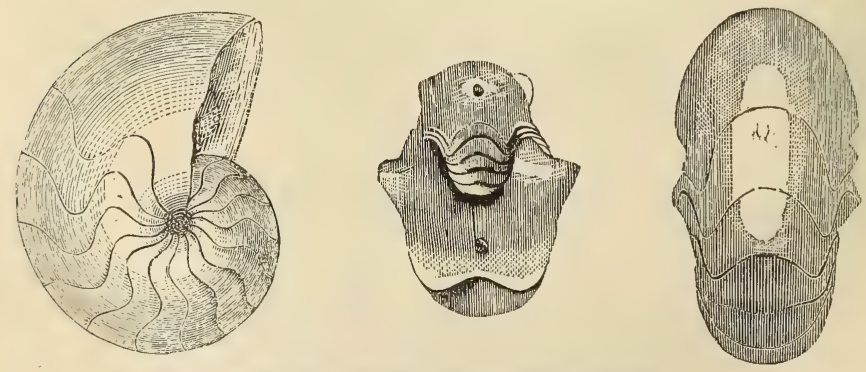

Nautilus Danicus, Schl. Faxoe, Denmark. 
observed in recent coral reefs. It has been quarried to the depth of more than 40 feet, but its thickness is unknown. The imbedded shells are chiefly casts, many of them of univalve mollusca, which are usually very rare in the white chalk of Europe. Thus, there are two species of Cyprcea, one of Oliva, two of Mitra, four of the genus Cerithium, six of Fusus, two of Trochus, one Patella, one Emarginula, \&e.; on the whole, more than thirty univalves, spiral or patelliform. At the same time, some of the accompanying bivalve shells, echinoderms, and zoophytes are specifically identical with fossils of the true Cretacoous series. Among the cephalopoda of Faxoe may be mentioned Baculites Faujasii and Belemnites mucronatus, shells of the white chalk. The Nautilus Danicus (see fig. 278) is characteristic of this formation; and it also occurs in France in the calcaire pisolitique of Laversin (Department of Oise).

The claws and entire skull of a small crab, Brachyurus rugosus (Schlottheim), are scattered through the Faxoe stone, reminding us of similar crustaceans enclosed in the rocks of modern coral reefs. Some small portions of this coralline formation consist of white earthy chalk; it is therefore clear that this substance must have been produced simultaneously-a fact of some importance, as bearing on the theory of the origin of white chalk; for the decomposition of such corals as we see at Faxoe is capable, we know, of forming white mud, undistinguishable from chalk, and which we may suppose to have been dispersed far and wide through the ocean, in which such reeis as that of Faxoe grew.

White chalk (see Tab., p. 314 et seq.).-The highest beds of chalk in England and France consist of a pure, white, calcareous mass, usually too soft for a building-stone, but sometimes passing into a more solid state. It consists, almost purely, of carbonate of lime; the stratification is often obscure, except where rendered distinct by interstratified layers of flint, a few inches thick, occasionally in continuous beds, but oftener in nodules, and recurring at intervals from two to four feet distant from each other.

This upper chalk is usually succeeded, in the descending order, by a great mass of white chalk

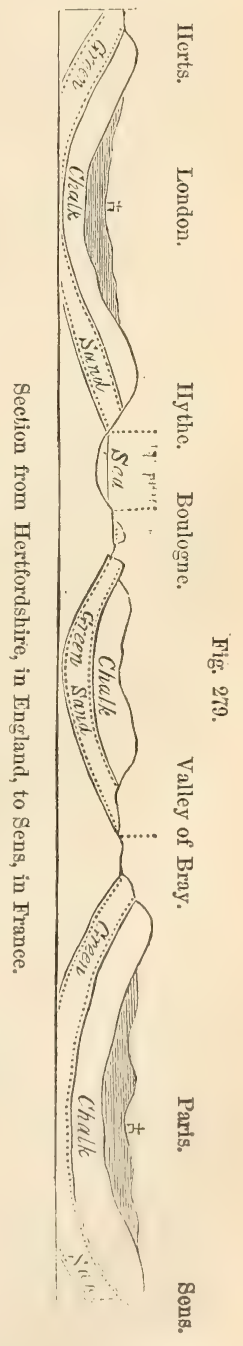
without flints, below which comes the chalk marl, in which there is a slight admixture of argillaccous matter. The united thickness of the 
three divisions in the south of England equals, in some places, 1000 feet.

The foregoing section (fig. 279) will show the manner in which the white chalk extends from England into France, covered by the tertiary strata described in former chapters, and reposing on lower cretaceous beds.

Geographical exient and origin of the White. Chalk.-The area over which the white chalk preserves a nearly homogeneous aspect is so vast, that the earlier geologists despaired of discovering any analogous deposits of recent date. Pure chalk, of nearly uniform aspect and composition, is met with in a northwest and southeast direction, from the north of Ireland to the Crimea, a distance of about 1140 geographical miles, and in an oppcsite direction it extends from the south of Sweden to the south of Bordeaux, a distance of about 840 geographical miles. In Southern Russia, according to Sir R. Murchison, it is sometimes 600 feet thick, and retains the same mineral character as in France and England, with the same fossils, including Inoceramus Cuvieri, Belemnites mucronatus, and Ostrea vesicularis.

But it would be an error to imagine that the chalk was ever spread out continuously over the whole of the space comprised within these limits, although it prevailed in greater or less thickness over large portions of that area. On turning to those regions of the Pacific where" coral reefs abound, we find some archipelagoes of lagoon islands, such as that of the Dangerous Archipelago, for instance, and that of Radack, with several adjoining groups, which are from 1100 to 1200 miles in length, and 300 or 400 miles broad; and the space to which Flinders proposed to give the name of the Coralline Sea is still larger, for it is bounded on the east by the Australian barrierall formed of coral rock-on the west by New Caledonia, and on the north by the reefs of Louisiade. Although the islands in these areas may be thinly sown, the mud of the decomposing zoophytes and foraminifera may be scattered far and wide by oceanic currents. That this mud would sometimes resemble chalk I have already hinted, when speaking of the Faxoe limestone, p. 316, and it was also remarked in an early part of this volume, that even some of that chalk, which appears to an ordinary observer quite destitute of organic remains, is nevertheless, when seen under the microscope, full of fragments of corals, bryozoa, and sponges; together with the valves of entomostraca, the shells of foraminifera, and still more minute infusoria. (See p. 26).

Now it had been often suspected, before these discoveries, that white chalk might be of animal origin, even where every trace of organic structure had vanished. This bold idea was partly founded on the fact, that the chalk consisted of carbonate of lime, such as would result from the decomposition of testacea, echini, and corals; and partly on the passage observable between these fossils when half decomposed and chalk. Bui this conjecture seemed to many naturalists 
quite rague and risionary, until its probability was strengthened by new evidence brought to light by modern geologists.

TTe learn from Captain Nelson that in the Bermuda Islands, and in the Bahamas, there are many basins or lagoons almost surrounded and enclosed by reefs of coral. At the bottom of these lagoons a soft white calcareous mud is formed, not merely from the comminution of corallines (or caleareous plants) and corals, together with the exuviæ of foraminifera, mollusks, echinoderms, and crustaceans, but also, as Irr. Darmin obserred upon studying the coral islands of the Pacific, from the fæcal matter ejected by echinoderms, conchs, and coral-eating fish. In the West Indian seas, the conch (Strombus gigas) adds largely to the chalky mud by means of its freal pellets composed of minute grains of soft calcareous matter, exhibiting some organic tissue. Mr. Darwin describes gregarious fishes of the genus Scarus, seen through the clear waters of the coral regions of the Pacific browsing quietly in great numbers on liring corals, like grazing herbs of graminivorous quadrupeds. On opening their bodies, their intestines were found to be filled with impure chalk. This circumstance is the more in point when we recollect how the fossilist was formerly puzzled by meeting, in chalk, with certain bodies, called "larchcones," which were afterwards recognized by Dr. Buckland to be the excrement of fish. Such spiral coprolites (fig. 280), like the scales and bones of fossil fish in the chalk, are composed chicfly of phosphate of lime.

Fig. $2 s 0$.

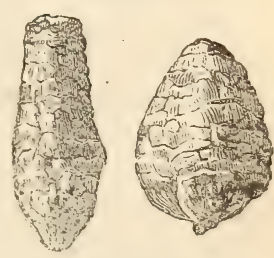

Coprolites of fish, from the chalk.

In the Bahamas, the angel-fish, and the unicorn or trumpet-fish, and many others, feed on shellifish, or on corals.

The mud derived from the sources above mentioned may be actually seen in the Maldiva Atolls to be washed out of the lagoons through narrow openings leading from the lagoon to the ocean, and the waters of the sea are discolored by it for some distance. When dried, this mud is very like common chalk, and might probably be made by a modern pressure to resemble it still more closely.*

Mr. Dana, when describing the elevated coral reef of Oahu, in the Sandwich Islands, says that some varieties of the rock consist of agregated shells, imbedded in a compact calcareous base as firm in texture as any secondary limestone; while others are like chalk, haring its color, its earthy fracture, its soft homogencous texture, and being an equally gond writing material. The same author describes, in sereral growing coral reefs, a similar formation of modern chalk, undistinguishable from the ancient. $\uparrow$ The extension orer a wide sub-

* See Nelson, Geol. Trans., 1837, vol. v. p. 108; and Geol. Quart. Journ., 1853, p. 200.

† Geol. of U. S. Exploring Exped., p. 252. 1849. 
marine area, of the calcareous matrix of the chalk, as well as of the imbedded fossils, would take place more readily in consequence of the low specific gravity of the shells of mollusca and zoophytes, when compared with ordinary sand and mineral matter. The mud also derived from their decomposition would be much lighter than argillaceous and inorganic mud, and very easily transported by currents, especially in salt water.

But the analogy of existing coral reefs would better illustrate such formations as the Oolitic limestones, to be described in Chapters XX. and XXI., which consists in great part of compact rock, than the soft and unconsolidated white chalk. A new light has recently been thrown upon the origin of the latter deposit by the deep soundings made in the North Atlantic, previous to laying down, in 1858, the electric telegraph between Ireland and Newfoundland. At depths sometimes exceeding two miles, the mud forming the floor of the ocean was found, when examined by Professor Huxley, to be almost, entirely composed (more than nineteen-twentieths of the whole) of minute Rhizopods, or foraminiferous shells of the genus Globigerina, especially the species of Globigerina bulloides (see fig. 281). In the remainder of the mud the organic bodies next in quantity were the siliceous shells called Polycystinece, and next to them the siliceous skeletons of plants called-Diatomacece (figs. 282, 283, 284), and occasionally some siliceous spiculæ of sponges (fig. 285), were intermixed.

Fig. 281.

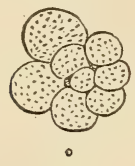

Fig. 282.

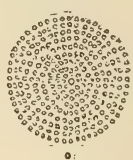

Fig. 283. Fig. 284. Fig. 285.
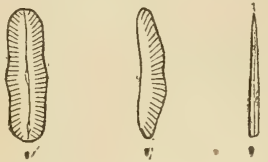

Organic bodies forming the ooze of the bet of the Atlantic at great depths.

Fig. 281. Globigerina bulloides. Calcareous Rhizopod.

282. Actinocyclas.

283. Pinnularia.

284. Eunotia bidens.

285. Spicula of sponge, Siliceous sponge.

In 1860, shells of the same Globigerina were observed by Sir Leopold MacClintoch and Dr. Wallich, during the cruise of the "Bulldog;" to form, over other wide areas of the Atlantic, a proportion of about 95 per cent. of the mud, both between the Faroe Islands and Iceland, and between Iceland and Greenland. The consistency of the ooze brought up from great depths in these areas is described as akin to that of putty. On the surface were found living Globigerinæ, while immediately below were countless calcareous grains, the relics of bygone generations. Each of these grains, as will be seen by the magnified drawing, instead of being solid, consists of a collection of cells, and as similar Globigerinæ form a large part of the white chalk, their 
structure, as Mr. Dana has well obserred, helps us to understand the imperfect aggregation of that remarkable rock. At the same time the continued growth of these Rhizopods orer a wide extent of deep ocean enables us to conceive how formerly in European areas a vast thickness of cretaccous limestone, very uniform in composition, and deroid of sand, pebbles, terrestrial and freshrrater plants and shells, and all other signs of a neighboring continent, may have been formed. That white chalk is now forming in the depths of the ocean, may now be regarded as an ascertained fact, becanse the Globigerina bulloides is specifically undistingruishable from a fossil which constitutes a large portion of the chalk of Europe. It is not figured (p. 26) among the cretaceotis foraminifera discorered by Mr. Lonsdale in 1835, because it occurs for the most part in fragments in the white chalk, and the perfect shell was not well understood before it was obtained living from the bed of the Atlantic. The Rosalina figured in the same page somewhat resembles externally a Globigerina, but it differs in the arrangement of its cells.

Chalk Flints.-The origin of the layers of flint, whether in continuous sheets or in the form of nodules, has always been found more difficult to account for than that of the white chalk. In modern coral reefs no such siliceous masses are known to be forming. But here again the late deep-sea soundings hare suggested a rery probable source of such mineral matter. During the cruise of the "Bulldog," already alluded to, it was ascertained that while the calcareous Globigerince had almost exclusive possession of certain tracts of the sea-bottom, they were wholly wanting in others, as between Greenland and Labrador. Dr. Wallich supposes that they flourished in those spaces where they may derive nutriment from organic and other matter, brought from the south by the warm waters of the Gulf Stream, and that they may be absent where the effects of that great current are not felt. In several of the spaces where the calcareous Rhizopods are wanting, the microscopic plants called Diatomacece, before mentioned (figs. 282, 281), the solid parts of which are siliceous, mouropolize the ground at a depth of nearly 400 fathoms, or 2400 feet.

Mr. Dana also has reminded us that in the soundings made in the Sea of Kamtschatka Professor Bailey found the same microscopic regetable organisms in as great profusion as are the Globigerina in the Atlantic, and he adds that when such Diatomacer decompose, the alkaline waters of the ocean can take up and hold in solution only a minute portion of the silica set free, so that an opportunity would be given for the remainder to form concretionary nodules, or to aggregate round any foreign body as a nucleus, especially when such a body is undergoing chemical change or decomposition. This would explain the frequent occurrence of fossils within nodules of flint, and the silicification of various organisms." In some parts of the 
Southern Hemisphere likewise, as Captain Maury observes, in lat. $13^{\circ}$ S., long. $16^{\circ} \mathrm{E}$., for example, siliceous Diatomaceæ and sponge spicules are the predominant forms instead of calcareous Rhizopods.

If it be asked how the Diatomaceæ above alluded to can obtain a constant supply of silex in solution, I may remind the reader of the decomposition of felspathic rocks mentioned above (p. 42) as a copious source of that mineral. Almost all the great rivers which flow into the ocean must contain some of it, and springs charged with silex in solution must rise up in many parts of the bed of the ocean as they do on dry land.

Dr. Buckland endeavored formerly to account for the recurrence, at so many distinct levels, of beds of nodular or tabular flint in the chall, by supposing the periodical accumulation of widely extended layers of mud, made up of calcareous and siliceous matter. When a stratum five or six feet or more in thickness had accumulated, its partial consolidation took place, during which the heavier silex sank to the bottom, forming nodules, or, if it was in sufficient quantity, continuous layers.* But the thickness of the masses of chalk intervening between some of the strata of fint has always made this hypothesis somewhat unsatisfactory, although such segregation of siliceous matter helps us to conceive how isolated and scattered flinty nodules may sometimes be formed in the midst of a calcareous matrix. To explain a regular succession of flinty layers, we must seek out some intermittent action, favoring alternately the deposition of calcareous and siliceous matter. Many centuries would probably be required for the growth of microscopic organisms sufficient in quantity to form a bed of white chalk

Fig. 286

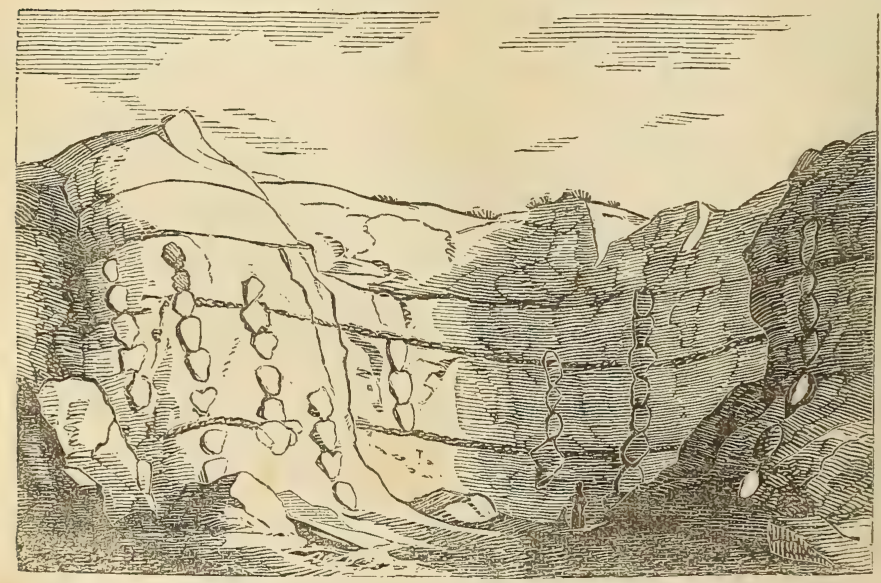

From a drawing by Mrs. Gunn.

View of a chalk-pit at Horstead, near Norwich, showing the position of the potstones.

* Geol. Trans., First Series, vol. iv. p. 413. 
several feet, and sometimes yards in thickness. We may imagine that after a lapse of many years or centuries, changes took place in the direction of the marine currents, faroring at one time a supply in the same area of siliceous, and at another of calcareous matter in excess, giring rise in the one case to a preponderance of Globigerinæ, and in the other of Diatomaceæ.

A more difficult enigma is presented by the occurrence of certain huge flints, or potstones, as they are called in Norfolk, occurring singly, or arranged in nearly continuous columns at right angles to the ordinary and horizontal layers of small flints. I visited, in the year 1825, an extensive range of quarries then open on the River Bure, near Horstead, about six miles from Norwich, which afforded a continuous section, a quarter of a mile in length, of white chalk, exposed to the depth of trenty-six feet, and covered by a thick bed of gravel. The potstones, many of them pear-shaped, were usually about three feet in height and one foot in their traversed diameter, placed in vertical rows, like pillars at irregular distances from each other, but usually from 20 to 30 feet apart, though sometimes nearer together, as in the above sketch. These rows did not terminate downwards in any instance which I could examine, nor upwards, except at the point where they were cut off abruptly by the bed of gravel. On breaking open the potstones, I found an internal cylindrical nucleus of pure chalk, much harder than the ordinary surrounding chalk, and not crumbling to pieces like it, when exposed to the winter's frost. At the distance of half a mile, the rertical piles of potstones were much farther apart from each other. Dr. Buckland has described very similar phenomena as characterizing the white chalk on the north coast of Antrim, in Ireland.*

These pear-shaped masses of flint often resemble in shape and size the large sponges called Neptune's cups (Spongia patera, Hardw.), which grow in the seas of Sumatra; and if we could suppose a series of such gigantic sponges to be separated from each other, like trees in a forest, and the individuals of each successive generation to grow on the exact spot where the parent sponge died and was enveloped in calcareous mud, so that they should become piled one abore the other in a rertical column, their growth keeping space with the accumulation of the enreloping, calcareous mud, a counterpart of the phenomena of the Horstead potstones might be obtained.

Single pebbles in chalk.-The general absence of sand and pebbles in the white chalk has been already mentioned; but the occurrence here and there, in the south-east of England, of a few isolated pebbles of quartz and green schist, some of them 2 or 3 inches in diameter, has justly excited much wonder. If these had been carried to the spots where we now find them by wares or currents from the lands once bordering the cretaceous sea, how happened it that no sand or mud

* Geol Trans., First Series, vol. iv. p. 413. "On Paramoudra, \&c." 
were transported thither at the same time? We cannot conceive such rounded stones to have been drifted like erratic blocks by ice (see Chaps. X., XI.), for that would imply a cold climate in the Cretaceous period-a supposition inconsistent with the luxuriant growth of large chambered univalves, numerous corals, and many fish, and other fossils of tropical forms.

Now in Keeling Island, one of those detached masses of coral which rise up in the wide Pacific, Captain Ross found a single fragment of greenstone, where every other particle of matter was calcareous; and Mr. Darwin concludes that it must have come there entangled in the roots of a large tree. He reminds us that Chamisso, the distinguished naturalist who accompanied Kotzebue, affirms that the inhabitants of the Radack archipelago, a group of lagoon islands in the midst of the Pacific, obtained stones for sharpening their instruments by searching the roots of trees which are cast up on the beach.*

It may perhaps be objected, that a similar mode of transport cannot have happened in the cretaceous sea, because fossil wood is very rare in the chalk. Nevertheless wood is sometimes met with, and in the same parts of the chalk where the pebbles are found, both in soft stone and in a silicified state in flints. In these cases it has often every appearance of having been floated from a distance, being usually perforated by boring-shells, such as the Teredo and Fistulana.t

The only other mode of transport which suggested itself is seaweed. Dr. Beck informs me that in the Lym-Fiord, in Jutland, the Fucus vesiculosus, often called kelp, sometimes grows to the height of 10 feet, and the branches rising from a single root form a cluster several feet in diameter. When the bladders are distended, the plant becomes so buoyant as to float up loose stones several inches in diameter, and these are often thrown by the waves high up on the beach. The Fucus giganteus of Solander (Macrocystes pyrifera, Hooker), so common in Terra del Fuego, was descried by Captain Cook as attaining the length of 360 feet, although the stem is not much thicker than a man's thumb. Dr. Hooker found the same seaweed 700 feet long. $\$$ It is often met with floating at sea, with shells attached, several hundred miles from the spots where it grew. Some of these plants, says Mr. Darwin, were found adhering to large loose stones in the inland channels of Terra del Fuego, during the voyage of the "Beagle" in 1834 ; and that so firmly, that the stones were drawn up from the bottom into the boat, although so heary that they could scarcely be lifted in by one person. Some fossil sea-weeds have been found in the Cretaceous formation, but none, as yet, of large size.

But we must not imagine that because pebbles are so rare in the

* Darwin, p. 549. Kotzebue's First Voyage, vol. iii. p. 155.

$\uparrow$ Mantell, Geol. of S.E. of England, p. 96.

\$Flora Antaretica, vol. ii. p. 464. 
white chalk of England and France there are no proofs of sand, shingle, and clay haring been accumulated contemporaneously even in European seas. The siliceous sandstone, called "upper quader" by the Germans, orerlies white argillaceous chalk or "planer-kalk," a deposit resembling in composition and organic remains the chalk marl of the English series. This sandstone contains as many fossil shells common to our white chalk as could be expected in a sea-bottom formed of such different materials. It sometimes attains a thickness of 600 feet, and, by its jointed structure and rertical precipices, plays a conspicuous part in the picturesque scenery of Saxon Switzerland, near Dresden.

\section{FOSSILS OF THE UPPER CRETACEOUS ROCKS.}

Among the fossils of the white chalk, echinoderms are very numerous; and some of the genera, like Ananchytes (see fig. 287), are ex-

Fig. 287.

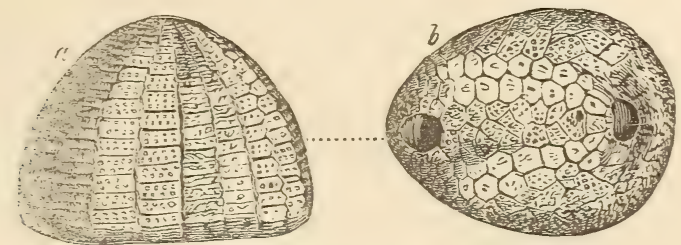

Ananchytes ovata. White chalk, upper and lower.

a. Side view.

6. Bottom of the shell on which both the oral and anal apertures are placed; the anal being more round, and at the smaller end.

clusively cretaceous. Among the Crinoidea, the Marsupite (fig. 294) is a characteristic genus. Among the mollusca, the cephalopoda, or

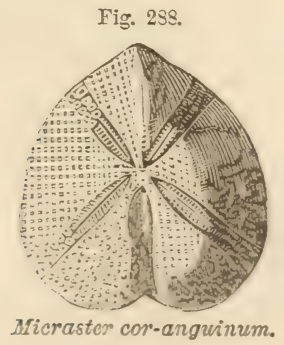

White chalk.
Fig. 289.

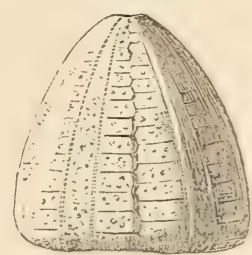

Galerites albogalems, Lam. White chalk.

Fig. 290.

a

\section{b}

\section{II: D. 1010}

a. Bolemnites mucronatus. Syn. Belemnitella mucronata.

b. Same, showing internal structure. Maestricht, Faxoe, and white chalk, 
chambered univalves, of the genera Ammonite, Scaphite, Belemnite (fig. 290), Baculite (291-293), and Turrilite $(296,297)$, with other

Fig. 291.

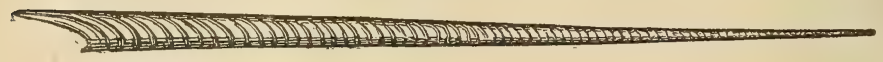

Baculites anceps. Upper Greensand, or chloritic marl, craie chloritée. France. A. d'Orb., Terr. Crét.

Fig. 292.

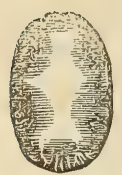

Portion of Baculites Fawjasii. Maestricht and Faxoe beds and white chalk.

Fig. 294.

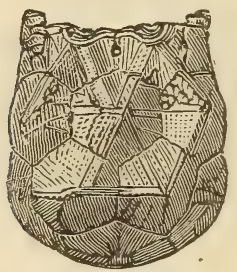

Marsupites Milleri.

White chalk.

Fig. 29) 0 .

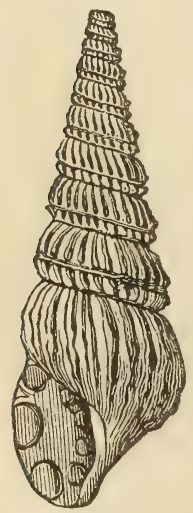

Turrilites costatus. Chalk.
Fig. 293.

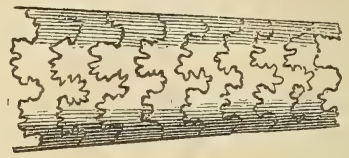

Portion of Baculites anceps.

Maestricht and Faxoe beds and white chalk.

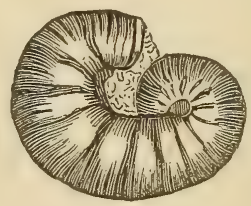

Scaphites cequalis. Chloritic marl of Upper Greensand, Dorsetshire.

Fig. 297.

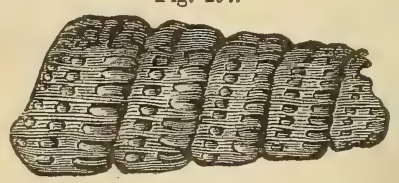

a. Fragment of Turrilites costatus. Chalk marl.

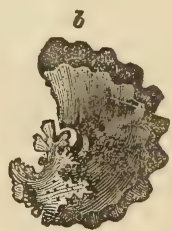

b. Same, showing the foliated border of the partition of the chambers.

allied forms, present a great contrast to the testacea of the same class in the Tertiary and Recent periods. 
Among the brachopoda in the white chalk, the Terebratuloe are very abundant. These shells are known to live at the bottom of the sea, where the water is tranquil and of some depth (see figs. 298, $299,300,301,302)$. With these are associated some forms of oyster

Fig. 298.

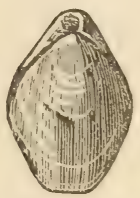

Terebratulina striata. Upper white chalk.
Fig. 299.

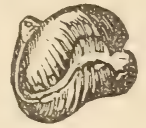

Rhynchonella octoplicata. Var. of T. plicatilis.

Upper white chalk.
Fig. 301.

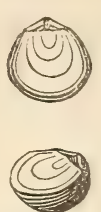

Magas pumila, Sow. Upper white chalk.

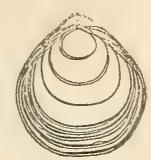

Terebratula carnea. Upper white chalk.

(see figs. 309, 310, 311), and other bivalves (figs. 303, 304, 305, $306,307)$.

Fig. 302.

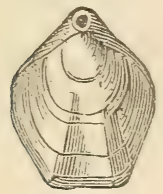

Terebratula biplicata, ouw. Upper cretaceous.

Fig. 305.

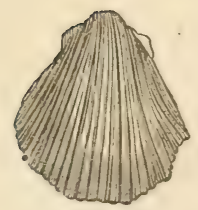

Pecten 5-costatus. White chalk, Upper and Lower Greensands.
Fig. 303.

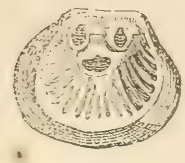

Crania Parisiensis, inferior or attached valve.

Upper white chalk.

Fig. 306.

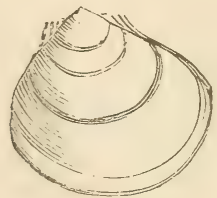

Plagiostoma Hoperi, Sow. Syn. Lima Hoperi.

White chalk and Upper Greensand.
Fig. 304.

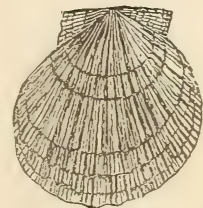

Pecten Beaveri, reduced to one-third diameter.

Lower white chalk and chalk marl. Maidstone.

Fig. 307.

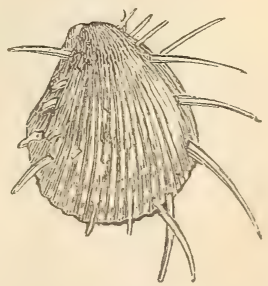

Lima spinosa, Sow. Syn. Spondyhes spinosus.

Upper white chalk.

Among the bivalve mollusca, no form marks the Cretaceous era in Europe, America, and India, in a more striking manner than the extinct genus Inoceramus (Catillus of Lam.; see fig. 308), the shells of which are distinguished by a fibrous texture, and are often mei with in fragments, having, probably, been extremely friable.

Of the singular family called Rudistes, by Lamarck, hereafter to be mentioned as extremely characteristic of the chalk of Southern 
Fig. 308,

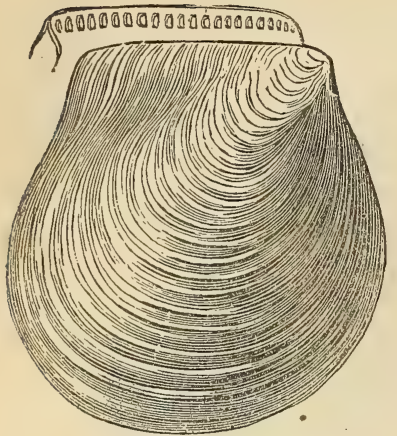

Inoceramus Lamarckii.

Syn. Catillus Lamarckii.

White chalk. (Dixon's Geol. Sussex, Tab. 28, fig. 29.)

Fig. 810.

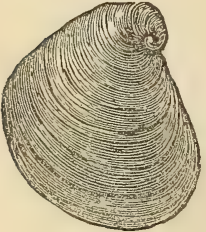

Ostrea columba.

Syn. Gryphcea columba

Upper Greensand.
Fig. 309.
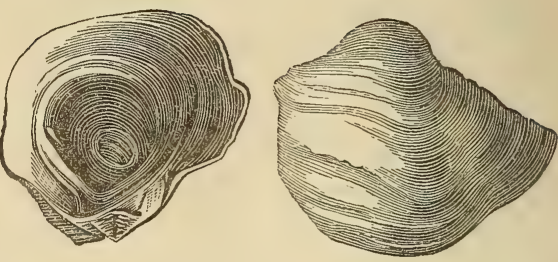

Ostrea vesicularis. Syn. Gryphoea globosa. Upper chalk and Upper Greensand.

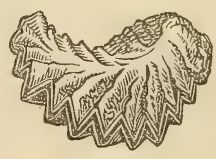

Ostrea carinata. "Chalk marl, Upper and Lower Greensand.
Fig. 312.

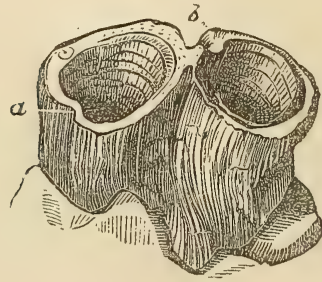

Fig. 314.

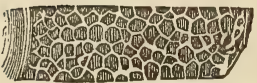

Fig. 313.

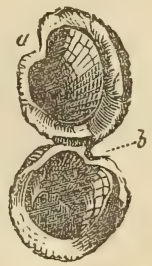

Fig. 815 .

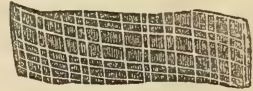

Radiolites Mortoni, Mantell. Houghton, Sussex, White chalk. Diameter one-seventh nat. size.

Fig. 312. Two individuals deprived of their upper valves, adhering together.

313. Same seen from above.

314. Transverse section of part of the wall of the shell, magnified to show the structur: 315. Vertical section of the same.

On the side where the shell is thinnest, there is one external furrow and corresponding internal ridge, $a, b$, figs. 312,313 ; but they are usually less prominent than in these figures. This species was first referred by Mantell to Hippurites, afterwards to the genus Radiolites. I have never seen the upper valve. The specimen above figured was discovered by the late Mr. Dison. 
Europe, a single representative only (fig. 312) has been discovered in the white chalk of England.

Fig. 316.

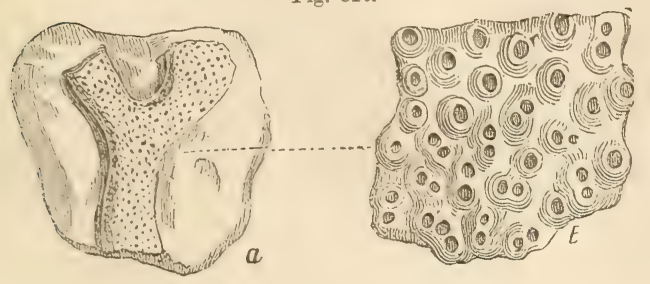

Fig. 317 .

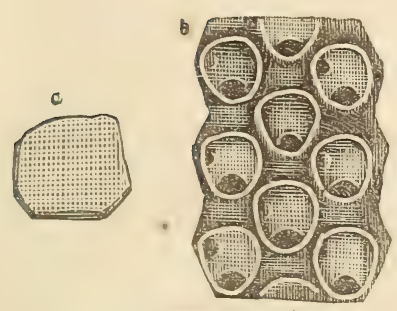

Eschcrina occani.

a. Natural size.

b. Part of the same magnified.

White chalk.
Fig. 318.

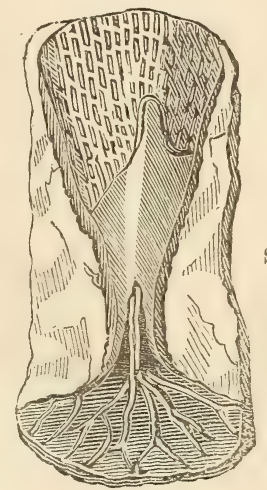

a. Natural size.

b. Portion magnified.

White chalk.

Ventriculites radiatus. Mántell.

Syn. Ocellaria radiata D'Orb. White chalk.

Fig. 320.

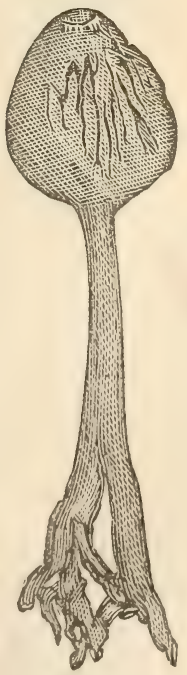

Siphonia pyriformis. Rlackdown beds. 
With these mollusca are associated many Bryozoa, such as Eschara and Escharina (figs. 316,317 ), which are alike marine, and, for the most part, indicative of a deep sea. These and other organic bodies, especially sponges, such as Ventriculites (fig. 318), are dispersed indifferently through the soft chalk and hard flint, and some of the flinty nodules owe their irregular forms to enclosed sponges such as fig. $319 a$, where the hollows in the exterior are caused by the branches of a sponge, seen on breaking open the flint (fig. $319 \mathrm{~b}$ ).

The remains of fishes of the Upper Cretaceous formations consist chiefly of tecth of the shark family of genera, in part common to the tertiary, and partly distinct. To the latter belongs the genus Ptychodus (fig. 321), which is allied to the living Port Jackson Shark, Cestracion Phillippi, the anterior teeth of which (see fig. 322 a) are sharp and cutting, while the posterior or palatal teeth $(b)$ are flat, and analogous to the fossil (fig. 321).

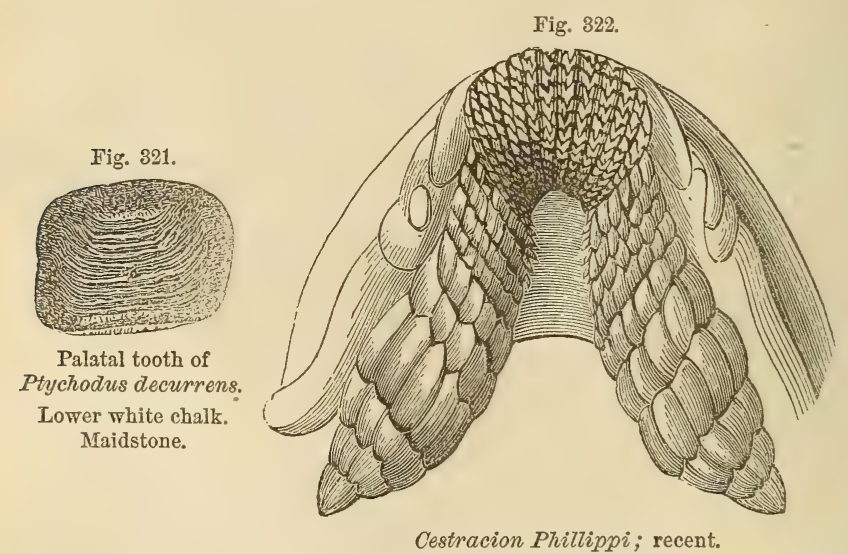

Port Jackson. Buckland, Bridgewater Treatise, pl. $27 d$.

But we meet with no bones of land animals, nor any terrestrial or fluviatile shells, nor any plants, except sea-weeds, and here and there a piece of drift-wood. All the appearances concur in leading us to conclude that the white chalk was the product of an open sea of considerable depth.

The existence of turtles and oviparous saurans, and of a Pterodactyl or winged lizard, found in the white chalk of Maidstone, implies, no doubt, some neighboring land; but a few small islets in mid-ocean, like Ascension, formerly so much frequented by migratory droves of turtle, might perhaps have afforded the required retreat where these creatures laid their eggs in the sand, or from which the flying species may have been blown out to sea. Of the vegetation of such islands we have scarcely any indication, but it consisted partly of cycadaceous plants ; for a fragment of one of these was found by Capt. Tbbetson in the Chalk Marl of the Isle of Wight, and is referred by A. Brong- 
niart to Clathraria Lyellii, Mantell, a species common to the antecedent Wealden period.

The Pterodactyl of the Kentish chalk, above alluded to, was of gigantic dimensions, measuring 16 feet 6 inches from tip to tip of its outstretched wings. Some of its elongated bones were at first mistaken by able anatomists for those of birds ; of which class no osseous remains have as yet been derived from the white chalk, although

\section{Fossils of the Upper Greensand.}

Fig. 823.

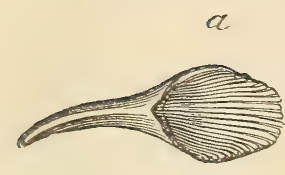

a. Terebrirostra tyra.

b. Same, seen in profile.

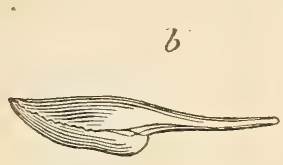

Upper Greensand. France.
Fig. 324.

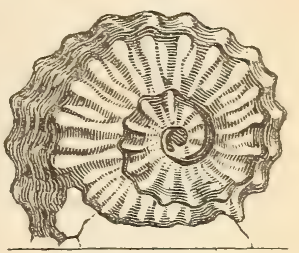

Ammonites Rhotomagensis. Upper Greensand.

they hare been found (as will be seen in the annexed figures) in the Upper Greensand.

Upper Greensand (A. 4, Table, p. 314).-The lower chalk without flints passes gradually domnwards, in the south of England, into an argillaceous limestone, "the chalk marl," already alluded to, in which ammonites and other cephalopoda, so rare in the higher parts of the series, appear. This marly deposit passes in its turn into beds called the Upper Greensand, containing green particles of sand of a chloritic mineral. In parts of Surrey, calcareous matter is largely intermixed, forming a stone called firestone. In the cliffs of the southern coast of the Isle of Wight, this upper greensand is 100 feet thick, and contains bands of siliceous limestone and calcareous sandstone with nodules of chert.

The Upper Greensand is regarded by Mr. Austen and Mr. D. Sharpe as a littoral deposit of the Chalk Ocean, and, therefore, contemporaneous with part of the chalk marl, and even, perhaps, with some part of the white chalk. For as the land went on sinking, and the cretaceous sea widened its area, white mud and chloritic sand were always forming somewhere, but the line of sea-shore was perpetually varying its position. Hence, though both sand and mud originated simultaneously, the one near the land, the other far from it, the sands and in every locality where a shore becane submerged might constitute the underlying deposit.

Gault.-The lowest member of the Upper Cretaceous group, usually about 100 feet thick in the S.E. of England, is provincially termed Gault. It consists of a dark blue marl, sometimes intermixed with greensand. Many peculiar forms of cephalopoda, such as the 
Hamite (fig. 325) and Scaphite, with other fossils, characterize this formation, which, small as is its thickness, can be traced by its organic remains to distant parts of Europe, as, for example, to the Alps.

Fig. 325 .

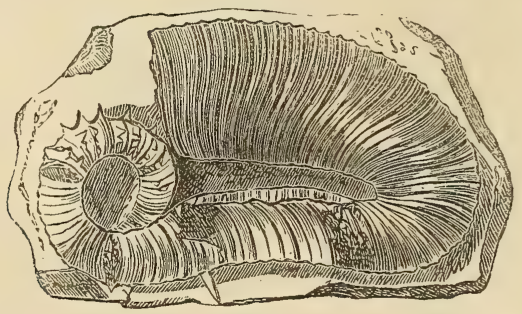

Ancyloceras spinigerum, D'Orb. Syn. Hamites spiniger, Sow. Near Folkestone. Ganit.

The Blackdown beds in Devonshire, celebrated for containing many species of fossils not found elsewhere, have been commonly referrea to the Upper Greensand, which they resemble in mineral character; but Mr. Sharpe has suggested, and apparently with reason, that they are rather the equivalent of the Gault, and were probably formed on the shores of the sea, in the deeper parts of which the fine mud called Gault was deposited. Several Blackdown species are common to the Lower Cretaceous series, as, for example, Trigonia caudata, fig. 334, p. 344. We learn from M. d'Archiac, that in France, at Mons, in the valley of the Loire, strata of greensand occur of the same age as the Blackdown beds, and containing many of the same fossils. They are also regarded as of littoral origin by M. d'Archiac.*

The phosphate of lime, found near Farnham, in Surrey, and near Cambridge, in such abundance as to be used largely by the agriculturist for fertilizing soils, occurs. in the Upper Greensand. It is doubtless of animal origin, and partly coprolitic, derived from the excrement of fish and reptiles. In this formation near Cambridge the late M. Louis Barrett discovered, in 1858, the remains of a bird, which was rather larger than the common pigeon, and probably of the Order Natatores, and which, like most of the Gull tribe, had well-developed wings. Portions of the metacarpus, metatarsus, tibia, and femur have been detected, and the determinations of Mr. Barrett have been confirmed by Professor Owen.

\section{FLORA OF THE UPPER CRETACEOUS PERIOD.}

As the upper cretaceous rocks of Europe are, for the most part, of purely marine origin, and formed in deep water far from the nearest shore, land-plants of this period, as we might naturally have antici-

* Hist. des Progrès de la Géol., \&c., vol. iv. p. 360. 1851. 
pated, are very rarely met with. In the neighborhood of Aix-la-Chapelle, however, an important exception occurs, for there certain white sands, 400 feet in thickness, contain the remains of terrestrial plants in a beautiful state of preservation. These have been diligently collected and studied by Dr. Debey, and as they afford the only example jet known of a terrestrial flora older than the Eocene, in which the great divisions of the vegetable kingdom are represented in nearly the same proportions as in our own times, they deserve particular attention. Dr. Debey estimates the number of species as amounting to more than two hundred, of which sixty-seven are cryptogamous, chiefly ferns, twenty species of which can be well determined, most of them being in fructification. The cicatrices on the bark of one or two are supposed to indicate tree-ferns. Of thirteen genera three are still existing, namely, Gleichenia, now inhabiting the Cape of Good Hope and New Holland; Lygodium, now living in Japan, Java, and North America; and Asplenium, a cosmopolite form. Among the phænogamous plants the Conifers are abundant, the most common belonging to a genus called Cycadopteris by Debey, and hardly separable from Sequoia (or Wellingtonia), of which both the cones and branches are preserved. When I risited Aix, I found the silicified wood of this plant very plentifully dispersed through the white sands in the pits near that city. In one silicified trunk 200 rings of annual growth had been counted. Species of Araucaria like those of Australia are also found. Cycads are extremely rare, and of Monocotyledons there are but few. No palms have been recognized with certainty, but the genus Pandanus, or screw pine, has been distinctly made out. The number of the Dicotyledonous Angiosperms is the most striking feature in so ancient a flora.*

Among them we find the familiar forms of the Oak, Fig, and Walnut, Quercus, Ficus, and Juglans, of the latter both the nuts and leaves; also several genera of the Myrtaceæ. But the predominant order is

* In this and subsequent remarks on fossil plants I shall often use Dr. Lindley's terms, as most familiar in this country; but as those of M. A. Brongniart are much cited, it may be useful to geologists to give a table explaining the corresponding names of groups so much spoken of in palæontology.

Brongniart.

हี $\left\{\begin{array}{c}\text { 1. Cryptogamous amphi- } \\ \text { gens, or cellular } \\ \text { cryptogamic. }\end{array}\right\}$

2. Cryptogamous acro gens.

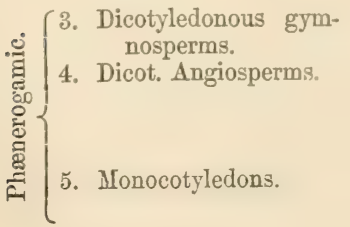

Lindley.

Thallogens.

Acrogens.

Gymnogens.

Exogens.

Endogens.
Lichens, sea-weeds, fungi.

Mosses, equisetums, ferns, lycopodiums,-Lepidodendron.

Conifers and Cycads.

Compositæ, leguminosæ, umbelliferæ, cruciferæ, heaths, \&c. All native European trees except conifers.

Palms, lilies, aloes, rushes, grasses, \&ic. 
the Proteaceæ, of which there are between sixty and seventy species, many of extinct genera, but some referred to the following living forms -Dryandra, Grevillea, Hakea, Banksia, Persoonia_all now belonging to Australia, and Leucospermum, species of which form small bushes at the Cape.

The epidermis of the leaves of many of these Aix plants, especially of the Proteacer, is so perfectly preserved in an envelope of fine clay that under the microscope the stomata, or polygonal cellules, can be detected, and their peculiar arrangement is identical with that known to characterize some living Proteaceæ (Grevillea, for example). An occasional admixture of Fucoids and Zosterites attests, like the shells, the presence of saltwater.

Of insects Dr. Debey has obtained about ten species of the families Curculionidæ and Carabidæ.

The, age of the beds containing this remarkable assemblage of plants was for a long time matter of dispute. They were at first erroneously referred to the Middle Tertiary, and afterwards to the Lower Cretaceous series, but they are in truth the equivalents of the white chalk and Chalk Marl, or Sénonien of D'Orbigny. Such was Ferdinand Römer's opinion in $1853,{ }^{*}$ and after examining the country in 1857 , I satisfied myself that he was right, although the white siliceous sands of the lower beds, and the green grains in the upper part of the formation, caused it to differ in mineral character from our white chalk.

In travelling from Maestricht to Aix-la-Chapelle, we first pass from the Maestricht beds to white chalk, with flints, about 300 feet thick, next to which, in descending order, we find chalk without flints, and Chalk Marl; and below this again, greensand, which contains Belemnitella mucronata (fig. 290, p. 325), and other fossils, showing that it is not the equivalent of the English Upper Greensand. Below this are the white and yellow sands of Aix, about 400 feet thick, which rest immediately on ancient Devonian rocks, highly inclined. Some of the sand in the lower beds has concreted into solid masses of sandstone, like the German Quader Sandstein.

Beds of fine clay, with fossil plants, and with seams of lignite and even perfect coal, are intercalated. Floating wood, containing perforating shells, such as Pholas, and Gastrochœna also occur. There are likewise a few beds of a yellowish brown limestone, with marine shells, which enable us to identify the lowest with the highest plant-beds. Among these shells are Pecten quadricostatus, and several others which are common to the upper and lower part of the series, and a Trigonia, called by some of the Aix naturalists T. alacformis, which, as M. Bosquet pointed out to me, agrees far better in character with D'Orbigny's T. limbata, a shell of the white chalk. On the whole the organic re-

* F. Römer, Kreidebiı̀dung der Gegend von Aachen. Deutsch. Geol. Gesellsch. vii. 534 . 
mains and the geological position of the strata prove distinctly that in the neighborhood of Air-la-Chapelle, a gulf of the ancient cretaceous sea was bounded by land composed of Deronian rocks. These rocks consisted of quartzose and schistose beds, the first of which supplied white sand and other argillaceous mud to a river which entered the sea at this point, carrying down in its turbid waters much drift-wood and the leaves of plants. Occasionally, when the force of the river abated, marine shells of the genera Trigonia, Turritella, Pecten, \&c., established themselves in the same area, and plants allied to Zosterca and Fucus grew on the bottom.

Before the cretaceous flora of Aix-la-Chapelle was known, a few leares of a dicotyledonous and angiospermous genus called "Credneria," were known in the "Quader Sandstein " and "Planer Kalk," of Germany, rocks corresponding in age to the white chalk and gault of England. But such fossil plants were the only representatives in rocks older than the Eocene period of those Exogens which now constitute three-fourths of the living vegetation of the globe.

II. Adolphe Brongniart, when dividing the whole fossiliferous series into three groups in reference solely to fossil plants, has named the primary strata "the age of acrogens;" the secondary, exclusive of the cretaceous, "the age of gymnosperms ;" and the third, comprising the cretaceous and tertiary, "the age of angiosperms." He considers the cretaceous flora as displaying a transitional character from that of a secondary to that of a tertiary regetation. Coniferce and Cycadece (or Gymnogens) still flourished, as in the preceding oolitic and triassic epochs; while, together with these, some well-marked leaves of dicotyledonous angiosperms appeared. But now that the fossil plants of Aix-la-Chapelle are with certainty referred to an Upper Cretaceous era, the line dividing the ages of gymnosperms and of angiosperms seems to run between the Lower and Upper Cretaceous formations, or between the Lower Greensand and the sand of Aix.

The resemblance of the flora of Aix-la-Chapelle to the tertiary and living floras in the proportional number of dicotyledonous angiosperms as compared to the gymnogens, is a subject of no small theoretical interest, because we can now affirm that these Aix plants flourished before the rich reptilian fauna of the secondary rocks had ceased to exist. The Ichthyosaurus, Pterodactyl, and Mosasaurus were of coeval date with the oak, the walnut, and the fig. Speculations have often been hazarded respecting a connection betreen the rarity of Exogens in the older rocks and a peculiar state of the atmosphere. A denser air, it was suggested, had in earlier times been alike adverse to the well being of the higher order of flowering plants, and of the quick-breathing animals such as mammalia and birds, while it was favorable to a cryptogamic and grmnospermous flora, and to a predominance of reptile life. But wre now learn that there is no incompatibility in the coexistence of a regetation like that of the present globe, and some of the most remarkable forms of the extinct reptiles of the age of gymnosperms. 
If the passage seem at present to be somewhat sudden from the flora of the Lower to that of the Upper Cretaceous period, the abruptness of the change will probably disappear when we are better acquainted with the fossil vegetation of the Lower Greensand, and with that of the Gault and Upper Greensand

\section{HIPPURITE LIMESTONE.}

Difference between the chalk of the North and South of Europe.By the aid of the three tests of relative age, namely, superposition, mineral character, and fossils, the geologist has been enabled to refer to the same Cretaceous period certain rocks in the north and south of Europe, which differ greatly both in their fossil contents and in their mineral composition and structure.

If we attempt to trace the cretaceous deposits from England and France to the countries bordering the Mediterranean, we perceive, in the first place, that the chalk and greensand in the neighborhood of London and Paris form one great continuous mass, the straits of Dover being a trifling interruption, a mere valley with chalk cliffs on both sides. We then observe that the main body of the chalk which surrounds Paris stretches from Tours to near Poitiors (see the annoxed

Fig. 326.

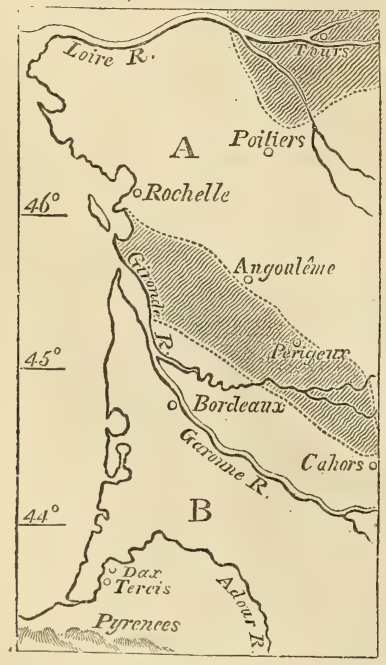
map, fig. 326, in which the shaded part represents chalk).

Between Poitiers and La Rochelle, the space marked A on the map separates two regions of chalk. This space is occupied by the Oolite and certain other formations older than the Chalk, and has been supposed by M. E. de Beaumont to have formed an island in the cretaceous sea. South of this space we again meet with a formation which we at once recognize by its mineral character to be chalk, although there are some places where the rock becomes oolitic. The fossils are, upon the whole, very similar; especially certain species of the genera Spatangus, Ananchytes, Cidarites, Nucula, Ostrea, Gryphoea (Exogyra), Pecten, Plagiostoma (Lima), Trigonia, Cati-lus (Inoceramus), and Terebratula.*

But Ammonites, as M. d'Archiac observes, of which so many species

* D'Archiac, Sur la Form. Crétacée de S.-0. de la France, Mém. de la Soc. Géol. de France, tom. ii. 
are met with in the chalk of the north of France, are scarcely ever found in the southern region; while the genera Hamite, Turrilite, and Scaplite, and perhaps Belemnite, are entirely wanting.

On the other hand, certain forms are common in the south which are rare or wholly unknown in the north of France. Among these may be mentioned many Hippurites, Sphcerulites, and other members of that great fumily of mollusca called Rudistes by Lamarek, to which nothing analogous has been discovered in the living creation, but which is quite characteristic of rocks of the Cretaceous era in the

Fig. 327.

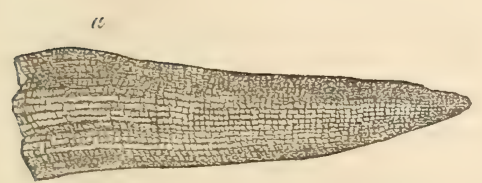

a. Radiolites radiosa, D'Orb. b. Upper valve of same, White chalk of France.
Fig. 328.
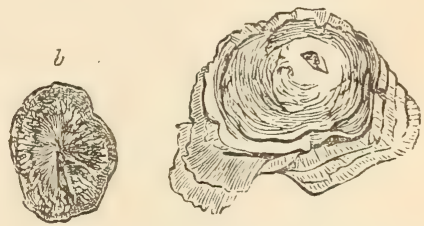

Radiolites foliaceus, D'Orb Syn. Sphorulites agariciformis, Blainv.

White chalk of France.

Fig. 323.
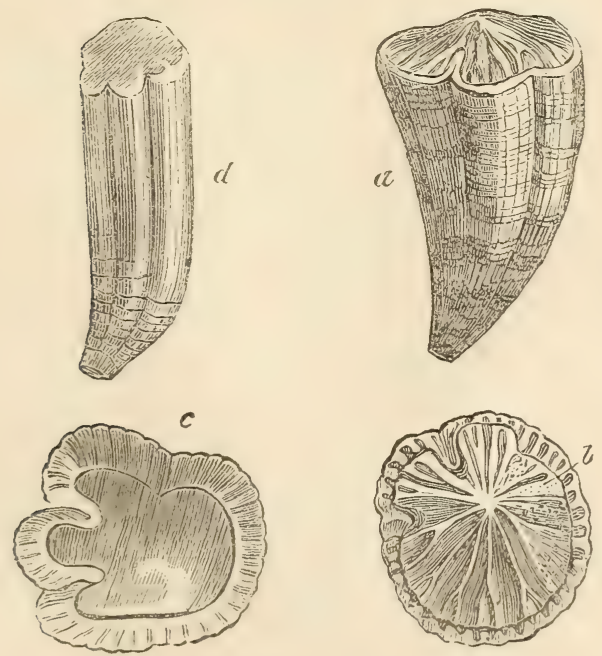

Hippurites organisans, Desmoulins.

Upper chalk:-chalk marl of Pyrenees? *

a. Toung individual; when full grown they occur in groups adhering laterally to each other.

b. Upper side of the upper valve, showing a reticulated structure in those parts, $b$, where the external coating is worn off.

c. Upper end or opening of the lower and cylindrical valve.

d. Cast of the interior of the lower conical valve.

* D’Orbigny's Paléontologie Française, pl, 533. 
south of France, Spain, Sicily, Greece, and other countries bordering the Mediterranean.

The species called Hippurites organisans (fig. 329) is more abun. dant than any other in the south of Europe; and the geologist should make himself well acquainted with the cast $d$, which is far more common in many compact marbles of the Upper Cretaceous period than the shell itself, this having often wholly disappeared. The flutings, or smooth, rounded, longitudinal ribs, representing the form of the interior, are wholly unlike the Hippurite itself, and in some individuals attain a great size and length.

Between the region of chalk last mentioned, in which Perigueux is situated, and the Pyrenees, the space B intervenes. (See Map, fig. 326.) Here the tertiary strata cover, and for the most part conceal, the cretaceous rocks, except in some, spots where they have been laid open by the denudation of the newer formations. In these places they are seen still preserving the form of a white chalky rock, which is charged in part with grains of greensand. Even as far south as Tercis, on the Adour, near Dax, cretaceous rocks retain this character. I examined them in 1828, and M. Grateloup found in them Ananchytes ovata (fig. 287, p. 325), and other fossils of the English chalk, together with Hippurites.

CRETACEOUS ROCKS IN THE UNITED STATES.

If we pass to the American continent, we find in the State of New Jersey a series of sandy and argillaceous beds wholly unlike our Upper Cretaceous system; which we can, nevertheless, recognize as referable, palæontologically, to the same division.

That they were about the same age generally as the European chalk and greensand, was the conclusion to which Dr. Morton and Mr. Conrad came after their investigation of the fossils in 1834. The strata consist chiefly of greensand and green marl, with an overlying coralline limestone of a pale yellow color, and the fossils, on the whole, agree most nearly with those of the Upper European series, from the Maestricht beds to the gault inclusive. I collected sixty shells from the New Jersey deposits in 1841, five of which were identical with European species-Ostrea larva, O. vesicularis, Gryphoea costata, Pecten quinque-costatus, Belemnites mucronatus. As some of these have the greatest vertical range in Europe, they might be expected more than any others to recur in distant parts of the globe. Even where the species were different, the generic forms, such as the Baculite and certain sections of Ammonites, as also the Inoceramus (see above, fig. 308, p. 328), and other bivalves, have a decidedly cretaceous aspect. Fifteen out of the sixty shells above alluded to were regarded by Professor Forbes as good geographical representatives of well-known cretaceous fossils of Europe. The correspondence, there- 
fore, is not small, when we reflect that the part of the United States where these strata occur is between 3000 and 4000 miles distant from the chalk of Central and Northern Europe, and that there is a difference of ten degrees in the latitude of the places compared on opposite sides of the Atlantic.*

Fish of the genera Lamna, Galeus, and Carcharodon are common to New Jersey and the European cretaceous rocks. So also is the genus Mosasaurus among reptiles. The rertebra of a Plesiosaurus, a reptile knomn in the English chalk, had often been cited on the authority of Dr. Harlan as occurring in the cretaceous marl, at Nullica Hill, in New Jersey. But Dr. Leidy has since shown that the bone in question is not saurian but cretaceous, and whether it can truly lay claim to the high antiquity assigned to it, is a point still open to discussion. The discovery of another mammal of the seal tribe (Stenorhynchus vetus, Leidy), from a lower bed in the cretaceous series in New Jersey, appears to rest on better evidence. $\dagger$

From New Jersey the cretaceous rocks extend southward to North Carolina and Georgia, cropping out at intervals from beneath the tertiary strata, betreen the Appalachian Mountains and the Atlantic. They then streep round the southern extremity of that chain, in Alabama and Mississippi, and stretch northmard again to Tennessee and Kentucky. They hare also been traced far up the ralley of the Missouri, as far north as lat. $48^{\circ}$, or to Fort Mandan; so that already the area which they are ascertained to occupy in North America may perhaps equal their extent in Europe, and exceeds that of any other fossiliferous formation in the United States. So little do they resemble mineralogically the European white chalk, that in North America, limestone is upon the whole an exception to the rule; and, even in Alabama, where I saw a calcareous member of this group, composed of marl-stone, it was more like the English and French Lias than any other European secondary deposit.

* See a paper by the Author, Quart. Journ. Geol. Soc., vol, i. p. 79.

+ In the Principles of Geology, ninth ed. p. 145, I cited Dr. Leidy of Philadelphia as haring described (Proceedings of Acad. Nat. Sci. Philad., 1851) two species of cetacea of a new genus which he called Priscodelphinus, from the greensand of New Jersey. In $1853 \mathrm{I}$ saw the two vertebræ at Philadelphia on which this new genus was founded, and afterwards, with the aid of Mr. Conrad, traced one of them to a Miocene marl pit in Cumberland County, New Jersey. The other (the Plesiosaurus of Harlan), labelled "Mullica Hill" in the Museum, would no doubt be an upper cretaceous fossil, if really derived from that locality, but its mineral condition makes the point rather doubtful. The tooth of Stenorhynchus vetus figured by Leidy from a drawing of Conrad's (Proceed. of Acad. Nat. Sci. Philad., 1853, p. 377 ), was found by Samuel R. Wetherill, Esq., in the greensand $1 \frac{1}{2}$ mile southeast of Burlington. This gentleman related to me and Mr. Conrad, in 1853, the circumstances under which he met with it, associated with Ammonites placenta, Ammonites Delawarensis, Trigonia thoracica, \&c. The tooth has been mislaid, but not until it had excited much interest and had been carefully examined by good zoologists. 
At the base of the system in Alabama, I found dense masses of shingle, perfectly loose and unconsolidated, derived froin the waste of palæozoic (or carboniferous) rocks, a mass in no way distinguishable, except by its position, from ordinary alluvium, but covered with marls abounding in Inocerami.

In Texas, according to F. Römer, the chalk assumes a new lithological type, a large portion of it consisting of hard siliceous limestone, but the organie remains leave no doubt in regard to its age, the Baculites anceps and 10 other European species occurring there. Fossil plants from New Jersey, and others, obtained from the cretaceous rocks by Messrs. Meek and Hayden in Nebraska, include, according to Dr. Newberry, many genera of dicotyledonous angiosperms in the same way as does the flora of Aix-la-Chapelle, above described, p. 335.

In South America the cretaceous strata have been discovered in Columbia, as at Bogota and elsewhere, containing Ammonites, Hamites, Inocerami, and other characteristic shells.*

In the south of India, also, at Pondicherry, Verdachellum, and Trinconopoly, Messrs. Kaye and Egerton have collected fossils belonging to the cretaceous system. Taken in connection with those from the United States, they prove, says Prof. E. Forbes, that those powerful causes which stamped a peculiar character on the forms of marine animal life at this period, exerted their full intensity through the Indian, European, and American seas. $\uparrow$ Here, as in North and South America, the cretaceous character can be recognized even where there is no specific identity in the fossils; and the same may be said of the organic type of those rocks in Europe and India which occur next to the chalk in the ascending and descending order, namely, the Eocene and the Oolitic.

* Proceed, of the Geol. Soc., vol, iv. p. 391.

† See Forbes, Quart. Geol. Journ., vol. i. p. 79. 


\title{
CHAPTER XVIII.
}

\author{
LOWER CRETACEOUS AND WEALDEN FORMATIONS.
}

Lower Greensand-Term "Neocomian"-Atherfield section, Isle of Wight-Fossils of Lower Greensand-Palæontological relations of the Upper and Lower Cretaceous strata-Wealden Formation-Freshwater strata intercalated between two marine groups-Weald Clay and Hastings Sand-Tunbridge rocks-Fossil shells, fish, and plants of Wealden-Their relation to the Cretaceous type-Geographical extent of Wealden-Movements in the earth's crust to which the Wealden owed its origin and submergence.

THe term "Lower Greensand" has hitherto been most commonly applied to such portions of the Cretaceous series as are older than the Gault. But the name has often been complained of as inconrenient, and not without reason, since green particles are wanting in a large part of the strata so designated, eren in England, and wholly so in some European countries. Moreover, a subdivision of the Upper Cretaceous group has likewise been called Greensand, and to prerent confusion the terms Tpper and Lower Greensand were introduced. Such a nomenclature naturally leads the uninitiated to suppose that the two formations so named are of somewhat coördinate ralue, which is so far from being true, that the Lower Greensand, in its widest acceptation, embraces a series nearly as important as the whole Upper Cretaceous group, from the Gault to the Maestricht beds inclusire; while the Upper Greensand is but one subordinate member of this same group. Many eminent geologists hare, therefore, proposed the term "Neocomian?" as a substitute for Lorrer Greensand; because, near Neufchatel (Neocomum), in Switzerland, these Lower Greensand strata are well developed, entering largely into the structure of the Jura mountains. By the same geologists the Tealden beds are usually classed as "Lower Neocomian," a classification which mill not appear inappropriate when we have explained, in the sequel, the intimate relation of the Lower Greensand and Wealden fossils.

Dr. Fitton, to whom we are indebted for an excellent monograph on the Lower Cretaceous (or Greensand) formation as developed in England, gires the following as the succession of rocks seen in parts of Kent:

No. 1. Sand, white, Jellowish, or ferruginous, with concretion of limestone and chert, - - - _ - 70 feet.

2. Sand with green matter, _ _ _ _ - 70 to 100 feet.

3. Calcareous stone, called Kentish rag, - - $\quad-60$ to 80 feet. 
In his detailed description of the fine section displayed at Atherfield, in the south of the Isle of Wight, we find the limestone wholly wanting; in fact, the variations in the mineral composition of this group, even in contiguous districts, is very great; and on comparing the Atherfield beds with corresponding strata at Hythe, in Kent, distant 95 miles, the whole series presents a most dissimilar aspect.*

On the other hand, Professor E. Forbes has shown that when the sixty-three strata at Atherfield are severally examined, the total thickness of which he gives as 843 feet, there are some fossils which range through the whole series, others which are peculiar to particular divisions. As a proof that all belong chronologically to one system, he states that whenever similar conditions are repeated in overlying strata the same species reappear. Changes of depth, or of the mineral nature of the sea-bottom, the presence or absence of lime or of peroxide of iron, the occurrence of a muddy, or a sandy, or a gravelly bottom, are marked by the banishment of certain species and the predominance of others. But these differences of conditions being mineral, chemical, and local in their nature, have nothing to do with the extinction, throughout a large area, of certain animals or plants. The rule laid down by this eminent naturalist for enabling us to test the arrival of a new state of things in the animate world, is the repre sentation by new and different species of corresponding genera of mollusca or other beings. When the forms proper to loose sand or soft clay, or to a stony or calcareous bottom, or to a moderate or great depth of water, recur with all the same species, the interval of time has been, geologically speaking, small, however dense the mass of matter accumulated. But if, the genera remaining the same, the species are changed, we have entered upon a new period; and no similarity of climate, or of geographical and local conditions, can then recall the old species which a long series of destructive causes in the animate and inanimate world has gradtually annihilated. On passing from the Lower Greensand to the Gault, we suddenly reach one of these new epochs, scarcely any of the fossil species being common to the lower and upper cretaceous systems, a break in the chain implying no doubt many missing links in the series of geological monuments, which we may some day be able to supply.

One of the largest and most abundant shells in the lowest strata of the Lower Greensand, as displayed in the Atherfield section, is the large Perna Mulleti, of which a reduced figure is here given (fig. 330).

In the south of England, during the accumulation of the Lower Greensand above described, the bed of the sea appears to have been continually sinking, from the commeneement of the period when the freshwater Wealden beds were submerged, to the deposition of those strata on which the gault immediately reposes.

* Dr. Fitton, Quart. Geol. Journ., vol. i. p. 179, ii. p. 55, and iii. p. 289, where comparative sections and a valuable table showing the vertical range of the various fossils of the Lower Greensand at Atherfield are given. 
Pebbles of quartzose sandstone, jasper, and flinty slate, together with grains of chlorite and mica, speak plainly of the nature of the

Fig. 330.

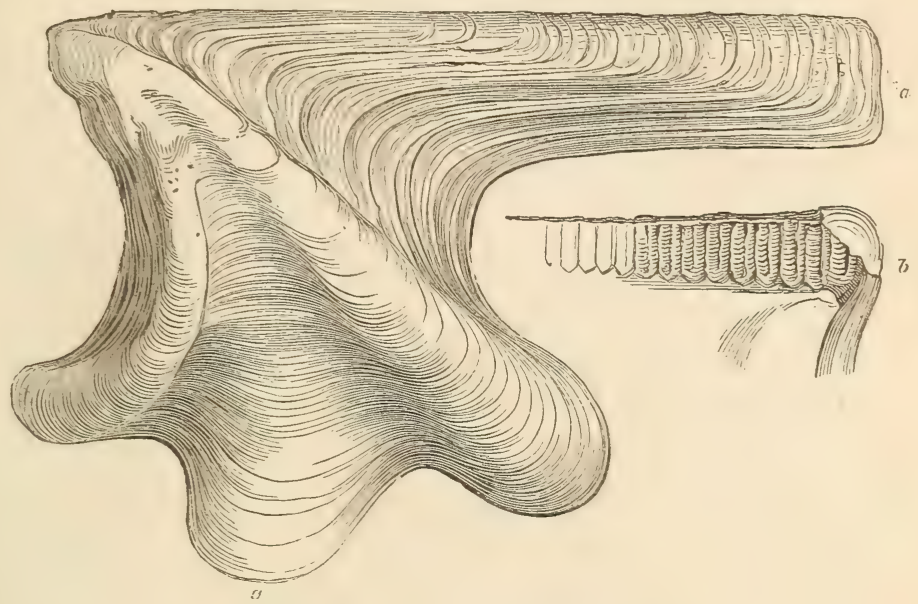

Perna Mulleti. Desh. and Leym.

a. Exterior. $\quad b$. Part of hinge of upper valve.

preëxisting rocks, from the wearing. down of which the Greensand beds were derived. The land, consisting of such rocks, was doubtless submerged before the origin of the white chalk, a deposit which originated in a more open sea, and in clearer waters.

The fossils of the Lower Cretaceous are for the most part specifically distinct from those of the Upper Cretaceous strata.

Among the former we often meet with the genus Scaphites or Ancyloceras (fig. 331), which has been aptly described as an ammo-

Fig. 331.

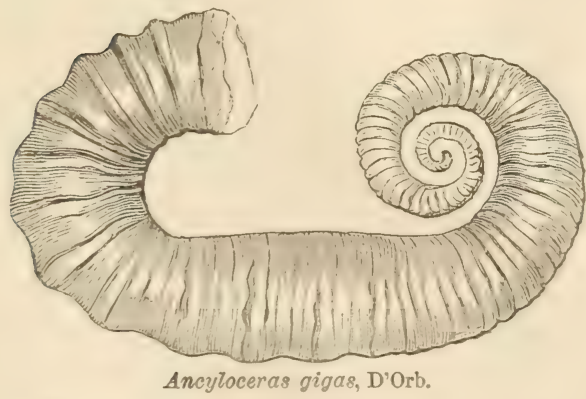

Fig. 332 .

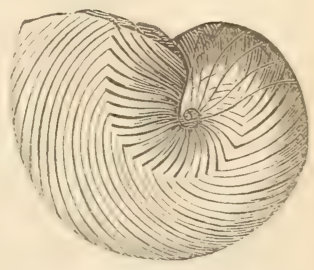

Nautilus plicatus, Sow., in Fitton's Monog.

nite more or less uncoiled; also a furrowed Nautitus, $N$. plicatus (fig. 332), Trigonia caudata (fig. 334), likewise found in the Blackdown bers (sec above, p. 332), and Gervillia, a biralve genus allied to 
Avicula; also the remarkable shell Diceras Lonsdatii, eminently characteristic of the ferruginous beds of the Lower. Greensand in

Fig. 333.

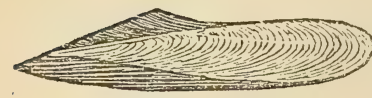

Gervillia anceps, Desh. Lower Greensand.
Fig. 334.

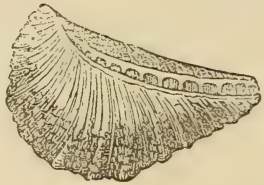

Trigonia caudata, Agass. Lower Greensand.
Fig. 335.

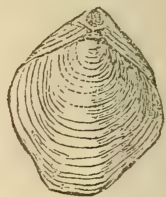

Terebratula sella, Sow. Lower Greensand.

Wilts. This genus is closely allied to Chama, and the cast of the interior has been compared to the horns of a goat. The same shell has been referred by some authors to Caprotina, and by others to Requienia.

Fig. 336.

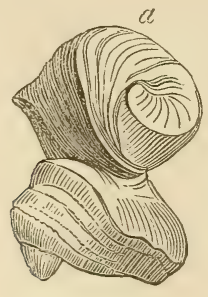

Diceras Lonsdati a. The bivalve shell.

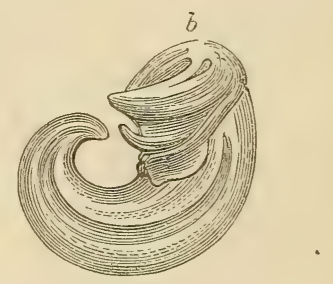

Lower Greensand, Wilts.

b. Cast of the same.

Palceontological relation of the Upper and Lower Cretaceous Rocks. -Professor Ramsay has deduced from an analysis of tables drawn up by Mr. Etheridge of the fossils of the Cretaceous series of Great Britain the following conclusions:-First, that a great number of species are common to the different subdivisions of the Upper Cretaceous group, such as the Gault, Upper Greensand, White Chalk, \&c.

Secondly, that there is a great break between the Lower and Upper Cretaceous series, for of 280 species of all kinds of animal remains known in the Lower Cretaceous, 233 are peculiar, and 51, or only about 18 per cent., pass from the Lower Greensand to the Gault and overlying strata.

The same geologist adds: "This break and disappearance of so many species in succession is accompanied by a stratigraphical break as well; for round the Weald it is known that in some of the very few exposures of junctions the Gault has been seen lying on eroded surfaces of Lower Greensand, while in the western and middle parts of England, on the west and north of the great chalk escarpment, the frequent and sudden overlaps of the Lower Greensand $b_{F}$ the 
Gault leave no doubt that the upper formation lies actually unconformably on the lower, and the time occupied by the denudation has been with us unrepresented by any stratified formation." * Yet while there is so much difference between the organic remains of the Upper and Lower Cretaceous rocks, the Cretaceous series, palæontologically considered, forms an independent whole, having scarcely any species in common with the Oolitic series which preceded it, or with the Eocene which followed. Thus, by referring to the tables above mentioned, we observe that 521 species are enumerated as known in the Upper Chalk of England, all of which, with the exception of Tercbratula caput-serpentis, and a few Foraminifera, had become extinct before the beginning of the Eocene epoch, as represented by the Thanet sands.

On the other hand, when the lowest marine strata or Atherfield beds of the Cretaceous series are compared with the marine formations of the Upper Oolite, we find that no British species pass from one to the other, and we know that this change in the organic world coincides in date with that enormous lapse of time during which the freshwater formations of the Wealden and Purbeck, more than 1500 feet in thickness, were deposited.

\section{WEALDEN FORMATION.}

Beneath the Lower Greensand in the S.E. of England, a freshwater formation is found, called the Wealdon (see Nos. 5 and 6, Map, fig. 355, p. 357), which, although it occupies a small horizontal area in Europe, as compared to the TWhite Chalk and Greensand, is nevertheless of great geological interest, since the imbedded remains gire us some insight into the nature of the terrestrial fauna and flora of the Lower Cretaceous epoch. The name of Wealden was given to this group because it was first studied in parts of Kent, Surrey, and Sussex, called the Weald (see Map, p. 357); and we are indebted to Dr. Mantell for haring shown, in 1822, in his "Geology of Sussex," that the whole group was of fluviatile origin. In proof of this he called attention to the entire absence of Ammonites, Belemnites, Terebratulæ, Echinites, Corals, and other marine fossils, so characteristic of the Cretaceous rocks above, and of the Oolitic strata below, and to the presence in the Teald of Paludinæ, Miclaniæ, and rarious fluviatile shells, as well as the bones of terrestrial reptiles and the trunks and leaves of land-plants.

The eridence of so unexpected a fact as the infra-position of a dense mass of purely freshwater origin to a deep-sea deposit (a phenomenon with which we hare since become familiar) was receired, at first, with no small doubt and incredulity. But the relative position of the beds

* Ramsay, Anniversary Address, Geol. Quart. Journ., vol. xx. p. 58. 
is unequivocal; the Weald Clay being distinctly seen to pass beneath the Lower Greensand in various parts of Surrey, Kent, and .Sussex, and to reappear in the Isle of Wight at the base of the Cretaceous series, being, no doubt, continuous far bencath the surface, as indicated by the dotted lines in the annexed diagram, fig. 337.

Fig. 337.

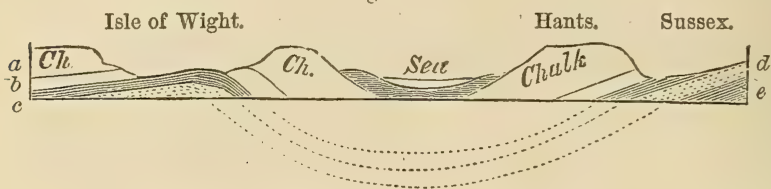
a. Chalk.
b. Greensand.
c. Weald Clay.
d. Hastings Sand.
e. Purbeck Beds.

The Wealden is divisible into two minor groups:

\section{Greatest known thickness.}

1st. Weald Clay-blue and brown clay and shale, sometimes including thin beds of sand and shelly limestone with Paludina, $600^{\circ}$ feet.

2d. Hastings Sand-chiefly arenaceous, but in which occur some clays and calcareous grits, *

$740 \quad 6$

Another freshwater formation, called the Purbeck, consisting of various limestones and marls, containing distinct species of molluses, Cyprides, and other fossils, lies immediately beneath the Wealden in the south-east of England. As it is now found to be more nearly related, by its organic remains, to the Oolitic than to the Cretaceous Series, it will be treated of in the twentieth chapter.

\section{Weald Clay.}

The upper division, or Weald Clay, is of purely freshwater origin. Its highest beds are not only conformable, as Dr. Fitton observes, to the inferior strata of the Lower Greensand, but of similar mineral composition. To explain this, we may suppose, that, as the delta of a great river was tranquilly subsiding, so as to allow the sea to encroach upon the space previously occupied by freshwater, the river still continued to carry down the same sediment into the sea. In confirmation of this view it may be stated, that the remains of the Igugnodon Mantelli, a gigantic terrestrial reptile, very characteristic of the Wealden, has been discovered near Maidstone, in the overlying Kentish rag, or marine limestone of the Lower Greensand. Hence we may infer, that some of the saurians which inhabited the country of the great river continued to live when part of the country had become submerged beneath the sea. Thus, in our own times, we may suppose the bones of large alligators to be frequently entombed in recent

* Dr. Fitton, Geol. Trans., Second Series, vol, iv. p. 320. 
freshwater strata in the delta of the Ganges. But if part of that delta should sink down so as to be covered by the sea, marine formations might begin to accumulate in the same space where freshwater beds had previously been formed; and yet the Ganges might still pour domn its turbid waters in the same direction, and carry seaward the carcases of the same species of alligator, in which case their bones might be included in marine as well as in subjacent freshwater strata.

The Iguanodon, first discovered by Dr. Mantell, has left more of its remains in the Wealden strata of the south-eastern counties and Isle of Wight than has any other genus of associated saurians. It was an herbivorous reptile, and regarded by Cuvier as more extraordinary than any with which he was acquainted; for the teeth, thongh bearing a great analngy, in their general form and crenated edges (see figs. $338 a, 338 b$ ), to the modern Iguanas which now frequent the tropi-

Fig. 338.
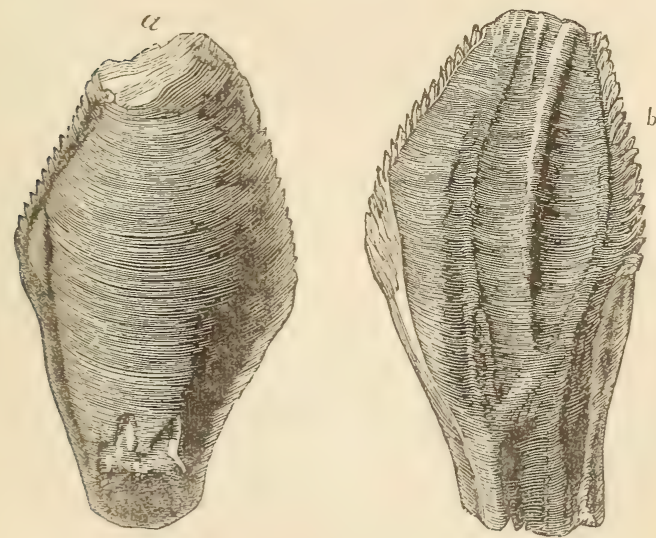

Fig. 339.

Fig. 338. $a, b$. Tooth of Iguanodon Mantelli.

339. $a$. Partially worn tooth of young individnal of the same.

b. Crown of tooth in adult, worn down. (Mantell.)

cal wnods of America and the West Indies, exhibit many striking and important differences. It appears that they have often been worn br the process of mastication ; whereas the existing herbivorous reptiles clip and gnaw off the regetable productions on which they feed, but do not chew them. Their teeth frequently present an appearance of haring been chipped off, but never, like the fossil teeth of the Iguanodon, have a flat ground surface (see fig. 339 b), resembling the grinders of herbirorous mammalia. Dr. Mantell computes that the teeth and bones of this species which passed under his examination during trenty years must have belonged to no less than seventy-one distinct indiriduals, varying in age and magnitude from the reptile just burst from the egg, to one of which the femur measured twenty-four 
inches in circumference. Yet, notwithstanding that the tecth were more numerous than any other bones, it is remarkable that it was not until the relics of all these individuals had been found, that a solitary example of part of a jawbone was obtained. More recently remains both of the upper and the lower jaw have been met with in the Hastings beds in Tilgate Forest. Their size was somewhat greater than, had been anticipated, and Dr. Mantell, who does not agree with Professor Owen that the tail was short, estimates the probable length of some of these saurians at between 50 and 60 feet. The largest femur yet found measures 4 feet 8 inches in length, the circumference of the shaft being 25 inches, and if measured round the condyles, 42 inches.

Occasionally bands of limestone, called Sussex Marble, occur in the Weald Clay, almost entirely composed of a spécies of Paludina, closely resembling the common $P$. vivipara of English rivers.

Shells of the Cypris, a genus of Crustaceans before mentioned (p. 31 ) as abounding in lakes and ponds, are also plentifully scattered through the clays of the Wealden, sometimes producing, like plates of mica, a thin lamination (see fig. 342). Similar cypris-bearing marls are found in the lacustrine tertiary beds of Auvergne (see above p. 224).

Fig. 340 .

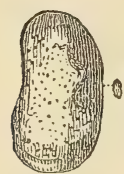

Cypris spinigera, Fitton.
Fig. 341 .

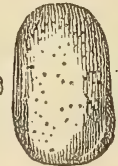

Cypris Valdensis, Fitton. (C. $f a b a$, Min. Con. 485.)

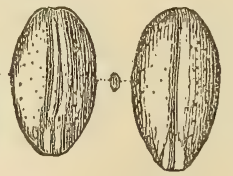

Hastings Sands.

This lower division of the Wealden consists of sand, sandstone; calciferous grit, clay, and shale ; the argillaceous strata, notwithstanding the name, predominating somewhat over the arenaceous, as will be seen by reference to the following section, drawn up by Messrs. Drew and Foster, of the Government Survey of Great Britain:

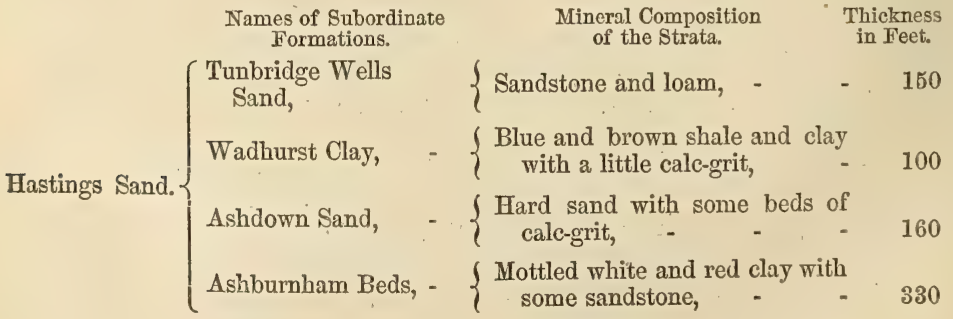


The picturesque scenery of the "High Rocks" and other places in the neighborhood of Tunbridge is caused by the steep ratural cliffs, to which a hard be of white sand, occurring in the upper part of the Tumbridge Wells Sand, mentioned in the preceding table, gires rise. Mr. Drem found this bed of "rock-sand" to vary in thickness from 25 to 48 feet. Large masses of it, which were by no means hard or capable of making a good building-stone, form, nerertheless, projecting rocks mith perpendicular faces, and resist the degrading action of the river because, says Mr. Drew, they present a solid mass without planes of division.* The calcareous sandstone and grit of Tilgate Forest near Cuckfield, in which the remains of the Iguanodon and Hylæosaurus were first found by Dr. Mantell, constitute an upper member of the Tunbridge Wells Sand, while the "sand-rock" of the Hastings cliffs, about 100 feet thick, is one of the lower members of the same. The reptiles, which are very abundant in this division, consist partly of saurians, referred by Owen and Mantell to eight genera, among which, besides those already enumerated, we find the Megalosaurus and Plesiosaurus. The Pterodactyl also, a flying reptile, is met with in the snme strata, and many remains of Chelonians of the genera Trionyx and Emys, now confined to tropical regions.

The fishes of the Wealden are chiefly referable to the Ganoid and Placoid orders. Among them the teeth and scales of Lejsidotus are most widely diffused (see fig. 343). These ganoids were allied to the

Fig. 343.
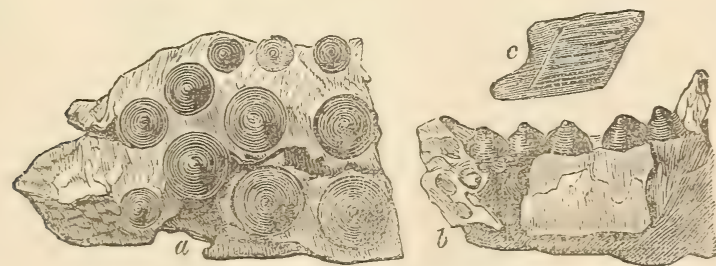

Lepidotus Mantelli, Agass. Wealden.

a. Palate and teeth.

b. Side view of teeth.

c. Scale.

Lepidosteus, or Gar-pike, of the American rivers. The whole body was corered with large rhomboidal scales, rery thick, and having the exposed part coated with enamel. Most of the species of this genus are supposed to hare been either rircr-fish, or inhabitants of the sea at the mouth of estuaries.

The shells of the Hasting's beds belong to the genera Mclanopsis, Melania, Paludina, Cyrena, Cyclas, Unio (see fig. 34.4), and others, which inhabit rivers or lakes; but one band has been found at Punfield, in Dorsetshire, indicating a brackish state of the water, where the genera Corbula (see fig. 345), Mytilus, and Ostrea occur; and in 
some places this bed becomes purely marine, the species being for the most part peculiar, but several of them well-known Lower Greensand

Fig. 344.
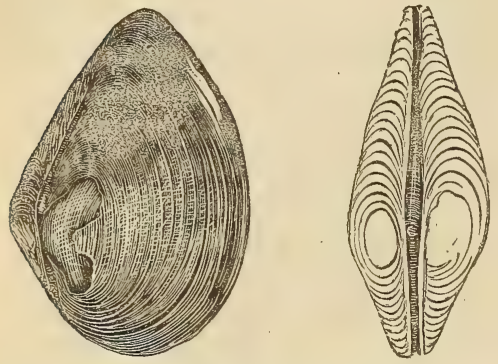

Fig. 345 .

Unio Valdensis, Mant.

Isle of Wight and Dorsetshire; in the lower beds of the Hastings Sands.
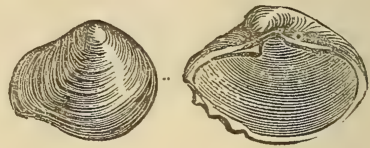

Corbula alata, Fitton. Magnified. In brackish-water beds of the Hastings Sands, Punfield Bay.

fossils, among which Ammonites Deshayesii may be mentioned. These facts show how closely related were the faunas of the Wealden and Cretaceous periods.

At different heights in the Hastings Sand, we find again and again slabs of sandstone with a strong ripple-mark, and between these slabs beds of clay many yards thick. In some places, as at Stammerham, near Horsham, there are indications of this clay having been exposed so as to dry and crack before the next layer was thrown down upon it. The open cracks in the clay have served as moulds, of which casts have been taken in relief, and which are, therefore, seen on the lower surface of the sandstone (see fig. 346).

Fig. 346.

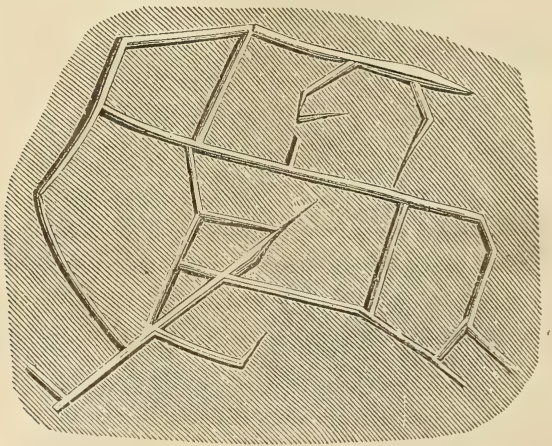

Underside of slab of sandstone about one yard in diameter. Stammerham, Sussex.

Near the same place a reddish sandstone occurs in which are innumerable traces of a fossil vegetable, apparently Sphenopteris, the stems and branches of which are disposed as if the plants were stand- 
ing erect on the spot where they originally grew, the sand having been gently deposited upon and around them; and similar appearances hare been remarked in other places in this formation.* In the same division also of the Wealden, at Cuckfield, is a bed of gravel or conglomerate, consisting of water-worn pebbles of quartz and jasper, with rolled bones of reptiles. These must have been drifted by a current, probably in water of no great depth.

From such facts we may infer that, notwithstanding the great thickness of this division of the Wealden, the whole of it was a deposit in water of a moderate depth, and often extremely shallow. This idea may seem startling at first, yet such would be the natural consequence of a gradual and continuous sinking of the ground in an estuary or bay, into which a great rirer discharged its turbid waters. By each foot of subsidence, the fun-

Fig. 347.

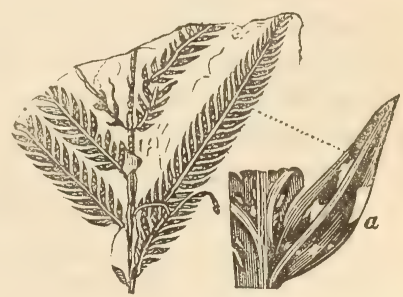

Sphenopteris gracilis (Fitton), from the Hastings Sands near Tunbridge Wells. a. A portion of the same magnified. damental rock would be depressed one foot farther from the surface; but the bay would not be deepened, if newly deposited mud and sand should raise the bottom one foot. On the contrary, such new strata of sand and mud might be frequently laid dry at low water, or overgrown for a season by a vegetation proper to marshes.

Area of the Wealden.-In regard to the geographical extent of the Wealden, it cannot be accurately laid down; because so much of it is concealed beneath the newer marine formations. It has been traced about 200 English miles from west to east, from the coast of Dorsetshire to near Boulogne, in France; and nearly 200 miles from northwest to southeast, from Surrey and Hampshire to Beauvais, in France. If the formation be continuous throughout this space, which is very doubtful, it does not follow that the whole was contemporaneous; because, in all likelihood, the physical geography of the region underwent frequent changes throughout the whole period, and the estuary may have altered its form, and even shifted its place. Dr. Dunker, of Cassel, and H. von Meyer, in an excellent monograph on the Wealdens of Hanorer and Westphalia, have shown that they correspond so closely, not only in their fossils, but also in their mincral characters, with the English series, that we can scarccly hesitate to refer the whole to one great delta. Even then, the magnitude of the deposit may not exceed that of many modern rivers. Thus, the delta of the Quorra or Niger, in Africa, stretches into the interior for more than 170 miles, and occupies, it is supposed, a space of more than 300 miles along the coast, thus forming a surface of more than 25,000

* Mantell, Geol. of S. E. of England, p. 244.

+ Fitton, Geol. of Hastings, p. 58, who cites Lander's Travels. 
square miles, or equal to about one half of England.* Besides, we know not, in such cases, how far the fluviatile sediment and.organic remains of the river and the land may be carried out from the coast, and spread over the bed of the sea. I have shown, when treating of the Mississippi, that a more ancient delta, including species of shells, such as now inhabit Louisiana, has been upraised, and made to occupy a wide geographical area, while a newer delta is forming; ; and the possibility of such morements, and their effects, must not be lost sight of when we speculate on the origin of the Wealden.

If it be asked where the continent was placed from the ruins of which the Wealden strata was derived, and by the drainage of which a great river was fed, we are half tempted to speculate on the former existence of the Atlantis of Plato. The story of the submergence of an ancient continent, however fabulous in history, must have been true again and again as a geological event.

The real difficulty consists in the persistence of a large hydrographical basin, from whence a great body of fresh water was poured into the sea, precisely at a period when the neighboring area of the Wealden was gradually going downward 1000 feet or more perpendicularly. If the adjoining land participated in the movement, how could it escape being submerged, or how could it retain its size and altitude so as to continue to be the source of such an inexhaustible supply of fresh water and sediment? In answer to this question, we are fairly entitled to suggest that the neighboring land may have been stationary, or may even have undergone a contemporaneous slow upheaval. There may have been an ascending movement in one region, and a descending one in a contiguous parallel zone of country; just as the northern part of Scandinavia is now rising, while the middle portion (that south of Stockholm) is unmoved, and the southern extremity in Scania is sinking, or at least has sunk within the historical period. We must, nevertheless, conclude, if we adopt the above hypothesis, that the depression of the land became general throughout a large part of Europe at the close of the Wealden period, and this subsidence brought in the cretaceous ocean.

The flora of the Wealden and the Lower Greensand is characterized by a great abundance of Coniferæ, Cycadex, and Ferns, and by the absence of leaves and fruits of dicotyledonous angiosperms. The discovery, in 1855, in the Hastings beds of the Isle of Wight, of Gyrogonites, or spore-vessels of the Chara, supplied a link between the secondary and tertiary flora which was previously wanting.

* See above, p. 84 ; and Second Visit to the U. S., vol. ii. chap. xxxiv.

†. See the Author's Anniversary Address, Geol. Soc., 1850, Quart. Geol. Journ. vol. vi. p. 52. 


\section{CHAPTER XIX.}

\section{DENUDATION OF THE CHALK AND WEALDEN.}

Physical geography of certain districts composed of Cretaceous and Wealden strata - Lines of inland chalk-cliffs on the Seine in Normandy-Outstanding pillars and needles of chalk-Denudation of the chalk and Wealden in Surrey, Kent, and Sussex-Chalk once continuous from the North to the South Downs-Anticlinal axis and parallel ridges-Longitudinal and transverse valleys-Chalk escarpments-Rise and denudation of the strata gradual-Ridges formed by harder, valleys by softer beds-At what periods the Weald Valley was denuded-Why no alluvium, or wreck of the chalk, in the central district of the Weald-Successive periods of marine denudation-The latest of these posterior to the Upper Miocene era-Elephant-bed, Brighton-Sangatte Cliff-The great escarpments and transverse valleys of the chalk mainly due to the waves and tides of the sea-Paroxysmal causes unnecessary for explaining the external configuration of the Wealden.

Alt the fossiliferous formations may be studied by the geologist in ¿wo distinct points of view: 1st, in reference to their position in the series, their mineral character and fossils; and, $2 \mathrm{dly}$, in regard to their physical geography, or the manner in which they now enter, as mineral masses, into the external structure of the earth; forming the bed of lakes and seas, or the surface or foundation of hills and valleys, plains and table-lands. Some account has already been given, on the first head, of the Tertiary, the Cretaceous, and the Wealden strata; and we now proceed to consicier certain features in the physical geography of these groups as they occur in parts of England and France.

The hills composed of white chalk in the S. E. of England have a smooth rounded outline, and, being usually in the state of sheep-pastures, are free from trees or hedgerows; so that we have an opportunity of observing how the ralleys by which they are drained ramify in all directious, and become wider and deeper as they descend. Although these valleys are now for the most part dry, except during heavy rains and the melting of snow, they may have been due to aqueous denudation, having been excarated when the chalk emerged gradually from the sea. This opinion is confirmed by the occasional occurrence of what appear to be long lines of inland cliffs, in which the strata are cut off abruptly in steep and often vertical precipices. The true nature of such escarpments is nowhere more obvious than in parts of Normandy, where the river Seine and its tributaries flow through deep winding valleys, hollowed out of chalk horizontally stratified. Thus, for example, if we follow the Seine fur a distanco of about 30 miles from Andelys to Elbœuf, we find the valley flanlicd on both sides by a steep slope of chalk, with numerous beds of flint, the formation being laid open for a thickness of about 250 and 300 feet. Abore the chalk is an overlying 


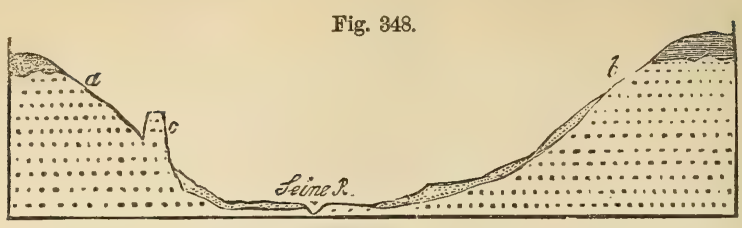

Section across Valley of Seine.

mass of sand, gravel, and clay, from 30 to 100 feet thick. The two opposite slopes of the hills $\alpha$ and $b$, fig. 348, where the chalk appears at the surface, are from 2 to 4 miles apart, and they are often perfectly smooth and even, like the steepest of our downs in England; but at many points they are broken by one, two, or more ranges of vertical and even overhanging cliffs of bare white chalk with flints. At some points detached needles and pinnacles stand in the line of the cliffs, or in front of them, as at $c$, fig. 348. On the right bank of the Seine, at Andelys, one range, about 2 miles long, is seen varying from 50 to 100 feet in perpendicular height, and having its continuity broken by a number of dry valleys or coombs, in one of which occurs a detached rock or needle, called the Tête d'Homme (see figs. 349, 350). The top of this rock presents a precipitous face toward every point of the compass ; its vertical height being more than 20 feet on the side of the downs, and 40 toward the Seine, the average diameter of the pillar being 36 feet. Its composition is the same as that of the larger cliffs in its neighborhood, namely, white chalk, having occasionally a crystalline texture like marble, with layers of flint in nodules and tabular masses. The flinty beds

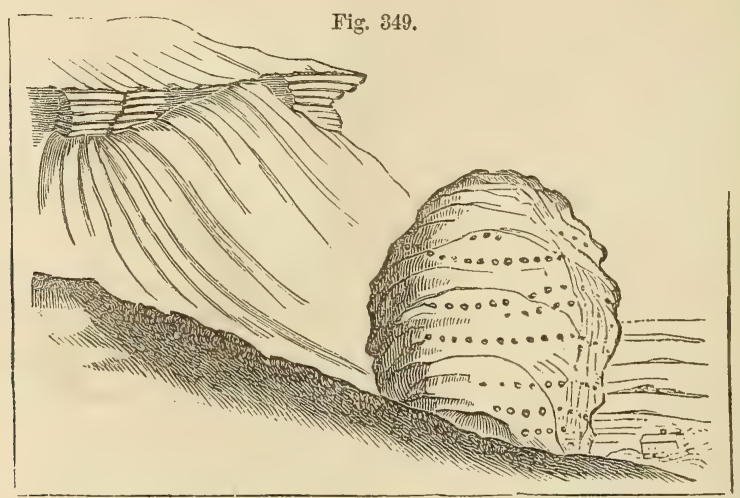

Vicw of the Tête d'Homme, Andelys, seen from above.

often project in relief 4 or 5 feet beyond the white chalk, which is generally in a state of slow decomposition, either exfoliating or being covered with white powder, like the chalk cliffs on the English coast; and, as in them, this superficial powder contains in some places common salt.

Other cliffs are situated on the right bank of the Seine, opposite Tournedos, between Andelys and Pont de l'Arche, where the precipices are 


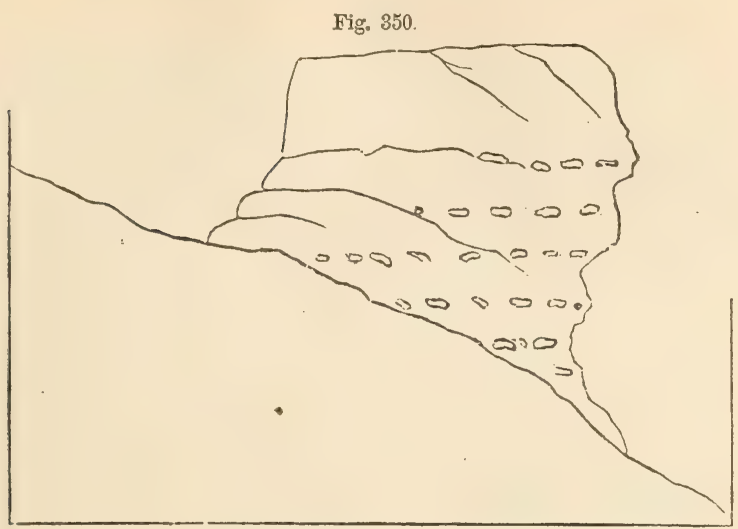

Side view of the Tête d'Homme. White chalk with flints.

from 50 to 80 feet high : sereral of their summits terminate in pinnacles; and one of them, in particular, is so completely detached as to present a perpendicular face 50 feet high toward the sloping down. On these cliffs sereral ledges are seen, which mark so many levels at which the waves of the sea may be supposed to have encroached for a long period. At a still greater height, immediately above the top of this range, are three much smaller cliffs, each about 4 feet high, with as many intervening terraces, which are continued so as to sweep in a semicircular form round an adjoining coomb, like those in Sicily before described (p. 76).

If we then descend the river from Vatteville to a place called Senneville, we meet with a singular needle about 50 feet high, perfectly isolated on the escarpment of chalk on the right bank of the Seine (see fig. 351). Another conspicuous range of inland cliffs is situated about 12

Fig. 351.

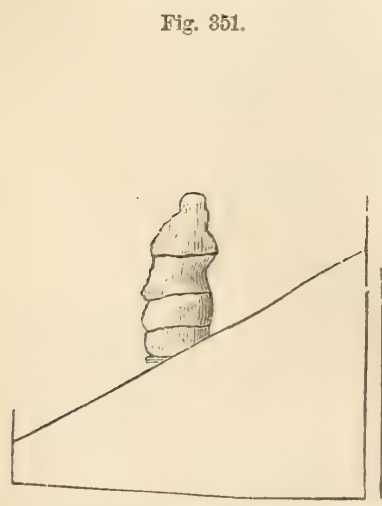

Chalk pinnacle at Senneville.
Fig. 352.

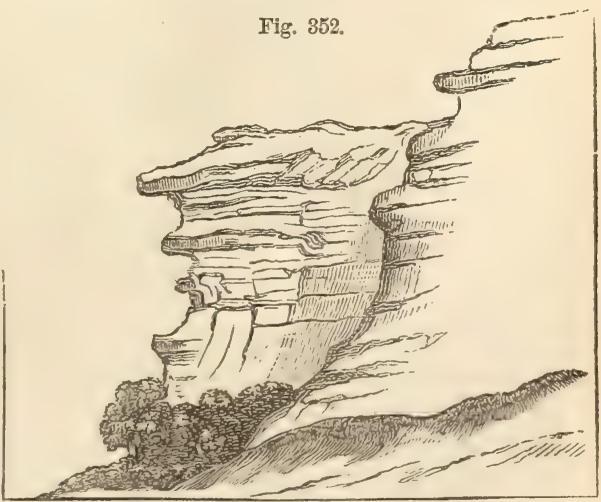

Roches d'Orival, Elbœuf.

miles below on the left bank of the Seine, beginning at Elbœuf, and comprehencing the Roches d'Orival (see fig. 352). Like those before described, it has an irregular surface, often overhanging, and with beds 
of flint projecting several feet. 'Like them, also, it exhibits a white powdery surface, and consists entirely of horizontal chalk with flints. It is 40 miles inland, its height, in some parts, exceeds 200 feet, and its base is only a few feet above the level of the Seine. It is broken, in one place, by a pyramidal mass or needle, 200 feet high, called the Roche de Pignon, which stands out about 25 feet in front of the upper portion of the main cliffs, with which it is united by a narrow ridge about 40 feet lower than its summit (see fig. 353). Like the detached

Fig. 353.

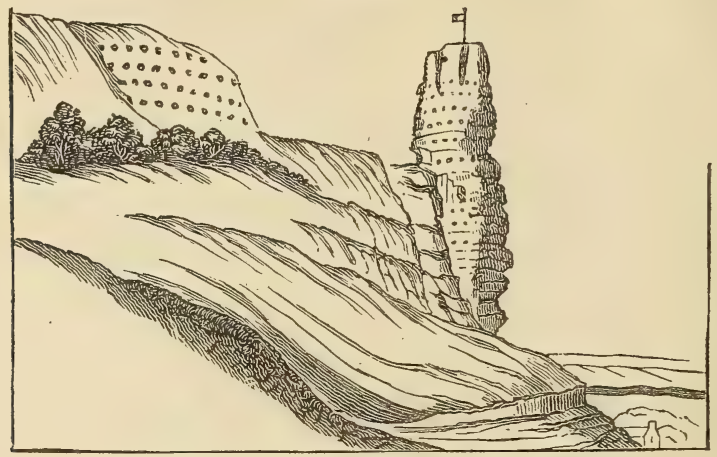

View of the Roche de Pignon, seen from the south.

rocks before mentioned at Senneville, Vatteville, and Andelys, it may be compared to those needles of chalk which occur on the coast of Normandy* (see fig. 354), as well as in the Isle of Wight and in Purbeck.

Fig. 354 .

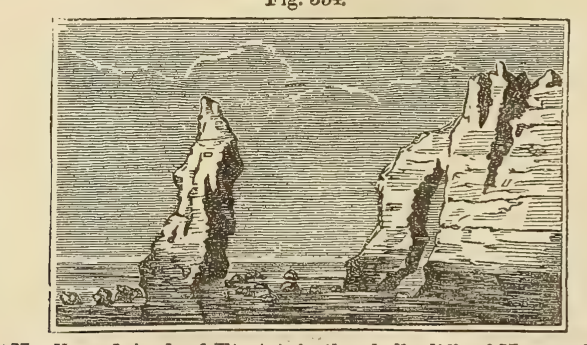

Needle and Arch of Etretat, in the chalk cliffs of Normandy. Height of Arch 100 feet. (Passy.) $\dagger$

The foregoing description and drawings will show, that the evidence of certain escarpments of the chalk having been originally sea-cliffs, is far more full and satisfactory in France than in England. If it be asked why, in the interior of our own country, we meet with no ranges of precipices equally vertical and overhanging, and no isolated pillars or needles, we may reply that the greater hardness of the chalk in Normandy may, no doubt, be the chief cause of this difference. But the

* An account of these cliffs was read by the author to the British Assoc. at Glasgow, Sept. 1840.

† Seine-Inférieure, p. 142, and pl. 6, fig. 1. 
frequent absence of all signs of littoral denudation in the valley of the Seine itself is a negative fact of a far more striking and perplexing character. The cliffs, after being almost continuous for miles, are then wholly wanting for much greater distances, being replaced by a green sloping down, although the beds remain of the same composition, and are equally horizontal; and although we may feel assured that the manner of the uphearal of the land, whether intermittent or not, must have been the same at those intermediate points where no.cliffs exist, as at others where they are so fully developed. But, in order to explain such apparent anomalies, the reader must refer again to the theory of denudation, as expounded in the 6th chapter; where it was shown, first, that the undermining force of the wares and marine currents varies greatly at different parts of every coast; secondly, that precipitous rocks have often decomposed and crumbled down; and thirdly, that terraces and small cliffs may occasionally lie concealed beneath a talus of detrital matter.

Denudation of the Weald Valley.-No district is better fitted to illustrate the manner in which a great series of strata may have been upheared and gradually denuded than the country intervening between the North and South Downs. This region, of which a ground-plan is given in the accompanying map (fig. 355), comprises within it the whole of Sussex, and parts of the counties of Kent, Surrey, and Hampshire. The space in which the formations older than the White Chalk, or those from the Gault to the Hastings sands inclusive, crop out, is bounded everywhere by a great escarpment of chalk, which is continued on the opposite side of the channel in the Bas Boulonnais in France, where it forms the semicircular boundary of a tract in which older strata also appear at the surface. The whole of this district may therefore be considered geologically as one and the same.

Fig. 355 .

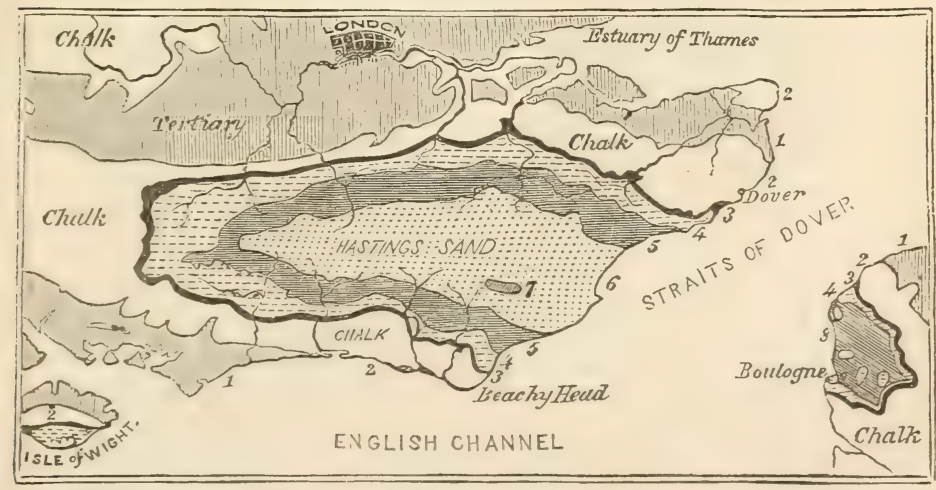

Goological map of the southeast of England and part of France, exhibiting the denudation of the Weald.
1. $\square$ Tertiary.
2. Chalk and upper greensqnd.
3. Gault.
4. E- Lower Greensand.

5. Weald clay.

6. Hastings sands.

7. एय Purbeck beds.

8. Oolite. 
The space here inclosed within the escarpment of the chalk affords an example of what has been sometimes called a "valley of elevation" (more properly "of denudation"); where the strata, partially removed by aqueous excavation, dip away on all sides from a central axis. Thus, it
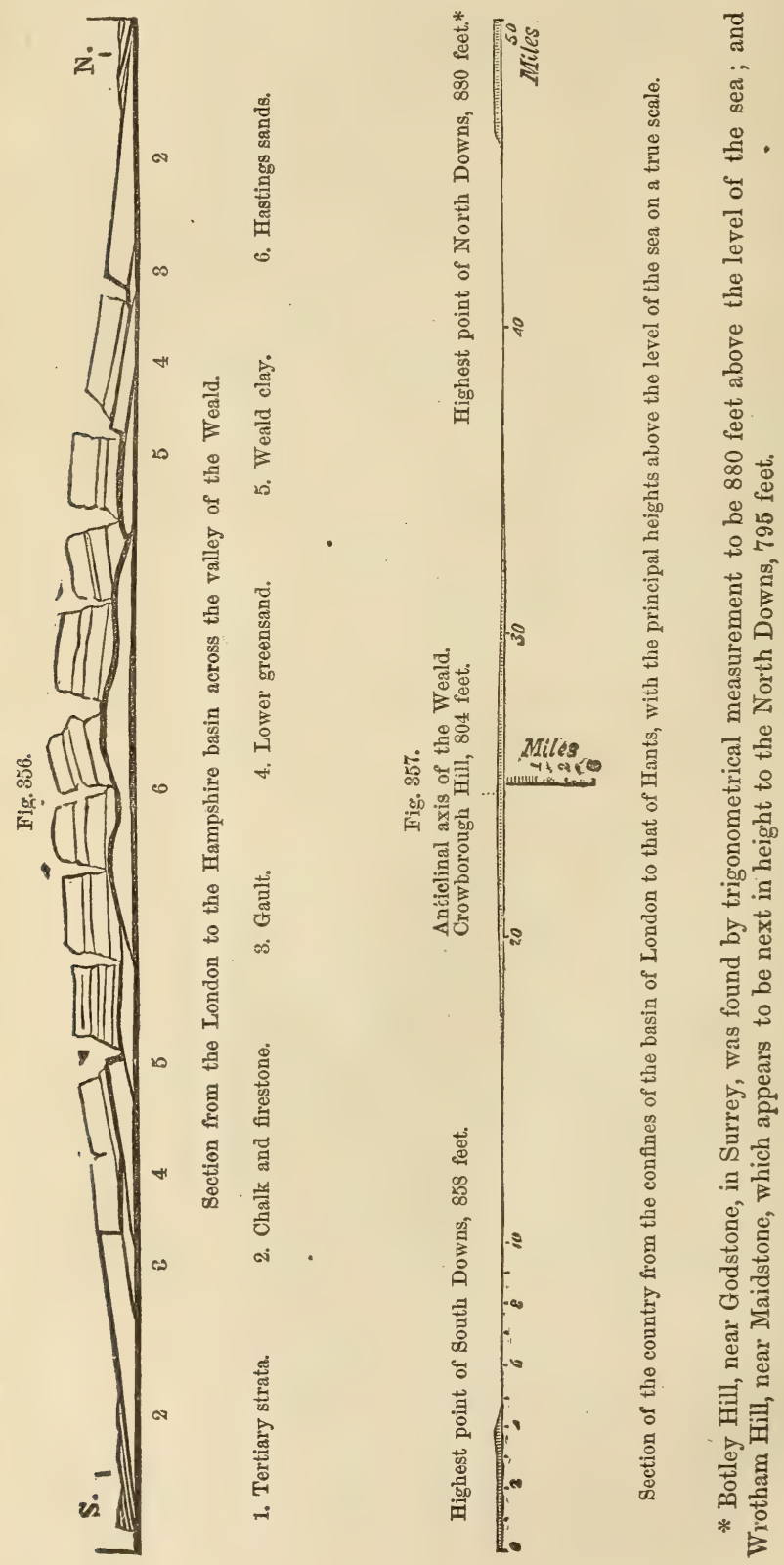
is supposed, that the area now occupied by the Hastmgs sand (No.6) was once covered by the Weald clay (No.5), and this again by the Greensand (No. 4), and this by the Gault (No. 3); and, lastly, that the Chalk (No.2) extended originally over the whole space between the North and the South Downs. This theory will be better understood by consulting the annexed diagram (fig. 356), where the dark lines represent what now remains, and the fainter ones those portions of rock which are believed to have been carried away.

At each end of the diagram the tertiary strata (No. 1) are exhibited reposing on the chalk. In the middle are seen the Hastings sands (No. 6.) forming an anticlinal axis, on each side of which the other formations are arranged with an opposite dip. It has been necessary, however, in order to give a clear view of the different formations, to exaggerate the proportional height of each in comparison to its horizontal extent : and a true scale is therefore subjoined in another diagram (fig. 357), in order to correct the erroneous impression which might otherwise be made on the reader's mind. In this section the distance between the North and South Downs is represented to exceed forty miles; for the Valley of the Weald is here intersected in its longest diameter, in the direction of a line between Lewes and Maidstone.

Through the central portion, then, of the district supposed to. be denuded runs a great anticlinal line, having a direction nearly east and west, on both sides of which the beds $5,4,3$, and 2, crop out in succession. But, although, for the sake of rendering the physical structure of this region more intelligible, the central line of elevation has alone been introduced, as in the diagrams of Smith, Mantell, Conybeare, and others, geologists have always been well aware that numerous minor lines of dislocation and flexure run parallel to the great central axis.

In the central area of the Hastings sand the strata have undergone the greatest displacement; one fault being known, where the vertical shift of a bed of calcareous grit is no less than 60 fathoms.* Much of the picturesque scenery of this district arises from the depth of the narrow valleys and ridges to which the sharp bends and fractures of the strata have given rise; but it is also in part to be attributed to the excavating power exerted by water, especially on the interstratified argillaceous beds.

Besides the series of longitudinal ralleys and ridges in the Weald, there are valleys which run in a transverse direction, passing through the chalk to the basin of the Thames on the one side, and to the English Channel on the other. In this manner the chain of the North Downs is broken by the rivers Wey, Mole, Darent, Medway, and Stour; the South Downs by the Arun, Adur, Ouse, and Cuckmere. If these transverse hollows could be filled up, all the rivers, observes Dr. Conybeare, would be forced to take an easterly course, and to empty themselves into the sea by Romney Marsh and Pevensey Levels.t.

* Fitton, Geol. of Hastings, p. 55. † Conybeare Outlines of Geol. p. 81. 
Mr. Martin has suggested that the great cross fractures of the chalk, which have become river channels, have a remarkable correspondence on each side of the valley of the Weald; in several instances the gorges in the North and South Downs appearing to be directly opposed to each other. Thus, for example, the defiles of the Wey in the North Downs, and of the Arun in the South, seemed to coincide in direction; and in

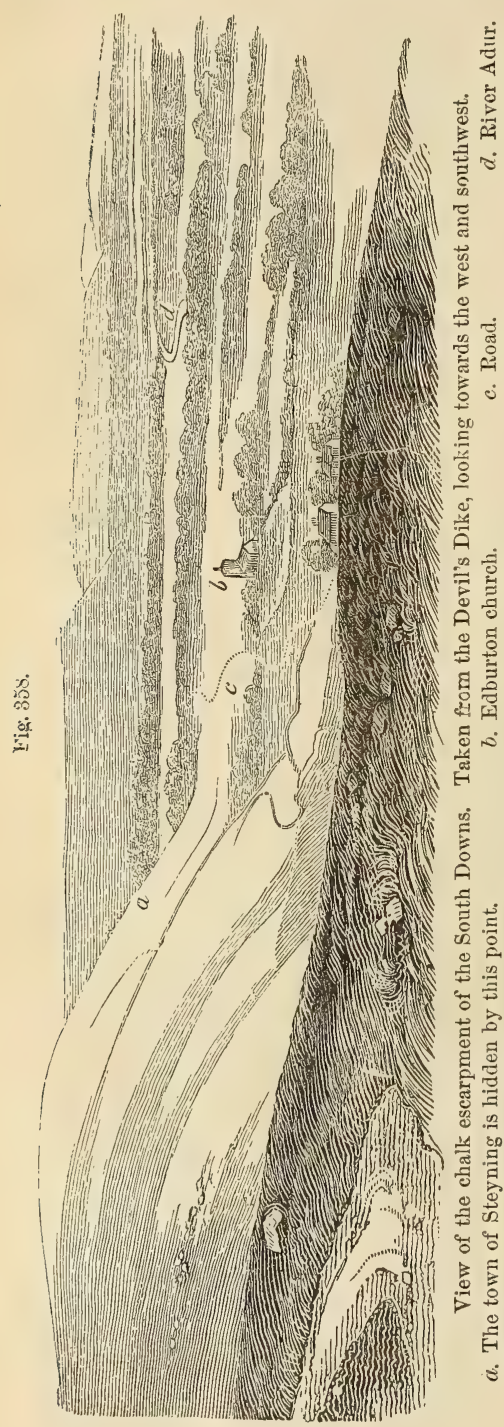

like manner, the Ouse corresponds to the Darent, and the Cuckmere to the Medway.*

Although these coincidences may, perhaps, be accidental, it is by no means improbable, as hinted by the author above mentioned, that great amount of elevation towards the centre of the Weald district gave rise to transverse fissures. And as the longitudinal valleys were connected with that linear movement which caused the anticlinal lines running east and west, so the cross fissures migh have been occasioned by the intensity of the upheaving force towards the centre of the line.

But before treating of the manner in which the upheaving movement may have acted, shall endeavor to make the reader more intimately acquainted with the leading geographical features of the district, so far as they are of geological interest.

In whatever direction we travel from the tertiary strata of the basins of London and Hampshire towards the valley of the Weald, we first ascend a slope of white chalk, with flints, and then find ourselves on the summit of a declivity consisting, for the most part, of different members of the chalk formation; below which the upper green.

* Geol, of Western Sussex, p. 61. 
sand, and sometimes, also, the gault, crop out. This steep declivity, is the great escarpment of the chalk before mentioned, which overhangs a valley excavated chiefly out of the argillaceous or marly bed, termed Gault (No. 3). The escarpment is continuous along the southern termination of the North Downs, and may be traced from the sea, at Folkestone, westward to Guildford and the neighborhood of Petersfield, and from thence to the termination of the South Downs at Beachy Head. In this precipice or steep slope the strata are cut off abruptly, and it is evident that they must originally have extended farther. In the wood-cut (fig. 358, p. 360), part of the escarpment of the South Downs is faithfully represented, where the denudation at the base of the declivity has been somewhat more extensive than usual, in consequence of the upper and lower greensand being formed of very incoherent materials, the former, indeed, being extremely thin and almost wanting.

The geologist cannot fail to recognize in this view the exact likeness of a sea-cliff; and if he turns and looks in an opposite direction, or eastward, towards Beachy Head (see fig. 359), he will see the same line

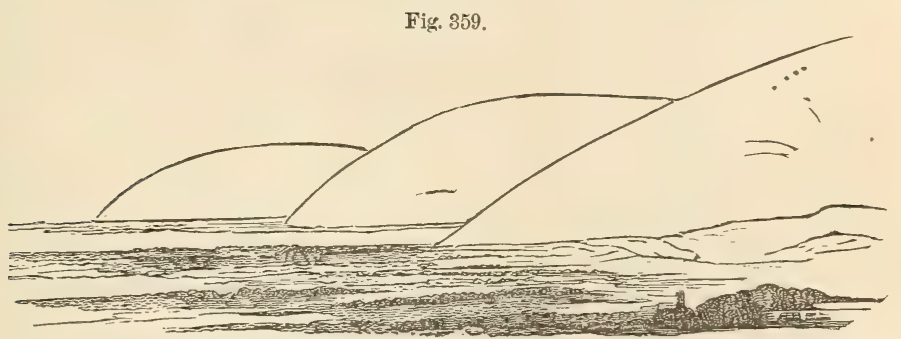

Chalk escarpment, as seen from the hill above Steyning, Sussex. The castle and village of Bramber in the foreground.

of heights prolonged. Even those who are not accustomed to speculate on the former changes which the surface has undergone may fancy the broad and level plain to resemble the flat sands which were laid dry by the receding tide, and the different projecting masses of chalk to be the headlands of a coast which separated the different bays from each other.

Occasionally in the North Downs sand-pipes are intersected in the slope of the escarpment, and have been regarded by some geologists as more modern than the slope; in which case they might afford an argument against the theory of these slopes having originated as seitcliffs or river-cliffs. But when we observe the great depth of many sand-pipes, those near Sevenoaks, for example, we perceive that the lower termination of such pipes must sometimes appear at the surface far from the summit of an escarpment, whenever portions of the chalk are cut away.

In regard to the transverse valleys before mentioned, as intersecting the chalk hills, some idea of them may be derived from the subjoined 
sketch (fig. 360) of the gorge of the River Adur, taken from the summit of the chalk-downs, at a point in the bridle-way leading from the towns of Bramber and Steyning to Shoreham. If the reader will refer again to the view given in a former woodcut (fig. 358, p. 360), he will there see the exact point where the gorge of which I am now speaking interrupts the chalk escarpment. A projecting hill, at the point $a$, hides the town of Steyning, near which the valley commences

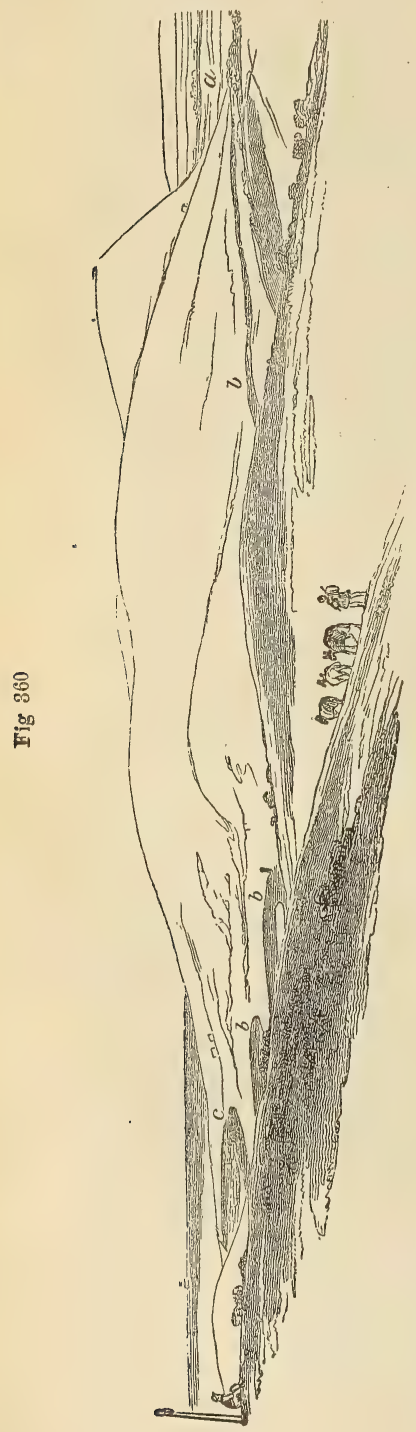

where the Adur passes directly to the sea at Old Shoreham. The river flows through a nearly level plain, as do most of the others which intersect the hills of Surrey, Kent, and Sussex ; and it is evident that these openings could not have been produced by rivers, except under conditions of physical geography entirely different from those now prevailing. Indeed, many of the existing rivers, like the Ouse near Lewes, have filled up arms of the sea, instead of deepening the hollows which they traverse.

That the place of some, if not of all, the gorges running north and south, has been originally determined by the fracture and displacement of the rocks, seems the more probable, when we reflect on the proofs obtained of a ravine running east and west, which branches off from the eastern side of the valley of the Ouse just mentioned, and which is undoubtedly due to dislocation. This ravine is called "the Coomb" (fig. 361), and is situated in the suburbs of the town of Lewes. It के was first traced out by Dr. ManE tell, in whose company I examis ined it. The steep declivities on \& each side are covered with green turf, as is the bottom, which is perfectly dry. No outward signs of disturbance are visible; and the connection of the hollow with subterranean movements would 
not have been suspected by the geologist, had not the evidence of great convulsions been clearly exposed in the escarpment of the valley of the

Fig. 361 .

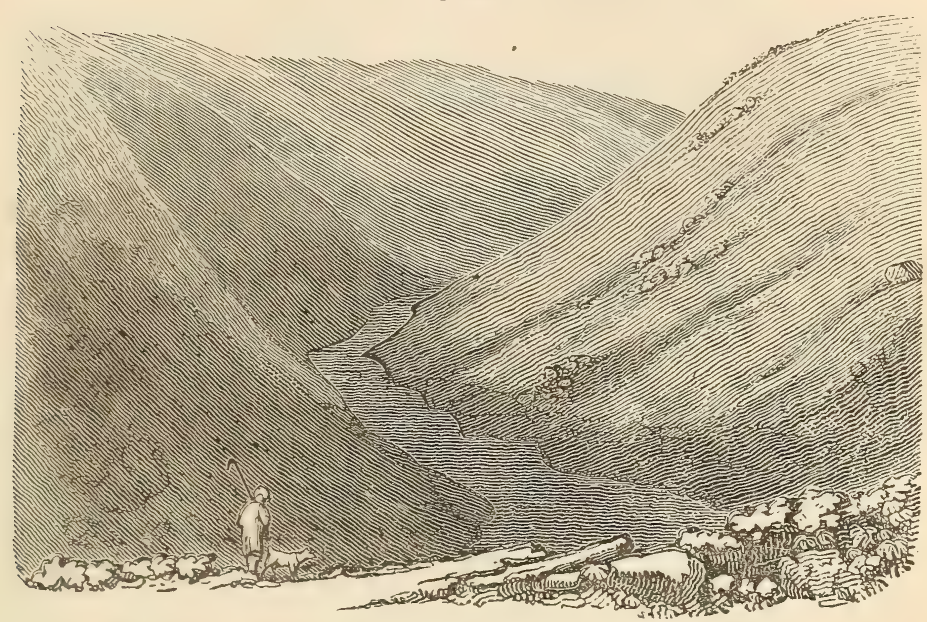

The Coomb, near Lewes.

Ouse, and the numerous chalk-pits worked at the termination of the Coomb. By the aid of these we discover that the ravine coincides precisely with a line of fault, on one side of which the chalk with flints $(\alpha$, fig. 362) appears at the summit of the hill, while it is thrown down to the bottom on the other.

Fig. 362.

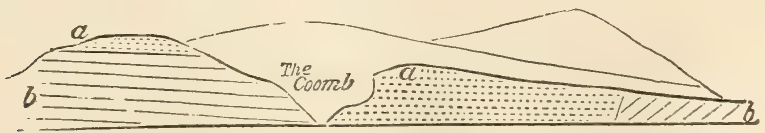

Fault coinciding with the Coomb, in the Cliff-hill near Lewes. Mantell. a. Chalk with flints.

b. Lower chalk.

In order to account for the manner in which the five groups of strata, $2,3,4,5,6$, represented in the map, fig. 355 , and in the section, fig. 356 , may have been brought into their present position, the following hypothesis has been suggested :- Suppose the five formations to lie in horizontal stratification at the bottom of the sea; then let a movement from below press them upwards into the form of a flattened dome, and let the crown of this dome be afterwards eut off, so that the incision should penetrate to she lowest of the five groups. The different beds would then be exposed on the surface, in the manner exhibited in the map, fig. $355 \%$ *

* See illustrations of this theory, by Dr. Fitton, Geol. Sketch of Hastings. 
The quantity of denudation, or removal by water, of stratified masses assumed to have once reached continuously from the North to the South Downs is so enormous, that the reader may at first be startled by the boldness of the hypothesis. But the difficulty will disappear when once sufficient time is allowed for the gradual rising and sinking of the strata at many successive geological periods, during which the waves and currents of the ocean, and the power of rain, rivers, and land-floods, might slowly accomplish operations which no sudden diluvial rush of waters could possibly effect.

Among other proofs of the action of water, it may be stated that the great longitudinal valleys follow the outcrop of the softer and more incoherent beds, while ridges or lines of cliff usually occur at those points where the strata are composed of harder stone. Thus, for example, the chalk with flints, together with the subjacent upper greensand, which is often used for building; under the provincial name of "firestone," have been cut into a steep cliff on that side on which the sea encroached. This escarpment bounds a deep valley, excavated chiefly out of the soft argillaceous bed, termed gault (No. 3, map, p. 357). In some places the upper greensand is in a loose and incoherent state, and there it has been as much denuded as the gault; as, for example, near Beachy Head; but farther to the westward it is of great thickness, and contains hard beds of blue chert and calcareous sandstone or firestone. Here, accordingly, we find that it produces a corresponding influence on the scenery of the country; for it runs out like a step beyond the foot of the chalk hills, and constitutes a lower terrace, varying in breadth from a quar ter of a mile to three miles, and following the sinuosities of the chalk escarpment.*

Fig. 363 .

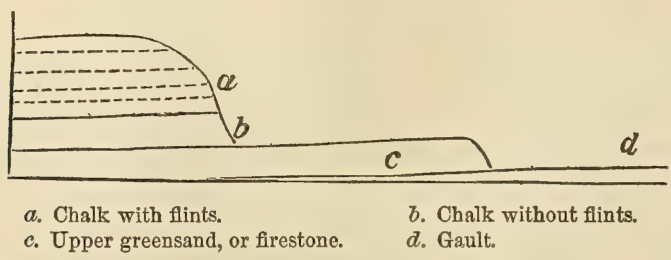

It is impossible to desire a more satisfactory proof that the escarpment is due to the excavating power of water during the rise of the strata, or during their rising and sinking at successive periods; for I have shown, in my account of the coast of Sicily (p. 76), in what manner the encroachments of the sea tend to efface that succession of terraces which must otherwise result from the intermittent-upheaval of a coast preyed upon by the waves. During the inter-

* Sir R. Murchison, Geol. Sketch of Sussex, \&c, Geol. Trans., Second Series, vol. ii. p. 99. 
ral between two eleratory movements, the lower terrace will usually be destroyed, wherever it is composed of incoherent materials ; whereas the sea will not hare time entirely to sweep away another part of the same terrace, or lower platform, which happens to be composed of rocks of a harder texture, and capable of offering a firmer resistance to the erosire action of water. As the yielding clay termed gault would be readily washed away, we find its outcrop marked ererywhere by a ralley which skirts the base of the chalk-hills, and which is usually bounded on the opposite side by the lower greensand; but as the upper beds of this last formation are most commonly loose and incoherent, they also have usually disappeared and increased the breadth of the valley. In those districts, however, where chert, limestone, and other solid materials enter largely into the composition of this formation (No. 4, map, p. 357), they give rise to a range of hills parallel to the chalk, which sometimes rival the escarpment of the chalk itself in height, or eren surpass it, as in Leith Hill, near Dorking. This ridge often presents a steep escarpment toward the soft argillaceous deposit called the Weald clay (as above, No. 5, fig. 356 , p. 358), which usually forms a broad valley, separating the lower greensand from the Hastings sands or Forest Ridge; but where subordinate beds of sandstone of a firmer texture occur, the uniformity of the plain of No. 5 is broken by waving irregularities and hillocks.

Pluvial action.-In considering, however, the comparative destructibility of the harder and softer rocks, we must not underrate the power of rain. The chalk-downs, even on their summits, are usually corered with unrounded chalk-flints, such as might remain after masses of white chalk had been softened and remored by water. This superficial accumulation of the hard or siliceous materials of disintegrated strata may be due in no small degree to plurial action; for during extraordinary rains a rush of water charged with calcareous matter, of a milk-white color, may be seen to descend even gently sloping hills of chalk. If a layer no thicker than the tenth of an inch be removed once in a century, a considerable mass may in the course of indefinite ages melt awar, learing nothing sare a stratum of flinty nodules to attest its former existence. A bed of fine clay sometimes covers the surface of slight depressions in the white chalk, which mar represent the aluminous residue of the rock, after the pure carbonate of lime has been dissolved by rain-water, charged with excess of carbonic acid derired from decayed regetable matter. The acidulous waters sometimes descend through "sand-pipes" and "swallow-holes" in the chalk, so that the surface may be undermined, and carrties may be formed or enlarged, eren by that part of the drainage which is subterranean.*

* See abore, p. 82, 83, "Sand-pipes in Chalk;" and Prestwich, Geol. Quart. Journ., vol. x. p. 222. 
Lines of Fracture.-Mr. Martin, in his work on the geology of Western Sussex, published in 1828, threw much light on the structure of the Wealden by tracing out continuously for miles the direction of many anticlinal lines and cross fractures; and the same course of investigation has since been followed out in greater detail by Mr. Hopkins. The geologist and mathematician last mentioned has shown that the observed direction of the lines of flexure and dislocation in the Weald district coincide with those which might have been anticipated theoretically on mechanical principles, if we assume certain simple conditions under which the strata were lifted up by an expansive subterranean force.*

His opinion, that both the longitudinal and transverse lines of fracture may have been produced simultaneously, accords well with that expressed by M. Thurmann, in his work on the anticlinal ridges and

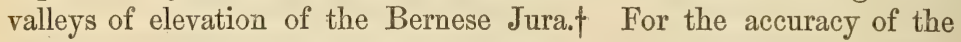
map and sections of the Swiss geologist I can vouch, from personal examination, in 1835, of part of the region surveyed by him. Among other results at which he arrived, it appears that the breadth of the anticlinal ridges and dome-shaped masses in the Jura is invariably great in proportion to the number of the formations exposed to view; or, in other words, to the depth to which the superimposed groups of secondary strata have been laid open. (See fig. 71, p. 55, for structure of Jura.). He also remarks, that the anticlinal lines are occasionally oblique and cross each other, in which case the greatest dislocation of the beds takes place. Some of the cross fractures are imagined by him to have been contemporaneous with others subsequent to the longitudinal ones.

I have assumed, in the former part of this chapter, that the rise of the Weald was gradual, whereas many geologists have attributed its elevation to a single effort of subterranean violence. There appears to them such a unity of effect in this and other lines of deranged strata in the southeast of England, such as that of the Isle of Wight, as is inconsistent with the supposition of a great number of separate movements recurring after long intervals of time. But we know that earthquakes are repeated throughout a long series of ages in the same spots, like volcanic eruptions. The oldest lavas of Etna were poured out many thousands, perhaps myriads of years before the newest, and yet they, and the movements accompanying their emission, have produced a symmetrical mountain; and if rivers of melted matter thus continue to flow upwards in the same direction, and towards the same point, for an indefinite lapse of ages, what difficulty is there in conceiving that the subterranean volcanic force, occasioning the rise or fall of certain parts of the earth's crust, may, by reiterated movements, produce the most perfect unity of result?

* Geol. Soc. Proceed. No. 74, p. 363, 1841, and G. S. Trans., 2 d Series, vol, vii.

† Soulèvemens Jurassiques. 1832. 
At what periods the Weald valley was denuded.-We may next inquire at what time the denudation of the Weald was effected, and we shall find, on considering all the facts brought to light by recent investigation, that it was accomplished in the course of so long a series of ages, that the greatest revolutions in the physical geography of the globe, yet known to us, have taken place within the same lapse of time. It has now been ascertained, that part of the denudation of the Weald was completed before the British Eocene strata, and consequently before the nummulitic rocks of Europe and Asia were formed. The date, therefore, of part of the changes now under contemplation was long antecedent to the existence of the Alps, Pyrenees, and many other European and Asiatic mountain-chains, and even to the accumulation of large portions of their component materials beneath the sea.

M. Elie de Beaumont suggested, in 1833, that there was an island in the Eocene sea in the area now occupied by the French and English Wealden strata, and he gave a map or hypothetical restoration of the ancient geography of that region at the era alluded to.* Mr. Prestwich has since shown that the materials of which the lower tertiary beds of England are made up, and their manner of resting on the chalk, imply, that such an island, or several islands and shoals, composed of Chalk, Upper Greensand, Gault, and probably of some of the Lower Cretaceous rocks, did exist somewhere between the present North and South Downs. The undermined cliffs and shores of those lands supplied the flints, which the action of the waves rounded into pebbles, such as now form the Woolwich and Blackheath shinglebeds below the London Clay. It is supposed, that the land referred to was drained by rivers flowing into the Eocene sea, and whence the brackish and freshwater deposits of Woolwich and other contem. poraneous strata $\nmid$ were derived. The large size of some of the rolled dints (eight inches and upwards in diameter) of the Blackheath shingle demonstrates the proximity of land. Such heavy masses could not have been transported from great distances, whether they owe their shape to waves breaking on a sea-beach, or to rivers descending a steep slope.

In the annexed diagram (fig. 364) Mr. Prestwich has represented a section from near Saffron Walden, in Essex, to the Weald, passing north and south through Godstone, in which we see how the chalk, $c$, had been disturbed and denuded before the lower Eocene beds, $b$, were deposited. Some small patches of the last-mentioned beds, $b$, consisting of clay and sand, extend occasionally, as in this instance, to the rery edge of the escarpment of the North Downs, proving that the surface of the white chalk, now covered with tertiary strata, is the same which originally constituted the bottom of the Eocene sea.

* Mém. de la Soc. Géol, de France, vol. i. part i. p. 111, pl, 7, fig. 5.

+ See p. 296, above. 


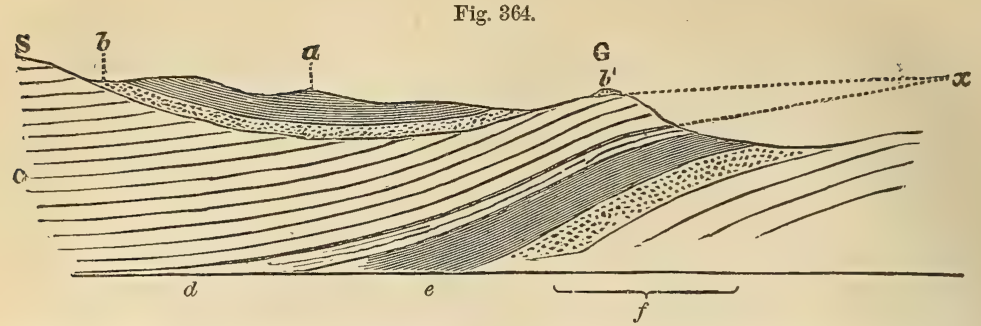

Section showing that the Weald had been denuded of chalk before the Lower Eocene strata were S. Relative position of SafPron Walden.

G. Chalk-escarpment above Godstone, surmounted by a patch of the Lower 'Tertiary beds, $b$ '. $a$. London Clay. $\quad b, b^{\prime}$. Lower Tertiaries. $\quad c$. Chalk.

d. Upper Greensand. e. Gault.

$\rightsquigarrow$. Point at which the present upper and under surfaces of the chalk, if they were prolonged would converge.

It is therefore inferred, that, if we prolong southwards the upper and under surfaces of the chalk, along the dotted line in the above section, they would converge at the point $x$; therefore, beyond that point, no white chalk existed at the time when the Eocene beds, $b, b^{\prime}$, were formed. In other words, the central parts of the Wealden, south of $x$, were already bared of their original covering of chalk, or had only some slight patches of that rock scattered over them.

The island, or islands, in the Eocene sea may be represented in the annexed diagram (fig. 365); but doubtless the denudation extended

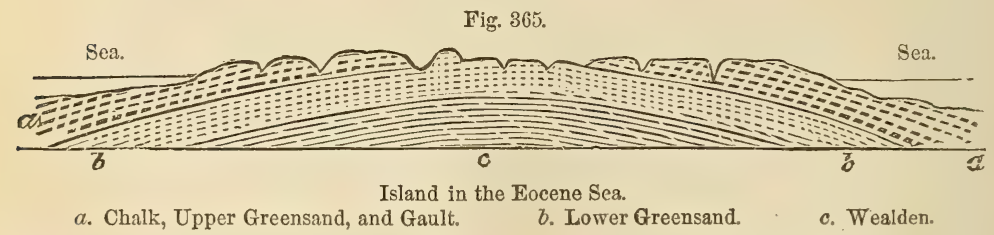

farther in width and depth before the close of the Eocene period, and the waves may have cut into the Lower Greensand, and perhaps in some places into the Wealden strata.

According to this view the mass of cretaceous and subcretaceous rocks, planed off by the waves and currents in the area between the North and South Downs before the origin of the oldest Eocene beds, may have been as voluminous as the mass removed by denudation since the commencement of the Eocene era.

But the reader may ask, why is it necessary to assume that so much white chalk first extended continuously over the Wealden beds in this part of England, and was then removed? May we not suppose that land began to exist between the North and South Downs at a much earlier epoch ; and that the upper Wealden beds rose in the midst of the Cretaceous Ocean, so as to check the accumulation of white chalk, and limit it to the deeper water of adjoining areas? This hypothesis has often been advanced, and as often rejected; for, had there been shoals or dry land 
so near, the white chalk would not have remained unsoiled, or without intermixture of mud and sand; nor would organic remains of terrestrial, fluviatile, or littoral origin have been so entirely wanting in the strata of the North and South Dorns, where the chalk terminates abruptly in the escarpments. It is admitted that the fossils now found there belong exclusively to classes which inhabit a deep sea. Moreover, the uppermost beds of the Wealden group, as Mr. Prestwich has remarked, would not have been so strictly conformable with the lowest beds of the Lower Greensand had the strata of the Wealden undergone upheaval before the deposition of the incumbent cretaceous series.

But, although we must assume that the white chalk was once continuous, orer what is now the Weald, it by no means follows that the first denudation was subsequent to the entire Cretaceous era. Most probably it commenced before a large portion of the Maestricht beds were formed, or while they were in progress. I have already stated (p.316, above), that in parts of Belgium I observed rolled pebbles of chalk-flints very abundant in the lowest Maestricht beds, where these last overlie the white chalk, showing at how early a date the chalk was upraised from deep water and exposed to aqueous abrasion.

Guided by the amount of change in organic life, we may estimate the interral between the Maestricht beds and the Thanet Sands to have been nearly equal in duration to. the time which elapsed between the deposition of those same Thanet Sands and the Glacial period. If so, it would be idle to expect to be able to make ideal restorations of the innumerable phases in physical geography through which the southeast of England must have passed since the Weald began to be denuded. In less than half the same lapse of time the aspect of the whole European area has been more than once entirely changed. Nevertheless, it may be useful to enumerate some of the known fluctuations in the physical conformation of the Weald and the regions immediately adjacent during the period alluded to.

First, we have to carry back our thoughts to those very remote movements which first brought up the white chall from a deep sea into exposed situations where the waves could plane off certain portions, as expressed in diagrain (fig. 361), before the British Lower Eocene beds originated.

Secondly, we have to take into account the gradual wear and tear of the chalk and its flints, to which the Thanct sands bear witness, as well as the subsequent Woolwich and Blackheath shingle-beds, occasionally 50 feet thick, and composed of rolled flint-pebbles.

Thirdiy, at a later period a great subsidence tool: place, by which the shallow-water and freshwater beds of Woolwich and other Lower Eocene deposits were depressed (see above, p. 296) so as to allow the London Clay and Bagshot series, of deep-sea origin, to accumulate orer them. The amount of this subsidence, according to Mr. Prestwich, exceeded 800 feet in the London, and 1800 feet in the Hampshire or Isle of Wight basin; and if so, the intervening area of the TVeald could scarcely fail to 
share in the movement, and some parts at least of the island before spoken of (fig. 365, p. 368) would become submerged.

Fourthly. After the London clay and the overlying Bagshot sands had been deposited, they appear to have been upraised in the London basin, during the Eocene period, and their conversion into land in the north seems to have preceded the upheaval of beds of corresponding age in the south, or in the Hampshire basin ; because none of the fluviomarine Eocene strata of Hordwell and the Isle of Wight (described in Chap. XVI.) are found in any part of the London area.

Fifthly. The fossils of the alternating marine, brackish, and freshwater beds of Hampshire, of Middle and Upper Eocene date, bear testimony to rivers draining adjacent lands, and to the existence of numerous quadrupeds in those lands. Instead of these phenomena, the signs of an open sea might naturally have been expected, as a consequence of the vast subsidence of the Middle Eocene beds before mentioned, had not some local upheaval taken place at the same time in the Isle of Wight, or in regions immediately adjacent. "Whatever hypothesis be adopted, we are entitled to assume that during the Middle and Upper Eocene periods there were risings and sinkings of land, and changes of level in the bed of the sea in the southeast of England, and that the movements were by no means uniform over the whole area during these periods. The extent and thickness of the missing beds in the Weald should of itself lead us to look for proofs of that area having, by repeated oscillations, changed its level frequently, and, oftener than any adjoining area, been turned from sea into land and land into sea; for the submergence and emergence of land augment, beyond any other cause, the wasting and removing power of water, whether of the waves and tides or of rivers and land-floods.

Sixthly. The Lower Miocene strata of the Isle of Wight (or the Hempstead beds before described) have been upraised several hundred feet above the level of the sea in which-they were originally formed. This upward movement may have occurred, in great part at least, during the Miocene period, when a large part of Europe is supposed to have become land, as before suggested (p. 242). Hence we are entitled to speculate on the probability of revolutions in the physical geography of the adjoining Weald in times intermediate between the deposition of the Hempstead beds and the origin of the Suffolk crag.

Seventhly. We have already seen (p. 235) that certain ferruginous sands lie in patches on the North Downs, some of them from 20 to 40 feet in thickness, and referable by their fossils to the same age as the Diest sands of Belgium. They are probably somewhat older than the coralline crag of Suffolk, and, as before explained, may constitute the only representative in the British Isles of the Upper Miocene or Falunian epoch. It is clear, from the relative position of the sands in question on the North Downs to the Lower Eocene deposits of the 
London clay, Woolwich, and Thanet series, that, before the waters of the Upper Miocene sea spread over this region and south of the Thames, all those Eocene strata had been much wasted and often reduced to mere isolated outliers scattered over the chalk. After the ferruginous sands were thrown down the bed of the sea must have been again raised 500 or 600 feet, in order that the North Downs might attain their present elevation.

We learn from these discoveries how impossible it may often be to demonstrate the former presence of the sea on any given area by organic remains, or by sea-beaches. Long and diligent inquiries had been made before the year 1856, for sea-shells of recent or crag species, and for the signs of old sea-margins within the area of the North and South Downs and the Wealden, or on Nos. 2, 3, 4, 5, 6, and 7 of the map (p. 357); but in vain, until at last a few shells and casts of others prove incontestibly the sojourn of the Older Pliocene or Upper Miocene sea in those very spaces. We must now, therefore, admit the retreat of its waters to have been an event as modern as the Upper Miocene, if not the Pliocene period. It follows that in many cases the land may have sunk and have emerged again without retaining on its surface any monuments of the kind usually demanded as indispensable to warrant our speculating on marine denudation as a great modifying cause in the physical geography of the globe.

Eighthly. But we have still to consider another vast interval of time, that which separated the end of the Miocene from the end of the Newer Pliocene era-a lapse of ages which, if measured by the fluctuations experienced in the marine fauna, may have sufficed to submerge and reëlevate whole continents by a process as slow as that which is now operating to upraise Sweden and depress Greenland.

Lastly. The reader must recall to mind what was said, in Chapters XI. and XII. respecting the vast geographical changes of Postpliocene date, especially those relating to the glacial drift and its far-transported materials. A wide extent of the British Isles appears to have been under the sea during some part or other of that epoch. Most of the submerged areas were afterwards converted into dry land, now several hundred and in Wales more than thirteen hundred feet high, as prored by marine fossil shells. It seems highly probable that the Wealden area was dry land when the most characteristic northern drift originated, no traces of northern erratics having been met with farther south than Highgate, near London. But it by no means follows that the area of the Weald was stationary during all these ages. It may have been raised and depressed, and its surface may have been modified by rain, rivers, and floods caused by the sudden melting of deep snow again and again during the Glacial era.*

* In my Geological Evidences of the Antiquity of Man, pp. 276, 278, I have given maps illustrating the changes in physical geography which have taken place 
It was long ago observed by Dr. Mantell that no vestige of the chalk and its flints has been seen on the central ridge of the Weald or on the Hastings Sands, but merely gravel and loam derived from the rocks in situ in the neighborhood. This distribution of alluvium, especially the absence of chalk-flints in the central district, agrees well with the theory of denudation before set forth; for by referring to fig. 356 (p. 358), the reader will see that had the chalk (No. 2) been once continuous, and covered everywhere with flint-gravel, this gravel would be the first to be carried away from the highest part of the dome long before any of the gault (No. 3) was laid bare. Now, if some ruins of the chalk remain at first on the gault, these would be, in a great degree, cleared away before any part of the lower greensand (No. 4) is denuded. Thus in proportion to the number and thickness of the groups removed in succession, is the probability lessened of our finding any remnants of the highest groups strewed over the bared surface of the lowest.

But it is objected, that, had the sea at one or several periods been the agent of denudation, we should have found ancient sea-beaches at the foot of the escarpments, and other signs of oceanic erosion. As a general rule, the wreck of the white chalk and its flints can only be traced to slight distances from the escarpments of the North and South Downs. Even where exceptions occur, and where flints are seen two or three miles from the nearest chalk, they are so angular as to be regarded by many as indicating fluviatile rather than marine denudation. Without wishing to gainsay the doctrine that many of the last superficial changes of the Weald may have been due to rain and rivers, combined with successive upheaval and depression of land, I may, nevertheless, remind the reader that, in the absence of organic remains, it is often impossible to distinguish between gravel formed in the bed of a river and that which accumulates on a sea-beach. For if we examine the broken flints at the base of a cliff, in places where they are not peculiarly exposed to the continuous and violent action of the waves, we may observe that they retain much angularity. This may be seen between the Old Harry rocks in Dorsetshire and Christchurch in Hampshire. Throughout the greater part of that line of coast the cliffs are composed of tertiary strata, capped by a dense covering of gravel formed of flints slightly abraded. As the waste of the cliffs is rapid, the old materials are gradually changed for new ones on the beach; nevertheless we have here an example of angles being retained after two poriods of attrition; first, that during which the gravel was spread originally over the Eocene deposits; and secondly, when the Eocene sands and clays were undermined and the modern cliff and sea-beach formed. As to the angularity of the flints, it has been thought by some authorities to imply great violence in

in Post-pliocene times, availing myself of the maps and memoirs of Mr. Trimmer, Mr. Godwin-Austen, and others. 
the removing power, especially in those cases where well-rounded pebbles washed out of Eocene strata are likewise found broken, sometimes with sharp edges, and often with irregular pieces chipped out of them as if by a smart blow. Such fractured pebbles occur not unfrequently in the drift of the valley of the Thames. In explanation I may remark that, in the Blackheath and other Eocene shingle-beds, hard egrg-shaped flint-pebbles may be found in such a state of decomposition as to break in the same manner on the application of a moderate blow, such as stones might encounter in the bed of a swollen river or on a sea-coast.

Angular flint-breccia is not confined to the Weald, nor to the transverse gorges in the chalk, but extends along the neighboring coast from Brighton to Rottingdean, where it was called by Dr. Nantell "the elephant-bed," because the bones of the mammoth, E. primigenius, abound in it with those of the horse, and, more rarely, the rhinoceros, $R$. tichorhinus. The following is a section of this formation as it appears in the Brighton cliff**

Fig. 366 .

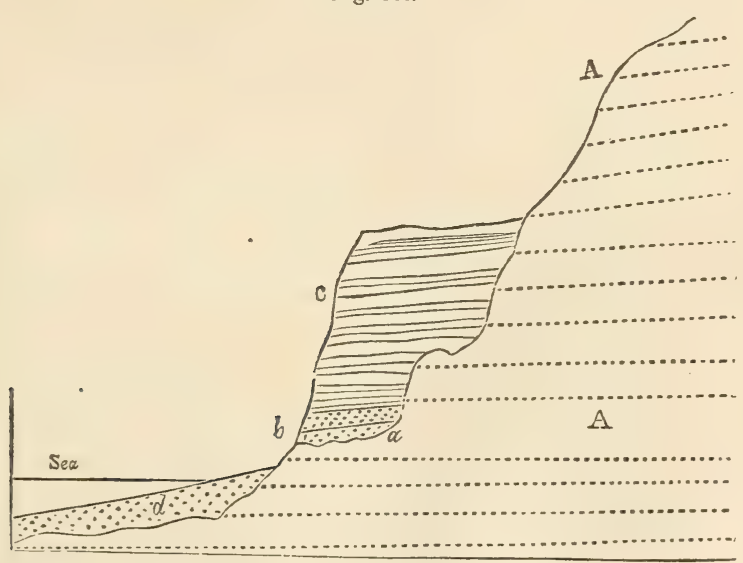

A. Chalk with layers of flint dipping slightly to the south.

b. Ancient beach, consisting of fine sand, from one to four feet thick, covered by shingle from five to eight feet thick of pebbles of chalk-flint, granite, and other rocks, with broken shells of recent marine species, and bones of cetacea.

c. Elephant-bed, about fifty feet thick, consisting of layers of white chalk rubble, with broken chalk-flints, often more confusedly stratified than is represented in this drawing, in which deposit are found bones of ox, deer, horse, and mammoth.

z. Sand and shingle of modern beach.

To explain this section we must suppose that, after the excavation of the cliff $A$, the beach of sand and shingle $b$ was formed by the long-continued action of the sea. The presence of Littorina littorea and other recent littoral shells, determines the modern date of the accumulation. The overlying beds are composed of such calcareous

* See alșo Sir R. Murchison, Geol. Quart. Journ., vol. vii. p. 365. 
rubble and flints; rudely stratified, as are often conspicuous in parts of the Norfolk coast, where they are associated with glacial drift, and were probably of contemporaneous origin. Similar flints and chalkrubble have been recently traced by Sir Roderick Murchison to Folkestone and along the face of the cliffs at Dover, where the teeth of the fossil elephant have been detected.

Mr. Prestwich also has shown that at Sangatte, near Calais, on the coast exactly opposite Dover, a similar water-worn beach, with an incumbent mass of angular flint-breccia, is visible. I have myself visited this spot, and found the deposit strictly analogous to that of Brighton. The fundamental ancient beach has been uplifted more than ten feet above its original level. The flint-pebbles in it have evidently been rounded at the base of an ancient chalk-cliff, the course of which can still be traced inland, nearly parallel with the present shore, but with a space intervening between them of about one-third of a mile in its greatest breadth.

Of a somewhat older date than the Brighton beach are some large erratic blocks, the greatest number of which are seen at Pagham and Selsea, fifteen miles south of Chichester, consisting of granite and many other rocks which are not of northern origin, but which seem to have been drifted into their present site by coast-ice from Normandy and Brittany. They overlie a Post-pliocene deposit of marine origin. Like the Brighton beach, they help to prove that during the Glacial period a sea-coast bounded the elevated district of the Weald to the south of the present South Downs.

Professor Ramsay,* and some other able geologists, who fully admit that the denudation of the Wealden area and that of the North and South Downs was mainly effected by the agency of the sea, incline, nevertheless, to the opinion that the great escarpments of the chalk may have been due to pluvial and fluviatile erosion, the sea, when it last retired, having left the secondary strata planed off at one and the same level. But this hypothesis seems to me untenable, because, assuming that the last of the submarine areas due to denudation had an even and level surface before it emerged, I cannot imagine that great superficial inequalities would not have been produced by the wares and tides of the sea during the time when the chalk, gault, greensand, and other formations, some composed of harder and some of softer materials, were raised gradually above the waters. The scooping out of the great longitudinal valleys must have commenced during such upheaval; and as to the transverso valleys, if it be true, as Mr. Jukes has suggested, that they originated at a very remote era by fluviatile erosion, when the chalk extended farther towards the central axis of the Wealden than now, still the subsequent deepening of these valleys must have been due in part to

* See Professor Ramsay's Physical Geology and Geography of Great Britain, 2d ed. : London, 1864. 
tidal action. As to the power of mere atmospheric causes, we have only to endow them with a small portion of the force ascribed to them by the geologists in question, and we can have no difficulty in explaining how all traces of the sea in the shape of littoral shells or beach deposits should have disappeared. Shells, once strewed over ancient shores, may have decomposed so as to make it impossible for us to assign an exact palæontological date to the period of emergence; but the leading inequalities of hill and dale, the long lines of escarpment, the longitudinal and transverse valleys, may still be mainly due to the power of the waves and currents of the sea.

In despair of solving the problem of the present geographicai configuration and geological structure of the Weald by an appeal to ordinary causation, some geologists have been fain to invoke the aid of imaginary "rushes of salt water" over the land during the sudden upthrow of the bed of the sea, when the anticlinal axis of the Weald was formed. Others refer to vast bodies of fresh water breaking forth from subterranean reservoirs, when the rocks were riven by earthquake shocks of intense violence. The singleness of the cause and the unity of the result are emphatically insisted upon : the catastrophe ras abrupt, tumultuous, transient, and paroxysmal ; fragments of stone were swept along to great distances without time being allowed for attrition; alluvium was thrown down unstratified, and often in strange situations, on the flanks or on the summits of hills, while the lowest levels were left bare. The convulsion was felt simultaneously over so wide an area, that all the individuals of certain species of quadrupeds were at once annihilated; yet the event was comparatively modern, for the species of testacea now living were already in existence.

This hypothesis is untenable and unnecessary. In the present chapter I have endeavored to show how numerous have been the periods of geographical change, and how vast their duration. Evidence to this effect is afforded by the relative position of the chalk and overlying tertiary deposits; by the nature, character, and position of the tertiary strata; and by the overlying alluvia of the Weald and adjacent countries. As to the superficial detritus, its insignificance in volume, when compared to the missing rocks, should never be lost sight of. A mountain-mass of solid matter, hundreds of square miles in extent, and hundreds of yards in thickness, has been carried away bodily. To what distance it has been transported we know not, but certainly beyond the limits of the Weald. For achieving such a task, if we are to judge by analogy, all transient and sudden agency is hopelessly inadequate. There is one power alone which is competent to the task, namely, the mechanical force of water in motion, operating gradually and for ages. We have seen in the sixth chapter that every stratified portion of the earth's crust is a monument of denudation on a grand scale, always effected slowly; for each superimposed stratum, however thin, has been successively and sepa- 
rately elaborated. Every attempt, therefore, to circumscribe the time in which any great amount of denudation, ancient or modern, has been accomplished, draws with it the gratuitous rejection of the only kind of machinery known to us which possessës the adequate power.

If, then, at every epoch, from the most ancient to the Pliocene inclusive, voluminous masses of matter, such as are missing in the Weald, have been transferred from place to place, and always removed gradually, it seems extravagant to imagine an exception in the very region where we can prove the first and last acts of denudation to have been separated by so vast an interval of time. Here, might we say, if anywhere within the range of geological inquiry, we have time enough, and without stint, at our command. 


\title{
CHAPTER XX.
}

\author{
JURASSIC GROUP.-PURBECK BEDS AND OOLITE.
}

The Purbeck beds a member of the Jurassic group-Subdivisions of that groupPhysical geography of the Oolite in England and France-Upper Oolite-Purbeck beds-New genera of fossil mammalia in the Middle Purbeck of DorsetshireDirt-bed or ancient soil-Fossils of the Purbeck beds-Portland stone and fossils -Lithographic stone of Solenhofen-Archæopteryx-Middle Oolite-Coral ragZoophytes-Nerinæan limestone-Diceras limestone-Oxford clay, Ammonites, and Belemnites-Kelloway Rock-Lower Oolite, Crinoideans-Great Oolite and Bradford clay-Stonesfield slate-Fossil mammalia-Resemblance to an Australian fauna-Northamptonshire slates-Yorkshire Oolitic coal-field-Brora coalFuller's earth-Inferior Oolite and fossils-Palæontological relations of the several subdivisions of the Oolitic group.

Imiediately below the Hastings Sands (the inferior member of the Wealden, as defined in Chapter XVIII.), we find in Dorsetshire, another remarkable freshwater formation, called the Purbeck, because it was first studied in the sea-cliffs of the peninsula of Purbeck in Dorsetshire. Thcsc beds were formerly grouped with the Wealden, but some organic remains recently discovered in certain intercalated marine beds show that the Purbeck series has a close affinity to the Oolitic group, of which it may be considered as the newest or uppermost member.

In England generally, and in the greater part of Europe, both the Wealden and Purbeck beds are wanting, and the marine cretaceous group is followred immediately, in the descending order, by another series called the Jurassic. In this term, the formations commonly designated as "the Oolite and Lias" are included, both being found in the Jura Mountains. The Oolite was so named because in the countries where it was first cxamined, the limestones belonging to it had an oolitic structure (p. 12). These rocks occupy in England a zone which is nearly 30 miles in average breadth, and extends across the island, from Yorkshire in the northeast, to Dorsetshire in the southwest. Their mineral characters are not uniform throughout this region; but the following are the names of the principal subdivisions observed in the central and southeastern parts of England:

\section{OOLITE.}

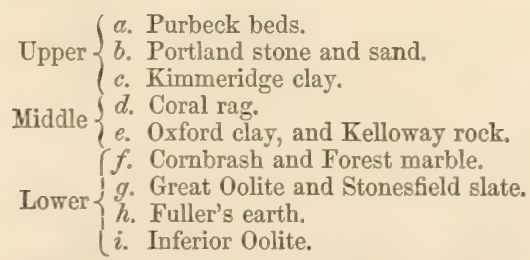

The Lias then succeeds to the Inferior Oolite. 
The Upper oolitic system of the above table has usually the Kimmeridge clay for its base; the Middle oolitic system, the Oxford clay. The Lower system reposes on the Lias, an argillo-calcareous formation, which some include in the Lower Oolite, but which will be treated of separately in the next chapter. Many of these subdivisions are distinguished by peculiar organic remains; and, though varying in thickness, may be traced in certain directions for great distances, especially if we compare the part of England to which the above-mentioned type refers with the northeast of France and the Jura mountains adjoining. In that country, distant above 400 geographical miles, the analogy to the accepted English type, notwithstanding the thinness or occasional absence of the clays, is more perfect than in Yorkshire or Normandy.

Physical geography.-The alternation, on a grand scale, of distinct formations of clay and limestone has caused the oolitic and liassic series to give rise to some marked features in the physical outline of parts of England and France. Wide valleys can usually be traced throughout the long bands of country where the argillaceous strata crop out; and between these valleys the limestones are observed, composing ranges of hills or more elevated grounds. These ranges terminate abruptly on the side on which the several clays rise up from beneath the calcareous strata.

The annexed cut will give the reader an idea of the configuration of the surface now alluded to, such as may be seen in passing from Liondon to Cheltenham, or in other parallel lines, from east to west, in the southern part of England. It has been necessary, however, in this drawing, greatly

Fig. 367.

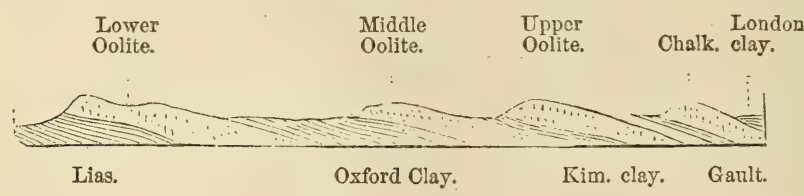

to exaggerate the inclination of the beds, and the height of the several formations, as compared to their horizontal extent. It will be remarked, that the lines of cliff, or escarpment, face towards the west in the great calcareous eminences formed by the Chalk and the Upper, Middle, and Lower Oolites; and at the base of which we have respectively the Gault, Kimmeridge clay, Oxford clay, and Lias. This last forms, generally, a broad vale at the foot of the escarpment of inferior oolite, but where it acquires considerable thickness, and contains solid beds of marl-stone, it occupies the lower part of the escarpment.

The external outline of the country which the geologist observes in travelling eastward from Paris to Metz is precisely analogous, and is caused by a similar succession of rocks intervening between the tertiary strata and the Lias; with this difference, however, that the escarpments of Chalk, Upper, Middle, and Lower Oolites face towards the east instead of the west. 
The Chalk crops out from beneath the tertiary sands and clays of the Paris basin, near Eperuay, and the Gault from beneath the Chall and Upper Greensand at Clermont-en-Argonne; and passing from this place by Verdun and Etain to Metz, we find two limestone ranges, with interrening rales of clay, precisely resembling those of southern and central England, until we reach the great plain of Lias at the base of the Inferior Oolite at Metz.

It is evident, therefore, that the denuding causes have acted similarly over an area several hundred miles in diameter, sweeping away the softer clays more extensively than the limestones, and undermining these last so as to cause them to form steep cliffs wherever the harder calcareous rock was based upon a more yielding and destructible clay.

UPPER OOLTTE.

Purbeck beds ( $\alpha$, Tab. p. 377).-These strata, which we class as the uppermost member of the Oolite, are of limited geographical extent in Europe, as already stated, but they acquire importance, when we consider the succession of three distinct sets of fossil remains which they contain. Such repeated changes in organic life must have reference to the history of a vast lapse of ages. The Purbeck beds are finely exposed to view in Durdlestone Bay, near Swanage, Dorsetshire, and at Lulworth Cove and the neighboring bays between Weymouth and Swanage. At Meup's Bay, in particular, Professor E. Forbes examined minutely in 1850 the organic remains of this group, displayed in a continuous, sea-cliff section; and he added largely to the information previously supplied in the works of Messis. Webster, Fitton, De la Beche, Buckland, and Mantell. It appears from these researches that the Upper, Middle, and Lower Purbecks are each marked by peculiar species of organic remains, these again being different, so far as a comparison has yet been instituted, from the fossils of the overlying Hastings Sands and Weald Clay.*

Upper Purbeck.-The highest of the three divisions is purely freshwater, the strata, about 50 feet in thickness, containing shells of the genera Paludina, Physa, Limnous, Planorbis, Valvata, Cyclas, and Unio, with Cyprides and fish. All the species seem peculiar, and among these the Cyprides are very abundant and characteristic. (See figs. $368, a, b, c$.

Fig. 368.
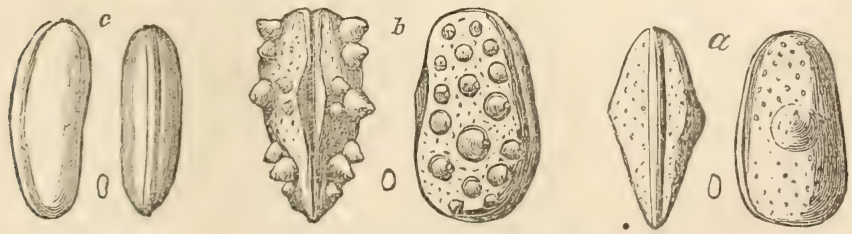

Cyprides from the Upper Purbecks.

a. Cypris gibbosn, E. Forbes. 6. Cypristuberculata, E.Forbes. c. Cyprisleguminella, E.Forbes

* "On the Dorsetshire Purbecks," by Prof. E. Forbes, Brit. Assoc. Edinb. 1850. 
The stone called "Purbeck marble," formerly much used in ornamental architecture in the old English cathedrals of the southern counties, is exclusively procured from this division.

Middle Purbeck.-Next in succession is the Middle Purbeck, about 30 feet thick, the uppermost part of which consists of freshwater limestone, with cyprides, turtles, and fish, of different species from those in the preceding strata. Below the limestone are brackish-water beds full of Cyrena, and traversed by bands abounding in Corbula and Melania. These are based on a purely marine deposit, with Pecten, Modiola, Avicula, Thracia, all undescribed shells. Below this, again, come limestones and shales, partly of brackish and partly of freshwater origin, in which many fish, especially species of Lepidotus and Microdon radiatus, are found, and a crocodilian reptile named Macrorhyncus. Among the mollusks, a remarkable ribbed Melania, of the section Chilina, occurs.

Immediately below is the great and conspicuous stratum, 12 feet thick, long familiar to geologists under the local name of "Cinder-bed," formed of a vast accumulation of shells of Ostrea distorta (fig. 369). In the uppermost part of this bed Professor Forbes discovered the first echinoderm (fig. 370) as yet known in the Purbeck series, a species of Hemicidaris, a genus characteristic of the Oolitic period, and scarcely, if at all, distinguishable from a previously known oolitic species. It was accom-

Fig. 369 .

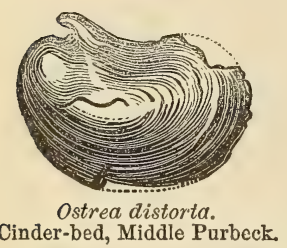

Fig. 370 .

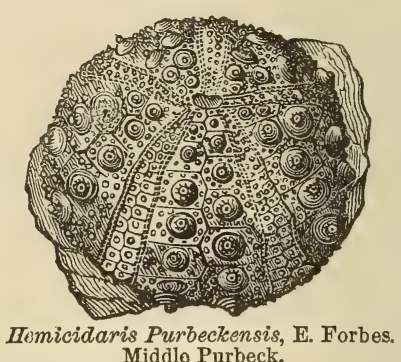

panied by a species of Perna. Below the Cinder-bed freshwater strata are again seen, filled in many places with species of Cypris (fig. 371,
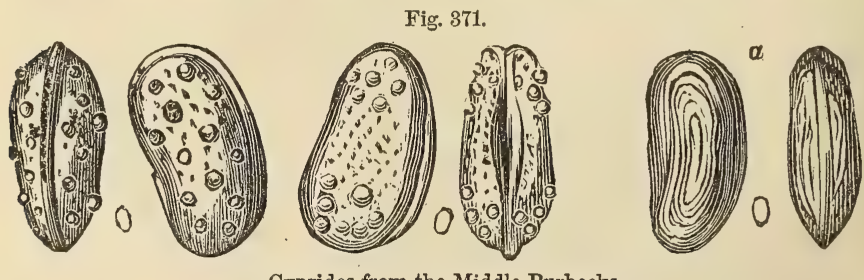

Cyprides from the Middle Purbecks.

a. Cypris striato-punctata, E. Forbes. b. Cypris fasciculata, E. Forbes c. Cypris granulata, Sow.

$a, b, c)$, and with Valvata, Paludina, Planorbis, Limnous, Physa (fig. 372), and Cyclas, all different from any occurring higher in the 
series. It will be seen that Cypris.fasciculata (fig. $371, b$ ) has tubercles at the end only of each valve, a character by which it can be immediately recognized. In fact, these minute crustaceans, almost as frequent in some cf the shales as plates of mica in a micaceous sandstone, enable geologists at once to identify the Middle Purbeck in places far from the Dorsetshire cliffs, as, for example, in the Vale of Wardour, in Wiltshire. Thick siliceous beds of chert occur in the Middle Purbeck filled with mollusca and cyprides of the genera already enumerated, in a beautiful state of

Fig. 372

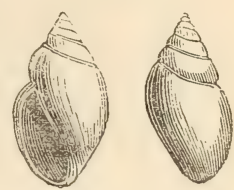

Physa Bristovii, E. Forbes. Middle Purbeck. preservation, often converted into chalcedony. Among these Professor Forbes met with gyrogonites (the spore-vessels of Charce), plants never until 1851 discovered in rocks older than Eocene.

Fossil Mammalia of the Middle Purbeck.-In the fourth edition of this work (1852), after alluding to the discovery of numerous insects and air-breathing mollusca in the "Purbeck," I remarked that, although no mammalia had then been found, "it was too soon to infer their non-existence on mere negative evidence." Only two years after this remark was in print, Mr. W. R. Brodie found in the Middle Purbeck, about twenty feet below the "Cinder" above alluded to, in Durdlestone Bay, portions of several small jaws with teeth, which Professor Owen, after clearing away the matrix, recognized as belonging to a small mammifer of the insectivorous class. The teeth with pointed cusps resemble in some degree those of the Cape Mole (Chrysochlora aurea); but the number of the molar teeth (at least ten in each ramus of the lower jaw) accords better with some of the ex tinct mammalia of the Stonesfield Oolite (see below, p. 406). This newly-found quadruped, therefore, seems to have been more closely allied in its dentition to the Amphitherium (or Thylacotherium) than to any existing insectivorous type. The angular process of the jaw, as in Amphitherium, is not bent inwards, an osteological peculiarity confined to the marsupial tribes, and Professor Owen therefore at first referred the Spalacotherium to the placental or ordinary monodelphous mammalia.

Four years later (in 1856) the remains of twelve or more species of warm-blooded quadrupeds were exhumed by Mr. S. H. Beckles, F.R.S., from the same thin bed of marl near the base of the Mifddle Purbeck. In this marly stratum many reptiles, sercral insects, and some freshwater shells of the genera Paludina, Planorbis, and Cyclas were found.

Mr. Beckles had determined thoroughly to explore the thin layer of calcareous mud from which in the suburbs of Swanage the bones of the Spalacotherium had already been obtained, and in three weeks he brought to light from an area forty feet long and ten wide, and from a layer the arerage thickness of which was only five inches, 
portions of the skeletons of six new species of mammalia, as interpreted by Dr. Falconer, who first examined them. Before the begin ning of the year 1857 the number of species recognized by the eninent zoologist last mentioned amounted to seven or eight, exclusive of twc which had already been found by Mr. Brodie and named by Professor Owen. Before these interesting inquiries were brought to a close, the joint labors of Professor Owen and Dr. Falconer. had made it clear that twelve or more species of mammalia characterized this portion of the Middle Purbeck, most of them insectivorous or predaceous, varying in size from that of a mole to that of the common polecat, Mustela putorius. While the majority had the character of insectivorous marsupials, Dr. Falconer selected one as differing widely from the rest, and pointed out that in certain characters it was allied to the living Kangaroo-rat, or Hypsiprymnus, ten species' of which now inhabit the prairies and scrub-jungle of Australia, feeding on plants and gnawing scratched-up roots. A striking peculiarity of their dentition, one in which they differ from all other quadrupeds, consists in their having a single large pre-molar, the enamel of which is furrowed with vertical grooves, usually seven in number (see $l$, fig: 373 , where the pre-molar of the recent Hypsiorymmus Gaimardi is represented).

The largest pre-molar in the fossil genus exhibits in like manner seven parallel grooves, producing by their termination a similar serrated edge in the crown; but their direction is diagonal-a distinction, says Dr. Falconer, which is "trivial, not typical."

As these oblique furrows form so marked a character of the majority of the teeth, Dr. Falconer has proposed for the fossil the generic name of Plagiaulax. The shape and relative size of the incisor $\alpha$, figs. 373 and 374, exhibit a no less striking similarity to Hypsiprymnus. Nevertheless, the more sudden upward curve of this incisor, especially in the larger species, as well as the number and characters of the other teeth, and the shortening, compression, and depth of the jaw, taken together with the backward projection of the condyle ( $d$, fig. 373 ), indicate a great deviation in the form of Plagiaulax from that of the living kangaroo-rats.

Our knowledge is at present confined to two fossil specimens of lower jaws, * evidently referable to two distinct species, extremely unequal in size and otherwise distinguishable. The largest, $P$. Becklesii (fig. 373), was about as big as the English squirrel or the flying phalanger of Australia (Petaurus Australis, Waterhouse). The skeleton of this phalanger (named P. macrurus, No. 1849, Museum of College of Surgeons) measures fifteen inches in length, exclusive of the tail, which is more than eleven inches long. The

* Three additional specimens of $P$. Becklesii have since been found, some with the two back molars entire. They confirm Dr. Falconer's conclusion previously expressed in regard to the affinity of Plagiaulax and Microlestes. 
smaller fossil ( $P$. minor, fig. 374), having only half the linear dimensions of the other, was probably only 1-12th of its bulk. It is of

Fig. 373 .
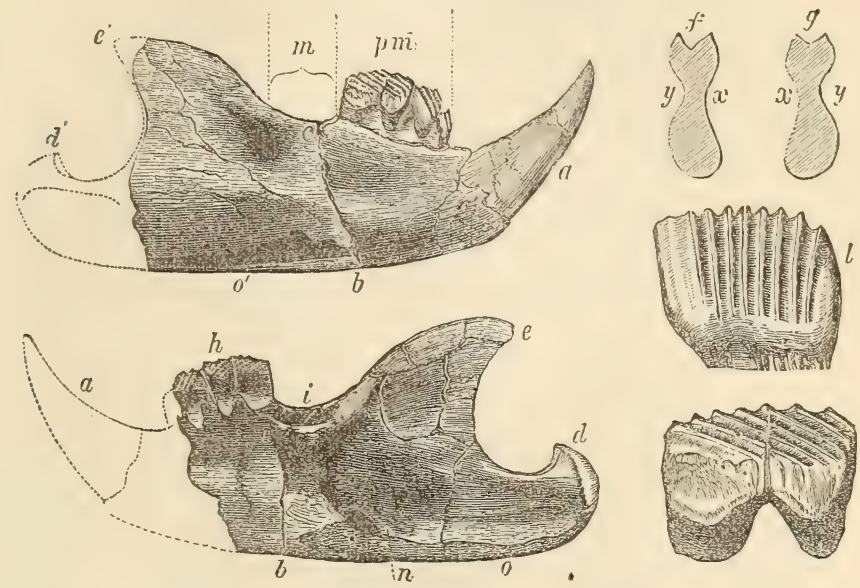

Plagiaulaw Becklesii, Falconer.

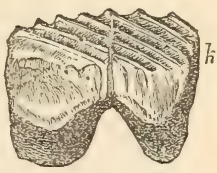

These two figures represent the same right ramus of the lower jav seen on the opposite surfaces of a split stone, the two taken together affording data for a complete restoration of the jaw.

\section{Tpper figure (outer side).}

$a, b, e^{\prime}$. Right ramus of lower jaw magnified two diameters. $a, b$. Outer side. $\quad b, o^{\prime}, d, e^{\prime}$. Impression of inner side.

a. Incisor.

b,c. Line of vertical fracture behind the pre-molars.

d. Impression of the condyle in the matrix.

$e^{\prime}$. Impression of top of coronoid process.

$f$. Section of the anterior piece of the jaw at the fracture $b, c,-a$, inner surface; $y$, outer. The notch at the top is formed by one of the sockets of the double-fanged true molar.

g. Section of the hinder piece near $b, c ; x$, inner; $y$, outer suriace.

$\checkmark$. Broken-off inflected fold of inner margin buried in the matrix.

m. Sockets of two molars.

$p, m$. Three pre-molars, the third and last divided by a crack.

\section{Lozoer figure (inner side).}

$a^{\prime}, d$. Same lower jaw on the opposite slab of stone; $b, d, e$, inner side; $b, a, h$, cast and impression of outer side.

$a^{\prime}$. Ontline of the incisor restored.

b, c. Line of vertical fracture.

d. Condyle.

e. Coronoid.

$h$. Impression on the matrix of the three pre-molars.

i. Empty sockets of the two true molars.

$n$. Orifice of dentary canal.

$o$. Indication of the raised and inflected fold of the posterior inner margin.

k. Third or largest pre-molar, magnified $5 \frac{1}{2}$ diameters, showing the 7 diagonal grooves.

l. Correaponding pre-molar in the recent Australian Hypsipryman Gaimardi, showing the 7 vertical grooves, magnified $3 \frac{1}{2}$ diameters.

peculiar geological interest, because, as shown by Dr. Falconer, its two back molars bear a decided resemblance to those of the Triassic Microlestes ( $b, c$, fig. 375$)$, the most ancient of known mammalia, of 
which an account will be given in Chapter XXII. When Dr. Falconer, in 1857, pronounced the Plagiaulax to be marsupial and herbivorous, he also regarded it as having the form of a rodent; but he did not overlook that in some of its characters, especially in the coronoid, it resembled certain predaceous marsupials more than those of the herbivorous class. Professor Owen attaches greater importance to these characters, and he has declared his opinion that the Plagiaulax was carnivorous, or that it fed on small insectivorous mammalia and lizards.* Dr. Falconer objects that the inference as to the predaceous habits of Plagiaulax Becklesii, drawn from the upward curve of the incisor ( $\alpha$, fig. 373, p. 383), is neutralized by the more horizontal position of the same incisor in the smaller species ( $a$, fig. 374),

Fig. 374 .
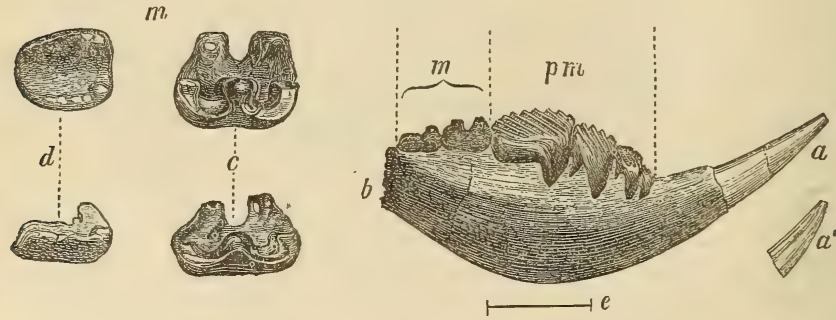

Plagiaulax minor, Falc.

(Magnified 4 diameters.)

All the teeth in this specimen are in place and well preserved. The hinder part of the jawbone, with the ascending ramus and posterior angle, are broken away.

$a, b$. Right ramus of lower jaw, with all the teeth magnified 4 diameters.

a. Incisor with point brokon off. $a^{\prime}$. Impression of same, showing that the inner side near the apex was hollowed out in a longitudinal direction.

$b$. Offset of coronoid, the rest of which is wanting.

$m$. The two true molars.

$p, m$. The four pre-molars.

c. The first molar, magnified 8 diameters.

Upper figure, the crown.

Lower flgure, side view.

d. Second molar, crown and side view.

e. Straight line indicating the length of the jaw, natural size.

to say nothing of the fact that in the living vegetable-feeding Koala (Phascolarctus cinereus) the incisor is also projected forwards with a slight upward inclination, as in P. Becklesii. $\uparrow$ The same anatomist also insists, and apparently with no small force of reasoning, on the analogy of the pre-molar of Plagiaulax ( $k$, fig. 373, p. 383), with that of the kangaroo-rat $(l, \mathrm{ibid})$. The reader will see that the grooves in Plagiaulax are close set, perfectly parallel, and that they also correspond in number with those of the living hypsiprymnus; and if he will compare them, as I have done, with the sinuous and bifurcating furrows on the pre-molar of the fossil Thylacoleo, to which Professor

* Owen's Palæontology, p. 353.

+ Falconer, Geol. Quart. Journ., vol. xviii. p. 357. 
Owen has likened them, he will, I think, be as much at a loss as Dr. Falconer to recognize any resemblance between them.

All the fossil bones of mammalia discovered before the year $\mathbf{1 8 5} \boldsymbol{h}$, in rocks older than the tertiary, had consisted exclusively of single branches of lower-jaws, and it is a singular fact that Mr. Beckles shoula hare sent to London in that year the first knomn example of the upper portion of the skull of a secondary mammal consisting, as - Dr. Falconer pointed out to me at the time, of the two frontal and the two parictal bones in a good state of preservation, with the sagittal crest well marked, and the occipital also with its crest. Although the lateral and basal portions of this cranium were wanting, enough remained to show that it agreed with the ordinary type of living warmblooded quadrupeds.

In the same slab with this cranium occurred the entire side of the lower jaw of another quadruped, to which Professor Owen gave the generic name of Triconodon. It contains eight molars, a large and prominent canine, and one broad and thick incisior. This creature must have been nearly as large as the common hedgehog.

Sereral other jars with similar tricuspid tecth of larger dimensions, found by Mr. Beckles, indicate the existence of another species of Triconodon of a more elongated form, and about one-third larger in size. Its marsupial character was inferred by Dr. Falconer from the number of the true molars, the strong inflected angular process, the broad salient everted rim of the ridge which is decurrent on the outer side from the condyle along the inferior margin, and the marked development of the milo-hyoid groore. He also observed that these two species of Triconodon were more like small ferine animals than mere insectivorous marsupials, and that they probably fed on prey less minute than insects. This opinion he deduced from the cutting character of their teeth, and their comparatively formidable canines, together with the form of the ascending ramus.

Professor Oren has proposed the name of Galestes for the largest of the mammalia discovered in 1858 in Purbeck, equalling the polecat (M Irstela putorius) in size. It is supposed to have been predaceous and marsupial. Its generic character is derived from a peculiar modification in the form of one of the pre-molars, which has a single external vertical groove.

When Mr. Beckles had found the remains of twenty-eight distinct indiriduals of Purbeck mammalia, and Mr. Brodie seren other specimens, they all consisted of lower jaws, and only fire of them had upper jars in connection; and the ten othur specimens of oolitic mammalia belonging to four species discorered at Stonesficld were in like manner all represented by lower jaws. That between forty or fifty species or sides of lower jaws with tecth shoulil have been found in oolitic strata, and with them only five upper maxillaries, together with one portion of a separate cranium, will naturally excite surprise. There were no examples in Purbeck of an entire slicleton, nor of ais considerable num- 
ber of bones in juxtaposition. In several portions of the matrix there were detached bones, often much decomposed, and fragments of others apparently mammalian; but, if all of them were restored, they would scarcely suffice to complete the five skeletons to which the five upper maxillaries above alluded to belonged. As the average number of pieces in each mammalian skeleton is about 250 , there must be many thousands of missing bones; and when we endeavour to acoount for their absence, we are almost tempted to indulge in speculations like those once suggested to me by Dr. Buckland, when he tried to solve the enigma in reference to Stonesfield :- "The corpses," he said, "of drowned animals, when they float in a river, distended by gases during putrefaction, have often their lower jaw hanging loose, and sometimes it has, dropped off. The rest of the body may then be drifted elsewhere, and sometimes may be swallowed entire by a predacenus reptile or fish, such as an ichthyosaur or a shark."

We may also suppose that when fish or other aquatic animals attack a decaying carcase, whether it be floating or has sunk to the bottom, they will first devour those parts which are covered with flesh. A lower jaw, consisting of little else than bones and teeth, will be neglected, and becoming detached, may be drifted away by a current of moderate velocity, and buried apart from the other bones in sand or mud.

As all the above-mentioned Purbeck mammalia, belonging to eight or nine genera and to about fourteen species of insectivorous, predaceous and herbivorous marsupials, have been obtained from an area less thạn 500. square yards in extent, and from a single stratum not more than a few inches thick, we may safely conclude that the whole lived together in the same region, and in all likelihood they constituted a mere fraction of the mammalia which inhabited the lands drained by one river and its tributaries. They afford the first positive proof as yet obtained of the coexistence of a varied fauna of the highest class of vertebrata with that ample development of reptile life which marks all the periods from the Trias to the Lower Cretaceous inclusive, and with a gymnospermous flora, or that state of the vegetable kingdom when cycads and conifers predominated over all kinds of plants, except the ferns, so far at least as our present imperfect knowledge of fossil botany entitles us to speak.

The annexed table will enable the reader to see at a glance how conspicuous a part, numerically considered, the mammalian species of the Middle Purbeck now play when compared with those of other formations more ancient than the Paris gypsum, and at the same time it will help him to appreciate the enormous hiatus in the history of fossil mammalia, which at present occurs between the Purbeck and Eocene periods. 
Number and Distribution of all the known Species of Fossil Mammalia from Strata older than the Paris Gypsum, or than the Bembridge Series of the Isle of Wight.

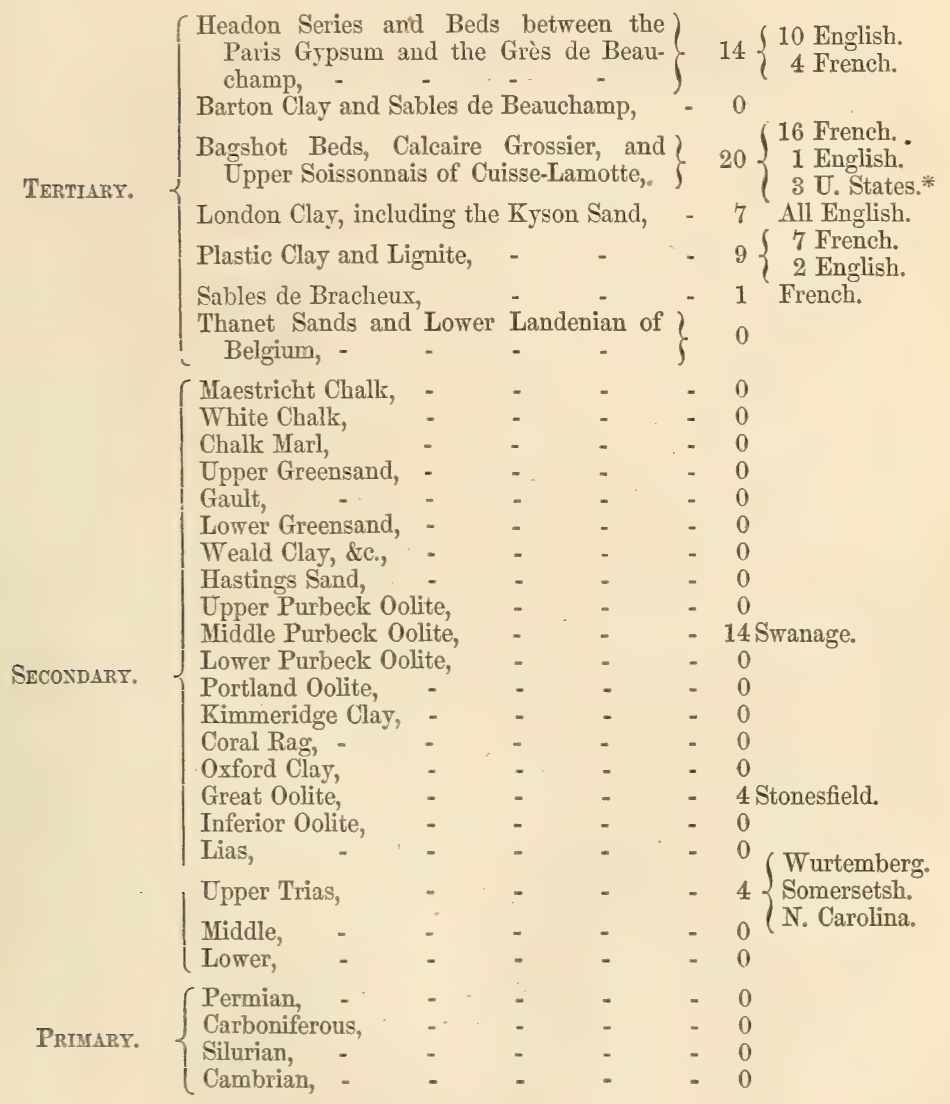

In drawing up the above table I have been assisted by Professor 0wen in reference to the British, and by MM. Lartet and Hébert in reference to the fossil mammalia of the French Eocene strata. There are, besides, several undescribed species in the collection of the two last-mentioned palæontologists, or in museums known to them; and, in regard to one or two of the Eocene continental localities out of the Paris basin, the age of the deposits is too little known to allow us to include their fossils in the table.

The Sables de Bracheux, enumerated in the Tertiary division of the table, supposed by Mr. Prestrich to be somewhat newer than the Thanet Sands, and by M. Hébert to be of about that age, have yielded at La Fère the Arctocyon (Palcoocyon) primovurs, the oldest known tertiary mammal.

I allude to several Zeuglodons found in Alabama, and referred by some zoologists to three species. 
It is worthy of notice, that in the Hastings Sands there are certain layers of clay and sandstone in which numerous footprints of quadru. peds have been found by Mr. Beckles, and traced by him in the same set of rocks through Sussex and the Isle of Wight. They appear to belong to three or four species of reptiles, and no one of them to any warm-blooded quadruped. They ought, therefore, to serve as a warning to us, when we fail in like manner to detect mammalian footprints in older rocks (such as the New Red Sandstone), to refrain from inferring that quadrupeds, other than reptilian, did not exist or preëxist.

But the most instructive lesson read to us by the Purbeck strata consists in this: They are all, with the exception of a few intercalated brackish and marine layers, of freshwater origin; they are 160 feet in thickness, have been well searched by skilful collectors, and by the late Edward Forbes in particular, who studied them for months consecutively. They have been numbered, and the contents of each stratum recorded separately, by the officers of the Government Survey of Great Britain. They have been divided into three distinct groups by Forbes, each characterized by the same genera of pulmoniferous mollusca and cyprides, but these genera being represented in each group by different species; they have yielded insects of many orders, and the fruits of several plants; and lastly, they contain "dirt beds," or old terrestrial surfaces and soils at different levels, in some of which erect trunks and stumps of cycads and conifers, with their roots still attached to them, are preserved. Yet when the geologist inquires if any land-animals of a higher grade than reptiles lived during any one of these three periods, the rocks are all silent, save one thin layer a few inches in thickness; and this single page of the earth's history has suddenly revealed to us in a few weeks the memorials of so many species of fossil mammalia, that they already outnumber those of many a subdivision of the tertiary series, and far surpass those of all the other secondary rocks put together!

Next anterior in age to the Purbeck mammalia are those of the Lower Oolite at Stonesfield, to be mentioned at page 407. These are all very small, comprising four species, three of which are certainly marsupial, and the other possibly placental, but so unlike any living type that some doubts are entertained as to whether it may not have been marsupial. Still older than the above are some fossil quadrupeds, also of small size, found in the Upper Trias of Stuttgardt, in Germany, and more lately by Messrs. Charles Moore and W. Boyd Dawkins, in beds of corresponding age in Somersetshire, which are also of a very low grade, like the living Myrmecobius of Australia.

If the three localities where the most ancient mammalia have been found-Purbeck, Stonesfield, and Stuttgardt-had belonged all of them to formations of the same age, we might well have imagined so limited an area to have been peopled exclusively with pouched quadrupeds, just as Australia now is, while other parts of the globe were 
inhabited by placentals, for Australia now supports one hundred and sixty species of marsupials, while the rest of the continents and islands are tenanted by about seventeen hundred species of mammalia, of which only forty-six are marsupial, namely, the opossums of North and South America. But the great difference of age of the strata in each of these three localities seems to indicate the predominance throughout a rast lapse of time (from the era of the Upper Trias to that of the Purbeck beds) of a low grade of quadrupeds; and this persistency of similar generic and ordinal types in Europe while the species were changing, and while the fish, reptiles, and mollusca were undergoing vast modifications, would naturally lead us to suspect that there must also have been a vast extension in space of the same marsupial forms during that portion of the secondary epoch which has been termed "the age of reptiles." Such an inference as to the wide geographical range of the marsupials of the olden time has been confirmed by the discovery in the Trias of North America of three lower jaws of a quadruped allied to Myrmecobius. It was found by the late Dr. Emmons in beds probably coeval with the "Keuper" of Europe. The predominance in earlier ages of these mammalia of a low grade, and the absence at present of species of higher organization, is certainly in favor of the theory of progressive development.

Beneath the freshwater strata to which the mammaliferous marl belongs is a thin band of greenish shales, with marine shells and impressions of leares, like those of a large Zostera, forming the base of the Middle Purbeck.

Lower Purbeck.-Beneath the thin marine band last mentioned, purely freshwater marls occur, containing species of Cypris (fig. 375, $a, b)$, Valvata, and Limnoca, different from those of the Middle Purbeck. This is the beginning of the inferior division, which is about 80 feet thick. Below the marls are seen, at Meup's Bay, more than 30 feet of brackish-water strata, abounding in a species of Serpula, allied to, if not identical with, Serpula coacervites, found in beds of the same age in Hanover. There

Fig. 375 .
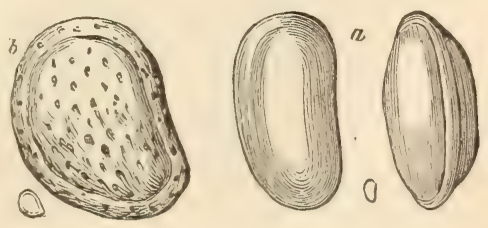

Cyprides from the Lower Purbecks.

a. Cypris Purbeckensis, o. Cypris punctata, E. Forbes.

E. Forbes. are also shells of the genus Rissoa (of the subgenus Hydrobia), and a little Cardium of the subgenus Protocardium, in these marine beds, together with Cypris. Some of the cypris-bearing shales are strangely contorted and broken up, at the west end of the Isle of Purbeck. The great dirt-bed or regetable soil containing the roots and stools of Cycadece, which I shall presently describe, underlies these marls, and rests upon the lowest freshwater limestone, a rock about 8 feet thick, 
containing Cyclas, Valvata, and Limnoea, of the same species as those of the uppermost part of the Lower Purbeck, or above the dirt-bed.

Fig. 376.

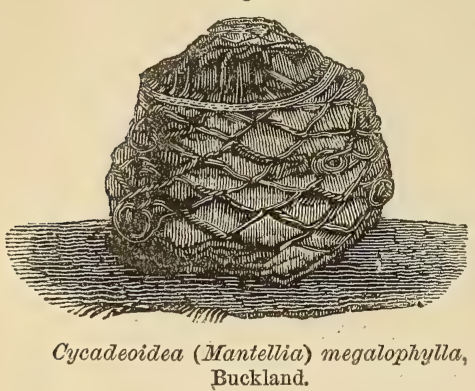
The freshwater limestone in its turn rests upon the top beds of the Portland stone, which, although it contains purely marine remains, often consists of a rock quite homogeneous in mineral character with the Lowest Purbeck limestone.*

The most remarkable of all the varied succession of beds enumerated in the above list, is that called by the quarrymen " the dirt," or "black dirt,"

which was evidently an ancient vegetable soil. It is from 12 to 18 inches thick, is of a dark brown or black color, and contains a large proportion of earthy lignite. : Through it are dispersed rounded fragments of stone, from 3 to 9 inches in diameter, in such numbers that it almost deserves the name of gravel. Many silicified trunks of coniferous trees, and the remains of plants allied to Zamia and Cycas, are buried in this dirt-bed (see figure of fossil species, fig. 376, and of living Zamia, fig. 377).

Fig. 377 .

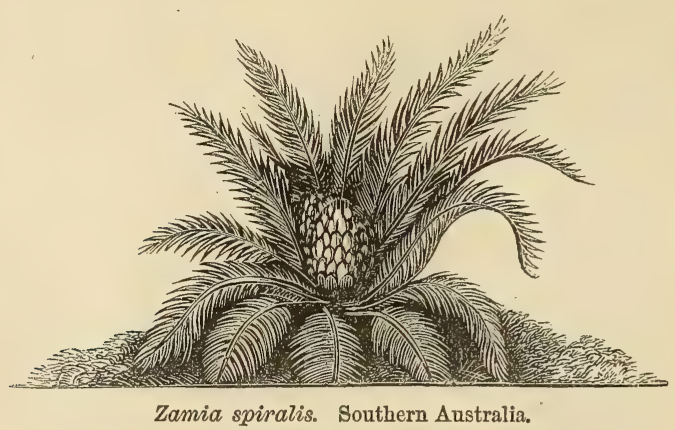

These plants must have become fossil on the spots where they grew. The stumps of the trees stand erect for a height of from one to three feet, and even in one instance to six feet, with their roots attached to the soil at about the same distances from one another as the trees in a modern forest. $\uparrow$. The carbonaceous matter is most abundant immediately around the stumps, and round the remains of fossil Cycadece.

* Weston, Geol. Quart. Journ., vol. viii. p. 117.

$+\mathrm{Mr}$. Webster first noticed the erect position of the trees, and described the Dirt-bed,

¥ Fitton, Geol. Trans., Second Series, vol. iv. pp. 220, 221. 
Besides the upright stumps above mentioned, the dirt-bed contains the stems of silicified trees laid prostrate. These are partly sunk into the black earth, and partly enveloped by a calcareous slate which covers the dirt-bed. The fragments of the prostrate trees are rarely more than 3 or 4 feet in length; but by joining many of them together, trunks have been restored, having a length from the root to the branches of from 20 to 23 feet, the stems being undivided for 17 or 20 feet, and then forked. The diameter of these near the root is about one foot. Root-shaped cavities were observed by Professor Henslow to descend from the bottom of the dirt-bed into the subjacent freshwater stone, which, though now solid, must have been in a soft and penetrable state when the trees grew.*

Fig. 378.

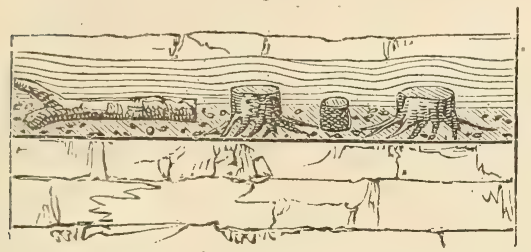

Freshwater calcareous slate.

Dirt-bed and ancient forest.

Lowest freshwater beds of the Lower Purbeck.

Portland stone, marine.

Section in Isle of Portland, Dorset. (Buckiand and De la Beche.)

The thin layers of calcareous slate (fig. 378) were evidently deposited tranquilly, and would have been horizontal but for the protrusion of the stumps of the trees, around the top of each of which they form hemispherical concretions.

The dirt-bed is by no means confined to the island of Portland, where it has been most carefully studied, but is seen in the same relative position in the cliffs east of Lulworth Core, in Dorsetshire,

Fig. 379 ,

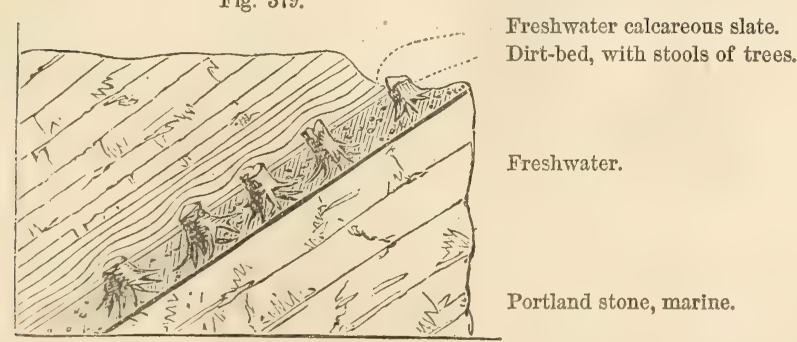

Section in cliff east of Lulworth Cove. (Buckland and De la Beche.)

where, as the strata hare been disturbed, and are now inclined at an angle of $45^{\circ}$, the stumps of the trees are also inclined at the same

* Buckland and De la Beche, Geol. Trans., Second Series, vol. iv. p. 16. Prof. Forbes has ascertained that the subjacent rock is a freshwater limestone, and not a portion of the Portland oolite, as was previously imagined. 
angle in an opposite direction-a beautiful illustration of a change in the position of beds originally horizontal (see fig. 379). Traces of the dirt-bed have also been observed by Mr. Fisher, at Ridgway ; by Dr. Buckland, about two miles north of Thame, in Oxfordshire; and by Dr. Fitton, in the cliffs in the Boulonnois, on the French coast: but, as might be expected, this freshwater deposit is of limited extent when compared to most marine formations.

From the facts above described we may infer, first, that those beds of the Upper Oolite, called "the Portland," which are full of marine shells, were overspread with fluviatile mud, which became dry land, and covered by a forest, throughout a portion of the space now occupied by the south of England, the climate being such as to admit the growth of the Zamia and Cycas. 2dly. This land at length sank down and was submerged with its forests beneath a body of fresh water, from which sediment was thrown down enveloping fluviatile shells. 3dly. The regular and uniform preservation of this thin bed of black earth over a distance of many miles, shows that the change from dry land to the state of a freshwater lake or estuary, was not accompanied by any violent denudation, or rush of water, since the loose black earth, together with the trees which lay prostrate on its surface, must inevitably have been swept away had any such violent catastrophe taken place.

The dirt-bed has been described above in its most simple form, but in some sections the appearances are more complicated. The forest of the dirt-bed was not everywhere the first vegetation which grew in this region. Two other beds of carbonaceous clay, one of them containing Cycadece, in an upright position, have been found below it, and one above it, which implies other oscillations in the level of the same ground, and its alternate occupation by land and water more than once.

Table showing the changes of Medium in which the strata were formed, from the Portland Stone up to the Lower Greensand inclusive, in the southeast of England (beginning with the lowest).

1. Marine

2. Freshwater

Land

Freshwater

Land

Freshwater

Land (Dirt-bed)

Freshwater

Land

Brackish

Freshwater

$\left\{\begin{array}{c}\text { Portland Stone. } \\ \text { Lower Purbeck. }\end{array}\right.$

3. Marine Freshwater Marine Brackish Marine Brackish Freshwater

4. Freshwater

5. Freshwater Brackish Freshwater

6. Freshwater

7. Marine

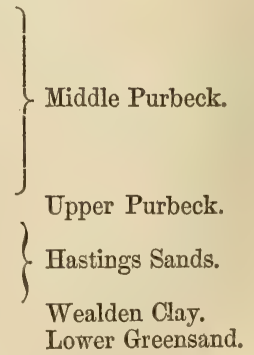

The annexed tabular view will enable the reader to take in at a glance the succossive changes from sea to river, and from river to sea, 
or from these again to a state of land, which have occurred in this part of England, between the Oolitic and Cretaceous periods. That there hare been at least four changes in the species of testacea during the deposition of the Wealden and Purbeck beds, seems to follow from the observations recently made by Professor Forbes; so that, should we hereafter find the signs of many more alternate occupations of the same area by different elements, it is no more than we might expect. Eren during a small part of a zoological period, not sufficient to allow time for many species to die out, we find that the same area has been laid dry, and then submerged, and then again laid dry, as in the Deltas of the Po and Ganges, the history of which has been brought to light by Artesian boring's." TVe also know that similar revolutions have occurred within the present century (1819) in the delta of the Indus in Cutch, $\uparrow$ where land has been laid permanently under the waters both of the river and sea, without its soil or shrubs having been swept away. Even independently of any vertical movements of the ground, we see in the principal deltas, such as that of the Mississippi, that the sea extends its salt waters annually for many months over considerable spaces which, at other seasons, are occupied by the river during its inundations.

It will be observed that the division of the Purbecks into upper, middle, and lower has been made by Professor Forbes strictly on the principle of the entire distinctness of the species of organic remains which they include. The lines of demarcation are not lines of disturbance, nor indicated by any striking physical characters or mineral changes. The features which atiract the eye in the Purbecks, such as the dirt-beds, the dislocated strata at Lulworth, and the Cinderbed, do not indicate any breaks in the distribution of organized beings. "The causes which led to a complete change of life three times during the deposition of the freshwater and brackish strata must," says this naturalist, "be sought for, not simply in either a rapid or a sudden change of their area into land or sea, but in the great lapse of time which intervened between the epochs of deposition at certain periods during their formation."

Each dirt-bed may, no doubt, be the memorial of many thousand years or centuries, because we find that 2 or 3 feet of vegetable soil is the only monument which many a tropical forest has left of its existence erer since the ground on which it now stands mas first covered with its shade. Yet, even if we imagine the fossil soils of the Lower Purbeck to represent as many ages, we need not expect on that account to find them constituting the lines of separation between successive strata characterized by different zoological types. The preservation of a layer of regetable soil, when in the act of being submerged, must be regarded as a rare exception to a general rule. It is of so perishable a nature, that it must usually be carried away by the

* See Principles of Geol, 9th ed., pp. 255, 275.

† Ibid., p. 460. 
denuding waves or currents of the sea, or by a river; and many Purbeck dirt-beds were probably formed in succession and annibilated,

Fig. 380.

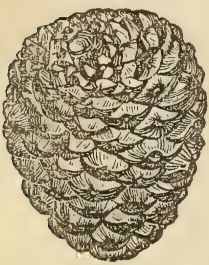

Cone of a pine from the Isle of Purbeck. (Fitton.) besides those few which now remain.

The plants of the Purbeck beds, so far as our knowledge extends at present, consists chiefly of Ferns, Coniferæ (fig. 380), and Cycadeæ (fig. 376), without any angiosperms; the whole more allied to the Oolitic than to the Cretaceous vegetation. The vertebrate and invertebrate animals indicate, like the plants, a somewhat nearer relationship to the Oolitic than to the Cretaceous period. $\mathrm{Mr}$. Brodie has found the remains of beetles and several insects of the homopterous and trichopterous orders, some of which now live on plants, while others are of such forms as hover over the surface of our present rivers.

Portland Oolite and Sand (b, Tab., p. 375).-The Portland oolite has already been mentioned as forming in Dorsetshire the foundation on which the freshwater limestone of the Lower Purbeck reposes (see p. 389). It supplies the well-known building-stone of which St. Paul's and so many of the principal edifices of London are constructcd. This upper member rests on a dense bed of sand, called the Portland sand, containing for the most part similar marine fossils, below which is the Kimmeridge clay. In England these Upper Oolite formations are almost wholly confined to the southern counties. Corals are rare in them, although one species is found plentifully at Tisbury, Wiltshire, in the Portland sand, converted into flint and chert, the original calcareous matter being replaced by silex (fig. 381).

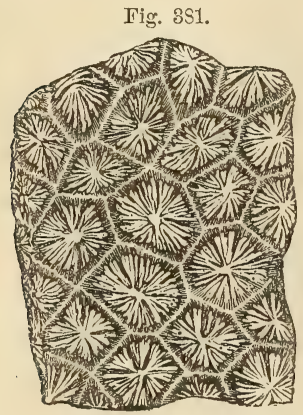

Isastrce a oblonga, M. Edw. and J. Haime. As seen on a polished slab of chert from the Portland Sand, Tisbury.
Fig. 382

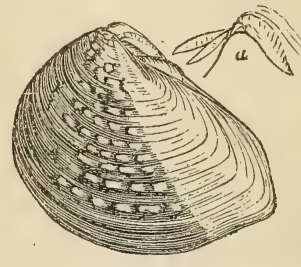

Trigonia gibbosa. $\frac{1}{2}$ nat. size. a. The hinge.

Portland Stone, Tisbury.

The Kimmeridge clay consists, in great part, of a bituminous shale, sometimes forming an impure coal, several hundred feet in thickness In some places in Wiltshire it much resembles peat; and the bitu- 
minous matter mar hare been, in part at least, derired from the decomposition of regetables. But as impressions of plants are rare in

Fig. 3 :

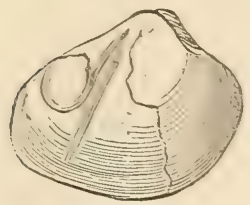

Curdiun dissimile. $\frac{1}{4}$ nai. size Portland Stone.
Fig. 3st.

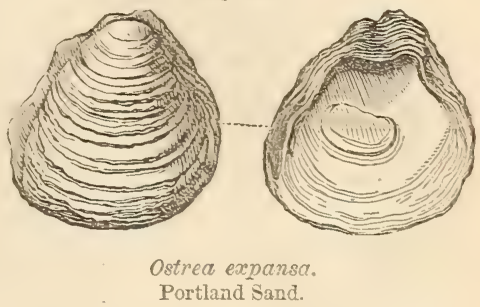

these shales, which contain ammonites, oysters, and other marine shells, the bitumen may perhaps be of animal origin.

Among the characteristic fossils may be mentioned Cardium striatutum (iig. 385) and Ostrea deltoidea (fig. 386), the latter found in the Fimmeridge clar throughout England and the north of France, and also in Scotland, near Brora. The Gryphcea virgula (fig. 387),

Fig. 335.

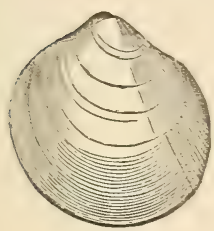

Cardium striatulum. Kimmeridge clay, Hartwell.
Fig. 386.

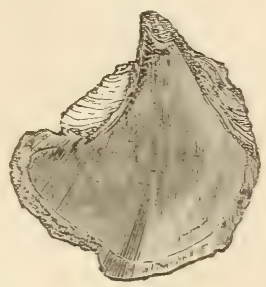

Ostrea deltoidea.

Kimmeridge clay, $\frac{1}{4}$ nat. size.
Fig. 38T.

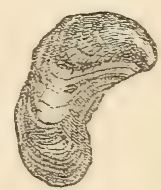

Gryphcea (Lxogyra) virgula. Kimmeridge clay.

also met with in the same clay near Oxford, is so abundant in the Tpper Oolite of parts of France as to hare caused the deposit to bo termed "marnes ¿̀ gryphées rirgules." Near Clermont in Argonne, a fem leagues from St. Menehould, where these indurated marls crop out from beneath the gault, I hare seen them, on decomposing, leare the surlince of erery plonghed field literally stremed orer with this fossil oyster. The Trigonellites latus (Aptychus, of some authors) (fig. 388) is also widely dispersed through this clay. The real nature of the shell, of which there are many species in oolitic rocks, is still a matter of conjecture. Some are of opinion that the two plates formed the gizzard of a cephalopod; for the liring Nautilus has a gizzard with horny folds, and the Bulla is well known to

Fig. 3ss.

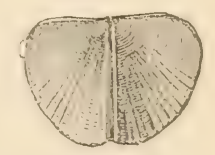

Trigonellites latus. Kirumeridge clay. possess one formed of calcareous plates.

The celebrated lithographic stone of Solenhofen, in Bararia, belongs to one of the upper divisions of the oolite, and affords a re- 
markable example of the variety of fossils which may be preserved under favorable circumstances, and what delicate impressions of the tender parts of certain animals and

Fig. 389.

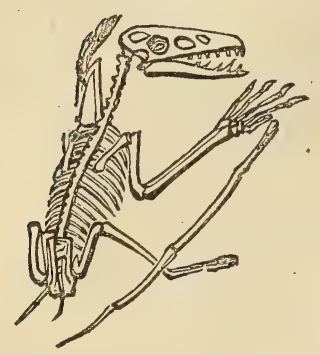

Skeleton of Pterodactylus crassirostris.

Oolite of Pappenheim, near Solenhofen. plants may be retained where the sediment is of extreme fineness. Although the number of testacea in this slate is small, and the plants few, and those all marine, Count Münster had determined no less than 237 species of fossils when I saw his collection in 1833 ; and among them no less than seven species of flying lizards or pterodactyls (see fig. 389), six saurians, three tortoises, sixty species of fish, forty-six of crustacea, and twenty-six of insects. These insects, among which is a libellula, or dragon-fly, must have been blown out to sea, probably from the same land to which the flying lizards, and other contemporaneous reptiles, resorted.

In the same slate of Solenhofen a fine example was met with in 1862 of the skeleton of a bird almost entire, with the exception of the head, and retaining even its feathers. This valuable specimen is now in the British Museum, and has been called by Professor Owen Archocopteryx macrura. According to his interpretation, it is a true bird, and not intermediate, as was at first imagined, between a bird and reptile. It was about the size of a rook. It differs remarkably from all known birds in having two free claws belonging to the wing, and in the structure of its tail; for in almost all living representatives of the class Aves, the tail feathers are attached to a coccygian bone, consisting of several vertebræ united together, whereas in the Archæopteryx the tail is composed of twenty vertebræ, each of which supports a pair of quill feathers so perfect that the vanes as well as the shaft are preserved. The first five only of the vertebræ as seen in A have transverse processes, the fifteen remaining ones become gradually longer and more tapering. The feathers diverge outward from them at an angle of $45^{\circ}$; but this departure from the true ornithic type occurs, says Professor Owen, in that part of the skeleton which is most subject to variation.

Thus there are short and long-tailed species of bats, rodents, and pterodactyles, with great variation in the number of their caudal vertebræ; he also observes that although in living birds a short bony tail, and generally accompanied by a coalescence of the terminal vertebrre to form the ploughshare bone $f \mathrm{E}$, is a constant character, yet all birds in their embryonic state exhibit the vertebræ distinct and separate, so that the tail of the Archæopteryx exhibits a retention of structure which is "embryonal and transitory in the modern representatives of the class, and consequently a closer adhesion to the general vertebrate 
type." In the young ostrich from eighteen to twenty caudal rertebræ may be counted, seven or eight of which are annexed to the sacrum,

Fig. 890 .
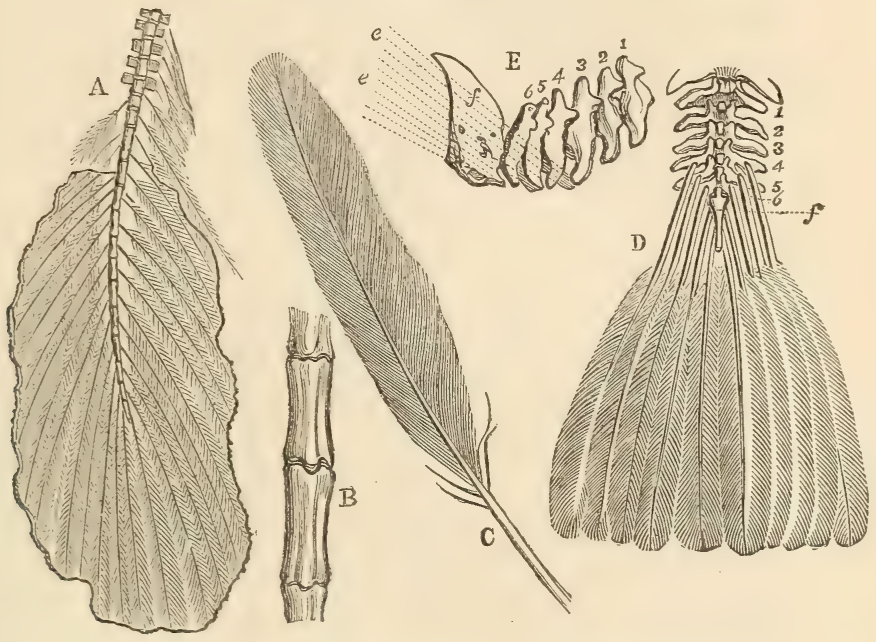

Tail of Archoopteryx macmura, Owen, and Feather of A. lithographia, Meyer, from the slate of Solenhofen; and tail of living bird for comparison.

A. Series of caudal vertebræ (with impressions of the tail-feathers preserved in situ) of $A r$. chceopteryx macrura, Owen. $\frac{1}{5}$ nat. size. Drawn from the specimen in the British Museum (ventral aspect).

B. Two of the caudal vertebræ, nat. size, showing their shape and the absence of transverse processes.

C. Single feather, called Archoopteryx lithographica by Von Meyer. Natural size.

This feather, upon which the genus was established in 1861, was discovered at Solerhofen. See "Jahrbuch für Mineralogie," 1861, p. 561.

D. Tail of recent vulture (Gyps Bengalensis), showing the points of attachment for the principal tail-feathers (dorsal view, $\frac{x}{4}$ nat. size).

E. Profile of caudal vertebræ of same, to show the broad terminal joint, or "ploughshare" bone, $f$, of the tail, the same as that seen foreshortened at $f \mathrm{D}$, so largely dereloped in nearly all living birds. $\frac{1}{3}$ nat. size.

N. B.-The figures 1 to 6 indicate the correspondence between the vertebræ in the two views $\mathrm{D}$ and $\mathrm{E}$.

$f \mathrm{E}$ and $f \mathrm{D}$ indicate the position of the terminal joint.

The dotted lines $\mathbf{E}, e, e$, show the direction of the quill feathers of the tail when seen in profile.

The ploughshare bone can be elevated at pleasure (as seen at $f \mathrm{E}$ ), to meet the extended beak of the bird when seeking the coccigian oil-gland (which is placed upon this terminal joint) to lubricate its feathers while preening. Only the "primaries" or great tail feathers are represented in fig. $\mathrm{D}$; the bases of these and the rest of tho vertebra are clothed in secondary feathert and down.

while two or three are welded together to form the slender terminal bone, which in this and other running birds (cursores) is not ploughshare-shaped.

It has been already stated that no species of British fossil, whether of the rertebrata or invertebrata, are common to the Oolite and Chalk, or, to speak more strictly, are common to the marine beds of these two groups which stand nearest to each other, namely, the Portland limestone and the Atherfield berds; but while there is this great break 
In an upward direction, there is no similar discordance as we proceed downwards, and pass from one to another of the several members of the Jurassic group, the Upper, Middle, and Lower Oolite, and the Lias. Thus, for example, I find on consulting Mr. Etheridge's tables of British Fossils,* that of sixty species of all classes that lived in the period of the Kimmeridge clay, twenty, or about 33 per cent., pass down into the Coral-Rag; or, if we confine our attention exclusively to the mollusca, of thirty-three species in the Kimmeridge clay, eight, or 24 per cent., are common to the Coral-Rag.

\section{MIDDLE OOLITE.}

Coral-Rag.-One of the limestones of the Middle Oolite has been called the "Coral-Rag," because it consists, in part, of continuous beds of petrified corals, for the most part retaining the position in which they grew at the bottom of the sea. In their forms they more frequently resemble the reef-building poliparia of the Pacific than do the corals of any other member of the Oolite. They belong chiefly to the genera Thecosmilia (fig. 391), Protosseis, and Thamnastrcea, and sometimes form masses of coral 15 feet thick. In the annexed figure of a Thamnastrcea (fig. 392), from this formation, it

Fig. 391.

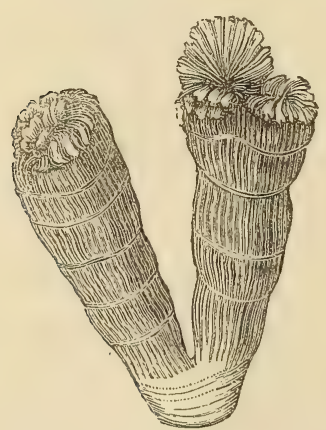

Thecosmilia annularis, Milne Edw, and J. Haime. Coral-rag, Steeple Ashton.

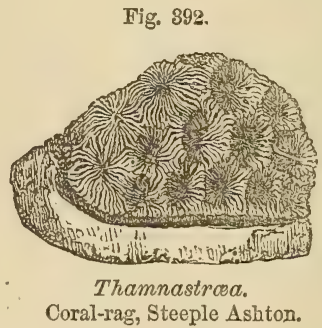

will be seen that the cup-shaped cavities are deepest on the righthand side, and that they grow more and more shallow, until those on the left side are nearly filled up. The last-mentioned stars are supposed to represent a perfected condition, and the others an immature state. These coralline strata extend through the calcareous hills of the N.W. of Berkshire, and north of Wilts, and again recur in Yorkshire, near Scarborough. The Ostrea gregarea (fig. 393) is very characteristic of the formation in England and on the Continent.

* Compiled for a work entitled "Stratigraphical Arrangement of British Fossils," now preparing for publication by Mr. Etheridge. 
One of the limestones of the Jura, referred to the age of the Euglish coral-rag, has been called "Nerinæan limestone" (Calcaire à Nérinées) by M. Thirria ; Nerincea being an extinct genus of univalve shells, much resembling the Cerithium in external form. The amnered section (ig. 39t) shows the curious form of the hollow part of each whorl, and also the perforation which passes up the middle

Fig. 394.

Fig. 393.

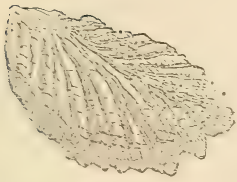

Ostrea gregarea. Coral-rag, Steeple Ashton.

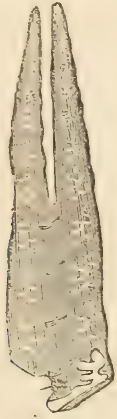

Nerincea hierogtyphica. Coral-rag.
Fig. 395 .

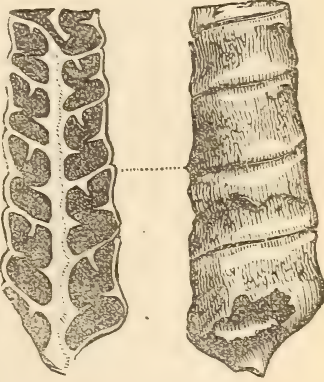

Nerinced Goodhallii, Fitton. Coral-rag, Weymouth. $\frac{1}{2}$ nat. size.

of the columella. N. Goodhallii (fig. 395) is another English species of the same genus, from a formation which seems to form a passage from the Kimmeridge clay to the coral-rag:"

A division of the oolite in the Alps, regarded by most geologists as coeval with the English coral-rag, has been often named "Calcaire à Dicerates," or "Diceras lfmestone," from its containing abundantly a biralve shell (see fig. 396) of a genus allied to the Chama.

Fig. 397.

Fig. 396.

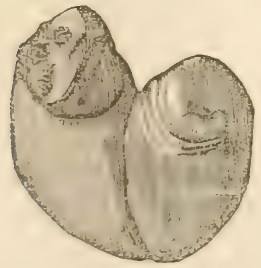

Cast eî Diceras arietina. Coral-rag, France.

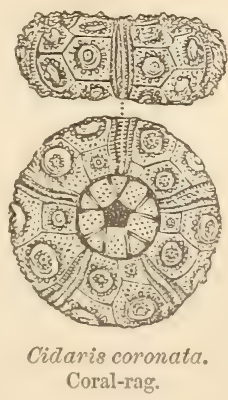

Oxford Clay.-The coralline limestone, or "coral-rag," above described, and the accompansing sandy beds, called "calcarcous grits," of the Middle Oolite, rest on a thick bed of clay, called the "Oxford 
clay," sometimes not less than 500 feet thick. In this there are no corals, but great abundance of cephalopoda, of the genera Ammonite and Belemnite. (See figs. 398, 399.) In some of the finely lami-

Fig. 398.

Belemnites hastatus. Oxford clay.

nated clays ammonites are very perfect, although somewhat compressed, and are frequently found with the lateral lobe expanded on each side of the opening of the mouth into a single horn-like projection (see fig. 399). These were discovered in the cuttings of the Great Western Railway, near Chippenham, in 1841, and have been described by Mr. Pratt (An. Nat. Hist., Nov, 1841).

Fig. 399.

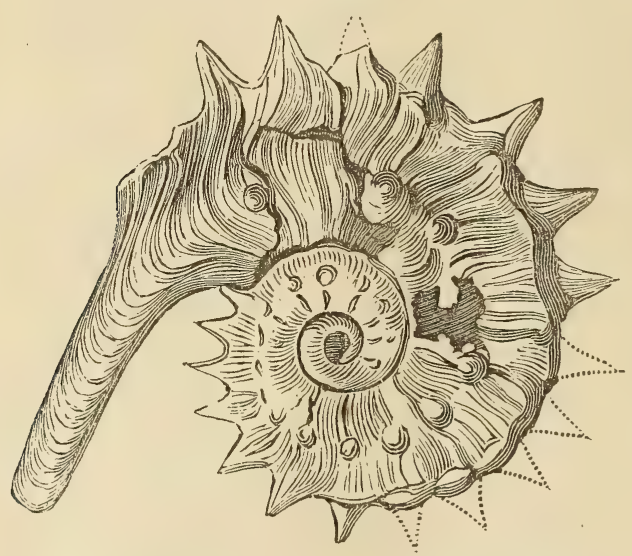

Ammonites (Jason, Reinecke. Syn. A. Elizabetho, Pratt). Oxford clay, Christian Malford, Wiltshire.

Similar elongated processes have been also observed to extend from the shells of some belemnites discovered by Dr. Mantell, in the same clay (see fig. 400), who, by the aid of this and other specimens, has been able to throw much light on the structure of this and other singular extinct forms of cuttle-fish.*

Kelloway Rock.-The arenaceous limestone which passes under this name is generally grouped as a member of the Oxford clay, in which it forms, in the south-west of England, lenticular masses, 8 or 10 feet thick, containing at Kelloway, in Wiltshire, numerous casts of ammonites and other shells. But in Yorkshire this calcareo-arenaceous formation thickens to about 30 feet, and constitutes the lower part of

* See Phil. Trans., 1850, p. 393; also fluxley, Memoirs of Geol. Survey, 1864. 
the Middle Oolite, extending inland from Scarborough in a southerly direction. The number of mollusea which it contains is, according to Mr. Etheridge, 106, of which only twenty-three, or $22 \frac{1}{2}$ per cent., are common to the Oxford clay proper. Of the twenty Cephalopoda, eight (namely, one of the Sepia family, six species of ammonite, and the Ancyloceras Calloviense) are common to the Oxford Clay, giving a proportion of 40 per cent.

If, on the other hand, we compare the fossils of all kinds in the Kelloway rock, amounting to 151 species, with the fossils of the underlying Lower Oolite, we find that seventy-four pass down into the older rocks, or about 49 per cent. ; or if we confine our attention to the mollusca alone of the Kelloway considered as the base of the Middle Oolite, and compare them with those of the Cornbrash, or the top member of the Lower Oolite, we find 106 species in the Kelloway, and 123 in the Cornbrash, and 22 species common to the two, implying a community of 21 per cent. between the two formations.

\section{LOWER OOLITE.}

Cornbrash and Forest Marble. - The upper division of this series, which is more extensive than the preceding or Middle Oolite, is called in England the Cormbrash. It consists of clays and calcareous sandstones, which pass downwards into the Forest Marble, an argillaceous limestone, abounding in marine fossils. In some places, as at Bradford, this limestone is replaced by a mass of clay. The sandstones of the Forest Marble of Wiltshire are often ripple-marked and filled with fragments of broken shells and pieces of drift-wood, having evidently been formed on a coast. Rippled slabs of fissile oolite are used for roofing, and have been traced over a broad band of country from Brad-
Fig. 347.

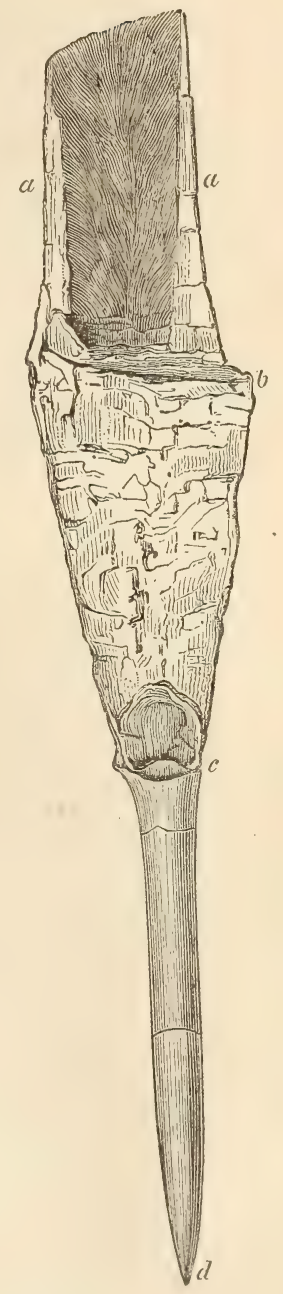

Belemnites Puzosianus, $B$. Orenii, Pierce.

Oxford Clay, Christian Malford.

$a, a$. Projecting processes of the shell or phragmocone.

b, c. Broken exterior of a conical shell called the phragmocone, which is chambered within, or composed of a series of shallow concave cells pierced by a siphuncle.

$c, d$. The guard or osselet, which is commonly ealled the belemnite. 
ford in Wilts, to Tetbury in Gloucestershire. These calcareous tilestones are separated from each other by thin seams of clay, which have been deposited upon them, and have taken their form, preserving the undulating ridges and furrows of the sand in such complete integrity, that the impressions of small footsteps, apparently of crustaceans, which walked over the soft wet sands, are still visible. In the same stone the claws of crabs, fragments of echini, and other signs of a neighboring beach, are observed.*

Great Oolite.-Although the name of coral-rag has been appropriated, as we have seen, to a member of the Upper Oolite before described, some portions of the Lower Oolite are equally entitled in many places to be called coralline limestones. Thus the Great Oolite near Bath contains various corals, among which the Eunomia radiata (fig. 401) is very conspicuous, single individuals forming masses sev-

Fig. 401.

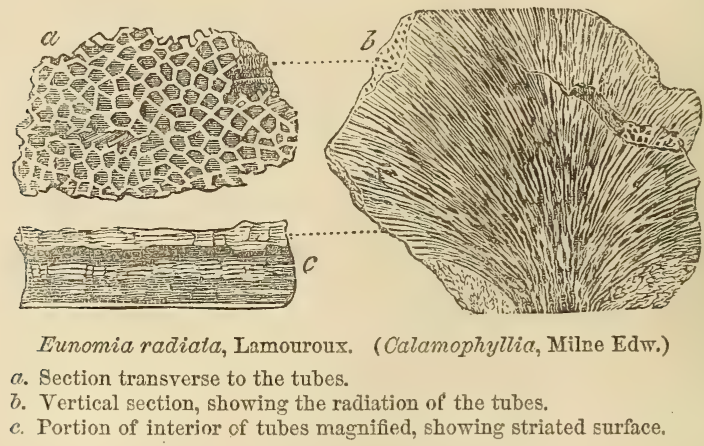

eral feet in diameter; and having probably required, like the large existing brain-coral (Meandrina) of the tropics, many centuries before their growth was completed.

Different species of crinoids, or stone-lilies, are also common in the same rocks with corals; and, like them, must have enjoyed a firm bottom, where their root, or base of attachment, remained undisturbed for years (c, fig. 402). Such fossils, therefore, are almost confined to the limestones; but an exception occurs at Bradford, near Bath, where they are enveloped in clay. In this case, however, it appears that the solid upper surface of the "Great Oolite" had supported, for a time, a thick submarine forest of these beautiful zoophytes, until the clear and still water was invaded by a current charged with mud, which threw down the stone-lilies, and broke most of their stems short off near the point of attachment. The stumps still remain in their original position; but the numerous articulations, once composing the stem, arms, and body of the encrinite, were scat- 
tered at random through the argillaceous deposit in which some now lie prostrate. These appearances are represented in the section $b$, fig. 402, where the darker strata represent the Bradford clay, which some

Fig. 402 .

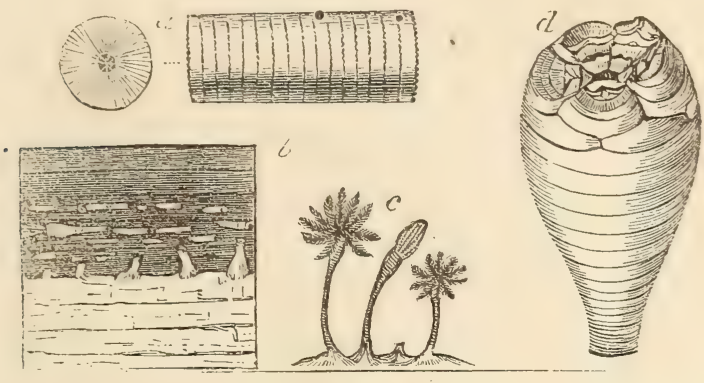

Apiocrinites rotundus, or Pear Encrinite; Miller. Fossil at Bradford, Wilts.

a. Stem of Apiocrinites, and one of the articulations, natural size.

b. Section at Bradford of Great Oolite and overlying clay, containing the fossil encrinites. See text.

c. Three perfect individuals of Apiocrinites, represented as they grew on the surface of the Great Oolite.

d. Body of the Apiocrinites rotundus.

geologists class with the Forest Marble, others with the Great Oolite. The upper surface of the calcareous stone below is completely encrusted over with a continuous parement, formed by the stony roots or attachments of the Crinoidea; and besides this evidence of the length of time they had lived on the spot, we find great numbers of single joints, or circular plates of the stem and body of the encrinite, covered over with serpulce. Now these serpulce could only have

Fig. 403.
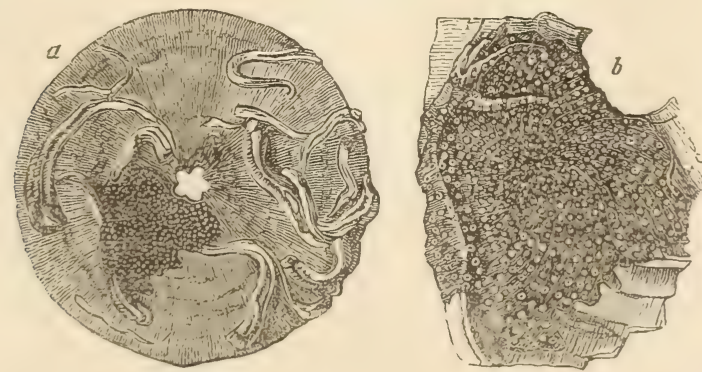

a. Single plate or articulation of an Encrinite overgrown with serpuloe and bryozoa. Natural size, Bradford clay.

b. Portion of the same magnified, showing the bryozoan Diastopora dituviana covering one of the serpulce.

begun to grow aiter the death of some of the stone-lilies, parts of whose skeletons had been strewed over the floor of the ocean before the irruption of argillaceous mud. In some instances we find that, 
after the parasitic serpuloe were full grown, they had become incrusted over with a bryozoan, called Diastopora diluviana; and many generations of these molluscoids had succeeded each other in the purc water before they became fossil.

We may, therefore, perceive distinctly that, as the pines and cycadeous plants of the ancient " dirt-bed," or fossil forest, of the Lower Purbeck were killed by submergence under fresh water, and soon buried beneath muddy sediment, so an invasion of argillaceous matter put a sudden stop to the growth of the Bradford Encrinites and led to their preservation in marine strata.*

Such differences in the fossils as distinguish the calcareous and argillaceous deposits from each other, would be described by naturalists as arising out of a difference in the stations of species; but besides these, there are variations in the fossils of the higher, middle, and lower part of the oolitic series, which must be ascribed to that great law of change in organic life by which distinct assemblages of species have been adapted, at successive geological periods, to the varying conditions of the habitable surface. . In a single district it is difficult to decide how far the limitation of species to certain minor formations has been due to the local influence of stations, or how far it has been caused by time or the creative and destroying law above alluded to. But we recognize the reality of the last-mentioned influence, when we contrast the whole oolitic series of England with that of parts of the Jura, Alps, and other distant regions, where there is scarcely any lithological resemblance; and yet some of the same fossils remain peculiar in each country to the Upper, Middle, and Lower Oolite formations respectively. Mr. Thurmann has shown how remarkably this fact holds true in the Bernese Jura, although the argillaceous divisions, so conspicuous in England, are feebly represented there, and some entirely wanting.

The Bradford clay, above alluded to, is sometimes 60 feet thick, but in many places it is wanting; and in others, where there are no limestones, it cannot easily be separated from the clays of the overlying "forest marble" and underlying "fuller's earth."

The calcareous portion of the Great Oolite consists of several shelly limestones, one of which, called the Bath Oolite, is much celebrated as a building-stone. In parts of Gloucestershire, especially near Minchinhampton, the Great Oolite, says Mr. Lycett, "must have been deposited in a shallow sea, where strong currents prevailed, for there are frequent changes in the mineral character of the deposit, and some beds exhibit false stratification. In others, heaps of broken shells are mingled with pebbles of rocks foreign to the neighborhood, and with fragments of abraded madrepores, dicotyledonous wood, and crabs' claws. The shelly strata, also, have occasionally suffered denudation, and the

* For a fuller account of these Encrinites, see Buckland's Bridgewater Treatise, vol, i. p. 429. 
removed portions have been replaced by clay." * In such shallowwater beds shells of the genera Patella, Nerita, Rimula, and Cylindrites are common (see figs. 406 to 409 ); while cephalopods are rare, and, in-

Fig. 405 .

Fig. 404

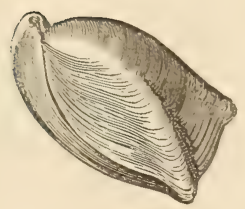

Terebratula digona. Nat. size. Bradford clay.

Fig. 407 .
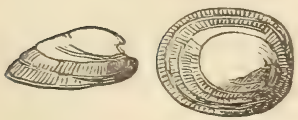

Patella megosa, Sow. Great Oolite.

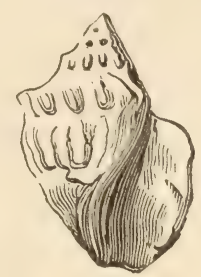

Purpuroidea nodulata. $\frac{1}{6}$ nat. size. Great Oolite, Minchinhampton.

Fig. 408.

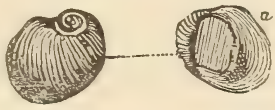

Nerita cosiulata, Desh. Rimula (Emarginula) clathGreat Oolite.
Fig. 406.

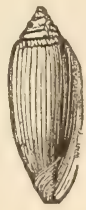

Cylindrites acutus, Sow. Syn. Actoon acutus. Great Oolite, Minchinhampton.

Fig. 409 .

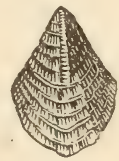

rata, Sow. Great Oolite.

stead of ammonites and belemnites, numerous genera of carnivorous trachelipods appear. Out of 142 species of uniralves obtained from the Ninchinhampton beds, Mr. Lycett found no less than 41 to be carnirorous. They belong principally to the genera Buccinum, Pleurotoma, Rostellaria, Murex, Purpuroidea (fig. 405), and Fusus, and exhibit a proportion of zoophagous species not very different from that which obtains in warm seas of the Recent period. These zoological results are curious and unexpected, since it was imagined that we might look in rain for the carnirorous trachelipods in rocks of such high antiquity as the Great Oolite, and it was a receired doctrine that they did not begin to appear in considerable numbers till the Eocene period, when those two great families of cephalopoda, the ammonites and belemnites, had become extinct.

Stonesfield slate.-The slate of Stonesfield has been slown by Mr. Lonsdale to lie at the base of the Great Oolite. It is a slightly oolitic shelly limestone, forming large lenticular masses imbedded in sand, only 6 fect thick, but rery rich in organic remains. It contains some pebbles of a rock rery similar to itself, and which may be portions of the deposit, broken up on a shore at low water or during storms, and redeposited. The remains of belemnites, trigonix, and other marine 
shells, with fragments of wood, are common, and impressions of ferns, cycadex, and other plants. Several insects, also, and, among the rest,

Fig. 410. the wing-covers of beetles, are perfectly preserved (see fig. 410), some of them approaching nearly to the genus Bupres$t i$ s.* $^{*}$. The remains, also, of many genera of reptiles, such as Pleiosaur, Crocodile, and Pterodactyl, have been discovered in the same limestone.

But the remarkable fossils for which the Stonesfield slate is most celebrated are those referred to the mammiferous class. The student should be reminded that in all the rocks described in the preceding chapters as older than the Eocene, no bones of any land-quadruped, or of

Elytron of Buprestis? any cetacean, had been discovered until the SpalacotheStonesfield. rium of the Purbeck beds came to light in 1854 (see above, p. 381). Yet we have seen that terrestrial plants were not rare in the lower cretaceous formation, and that in the Wealden there was evidence of freshwater sediment on a large scale, containing various plants, and even ancient vegetable soils. We had also in the same Wealden many land-reptiles and winged insects, which render the absence of terrestrial quadrupeds the more striking. The want, however, of any bones of whales, seals, dolphins, and other aquatic mammalia, whether in the chalk. or in the upper or middle oolite, is certainly still more remarkable. Formerly, indeed, a bone, from the Great Oolite of Enstone, near .Woodstock, in Oxfordshire, was cited, on the authority of Cuvier, as referable to this class. Dr. Buckland, who stated this in his Bridgewater Treatise, $\nmid$ had the kindness to send me the supposed ulna of a whale, that Prof. Owen might examine into its claims to be considered as cetacean. It is the opinion of that eminent comparative anatomist that it cannot have belonged to the cetacea, because the fore-arm in these marine mammalia is invariably much

Fig. 411.

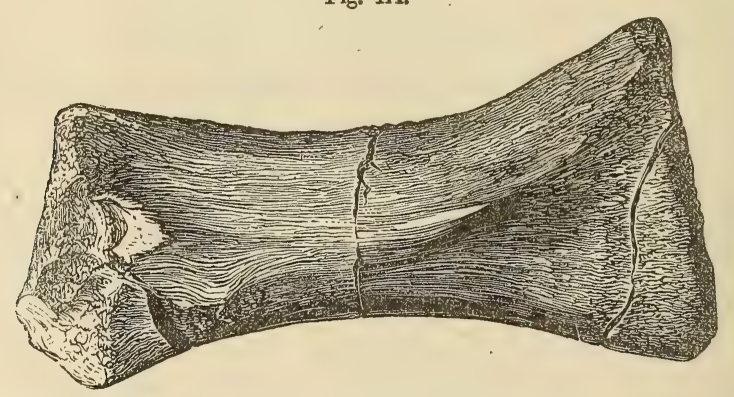

Bone of a Reptile, formerly supposed to be the ulna of a Cetacean; from the Great Oolite of Enstone, near Woodstock.

* See Buckland's Bridgewater Treatise; and Brodie's Fossil Insects, where it is suggested that these elytra may belong to Prionus.

† Vol. i. p. 115. 
flatter, and devoid of all muscular depressions and ridges, one of which is so prominent in the middle of this bone, represented in the preceding cut (fig. 411). In saurians, on the contrary, such ridges exist for the attachment of muscles; and to some animal of that class the bone is probably referable.

Thess observations are made to prepare the reader to appreciate more justly the interest felt by every geologist in the discovery in the Stonesfield slate of no less than ten specimens of lower jaws of mammiferous quadrupeds, belonging to four different species and to three distinct genera, for which the names of Amphitherium, Phascolotherium, and Stereognathus, have been adopted. When Cuvier was first shown one of these fossils in 1818 (namely, the Amphitherium), he pronounced it to belong to a small ferine mammal, with a jaw much resembling that of an opossum, but differing from all known ferine genera in the great number of the molar teeth, of which it had at least ten in a row. Since that period a much more perfect specimen of the same fossil, obtained by Dr. Buckland (see fig. 412), has been examined by Professor Owen, who finds that the jaw contained on the whole twelve molar teeth, with the socket of a small canine, and three small incisors, which are in situ, altogether amounting to sixteen teeth on each side of the lower jaw.

The only question which could be raised respecting the nature of these fossils was, whether they belonged to a mammifer, a reptile, or a fish. Now on this head the osteologist observes that each of the half jaws in question is composed of but one single piece, and not of two or more separate bones, as in fishes and most reptiles, or of two bones united by a suture, as in some few species belonging to those classes.

Fig. 412.
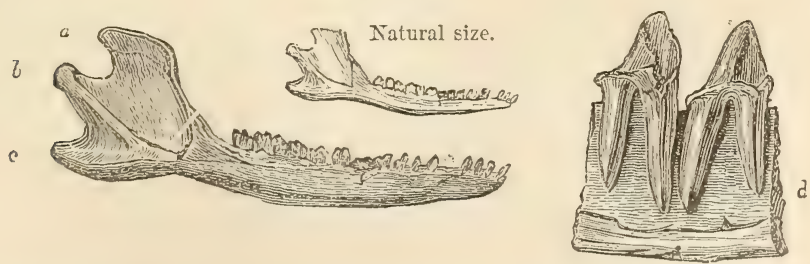

Amplitherium Prevostii, Cuv. sp. Stonesfield slate. Syn. Thylacotherium Prevostii, Valenc. a. Coronoid process. b. Condyle. c. Angle of jaw, d. Double-fanged molars.

The condyle, moreover (b, fig. 412), or articular surface, by which the lower jaw unites with the upper, is convex in the Stonesfield specimens, and not concave as in fishes and reptiles. The coronoid process ( $a$, fig. 412$)$ is well developed, whereas it is wanting, or very small, in the inferior Fig. 413. classes of vertebrata. Lastly, the molar tecth in the Amplitherium 
and Phascolotherium have complicated crowns and two roots (see $d$, fig. 412), instead of being simple and with single fangs.*

The only question, therefore, which could fairly admit of controversy was limited to this point, whether the fossil mammalia found in the Lower Oolite of Oxfordshire ought to be referred to the marsupial quadrupeds, or to the ordinary placental series. Cuvier had long ago pointed out a peculiarity in the form of the angular process ( $c$, figs. 417 and 418) of the lower jaw, as a character of the genus Didelphys;

Fig. 414.

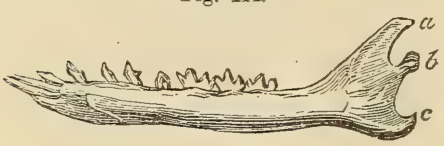

Fig. 415.

Fig, 416.
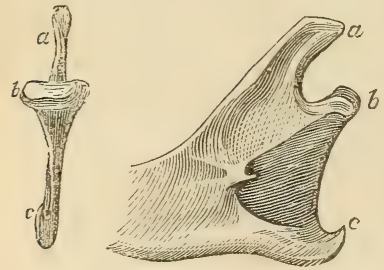

Part of lower jaw of Tupaia Tana; twice natural size.

Fig. 415. End view seen from behind, showing the very slight inflection of the angle at $c$.

Fig. 416. Side view of same.
Tupaia Tana.

Right ramus of lower jaw. Natural size.

A recent insectivorous placental marnmal, from Sumatra.

and Professor Owen has since confirmed the doctrine of its generality in the entire marsupial series. In all these pouched quadrupeds this process is turned inwards, as at $c d$, fig. 417 , in the Brazilian opossum, whereas in the placental series, as at $c$, figs. 415 and 416 , there is an almost entire absence of such inflection. The Tupaia Tana of Sumatra has been selected by my friend Mr. Waterhouse for this illustration, because the jaws of that small insectivorous quadruped bear a great resemblance to those of the Stonesfield Amphitherium. By clearing: away the matrix from the specimen of Amphitherium Prevostii above represented (fig. 412), Professor Owen ascertained that the angular process $(c)$ bent inwards in a slighter degree than in any of the known marsupialia; in short, the inflection does not exceed that of the mole or hedgehog. This fact made him doubt whether the Amphitherium might not be an insectivorous placental, although it offered some

* I have given a figure in the Principles of Geology, chapter ix., of another Stonesfield specimen of Amphitherium Prevostii, in which the sockets and roots of the teeth are finely exposed. 
points of approximation in its osteology to the marsupials, especially to the Myrmecobius, a small insectirorous quadruped of Australia, which has nine molar's on each side of the lower jaw, besides a canine and three incisors.*

Another species of Amphitherium has been found at Stonesfield (fig. 413, p. $40 \tau$ ), which differs from the former (fig. 412) principally in being larger.

The second mammiferous genus discovered in the same slates was named originally by Mr. Broderip Didelphys Bucklandi (see fig: 419),

Fig. 419.

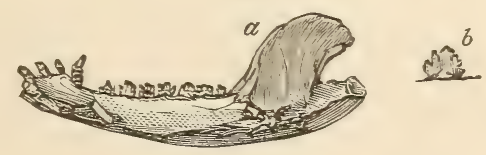

Phascolotherium Bucklandi, Broderip, sp. a. Natural size.

b. Molar of same, magnified.

and has since been called Phascolotherium by Owen. It manifests a much stronger likeness to the marsupials in the general form of the jaw, and in the extent and position of its inflected angle, while the agreement with the living geuus Didelphys in the number of the premolar and molar teeth is complete. $\uparrow$

In 1854 the remains of another mammifer, small in size, but larger than any of those previously known, was announced by Mr. Charlesworth to the British Association as haring been obtained many years before from the Stonesfield slate by the Rer. J. P. Dennis. This fossil, to which the generic name of Stereognathus was giren, consisted, as is usually the case in these old rocks (see above, p. 385), of part of a lower jaw, in which were implanted three double-fanged teeth, differing in structure from those of all other known recent or extinct mammals. According to Professor Owen, the molar of Pliolophus, a small extinct herbirorous genus of the London clay, makes the nearest approach to it. The form and structure of the teeth in Stereognathus seemed to imply that this quadruped possessed a higher organization than any other secondary mammal jet discorered, but the doubts cntertained respecting its true affinities afford a somewhat disappointing illustration of the limited extent to which Cuvier's law of correllation or the coexistence of animal structures is arailable in palæontology. Given a lower jawbone with three perfect molar teeth, haring two or more fangs each implanted in separate sockets, to find the rest of the organization, or at least to determine the family and sub-class to which the animal belonged-such being the problem, Professor Oren tells us that he belicres that Stercognathus mas hoofed, herbirorous, and placental, but he adds, that for anything that physio-

* A figure of this recent Myrmecobius will be found in the Principles, chap. ix.

† Owen's British Fossil Mammals, p. 62. 
logical science can prove to the contrary, it may have been unguiculate, insectivorous, and marsupial! *

Professor Owen has remarked that, as the marsupial genera, to which the Phascolotherium is most nearly allied, are now confined to New South Wales and Van Dieman's Land, so also is it in the Australian seas that we find the Cestracion, a cartilaginous fish which has a bony palate, allied to those called Acrodus (see fig. 453, p. 421) and Strophodus, so common in the Oolite and Lias. In the same Australian seas, also, near the shore, we find the living Trigonia, a genus of mollusca so frequently met with in the Stonesfield slate. So, also, the Araucarian pines are now abundant, together with ferns, in Australia and its islands, as they were in Europe in the Oolitic period (see fig. 421). Endogens of the most perfect structure are met with in oolitic rocks, as, for example, the Podocarya of Buckland, a fruit allied to the Pandanus, found in the Inferior Oolite (see fig. 420).

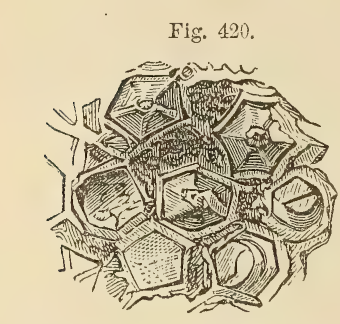

Portion of a fossil fruit of Podocarya, magnified. (Buckland's Bridgew. Treat., pl. 63.) Inferior OJlite, Charmouth, Dorset.

Fig. 421.

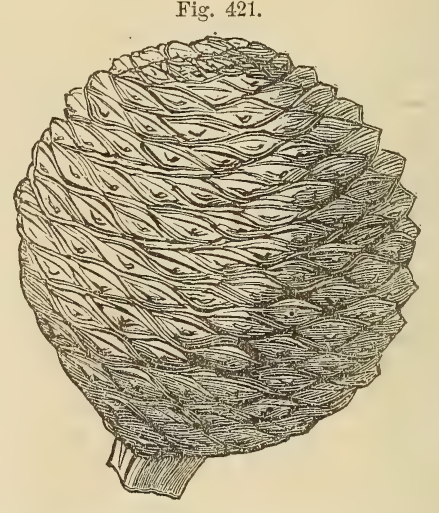

Cone of fossil Araucaria. Inferior Oolite. Bruton, Somersetshire. $\frac{1}{3}$ diam. of original.

In the collection of the British Museum.

The Stonesfield slate, in its range from Oxfordshire to the northeast is represented by flaggy and fissile sandstones, as at Collyweston in Northamptonshire, where, according to the researches of Messrs. Ibbetson and Morris, $\uparrow$ it contains many shells, such as Trigonia angulata, also found at Stonesfield. But the Northamptonshire strata of this age assume a more marine character, or appear at least to have been formed farther from land. They enclose, however, some fossil ferns, such as Pecopteris polypodioides, of species common to the oolites of the Yorkshire coast, where rocks of this age put on all the aspect of a true coal-field; thin seams of coal having actually been worked in them for more than a century.

* Owen's Paleontology, 2 d ed., p. 348.

† Ibbetson and Morris, Report of Brit. Ass., 1847, p. 131 ; and Morris, Geol. Journ., ix. p. 334. 
In the northrrest of Yorkshire, the formation alluded to consists of an upper and a lower carbonaceous shale, abounding in impressions of plants, dirided by a limestone considered by many geologists as the representative of the Great Oolite; but the scarcity of marine fossils makes all comparisons with the subdivisions adopted in the south extremely difficult. A rich harvest of fossil ferns has been obtained from the upper carbonaceous shales and sandstones at Gristhorpe, near Scarborough (see figs. 422, 423). The lower

Fig. 422 .

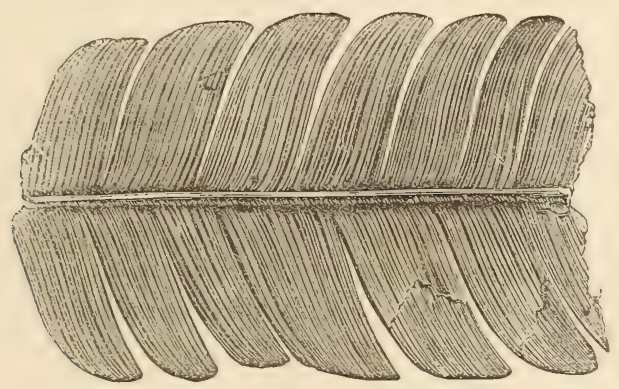

Pierophyllum comptum. Syn. Cycadites comptus. Upper Sandstone and Shale, Gristhorpe, near Scarborough.

Fig. 423.

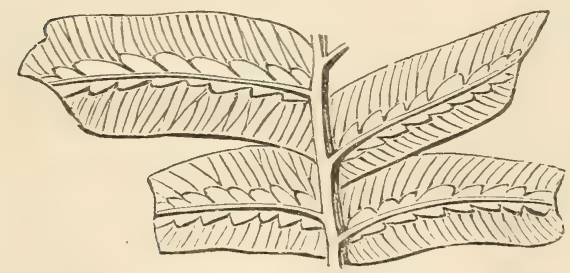

Hemitelites Brononii, Goepp. Syn. Phtebopteris contigua, Lind. \& Hutt.

Upper Carbonaceous strata, Lower Oolite, Gristhorpe, Iorkshire.

shales are well exposed in the sea-cliffs at Whitby, and are chiefly characterized by ferns and cycadeæ. They contain, also, a species of calamnite, and a fossil called Equisetum columnare, which maintains an upright position in sandstone strata, over a wide area. Shells of Estheria and Unio, collected by Mr. Bean from these Yorkshire coal-bearing beds, point to the estuary or fluriatile origin of the deposit.

At Brora in Sutherlandshire, a coal formation, probably coeral with the abore, or belonging to some of the lower dirisions of the Oolitic period, has been mined extensirely for a century or more. It affords the thickest stratum of pure regetable matter hitherto detected in any secondary rock in England. One seam of coal of good quality has been worked $3 \frac{1}{2}$ feet thick, and there are several feet more of pyritous coal resting upon it. 
Fig. 424

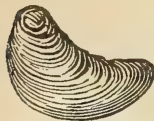

Ostrea acummata. Fuller's Earth

Fuller's Earth (h, Tab., p. 377).-Between the Great and Inferior Oolite, near Bath, an argillaceous deposit, called "the fuller's earth," occurs; but it is wanting in the north of England. It abounds in the small oyster presented in fig. 424. The number of mollusca known in this deposit is only 22; viz. 17 lamellibranchiate bivalves, 4 Brachiopods, and 1 Cephalopod (Belemnites giganteus).

Inferior Oolite.-This formation consists of a calcareous freestone, usually of small thickness, which sometimes rests upon, or is replaced by, yellow sands, called the sands of the Inferior Oolite. These last,

Fig. 425.

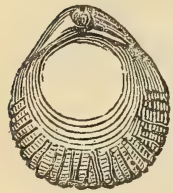

Terebratula fimbria. Inferior Oolite.
Fig. 426.

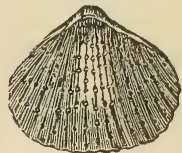

Rhynchonella spinosa. Inferior Oolite.
Fig. 427.

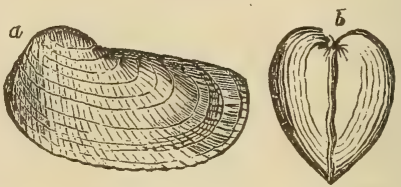

a. Pholadomya fidicula. $\frac{1}{3}$ nat size. Inf. Ool. b. Heart-shaped anterior termination of same.

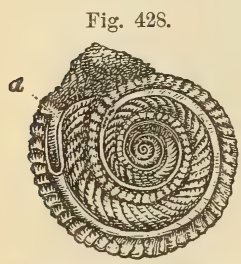

Pleurotomaria granulata. Ferruginous Oolite. Normandy. Inferior Oolite, England.
Fig. 429.

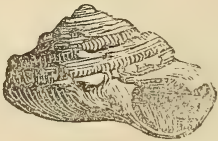

Pleurotomaria ornata, Sow. sp. Inferior Oolite.

Fig. 431 .
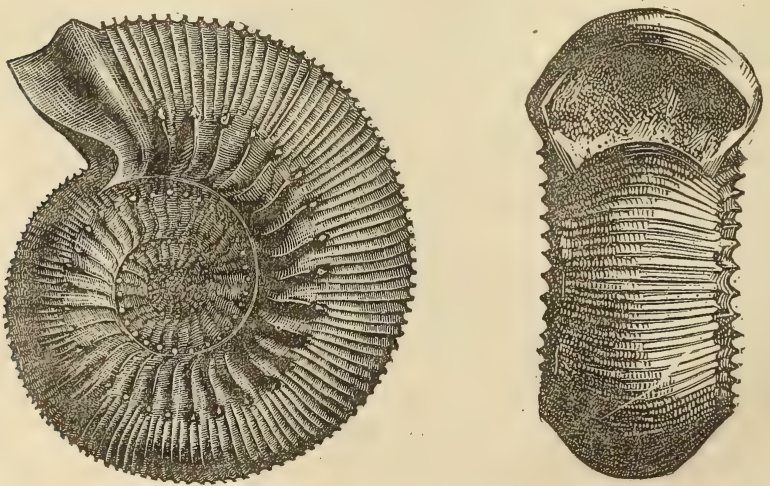

Ammonites Humphresianus; Sow. Inferior Oolite. 
in their turn, repose upon the lias in the south and west of England. Among the characteristic shells of the Inferior Oolite, I may instance -Terebratula fimbria (fig. 425), Rhynchonella spinosa (fig. 426), and Pholadomya fidicula (fig. 427). The extinct genus Pleurotomaria is also a form very common in this division as well as in the Oolitic system generally: It resembles the Trochus in form, but is marked by a deep cleft ( $a$, fig. 428 and 429) on one side of the mouth. The Collyrites ringens. (fig. 430) is an Echinoderm common to the Inferior Oolite of England and France, as are the two Ammonites of which representations are here given (figs. 431, 432).

Fig. 432.

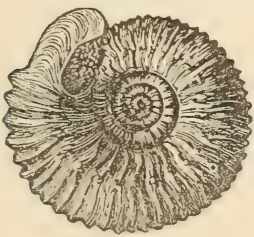

Ammonites Braikenridgii, sow. Oolite, Scarborough.

Inf. Ool., Dundry; Calrados; \&c.
Fig. 433 .

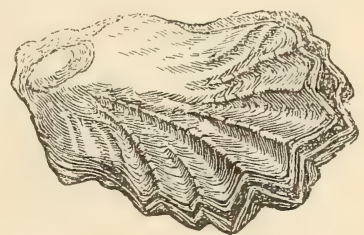

Ostrea Marshii. $\frac{\lambda}{2}$ nat. size.

Middle and Lower Oolite, or ranging from Coral Bay to Combrash.

Palcoontological relations of the Oolitic strata.-Observations have already been made, p. 345 , on the distinctness of organic remains of the Oolitic and Cretaceous strata, and at pp. 398 and 401 of the proportion of species common to the Upper and Middle, and to the Middle and Lower Oolite. Between the latter and the Lias there is a somewhat greater break, for out of 120 mollusca of the Upper Lias 13 species only pass up into the Inferior Oolite. Professor Ramsay has called our attention to an important generalization not yet alluded to, name$l y$, that there are at present wider breaks between some of our minor subdirisions, and especially between the Inferior and the Great Oolite, palæontologically considered, than between what we generally regard as divisions of a higher order, such as the Lower, Middle, and Upper Oolites. Thus, for example, there are, according to Mr. Etheridge's tables, 518 species of mollusca known in the Great Oolite and 370 in the Inferior, and of these only 93, or about 12 per cent., are common to the two; and, what is very remarkable, of 39 species of Cephalopoda known in the Inferior Oolite, only one passes upwards into the Great Oolite, namely, Belemnites giganteus, and it has been questioned by some palæontologists whether eren this Belemnite has really been found in the Upper of the two formations. This distinctness of the Cephalopoda is the more striking, because both the Great and Inferior Oolites are calcareous formations, and we cannot, therefore, account for the difference of species by any marked dissimilarity in the nature of the sea-bottom. As to the intervening Fuller's Earth, it affords us 
but little information in regard to the condition of marine life, having yielded at present only 22 mollusca, as before mentioned (p. 412).

While, therefore, the break between two great members of the Lower Oolite is expressed by saying that the proportion of species in common only amounts to 12 per cent, we have seen that there is a connection of 24 per cent. betwieen the Upper and Middle, and 21 per cent. between the Middle and Lower Oolite; in other words, there is twice as great a connection between our larger divisions as between two separate members of one of them.

In illustration of shells having a great vertical range, it may be stated that in England 4 species, and 4 only, are known to pass up from the Lower to the Upper Oolite, namely, Phynchonella obsoleta, Lithodomus inclusus, Pholadomya ovalis, and Trigonia elongata.

Of all the Jurassic Ammonites of Great

Fig. 434

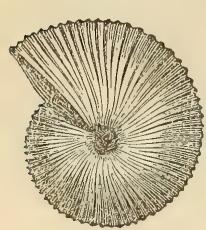

Ammonites macrocephatus, 'Schloth. $\frac{1}{3}$ nat. size. Great Oolite and Oxford Clay. Britain, A. Macrocephalus, Schloth, which is common to the Great Oolite and Oxford Clay, has the widest range.

That most of the sudden changes of species were due to migration, may be inferred, as Prof. Ramsay remarks, from the fact that, after disappearing from an intermediate formation, they often reappear in a higher one. But the phenomena, on the whole, indicate a constant dying out of preëxisting species and a coming in of new ones. We have everry reason to conclude that the gaps which occur, both between the larger and smaller sections of the English Oolites, imply intervals of time, elsewhere represented by fossiliferous strąta, although no deposit may have taken place in the British area. This conclusion is warranted by the partial extent of many of the minor and some of the larger divisions even in England. "Thus, the Inferior Oolite," says Prof. Ramsay, "attains its maximum development near Cheltenham, where it can be subdivided into at least three parts. Passing north, the two lower divisions, each more or less characterized by its own fossils, disappear, and the rag-stone, northeast of Cheltenham, lies directly upon the Lias, apparently as conformably as if it formed its true and immediate successor. In Dorsetshire, on the coast, the series is again perfect, though thin. Near Chipping Norton, in Oxfordshire, the Inferior Oolite disappears altogether, and the Great Oolite, having first overlapped the Fuller's Earth, passes across the Inferior Oolite, and in its turn seems to lie on the Upper Lias with a regularity as perfect as if no formation anywhere in the neighborhood came between them. In Yorkshire the changed type of the Inferior Oolite, the prevalence of sands, land-plants, and beds of coal, leave no doubt of the presence of terrestrial surfaces on which the plants grew, and all these phenomena lead to the conclusion that various and considerable oscillations of level took place in the British area during the deposition of 
the strata, both of the Inferior Oolite ard of the formations that immediately succeed it." *

Mr. Horrell has pointed out that in Bedfordshire the Cornbrash and Kelloway rocks are sometimes both absent, and the Oxford clay rests conformably on the Great Oolite, showing, like the examples before cited, that conformity is no proof of direct sequence, and aiding us more and more to conceive that the changes in the organic world may in reality hare been gradual and uninterrupted, although the fragmentary character of the records handed down to us might lead us to infer, unless we were constantly on our guard against being deceired, that there had been many general and sudden breaks in the recording process, and abruot transitions from one set of organic types to another.

\title{
CHAPTER XXI.
}

\author{
JURASSIC GROUP, contingued-LIAS.
}

Mineral character of Lias-Numerous successive Zones in the Lias, marked by distinct fossils, without unconformity in the stratification, or change in the mineral character of the deposits-Name of Gryphite limestone-Fossil shells and fishRadiata-Ichthyodorulites-Reptiles of the Lias-Ichthyosaur and PlesiosaurSarine Reptile of the Galapagos Islands-Sudden destruction and burial of fossil animals in Lias-Fluvio-marine beds in Gloucestershire, and insect limestone -Fossil plants_Origin of the Oolite and Lias, and of alternating calcareous and argillaceous formations.

Liss.-The English provincial name of Lias has been very generally adopted for a formation of argillaceous limestone, marl, and clay, which forms the base of the Oolite, and is classed by many geologists as part of that group. They pass, indeed, into each other in some places, ąs near Bath, a sandy marl called the marlstone of the Lias being interposed, and partaking of the mineral characters of the lias and the inferior oolite. These last-mentioned divisions have also some fossils in common, such as the Avicula incequivalvis (fig. 435). Nevertheless the Lias may be traced throughout a great part of Europe as a separate and independent group, of considerable thickness, varying from 500 to 1000 feet, containing many peculiar fossils, and having a very uniform lithological aspect. Although usually conformable to the oolite, it is sometimes, as in the Jura, unconformable. In the environs of Lons-le-Saulnier, for instance, in the depariment of Jura, the strata of Lias are inclined

* Geol. Quart. Journ., vol. xx. p. 56. '1864. 
at an angle of about $45^{\circ}$, while the incumbent oolitic marls are horizontal.

Fig. 436.

Fig. 435 .

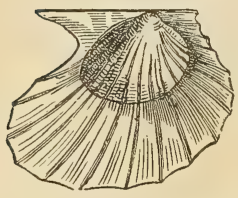

Avicula incequivalvis, Sow. Lower Oolite, and Lias.

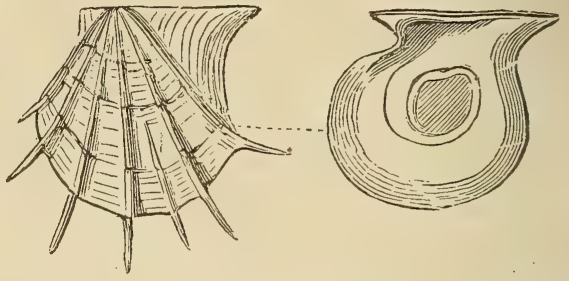

Avicula cygnipes, Phil. Lias, Gloucestershire and Yorkshire.

The peculiar aspect which is most characteristic of the Lias in England, France, and Germany, is an alternation of thin beds of blue or gray limestone, having a surface which becomes light-brown when weathered, these beds being separated by dark-colored, narrow argillaceous partings, so that the quarries of this rock, at a distance, assume a striped and riband-like aspect.*

The Lias has been divided in England into three formations, the Upper, Middle, and Lower. The Upper Lias consists first of sands, which were formerly regarded as the base of the Oolite, but which, according to Dr. Wright, are by their fossils more properly referable to the Lias; secondly, of clay shale and thin beds of limestone. The Middle Lias, or marlstone series, has been divided into three zones; and the Lower Lias, according to the labors of Quenstedt, Oppel, Strickland, Wright, and others, into six zones, each marked by its own group of fossils. This Lower Lias averages from 600 to 900 feet in thickness.

From Devon and Dorsetshire to Yorkshire all these divisions, observes Professor Ramsay, are constant; and from bottom to top we cannot assert that anywhere there is actual unconformity between any two subdivisions, whether of the larger or smaller kind. In the whole of the English Lias, there are about 243 genera, and 467 known species.t The whole series has been divided by zones characterized by particular ammonites; for while other families of shells pass from one division to another in numbers varying from about 20 to 50 per cent., these cephalopods are almost always limited to single zones, as Quenstedt and Oppel have shown for Germany, and Dr. Wright for England. $\$$

As no actual unconformity is known from the bottom of the Lower to the top of the Upper Lias, and as there is a marked uniformity in the mineral character of almost all the strata, it is somewhat difficult

\footnotetext{
* Conyb. and Phil., p. 261.

† Ramsay, Geol. Quart. Journ., vol. xx. p. 50. 1864.

† Dr. Wright, ibid., vol. xvi. p. 10. 1859.
} 
to account eren for such partial breaks as have been alluded to in the succession of species, if we reject the hypothesis that the old species were in each case destroyed at the close of the deposition of the rocks containing them, and replaced by the creation of new forms when the succeeding formation began. I agree with Professor Ramsay in not accepting this hypothesis. No doubt some of the old species occasionally died out, and left no representatives in Europe or clsewhere; others were locally exterminated in the struggle for life by species, which invaded their ancient domain, or by rarieties better fitted for a new state of things. Pauses also of vast duration may have occurred in the deposition of strata, allowing time for the modification of organic life throughout the globe, slowly brought about by variation as well as by extinction.

In some parts of France, near the Vosges Mountains, and in Luxembourg, M. E. de Beaumont has shown that the lias containing Gryphcea arcuata, Plagiostoma giganteim (see fig. 437), and other characteristic fossils, becomes arenaceous; and around the Hartz, in Westphalia and Bavaria, the inferior parts of the lias are sandy, and sometimes afford a building-stone.

The name of Gryphite limestone has sometimes been applied to the lias, in consequence of the great number of shells which it contains of a species of oyster, or Gryphoea (fig. 438, see also fig. 387, p. 395). A large heary shell called Hippopodium (fig. 439), allied to

Fig. 43i.

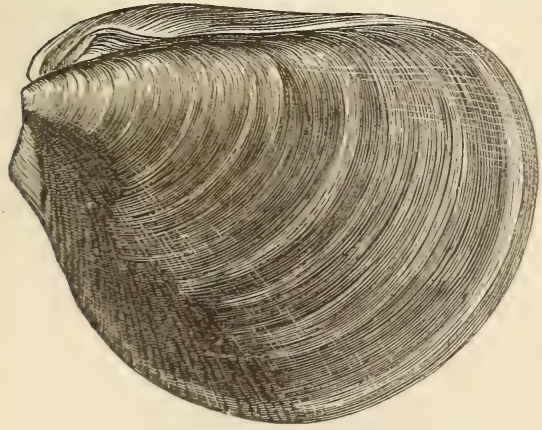

Fig. 438

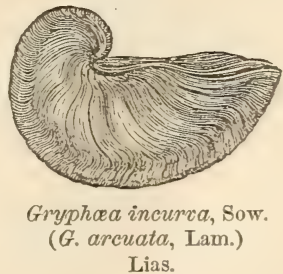

Plagiostoma (Lima) giganteum, Sow. Inf. Ool. and Lias.

Cypricardia, is also characteristic of the lower lias shales. The Lias formation is also remarkable for being the newest of the secondary rocks in which brachiopoda of the grenera Spirifer and Lepicena (figs. $440,441)$ occur: no less than nine species of Spirifers are enumerated by Mr. Daridson as belonging to the Lias. These palliobranchiate mollusca predominate greatly in strata older than the Trias; but, so far as we yet know, they did not survive the Liassic epoch. The marine beds of the Lias also abound in cephalopod: 
of the genera Belemnites, Nautilus, and Ammonites (see figs. 442, $443,444)$.

Fig. 439.
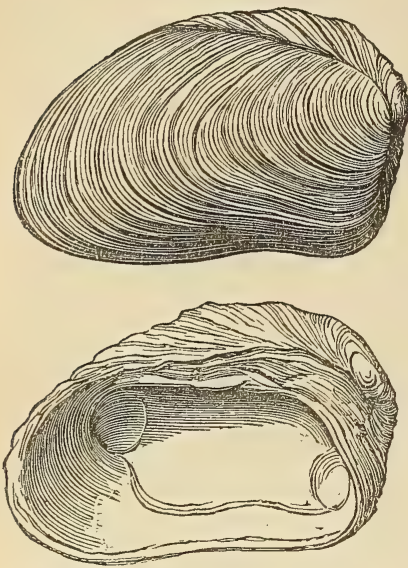

Hippopodium ponderosum, Sow. 考 diam. Lias, Cheltenham.

Fig. 442.

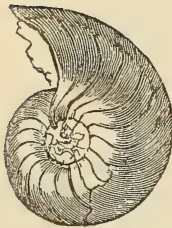

Nautitus truncatus, Lias.

Fig. 444.

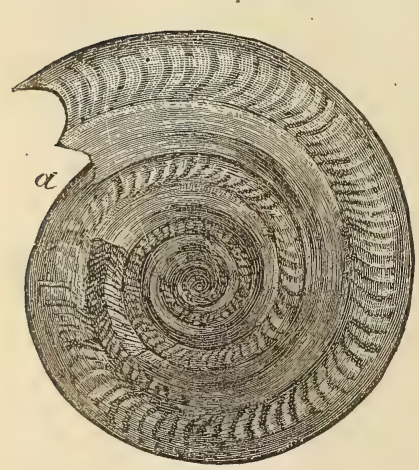

Fig. 440.

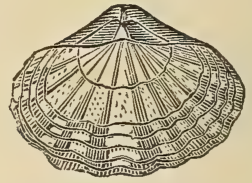

Spirifer Walcotti, Sow. Lower Lias.

Fig. 441.

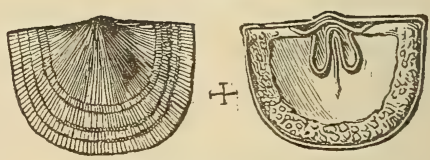

Teptoena Moorei, Dav.

Upper Lias, Ilminster.

Fig. 443.

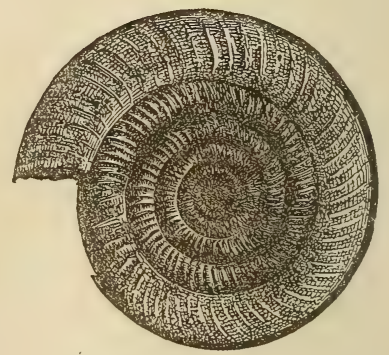

Ammonites Nodotianus? A. striatulus, Sow. Lias.

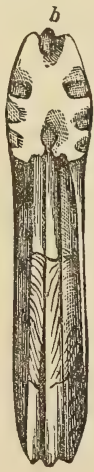

Ammonites bifrons, Brug, A Walcotii, Sow.

Upper Lias shales, 
Fig. 445 .

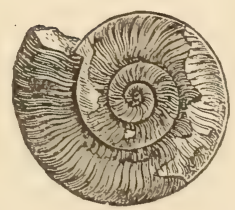

Ammonites striatulus, Sow.

$\frac{1}{3}$ nat. size. Upper Lias.

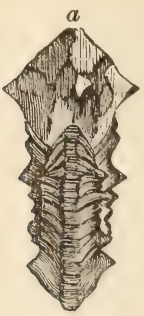

Fig. 446.

. 446.

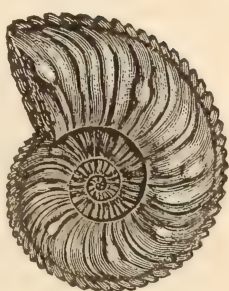

Ammonites margaritatus, Montf. Syn. $A$ Stokesii, Sow. Middle Lias.

Among the Crinoids or Stone-lilies of the Lias, the Pentacrinites are conspicuous. (See fig. 449.) Of Ophioderma Egertoni (fig. 450), referable to the Ophiuridce of Muller, perfect specimens have been met with in the Middle Lias beds of Dorset and Yorkshire,

Allusion has already been made, p. 416, to numerous zones in the Lias characterized by distinct Ammonites. Two of these occur near the base of the Lower Lias, having a united thickness, varying from 40 to 80 feet. The upper and larger of these is characterized, especially in the southwest of England, by Ammonites Bucklandi, and the lower by Ammonites Planorbis (figs. 447, 448).*

Fig. 417.
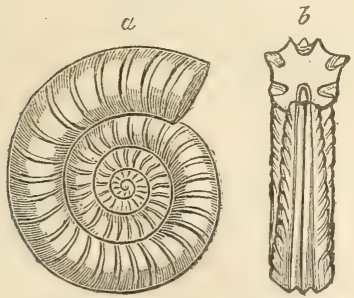

Ammonites Bucklandi, Sow. $\frac{1}{8}$ diam. of original.

a. Side view.

b. Front view, showing mouth and bisulcated keel.

Characteristic of the lower part of the Lias of England and the Continent.
Fig. 448.

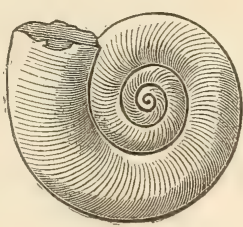

A. Planorbis, Sow. $\frac{1}{3}$ diam, of original. From the base of the Lower Lias of England and the Continent.

These two shells have a wide range on the Continent of Europe, occurring in beds which occupy similar positions in the Liassic series.

The Extracrinus Briareus (removed by Major Austin from Penta. crinus on account of generic differences) occurs in tangled masses, forming thin beds of considerable extent, in the Lower Lias of Dorset, Gloucestershire, and Yorkshire. The remains are often highly charged with pyrites. This Crinoid, with its innumerable tentacular 
arms, appears to have been frequently attached to the driftwood of the liassic sea, in the same manner as Barnacles float about at the

Fig. 449.

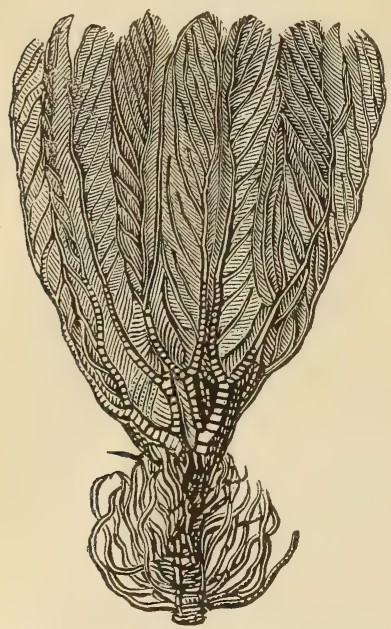

Extracrinus Briareus = Pentacrinus Briareus. ${ }_{1}$ nat. size.

(Body, arms, and part of stem.) Lias, Lyme Regis.
Fig. 450 .

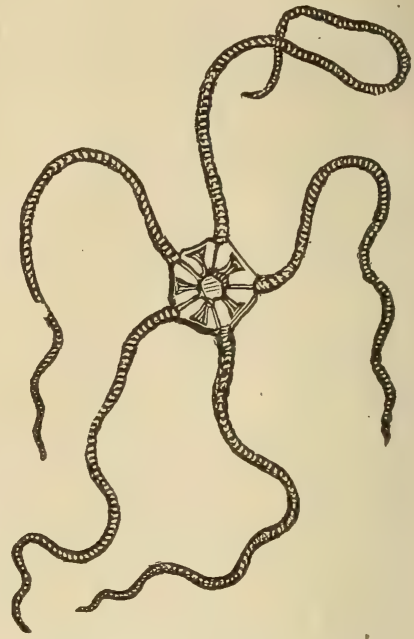

Ophioderma Egertoni, E. Forbes. Middle Lias, Seatown, Dorset.

present day. There is another species of Extracrinus and several of Pentacrinus in the lias; and the latter genus is found in nearly all the formations from the lias to the London clay inclusive. It is represented in the present seas by the delicate and rare Pentacrinus Caputmedusce of the Antilles, which, with Comatula, are the only surviving members of the great and ancient family of the Crinoids, so widely represented throughout the older formations by the genera Taxocrinus, Actinocrinus, Cyathocrinus, Encrinus, Apiocrinus, and many others.

Fig. 451.
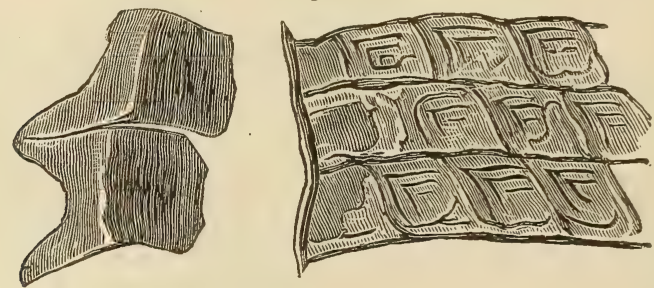

Scales of Lepidotus gigas, Agass.

a. Two of the scales, detached.

The fossil fish resemble generically those of the oolite, belonging all, according to M. Agassiz, to extinct genera, and differing for the most part from the ichthyolites of the Cretaceous period. Among 
them is a species of Lepidotus ( $L$. gigas, Agass.), fig. 451, which is found in the lias of England, France, and Germany.* This genus was before mentioned ( $\mathrm{p}$. 349) as occurring in the Wealden, and is supposed to have frequented both rivers and coasts. Another genus of Ganoids (or fish with hard, shining, and enamelled scales), called AEchmodus (see fig. 452), is almost exclusively Liassic. The teeth

Fig. 452
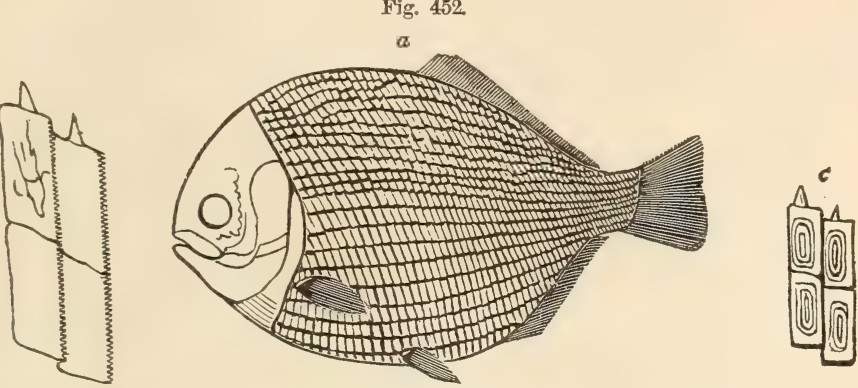

b. Scales of Aichmodus Leachii.

a. Aichmodus. Restored outline.

c. Scales of Dapedius monilifer.

of a species of Acrodus, also, are very abundant in the lias (fig. 453).

Eig. 453.
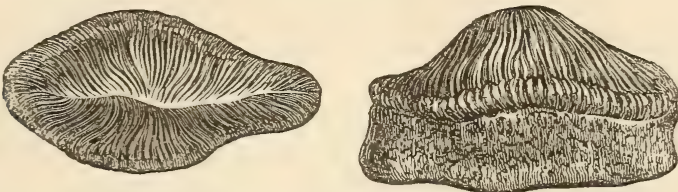

Acrodus nobilis, Agass. (tooth); commonly called "fossil leech." Lias, Lyme Regis and Germany.

But the remains of fish which have excited more attention than any others are those large bony spines called ichthyodorulites ( $a$, fig.

Fig. 454 .

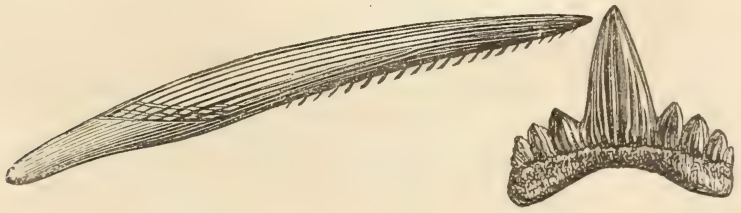

Hybodus reticulatus, Agass. Lias, Lymé Regis.

a. Part of fin, commonly called Ichthyodorulite $\quad$. Tooth.

454), which were once supposed by some naturalists to be jaws, and by others weapons, resembling those of the living Balistes and Silu- 
rus ; but which M. Agassiz has shown to be neither the one nor the other. The spines, in the genera last mentioned, articulate with the backbone, whereas there are no signs of any such articulation in the ichthyodorulites. . These last appear to have been bony spines which formed the anterior part of the dorsal fin, like that of the living Cestracion and Chimcera (see $\alpha$, fig. 455). In both of these genera, the

Fig. 455 .

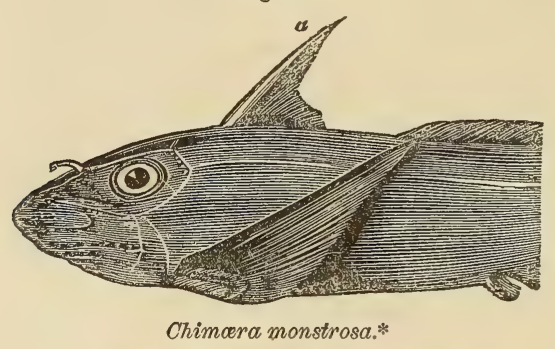

a. Spine forming anterior part of dorsal fin.

posterior concave face is armed with small spines, as in that of the fossil Hybodus (fig. 454), a placoid fish of the shark family found fossil at Lyme Regis. Such spines are simply imbedded in the flesh, and attached to strong muscles. "They serve," says Dr. Buckland, "as in the Chimcera (fig. 455), to raise and depress the fin, their action resembling that of a movable mast, raising and lowering backwards the sail of a barge." $\dagger$

Reptiles of the Lias.-It is not, however, the fossil fish which form the most striking feature in the organic remains of the Lias; but the Enaliosaurian reptiles, which are extraordinary for their number, size, and structure. Among the most singular of these are several species of Ichthyosaurus and Plesiosaurus (figs. 456, 457). The genus Ichthyosaurus, or fish-lizard, is not confined to this formation, but has been found in strata as high as the white chalk of England, and as low as the trias of Germany, a formation which immediately sueceeds the lias in the descending order.\$. It is evident from their fish-like vertebræ, their paddles, resembling those of a porpoise or whale, the length of their tail, and other parts of their structure, that the habits of the Ichthyosaurs were aquatic. Their jaws and teeth show that they were carnivorous; and the half-digested remains of fishes and reptiles, found within their skeletons, indicate the precise nature of their food.§

A specimen of the hinder fin or paddle of Ichthyosaurus communis was discovered in 1840 at Barrow-on-Soar, by Sir P. Egerton, which distinctly exhibits on its posterior margin the remains of cartila-

* Agassiz, Poissons Fossiles, vol. iii., tab. C, fig. 1.

$\uparrow$ Bridgewater Treatise, p. 290.

$\ddagger$ Ibid., p. 168.

$\S$ Ibid., p. 187. 

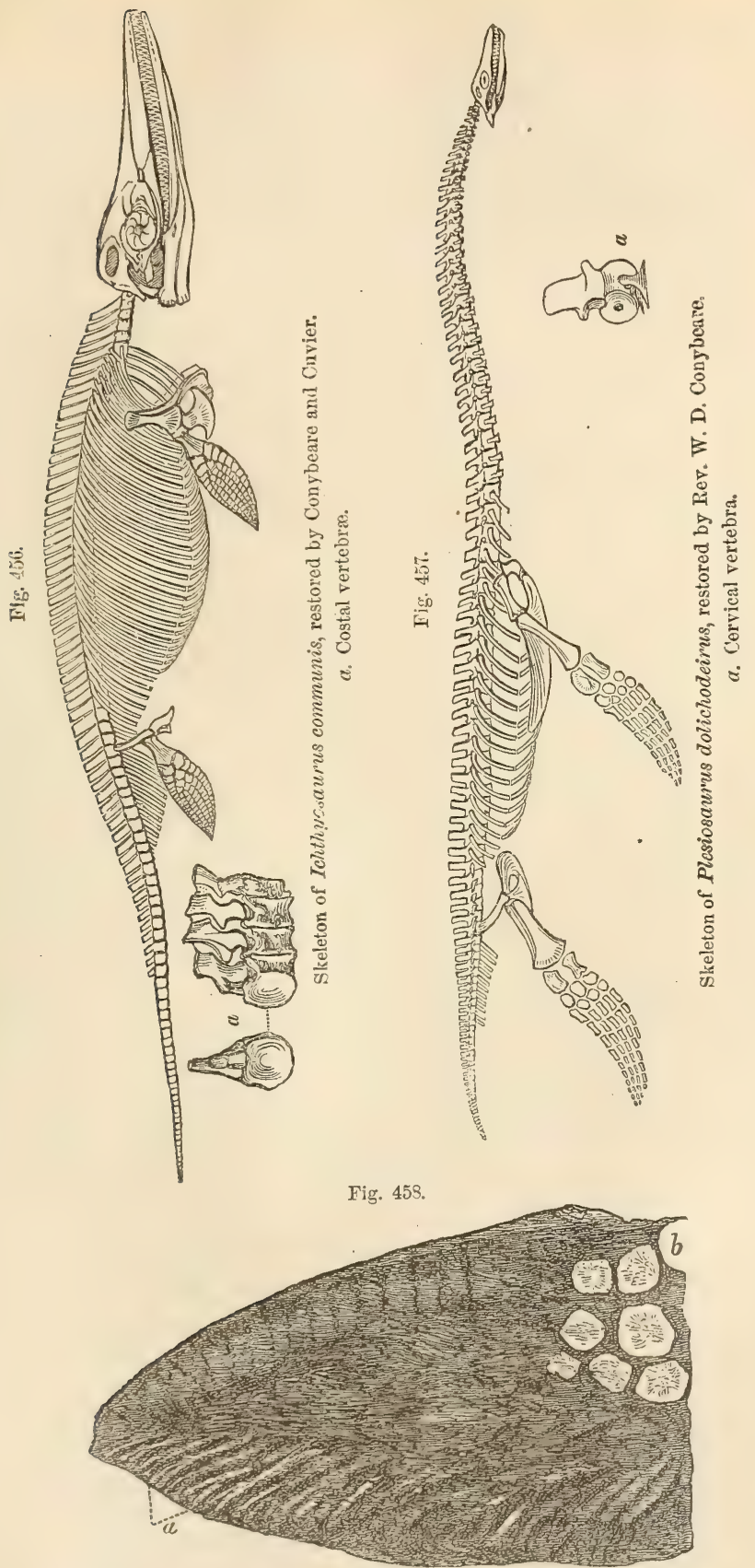

Posterior part of hind fin or paddle of Ichthyosaumes communis. 
ginous rays that bifurcate as they approach the edge, like those in the fin of a fish. (See $a$, fig 458.) It had previously been supposed, says Prof. Owen, that the locomotive organs of the Ichthyosaurus were envcloped, while living, in a smooth integument, like that of the turtle and porpoise, which has no other support than is afforded by the bones and ligaments within; but it now appears that the fin was much larger, expanding far beyond its osseous framework, and deviating widely in its fish-like rays from the ordinary reptilian type. In fig. 458 the posterior bones, or digital ossicles of the paddle, are seen near $b$; and beyond these is the dark carbonized integument of the terminal half of the fin, the outline of which is beautifully defined.* Prof. Owen believes that, besides the fore-paddles, these short and stiff-necked saurians were furnished with a tail-fin without radiating bones, and purely tegumentary, expanding in a vertical direction; an organ of motion which enabled them to turn their heads rapidly. $\dagger$

Mr. Conybeare was enabled, in 1824, after examining many skeletons nearly perfect, to give an ideal restoration of the osteology of this genus, and of that of the Plesiosaurus.t (See figs. 456, 457.) The latter animal had an extremely long neck and small head, with teeth like those of the crocodile, and paddles analogous to those of the Ichthyosaurus, but larger. It is supposed to have lived in shallow seas and estuaries, and to have breathed air like the Ichthyosaur and our modern cetacea. $\S$ Some of the reptiles above mentioned were of formidable dimensions. One specimen of Ichthyosaurus platyodon, from the lias at Lyme, now in the British Museum, must have belonged to an animal more than 24 feet in length; and there are species of Plesiosaurus which measure from 18 to 20 feet in length. The form of the Ichthyosaurus may have fitted it to cut through the waves like the porpoise; but it is supposed that the Plesiosaurus, at least the long-necked species (fig. 457 ), was better suited to fish in shallow creeks and bays defended from heavy breakers.

In many specimens both of Ichthyosaur and Plesiosaur the bones of the head, neck, and tail are in their natural position, while those of the rest of the skeleton are detached and in confusion. Mr: Stutchbury has suggested that their bodies after death became inflated with gases, and while the abdominal viscera were decomposing, the bones, though disunited, were retained within the tough dermal covering as in a bag, until the whole, becoming water-logged, sank to the bottom.\| As they belonged to individuals of all ages they are supposed, by Dr. Buckland, to have experienced a violent death; and the same conclusion might also be drawn from their having escaped the attacks

* Geol. Soc. Transact, Second Series, vol. vi. p. 199, pl, xx.

+ Ibid., Second Series, vol. v. p. 511.

¥ Ibid., Second Series, vol. i. p. 49.

$\S$ Conybeare and De la Beche, Geol. Trans., First Series, vol, v. p. 559; and Buckland, Bridgew. Treat., p. 203.

IQ Quart. Geol. Journ., vol. ii. p. 411. 
of their orrn predaceous race, or of fishes found fossil in the same beds.

For the last twenty years, anatomists hare agreed that these extinct saurians must hare inhabited the sea : and it was urged that as there are nom chelonians, like the tortoise, living in fresh water, and others, as the turtle, frequenting the ocean, so there may hare been formerly some saurians proper to salt, other's to freshwater. The common crocodile of the Ganges is well knomn to frequent equally that river and the brackish and salt water near its mouth; and crocodiles are said in like manner to be abundant both in the rirers of the Isla de Pinos (or Isle of Pines), south of Cuba, and in the open sea round the coast. More recently a saurian has been discorered of aquatic habits and exclusirelr marine. This creature was found in the Galapagos Islands, during the risit of H.M.S. "Beagle" to that archipelago, in 1835, and its habits were then observed by Mr. Darwin. The islands alluded to are situated under the equator, nearly 600 miles to the westward of the coast of South America. They are volcanic; some of them being 3000 or 4000 feet high; and one of them, Albemarle Island, 75 miles long. The climate is mild; rery little rain falls; and in the whole archipelago there is only one rill of fresh water that reaches the coast. The soil is for the most part dry and harsh, and the regetation scanty. The birds, reptiles, plants, and insects are, with rery fert exceptions, of species found nowhere else in the world, although all partake, in their general form, of a South American type. Of the mammalia, says Mr. Darwin, one species alone appears to be indigenous, namelr, a large and peculiar kind of mouse ; but the number of lizards, tortoises, and snakes is so great, that it may be called a land of reptiles. The rarietr, indeed, of species is small; but the indiriduals of each are in wonderful abundance. There is a turtle, a large tortoise (Testudo Indicus), four lizards, and about the same number of snakes, but no frogs or toads. Two of the lizards belong to the family Iguanidae of Bell, and to a peculiar genus (Amblyrhynchus) established by that naturalist, and so named from their obtusely truncated head and

Fig. 459.

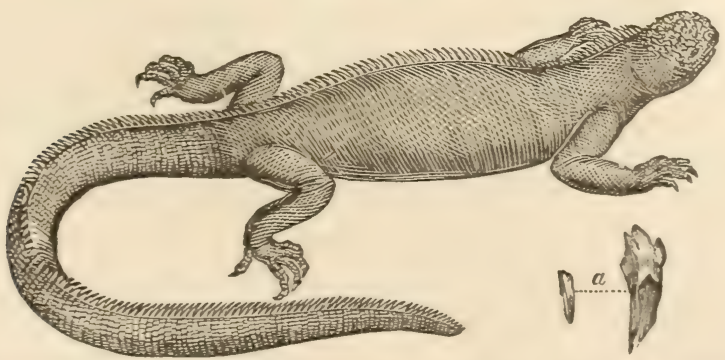

Amblyrhynchus cristatus, Bell. Length rarying from 3 to 4 feet. The only existing marine lizard now known.

a. Tooth, natural size and magnified. 
short snout.* Of these lizards one is terrestrial in its habits, and burrows in the ground, swarming everywhere on the land, having a round tail, and a mouth somewhat resembling in form that of a tortoise. The other is aquatic, and has its tail flattened laterally for swimming (see fig. 459). " "This marine saurian," says Mr. Darwin, "is extremely common on all the islands throughout the Archipelago. : It lives exclusively on the rocky sea-beaches, and I never saw one even ten yards in shore. The usual length is about a yard, but there are some even 4 feet long. It is of a dirty black color, sluggish in its movements on the land; but, when in the water, it swims with perfect ease and quickness by a serpentine movement of its body and flattened tail, the legs during this time being motionless, and closely collapsed on its sides. Their limbs and strong claws are admirably adapted for crawling over the rugged and fissured masses of lava which everywhere form the coast. In such situations, a group of six or seven of these hideous reptiles may oftentimes be seen on the black rocks, a few feet above the surf, basking in the sun, with outstretched legs. Their stomachs, on being opened, were found to be largely distended with minced sea-weed, of a king which grows at the bottom of the sea at some little distance from the coast. To obtain this the lizards go out to sea in shoals. One of these animals was sunk in salt water from the ship, with a heavy weight attached to it, and on being drawn up again after an hour it was quite active and unharmed. It is not yet known by the inhabitants where this animal lays its egggs; a singular fact, considering its abundance, and that the natives are well acquainted with the eggs of the terrestrial Amblyrhynchus, which is also herbivorous." i

In those deposits now forming by the sediment washed away from the wasting shores of the Galapagos Islands, the remains of saurians, both of the land and sea, as well as of chelonians and fish, may be mingled with marine shells, without any bones of land quadrupeds or batrachian reptiles; yet even here we should expect the remains of marine mammalia to be imbedded in the strata, for there are seals, besides several kinds of cetacea, on the Galapagian shores; and, in this respect, the parallel between the modern fauna, above described, and the ancient one of the lias would not hold good.

Sudden destruction of Saurians.-It has been remarked, and truly, that many of the fish and saurians, found fossil in the lias, must have met with sudden death and immediate burial; and that the destructive operation, whatever may have been its nature, was often repeated.

"Sometimes," says Dr. Buckland, "scarcely a single bone or scale has been removed from the place it occupied during life; which could not have happened had the uncovered bodies of these saurians been 
left, even for a few hours, exposed to putrefaction, and to the attacks of fishes and other smaller animals at the bottom of the sea." * . Not only are the skeletons of the Ichthyosaurs entire, but sometimes the contents of their stomachs still remain between their ribs, as before remarked, so that we can discover the particular species of fish on which they lived, and the form of their excrements. Not unfrequently there are layers of these coprolites, at different depths in the lias, at a distance from any entire skeletons of the marine lizards from which they were derived; " as if," says Sir H. de la Beche, "the muddy bottom of the sea received small sudden accessions of matter from time to time, covering up the coprolites and other exuviæ which had accumulated during the intervals." $\uparrow$ It is further stated that, at Lyme Regis, those surfaces only of the coprolites which lay uppermost at the bottom of the sea have suffered partial decay, from the action of water before they were covered and protected by the muddy sediment that has afterwards permanently enveloped them.\$

Numerous specimens of the Calamary or pen-and-ink fish (Geoteuthis Bollensis, Schuble sp.) have also been met with in the lias at Lyme, with the ink-bags still distended, containing the ink in a dried state, chiefly composed of carbon, and but slightly impregnated with carbonate of lime. These cephalopoda, therefore, must, like the saurians, have been soon buried in sediment; for, if long exposed after death, the membrane containing the ink would have decayed.§

As we know that river-fish are sometimes stifled, even in their own element, by muddy water during floods, it cannot be doubted that the periodical discharge of large bodies of turbid fresh water into the sea may be still more fatal to marine tribes. In the "Principles of Geology" I have shown that large quantities of mud and drowned animals have been swept down into the sea by rivers during earthquakes, as in Java in 1699; and that indescribable multitudes of dead fishes have been seen floating on the sea after a discharge of noxious rapors during similar convulsions.\| But in the intervals between such catastrophes, strata may have accumulated slowly in the sea of the lias, some being formed chiefly of one description of shell, such as ammonites, others of gryphites.

From the above remarks the reader will infer that the lias is for the most part a marine deposit. Some members, however, of the series, especially in the lowest part of it, have an estuary character, and must have been formed within the influence of rivers. In Gloucestershire, where the lias of the West of England is well developed, it is divisible into an upper mass of sand and shale with a base of marlstone, and a lower series of shales with underlying limestones and shales. We learn from the researches of the Rer. P. B. Brodie, बा that in the inferior

\footnotetext{
* Bridgew. Treat., p. 125.

$\uparrow$ Geological Researches, p. 334.

$\ddagger$ Buckland, Bridgew. Treat., p. 307. \& Buckland, Bridgew. Treat., p. 307.

I| See Principles, Index, Lancerote, Graham Island, Calabria.

T A History of Fossil Insects, \&c., 1846. London.
} 
of these two divisions numerous remains of insects and plants have been detected in several places, mingled with marine shells. One band, rarely exceeding a foot in thickness, has been named the "insect limestone." It passes upwards into a shale containing Cypris and Estheria, and is charged with the wing-cases of several genera of coleoptera, and

Fig. 460 .

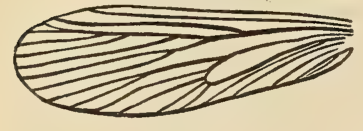

Nat. size.

Wing of a neuropterous insect, from the Lower Lias, Gloucesteshire. (Rev. P. B. Brodie.) with some nearly entire beetles, of which the eyes are preserved. The nervures of the wings of neuropterous insects (fig. 460) are beautifully perfect in this bed. Ferns, with cycads and leaves of monocotyledonous plants, and some apparently brackish and freshwater shells, accompany the insects in several places, while in others marine shells predominate, the fossils varying apparently as we examine the bed nearer or further from the ancient land, or the source whence the freshwater was derived. There are two, or even three, bands of "insect limestone" in several sections, and they have been ascertained by Mr. Brodie to retain the same lithological and zoslogical characters when traced from the centre of Warwickshire to the borders of the southern part of Wales. After studying 300 specimens of these insects from the lias, Mr. Westwood declares that they comprise both wood-eating and herb-devouring beetles, of the Linnean genera Elater, Carabus, \&c., besides grasshoppers (Gryllus), and detached wings of dragon-flies and mayflies, or insects referable to the Linnean genera, Libellula, Ephemera, Hemerobius, and Panorpa, in all belonging to no less than twenty-four families. The size of the species is usually small, and such as taken alone would imply a temperate climate; but many of the associated organic remains of other classes must lead to a different conclusion.

Fossil plants.-Among the vegetable remains of the Lias, several

Fig. 461.

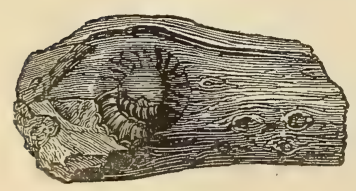
species of Zamia have been found at Lyme Regis, and the remains of coniferous plants at Whitby. Fragments of wood are common, and often converted into limestone. That some of this wood, though now petrified, was soft when it first lay at the bottom of the sea, is shown by a specimen now in the museum of the Geological Society (see fig. 461), which has the form of an ammonite indented on its surface.

M. Ad. Brongniart enumerates 47 liassic acrogens, most of them ferns; and 50 gymnosperms, of which 39 are cycads and 11 conifers. Among the cycads the predominance of Zamites, and among the ferns the numerous genera with leaves having reticulated veins (as in fig. 423, p. 411 ), are mentioned as botanical characteristics of 
this era* The absence as yet from the Lias and Oolite of all signs of dicotyledonous angiosperms is worthy of notice. The leaves of such plants are frequent in tertiary strata, and occur in the Cretaceous, though less plentifully (see abore, p. 335). The angiosperms seem, therefore, to have been at the least comparatively rare in these older secondary periods, when more space was occupied by the Cycads and Conifers.

Origin of the Oolite and Lias.-If we now endeavor to restore, in imagination, the ancient condition of the European area at the period of the Oolite and Lias, we must conceive a sea in which the growth of coral-reefs and shelly limestones, after proceeding without interruption for ages, was liable to be stopped suddenly by the deposition of clarey sediment. Then, again, the argillaceous matter, devoid of corals, was deposited for ages, and attained a thickness of hundreds of feet, until another period arrired when the same space was again occupied by calcareous sand, or solid rocks of shell and coral, to be again succeeded by the recurrence of another period of argillaceous deposition. Mr. Conrbeare has remarked of the entire group of Oolite and Lias, that it consists of repeated alternations of clay, sandstone, and limestone, following each other in the same order. Thus the clays of the lias are followed br the sands of the inferior oolite, and those again by shelly and coralline limestone (Bath oolite, drc.); so, in the middle oolite, the Oxford clay is followed by calcareous grit and coral-rag; lastly, in the upper oolite, the Kimmeridge clay is followed by the Portland sand and limestone. $\nmid$ The clay beds, howerer, as Sir H. De la Beche remarks, can be followed over larger areas than the sands or sandstones.+ It should also be remembered that while the oolitic system becomes arenaceous and resembles a coal-field in Yorkshire, it assumes in the Alps an almost purely calcareous form, the sands and clays being omitted; and even in the intervening tracts it is more complicated and rariable than appears in ordinary descriptions. Nevertheless, some of the clars and interrening limestones do retain, in reality, a pretty uniform character for distances of from 400 to 600 miles from east to west and north to south.

According to M. Thirria, the entire oolitic group in the Department of the Haute Saône, in France, may be equal in thickness to that of England; but the importance of the argillaceous divisions is in the inverse ratio to that which they exhibit in England, where they are about equal to trice the thickness of the limestones, whereas, in the part of France alluded to, they reach only about a third of that thickness. $\$$ In the Jura the clays are still thinner and in the Alps they thin out and almost vanish.

\footnotetext{
* Tableau des Vég. Foss., 1849, p. 105.

† Con, and Phil., p. 166.

$\ddagger$ Geol. Researches, p. 337 .

§ Burat's D'Aubuisson, tom. iii. p. 456.
} 
In order to account for such a succession of events, we may imagine, first, the bed of the ocean to be the receptacle for ages of fine argillaceous sediment, brought by oceanic currents, which may have communicated with rivers, or with part of the sea near a wasting coast. This mud ceases, at length, to be conveyed to the same region, either because the land which had previously suffered denudation is depressed and submerged, or because the current is deflected in another direction by the altered shape of the bed of the ocean and neighboring dry land. By such changes the water becomes once more clear and fit for the growth of stony zoophytes. Calcareous sand is then formed from comminuted shell and coral, or, in some cases, arenaceous matter replaces the clay; because it commonly happens that the finer sediment, being first drifted farthest from coasts, is subsequently overspread by coarse sand, after the sea has grown shallower, or when the land increasing in extent, whether by upheaval or by sediment filling up parts of the sea, has approached nearer to the spots occupied by fine mud.

In order to account for another great formation, like the Oxford clay, again covering one of coral limestone, we must suppose a sinking down like that which is now taking place in some existing regions of coral between Australia and South America. The occurrence of subsidences, on so vast a scale, may have caused the bed of the ocean and the adjoining land, throughout great parts of the European area, to assume a shape favorable to the deposition of another set of clayey strata; and this change may have been succeeded by a series of events analogous to that already explained, and these again by a third series in similar order. Both the ascending and descending movements may have been extremely slow, like those now going on in the Pacific; and the growth of every stratum of coral, a few feet of thickness, may have required centuries for its completion, during which certain species of organic beings disappeared from the earth, and others were introduced in their place; so that, in each set of strata, from the Lias to the Upper Oolite, some peculiar and characteristic fossils were imbedded. 


\section{CHAPTER XXII}

TRIAS OR NEW RED SANDSTONE GROUP.

Distinction between New and Old Red Sandstone-Between Upper and Lower New Red-The Trias and its three divisions-Most largely developed in GermanyRecognition of a Marine equivalent of the Upper Trias in the Austrian AlpsTrue position of the St. Cassian and Hallstadt Beds-800 new species of triassic Mollusca and Radiata-Links thus supplied for connecting the Palæozoic and Neozoic faunas-Keuper and its fossils-Muschelkalk and fossils-Fossil plants of the Bunter-Triassic group in England-Bone-bed of Axmouth and AustRed Sandstone of Warwickshire and Cheshire-Footsteps of Cheirotherium in England and Germany-Osteology of the Labyrinthodon-Whether this Batrachian was identical with Cheirotherium-Dolomitic Conglomerate of BristolOrigin of Red Sandstone and Rock-salt-Hypothesis of saline volcanic exhalations-Theory of the precipitation of salt from inland lakes or lagoons-Saltness of the Red Sea-Triassic coal-field of Eastern Virginia, near Richmond-New Red Sandstone in the United States-Fossil footprints of birds and reptiles in the valley of the Connecticut-Antiquity of the Red Sandstone containing themTriassie mannmifer of North Carolina.

Between the Lias and the Coal (or Carboniferous group) there is interposed, in the midland and western counties of England, a great series of red loams, shales, and sandstones, to which the name of the "New Red Sandstone formation" was first given, to distinguish it from other shales and sandstones called the "Old Red" (c, fig. 462), often identical in mineral character, which lie immediately beneath the coal (b).

Fig. 462.

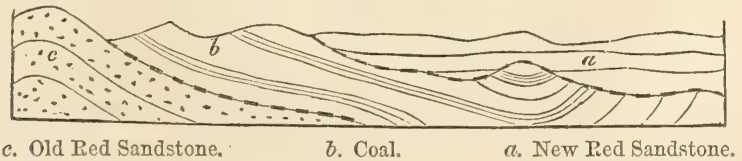

The name of "Red Marl" has been incorrectly applied to the red clays of this formation, as before explained (p. 13), for they are remarkably free from calcareous matter. The absence, indeed, of carbonate of lime, as well as the scarcity of organic remains, together with the bright red color of most of the rocks of this group, causes a strong contrast between it and the Jurassic formations before described.

Before the distinctness of the fossil remains characterizing the upper and lower part of the English New Red had been clearly recog- 
nized, it was found convenient to have a common name for all the strata intermediate in position between the Lias and Coal; and the term "Poikilitic" was proposed by Messrs. Conybeare and Buck-

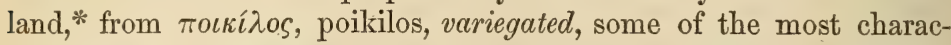
teristic strata of this group having been called variegated by Werner, from their exhibiting spots and streaks of light-blue, green, and buff color, in a red base.

A single term, thus eomprehending both Upper and Lower New Red, or the Triassic and Permian groups of modern classification, may still be useful in describing districts where we have to speak of masses of red sandstone and shale, referable, in part, to both these eras, but which, in the absence of fossils, it is impossible to divide.

Trias or Upper New Red Sandstone Group.-As the group of strata now to be considered is more fully developed in Germany than in England or France, it will be well to consider in the first place the manner in which it presents itself in that country. It has been called the Trias by German writers, or the Triple Group, because it is separable into three distinct formations, called the "Keuper," the "Muschelkalk," and the "Bunter-sandstein."

\section{Nomienclature of Trias.}

German,

Keuper,

Muschelkalk, -

Bunter-sandstein,
French.

Marnes irisées, -

$\left\{\begin{array}{c}\text { Muschelkalk, ou } \\ \text { coquillier, - }\end{array}\right.$

Grès bigarré, -

\footnotetext{
English.

$\{$ Saliferous and gypseous $\left\{\begin{array}{l}\text { shales and sandstone } \\ \text { satis }\end{array}\right.$ calcaire $\}$ wanting in England.

$\{$ Sandstone and quartzose conglomerate.
}

Upper Trias, or Keuper.-It has been already stated, p. 419, that near the base of the Lower Lias are certain zones of strata, distinguished by the abundance of peculiar species of ammonite, in one of which $A$. Bucklandi, and in another still lower A. Planorbis abound. In Northwestern Germany, as in England, beneath these ammonitiferous zones, there occurs a remarkable bone breccia, a marine formation, the shells of which are distinct from those of the Lias. It is filled with the remains of fishes and reptiles, almost all the genera of which, and some even of the species, agree with those of the subjacent Trias. This breccia has accordingly been considered by Professor Quenstedt and other German geologists of high authority, as the newest or uppermost part of the Trias. Professor Plieninger found in it, in 1847, the molar tooth of a small Triassic Mammifer, called by him Microlestes antiquus. He inferred its true nature from its double fangs, and from the form and number of the protuberances or cusps on the flat crown; and considering it as predaceous, probably

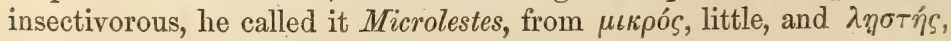


a beast of prer. Soon afteriards he found a second tooth, also at the same localitr, Diegerloch, about two miles to the southeast of Stuttgart. Some of its cusps are broken, but there seem to have been six of them originally. From its agreement in general character, it mas supposed by Professor Plieninger to belong to the same animal; but as it is four times as big, it may perhaps hare been the tooth of another allied species. This molar is attached to the matrix consisting of sandstone, whereas the tóoth (fig. 463) is isolated. Sev-

Fig. 463 .

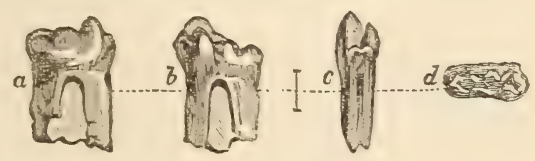

Microlestes antiquus, Plieninger. Molar tnoth, magnified. Upper Trias, Diegerloch, near Stuttgart, Würtemberg.
a. View of inner side?
b. Same, outer side?
c. Same in proflle.
d. Crown of same.

Fig. 464.

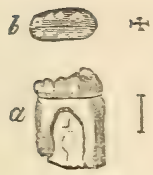

Microlestes antiquns, Plien.

View of same molar as fig. 463. From a drawing by Hermann Von Mever.

a. View of inner side? b. Crown of same.

c. Crown of the same, magnified.
Fig. 465.

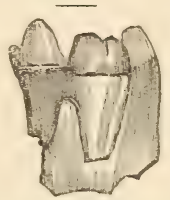

Molar of Microlestes? Plicn. 4 times as large as the fig. 463. From the Trias of Diegerloch, Stuttgart.

cral fragments of bone, differing in structure trom that of the associated saurians and fish, and beliered to be mammalian, nere imbedded near them in the same rock. No anatomist had been able to gire ant feasible conjecture as to the affinities of this minute quadruped until Dr. Falconer, in 185\%, recognized an unmistakable resemblance between its teeth and the tro back molars of his new genus Plagiaulax (see abore, fig. 373, p. 383), from the Purbeck strata. This mould lead us to the conclusion that Microlestes was marsupial and plant-eating.

In Türtemberg there are tro bone-beds, namely, that containing the Nicrolestes, which has just been described, which constitutes, as we hare seen, the uppermost member of the Trias, and another of still greater extent, and still more rich in the remains of fish and reptiles, which is of older date, intervening hetreen the Keuper and Muschelkalk.

The genera Sumrichthys, Hybodus, and Gyrolepis, are found in

- both these breccias, and one of the species, Saurichthys. Mongeoti, is common to both bone-beds, as is also a remarkable reptile called 
Nothosaurus mirabilis. The saurian called Belodon by H. Von Meyer, of the Thecodont family, is another Triassic form, associated at Diegerloch with Microlestes.

Beneath this bone-breccia follows the regular series of strata called Keuper, which in Würtemberg is about 1000 feet thick. It is divided by Alberti into sandstone, gypsum, and carbonaceous slate clay.* Remains of reptiles called Nothosaurus and Phytosaurus have been

Fig. 466.

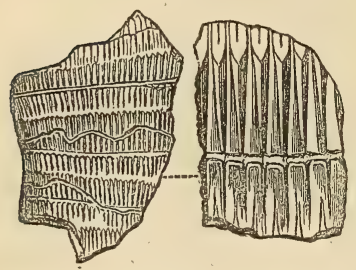

Equisetites columnaris. (Syn. Equisetum columnare.) Fragment of stem, and a small portion of same magnified. Keuper. found in it with Labyrinthodon; the detached teeth, also, of placoid fish and of rays, and of the genera Saurichthys and Gyrolepis (figs. 481, 482, p. 442).

The plants of the Keuper are generically very analogous to those of the lias and oolite, consisting of ferns, equisetaceous plants, cycads, and conifers, with a few doubtful monocotyledons. A few species such as Equisetites columnaris, are common to this group and the oolite.

St. Cassian and Hallstadt Beds.-The sandstones and clay of the Keuper resemble the deposits of estuaries and a shallow sea near the land, and afford, in the N. W. of Germany, as in France and England, but a scanty representation of the marine life of that period. We might, however, have anticipated, from its rich reptilian fauna, that the contemporaneous inhabitants of the sea of the Keuper period would be very numerous, should we ever have an opportunity of bringing their remains to light. This, it is believed, has at length been accomplished, by the position now assigned to certain Alpine rocks called the "St. Cassian beds," the true place of which in the series was until lately a subject of much doubt and discussion. For valuable researches relating to these formations, we are indebted to many eminent geologists, especially to MM. Von Buch, E. de Beaumont, Murchison, Sedgwick, and Klipstein, and in Switzerland to MM. Escher and Merian, and more lately in Austria to MM. Von Hauer, Suess, Hörnes, and Gümbel. It has been proved that the Hallstadt beds on the Northern flanks of the Austrian Alps correspond in age with the St. Cassian beds on their southern declivity, and the Austrian geologists hence satisfied themselves that the Hallstadt formation is referable to the period of the Upper Trias. Assuming this conclusion to be correct, we become acquainted suddenly and unexpectedly with a rich marine fauna belonging to a period previously believed to be very barren of organic remains, because in England, France, and Northern Germany the Upper Trias is chiefly represented by beds of fresh or brackish-water origin. Mr. Edward Suess, of Vienna, to whom we are indebted for 
several memoirs on the rocks in question, has favored me with the following summary of the order of succession of the Hallstadt beds in the Austrian Alps, which I had an opportunity, when travelling in the autumn of 1856, of verifying in company with Mr. Gümbel, of Munich.

The uppermost strata first enumerated immediately underlie the Lower Lias of the Swabian Jura. This lias is represented near Vienna by a brown limestone, containing Ammonites Bucklandi, A. Conybearii, \&c.

\section{Strata below the Lias in the Austrian Alps, in Descending Order.}

1. Koessen beds.

(Synonyms, Upper St. Cassian beds of Escher and Merian.)

2. Dachstein beds.

3. Hallstadt beds (or St. Cassian).

4. A. Guttenstein beds.

$B$. Werfen beds, base of Upper Trias?

Lower Trias of some geologists.

(Gray and black limestone, with calcareous marls having a thickness of about 50 feet. Among the fossils, Brachiopoda very numerous; some few species common to the genuine Lias; many peculiar. Avicula contorta, Pecten Valoniensis, Cardium Rhoeticum, Avicula incequivalvis, Spirifer Müsteri, Dav. Strata containing the above fossils alternate with the Dachstein beds, lying next below.

White or grayish limestone, often in beds 3 or 4 feet thick. Total thickness of the formation above 2000 feet. Upper part fossiliferous, with some strata composed of corals. (Lithodendron.) Lower portion without fossils. Among the characteristic shells are Hemicardium Wulferii, Megalodon triqueter, and other large bivalves.

(Red, pink, or white marble, from 800 to 1000 feet in thickness, containing more than 800 species of marine fossils, for the most part mollusea. Many species of Orthoceras. True Amnionites, besides Ceratites and Goniatites, Belemnites (rare), Porcellia, Pleurotomaria, Trochus, Monotis salinaria, \&c.

A. Black and gray limestone 150 feet thick, alternating with the underlying Werfen beds.

$B$. Red and green shale and sandstone, with Salt and Gypsum.

Among the fossils are Ceratites cassianus, Myacites fassaen sis, Naticella costata, \&c.

In regard to the age of the rocks above mentioned, the Koessen and Dachstein beds have been referred by some to the Lias, by others to the Trias, while many have considered them to be of intermediate date. But Mr. Suess has shown that the Koessen beds correspond to the upper bone-bed of Swabia, in which the Microlestes was found (see p. 432), and the same geologist remarks that some of the fossils of the beds 1 and 2 are identical with the Irish "Portrush beds" of General Portlock, described in his Peport on Londonderry. The Koessen beds have been traced for 100 geographical miles from near Geneva to the environs of Vienna.

The German geologists are now generally agreed, as already stated, that the Hallstadt and St. Cassian beds are of the age of the lower 
part of the Keuper or Upper Trias; but whether the Werfen sandstone, No. 4, should form part of the same series, or, as Von Hauer inclines to believe, should be classed as the equivalent of "the Bunter or Lower Trias," is still undetermined. The absence of wellcharacterized Muschelkalk fossils in the Austrian Alps renders this point very difficult to decide. Rich deposits of salt, associated with the Werfen beds, have inclined some geologists to presume that they belong to the Upper Trias. Should they be classed as "Bunter," the Guttenstein limestone would then correspond in position with the Muschelkalk, but no Muschelkalk fossils have ever been met with in it or in the Werfen.

Among the 800 species of fossils of the Hallstadt and St. Cassian beds, many are still undescribed; some are of new and peculiar genera, as Scoliostoma, fig. 467, Platystoma, fig. 468, among the Gasteropoda; and Koninckia, fig. 469, among the Brachiopoda.

Fig. 467 .

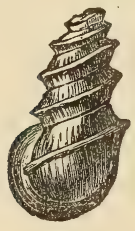

Scoliostoma, St. Cassian.

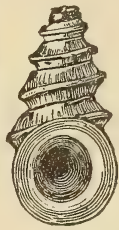

Fig. 468.

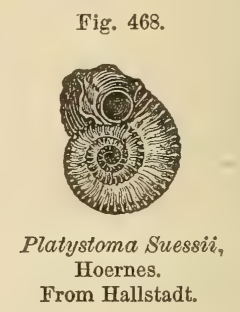

From Hallstadt.

Fig. 469 .

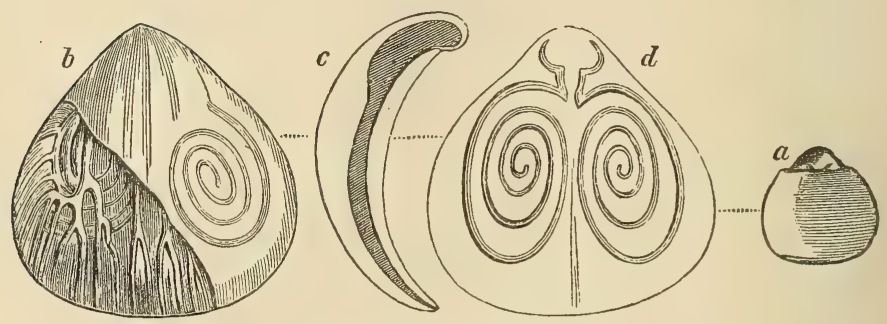

Koninckia Leonharäi, Wissmann.

a. Dorsal view, natural size.

b. Ventral view, part of the converse ventral valve removed to show the interior of dorsal valve and its vascular impressions. One of the spiral processes is seen through the translucent shell.

c. Section of both valves.

d. Interior of dorsal valve, with spiral processes restored. (Suess.)

The following table of genera of marine shells from the Hallstadt and St. Cassian beds, drawn up on the joint authority of MM. Suess and Woodward, shows how many connecting links between the fauna of primary and secondary rocks are supplied by the St. Cassian anci Hallstadt beds. 
Genera of Fossil Mollusca in the St. Cassian and Hallstadt Beds.

Common to Older Rocks.
Cyrtoceras.
Orthoceras.
Goniatites.
*Loxonema.
*Holopella.
Murchisonia.
Euomphalus.
Porcellia.
* Megalodon.
Cyrtia.

\begin{tabular}{|c|} 
Characteristic Triassic Genera. \\
Ceratites. \\
Scoliostoma (or \\
Cochlearia). \\
Naticella. \\
Platystoma. \\
Isoarca. \\
Pleurophorus. \\
Myophoria. \\
Monotis. \\
Koninckia.
\end{tabular}

Common to Newer Rosks,

The genera marked by an asterisk are given on the authority of Mr. Suess, the rest on that of Mr. Woodward from fossils of the St. Cassian rocks in the British Museum.

The first column marks the last appearance of several genera which are characteristic of Palæozoic strata. The second shows those genera which are characteristic of the Upper Trias, either as peculiar to it or as reaching their maximum of development at this era. The third column marks the first appearance of genera destined to become more abundant in later ages.

As the Orthoceras had never been met with in the marine Muschelkalk, much surprise was naturally felt that 7 or 8 species of the genus should appear in the Hallstadt beds, assuming these last to belong to the Upper Trias. Among these species are some of large dimensions, associated with large Ammonites with foliated lobes, a form never seen before so low in the series, while the Orthoceras had never been seen so high. But the latter genus has also been met with in the Adnet, or lias strata of Austria, as I was assured in 1856 by several eminent geologists of Germany.

Professor Ramsay has lately made a careful analysis of the lists given by Bronn of 104 genera and 774 species of fossils, derived from the St. Cassian beds, of all classes of the animal kingdom, nearly the whole of them invertebrata; and he has also made an analysis of another list of 79 genera and 427 species of fossils from the same beds, drawn up by a skilful naturalist, the late Count Munster. The results arrived at in both cases agree very closely, proving that somewhat less that onethird of the St. Cassian fossils have a primary or palæozoic, and twothirds of them a secondary or mesozoic character. There would be nothing wondcrful or anomalous in such a result, were it not that the fossils of the Muschelkalk, which are supposed to be older than the St. Cassian beds, contain a comparatively small proportion of primary types, so that a palæontologist would naturally presume, says Professor Ramsay, that the St. Cassian beds were a stage nearer in time than is the Muschelkalk to the Permian period. Bronn, accordingly, in drawing up his catalogue, placed the St. Cassian beds in that position, or as intermediate between the Bunter-sandstein and the Upper Permian, or Zeckstein. It must, I think, be admitted that, were we not 
controlled by the decided opinion as to the order of superposition to which the most able living surveyors of the Austrian Alps have come, we should naturally take for granted, when presented with such a section as that given at p. 435, that the Muschelkalk, if it happened to be present at Hallstadt, would have overlaid the bed No. 3, instead of having to be intercalated between Nos. 3 and 4 , or even placed below No. 4 .

Whatever ambiguity may still remain in many minds respecting the precise chronological relations of the St. Cassian beds, no one questions that they are Triassic, and they have entirely dissipated the notion formerly entertained as to the marine fauna of the whole Triassic era having been poverty-stricken. The St. Cassian fauna, moreover, leads us to expect that, should we hereafter have an opportunity of studying the marine fossils of the lowest division of the Bunter sandstone, the present break between the Palæozoic and Neozoic forms will almost entirely disappear.

\section{Muschelkalk.}

The next member of the Trias in Germany, the Muschelkalk, which underlies the Keuper before described, consists chiefly of a compact grayish limestone, but includes beds of dolomite in many places, together with gypsum and rock salt. This limestone, a formation wholly unrepresented in England, abounds in fossil shells, as the name implies. Among the Cephalopoda there are no belemnites; and no ammonites with foliated sutures, as in the lias and oolite as well as in the Hallstadt beds; but we find instead a genus allied to the Ammonite, called Ceratites by De Hann, in which the descending lobes (see $a, b, c$, fig. 470 ) terminate in a few small denticulations point-

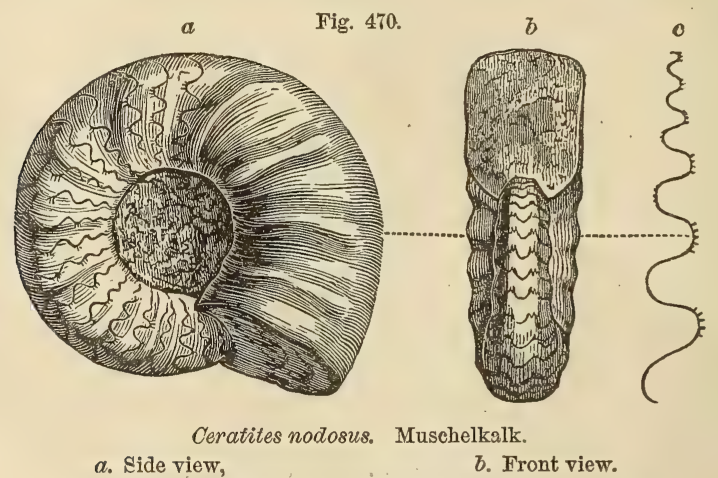

c. Partially denticulated outline of the septa diving the chambers.

ing inwards, the saddles being plane. Among the bivalve shells, the Posidonia minuta, Goldf. (Estheria minuta, Bronn), (see fig. 471), is abundant, ranging through the Keuper, Muschelkalk, and Bunter- 
sandstein; and Avicula socialis (fig. 472), having a similar range, is found in great numbers in the Muschelkalk of Germany, France, and Poland.

Fig. 471.

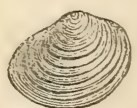

Estheria (Posidonia) minuta, Goldf. (Posidonomya minuta, Bronn.)
Fig. 472.

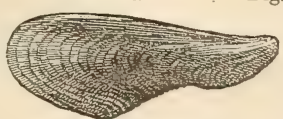

a. Avicula socialis.

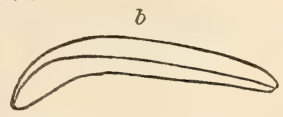

b. Side view of same.

Characteristic of the Muschelkalk.

The abundance of the heads and stems of lily encrinites, Encrinus liliiformis (fig. 473), (or Encrinites moniliformis), shows the slow manner in which some beds of this limestone have

Fig. 473.

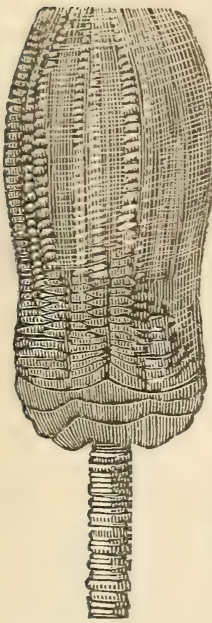

Encrinus litiiformis, Schlott. Syn. E, moniliformis. Body, arms, and part of stem. a. Section of stem. Muschelkalk,
Fig. 474.

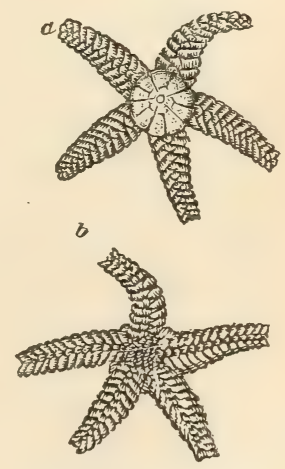

Aspidura.loricata, Agass.

a. Upper side.

b. Lower side Muschelkalk.
Fig. 475 .

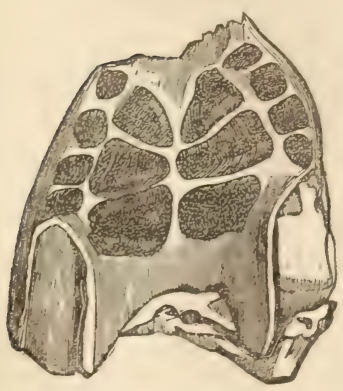

Palatal teeth of Placodus gigas. Muschelkalk.
Fig. 476 .

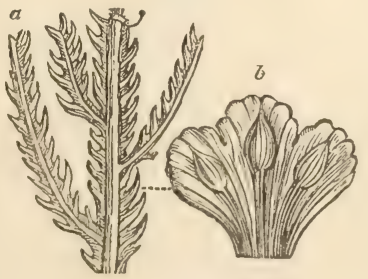

a. Voltzia heterophylla. (Syn. Voltzia brevifolia.)

b. Portion of same magnified to show fructification, Sulzbad. Bunter-sandstein 
found the skull and teeth of a reptile of the genus Placodus (see fig 475), which was referred originally by Count Münster, and afterwards by Agassiz, to the class of fishes. But more perfect specimens enabled Professor Owen, in 1858, to show that this fossil animal was a Saurian reptile, which probably fed on shell-bearing mollusks, and used its short and flat teeth, so thickly coated with enamel, for pounding and crushing the shells.*

\title{
Bunter-sandstein.
}

The Bunter-sandstein consists of various-colored sandstones, dolomites, and red clays, with some beds, especially in the Hartz, of calcareous pisolite or roe-stone, the whole sometimes attaining a thickness of more than 1000 feet. The sandstone of the Vosges, according to Von Meyer, is proved, by the presence of Labyrinthodon and other fossills, to belong to this lowest member of the Triassic group. At Sulzbad (or Soultz-les-bains), near Strasburg, on the flanks of the Vosges, many plants have been obtained from the "Bunter," especially conifers of the extinct genus Voltzia, peculiar to this period, in which even the fructification has been preserved. (See fig. 476.)

Out of thirty species of ferns, cycads, conifers, and other plants, enumerated by M. Ad. Brongniart, in 1849, as coming from the "Grès bigarré," or Bunter, not one is common to the Keuper.† This difference, however, may arise, partly from the fact that the flora of the "Bunter" has been almost entirely derived from one district (the neighborhood of Strasburg), and its peculiarities may be local.

The footprints of a reptile (Labyrinthodon) have been observed on the clays of this member of the Trias, near Hildburghausen, in Saxony, impressed on the upper surface of the beds, and standing out as casts in relief from the under sides of incumbent slabs of sandstone. To these I shall again allude in the sequel; they attest, as well as the accompanying ripple-marks, and the tracks which traverse the clays, the gradual deposition of the beds of this formation in shallow water, and sometimes between high and low water.

\section{Triassic Group in England.}

The Trias or New Red series of England is subdivided by Professor Ramsay in the following manner :

\author{
Keuper $\left\{\begin{array}{l}\text { Koessen or Penarth beds (Avicula contorta zone). } \\ \text { New Red Marl, with streaks of Sandstone. }\end{array}\right.$ \\ White and Brown Sandstone and Marl. \\ Upper Variegated Sandstone. \\ Bunter $\{$ Conglomerate or Pebble beds. \\ Lower Variegated Marble. \\ * Owen, Phil. Trans., 1858, p. 169. \\ + Tableau des Genres de Vég. Foss., Dict. Univ., 1849.
}


Different members of the above group rest in England, in some region or other, on almost every principal member of the palæozoic series, on Cambrian, Silurian, Devonian, Carboniferous, and Permian rocks, and there is evidence everywhere of disturbance, contortion, partial upheaval into land, and vast denudations which the older rocks underwent before and during the deposition of the successive strata of the New Red Sandstone group. It was stated (p. 419) that the Lower Lias in the southwest of England contained near its base strata characterized by Ammonites planorbis, below which beds with many reptilian remains sometimes occur.

Still lower, on the boundary line between the Lias and Trias, certain cream-colored limestones, called White Lias by Smith, are found usually, but not always, without fossils. These white beds have lately been referred by Mr. Chas. Moore to what he calls the Rhætic beds, * because largely developed in the Rhrtian Alps, and which are the same as the Koessen beds of Germany, No. 1, p. 435. The marine organic remains observed in them near Frome, in Somersetshire, show that they appertain to the highest member of the Upper Trias, in which occur the sandstones and shales with Avicula contorta (fig. 479), together with other fossil shells belonging to the same zone in Germany, France, and Lombardy. Among the most abundant of the shells in all these countries is the above-mentioned Avicula (fig. 479), and with it Cardium rhoeticum (fig. 477) and Pecten Valoniensis (fig. 478).

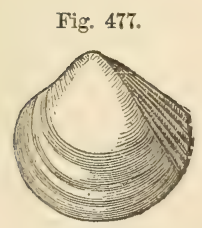

Cardium rhaticum. Nat. size. Uppermost Trias.
Fig. 478.

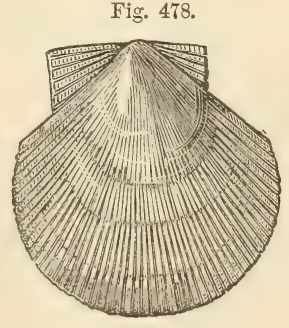

Pecten Valoniensis, Dfr. $\frac{1}{3}$ nat. size. Portrush, Ireland, \&c. Uppermost Trias.
Fig." 479

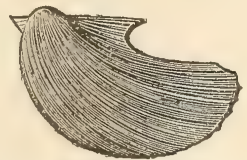

Avicula contorta. Portlock. Portrush, Ireland, \&c. Nat. size. Uppermost Trias.

The principal member of this group has been called by Dr. Wright the Avicula contorta bed, $\uparrow$ as this shell is very abundant, and has a wide range in Europe. General Portlock first described the formation as it occurs at Portrush, in Antrim, where the Avicula contorta is accompanied by Pecten Vuloniensis, as in Germany. The beds under consideration, although of moderate thickness, are already rich in synonyms, as, besides the German names mentioned at page 435

* Moore, Rhætic Beds, Quart. Geol. Journ., 1861, vol. xvii.

$\dagger$ Dr. Wright, on Lias and Bone-bed, Quart. Geol. Journ., 1860, vol. xn. 
and the Bone-bed series of many geologists, as well as the Rhætic beds of Mr. C. Moore, it has lately been named the Penarth beds by the Government surveyors of Great Britain, from Penarth, near Cardiff, in Glamorganshire, where these strata are finely exhibited in the sea-cliffs.

The best-known member of the group, a thin band or bone-breccia, is conspicuous among the black shales in the neighborhood of Axmouth, in Devonshire, and in the cliffs of Westbury-on-Severn, as well as at Aust and other places on the borders of the British Channel. It abounds in the remains of saurians and fish, and was formerly classed as the lowest bed of the Liąs; but Sir P. Egerton first pointed out, in 1841, that it should be referred to the Upper New Red Sandstone, because it contained an assemblage of fossil fish which are either peculiar to this stratum, or belong to species well known in the Muschelkalk of Germany. These fish belong to the genera Acrodus, Hybodus, Gyrolepis, and Saurichthys.

Among those common to the English bone-bed and the Muschelkalk of Germany are Hybodus plicatilis (fig. 480), Saurichthys apicalis (fig. 481), Gyrolepis tenuistriatus (fig. 482), and G. Albertii. Remains of saurians, Plesiosaurus among others, have also been found in the bonebed, and plates of an Encrinus.

Fig. 480.

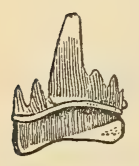

Hybodus plicatilis, Teeth. Bone-bed, Aust and Axmouth.
Fig. 481.

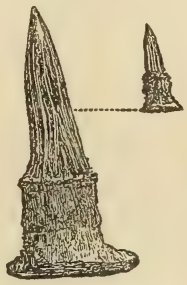

Saurichthys apicalis. Tooth; nat. size, and magnified. Axmouth.
Fig. 482 .

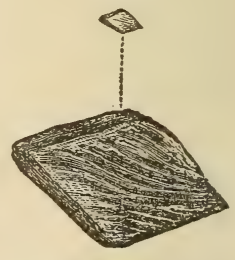

Gyrolepis tenuistriatus. Scale; nat. size and magnified. Axmouth.

In certain gray indurated marls below the bone-bed, Mr. Dawkins found, at Watchett, on the coast of Somersetshire, in 1863, a two-fanged molar tooth of a fossil mammifer of the Microlestes family. Mr. Chas. Moore had previously discovered twenty-seven teeth of mammalia of the same family near Frome, in Somersetshire, in the contents of a vertical fissure traversing a mass of carboniferous limestone. The top of this fissure must have communicated with the bed of the Triassic sea, and probably at a point not far from the ancient shore on which the small marsupials of that era abounded.

The strata of red and green marl, which follow the bone-bed in the descending order at Axmouth and Aust, are destitute of organic remains: as is the case, for the most part, in the corresponding beds in almost every part of England. But fossils have been found at a few localities in sandstones of this formation, in Worcestershire and Warwickshire, 
and among them the bivalve shell called Posidonia minuta, Goldf., before mentioned (fig. 471, p. 439).

The member of the English "New Red" containing this shell, in those parts of England, is, according to Sir Roderick Murchison and Mr. Strickland, 600 feet thick, and consists chiefly of red marl or slate, with a band of sandstone. Ichthyodorulites, or spines of Hybodus, teeth of fishes, and footprints of reptiles were observed by the same geologists in these strata; * and the remains of a saurian, called Rhynchosaumus, have been found in this portion of the Trias at Grinsell, near Shrewsbury.

In Cheshire and Lancashire the gypseous and saliferous red shales and clays of the Trias are between 1000 and 1500 feet thick. In some places lenticular masses of rock-salt are interpolated between the argillaceous beds, the origin of which will be spoken of in the sequel.

The lower division or English representative of the "Bunter" attains a thickness of 600 feet in the counties last mentioned. Besides red and green shales and red sandstones, it comprises much soft white quartzose sandstone in which the trunks of silicified trees have been met with at Allesley Hill, near Coventry. Several of them were a foot and a half in diameter, and some yards in length, decidedly of coniferous wood, and showing rings of annual growth. $\dagger$ Impressions, also, of the footsteps of animals have been detected in Lancashire and Cheshire in this formation. Some of the most remarkable occur a few miles from Liverpool, in the whitish quartzose sandstone of Storton Hill, on the west side of the Mersey. They bear a close resemblance to tracks first observed in a member of the Upper New Red Sandstone, at the village of Hesseberg, near Hildburghausen, in Saxony, to which I have already alluded. For many years these footprints have been referred to a large unknown quadruped, provisionally named Cheirotherium by Professor Kaup, because the marks both of the fore and hind feet resembled impressions made by a human hand. (See fig. 483.) The footmarks at Hesseberg are partly concave, and partly in relief; the former, or the depressions, are seen upon the upper surface of the sandstone slabs, but those in relief are only upon the lower surfaces, being in fact natural casts, formed in the subjacent footprints as in moulds. The larger impressions, which scem to be those of the

* Geol. Trans., Second Series, vol. v. p. 318, \&c.

† Buckland, Proc. Geol. Soc., vol. ii. p. 439; and Murchison and Strickland, Geol. Trans., Second Series, vol. v. p. 347. 
hind foot, are generally 8 inches in length, and 5 in width, and one was 12 inches long. Near each large footstep, and at a regular dis-
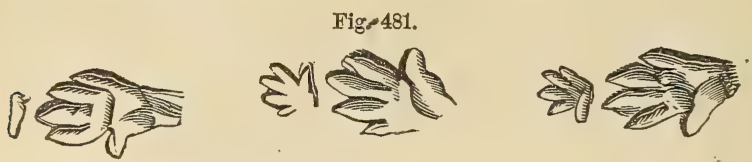

Line of footsteps on slab of sandstone. Hildburghausen, in Saxony.

tance (about an inch and a half), before it, a similar print of a fore foot, 4 inches long and 3 inches wide, occurs. The footsteps follow each other in pairs, each pair in the same line, at intervals of 14 inches from pair to pair. The large as well as the small steps show the great toes alternately on the right and left side; each step makes the print of five toes, the first or great toe being bent inwards like a thumb. Though the fore and hind foot differ so much in size, they are nearly similar in form.

The similar footmarks afterwards observed in a rock of corresponding age at Stornton Hill were imprinted on five thin beds of clay, superimposed one upon the other in the same quarry, and separated by beds of sandstone. On the lower surface of the sandstone strata, the solid casts of each impression are salient, in high relief, and afford models of the feet, toes, and claws of the animals which trod on the clay. On the same surfaces Mr. J. Cunningham discovered (1839) distinct casts of rain-drop markings.

As neither in Germany nor in England any bones or teeth had been met with in the same identical strata as the footsteps, anatomists indulged, for several years, in various conjectures respecting the mysterious animals from which they might have been derived. Professor Kaup suggested that the unknown quadruped might have been allied to the Marsupialia ; for in the kangaroo the first toe of the fore foot is in a similar manner set obliquely to the others, like a thumb, and the -disproportion between the fore and hind feet is also very great. But M. Link conceived that some of the four species of animals of which the tracks had been found in Saxony might have been gigantic Batrachians; and Dr. Buckland designated some of the footsteps as those of a small web-footed animal, probably crocodilian.

In the course of these discussions several naturalists of Liverpool, in their report on the Storton quarries, declared their opinion that each of the thin seams of clay in which the sandstone casts were moulded had formed successively a surface above water, over which the Cheirotherium and other animals walked, leaving impressions of their footsteps, and that each layer had been afterwards submerged by a sinking down of the surface, so that a new beach was formed at low water above the former, on which other tracks were then made. The repeated occurrence of ripple-marks at various heights and depths in red sandstone of Cheshire had been explained in the same mauncr. It 
was also remarked that impressions of such depth and clearness could only have been made by animals walking on the land, as their weight would have been insufficient to make them sink so deeply in yielding clay under water. They must, therefore, have been air-breathers.

When the inquiry had been brought to this point, the reptilian remains discovered in the Trias, both of Germany and England, were carefully examined by Prof. Owen. He found, after a microscopic investigation of the teeth from the German sandstone called Keuper, and from the sandstone of Warwick and Leamington (fig. 485), that neither of them could be referred to true saurians, although they had been named Mastodonsaurus and Phytosaurus by Jäger. It appeared that they were of the Batrachian order, and of gigantic dimensions in comparison with any representatives of that order now living. Both the Continental and English fossil teeth exhibited a most complicated texture, differing from that previously observed in any reptile, whether recent or extinct, but most nearly analogous to the Ichthyosaurus. A section of one of these teeth ex-

Fig. 485 .

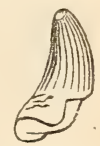

Tooth of Labyrinthadon; nat. size. Warwick sandstone. hibits a series of irregular folds, resembling the labyrinthic windings of the surface of the brain; and from this character Prof. Owen has proposed the name Labyrinthodon for the new genus. The annexed representation (fig. 486) of part of one is .

Fig. 486.

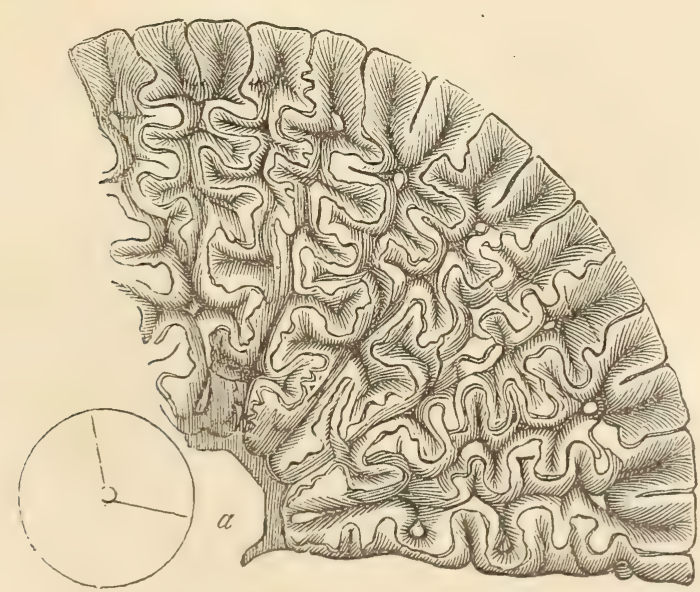

Transverse section of tooth of Labyrinthodon Jaegeri, Owen (Mastodonsaurus Jaegeri, Meyer); nat. size, and a segment magnified.

a. Pulp cavity, from which the processes of pulp and dentine radiate.

given from his "Odontography," plate $64 \mathrm{~A}$. The entire length of this tooth is supposed to have been about three inches and a half, and the breadth at the base one inch and a half. 
When Prof. Owen had satisfied himself, from an inspection of the cranium, jaws, and teeth, that a gigantic Batrachian had existed at the period of the Trias or Upper New Red Sandstone, he soon found, from the examination of various bones derived from the same formation, that he could define three species of Labyrinthodon, and that in this genus the hind extremities were much larger than the anterior ones. This circumstance, coupled with the fact of the Labyrinthodon having existed at the period when the Cheirotherium footsteps were made, was the first step towards the identification of those tracks with the newly-discovered Batrachian. It was at the same time observed that the footmarks of Cheirotherium were more like those of toads than of any other living animal; and, lastly, that the size of the three species of Labyrinthodon corresponded with the size of three different kinds of footprints which had already been supposed to belong to three distinct Cheirotheria. It was moreover inferred, with confidence, that the Labyrinthodon was an air-breathing reptile from the structure of the nasal cavity, in which the posterior outlets were at the back part of the mouth, instead of being directly under the anterior or external nostrils. It must have respired air after the manner of saurians, and may therefore have imprinted on the shore those footsteps, which, as we have seen, could not have originated from an animal walking under water.

But the structure of the foot is still wanting, and a more connected and complete skeleton is required for demonstration; for the circumstantial evidence above stated is not strong enough to produce in the minds of some eminent anatomists the conviction that the Cheirotherium and Labyrinthodon are one and the same.

Dolomitic Conglomerate of Bristol.-Near Bristol, in Somersetshire, and in other countries bordering the Severn, are certain strata which rest unconformably upon the coal-measures, and consist of a conglomerate called "dolomitic," because the pebbles of older rocks contained in it are cemented together by a red or yellow base of dolomite. This conglomerate or breccia occurs in patches over the downs near Bristol, and upon the flanks of the hills, filling up hollows and irregularities in the Old Red Sandstone, Millstone Grit, and Mountain Limestone. The imbedded fragments are both rounded and angular, and some of them of vast size, especially those of millstone grit, weighing nearly a ton. It is principally composed, at every spot of the debris, of those rocks on which it immediately rests. At one point we find pieces of coal-shale $e_{2}$ in another of mountain limestone, recognizable by its peculiar, shells and zoophytes. Fractured bones, also, and teeth of saurians of contemporaneous origin, are dispersed through some parts of the breccia.

These saurians are distinguished by having the teeth implanted deeply in the jaw-bone, and in distinct sockets, instead of being soldered, as in frogs, to a simple alveolar parapet. In the dolomitic conglomerate near Bristol the remains of species of two genera have been 
found, called Thecodontosaurus and Palcoosaurus by Dr. Riley and Mr. Stutchbury; * the teeth of which are conical, compressed, and with finely serrated edges (figs. 487 and 488).

Teeth of Saurians. Dolomitic conglomerate; Redland, near Bristol.

Fig. 487.

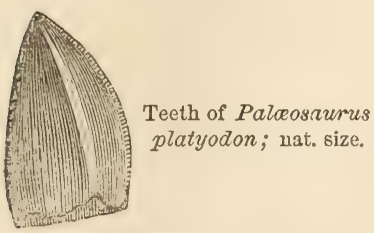

Fig. 488.

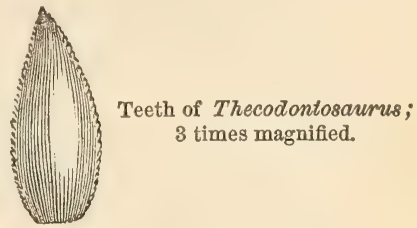

Messrs. Conybeare and Buckland referred the strata containing these saurians to the period of the magnesian limestone, or the lowest part of their Poikilitic series, and for a long time these reptiles ranked as the most ancient representatives of their class which had been found in any British rocks; but Sir H. De la Beche afterwards pointed out that, in consequence of the isolated position of the breccia containing the fossils in question, it was very difficult to determine to what precise part of the Poikilitic series they belonged. $\uparrow$ More lately, our Government surveyors have satisfied themselves that the breccia is of Triassic date, probably referable to the base of the Keuper.

\section{Origin of Red Sandstone and Rock Sult.}

We have seen that, in various parts of the world, red and mottled clays and sandstones, of several distinct geological epochs, are found associated with salt, gypsum, magnesian limestone, or with one or all of these substances. There is, therefore, in all likelihood, a general cause for such a coincidence. Nevertheless, we must not forget that there are dense masses of red and rariegated sandstones and clays, thousands of feet in thickness, and of vast horizontal extent, wholly devoid of saliferous or gypseous matter. There are also deposits of gypsum and of muriate of soda, as in the blue clay formation of Sicily, without any accompanying red sandstone or red clay.

To account for deposits of red mud and red sand, we have simply to suppose the disintegration of ordinary crystalline or metamorphic schists. Thus, in the eastern Grampians of Scotland, in the north of Forfarshire, for example, the mountains of gneiss, mica-schist, and clayslate are overspread with alluvium, derived from the disintegration of those rocks; and the mass of detritus is stained by oxide of iron, of precisely the same color as the Old Red Sandstone of the adjoining lowlands. Now this alluvium merely requires to be swept down to the

* Geol. Trans., Second Series, vol. v. p. 349, pl. 29, figs. 2 and 5.

$\uparrow$ Memoirs of Geol. Survey of Great Britain, vol, i. p. 268. 
sea, or into a lake, to form strata of red sandstone and red marl, precisely like the mass of the "Old Red". or "New Red" systems of England, or those tertiary deposits of Auvergne (see p. 224), before described, which are in lithological characters quite undistinguishable. The pebbles of gneiss in the Eocene red sandstone of Auvergne point clearly to the rocks from which it has been derived. The red coloring matter may, as in the Grampians, have been furnished by the decomposition of hornblende or mica, which contain oxide of iron in large quantity.

It is a general fact, and one not yet accounted for, that scarcely any fossil remains are preserved in stratified rocks in which this oxide of iron abounds; and when we find fossils in the New or Old Red Sandstone in England, it is in the gray, and usually calcareous beds, that they occur.

The gypsum and saline matter, occasionally interstratified with such red clays and sandstones of various ages, primary, secondary, and tertiary, have been thought by some geologists to be of volcanic origin. Submarine and subaërial exhalations often occur in regions of earthquakes and volcanoes far from points of actual eruption, and charged with sulphur, sulphuric salts, and with common salt or muriate of soda. In a word, such "solfataras" are vents by which all the products which issue in a state of sublimation from the craters of active volcanoes obtain a passage from the interior of the earth to the surface. That such gaseous emanations and mineral springs, impregnated with the ingredients before enumerated, and often intensely heated, continue to flow out unaltered in composition and temperature for ages, is well known. But before we can decide on their real instrumentality in producing in the course of ages beds of gypsum, salt, and dolomite, we require to know more respecting the chemical changes actually in progress in seas where volcanic agency is at work. .

The origin of rock salt, however, is a problem of so much interest in theoretical geology as to demand the discussion of another hypothesis advanced on the subject; namely, that which attributes the precipitation of the salt to evaporation, whether of inland lakes or of lagoons communicating with the ocean.

At Northwich, in Cheshire, in the Upper Trias or Keuper, two beds of salt, in great part unmixed with earthy matter, attain the extraordinary thickness of 90 and even 100 feet. The upper suriace of the highest bed is very uneven, forming cones and irregular figures. Between the two masses there intervenes a bed of indurated clay, traversed with veins of salt. The highest bed thins off towards the southwest, losing 15 feet in thickness in the course of a mile.* The horizontal extent of these particular masses in Cheshire and Lancashire is not exactly known; but the area, containing saliferous clays and sandstones, is supposed to exceed 150 miles in diameter, while the total

* Ormerod, Quart. Geol. Journ., 1848, vol. iv. p. 277. 
thickness of the trias in the same region is estimated by Mr. Ormerod at more than 1\%00 feet. Ripple-marked sandstones, and the footprints of animals, before described, are observed at so many lerels that we mar safely assume the whole area to hare undergone a slow and gradual depression during the formation of the Red Sandstone. The eridence of such a morement, wholly independent of the presence of salt itself, is rerr important in reference to the theory under consideration.

In the "Principles of Geologr" (chap. xxrii.), I published a map, furnished to me br the late Sir Alexander Burnes, of that singular flat region called the Runn of Cutch, near the delta of the Indus, which is 7000 square miles in area, or equal in extent to about one-fourth of Ireland. It is neither land nor sea, but is dry during a part of every year, and again covered by salt water during the monsoons. Some parts of it are liable, after long intervals, to be overflowed by riverwater. Its surface supports no grass, but is encrusted over, here and there, br a larer of salt, about an inch in depth, caused br the eraporation of sea-water. Certain tracts have been converted into dry land br uphearal during earthquakes since the commencement of the present centurr, and, in other directions, the boundaries of the Runn hare been enlarged br subsidence. That successire larers of salt might br thrown down, one upon the other, over thousands of square miles, in such a region, is undeniable. The suppls of brine from the ocean would be as inerhatustible as the supply of heat from the sun to cause eraporation. The only assumption required to enable us to explain a great thickness of salt in such an area is, the continuance, for an indefinite period, of a subsiding morement, the countrs preserving all the time a general approach to horizontality. Pure salt could onls be formed in the central parts of basins, where no sand could be drifted by the wind, or sediment be brought br currents. Should the sinking of the ground be accelerated, so as to let in the sea freelr, and deepea the water, a temporar suspension of the precipitation of salt mould be the only result. On the other hand, if the area should dry up, ripple-marked sands and the footprints of animals might be formed, where salt had preriously accumulated. According to this rier, the thickness of the salt, as rell as of the accompanring beds of mud and sand, becomes a mere question of time, or requires simply a repetition of similar operations.

Mr. Hugh Miller, in an able discussion of this question, refers to Dr. Frederick Parrot's account, in his journer to Ararat (18.36), of the salt lakes of Asia. In several of these lakes west of the river Manech, "the water, during the hottest season of the year, is covered on its surface $\pi$ ith a crust of salt nearly an inch thick, which is collected mith shorels into boats. The crrstallization of the salt is effected by rapid eraporation from the sun's heat and the supersaturation of the water with muriate of soda; the lake being so shallow that the little boats trail on the bottom and leare a furrow behind them, so that the lake 
must be regarded as a wide pan of enormous superficial extent, in which the brine can easily reach the degree of concentration required." -Another traveller, Major Harris, in his "Highlands of Ethiopia," describes a salt lake, called the Bahr Assal, near the Abyssinian frontier, which once formed the prolongation of the Gulf of Tadjara, but was afterwards cut off from the gulf by a broad bar of lava or of land upraised by an earthquake. "Fed by no rivers, and exposed in a burning climate to the unmitigated rays of the sun, it has shrunk into an elliptical basin, seven miles in its transverse axis, half filled with smooth water of the deepest cærulean hue, and half with a solid sheet of glittering snow-white salt, the offspring of evaporation." " "If," says Mr. Hugh Miller, "we suppose, instead of a barrier of lava, that sandbars were raised by the surf on a flat arenaceous coast during a slow and equable sinking of the surface, the waters of the outer gulf might occasionally topple over the bar, and supply fresh brine when the first stock had been exhausted by evaporation." *

We may add that the permanent impregnation of the waters of a large shallow basin with salt, beyond the proportion which is usual in the ocean, would cause it to be uninhabitable by mollusks or fish, as is the case in the Dead Sea, and the muriate of soda might remain in excess, even if it were occasionally replenished by irruptions of the sea. Should the saline deposit be eventually submerged, it might, as we have seen from the example of the Runn of Cutch, be covered by a freshwater formation containing fluviatile organic remains; and in this way the apparent anomaly of beds of sea-salt and clays devoid of marine fossils, alternating with others of freshwater origin, may be explained.

Dr. G. Buist, in a communication to the Bombay Geographical Society (vol. ix.), has asked how it happens that the Red Sea should not exceed the open ocean in saltness by more than $\frac{1}{10}$ th per cent. The Red Sea receives no supply of water from any quarter save through the Straits of Babelmandeb; and there is not a single river or rivulet flowing into it from a circuit of 4000 miles of shore. The countries around are all excessively sterile and arid, and composed, for the most part, of burning deserts. From the ascertained evaporation in the sea itself, Dr. Buist computes that nearly 8 feet of pure water must be carried off from the whole of its surface annually, this being probably equivalent to $\frac{1}{100}$ th part of its whole volume. The Red Sea, therefore, ought to have 1 per cent. added annually to its saline contents; and as these constitute 4 per cent. by weight, or $2 \frac{1}{2}$ per cent. in volume of its entire mass, it ought, assuming the average depth to be 800 feet, which is supposed to be far beyond the truth, to have been converted into one solid salt formation in less than 3000 years. $\nmid$ Does the Red Sea receive a supply of water from the ocean, through the narrow Straits of Babelmandeb, sufficient to balance the loss by evaporation?

* Hugh Miller, First Impressions of England, 1847, pp. 183, 214.

+ Buist. Trans. of Bombay Geograph. Soc., 1850, vol, ix. p. 38. 
And is there an undercurrent of heavier saline water annually flowing outwards? If not, in what manner is the excess of salt disposed of? An investigation of this subject by our nautical surveyors may perhaps aid the geologist in framing a true theory of the origin of rock-salt.

\section{Trias of the United States.}

Coal-field of Richmond, Virginia.-There are large tracts on the globe, as in Russia and the Atlantic border of the United States, where all the members of the oolitic series are unrepresented. In the State of Virginia, at the distance of about 13 miles eastward of Richmond, the capital of that State, there is a regular coal-field occurring in a depression of the granite rocks (see section, fig. 489). It extends 26

Fig. 489.

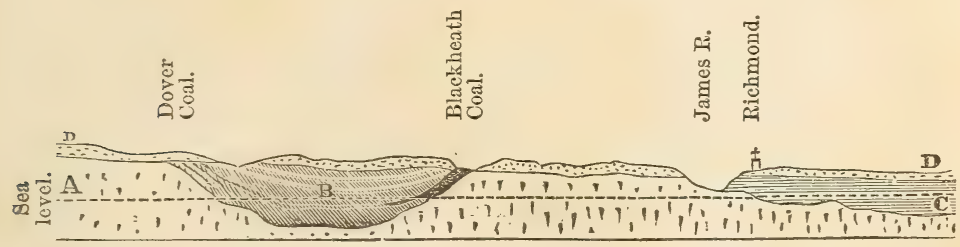

Section showing the geological position of the James River, or East Virginian Coal-field.
A. Granite, gneiss, \&c.
B. Coal-measures.
C. Tertiary strata.
D. Drift or ancient alluvium.

miles from north to south, and from 4 to 12 from east to west. Professor W. B. Rogers formerly referred these strata to the lower part of the Jurassic group; and this opinion I adopted in former editions of this work, after collecting a large number of fossil plants, fish, and shells, and examining the coal-field throughout its whole area. The plants consist chiefly of zamites, calamites, equiseta, and ferns. The equiseta are very commonly met with in a vertical position more or less compressed perpendicularly. It is clear that they grew in the places where they are now buried in strata of hardened sand and mud. I found them maintaining their erect attitude, at points many miles distant from others, in beds both above and between the seams of coal. In order to explain this fact we must suppose such shales and sand stones to have been gradually accumulated during the slow and repeated subsidencé of the whole region.

It is worthy of remark that the Equisetum columnare of these Virginian rocks appears to be undistinguishable from the species found in the oolitic sandstones near Whitby in Yorkshire, where it also is met with in an upright position. One of the Virginian fossil ferns, Pecopteris Whitbyensis, is also a species which has been considered as common to the Yorkshire oolites, although Professor Heer doubts its identity.*

* See description of the coal-field by the Author, and of the plants by C. J. F. Bunbury, Esq., Quart. Geol. Journ., vol. iii. p. 281. 
But tne plants upon the whole are considered by Professor Heer to have the nearest affinity to those of the European Keuper. When Sir Charles Bunbury compared them in 1847 to the fossil plants of Neueweld near Basle, and of other plant-bearing rocks near Baireuth, he supposed, as Unger had done before him, that those localities were Liassic, whereas geologists afterwards determined them to be of Upper Triassic date.

The fossil fish are Ganoids, some of them of the genus Catopterus, others belonging to the Liassic genus Tetragonolepis (AEchmodus), see fig. 452 p. 421 . Fossil mollusea are very rare, as usually in all coalbearing deposits, but two species of Entomostraca called Estheria are in such profusion in some shaly beds as to divide them like the plates of mica in micaceous shales (see fig. 490).

Fig, 490 .

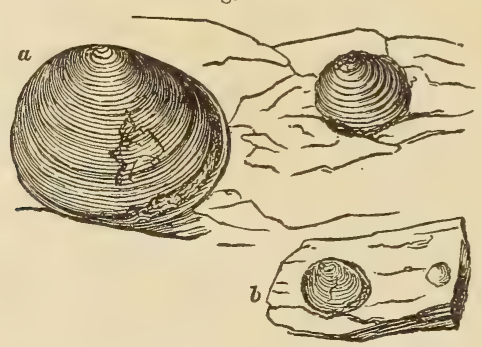

a. Estheria orata.

b. Young of same.

Oolitic coal-shale, Richmond, Virginia.

These Virginian coal-measures are composed of grits, sandstones, and shales, exactly resembling those of older or primary date in America and Europe, and they rival or even surpass the latter in the richness and thickness of the coal-seams. One of these, the main seam, is in some places from 30 to 40 feet thick, composed of pure bituminous coal. On descending a shaft 800 feet deep, in the Blackheath mines in Chesterfield County, I found myself in a chamber more than 40 feet high, caused by the removal of this coal. Timber props of great strength supported the roof, but they were seen to bend under the incumbent weight. The coal is like the finest kinds shipped at Newcastle, and when analysed yields the same proportions of carbon and hydrogen - a fact worthy of notice when we consider that this fuel has been derived from an assemblage of plants very distinct specifically, and in part generically from those which have contributed to the formation of the ancient or palæozoic coal.

New Red Sandstone of the Valley of the Connecticut River.-In a depression of the granitic or hypogene rocks in the States of Massachusetts and Connecticut, strata of red sandstone, shale, and conglomerate are found, occupying an area more than 150 miles in length from north to south, and about 5 to 10 miles in breadth, the beds dipping to the eastward at angles varying from 5 to 50 degrees. The 
extreme inclination of 50 degrees is rare, and only observed in the neighborhood of masses of trap which have been intruded into the red sandstone while it was forming, or before the newer parts of the deposit had been completed. Having examined this series of rocks in many places, I feel satisfied that they were formed in shallow water, and for the most part near the shore, and that some of the beds were from time to time raised above the level of the water, and laid dry, while a newrer series, composed of similar sediment, was forming. The red flags of thin-bedded sandstone are often ripple-marked, and exhibit on their under-sides casts of cracks formed in the underlying red and green shales. These last must have shrunk by drying before the sand was spread over them. On some shales of the finest texture impressions of rain-drops may be seen, and casts of them in the incumbent argillaceous sandstones. Having observed similar markings produced by showers, of which the precise date was known, on the recent red mud of the Bay of Fundy, and casts in relief of the same on layers of dried mud thrown down by subsequent tides, * I feel no doubt in regard to the origin of some of the ancient Connecticut impressions. I have also seen on the mud-flats of the Bay of Fundy the footmarks of birds (Tringa minuta), which daily run along the borders of that estuary at low water and which I have described in my travels. $\nmid$ Similar layers of red mud, now hardened and compressed into shale, are laid open on the banks of the Connecticut, and retain faithfully the impressions and casts of the feet of numerous birds and reptiles which walked over them at the time when they were deposited, probably in the Triassic period.

According to Professor Hitchcock, the footprints of no less than thirty-two species of bipeds, and twelve of quadrupeds, have been already detected in these rocks. Thirty of these are believed to be those of birds, four of lizards, two of chelonians, and six of batrachians. The tracks have been found in more than twenty places, scattered through an extent of nearly 80 miles from north to south, and they are repeated through a succession of beds attaining at some points a thickness of more than 1000 feet, which may have been thousands of years in forming:t

As considerable skepticism is naturally entertained in regard to the nature of the evidence derived from footprints, it may be well to enumerate some facts respecting them on which the faith of the geologist may rest. When I visited the United States in 1842, more than 2000 impressions had been observed by Professor Hitchcock, in the district alluded to, and all of them were indented on the upper surface of the layers, while the corresponding casts, standing out in relief, were always on the lower surfaces or planes of the strata. If

\footnotetext{
* Principles of Geology, 9th ed., p. 203.

+ Travels in N. America, vol, ii. p. 168.

$\ddagger$ Hitchcock, Mem. of Amer. Acad., New Series, vol. iii. p. 129; 1848.
} 
we follow a single line of marks we find them uniform in size, and nearly uniform in distance from each other, the toes of two successive footprints turning alternately right and left (see fig. 491). Such

Fig. 491.

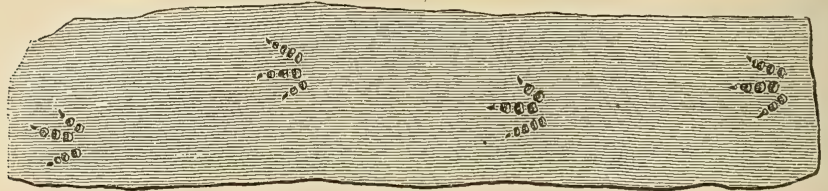

Footprints of a 'bird. Turner's Falls, Valley of the Connecticut. (See Dr. Deane, Mem. of Amer. Acađ., vol. iv. 1849.)

single lines indicate a biped; and there is generally such a deviation from a straight line in any three successive prints, as we remark in the tracks left by birds. There is also a striking relation between the distance separating two footprints in one series, and the size of the impressions; in other words, an obvious proportion between the length of the stride and the dimension of the creature which walked over the mud. If the marks are small, they may be haif an inch asunder; if gigantic, as, for example, where the toes are 20 inches long, they are occasionally 4 feet and a half apart. The bipedal impressions are for the most part trifid, and show the same number of joints as exist in the feet of living tridactylous birds. Now, such birds have three phalangeal bones for the inner toe, four for the middle, and five for the outer one (see fig. 491); but the impression of the terminal joint is that of the nail only. The fossil footprints exhibit regularly, where the joints are seen, the same number; and we see in each continuous line of tracks the three-jointed and five-jointed toes placed alternately outwards, first on the one side and then on the other. In some specimens, besides impressions of the three toes in front, the rudiment is seen of the fourth toe behind. It is not often that the matrix has been fine enough to retain impressions of the integument or skin of the foot; but in one fine specimen found at Turner's Falls on the Connecticut, by Dr. Deane, these markings are well preserved, and have been recognized by Professor Owen as resembling the skin of the ostrich, and not that of reptiles.* Much care is required to ascertain the precise layer of a laminated rock on which an animal has walked, because the impression usually extends downwards through several laminæ; and if the upper layer originally trodden upon is wanting, the mark of one or more joints, or even in some cases an entire toe, which sank less deep into the soft ground, may disappear, and yet the remainder of the footprint be well defined.

* This specimen was in the late Dr. Mantell's museum, and indicated a bird of a size intermediate between the small and the largest of the Connecticut species. 
The size of several of the fossil impressions of the Connecticut red sandstone so. far exceeds that of any living ostrich, that naturalists at first were extremely adverse to the opinion of their having been made by birds, until the bones and almost entire skeleton of the Dinornis and of other feathered giants of New Zealand were discovered. Their dimensions have at least destroyed the force of this particular objection. The magnitude of the impressions of the feet of a heavy animal, which has walked on soft mud, increases for some distance below the surface originally trodden upon. In order, therefore, to guard against exaggeration, the casts rather than the mould are relied on. These casts show that some of the fossil bipeds. had feet four times as large as the ostrich, but not perhaps much larger than the Dinornis.

The eggs of another gigantic bird, called Aipiornis, which has probably been exterminated by man, have recently been discovered in an alluvial deposit in Madagascar. The egg has six times the capacity of that of the ostrich; but, judging from the large size of the egg of the Apteryx, Professor Owen does not believe that the LEpiornis exceeded, if indeed it equalled, the Dinornis in stature.

Among the supposed bipedal tracks, a single distinct animal only has been observed of feet in which there are four toes directed forwards. In this case a series of four footprints is seen, each 22 inches long and 12 wide, with joints much resembling those in the toes of birds. Professor Agassiz has suggested that it might have belonged to a gigantic bipedal batrachian. Other naturalists have called our attention to the fact, that some quadrupeds, when walking, place the hïnd foot so precisely on the same spot just quitted by the fore foot, as to produce a single line of imprints, like those of a biped; and $\mathrm{Mr}$. Waterhouse Hawkins has remarked that certain species of frogs and lizards in Australia have the two outer toes so slightly developed and so much raised that they might leave tridactylous footprints on mud and sand. Another osteologist, Dr. Leidy, in the United States, observed to me that the pterodactyl was a biped reptile approaching the bird so nearly in the structure and shape of its wing-bones and tibir, that some of these last, obtained from the Chalk and Wealden in England, had been mistaken by the highest authorities for true birds' bones. May not the foot, therefore, of a pterodactyl have equally resembled that of a bird? Be this as it may, the greater number of the American impressions agree so precisely in form and size with the footmarks of known liring birds, especially with those of waders, that we shall act most in accordance with known analogies by referring most of them at present to feathered, rather than to featherless bipeds.

No bones have as yet been met with, whether of pterodactyl or bird, in the rocks of the Connecticut, but there are numerous coprolites; and an ingenious argument has been derived by Dr. Dana from the analysis of these bodies, and the proportion they contain of uric acid, phosphate of lime, carbonate of lime, and organic matter, to show 
that, like guano, they are the droppings of birds rather than of reptiles.

Some of the quadrupedal footprints which accompany those of birds are analogous to European Cheirotheria, and with a similar disproportion between the hind and fore feet. Others resemble that remarkable reptile, the Rhynchosaurus of the English Trias, a creature having some relation in its osteology both to chelonians and birds. Other imprints, again, are like those of turtles.

Mr. Darwin, in his "Journal of a Voyage in the Beagle," informs us that the "South American ostriches, although they live on vegetable matter, such as roots and grass, are repeatedly seen at Bahia Blanea (lat. $39^{\circ} \mathrm{S}$.), on the coast of Buenos Ayres, coming down at low water to the extensive mud-banks which are then dry, for the sake, as the Guachos say, of feeding on small fish." They readily take to the water, and have been seen at the Bay of San Blas, and at Port Valdez, in Patagonia, swimming from island to island.* It is therefore evident, that in our times a South American mud-bank might be trodden simultaneously by ostriches, alligators, tortoises, and frogs; and the impressions left, in the nineteenth century, by the feet of these various tribes of animals, would not differ from each other more entirely than do those attributed to birds, saurians, chelonians, and batrachians in the rocks of the Connecticut.

To determine the exact age of the red sandstone and shale containing these ancient footprints in the United States, is not possible at present. No fossil shells have yet been found in the deposit, nor plants in a determinable state. The fossil fish are numerous and very perfect; but they are of a peculiar type, which was originally referred to the genus Paloconiscus, but has since, with propriety, been ascribed, by Sir Philip Egerton, to a new genus. To this he has given the name of Ischypterus, from the great size and strength of the fulcral rays of the dorsal fin (from i $\sigma \chi \grave{v} \varsigma$, strength, and $\pi \tau \varepsilon \rho \partial े$, a fin). They differ from Palcooniscus, as Mr. Redfield first pointed out, by having the vertebral column prolonged to a more limited extent into the upper lobe of the tail, or, in the language of M. Agassiz, they are less heterocercal. The teeth also, according to Sir P. Egerton, who, in 1844, examined for me a fine series of specimens which I procured at Durham, Connecticut, differ from those of Paloconiscus in being strong and conical.

That the sandstones containing these fish are of older date than the coal-bearing strata near Richmond in Virginia, which have been shown (p. 451) to be about the age of the European Keuper, is probable. The high antiquity of the Connecticut beds cannot be proved by direct superposition, but may be presumed from the general structure of the country. That structure proves them to be newer than the movements to which the Appalachian or Alleghany chain owes its flexures, and this chain includes the ancient or palæozoic coal-formation among its

* Journal of Voyage of Beagle, \&c., 2 d edit., p. $89 ; 1845$. 
contorted rocks. The unconformable position of this New Red with ornithichnites on the edges of the inclined primary or palæozoic rocks of the Appalachians is seen at 4 of the section, fig. 552 p. 497. The absence of fish with decidedly heterocercal tails may afford an argument against the Permian age of the formation; and the opinion that the red sandstone is triassic seems, on the whole, the best that we can embrace in the present state of our knowledge.

In North Carolina, the late Professor Emmons has described the strata of the Chatham coal-field, which correspond in age to those near Richmond in Virginia. In beds underlying them he has met with three jars of a small insectirorous mammal, which he has called Dromatherium sylvestre, closely allied to Spalacotherium. Its nearest liring" analogue, says Professor Owen, "is found in Myrmecobius; for each ramus of the lower jaw contained ten small molars in a continuous series, one canine, and three conical incisors-the latter being divided by short intervals." There is every reason to believe that this fossil quadruped is at least as ancient as the Microlestes of the European Trias abore described; and the fact, as I hare already remarked (p. 389), is highly important, as proving that a certain low grade of marsupials had not only a wide range in time from the Trias to the Purbeck or uppermost oolitic strata of Europe, but had also a wide range in space, namely, from Europe to North America, in an east and $\pi c s t$ direction, and, in regard to latitude, from Stonesfield, in $52^{\circ} \mathrm{N}$., to that of North Carolina, $35^{\circ} \mathrm{N}$. 


\section{CHAPTER XXIII.}

\section{PERMIAN OR MAGNESIAN LIMESTONE GROUP.}

Fossils of Magnesian Limestone and Lower New Red distinct from the TriassicTerm "Permian"-English and German equivalents-Marine shells and corals of English Magnesian Limestone-Palæoniscus and other fish of the marl-slateZechstein and Rothliegendes of Thuringia-Permian Flora-Its generic affinity to the Carboniferous-Psaronites or tree-ferns.

WHeN the use of the term "Poikilitic" was explained in the last chapter, I stated, that in some parts of England it is scarcely possible to separate the red marls and sandstones so called (originally named "the New Red") into two distinct geological systems. Nevertheless, the progress of investigation, and a careful comparison of English rocks between the lias and the coal with those occupying a similar geological position in Germany and Russia, have enabled gaologists to divide the Poikilitic formation; and have even shown that the lowermost of the two divisions is more closely connected, by its fossil remains, with the earboniferous group than with the trias. If, therefore, we are to draw a line between the secondary and primary fossiliferous strata, as between the tertiary and secondary, it must run through the middle of what was once called the "New Red," or Poikilitic group. The inferior half of this group will rank as Primary or Palæozoic, while its upper member will form the base of the Secondary or Mesozoic series. For the lower, or Magnesian Limestone division of English geologists, Sir R. Murchison proposed, in 1841, the name of Permian, from Perm, a Russian government where these strata are more extensively developed than elsewhere, occupying an area twice the size of France, and containing an abundant and varied suite of fossils.

Professor King, in his valuable monograph * of the Permian fossils of England, has given a table of the following six members of the Permian system of the north of England, with what he conceives to be the corresponding formations in Thuringia:

North of England.

1. Crystalline or concretionary, and non-crystalline limestone.

2. Brecciated and pseudo-brecciated limestone.

3. Fossiliferous limestone.

4. Compact limestone.

5. Marl-slate.

6. Inferior sandstones of various colors.
1. Stinkstein

Thuringia.

2. Rauchwacke.

3. Dolomite, or Upper Zechstein.

4. Zechstein, or Lower Zechstein.

5. Mergel-schiefer, or Kupferschiefer.

6. Rothliegendes.

* Palæontographical Society, 1850, London. 
I shall proceed, therefore, to treat briefly of these subdivisions, beginning with the highest, and referring the reader, for a fuller description of the lithological character of the whole group, as it occurs in. the north of England, to a valuable memoir by Professor Sedgwick, published in 1835 .*

Crystalline or Concretionary Limestone (No. 1). - This formation is seen upon the coast of Durham and Yorkshire, between the Wear and the Tees. Among its characteristic fossils are Schizodus Schlotheimi (fig. 492) and Mytilus septifer (fig. 494).

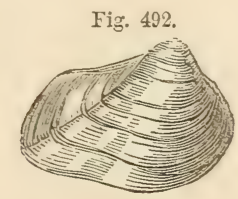

Schizodus Schlotheimi, Geinitz. Crystalline Limestone, Permian.
Fig. 493 ,

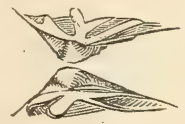

The hinge of Schizodus truncatus, King. Permian.
Fig. 494 .

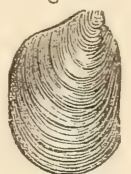

Mytilus septifer, King. Syn. Modiola acuminata. James Sor.

Permian crystalline limestone.

These shells occur at Hartlepool and Sunderland, where the rock assumes an oolitic and botryoidal character. Some of the beds in this division are ripple-marked; and $\mathrm{Mr}$. King imagines that the absence of corals and the character of the shells indicate shallow water. In some parts of the coast of Durham, where the rock is not crystalline, it contains as much as 44 per cent. of carbonate of magnesia, mixed with carbonate of lime. In other places-for it is extremely variable in structure-it consists chiefly of carbonate of lime, and has concreted into globular and hemispherical masses, varying from the size of a marble to that of a cannon-ball, and radiating from the centre. Occasionally earthy and pulverulent beds pass into compact limestone or hard granular dolomite. The stratification is very mregular, in some places $\pi$ ell defined, in others obliterated by the concretionary action which has rearranged the materials of the rocks subsequently to their original deposition. Examples of this are seen at Pontefract and Ripon in Yorkshire.

The brecciated limestone (No. 2) contains no fragments of foreign rocks, but seems composed of the breaking-up of the Permian limestone itself, about the time of its consolidation. Some of the angular masses in Tynemouth Cliff are 2 feet in diameter. This breccia is considered by Professor Sedgwick as one of the forms of the preceding limestone, No. 1, rather than as regularly underlying it. The fragments are angular and never water-worn, and appear to hare been recemented on the spot where they were formed. It is, therefore, suggested that they may have been due to those internal morements of the mass which produced the concretionary structure; but the 
subject is very obscure, and after studying the phenomenon in the Marston Rocks, on the coast of Durham, I found it impossible to form any positive opinion on the subject. The well-known brecciated limestones of the Pyrenees appeared to me to present the nearest analogy, but on a much smaller scale.

The fossiliferous limestone (No. 3) is regarded by Mr. King as a deep-water formation, from the numerous delicate bryozoa which it includes. One of these, Fenestella retiformis (fig. 495), is a very

Fig. 405 .
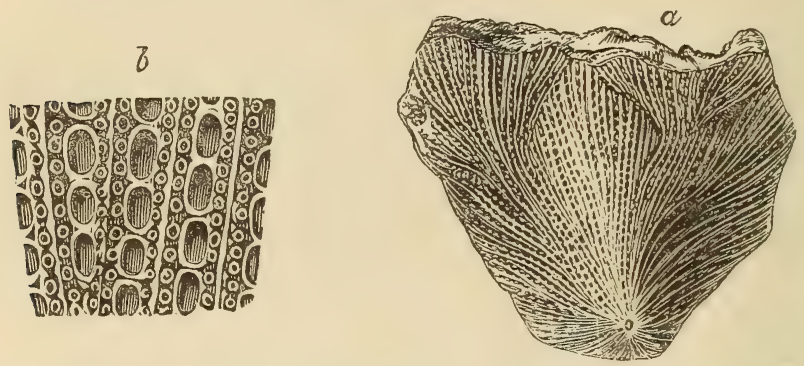

a. Fenestella retiformis, Schlot. sp.

Syn. Gorgonia infundibuliformis, Goldf.; Retepora fiustracea, Phillips.

b. Part of the same highly magnified.

Magnesian Limestone, Humbleton Hill, near Sunderland.*

variable species, and has received many different names. It sometimes attains a large size, measuring 8 inches in width. The same zoophyte, or rather mollusk, with several other British species, is also found abundantly in the Permian of Germany.

Shells of the genera Productus (fig. 496) and Strophalosia (the latter of allied form with teeth in the hinge), which do not occur in

Fig. 496.

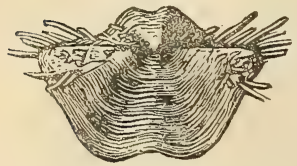

Productus horridus, Sowerby (including $P$. calvus, Sow.) Sunderland and Durham, in Magnesian Limestone; Zechstein and Kupferschiefer, Germany.
Fig. 497.

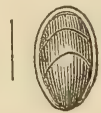

Iingula Crednerii.

(Geinitz.)

Magnesian.

Limestone;

Marl-slate Durham;

Zechstein, Thuringia.
Fig. 498.

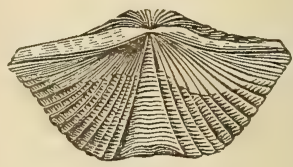

Spirifer undulatus, Sow. Min. Con. Syn. Triogonotreta undulata, King's Monogr.

Magnesian Limestone.

strata newer than the Permian, are abundant in this division of the series in the ordinary yellow magnesian limestone. They are accompanied by certain species of Spirifer (fig. 498), Lingula Crednerii (fig. 497), and other brachiopoda of the true primary or palæozois,

* King's Monograph, pl. 2. 
type. Some of this same tribe of shells, such as Athyris Roissyn, allied to Terebratula, are specifically the same as fossils of the carboniferous rocks. Avicula, Arca, and Schizodus (see abore, fig. 492), and other lamellibranchiate bibalres, are abundant, but spiral univalves are very rare.

The compact limestone (No. 4) also ecntains organic remains, especially bryozoa, and is intimately connected with the preceding. Beneath it lies the marl-slate (No. 5), which consists of hard, calcareous shales, marl-slate, and thin-bedded limestones. At East Thickley, in Durham, where it is thirty feet thick, this slate has yielded many fine specimens of fossil fish of the genera Palceoniscus, Pygopterus, Ccelacanthus, and Platysomus, genera which are all found in the coalmeasures of the Carboniferous epoch, and which therefore, says Mr. King, probably lived at no great distance from the shore. But the Permian species are peculiar, and, for the most part, identical with those found in the marl-slate or copper-slate of Thuringia.

Fig. 499 .

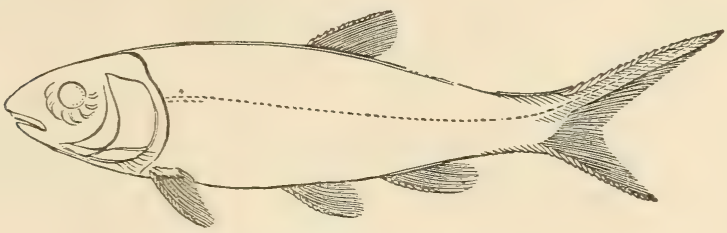

Restored outline of a fish of the genus Palceoniscus, Agass. Paloothrissum, Blainville.

The Palconiscus above mentioned belongs to that division of fishes which M. Agassiz has called "Hcterocercal," which have their tails unequally bilobate, like the recent shark and sturgeon, and the vertebral column running along the upper caudal lobe. (See fig. 500.)

Fig. 500.

Fig. 501.

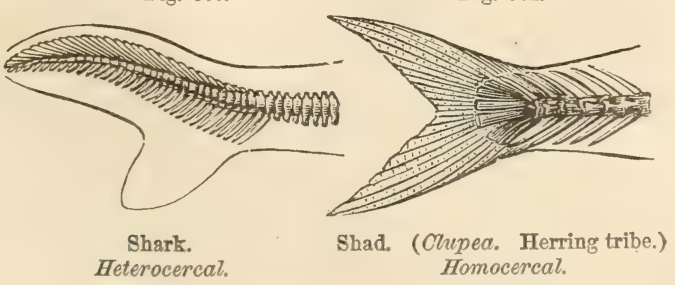

The "Homocercal" fish, which comprise almost all the 9000 species $a^{\dagger}$ present known in the living creation, have the tail-fin either single or equally divided; and the rertebral column stops short, and is not prolonged into either lobe. (See fig. 501.)

Now it is a singular fact, first pointed out by Agrassiz, that the heterocercal form, which is confined to a small number of genera in the existing creation, is universal in the magnesian limestone, and 
all the more ancient formations. It characterizes the earlier periods of the earth's history, whereas in the secondary strata, or those newer than the Permian, the homocercal tail predominates.

A fuli description has been given by Sir Philip Egerton of the species of fish characteristic of the marl-slate, in Prof. King's monograph before referred to, where figures of the ichthyolites, which are very entire and well preserved, will be found. Even a single scale is usually so characteristically marked as to indicate the genus, and sometimes even the particular species. They are often scattered through the beds singly, and may be useful to a geologist in determining the age of the rock.

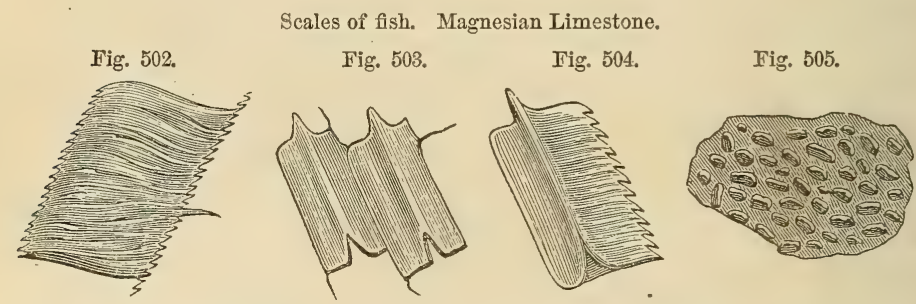

Fig. 502. Palceoniscus comptus, Agassiz. Scale, magnified. Marl-slate.

Fig. 503. Palceoniscus elegans, Sedg. Under surface of scale, magnified. Marl-slate.

Fig. 504. Palceoniscus glaphyrus, Ag. Under surface of scale, magnified. Marl-slate.

Fig. 505. Coelacanthus granulatus, Ag. Granulated surface of scale, magnified. Marl-slate.

Fig. 506.

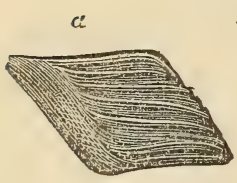

Pygopterus mandibularis, Ag. Marl-slate. a. Outside of scale, magnified. ठ. Under surface of same.
Fig. 507.

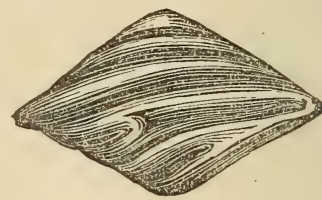

Acrolepis Sedgroickii, Ag. Outside of scale, magnified. Marl-slate.

The inferior sandstones (No. 6, Tab., p. 458), which lie beneath the marl-slate, consist of sandstone and sand, separating the magnesian limestone from the coal, in Yorkshire and Durham. In some instances, red marl and gypsum have been found associated with these beds. They have been classed with the magnesian limestone by Professor Sedgwick, as being nearly coextensive with it in geographical range, though their relations are very obscure. In some regions we find it stated that the imbedded plants are all specifically identical with those of the carboniferous series; and, if so, they probably belong to that epoch; for the true Permian flora appears, from the researches of MM. Murchison and de Verneuil in Russia, and of MM. Geinitz and Von Gutbier in Saxony, to be, with few exceptions, distinct from that of the coal (see p. 463). 
According to Sir R. Murchison," the Permian rocks are composed, In Russia, of white limestone, with gypsum and white salt: and of red and green grits, occasionally with copper-ore; also magnesian limestones, marlstones, and conglomerates.

The country of Mansield, in Thuringia, may be called the classic ground of the Lomer New Red, or Magnesian Limestone, or Permian formation, on the Continent. It consists there principally of, first, the Zechstein, corresponding to the upper portion of our English series; and, secondly, the marl-slate, with fish of species identical with those of the bed so called in Durham. This slaty marlstone is richly impregnated with copper-pyrites, for which it is extensively worked. Magnesian limestone, grpsum, and rock-salt occur among the superior strata of this group. At its base lies the Rothliegendes, supposed to correspond with the Inferior or Lower New Red Sandstone, which occupies a similar place in England between the marlslate and coal. Its local name of "Rothliegendes," red-lyer, or "Roth-todt-liegendes," red-dead-lyer, was given by the workmen in the German mines from its red color, and because the copper has cied out when they reach this rock, which is not metalliferous. It is, in fact, a great deposit of red sandstone and conglomerate, with associated porphyry, basaltic trap, and amygdaloid.

In the "Kupferschiefer," or marl-slate, a highly organized reptile allied to the living monitor, was found in 1709 , which has been named Protorosaurus, and it remained for a century and a quarter the oldest known fossil reptile, when, at length, in 1844, the Archeycsaurus was discovered in the coal of Saarbruch, near Treves.

Permian Flora.-We learn from the investigations of Colonel Von Gutbier, that in the Permian rocks of Saxony no less than 60 species of fossil plants have been met with, 40 of which have not yet been found elsewhere. Two or three of these, as Calamites gigas, Sphe-

Fig. 508.

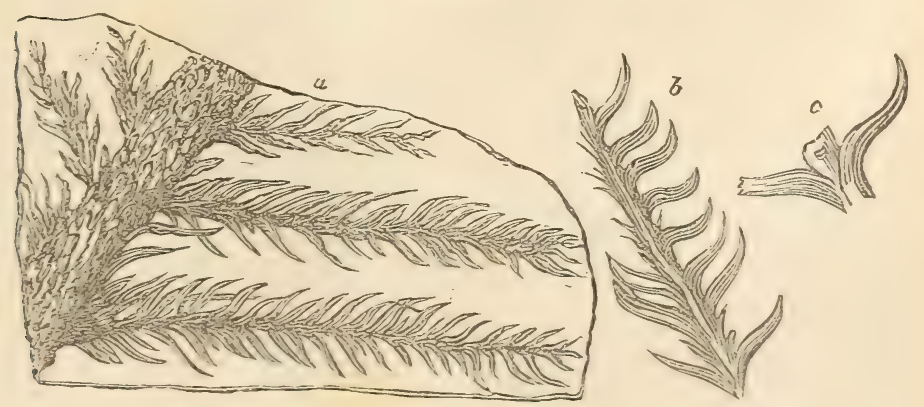

Walchia piniformis, Sternb. Permian, Saxony. (Gutbier, Die Ve1'steinerungen des permischen Systemes in Sachsen, vol, ii. pl. z.)

a. Branch.

b. Twig of the same.

c. Leaf, magnified.

* Russia and the Ural Mountains, 1845 ; and Siluria, chap. xii. 1854. 
nopteris erosa, and S. lobata, are also met with in the government of Perm in Russia. Seven others, and among them Neuropteris Loshii, Pecopteris arborescens, and $P$. similis, with several species of Walchia (see fig. 508), a genus of Conifers, called LycoFig. 509. podites by some authors, are common to the coal-

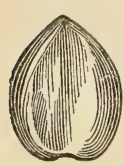
measures.

Among the genera also enumerated by Colonel Gutbier are the fruit called Cardiocarpon (see fig. 509), Asterophyllites, and Annularia, so characteristic of the Carboniferous period; also Lepidodendron, Oardiocarpon ot-
tonis. Gutbier. Permian, Saxony. gia, and Russia, although not abundant. Noeggeru$\frac{1}{2}$ diam. thia (see fig. 510), supposed by A. Brongniart to be

allied to Cycas, is another link between the Permian and Carboniferous vegetation. Coniferæ, of the Araucarian division, also occur;

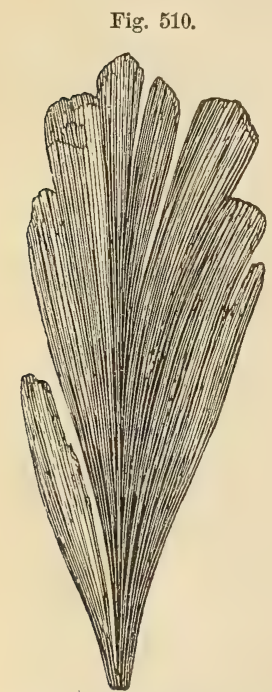

Noeggerathia cuneifolia Ad. Brongniart,* but these are likewise met with both in older and newer rocks. The plants called Sigillaria and Stigmaria, so marked a feature in the Carboniferous period, are as yet wanting.

Among the remarkable fossils of the rothliegendes, or lowest part of the Permian in Saxony and Bohemia, are the silicified trunks of tree-ferns called generically Psaronius. Their bark was surrounded by a dense mass of air-roots, which often constituted a great addition to the original stem, so as to double or quadruple its diameter. The same remark holds good in regard to certain living extratropical arborescent ferus, particularly those of New Zealand.

Psaronites are also found in the uppermost coal of Autun in France, and in the upper coalmeasures of the State of Ohio in the United States, but specifically different from those of the rothliegendes. They serve to connect the Permian flora with the more modern portion of the preceding or carboniferous group. Upon the whole, it is evident that the Permian plants approach much nearer to the carboniferous flora than to the triassic; and the same may be said of the Permian fauna.

* Murchison's Russia, vol. ii. pl. A, fig. 8 . 


\title{
CHAPTER XXIV.
}

\author{
THE COAL, OR CARBONIFEROUS GROUP.
}

Carboniferous strata in the southwest of England-Superposition of Coal-measures to Mountain Limestone-Departure from this type in North of England and Scotland-Carboniferous series in Ireland-Section in South Wales-Under-clays with Stigmaria-Carboniferous Flora-Ferns, Lepidodendra, Equisetaceæ, Calamites, Asterophyllites, Sigillariæ, Stigmariæ-Coniferæ-Sternbergia-Trigonocarpon-Grade of Coniferæ in the Vegetable Kingdom-Absence of Angiosperms -Coal, how formed-Erect fossil trees-Parkfield Colliery-St. Etienne Coalfield-Oblique trees or snags-Fossil forests in Nova Scotia-Rain-prints-Purity of the Coal explained-Time required for the accumulation of the Coal-measures - Brackish-water and marine strata-Crustaceans of the Coal-Origin of Clayiron-stone.

THE next group which we meet with in the descending order is the Carboniferous, commonly called "The Coal;" because it contains many beds of that mineral, in a more or less pure state, interstratified with sandstones, shales, and limestones. The coal itself, even in Great Britain and Belgium, where it is most abundant, constitutes but an insignificant portion of the whole mass. In the north of England, for example, the thickness of the coal-bearing strata has been estimated by Professor Phillips at 3000 feet, while the various coal-seams, 20 or 30 in number, do not in the aggregate exceed 60 feet.

The carboniferous formation assumes various characters in different parts even of the British Islands. It usually comprises two very distinct members: 1st, that usually called the Coal-measures, of mixed freshwater, terrestrial, and marine origin, often including seams of coal; $2 \mathrm{dly}_{5}$, that named in England the Mountain or Carboniferous Limestone, of purely marine origin, and containing corals, shells, and encrinites.

In the southwestern part of our island, in Somersetshire and South Trales, the three divisions usually spoken of by English geologists are :

1. Coal-measures. \{ Strata of shale, sandstone, and grit, with occasional seams

2. Millstone-grit. $\left\{\begin{array}{c}A \text { coarse quartzose sandstone passing into a conglomerate, } \\ \text { sometimes used for millstones, with beds of shale; usually }\end{array}\right.$

- devoid of coal ; occasionally above 600 feet thick.

3. Mountain or (A calcareous rock containing marine shells and corals ; Carboniferous devoid of coal; thickness variable, sometimes 1500 Limestone. I feet. 
The millstone-grit may be considered as one of the coal-sandstones of coarser texture than usual, with some accompanying shales, in which coal-plants are occasionally found. In the north of England some bands of limestione, with pectens, oysters, and other marine shells, occur in this grit, just as in the regular coal-measures, and even a few seams of coal. I shall treat, therefore, of the whole group as consisting of two divisions only, the Coal-measures and the Mountain Limestone. The latter is found in the southern British coal-fields, at the base of the system, or immediately in contact with the subjacent Old Red Sandstone; but as we proceed northwards to Yorkshire and Northumberland it begins to alternate with true coal-measures, the two deposits forming together a series of strata about 1000 fect in thickness. To this mixed formation succeeds the great mass of genuine mountain limestone.* Farther north, in the Fifeshire coalfield in Scotland, we observe a still wider departure from the type of the south of England, or a more complete intercalation of dense masses of marine limestones with sandstones and shales containing coal.

In Ireland a series of shales and slates, constituting the base of the Mountain Limestone, attain so great a thickness, often upwards of 1000 feet, as to be classed as a separate division. Under these slates is a Yellow Sandstone, also considered as carboniferous from its marine fossils, although passing into the underlying Devonian. A similar sandstone of much less thickness occurs in the same position in Gloucestershire and South Wales.

The following are the subdivisions adopted in the geological map of Ireland, constructed by Sir Richard Griffiths :
1. Coal-measures, Upper and Lower, -
2. Millstone-grit, -
3. Mountain limestone, Upper, Middle (or Calp), and
Lower, -
4. Carboniferous slate, - - - - -
.5. Yellow sandstone (of Mayo, \&c.) with shales and lime- stone,
Thickness in Feet. 1000 to 2200 350 to 1800
1200 to 6400 700 to 1200
400 to 2000

\section{COAL-MEASURES.}

In South Wales the coal-measures have been ascertained by actual measurement to attain the extraordinary thickness of 12,000 feet; the beds throughout, with the exception of the coal itself, appearing to have been formed in water of moderate depth, during a slow, but perhaps intermittent, depression of the ground, in a region to which rivers were bringing a never-failing supply of muddy sediment and sand. The same area was sometimes covered with vast forests, such

* Sedgwick, Geol. Trans., Second Series, vol. iv. ; and Phillips, Geol. of Yorkshire, Part 2. 
as we see in the deltas of great rivers in warm climates, which are liable to be submerged beneath fresh or salt water should the ground sink vertically a few feet.

In one section near Swansea, in South Wales, where the total thickness of strata is 3246 feet, we learn from Sir H. De la Beche that there are ten principal masses of sandstone. One of these is 500 feet thick, and the whole of them make together a thickness of 2125 feet. They are separated by masses of shale, varying in thickness from 10 to 50 feet. The intercalated coal-beds, sixteen in number, are generally from 1 to 5 feet thick, one of them, which has two or three layers of clay interposed, attaining 9 feet.* At other points in the same coal-field the shales predominate over the sandstones. The horizontal extent of some seams of coal is much greater than that of others, but they all present one characteristic feature, in having, each of them, what is called its underclay. These underclays, coextensive with every layer of coal, consist of arenaceous shale, sometimes called fire-stone, because it can be made into bricks which stand the fire of a furnace. They vary in thickness from 6 inches to . more than 10 feet; and Sir William Logan first announced to the scientific world in 1841 that they were regarded by the colliers in South Wales as an essential accompaniment of each of the one hundred seams of coal met with in their' coal-field. They are said to form the floor on which the coal rests; and some of them have a slight admixture of carbonaceous matter, while others are quite blackened by it.

All of them, as Sir William Logan pointed out, are characterized by enclosing a peculiar species of fossil vegetable called Stigmaria, to the exclusion of other plants. It was also observed that, while in the overlying shales or "roof" of the coal, ferns and trunks of trees abound without any Stigmarise, and are flattened and compressed, those singular plants of the underclay very often retain their natural forms, branching freely, and sending out their slender leaf-like rootlets, formerly thought to be leaves, through the mud in all directions. Several species of Stigmaria had long been known to botanists, and described by them, before their position under each seam of coal was pointed out, and before their true nature as the roots of trees was recognized. It was conjectured that they might be aquatic, perhaps floating plants, which sometimes extended their branches and leaves freely in fluid mud, and which were finally enveloped in the same mud.

\section{CARBONIFEROUS FLORA.}

These statements will suffice to convince the reader that we cannot arrive at a satisfactory theory of the origin of coal until we under- 
stand the true nature of Stigmaria; and in order to explain what is now known of this plant, and of others which have contributed by their decay to produce coal, it will be necessary to offer a brief preliminary sketch of the whole carboniferous flora-an assemblage of fossil plants with which we are better acquainted than with any other which flourished antecedently to the Tertiary epoch. It should also be marked that Göppert has ascertained that the remains of every family of plants scattered through the coal-measures are sometimes met with in the pure coal itself-a fact which adds greatly to the geological interest attached to this flora.

Ferns.-The number of species of carboniferous plants hitherto described amounts, according to M. Ad. Brongniart, to about 500 . These may perhaps be a fragment only of the entire flora, but they are enough to show that the state of the vegetable world was then extremely different from that now prevailing. We are struck at the first glance with the similarity of many of the ferns to those now living, and the dissimilarity of almost all the other fossils except the Coniferæ. Among the ferns, as in the case of Pecopteris for example (fig. 511), it is not always easy to decide whether they should be re-

Fig. 511 .

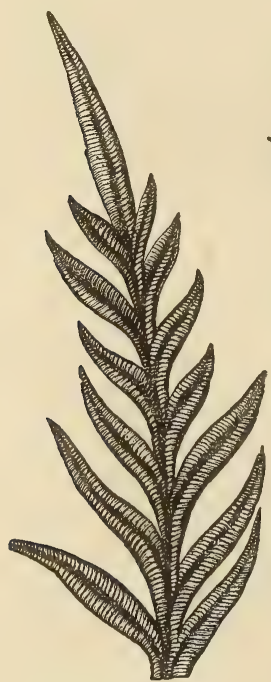

Pecopteris lonchitica. (Foss. Flo., 153.)
Fig. 512.

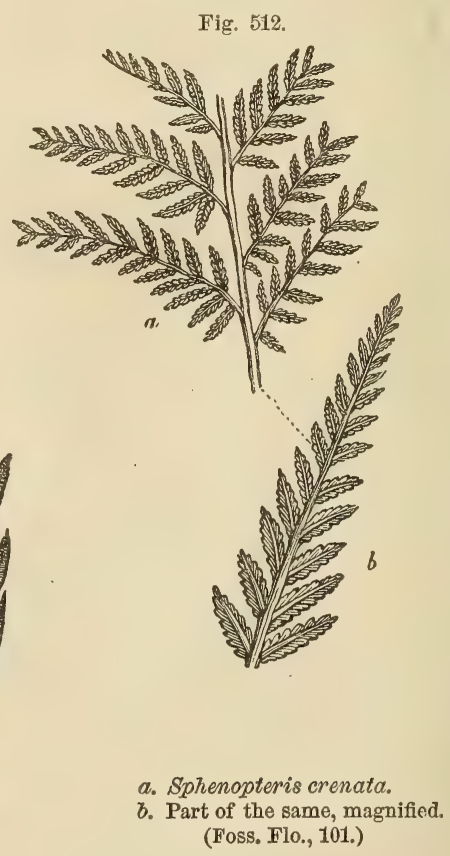

ferred to different genera from those established for the classification of living species; whereas, in regard to most of the other contemporary tribes, with the exception of the fir tribe, it is often difficult to guess the family, or even the class, to which they belong. The ferns 
of the Carboniferous period are generally without organs of fructification, but in some specimens these are well preserved. In the general absence of such characters, they have been divided into genera distinguished chiefly by the branching of the fronds, and the way in which the reins of the leaves are disposed. The larger portion are supposed to have been of the size of ordinary European ferns, but some were decidedly arborescent, especially the group called Caulopteris by Lindley, and the Psaronius of the upper or newest coalmeasures, before alluded to (p. 464).

All the recent tree-ferns belong to one tribe (Polypodiacece), and to a small num-

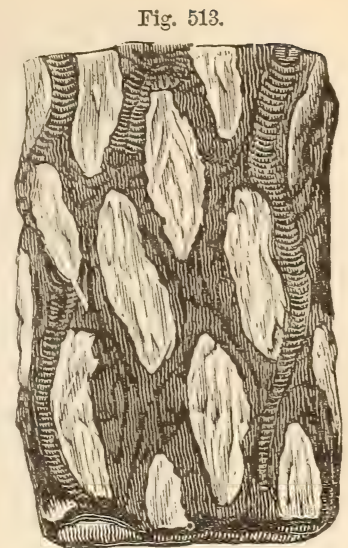

Caulopteris primceva, Lindley. ber only of genera in that tribe, in which the surface of the trunk is marked with scars, or cicatrices, left after the fall of the fronds. These scars resemble those of Caulopteris (see fig. 513). No less than 250 ferns have already been obtained from the coal-strata; and eren if we make some reduction on the ground of varieties which

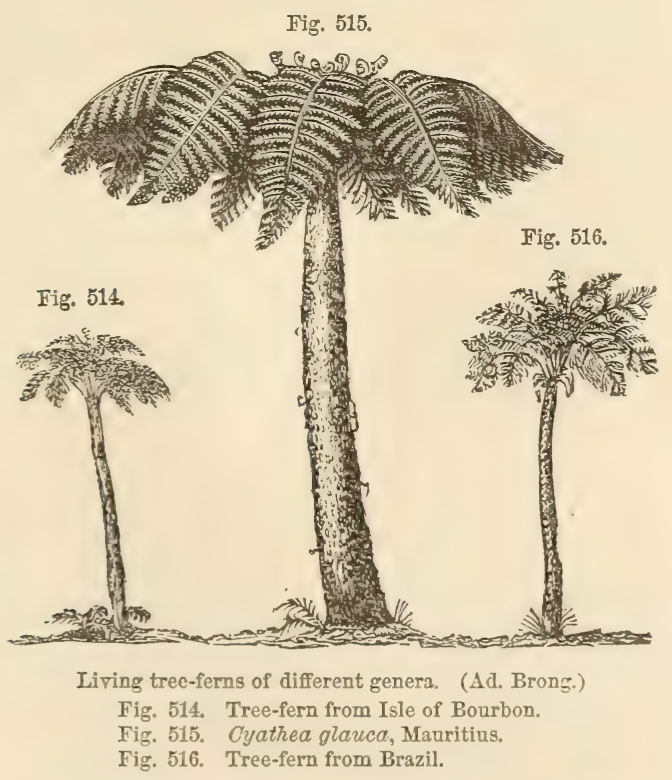

have been mistaken, in the absence of their fructification, for species, still the result is singular, because the whole of Europe affords at present no more than sixty indigenous species.

Lepidodendron.-About 40 species of fossil plants of the Coal have 
been referred to this genus. They consist of cylindrical stems or trunks, covered with leaf-scars. In their mode of branching, they are always dichotomous (see fig. 518). They are considered by Brongniart and Hooker to belong to the Lycopodiacece, plants of this family bearing cones, with similar sporangia and spores (fig. 521). Most of them grew to the size of large trees. The figs. 517-519

Fig. 517.

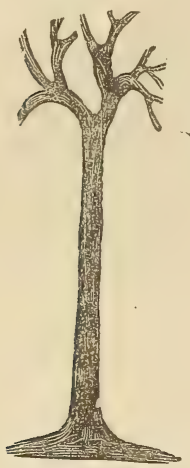

Lepidodendron Sternbergii. Coal-meusures, near Newcastle.

Fig. 517. Branching trunk, 49 feet long, supposed to have belonged to L. Sternbergii. (Foss. Flo., 203.)

Fig. 518. Branching stem with bark and leaves of $L$. Sternbergii. (Foss. Flo., 4.)

Fig. 519. Portion of same nearer the root; natural size. (Ibid.)

represent a fossil Lepidodendron, 49 feet long, found in Jarrow Colliery, near Neweastle, lying in shale parallel to the planes of 'stratification. Fragments of others, found in the same shale, indicate, by the size of the rhomboidal scars which cover them, a still greater magnitude. The living club-mosses, of which there are about 200 species, are most abundant in tropical climates. They usually creep on the

- ground, but some stand erect, as the Lycopodium densum from New Zealand (fig. 520), which attains a height of 3 feet.

Fig. 520.
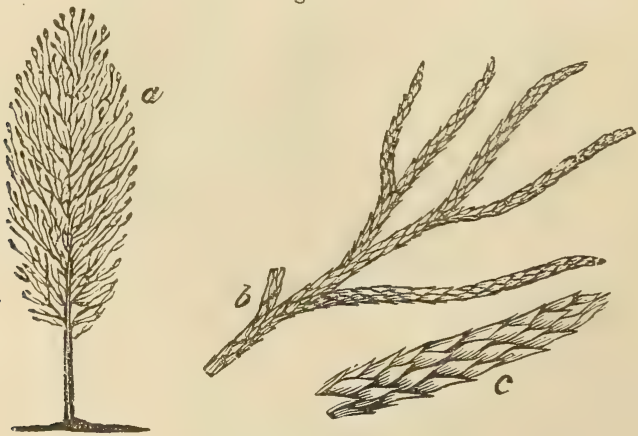

a. Iycopodium densum; banks of R. Thames, New Zealand.

b. Branch, natural size. c. Part of same, magnified. 
In the carboniferous strata of Coalbrook Dale, and in many other coal-fields, clongated crlindrical bodies, called fossil cones, named Lepidostrobus by M. Adolphe Brongniart, are met with. (See fig. 521.) They often form the nucleus of concretionary balls of clay-
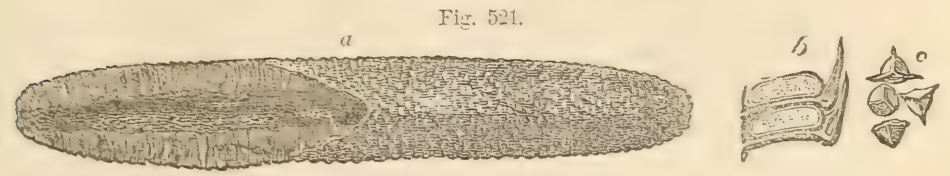

a. Lepidostrobus ornatus, Brong. Shropshire; half natural size.

0. Portion of a section, showing the large sporangia in their natural position, and each supported by its bract or scale.

c. Spores in these sporangia, highly magnified. (Hooker, Mem. Geol. Survey, vol. ii. part 2, p. 410.)

ironstone, and are well preserved, exhibiting a conical axis, around which a great quantity of scales were compactly imbricated. The opinion of M. Brongniart is now generally adopted, that the Lepidostrobus is the fruit of Lepidodendron; indeed, it is not uncommon in Coalbrook Dale and elsewhere to find these stiobili or fruits terminating the tip of a branch of a well-characterized Lepidodendron.

Equisetacece.-To this family belong two fossil species of the Coal, one called Equiectum infundibuliforme by Bronguiart, and found also in Nova Scotia, which has sheaths, regularly toothed, ribbed, and overlapping like those on the young fertile stems of Equisetum flu-. viatile. It was much larger than any living "Horsetail." The Equisetum gigentemin, diseorered by Humboldt and Bonpland in South America, attained a height of about 5 feet, the stem being an inch in diameter; but more recently Gardner has met with one in Brazil 15 feet high, and Meren gires the height of $E$. Bogotense in Chili as 15 to 20 feet.

Calamites.-The fossil plants so called were originally classed by most botanists as crrptogamous, being regarded as gigantic Equiseta;

Fig. 5.2.

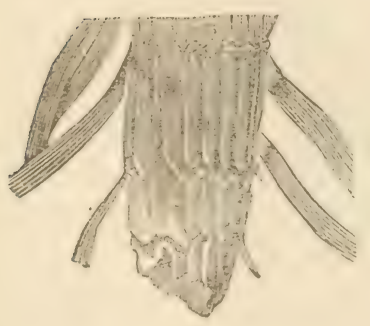

Calamites cannaformis, Schlot. (Foss, Flo., 79.) Common in English cosl.
Fig. 5.2.

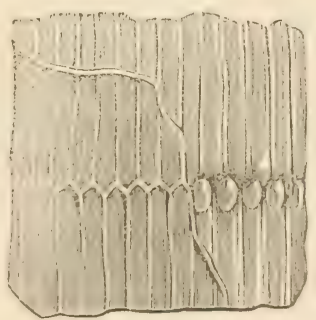

Calamites Sucoroii, Brong.; natural size. Common in coal throughout Europe.
Fig. 524.

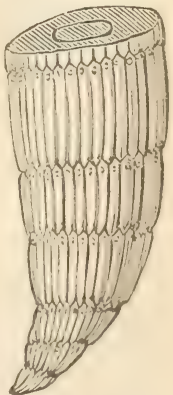

Radical termination of a Calamite. Nova Scotia. 
for, like the common "horsetail," they usually exhibit little more than hollow jointed stems, furrowed externally. (See figs. 522, 523, 524.)

Mr. Salter stated to me many years ago his conviction that the calamite as frequently represented by palæontologists was in an inverted position, and that the conical part given as the top of the stem was in truth the root. This point Dr. Dawson and I had opportunities of testing in Nova Scotia, in 1853, where we saw many erect calamites, having their radical termination as in the foregoing figure (fig. 524). The scars, from which whorls of vessels have proceeded, are observed at the upper, not the lower, end of each joint or internode.* The specimen (fig. 522), therefore, is no doubt the lower end of the plant, and I have therefore reversed its position as given in the work of Lindley and Hutton.

M. Adolphe Brongniart, following up the discoveries of Germar and Corda, has shown in his "Genres de Végétaux Fossiles," 1849, that many Calamites cannot belong to the Equiseta, nor probably to any tribe of flowerless plants. He conceives that they are more nearly allied to the Gymnospermous Dicotyledons. They possessed a central pith, surrounded by a ligneous cylinder, which was divided by regular medullary rays. This cylinder was surrounded in iurn by a thick bark. Of fossil stems having this structure Brongniart formed his genus Calamodendron, which includes many species re-

Fig. 525 .

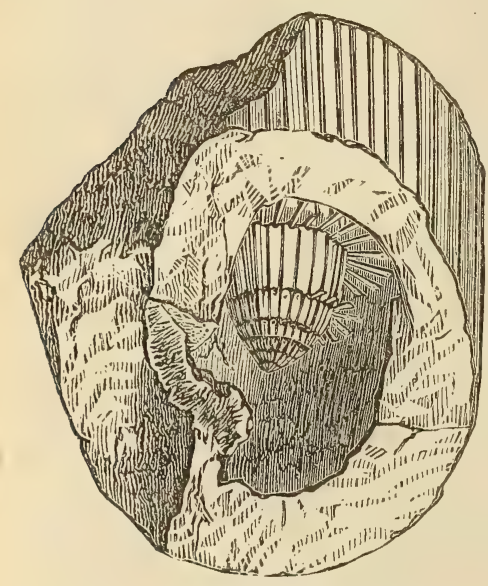

Portion of a Calamite, near the base, showing the external cylinder, connected by radiating vessels with the cast of the pith.

Communicated by Prof, C. Williamson. ferred by Cotta, Petzholdt, and Unger to the genus Calamitea. The Calamodendron is described as smooth externally, its pith being articulated and marked with deep external vertical striæ, agreeing, in short, with what geologists commonly call a Calamite. Since the appearance of Brongniart's essay, Mr. E. W. Binney has made many important discoveries on the same subject; and Mr. J. S. Dawes has published a more complete account of this singular fossil. $\nmid$ Their views have been confirmed by Professor Williamson of Manchester, who has communicated to me a specimen figured in the annexed cut (fig. 525), in which we see 
an internal pith answering in character to the Calamodendron, and yet having outside of it another jointed cylinder vertically grooved on its outer surface, so that in the same stem we have one calamite enveloping another. Yet that they both formed part of the same plant is proved by the following circumstances:-1st. Near each articulation of the pith radiating spokes are seen to proceed and penetrate the ligneous zone. One complete whorl or circle of these radii is visible in the foregoing figure near the bottom of the hollow carity, whilst another and superior whorl is incomplete; several radii, corresponding to the first, remaining, while the rest have been broken away, their place being shown by scars which they have left. 2 dly. In addition to these whorls, called medullary by Professor Williamson, there are seen in other specimens a set of true or ordinary medullary rays. 3dly. The woody zone, penetrated both by the spokelike vessels before mentioned and by the medullary rays, is usually reduced to brown carbonaceous matter, preserving merely a tendency to break in longitudinal slips, but in some specimens its fibrous tissue is retained, and resembles that of Dadoxylon. 4thly. Outside of this zone again is another cylinder, supposed to have been originally a thick cellular bark, nearly equal to one-third of the whole stem in diameter, grooved and jointed externally like the pith.

In conclusion, I may remark that these discoveries make it more and more doubtful to what family the greater number of Calamites should be referred. Their internal organization, says Professor Williamson, was very peculiar; for while they exhibit remarkable affinities with gymnospermous dicotyledons, the arrangement of their tissues differs widely from that of all known forms of gymnosperms.

Asterophyllites.-The graceful plant represented in the annexed figure is supposed by M. Brongniart to be a branch of the Calamodendron, and he infers from its pith and medullary rays that it was

Fig. 526.

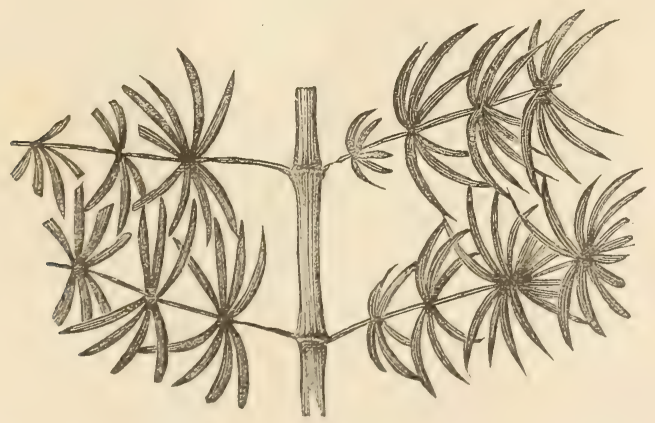

Asterophyllites foliosus. (Foss. Flo., 25.) Coal-measures, Newcastle.

dicotyledonous. It appears to have been allied, by the nature of its tissue, to the gymnogens, and to Sigillari:. But under the head of 
Asterophyllites many vegetable fragments have been grouped which probably belong to different genera. They have, in short, no character in common, except that of possessing narrow, verticillate, oneribbed leaves. Dr. Newberry, of Ohio, has discovered in the coal of that country fossil stems which in their upper part bear wedge-shaped leaves, corresponding to Sphenophyllum, while below the leaves are stalk-like and capillary, and would have been called Asterophyllites if found detached. From this he infers that Sphenophyllum was an aquatic plant, the superior and floating leaves of which were broad, and possessed a compound nervation, while the inferior or submersed leaves were linear and one-ribbed. "This supposition," he adds, "is further strengthened by the extreme length and tenuity of the branches of this apparently herbaceous plant, which would seem to have required the support of a denser medium than air." *

Sigillaria.-A large portion of the trees of the Carboniferous period belonged to this genus, of which about thirty-five species are known. The structure, both internal and external, was very peculiar, and, with reference to existing types, very anomalous. They were formerly referred, by M. Ad. Brongniart, to ferns, which they resemble in the scalariform texture of their vessels, and, in some degree, in the form of the cicatrices left by the base of the leaf-stalks

Fig. 527.

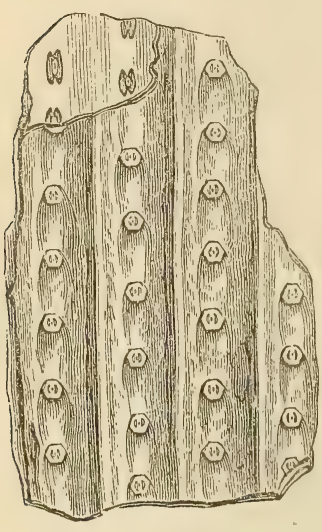

Sigillaria lovigata, Brong. which have fallen off (see fig. 527). But with these points of analogy to cryptogamia, they combine an internal organization much resembling that of cycads, and some of them are ascertained to have had long linear leaves, quite unlike those of ferns. They grew to a great height, from 30 to 60 , or even 70 feet, with regular cylindrical stems, and without branches, although some species were dichotomous towards the top. Their fluted trunks, from 1 to 5 feet in diameter, appear to have decayed more rapidly in the interior than externally, so that they became hollow when standing; and when thrown prostrate on the mud, they were squeezed down and flattened. Hence, we find the bark of the two opposite sides (now converted into bright shining coal) to constitute two horizontal layers, one upon the other, half an inch, or an inch, in thickness. These same trunks, when they are placed obliquely or vertically to the planes of stratification, retain their original rounded form, and are uncompressed, the cylinder of bark having been filled with sand, which now affords a cast of the interior. 
Dr. Hooker still inclines to the belief that the Sigillarice may have been cryptogamous, though more highly developed than any flowerless plants now liring. The scalariform structure of their vessel agrees precisely with that of ferns.

Stigmaria. - This fossil, the importance of which has already been pointed out, was formerly conjectured to be an aquatic plant. It is now ascertained to be the root of Sigillaria. The connection of the roots with the stem, previously suspected, on botanical grounds, by Brongniart, was first proved, by actual contact, in the Lancashire coalfield, by Mr. Binney. The fact has lately been shown, even more distinctly, by Mr. Richard Brown, in his description of the Stigmarice occurring in the underclays of the coal-seams of the Island of Cape Breton, in Nova Scotia.

In a specimen of one of these, represented in the annexed figure (fig. 528), the spread of the roots was sixteen feet, and some of them sent out rootlets, in all directions, into the surrounding clay.

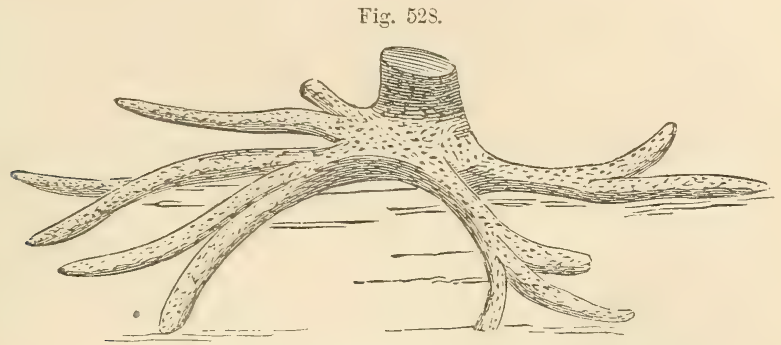

Stigmaria attached to a trunk of Sigillaria.*

In the sea-cliffs of the South Joggins in Nova Scotia I examined several erect Sigillarice, in company with Dr. Dawson, and we found that from the lower extremities of the trunk they sent out Stigmaria as roots. All the stools of the fossil trees dug out by us divided into four parts, and these again bifureated, forming eight roots, which were also dichotomous when traceable far enough.

The cylindrical rootlets formerly regarded as leaves are now shown by more perfect specimens to hare been originally attached to the root by fitting into deep cylindrical pits. In the fossil there is rarely any trace of the form of these carities, in consequence of the shrinkage of the surrounding tissues. Where the rootlets are removed nothing remains on the surface of the Stigmaria but rows of mammillated tubercles (see figs. 529, 530), which have formed the base of each rootlet. These protuberances may possibly indicate the place of a joint at the lower extremity of the rootlet. Rows of these tubercles are arranged spirally round each root, which have always a medullary axis and

* The trunk in this case is referred by Mr. Brown to Lepidodendron, but his illustrations seem to show the usual markings assumed by Sigillaria near its base. 
Fig. 529.

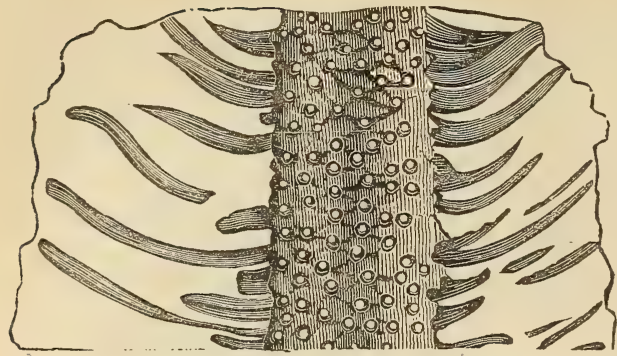

Fig. 530.

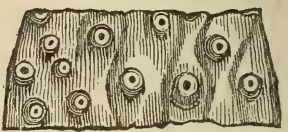

Surface of another individual of same species, showing form of tubercles. (Foss. Flo., 34.)

Stigmama ficoides, Brong. $\frac{1}{4}$ nat. size. (Foss. Flo., 32).

woody system much resembling that of Sigillaria, the structure of the vessels being, like it, scalariform.

Coniferce.-The coniferous trees of this period are referred to five genera; the woody structure of some of them showing that they were allied to the Araucarian division of pines, more than to any of our common European firs. Some of their trunks exceeded 44 feet in height. Many, if not all of them, seem to have differed from living Coniferce in having large piths ; for Professor Williamson has demonstrated the fossil of the coal-measures called Sternbergia to be the pith of these trees, or rather the cast of cavities formed by the shrinking

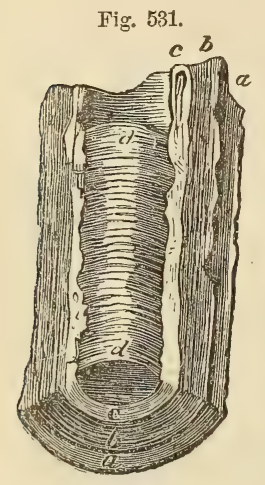

Fig. 531. Fragment of coniferous wood, Dadoxylon, Endlicher, fractured longitudinally; from Coalbrook Dale. W. C. Williamson.*

a. Bark,

$b$. Woody zone or fibre (pleurenchyma).

c. Medulla or pith.

d. Cast of hollow pith, or "Sternbergia."

Fig. 532.

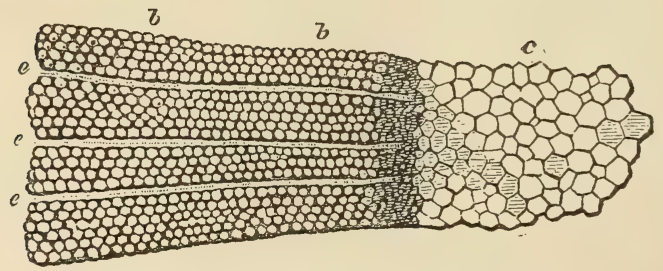

Magnified portion of fig. 531; transverse section.

$\begin{array}{lll}c . \text { Pith. } & b, b \text {. Woody fibre. } & e, e . \text { Medullary rays. }\end{array}$

* Mañchester Philos. Mem., vol. ix., 1851. 
or partial absorption of the original medullary axis (see figs. 531 and 532). This peculiar type of pith is observed in living plants of very different families, such as the common Walnut and the White Jasmine, in which the pith becomes so reduced as simply to form a thin lining of the medullary cavity, across which transverse plates of pith extend horizontally, so as to divide the cylindrical hollow into discoid interspaces. When these interspaces have been filled up with inorganic matter, they constitute an axis to which, before their true nature was known, the provisional name of Sternbergia $(d, d$, fig. 531) was given.

In the above specimen the structure of the wood ( $b$, figs. 531 and 532 ) is coniferous, and the fossil is referable to Endlicher's fossil genus Dadoxylon.

The fossil named Trigonocarpon (figs. 553 and 554), formerly supposed to be the fruit of a palm, may now, according to Dr. Hooker, be referred, like the Sternbergia, to the Coniferce. Its geological importance is great, for so abundant is it in the Coal-Measures, that in certain localities the fruit of some species may be procured by the bushel; nor is there any part of the formation where they do not occur, except the underclays and limestone. The sandstone, ironstone, shales, and coal itself, all contain them. Mr. Binney has at length found in the clay-ironstone at Lancashire several specimens displaying structure, and from these, says Dr. Hooker, we learn that the Trigonocarpon belonged to that large section of existing coniferous plants which bear fleshy solitary fruits, and not cones. It resembled very closely the fruit of the Chinese genus Salisburia, one of the Yew tribe, or Taxoid conifers. In five of the fossil specimens there is evi-

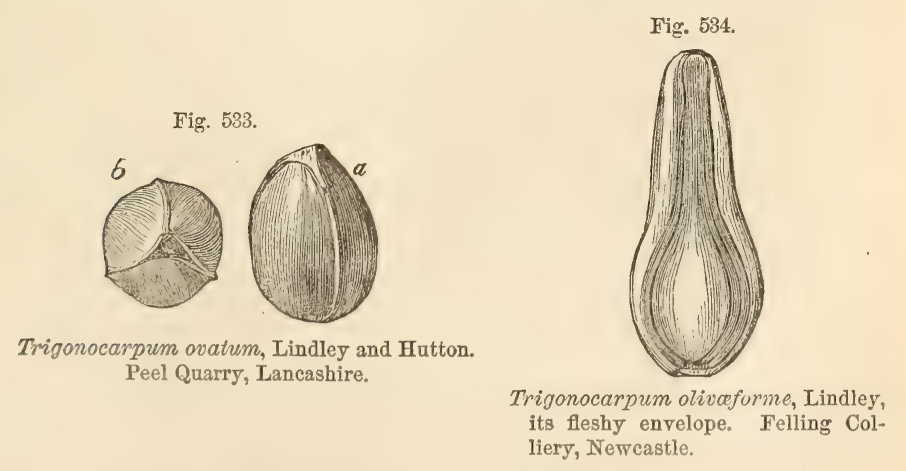

dence of four distinct integuments, and of a large internal cavity filled with carbonate of lime and magnesia, and probably once occupied by the albumen and embryo of the seed. The general form of the fossil when perfect is an elongated ovoid, rather larger than a bazel-nut. The exterior integument is very thick and cellular, and was no doubt once fleshy (see fig. 534). It alone is produced beyond the seed, and forms the beak. The second coat was thinner, but hard, and marked by 
three ridges. This coat, being all that commonly remains in a fossil state, has suggested the name of Trigonocarpon. Within this were the third and fourth coats, both of which are very delicate membranes, and may possibly have been two plates belonging to one membrane.

Grade of the Carboniferous Flora.-On the whole, these fruits, says Dr. Hooker, are referable to " a highly developed type, exhibiting extensive modifications of elementary organns for the purpose of their adaptation to special functions, and these modifications are as great, and the adaptations as special, as any to be found amongst analogous fruits in the existing vegetable world." * Professor Williamson, in his paper on Sternbergia, has likewise remarked that its structure was complex, and that "at a period so early as the carboniferous all the now-existing forms of vegetable tissue appear to have been created." These observations deserve notice, because a question has arisen, whether the Coniferce hold a high or a low position among flowering plants - a point bearing directly on the theory of progressive development. By some botanists all the Gymnospermous Dicotyledons are regarded as inferior in grade to the Angiosperms. Others hold, with Dr. Hooker, that the Gymnosperms are not inferior in rank, having every typical character of the dicotyledons highly developed. Thus Coniferæ have flowers, and are propagated by seeds which are developed through the mutual action of the stamens and ovules; they have dicotyledonous and polycotyledonous embryos, and germinate in the same manner as other dicotyledons. The seed-vessel (or ovary) is not closed, but this is also the case in some genera of angiosperms, in which the ovary is open before or after impregnation, so that this character cannot be relied on as constituting a fundamental difference in structural development. The Coniferæ are exogenous, and have the same arrangement of pith, wood, bark, and medullary rays as have the typical dicotyledonous trees. Whether the woody fibre with discs characteristic of Coniferæ be a more or a less complex tissue than the spiral vessels, is a controverted point. As the spiral vessels occur in the young shoots, and are lost in the mature growth of some plants, and as they appear in many acrogens, they do not seem to mark a high development. In fine, there is much ambiguity in deciding what should or should not be called high or low in vegetable structure, and physiologists entertain very different abstract ideas as to the perfection of certain organs and their relative functional-importance, even where the function is clearly ascertained, It is enough for the geologist to know, that fossil Coniferæ abound in the oldest rocks, yielding a considerable number of vegetable remains, and that plants of this order lay claim, if not to the highest, at least to so high a place in the scale of regetable life, as to preclude us from characterizing the carboniferous flora as consisting of imperfectly developed plants.

* Proceedings of the Royal Society, vol, vii., March, 1854, p. 28. 
Although our data are confessedly too defective to entitle us to generalize respecting the entire regetable creation of this era, yet we mar affirm that so firm as it is known it differed widely from any flora notr existing. The comparatire rarity of Monocotyledons and of Dicotrledonous Angiosperms seems clear, and the abundance of Ferns and Lreopods may justify Adolphe Bronguiart in calling the primary periods the age of Acrogens * ("le règne des Acrogens"). As to the Sigillarire and Calamites, they seem to have been distinct from all tribes of now-existing plants. That the abundance of ferns implies a moist atmosphere, is admitted by all botanists; but no safe conclusion, says Hooker, can be drawn from the Coniferæe alone, as they are found in hot and dry and in cold and dry climates, in hot and moist and in cold and moist regions. In New Zealand the Coniferæ attain their maximum in numbers, constituting $\frac{1}{62} \mathrm{~d}$ part of all the florrering plants; whereas in a mide district around the Cape of Good Hope they do not wim $\frac{1}{1006}$ th of the phenogamic flora. Besides the conifers, many species of ferns flourish in New Zealand, some of them arborescent, together with many lycopodiums; so that a forest in that country may make a nearer approach to the carboniferous vegetation than any other now existing on the globe.

Angiosperms.-Some of the grass-like leaves termed Poacites, having fine longitudinal striæ, are conjectured to belong to Monocotyledons; but the determination is doubtful, as some of them may be the leaves of Lepidodendra, others the stems of Ferns. The curious plants called Antholithes by Lindley have usually been considered to be flower-spikes, haring what seems a calyx and linear petals (see fig. 535). Dr. Hooker suggested that they might be tufts of young leaves like those of the larch, but, after seeing the most perfect specimens, he no longer thought them oniferous, but resembling rather the spike of a highly organized plant in full flower, such Fir. 535.

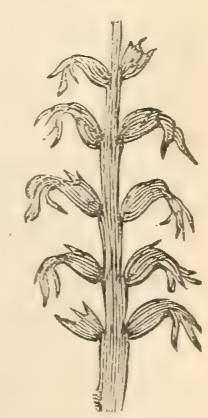
pite Antholithes. Felling as one of the Bromeliaceæ, to which Professor Lind-Colliery, Newcastle. ley first compared them. In the absence, however, of all structure, the affinities of these fossils are still considered very uncertain.

Coal, how formed.-Erect trees.-I shall now consider the manner in which the abore-mentioned plants are imbedded in the strata, and how they mar hare contributed to produce coal. Professor Göppert, after examining the fossil vegetables of the coal-fields of Germany, has detected, in beds of pure coal, remains of plants of erery family hitherto kiown to occur fossil in the carboniferous rocks. Many seams, he remarks, are rich in Sigillarice, Lepedodendra, and Stigmarice, the latter in such abundaces as to appear to form the bulk of 
the coal. In some places, almost all the plants were calamites, in others ferns." "Some of the plants of our coal," says Dr. Buckland, "grew on the identical banks of sand, silt, and mud which, being now indurated to stone and shale, form the strata that accompany the coal; whilst other portions of these plants have been drifted to various distances from the swamps, savannahs, and forests that gave them birth, particularly those that are dispersed through the sandstones, or mixed with fishes in the shale beds." "At Balgray, three miles north of Glasgow," says the same author, "I saw in the year 1824, as there still may be seen, an unequivocal example of the stumps of several stems of large trees, standing close together in their native place, in a quarry of sandstone of the coal-formation." $\dagger$

Between the years 1837 and 1840, six fossil trees were discovered in the coal-fields of Lancashire, where it is intersected by the Bolton railway. They were all in a vertical position, with respect to the plane of the bed which dips about $15^{\circ}$ to the south. The distance between the first and the last was more than 100 feet, and the roots of all were imbedded in a soft argillaceous shale. In the same plane with the roots is a bed of coal, eight or ten inches thick, which has been found to extend across the railway, or to the distance of at least ten yards. Just above the covering of the roots, yet beneath the coal seam, so large a quantity of the Lepidostrobus variabilis was discovered enclosed in nodules of hard clay, that more than a bushel was collected from the small openings around the base of the trees (see figure of this genus, p. 471). The exterior trunk of each was marked by a coating of friable coal, varying from one quarter to three quarters of an inch in thickness; but it crumbled away on removing the matrix. The dimensions of one of the trees is $15 \frac{1}{2}$ feet in circumference at the base, $7 \frac{1}{2}$ feet at the top, its height being 11 feet. All the trees have large spreading roots, solid and strong, sometimes branching, and traced to a distance of several feet, and presumed to extend much farther. Mr. Hawkshaw, who has described these fossils, thinks that, although they were hollow when submerged, they may have consisted originally of hard wood throughout; for solid dicotyledonous trees, when prostrated in tropical forests, as in Venezuela, on the shore of the Caribbean Sea, were observed by him to be destroyed in the interior, so that little more is left than an outer shell, consisting chiefly of the bark. This decay, he says, goes on most rapidly in low and flat tracts, in which there is a deep rich soil and excessive moisture, supporting tall forest trees and large palms, below which bamboos, canes, and minor palms flourish luxuriantly. Such tracts, from their lowness, would be most easily submerged, and their dense vegetation might then give rise to a seam of coal.\$

In a deep valley near Capel-Coelbren, branching from "the higher

* Quart. Geol, Journ., vol. v., Mem., p. 17.

† Anniv. Address to Geol. Soc., 1840.

‡ Hawkshaw, Geol. Trans., Second Series, vol. vi. pp. 173, 177, pl. 17. 
part of the Swansea valley, four stems of upright Sigillarioe were seen in 1838, piercing through the coal-measures of S. Wales; one of them was 2 feet in diameter, and one $13 \frac{1}{2}$ feet high, and they were all found to terminate downwards in a bed of coal. "They appear," says Sir H. De la Beche, "to have constituted a portion of a subterranean forest at the epoch when the lower carboniferous strata were formed." *

In a colliery near Newcastle, say the authors of the Fossil Flora, a great number of Sigillarice were placed in the rock as if they had retained the position in which they grew. Not less than thirty, some of them 4 or 5 feet in diameter, were visible within an area of 50 yards square, the interior being sandstone, and the bark having been converted into coal. The roots of one individual were found imbedded in shale; and the trunk, after maintaining a perpendicular course and circular form for the height of about ten feet, was then bent over so as to become horizontal. Here it was distended laterally, and flattened so as to be only one inch thick, the flutings being comparatively distinct. $\uparrow$ Such vertical stems are familiar to our miners, under the name of coal-pipes. One of them, 72 feet in length, was discovered, in 1829, near Gosforth, about five miles from Newcastle, in coal-grit, the strata of which it penetrated. The exterior of the trunk was marked at intervals with knots, indicating the points at which branches had shot off. The wood of the interior had been converted into carbonate of lime; and its structure was beautifully shown by cutting transverse slices, so thin as to be transparent. (See p. 40.)

- These "coal pipes" are much dreaded by our miners, for almost every year in the Bristol, Newcastle, and other coal-fields, they are the cause of fatal accidents. Each cylindrical cast of a tree, formed of solid sandstone, and increasing gradually in size towards the base, and being without branches, has its whole weight thrown downwards, and receives no support from the coating of friable coal which has replaced the bark. As soon, therefore, as the cohesion of this external layer is, overcome, the heavy column falls suddenly in a perpendicular or oblique direction from the roof of the gallery whence coal has been extracted, wounding or killing the workman who stands below. It is strange to reflect how many thousands of these trees fell originally in their native forests in obedience to the law of gravity; and how the few which continued to stand erect, obeying, after myriads of ages, the same force, are cast down to immolate their human victims.

It has been remarked, that if', instead of working in the dark, the miner was accustomed to remove the upper covering of rock from each seam of coal, and to expose to the day the soils on which ancient forests grew, the evidence of their former growth would be obvious. Thus in South Staffordshire a seam of coal was laid bare in the year 1844, in what is called an open work at Parkficld Colliery, near

* Geol. Report on Cornwall, Devon, and Somerset, p. 143.

† Lindley and Hutton, Foss. Flo., Part. 6, p. 150. 
Wolverhampton. In the space of about a quarter of an acre the stumps of no less than seventy-three trees with their roots attached appeared, as shown in the annexed plan (fig. 536), some of them more

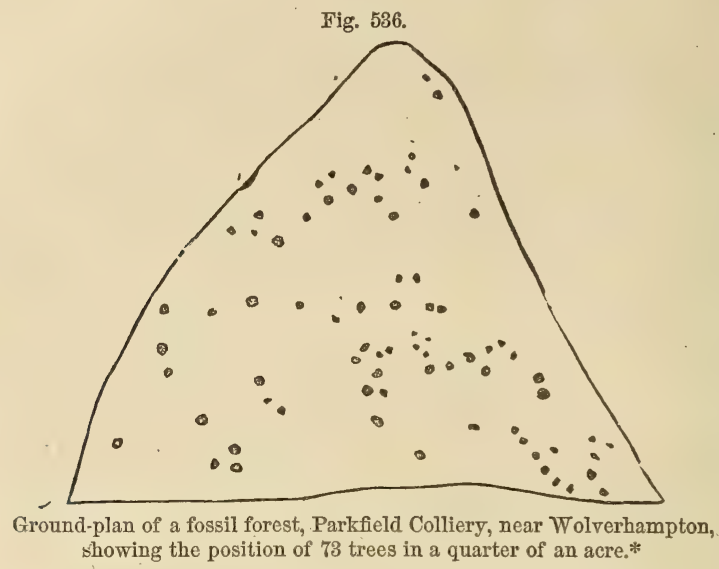

than 8 feet in circumference. The trunks broken off close to the root, were lying prostrate in every direction, often crossing each other. One of them measured 15, another 30 feet in length, and others less. They were invariably flattened to the thickness of one or two inches, and converted into coal. Their roots formed part of a stratum of coal 10 inches thick, which rested on a layer of clay 2 inches thick, below which was a second forest, resting on a 2-foot seam of coal. Five feet below this again was a third forest with large stumps of Lepidodendra, Calamites, and other trees.

In the account given, in 1821, by M. Alex. Brongniart $\uparrow$ of the coalmine of Treuil, at St. Etienne, near Lyons, he states that distinct horizontal strata of micaceous sandstone are traversed by vertical trunks of monocotyledonous vegetables, resembling bamboos or large Equiseta (fig. 537). Since the consolidation of the stone, there has been here and there a sliding movement, which has broken the continuity of the stems, throwing the upper parts of them on one side, so that they are often not continuous with the lower.

From these appearances it was inferred that we have here the monuments of a submerged forest. I formerly objected to this conclusion, suggesting that, in that case, all the roots ought to have been found at one and the same level, and not scattered irregularly through the mass. I also imagined that the soil to which the roots were attached should have been different from the sandstone in which the trunks are enclosed. Having, however, seen calamites near Pictou, in Nova Scotia, buried at various heights in sandstone and in similar erect attitudes, $I$ have 
Fig. 537.

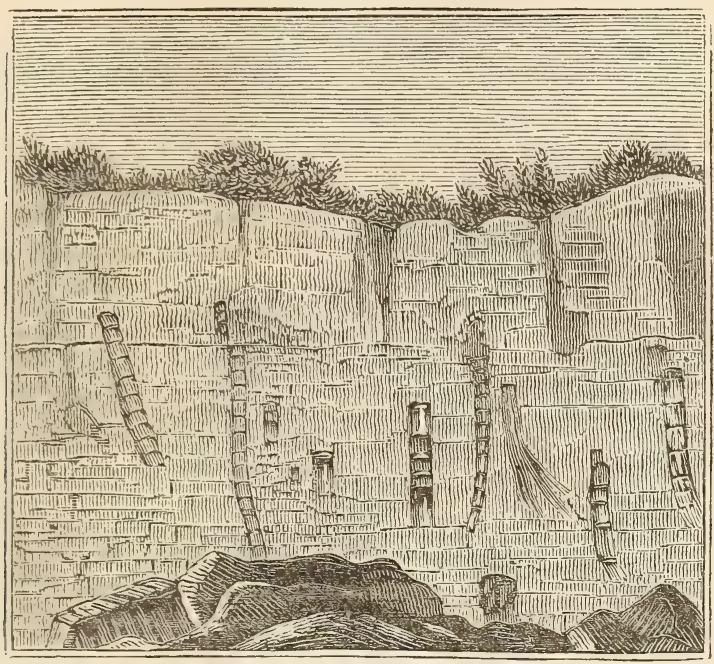

Section showing the erect position of fossil trees in coal-sandstone at St. Etienne. (Alex. Brongniart.)

now little doubt that M. Brongniart's view was correct. These plants seem to have grown on a sandy soil, liable to be flooded from time to time, and raised by new accessions of sediment, as may happen in swamps near the banks of a large river in its delta. Trees which delight in marshy grounds are not injured by being buried several feet deep at their base; and other trees are continually rising up from new soils, several feet above the level of the original foundation of the morass. In the banks of the Mississippi, when the water has fallen, I have seen sections of a similar deposit in which portions of the stumps of trees with their roots in situ appeared at many different heights.*

When I visited, in 1843, the quarries of Treuil above mentioned, the fossil trees seen in fig. 537 were removed, but I obtained proofs of other forests of erect trees in the same coalfield.

Snags.-In 1830, a slanting trunk rras exposed in Craigleith quarry, near Edinburgh, the total length of which exceeded 60 feet. Its diameter at the top was about 7 inches, and near the base it measured 5 feet in its

Fig. 538.

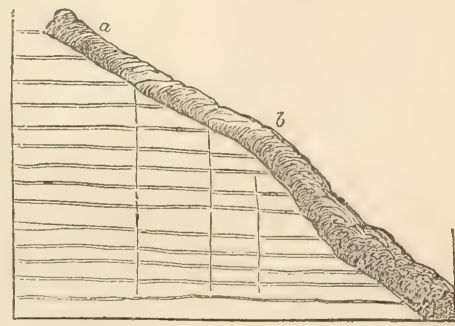

Inclined position of a fossil tree, cutting through horizontal beds of sandstone, Craigleith quarry, Edinburgh. Angle of inclination from $a$ to $b$ $27^{\circ}$. 
greater, and 2 feet in its lesser width. The bark was converted into a thin coating of the purest and finest coal, forming a striking contrast in color with the white quartzose sandstone in which it lay. The foregoing cut (fig. 538) represents a portion of this tree, about 15 feet long, which I saw exposed in 1830 , when all the strata had been removed from one side. The beds which remained were so unaltered and undisturbed at the point of junction, as clearly to show that they had been tranquilly deposited round the tree, and that the tree had not subsequently pierced through them while they were yet in a soft state. They were composed chiefly. of siliceous sandstone, for the most part white; and divided into laminæ so thin, that from six to fourteen of them might be reckoned in the thickness of an inch. Some of these thin layers were dark, and contained coaly matter; but the lowest of the intersected beds were calcareous. The tree could not have been hollow when imbedded, for the interior still preserved the woody texture in a perfect state, the petrifying matter being, for the most part, calcareous.* It is also clear that the lapidifying matter was not introduced laterally from the strata through which the fossil passes, as most of these were not calcareous. It is well known that, in the Mississippi and other great American rivers, where thousands of trees float annually down the streams, some sink with their roots downwards, and become fixed in the mud. Thus placed they have been compared to a lance in rest; and so often do they pierce through the bows of vessels which run against them, that they render the navigation extremely dangerous. Mr. Hugh Miller mentions four other huge trunks exposed in quarries near Edinburgh, which lny diagonally across the strata at an angle of about $30^{\circ}$, with their lower or heavier portions downwards, the roots of all, save one, rubbed off by attrition. One of these was 60 and another. 70 feet in length, and from 4 to 6 feet in diameter.

The number of years for which the trunks of trees, when constantly submerged, can resist decomposition, is very great; as we might suppose from the durability of wood, in artificial piles, permanently covered by water. Hence these fossil snags may not imply a rapid accumulation of beds of sand, although the channel of a river or part of a lagoon is often filled up in a very few years.

Nova Scotia.-One of the finest examples in the world of a succession of fossil forests of the Carboniferous period, laid open to view in a natural section, is that seen in the lofty cliffs called the South Joggins, bordering the Chignecto Channel, a branch of the Bay of Fundy, in Nova Scotia. $\nmid$

In the annexed section (fig. 539), which I examined in July, 1842,

* See figures of texture, Witham, Foss. Veget., pl. 3.

$\uparrow$ See Lyell's Travels in N. America, vol. ii. p. 179; and Dawson, Geol. Journ., No. 37. 
the beds from $c$ to $i$ are seen all dipping the same way, their average inclination being at an angle of $24^{\circ}$ S.S.W. The vertical height of the cliffs is from 150 to 200 feet; and between $d$, and $g$, in which space I observed seventeen trees in an upright position, or, to speak more correctly, at right angles to the planes of stratification, I counted nineteen seams of coal, varying in thickness from 2 inches to 4 feet. At low tide a fine horizontal section of the same beds is exposed to view on the beach. The thickness of the beds alluded to, between $d$ and $g$, is about 2500 feet, the erect trees consisting chiefly of large Sigillarice, occurring at ten distinct levels, one above the other; but Mr. Logan, who afterwards made a more detailed survey of the same line of cliffs, found erect trees at seventeen levels, extending through a vertical thickness of 4515 feet of strata; and he estimated the total thickness of the carboniferous formation, with and without coal, at no less than 14,570 feet, everywhere devoid of marine organic remains.* The usual height of the buried trees seen by me was from 6 to 8 feet; but one trunk was about 25 feet high and 4 feet in diameter, with a considerable bulge at the base. In no instance could I detect any trunk intersecting a layer of coal, however thin; and most of the trees terminated downwards in seams of coal. Some few only were based in clay and shale; none of them, except calamites, in sandstone. The erect trees, therefore, appeared in general to have grown on beds of coal. In the underclays Stigmaria abounds.

In 1852 Dr. Dawson and the author made a detailed examination of one portion of the strata, 1400 feet thick, where the coal-seams are most frequent, and found evidence of root-bearing soils at sixty-eight different levels. Like the seams of coal which often cover them, these root-beds or old

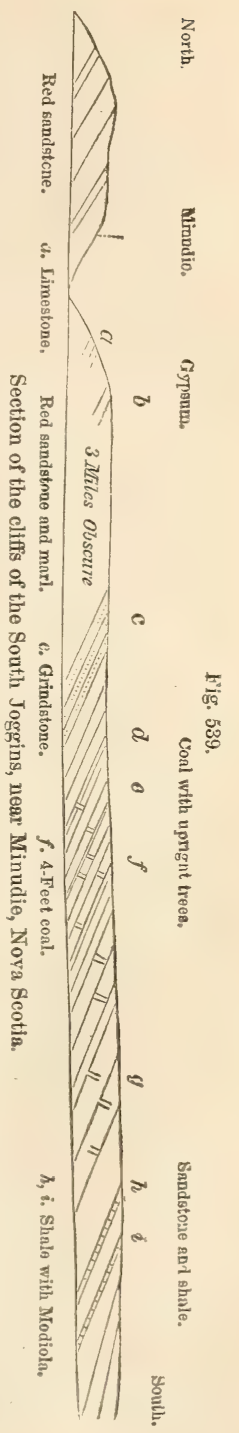
soils are at present the most destructible masses in the whole cliff, the sandstones and laminated shales being harder and more capable of resisting the action of the waves and the weather. Originally the reverse was doubtless true, for in the existing delta of the Mississippi those clays in which the innumerable roots of the deciduous cypress and other swamp trees ramify in all directions are seen to 
withstand far more effectually the undermining power of the river, or of the sea at the base of the delta, than do beds of loose sand or layers of mud not supporting trees.

This fact may explain why seams of coal have so often escaped denudation, and remain continuous over wide areas, since the tough roots, now turned to coal, which once traversed them, would enable them to resist a current of water, whilst other members of the coalformation, in their original and unconsolidated state of sand and mud, would be readily removed.

In regard to the plants, they belonged to the same genera and most of them to the same species, as those met with in the distant coralfields of Europe. In the sandstone, which filled their interiors, I frequently observed fern-leaves, and sometimes fragments of Stigmaria, which had evidently entered together with sediment after the trunk had decayed and become hollow, and while it was still standing under water. Thus the tree, $a b$, fig. 540 , the same which is represented at $a$, fig. 541 , or in the bed $e$ in the larger section, fig. 539, is a hollow

Fìg. 540.

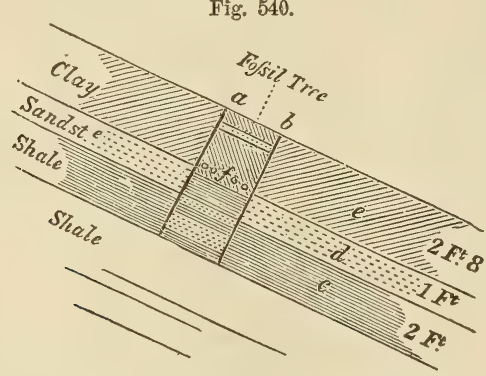

Fossil tree at right angles to the planes of stratification. Coal-measures, Nova Scotia.

Fig. 511.

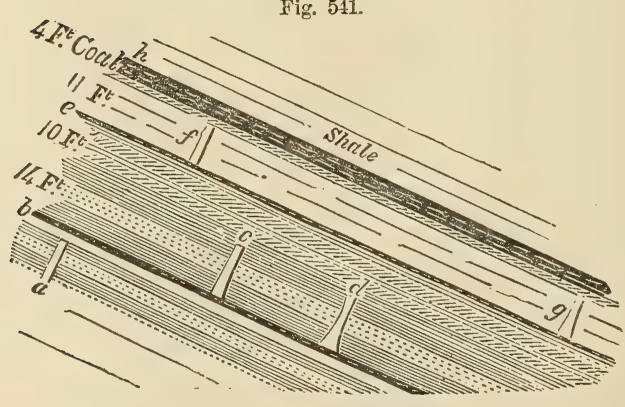

Erect fossil trees. Coal-measures, Nova Scotia.

trunk 5 feet 8 inches in length, traversing various strata, and cut off at the top by a layer of clay 2 feet thick, on which rests a seam of coal ( $b$, fig. 541) 1 foot thick. On this coal again stood two large 
trees $(c$ and $d)$, while at a greater height the trees $f$ and $g$ rest upon a thin seam of coal $(e)$, and abore them is an underclay, supporting the 4-feet coal.

If we now return to the tree first mentioned (fig. 540), we find the diameter $(a b) 14$ inches at the top and 16 inches at the bottom, the length of the trunk 5 feet 8 inches. The strata in the interior consisted of a series entirely different from those on the outside. The lowest of the three outer beds which it traversed consisted of purplish and blue shale (c, fig. 540), 2 feet thick, above which was sandstone $(d) 1$ foot thick, and, above this, clay (e) 2 feet 8 inches. But in the interior were nine distinct layers of different composition : at the bottom, first, shale 4 inches, then sandstone 1 foot, then shale 4 inches, then sandstone 4 inches, then shale 11 inches, then clay $(f)$ with nodules of ironstone 2 inches, then pure clay 2 feet, then sandstone 3 inches, and, lastly, clay 4 inches. Owing to the outward slope of the face of the cliff, the section (fig. 540) was not exactly perpendicular to the axis of the tree; and hence, probably, the apparent sudden termination at the base without a stump and roots.

In this example the layers of matter in the inside of the tree are more numerous than those without; but it is more common in the coal-measures of all countries to find a cylinder of pure sandstonethe cast of the interior of a tree-intersecting a great many alternating beds of shale and sandstone, which originally enveloped the trunk as it stood erect in the water. Such a want of correspondence in the materials outside and inside, is just what we might expect if we reflect on the difference of time at which the deposition of sediment will take place in the two cases; the imbedding of the tree having gone on for many years before its decay had made much progress.

In many places distinct proof is seen that the enveloping strata took years to accumulate, for some of the sandstones surrounding erect sigillarian trunks support at different levels roots and stems of Calamites; the Calamites having begun to grow after the older Sigillarice had been partially buried.

The general absence of structure in the interior of the large fossil trees of the Coal implies the very durable nature of their bark, as compared with their woody portion. The same difference of durability of bark and wood exists in modern trees, and was first pointed out to me by Dr. Dawson, in the forests of Nova Scotia, where the Canoe Birch (Betula papyracea) has such tough bark that it may sometimes be seen in the swamps looking externally sound and fresh, although consisting simply of a hollow cylinder with all the wood decayed and gone. In such cases the submerged portion is sometimes found filled with mud.

One of the erect fossil trees of the South Joggins has been shown by Dr. Dawson to have Arancarian structure, so that some Coniferce of the Coal period grew in the same swamps as Sigillarice, just as now 
the deciduous cypress (Traxodium distichum) 'abounds in the marshes of Louisiana even to the edge of the sea.

When the carboniferous forests sank below high-water mark, a species of Spirorbis or Serpula (fig. 545) attached itself to the outside of the stumps and stems of the erect trees, adhering occasionally even to the interior of the bark-another proof that the process of envelopment was very gradual. These hollow upright trees, covered with innumerable marine annelids, reminded me of a "cane-brake," as it is commonly called, consisting of tall reeds of Arundinaria macrosperma, which I saw in 1846, at the Balize, or extremity of the delta of the Mississippi. Although these reeds are freshwater plants, they were covered with barnacles, having been killed by an incursion of salt water over an extent of many acres, where the sea had for a season usurped a space previously gained from it by the river. Yet the dead reeds, in spite of this change, remained standing in the soft mud, showing how easily the Sigillarice, hollow as they were but supported by strong roots, may have resisted an incursion of the sea.

The high tides of the Bay of Fundy, rising more than 60 feet, are so destructive as to undermine and sweep away continually the whole face of the cliffs, and thus a new crop of erect fossil trees is brought into view every. three or four years. They are known to extend over a space between two or three miles from north to south, and more than twice that distance from east to west, being seen in the banks of streams intersecting the coal-field.

In Cape Breton, Mr. Richard Brown has observed in the Sydney coal-field a total thickness of coal-measures, without including the underlying millstone-grit, of 1843 feet, dipping at an angle of $80^{\circ}$. He has published minute details of the whole series, showing at how many different levels erect trees occur, consisting of Sigillarice, Lepidodendron, Calamites, and other genera. In one place eight erect trunks, with roots and rootlets attached to them, were seen at the same level, within a horizontal space 80 feet in length. Beds of coal of various thickness are interstratified. Taking into account fortyone clays, filled with roots of Stigmaria in their natural position, and eighteen layers of upright trees at other levels, there is, on the whole, clear evidence of at least fifty-nine fossil forests, ranged one above the other, in this coal-field, in the above-mentioned thickness of strata.*

The fossil shells of Cape Breton and those of the Nova Scotia section, consist of species of Unionidce, or an allied extinct family. None of them agree with any shells known in the marine carboniferous limestones. In some strata the shells of an annelid allied to the genus Spirorbis (see fig. 545) seem to indicate brackish water; but we ought never to be surprised if, in pursuing the same stratum, we should come either to a freshwater or a purely marine deposit; for this will depend

* Geol. Quart. Journ., vol. ii. p. 393 ; and vol. vi. p. 116. 
upon our taking a direction higher up or lower down the ancient river or delta deposit.

In the strata above described, the association of clays supporting upright trees, with other beds containing brackish-water shells, implies such a repeated change in the same area, from land to sea and from sea to land, that here, if anywhere, we should expect to meet with evidence of the fall of rain on ancient sea-beaches. Accordingly, rainprints were seen by Dr. Dawson and myself at various levels, but the most perfect hitherto observed were discovered by Mr. Brown near Sydney in Cape Breton. They consist of very delicate impressions

Fig. 542.

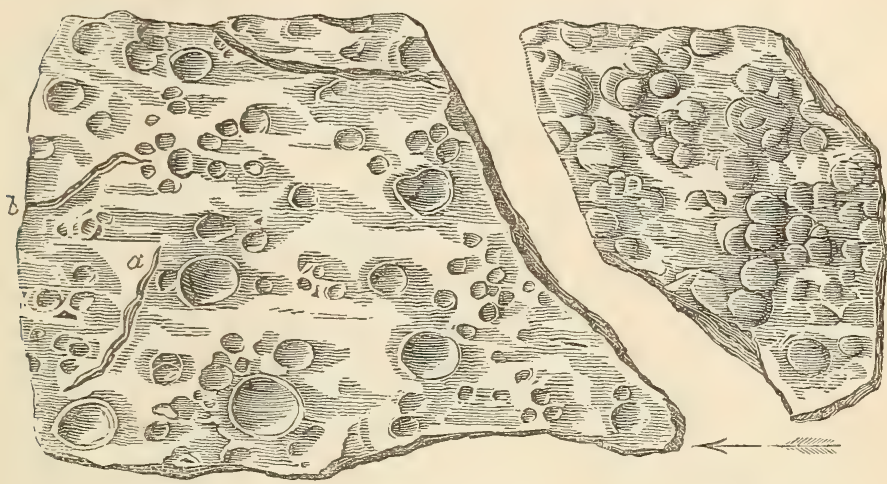

Fig. 542. Carboniferous rain-prints with worm-tracks $(a, b)$ on green shale, from Cape Breton, Nova Scotia. Natural size.

Fig. 543. Casts of rain-prints on a portion of the same slab, fig. 542, seen on the under side of an incumbent layer of arenaceous shale. Natural size.

The arrow represents the supposed direction of the shower.

Fig. 541.

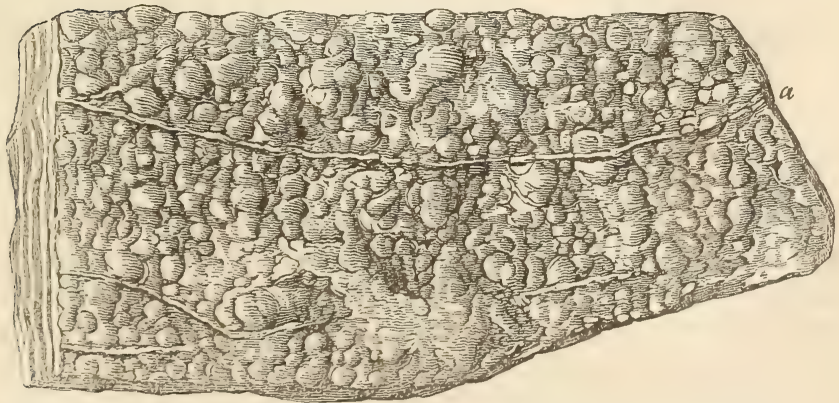

Casts of carboniferous rain-prints and shrinkage-cracks $(a)$ on the under side of a layer of sandstone, Cape Breton, Nova Scotia. Natural size.

of rain-drops on greenish slates, with several worm-tracks $(a, b$, fig. 542), such as usually accompany rain-marks on the recent mud of the Bay of Fundy, and other modern beaches. 
The casts of rain-prints in figs. 543 and 544, project from the under side of two layers, occurring at different levels, the one a sandy shale, resting on the green shale (fig. 542), the other a sandstone presenting a similar warty or blistered surface, on which are also observable some small ridges as at $\alpha$, which stand out in relief, and afford evidence of cracks formed by the shrinkage of subjacent clay, on which rain had fallen. Many of the associated sandstones are ripple-marked.

The great humidity of the climate of the Coal period had been previously inferred from the nature of its vegetation and the continuity of its forests for hundreds of miles; but it is satisfactory to have at length obtained such positive proofs of showers of rain, the drops of which resembled in their average size those which now fall from the clouds. From such data we may presume that the atmosphere of the Carboniferous period corresponded in density with that now investing the globe, and that different currents of air varied then as now in temperature, so as to give rise, by their mixture, to the condensation of aqueous vapor.

The more closely the strata productive of coal have been studied, the greater has become the force of the evidence in favor of their having originated in the manner of modern deltas. They display a vast thickness of stratified mud and fine sand without pebbles, and in them are seen countless stems, leaves, and roots of terrestrial plants, free for the most part from all intermixture of marine remains-circumstances which imply the persistency in the same region of a vast body of fresh water. This water was also charmed; like that of a great river, with an inexhaustible supply of sediment, which seems to have been transported over alluvial plains so far from the higher grounds that all coarser particles and gravel were left behind. Such phenomena imply the drainage and denudation of a continent or large island, having within it one or more ranges of mountains. The partial intercalation of brackish-water beds at certain points is equally consistent with the theory of a delta, the lower parts of which are always exposed to be overflowed by the sea, even where no oscillations of level are experienced.

The purity of the coal itself, or the absence in it of earthy particles and sand, throughout areas of vast extent, is a fact which appears very difficult to explain when we attribute each coal-seam to a vegetation growing in swamps. It has been asked how, during river inundations capable of sweeping away the leaves of ferus and the stems and roots of Sigillarice and other trees, could the waters fail to transport some fine mud into the swamps? One generation after another of tall trees grew with their roots in mud, and their leaves and prostrate trunks formed layers of vegetable matter, which was afterwards covered with mud since turned to shale. Yet the coal itself, or altered vegetable matter, remained all the while unsoiled by earthy particles. This enigma, however perplexing at first sight, may, I think, be solved by attending to what is now taking place in deltas. The dense growth 
of reeds and herbage which encompasses the margins of forest-covered swamps in the valley and delta of the Mississippi is such that the fluviatile water's, in passing through them, are filtered and made to clear themselres entirely before they reach the areas in which vegetable matter mar accumulate for centuries, forming coal if the climate be farorable. There is no possibility of the least intermixture of earthy matter in such cases. Thus in the large submerged tract called the "Sunk Country," near Nerw Madrid, forming part of the western side of the ralley of the Mississippi, erect trees have been standing ever since the year 1811-'12, killed by the great earthquake of that date; lacustrine and swamp plants hare been growing there in the shallows, and several rivers have annually inundated the whole space, and yet hare been unable to carry in any sediment within the outer boundaries of the morass, so dense is the marginal belt of reeds and brushwood. It may be affirmed that generally in the "cypress swamps" of the Mississippi no sediment mingles with the regetable matter accumulated there from the decay of trees and semi-aquatic plants. As a singular proof of this fact, I may mention that whenever any part of a swamp in Louisiana is dried up, during an unusually hot season, and the wood set on fire, pits are burnt into the ground many fect deep, or as far down as the fire can descend, without meeting with water, and it is then found that scarcely any residuum or earthy matter is left.* At the bottom of all these "cypress swamps" a bed of clay is found, with roots of the tall cypress (Taxodium distichum), just as the underelays of the coal are filled with Stigmaria.

It has been already stated that the earboniferous strata at the South Joggins, in Nora Scotia, are nearly three miles thick, and the coalmeasures are ascertained to be of rast thickness near Pictou, more than 100 miles to the eastward. If, therefore, we speculate on the probable volume of solid matter contained in the Nora Scotia coal-fields, there appears little danger of erring on the side of excess if we take the average thickness of the beds at 7500 feet, or about half that ascertained to exist in one carefully-measured section. As to the area of the coal-field, it includes a large part of New Brunswick to the west, and extends north to Prince Edward's Island, and probably to the Magdalen Isles. When we add the Cape Breton beds, and the connecting strata, which must hare been denuded or are still concealed beneath the waters of the Gulf of St. Lawrence, we obtain an area comprising about 36,000 square miles. This, with the thickness of 7500 feet before assumed, will give 51,000 cubic miles of solid matter as the volume of the carboniferous rocks.

According to the latest estimate of the annual discharge of water by the Mississippi, and the proportion of sediment held in suspension in its waters at different seasons of the year, after making due allowance

* Lyell's Second Visit to the U. S., vol. ii. p. 245 ; and American Journ. of Science, Second Series, vol, v. p. 17. 
for the sand and coarser particles pushed along the bottom, it would take, according to the late survey of Messrs. Humphreys and Abbot; more than a million years for the great river to carry down from the continent to the gulf an amount of solid matter equal to that of the rocks above alluded to.*

The Ganges, according to the data supplied to mo by Mr. Everest and Captain Strachey, conveys so much larger a volume of solid matter annually to the Bay of Bengal, that it might accomplish a similar task in 375,000 years.

As the lowest of the carboniferous strata of Nova Scotia, like the middle and uppermost, consist of shallow-water beds, the whole vertical subsidence of three miles, at the South Joggins, must have taken place gradually. Even if this depression was brought about in the course of 375,000 years, it may have been accomplished at the average rate of 4 feet in a century, resembling that now experienced in certain countries, where, whether the movement be upward or downward, it is quite insensible to the inhabitants, and only known by scientific inquiry. If, on the other hand, it was brought about in rather more than a million of years according to the other standard before alluded to, the rate would be little more than a foot in a century. The same movement taking place in an upward direction would be sufficient to uplift a portion of the earth's crust to the height of Mont Blanc, or to a vertical elevation of three miles above the level of the sea.

The delta of the Ganges presents in one respect a striking parallel to the Nova Scotia coal-field, since at Calcutta, at the depth of eight or ten feet from the surface, the buried stools of trees with their roots attached have been found in digging tanks, indicating an ancient soil now underground; and, in boring on the same site for an Artesian well, to the depth of 481 feet, other signs of ancient forest-covered lands and peaty soils have been observed at several depths, even as far down as 300 feet and more below the level of the sea. As the strata pierced through contained freshwater remains of recent species of plants and animals, they imply a subsidence which has been going on con temporaneously with the accumulation of fluviatile mud.

In the English coal-fields the same association of fresh, or rather brackish-water strata, with marine, in close connection with beds of coal of terrestrial origin, has been frequently recognized. Thus, for example, a deposit near Shrewsbury, probably formed in brackish water, has been described by Sir R. Murchison as the youngest member of the carboniferous series of that district, at the point where the coalmeasures are in contact with the Permian or "Lower New Red." It consists of shales and sandstones about 150 feet thick, with coal and traces of plants; including a bed of limestone varying from 2 to 9 feet in thickness, which is cellular, and resembles some lacustrine limestones

* Principles of Geology, 9th ed., 1853, p. 273; and Antiquity of Man, 3d ed., Appendix D, p. 522. 
of France and Germany. It has been traced for thirty miles in a straight line, and can be recognized at still more distant points. The characteristic fossils are a small bivalve, having the form of a Cyclas or Cyrena, also a small entomostracan which may be a Cypris, or, if marine, a Cythere (fig. 546), and the microscopic shell of an annelid of an extinct genus called Microconchus (fig. 545) allied to Serpula or Spirorbis.

Fig. 545 .

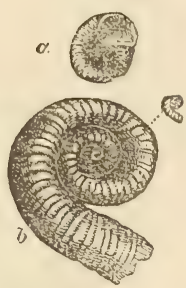

a. Microconchus (Spirorbis) carbonarius. Nat. size, and magnified. b. Var. of same.

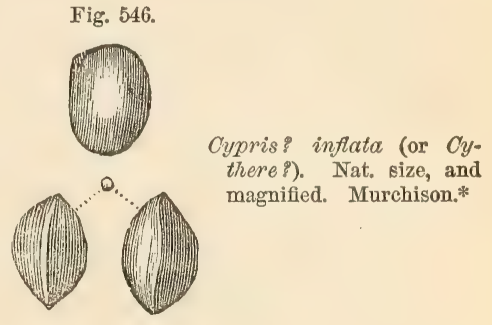

In the lower coal-measures of Coalbrook Dale, the strata, according to Mr. Prestwich, often change completely within very short distances, beds of sandstone passing horizontally into clay, and clay into sandstone. The coal-seams often wedge out or disappear; and sections, at places nearly contiguous, present marked lithological distinctions. In this single field, in which the strata are from 700 to 800 feet thick, between forty and fifty species of terrestrial plants have been discovered, besides several fishes of the genera Megalichthys, Holoptychius, and others. Crustacea are also met with, of the genus Limulus (see fig. 547), resembling in all essential characters

Fig. 547.

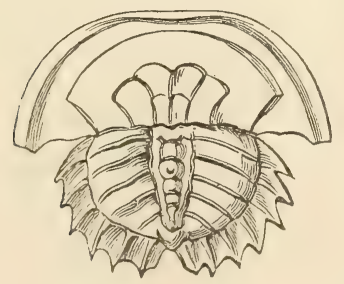

Limulus rotundatus, Prestwich. Coal, Coalbrook Dale.
Fig. 548.

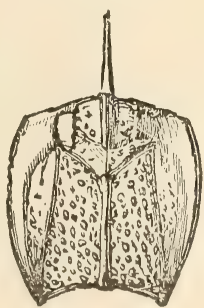

Glyphea? aubia, Salter. Syn. Аpus dubius, Milne Edwards. The oldest recorded decapod (or long-tailed) crustacean. Coal-measures, Coalbrook Dale.

the Limuli of the Oolitic period, and the king-crab of the modern seas. They were smaller, however, than the living form, and had the abdomen deeply grooved across, and serrated at its edges. In this 
specimen the tail is wanting; but in another, of a second species, from Coalbrook Dale, the tail is seen to agree with that of the living Limulus.

The perfect carapace of a long-tailed or decapod crustacean has also been found in the iron-stone of these strata by Mr. Ick (see fig. 548). It is referred by Mr. Salter to Glyphea, a genus also occurring in the Lias and Oolite. There are also upwards of forty species of mollusca, among which are two or three referred to the freshwater genus Unio, and others of marine forms, such as Nautilus, Orthoceras, Spirifer, and Productus. Mr. Prestwich suggests that the intermixture of beds containing freshwater shells with others full of marine remains and the alternation of coarse sandstone and conglomerate with beds of fine clay or shale containing the remains of plants, may be explained by supposing the deposit of Coalbrook Dale to have originated in a bay of the sea or estuary into which flowed a considerable river subject to occasional freshes.*

One or more species of scorpions, two beetles of the family Curculionidoce, and a neuropterous insect resembling the genus Corydalis, and another related to Phasmido, have been found at Coalbrook Dale. From the coal of Wetting in Westphalia several specimens of the cockroach or Blatta family, and the wing of a cricket (Acridites), have been described by Germar. $\dagger$

More recently (1854) Mr. Fr. Goldenberg has published descriptions of no less than twelve species of insects from the nodular clay-iron-stone of Saarbrück, near Treves. . They are associated with the leaves and branches of fossil ferns. Among them are several Blattince, three species of Neuroptera, one beetle of the Scarabceus family, a grasshopper or locust, Gryllacris (see fig. 549), and several white ants or

Fig. 549 .

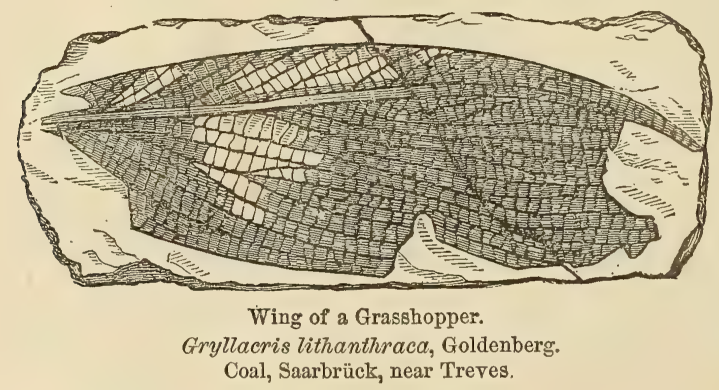

Termites. These newly added species probably outnumber all we knew before of the fossil insects of the coal.

* Prestwich, Geol. Trans., Second Series, vol. v. p. 440.

† See Münster's Beitr., vol. .v. pl. 13, 1842.

$\ddagger$ Palæont., Dunker and V. Meyer, vol. iv. p. 17. 
In the Edinburgh coal-field, at Birdiehouse, fossil fishes, mollusks, and cyprides (?), very similar to those in Shropshire and Staffordshire, hare been found by Dr. Hibbert. In the coal-field also of Yorkshire, there are freshwater strata, some of which contain shells referred to the family Unionidae; but in the midst of the series there is one thin but very widely spread stratum, abounding in fishes and marine shells, such as Goniatites Listeri (fig. 550), Orthoceras and Avicula papyracea, Goldf. (fig. 551).

Fig. 550 .

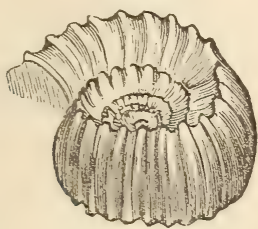

Goniatites Listeri, Martin sp.
Fig. 551 .

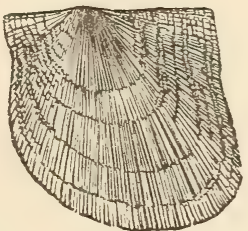

Avicula papyracea, Goldf. (Pecten papyraceus, Sow.)

No similarly intercalated layer of marine shells has been noticed in the neighboring coal-nield of Newcastle, where, as in South Wales and Somersetshire, the marine deposits are entirely below those containing terrestrial and freshwater remains.*

Clay-iron-stone.-Bands and nodules of clay-iron-stone are common in coal-measures, and are formed, says Sir H. De la Beche, of carbonate of iron mingled mechanically with earthy matter, like that constituting the shales. Mr. Hunt, of the Museum of Practical Geology, instituted a series of experiments to illustrate the production of this substance, and found that decomposing vegetable matter, such as would be distributed through all coal strata, prevented the farther oxidation of the proto-salts of iron, and converted the peroxide into protoxide by taking a portion of its oxygen to form carbonic acid. Such carbonic acid, meeting with the protoxide of iron in solution, would unite with it and form a carbonate of iron; and this mingling with fine mud, when the excess of carbonic acid was removed, might form beds or nodules of argillaceous iron-stone. $\dagger$

* Phillips; art. "Geology," Encyc. Metrop., p. 592.

† Memoirs of Geol. Survey, pp. 51, 255, \&c. 


\section{CHAPTER .XXV.}

\section{CARBONIFEROUS GROUP, continued.}

Coal-fields of the United States-Section of the country between the Atlantic and Mississippi-Position of land in the carboniferous period eastward of the Alleghanies-Mechanically formed rocks thiming out westward, and limestones thickening-Uniting of many coal-seams into one thick bed-Horizontal coal at Brownsville, Pennsylvania-Vast extent and continuity of single seams of coal-Ancient river-channel in Forest of Dean coal-field-Climate of carboniferous period-Insects in coal-Rarity of air-breathing animals-Great number of fossil fish-First discovery of the skeletons of fossil reptiles-Footprints of reptilians-First land-shell found-Rarity of air-breathers, whether vertebrate or invertebrate, in Coal-measures-Mountain limestone-Its corals and marine shells.

IT was stated in the last chapter that a great uniformity prevails in the fossil plants of the coal-measures of Europe and North America; and I may add that four-fifths of those collected in Nova Scotia have been identified with European species. Hence the former existence, at the remote period under consideration (the carboniferous), of a continent or shain of islands where the Atlantic now rolls its waves seems a fair inference. Nor are there wanting other and independent proofs of such an ancient land situated to the eastward of the present Atlantic coast of North America ; for the geologist deduces the same conclusion from the mineral composition of the carboniferous and some older groups of rocks as they are developed on the eastern flanks of the Alleghanies, contrasted with their character in the low country to the westward of those mountains.

The annexed diagram (fig. 552) will assist the reader in understanding the phenomena now alluded to, although I must guard him against supposing that it is a true section. A great number of details have of necessity been omitted, and the scale of heights and horizontal distances are unavoidably falsified.

Starting from the shores of the Atlantic, on the eastern side of the Continent, we first come to a low region (A B), which was called the alluvial plain by the first geographers. It is occupied by tertiary and cretaceous strata, before described (pp. 242, 309, and 338), which are nearly horizontal. The next belt, from i to $\mathrm{c}$, consists of granitic rocks (hypogene), chiefly gneiss and mica-schist, covered occasionally with unconformable red sandstone, No. 4 (New Red or Trias?), remarkäble for its footprints (see p. 454). Sometimes, also, this sand- 


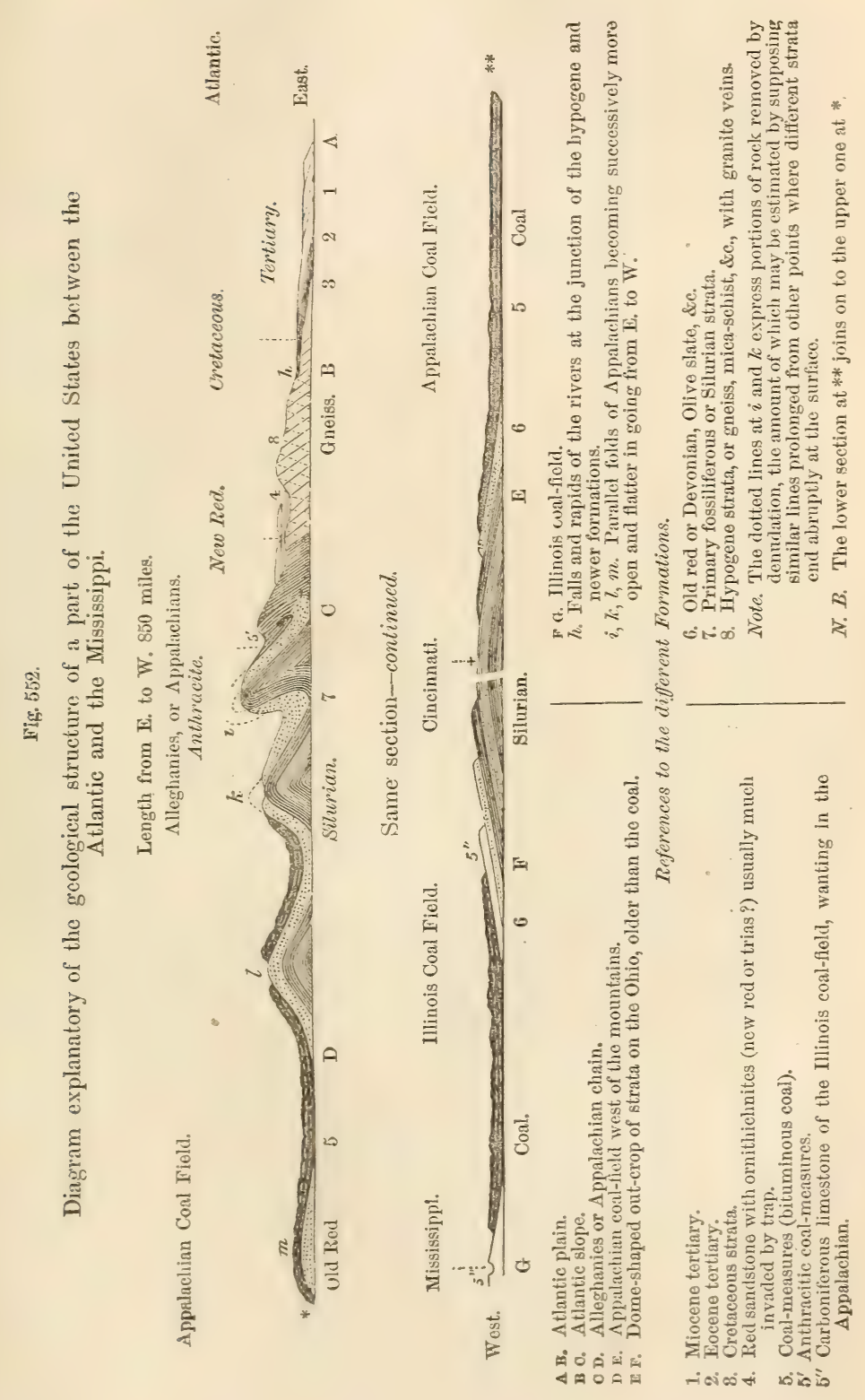


stone rests on the edges of the disturbed palæozoic rocks (as seen in the section). The region (в с), sometimes called the "Atlantic Slope," corresponds nearly in average width with the low and flat plain (A B), and is characterized by hills of moderate height, contrasting strongly, in their rounded shape and altitude, with the long; steep, and lofty parallel ridges of the Alleghany Mountains. The outcrop of the strata in these ridges, like the two belts of hypogene and newer rocks ( geological map, exhibit long stripes of different colors, running in a N.E. and S. W. direction, in the same way as the lias, chalk, and other secondary formations in the middle and eastern half of England.

The narrow and parallel zones of the Appalachians, here mentioned, consist of strata, folded into a succession of convex and concave flexures, subsequently laid open by denudation. The component rocks are of great thickness, all referable to the Silurian, Devonian, and Carboniferous formations. There is no principal or central axis, as in the Pyrenees and many other chains-no nucleus to which all the minor ridges conform; but the chain consists of many nearly equal and parallel foldings, having what is termed an anticlinal and synclinal arrangement (see above, p. 48). This system of hills extends, geologically considered, from Vermont to Alabama, being more than 1000 miles long, from 50 to 1.50 miles broad, and varying in height from 2000 to 6000 feet. Sometimes the whole assemblage of ridges runs perfectly straight for a distance of more than 50 miles, after which all of them wheel round altogether, and take a new direction, at an angle of 20 or 30 degrees to the first.

We are indebted to the state surveyors of Virginia and Pennsylvania, Prof. W. B. Rogers and his brother Prof. H. D. Rogers, for the important discovery of a clue to the general law of structure prevail-. ing throughout this range of mountains, which, however simple it may appear when once made out and clearly explained, might long have been overlooked, amidst so great a mass of complicated details. It appears that the bending and fracture of the beds is greatest on the southeastern or Atlantic side of the chain, and the strata become less and less disturbed as we go westward, until at length they regain their original or horizontal position. By reference to the section (fig. 552), it will be seen that on the eastern side, or in the ridges and troughs nearest the Atlantic, southeastern dips predominate, in consequence of the beds having been folded back upon themselves as in $i$, those on the northwestern side of each arch having been inverted. The next set of arches (such as $k$ ) are more open, each having its western side steepest; the next $(l)$ open out still more widely, the next $(m)$ still more, and this continues. until we arrive at the low and level part of the Appalachian coal field (D E).

In nature or in a true section, the number of bendings or parallel folds is so much greater that they could not be expressed in a diagram 
without confusion. It is also clear that large quantities of rock have been remored by aqueous action or denudation, as will appear if we attempt to complete all the curres in the manner indicated by the dotted lines at $i$ and $k$.

The morements which imparted so uniform an order of arrangement to this vast system of rocks must have been, if not contemporaneous, at least parts of one and the same series, depending on some common cause. Their geological date is svell defined, at least within certain limits, for they must have taken place after the deposition of the carboniferous strata (No. 5), and before the formation of the red sandstone (No. 4). The greatest disturbing and denuding forces have evidently been exerted on the southeastern side of the chain; and it is here that igneous or plutonic rocks are observed to have invaded the strata, forming dykes, not expressed in the section, some of which run for miles in lines parallel to the main direction of the Appalachians, or N.N.E. and S.S.W.

The thickness of the carboniferous rocks in the region $\mathrm{c}$ is very great, and diminishes rapidly as we proceed to the westward. The surveys of Pennsylvania and Virginia show that the southeast was the quarter whence the coarser materials of these strata were derived, so that the ancient land lay in that direction. The conglomerate which forms the general base of the coal-measures is 1500 feet thick in the Sharp Mountain, where I saw it (at c) near Pottsville; whereas it has only a thickness of 500 feet, about thirty miles to the northwest, and dwindles gradually away when followed still farther in the same direction, until its thickness is reduced to 30 feet.* The limestones, on the other hand, of the coal-measures augment as we trace them westward. Similar observations have been made in regard to the Silurian and Devonian formations in New York; the sandstones and all the mechanically-formed rocks thinning out as they go westward, and the limestones thickening, as it were, at their expense. It is, therefore, clear that the ancient land was to the east, where the Atlantic now is; the deep sea, with its banks of coral and shells to the west, or where the hydrographical basin of the Mississippi is now situated.

In that region, near Pottsville, where the thickness of the coalmeasures is greatest, there are thirteen seams of anthracitic coal, several of them more than 2 yards thick. Some of the lowest of these alternate with beds of white grit and conglomerate of coarser grain than I ever saw elsewhere, associated with pure coal. The pebbles of quartz are often of the size of a hen's egg. On following these puddingstones and grits for several miles from Pottsville, by Tamaqua, to the Lehigh Summit Miue, in company with MIr. II. D. Rogers, in 1841, he pointed out to me that the coarse-grained strata and their accompanying shales gradually thin out, until seren seams of coal, at first widely separated, are brought nearer and nearer together, until they succes- 
sively unite; so that at last they form one mass, between 40 and 50 feet thick. I saw this enormous bed of anthracitic coal quarried in the open air at Mauch Chunk (or the Bear Mountain), the overlying sandstone, 40 feet thick, having been removed bodily from the top of the hill, which, to use the miner's expression, had been "scalped." The accumulation of vegetable matter now constituting this vast bed of anthracite, may perhaps, before it was condensed by pressure and the discharge of its hydrogen, oxygen, and other volatile ingredients, have been between 200 and 300 feet thick. The origin of such a vast thickness of regetable remains, so unmixed with earthy ingredients, can, I think, be accounted for in no other way, than by the growth, during thousands of years, of trees and ferns, in the manner of peat,a theory which the presence of the Stigmaria in situ under each of the seven layers of anthracite, fully bears out. The rival hypothesis, of the drifting of plants into a sea or estuary, leaves the absence of sediment, or, in this case, of clay, sand, and pebbles, wholly unexplained.

But the student will naturally ask, what can have caused so many seams of coal, after they had been persistent for miles, to come together and blend into one single seam, and that one equal in the aggregate to the thickness of the several separate seams? Oiten had the same question been put by English miners before a satisfactory answer was given to it by the late Mr. Bowman. The following is his solution of the problem: Let $a a^{\prime}$, fig. 553 , be a mass of vegetable

Fig. 55ั3.

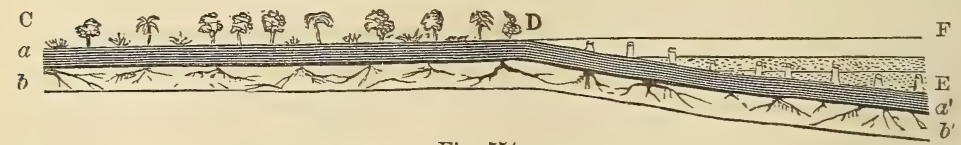

Fig. 554 .

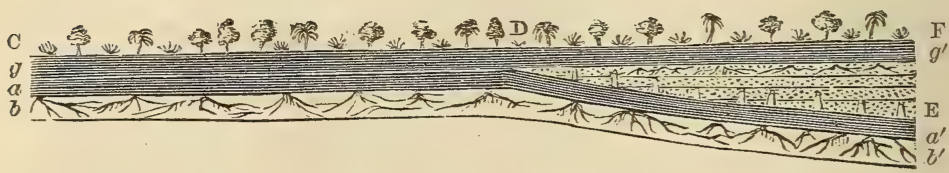

matter, capable, when condensed, of forming a 3 -foot seam of coal. It rests on the underclay $b b^{\prime}$, filled with roots of trees in situ, and it supports a growing forest (C D). Suppose that part of the same forest D E had become submerged by the ground sinking down 25 feet, so that the trees have been partly thrown down and partly remain erect in water, slowly decaying, their stumps and the lower parts of their trunks being enveloped in layers of sand and mud, which are gradually filling up the lake D F. When this lake or lagoon has at length been entirely silted up and eonverted into land, say, in the course of a century, the forest C D will extend once more continuously over the whole area C F, as in fig. 554, and another mass of vegetable matter 
$\left(g g^{\prime}\right)$, forming 3 feet more of coal, may accumulate from c to $\mathrm{F}$. We then find in the region $\mathrm{F}$, two seams of coal $\left(a^{\prime}\right.$ and $\left.g^{\prime}\right)$ each 3 feet thick, and separated by 25 feet of sandstone and shale, with erect trees based upon the lower coal, while, between $\mathrm{D}$ and $\mathrm{c}$, we find these two seams united in a 2-yard coal. It may be objected that the uninterrupted growth of plants during the interval of a century will have caused the regetable matter in the region $\mathrm{C} D$ to be thicker than the two distinct scams $a^{\prime}$ and $g^{\prime}$ at $\mathrm{F}$; and no doubt there would actually be a slight excess representing one gencration of trees with the remains of other plants, forming half an inch or an inch of coal; but this would not prevent the miner from affirming that the seam $a g$, throughout the area $\mathrm{C} \mathrm{D}$, was equal to the two seams $a^{\prime}$ and $g^{\prime}$ at $\mathrm{F}$.

The reader has seen, by reference to the section (fig. 552 p. 497), that the strata of the Appalachian coal-field assume an horizontal position west of the mountains. In that less elevated country, the coalmeasures are intersected by three great navigable rivers, and are capable of furnishing for ages, to the inhabitants of a densely peopled region, an inexhaustible supply of fuel. These rivers are the Monongahela, the Alleghany, and the Ohio, all of which lay open on their banks the level seams of coal. Looking down the first of these at Brownsville, we have a fine view of the main seam of bituminous coal 10 feet thick, commonly called the Pittsburg seam, breaking out in the steep cliff at the water's edge; and I made the accompanying sketch of its appearance from the bridge over the river (see fig. 555). Here the coal, 10 feet thick, is covered by carbonaceous shale $(b)$, and this again by micaceous sandstone $(c)$. Horizontal galleries may be driven everywhere at very slight expense, and so worked as to drain themselves, while the cars, laden with coal and attached to each other, glide down on a railway, so as to deliver their burden into barges moored to the river's bank. The same seam is seen at a distance, on the right bank (at $a$ ), and may be followed the whole way to Pittsburg, fifty miles distant. As it is nearly horizontal, while the river descends it crops out at a continually increasing, but never at an inconrenient, height above the Monongahela. Below the great bed of coal at Brownsville is a fire-clay 18 inches thick, and below this, several beds of limestone, below which again are other coal seams. I have also shown in my sketch another layer of workable coal (at $d d$ ), which breaks out on the slope of the hills at a greater height. Here almost every proprietor can open a coal-pit on his own land, and the stratification being rery regular, he may calculate with precision the depth at which coal may be won.

The Appalachian coal-fichl, of which these strata form a part (from c to $\mathrm{E}$, section, fig. 552, p. 497), is remarkable for its vast area ; for, according to Professor H. D. Rogers, it stretches continuously from N.E. to S.W., for a distance of 720 miles, its greatest width being about 180 miles. On a moderate estimate, its superficial area amounts to 63,000 square miles. 


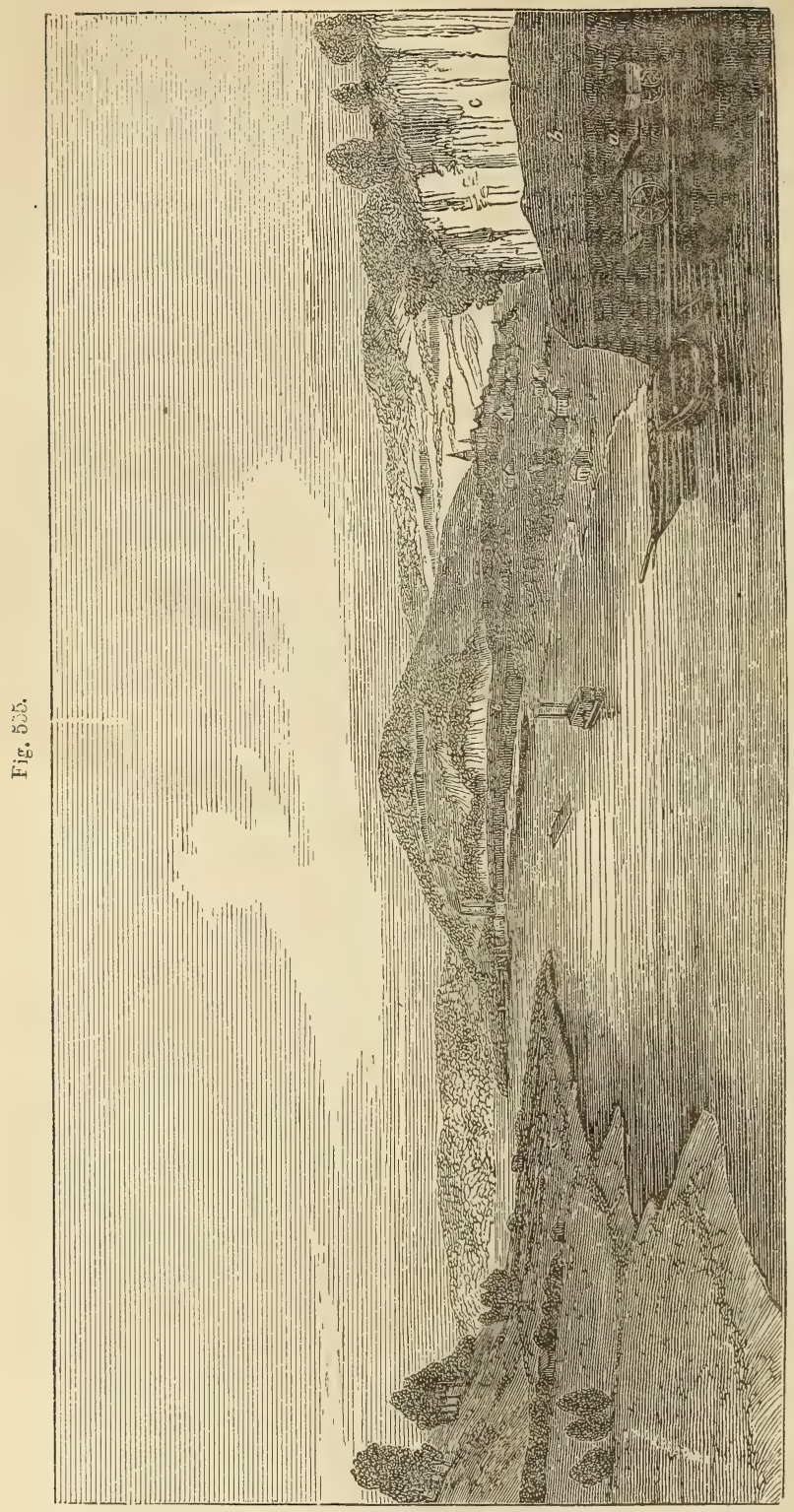

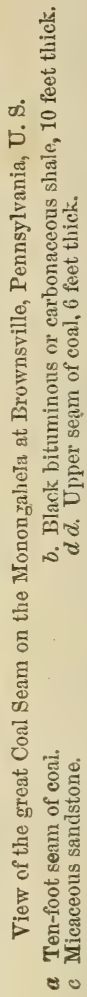

This coal-formation, before its original limits were reduced by denuuation, must have measured 900 miles in length, and in some places more than 200 miles in breadth. By again referring to the section (fig. 552, p. 497), it will be seen that the strata of coal are horizontal to the westward of the mountains in the region $\mathrm{D} \mathrm{E}$, and become more and more inclined and folded as we proceed eastward. Now it is 
invariably found, as Professor H. D. Rogers has shown by chemical analysis, that the coal is most bituminous towards its western limit, where it remains level and unbroken, and that it become progressively debituminized as we travel southeastward towards the more bent and distorted rocks. Thus, on the Ohio, the proportion of hydrogen, oxygen, and other volatile matters, ranges from 40 to 50 per cent. Eastward of this line, on the Monongahela, it still approaches 40 per cent., where the strata begin to experience some gentle flexures. On entering the Alleghany Mountains, where the distinct anticlinal axes begin to show themselves, but before the dislocations are considerable, the rolatile matter is generally in the proportion of eighteen or twenty per cent. At length, when we arrive at some insulated coal-fields $\left(5^{\prime}\right.$, fig. 552) associated with the boldest flexures of the Appalachian chain, where the strata have been actually turned over, as near Pottsville, we find the coal to contain only from 6 to 12 per cent. of bitumen, thus becoming a genuine anthracite.*

It appears from the researches of Liebig and other eminent chemists, that when wood and vegetable matter are buried in the earth exposed to moisture, and partially or entirely excluded from the air, they decompose slowly and evolve carbonic acid gas, thus parting with a portion of their original oxygen. By this means, they become gradually converted into lignite or wood-coal, which contains a larger proportion of hydrogen than wood does. A continuance of decomposition changes this lignite into common or bituminous coal, chiefly by the discharge of carburetted hydrogen, or the gas by which we illuminate our streets and houses. According to Bischoff, the inflammable gases which are always escaping from mineral coal, and are so often the cause of fatal accidents in mines, always contain carbonic acid, carburetted hydrogen, nitrogen, and olifiant gas. The disengagement of all these gradually transforms ordinary or bituminous coal into anthracite, to which the various names of splint-coal, glance-coal, hard-coal, culm, and many others, have been given.

We have seen that, in the Appalachian coal-field, there is an intimate connection between the extent to which the coal has parted with its gaseous contents, and the amount of disturbance which strata have undergone. The coincidence of these phenomena may be attributed partly to the greater facility afforded for the escape of volatile matter, where the fracturing of the rocks had produced an infinite number of cracks and crevices, and also to the heat of the gases and water penetrating these cracks, when the great movements took place, which have rent and folded the $\Lambda$ ppalachian strata. It is well known that, at the present periorl, thermal waters and hot rapors burst out from the earth during earthquakes, and these would not fail to promote the disengagement of volatile matter from the carboniferous rocks.

Continuiiy of seams of coal.-As single seams of coal are continuous

* Trans. of Assoc. of Amer. Geol., p. 470. 
over very wide areas, it has been asked, how forests could have prevailed uninterruptedly over such wide spaces. In reply, it may be said that swamp-forests in one delta may extend for 25,50 , or 100 miles, while in a contiguous delta, as on the borders of the Gulf of Mexico, another of precisely the same character may be growing; and these may in after ages appear to geologists to have been continuous, although in fact they were simply contemporaneous. Denudation may easily be imagined in such cases as the cause of interruptions, which were in fact, original. But as in all the American coal-fields there are numerous root-beds without any superincumbent coal, we may presume that frequently layers of vegetable matter were removed by floods; and in other cases, where the stigmaria-clays are for a certain space covered with coal, and then prolonged without any such covering, the inference of partial denudation is still more obvious.

In the Forest of Dean, in Gloucestershire, ancient river-channels are found, which pass through beds of coal, and in which rounded pebbles of coal occur. They are of older date than the overlying and undisturbed coal-measures. The late Mr. Buddle, who described them to me, told me he had seen similar phenomena in the Newcastle coalfield. Nevertheless, instances of these channels are much more rare than we might have anticipated, especially when we remember how often the roots of trees (Stigmarice) have been torn up, and drifted in broken fragments into the grits and sandstones. The prevalence of a downward movement is, no doubt, the principal cause which has saved so many extensive seams of coal from destruction by fluviatile action.

Climate of Coal Period.--So long as the botanist taught that a tropical climate was implied by the carboniferous flora, geologists might well be at a loss to reconcile the preservation of so much vegetable matter with a high temperature; for heat hastens the decomposition of fallen leaves and trunks of trees, whether in the atmosphere or in water. It is well known that peat, so abundant in the bogrs of high latitudes, ceases to grow in the swamps of warmer regions. It seems, however, to have become a more and more received opinion, that the coal-plants do not, on the whole, indicate a climate resembling that now enjoyed in the equatorial zone. Tree-ferns range as far south as the southern part of New Zealand, and Araucarian pines occur in Norfolk Island and Chili. A great predominance of ferns and lycopodiums indicates moisture, equability of temperature, and freedom from frost, rather than intense heat; and we know too little of the sigillariæ, calamites, asterophyllites, and other peculiar forms of the Carboniferous period, to be able to speculate with confidence on the kind of climate they may have required.

The same may be said of the corals, and cephalopoda of the Mountain Limestone,- they belong to families of whose climatal habits we know nothing; and even if they should be thought to imply that a warm temperature characterized the northern seas in the carboniferous 
era, the absence of cold may have given rise (as at present in the seas of the Bermudas, under the influence of the gulf-stream) to a very wide geographical range of stone-building corals and shell-bearing cuttle-fish, without its being necessary to call in the aid of tropical heat.

\section{CARBONIFEROUS REPTILES.}

Where we have evidence in a single coal-field, as in that of Nova Scotia, or of South Wales, of fifty or even a hundred ancient forests buried one above the other, with the roots of trees still in their original position, and with some of the trunks still remaining erect, we are apt to wonder that until the year 1844 no remains of contemporaneous air-breathing creatures should have been discovered. No vertebrated animals more highly organized than fish, no mammalia or birds, no saurians, frogs, tortoises, or snakes were known in rocks of such high antiquity. In the coal-fields of Europe mention has been made of beetles, locusts, and a few other insects, but no land-shells have even now been met with. Agassiz described in his great work on fossil fishes more than one hundred and fifty species of ichthyolites from the coal strata, ninety-four belonging to the families of shark and ray, and fifty-eight to the class of ganoids. Some of these fish are very remote in their organization from any now living, especially those of the family called Sauroid by Agassiz; as Megalichthys, Holoptychius, and others, which were often of great size, and all predaceous. Their osteology, says M. Agassiz, reminds us in many respects of the skeletons of saurian reptiles, both by the close sutures of the bones of the skull, their large conical teeth striated longitudinally, (see fig. 556), the articulations of the spinous processes with the vertebræ, and other characters. Yet they do not form a family intermediate between fish and reptiles, but are true fish, though doubtless more highly organized than any living fish.*

The annexed figure represents a large tooth of the Holoptychius, found by Mr. Horner in the Cannel coal of Fifeshire. This fish probably inhabited an estuary, like many of its contemporaries, and frequented both rivers and the Holoptyctivus Hibberii, $\mathbf{A g}$. sea.

At length, in 1844, the first skeleton of a

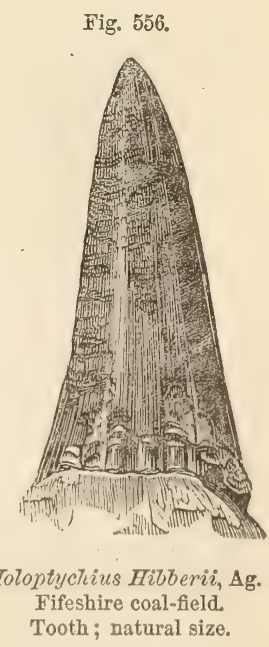
true reptile was announced from the coal of Münster-Appel in Rhenish Bararia, by H. ron Meyer, under the name of Apateon pedestris, 
the animal being supposed to be nearly related to the salamanders. Three years later, in 1847, Prof. von Dechen found in the coal-field of Saarbrück, at the village of Lebach, between Strasburg and Treves, the skeletons of no less than three distinct species of air-breathing reptiles, which were described by the late Prof. Goldfuss under the generic name of Archegosaurus. The ichthyolites and plants found in the same strata left no doubt that these remains belonged to tho

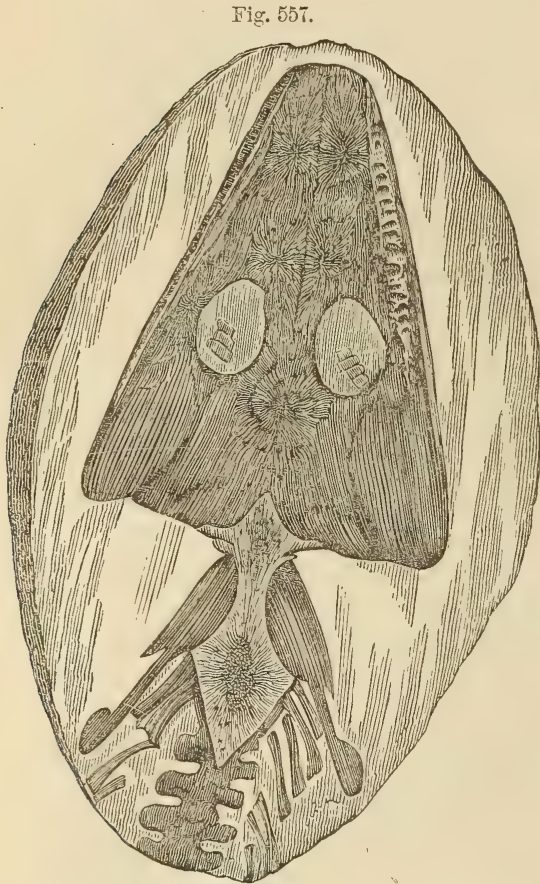

Archegosaurus minor, Goldfuss. Fossil reptile from the coal-measures, Saarbrück. true coal period. The skulls, teeth, and the greater por tions of the skeleton, nay, even a large part of the skin, of two of these reptiles have been faithfully preserved in the centre of spheroidal con cretions of clay-iron-stone The largest of these lizards, Archegosaurus Decheni, must have been 3 feet 6 inches long. The annexed drawing represents the skull and neck bones of the smallest of the three, of the natural size. They were considered by Goldfuss as saurians, but by Herman von Meyer as most nearly allied to the Labyrinthodon before mentioned (p. 445), and, therefore, as having many characters intermediate between batrachians and saurians. The remains of the extremities leave no doubt that they were quadrupeds, "provided," says "Von Meyer, "with hands and feet terminating in distinct toes; but these limbs were weak, serving only for swimming or

Fig. 558.

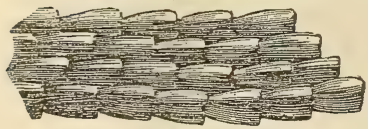

Imbricated covering of skin oî Archegosaurus medius, Goldf.; magnified.* creeping." The same anatomist has pointed out certain points of analogy between their bones and those of the Proteus anguinus; and Professor Owen has observed that they make an approach to the Proteus in the shortness of their ribs. Two specimens of these ancient reptiles retain a large part of the outer

* Goldfuss, Neue Jenaische Lit. Zeit., 1848; and Von Meyer, Quart. Geol. sourn.; vol. iv Miscell. p. 51. 
skin, which consisted of long, narrow, wedge-shaped, tile-like, and horny scales, arranged in rows (see fig. 558).

Cheirotherian Footprints in Coal-measures, United States.-In 1844 , the very year when the Apateon or Salamander of the coal was first. met with in the country between the Moselle and the Rhine, Dr. King published an account of the footprints of a large reptile discovered by him in North America. These occur in the coal-strata of Greensburg; in Westmoreland County, Pennsylvania; and I had an opportunity of examining them in 1846. I was at once convinced of their genuineness, and declared my conviction on that point, on which doubts had been entertained both in Europe and the United States. The footmarks were first observed standing out in relief from the lower surface of slabs of sandstone, resting on thin layers of fine unctuous clay. I brought away one of these masses,

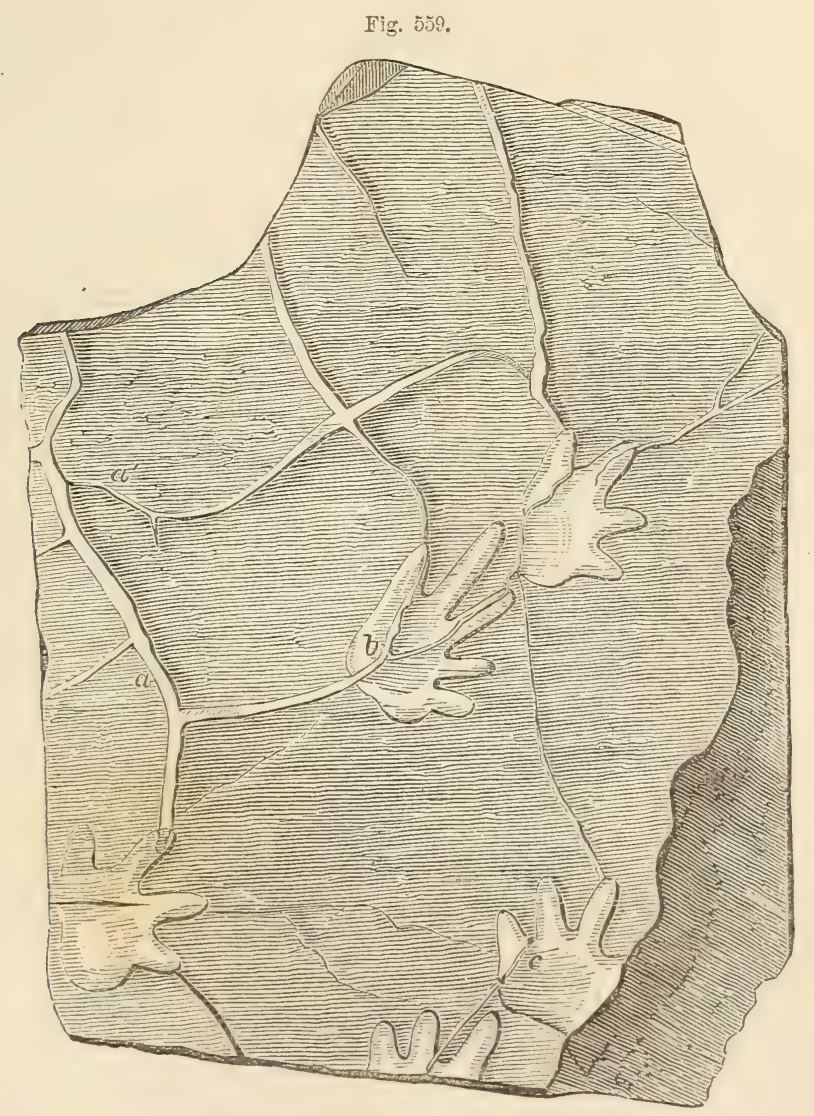

Scale one-sixth the ofiginal.

Slab of sandstone from the coal-measures of Pennsylvania, with footprints of air breathing reptile and casts of cracks. 
which is represented in the foregoing drawing (fig. 559). It displays, together with footprints, the casts of cracks $\left(a, a^{\prime}\right)$ of various sizes. The origin of such cracks in clay, and casts of the same, has before been explained, and referred to the drying and shrinking of mud, and the subsequent pouring of sand into open crevices. It will be seen that some of the cracks, as at $b, c$, traverse the footprints, and produce distortion in them, as might have been expected, for the mud must have been soft when the animal walked over it and left

Fig. 560 .

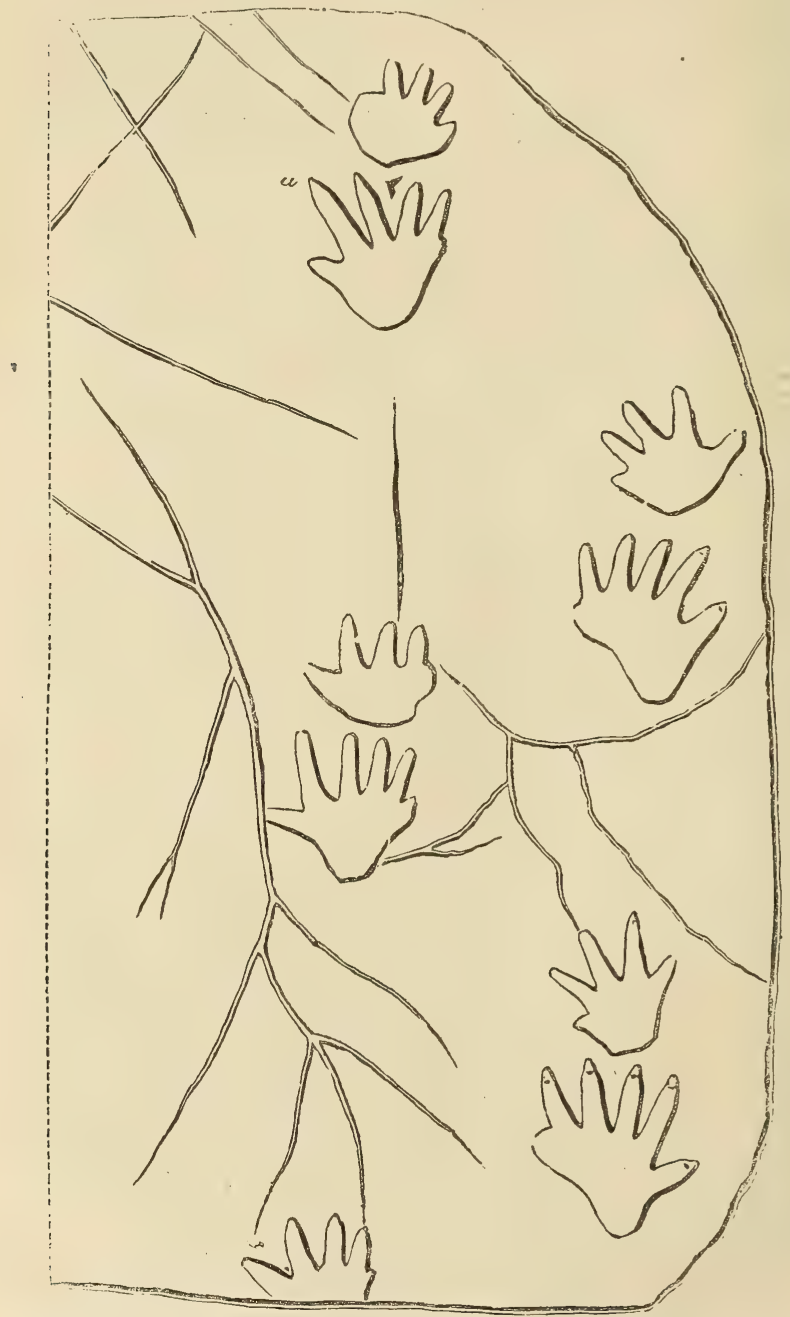

Series of reptilian footprints in the coal-strata of Westmoreland County, Pennsylvania. a. Mark of nail? 
the impressions; whereas, when it afterwards dried up and shrank, it would be too hard to receive such indentations.

No less than twenty-three footsteps were observed by Dr. King in the same quarry before it was abandoned, the greater part of them so arranged (sce fig. 560) on the surface of one stratum as to imply that they were made successively by the same animal. Everywhere there was a double row of tracks, and in each row they occur in pairs, each pair consisting of a hind and fore foot, and each being at nearly equal distances from the next pair. In each parallel row the toes turn the one set to the right, the other to the left. In the European Cheirotherium, before mentioned (p. 443), both the hind and the fore feet have each five toes, and the size of the hind foot is about five times as large as the fore foot. In the American fossil the posterior footprint is not even twice as large as the anterior, and the number of toes is unequal, being five in the hinder and four in the anterior foot. In this, as in the European Cheirotherium, one toe stands out like a thumb, and these thumb-like toes turn the one set to the right, and the other to the left. The American Cheirotherium was evidently a broader animal, and belonged to a distinct genus from that of the triassic age in Europe.*

We may assume that the reptile which left these prints on the ancient sands of the coal-measures was an air-breather, because its weight would not have been sufficient under water to have made impressions so deep and distinct. The same conclusion is also borne out by the casts of the cracks above described, for they show that the clay had been exposed to the air and sun, so as to have dried and shrunk.

The geological position of the sandstone of Greensburg is perfectly clear, being situated in the midst of the Appalachian coal-field, having the main bed of coal, called the Pittsburg seam, above mentioned (p. 501), 3 yards thick, 100 feet above it, and worked in the neigh borhood, with several other seams of coal at lower levels. The im pressions of Lepidodendron, Sigillaria, Stigmaria, and other characteristic carboniferous plants are found both above and below the level of the reptilian footsteps.

Analogous footprints of a large reptile of still older date were afterwards found (1849) at Pottsville, 70 miles N.E. of Philadelphia, by Mr. Isaac Lea, in a formation of red shales, called No. XI. by Prof. H. D. Rogers, in the State Survey of Pennsylvania, and referred by him to the base of the coal, but regarded by some geologists as the uppermost part of the Old Red Sandstone. A thickness of 1700 feet of strata intervenes between the footprints of Greensburg, before described, and these older Pottsville impressions. In the same Red Shale, No. XI., the "debatable ground" between the Carboniferous and Devonian group, Prof. H. D. Rogers announced in 
1851 that he had discovered other footprints, referred by him to three species of quadrupeds, all of them five-toed and in double rows, with an opposite symmetry, as if made by right and left feet, while they likewise display the alternation of fore foot and hind foot. One species, the largest of the three, presents a diameter for each footprint of about two inches, and shows the fore and hind feet to be nearly equal in dimensions. It exhibits a length of stride of about nine inches, and a breadth between the right and left footsteps of nearly four inches. The impressions of the hind feet are but little in the rear of the fore feet:. The animal which made them is supposed to have been allied to a Saurian, rather than to a Batrachian or Chelonian. With these footmarks were seen shrinkage cracks, such as are caused by the sun's heat in mud, and rain-spots, with the signs of the trickling of water on a wet, sandy beach; all confirming the conclusion derived from the footprints, that the quadrupeds belonged to airbreathers, and not to aquatic races.

In 1852 the first osseous remains of a reptile were obtained from the coal-measures of America by Dr. Dawson and myself. We detected them in the interior of one of the erect Sigillariæ before alluded to as of such frequent occurrence in Nova Scotia. The tree was about 2 feet in diameter, and consisted, as usual, of an external cyiinder of bark, converted into coal, and an internal stony axis of black sandstone, or rather mud and sand stained black by carbonaceous matter, and cemented together with fragments of wood into a rock. These fragments were in the state of charcoal, and seem to have fallen to the bottom of the hollow tree while it was rotting away. The skull, jaws, and vertebræ of a reptile, probably about $2 \frac{1}{2}$ feet in length (Dendrerpeton Acadianum, Owen), were scattered through this stony matrix. The shell, also, of a Pupa (see fig. 561, p. 512), the first land-shell ever met with in the coal or in beds older than the tertiary, was observed in the same stony mass. Dr. Wyman of Boston pronounced the reptile to be allied in structure to Menobranchus and Menopoma, species of batrachians, now inhabiting the North American rivers. The same view was afterwards confirmed by Professor Owen, who also pointed out the resemblance of the cranial plants to those seen in the skull of Archegosaurus and Labyrinthodon." Whether the creature had crept into the hollow tree while its top was still open to the air, or whether it was washed in with mud during a flood, or in whatever other manner it entered, must be matter of conjecture.

Footprints of two reptiles of different sizes had previously been observed by Dr. Harding and Dr. Gesner on ripple-marked flags of the lower coal-measures in Nova Scotia, evidently made by quadrupeds walking on the ancient beach, or out of the water, just as the recent Menopoma is sometimes observed to do.

The remains of a second and smaller species of Dendrerpetorı, $D$.

* Geol. Quart. Journ., vol. ix. p. 58. 
Oweni, were also found accompanying the larger one, and still retaining some of its dermal appendages; and in the same tree were the bones of a third small lizard-like reptile, Hylonomus Lyelli, 7 inches long, with stout hind limbs, and fore limbs comparatively slender supposed by Dr. Dawson to be capable of walking and running on land.*

In 1854, Prof. Owen described a "sauroid batrachian" (Baphetes planiceps), of the Labyrinthodon family, obtained by Dr. Dawson from the coal of Pictou in Nova Scotia. In 1859, another species of Hylonomus, twice as large as that above mentioned, was met with; and another reptile of the same family, but distinct genus, was obtained by Dr. Dawson, named by Owen Hylerpeton. Lastly, in 1862, Mr. Marsh discorered in the coal-measures of the South Joggins in Nova Scotia, two large caudal biconcave vertebræ, supposed at first to belong to an Enaliosor, and called Eosaurus Acadianus, but which, Mr. Inuxler suggests, mar probably be referable to a labyrinthodont batrachian.

Professor Owen had announced the first finding of fossil reptilian remains in British coal-measures in 1853. They were referred to a new genus of Batrachoids allied to Archegosaurus, and called Parabatrachus. In 1852, a large, new labyrinthodont reptile, Loxomma, from the Edinburgh coal-field, was described by Prof. Huxley, together with a second, from the same series of strata, of another new genus, called Pholidogaster, a specimen of which, containing the head and nearly the whole rertebral columi, measured 44 inches in length. In the same year a third genus, denominated Anthracosaurus, was founded by the same anatomist on a specimen detected by Mr. Rus sel in the Airdrie "black-band" iron of the Glasgow coal-field. This labyrinthodont was about 7 feet long, and the skull 15 inches in length; thirtr-screa teeth were preserved in its jaws, and its vertebro ware highly ossified, so as to resemble those of the Triassic labyrinthodonts of the Mastodonsaurian trpe, whereas Pholidogaster is supposed by Huxley to be more allied to the Archegosaurian dirision of labyrinthodonts. $\uparrow$ Thus, in nineteen years, the skeletons or bones of twelve or more species of reptiles referred to nine genera have been exhumed from the coal-measures, to say nothing of footprints, some of them, like that represented at fig. 559, seeming to differ from all those to which any of the known bones can belong:

A single species of land-shell, Pupa vetusta, Dawson, see fig. 561, was mentioned as having been found, in 1852, in the interior of an erect fossil Sigillaria in Nora Scotia, p. 510. Dr. Dawson has since discorered another bed at a much lower level, in which the same shell is very abundaut, a bed scparated from the tree containing Dendrerpeton by a mass of strata 121$\}$ feet thick, and comprising 21 seams

* Dawson, Air-Breathers of the Coal in Nova Scotia. Montreal, 1863.

† Huxley, Quart. Geol. Journ., 1862, 1863. 
Fig. 561.
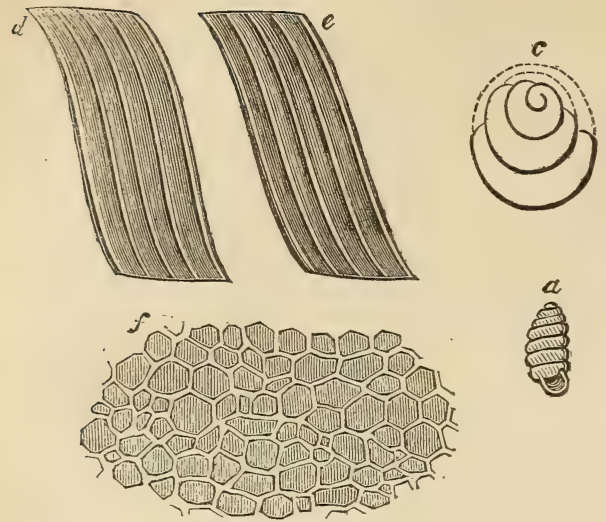

a. Pupa vetusta, Dawson, Nat, size.

b. The same, magnified.

c. View of the depressed apex.

d. Surface striæ, magnified 50 diam.

e. Surface striæ, of the recent English Pupa juniperi for comparison, magnified 50 diam.

$f$. Microscopic structure of the shell, showing hexagonal cells, magnified 500 diam.

of coal. This lower bed is an underclay 7 feet thick, with stigmarian rootlets, and the small land-shells occurring in it are in all stages of growth. They are chiefly confined to a layer about 2 inches thick, and are unmixed with any aquatic shells. They were all originally entire when imbedded, but are most of them now crushed, flattened, and distorted by pressure; they must have been accumulated, says Dr. Dawson, in mud deposited in a pond or creek.* The late Prof. Quekett, to whom I submitted the first specimen found in 1852 for microscopical examination, observed that the surface strix, on being magnified 50 diameters, $d$, fig. 561 , presented exactly the same appearance as a portion corresponding in size to the common English Pupa juniperi (e, fig. 561), and a cross-section of the fossil shell ( $f$, ibid.)

Fig. 562.
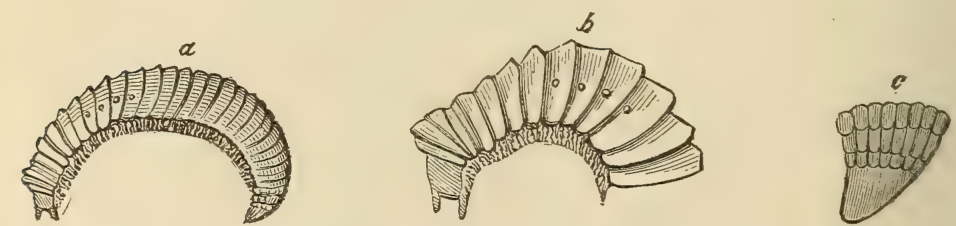

a. Nat. size.

Xylobius Sigillariae, Dawson.
b. Anterior part, magnified.

Coal, Nova Scotia.

c. Caudal extremity, magnified.

presents the hexagonal cells magnified 500 diameters, so like those of the recent Pupa that a figure of the latter is unnecessary. $\dagger$

* Dawson, Air-Breathers of the Coal.

1 Quart. Geol. Journ. 1853 vol. ix. p. 58. 
In a second specimen of an erect stump of a hollow tree 15 inches in diameter, the ribbed bark of which showed that it was a Sigillaria, and which belonged to the same forest as the specimen examined by us in 1852, Dr. Dawson obtained not only fifty specimens of $P$ upa vetusta and nine skeletons of reptiles belonging to four species, but also sereral examples of an articulated animal resembling the recent centipede or gally-worm, a creature which feeds on decayed vegetable matter, see fig. 562. Under the microscope, the head, with the eyes, mandible, and labrum are well seen. It is interesting, as being the earliest known representative of the myriapods none of which had previously been met with in rocks older than the oolite or lithographic slate of Germany.

\section{Rarity of Vertebrate and Invertebrate Air-breathers in Coat.}

Before the earliest date above mentioned (1844) it was common to hear geologists insisting on the non-existence of vertebrate animals of a higher grade than fishes in the Coal, or in any rocks older than the Permian. Even now, it may be said that we have made very little progress in obtaining a knowledge of the terrestrial fauna of the coal, since the reptiles above enumerated seem to have been almost all amphibious. Tegatire eridence should have its due weight in palæontological reasonings and speculations, but we are as yet quite unable to appreciate its ralue. In the United States, about five millions of tons of coal are annually extracted from the coal-measures, yet I am acquainted with no fossil insect which has yet been met with in the carboniferous rocks of North America. But as we have detected carboniferous insects in Europe (see p. 494), no one would now conclude that at the period of the Coal this class of invertebrata was unrepresented in the forests of the Western World. In like manner, no landshell, no Hclix, Bulimus, Pupa, or Clausilia, nor any aquatic pulmoniferous mollusk, such as Limnea or Planorbis, is recorded to have come from the coal of Europe, worked for centuries before America was discovered, and now quarried on so enormous a scale. But no one would now infer that land-shells had not been called into existence in European latitudes until after the Carboniferous period.

The theory of progressire derelopment might account plausibly for the absence of Chelonian and Saurian reptiles, or of Birds and Mammals, from the Coal-Measures, because it may be supposed that at so early a stage in the earth's history no organic beings higher than sauroid batrachians had made their appearance. But this same theory leares the scarcity of the invertebrata, or eren the entire absence of many important sections of them, wholly unexplained. When we generalize on this subject, we must not forget that, so lately as the year 1851, we knew of only two or three individual land-shells and some trenty specimens of insects, and scarcely double that number of individual reptiles in carboniferous rocks, and some of these reptiles 
had been recognized by the evidenee of footprints only. We have still but one species of land-sbell and one centipede. In regard to Archegosaurus, of which there are two species, M. Herman von Meyer informed me some years ago that the remains of more than 228 individuals passed through his hands soon after the true nature of the first specimen was recognized; and we have seen what great progress has since been made in bringing to light reptilian genera less aquatic in their organization. Nevertheless, the rarity of air-breathers is still a very remarkable fact, when we reflect that our opportunities of examining strata formed in close connection with ancient land exceed in this case all that we enjoy in regard to any other formations, whether primary, secondary, or tertiary. We have ransacked hundreds of soils replete with the fossil roots of trees-have dug out hundreds of erect trunks and stumps, which stood in the position in which they grew -have broken up myriads of cubic feet of fuel still retaining its vegetable structure-and, after all, we continue almost as much in the dark respecting the invertebrate air-breathers of this epoch, as if the Coal had been thrown down in mid-ocean. The early date of the car. boniferous strata cannot explain the enigma, because we know that while the land supported a luxuriant vegetation, the contemporaneous seas swarmed with life-with Articulata, Mollusca, Radiata, and Fishes. We must, therefore, collect more facts, if we expect to solve a problem which, in the present state of science, cannot but excite our wonder; and we must remember how much the conditions of this problem have varied within the last twenty years. We must be content to impute the scantiness of our data and our present perplexity partly to our want of diligence as collectors, and partly to our want of skill as interpreters. We must also confess that our ignorance is great of the laws which govern the fossilization of land-animals, whether of high or low degree.

\section{CARBONIFEROUS OR MOUNTAIN LIMESTONE.}

It has been already stated (p. 466), that this formation underlies the Coal-Measures in the South of England and Wales, whereas in the North and in Scotland marine limestones alternate with CoalMeasures, or with shale and sandstones, sometimes containing seams of Coal. In its most calcareous form the Mountain Limestone is destitute of land-plants, and is loaded with marine remains-the greater part, indeed, of the rock being made up bodily of corals and crinoids.

The Corals deserve special notice, as the cup and star corals, which have the most massive and stony skeletons, display peculiarities of structure by which they may be distinguished, as MM. Milne Edwards and Haime first pointed out, from all species found in strata newer than the Permian. There is, in short, an ancient or Palceozoic, and a 
modern or Neozoic type, if, by the latter term, we designate (as proposed by Prof. E. Forbes) all strata from the triassic to the most modern, inclusire. The accompanying diagrams (figs. 563, 564) may

Fig. 563.

Palcozoic type of lamelliferous eup-shaped Coral. Order ZoAvtmanIA BUGosa, Milne Edwards and Jules Haime.

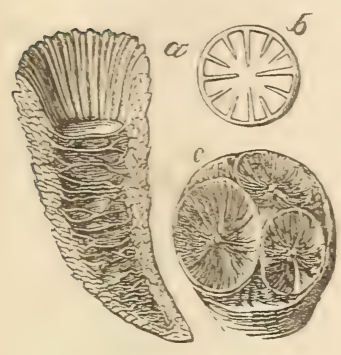

a. Vertical section of Campophyllum flexuosum (Cyathophyllum, Goldfuss); $\frac{1}{2}$ nat. size: from the Devonian of the Eitel. The limellos are seen around the inside of the cup; the walls consist of cellular tissue; and large transverse plates, called tabulco, divide the interior into chambers.

b. Arrangement of the lamelloc in Polycelia profunda. Germar, sp. ; nat. size: from the Magnesian Limestone, Durham. This diagram shows the quadripartite arrangement of the lamellæ characterlstic of palæozoic corals, there being 4 principal and 8 intermediate lamellæ, the whole number in this type being always a multiple of 4 .

c. Stauria astraformis, Milne Edwards. Young group, nat. size. Upper Silurian, Gothland. The lamella in each cup are divided by 4 prominent ridges into 4 groups.

Fig. 564.

Neozoic type of lamelliferous cup-shaped Coral. Order Zoartharia APorosa, M. Edwards and J. Haime.

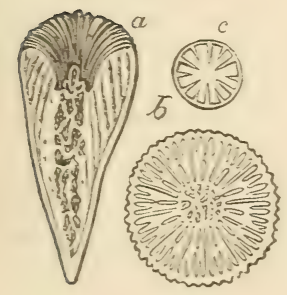

a. Parasmilia centratis, Mantell, sp. Vertical section, nat. size. Upper chalk, Gravesend. In this type the lamelle are massive, and extend to the axis of loose cellular tissue without any transverse plates like those in fig. $563 a$.

b. Cyathina Boverbankii, Edwards and Haime. Transverse section, enlarged. Gault, Folkestone. In this coral the lamelloe are a multiple of six. The twelve principal plates reach the central axis or columella, and between each pair there are three secondary plates, in all forty-eight. The short intermediate plates which proceed from the columella are not counted. They are called pali.

c. Fungia patellaris, Lamk. Recent: very young state. Diagram oî its six priacipal and six intermediate septa, magnified. The sextuple arrangement is always more manifest in the young than in the adult state."

illustrate these trpes; and, although it mas not alwars be eas 5 for any but a practised naturalist to recognize the points of structure here described, every geologist should understand them, as the reality of the distinction is of no small theoretical interest.

It will be seen that the more ancient corals hare what is called.a quadripartite arrangement of the stony plates or lamella-parts of the skeleton rhich support the organs of reproduction. The number of these lamellæ in the palæozoic type is $4,8,16$, dc.; while in the newer trpe the number is alwars $6,12,24$, or some other multiple of six; and this holds good, whether they be simple cup-like forms, as in figs. $593 a$ and $564 a$, or aggregate clusters of cups, as in $564 c$.

It is not enough, therefore, to say that the primary or more ancient corals are generically and specifically dissimilar from the secondary, tertiary, and living corals,-for, more than this, all the most conspicu- 
ous forms, viz., the cup and star corals, belong, as before mentioned (p. 515), to a distinct order, although they are often so like in out ward form as to have been referred in many cases to living reef-building genera. Hence we must not too confidently draw conclusions from the modern to the palæozoic polyps, respecting climate and the temperature of the waters of the primeval seas, inasmuch as the two groups of zoophytes are constructed on essentially different types. When the great number of the palæozoic and neozoic species is taken into account, it is truly wonderful to find how constant the rule above

Tig. 565.

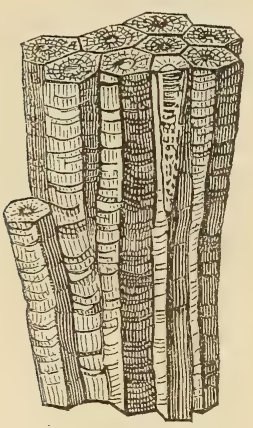

Lithostrotion basattiforme, Phil. sp. ( $L i$ thostrotion striatum, Fleming: Astrcea basaltiformis, Conyb. and Phill.) Kendall; Ireland; Russia; Iowa, and westward of the Mississippi, United States. (D. D. Owen.)
Fig. 566.

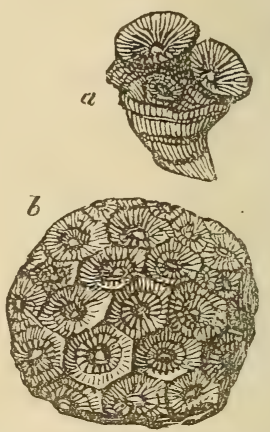

Lonsdalera floriformis (Martin, sp.), M. Edwards. (Lithostrotion floriforme, Fleming. Strombodes.)

a. Young specimen, with buds on the disk.

b. Part of a full-grown compound mass. Bristol, \&c.; Russia.

explained holds good; only one exception having as yet occurred of a quadripartite coral in a neozoic formation (the cretaceous), and one only of the sextuple class (a Fungia?) in palæozoic (Silurian) rocks.

From a great number of lamelliferous corals met with in the Mountain Limestone, two species have been selected, as having a very wide range, extending from the eastern borders of Russia to the British - Isles, and being found almost everywhere in each country.

These fossils, together with numerous species of Zaphrentis, Amplexus, Cyathophyllum, Clisiophyllum, Syringopora, and Michelinea,* form a group widely different from any that preceded or followed them.

Of the Bryozoa, the prevailing forms are Fenestella and Polypora, and these often form considerable beds. Their net-like fronds are easily recognized.

Crinoidea are also numerous in the Mountain Limestone. (See figs. $567,568$.

* For figures of these corals, see Palæontographical Society's Monographs, 1852. 
Fig. 567.

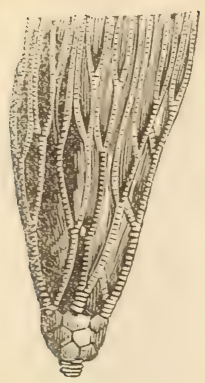

Cyathocrinites planus, Miller. Body and arms. Mountain Limestone.
Fig. 568.
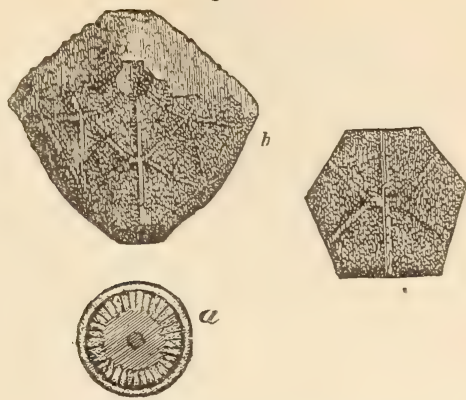

Cyathocrinus caryocrinoides, $\mathrm{M}^{\circ} \mathrm{Coy}$. a. Surface of one of the joints of the stem.

b. Pelvis or body; called also calyx or cup. $c$. One of the pelvic plates.

In the greater part of them, the cup or pelvis, fig. $568 b$, is greatly dereloped in size in proportion to the arms, although this is not the case in fig. 567. The genera Poteriocrinus, Cyathocrinus, Pentremites, Antinocrinus, and Platycrinus are all of them characteristic of this formation. Other Echinoderms are rare, a few Sea-Urchins only being known: these have a complex structure, with many more plates on their surface than are seen in the modern genera of the same group. One genus, the Palcechinus (fig. 569), is the analogie of the modern

Fig. 569.

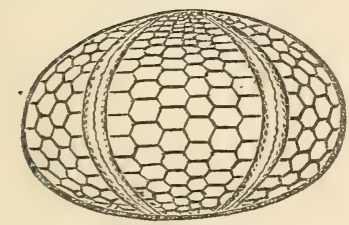

Paloechinus gigas, $\mathrm{M}^{6} \mathrm{Coy}$. Reduced. Mountain Limestone. Ireland.
Fig. 570

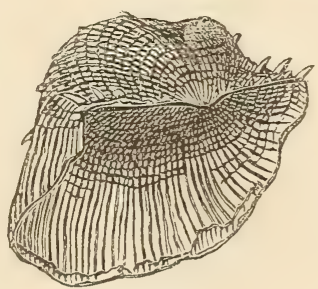

Productus semireticulatus, Martin, sp. ( $P$. antiquatus, Sow.) Mountain Limestone. England; Russia; the Andes, \&c.

Echinus. The other, Archcoocidaris, represents, in like manner, the Cidaris of the present seas.

Of Mollusca the Brachiopoda (or Palliobranchiates) constitute the larger part, and are not only numerous, but often of large size. Perhaps the most characteristic shells of the formation are large species of $P$ roductus, such as $P$. giganteus, $P$. hemisphcericus, $P$. semireticulatus (fig. 570), and $P$. scabriculus. Large plaited spirifers, as Spirifer striatus, S. rotundatus, and S. trigonalis (fig. 571), also abound; and smooth species, such as Spirifer glaber (fig. 572), with its numerous varieties.

The family of the brachiopoda to which these shells belong, is far 


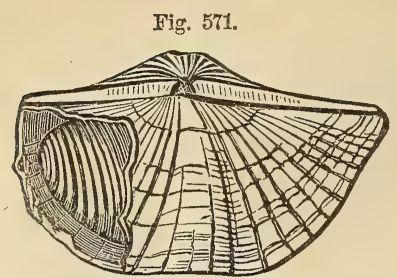

Spirifer trigonalis, Martin, sp. Mountain Limestone. Derbyshire, \&c.
Fig. 572.

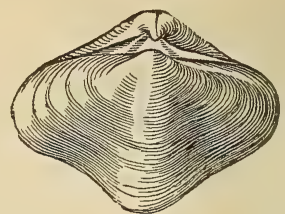

Spirifer glaber, Martin, sp. Mountain Limestone.

more numerously represented in these carboniferous rocks than in the secondary formations described in former chapters; individually, as Professor Ramsay has observed,* they may outnumber the lamellibranchiate mollusks, although the species of carboniferous lamellibranchiate more than double the contemporary brachiopoda. The increasing num ber of the last-mentioned group among the bivalve mollusca, both in genera, species, and individuals, will be found to be a marked feature in the fauna of the primary rocks the lower we descend in the series.

Among the brachiopoda or palliobranchiate mollusks, Terebratula hastata deserves mention, not only for its wide range, but because it often retains the pattern of the original colored stripes which ornamented the living shell. (See fig. 573.) These colored bands are also preserved in several lamellibranchiate bivalves, as in Aviculopecten (fig. 574), in which dark stripes alternate with a light ground. In some also of the spiral univalves, the pattern of the original painting is dis tinctly retained, as in Pleurotomaria (fig. 575), which displays wavy blotches, resembling the coloring in many recent Trochidæ.

Fig. 573.

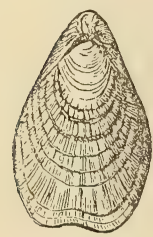

Terebratula hastata, Sow., with radiating bands of color. Mountain Limestone. Derbyshire; Ireland; Russia, \&c.
Fig. 574

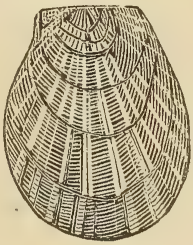

Aviculopecten sublobatus, Phill. Mountain Limestone, Derbyshire; Yorkshire.
Fig. 575.

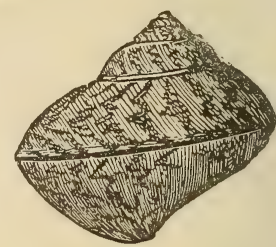

Pleurotomaria carinata, Sow. ( $P$. flammigera, Phill.)

Mo untain Limestone. Derbyshire, \&e.

The mere fact that shells of such high antiquity should have preserved the patterns of their coloring is striking and unexpected; but Professor E. Forbes has deduced from it an important geological conclusion. He infers that the depth of the primeval seas in which the Mountain Limestone was formed did not exceed fifty fathoms. To 
this opinion he is led by observing that in the existing seas the testacea which have colors and well-defined patterns rarely inhabit greater depths than 50 fathoms; and the greater number are found where there is most light in very shallow water, not more than two fathoms deep. There are eren examples in the British seas of testacea which are always white or colorless when taken from below 100 fathoms; and yet indiriduals of the same species, if taken from shallower zones, are vividly striped or banded.

This information, derived from the color of the shells, is the more welcome, because the Radiata, Articulata, and Mollusca of the Carboniferous period belong almost entirely to genera no longer found in the living creation, and respecting the habits of which we can only hazard conjectures.

Some few of the carboniferous mollusca, such as Avicula, Nucula, Solemya, and Lithodomus, belong no doubt to existing genera; but the majority, though often referred to living types, such as Isocardia, Turritella, and Buccinum, belong really to forms which appear to have become extinct at the close of the Palæozoic epoch. Euomphalus is a characteristic univalve shell of this period. In the inte-

\section{Fig. 576.}
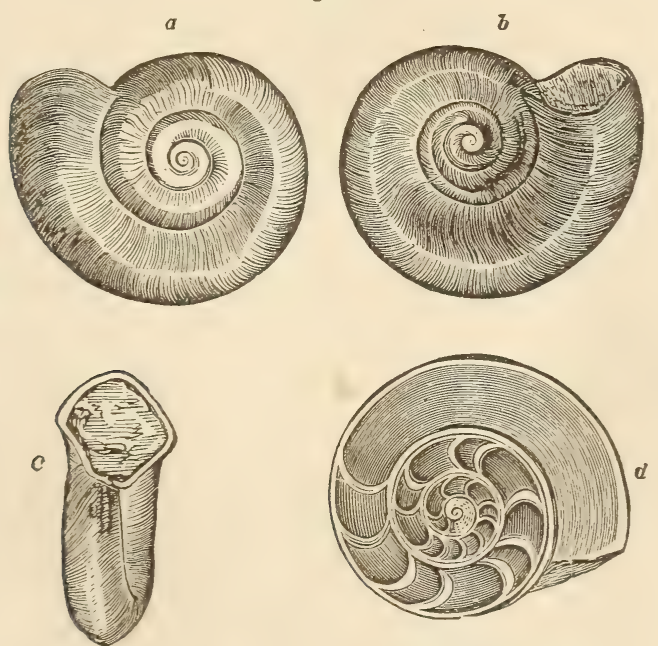

Euomphalus pentagulatus, Sowerby. Mountain Limestone.

a. Upper side. b. Lower, or umbilical side. c. View showing mouth, which is less nentagonal in older individuals. $d$. View of polished section, showing internal chambers.

rior it is often divided into chambers (fig. $576 d$ ), the septa or partitions not, being perforated as in foraminiferous shells, or in those having siphuncles, like the Nautilus. The animal appears to have retreated at different periods of its growth from the internal cavity previously formed, and to have closed all communication with it by 
Fig. 577.

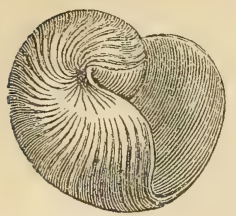

Bellerophon costatus, Sow. Mountain Limestone. a septum. The number of chambers is irregular, and they are generally wanting in the innermost whorl. The animal of the recent Turritella communis partitions off in like manner as it advances in age a part of its spire, forming a shelly septum.

Nearly twenty species of the genus Bellerophon (see fig. 577), a shell without chambers like the living Argonaut, occur in the Mountain

Limestone. The genus is not met with in strata of later date. It is most generally regarded as belonging to the Heteropoda, and allied to the Glass-Shell, Carinaria; but by some few it is thought to be a simple form of Cephalopod.

The carboniferous Cephalopoda do not depart so widely from the living type (the Nautilus) as do the more ancient Silurian representatives of the same order; yet they offer some remarkable forms scarcely known in strata newer than the coal. Among these is Orthoceras, a siphuncled and chambered shell, like a Nautilus uncoiled and straightened (fig. 578). Some species of this genus are

Fig. 578.

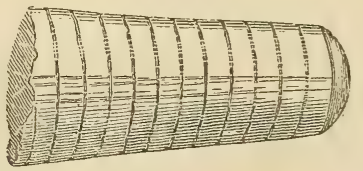

Portion of Orthoceras laterale, Phillips. Mountain Limestone.

several feet long. The Goniatite is another genus, nearly allied to the Ammonite, from which it differs in having the lobes of the septa free from lateral denticulations, or crenatures; so that the outline of these is continuous and uninterrupted.

Fig. 579.

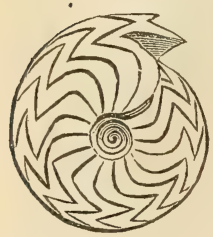

Goniatites crenistria, Phill. Mountain Limestone. N. America; Britain; Germany, \&c. a. Lateral view.

b. Front view, showing the mouth.
Fig. 580 .

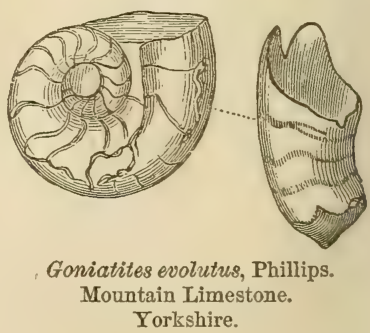
Yorkshire.

The species represented in fig. 579 is found in almost all localities, and presents the zigzag character of the septal lobes in perfection.

In another species (fig. 580), the septa are but slightly wared, and so approach nearer to the form of those of the Nautilus. The dorsal 
position of the siphuncle, howerer, clearly distinguishes the Goniatite from the Nautilus, and proves it to have belonged to the family of the Ammonites, from which, indeed, some authors do not believe it to be generically distinct.

Fossil Fish.-The distribution of these is singularly partial; so much so, that M. de Koninck of Liege, the eminent palæontologist, once stated to me that, in making his extensive collection of the fossils of the Mountain Limestone of Belgium, he had found no more than four or five examples of the bones or teeth of fishes. Judging from Belgian data, he might have concluded that this class of vertebrata was of extreme rarity in the carboniferous seas; whereas the investigation of other countries has led to quite a different result. Thus, near Clifton, on the Avon, there is a celebrated "bone-bed," almost entirely made up of ichthyolites; and the same may be said of the "fish-beads" of Armagh, in Ireland. They consist chiefly of the teeth of fishes of the Placoid order, nearly all of them rolled as if drifted from a distance. Some teeth are sharp and pointed, as in ordinary sharks, of which the genus Cladodus affords an illustration; but the majority, as in Psammodus and Cochliodus, are, like the teeth of the Cestracion of Port Jackson (see above, fig. 322, p. 330), massive palatal teeth fitted for grinding. (See figs. 581, 582.)

Fig. 581.

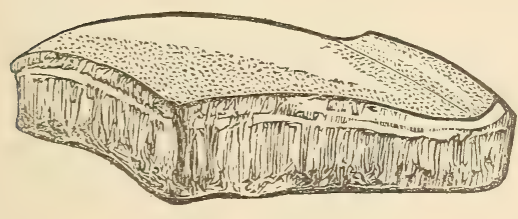

Psammodus porosus, Agass. Bonc-bed, Moun tain Limestone. Bristol; Armagh.
Fig. 582 .

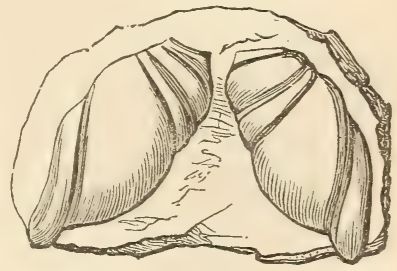

Cochtiodus contortus, Agass. Bonebed, Mountain Limestone. Bristol; Armagh.

There are upwards of seventy other species of fossil fish known in the Mountain Limestone of the British Islands. The defensive finbones of these creatures are not unfrequent at Armagh and Bristol; those known as Oracanthus are often of a very large size. Ganoid fish, such as Holoptychins, also occur; but these are far less numerous. The great Megalichthys Hibberti appears to range from the Upper Coal-measures to the lowest Carboniferous strata.

Foraminifera.-In the upper part of the Mountain Limestone group m the S.IW. of England, near Bristol, limestones having a distinct oolitic structure alternate with shales. In these rocks the nucleus of every minute spherule is seen, under the microscope, to consist of a small rhizopod or foraminifer. This division of the lower animals, which is represented so fully at later epochs by the Nummulites and their numerous minute allies, appears in the Mountain Limestone to 
be restricted to a very few species, among which Textularia, Nodo-

Fig. 583.

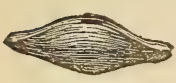

Frusutina cytin. drica, D’Orb.

Magnified 3 diam.

Mountain Limestone. saria, Endothyra, and Fusulina (fig. 583), have been recognized. The first two genera are common to this and all the after periods; the third has been found in the Upper Silurian, but is not known above the Carboniferous strata; the fourth (fig. 583) is peculiar to the Mountain Limestone, and is characteristic of the formation in the United States, Arctic America, Russia, and Asia Minor.

\section{STRATA CONTEMPORANEOUS WITH THE MOUNTAIN LIMESTONE.}

In countries where limestone does not form the principal part of the Lower Carboniferous series, this formation assumes a very different character, as in the Rhenish Provinces of Prussia, and in the Hartz. The slates and sandstones called Kiesel-schiefer and Younger Greywacke (Jungere Grauwacke) by the Germans, were formerly referred to the Devonian group, but are now ascertained to belong to the "Lower Carboniferous." The prevailing shell which characterizes the carbonaceous schists of this series, both on the Contirient and

Fig. 5\$4.

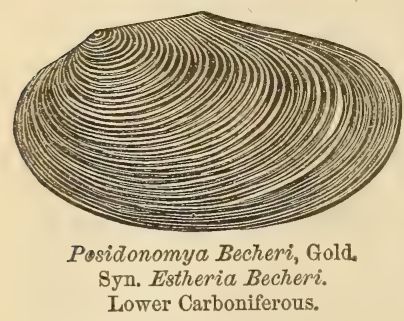
in England, is Posidonomya Becheri (fig. 584). Some well-known mountain-limestone species, such as Goniatites crenistria (see fig. 579), and G. reticulatus, also occur in the Hartz. In the associated sandstones of the same region, fossil plants, such as Lepidodendron and the allied genus Sagenaria, are eommon; also Knorria, Calamites Suckovii, and C. transitionis, Göpp., some peculiar, others specifically identical with ordinary coal-measure fossils. The true geological position of these rocks in the Hartz was first determined by MM. Murchison and Sedgwick in 1840.*

\section{CARBONIFEROUS LIMESTONE IN NORTH AMERICA.}

The coal-measures of Nova Scotia have been described, page 484 . The lower division contains, besides large stratified masses of gypsum, some bands of marine limestone almost entirely made up of encrinites, and, in some places, containing shells of genera common to the mountain limestone of Europe.

In the United States the carboniferous limestone underlies the pro-

* Trans., Geol. Soc. London, Second Series, vol. vi. p. 228. 
ductive coal-measures; and, although very inconspicuous on the margin of the Alleghany or Great Appalachian coal-field in Pennsylvania, it expands in Virginia and Temnessee. Its still greater extent and importance in the Western or Mississippi coal-fields, in Kentucky, Indiana, Iowa, Missouri, and other Western States, has been well shown by Dr. D. Dale Owen. In those regions * it is abont 400 feet thick, and abounds, as in Europe, in shells of the genera Productus and Spirifer, with Pentremites, and other crinoids and corals. Among the latter, Lithostrotion basaltiforme or striatum (fig. 565, p. 516), or a closely-allied species is common.

\section{CHAPTER XXVI.}

OLD RED SANDSTONE, OR DEVONIAN GROUP.

Old Red Sandstone of the Borders of Wales-Of Scotland and the South of Ireland-Fossil Devonian plants at Kilkenny-Holoptychius of the Middle and Cephalaspis of the Lower Old Red of Forfarshire-Pterygotus and supposed eggs of Crustaceans-Northern type of Old Red in Scotland-Classification of the Ichthyolites of the Old Red, and their relation to living types-Distinct lithological type of Old Red in Devon and Cornwall-Term "Devonian"-Organic remains of intermediate character between those of the Carboniferous and Silurian systems-Devonian series of England and the Continent-Upper Devonian rocks and fossils-Middle-Lower-Old Red Sandstone of Russia-Preponderance of Brachiopoda-Deronian strata of the United States and CanadaCoral reefs at the falls of the Ohio-Gaspé Sandstone-Vegetation of the Devonian period.

IT has been already shown in the section (p. 431), that the carboniferous strata are surmounted by a system called "The New Red," and underlaid by another termed the "Old Red Sandstone." The last-mentioned group acquired this name because in Herefordshire and Scotland, where it was originally studied, it consisted chiefly of red sandstone, shale, and conglomerate. It was afterwards termed "Devonian," for reasons which will be explained in the sequel. For many years it was regarded as very barren of organic remains; and such is undoubtedly its character, over very wide areas where calcareous matter is wanting, and where its color is determined by the red oxide of iron.

"Old Red" in Herefordshire, \&c.-In Herefordshire, Worcestershire, Shropshire, and South Wales, this formation attains a great

* Owen's Geol. Survey of Wisconsin, \&c., 1852. 
thickness, sometimes between 8000 and 10,000 feet. In these regions it has been subdivided into

1st. Conglomerate.

2dly. Brownstone series-chiefly reddish-green and brown sandstones, with large Eurypterus.

3dly. Marl and Cornstone-red and green argillaceous spotted marls, with irregular courses of impure concretionary limestone, provincially called Cornstone, and some beds of white sandstone. In the cornstones, and in those flagstones and marls through which calcareous matter is most diffused, some spines of fish of the family Acanthodidoe, and remains of Cephalaspis and Pteraspis occur.

4thly. Ledbury Shales-thin olive shales of Ledbury and Ludlow, and sandstones intercalated in thick beds of red marl. Fish of the genera Cephalaspis, Auchenaspis, \&c., specifically distinct from those of the underlying Silurian.

Old Red Sandstone of Scotland and Ireland.-South of the Grampians, in Forfarshire, Kincardineshire, and Fife, the Old Red Sandstone may be divided into three groups :

A. Yellow sandstone.

B. Red shale, sandstone with cornstone, and at the base a con glomerate (Nos. 1, 2, and 3, Section, p. 48).

C. Roofing and paving stone, highly micaceous, and containing a slight admixture of carbonate of lime (No. 4, p. 48).

The united thickness of A, B, and C, in Fife and Forfarshire, must amount to 3000 or 4000 feet; and perhaps in some places, where the conglomerates of $B$ are largely developed, to much more than 4000 .

A.-The upper member, or yellow sandstone, is seen at Dura Den, near Cupar, in Fife, immediately underlying the coal, It consists of a yellow sandstone in which fish of the genera Pterichthys (for genus see fig. 600), Pamphractus, Bothriolepis, Glyptopomus, Holoptychius, and others abound.

In Ireland the upper beds of the Old Red, or yellow sandstone of Kilkenny, contain fish of the genera Coccosteus and Dendrodus, characteristic forms of this period, together with plants specifically distinct from any known in the coal-measures, but referable to the genera found in them; as, for example, Lepidodendron, Cyclopteris

Fig. 585 .

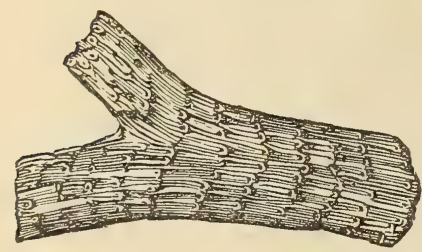

Stem of Lepidodendron, so compressed as to destroy the quincunx arrangement of the scars. Upper Devonian, Kilkenny.
Fig. 586.

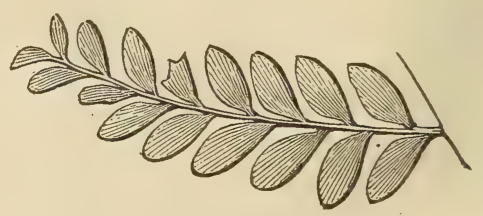

Cyclopteris Hibernica, Forbes. Upper Devonian, Kilkenny. 
(see fig's. 585 and 586). The stems of the latter have, in some specimens, broad bases of attachment, and may therefore have been treeferns.

In the same strata shells having the form of the genus Anodon, and which probably belonged to freshwater testacea, occur. Some geologists, it is true, still doubt whether these beds ought not rather to be classed as the lowest beds of the carboniferous series, together with the yellow sandstone of Sir R. Griffiths (see p. 466); but the associated ichthyolites and the distinct specific character of the plants, strongly favor the opinion above expressed.

B.-We come next to the middle division of the "Old Red," as exhibited south of the Grampians, and consisting of-1st, red shale and sandstone, with some cornstone, occupying the Valley of Strathmore, in its course from Stonehaven to the Firth of Clyde; and, 2 dly, of a conglomerate, seen both at the foot of the Grampians, and on the flanks of the Sidlaw Hills, as shown in the section at p. 48, Nos. 1, 2, and 3. In the uppermost part of the division No. 1, or in the beds which, in Fife, underlie the yellow sandstone, the scales of a large ganoid fish, of the genus Holoptychius, were first observed by Dr. Fleming at Clashbinnie, near Perth, and an entire specimen, more than 2 feet in

Fig. 587.

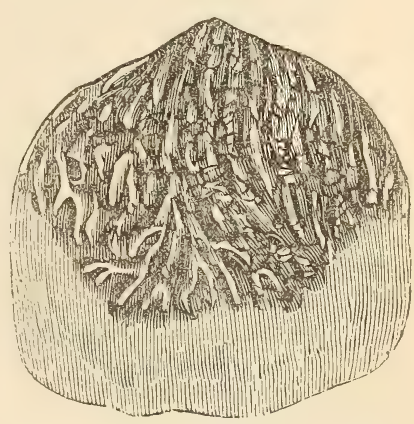

Scale of Holoptychius nobitissimus, Agass, Clashbinnie. Nat. size.

length, was afterwards found by Mr. Noble. Some of these scales (see fig. 587) measured 3 inches in length and $2 \frac{1}{2}$ in breadth.

Fig. 588.

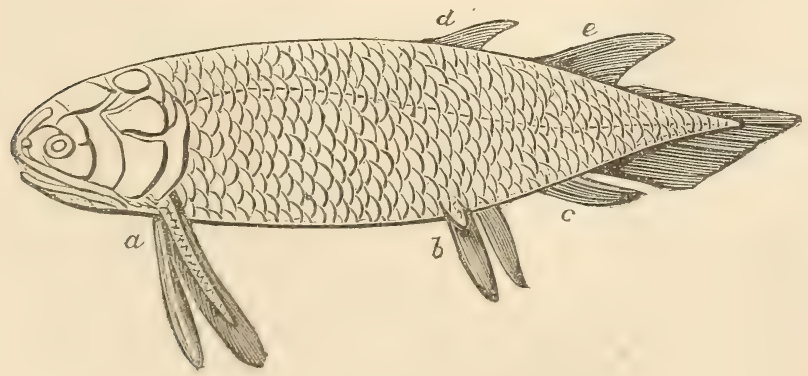

Holoptychius. As restored by Professor Huxlcy. For tooth of this genus, see p. 505, fig. 556 .

$a$. The fringed pectoral fins.

b. The fringed ventral fins.

c. Anal fin.

d, e. Dorsal fins.

C (Table, p. 524). - The third or lowest division south of the 
Grampians consists of gray paving-stone and roofing-slate, with associated red and gray shales; these strata underlie a dense mass of conglomerate. In these gray beds several remarkable fish have been found of the genus named by Agassiz Cephalaspis, or "bucklerheaded," from the extraordinary shield which covers the head (see fig. 589), and which has often been mistaken for that of a trilobite such as Asaphus.

Fig. 589.

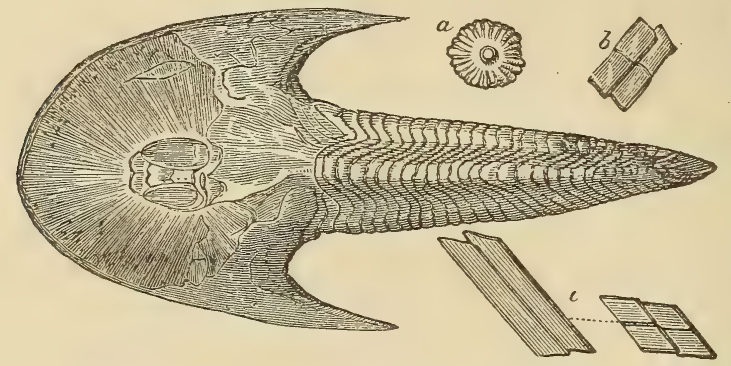

Cephalaspis Iyellii, Agass. Length $6 \frac{8}{4}$ inches.

From a specimen in my collection found at Glammiss, in Forfarshire; see other igures, Agassiz, vol. ii. tab. $1 a$ and $1 b$.

$a$. One of the peculiar scales with which the head is covered when perfect. These scales are generally removed, as in the specimen above figured.

$\zeta, c$. Scales from different parts of the body and tail.

A species of Pteraspis, of the same family, has also been found by the Rev. Hugh Mitchell in beds of corresponding age in Perthshire, and Mr. Powrie enumerates no less than five genera of the family Acanthodidæ, the spines, scales, and other remains of which have been detected in the gray flaggy sandstones.*

In the same formation at Carmylie, in Forfarshire, commonly known as the Arbroath paving-stone, fragments of a huge crustacean have been met with from time to time. They are called by the Scotch quarrymen the "Seraphim," from the wing-like form and feather-like ornament of the thoracic appendage, the part most usually met with. Agassiz, having previously referred some of these fragments to the class of fishes, was the first to recognize their crustacean character, and, although at the time unable correctly to determine the true relation of the several parts, he figured the portions on which he founded his opinion, in the first plate of his "Poissons Fossiles du Vieux Grès Rouge."

A restoration in correct proportion to the size of the fragments of $P$. anglicus, from the Lower Old Red Sandstone of Perthshire and Forfarshire, would give us a creature measuring from 5 to 6 feet in length, and more than 1 foot across; and Mr. Salter is of opinion that $P$. problematicus, Ag., from the Downton Sandstone, and $P$. 
gigas, Salt., from the Tpper Ludlow Rock, attained dimensions fu.ly as large, even up to 7 feet.

Fig. 590 .

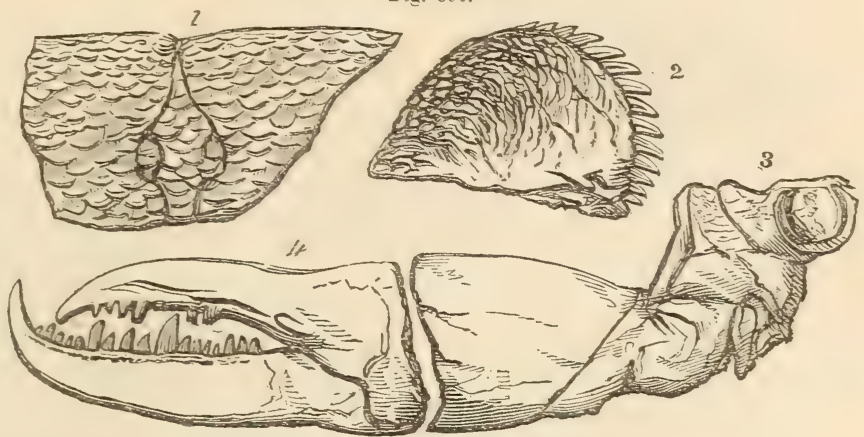

Portion of the Pterygotus anglicus, Agassiz.

1. Middle portion of the "Seraphim," or back of the head, with the scale-like sculpturing.

2. Portion of the dilated base of one of the anterior feet, with its strong spines or teeth, used as masticating organs.

3. The proximal portion of one of the great anterior claws.

4. Termination of the same, with the serrated pincers. (See Agass., Poiss. Foss, du Vieux Grès Ronge, plate A.).

1 and 2 are of the natural size; 3 and 4 are reduced one-half.

Pterygotus anglicus. Ag., Forfarshire, Ventral aspect. Restored by H. Woodward, F.G.S., from nearly perfect specimens of allied species, found in the Upper Ludlow Rock of Lestmahagow.

a. Carapace, showing the large sessile eyes at the anterior angles.

b. The metastoma or post-oral plate (serving the office of a lower lip).

$c, c$. Chelate appendages (antennules).

d. First pair of simple palpi (antenne).

e. Second pair of simple palpi (mandibles).

$f$. Third pair of simple palpi (first maxitlo).

g. Pair of swimming feet with their broad basal joints, whose serrated edges serve the office of maxillce.

$h$. Thoracic or genital plate covering the reproductive organs (and probably also the branchiæ), composed of two broad lateral alæ, and a slender median lobe, varying in form according to the sex. This thoracic plate covers the first two thoracic segments, which are indicated by figures and a dotted line.

1-6. Thoracic segments.

7-12. Abdominal segments.

13. Telson, or tail-plate.
Fig. 591.

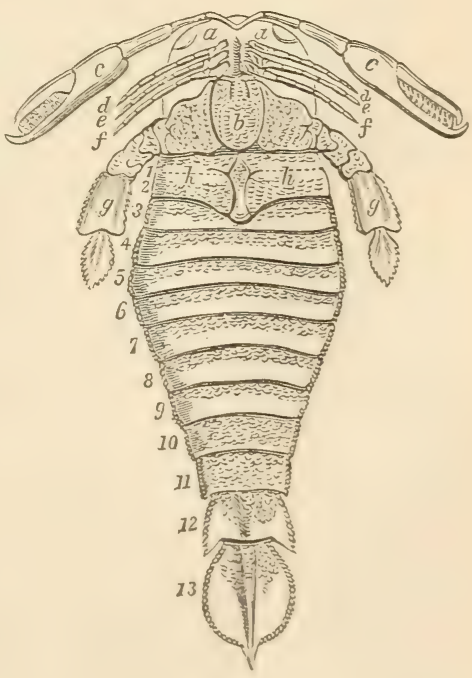

The largest crustaceans living at the present day are the Inachus Kcempferi of De Haan, from Japan (a brachyurous or short-tailed crab), chiefly remarkable for the extraordinary length of its limbs; the fore arm measuring 4 feet in length, and the others in proportion, 
so that it covers about 25 square feet of ground; and the Limulus Moluccanus, the great King Crab of China and the eastern seas, which, when adult, measures $1 \frac{1}{2}$ foot across its carapace, and is 3 feet -in length.

Parka decipiens.-In the same gray paving-stones and coarse roofing-slates in which the Cephalaspis and Pterygotus occur, in Forfarshire and Kincardineshire, the remains of grass-like plants abound in such numbers as to be useful to the geologist by enabling him to identify corresponding strata at distant points. Whether these be fucoids, as I formerly conjectured, or freshwater plants of the family Fluviales, as some botanists suggest, cannot yet be determined, They are often accompanied by fossils, called "berries" by the quarrymen, and which are not unlike the form which a compressed blackberry or raspberry might assume (see figs. 592 and 593). Some of these were first observed in the year 1828, in gray sandstone of the same age as that of Forfarshire, at Parkhill near Newburgh, in the north of Fife, by Dr. Fleming. I afterwards found them on the north side of Strathmore, in the vertical shale beneath the conglomerate, and in the same beds in the Sidlaw Hills, at all points where fig. 4 is introduced in the section, p. 48 .

Dr. Fleming has compared these fossils to the panicles of a Juncus, or the catkins of Sparganium, or some allied plant, and he was confirmed in this opinion by finding a specimen at Balrudderie, showing the under surface smoother than the upper, and displaying what may

Fig. 592 .

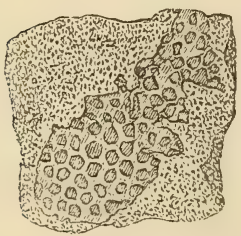

Parka decipiens, Fleming. In sandstone of lower beds of Old Red, Ley's Mill, Forfarshire.
Fig. 593,

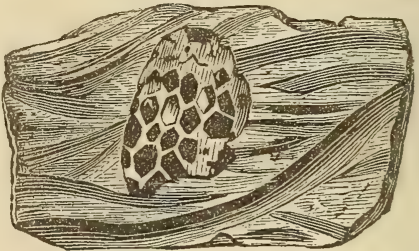

Parta decipiens, Fleming. In shale of lower beds of Old Red, Fife.
Fig. 594.

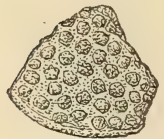

Fragment of spawn of British species of Natica.

be the place of attachment of a stalk. I have met with some specimens in Forfarshire imbedded in sandstone, and not associated with the leaves of plants (see fig. 592), which bore a considerable resemblance to the spawn of a. recent Natica (fig. 594 ), in which the eggs are arranged in a thin layer of sand, and seem to have acquired a polygonal form by pressing against each other; but, as no gasteropodous shells have been detected in the same formation, the Parka has probably no connection with this class of organisms. 
The late Dr. Mantell was so much struck with the resemblance of one of my specimens (see fig. 595) to a small bundle of the dried-up eggs of the common English frog, which he had obtained in a black and carbonaceous state (see fig. 596) from the mud of a pond near

Fig. 595.

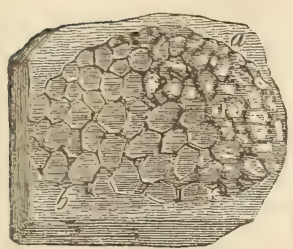

Fossil._old Red.
Fig. 596.

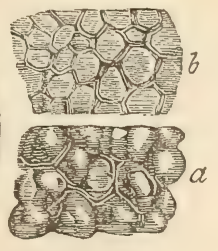

Recent.

Fig. 595. Slab of Old Red Sandstone, Forfarshire, with bodies like the ova of Batrachians.

a. Ora? in a carbonized state.

b. Egg-cells ? the ova shed.

Fig. 596. Eggs of the common frog, Rana temporaria, in a carbonized state, from a dried-up pond in Clapham Common.

a. The ova.

b. A transverse section of the mass, exhibiting the form of the egg-cells.

London, that he suggested a batrachian origin for the fossil ; and Mr. Newport concurred in the idea, adding that other larger and more circular fossils (fig. 597), which I procured from shale in the same "Old Red," occurring singly or in pairs, and attached to the leaves of plants, might possibly be the ora of some gigantic Triton or Salamander.

Fig. 59i.

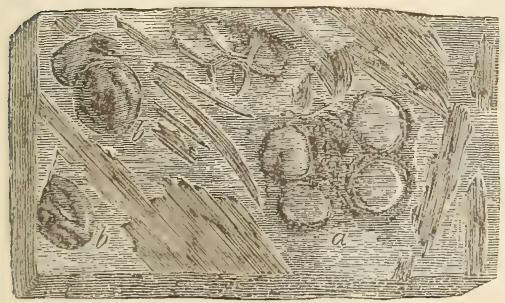

Fig. 597. Shale of Old Red Sandstone, or Devonian. Forfarshire, with impression of plants and eggs of Crustaceans. a. Two pair of ova? resembling those of large Salamanders or Tritons.

b, b. Detached ova.

The general absence of reptilian remains from strata of the Devonian period always weighed strongly with most geologists against such conjectures, and Mr. Salter in 1859, and more lately Mr. Powrie, have suggested that Paika decipiens occurs too often associated with Pterygotus not to incline one to suspect that they are the egg's of that crustacean. They have not only been found with $P$. anglicus in Forfarshire and Perthshire, but also with $P$. problematicus at Ludlow, and with $P$. ludensis at Kidderminster, in the uppermost Silurian strata. Against the hrpothesis of these bodies being seed-ressels, it is urged that there is no trace of a style nor of a leafy involucrum. They are supposed to hare constituted a single layer of ora enclosed in a membrane, and not a number of egres lying crowded one orer the other in a sack.

"Old Red" in the North of Scotland.-The whole of the northern part of Scotland, from Cape Wrath to the southern flank of the Gram- 
pians, has been well described by the late Hugh Miller as consisting of a nucleus of granite, gneiss, and other hypogene rocks, which seem as if set in a sandstone frame. The beds of the Old Red Sandstone constituting this frame may once perhaps have extended continuously over the entire Grampians before the upheaval of that mountain range; for one band of the sandstone follows the course of the Moray Frith far into the interior of the Great Caledonian valley, and detached hills and island-like patches occur in several parts of the interior, capping some of the higher summits in Sutherlandshire, and appearing in Morayshire like oases among the granite rocks of Strathspey.

As the mineral character of the "Old Red" north of the Grampians differs considerably from that of the south; especially in the middle and lower divisions, I shall now allude to it separately. The uppermost portion was formerly supposed to include certain light-colored sandstones near Elgin containing reptilian remains (Telerpeton, \&c.), which we have now good reason to suspect are of much newer or Triassic date ; * but, besides these whitish sandstones, there are others of a yellowish color near Elgin, which are perhaps the true equivalents of the yellow sandstone of Fife (A, p. 524). This upper division passes downwards into red and variegated sandstone and conglomerate, which may correspond with the beds called $B$ of the same table, p. 524 .

In this part of the series certain bituminous schists and flagstones occur in the Orkneys and Caithness, Cromarty, Moray, Nairn, and Banff, which are very rich in fossil fishes. Below the fish-beds are sandstones and shales, barren of organic remains, several hundred and sometimes nearly a thousand feet thick. As the ichthyolitic zone was the lowest in which fossils had been discovered in the North, it was classed palæontologically by Hugh Miller as the base of the Old Red

* Supposed Reptilian Remains of the Old Red.-In a former edition of this work I noticed the discovery of the bones of a reptile found in some white sandstone charged with carbonate of lime forming the upper part of a long series of conformable strata in the neighborhood of Elgin. To this reptile the late Dr. Mantell gave the name of Telerpeton Elginense; it was associated with scales or scutes supposed by Agassiz to be those of a fish, and called by him Stagonolepis, but which Prof. Huxley has since shown to be crocodilian, and of the Teleosaurian type. The jaw, teeth, femur, and some caudal vertebræ have now been found, and they indicate an animal about eight feet long. Another reptile, Hyperodapedon, Huxley, closely allied to the triassic Rluynchosaurus, has also been met with in the same beds, so that it appears highly probable that the light-colored stones near Elgin containing these fossils are referable to the Triassic, and not, as was formerly imagined, to the "Old Red," or Devonian period.

The strata in question have been shown in 1863 by Prof. Harkness to be perfectly conformable, both near Elgin and in Ross-shire, with sandstones containing unequivocal "Old Red" fishes, but between these and the reptiliferous strata there intervenes everywhere a conglomerate, and Mr. C. Moore has justly remarked (Harkness, Geol. Quart. Journ., vol. xx. p. 429, 1864), that the destruction of older rocks atiested by such pebble beds may imply a break in the series, andla lapse of unrepresented time of indefinite extent. 
system, and considered by him to be older than the division C, of the table, p. 524, or those paring-stones and roofing-slates of Forfarshire, which contain Cephalaspis and Pterygotus before described, p. 526. He fell naturally into this mistake by observing that the fish-beds where he studied them most carefully, at Cromarty, were in almost immediate juxtaposition with certain crystalline or metamorphic rocks, so that they seemed to form the base of the Devonian system. Another source of error, says Sir R. Murchison, arose from the gradual thinning out of the bituminous and calcareous schists and flag stones as we proceed from north to south. Already these schists, when we reach Nairn and Elgin, are represented by clays with calcareous nodules only; and this is still more the case at Gamrie in Banff. Still further southwards even these nodules are no longer traceable in the middle portion of the Old Red Sandstone.*

Hence the relative position of the middle and lower beds could not be prored by direct superposition, the Caithness fish-beds being wanting in Forfarshire, and the Forfarshire Cephalaspis beds alike absent in Caithness. But all doubt as to the true order of superposition, if any still remained, was set at rest in 1861, when Mr. Peach, under the direction of Sir R. Murchison, searching for fossils in Caithness, found in sandstones, many hundreds of feet below the fish-zone, undoubted remains of Pterygotus. These crustaceans are characteristic of the Cephalaspis zone, and hare never been found in the great fish-bed of the middle dirision of the Old Red. This discovery, therefore, confirmed the anticipations of Sir Roderick, who had previously maintained that the lower sandstones of Caithness were the equivalents of the Forfarshire paring-stone, and of certain beds of Herefordshire and Shropshire, which immediately overlie the bone-bed of the Upper Ludlow. $\dagger$

Mr. Powrie remarks that very few genera and no species of fish are common to this Lower or Cephalaspis division, and to the Middle or Caithness beds, whereas no such marked break occurs between the ichthyic forms of the Middle and those of the Upper or Yellow Sandstone division.

\section{Classification of the Fossil Fish of the Old Red Sandstone.}

The fish of the schists and flagstones in question are very peculiar and characteristic. They mere first successfully studied by the late Hugh Miller, who gave an admirable description and restorations of many of them. They were also the subject in 1844 of a special monograph by Agassiz, in which he described no less than sixty-five British species alone, and several important memoirs on Pterichthys and other

* Murchison, Siluria, 3d ed., p. 286, 1859.

$\uparrow$ Powrie, Geol. Quart. Journ., vol. xiv. p. 503, 1858; and Murchison, Siluria, 3d ed., p. 280, \&c., 1859.

$\ddagger$ Powrie, ibid., p. 428. 
genera were afterwards published by Sir P. Egerton, whose labor's in this field (including a synopsis of all the genera known in 1857) have been acknowledged by Professor Huxley as having powerfully contributed to clear up his ideas when he undertook, in 1861, the difficult task of classifying these fishes. To the Russian zoologist, Pander, we are also indebted for a most able treatise on these ichthyolites. Professor Huxley's masterly essay is of a later date 'than Pander's, and contains a systematic arrangement of the British Devonian fish, which, he observes, are of surpassing interest, as comprising the oldest assemblage of vertebrate animals of which we can be said to have any tolerably complete knowledge; for no reptiles have yet been found older than those of the coal, and the Silurian fish are confined to a few isolated specimens, affording us a very scanty insight into the character of the piscine fauna anterior to the period of the Old Red Sandstone.

The Devonian fish were referred by Agassiz to two of his great orders, namely, the Placoids and Ganoids. Of the first of these, which in the Recent period comprise the shark, the dog-fish, and the ray, no entire skeletons are preserved, but fin-spines called Ichthyodorulites, and teeth occur. On such remains the genera Onchus; Odontacanthus and Ctenodus, a supposed cestraciont, and some others, have been established. There are also some spiny fish of a family called Acanthodidæ, not yet well understood, and thought by Huxley to have some connection with the Placoids, although he admits that they may perhaps have still more claims to rank with the Ganoids, with which they have been usually classed.

Among the Ganoids are the Cephalaspidæ (see fig. 589, p. 526), represented by several genera, Cephalaspis, Pteraspis, \&c., and forming a very distinct family, but having, according to Huxlev, a considerable relationship with the sturgeon.

By far the greater number, however, of the Old Red Sandstone fishes belong to a sub-order of Ganoids instituted by Huxley in 1861, and for which he has proposed the name of Crossopterygidce, ${ }^{*}$ or the fringefinned, in consideration of the peculiar manner in which the fin-rays of the paired fins are arranged so as to form a fringe round a central lobe, as in the Polypterus (see $a$, fig. 598), a genus of which there are

Fig. 598.

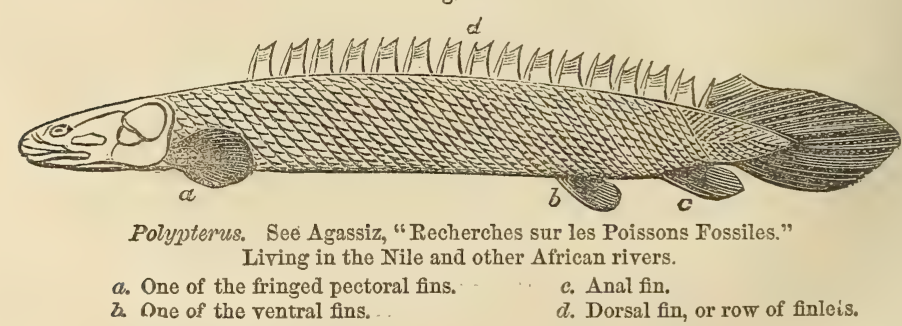

* Abridged from $\kappa \rho \circ \sigma \sigma \omega \tau o \varsigma$, crossotos, a fringe, and $\pi \tau \varepsilon \rho v \xi$, pteryx, a fin. 
sereral species now inhabiting the Nile and other African rirers. The reader will at, once recognize in Osteolepis (fig. 599) one of the com

Fig. 599.

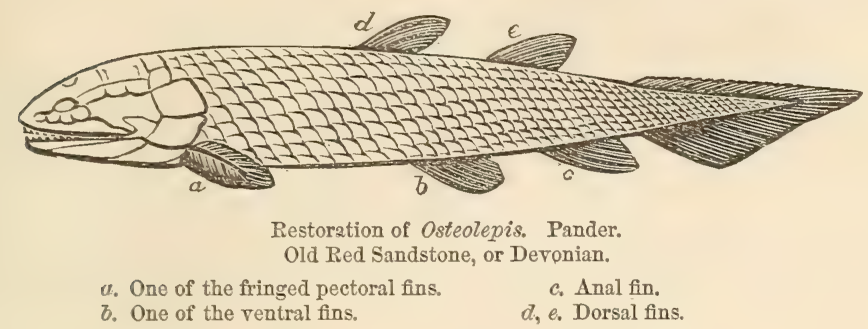

mon fishes of the Old Red Sandstone, many points of analogy with Polypterus. They not only agree in the structure of the fin, as first pointed out by Huxley, but also in the position of the pectoral, rentral, and anal fins, and in haring an elongated body and rhomboidal scales. On the other hand, the tail is more symmetrical in the recent fish, which has also an apparatus of dorsal finlets of a very abnormal character, both as to number and structure. As to the dorsals of Osteolepis, they are regular in structure and position, haring nothing remarkable about them, except that there are two of them, which is comparatively unusual in living fish.

Among the "fringe-finned" Ganoids we find some with rhomboidal scales, such as Osteolepis, abore figured, and Diplopterus, Glyptolcemus, and Glyptopomus; others with cycloidal scales, as Holoptychius (see fig. 5ss, p. 525), Dipterus, \&c. The new genus Glyptolcem us, founded by Huxley on specimens from the Deronian jellow sandstone of Dura Den in Fife, is remarkable for haring not only a fringe of rays entirely surrounding a central lobe in the pectoral and rentral fins, but in having the same structure repeated in the anal and both the dorsal fins. In the genera Dipterus and Diplopterus, as Hugh Miller pointed out, and in sereral other of the fringe-finned genera, as in Gyroptychius and Glytolepis, the two dorsals are placed far backwards, or directly orer the ventral and anal fins.

The Asterolepis was a ganoid fish of gigantic dimensions. A. Asmusii, Eichwald, a species characteristic of the Old Red Sandstone of Russia, as riell as that of Scotland, attained the length of between 20 and 30 feet. It was clothed with strong bony armor, embossed with star-like tubercles, but it had only a cartilaginous skeleton. The mouth was furnished with two rows of teeth, the outer ones small and fish-like, the inner larger, but with a reptilian character. The Asterolepis occurs also in the Devonian rocks of North America.

If we except the Placoids already alluded to, and a few other families of doubtful affinities, all the Old Red Sandstone fishes are Ganoids, an order so named by Agassiz from the shining outer surface 
of their scales. The same remark would hold true of the fish of the primary and secondary formations generally, those of the primary and older secondary type having heterocercal tails, while the tails of those of the tertiary rocks are almost all equilobed or homocercal, like the vast majority of living fish ; but Prof. Huxley has also called our attention to the fact that, while a few of the primary and the great majority of the secondary Ganoids resemble the living Lepidosteus, or bony pike, or the Amia, genera now found in North American rivers, and one of them, Lepidosteus, extending as far south as Guatemala, the Crossopterygii, or fringe-finned Ichthyolites, of the Old Red are closely related to the African Polypterus, which is represented by five or six species now inhabiting the Nile and the rivers of Senegal. These North American and African Ganoids are quite exceptional in the living creation; they are entirely confined to the northern hemisphere, unless some species of Polypterus range to the south of the line in Africa; and, out of about 9000 living species of fish known to M. Günther, and of which more than 6000 are now preserved in the British Museum, they probably constitute no more than 27 .

All the living fish, exclusive of the 27 species just mentioned, and the Elasmobranchii or Placoids, have equilobed or homocercal tails, and are called Teleostei, because their skeletons are perfectly ossified.* The living Ganoids, however, most resembling those of the primary and secondary periods, namely, the Lepidostei and Polypteri, have also internal skeletons as perfect as those of any Telostei; and we find the same combination of a hard external or dermal skeleton, and a wellossified endo-skeleton in Dipterus, one of the Old Red Ganoids already alluded to. In this respect, therefore, Dipterus and Polypterus agree, although they differ in their scales, Dipterus having cycloidal, and

Fig. 600 .

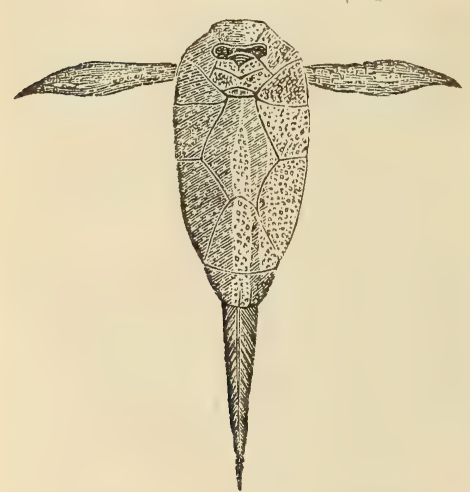

Plerichthys, Agassiz; upper side, showing mouth; as restored by H. Miller. Polypterus rhomboidal scales. $M e-$ galichthys, a carboniferous genus, agrees with Polypterus in the form of its scales, which are rhomboidal, while its internal sketeton, as first observed by Huxley, is so far ossified that in each vertebra there is a ring or hoop of bone.

The fossil Ganoids, therefore, although generally contrasted with the Teleostei, cannot be said to have in all cases imperfect internal skeletons any more than the most typical living representatives of the order.

Among the anomalous forms of Old Red fishes not referable to

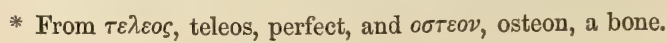


Huxley's Crossopterygii is the Pterichthys, of which five species have been found in the middle division of the Old Red of Scotland. Some writers hare compared their shelly covering to that of Crustaceans, with which, however, they have no real affinity. The winglike appendages, whence the genus is named, were first supposed by Hugh Miller to be paddles, like those of the turtle; and there can now be no doubt that they do really correspond with the pectoral fins. Professor Huxley, when speaking of the allied genus Coccosteus, has speculated on its relationship with the Siluridæ, a large family of living Teleosteans, the bony shields covering the roof of the cranium in Coccosteus being compared by him with those which cover the head and anterior part of the body of certain Siluroids, more particularly those belonging to the genus Clarias.

South Devon and Cornwall.-Term Devonian.-A great step was made in the classification of the slaty and calciferous strata of South Devon and Cornwall in 1837, when a large portion of the beds, previously referred to the "transition" or Silurian series, were found to belong in reality to the period of the Old Red Sandstone. For this reform we are indebted to the labors of Professor Sedgwick and Sir R. Nurchison, assisted by a suggestion of Mr. Lonsdale, who, in 1837, after examining the South Devonshire fossils, perceived that some of them agreed with those of the Carboniferous group, others with those of the Silurian, while many could not be assigned to either system, the whole taken together exhibiting a peculiar type, but of intermediate character between the older and newer groups alluded to. But these palæontological observations alone would not have enabled us to assign, with accuracy, the true place in the geological series of these slaterocks and limestones of South Deron, had not Messrs. Sedgwick and Murchison, in 1836 and 1837, discovered that the culmiferous or anthracitic shales of North Devon belonged to the Coal, and not, as preceding observers had imagined, to the "transition" period.

As the strata of South Devon here alluded to are far richer in organic remains than the red sandstones of contemporaneous date in Herefordshire and Scotland, the new name of the "Devonian system" was proposed as a substitute for that of Old Red Sandstone.

The link supplied by the whole assemblage of imbedded fossils, connecting as it does the palæontology of the Silurian and Carboniferous groups, is one of the highest interest, and equally striking whether we regard the genera of the corals or of the shells. The species are mostly distinct except in the upper group.

The rocks of this group in South Devon consist, in great part, of green chloritic slates, alternating with large quartzose slates and sandstones. Here and there calcareous slates are interstratified with blue crystalline limestone, and in some divisions conglomerates, passing into red sandstone. But the whole series is much altered and disturbed by the intrusion of the granite of Dartmoor and other igneous rocks. 
In North Devon, on the contrary, the Devonian group has been less changed, and its relations to the overlying carboniferous rocks or "Culm Measures" are somewhat more clearly seen. The following sequence is exhibited in the coast section on the Bristol Channel between Barnstaple and the North Foreland.*

\section{Devonian Series in North Devon.}

Upper or Pilton
group. $\left\{\begin{array}{c}\text { a. Calcareous brown slates; with fossils, some of them } \\ \text { common to the Carboniferous group, but most of } \\ \text { them distinct. (Barnstaple, Pilton, \&c.) } \\ \text { b. Brown and yellow sandstone, with marine shells and } \\ \text { land-plants-Stigmaria, Sagenaria, and others. Bag- } \\ \text { gy Point, Marwood, \&c. }\end{array}\right.$

2. Hard gray and reddish sandstones and micaceous flags, without fossils, resting on soft greenish schists of considerable thickness. (Morte Bay, Bull Point, \&c.)

Middle or Ifra- 3. Calcareous slates, with eight or nine courses of limestone, combe group. full of corals and shells like those of the Plymouth limestone, viz., Cyathophyllum caspitosum, see fig. 606, Favosites polymorpha, see fig. 605, \&c. (Combe Martin, Ilfracombe Harbor, \&c.)

Lower or Linton
group. $\left\{\begin{array}{c}\text { 4. Hard, greenish, red, and purple sandstones ; with occasional } \\ \text { fossils, Spirifers, \&c. (Linton, North Foreland, \&c.) } \\ 5 . \text { Soft chloritous slates, with some sandstones; Orthis, Spiri- } \\ \text { fer, and Corals. (Valley of Rocks, Lynmouth, \&c.) }\end{array}\right.$

The successive beds of this section have been compared with those of South Devon and Cornwall both by the authors of the "Devoniann" system and by other observers. And Professor Sedgwick has again lately brought them into closer comparison. $\uparrow$ Other geologists at home and abroad have successively identified them with the Devonian series in France, Belgium, the Rhenish Provinces, Central Germany, and America.t. I shall proceed first to treat of the main divisions which have been established in Europe.

\section{Upper Devonian Rocks.}

Pilton Group.-The slates and sandstone of Barnstaple (No. 1, $a, b$, of the preceding section) were formerly considered to be represented in Cornwall by the limestones of Petherwyn, which rise from under the Culm Measures, constituting the Petherwyn group of Professor Sedgwick. But later researches $\S$ have rendered it probable that these beds overlie the Petherwyn group; they contain the shell Spirifer

* Seägwick and Murchison, Trans. Geol. Soc., New Series, vol. v. p. 644. De la Beche, Geol. Report, Devon and Cornwall, pl. 3. Murchison's Siluria, p. 256.

† Quart. Journ. Geol. Soc., vol. viii. p. 1, et seq.

$\ddagger$ See Dr. Fridolin Sandberger on the Devonian Rocks of Nassau (Geol. Verhalt. Nassau); Fried. A. Römer, on the Hartz Devonian Rocks, in Dunker and Von Meyer's Palæontographica, 3A vol. pt. 1.

$\S$ See Murchison's Siluria, $2 d$ ed., p. 247. 
disjunctus, Sow. (S. Verneuilii, Murch.), (see fig. 601), found in Europe, Asia Minor, and even China; Spirifer Barriensis, S. Urii, and Strophalosia caperata, together with the large trilobite Phacops latifrons, Bronn. (see fig. 602), which is all but world-wide in its distribution. The fossils are numerous, and 80 per cent. of them are distinct from those of even the Lower Carboniferous.

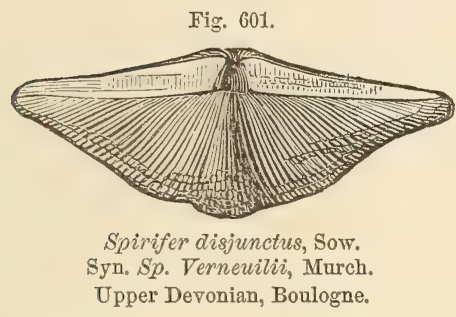

Fig. 602.

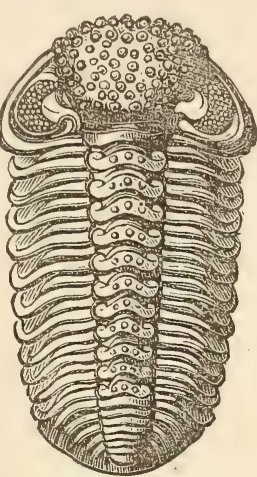

Phacops latifrons, Bronn.

Characteristic of the Devonian in Earope, Asia, and $\mathrm{N}$. and S. America.

Petherwyn Group.-A series of limestones and slates best developed at Petherwyn, in Cornwall. Among many other fossils, the Clymenia lincaris (fig. 603) and the minute crustacean, Cypridina serrato-striata (fig. 604), are so characteristic of these upper beds in Belgium, the

Fig. 603.

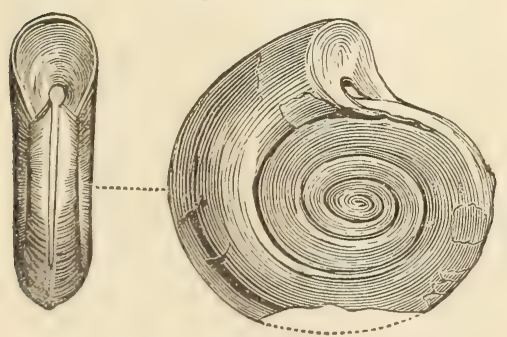

Fig. 604.

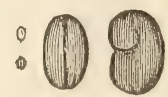

Cypridina serrato-striata, Sand-

berger, Weilburg, \&c, ; Nassan;

Saxony; Belgium.

Clymenia linearis, Münster.

Petherwyn, Cornwall; Elbersreuth, Bavaria.

Rhenish Prorinces, the Hartz, Saxony, and Silesia, that strata of this division in Germany are distinguished by the names of "ClymenienKalk" and "Cypridinen-schiefer." *

With these are many Goniatites (G. subsulcatus, Münster, and other

* See Murchison's Siluria, $2 \mathrm{~d}$ ed., chaps. x., xiv., and xv. 
species), both in England and on the Continent. In Germany they are usually confined to distinct beds, as at Oberscheld, also at Couvin in Belgium, \&c. Trilobites are not unfrequent in Cornwall; they are chiefly restricted to species of Phacops, $P$. loevis, \&c., but in the upper Devonian limestones of the Fichtelgebirge, as at Elbersreuth in Bavaria, there are numerous other genera and species, such as Brontes, Cyphastis, \&c., which never rise higher in the series or appear in any portion of the carboniferous limestone.

\section{Middle Devonian.}

The unfossiliferous series (No. 2, p. 536) of North Devon, and the calcareous beds of Ilfracombe (3), correspond to the Dartmouth and Plymouth groups of Prof. Sedgwick's South Devon series, and are the most typical portion of the Devonian system. They include the great limestones of Plymouth and Torbay, replete with shells, trilobites, and corals, A thick accumulation of slate and schist, full of the same fossils, occupies nearly all the southern portion of Devonshire and a large part of Cornwall. Among the corals we find the genera Favosites, Heliolites and Cyathophyllum, the last genus equally abundant in the Silurian and Carboniferous systems, the two former so frequent in Silurian rocks. Some few even of the species are common to the Devonian and Silurian groups, as, for example, Favosites polymorpha (fig. 605), one of the commonest of all the Devonshire fossils. The Cyathophyllum coespitosum (fig. 606) and Heliolites pyriformis (fig.

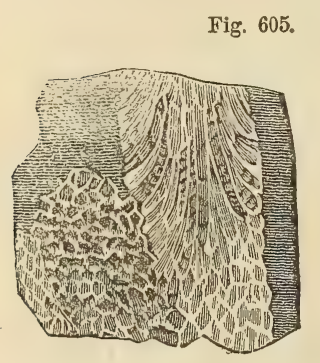

Favosites potymorpha, Goldf. S. Devon, from a polished specimen.

a. Portion of the same magnified, to show the pores.
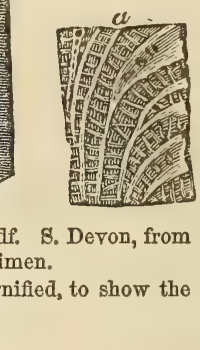

Fig. 605.

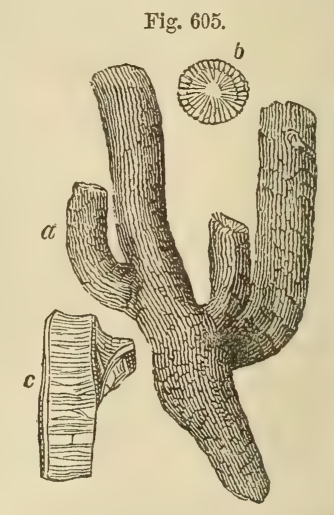

a. Cyathophyllum coespitosum, Goldf Plymouth and Ilfracombe.

b. A terminal star:

c. Vertical section, exhibiting transverse plates, and part of another branch,

$607)$ are peculiarly characteristic; as is another very common species, the Aulopora serpens (fig. 608), which creeps over corals and shells in its young state, as here figured, but afterwards grows upwards and 
Fig. 607 .

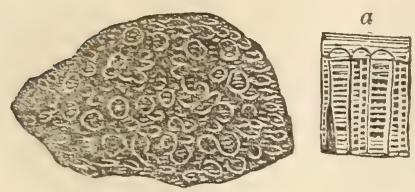

Heliolites porosa, Goldf., sp. Porites pyriformis, Lonsd.

a. Portion of the same, magnified. Middle Devonian, Torquay; Plymonth; Eifel.
Fig. 608 .

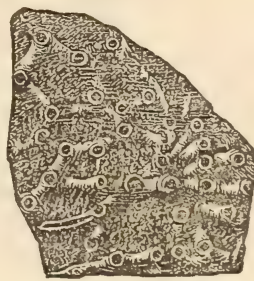

Aulopora serpens, Goldf.

(The young basal portion of a Syrin. gopora, Milne Edw. and Haime.)

becomes a cluster of tubes connected by minute processes. In this state it has been supposed to be a distinct coral, and has been called Syringopora.

With the above are found many stone-lilies or crinoids, some of them, such as Cupressocrinites, of forms generically distinct from those of the Carboniferous Limestone. The mollusks also are no less characteristic, among which the genus Stringocephalus (fig. 609) may be

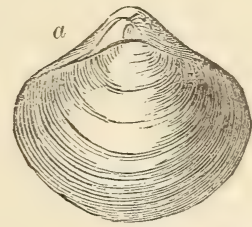

Fig. 609.
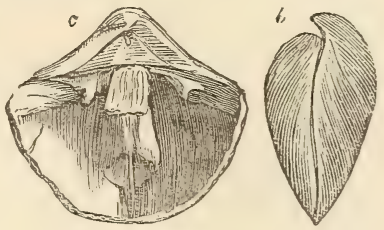

Stringocephatus Burtini, Defr. (Terebratula porrecta, Sow.) Eifel; also South Devon.
a. Valves united.
b. Side view of same.

c. Interior of larger valve, showing thick partition, and part of a large process which projects from the other valve quite across the shell.

mentioned as exclusirely Devonian. Nany other Brachiopod shells, of the genus Spirifer, \&c., abounded, and among them the Atrypa reticularis, Linn. sp. (fig. 627 , p. 554 ), which seems to have been a cosmopolite species occurring in Devonian strata from America to Asia Minor, and which, as we shall hereafter see (p. 554), lived also in the Silurian seas. Among the peculiar lamellibranchiate bivalves common to the Plymouth Limestone of Devonshire and the Continent, we find the Megaloclon (fig. 610), together with many spiral univalves, such as Murchisonia, Euomphalus, and Macrocheilus; and Pteropods such as Conularia (fig. 611). The cephalopoda, such as Cyrtoceras, Gyrocerus, and others, are nearly all of genera distinct from those prevailing in the Upper Deronian Limestone, or Clymenien-Kalk of the Germans already mentioned (p. 537). Although but few species of Trilobites occur, the characteristic Brontes fabellifer (fig. 612) is far from rare, and all collectors are familiar with its fan-like tail. The 
Fig. 610.
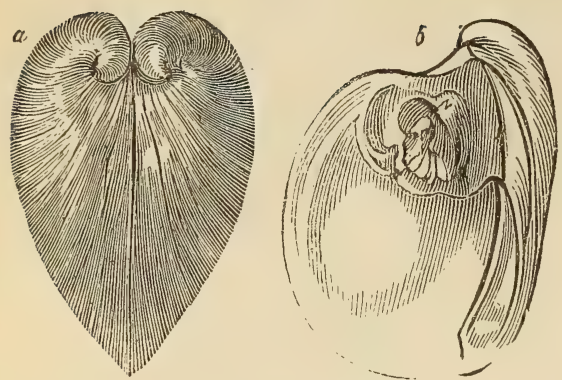

Megalodon cucullatus, Sow. Eifel; also Bradley, S. Devon

$a$. The valves united.

b. Interior of valve, showing the large cardinal tooth.
Fig. 611.

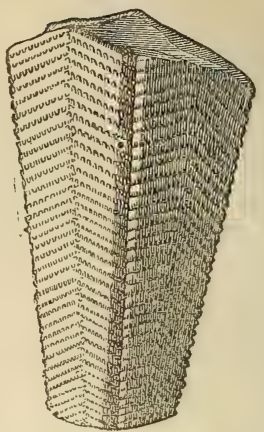

Conularia ornata, D'Arch. and De Vern.

(Geol. Trans., Sec. Ser., vol. vi. pl, 29.) Refrath, near Cologne.

head is seldom found perfect; a restoration of it has been attempted by Mr. Salter, (fig. 613).

Fig. 612.

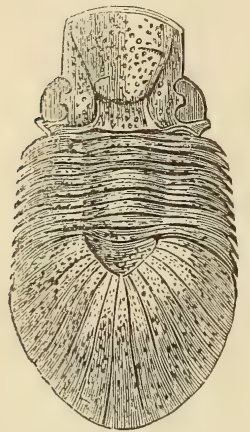

Fig. 613.

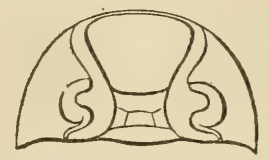

Restored outline of head of Brontes flabellifer.

Brontes flabellifer, Goldf. Eifel; also S. Devon.

In this same formation, comprising in it the "Stringocephalus limestone," or "Eifel Limestone" of Germany, several remains of Coccosteus and other ichthyolites have been detected, and they serve, as Sir R. Murchison.observes (Siluria, p. 371), to identify the rock with the

Fig. 614 .

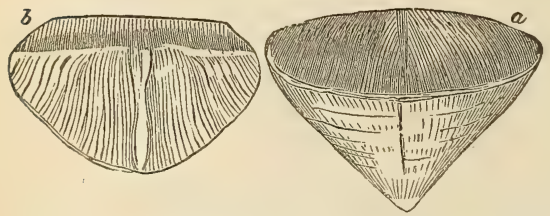

Calceola sandalina, Lam. Eifel; also South Devon. a. Ventral valve.

b. Inner side of dorsal valve.
Old Red Sandstone of Britain and Russia.

Beneath the Eifel Limestone (the great central and typical member of "the Devonian" on the Continent) lie certain schists called by German writers "Calceola-schie- 
fer," because they contain in abundance a fossil body of very curious structure, Calceola sandalina (fig. 614), which has been usually considered a brachiopod, but which some naturalists have lately referred to a coral. They suppose it to be an abnormal form of the order Zoantharia rugosa (see fig. 563, p. 515), differing from all other corals in being furnished with a strong operculum.

\section{Lower Devonian.}

Beneath the Middie Devonian limestones and schists already enumerated, a series of slaty beds and quartzose sandstones, the latter constituting the "Older Rhenish Greywacke" of Römer, and the "Spirifer sandstone" of Sandberger, are exhibited between Coblentz and Caub.* A portion of these rocks on the Rhine and in some of the adjacent countries was regarded as "Upper Silurian" by Prof. Sedgwick and Sir R. Murchison in 1839, but their true age has since been determined. Their equivalents are found in England in the sandstones and slates of the Foreland and Linton in Devon (Nos. 4 and 5 of the table, p. 536), and, according to Mr. Salter, in the sandstone of Torquay in South Devon,

Fig. 615 .

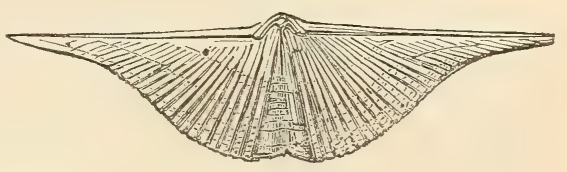
where many of the char- Spirifer mucronatus, Hall, Deronian of Pennsylvania.

Fig. 616.

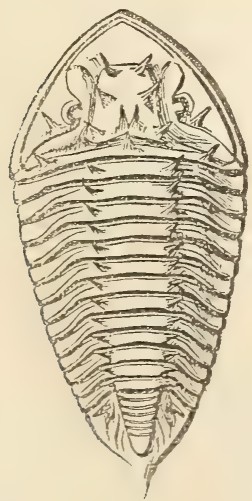

Homalonotus armatus, Burmeister. Lower Deronian; Daun, in the Eifel.

Obs. The two rows of spines down the body give an appearance of more distinct trilobation than really occurs in this or most other species of the genus.
Fig. 617.

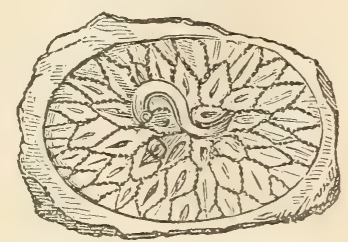

Pleurodictyum problematicum, Goldfuss. Lower Devonian; of Plymouth and Torquay; Looe; Forez, \&c. ; also in Germany at Dietz, Nassan, \&c.

Obs. Attached to a worm-like body (Serpula). The specimen is a cast in sandstone, the thin expanded basc of the coral being removed, and exposing the large polygonal cells ; the walls of these cells are perforated, and the casts of these perforations produce the chain-like rows of dots between the cells.

* Murchison's Siluria, p. 368 . 
acteristic Rhenish fossils are met with. The broad-winged Spirifers which distinguish the "Spirifer-sandstein" of Germany have their representatives in the Devonian strata of North America (see fig. 615).

Among the Trilobites of this era several large species of Homalonotus (fig. 616) are conspiucous. The genus is still better known as a Silurian form, but the spinose species appear to belong exclusively to the "Lower Devonian," and are found in Britain, Europe, and the Cape of Good Hope.

With the above are associated many species of Brachiopods, such as Orthis, Leptcena, and Chonetes, and numerous Lamellibranchiata, such as Pterinea; also the very remarkable fossil coral called Pleurodictyum problematicum (fig. 617).

Devonian of Russia.-The Devonian strata of Russia extend, according to Sir R. Murchison, over a region more spacious than the British Isles; and it is remarkable that, where they consist of sandstone like the "Old Red" of Scotland and Central England, they are tenanted by fossil fishes often of the same species and still oftener of the same genera as the British, whereas when they consist of limestone they contain shells similar to those of Devonshire; thus confirming, as Sir Roderick observes, the contemporaneous origin previously assigned to formations exhibiting two very distinct mineral types in different parts of Britain.* The calcareous and the arenaceous rocks of Russia above alluded to alternate in such a manner as to leave no doubt of their having been deposited at the same period. Among the fish common to the Russian and the British strata are Asterolepis Asmusii before mentioned; a smaller species, A. Minor, Ag.; Holoptychius nobilissimus (p. 525); Dendrodus strigatus, Owen; Pterichthys major, Ag.; and many others. But some of the most marked of the Scottish genera, such as Cephalaspis, Coccosteus, Diplacanthus, Cheiracanthus, \&c., have not yet been found in Russia, owing perhaps to the present imperfect state of our researches, or possibly to geographical causes limiting the range of the extinct species. On the whole, no less than forty species of placoid and ganoid fish have been already collected in Russia, some of the placoids being of enormous size, as before stated, p. 533.

\section{Devonian Brachiopoda.}

The preponderance of the Brachiopods or Palliobranchiata among the bivalve shells forms a decided feature in the conchology of the Devonian strata as contrasted with that of rocks newer in the series, such as have been described in the preceding chapters. In a table of British fossils, constructed by Professor Ramsay, it appears that there are twice as many species of Brachiopods as of Lamellibranchiate bivalves in the Devonian rocks, there being ninety-six known Brachio- 
pods to fortr-seren Lamellibranchiata. In the antecedent Silurian rocks the relatire numbers are still more in faror of the Brachiopods, whereas, in the more modern Carboniferous formation, the proportions are more than rerersed, for there are of the Carboniferous Lamelli branchiata 282 species, and only 123 Brachiopoda.

The reader will of course conclude from what was said at p. 414 that all these oolitic species were not living at one and the same time, there haring been continual changes going on in the fauna from the period of the lowrest to that of the uppermost member of the oolitic series; but the proportions of the two families of shells mar be correctly deduced from the data above given. If we consult the same table to obtain the relative numbers of these same orders of mollusea in the oolites, we find 536 Lamellibranchiata and only sixtr-nine Brachiopoda, these last therefore being reduced to nearly an eighth part of the whole biralre fauna. If $\pi$ e then turn to the actual British seas, we obserre that Forbes and Hanler gire 220 liring species of Lamellibranchiata and onls fire Brachiopods, the latter being reduced to a fortr-fourth part of the whole fauna. As the lamellibranchiate mollusks hare an organization of a more complex and higher grade, the fact of their increasing preponderance from the earliest to the latest times has been often cited, and not without reason, as faroring the theory of progressire development.

\section{Devonian Strata in the United States and Canada.}

In no country hitherto explored is there so complete a series of strata interrening betreen the Carboniferous and Silurian as in the United States. This intermediate or Deronian group was first studied in all its details, and with due attention to its fossil remains, by the Gorernment Surverors of Terr Tork. In its geographical estent, that State, taken singlr, is about equal in size to Great Britain; and the geologist has the adrantage of finding the Deronian rocks there in a nearly horizontal and undisturbed condition, so that the relatire position of each formation can be ascertained with certainty.

\section{Subdivisions of the New York Deronian Strata, in the Reports of the Government Surveyors.}

Names of Groups.

1. Catskill group, or Old Red Sandstone,

2. Chemung group,

3. Portage,

4. Genesee,

5. Tully, -

6. Hamilton,

7. Marcellus,

8. Corniferous, ?

9. Onondaga,

10. Schoharie,

12. Oriskany sandstone,
Thickness in Feet.

$\begin{array}{rrrr} & & \text { Thickness in } \\ - & - & - & 2000 \\ - & - & - & 1500 \\ - & - & - & 1000 \\ - & - & - & 1500 \\ - & - & - & 50 \\ - & - & - & 50 \\ - & - & - & 10 \\ - & - & -5 \text { to } 30\end{array}$


These subdivisions are of very unequal value, whether we regard the thickness of the beds or the distinctness of their fossils; but they have each some mineral or organic character to distinguish them from the rest. Moreover, it has been found, on comparing the geology of other North American States with the New York standard, that some of the above-mentioned groups, such as Nos. 2 and 3, which are respectively 1500 and 1000 feet thick in New York, are very local, and thin out when followed into adjoining States; whereas others, such as Nos. 8 and 9, the total thickness of which is scarcely 50 feet in New York, can be traced over an area nearly as large as Europe.

Respecting the upper limit of the above system, there has been very little difference of opinion, since the Red Sandstone No. 1 contains Holoptychius nobilissimus and other fish characteristic generically or specifically of the European Old Red. More doubt has been entertained in regard to the classification of Nos. 10, 11, and 12. M. de Verneuil proposed in 1847, after visiting the United States, to include the Oriskany sandstone in the Devonian; and Mr. D. Sharpe, after examining the fossils which I had collected in America in 1842, arrived independently at the same conclusion.* The resemblance of the Spirifers of this Oriskany sandstone to those of the Lower Devonian of the Eifel was the chief motive assigned by M. de Verneuil for his view; and the overlying Schoharie grit, No. 10, was classed as Devonian because it contained a species of Asterolepis. On the other hand, Prof. Hall adduces many fossils from Nos. 10 and 12 which resemble more nearly the Ludlow group of Murchison than any other European type; and he thinks, therefore, that those groups may be "Upper Silurian." Sir William Logan has shown that the fossils of the Gaspé limestones in Eastern Canada favor the same opinion, and demonstrate at least how difficult it is to draw a dividing line in that country between the Devonian and Silurian systems. Although the Oriskany sandstone is no more than 30 feet thick in New York, it is sometimes 300 feet thick in Pennsylvania and Virginia, where, together with other primary or palæozoic strata, it has been well studied by Professors W. B. and H. D. Rogers.

The upper divisions (from the Catskill to the Genesee groups inclusive, Nos. 1 to 4) eonsist of arenaceous and shaly beds, and may have been of littoral origin. They vary greatly in thickness, and few of them can be traced into the "far West;" whereas the calcareous groups, Nos. 8 and 9, although in New York they have seldom a united thickness of more than 50 feet, are observed to constitute an almost continuous coral-reef over an area of not less than 500,000 square miles, from the State of New York to the Mississippi, and between Lakes Huron and Michigan, in the north, and the Ohio River and Tennessee in the south. In the Western States they are repre-

* De Verneuil, Bulletin, 4, 678, 1847; D. Sharpe, Quart. Journ. Geol. Soc., vol. iv. p. 145,1847 . 
sented by the upper part of what is termed "the Cliff Limestone." There is a grand display of this calcareous formation at the falls or rapids of the Ohio River at Louisville in Kentucky, where it much resembles a modern coral-reef. A wide extent of surface is exposed in a series of horizontal ledges, at all seasons when the water is not high; and, the softer parts of the stone having decomposed and wasted away, the harder calcareous corals stand out in relief, their erect stems sending out branches precisely as when they were living. Among other species I observed single corals, not less than 5 feet in diameter, of Favosites gothlandica, with its beautiful honeycomb structure well displayed, and, by the side of it, the Favistella, combining a similar honeycombed form with the star of the Astrced. There was also the cup-shaped Cyathophyllum, and the delicate network of the Fenestella, and that elegant and well-known European species of fossil called "the chain coral," Catenipora escharoides (see fig. 631, p. 557), with a profusion of others. These coralline forms were mingled with the joints, stems, and occasionally the heads of lily encrinites. Although hundreds of fine specimens have been detached from these rocks to enrich the museums of Europe and America, another crop is constantly working its way out, under the action of the stream, and of the sun and rain in the warm season when the channel is laid dry. The waters of the Ohio, when I visited the spot in April, 1846, were more than 40 feet below their highest level, and 20 feet above their lowest, so that large spaces of bare rock were exposed to view.*

No less than 46 species of British Devonian corals are described in the monograph published in 1853 by Messrs. M. Edwards and Jules Haime (Palæontographical Society), and only six of these occur in America; a fact, observes Prof. E. Forbes, which, when we call to mind the wide latitudinal range of the Anthozoa, has an important bearing on the determination of the geography of the northern hemisphere during the Devonian epoch. We must also remember that the more conspicuous corals of these ancient reefs, viz., those which are like our cup and star corals, all belong to the Zoantharia rugosa, a sub-order which, as before stated (p. 515 et seq.), has no living representative. Hence great caution must be used in admitting all inductions drawn from the presence and forms of these zoophytes, respecting the prevalence of a warm or tropical climate in high latitudes at the time when they flourished-for such inductions, says Prof. E. Forbes, have been founded "on the mistaking of analogies for affinities." †

This calcareous division also contains. Goniatites, Spirifers, Pentremites, and many other genera of Mollusea and Crinoidea, corresponding to those which abound in the Devonian of Europe, and some few of the forms are the same. But the difficulty of deciding on the

* Lyell's Second Visit to the United States, vol, ii. p. 277.

† Geol. Quart. Journ, vol. x. p. 60, 1854. 
exact parallelism of the New York subdivisions, as above enumerated, with the members of the European Devonian, is very great, so few are the species in common. This difficulty will best be appreciated by consulting the critical essay published by Mr. Hall in 1851, on the writings of European authors on this interesting question.*. Indeed we are scarcely as yet able to decide on the parallelism of the principal groups even of the north and south of Scotland, or on the agreement of these again with the Devonian and Rhenish subdivisions.

Canada.-In Western Canada many of the subdivisions of the New York Devonian system, as above enumerated, from the Chemung to the Oriskany formation, have been recognized by the British surveyors, and are even traceable continuously, as in the Niagara district, from the one country to the other.

In Eastern Canada, or in the peninsula of Gaspé, south of the estuary of St. Lawrence, there is a great thickness of sandstone, conglomerate, and shales, referable to the Devonian period, and rich in fossil plants. The conglomerates occur in massive beds, one of them being 156 feet thick, including pebbles of white quartz, black chert, jaspers of various colors, porphyries and limestones, with a base of sandstone. They contain fragments of plants and fish-spines or Ichthyodorulites of the genera Onchus and Machoracanihum. Above these beds occur sandstones and shales of great thickness, some of the sandstones being ripple-marked. Towards the upper part of the whole series a small seam of coal has been observed. with carbonaceous shale, measuring together about three inches; it rests on a bed of clay, in which are the roots of Psilophyton (see fig. 518), while stems and leaflets of the same plant are met with in the shale above the coal, and in the carbonaceous shale associated with it. At several other levels strata much like the fine clays of the Carboniferous period are penetrated vertically by the rootlets of this same Psilophyton. $\dagger$

South Africa.-The researches of Mr. Bain and Mr. Rubidge, at the Cape of Good Hope, have established the existence of a large Lower Devonian formation in that part of the southern hemisphere. Curiously enough, the fauna is strictly representative of that in northern regions, even to minute coincidences. The late Daniel Sharpe and Mr. Salter described many species referable to Trilobites (Homalonotus and Phacops), Annelids (Tentaculites), Mollusks (Cucullella), and large species of Crinoids allied to Rhodocrinus, \&c., all of the same genera as those found in Cornwall and Germany.

\section{Vegetation of the Devonian Period.}

From the works of Göppert, Unger, and Bronn, we learn that the fossil plants of the Devonian rocks in Europe resemble generically, with very few exceptions, those of the coal-measures, and more ample

* Report of Foster and Whitney on Geol. of L. Superior, p. 302, Washington, 1851.

† Sir W. E. Logan, Report of Geol. Survey of Canada, p. 394, 1863. 
botanical data obtained from Canada and the United States lead to a similar conclusion respecting the flora of the same age in America. Dr. Dawson, of Montreal, in an important memoir * on this subject, after entumeratiug thirty-two genera of Devonian plants and sixty-nine species collected in the State of New York and in Canada, observes that they belong chiefly, as in the Carboniferous period, to Gymnosperms and Cryptogams. When we peruse his catalogue of Coniferce, Sigillarice, Calamites, Asterophyllites, Lepidodendra, Lepidostrobi, and ferns of the genera Cyclopteris, Neuropteris, Sphenopteris, \&c., together with fruits, such as Cardiocarpum and Trigonocarpum, we might wel! suppose that we were presented with a list of carboniferous fossils; and, if told that the species differed, and that there was some admixture even of genera unknown in Europe, we might be inclined to ascribe such a want of agreement to geographical circumstances, and especially to the distance of the New from the Old World. But fortunately the coal formation is most fully developed on the other side of the Atlantic, and is singularly like that of Europe, both lithologically and in a large proportion even of the species of its fossil plants. There is also the most unequivocal evidence of relative age afforded by superposition, for the Devonian strata in the United States are seen to crop out from beneath the carboniferous on the borders of Pennsylvania and New York, where both formations are of great thickness.

On comparing the species of the Middle Devonian in these countries with those of the Middle Coal-Measures, we find them all distinct, whereas some few species pass from the Upper Devonian into the Lower Carboniferous rocks. The genus most characteristic of the Devonian, and not found in the Coal, is one already alluded to, namely, Psilophyton, believed by Dr. Dawson to be a lycopodiaceous plant, branching dichotomously (see $P$. princeps, fig. 618 A), with stems springing from a rhizome, $\mathrm{A} b$, which last has circular areoles, $d e$, much resembling those of Stigmaria, and like it sending forth cylindrical rootlets, such as at $\mathrm{A} c$. The extreme points of some of the branchlets are rolled up so as to resemble the croziers or circinate vernation of ferns, $h$; the leaves or bracts, $i$, supposed to belong to the same plant, are described by Dawson as having enclosed the fructification. The remains of Psilophyton princeps have been traced through all the members of the Devonian series in Canada and the State of New York. Some underclars in Gaspé are filled, as already stated, with its vertical rootlets just as are the fire-clays of the coal, both in Europe and America, with those of Stigmaria.

One fragment of fossil wood, found some years ago by Professor Hall, in a Deronian limestone of the Hamilton group, on Lake Erie, has, according to Darrson, $\uparrow$ the structure of an angiospermous exo-

* Geol. Quart. Journ., vol. xv. p. 477, 1859 ; also vol. xviii. p. 296, 1862.

+ Ibid., vol, xviii. p. 305, 1862. 
Fig. 618

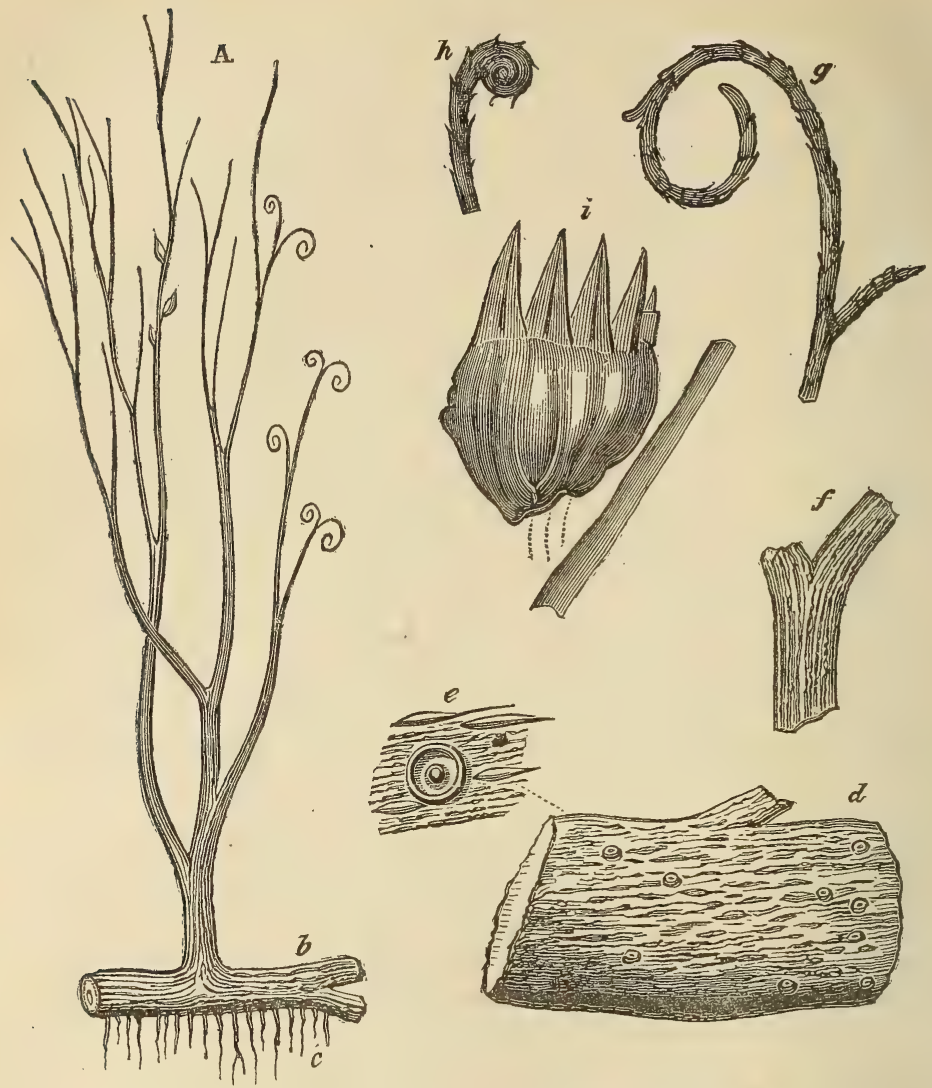

Psilophyton princeps. Dawson, Geol. Quart. Journ., vol. xv., 1863; and Canada Survey, 1863. Species characteristic of the whole Devonian period in North America.

A. Psilophyton princeps, plant restored by Dawson. $f$. Stem, twice natural size.

Ab. Rhizome, or underground root-like stem. $\quad g$. Termination of branches.

Ac. Cylindrical rootlets.

$h$. Crazier-like, or circinate vernation.

d. Rhizome.

e. Areole of rhizome.

i. Fructification.

gen; but with this single exception the American Devonian flora affords, like the Carboniferous, no evidence of the existence of plants of higher organization than the gymnosperms.

The monotonous character of the Carboniferous flora might be explained by imagining that we have only the vegetation handed down to us of one set of stations, consisting of wide swampy flats. But Dr. Dawson supposes that the geographical conditions under which the Devonian plants grew were more varied, and had more of an upland character. If so, the limitation of a flora represented by so many genera and species to the gymnospermous and cryptogamous orders, and the absence of plants of higher grade, admit of no expla. 
nation hitherto advanced save that afforded by the theory of progressive derclopment. Nothing is known of the insects, land-shells, or other terrestrial animals which coexisted with this Devonian flora, but we need not despair of future discoveries in this direction when we remember that slow as has been our progress, we have at length begun to learn something respecting the terrestrial fauna of the Coal period.

Allusion bas already been made to freshwater shells and to Lepidodendra and ferns (see figs. 585 and 586, p. 524) found in Ireland associated with Devonian genera of fish.

\section{CHAPTER XXVII.}

\section{SILURIAN AND CAMBRIAN GROUPS.}

Silurian strata formerly called Transition-Term "Grauwacke"-Subdivisions of Upper, Middle, and Lower Silurians-Ludlow formation and fossils-Oldest known remains of fossil fish-Wenlock formation, corals, cystideans, trilobitesMiddle Silurian or Llandovery Beds-Lower Silurian rocks-Caradoc and Bala Beds-Upper and Lower Llandeilo formations-Cystideæ-Trilobites-Graptolites-Vast thickness of Lower Silurian strata, sedimentary and volcanic, in Wales-Foreign Silurian equivalents in Europe-Silurian strata of the United States-Amount of specific agreement of fossils with those of Europe-Canadian equivalents-Whether Silurian strata of deep-sea origin-Cambrian rocksClassification and nomenclature-Barrande's primordial fauna-- Upper Cambrian of Wales-Tremadoc slates-Lingula flags-Lower Cambrian-Longmynd group-Oldest organic remsins known in Europe-Foreign equivalents of the Cambrian group-Primordial zone of Bohemia-Characteristic trilobitesMetamorphosis of trilobites-Alum schists of Sweden and Norway-Potsdam sandstone of United States and Canada-Footprints near Montreal-Quebec strata and Huronian rocks-Minnesota trilobites-Rocks older than the Cambrian-Laurentian group, Upper and Lower-Oldest known fossil, Eozoon Canadense-No remains of vertebrate animals known in strata below the Upper Silurian-Progressive discovery of vertebrata in older rocks-Theoretical inferences from the rarity or absence of vertebrata in the most ancient fossiliferous formations.

$W_{E}$ come next in the descending order to the most ancient of the primary fossiliferous rocks, that series which comprises the greater part of the strata formerly called "Transition" by Werner, for reasons explained in Chapter VIII., p. 89. Geologists were also in the habit of applying to these older strata the general name of "Grauwacke," by which the German miners designate a particular variety of sandstone, usually an aggregate of small fragments of quartz, flinty slate (or Lydian stone), and clay-slate cemented to- 
gether by argillaceous matter. Far too much importance has been attached to this kind of rock, as if it belonged to a certain epoch in the earth's history, whereas a similar sandstone or grit is found in the Old Red, and in the Millstone Grit of the Coal, and sometimes in certain Cretaceous and even Eocene formations in the Alps.

The annexed table will explain to the reader the successive formations into which the strata called Silurian by Sir Roderick Murchison may be subdivided:

\section{UPPER SILURIAN ROCKS.}

\section{Ludlow Formation.}

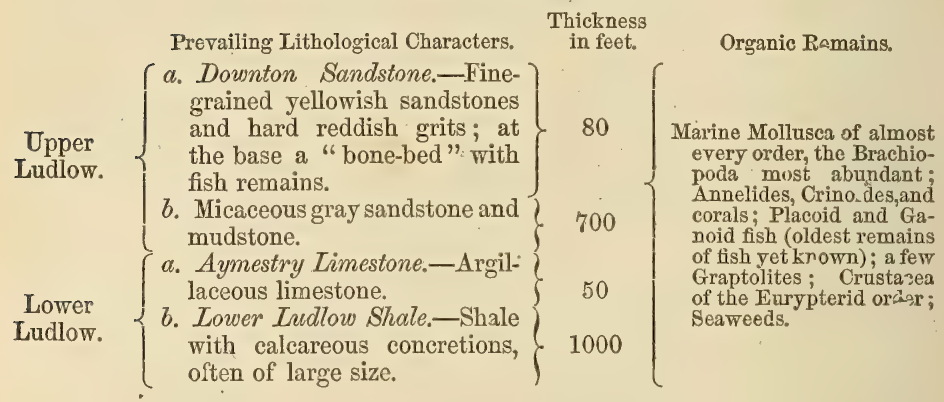

\section{Wenlock Formation.}

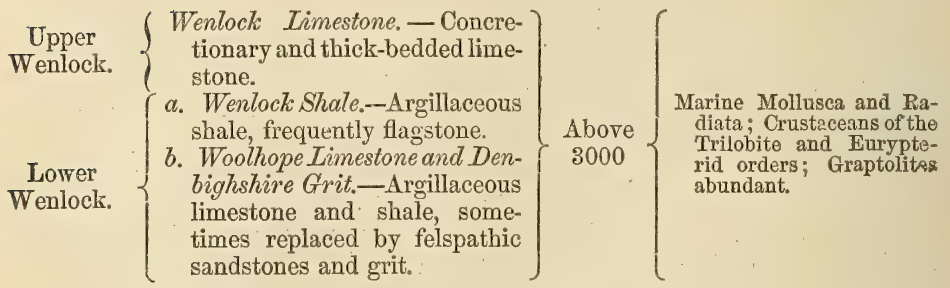

\section{MIDDLE SILURIAN ROCKS.}

\section{Llandovery Formation.}

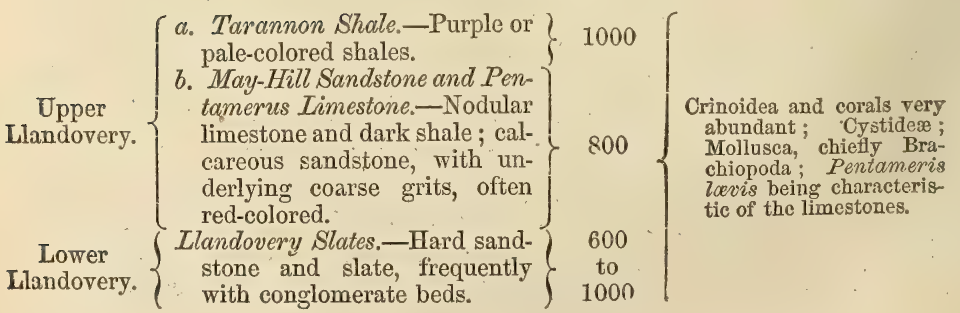




\section{- lower silurLaN ROCKS.}

\section{Caradoc Formation.}

Caradoc. $\left\{\begin{array}{c}\text { a. Caradoc Sandstone.-Shelly } \\ \text { sandstones and conglomerates } \\ \text { and shales. } \\ \text { 6. Bala Limestone.-Arenaceous } \\ \text { limestone; slate, and sand- } \\ \text { stones with trappean tuffs. }\end{array}\right\} 12,000\left\{\begin{array}{c}\text { Brachiopoda, numerous; } \\ \text { Lamellibranchiata; Ce- } \\ \text { phalopoda; Pteropoda } \\ \text { (Conularia) of large sizc; } \\ \text { Cystidex, abundant; } \\ \text { Trilobites, reaching their } \\ \text { maximum in specics; } \\ \text { Graptolites numerous. }\end{array}\right.$

\section{Llandeilo Formation.}

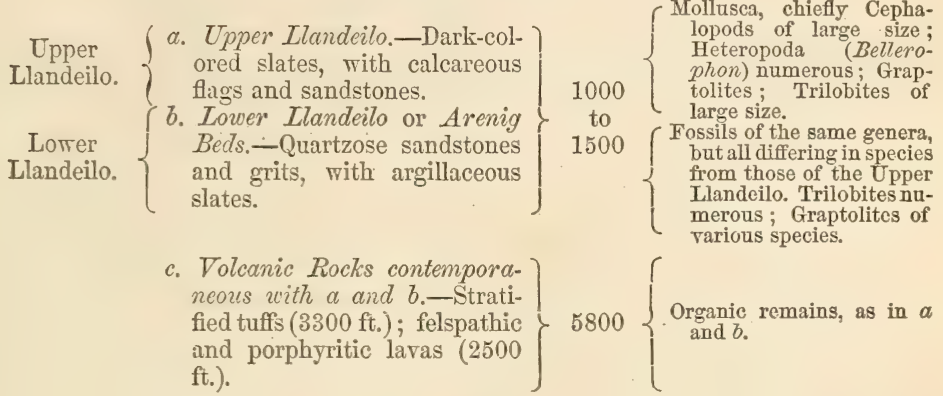

The name of Silurian was first proposed by Sir Roderick Murchison for that great series of fossiliferous strata which lie immediately below the Old Red Sandstone, and occupy that part of Wales and some contiguous counties of England which once constituted the kingdom of the Silures, a tribe of ancient Britons.

\section{UPPER SंILURIAN ROCKS.}

\section{Ludlow Formation.}

This member of the Upper Silurian group, as will be seen by the abore table, is about 800 feet thick, and subdivided into two partsthe Upper Ludlow and the Lower Ludlow-at or near the top of which last occurs the Aymestry limestone. Each of these may be distinguished near the town of Ludlow, and at other places in Shropshire and Herefordshire, by peculiar organic remains.

Upper Ludlow.-a. Downton Sandstone.-This uppermost subdivision was originally classed br Sir R. Murchison, under the name of "Tilestones," with the Old Red Sandstone, the beds being often of a similar red color. The whole was regarded as a transition group forming a passage from the Silurian strata to Old Red Sandstone; but it is now ascertained that the fossils agree in great part specifically, and in general character entirely, with those of the underlying Upper Ludlow rocks. Among these are Orthoceras bullatum, Platyschisma 
helicites, Bellerophon trilobatus, Chonetes lata, \&c., with numerous defences of fishes. These beds are well seen at Kington in Herefordshire, and at Downton Castle near Ludlow, where they are quarried for building.

Bone-bed.-The bone-bed of the Upper Ludlow deserves especial notice as affording the most ancient example of fossil fish occurring in any considerable quantity. It usually consists of one or two thin brown layers full of bony fragments near the junction of the Old Red Sandstone and the Ludlow rocks, and was first observed by Sir $R$. Murchison near the town of Ludlow, where it is three or four inches thick. It has since been traced to a distance of 45 miles from that point into Gloucestershire and other counties, and is commonly not more than an inch thick, but varies to nearly a foot. At May-Hill two bone-beds are observable, with 14 feet of intervening strata full of Upper Ludlow fossils.* At that point immediately above the upper fish-bed numerous small globular bodies have been found, which were determined by Dr. Hooker to be the sporangia of a cryptogamic land-plant, probably lycopodiaceous. These beds occur just beneath the lowest strata of the "Old Red," forming the uppermost part of the Downton sandstone.

Most of the fish have been referred by Agassiz to his placoid order, some of them to the genus Onchus, to which the spine (fig. 619) and the minute scales (fig. 620) are supposed to belong. It has been sug-

Fig. 619.

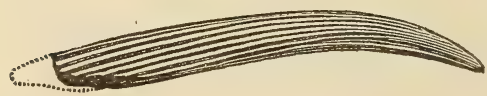

Onchus tenuistriatus, Agass. Bone-bed. Upper Silurian; Ludlow.
Fig. 620.

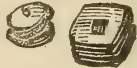

Shagreen scales of a placoid fish (Thelodus).

Bone-bed. Upper Ludlow.

gested, however, that Onchus may be one of those Acanthodian fish, referred by $\Lambda$ gassiz to his Ganoid order, which are so characteristic

Fig. 621.

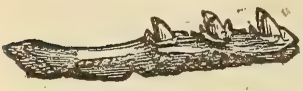

Plectrodus mirabilis, Agass. Bone-bed. Upper Ludlow. of the base of the Old Red Sandstone in Forfarshire, although the species of the Old Red are all different from those of the Silurian beds now under consideration. $\uparrow$ The jaw and teeth of another predaceous genus (fig. 621) have also been detected, together with some specimens of Pteraspis

Ludensis. As usual in bone-beds, the teeth and bones are, for the most part, fragmentary and rolled.

b. Gray Sandstone and Mudstone, \&c.-The next subdivision of the Upper Ludlow consists of gray calcareous sandstone, or very com-

* Murchison's Siluria, pp. 137-237.

† Powrie, Geol, Quart. Journ., vol. xx. p. 438. 
monly a micaceous stone, decomposing into soft mud, and contains besides the shells just quoted, a Lingula, which is common to it and the "Tilestone" (or Ledbury) beds at the base of the Old Red. The Orthis orbicularis, a round rariety of 0 . elegantula, is characteristic of the Upper Ludlow; and the lowest or mudstone beds contain Rhynchonella navicula (fig: 623), which is common to this bed and the

Fig. 622

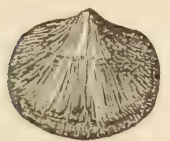

Orthis elegantula. Dalm. Var, orbicularis, J. Sow. Delbury. Upper Ludlow.

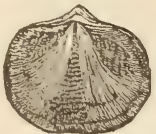

Fig. 623.

Athyris (Rhynchonella) navicula, J. Sow.

Aymestry limestone; also in Upper and Lower Ludlow.

Lower Ludlow. As usual in the strata of Primary periods older than the coal, the brachiopodous mollusca greatly outnumber the lamillibranchiate (see abore, p. 543); but the latter are by no means unrepresented. Among other genera, for example, we observe Avicula and Pterinea, Cardiola, Ctenodonta (subgenus of Nucula), Orthonota, and Modisla.

Some of the Upper Ludlow sandstones are ripple-marked, thus affording evidence of gradual deposition; and the same may be said of the accompanying fine argillaceous shales which are of great thickness, and have been provincially named "mudstones." In some of these shales stems of crinoidea are found in an erect position, having evidently become fossil on the spots where they grew at the bottom of the sea. The facility with which these rocks, when exposed to the weather, are resolved into mud, prores that, notwithstanding their antiquity, they are nearly in the state in which they were first thrown down.

Lower Ludlow.-a. Aymestry Limestone.-The next group is a subcrystalline and argillaceous limestone, which is in some places 50 feet thick, and distinguished around Aymestry and at Sedgley by the abundance of Pentamerus Knightii, Sow. (fig. 624); also found in the Lower Ludlow. This genus of brachiopoda was first found in Silurian strata, and is exclusively a palæozoic form. The name was derived from $\pi \varepsilon v \tau \varepsilon$, pente, five, and $\mu \varepsilon \rho \circ$, meros, a part, because both ralres are divided by a central septum, making four chambers, and in one ralve the septum itself contains a small chamber, making fire. The size of these septa is enormous compared with those of any other brachiopod shell; and they must nearly hare dirided the animal into two equal halres; but they are, nerertheless, of the same nature as the septa or plates which are found in the interior of Spirifer, Terebratula, and many other shells of this order. Messrs. Murchison and De Verneuil discovered this species dispersed in myriads through 
Fig. 624 .

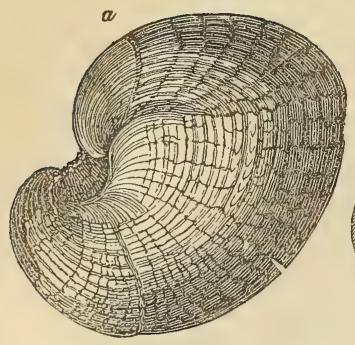

Pentamerus Knightii, Sow. Aymestry. $\frac{1}{2}$ nat. size. a.' View of both valves united.

b. Longitudinal section through both valves, showing the central plates or septa.
Fig. 625.

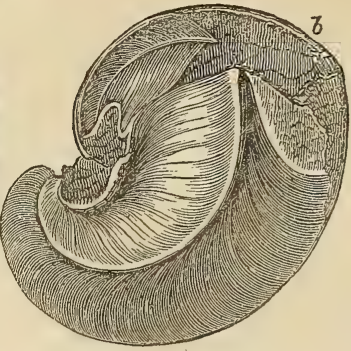
Lingula Lewisii,
J. Sow.

Abberley Hills.

a white limestone of Upper Silurian age, on the banks of the Is, on the eastern flank of the Urals in Russia, and a similar species is frequent in Sweden.

Three other abundant shells in the Aymestry limestone are, 1st, Lingula Lewisii (fig. 625); 2d, Rhynchonella Wilsoni, Sow. (fig. 626),

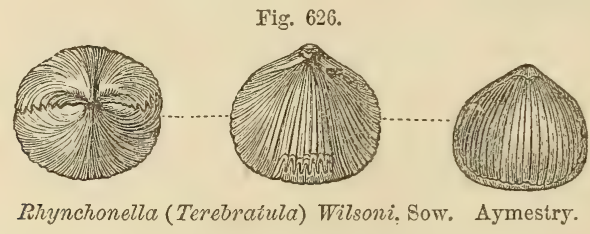

which is also common to the Lower Ludlow and Wenlock limestone; 3d, Atrypa reticularis, Linn. (fig. 627), which has a very wide range, being found in every part of the Upper Silurian system, and as far down as the Lower Llandovery rocks.
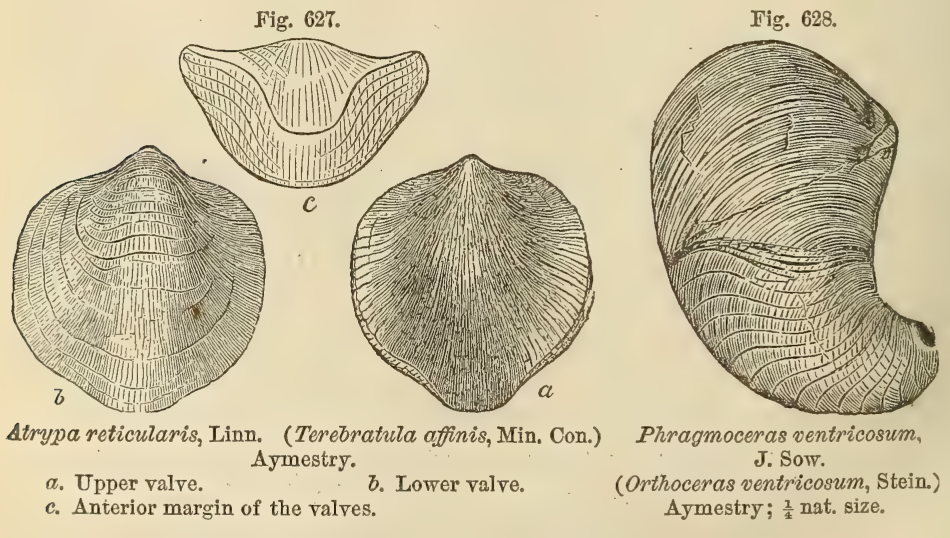

The Aymestry Limestone contains so many shells, corals, and trilo- 
bites, agreeing specifically with those of the subjacent Wenlock limestone, that it is scarcely distinguishable from it by its fossils alone. Nevertheless, many of the organic remains are common to the Aymestry limestone and the Upper Ludlow, and several of these are not found in the Wenlock.*

According to Mr. Lightbody, the Aymestry limestones should be considered as subordinate to the Lower Ludlow shales next to be mentioned, as in some places these shales with their characteristic fossils occur both above and below it. $\dagger$

b. Lower Ludlow Shate.-This mass is a dark gray argillaceous deposit, containing, among other fossils, many large chambered shells of genera scarcely known in newer rocks, as the Phragmoceras of Broderip, and the Trochoceras of Barrande (see figs. 628, 629). The latter is partly straight and partly convoluted in a very flat spire.

The Orthoceras Ludense (fig. 630), as well as the cephalopod last mentioned, is almost peculiar to this member of the series.

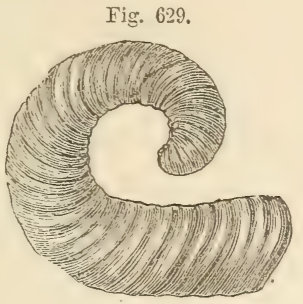

Trochoceras (Lituites) giganteus, J. Sow. Near Ludlow; also in the Aymestry and Wenlock limestones. $\frac{7}{4}$ nat. size.

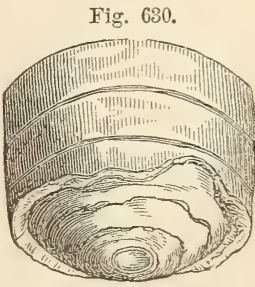

Fragment of Orthoceras Lud'nso, J. Sow. Leintwardine, Shro, stire.

A species of Graptolite, G. Ludensis, Murch. (fig. 640, 1. 559), a form of zoophyte or polyp which has not yet been met with in strata above the Silurian, occurs plentifully in the Lower Ludlow.

Starfish, as Sir R. Murchison points out, are by no means rare in the Lower Ludlow rock. These fossils present us with new genera, but they remind us of various living forms now found in our British seas, both of the families Asteriadae and Ophiurida.

Oldest known fossil fish.-In 1855, when the last edition of this work was published, I was unable to cite any example of a fossil fish older than the bone-bed of the Upper Ludlow, but in 1859, a specimen of Pteraspis was found at Church Hill, near Leintwardine in Shropshire, by Mr. J. E. Lee of Caerleon, F.G.S., in shale below the Aymestry limestone, associated with fossil shells of the Lower Ludlow formation-shells which differ considerably from those characterizing the Upper Ludlow already described.

The genus Pteraspis, as we have secn (p. 532), is regarded by Prof.

* Murchison's Siluria, p. 133.

† Quart. Geol. Journ, vol. xix. p. 371, 1863. 
Huxley as allied to the Sturgeon, and therefore by no means of low grade in the piscine class. Hence its detection in the rocks lower in the series than those to which the earliest. known vertebrata had previously been traced, is a fact of no slight interest; for they who have full faith in the doctrine of progressive development will naturally expect to meet with the earliest vestiges of the piscine class in still more ancient strata. They may look, for example, in the Lower Silurian, or in the Cambrian rocks, for representatives of such orders as the Marsipobranchii and Pharyngobranchii, to which the Lamprey and Amphioxus respectively belong. Professor Huxley remarks that some might argue that fish of those orders may be absent from the older rocks for the same reason that they are entirely missing in all the newer ones, whether palæozoic or neozoic, namely, because they are without bony skeletons or hard scales.* But the same author reminds us that the Lampreys at least might have left some definite traces of their horny teeth. Besides, the advocates of progression would scarcely be satisfied with such a way of accounting for the total absence of all traces of ichthyolites in strata more ancient than the Upper Silurian, for, according to them, the earliest types of each class resembling the embryonic states of more highly organized beings, exhibit, when they are first developed, a great diversity of form and structure, as, according to their view, did the batrachoid reptiles, before the true saurians came into existence, or the saurians before the placental mammalia had entered on the stage. Each primitive type, whether vertebrate or invertebrate, when first it became dominant and had the world to itself, unchecked in its struggle for life by the competition of rivals of more advanced structure, deviated in shape and organization in an infinite variety of ways, sometimes imitating in certain of its characters beings of higher grade. Under favorable conditions of this kind, we might expect some members of the lamprey and Amphioxus orders to have exchanged a gelatinous or semi-cartilaginous spiral cord for an ossified one, or to have aequired hard and scaly dermal coverings, or even to have been armed with teeth of more than horny consistency, and this without departing from the types of their respective orders. Had any such fossils been found in very ancient rocks, the progressionists would certainly have claimed them triumphantly as corroborating their views, and they are therefore bound in fairness to draw, from the absence of such remains in ancient strata which teem with organic forms, one of two conclusions; namely, either that the progressive theory is doubtful, or that we can place no reliance whatever on negative evidence as establishing the non-existence of certain types at remote eras. The latter is the alternative to which it appears to me we ought to incline in the present state of our knowledge.

* Memoirs of Survey Decade, vol. x. p. 40. 


\section{Wenlock Formation.}

We next como to the Wenlock formation, which has been divided (see Table, p. 550) into the Upper Wenlock, or Wenlock Limestone, and the Lower Wenlock, including, first, the Wenlock shale, and secondly, the Woolhope limestone and Denbighshire grits.

Upper Wenlock.-Wenlock Limestone.-This limestone, otherwise mell known to collectors by the name of the Dudley limestone, forms a continuous ridge in Shropshire, ranging for about twenty miles from S. TI. to N.E., about a mile distant from the nearly parallel escarpment of the Aymestry limestone. This ridgy prominence is due to the solidity of the rock, and to the softness of the shales abore and below it. Near Wenlock it consists of thick masses of gray subcrystalline limestone, replete with corals and encrinites. It is essentially of a concretionary nature; and the concretions, termed "ball-stones" in Shropshire, are often enormous, even 80 feet in diameter. They are of pure carbonate of lime, the surrounding rock being more or less argillaceous." Sometimes in the Malvern Hills this limestone, according to Professor Phillips, is oolitic.

Among the corals in which this formation is so rich, the "chaincoral," Halysites catemularius, or Catenipora escharoides (fig. 631), may

Fig. 631.

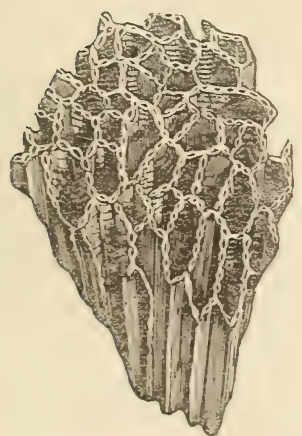

Halysites catenularius, Linn. sp. Syn. Catenipora escharoides, Goldf. Upper and Lower Silurian.
Fig. 632.

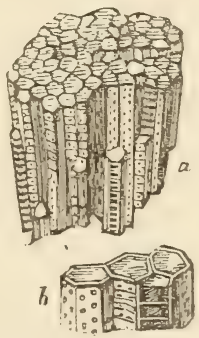

Favosites Gothlandica, Lam. Dudley.

a. Portion of a large mass; less than the natural size.

b. Magnified portion, to show the pores and the partitions in the tubes.
Fig. 633.

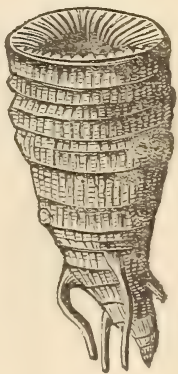

Omphyma turbinatum, Linn. sp. Cyathophyllum, Goldf.

Wenlock Limestone, Shropshire.

be pointer out as one very easily recognized, and widely spread in Europe, ranging through all parts of the Silurian group, from the Aymestry limestone to near the bottom of the series. Another coral, the Farosites Gothlandica (fig. 632), is also met with in profusion in large hemispherical masses, which break up into prismatic fragments,

* Murchison's Siluria, chap. vi. 
like that here figured (fig. 632). Another common form in the Wenlock limestone is the Omphyma (fig. 633), which, like many of its companions, reminds us of some modern cup-corals, but all the Silurian genera belong to the palæozoic type before mentioned (p. 515), exhibiting the quadripartite arrangement of the lamellæ within the cup.

Among the numerous Crinoids, several peculiar species of Cyathocrinus (for genus, see figs., p. 517) contribute their calcareous stems, arms, and cups towards the composition of the Wenlock limestone. Of Cystideans there are a few very remarkable forms, some of them peculiar to the Upper Silurian formation, as, for example, the Pseidocrinites, which was furnished with pinnated fixed arms, * as represented in the annexed figure (fig. 633).

The Brachiopoda are, many of them, of the same species as those of the Aymestry limestone; as, for example, Atrypa reticularis (fig. 627, p. 554), and Strophomena depressa, Sow., sp. (fig, 635); but the latter

Fig. 634 .

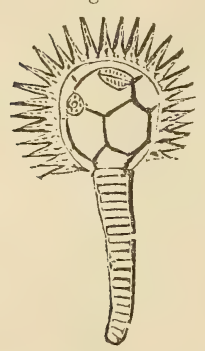

Pseudocrinites bifasciatus, Pearce.

Wenlock Limestone, Dudley.
Fig. 635 .

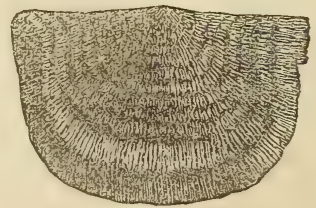

Strophomena (Leptcena) depressa, Sow. Wenlock and Ludlow Rocks.

species range also from the Ludlow rocks, Wenlock shale, and to the Caradoc Sandstone. There are some species, however, peculiar to the Upper Wenlock, of the genera Rhynchonella Retzia, Spirifer, Athyris, \&c.

The Crustaceans are represented almost exclusively by Trilobites, which are very conspicuous. The Calymene Blumenbachii, called the "Dudley Trilobite," was known to collectors long before its true place in the animal kingdom was ascertained. It is often found coiled up like the common Oniscus, or wood-louse, and this is so common a circumstance among the trilobites as to lead us to conclude that they must have habitually resorted to this mode of protecting themselves when alarmed. The other common species is the Phacops caudatus (Asaphus caudatus), Brong. (see fig. 637), and this is conspicuous for its large size and flattened form. Sphcerexochus mirus (fig. 638) is almost a globe when rolled up, the forehead of this species boing extremely inflated. The Homalonotus, a form of Trilobite in which the 
Fig. 636 .

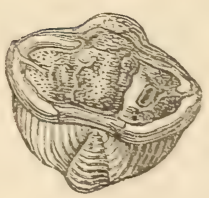

Calymene Blumenoachii, Brong.

Wenlock, Ludlow, and Aymestry limestones.
Fig. 637.

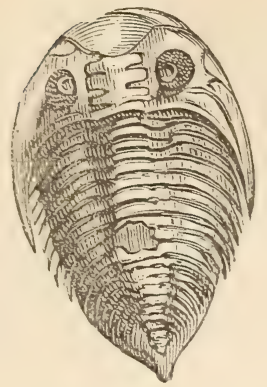

Fig. 633

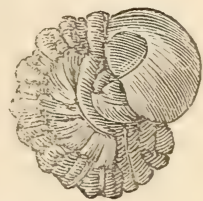

Sphcorexochus mirus, Beyrich, coiled up.

Dudley; also in Ohio, N. America

Phacops (Asaptus) caudatus, Brong.

Wenlock, Aymestry, and Ludlow rocks.

tripartite division of the dorsal crust is almost lost (see fig: 639), is very characteristic of this dirision of the Silurian series; and there are numerous other genera and species.

Fig. 639.

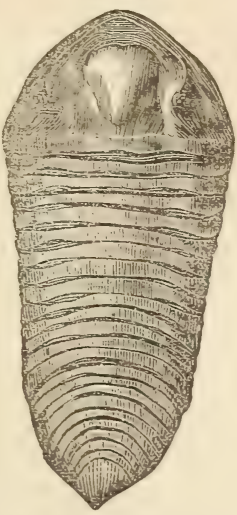

Fig. 640.

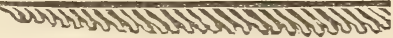

Graptolithus Ludensis, Murchison. Ludlow and Wenlock Shales.

Homalonotus delphinocephatus, Konig.

Dudley Castle. $\frac{2}{3}$ nat. size.

Lower Wenlock.-a. Wenlock Shale.-This, observes Sir R. Murchison, is infinitely the largest and most persistent member of the Tenlock formation, for the limestone often thins out and disappears. The shale, like the Lower Ludlow, often contains elliptical concretions of impure earthy limestone. In the Malvern district it is a mass of finely lerigated argillaceous matter, attaining, according to Prof. Phillips, a thickness of 610 fect, but is sometimes more than 1000 feet thick in Wales, and is worked for flagstones and slates. The prerailing fossils, besides corals and trilobites, and some crinoids, are several small species of Orthis, Cardiola, and numerous thin-shelled species of Orthoceratites. More than one species of Graptolite, a group of zoophytes before alluded to as being confined to Silurian rocks, is very 
abundant in this shale, and occurs more sparingly in "the Ludlow." Of these fossils, which are more characteristic of the Lower Silurian, I shall again speak in the sequel (p. 565).

b. Woolhope Limestone and Grit.-Though not always recognized as a separate subdivision of the Wenlock, the Woolhope beds which underlie the Wenlock shale are of great importance. Usually they occur as massive or nodular limestones, underlaid by a fine shale or flagstone; and in other cases, as in the noted Denbighshire sandstones, as a coarse grit of very great thickness. This grit forms mountain ranges through North and South Wales, and is generally marked by the great sterility of the soil where it occurs. It contains the usual Wenlock fossils, but with the addition of some common in the uppermost Ludlow rock, such as Chonetes lata and Bellerophon trilobatus.* The chief fossils of the Woolhope limestone are Mloenus Barriensis, Homalonotus delphinocephalus (fig. 639), Strophomena imbrex, and Rhynchonella Wilsoni (fig. 626). The latter attains in the Woolhope beds an unusual size for the species, the specimens being sometimes twice as large as those found in the Wenlock limestone.

\section{MIDDLE SILURIAN ROCKS.}

Upper Llandovery.-a. Tarannon shale.-Next below the Wenlock formation are found in some places the Tarannon shales or pale slates, sometimes purple, which are of small thickness near Llandovery, but acquire large dimensions at Tarannon in Montgomeryshire, being, according to Ramsay, about 1000 feet thick in that locality; according to Mr. Jukes and Mr. Aveline, they form a band of great persistence, extending from Llandovery, through Radnor and Montgomerey, to North Wales. Fossils are rare in them, and most of them are of species common to the Wenlock formation.

b. May-Hill Sandstone.-Next in descending order comes the MayHill sandstone, which may be advantageously studied at May-Hill in Gloucestershire, and in the Malvern and Abberley Hills; its position was first accurately determined by Prof. Sedgwick, who considered it as the true base of the Upper Silurian rocks. In the Malvern range it attains a thickness of 600 feet. These beds were formerly called Upper Caradoc, when they were supposed to be part of the Caradoc formation, to be mentioned in the sequel; but this nomenclature has been abandoned for good reasons, with which I need not here detain the reader. They are named Upper Llandovery by Sir R. Murchison in the last edition of his "Siluria." Conjointly with the Lower Llandovery rocks, they have been called the Pentamerus beds, because Pentamerus loevis is very abundant in them, a brachiopod wanting both in the Upper and Lower Silurian. It is usually accompanied by $P$.

* Sedgwick, Quart. Geol. Journ., vol. i. p. 20, 1845. 
oblongus, which some zoologists consider as the young of $P$. lcevis, others as a distinct species: both forms have a wide geographical range, being also met with in the same part of the Silurian series in Russia and the United States.

Fig. 641 .
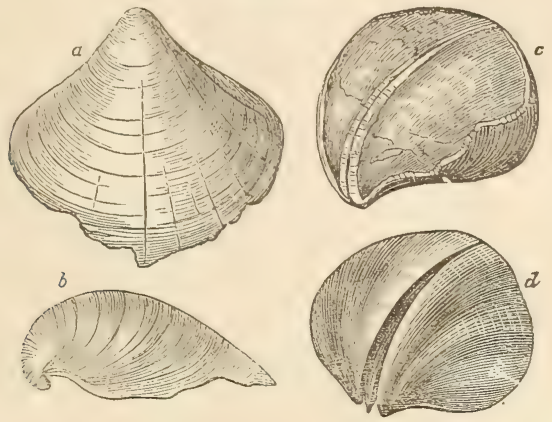

Pentamerus lcevis, Sow. Upper and Lower Llandovery beds. Perhaps the young of Pentamemus oblongus.

a, b. Views of the shell itself, from figures in Murchison's "Silurian System."

c. Cast with portion of shell remaining, and with the hollow of the central septum filled with spar.

d. Internal cast of a valve, the space once occupied by the septum being represented by a hollow in which is seen a cast of the chamber within the septum.

The May-Hill or Upper Llandovery group sometimes consists of a conglomerate, but oftener of limestones and shales, especially in the upper part. It ranges from the skirts of the Longmynd by Builth, Llandovery, and Llandeilo, to the sea in Marlow's Bay, where it is particularly $\pi$ ell exhibited in the cliffs. The conglomerate is derived from the waste of the Lower Silurian rocks. About sixty species of fossils are known in the May-Hill division, more than half of which are, acFig. 612. cording to Mr. Salter, Wenlock species. They consist of trilobites of the genera Illanus and Calymene; Brachiopods of the genera Orthis, Atrypa, Leptona, Pentamerus, Strophomena, and others; Gasteropods of the genera Turbo, Murchisonia, and Bellerophon; and Pteropods of the genus Conularia. The Brachiopods are almost all Upper Silurian species.

Among the fossils of the May-Hill shelly saudstone at Malvern, Tentaculites aninulatus (fig. 642), an annelid probably allied to Serpula, is founc. It is also abundant in the Caradoc or Lower Silurian.

Llandorery Rocks (Lower Llandovery of Murchison).-Below the May-Hill group are the Llandorcry Rocks, so named from a town in 
South Wales, where they are well developed, and where they are overlaid unconformably by the equivalent of the May-Hill sandstone. They consist chiefly of hard slaty rocks, with bands of sandstone and beds of conglomerate from 600 to 1000 feet in thickness. The fossils, which are somewhat rare, consist of twenty-eight known species, some few peculiar, a part agreeing with the May-Hill beds, and the rest, sixteen in number, belonging to Lower Silurian species; besides these, no less than fifty-four species of fossils are given by Sir R. Murchison as common to the Lower Silurian (Caradoc) and the Wenlock formations, and we cannot doubt that all these existed in the intermediate Llandovery and May-Hill periods.

The whole May-Hill and Llandovery series has been considered by some geologists as constituting beds of passage between the Lower and Upper Silurian, while others have assigned to it the rank of a Middle Silurian group. It may, with some reason, be objected that the number of peculiar fossils are not sufficient to entitle it to so important a distinction; but there is no small difficulty at present in adopting any other classification. The two formations, the May-Hill and the Llandovery, are intimately connected by their fossils, the Lower having about two-thirds of its species common to the Upper zone. Again, half the species of the Llandovery pass down into the Lower Silurian, just as half the May-Hill species pass up into the Wenlock. In England we might draw the line, as Sir R. Murchison inclines to do, between Upper and Lower Silurian, by classing the May-Hill with the higher division, and the Llandovery with the lower; but in countries where there is no unconformability of strata between the two zones, such a line of demarcation between the middle of the Pentamerus beds would be impracticable. It has been sometimes suggested that we might form a better tripartite division of the Silurian rocks by including the Wenlock with the May-Hill and Llandovery beds as a middle group, classing the two Ludlow formations as Upper, and the Caradoc and Llandeilo formations as Lower Silurian;* but I am not prepared to adopt so great a change in the generallyreceived classification.

\section{LOWER SILURIAN ROCKS.}

Caradoc and Bala Beds.-The Lower Silurian has been divided into-1st, Caradoc Sandstone and Bala Beds; 2dly, the Llandeilo Flags; and 3dly, the Lower Llandeilo or Arenig formation. The Caradoc sandstone was originally so named by Sir R. I. Murchison from the Mountain called Caer Caradoc in Shropshire; it consists of shelly sandstones of great thickness, and sometimes containing much calcareous matter. The rock is frequently laden with the beautiful srilobite called by Murchison Trinucleus Caractaci (see fig. 647),

* See Report of Canada Survey Table of Equivalents, p. 932, 1863 
which ranges from the base to the summit of the formation, usually accompanicd by Strophomena grandis (see fig. 645), and Orthis vespertilio (fig. 644 ), with many other fossils.

Fig. 613.

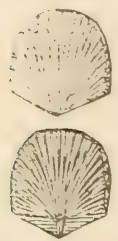

Orthis tricenaria, Hall.

New York. Canada. $\frac{1}{3}$ nat. size.
Fi:. $64+1$.

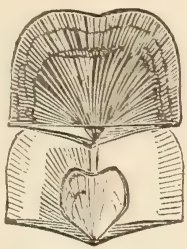

Ortiis vespertilio, Sow. Shropshire; N. and S. Wales.

$\frac{1}{2}$ nat. size.
Fig. 615.

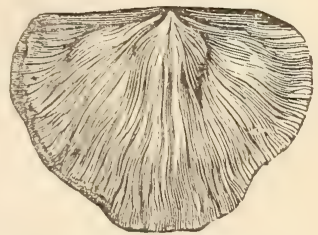

Strophomena (Orthis) grandis, Sowerby. $\frac{2}{3}$ nat. size.

Horderly, Shropshire ; also Coniston, Lancashire.

Burmeister, in his work on the organization of trilobites, supposes them to have swum at the surface of the water in the open sea and near coasts, feeding on smaller marine animals, and to have had the power of rolling themselves into a ball as a defence against injury. He was also of opinion that they underwent various transformations analogous to those of living crustaceans. M. Barrande, author of an admirable work on the Silurian rocks of Bohemia, confirms the doctrine of their metamorphosis, having traced more than twenty species through different stages of growth from the young state just after its escape from the egg to the adult form. He has followed some of them from a point in which they show no eyes, no joints to the body, and no distinct tail, up to the complete form with the full

Fig. 646

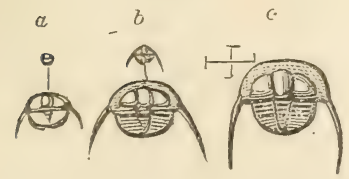

Young individuals of Trinucleus concentricus ( $T$. ornatus, Barr).

a. Youngest state. Natural size and magnified; the body rings not at all developed.

b. A little older. Onc thorax joint.

c. Still more adranced. Three thorax joints. The fourth, fifth, and sixth segments are successively produced, probably each time the animal moulted its crust.
Fig. 617.

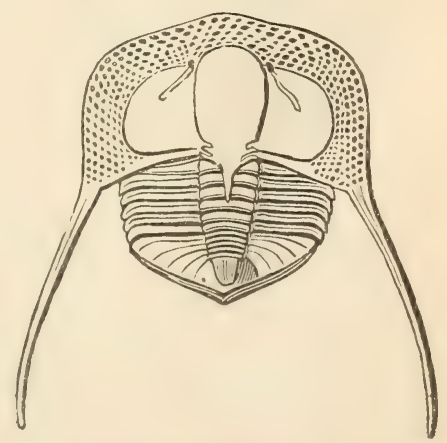

Trinucleus concentricus, Eaton. Syn. T. Caractaci, Murch. N. Ireland; Wales; Shropshire; N. America; Bohemin.

number of segments. This change is brought about before the animal has attained a tenth part of its full dimensions, and hence such minute and delicate specimens are rarely met with. Some of 
his figures of the metamorphoses of the common Trinucleus are copied in the foregoing woodeuts (figs. 646,647 ).

In Mr. Salter's monograph of the British trilobites, he expresses his opinion that their habit was to live on the sea-bottom and devour the silt charged with organic matter as sea-worms do, or else, possibly, to devour the worms themselves. He supposes the trilobite to have had no jaws, and to have been provided with a suctorial mouth.*

It has been ascertained that a great thickness of slaty and crystalline rocks of South Wales, as well as those of Snowdon and Bala in North Wales, which were first supposed to be of older date than the Silurian sandstones and mudstones of Shropshire, are in fact identical in age with the Caradoc formation now under consideration, and contain the same organic remains. At Bala in Merionethshire, a limestone rich in fossils occurs, and below it sandstones some thousands of feet in thickness. In this limestone several rare starfishes are found, and abundance of those peculiar bodies called Cystidce. These last are amongst the most recent additions made by palæontologists to the Radiata. Their structure and relations were first elucidated in an essay published by Von Buch at Berlin in 1845. They are the Sphceronites of old authors, and are usually met with as spheroidal bodies covered with polygonal plates, with a mouth on the upper side; and a point of attachment for a stem

Fig. 648.

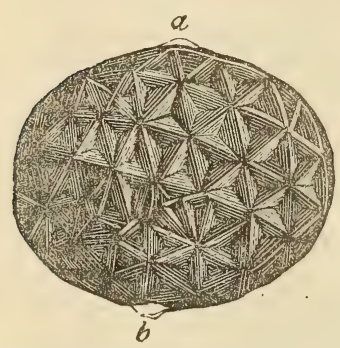

Echinospharites balticus, Eichwald, sp. (Of the family Cystideoe.)

a. Mouth.

b. Point of attachment of stem.

Lower Silurian, S. and N. Wales. (which is almost always broken off) on the lower (fig. 648 b). They were considered by Prof. E. Forbes as intermediate between the crinoids and echinoderms. The Echinosphoronite here represented (fig. 648) is characteristic of the Caradoc beds in Wales, $\nmid$ and of their equivalents in Sweden and Russia.

With it have been found several other genera of the same family, such as Sphceronites, Hemicosmites, \&c. Among the mollusea are Pteropods of the genus Conularia of large size (for genus, see fig. 611, p. 540); Graptolites are rare, except in pecu-

liar localities where black mud abounds. The formation, when traced into South. Wales and Ireland, assumes a greatly altered mineral aspect, but still retains its characteristic fossils. In Tyrol it is especially rich in organic remains. $\ddagger$ It is worthy of remark that, when it

* Palæontographica, vol, xvi. p. 9, 1864.

† Quart. Geol. Journ., vol. vii. p. 11; and Mem. Geol. Surv., vol. ii. p. 518.

t See Portlock's Report of Londonderry, 1843. 
occurs under the form of trappean tuff (volcanic ashes of De la Beche), as in the crest of Snowdon, the peculiar species which distinguish it from the Llandeilo beds are still observable. The formation generally appears to be of shallow-water origin, and in that respect is contrasted with the group next to be described. Professor Ramsay estimates the thickness of the Bala Beds, including the contemporaneous rolcanic rocks, stratified and unstratified, as being from 10,000 to 12,000 feet in thickness.

Llandeilo Flags.-The Lowcr Silurian strata were originally divided by Sir R. Murchison into the upper group already described, under the name of Caradoc Sandstone, and a lower one, called, from a town in Caermarthenshire, the Llandeito flags. The last-mentioned strata consist of dark-colored micaceous flags, frequently calcareous, with a great thickness of shales, generally black, below them. The same beds are also seen at Builth in Radnorshire, and here they are interstratified with volcanic matter.

A still lower part of the Llandeilo rocks consists of a black carbonaceous slate of great thickness, frequently containing sulphate of alumina, and sometimes, as in Dumfriesshire, beds of anthracite. It has been conjectured that this carbonaceous matter may be due in great measure to large quantities of imbedded animal remains, for the number of Graptolites included in these slates was certainly very great. I collected these same bodies in great numbers in Sweden and Norway in 1835-'6, both in the higher and lower graptolitic shales of the Silurian system; and was informed by Dr. Beck of Copen-

Fig. 649 .

(Old plate, fig. 599, p. 442.)

\section{Didymograpsus (Graptolites) Murchisonii, Beck. Llandeilo flags. Wales.}

Fig. 651.

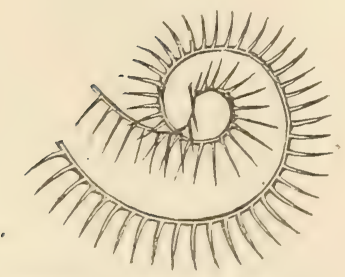

Rastrites peregrinus, Barrande. Scotland; Bohemia; Saxony: Llandeilo flags.
Fig. 650 .

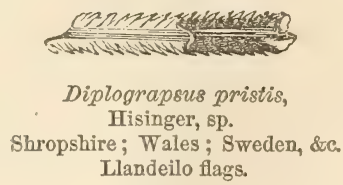

Llandeilo flags.

Fig. 652

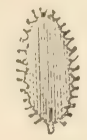

Diplograpsus folium, Hisinger. Dumfriesshire; Sweden. Llandeilo flags.

hagen that they were fossil zoophytes related to the Virgularia and Pennatula, genera of which the living species now inhabit mud and 
slimy searment. Some of our most eminent naturalists still hold to this opinion, others refer them to Bryozoa.

The brachiopoda of the Llandeilo flags, which are very abundant, are in the main the same as those of the Caradoc Sandstone, but the other mollusca are in great part of different species.

In Europe generally, as, for example, in Sweden and Russia, no shells are so characteristic of this formation as Orthoceratites, usually of great size, and with a wide siphuncle placed on one side instead of being central (see fig. 653). The same form also occurs in

Fig. 653.

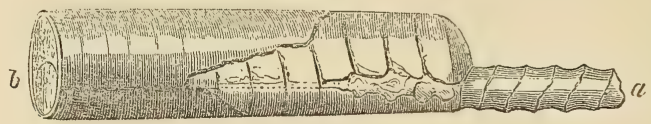

Orthoceras duplex, Wahlenberg. Russia and Sweden.

(From Murchison's "Siluria.")

a. LateraI siphuncle laid bare by the removal of a portion of the chambered shell.

b. Continuation of the same seen in a transverse section of the shell.

the Bala beds in England. Among other Cephalopods in the Llandeilo flags are Lituites (see fig. 629); in the same beds also are found Bellerophon (see fig. 577, p. 52Q) and some Pteropod shells (Conularia, Theca, \&c.), also in spots where sand abounded lamellibranchiate bivalves of large size. The Crustaceans were plentifully represented by the Trilobites, which appear to have swarmed in the Silurian seas just as crabs and shrimps do in our own. The genera Asaphus (fig. 654), Ogygia (fig. 655), and Trinucleus (figs. 646, 647), form a marked feature of the rich and varied Trilobitic fauna of this age.

Fim. 654 .

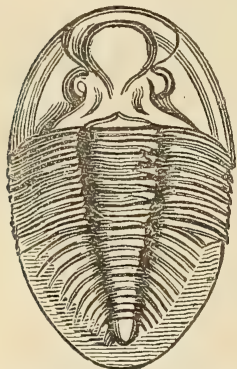

Asaphus tyrannus. Murch Llandeilo; Bishop's Castle, \&c.
Fig. 655 .

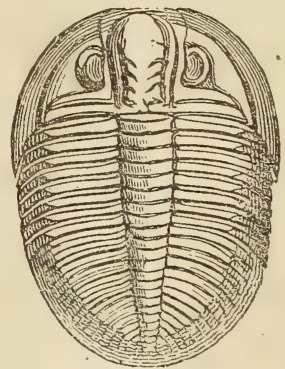

Ogygia Buchii, Burm.

Syn. Asaphus Buchii, Brongn. Builth, Radnorshire; Llandeilo, Caermarthenshtre.

Beneath the black slates above described of the Llandeilo formation, graptolites are still found in great variety and abundance, and the characteristic genera of shells and trilobites of the Lower Silurian rocks are still traceable downwards, in Shropshire, Cumberland, and 
North and South Wales, through a vast depth of shaly beds, interstratified with trappean formations of contemporaneous origin; these consist of tuffs and laras, the tuffs being formed of such materials as are ejected from craters and deposited immediately on the bed of the ocean, or washed into it from the land. According to Professor Ramsar, their thickness is about 3300 feet in North Wales, including those of the Lower Llandeilo. The lavas are felspathic, and of porphyritic structure, and, according to the same authority, of an aggregate thickness of 2500 feet.

Lower Llandeilo Formation, Murchison; Arenig, Sedgwick.-Next in the descending order are the shales and sandstones in which the quartzose rocks called Stiper-stones in Shropshire occur. When the term "Silurian" was given by Sir R. Murchison, in 1835, to the whole series, he considered the Stiper-stones as the base of the Silurian system, but no fossil fauna had then been obtained, such as could alone enable the geologist to draw a definite line between this member of the series and the Llandeilo flags above, or a vast thickness of rock below which was seen to form the Longmynd hills, and was called "unfossiliferous graywacke." Professor Sedgwick had described strata now ascertained to be of the same age as largely developed in the Arenig mountain in Merionethshire, in 1843, and the Skiddaw slates, studied by the same author, were of corresponding date, though the number of fossils was, in both cases, too few for the determination of their true chronological relations. The subsequent researches of MM. Sedgwick and Harkness in Cumberland, and of Sir R. I. Murchison and the Government surveyors in Shropshire, have increased the species to more than sixty. These have been examined by Mr. Salter, and shown in the last edition of "Siluria" (p. 52, 1859) to be quite distinct from the fossils of the overlying Llandeilo flags. Among these the Lingula plumbea, Agtina

Fig. 656.

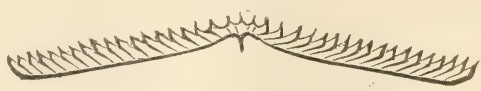

Didymograpsus geminus, Hisinger, sp. Sweden. binodosa, Ogygia Selwynii, and Didymograpsus geminus (fig. 656), and $D$. hirundo, are characteristic.

In reference to the classification of the Silurian rocks, two questions have been raised; first, whether the Lower Silurian, comprising the Caradoc and Llandeilo beds already described, should be scparated from the Upper Silurian under some new title, such as CambroSilurian; and secondly, whether, if we reject this, the Arenig or Stiperstones group (Lower Llandeilo of Nurchison) should be regarded as the base of the Lower Silurian or as the top of a distinct and older series. In reference to the first question Sir R. Murchison, in his important work above cited, * has given a list of no less than fifty or 
sixty species of fossils (of which specimens had been examined either by Mr. Salter or Prof. McCoy), all common to the Upper and Lower Silurian strata, or, in other words, which, being found in the Caradoc, are also met with in the Wenlock formation. The range upwards of so many species from the inferior to the superior group shows that, independently of the link supplied by the Llandovery or Middle Silurian, there is such a connection between the two principal divisions (Upper and Lower Silurian) as makes it natural to assign the whole to one great system. To attempt, therefore, to give a new name to the Llandeilo beds, or to call them Cambrian or Cambro-Silurian, as has been proposed, would be to act in violation of the ordinary rules of elassification, and would create much confusion by disturbing a nomenclature long received and originally established, by Sir R. I. Murchison, on well-defined palæontological and stratigraphical data.

As to the second question, whether a line should not be drawn between the Llandeilo flags and the subjacent Stiper-stones or Arenig group, more may be said in its faror, since while so many species pass from Lower to Upper Silurian, there are none, according to $\mathrm{Mr}$. Salter, which pass down from the Llandeilo flags or Upper Llandeilo, into the Arenig or Lower Llandeilo beds. But, although the species are distinct, the genera are the same as those which characterize the Silurian rocks above, and none of the primordial or Cambrian forms, presently to be mentioned, are intermixed. This Arenig group may therefore be conveniently regarded as the base of the great Silurian system, which, by the thickness of its strata and the changes in animal life of which it contains the record, is more than equal in value to the Devonian, or Carboniferous, or other principal divisions, whether of primary or secondary date.

It would be unsafe to rely on the mere thickness of the strata, considered apart from the great fluctuations in organic life which took place between the era of the Llandeilo and that of the Ludlow formation, especially as the enormous pile of Silurian rocks observed in Great Britain, and, especially in Wales, is derived in great part from igneous action, and is not confined to the ordinary deposition of sediment from rivers or the waste of cliffs.

In volcanic archipelagoes, such as the Canaries, we see the most active of all known causes, aqueous and igneous, simultaneously at work to produce great results in a comparatively moderate lapse of time. The outpouring of repeated streams of lava-the showering down upon land and sea of volcanic ashes-the sweeping seaward of loose sand and cinders, or of rocks ground down to pebbles and sand, by rivers and torrents descending steeply inclined channels-the undermining and eating away of long lines of sea-cliff exposed to the swell of a deep and open ocean-these operations combine to produce a considerable volume of superimposed matter, without there being time for any extensive change of species. Nevertheless, there would seem to be a limit to the thickness of stony masses formed 
even under such farorable circumstances, for the analogy of tertiary volcanic regions lends no countenance to the notion that sedimentary and igneous rocks 25,000 , much less 45,000 feet thick, like those of Wales, could originate while one and the same fauna should continue to people the earth. If, then, we allow that about 25,000 feet of matter may be ascribed to one system, such as the Silurian, as above described, we may be prepared to discover in the next series of subjacent rocks a distinct asscmblage of species, or even in great part of genera, of organic remains. Such appears to be the fact, and I shall therefore conclude, with the Lower Llandeilo or Arenig beds, my enumeration of the Silurian formations in Great Britain, and proceed to say something of their foreign equivalents, before treating of rocks older than the Silurian.

\section{SILURIAN STRATA OF THE CONTINENT OF EUROPE.}

When we turn to the Continent of Europe, we discover the same ancient series occupying a wide area, but in no region as yet has it been observed to attain great thickness. Thus, in Norway and Sweden, the total thickness of strata of Silurian age is scarcely equal to 1000 feet," although the representatives both of the Upper and Lower Silurian of England are not wanting there, and even some beds of schist have been included, which, as we shall hereafter see, lie below the Llandeilo group. In Russia the Silurian strata, so far as they are yet known, seem to be even of smaller vertical dimensions than in Scandinaria, and they appear to consist chiefly of Middle and Lower Silurian, or of a limestone containing Pentamerus oblongus, below which are strata with fossils corresponding to those of the Llandeilo beds of England. The lowest rock with organic remains yet discovered is "the Ungulite or Obolus grit" of St. Petersburg, probably coeval with the Llandeilo flags of Wales.

The shales and grits near St. Petersburg, above alluded to, contain green grains in their sandy layers, and are in a singularly unaltered state, taking into account their high antiquity. The prevailing

Shells of the lowest known Fossiliferous Beds in Russia.

Fig. 657 .

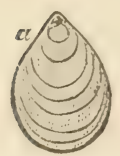

Siphonotreta unguiculata, Eichwald.

From the Lowest Silurian Sandstone "Obolus grits," of Petersburg.

a. Outside of perforated valve.

b. Interior of same, showing the termination of the foramen within. (Davidson.)
Fig. 658 .
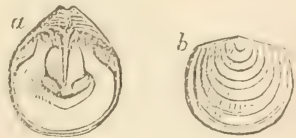

Obolus Apoltinis, Eichwald. From the same locality.

a. Interior of the larger or ventral valve.

b. Exterior of the upper (dorsal) valve.

(Davidson, "Palæontograph. Monog.")

* Murchison's Siluria, p. 321. 
brachiopods consist of the Obolus or Ungulite of Pander, and a Siphonotreta (figs. 657,658). Notwithstanding the antiquity of this Russian formation, it should be stated that both of these genera of brachiopods have been also found in the Upper Silurian of England, $i$. e. in the Dudley limestone.

Among the green grains of the sandy strata above mentioned, Prof. Ehrenberg has announced (1854) his discovery of remains of foraminifera. These are casts of the cells; and amongst five or six forms three are considered by him as referable to existing genera (e. g. Textularia, Rotalia, and Guttulina).

\section{SILURIAN STRATA OF THE UNITED STATES.}

The position of some of these strata, where they are bent and highly inclined in the Appalachian chain, or where they are nearly horizontal to the west of that chain, is shown in the section, fig. 552, p. 497. But these formations can be studied still more advantageously north of the same line of section, in the States of New York, Ohio, and other regions north and south of the great Canadian lakes. Here they are found, as in Russia, nearly in horizontal position, and are more rich in well-preserved fossils than in almost any spot in Europe. In the State of New York, where the succession of the beds and their fossils have been most carefully worked out by the Government surveyors, the subdivisions given in the first column of the annexed list have been adopted.

Subdivisions of the Silurian Strata of New York. (Strata below the Oriskany Sandstone, see Table, p. 543.)

New York Names.

British Equivalents.

1. Upper Pentamerus Limestone.

2. Encrinal Limestone.

3. Delthyris Shaly Limestone.

4. Pentamerus and Tentaculite Limestones.

5. Water Lime Group.

6. Onondaga Salt Group.

7. Niagara Group.

8. Clinton Group.

9. Medina Sandstone.

10. Oneida Conglomerate.

11. Gray Sandstone.

12. Hudson River Group.

13. Utica Slate.

14. Trenton Limestone.

15. Black-River Limestone.

16. Bird's-Eye Limestone.

17. Chazy Limestone.

18. Calciferous Sandstone.

19. Potsdam Saudstone.

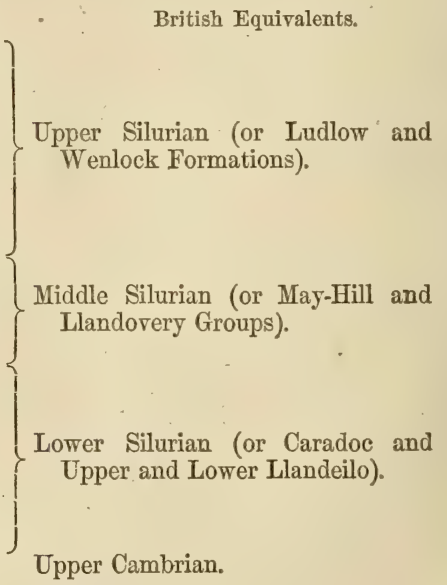

In the second column of the same table I have added the supposed British equivalents. All palæontologists, European and American. 
such as MMr. de Verneuil, D. Sharpe, Prof. Hall, E. Billings, and others, who have entered upon this comparison, admit that there is a marked general correspondence in the succession of fossil forms, and even species, as we trace the organic remains downwards from the highest to the lowest beds; but it is imrossible to parallel each minor subdivision. In regard to the three following points there is little difference of opinion.

1st. That the Niagara limestone, No. 7, over which the river of that name is precipitated at the great cataract, together with its underlying shales, corresponds to the Wenlock limestone and shale of England. Among the species common to this formation in America and Europe are Calymene Blumenbachii, Homalonotus delphinocephalus (fig. 639, p. 559), with several other trilobites; Rhynchonella Wilsoni, and Retzia cuneata; Orthis elegantula, Pentamerus galeatus, with many more brachiopods; Orthoceras annulatum, among the cephalopodous shells; and Fuvosites gothlandica, with other large corals.

2d. That the Clinton Group, No. 8, containing Pentamerus oblongus and $P$. lowvis, and related more nearly by its fossil species with the beds above than with those below, is the equivalent of the Middle Silurian as above defined, p. 560.

$3 \mathrm{~d}$. That the Hudson River Group, No. 12, and the Trenton Limestone, No. 14, agree palæontologically with the Caradoc or Bala group, containing in common with them several species of trilobites, such as Ascphus (Isotelus) gigas, Trinucleus concentricus (fig. 647, p. 563); and rarious shells, such as Orthis striatula, Oithis biforata (or O. lynx), O. porcata (O. occidentalis of Hall), Bellerophon bilobatus, \&c.*

Mr. D. Sharpe, in his report on the mollusca collected by me from these strata in North America, $\nmid$ has concluded that the number of species common to the Silurian rocks on both sides of the Atlartic is between 30 and 40 per cent.; a result which, although no doubt liable to future modification, when a larger comparison shall have been made, proves, nevertheless, that many of the species had a wide geographical range. It seems that comparatively few of the gasteropods and lamellibranchiate bivalves of North America can be identified specifically with European fossils, while no less than two fifths of the brachiopoda, of which my collection chiefly consisted, are the same. In explanation of these facts, it is suggested that most of the recent brachiopoda (especially the orthidiform ones) are inhabitants of deep water, and that ther may have had a wider geographical range than shells liring near shore. The predominance of biralve mollusea of this peculiar class lias caused the Silurian period to be sometimes styled "the age of brachiopods."

The calcareous beds, Nos. 15, 16, 17, and 18, below the Trenton Limestone, hare been considered by MI. de Verneuil as Lotrer Silurian, 
because they contain certain species, such as Asaphus (Isotelus) gigas, Illcenus crassicauda and Orthoceras bilineatum, in common with the overlying Trenton Limestone.* But, according to Prof. Hall, the Illcenus-was erroneously identified, an error to which he confesses that he himself contributed; and on the whole these lower beds contain, he thinks, a very distinct set of species, only 3 or 4 of them out of 83 passing upwards into the incumbent formations. $\dagger$

Be this as it may, the Black River Limestone, No. 15, contains certain forms of Orthocerces of enormous size (some of them 8 or 9 feet long!), of the subgenera Ormoceras and Endoceras, seeming to represent the Lower Silurian or Orthoceras limestone of Sweden. Moreover, the general facies of the fauna of all these beds is essentially similar. Another ground for extending our comparison of the Llandeilo beds of Europe as far down as the calciferous sandstone is derived from the researches of Sir William Logan in Canada, and the study by Mr. Salter of the fossils collected by the Canadian surveyor near the S.E. end of the Ottawa River, where one mass of limestone

Fossits from Allumette Rapids, River Ottawa, Canada.

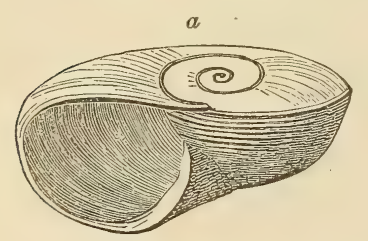

Fig. 659 .

Machrea Logani, Salter.

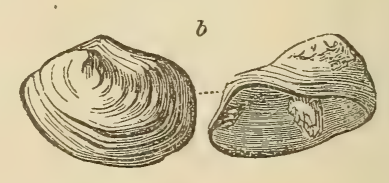

a. View of the shell.

b. Its curious operculum.

Fig. 660 .

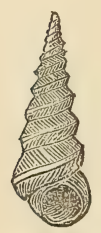

Murchisonia gracilis, Hall. A fossil characteristic of the Trenton Limestone. The genus is common in Lower Silurian rocks. encloses species common to all the beds from the Calciferous Sandstone (No. 18) up to the Trenton Limestone (No. 14). In this rock, the Asaphus gigas and other well-known Trenton species are blended with the Maclurea (fig. 659), a left-handed shell, considered by Woodward as probably a massive heteropod, a genus characteristic of the Chazy Limestone, or No. 17; and Murchisonia gracilis (fig. $660)$ is another Trenton Limestone species found in the same Silurian limestone of Canada; '. while one of the most common shells in it is the Raphistoma? (Euomphalus) uniangulatum, Hall, a species characteristic in New York of the Calciferous Sandstone itself. On the whole, if we identify the beds from the Black River Limestone

* Soc. Géol. France, Bulletin, vol. iv. p. 651, 1847.

+ Hall ; Forster and Whitney's Report on Lake Superior, Pt. II, 1851

$\ddagger$ Logan, Report, Brit. Assoc. Ipswich, pp. 59, 63. 
down to the Calciferous Sandstone inclusively with the Upper and Lower Llandeilo, we shall be in harmony with the latest opinions of American and British geologists.

In Canada, as in the State of New York, the Potsdam Sandstone underlies the above-mentioned calcareous rocks, but contains a different suite of fossils, as will be hereafter explained. In parts of the globe still more remote from Europe the Silurian strata have also been recognized, as in South America, Australia, and recently by Captain Strachey in India. In all these regions the facies of the fauna, or the types of organic life, enable us to recognize the contemporaneous origin of the rocks; but the fossil species are distinct, showing that the old notion of a universal diffusion throughout the "primeval seas" of one uniform specific fauna was quite unfounded, geographical provinces having evidently existed in the oldest as in the most modern times.

Whether the Silurian rocks are of deep-waier origin.-The grounds relied upon by Professor $\mathrm{E}$. Forbes for inferring that the larger part of the Silurian Fauna is indicative of a sea more than 70 fathoms deep, are the following: first, the small size of the greater number of conchifera; secondly, the paucity of pectinibranchiata (or spiral univalves); thirdly, the great number of floating shells, such as Bellerophon, Orthoceras, \&c. ; fourthly, the abundance of orthidiform brachiopoda; fifthly, the absence or great rarity of fossil fish.

It is doubtless true that some living Terebratula, on the coast of Australia, inhabit shallow water; but all the known species, allied in form to the extinct Orthis, inhabit the depths of the sea. It should alşo be remarked that $\mathrm{Mr}$. Forbes, in advocating these views, was well aware of the existence of shores, bounding the Silurian sea in Shropshire, and of the occurrence of littoral species of this early date in the northern hemisphere. Such facts are not inconsistent with his theory; for he has shown, in another work, how, on the coast of Lycia, deep-sea strata are at present forming in the Mediterranean, in the vicinity of high and steep land.

Had we discovered the ancient delta of some large Silurian river, wo should doubtless have known more of the shallow-water, brackishwater, and fluviatile animals, and of the terrestrial flora of the period under consideration. To assume that there were no such deltas in the Silurian world, would be almost as gratuitous an hypothesis, as for the inhabitants of the coral islands of the Pacific to indulge in a similar generalization respecting the actual condition of the globe.

\section{"CAMBRIAN GROUP."}

\section{(Primordial Zone of Barrande.)}

The characters of the Upper and Lower Silurian rocks were established so fully, both on stratigraphical and palicontological data, by 
Sir Roderick Murchison after five years' labor, in 1839, when his "Silurian System" was published, that these formations could from that period be recognized and identified in all other parts of Europe and in North America, even in countries where the fossils differed specifically from those of the classical region in Britain, where they were first studied. But it was not till the year 1846 that M. Joachim Barrande, after ten years' exploration of Bohemia, and after collecting more than a thousand species of fossils, ascertained the existence in that country not only of the equivalents of the two formations above alluded to, but of another set of strata, characterized by a new and distinct fauna, to which, in the introduction to a treatise on trilobites, he gave the name of Etage C, or the "first fauna." His two first stages, A and B, consisted of crystalline and metamorphic rocks, and unfossiliferous schists. In the zone C, called soon afterwards by him "primordial," he had discovered in 1846 no less than twenty-six species of trilobites contained in shales and slates of considerable thick ness, all of them belonging to new species and the greater part of them to new genera, called by him Paradoxides, Conocephalus (syn. Conocoryphe), Ellipsocephalus, Arion, Sao, and Hydrocephalus, and some of them to the genus Agnostus, the only form commun to his first and second fauna, the latter corresponding to the Lower Silurian of Murchison. M. Barrande classed this first fauna as the oldest member of the Silurian period, applying the term Silurian in Sir R. Murchison's sense as comprehending all the fossiliferous strata older than the Devonian. He spoke of it as occupying "le même horizon que les formations fossilifères les plus anciennes de Suède, de Norvège et des Isles Britanniques;" and he added, still speaking of Etage C, "Il forme donc la base des terrains protozoïques, selon la dernière classification du Rev. Professeur Sedgwick." * It was impossible in 1846 for M. Barrande to make a nearer approach towards a just correlation of the Bohemian and British groups of strata, since at that time the Lower Silurian of Murchison had no well-defined base-line, physical or zoological, while the Cambrian or protozoic of Sedgivick, as distinguished from the Lower Silurian, was without a fauna. Even the Lingula Davisii, which will presently be mentioned, was not discovered till 1846, at which time the new organic types of Bohemia,

- older than the Lower Llandeilo beds above described, were so peculiar as to enable geologists from that time forth to identify by their means alone in Scandinavia, Russia, Canada, and the United States, strata of corresponding age. It was some years before a sufficient number of British fossils were found below the Lower Llandeilo beds to enable the geologist to identify the different members of the Cambrian group with their equivalents in Ireland and Scotland, and other parts of Europe. If, therefore, M. Barrande had, in 1846, called the fossiliferous rocks of his Etage C "Bohemian," that name would, 
I have little doubt, have been universally accepted, since he had acquired full right to give a name to the new group or system of rocks, the position and characteristic fossils of which he had first truly defined.

The term "primordial" was intended to express M. Barrande's own belief that the fossils of Etage C afforded eridence of the first appearance of vital phenomena on this planet, and that consequently no fossiliferous strata of older date would or could ever be discovered.

I have been opposed from the first to a nomenclature the adoption of which would seem to imply the acceptance of such a theory, for I always felt sure, on contemplating the past history of geology, that we had not yet pushed our inquiries into the past so far as to lead us to despair of extending our discoveries at some future day, when vast purtions of the globe hitherto unexplored should hare been thoroughly surveyed.

The term "Cambrian" had, long before 1846, been applied by Prof. Sedgrick to rocks, some of which we now know to be of contemporaneous date with Barrande's "primordial zone." Sedgwick had begun his exploration of these rocks in 1831, and in 1843 published memoirs on what he then termed the protozoic rocks of North Wales, giving detailed sections by which the geological structure of an intricate region was admirably worked out.

Large portions of the strata both of South and North Wales at first called Cambrian, and supposed to be older than the Silurian rocks of Murchison, were afterwards proved by our surveyors, chiefly by the labors of Prof. Ramsay, to be the equivalents of the Lower Silurian rocks above described.

The folloming table will show the succession of the strata in England and Wales which belong to the Cambrian group or the fossiliferous rocks older than the Lower Llandeilo, to which are added the Laurentian formations of Canada, as the oldest in the world in which organic remains have yet been found:

\section{CAMBRLAN GROUP.}

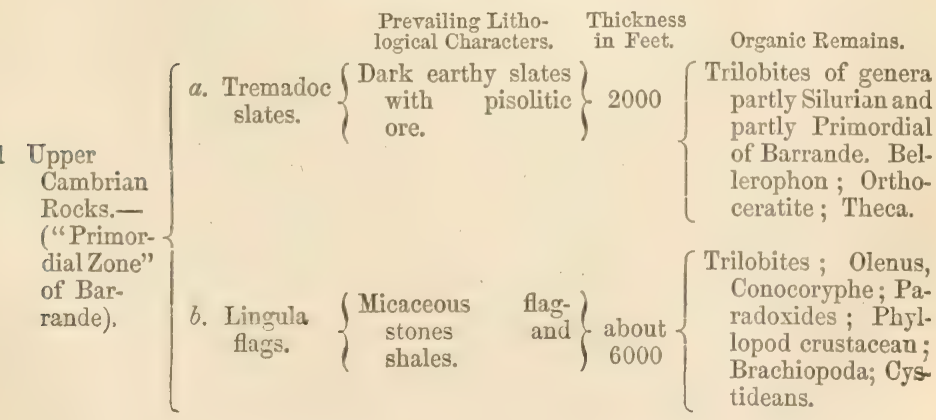




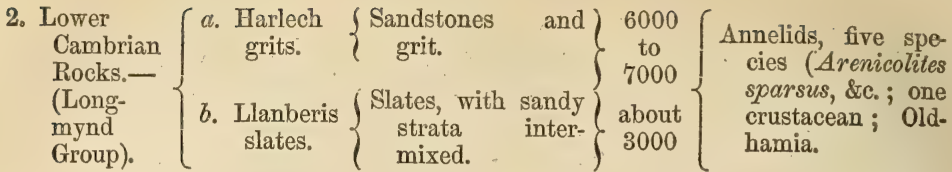

\section{LAURENTIAN GROUP.}

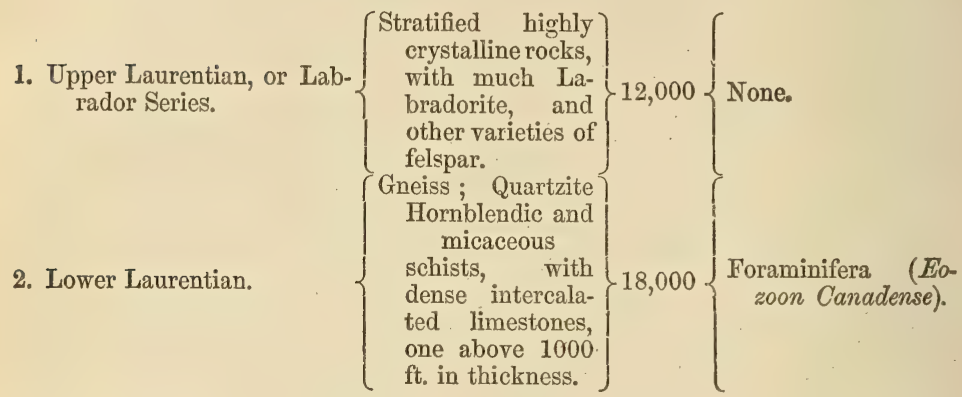

UPPER CAMBRIAN.

Tremadoc Slates.-The Tremadoc slates of Sedgwick are more than 1000 feet in thickness, and consist of dark earthy slates occurring near the little town of Tremadoc, situated on the north side of Cardigan Bay in Carnarvonshire. These slates were first examined by Sedgwick in 1831, and were reëxamined by him and described in $1846, *$ after some fossils had been found in the underlying Lingula flags by Mr. Davis. The inferiority in position of these Lingula flags to the Tremadoc beds was at the same time established. The overlying Tremadoc beds were traced by their pisolitic ore from Tremadoc to Dolgelly. No fossils proper to the Tremadoc slates were then observed, but subsequently, when the same beds were well searched by the collectors of the Government Survey in 1853 and 1857, thirtyone species of all classes were found in them and determined by Mr. Salter. By their means he was able to separate the beds into an upper and lower division: in the upper of which there are about twenty species, and about fifteen in the lower. We have already seen that in the Lower Llandeilo (Stiper-stones or Arenig group), where the species are distinct, the genera agree with Silurian types; but in these Tremadoc slates, where the species are also peculiar, there is about an equal admixture of Silurian types with those which Barrande has termed "primordial." Here, therefore, it may truly be said that we are entering upon a new domain of life in our retrospective survey of the past. The trilobites of new species, but of

* Geol. Quart. Journ., vol. iii. p. 156. 
Lower Silurian forms, belong to the genera, Ogygia, Asaphus, and Cheirurus; whereas those belonging to primordial types, or Bar rande's first fauna, as well as to the Lingula flag's of Wales, comprise Conocoryphe, Olenus, sereral species, and Angelina. In the Upper Tremadoc slates are found Bellerophon, Orthoceras, and Cyrtoceras, all specifically distinct from Lower Silurian fossils of the same genera: the Pteropod Theca ranges throughout these slates; there are no Graptolites. The only Tremadoc species which, according to Salter, is not peculiar, is Lingula Davisii, which ranges from the top to the bottom of the formation, and links it with the zone next to be described. The Tremadoc slates are very local, and seem to be confined to a small part of North Wales; and Prof. Ramsay supposes them to lie unconformably on the Lingula flags, and that a long interval of time elapsed between these formations.

Lingula Flags.-Next below the Tremadoc slates in North Wales, lie micaceous flagstones and slates, in which, in 1846, Mr. E. Davis discovered the Lingula named after him, and from which was derived the name of Lingula Flags. $\dagger^{\prime}$ In these flags and shales, other fossils were found by subsequent researches, which were observed to differ specifically from those of the Llandeilo beds, or the lowest portion of the Lower Silurian then palæontologically known. Trilobites of the genera Olenus and Conocoryphe (for genus, see fig. 667), and other forms, which will soon be published by our Government Surrey, were detected; and Paradoxides (for genus, see fig. 666), another

\section{Fossils of the "Lingula Flags," or lowest Fossiliferous Rocks of Britain.}

Fig. 661 .

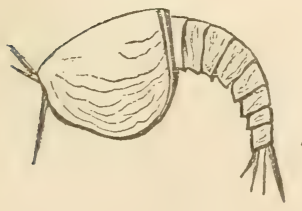

Hymenocaris vermicauda, Salter.

A Phyllopod Crustacean. $\frac{1}{2}$ nat. size.
Fig. 662 .

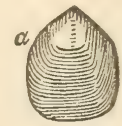

8

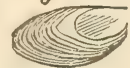

Lingula Davisii, M'Coy

a. $\frac{\pi}{2}$ nat. size.

b. Distorted by cleavage.
Fig. 663.

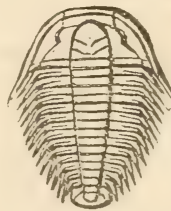

Olenus micrurus, Salter.

1 nat. size.

"Lingula Flags" of Dolgelly, and Ffestiniog; N. Wales.f

of Barrande's primordial forms of Bohemia, was also found both in North and South Tales, in the black slates of this era. With these

* This genus has been substituted for Barrande's Conocephalus, as the latter term had been preoccupied by the entomologists.

+ This shell has since been referred by Salter to a subgenus Lingulella, but I retain the original name in this chapter, because it has long been used by geologists in their designation of the beds where it is so abundant.

† These figures were given in Sir R. Murchison's Siluria (2d ed., 1854), chap. ï. 
also a phyllopod crustacean (fig. 661), and several genera of Brachiopoda, with a rare Cystidean and a sponge, were obtained. In all, about forty or forty-five species are already described by Mr. Salter, and other forms are still in his hands for investigation.

In Merionethshire, says Prof. Ramsay, the Lingula flags are from 5000 to 6000 feet thick; in Carnarvonshire, near Llanberis, only about 2000 feet, having, in the space of about 11 miles, lost 4000 feet of their thickness. In Anglesea and on the Menai Straits, the Llandeilo and Bala Beds lie directly on (Lower) Cambrian strata, both the Lingula flags and Tremadoc slates being absent.*

\section{O W E R C A M B I A N.}

\section{(Longmynd Group.)}

Harlech Grits.-Older than the Lingula flags are stratified formations of great thickness, but which have as yet proved very barren of organic remains, and have been variously called by Prof. Sedgwick the Longmynd and Bangor group, comprising, first, the Barmouth and Harlech sandstones, and secondly, the Llanberis slates. The sandstones of this period attain in the Longmynd Hills in Shropshire a thickness of no less than 6000 feet, without any interposition of volcanic matter. In some places in Merionethshire they are still thicker. The labors of Mr. Salter in Shropshire and those of the late Dr. Kinahan in Wicklow have brought to light at least five species of Annelides in these rocks, two of which have been named Arenicolites sparsus and $A$. didymus. They occur in countless myriads through a mile of thickness in the Longmynd, where also an obscure crustacean form has been discovered and named Palocopyge Ramsayi. The sands of this formation are often rippled, and were evidently left dry at low tides, so that the surface was dried by the sun and made to shrink and present sun-cracks. There are also distinct impressions of rain-drops, like those figured at p. 490, on many surfaces. $\uparrow$

Llanberis Slates.-The slates of Llanberis and Penrhyn in Carnarvonshire, with their associated sandy strata, attain a great thickness, sometimes about 3000 feet. They are perhaps not more ancient than the Harlech and Barmouth beds last mentioned, for they may represent the deposits of fine mud thrown down in the same sea, on the borders of which the sands above mentioned were accumulating. In some of these slaty rocks in Ireland, immediately opposite Anglesea and Carnarvon, two species of zoophytes have been found, to which the late Prof. E. Forbes gave the name of Oldhamia. They

* Anniversary Address, Geol, Quart. Journ., vol. xix. p. 39, 1863.

† Salter, Quart. Geol. Journ., vol. xiii., 1857. 
may be considered as the most ancient fossils yet known in Europe.

The mar reasonably anticipate that the Longmynd fauna, if ever it shall become extensirely known in the British Isles or elsewhere, will be found to differ considerably from that of the Upper Cambrian rocks, for the thickness of the beds unmixed with rolcanic matter is very great, and they must have required a great lapse of time for their deposition.

The most ancient fossils yet known in Europe (1864).

Fig. 665 .
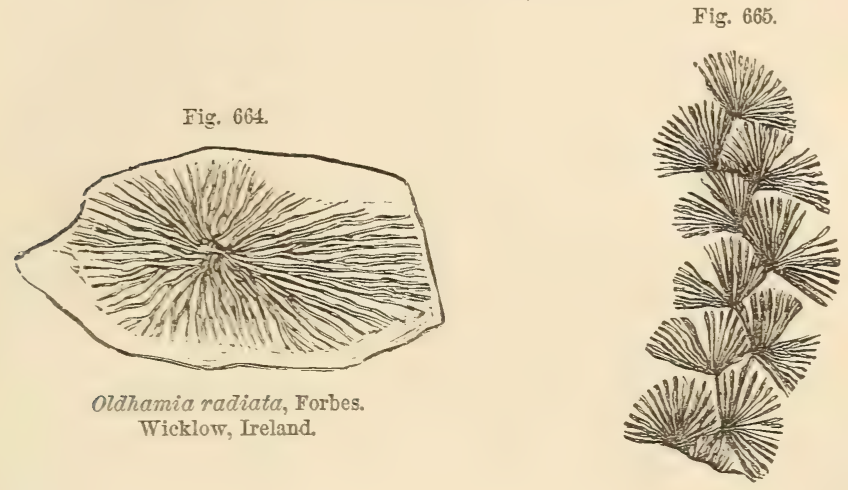

Oldhamia antiqua, Forbes. Wicklow, Ireland.

C A B RIA R R C K O F B H EMIA.

\section{(Primordial Zone of Barrande.)}

I hare alread̦ spoken (p. 554 ) of the splendid resuits of M. Barrande's labors, published in 1816, in which year, after a prolonged inrestigation of the geology of Bohemia, he discorered a great series of palæozoic formations, for which he adopted Sir R. Murchison's general name of Silurian. The first or most ancient of his three Silurian faunas, called by him primordial, corresponds with the British Upper Cambrian, as above described. The second tallies with Murchison's Lomer Silurian, and the third with the Upper Silurian of the same author. When M. Barrande, a French naturalist, undertook single-handed the survey of Bohemia, all the described species of fossils previously outained from that country scarcely exceeded twent 5 in number, whereas he had already acquired in 1850 no less than 1100 species; namelr, 250 crustaceans (chiefly trilobites), 250 cephalopods, 160 gasteropods and pteropods, 130 acephalous mollusks, 210 brachiopods, and 110 corals and other fossils. At a later period, 1856, M. Barrande states that he had in his collection be- 
tween 1400 and 1500 species from the same Silurian and primordial rocks of Bohemia.*

In the primordial zone he discovered trilobites of the genera Paradoxides, Conocephalus (Conocoryphe), Ellipsocephalus, Sao, Arionellus, Hydrocephalus, and Agnostus. These primordial trilobites have a peculiar facies of their own dependent on the multiplication of their thoracic segments and the diminution of their caudal shield or pygidium.

One of the "primordial" or Upper Cambrian Trilobites of the genus $S a o$, a form not found as yet elsewhere in the world, has afforded M. Barrande a fine illustration of the metamorphosis of these creatures, for he has traced them through no less than twenty stages of their derelopment. A few of these changes have been selected for representation in the accompanying figures, that the

\section{Fossils of the lowest Fossiliferous Beds in Bohemia, or "Primordial Zone" of Barrande.}

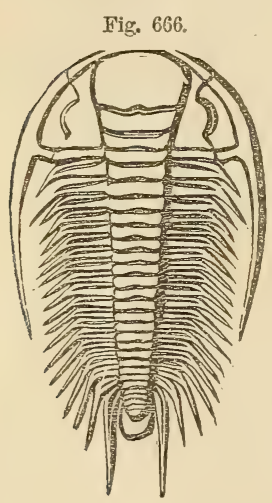

Paradoxides Bohemicus, Barr. About $\frac{1}{3}$ natural size. "Lowest Silurian beds" of Ginetz, Bohemia. (ḱtage $\mathrm{C}$ of Barrande.)
Fig. 667.

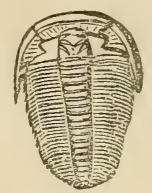

Conocoryphe striata. Syn. Conocephalus striatus, Emmrich. $\frac{1}{3}$ nat. size. Ginetz and Skrey.

Fig. 668 .

Fig. 669 .

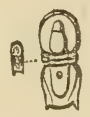

Agnostus integer, Beyrich. Nat. size and magnified.

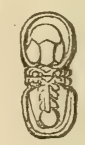

Agnostus Rex, Barr. Nat. size. Skrey.

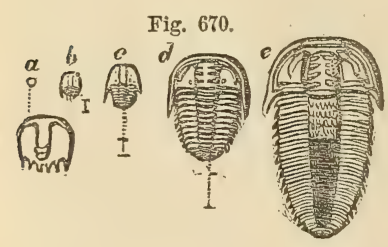

Sao hirsuta, Barrande, in its various stages of growth. Skrey.

The small lines beneath indicate the true size. In the youngest state, $a$, no segments are visible; as the metamorphosis progresses, $b, c$, the body segments begin to be developed; in the stage $d$ the eyes are introduced, but the facial sutures are not completed; at $e$ the full-grown animal, half its true size, is shown.

reader may learn the gradual manner in which different segments of the body and the eyes make their appearance. When we reflect on the altered and crystalline condition usually belonging to rocks of

* Parallèle entre les Dépôts Siluriens de Bohême et de Scandinavie. 
this age, and how deroid of life they are for the most part in North Wales, Ireland, and Shropshire, the information respecting such minute details of the Natural History of these crustaceans, as is supplied by the Bohemian strata, may well excite our astonishment, and may reasonably lead us to indulge a hope that geologists may one day gain an insight into the condition of the planet and its inhabitants at eras long antecedent to the Cambrian ; for those areas which have been subjected to a scrutiny as rigorous as North Wales and Bohemia form truly insignificant spots on a map of the whole globe.

In Bohemia the primordial fauna of Barrande derived its importance exclusirely from its numerous and peculiar trilobites. Besides these, however, the same ancient schists have yielded two genera of brachiopods, Orthis and Orbicula, a pteropod of the genus Theca, and four echinoderms of the Cystidean family.

All the Bohemian species differ as yet from any found in England, which may be due entirely to the influence of geographical causes. It seems, nevertheless, to confirm the view here taken, of the "primordial zone" being characterized by fossils distinguishable from the whole Lower Silurian group; because the other and higher Silurian formations of Barrande have each of them several species in common with the successive subdivisions of the British series.

Sweden and Norway.-The Upper Cambrian beds of North Wales are represented in Sweden by strata, the fossils of which have been described by a most able naturalist, M. Angelin, in his "Palæontologica Suecica (1855-'4)". The "alum-schists," as they are called in Sweden, resting on a fucoid-sandstone, contain trilobites belonging to the genera Paradoxides, Olenus, Agnostus, and others, some of which present rudimentary forms, like the genus last mentioned, without eyes, and with the body segments scarcely developed, and others again have the number of segments excessively multiplied, as in Paradoxides. These peculiarities agree with the characters of the crustaceans met with in the Upper Cambrian strata, before mentioned.

The Swedish rocks have also yielded crustaceans of the family Cytherinidee, and among the mollusea a small species of Orthoceras, the only primordial cephalopod yet known, and also a Graptolite, together with most of the fossil forms discorered by Barrande in the Bohemian strata of the same age.

United States and Canada.-In the table at p. 570, I have already pointed out the relative position of the Potsdam Sandstone, which has long been supposed to be the lowest fossiliferous formation in the United States and Canada. The late Dr. Dale Owen published in 1852 a graphic sketch, in his survey of Wisconsin, of the lowest sedimentary rocks near the head-maters of the Mississippi, lying at the base of the whole Silurian series. They are many hundred feet thick, and for the most part similar in character to the Potsdam sandstone abore described, but including in their upper portions interca- 
lated bands of magnesian limestone, and in their lower some argillaceous beds. Among the shells of these strata are species of Lingula and Orthis, and several trilobites of the new genus Dikelocephalus

Fig. 671 .

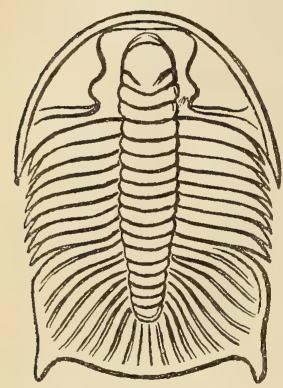

Dikelocephalus Minnesotensis, Dale Owen. $\frac{1}{3}$ diameter.

A large crustacean of the Olenoid group. Potsdam Sandstone. Falls of St. Croix, on the upper Mississippi. (fig. 671). These rocks, occurring in Iowa, Wisconsin, and Minnesota, seem destined hereafter to throw great light on the state of organic life in the Cambrian period. Six beds containing trilobites, separated by strata from 10 to 150 feet thick, are already enumerated.

I have seen the Potsdam sandstone on the banks of the St. Lawrence in Canada, and on the borders of Lake Champlain, where, as at Keesvilie, it is a white quartzose fine-grained grit, almost passing into quartzite. It is divided into horizontal ripple-marked beds, very like those of the Lingula flags of Britain, and replete with a small round-shaped Lingula (Obolella of Billings), in such numbers as to divide the rock into parallel planes, in the same manner as do the scales of mica in some micaceous sandstones. This formation, as we learn from Sir W. Logan, is 700 feet thick in Canada; the lower portion consisting of a conglomerate with quartz pebbles ; the upper part of sandstone containing fucoids, and perforated by small vertical holes, which are very characteristic of the rock, and appear to have been made by annelids (Scolithus linearis).

On the banks of the St. Lawrence, near Beauharnois and elsewhere, many fossil footprints have been observed on the surface of its rippled layers. These impressions were first noticed by Mr. Abraham, of Montreal, in 1847, and were supposed to be tracks of a tortoise; but Sir W. Logan brought in 1851 some of the slabs to London, together with numerous casts of other slabs, enabling Professor Owen to correct the idea first entertained, and to decide that they were not due to a chelonian, nor, as he imagines, to any vertebrate creature. The Professor inclines to the belief that they are the trails of more than one species of articulate animal, probably allied to the King Crab, or Limulus. Between the two rows of foot-tracks runs an impressed median line or channel, supposed by the Professor to have been made by a caudal appendage rather than by a prominent part of the trunk. Some individuals appear to have had three, and others five pairs, of limbs used for locomotion. The width of the tracks between the outermost impressions varies from $3 \frac{1}{2}$ to $5 \frac{1}{2}$ inches, which would imply a creature of much larger dimensions than any organic body yet obtained from strata of such antiquity. In this respect they agree with the gigantic Eurypteridoe, detected in the Lowest Devonian and uppermost Silurian rocks. Their size alone is important, as 
warning us of the danger of drawing any inference from mere negative evidence, as to the extreme poverty of the fauna of the earlier seas.

Recent investigations by the naturalists of the Canadian survey have rendered it certain that below the level of the Potsdam sand. stone there are slates and schists extending from New York to Newfoundland, occupied by a series of trilobitic forms similar in genera though not in species to those found in the European Upper Cambrian strata.

Quebec Group.-The Dikelocephalus above mentioned is one of the most striking fossils found in the limestones of Quebec, which have recently attracted much attention. But there seems in these limestones to be a mixed fauna, which renders it probable that the Quebec group, as defined by Sir W. Logan and Mr. E. Billings, is the representatire of our Lower Llandeilo (Arenig) and Tremadoc groups united. The characteristic graptolites lie in the upper portion, and are identical with those of Skiddaw; and the mixture of primordial and Lower Silurian genera in the lower portion exactly reminds us of the similar mixture in the Tremadoc slate, while, according to $\mathrm{Mr}$. Billing's, there are many species identical with those of the calciferous sand-rock, the formation which immediately overlies the Potsdam sandstone and passes down into it imperceptibly.

Huronian Series.-Next below the Upper Cambrian occur strata called the Huronian by Sir W. Logan, which are of vast thickness, consisting chiefly of quartzite, with great masses of greenish chloritic slate, which sometimes include pebbles of crystalline rocks derived from the Laurentian formation, next to be described. Limestones are rare in this series, but one band of 300 feet in thickness has been traced for considerable distances to the north of Lake Huron. Beds of greenstone are intercalated conformably with the quartzose and argillaceous members of this series. No organic remains have yet been found in any of the beds; and whether they may be altered Lower Cambrian or some still older sedimentary formation in a semimetamorphic state is uncertain. The Huronian strata are about 18,000 feet thick, and rest unconformably on the Laurentian, next to be described.

\section{LAURENTIAN ROCKS.}

In the course of the geological survey carried on under the direction of Sir W. E. Logan, it has been shown that, northward of the river St. Lawrence, there is a rast series of crystalline rocks of gneiss, mica-schist, quartzite, and limestone, more than 30,000 feet in thickness, which hare been called Laurentian, and which are already known to occupy an area of about 200,000 square miles. They are not only more ancient than the fossiliferous Cambrian formations above described, but are older than the Huronian last mentioned, and had undergone great disturbing morements before the Potsdam sand- 
stone and the other "primordial" rocks were formed. The older half of this Laurentian series is unconformable to the newer portion of the same.

Upper Laurentian or Labrador Series.-The Upper Group, more than 10,000 feet thick, consists of stratified crystalline rocks in which no organic remains have yet been found. They consist in great part of felspars, which vary in composition from anorthite to andesine, or from those kinds in which there is less than one per cent. of potash and soda to those in which there is more than seven per cent. of these alkalies, the soda preponderating greatly. These felsparites sometimes form mountain masses almost without any admixture of other minerals; but at other times they include pyroxene, which passes into hypersthene. They are often granitoid in structure. One of the varieties is the same as the opalescent labradorite rock of Labrador. The Adirondack Mountains in the State of New York are referred to the same series, and it is conjectured that the hypersthene rocks of Skye, which resemble this formation in mineral character, may be of the same geological age.

Lower Laurentian.-This series, about 20,000 feet in thickness, is, as before stated, unconformable to that last mentioned; it consists in great part of gneiss of a reddish tint with orthoclase felspar. Beds of nearly pure quartz, from 400 to 600 feet thick, occur in some places. Hornblendic and micaceous schists are often interstratified, and beds of limestone usually crystalline.

There are several of these limestones which have been traced to great distances, and one of them is from 700 to 1500 feet thick. In the most massive of them Sir W. Logan observed in 1859 what he considered to be an organic body much resembling the Silurian fossil called Stromatopora rugosa. It had been obtained the year before by Mr. J. McCulloch at the Grand Calumet on the river Ottawa. This fossil was examined in 1864 by Dr. Dawson of Montreal, who detected in it, by aid of the microscope, the distinct structure of a Rhizopod or Foraminifer. Dr. Carpenter and Prof. T. Rupert Jones have since confirmed this opinion, comparing the structure to that of the wellknown nummulite. It appears to have grown one layer over another, and to have formed reefs of limestone as do the living coral-building polyp animals. Parts of the original skeleton, consisting of carbonate of lime, are still preserved; while certain interspaces in the calcareous fossil have been filled up with serpentine and white augite. On this oldest of known organic remains Dr. Dawson has conferred the name of Eozoon Canadense; its antiquity is such that the distance of time which separated it from the Upper Cambrian period, or that of the Potsdam sandstone, may, says Sir W. Logan, be equal to the time which elapsed between the Potsdam sandstone and the nummulitic limestones of the Tertiary period. The Laurentian and Huronian rocks united are about 50,000 feet in thickness, and the Lower Laurentian was disturbed before the newer series was deposited. We may 
naturally expect that other proofs of unconformability will hereafter be detected at more than one point in so vast a succession of strata.

The mineral character of the Upper Laurentian differs, as we have seen, from that of the Lower, and the pebbles of g'meiss in the Huronian conglomerates are thought to prore that the Laurentian strata were already in a metamorphic state before they rere broken up to supply materials for the Huronian. Even if we had not discovered the Eozoon, we might fairly hare inferred from analogy that as the quartzites were once beds of sand, and the gneiss and mica-schist derived from shales and argillaceous sandstones, so the calcareous masses, from 400 to 1000 feet and more in thickness, were originally of organic origin. This is now generally believed to have been the case with the Silurian, Deronian, Carboniferous, Oolitic, and Cretaceous limestones and those nummulitic rocks of tertiary date which bear the closest affinity to the Eozoon reefs of the Lower Laurentian. The oldest stratified rock in Scotland is that called by Sir R. Murchison "the fundamental grneiss," which forms the whole of the Island of Lewis in the Hebrides. On this gneiss, in parts of the Western Highlands, the Lotrer Cambrian and rarious metamorphie rocks rest unconformably. It is conjectured that this ancient gneiss of Scotland may correspond in date with part of the great Laurentian group of North America.

\section{ON THE ABSENCE OF VERTEBRATA IN ROCKS BELOW THE UPPER SILURIAN.}

Supposed Period of Invertebrate Animals.-We have seen that in the upper part of the Silurian system a bone-bed occurs near Ludlow, in which the remains of fish are abundant, and amongst them some of highly organized structure, referred to the genera Onchus and Pteraspis. We are indebted to Sir R. Murchison for having first announced, in 1840, the discovery of these ichthyolites, and he then spoke of them as "the most ancient beings of their class." In the third edition of his classical work, * he has reverted to the opinion formerly expressed by him, obscrring that the active researches of the last twenty years in Europe and America "had failed to modify that generalization." He also adds: "The Silurian system therefore may be regarded as representing a long period in which no rertebrated animals had been called into existence."

In the same year (1859) in which this remark was hazarded, the discovery of the Pteraspis, mentioned by us at p. 555, in the Lower Ludlow rocks, carried back our linowledge of the existence of fish one step farther into the history of the past. But it is still a fact well worthy of notice, that no remains of vertebrata have yet been met with in any strata older than the Lower Ludlow.

When we reflect on the hundreds of Mollusks, Echinoderms, Trilo- 
bites, Corals, and other fossils already obtained from more ancient Silurian formations, Upper, Middle, and Lower, we may well ask whether any set of fossiliferous rocks newer in the series were ever studied with equal diligence and over so vast an area without yielding a single ichthyolite.

Yet we ought to hesitate before we accept, even on such evidence, so sweeping a conclusion, as that the globe, for ages after it was inhabited by all the great classes of invertebrata, remained wholly untenanted by vertebrate animals. In the first place, we must remember that we have detected no insects, or land-shells, or freshwater pulmoniferous mollusks, or terrestrial crustaceans, or plants (with the exception of fucoids), in rocks below the Upper Silurian. Their absence may admit of explanation, by supposing almost all the deposits of that era hitherto examined to have been formed in seas far from land or beyond the influence of rivers. Here and there, indeed, a shallowwater or even a littoral deposit may have been met with in North Wales or North America; but, speaking generally, the Silurian deposits, as at present known, have certainly a more pelagic character than any other of equal extent and thickness.

It is a curious fact, and not perhaps a mere fortuitous coincidence, that the only stratum in.which land-plants occur is also the only one which has yielded the remains of fish in any considerable abundance. Bone-beds in general, such as that of the uppermost Trias at Bristol and Stuttgart, or that of the Carboniferous Limestone near Bristol and Armagh, or, lastly, that of the "Upper Ludlow," are remarkable for containing teeth and bones, much rolled, and implying transportation from a distance. The association of the sporangia of Lycopodiaceæ (see p. 552) with the Ludlow fish-bones shows that plants had been washed from some dry land then existing, and had been drifted into a common submarine receptacle with the bones; and it is well known that in the present state of the globe fish occur in the greatest numbers at the junction of rivers with the sea. Where the Upper Ludlow is devoid of plants, as is usually the case, it is as destitute of ichthyolites as are the Wenlock or Llandeilo beds.

It has been suggested in explanation, that Cephalopoda were so abundant in the Silurian period that they may have discharged the functions of fish; to which we may reply that both classes coexisted in the Upper Silurian period, and both of them swarmed together in the Carboniferous and Liassic seas, as they do now in certain parts of the ocean. We may also remark that we are too imperfectly acquainted with the distribution of scattered bones and teeth or the skeletons of dead fish on the floor of the existing ocean, to have a right to theorize with confidence on the absence of such relics over wide spaces at any former era.

They who in our own times have explored the bed of the sea inform us that it is in géneral as barren of vertebrate remains as the soil of a forest on which thousands of mammalia and reptiles have 
flourished for centuries. In the summer of 1850 , Prof. E. Forbes and Mr. McAndrew dredged the bed of the British seas from the Isle of Portland to the Land's End in Cornwall, and thence again to Shetland, recording and tabulating the numbers of the various organic bodies brought up by them in the course of 140 distinct dredgings, made at different distances from the shore, some a quarter of a mile, others forty miles distant. The list of species of marine invertebrate animals, whether Radiata, Mollusca, or Articulata, was very great, and the number of individuals enormous; but the only instances of vertebrate animals consisted of a few ear-bones, and two or three vertebræ of fish, in all not above six relics.

It is still more extraordinary that Mr. McAndrew should hare dredged the great "Ling Banks" or cod-fishery grounds off the Shetland Islands for shells without obtaining the bones or teeth of any dead fish, although he sometimes drew up live fish from the mud. This is the more singular because there are some areas where recent fish-bones occur in the same northern seas in profusion, as I have shown in the "Principles of Geology" (see Index, "Vidal"); two bone-beds having beẻn discovered by British hydrographers, one in the Irish Sea, and the other in the sea near the Faroe Isles, the first of them two, and the other three and a half miles in length, where the lead brings up everywhere the vertebræ of fish from various depths between 45 to 235 fathoms. These may be compared to the Upper Ludlow bone-bed; and on the floor of the ocean of our times, as on that of the Silurian epoch, there are other wide spaces where no bones are imbedded in mud or sand.

It may be true, though it sounds somewhat like a paradox, that fish leave behind them no memorials of their presence in places where they swarm and multiply freely; whereas currents may drift their bones in great numbers to regions wholly destitute of living fish. Such a state of things would be quite analogous to what takes place on the habitable land, where, instead of the surface becoming encumbered with heaps of skeletons of quadrupeds, birds, and landreptiles, all solid bony substances are removed after death by chemical processes, or by the digestive powers of predaceous beasts; so that, if at some future period a geologist should seek for monuments of the former existence of such creatures, he must look anywhere rather than in the area where they flourished. He must search for them in spots which were covered at the time with water, and to which some bones or carcases may have been occasionally carried by floods and permanently buried in sediment.

In the annexed Table, a few dates are set before the reader of the discorery of different classes of animals in ancient rocks, to enable him to perceive at a glance how gradual has been our progress in tracing back the signs of rertebrata to formations of high antiquity. Such facts may be useful in warning us not to assume too hastily that the point which our retrospect may hare reached at the present 
moment can be regarded as fixing the date of the first introduction of any one class of beings upon the earth.

\section{Dates of the Discovery of different Classes of Fossil Vertebrata; showing the gradual Progress made in tracing them to Rocks of higher antiquity.}

\begin{tabular}{|c|c|c|c|}
\hline & Year. & Formations. & Geographical Localities. \\
\hline \multirow{2}{*}{ Mammalia. } & 1798. & Upper Eocene. & Paris (Gypsum of Mont \\
\hline & 1818. & Lower Oolite. & Stonesfield. $^{2}$ \\
\hline \multirow{4}{*}{ Aves. } & $\begin{array}{l}1847 . \\
1782 .\end{array}$ & $\begin{array}{l}\text { Upper Trias. } \\
\text { Upper Eocene. }\end{array}$ & $\begin{array}{l}\text { Stuttgart. } \\
\text { Paris (Gypsum of Mont- } \\
\text { martre). }{ }_{4}^{4} \text { of }\end{array}$ \\
\hline & 1839. & Lower Eocene. & $\begin{array}{l}\text { Isle of Sheppey (London } \\
\text { Clay). }{ }^{5}\end{array}$ \\
\hline & $\begin{array}{l}1854 . \\
1855 .\end{array}$ & "6 6 & $\begin{array}{l}\text { Woolwich Beds. } \\
\text { Meudon (Plastic }\end{array}$ \\
\hline & $\begin{array}{l}1858 . \\
1863 .\end{array}$ & $\begin{array}{l}\text { Upper Greensand. } \\
\text { Upper Oolite. }\end{array}$ & $\begin{array}{l}\text { Cambridge. }{ }^{8} \\
\text { Solenhofen. }\end{array}$ \\
\hline Reptilia. & $\begin{array}{l}1710 . \\
1844 . \\
1709 .\end{array}$ & $\begin{array}{l}\text { Permian (or Zechstein). } \\
\text { Carboniferous. } \\
\text { Permian (or Kupfer-Schiefer). }\end{array}$ & $\begin{array}{l}\text { Thuringia. }{ }^{10} \\
\text { Saarbruck, near Treves. }{ }^{11} \\
\text { Thuringia. }\end{array}$ \\
\hline \multirow{4}{*}{ Pisces. } & 179 & $\begin{array}{l}\text { Carboniferous (Mountain Lime- } \\
\text { stone). }\end{array}$ & Glasgow. ${ }^{13}$ \\
\hline & 182 & Devonian. & S. ${ }^{44}$ \\
\hline & & Upper Ludlow. & \\
\hline & 1859. & Lower Ludlow. & Leintwardine. ${ }^{16}$ \\
\hline
\end{tabular}

2 George Cuvier. Bulletin Soc. Philom., xx. Scattered bones had been found in the gypsum some years before; but they were determined osteologically, and their true geological position was assigned to them in this memair.

${ }^{2}$ In 1818, Cuvier, visiting the Museum of Oxford, decided on the mammalian character of a jaw from Stonesield. See also above, p. 408.

3 Plieninger, Prof. See above, p. 432.

4 M. Darcet discovered, and Lamanon figured, as a fossil bird, some remains from Montmartre, afterwards recognized as such by Cuvier (Ossemens Foss., Art. "Oiseaux").

5 Owen, Prof., Geol. Trans., Second Ser., vol. vi. p. 203, 1839. The fossil bird discovered in the same year in the slates of Glaris in the Alps, and at first referred to the chalk, is now supposed to belong to the Nummulitic beds, and may therefore be of newer date than the Sheppey Clay.

${ }^{6}$ A bird's bone is also recorded by Mr. Prestwich as having been found by M. de la Condamine in the Upper part of the Woolwich beds. (Quart. Geol. Journ., vol. x. p. 157.)

7 Early in 1855 the tibia and femur of a large bird equalling at least the ostrich in size were found at Meudon near Paris, at the base of the Plastic Clay. This bird, to which the name of Gastornis Parisiensis has been assigned, appears, from the Memoirs of MM. Hébert, Lartet, and Owen, to belong to an extinct genus. Professor 0 wen refers it to the class of wadiing land-birds rather than to an aquatic species. (Quart. Geol, Journ., vol, xii. p. 204, 1856.)

8 Mr. Louis Barrett found many parts of the skeleton of a bird of the gull tribe in the coprolitic bed, in the Upper Greensand (see above, p. 332).

9 The Archooopteryx macrura, Owen, was determined to be a bird by Owen in 1863. It occurred in the lithographic stone of Solenhofen, in which a single feather, probably of the same bird, had previously been found (see above, $p$. $306)$. 
10 The fossil monitor of Thuringia (Protorosaurus Speneri, V. Meyer) was fig. ured by Spener, of Berlin, in 1810. (Miscel. Berlin.)

${ }^{11}$ See above, p. 506.

12 Memorabilia Saxoniæ Subterr., Leipsic, 1709.

13 History of Rutherglen, by Rev. David Ure, 1793.

${ }_{14}$ "Sedgrick and Murchison, Geol. Trans., Second Ser., vol. iii. p. 141, 1828.

${ }^{15}$ Sir R. Murchison. See above, p. 551.

$16 \mathrm{Mr}$. Lec, of the Priory, Caerleon (see abore, p. 555), found Pteraspis in presence of Mr. Lightbody, F.G.S.

Obs.-The evidence derived from footprints, though often to be relied on, is omitted in the above table, as being less exact than that founded on bones and teeth.

There are many writers still living who, before the year 1854, generalized fearlessly on the non-existence of reptiles in times antecedent to the Permian; yet in the course of nineteen years they have lived to see the remains of reptiles of more than one family exhumed from various parts of the Carboniferous series. Before the year 1818, it was the popular belief that the Palæotherium of the Paris grpsum and its associates were the first warm-blooded quadrupeds that ever trod the surface of this planet. So fixed was this idea in the minds of the majority of naturalists, that, when at length the Stonesfield Mammalia were brought to light, they were most unwilling to renounce their creed. First, the antiquity of the rock was called in question; and then the mammalian character of the relics. But when at length all controversy was set at rest on this point, the real import of the new revelation, as bearing on the doctrine of progressire derelopment, was far from being duly appreciated.

Their significance arose from the aid they afforded us in estimating the true value of negative evidence, when adduced to establish the non-existence of certain classes of animals at given periods of the past. Every zoologist will admit that between the first creation and the final extinction of any one of the oolitic mammalia now known, whether at Stonesfield or Purbeck, there were many successive generations; and, even if the geographical range of each species was very limited (which we have no right to assume), still there must have been sereral hundred individuals in cach generation, and probably when the species reached its maximum, several thousands. When, therefore, we encounter for the first time in 1854 two or three jaws of Stcrcognathus or Spalacotherium, after countless specimens of Mollusca and Crustacer, and many iusects, fish, and reptiles har been previously collected from the same beds, we are not simply taight that these individual quadrupeds flourished at the eras in question, but that thousands, perhaps hundreds of thousands, of the same species peopled the land without learing behind them any trace of their existence, whether in the shape of fossil bones or footprints ; or, if they left any traces, these hare eluded a long and most laborious search.

Moreover, we must never forget how many of the dates given in the abore table (p. 588) are due to British skill and energy, Great 
Britain being still the only country in the world in which mammalia have been found in oolitic rocks. And if geology had been cultivated with less zeal in our island, we should know very little as yet of two extensive assemblages of tertiary mammalia of higher antiquity than the fauna of the Paris gypsum (already cited as having once laid claim to be the earliest that ever flourished on the earth)namely, first, that of the Headon series (see above, p. 284), and, secondly, one long prior to it in date, and antecedent to the London Clay. This last has already afforded us indications of Cheiroptera, Pachydermata, and Marsupialia (see p. 292). How then can we doubt, if the globe were to be studied with the same diligence, if the six great continents, Europe, Asia, Africa, North and South America, and Australia, were equally well known, that every date assigned by us in the above Table for the earliest recorded appearance of fish, reptiles, birds, and mammals, would have to be altered and shifted back? Nay, if one other area, such as part of Spain, of the size of England and Scotland, were subjected to the same scrutiny (and we are still very imperfectly acquainted even with Great Britain), each class of vertebrata would perhaps recede one or more steps farther back into the abyss of time; fish might penetrate into the Lower Silurian-reptiles into the Upper Devonian-mammalia into the Lower Trias-birds into the Middle Oolite-and, if we turn to the Invertebrata, Trilobites and Cephalopods might descend into the Lower Cambrian-and Foraminifera into rocks now styled Azoic, and older than the Lower Laurentian.

Yet, after these and many more analogous revisions of the Table, the order of chronological succession in the different classes of fossil animals would probably continue the same as now; -in other words, our success in tracing back the remains of each class to remote eras would be the greatest in fishes, next in reptiles, and least in mammalia and birds.

We have of late years acquired striking proofs of the difficulty of detecting the bones of man in those strata in which the works of his hands in the shape of flint implements abound. There are also large tracts of Eocene rocks very prolific of shells and other organ isms, as in Belgium, for example, which have been diligently studied for nearly a century without yielding a single bone of a mammifer. In the whole world the cretaceous and oolitic rocks have each of them only afforded as yet a single example of a fossil bird. It would almost seem as if the higher the type of organization the more powerful the spell required to evoke the remains of a fossil being from its stony sepulchre.

"Unwilling I my lips unclose-

Leave, oh! leave me to repose."

That we should meet with ichthyolites more universally at each era, and at greater depths in the series, than any other class of fossil 
vertebrata, would follow partly from our having as palæontologists to do chiefly with strata of marine origin, and partly because bones of fish, howerer partial and capricious their distribution on the bed of the sea, are nerertheless more easily met with than those of reptiles or mammalia. In like manner the extreme rarity of birds in Recent and Pliocene strata, eren in those of freshwater origin, might lead us to anticipate that thcir remains would be obtained with the greatest difficulty in the older rocks, as the Table proves to be the case-even in tertiary strata, wherein we can more readily find deposits formed in lakes and estuaries.

The only incongruity between the geological results and those which our dredging experiences might have led us to anticipate à priori, consists in the frequency of fossil reptiles, and the comparatice scarcity of mammalia. It would appear that during all the secondary periods, not even excepting the newest part of the cretaccous, there was a greater derelopment of reptile life than is now witnessed in any part of the globe. The preponderance of this class over the mammalia may have depended in part on climatal conditions, but it seems also clearly to imply the limited development, if not the total absence, before the Tertiary period, of the placental mammalia, whether terrestrial or aquatic, which, when they became dominant, acquired power to check and keep down the class of vertebrata nearly allied to them in structure, and coming most directly in competition with them in the struggle for life. For notwithstanding the impossibility of assigning eren conjectural limits to the chronological extension of each class of rertebrata as we trace them farther and farther back into the past, it cannot be denied that our failure to detect signs of them in older strata, in proportion to the rank of their organization, favors the doctrine of derclopment, or at least of the successive appearance on the earth of beings more and more highly organized, culminating at last in the advent of Man himself. 


\title{
CHAPTER XXVIII.
}

\author{
VOLCANIC ROCKS.
}

Trap Rocks-Name, whence derived-Their igneous origin at first doubted-Their general appearance and character-Volcanic cones and craters, how formedMineral composition and texture of volcanic rocks-Varieties of felsparHornblende and augite-Isomorphism-Rocks, how to be studied-Basalt; trachyte, greenstone, porphyry, scoria, amygdaloid, lava, tuff-AgglomerateLaterite-Alphabetical list, and explanation of names and synonyms, of volcanic rocks-Table of the analyses of minerals most abundant in the volcanic and hypogene rocks.

The aqueous or fossiliferous rocks having now been described, we have next to examine those which may be called rolcanic, in the most extended sense of that term. Suppose $a \alpha$, in the annexed diagram,

Fig. 672 .

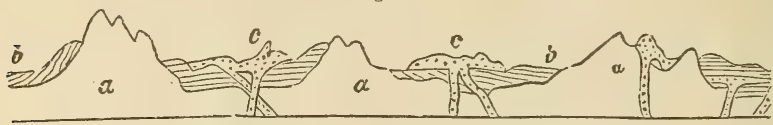

a. Hypogene formations, stratified and unstratified.

b. Aqueous formations. $\quad$ c. Volcanic rocks.

to represent the crystalline formations, such as the granitic and metamorphic; $b b$ the fossiliferous strata; and $c c$ the volcanic rocks. These last are sometimes found, as was explained in the first chapter, breaking through $a$ and $b$, sometimes overlying both, and occasionally alternating with the strata $b b$. They also are seen, in some instances, to pass insensibly into the unstratified division of $a$, or the Plutonic rocks.

When geologists first began to examine attentively the structure of the northern and western parts of Europe, they were almost entirely ignorant of the phenomena of existing volcanoes. They found certain rocks, for the most part, without stratification, and of a peculiar mineral composition, to which they gave different names, such as basalt, greenstone, porphyry, and amygdaloid. All these, which were recognized as belonging to one family, were called "trap" by Bergmann, from trappa, Swedish for a flight of steps-a name since adopted very generally into the nomenclature of the science; for it was observed that many rocks of this class occurred in great tabular masses of unequal extent, so as to form a succession of terraces or steps on the sides of hills. This configuration appears to be derived from two causes. First, the abrupt original terminations of sheets of melted matter, which have spread, whether on the land or bottom of the sea, over a level surface. For we know, in the case of lava flow 
ing from a rolcano, that a stream, when it has ceased to flow, and grown solid, rery commonly ends in a steep slope, as at $a$, fig. 673 . But, secondly, the step-like appearance arises more frequently from the mode in which horizontal masses of igneous rock, such as $b c$, intercalated between aqueous strata, or showers of volcanic dust and ashes, have, subsequently to their origin, been exposed, at different heights, by denudation. "Such an outline, it is true, is not peculiar to trap rocks; great beds of limestone, and other hard kinds of stone,

Fig. 673.

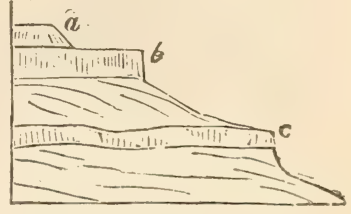

Step-like appearance of trap. often presenting similar terraces and precipices : but these are usually on a smaller scale, or less numerous, than the volcanic steps, or form less decided features in the landscape, as being less distinct in structure and composition from the associated rocks.

Although the characters of trap rocks are greatly diversified, the beginner will easily learn to distinguish them as a-class from the aqueous formations. Sometimes they present themselves, as already stated, in tabular masses, which are not divided by horizontal planes of stratification in the manier of sedimentary deposits. Sometimes they form chains of hills often conical in shape. Not unfrequently they are seen as "dikes" or wall-like masses, intersecting fossiliferous beds. The rock is occasionally columnar, the columns sometimes decomposing into balls of various sizes, from a few inches to several feet in diameter. The decomposing surface very commonly assumes a coating of a rusty iron color, from the oxidation of ferruginous matter, so abundant in the traps in which augite or hornblende occur; or, in the felspathic rarieties of trap, it acquires a white opaque coating, from the bleaching of the mineral called felspar. On examining any of these rolcanic rocks, where they have not suffered disintegration, we rarely fail to detect a crystalline arrangement in one or more of the component minerals. Sometimes the texture of the mass is cellular or porous, or we perceive that it has once been full of pores and cells, which have afterwards become filled with carbonate of lime, or other infiltrated mineral.

Most of the rolcanic rocks produce a fertile soil by their disintegration. It seems that their component ingredients, silica, alumina, lime, potash, iron, and the rest, are in proportions well fitted for the growth of regetation. As they do not efferresce with acids, a deficiency of calcareous matter might at first be suspected; but although the carbonate of lime is rare, except in the nodules of amygdaloids, jet it will be seen that lime sometimes enters largely into the composition of augite and hornblende. (See Table, p. 608.)

Cones and Craters.-In regions where the eruption of volcanic matter has taken place in the open air, and where the surface has never since been subjected to great aqueous denudation, cones and craters 
constitute the most striking peculiarity of this class of formations. Many hundreds of these cones are seen in central France, in the ancient provinces of Auvergne, Velay, and Vivarais, where they observe, for the most part, a linear arrangement, and form chains of hills. Although none of the eruptions have happened within the historical era, the streams of lava may still be traced distinctly descending from many of the craters, and following the lowest levels of the existing valleys. The origin of the cone and crater-shaped hill is well under-

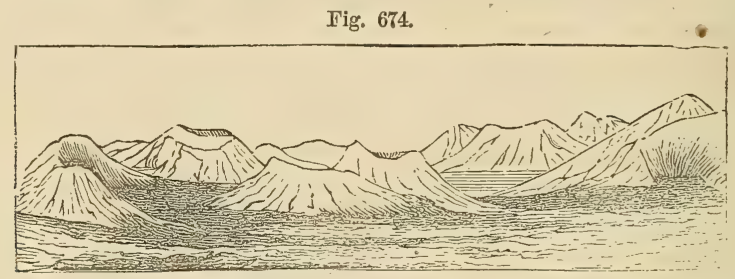

Part of the chain of extinct volcanoes called the Monts Dome, Auvergne. (Scrope.)

stood, the growth of many having been watched during volcanic eruptions. A chasm or fissure first opens in the earth, from which great volumes of steam and other gases are evolved. The explosions are so violent as to hurl up into the air fragments of broken stone, parts of which are shivered into minute atoms. At the same time melted stone or lava usually ascends through the chimney or vent by which the gases make their escape. Although extremely heavy, this lava is forced up by the expansive power of entangled gaseous fluids, chiefly steam or aqueous vapor, exactly in the same manner as water is made to boil over the edge of a vessel when steam has been generated at the bottom by heat. Large quantities of the lava are also shot up into the air, where it separates into fragments, and acquires a spongy texture by the sudden enlargement of the included gases, and thus forms scorice, other portions being reduced to an impalpable powder or dust. The showering down of the various ejected materials round the orifice of eruption gives rise to a conical mound, in which the successive envelopes of sand and scoriæ form layers, dipping on all sides from a central axis. In the mean time a hollow, called a crater, has been kept open in the middle of the mound by the continued passage upwards of steam and other gaseous fluids. The lava sometimes flows over the edge of the crater, and thus thickens and strengthens the sides of the cone; but sometimes it breaks down the cone on one side (see fig. 674), and often flows out from a fissure at the base of the hill, or at some distance from its base.*

Composition and Nomenclature.-Before speaking of the connection between the products of modern volcanoes and the rocks usually styled trappean, and before describing the external forms of both, and the

* For a description and theory of active volcanoes, see Principles of Geology, chaps. xxiv, et seq. and xxxii. 
manner and position in which they occur in the earth's crust, it will be desirable to treat of their mincral composition and names. The varieties most frequently spoken of are basalt and trachyte, to which dolerite, greenstone, clinkstone, and others might be added; while those founded chicty on peculiarities of texture, are porphyry, amygdaloid, lava, volcanic breceia or agglomerate, turf, scorie, and pumice. It mar be stated generally, that all these are mainly composed of two minerals, or fimilies of simple minerals, fetspar and hornblende; but the felspar preponderates greatly even in those rocks to which the hornblendic mincral imparts its distinctive character and prevailing color.

The two minerals alluded to may be regarded as two groups, rather than species. Felspar, for example, may be, first, common felspar (often called Orthoclase), that is to say, potash-felspar, in which the predominant alkali is potash (see Table, p. 608); or, secondly, albite, i. e. soda-felspar, where the predominant alkali is soda; or, thirdly, Oligoclase, in which there is also more soda than potash, but which contains less silica than albite; or, fourthly, Labrador-felspar (Labradorite), which differ's not only in its iridescent hues and cleavage, but also in containing less silica than albite, and in having lime in its base. Anorthite, so called from the oblique interfacial angles of its rhomboidal prisms, is nearly allied in composition with Labradorite. As to "glassy felspar" and "compact felspar," they cannot rank as rarieties of equal importance, for both the albitic and common felspar appear sometimes in transparent or glassy crystals; and compact felspar, or petrosilex, is a compound of a less definite nature, sometimes containing largely both soda and potash. It might be called a felspathic paste, being the residuary matter after portions of the original matrix have crystallized. Recent analysis has shown that all the varieties of felspar may contain both potash and soda, although in some of them the potash, and in others the soda, greatly prevails.

The hornblenclic group consists principally of two varieties; first, hornblende, and, secondly, augite, which were once regarded as very distinct, although now some eminent mineralogists are in doubt whether they are not one and the same mineral, differing only as one crystalline form of native sulphur differs from another.

The history of the changes of opinion on this point is curious and instructire. Werner first distinguished augite from hornblende; and his proposal to separate them obtained afterwards the sanction of Haüy, Mohs, and other celebrated mineralogists. It was agreed that the form of the crystals of the two spccies were different, and their structure, as shown by cleavage, that is to say, by breaking or cleaving the mineral with a chisel, or a blow of the hammer, in the direction in which it rields most readily. It was also found by analysis that augite usually contained more lime, less alumina, and no fluoric acid; which last, though not always found in hormblende, often enters into its composition in minute quantity. In addition to these characters, it was remarked as a geological fact, that augite and hornblende are 
very rarely associated together in the same rock; and that when this happened, as in some lavas of modern date, the hornblende occurs in the mass of the rock, where crystallization may have taken place more slowly, while the augite merely lines cavities where the crystals may have been produced rapidly. It was also remarked, that in the crystalline slags of furnaces, augitic forms were frequent, the hornblendic entirely absent; hence it was conjectured that hornblende might be the result of slow, and augite of rapid cooling. This view was confirmed by the fact, that Mitscherlich and Berthier were able to make augite artificially, but could never succeed in forming hornblende. Lastly, Gustavus Rose fused a mass of hornblende in a porcelain furnace, and found that it did not, on cooling, assume its previous shape, but invariably took that of augite. The same mineralogist observed certain crystals in rocks from Siberia which presented a hornblende cleavage, while they had the external form of augite.

If, from these data, it is inferred that the same substance may assume the crystalline forms of hornblende or augite indifferently, according to the more or less rapid cooling of the melted mass, it is nevertheless certain that the variety commonly called augite, and recognized by a peculiar crystalline form, has usually more lime in it, and less alumina, than that called hornblende, although the quantities of these elements do not seem to be always the same. Unquestionably the facts and experiments above mentioned show the very near affinity of hornblende and augite; but eren the convertibility of one into the other, by melting and recrystallizing, does not perhaps demonstrate their absolute identity. For there is often some portion of the materials in a crystal which are not in perfect chemical combination with the rest. Carbonate of lime, for example, sometimes carries with it a considerable quantity of silex into its own form of crystal, the silex being mechanically mixed as sand, and yet not preventing the carbonate of lime from assuming the form proper to it. This is an extreme case, but in many others some one or more of the ingredients in a crystal may be excluded from perfect chemical union; and after fusion, when the mass recrystallizes, the same elements may combine perfectly or in new proportions, and thus a new mineral may be produced. Or some one of the gaseous elements of the atmosphere, the oxygen for example, may, when the inelted matter reconsolidates, combine with some one of the component elements.

The different quantity of the impurities or refuse above alluded to, which may occur in all but the most transparent and perfect crystals, may partly explain the discordant results at which experienced chemists have arrived in their analysis of the sane mineral. For the reader will find that crystals of a mineral determined to be the same by physical characters, crystalline form, and optical properties, have often been Aleclared by skilful analyzers to be composed of distinct elements. (See the table at p. 608.) This disagreement seemed at first subversive of the atomic theory, or the doctrine that there is a fixed and 
constant relation between the crystalline form and structure of a mineral and its chemical composition. The apparest anomaly, however, which threatened to throw the whole science of mineralogy into confusion, was in a great degree reconciled to fixed principles by the discoreries of Professor Mitscherlich at Berlin, who ascertained that the composition of the minerals which had appeared so rariable, was governed by a general law, to which he gave the name of isomorphism (from $\iota 0 \%$, isos, equal, and $\mu \circ \rho \phi \eta$, morphe, form). According to this lar, the ingredients of a giren species of mineral are not absolutely fixed as to their kind and quality; but one ingredient may be replaced by an equivalent portion of some analogous ingredient. Thus, in augite, the lime may be in part replaced by portions of protoxide of iron, or of manganese, while the form of the crystal, and the angle of its clearage planes, remain the same. These ricarious substitutions, howerer, of particular elements cannot exceed certain defined limits.

Pyroxene, a name of Haüy's, is often used for augite in descriptions of rolcanic rocks. It is properly, according to M. Delesse, a general name, under which Augite, Diallage, and Hypersthene may be united, for these three are rarieties of ons and the same mineral species, having the same chemical formula with variable bases.

Amphibole is in like manner a general term under which Hornblende and Actinolite may be united.

Having been led into this digression on some recent steps made in the progress of mineralogy, I may here observe that the geological student must endearor as soon as possible to familiarize himself with the characters of fire at least of the most aburdant simple minerals of which rocks are composed. These are felspar, quartz, mica, hornblende, and carbonate of lime. This knowledge cannot be acquired from books, but requires personal inspection, and the aid of a teacher. It is well to accustom the eye to know the appearance of rocks under the lens. To learn to distinguish felspar from quartz is the most important step to be first aimed at. In general we may know the felspar because it can be scratched with the point of a knife, whereas the quartz, from its extreme hardness, receives no impression. If both minerals are crystalline, the felspar may be krown by its lamellar, and the quartz by its glass-like fracture; but when they occur in a granular or uncrystallized state, the young geologist must not be discouraged if, after considerable practice, he often fails to distinguish them by the eye alone. If the felspar is granular, the blow-pipe may be used, for the edges of the grains can be rounded in the flame, whereas those of quartz are infusible. In order to detect the raricties of felspar abore enumerated, and to distinguish hornblende from augite, the reflecting goniometer will often be useful, enabling the mineralogist to ascertain the angle of clearage and shape of the crystal.

The external characters and composition of the felspars are extremely different from those of augite or hornblende; so that the volcanic 
rocks in which either of these minerals play a conspicuous part are easily recognizable. But there are mixtures of the two elements in very different proportions, the mass being sometimes exclusively composed of felspar, and at other times largely of augite. Between the two extremes there is almost every intermediate gradation; yet certain compounds prevail so extensively in nature, and preserve so much uniformity of aspect and composition, that it is useful in geology to regard them as distinct rocks, and to assign names to them, such as basalt, greenstone, trachyte, and others presently to be mentioned.

Basalt.-As an example of rocks in which augite is a conspicuous ingredient, basalt may first be mentioned. Although we are more familiar with this term than with that of any other kind of trap, it is difficult to define it, the name having been used so comprehensively, and sometimes so vaguely. It has been generally applied to any trap rock of a black, bluish, or leaden-gray color, having a uniform and compact texture. Most strictly, it consists of an intimate mixture of felspar, augite, and iron, to which a mineral of an olive-green color, called olivine, is often superadded, in distinct grains or nodular masses. The iron is usually magnetic (oxydulated iron), and is often accompanied by another metal, titanium. The term "Dolerite" is now much used for this rock, when the felspar is of the variety called Labradorite, as in the lavas of Etna. Basalt, according to Dr. Daubeny, in its more strict sense, is composed of " an intimate mixture of augite with a zeolitic mincral which appears to have been formed out of Labradorite by the addition of water, the presence of water being in all zeolites the cause of that bubbling up under the blow-pipe to which they owe their appellation." * Of late years the analyses of M. Delesse and other eminent mineralogists have shown that the opinion once entertained that augite was the prevailing mineral in basalt, or even in the most augitic trap rocks, must be abandoned. Although its presence gives to these rocks their distinctive character as contrasted with trachytes, still the principal element in their composition is felspar.

Augite rock has, indeed, been defined by Leonhard as being made up principally or wholly of augite, $\uparrow$ and in some veinstones, says Delesse, such a rock may be found; but the greater part of what passes by the name of augite rock is more rich in green felspar than in augite. Amphibolite, in like manner, or Hornblende rock, is a trap of the basaltic family, in which there is much hornblende, and in which this mineral has been supposed to predominate; but Delesse finds, by analysis, that the felspar may be in excess, the base being felspathic.

In some varieties of basalt the quantity of olivine is very great; and as this mineral differs but slightly in its chemical composition from serpentine (see Table of Analyses, p. 608), containing even a larger 
proportion of magnesia than serpentine, it has been suggested with much probability that in the course of ages some basalts highly charged with olivine may be turned, by metamorphic action, into serpentine.

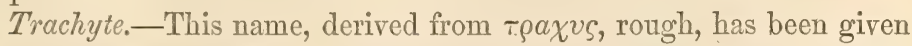
to the felspathic class of volcanic rocks which have a coarse, cellular paste, rough and gritty to the touch. This paste has commonly been supposed to consist chiefly of albite, but according to M. Delesse it is variable in composition, its prevailing alkali being' soda Through the base are disseminated crystals of glassy felspar, mica, and sometimes quartz and hornblende, although in the trachyte, properly so called, there is no quartz. The varieties of felspar which occur in trachyte are trisilicates, or those in which the silica is to the alumina in the proportion of three atoms to one.*

Trachytic Porphyry, according to Abich, has the ordinary compo. sition of trachyte, with quartz superadded, and without any augite or titaniferous iron. Andesite is a name given by Gustavus Rose to a trachyte of the Andes, which contains the felspar called Andesin, together with glassy felspar (orthoclase) and homblende disseminated through a dark-colored base.

Clinkstone, or Phonolite.-Among the felspathic products of volcauic action, this rock is remarkable for its tendency to lamination, which is sometimes such that it affords tiles for roofing. It ring's when struck with the hammer, whence its name; is compact, and usually of a grayish blue or brownish color; is variable in composition, but almost entirely composed of felspar, and in some cases, according to Gmelin, of felspar and mesotype. When it contains disseminated crystals of felspar, it is called Clinkstone porphyry.

Greenstone is the most abundant of those volcanic rocks which are intermediate in their composition between the Basalts and Trachytes. The name has usually been extended to all granular mixtures, whether of hornblende and felspar, or of augite and felspar. The term diorite has been applied exclusively to compounds of hormblende and felspar. According to the analyses of Delesse and others, the chief cause of the green color, in most greenstones, is not green hornblende nor augite, but a green siliccous base, very variable and indefnite in its composition. The dark color, however, of diorite is usually derived from disseminated plates of hornblende.

The Basalts contain a smaller quantity of silica than the Trachytes, and a larger proportion of lime and magnesia. Incnce, independently of the frequent prescnes of iron, basalt is hearier. Abich has therefore proposed that we should weigh these rocks, in orier to appreciate their composition in cases where it it is impossible to scparate their component minerals. Thus, the rariety of basalt called dolerite, which contains 53 per cent. of silica, has a specific grarity of $2 \cdot 86$; whereas

* Dr. Daubeny on Volcanoes, 2d ed. pp. 14, 15. 
trachyte, which has 66 per cent. of silica, has a sp. gr. of only $2 \cdot 68$; trachytic porphyry, containing 69 per cent. of silica, a sp. gr. of only $2 \cdot 58$. If we then take a rock of intermediate composition, such as that prevailing in the Peak of Teneriffe, which Abich calls Trachytedolerite, its proportion of silica being intermediate, or 58 per cent., it weighs $2 \cdot 78$, or more than trachyte, and less than basalt.* The basalts are generally dark in color, sometimes almost black, whereas the trachytes are gray, and even occasionally white. As compared with the granitic rocks, basalts and trachytes contain both of them more soda in their composition, the potash-felspars being generally abundant in the granites. The volcanic rocks moreover, whether basaltic or trachytic, contain less silica than the granites, in which last the excess of silica has gone to form quartz. This mineral, so conspicuous in granite, is usually wanting in the volcanic formations, and never predominates in them.

The fusibility of the igneous rocks generally exceeds that of other rocks, for the alkaline matter and lime which commonly abound in their composition serve as a flux to the large quantity of silica, which would be otherwise so refractory an ingredient.

We may now pass to the consideration of those igneous rocks, the characters of which are founded on their form rather than their composition.

Porphyry is one of this class, and very characteristic of the volcanic formations. When distinct crystals of one or more minerals are scattered through an earthy or compact base, the rock is termed a porphyry (see fig. 675). Thus trachyte is porphyritic; for in it, as in

Fig. 675 .

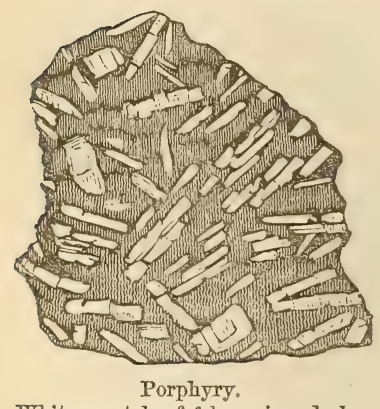

White crystals of felspar in a dark base of hornblende and felspar.
Fig. 676 .

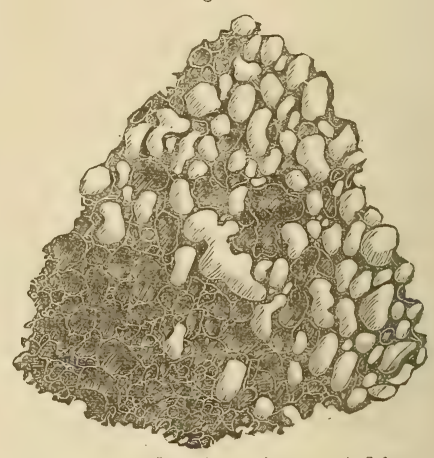

Scoriaceous lava in part converted into an amygdaloid.

Montagne de la Veille, Department of Puy de Dome, France.

many modern lavas, there are crystals of felspar; but in some porphyries the crystals are of augite, olivine, or other minerals. If the base

* Dr. Daubeny on Volcanoes, $2 d$ ed. pp. 14, 15. 
be greenstone, basalt, or pitchstone, the rock may be denominated greenstone-porphyry, pitch-stone porphyry, and so forth. The old classical trpe of this form of rock is the red porphyry of Egypt, or the well known "Rosso antico." It consists, according to Delesse, of a red felspathic base in mhich are disseminated rose-colored crystals of the felspar called oligoclase, with some plates of blackish hornblende and grains of oxidized iron-ore (fer oligiste). Red quaritziferous porphyry is a much more siliceous rock, containing about 70 or 80 per cent. of silex, while that of Egypt has only 62 per cent.

Amygdaloid.-This is also another form of igneous rock, admitting: of every variety of composition. It comprehends any rock in which round or almond-shaped nodules of some mineral, such as agate, chalcedony, calcareous spar, or zeolite, are scattered through a base of wacke, basalt, greenstone, or other kind of trap. It derives its name from the Greek rord amygdala, an almond. The origin of this structure cannot be doubted, for we may trace the process of its forma tion in modern lavas. Small pores or cells are caused by bubbles of steam and gas confined in the melted matter. After or during consolidation, these empty spaces are gradually filled up by matter separating from the mass, or infiltered by water permeating the rock. As these bubbles have been sometimes lengthened by the flow of the lava before it finally cooled, the contents of such cavities have the form of almonds. In some of the amygodaloidal traps of Scotland, where the nodules have decomposed, the empty cells are seen to have a glazed or ritreous coating, and in this respect exactly resemble scoriaceous lavas, or the slags of furnaces.

The foregoing figure (676) represents a fragment of stone taken from the upper part of a sheet of basaltic lava in Auvergne. Onehalf is scoriaceous, the pores being perfectly empty; the other part is amygdaloidal, the pores or cells being mostly filled up with carbonate of lime, forming white kernels.

Lav'a.-This term has a somerrhat rague signification, having been applied to all melted matter observed to flow in streams from rolcanic vents. Then this matter consolidates in the open air, the upper part is ustally scoriaceous, and the mass becomes more and more stony as we descend, or in proportion as it has consolidated more slowly and under greater pressure. At the bottom, howerer, of a stream of lava, a small portion of scoriaccons rock verr frequently occurs, formed by the first thin sheet of liquid matter, which often precedes the main current, or in consequence of the contact with water in or upon the damp soil.

The more compact laras are often porphyritic, but eren the scoriaceous part sometimes contains imperfect crystals, which hare been derived from some older rocks, in which the cresstals preëxisted, but were not melted, as being more infusible in their nature.

Although melted matter rising in a crater, and eren that which enters a rent on the side of a crater, is called lava, jet this term be- 
longs more properly to that which has flowed either in the open air or on the bed of a lake or sea. If the same fluid has not reached the surface, but has been merely injected into fissures below ground, it is called trap.

There is every variety of composition in lavas; some are trachytic, as in the Peak of Teneriffe; a great number are basaltic, as in Vesuvius and Auvergne; others are Andesitic, as those of Chili; some of the most modern in Vesuvius consist of green augite, and many of those of Etna of augite and Labrador-felspar.*

Scorioe and Pumice may next be mentioned as porous rocks, produced by the action of gases on materials melted by volcanic heat. Scorice are usually of a reddish-brown and black color, and are the cinders and slags of basaltic or augitic lavas. Pumice is a light, spongy, fibrous substance, produced by the action of gases on trachytic and other lavas; the relation, however, of its origin to the composition of lava is not yet well understood. Von Buch says that it never occurs where only Labrador-felspar is present.

Volcanic Tuff, Trap Tuff--Small angular fragments of the scoriæ and pumice, above mentioned, and the dust of the same, produced by volcanic explosions, form the tuffs which abound in all regions of active volcanoes, where showers of these materials, together with small pieces of other rocks ejected from the crater, fall down upon. the land or into the sea. Here they often become mingled with shells, and are stratified. Such tuffs are sometimes bound together by a calcareous cement, and form a stone susceptible of a beautiful polish. But even when little or no lime is present, there is a great tendency in the materials of ordinary tuffs to cohere together. Besides the peculiarity of their composition, some tuffs, or volcanic grits, as they have been termed, differ from ordinary sandstones by the angularity of their grains, and they often pass into volcanic breccias.

According to Mr. Scrope, the Italian geologists confine the term tuff, or tufa, to felspathose mixtures, and those eomposed principally of pumice, using the term peperino for the basaltic tuffs. $\uparrow$ The peperinos thus distinguished are usually brown, and the tuffs gray or white.

We meet occasionally with extremely compact beds of volcanic materials, interstratified with fossiliferous rocks. These may sometimes be tuffs, although their density or compactness is such as to cause them to resemble many of those kinds of trap which are found in ordinary dikes. The chocolate-colored mud, which was poured for weeks out of the crater of Graham's Island, in the Mediterranean, in 1831, must, when unmixed with other materials, have constituted a stone heavier than granite. Each cubic inch of the impalpable powder which has fallen for days through the atmosphere, during some modern eruptions, has been found to weigh, without being com- 
pressed, as much as ordinary trap rocks, and to be often identical with these in mineral composition.

Palagonite Tuff.-The nature of volcanic tuffs must vary according to the mineral composition of the ashes and cinders thrown out of each vent, or from the same vent, at different times. In descriptions of Iceland, we read of Palagonite tuffs as rery common. The name Palagonite was first giren by Prof. Bunsen to a mineral occurring in the volcanic formations of Palagonia, in 'Sicily. It is rather a mineral substance than a mineral, as it is always amorphous, and has never been found crystallized. Its composition is variable, but it may be defined as a hydrosilicate of alumina, containing oxide of iron, lime, magnesia, and some alkali. It is of a brown or blackish-brown color, and its specific density, $2 \cdot 43$. It enters largely into the composition of volcanic tuffs and breccias, and is considered by Bunsen as an altered rock, resulting from the action of steam on volcanic tuffs.

Agglomerate. - In the neighborhood of volcanic vents, we frequently obscrve accumulations of angular fragments of rock, formed during criptions by the explosive action of steam, which shatters the subjacent stony formations, and hurls them up into the air. They then fall in showers around the cone or crater, or may be spread for some distance orer the surrounding country. The fragments consist usually of different varieties of scoriaceous and compact lavas ; but other kinds of rock, such as granite or eren fossiliferous limestones, may be intermixed; in short, any substance through which the expansive gases have forced their way. The dispersion of such materials may be aided by the wind, as it varies in direction or intensity, and by the slope of the cone down which they roll, or by floods of rain, which often accompany eruptions. But if the power of running water, or of the waves and currents of the sea, be sufficient to carry the fragments to a distance, it can scarcely fail (unless where ice intervenes) to wear off their angles, and the formation then becomes a conglomerate. If occasionally globular pieces of scoriæ abound in an agglomerate, they do not owe their round form to attrition.

The size of the angular stones in some agglomerates is enormous; for they may be two or three yards in diameter. The mass is often 50 or 100 feet thick, without showing any marks of stratification. The term v'olcanic breccia may be restricted to those tuffs which are made up of small angular pieces of rock.

The slaggy crust of a stream of lava will often, while yet in motion, split up into angular pieces, some of which, after the current has ceased to flow, may be secn to stick up fire or six feet abore the general surface. Such broken-up crists resemble closely in structure the agglomerate alove described, although the composition of the materials will usually be more homogeneous.

Laterite is a red or brick-like rock composed of silicate of alumina and oxide of iron. The red layers, called "ochre beds," dividing the lavas of the Giant's Causerray, are laterites. These were found by 
Delesse to be trap impregnated with the red oxide of iron, and in part reduced to kaolin. - When still more decomposed they were found to be clay colored by red ochre. As two of the lavas of the Giant's Causeway are parted by a bed of lignite, it is not improbable that the layers of laterite seen in the Antrim cliffs resulted from atmospheric decomposition. In Madeira and the Canary Islands streams of lava of subaërial origin are often divided by red bands of laterite, probably ancient soils formed by the decomposition of the surfaces of lava-currents, many of these soils having been colored red in the atmosphere by oxide of iron, others burnt into a red brick by the overflowing of heated lavas. These red bands are sometimes prismatic, the small prisms being at right angles to the sheets of lava. Red clay or red marl, formed as above stated by the disintegration of lava, scoriæ, or tuff, has often accumulated to a great thickness in the valleys of Madeira, being washed into them by alluvial action; and some of the thick beds of laterite in India may have had a similar origin. In India, however, especially in the Deccan, the term "laterite" seems to have been used too vaguely.

It would be tedious to enumerate all the varieties of trap and lava which have been regarded by different observers as sufficiently abundant to deserve distinct names, especially as each investigater is too apt to exaggerate the importance of local varieties which happen to prevail in districts best known to him. It will be useful, however, to subjoin here, in the form of a glossary, an alphabetical list of the names and synonyms most commonly in use, with brief explanations, to which I have added a table of the analysis of the simple minerals most abundant in the volcanic and hypogene rocks.

\section{Explanation of the Names, Synonyms, and Mineral Composition of the more abundant Volcanic Rocks.}

AGglomerate. A coarse breccia, composed of fragments of rock, cast out of volcanic vents, for the most part angular and without any admixture of waterworn stones. "Volcanic conglomerates" may be applied to mixtures in which water-worn stones occur.

APHANITE. Sce Cornean.

Ampmibolite, or Hornblendic Rock, which see.

AMrgDaloid. A particular form of volcanic rock; see p. 601.

Avgrte Rock. A rock of the basaltic family, composed of felspar and augite. See p. 598.

AUGITIC-PORPHYRY. Crystals of Labrador-felspar and of augite, in a green or dark gray base. (Rose, Ann. des Mines, tom. 8, p. 22, 1835.)

BASALT. 'An intimate mixture of felspar and augite with magnetic iron, olivine, sc. See p. 598.

BASANITE. Name given by Alex. Brongniart to a rock, having a base of basalt, with more or less distinct crystals of augite disseminated through it.

Clatstone and Claystone-porphyry. An earthy and compact stone, usually of a 
purplish color, like an indurated clay; passes into hornstone ; generally con. tains scattered crystals of felspar and sometizaes of quartz.

Chrnkstoxe. Syn. Phonolite, fissile Petrosilex, see p. 599; a grayish-blue rock, having a tendency to divide into slabs; hard, with clean fracture, ringing under the hammer; principally composed of felspar, and, according to Gmelin, of felspar and mesotype. (Leonhard, Mineralreich, p. 102.)

Conpact Felspar, which has also been called Petrosilex; the rock so called includes the hornstone of some mineralogists, is allied to clinkstone, but is harder, more compact, and translucent. It is a varying rock, of which the chemical composition is not well defined. (MacCulloch's Classification of Rocks, p. 481.)

CoRsear or APHANTte. A compact homogeneous rock without a trace of crystallization, breaking with a smooth surface like some compact basalts; consists of hornblende, quartz, and felspar in intimate combination. It derives its name from the Latin word-cornu, horn, in allusion to its toughness and compact texture.

Diallage Rock. Syn. Euphotide, Gabbro, and some Ophiolites. Compounded of felspar and diallage.

Diorite. A kind of Greenstone, which see. Components, felspar and hornblende in grains. According to Rose, Ann. des Mines, tom. 8, p. 4, diorite consists of albite and hornblende, but Delesse has shown that the felspar may be Oligoclase or Labradorite. (Ann. des Mines, 1849, tom. 16, p. 323.) Its dark color is due to disseminated plates of hornblende. See above, p. 599 .

Dolerite. According to Rose (ibid. p. 32), its composition is black augite and Labrador-felspar; according to Leonhard (MFineralreich, \&c., p. 77), augite, Labrador-felspar, and magnetic iron. See above, p. 598.

Dosmte. An early trachyte, found in the Puy de Dome, in Aurergne.

EтpHotide. A mixture of grains of Labrador-felspar and diallage. (Rose, ibid. p. 19.) According to some, this rock is defined to be a mixture of augite or hornblende and Saussurite, a mineral allied to jade. (Allan's Mineralogy, p. 158.) Haidinger first observed that in this rock hornblende surrounds the crystals of diallage.

Felstowe. Same as compact felspar (which see). When crystals of felspar occur in it, it becomes felstone or felspar-porphyry. See also Hornstone.

G.ABRRo, see Diallage rock.

Greexstoxe. Syn. A misture of felspar and hormblende. See above, p. 599.

Grarstose. (Graustein of Terner.) Lead-grar and grecuish rock composed of felspar and augite, the felspar being more than serenty-five per cent. (Scrope, Journ. of Sci. No. 42, p. 221.) Graystone lavas are intermediate in composition between basaltic and trachytic lavas.

HorsBlexDE Rock, or AMPHBoltte. This rock, as defined by Leonhard, is composed entirely of hornblende; but such a rock appears to be exceptional, and confined to mineral veins. Any rocks in which hornblende plays a conspicuous part, constituting the "roches amphiboliques" of French writers, may be called hornblende rock. They always contain more or less felspar in their composition, and pass into basalt or greenstone, or aphanite. See p. 597.

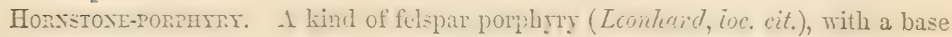
of hornstone, a mineral approaching near to flint, which differs from compact felspar in being infusible. 
HYPERSTHENE Rock, a mixture of grains of Labrador-felspar and hypersthene (Rose, Ann. des Mines, tom. 8, p. 13), having the structure of syenite or granite; abundant among the traps of Skye. It is extremely tough, grayish, and greenish black. Some geologists consider it a greenstone, in which hypersthene replaces hornblende; and this opinion, says Delesse, is borne out by the fact that hornblende usually oceurs in hypersthene rock, often enveloping the crystals of hypersthene. The latter have a pearly or metallic-pearly lustre.

LATERIte. A red, jaspery, brick-like rock, composed of silicate of alumina and oxide of iron, or sometimes consisting of clay colored with red ochre. See above, p. 603.

MeLaphyre. A variety of black porphyry composed of Labrador-felspar and a small quantity of augite. Its black color was formerly attributed to disseminated microscopic crystals of augite, but M. Delesse has shown that the paste is discolored by hydrochloric acid, whereas this acid does not attack the crystals of augite, which are seen to be isolated, and few in number. (Ann. des Mines, 4th. ser. tom. xii. p. 228.) From $\mu \varepsilon \lambda a s$, melas, black.

Obsidian. Vitreous lava like melted glass, nearly allied to pitchstone.

OpHiolite. A name given by Alex. Brongniart to serpentine.

OpHixte. A name given by Palassou to certain trap rocks of the Pyrenees, very variable in composition, usually composed of Labrader-felspar and hornblende, and sometimes augite, occasionally of a green color, and passing into serpentine.

Patagonite Turr. An altered volcanic tuff containing the substance termed palagonite. See p. 603.

Pearlstone. A volcanic rock, having the lustre of mother of pearl; usually having a nodular structure; intimately related to obsidian, but less glassy.

Peperivo. A form of volcanic tuff, composed of basaltic scoriæ. See p. 602.

Petrosilex. See Clinkstone and Compact Felspar.

РнолоLIте. Syn. of Clinkstone, which see.

Pitchstone, or Retinite of the French. Vitreous lava, less glassy than obsidian; a blackish green rock resembling glass, having a resinous lustre and appearance of pitch; composition usually of glassy felspar (orthoclase) with a little mica, quartz, and hornblende; in Arran it forms a dike thirty feet wide, cutting through sandstone.

Ponice. A light, spongy, fibrous form of trachyte. See p. 602.

Pyroxenic-PoRphyry, same as augitic-porphyry, pyroxene being Haüy's name for augite.

Scorize. Syn. volcanic cinders; reddish brown or black porous form of lava. See p. 602 .

SERPENTINE. A greenish rock in which there is much magnesia. Its composition always approaches very near to the mineral called "noble serpentine" (see Table of Analyses, p. 608), which forms veins in this rock. The minerals most commonly found in Serpentine are diallage, garnet, chlorite, oxydulous iron, and chromate of iron. The diallage and garnet occurring in serpentine are richer in magnesia than when they are crystallized in other rocks. (Delesse ${ }_{2}$ Ann. des Mines, 1851, tom. xviii. p. 309.) Occurs sometimes, though rarely, in dikes, altering the contiguous strata; is indifferently a member of the trappean or hypogene series. Its absence from recent vol- 
canic products seems to imply that it belongs properly to the metamorphic class; and, even when it is found in dikes cutting through aqueous formations, it may be an altered basalt, which abounded greatly in olivine.

TePHrine, synonymous with lava. Name proposed by Alex. Brongniart.

TOADSTONE. A local name in Derbyshire for a kind of wacke, which see.

Trachyte. Chiefly composed of glassy felspar, with crystals of glassy felspar. See p. 599.

Trap TuFr. See p. 602.

TRASS. A kind of tuff or mud poured out by lake-craters during eruptions; common in the Eifel, in Germany.

TuFf. Syn. Trap tuff, volcanic tuff. See p. 602.

Vitreous Lava, See Pitchstone and Obsidian.

Volcanic Turf. See p. 602.

W $\triangle$ CKE. A soft and earthy variety of trap, having an argillaceous aspect. It resembles indurated clay, and when scratched, exhibits a shining streak.

Whinstone. A Scotch provincial term for greenstone and other hard trap rocks. 
ANALYSIS OF MINERALS MOST ABUNDANT IN THE VOLCANIC AND HYPOGENE ROCKS.

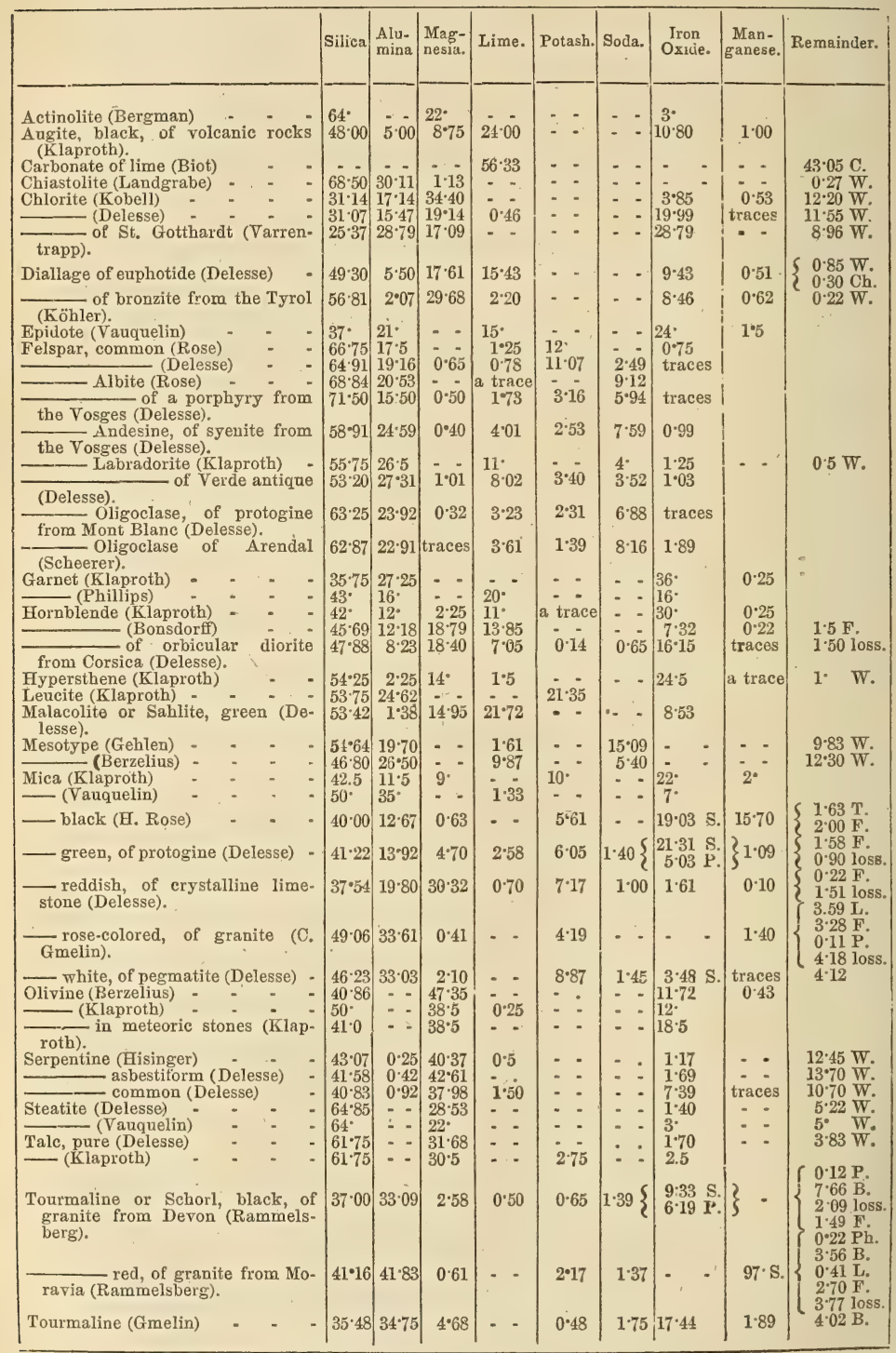

In the last column of the above Table, the following signs are used: B, Boracic acid, C. Carbonic acid Ch. Oxide of Chrome, F. Fluoric acid, I, Lithine, P. Phosphoric acid, T. Oxide of Titanium, W. Water In the 7 th column of numbers, $P$. means Protoxide, and S. Sesquioxide. 


\title{
CHAPTER XXIX.
}

\author{
VOLCANIC ROCKS, continued.
}

Trap dikes-sometimes project-sometimes leave fissures vacant by decomposition-Branches and veins of trap-Dikes more crystalline in the centreStrata altered at or near the contact-Obliteration of organic remains-Conversion of chalk into marble-Trap interposed between strata-Columnar and globular structure-Relation of trappean rocks to the products of active volcanoes-Form, external structure, and origin of volcanic mountains-Craters and Calderas-Sandwich Islands-Lava flowing underground-Truncation of cones-Javanese calderas-Canary Islauds-Structure and origin of the Caldera of Palma-Older and newer volcanic rocks in, unconformable-Aqueous conglomerate in Palma-Hypothesis of upheaval considered-Slope on which stony lavas may form-Extent and nature of aqueous erosion in Palma-Island of St. Paul in the Indian Ocean-Peak of Teneriffe, and ruins of older coneMadeira-Its volcanic rocks, partly of marine, and partly of subaërial originCentral axis of eruptions-Varying dip of solid lavas near the axis, and further from it-Leaf-bed, and fossil land-plants-Central valleys of Madeira not craters, or calderas.

HAving in the last chapter spoken of the composition and mineral characters of volcanic rocks, I shall next describe the manner and position in which they occur in the earth's crust, and their external forms. The leading varieties both of the basaltic and trachytic rocks, as well as of greenstone and the rest, are found sometimes in dikes penetrating stratified and unstratined formations, sometimes in shapeless masses protruding through or orerlying them, or in horizontal sheets intercalated between strata.

Volcanic or Trap Dikes.-Fissures have already been spoken of as occurring in all kinds of rocks, some a few feet, others many yards in width, and often filled up with earth or angular pieces of stone, or with sanc and pebbles. Instead of such materials, suppose a quantity of melted stone to be driven or injected into an open rent, and there consolidated, we have then a tabular mass resembling a wall, and calied a trap dike. It is not uncommon to find such dikes passing through strata of soft materials, such as tuff, scorix, or shale, which, being more perishable than the trap, are often washed away by the sea, rivers, or rain, in which case the dike stands prominently out in the face of precipices, or on the level surface of a country (see fig. 677 ).

In the is 'ands of Arran and Slkye, and in other parts of Scotland, where sandstone, conglomerate, and other liard rocks are traversed by 
dikes of trap, the converse of the above phenomenon is seen. The dike, having decomposed more rapidly than the containing rock, has once more left open the original fissure, often for a distance of many yards inland from the seacoast, as represented in the annexed view (fig. 678). In these instances, the greenstone of the dike is usually

Fig. 677.

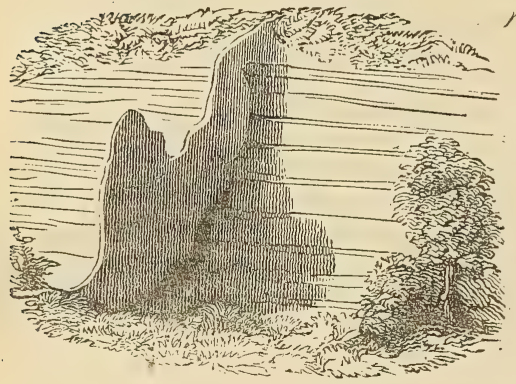

Dike in a valley near Brazen Head, Madeira. (From a drawing of Capt. Basil Hall, R. N.)
Fig. 678 .

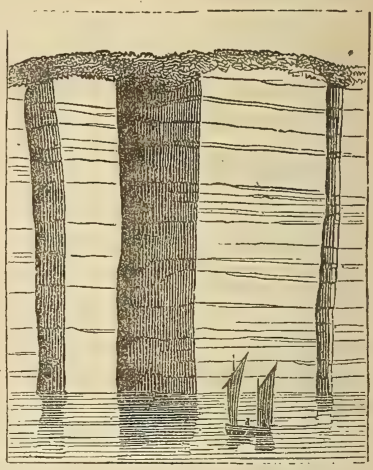

Fissures left vacant by decomposed trap. Strathaird, Skye. (MacCulloch.)

more tough and hard than the sandstone; but chemical action, and chiefly the oxidation of the iron, has given rise to the more rapid decay.

There is yet another case, by no means uncommon in Arran and other parts of Scotland, where the strata in contact with the dike, and for a certain distance from it, have been hardened, so as to resist the action of the weather more than the dike itself, or the surrounding rocks. When this happens, two parallel walls of indurated strata are seen protruding above the general level of the country and following the course of the dike.

As fissures sometimes send off branches, or divide into two or

Fig. 679 .

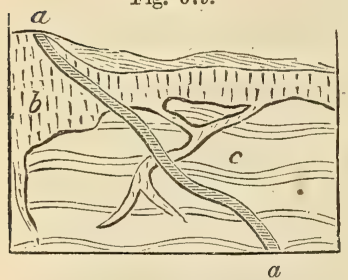

Trap veins in Airdnamurchan. more fissures of equal size, so also we find trap dikes bifurcating and ramifying, and sometimes they are so tortuous as to be called veins, though this is more common in granite than in trap. The accompanying sketch (fig. 679) by Dr. MacCulloch represents part of a sea-cliff in Argyleshire, where an overlying mass of trap, $b$, sends out some veins which terminate downwards. Another trap vein, $\alpha . a$, cuts through both the limestone, $c$, and the trap, $b$.

In fig. 680, a ground plan is given of a ramifying dike of greenstone, which I observed cutting through sandstone on the beach near Kildonan Castle, in Arran. The larger branch varies from 5 
to 7 feet in width, which will afford a scale of measurement for the whole.

Fig. 680 .

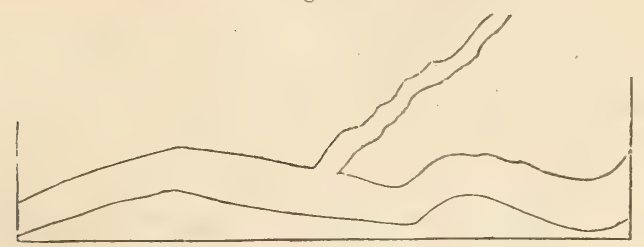

Ground plan of greenstone dike traversing sandstone. Arran.

In the Hebrides and other countries, the same masses of trap which occupy the surface of the country far and wide, concealing: the subjacent stratified rocks, are seen also in the sea cliffs, prolonged downwards in veins or dikes, which probably unite with other masses of igneous rock at a greater depth. The largest of the dilies represented in the annexed diagram, and which are seen in part of the coast of Skye, is no less than 100 feet in width.

Fig. 681 .

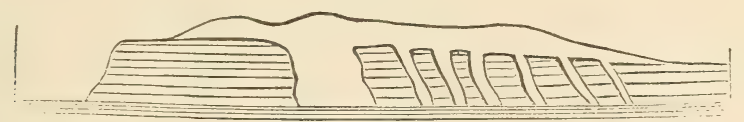

Trap dividing and coviering sandstone near Suishnish in Skye. (MacCulloch.)

Every variety of trap-rock is sometimes found in diles, as basalt, greenstone, felspar-porphyry, and trachyte. The amygdaloidal traps also occur, though more rarely, and even tuff and breccia, for the materials of these last may be washed down into open fissures at the bottom of the sea, or during eruptions on the land may be showered into them from the air.

Some dikes of trap may be followed for leagues uninterruptedly in nearly a straight direction, as in the north of England, showing that the fissures which they fill must have been of extraordinary length.

In many cases trap at the edges or sides of a dilic is less crystalline or more earthy than in the centre, in consequence of the melted matter having cooled more rapidly by coming in contact with the cold sides of the fissure; whereas, in the centre, where the matter of the dike is liept longer in a fluid or soft state, crystals are slowly formed. But I observed the converse of the above phenomena in Teneriffe, in the neighborhood of Santa Cruz, where a dike is seen cutting through horizontal beds of scorix in the sea-cliff near the Barranco de Bufadero. It is rertical in its main direction, slightly flexuous, and about one foot thick. On each side are walls of compact basalt, but in the centre the rock is highly resicular for a width of about 4 inches. In this instance, the fissure may have become 
wider after the lava on each side had consolidated, and the additionai melted matter poured into the middle space may have cooled more rapidly than that at the sides.

In the ancient part of Vesurius, called Somma, a thin band of half-vitreous lava is found at the edge of some dikes. At the junction of greenstone dikes with limestone, a sahlband, or selvage, of serpentine is occasionally observed. On the left shore of the fiord of Christiania, in Norway, I examined, in company with Professor Keilhau, a remarkable dike of syenitic greenstone, which is traced through Silurian strata, until at length, in the promontory of Næsodden, it enters mica-schist. Fig. 682 represents a ground plan, where the dike appears 8 paces in width. In the middle it is highly crystalline and granitiform, of a purplish color, and containing a few crystals of mica, and strongly contrasted with the whitish mica-schist, between which and the syenitic rock there is usually on each side a distinct black band, 18 inches wide, of dark greenstone. When first seen, these bands have the appearance of two accompanying dikes; yet they are, in fact, only the different form which the syenitic materials have assumed where near to or in contact with the mica-schist. At one point, $a$, one of the sahlbands terminates for a space; but near this there is a large detached block, $b$, having a gneiss-like structure, consisting of hornblende and felspar, which is included in the midst of the dike. Round this a smaller encircling zone is seen, of dark basalt, or fine-grained greenstone, nearly corresponding to the larger ones which border the dike, but only 1 inch wide.

It seems, therefore, evident that the fragment, $b$, has acted on the matter of the dike, probably by causing it to cool more rapidly, in the same manner as the walls of the fissure have acted on a larger scale. The facts, also, illustrate the facility with which a granitiform syenite may pass into ordinary rocks of the voleanic family.

Fig. 682.

Syenitic greenstone dike of Næsodden, Christiania.

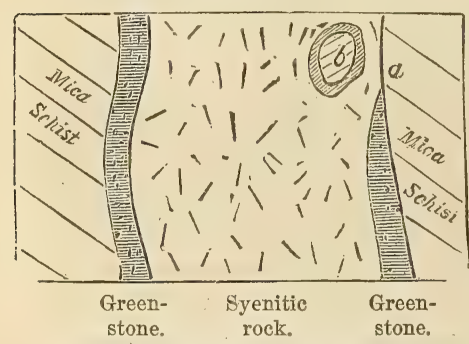

b. Imbedded fragment of crystalline schist surrounded by a band of greenstone.
Fig. 683.

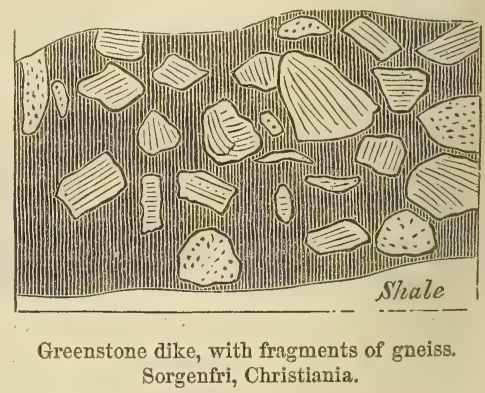

The fact above alluded to, of a foreign fragment, such as $b$, fig. 682 , included in the midst of the trap, as if torn off from some sub- 
jacent rock or the walls of a fissure, is by no means uncommon. A fine example is seen in another dike of greenstone, 10 feet wide, in the northern suburbs of Christiania, in Norway, of which the foregoing figure (683) is a ground plan. The dike passes through shale, known by its fossils to belong to the Silurian series. In the black base of greenstone are angular and romdish pieces of gneiss, some white, others of a light flesh-color; some without lamination, like granite, other's with laminæ, which, by their various and often opposite directions, show that they hare been scattered at random through the matrix. These imbedded pieces of gneiss measure from 1 to about 8 inches in diameter.

Rocks altered by Volcunic Dikes. - After these remarks on the form and composition of dikes themselves, I shall describe the alterations which they sometimes produce in the rocks in contact with them. The changes are usually such as the intense heat of melted matter and the entangled gases might be expected to cause.

Plas-_Terydd._A striking example, near Plas-Newydd, in Anglesea, has been described by Professor Henslow.* The dike is 134 feet wide, and consists of a rock which is a compound of felspar and augite (dolerite of some authors). Strata of shale and argillaceous limestone, through which it cuts perpendicularly, are altered to a distance of 30 , or even, in some places, to 35 feet from the edge of the dike. The shale, as it approaches the trap, becomes gradually more compact, and is most indurated where nearest the junction. Here it loses part of its schistose structure, but the separation into parallel layers is still discernible. In sereral places the shale is converted into hard porcellanous jasper. In the most hardened part of the mass the fossil shells, principally Producti, are nearly obliterated; yet even here their impressions may frequently be traced. The argillaceous limestone undergoes analogous mutations, losing its earthy texture as it approaches the dike, and becoming granular and crystalline. But the most extraordinary phenomenon is the appearance in the shale of numerous crystals of analcime and garnet, which are distinctly confined to those portions of the rock affected by the dike. $\uparrow$. Some garnets contain as much as 20 per cent. of lime, which they may have derived from the decomposition of the fossil shells or Producti. The same mineral has been obserred, under rery analogous circumstances, in High Teesdale, br Professor Sedgrwick, where it also occurs in shale and limestone, altered by basalt.

Antrim.-In several parts of the county of Antrim, in the north of Ireland, chalk with flints is traversed by basaltic dikes. The chalk is there converted into granular marble near the basalt, the change sometimes extending 8 or 10 feet from the wall of the dike, being greatest near the point of contact, and thence gradually decreasing

* Cambridge Transactions, vol. i. p. 402.

† Ibid., vol. i. p. 410.

$\ddagger$ Ibid, vol. ii. p. 175. 
till it becomes evanescent. "The extreme effect," says Dr. Berger, "presents a dark brown crystalline limestone, the crystals running in flakes as large as those of coarse primitive (metamorphic) limestone the next state is saccharine, then fine grained and arenaceous; a compact variety, having a porcellanous aspect and a bluish-gray color, succeeds : this, towards the outer edge, becomes yellowish-white, and insensibly graduates into the unaltered chalk. The flints in the altered chalk usually assume a gray yellowish color." * All traces of organic remains are effaced in that part of the limestone which is most crystalline.

The annexed drawing (fig. 684) represents three basaltic dikes

Fig. 684.

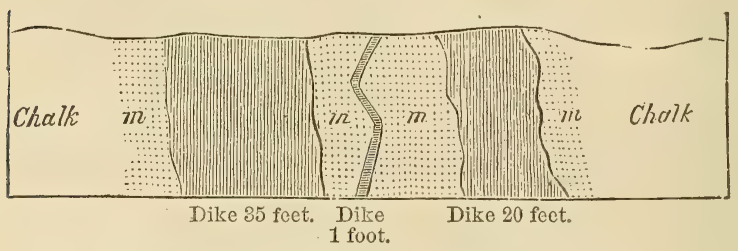

Basaltic dikes in chalk in island of Rathlin, Antrim.

Ground plan, as seen on the beach. (Conybeare and Buckland.t)

traversing the chalk, all within the distance of 90 feet. The chalk contiguous to the two outer dikes is converted into a finely granular marble, $m m$, as are the whole of the masses between the outer dikes and the central one. The entire contrast in the composition and color of the intrusive and invaded rocks, in these cases, renders the phenomena peculiarly clear and interesting.

Another of the dikes of the northeast of Ireland has converted a mass of red sandstone into hornstone. By another, the shale of the coal-measures has been indurated, assuming the character of flinty slate; and in another place the slate-clay of the lias has been changed into flinty slate, which still retains numerous impressions of ammonites.".

It might have been anticipated that beds of coal would, from their combustible nature, be affected in an extraordinary degree by the contact of melted rock. Accordingly, one of the greenstone dikes of Antrim, on passing through a bed of coal, reduces it to a cinder for the space of 9 feet on each side.

At Cockfield Fell, in the north of England, a similar change is observed. Specimens taken at the distance of about 30 yards from the trap are not distinguishable from ordinary pit-coal; those nearer the dike are like cinders, and have all the character of coke;

* Dr. Berger, Geol. Trans., First Series, vol. iii. p. 172.

+ Geol. Trans., First Series, vol. iii. p. 210, and plate 10.

$¥$ Ibid., p. 213 ; and Playfair, Illust. of Hutt. Theory, s. 258. 
while those close to it are converted into a substance resembling soot.*

As examples might be multiplied without end, I shall merely select one or two others, and then conclude. The rock of Stirling Castle is a. calcareous sandstonc, fractured and forcibly displaced by a mass of grecnstone which has evidently invaded the strata in a melted state. The sandstone has been indurated, and has assumed a texture approaching to hornstone near the juuction. In Arthur's Seat and Salisbury Craig, near Edinburgh, a sandstone which comes in contact with greenstone is converted into a jaspideous rock.

The secondary sandstones in Skye are converted into solid quartz in several places, where they come in contact with veins or masses of trap; and a bed of quartz, says Dr. MacCulloch, found near a mass of trap, among the coal strata of Fife, was in all probability a stratum of ordinary sandstone, having been subsequently indurated and turned into quartzite by the action of heat. $\uparrow$

But although strata in the neighborhood of dikes are thus altered in a varicty of cases, shale being turned into flinty slate or jasper, limestone into crystalline marble, sandstone into quartz, coal into coke, and the fossil remains of all such strata wholly and in part obliterated, it is by no means uncommon to meet with the same rocks, even in the same districts, absolutely unchanged in the proximity of volcanic dikes.

This great inequality in the effects of the igneous rocks may often arise from an original difference in their temperature, and in that of the entangled gases, such as is ascertained to prevail in different lavas, or in the same lava near its source and at a distance from it. The power also of the invaded rocks to conduct heat may vary, according to their composition, structure, and the fractures which they may have experienced, and perhaps, also, according to the quantity of water (so capable of being heated) which they contain. It must happen in some cases that the component materials are mixed in such proportions as prepare them readily to enter into chemical union, and form new minerals; while in other cases the mass may be more homogeneous, or the proportions less adapted for such union.

We must also take into consideration, that one fissure may be simply filled with lava, which may begin to cool from the first; whereas in other cases the fissure may give passage to a current of melted matter, which may ascend for days or months, fecding streams which are overflowing the country above, or are ejected in the shape of scoriæ from some crater. If the walls of a rent, moreover, are heated by hot vapor before the lava rises, as we know may happen on the flanks of a volcano, the additional caloric supplied by the dike and its gases will act more powerfully.

* Sedgwick, Camb. Trans., vol. ii. p. 37 .

† Syst, of Geol.s vol. i. p. 206. 
Intrusion of Trap between Strata.-In proof of the mechanical force which the fluid trap has sometimes exerted on the rocks into which it has intruded itself, I may refer to the Whin-Sill, where a mass of basalt, from 60 to 80 feet in height, represented by $a$, fig. 685 , is in part wedged in between the rocks of limestone, $b$, and shale, $c$, which have been separated from the great mass of limestone and shale, $d$, with which they were united.

Fig. 685 .

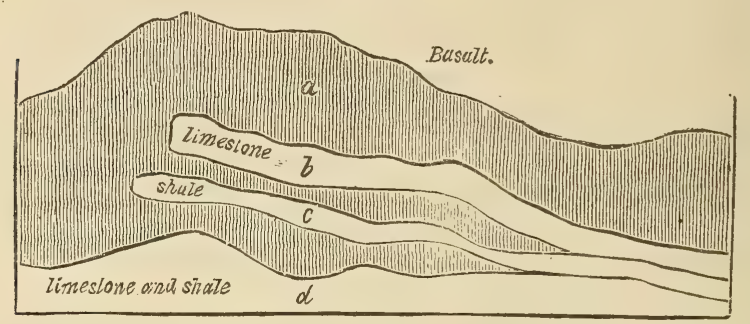

Trap interposed between displaced beds of limestone and shale, at White Force, High Teesdale, Durham. (Sedgwick.*)

The shale in this place is indurated; and the limestone, which at a distance from the trap is blue, and contains fossil corals, is here converted into white granular marble without fossils.

Masses of trap are not unfrequently met with intercalated between strata, and maintaining their parallelism to the planes of stratification throughout large areas. They must in some places have forced their way laterally between the divisions of the strata, a direction in which there would be the least resistance to an advancing fluid, if no vertical rents communicated with the surface, and a powerful hydrostatic pressure were caused by gases propelling the lava upwards.

Columnar and Globular Structure.-One of the characteristic forms of volcanic rocks, especially of basalt, is the columnar, where large masses are divided into regular prisms, sometimes easily separable, but in other cases adhering firmly together. The columns vary in the number of angles, from three to twelve; but they have most commonly from five to seven sides. They are often divided transversely, at nearly equal distances, like the joints in a vertebral column, as in the Giant's Causeway, in Ireland. They vary exceedingly in respect to length and diameter. Dr. MacCulloch mentions some in Skye which are about 400 feet long; others, in Morven, not exceeding an inch. In regard to diameter, those of Ailsa measure 9 feet, and those of Morven an inch or less. $\left.\right|^{\dagger}$ They are usually straight, but sometimes curved; and examples of both these occur in the island of Staffa. In a horizontal bed or sheet of trap the columns are ver- 
tical; in a rertical dike they are horizontal. Among other examples of the last-mentioned phenomenon is the mass of basalt, called the Chimney, in St. Helena (see fig. 686), a pile of hexagonal prisms, 64

Fig. 6S6.

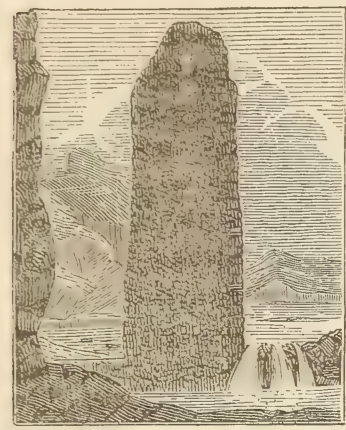

Fig. 657.

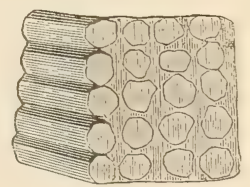

Small portion of the dike in fig. 686 .

Volcanic dike composorl of horizontal prisms. St. Ificlon:.

feet high, evidently the remainder of a narrow dike, the walls of rock which the dike originally traversed having been removed down to the level of the sea. In fig. 687, a small portion of this dike is represented on a less reduced scale.*

It being assumed that columnar trap has consolidated from a fluid state, the prisms are said to be always at right angles to the cooling surfaces. If these surfaces, therefore, instead of being either perpendicular or horizontal, are curred, the columns ought to be inclined at every angle to the horizon; and there is a beautiful exemplification of this phenomenon in one of the valleys of the Vivarais, a mountainous district in the south of France, where, in the midst of a region of gneiss, a geologist encounters unexpectedly several volcanic

Fig. 688.

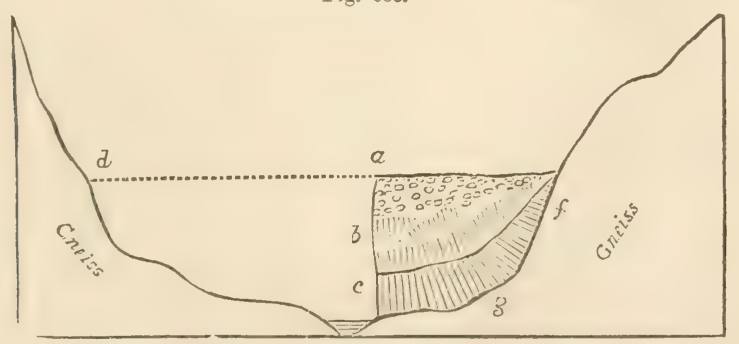

Lava of La Coupe d'Ayzac, near Antraigues, in the Department of Ardéche.

cones of loose sand and scoriæ. From the crater of one of these cones, called La Coupe d'Ayzac, a stream of lava descends and occu-

* Seale's Geognosy of St. Helena, plate 9. 
pies the bottom of a narrow valley, except at those points where the river Volant, or the torrents which join it, have cut away portions of the solid lava. The foregoing sketch (fig. 688) represents the remnant of the lava at one of the points where a lateral torrent joins the main valley of the Volant. It is clear that the lava once filled the whole valley up to the dotted line $d . a$; but the river has gradually swept away all below that line, while the tributary torrent has laid open a transverse section; by which we perceive, in the first place, that the lava is composed, as tsual in this country, of three parts: the uppermost, at $a$, being scoriaceous; the second, $b$, presenting irregular prisms; and the third, $c$, with regular columns, which are vertical on the banks of the Volant, where they rest on a horizontal base of gneiss, but which are inclined at an angle of $45^{\circ}$ at $g$, and are horizontal at $f$, their position having been everywhere determined, according to the law before mentioned, by the concave form of the original valley.

Fig. 689.

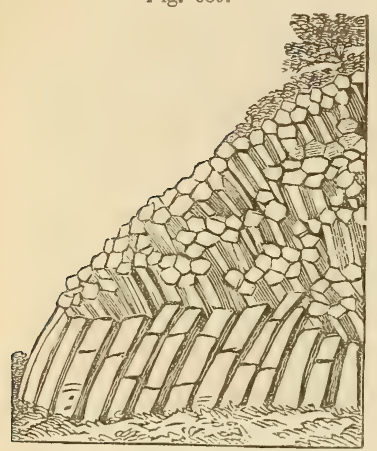

Columnar basalt in the Vieentin. (Fortis.)

In the annexed figure (689) a view is given of some of the inclined and curved columns which present themselves on the sides of the valleys in the hilly region north of Vicenza, in Italy, and at the foot of the higher Alps.* Unlike those of the Vivarais, last mentioned, the basalt of this country was evidently submarine, and the present valleys have since been hollowed out by denudation.

The columnar structure is by no means peculiar to the trap rocks in which augite abounds; it is also observed in clinkstone, trachyte, and other felspathic rocks of the igneous class, although in. these it is rarely exhibited in such regular polygonal forms.

It has been already stated that basaltic columns are often divided by cross joints. Sometimes each segment, instead of an angular, assumes a spheroidal form, so that a pillar is made up of a pile of balls, usually flattened, as in the Cheese-grotto at Bertrich-Baden, in the Eifel, near the Moselle (fig. 690). The basalt there is part of a - Il stream of lava, from 30 to 40 feet thick, which has proceeded from one of several volcanic craters, still extant, on the neighboring heights. The position of the lava bordering the river in this valley might be represented by a section like that already given at fig. 635 , if we merely supposed inclined strata of slate and the argillaceous. sandstone called graywacke to be substituted for gneiss.

In some masses of decomposing greenstone, basalt, and other trap

* Fortis. Mém. sur l'Hist. Nat. de l'Italie, tom. i. p. 233, plate 7. 
Fig. 690 .

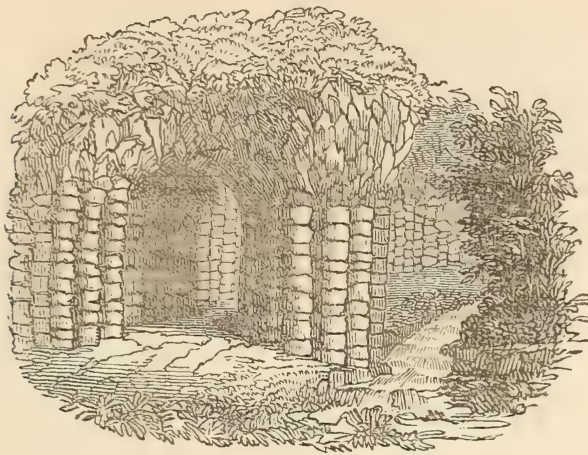

Basaltic pillars of the Käsegrotte, Bertrich-Baden, halfway between Treves and Coblentz. Height of grotto, from 7 to 8 feet.

rocks the globular structure is so conspicuous that the rock has the appearance of a heap of large cannon balls. According to the theory of M. Delesse, the centre of each spheroid has been a centre of crystallization, around which the different minerals of the rock arranged themselves symmetrically during the process of cooling. But it was also, he says, a centre of contraction, produced by the same cooling. The globular form, therefore, of such spheroids is the combined result of crystallization and contraction. *

A striking example of this structure Fig. 691. occurs in a resinous trachyte or pitchstone-porphyry in one of the Ponza islands, which rise from the Mediterranean, off the coast of Terracina and Gaeta. The globes vary from a few inches to three feet in diameter, and are of an ellipsoidal form (see fig. 691). The whole rock is in a state of decomposition, "and when the balls," says Mr. Scrope, "have been exposed a short time to the weather, they scale off at a touch into numerous concentric coats, like those of a bulbous root, inclosing a compact nucleus. The laminæ of this nucleus have not been so much loosened by decomposition; but the application of a ruder blow will produce a still further exfoliation." +

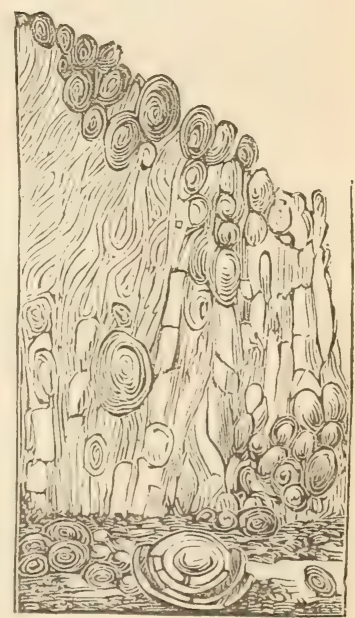

Globiform pitchstone. Chiaja di Luna, Isle of Ponza. (Scrope.)

* Delesse, sur les Roches Globuleuses, Mém. de la Soc. Géol. de France, 2 sór. tom. iv.

† Scrope, Geol. Trans., Second Series, vol. ii. p. 205. 
A fissile texture is occasionally assumed by clinkstone and other trap rocks, so that they have been used for roofing houses. Sometimes the prismatic and slaty structure is found in the same mass. The causes which give rise to such arrangements are very obscure, but are supposed to be connected with changes of temperature during the cooling of the mass, as will be pointed out in the sequel. (See Chaps. XXXV. and XXXVI.)

\section{Relation of Trappean Rocks to the products of active Volcanoes.}

When we reflect on the changes above described in the strata near their contact with trap dikes, and consider how complete is the analogy or often identity in composition and structure of the rocks called trappean and the lavas of active volcanoes, it seems difficult at first to understand how so much doubt could have prevailed for half a century as to whether trap was of igneous or aqueous origin. To a certain extent, however, there was a real distinction between the trappean formations and those to which the term volcanic was almost exclusively confined. A large portion of the trappean rocks first studied in the north of Germany, and in Norway, France, Scotland, and other countries, neere such as had been formed entirely under water, or had been injected into fissures and intruded between strata, and which had never flowed out in the air, or over the bottom of a shallow sea. When these products, therefore, of submarine or subterranean igneous action were contrasted with loose cones of scoriæ, tuff, and lava, or with narrow streams of lava in great part scoriaceous and porous, such as were observed to have proceeded from Vesuvius and Etna, the resemblance seemed remote and equivocal. It was, in truth, like comparing the roots of a tree with its leaves and branches, which, although they belong to the same plant, differ in form, texture, color, mode of growth, and position. The external cone, with its loose ashes and porous lava, may be likened to the light foliage and branches, and the rocks concealed far below, to the roots. But it is not enough to say of the volcano,

\section{"quantum vertice in auras \\ Etherias, tantum radice in Tartara tendit,"}

for its roots do literally reach downwards to Tartarus, or to the regions of subterranean fire; and what is concealed far below is probably always more important in volume and extent than what is visible above ground.

We have already stated how frequently dense masses of strata have been removed by denudation from wide areas (see Chap. VI.); and this fact prepares us to expent a similar destruction of whatever may once have formed the uppermost part of ancient submarine or subaërial volcanoes, more especially as those superficial parts are 
always of the lightest and most perishable materials. The abrupt manner in which dikes of trap usually terminate at the surface (see fig. 692), and the waterworn pebbles of trap in the alluvium which covers the dike, prove incontestably that whaterer was uppermost in these formations has been swept away. It is casy, therciore, to conceive that what is gone in regions of trap may have corresponded to what is now visible in active Fig. 692 . volcanoes.

It will be seen in the following chapters, that in the earth's crust there are volcanic tuffs of all ages, containing marine shells, which bear witness to eruptions at many successive geological periods. These tuffs, and the associated trappean rocks, must not be compared to lava and scoriæ which had cooled in the open air. Their counterparts must be sought in the products of modern submarine volcanic eruptions. If it be objected that we have no opportunity of studying these last, it may be answered, that subterranean movements have caused, almost everywhere in regions of active volcanoes, great changes in the relative level of land and sea, in times comparatively modern, so as to expose to view the effects of volcanic operations at the bottom of the sea.

Thus, for example, the examination of the igneous rocks of Sicily, especially those of the Val di Noto, has proved that all the more ordinary varieties of European trap have been there produced under the waters of the sea, at a modern period; that is to say, since the Mediterranean has been inhabited by a great proportion of the existing species of testacea.

These igneous rocks of the Val di Noto, and the more ancient trappean rocks of Scotland and other countries, differ from subaërial voleanic formations in being more compact and heavy, and in forming sometimes extensive sheets of matter intercalated between marine strata, and sometimes stratified conglomerates, of which the rounded pebbles are all trap. They differ also in the absence of regular cones and craters, and in the want of conformity of the lava to the lowest levels of existing valleys.

It is highly probable, however, that insular cones did exist in some parts of the Val di Noto; and that they were removed by the waves, in the same manner as the cone of Graham Island, in the Mediterranean, was swept away in 1831, and that of Nyöc, off Iceland, in 1783.* All that would remain in such cases, after the bed of the sea has been upheared and laid dry, would be dikes and shapeless masses of igne-

* See Princ. of Geol, Index, "Graham Island," "Nyöe," "Conglomerates, volcanic," \&c. 
ous rock, cutting through sheets of lava which may have spread over the level bottom of the sea, and strata of tuff, formed of materials first scattered far and wide by the winds and waves, and then deposited. Conglomerates also, with pebbles of trap, to which the action of the waves must give rise during the denudation of such volcanic islands, will emerge from the deep whenever the bottom of the sea becomes land. The proportion of volcanic unatter which is originally submarine must always be very great, as those volcanic vents which are not entirely beneath the sea are almost all of them in islands, or, if on continents, near the shore.

As to the absence of porosity in the trappean formations, the appearances are in a great degree deceptive, for all amygdaloids are, as already explained, porous rocks, into the cells of which mineral matter, such as silex, carbonate of lime, and other ingredients, have been subsequently introduced (see p. 601); sometimes, perhaps, by secretion during the cooling and consolidation of lavas.

In the Little Cumbray, one of the Western Islands, near Arran, the amygdaloid sometimes contains elongated cavities filled with brown spar; and when the nodules have been washed out, the interior of the cavities is glazed with the vitreous varnish so characteristic of the pores of slaggy lavas. Even in some parts of this rock which are excluded from air and water, the cells are empty, and seem to have always remained in this state, and are therefore undistinguishable from some modern lavas.:

Dr. MacCulloch, after examining with great attention those and the other igneous rocks of Scotland, observes, "that it is a mere dispute about terms, to refuse to the ancient eruptions of trap the name of submarine volcanoès; for they are such in every essential point, although they no longer eject fire and smoke." $\dagger$ The same author also considers it not improbable that some of the volcanic rocks of the same country may have been poured out in the open air.\$

Although the principal component minerals of subaërial lavas are the same as those of intrusive trap, and both the columnar and globular structure are common to both, there are, nevertheless, some volcanic rocks which never occur in currents of lava, such as greenstone, the more crystalline porphyries, and those traps in which quartz and mica appear as constituent parts. In short, the intrusive trap rocks, forming the intermediate step between lava and the plutonic rocks, depart in their characters from lava in proportion as they approximate to granite.

These views respecting the relations of the volcanic and trap rocks will be better understood when the reader has studied, in the $33 \mathrm{~d}$ chapter, what is said of the plutonic formations.

* MacCulloch, West. Islands, vol, ii. p. 487.

† Syst. of Geol., vol. ii. p. 114.

$\ddagger$ Ibid. 
EXTERNAL TORM, STRUCTURE, AND ORIGIN OF VOLCANIC MOUNTAINS.

The origin of volcanic cones with crater-shaped summits has been alluded to in the last chapter (p. 593), and more fully explained in the "Principles of Geology" (chaps. xxiv. to xxvii.), where Vesuvius, Etna, Santorin, and Barren Island are described. The more ancient portions of those mountains or islands, formed long before the times of history, exhibit the same external features and internal structure which belong to most of the extinct rolcanoes of still higher antiquity; and these last have eridently been due to a complicated series of operations, raried in kind according to circumstances; as, for example, whether the accumulation took place above or below the level of the sea, whether the lava issued from one or several contiguous vents, and, listly, whether the rocks reduced to fusion in the subterranean regions happen to have contained more or less silica, potash, soda, lime, iron, and other ingredients.

We are best acquainted with the effects of eruptions above water, or those called subaërial or supramarine; yet the products even of these are arranged in so many ways that their interpretation has given rise to a variety of contradictory opinions, some of which will have to be considered in this chapter.

Craters and Calderas, Sandwich Islands.-We learn from Mr. Dana's valuable work on the geology of the United States Exploring Expedition, published in 1849, that two of the principal volcanoes of Sandwich Islands, Mounts Loa and Kea in Oryhee, are buge flattened volcanic cones, about 14,000 feet high (see fig. 693), each equalling: two and a half Etnas in their dimensions.

Fig. 693.

\section{6}

\section{Mount Loa, in the Sandwich Islands. (Dana.)}

a. Crater at the summit.

b. The lateral crater at Kilanea.

The dotted lines indicate a supposed column of solid rock caused by the lava consolidating aiter eruptions.

From the summits of these lofty though featureless hills, and from vents not far below their summits, successive streams of lava, often 2 miles or more in width, and sometimes 26 miles long, have flowed. They have been poured out one after the other, some of them in recent times, in every direction from the apex of the cone, down slopes rarying on an arerage from 4 degrees to 8 degrees; but in some places considerably stecper. Sometimes deep rents are formed on the sides of those conical mountains, which are afterwards filled from above by streams of lara passing orer them, the liquid matter in such cases consolidating in the fissures and forming dikes.

The lateral crater of Kilauea, b, fig. 693, is between 3000 and 4000 feet above the sea-level, or about the height of Vesurius. It is an 
immense chasm, 1000 feet deep, and its outer circuit no less than from two to three miles in diameter. Lava is usually seen to boil up at the bottom in a lake, the level of which varies continually, for the liquid rises and falls several hundred feet according to the active or quiescent state of the volcano. But instead of overflowing the rim of the crater, as commonly happens in other vents, the column of melted rock, when its pressure becomes excessive, forces a passage through some subterranean galleries or rents leading towards the sea: Mr. Coan, an American missionary, has described an eruption which took place in June 1840, when the lava which had risen high in the great chasm began to escape from it. Its direction was first recognized by the emission of a vivid light from the bottom of an ancient wooded crater, called Arare, 400 feet deep and 6 miles to the eastward of Kilauea. The connection of this light with the discharge or tapping of the great reservoir was proved by a change in the level of the lava in Kilauea, which sank gradually for three weeks, or until the eruption ceased, when the lake stood 400 feet lower than at the commencement of the outbreak. The passage, therefore, of the fluid matter from Kilauea to Arare was underground, and it is supposed by Mr. Coan to have been at its first outflow 1000 feet deep below the surface. The next indication of the subterranean progress of the same lava was observed a mile or two from Arare, where the fiery flood broke out and spread itself superficially over 50 acres of land, and then again found its way underground for several miles farther towards the sea, to reappear at the bottom of a second ancient and wooded crater, which it partly filled up. The course of the fluid then became again invisible for several miles, until it broke out for the last time at a point ascertained by Captain Wilkes to be 1244 feet above the sea, and 27 miles distant from Kilauea. From thence it poured along for 12 miles in the open air, and then leapt over a cliff 50 feet high, and ran for three weeks into the sea. Its termination was at a place about 40 miles distant from Kilauea. The crust of the earth overlying the subterranean course of the lava was often traversed by innumerable fissures, which emitted steam, and in some places the incumbent rocks were uplifted 20 or 30 feet.

Thus in the same volcano examples are afforded of the overflowing of lava from the summit of a cone $2 \frac{1}{2}$ miles high, and of the underflowing of melted matter. Whether this last has formed sheets intercalated between the stratified products of previous eruptions, or whether it has penetrated through oblique or vertical fissures, cannot be determined. In one instance, however, for a certain space, it is said to have spread laterally, uplifting the incumbent soil.

The annexed section of the crater of Kilauea, as given by Mr. Dana, follows the line of its shortest diameter, $a, b$, which is about 7500 feet long. The boundary cliffs, $a, c$, and $b, d$, are for the most part quite vertical and 650 feet high. They are composed of compact rock in layers, not divided by scoriæ, some a few inches, others 30 feet in 


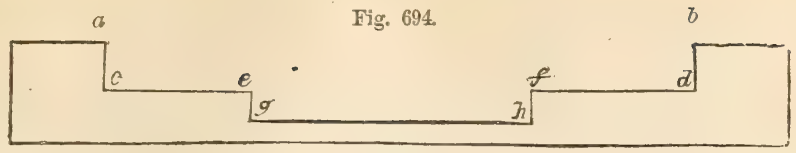

Section of the crater of Kilauea in the Sandwich Islands. (Dana.) $a, b$. External boundaries of the chasm in the line of its shortest diameter $c, e, f, d$. Black ledge.

$g, h$. Lake of lava.

thickness, and nearly horizontal. Before this, we come to what is called the "black ledge," $c, e$, and $f, d$, composed of similar stratified materials. This ledge is three hundred and forty-two feet in height above the lake of lava, $g$, $h$, which it encircles. The chasm, $a, b$, and its walls have probably been due to a former sinking down of the incumbent rocks undermined for a space by the fusion of their foundations. The lower ledge, $c, e$, and $f, d$, may consist in part of the mass which sank vertically, but part of it at least must be made up of layers of lava, which have been seen to pour one after the other over the "black ledge." If at any future period the heated fluid, ascending from the volcanic focus to the bottom of the great chasm, should augment in volume, and, before it can obtain relief, should spread itself subterraneously, it may. melt still farther the subjacent masses, and, causing a failure of support, may enlarge still more the limits of the amphitheatre of Kilauea. There are distinct signs of subsidences, from 100 to 200 feet perpendicular, which have occurred in the neighborhood of Kilauea at various points, and they are each bounded by vertical walls. If all of them were united, they would constitute a sunken area equal to eight square miles, or twice the extent of Kilauea itself. Similar accidents are also likely to occur near the summit of a dome like Monnt Loa, for the bydrostatic pressure of the lava, after it has risen to the edge or lip of the highest crater, $a$, fig. 693, must be great and must create a tendency to lateral fissuring, in which case lava will be injected into every opening, and may begin to undermine. If, then, some of the melted matter be drawn off by escaping at a lower level, where the pressure would be still greater, the whole top of the mountain, or a large part of it, might fall in.

Instances of such truncations, however caused, have occurred in Java and in the Andes within the times of history, and to such events we may perhaps refer a very common feature in the configuration of rolcanic mountains,-namelr, that the present actire cone of cruption is surrounded by the ruins of a larger and older cone, usually presenting a crescent-shaped precipice towards the newer cone. In rolcanoe long since extinct, the erosive power of running water, or, in certain cases, of the sea, mar have greatly molified the shape of the "atrium," or space between the older and newer cone, and the cavity may thereby be prolonged downwards, and end in a ravine. In such cases it may be impossible to determine how much of the missing rocks has been remored by explosion at the time when the original 
crater was active, or how much by subsequent engulphment and denudation.

Java.-One of the latest contributions to our knowledge of volcanoes will be found in Dr. Junghuhn's work on Java, where fortysix conical eminences of volcanic origin, varying in elevation from 4000 to nearly 12,000 feet above the sea, constitute the highest peaks of a mountain range, running through the island from east to west. All of them, with one exception, did this indefatigable traveller survey and map. In none of them could he discover any marine remains, whether adhering to their flanks or entering into their internal structure, although strata of marine origin are met with nearer the sea at lower levels. Dr. Junghuhn ascribes the origin of each volcano to a succession of subaërial eruptions from one or more central vents, whence scoriæ, pumice, and fragments of rock were thrown out, and whence have flowed streams of trachytic or basaltic lava. Such overflowings have been witnessed in modern times from the highest summits of several of the peaks. The external slope of each cone is generally greatest near its apex, where the volcanic strata have also the steepest dip, sometimes attaining angles of 20,30 , and 35 degrees, but becoming less and less inclined as they recede from the summit, until, near their base, the dip is reduced to 10 and often to 4 or 5 degrees.* The interference of the lavas of adjoining volcanoes sometimes produces elevated platforms, or "saddles," in which the layers of rock may be very slightly inclined. At the top of many of the loftiest mountains the active cone and crater are of small size, and surrounded by a plain of ashes and sand, this plain being encircled in its turn by what Dr. Junghuhn calls "the old crater-wall," which is often 1000 feet and more in vertical height. There is sometimes a terrace of intermediate height (as in the mountain called Tengger), comparable to the "black ledge" of Kilauea (fig. 694). Most of the spaces thus bounded by semicircular or more than semicircular ranges of eliffs are vastly superior in dimensions to the area of any known crater or hollow which has been observed in any part of the world to be occupied by a lake of liquid lava. As the Spaniards have given to such large cavities the name of Caldera (or cauldron), it may be useful to use this term in a technical sense, whatever views we may entertain as to their origin. Many of them in Java are no less than four geographical miles in diameter, and they are attributed by Junghuhn to the truncation by explosion and subsidence of ancient cones of eruption. Unfortunately, although several lofty cones have lost a portion of their height within the memory of man, neither the inhabitants of Java nor their Dutch rulers have transmitted to us any reliable accounts of the order of events which occurred. $\dagger$

Dr. Junghuhn believes that Papandayang lost some portion of its

* Java, deszelfs gedaante, bekleeding en invendige structuur, door F. Junghuhn. (German translation of $2 \mathrm{~d}$ edit. by Hasskarl, Leipzig, 1852.)

† See Principles of Geol., 9th edit., p. 493. 
summit in $177_{2}$; but affirms that most of the towns on its sides said to have been engulfed were in reality overflowed by lava.

From the highest parts of many Jaranese calderas rivers flow, which in the course of ages have cut out deep valleys in the mountain's side. As a general rule, the outer slopes of each cone are furrowed by straight and narrom ravines from 200 to 600 feet deep, radiating in all directions from the top, and increasing the number as we descend to lower zones. The ridges or "ribs" intervening between these furrows are very conspicuous, and compared to the spokes of an umbrella. In a mountain above 10,000 feet high, no furrows or intervening ribs are met with in the upper 300 or 400 feet. At the height of 10,000 feet there may be no more than 10 in number, whereas 500 feet lower 32 of them may be counted. They are all ascribed to the action of running water; and if they ever cut through the rim of a caldera, it is only because the cone has been truncated so low down as to cause the summit to intersect a middle region, where the torrents once exerted sufficient power to cause a series of such indentations. It appears from such facts, that, if a cone escapes destruction by explosion or engulfment, it may remain uninjured in its upper portion, while there is time for the excaration of deep ravines by lateral torrents.

It is remarked by Dr. Junghuhn, as also by Mr. Dana, in regard to the Pacific Islands, that volcanic mountains, however large and however much exposed to heavy falls of rain, support no rivers so long as they are in the process of growth, or while the highest crater emits from time to time showers of scorix and floods of lava. Such ejectamenta and such currents of melted rock fill up each superifial inequality or depression where water might otherwise collect, and are moreover so porous that no rill of water, however small, can be generated. But where the subterranean fires have been long since spent, or are mearly exhausted, and where the superficial scoriæ and lavas decompose and become corered with clarey soils, the erosire action of water begins to operate with a prodigious force, proportionate to the steepness of the declivities and the incoherent nature of the sand and ashes. Even the more solid lavas are occasionally cavernous, and almost almars alternate with scoriæ and perishable tuffs, so as to be readily undermined, and most of them are speedily reduced to fragments of a transportable size because they are divided by vertical joints or split into columns.

Canary Islands-Palma.-I have enlarged so fully in the "Principles of Geology" on the different views entertained by eminent authorities respecting the origin of rolcanic cones, and the laws governing the flow of lava, and its consolidation, that, in order not to repeat here what I have elsewhere published, I shall confine myself in the remainder of this chapter to the description of facts observed by me during an exploration of Madeira and some of the Canary Islands in 1853-'4. In these excursions, made in the winter of 1853-4, I was accompanied by an actire fellow-laborer, Mr. Hartung, 
of Konigsberg.* We visited, among other places, the beautiful island of Palma, a spot rendered classical by the description given of it in 1825 by the late Leopold Von Buch, who regarded it as a type of what he called a "crater of elevation."

Palma is 46 geographical miles west of Teneriffe. Seen from the channel which divides the two islands, Palma appears to consist of

Fig. 695.

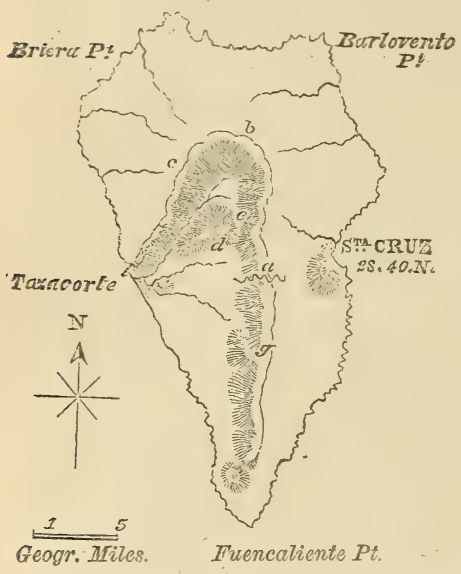

Map of Palma, from Survey of Capt. Vidai, R.N. two principal mountain masses, the depression between them being at the pass of Tacanda, or at $a$ (map, fig. 695), which is about 4600 feet above the ses level. The most northern o these masses makes, notwith standing certain irregularities hereafter to be mentioned, a considcrable approach in general form to a great truncated cone, having in the centre a huge and deep cavity called by the inhabitants "La Caldera." This cavity $(b, c, d, e$, fig. 695) is from 3 to 4 geographical miles in diameter, and the range of precipices surrounding it vary from about 1500 to 2500 feet in vertical height. From their base a steep slope, clothed by a splendid forest of pines, descends for a thousand and sometimes trro thousand feet lower, the centre of the Caldera being about 2000 feet above the sea. The northern half of the encircling ridge is more than 7000 English feet above the sea in its highest peaks, and is annually white with snow during the winter months.

Externally the flanks of this truncated cone incline outwards in every direction, the slopes being steepest near the crest, and lessening as they approach the lower country. A great number of ravines commence on the flanks of the mountain, a short distance below the summit, shallow at first, but getting deeper as they descend, and becoming at the same time more numerous, as in the cones of Java before mentioned.

So unbroken is the precipitous boundary-wall of the Caldera, except at its southwestern end, where the torrent which drains it through a deep gorge $\left(b, b^{\prime}\right.$, fig. 696$)$ issues, that there is not eren a footpath by which one can descend into it save at one place called the Cumbrecito (e, map, fig. 695). This Cumbrecito is a narrow col or watershed at the height of about 2000 feet above the bot-

\footnotetext{
* See Hartung, Geology of Madeira and Porto Santo. Leipzig, 1864.
} 
Fig. 696 ,

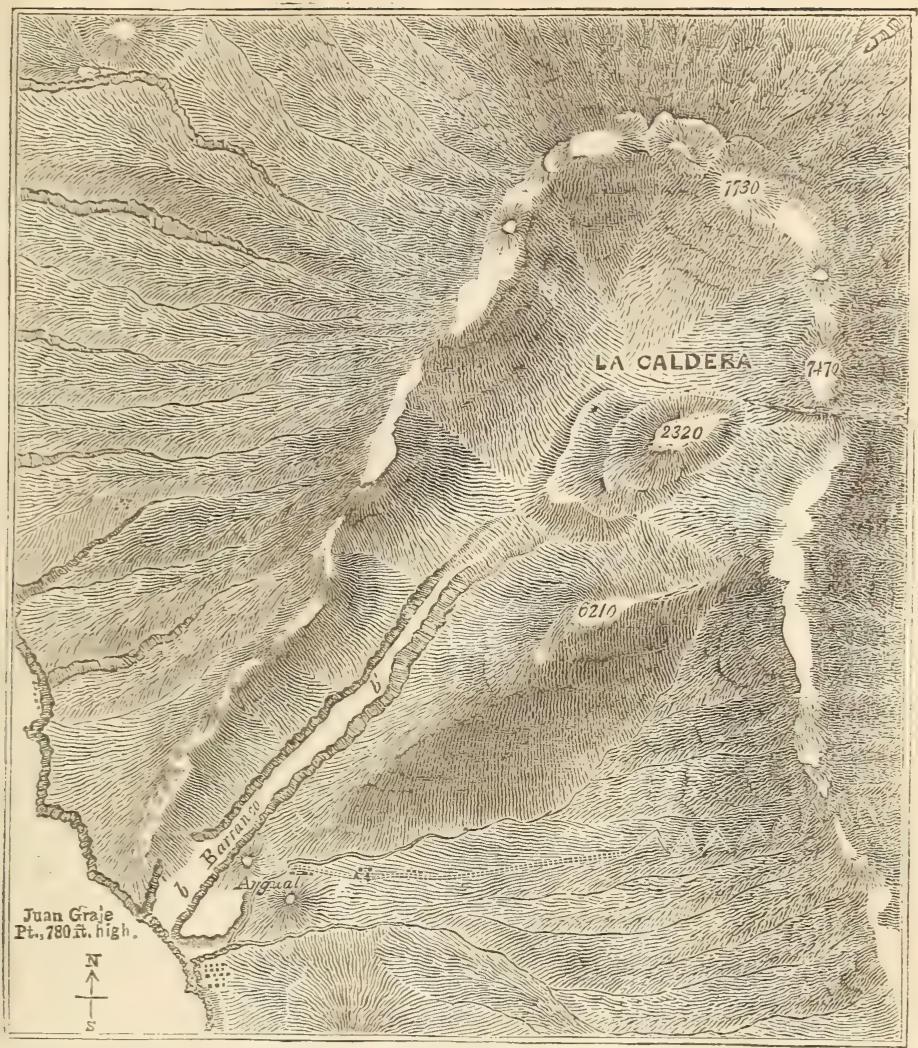

Nap of the Caldera of Palma and the great ravine, called "Barranco de las Angustias." From the Survey of Capt. Vidal, R. N., 1837. Scale, two geographical miles to an inch.

tom of the Caldera, and 4000 ahore the sea, and situated at the precise limit of two geological formations presently to be mentioned. This coi also occurs at the level where, in other parts of the Caldera, the rertical precipices join the talus-like, rocky slope, corered with pines. The other or principal entrance by which the Caldera is drained is the great ravine or barranro, as it is called (see $b, b^{\prime}$, fis: 696), which extends from the southrestem extremity of the Caldera to the sea, a distance of $\frac{1}{2}$ geographical miles, in which space the water of the torrent falls about 1500 feet.

This sketch ( $\mathrm{fg} .697$ ) was taken by Ton Buch from a point at sers not visited br us, but we saw enough to convince us that several latcral cones ought to have been introduced on the great slope to the left, besides numerous deep furrows radiating from near the sumnit to the sea (see the map, fig. 696). The sca does not enter the great Barranco, as might be inferred from this sketch. 
Fig. 697.

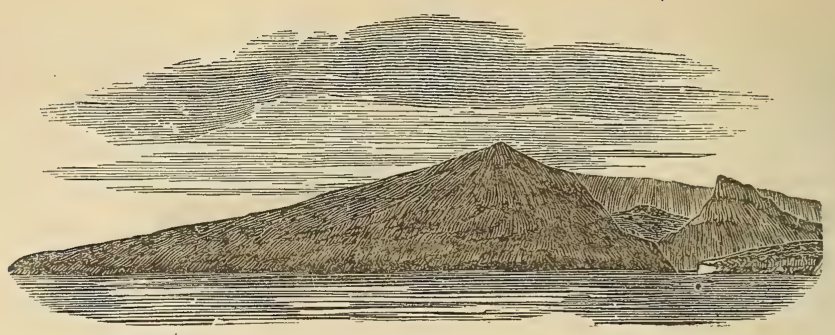

View of the Isle of Palma, and of the entrance into the central cavity or Caldera. From Von Buch's "Canary Islands."

The annexed section (fig. 698) passes through the island from Santa Cruz de Palma to Briera Point, or from southeast to northwest (see map, p. 628). It has been drawn up on a true scale of heights and horizontal distances from the observations of Mr. Hartung and my own.

Fig. 698.

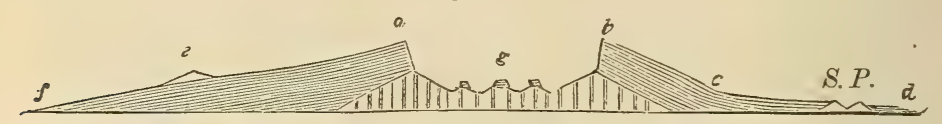

Section of the Island of Palma, from Point Briera, on the northwest, to Santa Cruz de Palma, on the southeast. See map, fig. 695, p. 628 .

$a, b$. The Caldera (height of $a, 6000$ feet).

c. Commencement of steeper dip.

d. Santa Cruz de Palma or Tedote.

e. Lateral cone, 3910 feet above the sea (Vidal's Map).

$f$. Briera Point.

g. One of several outliers of the upper formation in centre of Caldera.

S. P. Half-buried cone and crater of San Pectro.

The lavas are seen to be slightly inclined near the sea at Santa Cruz, where we observed them flowing round the cone of San Pedro, which they have more than half buried without entering the crater. On starting from the same part of the seacoast, and ascending the deep Barranco de la Madera, we saw just below $c$ the basaltic lavas dipping at an angle of 5 degrees, there being no dikes in that region. Farther up, where the dikes were still scarce, the dip of the beds increases to 10 and 15 degrees, and they become still steeper as they approach the Caldera at $b$, where dikes abound.

The section (fig. 699) is at right angles to the preceding, and euts through the cone in the direction of the great Barranco, or from northeast to southwest.

The lowest of the two slanting lines, $m, i$, descending from the Caldera to the sea along the bottom of the Barranco, represents the present bed of the torrent; the upper line, $k, l$, the height at which beds of gravel, elevated high above the present river-channel, are visible in detached patches, shown by dotted spaces at $k$, and to the southwest of it, on the same slope. These, and the continuous stratified 


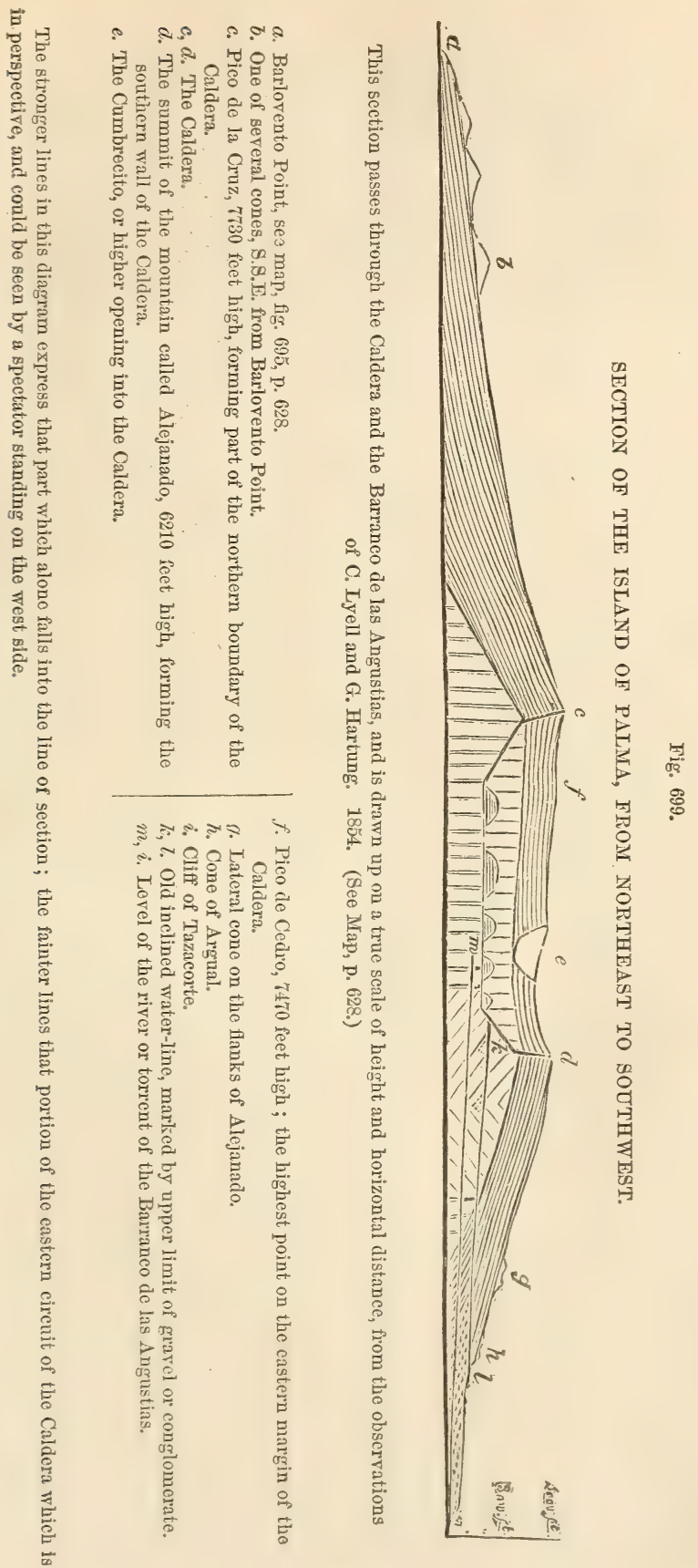


gravel and conglomerate lower down at $l$ and $i$, are newer than all the volcanic rocks seen in this section.

The upper volcanic formation, to be described in the sequel, is traversed by numerous dikes, which could not be expressed on this small scale. The vertical lines in the lower formation represent a few of the perpendicular dikes which abound there. Countless others, inclined and tortuous, are found penetrating the same rocks. The five outliers of somewhat pyramidal shape, at the bottom of the Caldera (on each side of $m$ ), agree in structure and composition with the upper formation, and may have subsided into their present position, if the Caldera was caused by engulfment, or may have slid down in the form of land-slips, if the cavity be attributed chiefly to aqueous erosion.

In the description above given of the section (fig.. 699), the cliffs which wall in the Caldera are spoken of as consisting of two formations. Of these the uppermost alone gives rise to rertical precipices, from the base of which the lower descends in steep slopes, which, although they have the external aspect of taluses, are not in fact made up of broken materials, or of ruins detached from the higher rocks, but consist of rocks in place. Both formations are of volcanic origin, but they differ in composition and structure. In the upper, the beds consist of agglomerate, scorix, lapilli, and lava, chiefly basaltic, the whole dipping outwards, as if from the axis of the original cone, at angles varying from 10 to 28 degrees. The solid lavas do not constitute more than a fourth of the entire mass, and are divided into beds of very variable thickness, some scoriaceous and vesicular, others more compact, and even in some cases rudely columnar. All these more stony masses are seen to thin out and come to an end wherever they can be traced horizontally for a distance of half or a quarter of a mile, and usually sooner. Coarse breccias or agglomerates predominate in the lower part, as if the commencement of the second series of rocks marked an era of violent gaseous explosions. Single beds of this aggregate of angular stones and scorix attain a thickness of from 200 to 300 feet. They are united together by a paste of volcanic dust or spongiform scorix.

At one point on the right side of the great Barranco, near its exit from the Caldera, we observed in the boundary precipice a lofty column of amorphous and scoriaceous rock in which the red or rustcolored scoriæ are as twisted and ropy as any to be seen on the slopes of Vesurius; seeming to imply that there was here an ancient vent or channel of discharge subsequently buried under the products of newer eruptions. Countless dikes, more or less vertical, consisting chiefly of basaltic lava, traverse the walls of the Caldera, some of them terminating upwards, but a great number reaching the very crest of the ridge, and therefore having been posterior in origin to the whole precipice.

We could not discover in any one of the fallen masses of agglomarate which strewed the base of the cliffs a'single pebble or water-worn 
fragment. Each imbedded stone is enther angular, or, if globular, consists of scorire more or less spongy, and evidently not owing its shape to attrition. It would be impossible to account for the absence of water-irorn pebbles if the coarse breccia in question had been spread by aqueous agency orer a horizontal area coextensire with the Caldera and the rolcanic iocks which surround it. The only cause known to us capable of dispersing such heary fragments, some of them 3 , 4 , or or 6 feet in diameter, without blunting their edges, is the porrer of steam, unless indeed re could suppose that ice had coöperated with water in motion; and the interference of ice cannot be suspected in this latitude $\left(28^{\circ} 40^{\prime}\right)$, especially as I looked in rain for sigus of glacial action here and in the other moumtainous regions of the Canary Islands.

The lower formation of the Caldera is, as before stated, equally of igneous origin. It differs in its prevailing color from the upper, exhibiting a tea-green and in parts a light yellow tint, instead of the usual brown, lead-colored, or reddish hues of basalt and its associated scorie. Beds of a light greenish tuff are common, together with trachrtic and greenstone rocks, the whole so reticulated by dikes, some vertical, others oblique, others tortuous, that me found it impossible to determine the general dip of the beds, although at the head of the great gorge or Barranco they certainly dip outrards, or to the south, as stated br Ton Buch. But in folloming the section domn the same rarine, where the mountain called Alejanado ( $d$, figs. pp. 628 and 631) is cut through, and where the rocks of the lower formation are very crystalline, we found what is not alladed to by the Prussian geologist, that the beds exposed to riew in cliffs 1500 feet high hare an anticlinal arrangement, exhibiting first a southerly and then a northerly dip at angles varying from 20 to 40 degrees (see section, fig. 699, at $k$ ). Hence we may presume that the older strata must have undergone great morements before the upper formation was superimposed. No organic remains haring been discorered in the older series, we cannot positirely decide whether it was of subaërial or submarine origin. We can only affirm that it has been produced by successive ertuptions, chieffy of felspathic laras and tuffs. Many beds which probably consisted at first of soft tuffs have been much hardened by the contact of dikes and apparently much altered by other plutonic influence, so that they hare acquired a semicrystalline and almost metamorphic character.

The existence of so great a mass of rolcanic rocks of ancient date on the exact site of an equally rast accumulation of comparatively modern laras and scorie is peculiarly worthy of notice as a general phenomenon observed in rery different parts of the globe. It proves that, notwithstanding the fact in the past history of volcanoes that one region after another has been for ages and has then ceased to be the chief theatre of igneous action, still the activity of subterranean heat may often be persistent for more than one geological period in 
the same place, relaxing perhaps its energies for a while, but then breaking out afresh with an intensity as great as ever.

We have still to consider the mode of origin of the higher volcanic mass, or the upper series of rocks with which the peculiar form of the Caldera is more intimately connected. The principal question here arising is this, whether the mass was dome-shaped from the beginning, having grown by the superposition of one conical enrelope of lava and ashes formed over another, or whether, as Von Buch and his followers imagine, its component materiáls were first spread out in horizontal or nearly horizontal deposits and then upheaved at once into a dome-shaped mountain with a caldera in its centre. According to the first hypothesis the cone was built up gradually, and completed with all its beds dipping as now, and traversed by all its dikes, before the Caldera originated. According to the other, the Caldera was the result of the same movements which gave a dome-shaped structure to the mass, and which caused the beds to be highly inclined; in other words, the cone and the Caldera were produced simultancously. So singularly opposite are these views, that the principal agency introduced by the one theory is upheaval, by the other the fall of matter from the air. The very name of "Elevation Craters" points to the kind of movement to which one school attributes the origin of a cone and caldera; whereas the chief agencies appealed to by the other are gaseous explosions, engulfment, and aqueous denudation.

The favorable reception of the doctrine of upheaval has arisen from the following circumstances: Streams of lava, it is said, which run down a declivity of more than three degrees, are never stony; and, if the slope exceed five or six degrees, they are mere shallow and narrow strings of vesicular or fragmentary slag. Whenever, therefore, we find parallel layers of stony lava, especially if they be of some thickness, high up in the walls of a caldera, we may be sure that they were solidified originally on a very gentle slope ; and if they are now inclined at angles of $10^{\circ}, 20^{\circ}$, or $30^{\circ}$, not only they, but all the interstratified beds of lapilli, scorix, tuff, and agglomerate, must have been at first nearly flat, and must have been afterwards lifted up with the solid beds into their present position. It is supposed that such a derangement of the strata could scarcely fail to give rise to a wide opening near the centre of upheaval, and in the case of Palma, the Caldera (which Von Buch called "the hollow axis of the cone") may represent this breach of continuity.

Among other objections to the elevation-crater theory often advanced and never yet answered are the following: First, in most calderas, as in Palma, the rim of the great cavity and the circular range of precipices surrounding it remain entire and unbroken on three sides, whereas it is difficult to conceive that a series of volcanic strata 2000 or 3000 feet thick could have once extended over an area six or seven miles in its shortest diameter and then have been upraised bodily, so that the beds should dip at steep angles towards all points 
of the compass from a centre, and yet that no great fractures should have been produced. We should expect to see some open fissures on every side, widening as they approach the Caldera. The dikes, it is true, do undoubtedly attest many dislocations of the mass, which have taken place at successire and often distant periods. But none of them can have belonged to the supposed period of terminal and paroxysmal uphearal, for, had the caldera existed when they originated, the melted matter now solidificd in each dike must, instead of filling a rent, have flowed down into the Caldera, tending so far to obliterate the great cavity.

The second objection is the impossibility of imagining that so vast a scries of agglomerates, tuffs, stratified lapilli, and highly scoriaceous lavas could have been poured out with a limited area without soon giving rise to a hill, and eventually to a lofty mountain. Such heavy angular fragments as are seen in the agglomerates, single beds of which are sometimes 200 or 300 feet thick, must, when hurled into the air have fallen down again near the vent, and would be arranged in inclined layers dipping outwards from the central axis of eruption. It is in perfect accordance with this hypothesis that we should behold agglomerate, lapilli, and scoriæ predominating in the walls of the Caldera; whereas in the ravines nearer the sea, where the inclination of the beds has diminished to 10 and even to 5 degrees, the proportion of stony as compared to fragmentary materials is precisely reversed. It is also natural that the dikes should be most numerous where the ejectamenta are to the more solid beds in the proportion of 3 to 1 , as at $b$, fig. 698, p. 630 ; while the dikes are few in number where the stony lavas predominate (as at $c$, ibid.). Many of the scoriaceous beds at $b$ may be the upper extremities of currents which became stony and compact when they reached $c$, and flowed over a more level country; but this suggestion cannot be assented to by the advocates of the uphearal theory, for it assumes the existence of a cone long before the time had arriced for the catastrophe which according to their views gave rise to a conical mountain.

If, however, we reject the doctrine that the beds were tilted by a morement postcrior to the accumulation of all the compact and fragmentary rocks, how are we to account for the steepness of the dip of some stony lavas high up in the walls of the Caldera? These masses are occasionally 50 or 100 feet thick, of lenticular shape, as seen in the cliffs from below, and to all appearance parallel to the associated layers of scorix and lapilli. But unfortunately no one can climb up and determine how far the supposed parallelism may be deceptive. The solid beds extend in general orer small horizontal spaces, and some of them may possibly be no other than intrusive lavas, in the nature of dikes, more or less parallel to the layers of ejectamenta. Such laras, when the crater was full, may have forced their way between highly inclined beds of scoria and lapilli. We know that lava often breaks out from the side or base of a cone, instead of rising: 
to the rim of the crater. Nevertheless one or two of the stony masses alluded to seemed to me to resemble lavas which had flowed out superficially. They may have solidified on a broad ledge formed by the rim of a crater. Such a rim might be of considerable breadth after a partial truncation of the cone. And some lavas may now and then have entirely filled up the atrium, or what in the case of Somma and Vesuvius is called the atrio del cavallo, that is to say, the interspace between the old and new cone. When by the products of new eruptions a uniform slope has been restored, and the two cones have blended into one (see $e, d, c$, fig. p. 645), the next breaking down of the side of the mountain may display a mass of compact rock of great thickness in the walls of a caldera, resting upon and covered by ejectamenta. Other extensive wedges of solid lava will be formed on the flanks of every volcanic mountain by the interference of lateral, or, as they are often termed, parasitic cones, which check or stop the downward flow of lava, and occasionally offer deep craters into which the melted matter is poured.

By aid of one or all the processes above enumerated we may certainly explain a few exceptional cases of intercalated stony beds, in the midst of others of a loose and scoriaceous nature, the whole being highly inclined. But to account for a succession of compact and truly parallel lavas, having a steep dip, we may suppose that they flowed originally down the flanks of a cone sloping at angles of from 10 to 15 degrees, or even much more, as in many active volcanoes. They may also have acquired subsequently a still steeper inclination, for it would be rash to assume the entire absence of local disturbances during the growth of a volcanic mountain. Some dikes are seen crossing others of a different composition, marking a distinctness in the periods of their origin. The volume of rock filling such a multitude of fissures as we see indicated by the dikes in Palma must be enormous; so that, could it be withdrawn, the mass of ejectamenta would collapse and lose both in height and bulk. The injection, therefore, of all this matter in a liquid state must have been attended by the gradual distension of the cone, the increase of which I have elsewhere compared botk to the exogenous and endogenous growth of a tree, as it has been affected alike by external and internal accessions.

But the acquisition of a steeper dip by such reiterated rendings and injections of a cone is altogether opposed to the views of those who defend the upheaval hypothesis, because it draws with it the conclusion that the slopes were always growing steeper and steeper in proportion as the cone waxed older and loftier. Once admit this, and it follows that the upper layers of solid lava must have conformed to surfaces already inclined at angles of 20 , or, in the case of the Caldera of Palma, 28 degrees.

For this reason the defenders of the upheaval hypothesis are consistent with themselves in assigning the whole movement by which 
the strata, whether solid or incoherent, have been tilted, exclusively to one terminal catastrophe. The whole development of subterranean force is represented as the last incident in every series of volcanic operations, the closing scene of the drama; and the sudden and paroxysmal nature of the catastrophe is inferred from the absence of all signs of successire and intermittent action so characteristic of the antecedent volcanic phenomena.

I have alluded to an opinion entertained by some able geologists, that no lava can acquire any degree of solidity if it flows down a declivity of more than three degrees. This doctrine I have, I think, proved in my memoir on Mount Etna * to be entirely erroneous. I have there shown, from observations made by me in 1857, that modern lavas, several of them of known date, have formed continuous beds of compact stone on slopes of 15,36 , and 38 degrees, and, in the case of the lava of 1852 , more than 40 degrees. The thickness of these tabular layers varies from $1 \frac{1}{2}$ foot to 26 feet; and their planes of stratification are parallel to those of the overlying and underlying scoriæ which form part of the same currents.

There are some lavas northeast of Fuencaliente, at the southern extremity of Palma, so modern as to be still black and uncovered with regetation, which descend slopes of no less than 22 degrees, and yet contain large masses of compact stone, formed chiefly on the sides of tunnel-shaped cavities, 15 or 20 feet deep, in which one layer has solidified within another on the walls of these channels, while in the central part the lava seems to have remained fluid so as to run out of the tumnel, learing an arched carity, the roof of which has in most cases fallen in. The strength of the enveloping crust of scoria at the lower end of a lava-current in which one of these tunncls existed, may have been sufficient to arrest the progress of the stream for hours or days, and during that time solidification may hare occurred under great hydrostatic pressure.

Before taking leave of Palma, we have yet to consider another distinct point, namely, what amount of denudation has taken place in the Caldera and its environs. Assuming that the great cavity or some part of it may have originated in the truncation of a cone in the manner before suggested, to what extent has its shape been subsequently enlarged or modified by aqueous erosion? It will be remembered that a conglomerate of well-rounded pebbles, no less than 800 feet thick, was spoken of as risible in the great Barranco (see description of section, pp. 630-632). That conspicucus deposit, 3 or 4 miles in length, was eridently derived from the destruction of rocks like those in the Caldera, for the present torrent brings down annually similar stones of erery size, some very large, and rounds them by attrition in its channel. By what changes in the configuration of the island after the old volcano and its Caldera were formed was so rast a thickness of 
gravel formed, to be afterwards cut through to a depth of 800 feet? The ravine through which the torrent now flows has been excavated to that depth through the old conglomerate. The occurrence of two or three layers of contemporaneous lava, intercalated between the strata of puddingstone, ought not to surprise us; for even in historical times eruptions have been witnessed in the southern half of Palma. Such basaltic lavas, one of them columnar in structure, had not come down from the Caldera, but from cones much nearer the sea, and immediately adjoining the Barranco, like the cone of Argual (see map, p. 629) and others. These lavas, of the same age as the conglomerate, consist of three or four currents of limited extent, for in many parts of the rivercliffs no volcanic formation is visible on either bank. On the right bank of the Barranco, the conglomerate, when traced westward, is soon found to come to an end as it abuts against the lofty precipice $\mathrm{E}$ (fig.
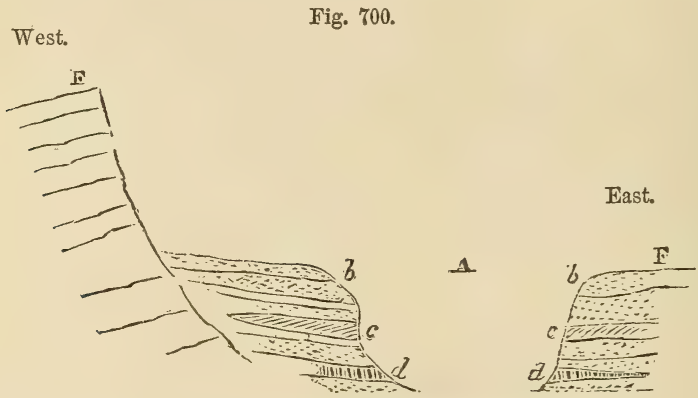

A. Ravine or Barranco de las Angustias, near its termination in Palma.

$b, b^{\prime}, b^{\prime \prime}$. Conglomerata, 800 feet thick in parts.

$c, c^{\prime}$. Lava intercalated between the beds of conglomerate.

$d, d^{\prime}$. Another and older current of basaltic lava, columnar in parts.

E. Cliff of ancient volcanic rocks of the Upper Formation (p. 634), a prolongation of the western wall of the Caldera.

F. Platform on which the town of Argual stands.

$700)$, which is a prolongation of the western wall of the Caldera. Its extent eastward from $b$, may be more considerable, but cannot be ascertained, as it is concealed under modern scoriæ and lava spread over the great platform, $\mathrm{F}$.

As we could find no organic remains in the old gravel, we have no positive means of deciding whether it be fluviatile or marine. The height of its base above the sea, where it is 800 feet thick, may be about 350 feet, but patches of it ascend to elevations of 1000 and 1500 feet near the top of the Barranco, as shown at $k$, \&c., in section, fig. 699 p. 631. Such a mass of gravel, therefore, bears testimony to the removal of a prodigious amount of materials from the Caldera by the action of water. Whatever may have been the mode of transportation, it is obvious that a large portion of the volcanic materials, consisting of sand, lapilli, and scoriæ, before described (p. 632) as belonging to the upper formation in the Caldera, would leave behind them few pebbles. Nearly all of these perishable deposits 
would be swept dorm in the shape of mud into the Atlantic. Even the hard rounded stones, since they were once angular and are now ground down into pebbles, must have lost more than half thcir original bulk, and bear witness to large quantities of sedimentary matter consigned to the bed of the ocean. We saw in the Caldera blocks of huge size thrown down by cascades from the upper precipices during the melting of the snows, a fortnight before our risit, and much destruction was likewise going on in the lower set of rocks by the same agency. The also learned that a great flood rushed down the Barranco in the spring of 1854 , shortly before our arrival, damaging several houses and farms, and I have therefore no doubt that the erosive power eren of rain and river water, aided by earthquakes, might in the course of ages cmpty out a valley as large as the Caldera, although probably not of the same shape. I am disposed to attribute the circular range of cliffs surrounding the Caldera to volcanic action, because they forcibly reminded me of the precipices encircling three sides of the Val del Bove, on Etna; and because they agree so well with Junghuhn's description of the "old crater-walls" of active volcanoes in Java, some of which equal or surpass in dimensions even the Caldera of Palma. The latter may have consisted at first of a true crater, enlarged afterwards into a caldera by the partial destruction of a great cone; but, if so, it has certainly been since modined by denudation. Nor can any geologist now define how much of the work has been accomplished by aqueous, and how much by volcanic agency. The phenomenon of a river cutting its channel through a dense mass of ancient allurium formed during oscillations in the level of the land is not confined to volcanic countries, and I need not dwell here on its interpretation, but refer to what was said in the seventh chapter. (See p. 84.)

There remains, however, another question of high theoretical interest; namely, whether the denudation was marine or fluviatile. It was stated that the materials of the great cone or assemblage of cones in the north of Palma are of subaërial origin, as proved by the angularity of the fragments of rock in the agglomerates; but it may be asked, whether, when the Caldera was formed long afterwards, it may not, like the crater of St. Paul's (fig. 702, p. 613), have had a communication with the sea, which may have entered by the great Barranco, and if, after a period of partial submergence, the island may not then have risen again to its original altitude. In such a case the retiring waters might leare behind them a conglomerate, partly of river-pebbles, collected at the points where the torrent successively entered the sea, and partly of stones rounded by the wares. The torrent may have finally cut a deep ravine in the gravel and associated lavas when the land was rising again. Such oscillations of level, amounting to more than 2000 fect, would not be deemed improbabie by any geologists, prorided they enable us to explain more naturally than by any other causation, the origin of the physical outlines of the 
country. As to the fact that no marine shells have yet been discovered in the conglomerate, sufficient search has not yet been made for them to entitle us to found an argument on such negative evidence. At the same time I confess that, having found sea-shells and bryozoa abundantly in certain elevated marine conglomerates in the Grand Canary, before I visited Palma, and being unable to meet with any in the Barranco de las Angustias, I regarded the old gravel when I was on the spot as of fluviatile origin. Such inferences are always doubtful in the absence of more positive data, and the intervention of the sea might perhaps account for some phenomena in the configuration of the Caldera and Barranco more naturally than river action. For example, we have the lofty cliff $\mathrm{E}$, fig. 700, p. 638 , already mentioned, and $c, f$, map, p. 628, extending four or five miles from the Caldera to the sea on the right bank of the Barranco, and no cliff of corresponding height or structure on the other bank, where for miles towards the southeast there is the platform F, fig. 700, p. 638, supporting several minor volcanic cones. The sea might be supposed to leave just such a cliff as $\mathrm{E}$, after cutting away a portion of the southwestern eXtremity of the old dome-shaped mountain in the north of Palma, whereas a torrent or river might be expected to leave a cliff of similar structure and nearly equal height on both. As to the fact of the old conglomerate ascending an inclined plane, $i, l, k, p .631$, from the sealevel to an elevation of about 1500 feet, near the entrance of the Caldera, this is by no means conclusive in favor of fluviatile action, although some elevated patches of the same may in truth belong to an old river-bed; but in South America gravel-beds of marine origin have a similar upward slope, when followed inland, and the cause of such an arrangement has been explained in a satisfactory manner by Mr. Darwin."

Another argument in favor of marine denudation may be derived from that peculiar feature in the configuration of Palma, before alluded to, called the pass of the Cumbrecito (e, fig. 699, p. 631), forming a notch in the uppermost line of precipices surrounding the Caldera. This break divides the mountain called Alejenado, $d$, p. 631, from the eastern wall, $c, f$, and cuts quite through the upper formation; yet the range of precipice, $f, e$, on the eastern side of the Caldera is continued uninterruptedly, and retains its full height of 1500 or 2000 feet above its base, to the southward of the Cumbrecito, or from $e$ towards $\alpha$, map, fig. 695, p. 628. In this prolongation of the cliff for half a mile southward, beds of volcanic matter and dikés are seen, as in the walls of the Caldera.

The indentation forming the pass of the Cumbrecito, e, p. 631, has more the appearance of an old channel, such as a current of water may have excavated, than of a rent or a chasm caused by a fault. In case of a fault the lower formation would not be persistent and uninter- 
rupted across the Cumbrecito, constituting the watershed; but would have sunk down and hare been replaced by the upper basaltic rocks. If we could assume that the sea once entered the Caldera here as well as by the great Barranco, it might have produced such a breach as $e$, and such an extension of the line of cliffs as that now observable betreen $e$ and $a$, map, p. 628, without any corresponding clifi to the westward of $e, a$.

Yet me could discorer no elerated outliers of conglomerate to attest the supposed erosion at the Cumbrecito, which is about 3500 feet abore the lerel of the sea. It might also be objected to the hypothesis of marine denudation in Palma, that there are no ranges of ancient sea-cliffs on the external slopes of the island. The flanks of the mountain, except where it is furromed by ravines or broken by lateral cones, descend to the sea with a uniform inclination. In reply to such a remark, I may observe that we do not require the submergence of the uppermost 3000 feet of the old cone in order to allow the sea to enter both the great Barranco and the Cumbrecito and to flow into the Caldera. It would be enough to suppose the land to sink down so as to permit the rares to mash the base of the basaltic cliffs in the interior of the Caldera, and to rear a passage through the Cumbrecito where there may have been always a considerable depression in the outline of the upper formation. But would not the same wares which had power to form in the Barranco a mass of conglomerate 800 feet thick hare left memorials of their beach-action on the external slope of the island? No such monuments are to be seen, and their absence raises an objection of no small weight against the supposition of the sea having ever entered the Caldera. It may, however, be said, in explanation, first, that cliffs are not so easily cut on the side of an island towards which the beds dip as on the side from which they dip; secondly, if some small cliff's and sea-beaches had existed, they may have been subsequently buried under showers of ashes and currents of lava proceeding from lateral cones during eruptions of the same date as those which were certainly contemporaneous with the conglomerate of the great Barranco.

On the eastern coast of Palma, about half a mile from the sea, in the ravine of Las Nieves, not far from Santa Cruz, we observed a conglomerate of well-rounded pebbles haring a thickness of 100 feet, corered by successive beds of lava, also about 100 feet thick. In this instance the ancient grarel beds oceupy a position rery analogous to the buried cone, s, P, fig. 698, p. 630 . When in Palma, I conceived them to be of fluriatile origin; but, whether marine or freshwater, it must be admitted that the superposition of so dense an accumulation of laras to a mass of conglomerate 100 fect thick shows how easily the outer slopes of the island may have been denuded by the sea and yet displar no supericial signs of marine denudation, erery old beach or delta once at the mouth of a torrent being concealed under newer volcanic outpourings. At the same time I should state that M. 
Hartung and I, when in Palma, came to the conclusion that the waves of the sea had never reached the Caldera, although they may have penetrated for some distance into the Barranco de las Angustias, and may have overflowed the space now overspread by certain strata of conglomerate to the east of the Barranco.

Since the cessation of volcanic action in the north of Palma, the most frequent eruptions appear to have taken place in a line running north and south, from $a$ to Fuencaliente, map, p. 628 ; one of the volcanoes in this range, called Verigojo, $g$, being no less than 6565 English feet high. The lavas descending from several vents in this chain reach the sea both on the east and west coast, and are many of them nearly as naked and barren of vegetation as when they first flowed. The tendency in volcanic vents to assume a linear arrangement, as seen in the volcanoes of the Andes and Java on a grand scale, is exemplified by the cones and craters of this small range in Palma. It has been conjectured that such linearity in the direction of superficial outbreaks is connected with deep fissures in the earth's crust communicating with a subjacent focus of subterranean heat.

By discussing at so much length the question whether the sea may or may not have played an important part in enlarging the Caldera

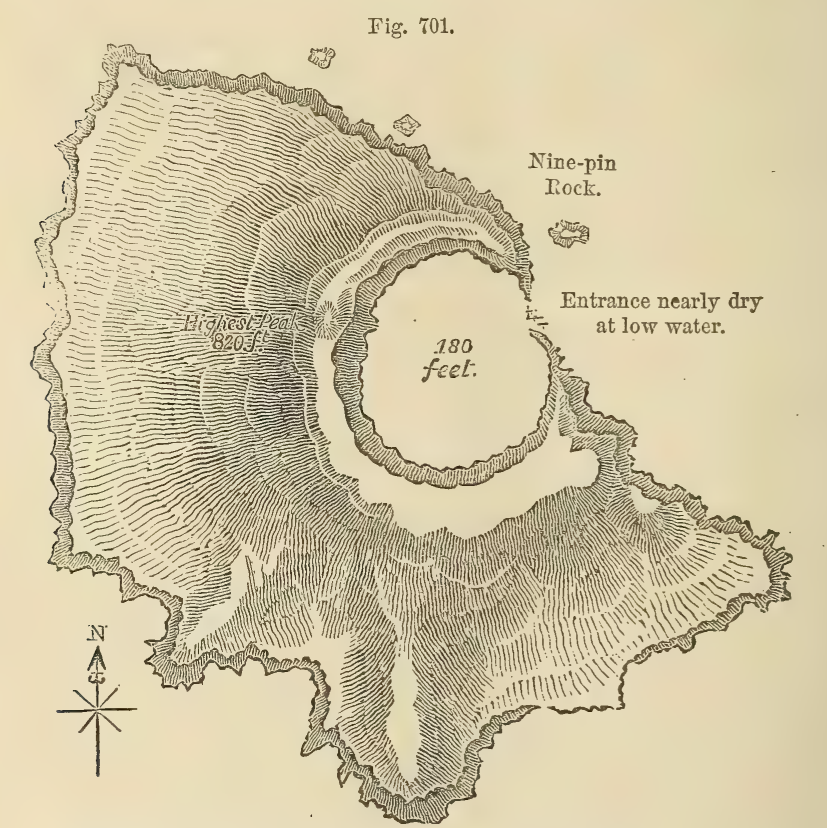

Map of the Island of St. Paul, in the Indian Ocean, lat. $38^{\circ} 44^{\prime}$ \$., long. $77^{\circ} 37^{\prime} \mathrm{E}_{\text {.g }}$ surveyed by Capt. Blackwood, R. N., 1842.

of Palma, I have been desirous at least to show how many facts and observations are required to explain the structure and configuration 
of such rolcanic islands. It may be uscful to cite, in illustration of the same subject, the present geographical condition of St. Paul's or Amsterdam Island, ii the Indian Occan, midway between the Cape of Good Hope and Australia.

In this case the crater is only a mile in diameter, and 180 feet deep, and the surrounding cliffs were loftiest about 800 feet high, so that in regard to size such a cone and crater are insignificant when compared to the cone and Caldera of Palma or to such volcanic domes as Mounts Loa and Kea in the Sandwich Islands. But the Island of St. Paul exemplifies a class of insular rolcanoes into which the ocean now enters by a single passage. Every crater must almost

Fig. 702 .

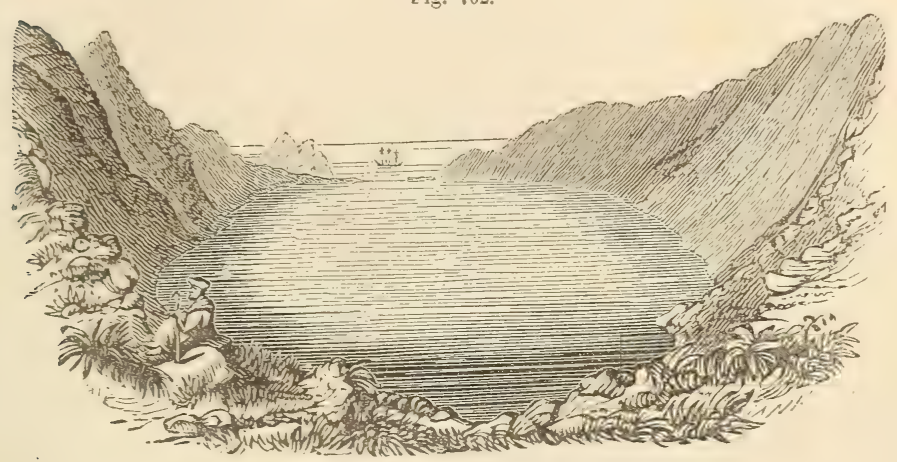

View of the Crater of the Island of St. Paul.

Fig. 703.

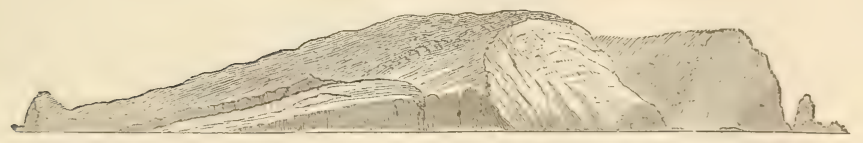

Side view of the Island of St. Panl (N. E. side). Nine-pin Rocks two miles distant. (Captain Blackwood.)

infariably hare one side much lower than all the others, namely, that side towards which the prerailing winds nerer blow, and to which, therefore, shotrers of dust and scorix are rarely carried during eruptions. There will also be one point on this windward or lowest side more depressed than all the rest, by which, in the erent of a partial submergence, the sea may enter as often as the ticie rises, or as often as the wind blows from that quarter. For the same reason that the sea continues to keep open a single entrance into the lagoon of an atoll or annular coral recf, it will not allow this passage into the crater to be stopped up, but will scour it out at low tide, or as often as the wind changes. The channel, therefore, will always be deepened in proportion as the island rises abore the level of the sea, at the rate perhaps of a few feet or yards in a century. 


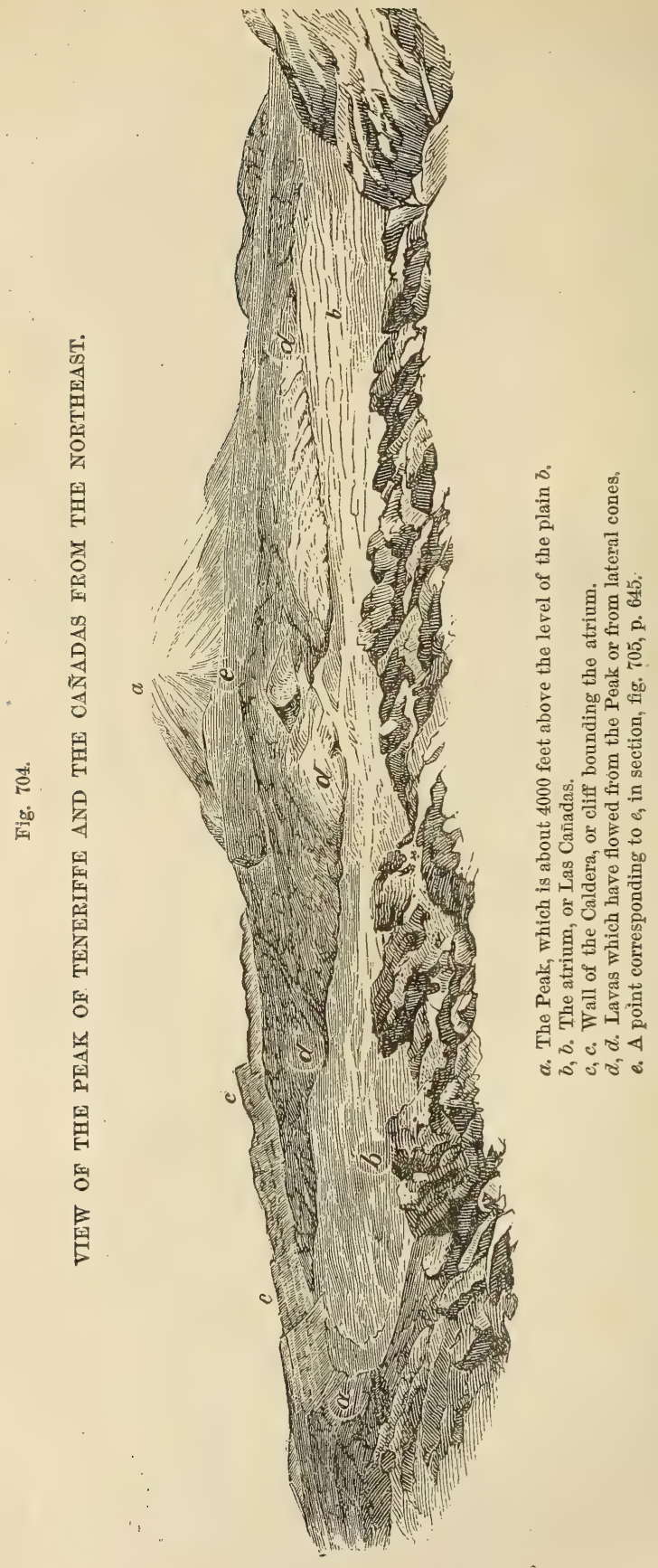


The crater of Vesurius in 1822 was 2000 feet deep; and, if it were a half-submerged cone like St. Paul, the excavating power of the ocean might, in conjunction with a gradual upheaving force, give rise to a large caldera. Whatever, thereiore, may have been the nature of the forces, igneous or aqueous, which hare shaped out the Tal del Bore on Etna, or the deep abyss called the Caldera in the north of Palma, we mar well conceire that some craters may have been enlarged into calderas by the denuding power of the ocean, whenerer considerable cscillations in the relative level of land and sea have occurred.

Peak of Teneriffe.-The accompanying riew of the Peak, taken from sketches made by II. Hartung and myself during our visit to Teneriffe in 185t, will show the manner in which that lofty cone is encircled on more than two sides by what I consider as the ruins of an older cone, chiefly formed by eruptions from a summit which has disappeared. That ancient culminating point from which one or more craters probably poured forth their lavas and ejectamenta may not hare been placed precisely where the present peak now rises, and mar not hare had the same form, but its position was probably not materially different. The great wall or semicircular range of precipices, $c, c$, surrounding the atrium, $b, b$, is obriously analogous to the walls of a Caldera like that of Palma; but here the cliffs are insignificant in dimensions when compared to those in Palma, being in general no more than 500 feet high and rarely exceeding 1000 feet. The plain or atrium, $b, b$, figs. 704 and 705 , lying at the base of the cliffs, is here called Las Cañadas, and is corered with sand and pumice thrown out from the Peak or from craters on its flanks. Copious streams of lara, $d, d$, hare also flowed down from lateral openings, especially from a crater called the Chahorra, $f$, fig. 705 , which is not seen in the view, fig. 704, as it is hidden by the Peak. The last eruption was as late as the year 1798 .

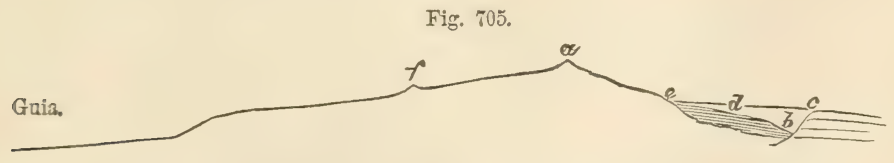

S.W.

Section through part of Teneriffe, from N.E. to S.W. On a true scale; as given in Von Buch's "Canary Islands."

a. Peak of Teneriffe.

b. The Cañadas or atrium.

c. Cliff bounding the atrium.
N.E.

d. Modern lavas.

$f$. Cone and crater of Chahorra.

To what extent the lavas, $d$, $d$, figs. 704 and 705 , may have narromed the circus or atrium, $b$, or talien away from the height of the cliff, $c$, no geologist can determine for want of sections; but should the Peak and the Chahorra continue to be active rolcanoes for ages, the new cone, $a$, might become united with the old one, and the lava 
might flow first from $e$ to $c$, and then from $a$ to $c$, fig. 705 , so that the slope might begin to resemble that formed by lavas and ejectamenta from the summit $\alpha$ to Guia, on the southwestern side of the cone.

Madeira.-Every volcanic island, so far as I have examined them, varies from every other one in the details of its geographical and geological structure so greatly that I have no expectation of finding any simple hypothesis, like that of "elevation craters," applicable to all, or capable of explaining their origin and mode of growth. Few islands, for example, resemble each other more than Madeira and Palma, inasmuch as both consist mainly of basaltic rocks of subaërial origin, but, when we compare them closely together, there is no end to the points in which they differ.

The oldest formation known in Madeira is of submarine volcanic origin, and referable to the Upper Miocene tertiary epoch, as will be explained in Chap. XXXI., p. 665. To this formation belong the tuffs and limestones containing marine shells and corals which occur at $\mathrm{S}$. Vicente on the northern coast, where they rise to the height of more than 1300 feet above the sea. They bear testimony to an upheaval to that amount, at least since the commencement of volcanic action in those parts.

The pebbles in these marine beds are well rounded and polished, strongly contrasting in that respect with the angular fragments of similar varieties of volcanic rocks so frequent in the superimposed tuffs and agglomerates formed above the level of the sea.

The length of Madeira from east to west is about 30 miles, its greatest breadth from north to south being 12 miles. The annexed section, fig. 705, drainn upon a true scale of heights and horizontal distances from the observations of M. Hartung and myself, will enable the reader to comprehend some of the points in which, geologically considered, Madeira resembles or varies from Palma. In the central region, at $\mathrm{A}$, as well as in the adjoining region on each side of it, are seen, as in the centre of Palma, a great number of dikes penetrating through a vast accumulation of ejectamenta, c. Here also, as in Palma, we observe as we recede from the centre, that the dikes decrease in number, and beds of scoriæ, lapilli, agglomerate, and tuff begin to alternate with stony lavas, $d, d$, until at the distance of a mile or more from the central axis the volcanic mass, below $f, h$, and $e, g$, consists almost exclusively of streams or sheets of basalt, with many red partings of laterite or red ochreous clay. These red beds vary in thickness from a few inches to two or three feet, and consist sometimes of layers of tuff, sometimes of ancient soils derived from decomposed lava, both of them burnt to a brick-red color, and altered by the contact of melted matter which has flowed over them. Some of these bands are represented in fig. 706, by interrupted lines, ...-. The darker divisions with vertical cross-bars flowed on the surface. Had there been room, many more alternations of such lavas would have been introduced. They consist chieflv of 
basalts more or less vesicular, and in some places of trachyte. The lighter tint, $c$, expresses an accumulation of scoriæ, agglomerate, and other materials, such as may have been piled up in the open air, in or around the chief orifices of eruption, and between volcanic conos. This older formation, though represented by an uniform tint, is by no means an amorphous mass, but is separated into innumerable layers which dip towarts all points of the compass, so that their mode of arrangement could not be expressed in a small diagram.

The Pico Torres, A, more than 6000 feet high, is one of many central peaks, composed of ejected materials. By the union of the foundations of many similar peaks, ridges or mountain crests are formed, from which the tops of rertical dikes project like turrets above the weathered surface of the softer beds of tuff and scoriæ. Hence the broken and picturesque outline, giving a singular and romantic character to the scenery of the highest part of Madeira. North of $A$ is seen Pico Ruivo (В), the most elevated peak in the island, yet.exceeding by a few feet only the height of Pico Torres. It is similar in composition, but its uppermost part, 300 feet high, retains a more perfectly conical form, and has a dike of basalt with olivene at its summit, with streams of scoriaceous lava adhering to its steep flanks. There are a great many such peaks east and west of $A$, which seem to be the rins of cones of eruption, the materials of some at least having: been arranged with a quâ-quâversal dip. Among. these is Pico Grande, c, fig. 708, now half-buried under more modern lavas which have flowed round it.

It will be seen that the beds of lava in the central region between $e$ and $f$ (fig. 706, p. 648) are nearly horizontal, or have a dip of no more than from three to five degrees, whereas the angle of slope of the beds between $f$ and $l_{i}$ is often serenteen degrees on the southern flank, and usually as much as ten on the northern, or between $e$ and $g$. The moderate inclination of the laras between $B, A$, and $R$ has been caused by the juxtaposition of a multitude of cones which have prerented the streams of melted matter from floming freely from the main axis or lava-shed towards the sea, whether in a north or south direction. The marked prolongation of this gentle slope on both sides of $\mathrm{R}$, and from $\mathrm{R}$ to $f$, may be attributed to the fact that below $f$ there is a rery ancient ridge of erupted materials, $c$, which has formed a barricr intercepting the free passage of the central laras to the sea. Between this secondary buried chain above $c$ or below $f$, and the higher central chain of scorie below $A$, the valley or carity, $d, s$, was filled up with horizontal beds of lava, over which an enormous mass of other sheets of basalt and deposits of tuff, from $d$ to $\mathrm{R}$ and from $\mathrm{R}$ to $f$, $\pi$ cre afterwards accumulated, until at last an aggregate thickness of 3500 feet of stratified materials was formed. Sections of this vast accumulation are exposed to riew in nearly rertical precipices in the deep ralley called the Curral. But when the lavas had surmounted the ancient ridge below $f$, and were no more obstructed in their sea- 


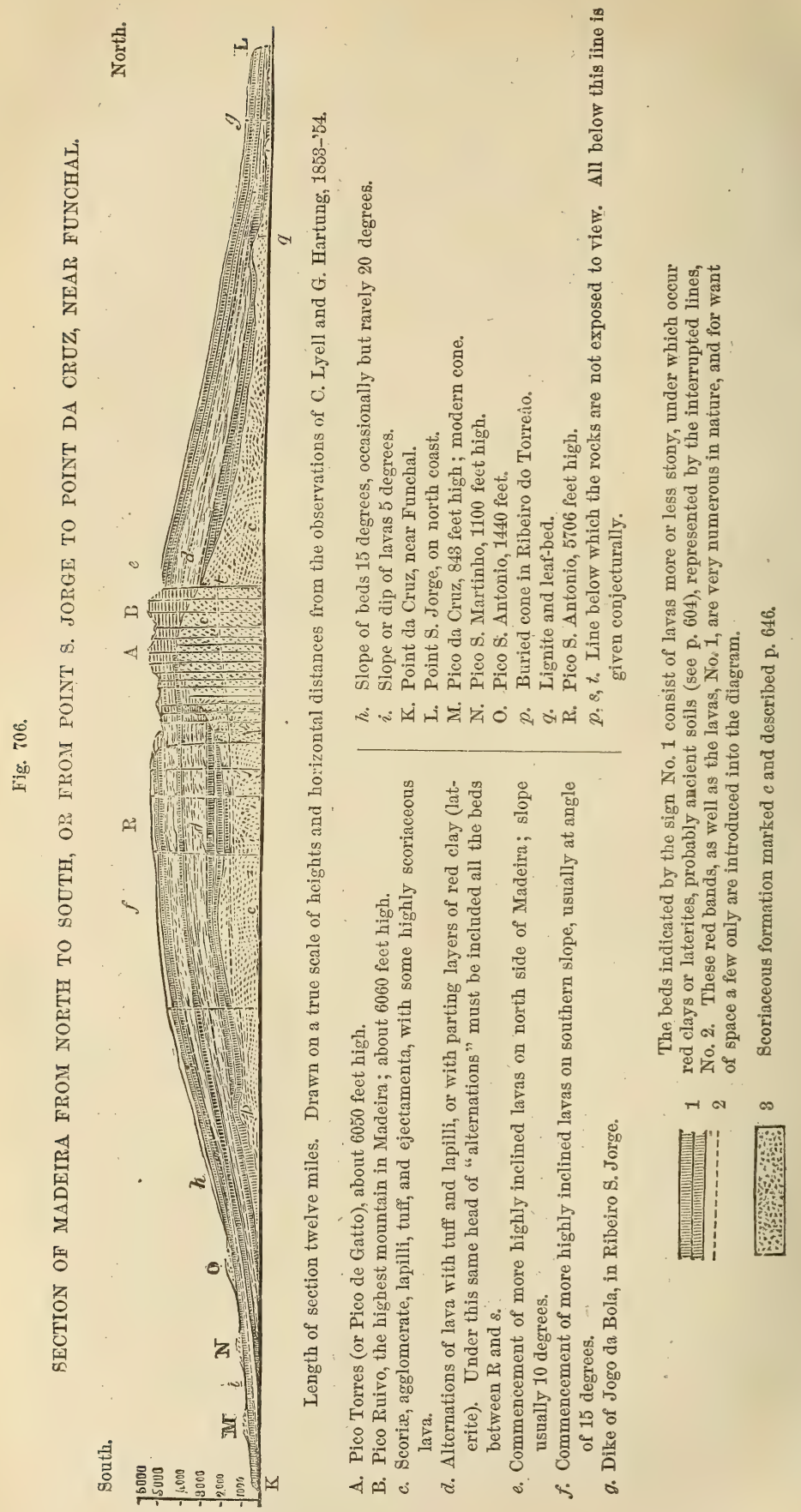


ward course, they flowed with a steep inclination, often at an angle of 17 degrees, tomards the south. Nearer the sea, as at $i$ and $\mathrm{L}$, on both sides of the island, where the most modern laras occur, the dip diminishes to $\check{5}$ degrees, and eren to $3 \frac{1}{2}$, as at $\mathrm{k}$, near Funchal. In this latter characteristic (the smaller inclination of the laras near the sea, and their association there with modern cones of eruption, such as ir, $x, 0$ ) there is a strict analogy between Madeira and Palma. Distinct buried cones of eruption also occur at many points, as at $p$ and $q$, fig. 706, which hare been orerwhelmed by lavas flowing from the central region.

As a general rule, the laras of Madeira, whether resicular or compact, do not constitute continuous sheets parallel to each other. Then riemed in the sea-cliffs in sections transrerse to the direction in which they flowed, they rary greatly in thickness, even if followed for a fer hundred feet or yards, and they usually thin out entirely in less than a quarter of a mile. In the ravines which radiate from the centre of the island, the bea's are more persistent, but eren here they usually are seen to terminate, if followred for a fer miles; their thickness also being rery rariable, and sometimes increasing suddenly from a few feet to many yards.

We saw no remains of fossil plants in any of the red partings or laterites abore alluded to; but Mr. Smith, of Jordanhill, was more fortunate in 1810, haring met with the carbonized branches and roots of shrubs in some red clars under basalt near Funchal. Nerertheless, M, Hartung and I obtained satisfactory eridence in the northern part of the island, in the rarine of S. Jorge, of the former existence of terrestrial regetation, and consequently of the subaërial origin of a large portion of the laras of Madeira. At $q$ in the section (fig. 706) the occurrence of a bed of impure lignite, corered by basalt, had long been known. Associated with it we obserred sereral layers of tuff and clay or hardened mud, $\mathrm{m}$ one of which leaves of aicotyledonous plants and of ferns abound. Sir Charles J. F. Bunbury, who was with me in Madeira during the winter of 1853-'4, at once pronounced one of the fossil ferns to agree in its peculiar rernation mith Woodwardia radicans, a species now common in Madeira; and he afterrards discorered the common Madeira fern, Davallia Canariensis, and a NTephrodium, and other ferns among the fossil remains. He also pointed out that, among the dicotrledonons leares, some were of the mrrtle family, the larger propor tion haring their surfaces smooth and unminkled, with a somewhat rigid and coriaceous texture, and with undirided or entire margins. "These characters," obserred Sir C. Bunburr, "belong to the laureltrpe, and indicate a certain analogy betrreen the ancient regetable remains and the modern forests of Madeira, in which laurels and other evergreens abound, with glossy coriaccous and entire-edged leaves, while below them there is an undergrowth of ferns and various other plants." *

* Bunbury, Quart. Geol. Journ., 1854, vol. x. p. 326. 
Professor Heer, of Zürich, has since published (1855) an account of some additional fossils collected by M. Hartung from the tuff of San Jorge, enumerating twenty-seven forms, referable to ferns and phenogamous plants, most of them agreeing with species now inhabiting Madeira, such as Pteris aquilina, Trichomanes radicans, \&c., and leaves like those of Osmunda regalis (?), no longer found in the island. Among the dicotyledonous plants the Professor describes Myrica Faya, Oreodaphne foetens, Erica arborea, \&c., also a few genera, such as Corylus and Ulmus, now foreign to Madeira. The botanical determinations both of Prof. Heer and Sir C. Bunbury would lead us to refer the leaf-bed to a period as modern as the Newer Pliocene, if not the Post-pliocene.*

The lignite above mentioned and the leaf-bed occur at the height of 1000 feet above the level of the sea, and are overlaid by superimposed basalts and scorix, 11.00 feet thick, implying the existence of an ancient terrestrial vegetation long before a large part of Madeira had been built up. The nature of the tuffs accompanying the lignite, together with some agglomerates in the vicinity, entitles us to presume that near this spot a series of eruptions once broke out. Nor is it improbable that there may have been here the crater of some lateral cone in which the lignite and leaf-bed accumulated; for, although craters are remarkably rare in Madeira, when we consider how great is the number of cones of eruption, yet on the mountain called Lagoa, $2 \frac{1}{2}$ miles west of Machico, a crater as perfect as that of Astroni near Naples may be seen.

At the bottom of this circular cavity (fig. 707), which is about

Fig. 707.

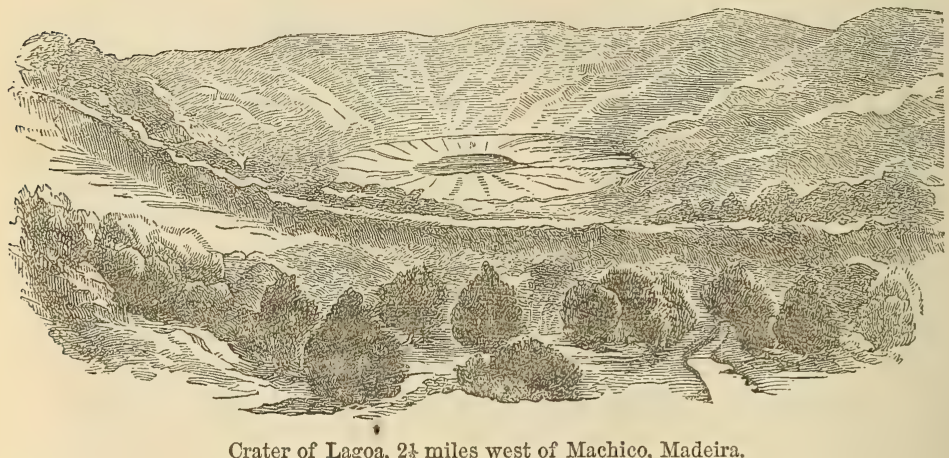

In this cut, taken from a sketch of my own, the depth of the crater may appear too great, unless it is borne in mind that there are no trees visible, and most of the bushes are of the Madeira whortleberry (Vaccinium Madeirense), five or six feet high. Immediately behind the foreground an artificial mound is seen thrown up as a fence.

* Heer, Schweiz. Gesellschaft für Naturwissenschaften, Band XV. 
150 feet decp, is a plain about 500 feet in diameter, having a pond in the middle, towards which the plain slopes gently from all sides. Such ponds are often seen in the interior of extinct craters. Except in the middle it is shallow, and supports aquatic plants. Many leaves must also be blown into it from the surrounding heights when high winds prevail, so that a mass of peaty matter convertible into lignite may collect here.

Had streams of lara descending from greater heights entered this Lagoa crater, they would hare formed dense masses of compact rock cooling slomly under great pressure, like those now incumbent on the impure lignite of S. Jorge. The dip of the latter cannot be clearly determined, since it is exposed to view for too short a distance; and the same may be said of the leaf-bed, part of which may be traced lower down the ravine. It seems, however, to dip to the north or towards the sea conformably with the general inclination of the basaltic and tufaceous strata.

A deep valley, called the Curral (В, fig. 708), surrounded by precipices from 1500 to 2500 fect high, and by peaks of still greater elevation, occurs in the middle of Madeira. It has been compared by some to a crater or caldera, for its upper portion is situated in the region where dikes and ejectamenta abound. The Curral, however, extends, without diminishing in depth, to below the region of numerous dikes, and it lays open to view all the beds $\mathrm{R}, s$, fig. 706. Nor do the volcanic masses dip away in all directions from the Curral, as from a central point, or from the hollow axis of a cone. The Curral is in fact one only of three great valleys which radiate from the most mountainous district, a second depression, called the Serra d'Agoa (D, fig. 708), being almost as deep. This cavity is also drained by a river flowing to the south; while a third valley, namely, that of the Janella, sends its waters to the north. The section alluded to (fig. 708), passing through part of the axis of the island in an east and west direction, shorrs how the Curral and Scrra d'Agoa, B and D, are

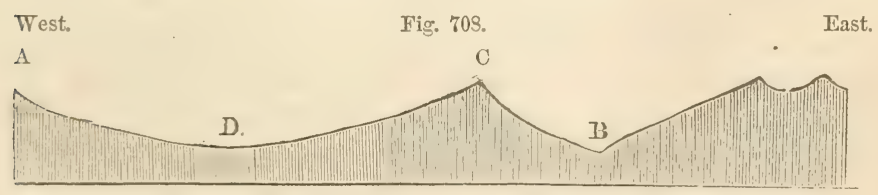

Section through the central region of Madeira, from East to West.

A. Part of the platform, called the Paul de Serra.

B. Curral; a valley, 3000 fect deep.

C. Pico Grande.

D. The valley of the Serra d'Agoa.

separated by a narrow and lofty ridge, e, part of which is surmounted by the Pico Grande, before mentioned, nearly 5400 feet high. There is no essential difierence betreen the shape of these three great ralleys and many of those in the Alps and Pyrenees, whore the valley-making process can have had no connection with any superficial rolcanic action. 
In the Alps, no doubt, as in other lofty chains, the formation of valleys has been greatly aided by subterranean movements, both gradual and violent, and by the dislocation of rocks. The same may be true of Madeira and of almost every lofty volcanic region; but, when we reflect that the central heights $\mathrm{A}$ and B, fig. 706, are more than 6000 feet above the sea, and that the waters flowing from them, swollen by melted snows, reach the sea by a course of not much more than 6 miles in the case of those draining the Curral, and by nearly as short a route in the Serra d'Agoa, we shall be prepared for almost any amount of denudation effected simply by subaërial erosion.

The general absence of water-worn pebbles in the tuffs underlying the Madeira lavas is very striking, and contrasts with the frequent occurrence of gravel-beds under so many of the Auvergne lavas. It simply proves that Madeira, like the volcanic mountains of Java, or like Mount Etna or Mona Loa in the Sandwich Islands, could not, so long as eruptions were frequent, and while the porous lavas absorbed all the rain-water, support a single torrent on its slopes.* The period, therefore, of fluviatile erosion must have been almost entirely subsequent in date to the formation of the central nucleus of ejectamenta, $c$, fig., p. 648 , and of the lavas $d$, ibid. When we infer that these were of supramarine origin as far down as the line $\mathscr{P}, s, t$, and perhaps lower, it follows that a lofty island, 4000 feet or more in height, must have resulted, even if no upheaval had ever occurred.

The movements which upraised the marine deposits of San Vicente may or may not have extended over a wide area. How far, when they occurred, they modified the form of the island, or added to its height, is a fair subject of speculation; and whether the steep dip of the lavas seen in the ravines intersecting the slopes of the mountain, $f h$ and $e g$ (fig. 706, p. 648), may be ascribable in part to such movements. The lavas of more modern date, near Funchal, may be imagined to remain comparatively horizontal, because they have escaped the influence of disturbing forces to which the older nucleus was exposed. Without discussing this point (so fully treated of in reference to Palma), I may observe that unquestionably different parts of Madeira have been formed in succession. Near Porto da Cruz, for example, on the northern coast, trachytes of a gray and yellow, and trachytic tuffs almost of a white color, in slightly inclined or almost horizontal beds, have partially filled up deep valleys previously excavated through the older and inclined basaltic rocks (dipping at an angle of $10^{\circ}$ to the north), under which the leaf-bed and lignite before mentioned (fig. 7.06, p. 648) lie buried. During the convulsions which accompanied the outpouring of every newer series

* See remarks on Etna, Lyell's Principles of Geology, chapter xxv. (9th ed., p. 405). 
of lavas the older rocks may have been more or less disturbed and tilted, without destroying the general form of the old dome-shaped mountain supposed by us to have been the result of repeated eruptions from the central vents.

The locality just referred to of Porto da Cruz exemplifies not only the long intervals of time which separated the outflowing of distinct sets of laras, but also the precedence of the basaltic to the trachytic outpourings. So also on the southern slope of Madeira, we observed between the Jardim and Pico Bodes, situated in a direct line about 6 miles northrest of Funchal, a well-marked series of trachytic rocks of considerable thickness occupying the highest geological position. They consist of white and gray trachytes, occurring at points varying from 2500 to 3500 feet above the sea. Their position may be understood by supposing them to constitute the uppermost beds represented at $h$ in the section (fig. 706, p. 648), and on the slope above $h$. The doctrine, therefore, that in each series of volcanic eruptions the trachytic lavas flow out first, and after them the basaltic (see p. 657 ), is by no means borne out in Madeira, although some of the newest currents, like those at the foot of the cones $\mathrm{M}, \mathrm{N}$, o (fig. 706), are basaltic.

Several of the latest and most powerful streams of lava which have issued from the central axis of Madeira are composed of a felspathic rock of a mixed character, on the whole more trachytic than basaltic. It divides into spheroidal masses, often several feet in diameter, which are very conspicuous when the contained iron has become more highly oxidated. M. Delesse, who had the kindness to analyze for me several of our specimens, found certain varieties of this rock to be without augite, and simply a mixture of blackishgreen felspar with olivine. These would, according to him, be classed by most of the French geologists under the general designation of basalt. Whatever name we assign to this product it indicates a change in the mineral nature of the materials last emitted from the central axis. Where the island is narrow this spheroidal trap often reaches the sea, but in the broadest and loftiest part of Madeira it forms a superficial entelope, which extends for a certain distance only from the central heights, as, for example, to near o (fig. 706, p. 648). Hence, near Funchal, we must ascend to a height of 1100 or 1200 feet before we meet with this felspathic formation, the lower grounds along the coast being occupied by true basalts, which never exhibit a spheroidal structure.

imong other contrasts of character in the superficial rolcanic formations of Madeira, I may remark that many of the central peaks, such as A, fig. 706, secm to be the mere skeletons of cones of eruption, whereas other cones of like origin, such as $\mathrm{x}, \mathrm{N}, \mathrm{o}$, met with at lower levels and nearer the sea, are more regular, and have no protruding dikes on their summits or flanks. This difference in form may imply that the more degraded hills are of higher antiquity; but 
it may quite as often arise from the circumstance that such accumulations of loose ejected materials have been exposed from the first to greater waste in regions where the snows melt suddenly, and where the winds are most violent. A dense covering of turf and shrubs, the most effective of all preservatives against pluvial degradation, cannot readily be formed in such mountainous and stormy regions.

Some few lavas in Madeira have a singularly recent aspect as compared to others which are covered with a considerable depth of vegetable soil. I allude particularly to the lava currents near Porł Moniz, one of which is as rough and bristling as are some streams before alluded to in Palma (p. 641) of historical date. I am indebted to M. Hartung for the annexed drawing of lava at Port Moniz, which I did

Fig. 709.

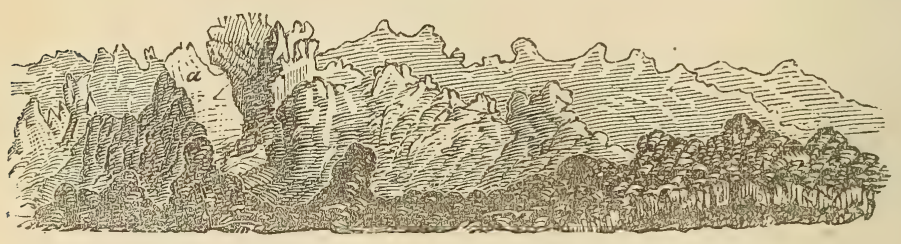

Surface of lava near Port Moniz, N. W. point of Madeira; from a drawing by M. Hartung. a. Channel traversing the lava.

not visit myself. It is traversed by a channel, a, like one of those already described (p. 637). For how long a period such characters may be retained is uncertain, so much does this depend on the mineral composition of the rock. Some of the lavas of Auvergne, of prehistorical date and certainly of high antiquity, are almost as rugged; so that this freshness of aspect is only a probable indication of a relatively modern origin. 


\section{CEAPTER XXX.}

ON THE DIFFERENT AGES OF THE VOLCANIC ROCKS.

Tests of relative age of volcanic rocks-Tests by superposition and intrusionTest by alteration of rocks in contact-Test by organic remains-Test of age by mineral character-Test by included fragments-Volcanic rocks of the PostPliocene period-Basalt of the Bay of Trezza in Sicily-Post-Pliocene voleanic rocks near Naples-Dikes of Somma.

HAVING referred the sedimentary strata to a long succession of geological periods, we have now to consider how far the volcanic for mations can be classed in a similar chronological order. The tests of relative age in this class of rocks are four: 1st, superposition and intrusion, with or without alteration of the rocks in contact; $2 \mathrm{~d}$, organic remains ; $3 \mathrm{~d}$, mineral characters ; 4 th, included fragments of older rocks.

Tests by Superposition, \&c.-If a volcanic rock rest upon an aqueous deposit, the former must be the newest of the two; but the like rule does not hold good where the aqueous formation rests upon the volcanic, for melted matter, rising from below, may penetrate a sedimentary mass without reaching the surface, or may be forced in conformably between two strata, as $b$ at $\mathrm{D}$ in the annexed figure (fig. 710), aiter which it may cool dowin and consolidate. Superposition,

Fig. 710.

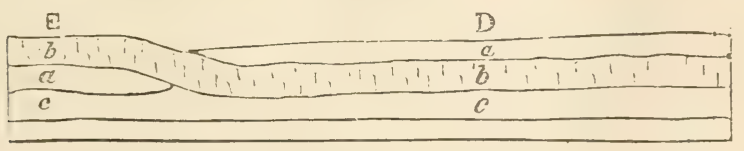

thercfore, is not of the same value as a test of age in the unstratifed volcanic rocks as in fossiliferous formations. We can only rely implicitly on this test where the rolcanic rocks are contemporaneous, not where thes are intrusire. Now, they are said to be contemporaneous if produced by rolcanic action which was going on simultaneously with the deposition of the strata with which they are associated. Thus in the section at D (fig. 710), we may perhaps ascertain that the trap $b$ flowed orer the fossiliferous bed $c$, and that, after its consolidation, $a$ was deposited upon it, $a$ and $c$ both belonging to the same geological period. But if the stratum $a$ be altered by $b$ at the point of contact, we must then conclude the trap to hare been intru- 
sive, or if, in pursuing $b$ for some distance, we find at length that it cuts through the stratum $a$, and then overlies it as at $\mathrm{E}$.

We may, however, be easily deceived in supposing the volcanic rock to be intrusive, when in reality it is contemporaneous; for a sheet of lava, as it spreads over the bottom of the sea, cannot rest everywhere upon the same stratum, either because these have been denuded, or because, if newly thrown down, they thin out in certain places, thus allowing the lava to cross their edges. Besides the heavy igneous fluid will often, as it moves along, cut a channel into

Fig. 711.

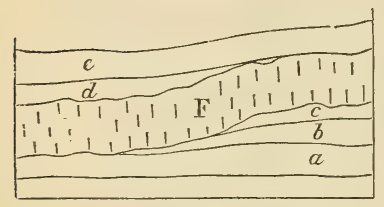
beds of soft mud and sand. Suppose the submarine lava F (fig. 711) to have come in contact in this manner with the strata, $a, b, c$, and that after its consolidation the strata, $d, e$, are thrown down in a nearly horizontal position, yet so as to lie unconformably to $\mathrm{F}$, the appearance of subsequent intrusion will here be complete, although the trap is in fact contemporaneous. We must not, therefore, hastily infer that the rock $\mathrm{F}$ is intrusive, unless we find the strata, $d, e$, or $c$, to have been altered at their junction, as if by heat.

The test of age by superposition is strictly applicable to all stratified volcanic tuffs, according to the rules aiready explained in the case of other sedimentary deposits (see p. 93).

Test of Age by Organic Remains.-We have seen how, in the vicinity of active volcanoes, scorix, pumice, fine sand, and fragments of rock are thrown up into the air, and then, showered down upon the land, or into neighboring lakes or seas. In the tuffs so formed, shells, corals, or any other durable organic bodies which may happen to be strewed over the bottom of a lake or sea will be imbedded, and thus continue as permanent memorials of the geological period when the volcanic eruption occurred. Tufaceous strata thus formed in the neighborhood of Vesuvius, Etna, Stromboli, and other volcanoes now active in islands or near the sea, may give information of the relative age of these tuffs at some remote future period when the fires of these mountains are extinguished. By evidence of this kind we can establish a coincidence in age between volcanic rocks and the different primary, secondary, and tertiary fossiliferous strata.

The tuffs alluded to may not always be marine, but may include, in some places, freshwater shells; in others, the bones of terrestrial quadrupeds. The diversity of organic remains in formations of this nature is perfectly intelligible, if we reflect on the wide dispersion of ejected matter dyring late eruptions, such as that of the volcano of Coseguina, in the province of Nicaragua, January 19,1835. Hot cinders and fine scoria were then cast up to a vast height, and covered the ground as they fell to the depth of more than 10 feet and for a distance of 8 leagues from the crater in a southerly direction. Birds, cattle, and 
wild animals were scorched to death in great numbers, and buried in ashes. Some rolcanic dust fell at Chiapa, upwards of 1200 miles, not to leeward of the volcano as might have been anticipated, but to rindward, a striking proof of a counter-current in the upper region of the atmosphere, and some on Jamaica, about 700 miles distant to the northeast. In the sea, also, at the distance of 1100 miles from the point of eruption, Captain Eden, of the "Conwar," sailed 40 miles through floating pumice, among which were some pieces of considerable size.*

Test of Alge by Minejal Composition.-As sediment of homogeneous composition, when discharged from the mouth of a large river, is often deposited simultancously orer a wide space, so a particular lind of lava floring from a crater during one eruption, may spread orer an extensire area; as in Iceland in 1783, when the melted matter, pouring from Skaptar Jokul, flored in streams in opposite directions, and caused a continuous mass the extreme points of which were 90 miles distant from each other. This enormous current of lava varied in thickness from 100 feet to 600 feet, and in breadth from that of a narrow river gorge to 15 miles. $\dagger$ Now, if such a mass should aftermards be diricied into separate fragments by denudation, we might still perhaps identify the detached portions by their similarity in mincral composition. Ferertheless, this test will not alwass arail the geologist; for, although there is usually a prevailing character in lava emitted during the same eruption, and eren in the successive currents flowing from the same rolcano, still, in many cases, the different parts even of one lava-stream, or, as before stated, of one continuous mass of trap, vary much in mineral composition and texture.

In Auvergne, the Eifel, and other countries where trachyte and basalt are both present, the trachytic rocks are for the most part older than the basaltic. These rocks do, indeed, sometimes alternate partially, as in the roleano of Mont Dor, in Aurergine; and we have seen that in Madeira trachytic rocks may orerlie an older basaltic series (p. 653); but the great mass of trachyte occupies more generally perhaps an inferior position, and is cut througin and orerflowed by basalt. It can by no means be inferred that trachyte predominated at one period of the earth's history and basalt at another, for we know that trachytic laras hare been formed at many successive periods, and are still emitted from many active craters; but it seems that in each region, where a long series of eruptions have occurred, the more felspathic laras hare been first emitted, and the escape of the more augitic kinds has follorred. The hypothesis suggested by Mr. Scrope mar, perhaps, afford a solution of this prolliun. The minerals, he observes, which abound in basalt are of greater specific gravity than those composing the felepathic lavas; thus, for example, hornblende, augite, and olirine are cach more than three times the weight of

* Caldcleugh, Phil. Trans., 1836, p. 27.

+ See Prineiples, Index, "Skaptar Jokul." 
water; whereas common felspar, albite, and Labrador felspar have each scarcely more than $2 \frac{1}{2}$ times the specific gravity of water; and the difference is increased in consequence of there being much more iron in a metallic state in basalt and greenstone than in trachyte and other felspathic lavas and trap rocks. If, therefore, a large quantity of rock be melted up in the bowels of the earth by volcanic heat, the denser ingredients of the boiling fluid may sink to the bottom, and the lighter remaining above would in that case be first propelled upwards to the surface by the expansive power of gases. Those materials, therefore, which occupy the lowest place in the subterranean reservoir will always be emitted last, and take the uppermost place on the exterior of the earth's crust.

Test by Included Fragments.-We may sometimes discover the relative age of two trap rocks, or of an aqueous deposit and the trap on which it rests, by finding fragments of one included in the other in cases such as those before alluded to, where the evidence of superposition alone would be insufficient. It is also not uncommon to find a conglomerate almost exclusively composed of rolled pebbles of trap, associated with some fossiliferous stratified formation in the neighborhood of massive trap. If the pebbles agree generally in mineral character with the latter, we are then enabled to determine its relative age by knowing that of the fossiliferous strata associated with the conglomerate. The origin of such conglomerates is explained by observing the shingle beaches composed of trap pebbles in modern volcanic islands, or at the base of Etna.

Newer Tertiary Pliocene Periods.-I shall now select examples of contemporaneous volcanic rocks of successive geological periods, to show that igneous causes have been in activity in all past ages of the world, and that they have been ever shifting the places where they have broken out at the earth's surface.

One portion of the lavas, tuffs, and trap-dikes of Etna, Vesuvius, and the island of Ischia has been produced within the historical era; another and a far more considerable part originated at times immediately antecedent, when the waters of the Mediterranean were already inhabited by the existing testacea, but when certain species of elephant, rhinoceros, and other quadrupeds now extinct, inhabited Europe. A third and more ancient portion again of these volcanoes originated at the close of the Newer Pliocene period, when less than ten, sometimes only one, in a hundred of the shells differed from those now living (see p. 190).

It has already been stated that in the case of Etna, Post-pliocene formations occur in the neighborhood of Catania, while the oldest lavas of the great volcano are Pliocene. These are seen associated with sedimentary deposits at Trezza and other places on the southern and eastern flanks of the great cone (see above, p. 190).

The Cyclopian Islands, called by the Sicilians Del Farraglioni, in the sea-cliffs of which these beds of clay, tuff, and associated lava are 
Fig. 712

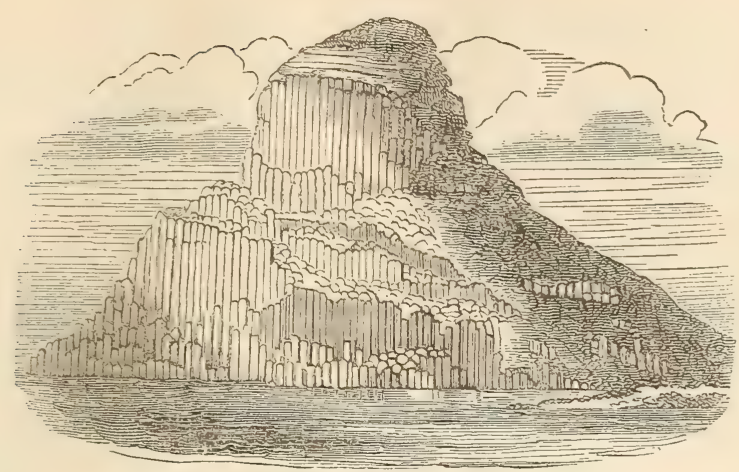

View of the Isle of Cyclops in the Bay of Trezza.*

laid open to view, are situated in the Bay of Trezza, and may be re garded as the extremity of a promontory severed from the main land. Here numerous proofs are seen of submarine eruptions, by which the argillaceous and sandy strata were invaded and cut through, and tufaceous breccias formed. Enclosed in these breccias are many angular and hardened fragments of laminated clay in different states of alteration by heat, and intermixed with volcanic sands.

The loftiest of the Cyclopian islets, or rather rocks, is about 200 feet in height, the summit being formed of a mass of stratified clay, the laminæ of which are occasionally subdivided by thin arenaceous layers. These strata dip to the N.W., and rest on a mass of columnar lava (see fig. 712) in which the tops of the pillars are weathered, and so rounded as to be often hemispherical. In some places in the adjoining and largest islet of the group, which lies to the northeastward of that represented in the draw-

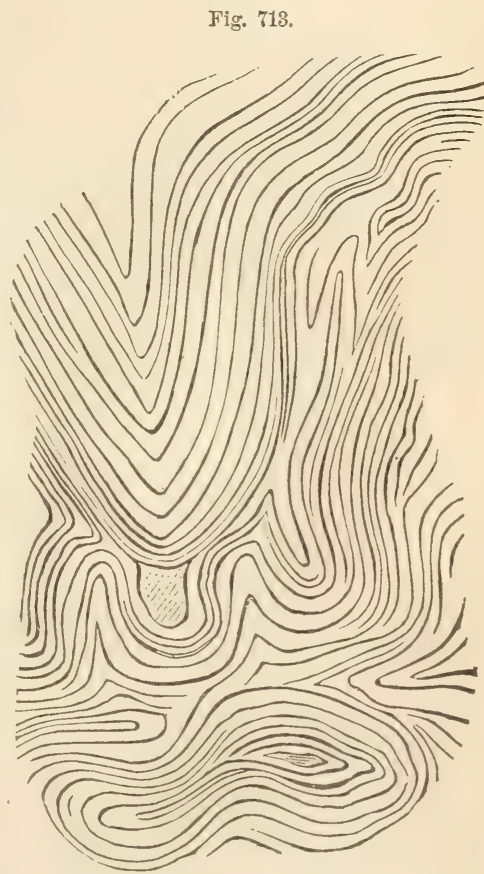

Contortions of strata in the largest of the Cyclopian Islands.

* This riew of the Isle of Cyclops is from an original drawing by my friend the late Captain Basil Hall, R.N. 
ing (fig. 712), the overlying clay has been greatly altered and hardened by the igneous rock, and occasionally contorted in the most extraordinary manner; yet the lamination has not been obliterated, but, on the contrary, rendered much more conspicuous, by the indurating process.

In the foregoing woodcut (fig. 713) I have represented a portion of the altered rock, a few feet square, where the alternating thin laminæ of sand and clay have put on the appearance which we often observe in some of the most contorted of the metamorphic schists.

A great fissure, running from east to west, nearly divides this larger island into two parts, and lays open its internal structure. In the section thus exhibited, a dike of lava is seen, first cutting through an older mass of lava, and then penetrating the superincumbent tertiary strata. In one place the lava ramifies and terminates in thin veins, from a few feet to a few inches in thickness (see fig. 714).

Fig. 714 .

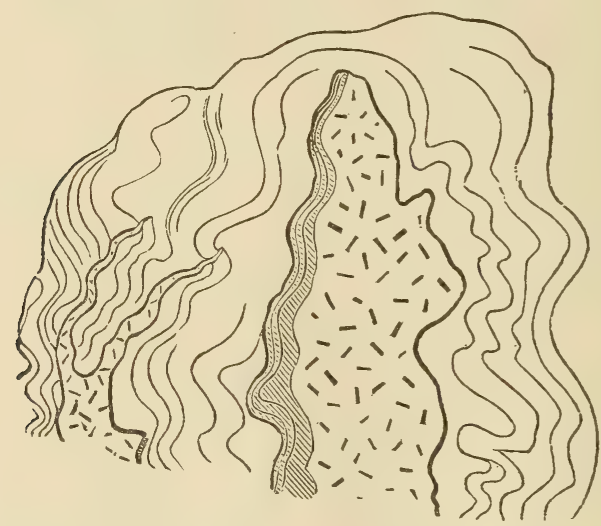

$\begin{array}{llllllll}b & a & b & c & a & b\end{array}$

Clay. Lava. Clay. Altered. Lava. Clay, \&c.

Newer Pliocene strata invaded by lava, Isle of Cyclops (horizontal section).

a. Lava. b. Laminated clay and sand. c. The same altered.

The arenaceous laminæ are much hardened at the point of contact, and the clays are converted into siliceous schist. In this island the altered rocks assume a honeycomb structure on their weathered surface, singularly contrasted with the smooth and even outline which the same beds present in their usual soft and yielding state.

The pores of the lava are sometimes coated, or entirely filled, with carbonate of lime, and with a zeolite resembling analcime, which has been called cyclopite. The latter mineral has also been found in small fissures traversing the altered marl, showing that the same cause which introduced the minerals into the cavities of the lava, whether we suppose sublimation or aqueous infiltration, conveyed it also into the open rents of the contiguous sedimentary strata. 
Post-Pliocene Formations near Naples.-I have traced in the "Principles of Geology" the history of the changes which the volcanic region of Campania is known to have undergone during the last 2000 years. The aggregate effect of igneous operations during that period is far from insignificant, comprising as it does the formation of the modern cone of Vesurius since the year 79, and the production of sereral minor cones in Ischia, together with that of Monte Nuovo in the year 1538. Lara-currents hare also flowed upon the land and along the bottom of the sea-rolcanic sand, pumice, and scorix have been shomered dorm so abundantly that whole cities were buriedtracts of the sea hare been filled up or converted into shoals-and tufaceous sediment has been transported by rivers and land-floods to the sea. There are also proofs, during the same recent period, of a permanent alteration of the relative levels of the land and sea in sevcral places, and of the same tract having, near Puzzuoli, been alternately upheared and depressed to the amount of more than 20 feet. In connection with these convulsions, there are found, on the shores of the Bay of Bair, recent tufaceous strata, filled with articles fabricated by the hands of man, and mingled with marine shells.

It was also stated in this work (p. 189), that when we examine this same region, it is found to consist largely of tufaceous strata, of a date anterior to human history or tradition, which are of such thickness as to constitute hills from 500 to more than 2000 feet in height. Some of these strata contain marine shells which are exclusively of living species, others contain a slight mixture, one or two per cent., of extinct species. Of the latier class is the ancient cone of Vesuvius, called Somma, which is of far greater rolume than the modern cone, and is intersected by a far greater number of dikes. In contrasting this ancient part of the mountain with that of modern date, one principal point of difference is observed: namely, the greater frequency in the older cone of fragments of altered sedimentary rocks ejected during eruptions. We mas easily conceive that the first explosions would act with the greatest riolence, rending and shattering whatever solid masses obstructed the escape of lara and the accompanying gases, so that great heaps of ejected pieces of rock would naturally occur in the tufaceous breccias formed by the earliest eruptions. But when a passage had once been opened and an habitual rent established, the materials thrown out would consist of liquid lava, which would take the form of sand and scorix, or of angular fragments of such solid lavas as may have choked up the vent.

Among the fragments which abound in the tufaceous breccias of Somma, none are more common than a saccharoid dolomite, supposed to hare been derired from an ordinary limestone altered by heat and volcanic vapors.

Carbonate of lime enters into the composition of so many of the simple minerals found in Somma, that M. Mitscherlich, with much probability, ascribes their great variety to the action of the rolcanic beat on subjacent masses of limestone. 
Dikes of Somma.-The dikes seen in the great escarpment which Somma presents towards the modern cone of Vesuvius are very numerous. They are for the most part vertical, and traverse at right angles the beds of lava, scorix, volcanic breccia, and sand, of which the ancient cone is composed. They project in relief several inches or sometimes feet, from the face of the cliff, being extremely compact, and less destructible than the intersected tuffs and porous lavas. In vertical extent they differ from a few yards to 500 feet, and in breadth from 1 to 12 feet. Many of them cut all the inclined beds in the escarpment of Somma from top to bottom, others stop short before they ascend above half way, and a few terminate at both ends, either in a point or abruptly. In mineral composition they scarcely differ from the lavas of Somma, the rock consisting of a base of leucite and augite, through which large crystals of augite and some of leucite are scattered.* Examples are not rare of one dike cutting through another, and in one instance a shift or fault is seen at the point of intersection.

In some cases, however, the rents seem to have been filled laterally, when the walls of the crater had been broken by star-shaped cracks, as seen in the accompanying wood-cut (fig. 715). But the shape of

Fig. 715 .

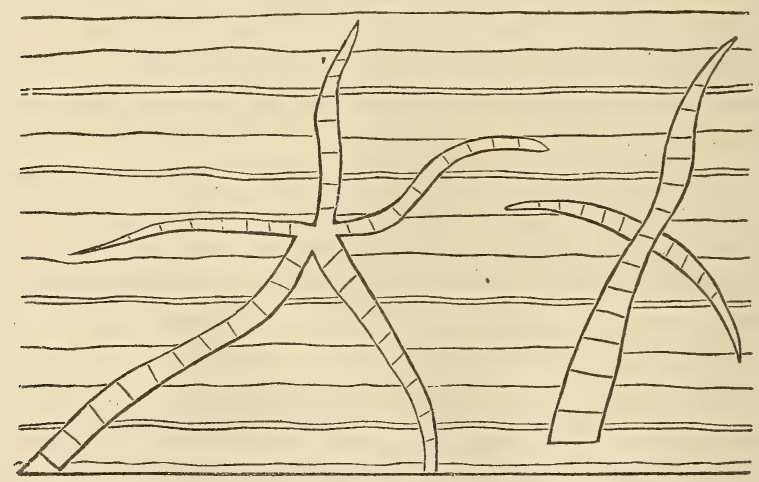

Dikes or veins at the Punto del Nasone on Somma. (Necker.t)

these rents is an exception to the general rule; for nothing is more remarkable than the usual parallelism of the opposite sides of the dikes, which correspond almost as regularly as the two opposite faces of a wall of masonry. This character appears at first the more inexplicable, when we consider how jagged and uneven are the rents caused be earthquakes in masses of heterogeneous composition, like those composing the cone of Somma. In explanation of this phenomenon,

* L. A. Necker, Mém. de la Soc. de Phys. et d'Hist. Nat. de Genève, tom. ii., part i., Nov. 1822 .

† From a drawing of M. Necker, in Mém. above cited. 
M. Necker refers us to Sir W. Hamilton's account of an eruption of Vesuvius in the year 1779, who records the following facts: "The lavas, when they either boiled orer the crater, or broke out from the conical parts of the rolcano, constantly formed channels as regular as if they had been cut by art dorn the steep part of the mountain; and, whilst in a state of perfect fusion, continued their course in those channels, which were sometimes full to the brim, and at other times more or less so, according to the quantity of matter in motion.

"These chamnels, upon examination after an eruption, I have found to be in general from two to five or six feet wide, and seven or eight feet deep. They were often hid from the sight by a quantity of scoria that had formed a crust over them; and the lava, having been conreyed in a covered way for some yards, came out fresh again into an open channel. After an eruption, I have walked in some of those subterraneous or corered galleries, which were exceedingly curious, the sides, top, and bottom being worn perfectly smooth and even in most parts, by the violence of the currents of the red-hot lavas which they had conveyed for many weeks successively." *

Now, the walls of a vertical fissure, through which lava has ascended in its way to a volcanic rent, must have been exposed to the same erosion as the sides of the channels before adverted to. The prolonged and uniform friction of the heary fluid, as it is forced and made to flow upwards, cannot fail to wear and smooth down the surfaces on which it rubs, and the intense heat must melt all such masses as project and obstruct the passage of the incandescent fluid.

The texture of the Vesurian dikes is different at the edges and in the middle. Towards the centre, observes M. Necker, the rock is larger grained, the component elements being in a far more crystalline state; while at the edge the lava is sometimes vitreous, and always finer grained. A thin parting band, approaching in its character to pitchstone, occasionally intertenes, at the contact of the vertical dike and intersected beds. NI. Necker mentions one of these at the place called Primo Monte, in the Atrio del Cavallo; and when I examined Somma, in 1828, I saw three or four others in different parts of the great escarpment. These phenomena are in perfect harmony with the results of the experiments of Sir James Hall and Mr. Gregory Watt, which have shown that a glassy texture is the effect of sudden cooling, while, on the contrary, a crystalline grain is produced where fused minerals are allowed to consolidate slowly and tranquilly under high pressure.

It is erident that the central portion of the lava in a fissure would, during consolidation, part with its heat more slowly than the sides, although the contrast of circumstances would not be so great as when we compare the lara near the bottom and at the surface of a current flowing in the open air. In this case the uppermost part, where it 
has been in contact with the atmosphere, and where refrigeration has been most rapid, is always found to consist of scoriform, vitreous, and porous lava; while at the greater depth the mass assumes a more lithoidal structure, and then becomes more and more stony as we descend, until at length we are able to recognize with a magnifying glass the simple minerals of which the rock is composed. On penetrating still deeper, we can detect the constituent parts by the naked eye, and in the Vesuvian currents distinct crystals of augite and leucite become apparent.

The same phenomenon, observes M. Necker, may readily be exhibited on a smaller scale, if we detach a piece of liquid lava from a moving current. The fragment cools instantly, and we find the surface covered with a vitreous coat; while the interior, although extremely fine-grained, has a more stony appearance.

It must, however, be observed, that although the lateral portions of the dikes are finer grained than the central, yet the vitreous parting: layer before alluded to is rare in Vesuvius. This may, perhaps, be accounted for, as the above-mentioned author suggests, by the great heat which the walls of a fissure may acquire before the fluid mass begins to consolidate, in which case the lava, even at the sides, would cool very slowly. Some fissures, also, may be filled from above, as frequently happens in the volcanoes of the Sandwich Islands, according to the observations of Mr. Dana; and in this case the refrigeration at the sides would be more rapid than when the melted matter flowed upwards from the volcanic foci, in an intensely heated state. Mr. Darwin informs me that in St. Helena almost every dike has a vitreous selvage.

The rock composing the dikes both in the modern and ancient part of Vesuvius is far more compact than that of ordinary lava, for the pressure of a column of melted matter in a fissure greatly exceeds that in an ordinary stream of lava; and pressure checks the expansion of those gases which give rise to vesicles in lava.

There is a tendency in almost all the Vesurian dikes to divide into horizontal prisms, a phenomenon in accordance with the formation of vertical columns in horizontal beds of lava; for in both cases the divisions which give rise to the prismatic structure are at right angles to the cooling surfaces. (See above, p. 617.) 


\section{CHAPTER XXXI.}

ON THE DIFFERENT AGES OF THE VOLCANIC ROCKS, continued.

Volcanic rocks of the Newer Pliocene period-Val di Noto-Sicilian dikes-Region of Olot in Catalonia-Volcanic rocks of the Older Pliocene period-TuscanyRome-Volcanic region of Olot in Catalonia-Cones and lava-currents-Ravines and ancient gravel-beds-Jets of air called Bufadors-Age of the Catalonian volcanoes-Upper Miocene period-Volcanic archipelagoes of Madeira, the Canaries, and the Azores-Lower Miocene period-Brown-coal of the Eifel and contemporaneous trachytic breccias-Age of the brown-coal-Peculiar characters of the rolcanoes of the upper and lower Eifel-Lake Craters-Trass-Hungarian volcanoes.

\section{VOLCANIC ROCKS OF THE NEWER PLIOCENE PERIOD.}

Val di Noto.-I have already alluded (see p. 192) to the igneous rocks which are associated with a great marine formation of limestone, sand, and marl in the southern part of Sicily, as at Vizzini and other places. In this formation, which was shown to belong to the Newer Pliocene period, large beds of oysters and corals repose upon lava, and are unaltered at the point of contact. In other places we find dikes of igneous rock intersecting the fossiliferous beds, and converting the clays into siliceous schist, the laminæ being contorted and shirered into innumerable fragments at the junction, as near the town of Vizzini.

The rolcanic formations of the Val di Noto usually consist of the most ordinary variety of basalt, with or without olivine. The rock is sometimes compact, often very vesicular. The resicles are occasionally empty, both in dikes and currents, and are in some localities filled with calcareous spar, arragonite, and zeolites. The structure is, in some places, spheroidal; in others, though rarely, columnar. I found dikes of amygdaloid, wacke, and prismatic basalt, intersecting the limestone at the bottom of the hollow called Gozzo degli Martiri, below Melilli.

Dikes in Sicily.-Dikes of resicular and amygdaloidal lava are also seen traversing marine tuff or peperino, west of Palagonia, some of the pores of the lara being empty, while others are filled with carbonate of lime. In such cases we may suppose the peperino to have resulted from showers of volcanic sand and scorix, together with fragments of limestone, thrown out by a submarine explosion, similar to that which gave rise to Graham Island in 1831. When the mass 
was, to a certain degree, consolidated, it may have been rent open, so that the lava ascended through fissures, the walls of which were perfectly even and parallel. After the melted matter that filled the rent (fig. 716) had cooled down, it must have been fractured and shifted horizontally by a lateral movement.

In the second figure (fig. 717 ) the lava has more the appearance of

Fig. 716.

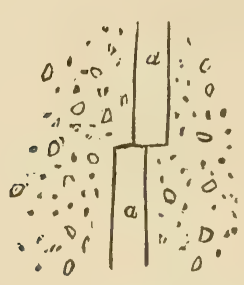

Fig. 717.

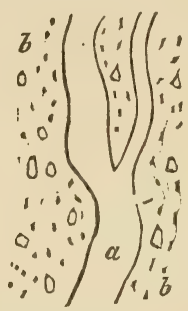

a. Lava.

Ground-plan of dikes near Palagonia.

b. Peperino, consisting of volcanic sand, mixed with fragments of lava and limestone.

a vein which forced its way through the peperino. It is highly probable that similar appearances would be seen, if we could examine the floor of the sea in that part of the Mediterranean where the waves have recently washed away the new volcanic island; for when a superincumbent mass of ejected fragments has been removed by denudation, we may expect to see sections of dikes traversing tuff, or, in other words, sections of the channels of communication by which the subterranean lavas reached the surface.

Volcanic Rocks of Olot in Catalonia.-Geologists are far from being able, as yet, to assign to each of the volcanic groups scattered over Europe a precise chronological place in the tertiary series; but I shall describe here, as probably referable in part to the Post-pliocene and in part to the Newer Pliocene period, a district of extinct volcanoes near Olot in the north of Spain, which is little known, and which I visited in the summer of 1830 .

The whole extent of country occupied by volcanic products in Catalonia is not more than fifteen geographical miles from north to south, and about six from east to west. The vents of eruption range entirely within a narrow band running north and south; and the branches, which are represented as extending eastward in the map, are formed simply of two lava-streams-those of Castell Follit and Cellent.

Dr. Maclure, the American geologist, was the first who made known the existence of these volcanoes; * and, according to his de-

* Maclure, Journ. de Phys., vol. lxvi. p. 219, 1808; cited by Daubeny, Descrip tion of Volcanoes. 
scription, the rolcanic region extended over twenty square leagues, from Amer to Massanet. I searched in vain in the environs of Massanet in the Prrenees for traces of a lara-current; and I can say with confidence, that the adjoining map gives a correct view of the true area of the volcanic action.

Fig. 718.

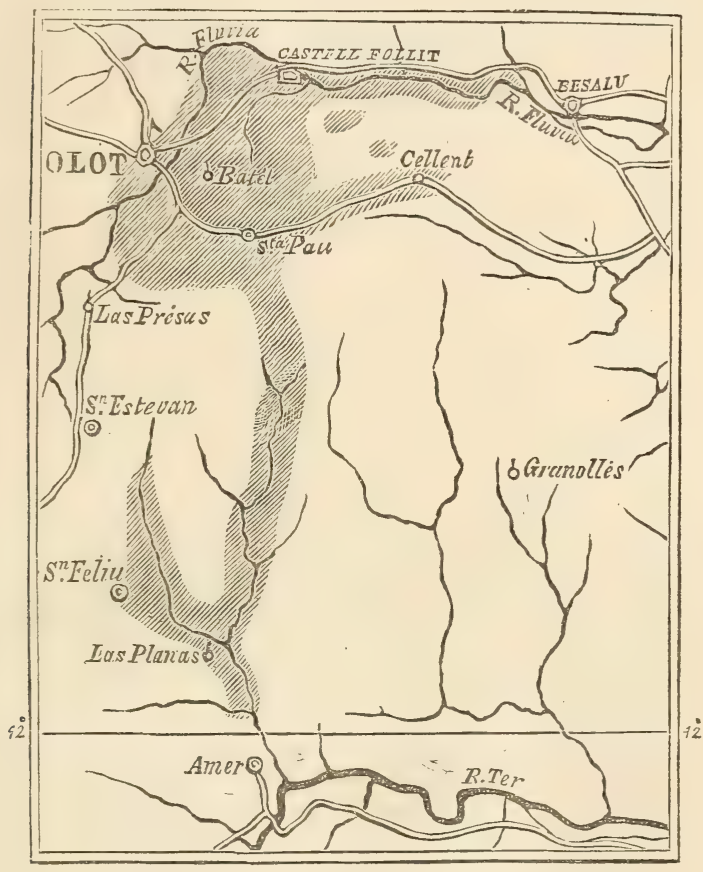

Volcanic district of Catalonia.

Geological Structure of the District.-The eruptions have burst entirely through fossiliferous rocks, composed in great part of gray and greenish sandstone and conglomerate, with some thick beds of rummulitic limestone. The conglomerate contains pebbles of quartz, limestone, and Lydian stone. This system of rocks is rery extensirely spread throughout Catalonia; one of its members being a red sandstone, to which the celebrated salt-rock of Cardona, usually considered as of the cretaceous era, is subordinate.

Near Amer, in the Valley of the Ter, on the southern borders of the region delineated in the map, crystalline rocks are scen, consisting of gneiss, mica-schist, and clay-slate. They run in a line nearly parallel to the Pyrenees, and throw off the fossiliferous strata from their flanks, causing them to dip to the north and northwest. This dip, which is towards the Pyrenees, is connected with a distinct axis of eleration, and prevails through the whole area described in the 
map, the inclination of the beds being sometimes at an angle of between 40 and 50 degrees.

It is evident that the physical geography of the country has undergone no material change since the commencement of the era of the volcanic eruptions, except such as has resulted from the introduction of new hills of scorix, and currents of lava upon the surface. If the lavas could be remelted and poured out again from their respective craters, they would descend the same valleys in which they are now seen, and reoccupy the spaces which they at present fill. The only difference in the external configuration of the fresh lavas would consist in this, that they would nowhere be intersected by ravines, or exhibit marks of erosion by running water.

Volcanic Cones and Lavas.-There are about fourteen distinct cones with craters in this part of Spain, besides several points whence lavas may have issued; all of them arranged along a narrow line running north and south, as will be seen in the map. The greatest number of perfect cones are in the immediate neighborhood of Olot, some of which (fig. 719, Nos. 2, 3, and 5) are represented in

Fig. 719.

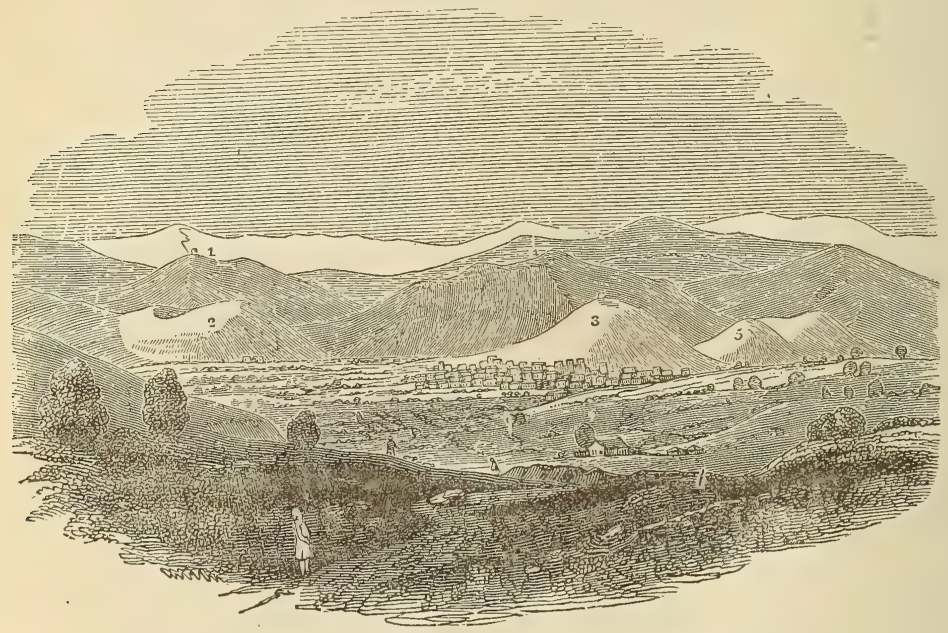

View of the volcanoes around Olot in Catalonia.

the annexed woodcut; and the level plain on which that town stands has clearly been produced by the flowing down of many lava-streams from those hills into the bottom of a valley, probably once of considerable depth, like those of the surrounding country.

In this drawing an attempt is made to represent, by the shading of the landscape, the different geological formations of which the country is composed.* The white line of mountains (No. 1) in the

* This view is taken from a sketch which I made on the spot in 1830 . 
distance is the Pyrenees, which are to the north of the spectator, and consist of hypogene and ancient fossiliferous rocks. In front of these are the fossiliferous formations (No. 4), which are in shade. Still nearer to us the hills 2, 3, 5, are volcanic cones, and the rest of the ground on which the sunshine falls is strewed over with volcanic ashes and lava.

The Fluvia, which flows near the town of Olot, has cut to the depth of only 40 feet through the lavas of the plain before mentioned. The bed of the river is hard basalt; and at the bridge of Santa Madelina are seen two distinct lava-currents, one abore the other, separated by a horizontal bed of scoriæ 8 feet thick.

In one place, to the south of Olot, the even surface of the plain is broken by a mound of lava called the "Bosque de Tosca," the upper part of which is scoriaceous, and covered with enormous heaps of fragments of basalt, more or less porous. Between the numerous hummocks thus formed are deep carities, having the appearance of small craters. The whole precisely resembles some of the modern currents of the Etna, or that of Côme, near Clermont; the last of which, like the Bosque de Tosca, supports only a scanty vegetation.

Most of the Catalonian volcanoes are as entire as those in the neighborhood of Naples, or on the flanks of Etna. One of these, called Montsacopa (No. 3, fig. 719), is of a very regular form, and has a circular depression or crater at the summit. It is chiefly made up of red scorix, undistinguishable from those of the minor cones of Etna. The neighboring hills of Olivet (No. 2) and Garrinada (No. 5) are of similar composition and shape. The largest crater of the whole district occurs farther to the east of Olot, and is called Santa Margarita. It is 455 feet deep, and about a mile in circumference. Like Astroni, near Naples, it is richly covered with wood, wherein game of various kinds abounds.

Although the volcanoes of Catalonia have broken out through sandstone, shale, and limestone, as have those of the Eifel, in Germany, to be described in the sequel, there is a remarkable difference in the nature of the ejections composing the cones in these two regions. In the Eifel, the quantity of pices of sandstone and shale thrown out from the vents is often so immense as far to exceed in volume the scorix, pumice, and lava; but I sought in vain in the cones near Olot for a single fragment of any extraneous rock; and Don Francisco Bolos, an eminent botanist of Olot, informed me that he had never been able to detect any.

Volcanic sand and ashes are not confined to the cones, but have been sometimes scattered by the wind over the country, and drifted into narrow valless, as is scen between Olot and Cellent, where the annexed section (fig. 520, p. 670) is exposed. The light cindery volcanic matter rests in thin regular layers, just as it alighted on the slope formed of the solid conglomerate. No flood could have passed through the ralley since the scoriæ fell, or these would have been for 
Fig. 720 .

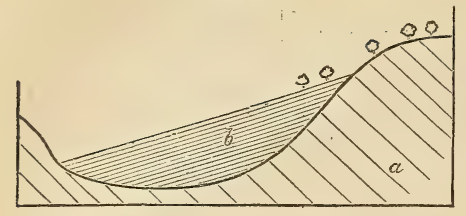

a. Conglomerate.

b. Thin seams of volcanic sand and scorix. the most part removed. The currents of lava in Catalonia, like those of Auvergne, the Vivarais, Iceland, and all mountainous countries, are of considerable depth in narrow defiles, but spread out into comparatively thin sheets in places. where the valleys widen. If a river has flowed on nearly level ground, as in the great plain near Olot, the water has only excavated a channel of slight depth; but where the declivity is great, the stream has cut a deep section, sometimes by penetrating directly through the central part of a lava-current, but more frequently by passing between the lava and the secondary or tertiary rock which bounds the valley. Thus, in the accompanying section (fig. 7.21), at

Fig. 721.

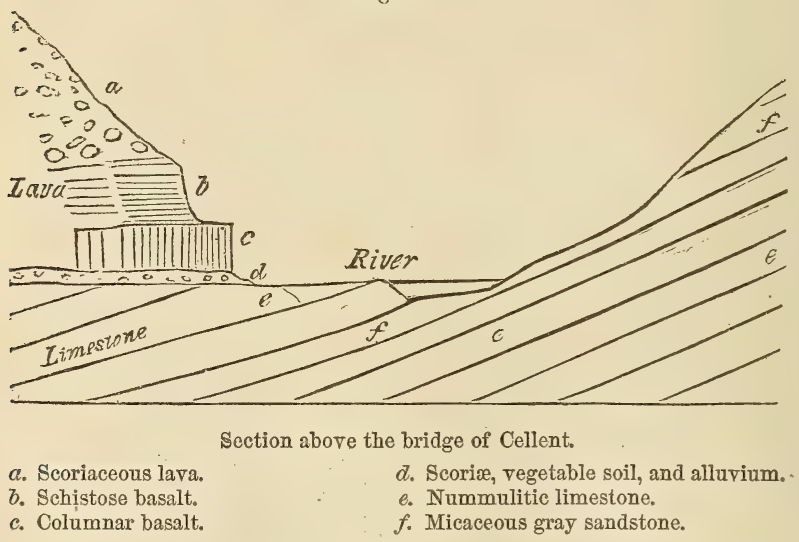

the bridge of Cellent, six miles east of Olot, we see the lava on one side of the small stream; while the inclined stratified rocks constitute the channel and opposite bank. The upper part of the lava at that place, as is usual in the currents of Etna and Vesuvius, is scoriaceous ; farther down it becomes less porous, and assumes a spheroidal structure; still lower it divides in horizontal plates, each about 2 inches in thickness, and is more compact. Lastly, at the bottom is a mass of prismatic basalt about 5 feet thick. The vertical columns often rest immediately on the subjacent stratified rocks; but there is sometimes an intervention of sand and scoriæ such as cover the country during volcanic eruptions, and which, unless protected, as here, by superincumbent lava, is washed away from the surface of the land. Sometimes the bed' $d$ contains a few pebbles and angular fragments of rock; in other places fine earth, which may have constituted an ancient vegetable soil. 
In sereral localities, beds of sand and ashes are interposed between the lava and subjacent stratified rock, as rnay be seen if we follow the course of the lava-current which descends from Las Planas towards Amer, and stops two miles short of that town. The river there has oftea cut through the lava, and through 18 feet of underlying limestone. Occasionally an allurium, several feet thick, is interposed between the igneous and marine formations; and it is interesting to remark that in this, as in other beds of pebbles occupring a similar position, there are no rounded fragments of lava; whereas in the most modern grarel-beds of the rivers of this country volcanic pebbles are abundant.

The deepest excavation made by a river through lava, which I obserred in this part of Spain, is seen in the bottom of a ralley near San Feliu de Palleróls, opposite the Castell de Stolles. The lava there has filled up the bottom of a valley, and a narrow ravine has been cut through it to the depth of 100 feet. In the lower part the lava has a columnar structure. A great number of ages were probably required for the erosion of so deep a ravine; but we have no reason to infer that this current is of higher antiquity than those of the plain near Olot. The fall of the ground, and consequent velocity of the stream, being in this case greater, a more considerable volume of rock may have been removed in the same time.

I shall describe one more section (fig. 722) to elucidate the phenomena of this district. A lava-stream, flowing from a ridge of hills

Fig. 722

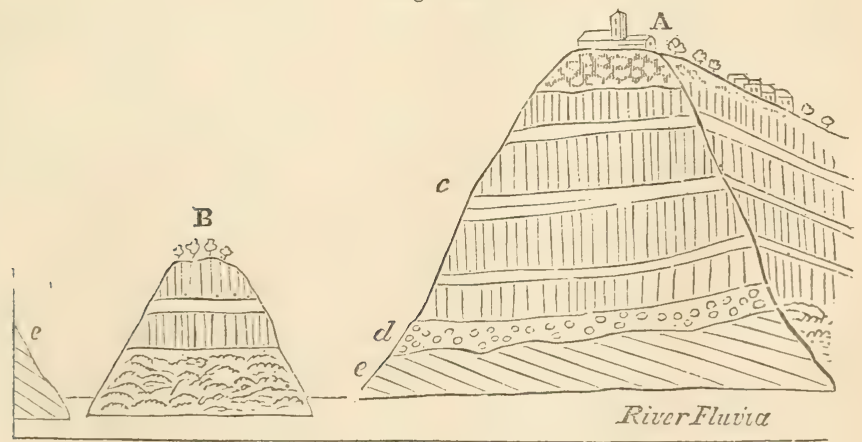

Section at Castell Follit.

A. Church and town of Castell Follit, overlooking precipices of basalt.

B. Small island, on each side of which branches of the river Teronel flow to meet the Fluvia.

c. Precipice of basaltic lava, chiefly columnar, about 130 feet in height.

d. Ancient alluvium, underlying the lava-current.

e. Inclined strata of sandstone.

on the east of Olot, descends a considerable slope, until it reaches the ralley of the river Fluvia. Here, for the first time, it comes in contact with running water, which has remored a portion, and laid 
open its internal structure in a precipice about 130 feet in height, at the edge of which stands the town of Castell Follit.

By the junction of the rivers Fluvia and Teronel, the mass of lava has been cut away on two sides; and the insular rock B (fig. 722) has been left, which was probably never so high as the cliff $\mathbf{A}$, as it may have constituted the lower part of the sloping side of the original current.

From an examination of the vertical cliffs, it appears that the upper part of the lava on which the town is built is scoriaceous, passing downwards into a spheroidal basalt; some of the huge spheroids being no less than 6 feet in diameter. Below this is a more compact basalt, with crystals of olivine. There are in all five distinct ranges of basalt, the uppermost spheroidal, and the rest prismatic, separated by thinner beds not columnar, and some of which are schistose. These were probably formed by successive flows of lava, whether during the same eruption or at difierent periods. The whole mass rests on alluvium, 10 or 12 feet in thickness, composed of pebbles of limestone and quartz, but without any intermixture of igneous rocks; in which circumstance alone it appears to differ from the modern gravel of the Fluvia.

Bufadors.-The volcanic rocks near Olot have often a cavernous structure, like some of the lavas of Etna; and in many parts of the hill of Batet, in the environs of the town, the sound returned by the earth, when struck, is like that of an archway. At the base of the same hill are the mouths of several subterranean caverns, about twelve in number, called in the country "bufadors," from which a current of cold air issues during summer, but in winter it is said to be scarcely perceptible. I visited one of these bufadors in the beginning of August, 1830, when the heat of the season was unusually intense, and found a cold wind blowing from it, which may easily be explained; for as the external air, when rarefied by heat, ascends, the pressure of the colder and heavier air of the caverns in the interior of the mountain causes it to rush out to supply its place.

In regard to the age of these Spanish volcanoes, attempts have been made to prove, that in this country, as well as in Auvergne and the Eifel, the earliest inhabitants were eye-witnesses to the volcanic action. In the year 1421, it is said, when Olot was destroyed by an earthquake, an eruption broke out near Amer, and consumed the town. The researches of Don Francisco Bolos have, I think, shown, in the most satisfactory manner, that there is no good historical foundation for the latter part of this story; and any geologist who has visited Amer must be convinced that there never was any eruption on that spot. It is true that in the year above mentioned, the whole of Olot, with the exception of a single house, was cast down by an earthquake; one of those shocks which, at distant intervals during the last five centuries, have shaken the Pyrenees, and particularly the country between Perpignan and Olot, where the movements, at the period alluder to, were most violent. 
The annililation of the torn may, perhaps, have been due to the carernous nature of the subjacent rocks; for Catalonia is beyond the line of those European earthquakes which have, within the period of history, destroyed towns throughout extensive areas.

As we have no historical records, then, to guide us in regard to the extinct rolcanoes, Tre must appeal to geological monuments. The annexed diagram (fig. 723) will present to the reader, in a synoptical form, the results obtained from numerous sections.

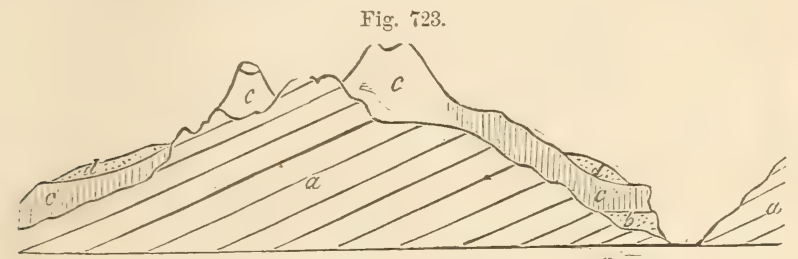

Superposition of rocks in the volcanic district of Catalonia.
$a$. Sandstone and nummulitic limestone.
c. Cones of scoriæ and lava.
$b$. Older alluvium without volcanic pebbles.
d. Newer alluvium.

The more modern allurium $(d)$ is partial, and has been formed by the action of rirers and floods upon the lara; whereas the older gravel (b) was stretred orer the country before the rolcanic eruptions. In neither have any organic remains been discovered; so that we can merely affirm, as ret, that the volcanoes broke out after the eleration of some of the newest rocks of the nummulitic (Eocene) series of Catalonia, and before the formation of an allurium $(d)$ of unknown date. The integrity of the cones merely shorrs that the country has not been agitated by riolent earthquakes, or subjected to the action of any great flood since their origin.

East of Olot, 'on the Catalonian coast, marine tertiary strata occur, which, near Barcelona, attain the height of about 500 fect. From the shells which I collected, these strata appear to correspond in age with the Subapennine beds; and it is not improbable that their uphearal from beneath the sea took place during the period of rolcanic cruption round Olot. In that case these eruptions may have occurred partly during the Nerrer Pliocene, and partly during the Post-pliocene period, but their exact age is at present uncertain.

Older Pliocene Period.-Italy.-In Tuscany, as at Radicofani, Titerlo, and Aquapendente, and in the Campagna di Roma, submarine rolcanic tuffs are interstratificd with the Older Pliocene strata of the Subajemine hills in such a manner as to leare no doubt that they were the products of eruptions which occurred when the shelly marls aud sands of the Sulbapennine lills were in the course of deposition. This opinion I expressed $*$ after my visit to Italy in 1828 ,

* See first edition of Principles of Geology, vol, iii. chaps, xiii. and xir., 1833 ; and former editions of this work, chap. xxxi. 
and it has recently (1850) been confirmed by the arguments adduced by Sir R. Murchison in favor of the submarine origin of the earlier volcanic rocks of Italy.* These rocks are well known to rest conformably on the Subapennine marls, even as far south as Monte Mario in the suburbs of Rome. On the exact age of the deposits of Monte Mario new light has recently been thrown by a careful study of their marine fossil shells, undertaken by MM. Rayneval, Vanden Hecke, and Ponzi. They have compared no less than 160 species $\uparrow$ with the shells of the Coralline Crag of Suffolk, so well described by Mr. Searles Wood; and the specific agreement between the British and Italian fossils is so great, if we make due allowance for geographical distance and the difference of latitude, that we can have little hesitation in referring both to the same period or to the Older Pliocene of this work. It is highly probable that, between the oldest trachytes of Tuscany and the newest rocks in the neighborhood of Naples; a series of volcanic products might be detected of every age from the Older Pliocene to the historical epoch.

\section{VOLCANIC ROCKS OF THE UPPER MIOCENE PERIOD.}

Madeira and Porto Santo.-When treating generally of the origin and structure of volcanic mountains, I have described (p. 646) at some length the volcanic tuffs and other igneous rocks of Tertiary and Posttertiary date in the island of Madeira. Among the submarine deposits, it was stated that some were as old as the Upper Miocene period, as shown by the fossil shells included in the tuffs which have been upraised at San Vicente in the northern part of the island to the height of 1300 feet above the level of the sea. A similar formation constitutes the fundamental portion of the neighboring island of Porto Santo, forty miles distant from Madeira. The marine beds are there elevated to an equal height, and covered, as in Madeira, with lavas of supramarine origin.

The largest number of fossils have been collected from tuffs and conglomerates and some beds of limestone in the island of Baixo, off the southern extremity of Porto Santo. They amount in this single locality to more than sixty in number, of which about fifty are mollusca, many of them in the state of casts only.

Some of the shells probably lived on the spot in the intervals between eruptions; some may have been cast up into the water or air together with muddy ejections, and, falling down again, were deposited on the bottom of the sea. The hollows in some fragments of vesicular lava, entering into the composition of the breccias and conglomerates, are partially filled with calc-sinter, being thus half converted into amygdaloids.

* Geol. Quart. Jourr., vol. vi. p. 281.

† Catalogue des Fossiles de Monte Mario, Rome, 1854. 
Among the fossil shells common to Madeira and Porto Santo, large cones, strombs, and cowries.are conspicuous among the univalves, and Cardium, Spondylus, and Lithodomus among the lamellibranchiate biralres. Among the Echinoderms the large Clypeaster, C. altus, an extinct European Miocene fossil, is seen.

The largest list of fossils has been published by M. Karl Meyer, in Hartung"s "Madeira ; but in the collection made by myself, and in a still larger one formed by Mr. J. Yate Jobnson, several remarkable forms not in Meyer's list occur, as, for example, Pholadomya, and a large Terebra. Mr. Johnson also found a fine specimen of Nautilus (Atiuria) zigzag, a well-known Falunian fossil of Europe; and in the same rolcanic tuff of Baixo, the Echinoderm Brissus Scillce, a liring Mediterranean species, found fossil in the Miocene strata of Malta. M. Meyer identifies one-third of the Madeira shells with known European Miocene (or Falunian) forms. The huge Strombus of San Vicente and Porto Santo, S. Italicus, is an extinct shell of the Subapennine or Older Pliocene formations.

The mollusca already obtained from various localities of Madeira and Forto Santo are not less than one hundred in number, and, according to Dr. S. P. Woodward, rather more than a third are of species still liring, but many of these are not now inhabitants of the neighboring sea.

It has been remarked. (p. 213) that in the Older Pliocene and Upper Miocene deposits of Europe, many forms occur of a more southern aspect than those now inhabiting the nearest sea. In like manner the fossil corals, or Zoantharia, six in number, which I obtained from Nadeira, of the genera Astrcea, Surcinula, Hydnophora, \&c., were pronounced by Mr. Lonsdale to be forms foreign to the adjacent coasts, and to agree with those of more tropical latitudes and parts of the Red Sea. So the Miocene shells of the Madeiras seem to belong to the fauna of a sea warmer than that now separating Madeira from the nearest part of the African coast. We learn, indeed, from the obserrations made in 1859 , by the Rer. R. T. Lowe, that more than onc-half, or fifty-three in ninety, of the marine mollusks collected by him from the sandy beach of Mogador are common British species, although Mogador is $18 \frac{1}{2}$ degrees south of the nearest shores of England. The living shells of Madeira and Porto Santo are in like manner those of a temperate climate, although in great part differing specifically from those of Mogador.*

Grand Canary.-In the Canaries, especially in the Grand Canary, the same marine Upper Miocene formation is found. Stratified tuffs, with intercalater conglomerates and lavas, are there seen in nearly horizontal layers in sea-cliffs about 300 feet high, near Las Palmas. M. Hartung and I were unable to find marine shells in these tuffs at a greater elevation than 400 feet abore the sea; but as the deposit to 
which they belong reaches to the height of 1100 feet or more in the interior, we conceive that an upheaval of at least that amount has taken place. The Clypeaster altus, Spondylus goederopus, Pectunculus pilosus, Cardita calyculata, and several other shells, serve to identify this formation with that of the Madeiras, and Ancillaria glandiformis, which is not rare, and some other fossils, remind us of the faluns of Touraine.

The sixty-two Miocene species which I collected in the Grand Canary are referred, by Dr. S. P. Woodward, to forty-seven genera, ten of which are no longer represented in the neighboring sea, namely, Corbis, an African form, Hinnites, now living in Oregon, Thecidium (T. Mediterraneum, identical with the Miocene fossil of St. Juvat, in Brittany), Calyptroea, Hipponyx, Nerita, Erato, Oliva, Ancillaria, and Fasciolaria.

These tuffs of the southern shores of the Grand Canary, containing the Upper Miocene shells, appear to be about the same age as the most ancient volcanic rocks of the island, composed of slaty diabase, phonolite, and trachyte. Over the marine lavas and tuffs trachytic and basaltic products of subaërial volcanic origin, between 4000 and 5000 feet in thickness, have been piled, the central parts of the Grand Canary reaching the heights of about 6000 feet above the level of the sea. Some lavas have a very fresh aspect, and have been poured out since the time when the valleys were already excavated to within a few feet of their present depth. They must be very modern, geologically speaking, but being anterior to the European colonization of the Grand Canary, their date is unknown.

A raised beach occurs at San Catalina, about a quarter of a mile north of Las Palmas, which is situated in the northeastern part of the island. It intervenes between the base of the high cliff formed of the tuffs with Miocene shells and the sea-shore. From this beach, elevated twenty-five feet above high-water mark, and at a distance of about 150 feet from the shore, I obtained, with the assistance of Don Pedro Maffiotte, more than fifty species of living marine shells. Many of them, according to Dr. S. P. Woodward, are no longer inhabitants of the contiguous sea, as, for example, Strombus bubonius, which is still living on the West coast of Africa, and Cerithium procerum, found at Mozambique: others are Mediterranean species, as Pecten Jacobceus and P. polymorphus. Some of these testacea, such as Cardita squamosa, are inhabitants of deep water, and the deposit on the whole seems to indicate a depth of water exceeding a hundred feet.

Azores.-In the island of St. Mary's, one of the Azores, marine fossil shells have long been known. They are found in the northeast coast in a small projecting promontory called Ponta do Papagaio (or Point-Parrot), chiefly in a limestone about 20 feet thick, which rests upon, and is again covered by, basaltic lavas, scorix, and conglomerates. The pebbles in the conglomerate are cemented together with carbonate of lime. 
M. Hartung, in his account of the Azores, published in 1860, describes twenty-three shells from St. Mary's, ${ }^{*}$ of which eight perhaps are identical with living species, and twelve are with more or less certainty referred to European Tertiary forms, chiefly Upper Miocene. One of the most characteristic and abundant of the new species, Cardium Hartungi, not known as fossil in Europe, is very common in Porto Santo and Baixo, and serves to connect the Miocene fauna of the Azores and the Madeiras.

It appears from what has been said in the twenty-ninth and in the present chapter, that the rolcanic eruptions of Madeira, the Canaries, and the Azores, commenced in the Upper Miocene period, and continued down to Post-pliocene times: in some islands of the Canarian and Azorian groups, the volcanic fires are not yet extinct, as the recorded eruptions of Lanzerote, Teneriffe, Palma, St. Michaels, and others attest.

In each of the three archipelagoes there are proofs of Miocene submarine formations having been gradually uplifted during the outpouring of successive lavas, in the same manner as the Pliocene marine strata of the oldest parts of Vesurius and Etna have been upraised during eruptions of Post-tertiary date. In the Grand Canary, in Teneriffe, and in Porto Santo, I obserred raised beaches, showing that movements of elevation have in each of them been continued down to the Post-tertiary period.

\section{LOWER MIOCENE VOLCANIC ROCKS.}

The Eifel.-A large portion of the volcanic rocks of the Lower Rbine and the Eifel are coeral with the Lower Miocene deposits to which most of the "Brown-Coal" of Germany belongs. The Tertiary strata of that age are seen on both sides of the Rhine, in the neighborhood of Bonn, resting unconformably on highly inclined and rertical strata of Silurian and Devonian rocks. Its geographical position, and the space occupied by the volcanic rocks, both of the Westerwald and Eifel, will be seen by referring to the map (fig. 724), for which I am indebted to the late Mr. Horner, whose residence for some rears in the country enabled him to verify the maps of MM. Noeggerath and Von Oernhausen, from which that now giren has been principally compiled. $\uparrow$

The Brown-Coal formation of that region consists of beds of loose sand, sandstone, and conglomerate, clay with nodules of clar-ironstone, and occasionally silex. Larers of light brown and sometimes black lignite are interstratified with the clays and sands, and often

\footnotetext{
* Hartung, Die Azoren, 1860; also Insel Gran Canaria, Madeira, und Porto Santo, 1864, Leipsig.

† Horner, Trans. of Geol. Søc., Second Series, vol. v.
} 
Fig. 724 .

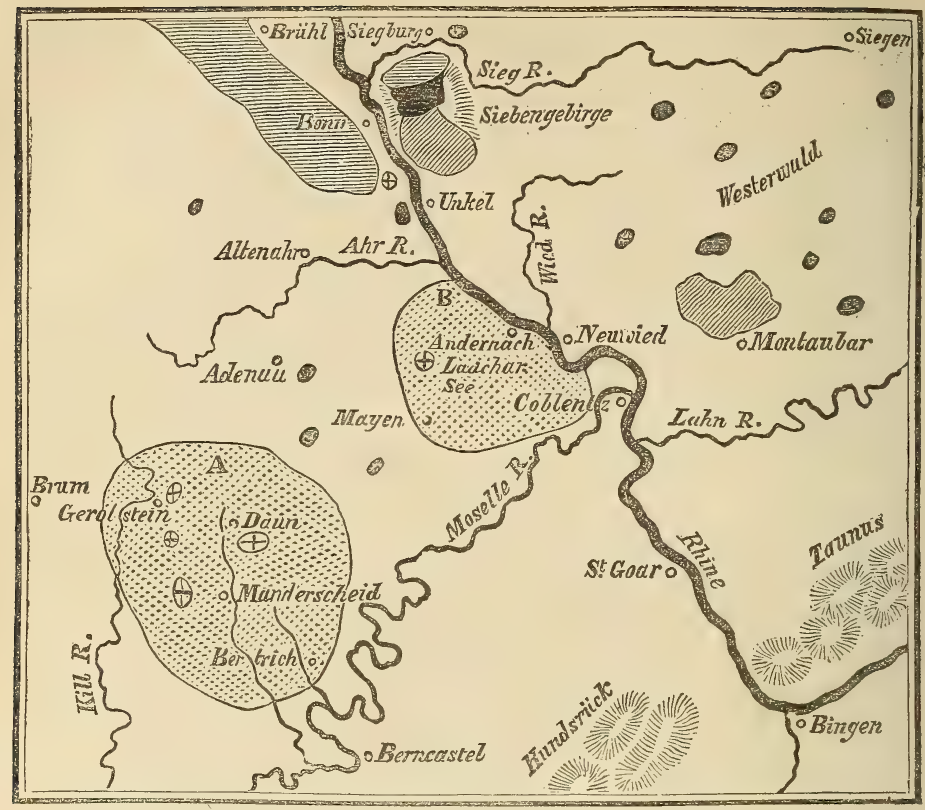

Map of the voleanic region of the Upper and Lower Eifel.

$\begin{array}{llllll} & 1 & 2 & 3 & 4 & 5 \\ 1 & 1 & 1 & 1 & 1 & \text { English Miles. }\end{array}$

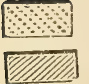

Volcanic District. Trachyte. f A. Of the Upper Eifel. $\{$ B. Of the Lower Eifel.

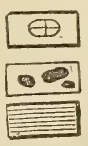

Points of eruption, with craters and scoriæ.

Basalt.

Brown-coal.

$N B$. The country in that part of the map which is left blank is composed of inclined Silurian and Devonian rocks.

irregularly diffused through them. They contain numerous impressions of leaves and stems of trees, and are extensively worked for fuel, whence the name of the formation.

In several places, layers of trachytic tuff are interstratified, and in these tuffs are leaves of plants identical with those found in the browncoal, showing that, during the period of the accumulation of the latter, some volcanic products were ejected.

M. Von Dechen, in his work on the Siebengebirge, ${ }^{*}$ has given a copious list of the animal and vegetable remains of the freshwater strata associated with the brown-coal. Plants of the genera Flabellaria, Ceanothus, and Daphnogene, including D. cinnamomifolia (fig. 204, p. 264), occur in these beds, with nearly 150 other plants.

The fishes of the brown-coal near Bonn are found in a bituminous

* Geognost. Beschreib. des Siebengebirges am Rhein. Bonn, 1852. 
shale, called paper-coal, from being divisible into extremely thin leaves. The individuals are very. numerous; but they appear to belong to a small number of species, some of which were referred by Agassiz to the genera Leuciscus, Aspius, and Perca. The remains of frogs also, of extinct species, hare been discorered in the paper-coal; and a complete scries may be seen in the museum at Bonn, from the most imperfect state of the tadpole to that of the full-grown animal. With these a salamander, scarcely distinguishable from the recent species, has been found, and the remains of many insects.

A vast deposit of gravel, chiefly composed of pebbles of white quartz, but containing also a few fragments of other rocks, lies over the brown-coal, forming sometimes only a thin covering, at others attaining a thickness of more than 100 feet. The gravel is very distinct in character from that now forming the bed of the Rhine. It is called "Kiesel-g"erölle" by the Germans, often reaches great elevations, and is covered in several places with volcanic ejections. It is evident that the country has undergone great changes in its physical geography since this gravel was formed; for its position has scarcely any relation to the existing drainage, and the great valley of the Rhine and all the more modern volcanic rocks of the same region are posterior to it in date.

Some of the newest beds of volcanic sand, pumice, and scoriæ are interstratified near Andernach and elsewhere with the loam called loess, which was before described as being full of land and freshwater shells of recent species, and referable to the Post-pliocene period. But this intercalation of volcanic matter between beds of loess may possibly be explained without supposing the last eruptions of the Lower Eifel to have taken place so recently as the era of the deposition of the loess.

The igneous rocks of the Westerwald, and of the mountains called the Siebengebirge, consist partly of basaltic and partly of trachytic lavas, the latter being in general the more ancient of the two. There are many varieties of trachyte, some of which are highly crystalline, resembling a coarse-grained granite, with large separate crystals of felspar. Trachytic tuff is also very abundant. These formations, some of which were certainly contemporaneous with the origin of the brown-coal, were the first of a long series of eruptions, the more recent of which happened when the country had acquired nearly all its present geographical features.

Newer Volcanoes of the Eifel_-Lake-Craters.-As I recognized in the more modern volcanoes of the Eifel characters distinct from any previously observed by me in those of France, Italy, or Spain, I shall briefly describe them. The fundamental rocks of the district are gray and red sandstones and shales, with some associated limestones, replete with fossils of the Deronian or Old Red Sandstone group. The roleanoes broke out in the midst of these inclined strata, and when the present systems of hills and valleys had already been 
formed. The eruptions occurred sometimes at the bottom of deep valleys, sometimes on the summit of hills, and frequently on intervening platforms. In travelling through this district we often fall upon them most unexpectedly, and may find ourselves on the very edge of a crater before, we had been led to suspect that we were approaching the site of any igneous outburst. Thus, for example, on arriving at the village of Gemund, immediately south of Daun, we leave the stream, which flows at the bottom of a deep valley in which strata of sandstone and shale crop out. We then climb a steep hill, on the surface of which we see the edges of the same strata dipping inwards towards the mountain. When we have ascended to a considerable height, we see fragments of scoriæ sparingly scattered over the surface; until, at length, on reaching the summit, we find ourselves suddenly on the edge of a tarn, or deep circular lake-basin (see fig. 725).

Fig. 725.

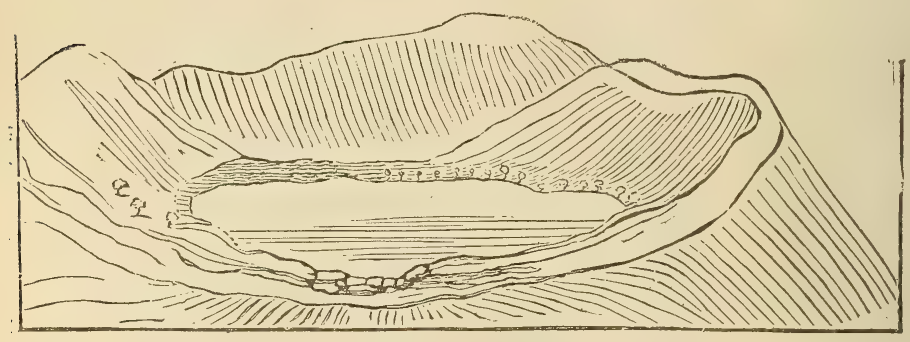

The Gemunder Maar.

This, which is called the Gemunder Maar, is one of three lakes which are in immediate contact, the same ridge forming the barrier of two neighboring cavities. On viewing the first of these (fig. 725), we recognize the ordinary form of a crater, for which we have been prepared by the occurrence of scoriæ, scattered over the surface of the soil. But on examining the walls of the crater we find precipices of sandstone and shale which exhibit no signs of the action of heat; and we look in vain for those beds of lava and scoriæ, dipping outwards on every side, which we have been accustomed to consider as characteristic of volcanic vents. As we proceed, however, to the opposite side of the lake, and afterwards visit the craters $c$ and $d$ (fig. 726), we find a considerable quantity of scoriæ and some lava, and see

Fig. 726.

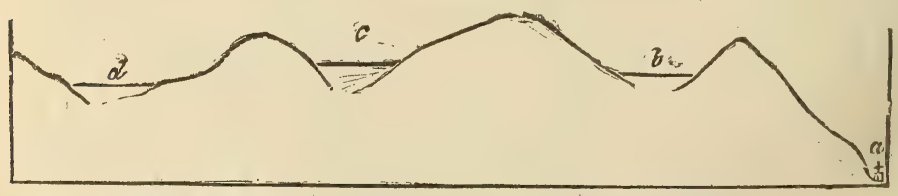

a. Village of Gemund.

b. Gemunder Maar.

c. Weinfelder Maar.

d. Schalkenmehren Maar. 
the whole surface of the soil sparkling with volcanic sand, and strewed with ejected fragments of half-fused shale, which preserves its laminated texture in the interior, while it has a vitrified or scoriform coating.

A few miles to the south of the lakes above mentioned occurs the Pulrermaar of Gillenfeld, an oval lake of very regular form, and surrounded by an unbroken ridge of fragmentary materials consisting of ejected shale and sandstone, and preserving a uniform height of about 150 feet above the water. The slope in the interior is at an angle of about 45 degrees; on the exterior, of 35 degrees. Volcanic substances are intermixed rery sparingly with the ejections, which in this place entirely conceal from view the stratified rocks of the country.*

The Meerfelder Maar is a cavity of far greater size and depth, hollowed out of similar strata; the sides presenting some abrupt sections of inclined secondary rocks, which in other places are buried under vast heaps of pulverized shale. I could discover no scoriæ amongst the ejected materials, but balls of olivine and other volcanic substances are mentioned as having been found. $\uparrow$ This cavity, which we must suppose to have discharged an immense volume of gas, is nearly a mile in diameter, and is said to be more than one hundred fathoms deep. "In the neighborhood is a mountain called the Mosenberg, which consists of red sandstone and shale in its lower parts, but supports on its summit a triple volcanic cone, while a distinct current of lara is seen descending the flanks of the mountain. The edge of the crater of the largest cone reminded me much of the form and characters of that Vesuvius; but I was much struck with the precipitous and almost overhanging. wall or parapet which the scoriæ presented towards the exterior, as at $a b$ (fig. 727); which I can only explain by

Fig. 727.

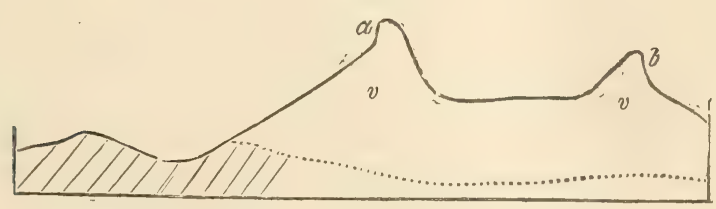

Stratified rocks.

v. Volcanic.

Outline of the Mosenberg, Upper Eifel.

supposing that fragments of red-hot lava, as they fell round the vent, were cemented together into one compact mass, in consequence of continuing to be in a half-melted state.

If we pass from the Upper to the Lower Eifel, from a to в (see Map, p. 678), we find that celebrated lake-crater of Laach, which has a greater resemblance than any of those before mentioned to the Lago

* Scrope, Edin. Journ. of Science, June, 1826, p. 145.

+ Hibbert, Extinct Volcanoes of the Rhine, p. 24. 
di Bolsena, and others in Italy, being surrounded by a ridge of gently sloping hills, composed of loose tuffs, scoriæ, and blocks of a variety of lavas.

One of the most interesting volcanoes on the left bank of the Rhine near Bonn is called the Roderberg. It forms a circular crater nearly a quarter of a mile in diameter, and 100 feet deep, now covered with fields of corn. The highly inclined strata of ancient sandstone and shale rise even to the rim of one side of the crater; but they are overspread by quartzose gravel, and this again is covered by volcanic scoriæ and tufaceous sand. The opposite wall of the crater is composed of cinders and scorified rock, like that at the summit of Vesuvius. It is quite evident that the eruption in this ease burst through the sandstone and alluvium which immediately overlies it; and I observed some of the quartz pebbles mixed with scoriæ on the flanks of the mountain, as if they had been cast up into the air, and had fallen again with the volcanic ashes. I have already observed, that a large part of this crater has been filled up with the loess.

The most striking peculiarity of a great many of the craters above described, is the absence of any signs of alteration or torrefaction in their walls, when these are composed of regular strata of ancient sandstone and shale. It is evident that the summits of hills formed of the above-mentioned stratified rocks have, in some cases, been carried away by gaseous explosions, while at the same time no lava, and often a very small quantity only of scorix, has escaped from the newly-formed cavity. There is, indeed, no feature in the Eifel volcanoes more worthy of note, than the proofs they afford of very copious aëriform discharges, unaccompanied by the pouring out of melted matter, except, here and there, in very insignificant volume. I know of no other extinct volcanoes where gaseous explosions of such magnitude have been attended by the emission of so small a quantity of lava. Yet I looked in vain in the Eifel for any appearances which could lend support to the hypothesis, that the sudden rushing out of such enormous volumes of gas had ever lifted up the stratified rocks immediately around the vent, so as to form conical masses, having their strata dipping outwards on all sides from a central axis, as is assumed in the theory of elevation craters, alluded to in Chapter XXIX.

Trass.-In the Lower Eifel, eruptions of trachytic lava preceded the emission of currents of basalt, and immense quantities of pumice were thrown out wherever trachyte issued. The tufaceous alluvium called trass, which has covered large areas in this region and choked up some valleys now partially reëxcavated, is unstratified. Its base consists almost entirely of pumice, in which are included fragments of basalt and other lavas, pieces of burnt shale, slate, and sandstone, and numerous trunks and branches of trees. If, as is probable, this trass was formed during the period of volcanic eruptions, it may have originated in the manner of the moya of the Andes. 
We may easily conceive that a similar mass might now be pro. duced, if a copious evolution of gases should occur in one of the lake-basins. The water might remain for weeks in a state of violent cbullition, until it became of the consistency of mud, just as the sea continued to be charged with red mud round Graham's Island, in the Mediterranean, in the year 1831. If a breach should then be made in the side of the cone, the flood would sweep array great heaps of ejected fragments of shale and sandstone, which would be borne down into the adjoining valleys. Forests might be torn by such a flood, and thus the occurrence of the numerous trunks of trees dispersed irregularly through the trass, can be explained.

The manner in which this trass conforms to the shape of the present valleys implies its comparatively modern origin, probably not dating farther back than the Post-pliocene, or, at farthest, the Nerrer Pliocene period. Of like modern date are numerous perfect cones of scoriæ and some streams of lava which occur in the Eifel, as, for example, the small cones with craters near Andernach, on the left bank of the Rhine, and the columnar lava of Bertrich-Baden, between Treves and Coblentz, of which I have given a figure at p. 619.

Hungary.-M. Beudant, in his elaborate work on Hungary, describes five distinct groups of volcanie rocks, which, although nowhere of great extent, form striking features in the physical geography of that country, rising as they do abruptly from extensire plains composed of tertiary strata. They may have constituted islands in the ancient sea, as Santorin and Milo now do in the Grecian Archipelago; and M. Beudant has remarked that the mineral products of the last-mentioned islands resemble remarkably those of the Hungarian extinct voleanoes, where many of the same minerals, as opal, chalcedony, resinous silex (silex resinite), pearlite, obsidian, and pitchstone abound.

The Hungarian laras are shiefly felspathic, consisting of different rarieties of trachyte; many are cellular, and used as millstones; some so porous and even scoriform as to resemble those which have issued in the open air. Pumice occurs in great quantity; and there are conglomerates, or rather breccias, wherein fragments of trachyte are bound together by pumiceous tuff, or sometimes by silex.

It is probable that these rocks were permeated by the watcrs of hot springs, impregnated, like the Geysers, with silica; or, in some instances, perhaps by aqueous rapors, which, like those of Lancerote, may have precipitated hydrate of silica.

$\mathrm{B}_{\text {r }}$ the influence of such springs or rapors the trunks and branches of trees washed domn during floods, and buricd in tuffs on the flanks of the mountains, are supposed to have become silicified. It is scarcely possible, says II. Beudant, to dig into any of the pumiceous deposits of these mountains without mecting with opalized wood, nnd sometimes entire silicified trunks of trees of great size and weight. 
It appears from the species of shells collected principally by M. Boué, and examined by M. Deshayes, that the fossil remains imbedded in the volcanic tuffs, and in strata alternating with them in Hungary, are of the Miocene type, and not identical, as was formerly supposed, with the fossils of the Paris basin.

\section{CHAPTER XXXII.}

ON THE DIFFERENT AGES OF THE VOLCANIC ROCKS, continued.

Volcanic rocks of the Tertiary period, continued-Extinct volcanoes of AuvergneMont Dor-Breccias and alluviums of Mont Perrier, with bones of quadrupedsRiver dammed up by lava-current-Range of minor cones from Auvergne to the Vivarais-Monts Dôme-Puy de Côme-Puy de Pariou-Cones not denuded by general flood-Lower Miocene volcanic rocks near Clermont-Hill of GergoviaEocene volcanic rocks of Monte Bolca-Trap of Cretaceous period-9olitic period-New Red Sandstone period-Carboniferous period- "Rock and Spindle" near St. Andrew's-old Red Sandstone period-Silurian period-Cambrian period-Laurentian volcanic rocks.

Volcanic Rocks of Auvergne.-The extinct volcanioes of Auvergne and Cantal, in Central France, seem to have commenced their eruptions in the Lower Miocene period, but to have been most active during the Upper Miocene and Pliocene eras. I have already alluded to the grand succession of events, of which there is evidence in Auvergne since the last retreat of the sea (see p. 228).

The earliest monuments of the tertiary period in that region are lacustrine deposits of great thickness (2, fig. 728, p. 686), in the lowest conglomerates of which are rounded pebbles of quartz, micaschist, granite, and other non-volcanic rocks, without the slightest intermixture of igneous products. To these conglomerates succeed argillaceous and calcareous marls and limestones (3, fig. 728), containing Lower Miocene shells and bones of mammalia, the higher beds of which sometimes alternate with volcanic tuff of contemporaneous origin. After the filling up or drainage of the ancient lakes, huge piles of trachytic and basaltic rocks, with volcanic breccias, accumulated to a thickness of several thousand feet, and were superimposed upon granite, or the contiguous lacustrine strata. The greater portion of these igneous rocks appear to have originated during the Upper Miocene and Pliocene periods ; and extinct quadrupeds of those eras, belonging to the genera Mastodon, Rhinoceros, and others, were buried in ashes and beds of alluvial sand and gravel, which owe their preservation to overspreading sheets of lava. 
In Auvergne, the most ancient and conspicuous of the volcanic masses is Mont Dor, which rests immediately on the granitic rocks standing apart from the freshwater strata.* This great mountain rises suddenly to the height of several thousand feet above the surrounding platform, and retains the shape of a flattened and somewhat irregular cone, all the sides sloping more or less rapidly, until their inclination is gradually lost in the high plain around. This cone is composed of layers of scoriæ, pumice-stcnes, and their fine detritus, with interposed beds of trachyte and basalt, which descend often in uninterrupted sheets until they reach and spread themselves round the base of the mountain. $\uparrow$ Conglomerates, also, composed of angular and rounded fragments of igneous rocks, are observed to alternate with the above; and the various masses are seen to dip off from the central axis, and to lie parallel to the sloping flanks of the mountain.

The summit of Mont Dor terminates in seven or eight rocky peaks, where no regular crater can now be traced, but where we may easily imagine one to have existed, which may have been shattered by earthquakes, and hare suffered degradation by aqueous agents. Originally, perhaps, like the highest crater of Etna, it may have formed an insignificant feature in the great pile, and may frequently have been destroyed and renovated.

According to some geologists, this mountain, as well as Vesurius, Etna, and all large voleanoes, has derived its dome-like form not from the preponderance of eruptions from one or more central points, but from the upheaval of horizontal beds of lava and scoriæ. I I have explained my reasons for objecting to this view in Chapter XXIX., when speaking of Palma, and in the "Principles of Geology." \$ The average inclination of the dome-shaped mass of Mont Dor is $8^{\circ} 6^{\prime}$, whereas in Mounts Loa and Kea, before mentioned, in the Sandwich Islands (see fig. 693, p. 623), the flanks of which have been raised by recent lavas, we find from Mr. Dana's description that the one has a slope of $6^{\circ} 30^{\prime}$, the other of $7^{\circ} 46^{\prime}$. There is therefore no reason whaterer for imagining, as some have supposed, that the basaltic currents of the ancient French volcano were at first more horizontal than they are now. Nevertheless it is possible that during the long series of eruptions required to give rise to so vast a pile of volcanic matter, which is thickest at the summit or centre of the dome, some dislocation and uphearal took place; and during the distension of the mass, beds of lava and scorix may, in some places, have acquired a greater, in others a less inclination, than that which at first belonged to them.

Respecting the age of the great mass of Mont Dor, we cannot come at present to any positive decision, because no organic remains have

* See the Map, p. 221.

+ Scrope's Central France, p. 98.

\$ See chaps. xxiv., xxv., and xxvi., 7th, 8th, and 9th editions. 
yet been found in the tuffs, except impressions of the leares of trees of species not yet determined. We may confidently assume that the earliest eruptions were posterior in origin to those grits and conglomerates of the freshwater formation of the Limagne which contain no pebbles of volcanic rocks; while, on the other hand, some eruptions took place before the great lakes were drained, and others occurred after the desiccation of those lakes, and when deep valleys had already been excavated through freshwater strata.

Fig. 728.

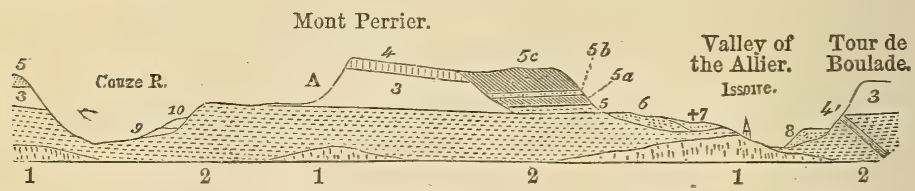

Section from the valley of the Couze at Nechers, through Mont Perrier and Issoire, to the Valley of the Allier and the Tour de Boulade, Auvergne.

10. Lava-current of Tartaret near its termination at Nechers.

9. Bone-bed, red sandy clay under the lava of Tartaret.

8. Bone-bed of the Tour de Boulade.

7. Alluvium newer than No. 6.

6. Alluvium with bones of hippopotamus.

5 c. Trachytic breccia resembling $5 a$.

5 b. Upper bone-bed of Perrier, gravel, \&c.

5 a. Pumiceous breccia and conglomerate, angular masses of trachyte, quartz, pebbles, \&c.

5. Lower bone-bed of Perrier, ochreous sand and gravel.

4a. Basaltic dike.

4. Basaltic platform.

3. Upper freshwater beds, limestone, marl, gypsum, \&c.

2. Lower freshwater formation, red clay, green sand, \&c.

1. Granite.

In the above section I have endearored to explain the geological structure of a portion of Auvergne, which I reëxamined in 1843.* It may convey some idea to the reader of the long and complicated series of events which have occurred in that country, since the first lacustrine strata (No. 2) were deposited on the granite (No. 1). The changes of which we have evidence are the more striking, because they imply great denudation, without there being any proofs of the intervention of the sea during the whole period. It will be seen that the upper freshwater beds (No. 3), once formed in a lake, must have suffered great destruction before the excavation of the valleys of the Couze and Allier had begun. In these freshwater beds, Lower Miocene fossils, as described in Chapter XV., have been found. The basaltic dike, $4^{\prime}$, is one of many examples of the intrusion of volcanic matter through the ancient freshwater beds, and may have been of Miocene or Pliocene date, giving rise, when it reached the surface and overflowed, to such platforms of basalt as often cap the tertiary hills in Auvergne, and one of which (4) is seen on Mont Perrier.

It not unfrequently happens that beds of gravel containing bones of extinct mammalia are detected under these very ancient sheets of basalt, as between No. 4 and the freshwater strata, No. 3, at A, from 
which it is clear that the surface of No. 3 formed at that period the lowest level at which the waters then draining the country flowed. Next in age to this basaltic platform comes a patch of ochreous sand and gravel (No. 5), containing many bones of quadrupeds. Upon this rests a pumiceous breccia or conglomerate, with angular masses of trachyte and some quartz pebbles. This deposit is followed by $5 b$ (which is similar to 5 ) and $5 c$ similar to the trachytic breccia $5 a$. These two breccias are supposed, from their similarity to others found on Mont Dor, to have descended from the flanks of that mountain during eruptions; and the interstratified alluvial deposits contain the remains of mastodon, rhinoceros, tapir, deer, beaver, and quadrupeds of other genera, referable to about forty species, all of which are extinct. I formerly supposed them to belong to the same era as the Miocene faluns of Touraine; but more recent researches seem to show that they ought rather to be ascribed to the older Pliocene epoch.

Whatever be their date in the tertiary series, they are quadrupeds which inhabited the country when the formations 5 and $5 c$ originated. Probably they were drowned during floods, such as rush down the flanks of volcanoes during eruptions, when great bodics of steam are emitted from the crater, or when, as we have seen, both on Etna and in Iceland in modern times, large masses of snow are suddenly melted by lava, causing a deluge of water to bear down fragments of igneous rocks mixed with mud to the valleys and plains below.

It will be seen that the valley of the Issoire, down which these ancient inundations swept, was first excavated at the expense of the formations 2,3 , and 4 , and then filled up by the masses 5 and $5 c$, after which it was reëxcavated before the more modern alluviums (Nos. 6 and 7) were formed. In these again other fossil mammalia of distinct species have been detected by M. Bravard, the bones of an hippopotamus having been found among the rest.

At length, when the valley of the Allier was eroded at Issoire down to its lowest level, a talus of angular fragments of basalt and freshwater limestone (No. 8) was formed, called the bone-bed of the Tour de Boulade, from which a great many other Newer Pliocene mammalia have been collected by MM. Bravard and Pomel. Among these, the Elephas primigenius, Rhinoceros tichorinus, Dcer (including. reindeer), Equus, Bos, Antelope, Felis, and Canis were included. Eren this deposit seems hardly to be the newest in the noighborhood, for if we cross from the town of Issoire (see fig. 728) orer MIont Perrier to the adjoining valley of the Couze, we find another bone-bed (No. 9) overlaid by a current of lava.

The history of this lava-current, which terminates a few hundred yards below the point, No. 10, in the suburbs of the village of Nechers, is interesting. It forms a long narrow stripe more than 13 miles in length, at the bottom of the valley of the Couze, which flows out of a lake at the foot of Mont Dor. This lake is caused by a bar- 
rier thrown across the ancient channel of the Couze, consisting partly of the volcanic cone called the Puy de Tartaret, formed of loose scorix, from the base of which has issued the lava-current before mentioned. The materials of the dam which blocked up the river, and caused the Lac de Chambon, are also, in part, derived from a landslip which may have happened at the time of the great eruption which formed the cone.

This cone of Tartaret affords an impressive monument of the very different dates at which the igneous eruptions of Auvergne have happened; for it was evidently thrown up at the bottom of the existing valley, which is bounded by lofty precipices composed of sheets of ancient columnar trachyte and basalt, which once flowed at very high levels from Mont Dor.*

When we follow the course of the river Couze, from its source in the lake of Chambon to the termination of the lava-current at Nechers, a distance of thirteen miles, we find that the torrent has in most places cut a deep channel through the lava, the lower portion of which is colimnar. In some narrow gorges the water has even had power to remove the entire mass of basaltic roek, though the work of erosion must have been very slow, as the basalt is tough and hard, and one column after another must have been undermined and reduced to pebbles, and then to sand. During the time required for this operation, the perishable cone of Tartaret, composed of sand and ashes, has stood uninjured, proving that no great flood or deluge can have passed over this region in the interval between the eruption of Tartaret and our own times.

If we now return to the section (fig. 728), I may observe that the lava-current of Tartaret, which has diminished greatly in height and volume near its termination, presents here a steep and perpendicular face 25 feet in height towards the river. Beneath it is the alluvium No. 9, consisting of a red sandy clay, which must have covered the bottom of the valley when the current of melted rock flowed down. The bones found in this alluvium, which I obtained myself, consisted of a species of field-mouse, Arvicola, and the molar tooth of an extinct horse, Equus fossilis. The other species, obtained from the same bed, are referable to the genera Sus, Bos, Cervus, Felis, Canis, Martes, Talpa, Sorex, Lepris, Sciurus, Mus, and Lagomys, in all no less than forty-three species, all closely allied to recent animals, yet nearly all of them, according to M. Bravard, showing some points of difference, like those which Mr. Owen discovered in the case of the horse above alluded to. The bones also of a frog, snake, and lizard, and of several birds, were associated with the fossils before enumerated, and several recent länd-shells, such as Cyclostoma elegans, Helix hortensis, $H$. nemoralis, $H$. lapicida, and Clausilia rugosa. If the

* For a view of Puy de Tartaret and Mont Dor, see Scrope's Volcanoes of Central France. 
animals were drowned by floods, which accompanied the eruptions of the Puy de Tartaret, they would give an exceedingly modern geological date to that event, which must, in that case, have belonged to the end of the Nerrer Pliocene, or, perhaps, to the Post-pliocene period. That the current which has issued from the Puy de Tartaret may, nevertheless, be very ancient in reference to the events of human history, we may conclude, not only from the divergence of the mammiferous fauna from that of our day, but from the fact that a Roman bridge of such form and construction as continued in use down to the fifth century, but which may be older, is now seen at a place about a mile and a half from St. Nectaire. This ancient bridge spans the river Couze with two arches, each about 14 feet wide. These arches spring from the lava of Tartaret, on both banks, showing that a ravine precisely like that now existing, had already been excavated by the river through that lava thirteen or fourteen centuries ago.

In Central France there are several hundred minor cones like that of Tartaret, a great number of which, like Monte Nuovo, near Naples, may have been principally due to a single eruption. Most of these cones range in a linear direction from Auvergne to the Vivarais, and they were faithfully described so early as the year 1802, by M. de Nontlosier. They have given rise chiefly to currents of basaltic lava. Those of Aurergne called the Mionts Dome, placed on a granitic platform, form an irregular ridge (see ifg. 624, p. 594), about 18 miles in length and 2 in breadth. They are usually truncated at the summit, where the crater is often preserved entire, the lava having issued from the base of the hill. But frequently the crater is broken down on one side, where the lava has flowed out. The hills are composed of loose scoriæ, blocks of lava, lapilli, and pozzuolana, with fragments of trachyte and granite.

Puy de Côme-The Puy de Côme and its lava-current, near Clermont, may be mentioned as one of these minor volcanoes. This conical hill rises from the granitic platform, at an angle of between $30^{\circ}$ and $40,^{\circ}$ to the height of more than 900 feet. Its summit presents two distinct craters, one of them with a vertical depth of 250 feet. A stream of lava takes its rise at the western base of the hill instead of issuing from either crater, and descends the granitic slope towards the present site of the town of Pont Gibaud. Thence it pours in a broad sheet down a steep declivity into the valley of the Sioule, filling the ancient river-channel for the distance of more than a mile. The Sioule, thus dispossessed of its bed, has worked out a fresh one between the lava and the granite of its western bank; and the excavation has disclosed, in one spot, a wall of columnar.basalt about 50 feet high.*

The excavation of the ravine is still in progress, every winter some columns of basalt being undermined and carried down the channel of 
the river, and in the course of a few miles rolled to sand and pebbles. Meanwhile the cone of Côme remains unimpaired, its loose materials being protected by a dense vegetation, and the hill standing on a ridge not commanded by any higher ground, so that no floods of rain-water can descend upon it. There is no end to the waste which the hard basalt may undergo in future, if the physical geography of the country continue unchanged, no limit to the number of years during which the heap of incoherent and transportable materials called the Puy de Côme may remain in a stationary condition. In this place, therefore, we behold in the results of aqueous and atmospheric agency in past times, a counterpart of what we must expect to recur in future ages.

Lava of Chaluzet.-At another point, farther down the course of the Sioule, we find a second illustration of the same phenomenon in the Puy Rouge, a conical hill to the north of the village of Pranal. The cone is composed entirely of red and black scorix, tuff, and volcanic bombs. On its western side, towards the village of Chaluzet, there is a worn-down crater, whence a powerful stream of lava has issued, and flowed into the valley of the Sioule. The river has since excavated a ravine through the lava and subjacent gneiss, to the depth in some places of 400 feet.

Fig. 729.

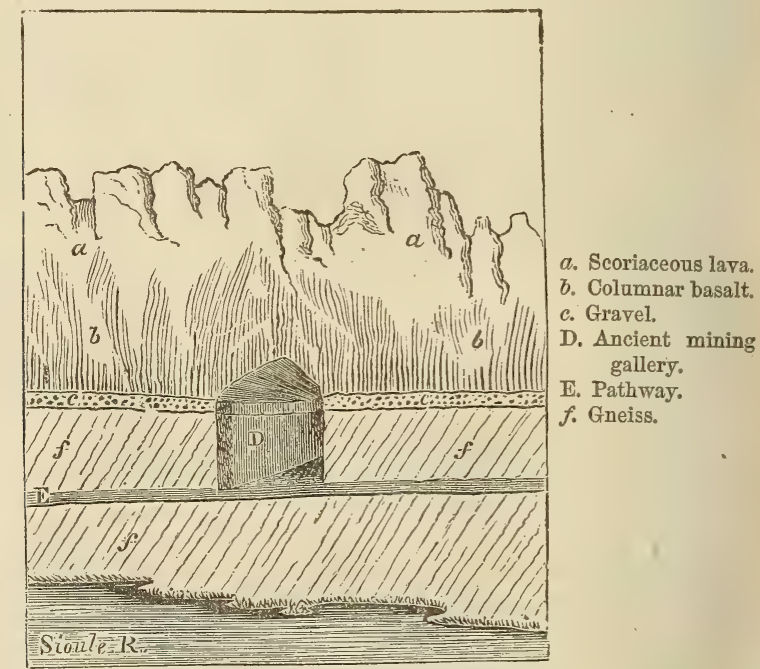

Lava-current of Chaluzet, Auvergne, near its termination.*

On the upper part of the precipice forming the left side of this ravine, we see a great mass of black and red scoriaceous lava becoming more and more columnar towards its base. (See fig. 729.) Below 
this is a bed of sand and gravel 3 feet thick, evidently an ancient river-bed, now at an elevation of 25 feet above the channel of the Sioule. This gravel, from which water gushes out, rests upon gneiss, $f$, which has been eroded to the depth of 25 feet at the point where the annexed riew is taken. At $\mathrm{D}$, close to the village of Les Combres, the entrance of a gallery is seen, in which lead has been worked in the gneiss. This mine shows that the pebble-bed is continuous, in a horizontal direction, between the gneiss and the roolcanic mass. Here again it is quite erident, that, while the basalt was gradually undermined and carried away by the force of running water, the cone whence the lava issued escaped destruction, because it stood upon a platform of gneiss several hundred feet above the level of the valley in which the force of running water "was exerted.

Puy de Pariou.-The brim of the crater of the Puy de Pariou, near Clermont, is so sharp, and has been so little blunted by time, that it scarcely affords room to stand upon. This and other cones in an equally remarkable state of integrity have stood, I conceive, uninjured, not in spite of their loose porous nature, as might at first be naturally supposed, but in consequence of it. No rills can collect where all the rain is instantly absorbed by the sand and scoriæ, as is remarkably the case on Etna; and nothing but a waterspout breaking directly upon the Puy de Pariou could carry away a portion of the hill, so long as it is not rent or engulfed by earthquakes.

Hence it is conceivable that even those cones which have the freshest aspect and most perfect shape may lay claim to very high antiquity. - Dr. Daubeny has justly observed, that had any of these volcanoes been in a state of activity in the age of Julius Cæsar, that general, who encamped upon the plains of Auvergne, and laid siege to its principal city (Gergovia, near Clermont), could hardly have failed to notice them. Had there been any record of their eruptions in the time of Pliny or Sidonius Apollinaris, the one would scarcely have omitted to make mention of it in his Natural History, nor the other to introduce some allusion to it among the descriptions of this his native province. This poet's residence was on the borders of the Lake Aidat, which owed its very existence to the damming up of a river by one of the most modern lava-currents.*

Plomb du Cantal.- -In regard to the age of the igneous rocks of the Cantal, we can at present merely affirm, that they overlie the Lower Mincene lacustrine strata of that country, which may be partly Upper Eocene and partly Lower Miocene (sce Map, p. 221). They form a great dome-shaped mass, having an average slope of only $\dot{4}^{\circ}$, which has eridently been accumulated, like the cone of Etna, during a long series of cruptions. It is composed of trachytic, phonolitic, and basaltic lavas, tuffs, and conglomerates, or breccias, forming a mountain sereral thousand feet in height. Dikes also of phonolite, trachyte, 
and basalt are numerous, especially in the neighborhood of the large cavity, probably once a crater, around which the loftiest summits of the Cantal are ranged circularly, few of them, except the Plomb du Cantal, rising far above the border or ridge of this supposed crater. A pyramidal hill, called the Puy Griou, occupies the middle of the cavity.* It is clear that the volcano of the Cantal broke out precisely on the site of the lacustrine deposit before described (p. 229), which had accumulated in a depression of a tract composed of micaceous schist. In the breccias, even to the very summit of the mountain, we find ejected masses of the freshwater beds, and sometimes fragments of flint, containing Lower Miocene shells. Valleys radiate in all directions from the central heights of the mountain, increasing in size as they recede from those heights. "Those of the Cer and Jourdanne, which are more than 20 miles in length, are of great depth, and lay open the geological structure of the mountain. No alternation of lavas with undisturbed lacustrine strata has been observed, nor any tuffs containing freshwater shells, although some of these tuffs include fossil remains of terrestrial plants, said to imply several distinct restorations of the regetation of the mountain in the intervals between great eruptions. On the northern side of the Plomb du Cantal, at La Vissière, near Murat, is a spot, pointed out on the Map (p. 221), where freshwater limestone and marl are seen covered by a thickness of about 800 feet of volcanic rock. Shifts are here seen of the strata of limestone and marl. $\dagger$

In treating of the lacustrine deposits of Central France, in the fifteenth chapter, it was stated that, in the arenaceous and pebbly group of the lacustrine basins of Auvergne, Cantal, and Velay, no volcanic pebbles had ever been detected, although massive piles of igneous rocks are now found in the immediate vicinity. As this observation has been confirmed by minute research, we are warranted in inferring that the volcanic eruptions had not commenced when the older subdivisions of the freshwater groups originated.

In Cantal and Velay no decisive proofs have yet been brought to light that any of the igneous outbursts happened during the deposition of the freshwater strata;-but there can be no doubt that in Aurergne some volcanic explosions took place before the drainage of the lakes, and at a time when the Lower Miocene species of animals and plants still flourished. Thus, for example, at Pont du Château, near Clermont, a section is seen in a precipice on the right bank of the river Allier, in which beds of volcanic tuff alternate with a freshwater limestone, which is in some places pure, but in others spotted with fragments of volcanic matter, as if it were deposited while showers of sand and scoriæ were projected from a neighboring vent. $\ddagger$

Another example ocours in the Puy de Marmont, near Veyres,

* Mém. de la Soc. Géol, de France, tom. i. p. 175.

$\uparrow$ See Lyell and Murchison, Ann. de Sci. Nat., Oct. 1829.

$\ddagger$ See Scrope's Central France, p. 21. 
where a freshwater marl alternates with volcanic tuff containing Miocene shells. The tuff or breccia in this locality is precisely such as is known to result from volcanic ashes falling into water, and subsiding together with ejected fragments of marl and other stratified rocks. These tuffs and marls are highly inclined, and traversed by a thick vein of basalt, which, as it rises in the hill, divides into two branches.

Gergovia.-The hill of Gergovia, near Clermont, affords a third example. I agree with MM. Dufrénoy and Jobert that there is no alternation here of a contemporaneous sheet of lava with freshwater strata, in the manner supposed by some other observers; * but the position and contents of some of the associated tuffs prove them to have been derived from volcanic eruptions which occurred during the deposition of the lacustrine strata.

The bottom of the hill consists of slightly inclined beds of white and greenish marls, more than 300 feet in thickness, intersected by a dike of basalt, which may be studied in the ravine abore the village of Merdogne. The dike here cuts through the marly strata at a considerable angle, producing, in general, great alteration and confusion in them for some distance from the point of contact. Above the white and green marls, a series of beds of limestone and marl, containing freshwater shells, are seen to alternate with volcanic tuff. In the lomest part of this dirision, beds of pure marl alternate with compact fissile tuff, resembling some of the subaqueous tuffs of Italy and Sicily called peperinos. Occasionally fragments of scoriæ are visible in this rock. Still higher is seen another group of some thickness consisting exclusively of tuff, upon which lie other marly strata inter-

Fig. 730.

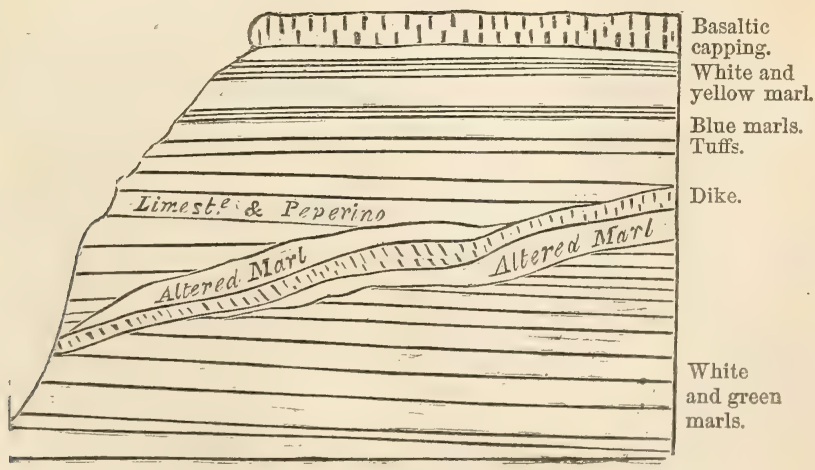

Hill of Gergovia.

mixed with rolcanic matter. Among the species of fossil shells which I found in these strata were Melania inquinata, a Unio, and a Mela- 
nopsis, but they were not sufficient to enable me to determine with precision the age of the formation.

There are many points in Auvergne where igneous rocks have been forced by subsequent injection through clays and marly limestones, in such a manner that the whole has become blended in one confused and brecciated mass, between which and the basalt there is sometimes no very distinct line of demarcation. In the cavities of such mixed rocks we often find chalcedony, and crystals of mesotype, stilbite, and arragonite. To formations of this class may belong some of the breccias immediately adjoining the dike in the hill of Gergovia; but it cannot be contended that the volcanic sand and scoriæ interstratified with the marls and limestones in the upper part of that hill were introduced, like the dike, subsequently, by intrusion from below. They must have been thrown down like sediment from water, and can only have resulted from igneous action, which was going on contemporaneously with the deposition of the lacustrine strata.

The reader will bear in mind that this conclusion agrees well with the proofs, adverted to in the fifteenth chapter, of the abundance of silex, travertin, and gypsum precipitated when the upper lacustrine strata were formed; for these rocks are such as the waters of mineral and thermal springs might generate.

Eocene Volcanic Rocks.-The fissile limestone of Monte Bolca, near Verona, has for many centuries been celebrated in Italy for the number of perfect Ichthyolites which it contains. Agassiz has described no less than 133 species of fossil fish from this single deposit, and the multitude of individuals by which many of the species are represented, is attested by the variety of specimens treasured up in the principal museums of Europe. They have been all obtained from quarries worked exclusively by lovers of natural history, for the sake of the fossils. Had the lithographic stone of Solenhofen, now regarded as so rich in fossils, been in like manner quarried solely for scientific objects, it would have remained almost a sealed book to palæontologists, so sparsely are the organic remains scattered through it. I visited Monte Bolca in company with Sir Roderick Murchison in 1828 , and we then satisfied ourselves that the fish-bearing strata formed part of the Eocene rocks of the adjacent Vicentine: we also. ascertained that the associated voleanic products, consisting chiefly of peperino or brown basaltic tuff, were contemporaneous and interstratified with marine deposits charged with the same fossils as those which characterize the Middle Eocene group of Monte Bolca. In some of the tuffs nummulites are met with, and two species, Nummulites globulus and $N$. mille-caput, were obtained by Sir R. Murchison in a subsequent visit from beds intervening between those which yield the chief supply of fossil fish. We observed dikes of basalt cutting through vast masses of the peperino in Monte Postale, which

* Murchison on the Structure of the Alps, Quart. Geol. Journ., vol. v. p. 225. 
adjoins Monte Bolca. There is evidence here of a long series of submarine volcanic eruptions of Eocene date, and during some of them, as Sir R. Murchison has suggested, shoals of fish were probably destroyed by the evolution of heat, noxious gases, and tufaceous mud, just as happened when Graham's Island was thrown up between Sicily and Africa in 1831, at which time the waters of the Mediterranean were seen to be charged with red mud, and covered with dead fish over a wide area.*

Associated with the marls and limestones of Monte Bolca are beds containing "lignite and shale with numerous plants, which have been described by Unger and Massalongo, and referred by them to the Eocene period. I have already cited (p. 291) Professor Heer's remark, that several of the species are common to Monte Bolca and the white clay of Alum Bay, a Middle Eocene deposit; and the same botanist dwells on the tropical character of the flora of Monte Bolca and its distinctness from the subtropical flora of the Lower Miocene of Switzerland and Italy, in which last there is a far more considerable mixture of forms of a temperate climate, such as the willow, poplar, birch, elm, and others. All these are wanting at Monte Bolea, while on the oflier hand the coniferæ are represented by five species of Podocarpus, the Dicotyledons by the fig and sandal-wood tribe, and by some Proteacece. There are also maniy tropical forms of Leguminose, together with fan-palms, and a palm allied to the cocoa-nut with its fruit; also, according to Massalongo, an orchideous epiphyte. That scarcely any one of the Monte Bolca fish should have been found in any other locality in Europe, is a striking illustration of the extreme imperfection of the palæontological record. We are in the habit of imagining that our insight into the geology of the Eocene period is more than usually perfect, and we are certainly ac: quainted with an almost unbroken succession of assemblages of shells passing one into the other from the era of the Thanet sands to that of the Bembridge beds or Paris grpsum. The general dearth, therefore, of fish might induce a hasty reasoner to conclude that there was a porerty of ichthyic forms during this long period; but when a local accident, like the volcanic eruptions of Monte Bolca, occurs, proofs are suddenly revealed to us of the richness and variety of this greast class of vertebrata in the Eocene sea. The number of genera of Monte Bolea fish is, according to Agassiz, no less than seventy-five, twenty of them peculiar to that locality, and only eight common to the antecedent Cretaceous period. No less than forty-seven out of the serentr-fire genera make their appearance for the first time in the Monte Bolca rocks, none of them having been met with as yet in the antecedent formations. They form a great contrast to the fish of the secondary period, as, with the exception of the Placoids, they are all Teleosteans, only one genus, Pycnodus, belonging to the order of

* Principles of Geology, chap. xxvi., 9th ed., p. 432. 
Ganoids, which form, as before stated, the vast majority of the ichthyolites entombed in the secondary rocks.

Cretaceous Period.-Although we have no proof of volcanic rocks erupted in England during the dęposition of the chalk and greensand, it would be an error to suppose that no theatres of igneous action existed in the Cretaceous period. M. Virlet, in his account of the geology of the Morea, p. 205, has clearly shown that certain traps in Greece, called by him ophiolites, are of this date; as those, for example, which alternate conformably with cretaceous limestone and greensand between Kastri and Damala in the Morea. They consist in great part of diallage rocks and serpentine, and of an amygdaloid with calcareous kernels, and a base of serpentine.

In certain parts of the Morea, the age of these volcanic rocks is established by the following proofs : first, the lithographic limestones of the Cretaceous era are cut through by trap, and then a conglomerate occurs, at Naupila and other places, containing in its calcareous cement many well-known fossils of the chalk and greensand, together with pebbles formed of rolled pieces of the same ophiolite, which appear in the dikes above alluded to.

Period of Oolite and Lias.-Although the green and serpentinous trap rocks of the Morea belong chiefly to the Cretaceous era, as before mentioned, yet it seems that some eruptions of similar rocks began during the Oolitic period;* and it is probable that a large part of the trappean masses, called ophiolites in the Apennines, and associated with the limestone of that chain, are of corresponding age.

That some part of the volcanic rocks of the Hebrides, in our own country, originated contemporaneously with the Oolite which they traverse and overlie, has been ascertained by Professor E. Forbes, in 1850. Some of the eruptions in Skye, for example, occurred at the close of the Middle and before the commencement of the Upper Oolitic period. $\uparrow$

Trap of the New Red Sandstone Period.-In the southern part of Devonshire, trappean rocks are associated with New Red Sandstone, and, according to Sir H. de la Beche, have not been intruded subsequently into the sandstone, but were produced by contemporaneous volcanic action. Some beds of grit, mingled with ordinary red marl, resemble sands ejected from a crater; and in the stratified conglomerates occurring near Tiverton are many angular fragments of trap porphyry, some of them one or two tons in weight, intermingled with pebbles of other rocks. These angular fragments were probably thrown out from volcanic vents, and fell upon sedimentary matter then in the course of deposition.:

Carboniferous Period.-Two elasses of contemporaneous trap rocks were ascertained by Dr. Fleming to occur in the coal-field of the

* Boblaye and Virlet, Morea, p. 23.

† Geol. Quart. Journ., 1851, vol. vii. p. 108.

$\ddagger$ De la Beche, Geol. Proceedings, vol, ii. p. 198. 
Forth in Scotland. The newest of these, connected with the higher series of coal-measures, is well exhibited along the shores of the Forth, in Fifeshire, where they consist of basalt with olivine, amygdaloid, greenstone, wacke, and tuff. They appear to have been erupted while the sedimentary strata were in a horizontal position, and to have suffered the same dislocations which those strata have subsequently undergone. In the rolcanic tuffs of this age are found not only fragments of limestone, shale, flinty slate, and sandstone, but also pieces of coal.

Fig. 781.

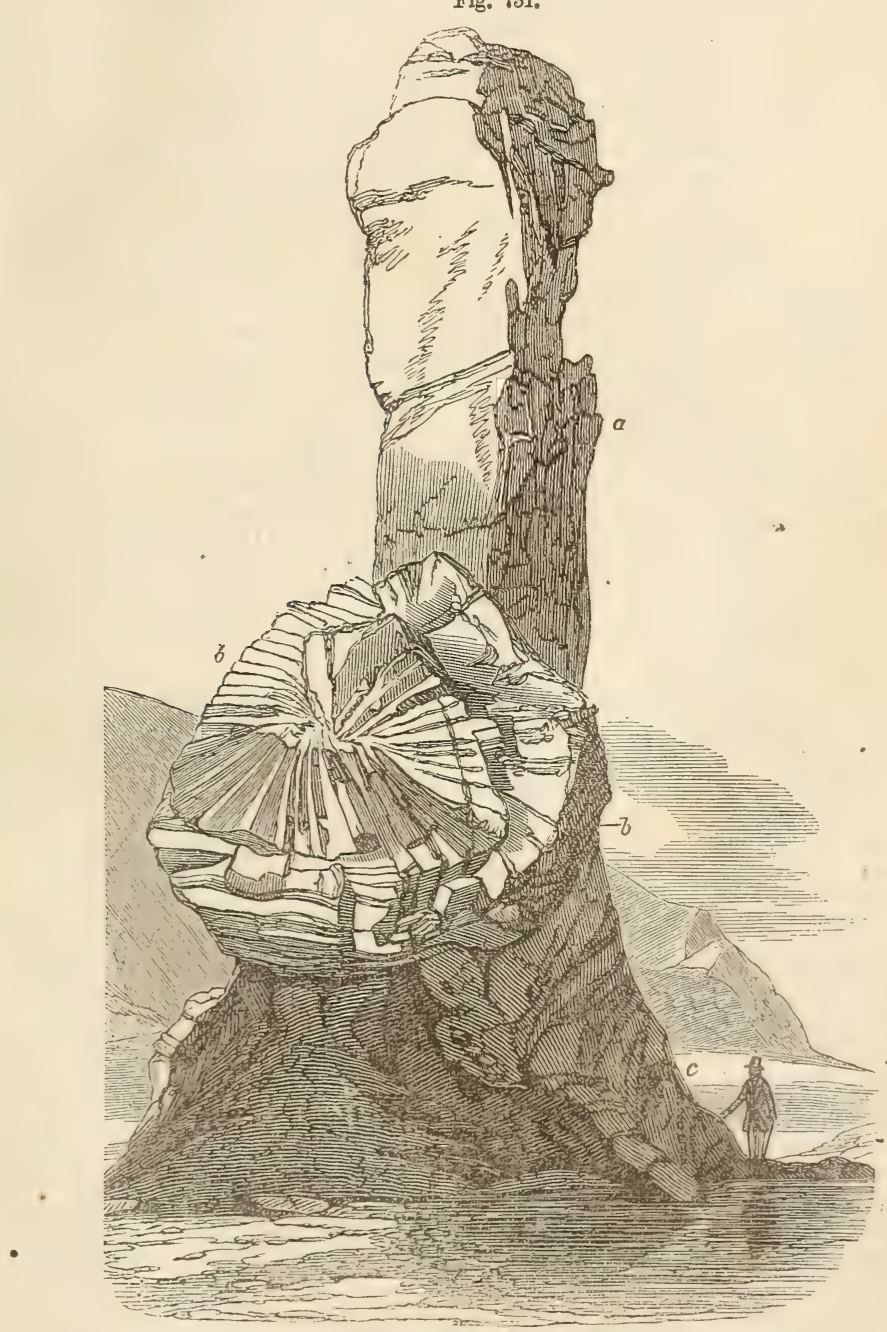

Rock and Spindle, Șt. Andrew's, as seen in 1838.

a. Unstratified tuff.

b. Columnar greenstone.

c. Stratified tuff. 
The other or older class of carboniferous traps are traced along the south margin of Stratheden, and constitute a ridge parallel with the Ochils, and extending from Stirling to near St. Andrew's. They consist almost exclusively of greenstone, becoming, in a few instances, earthy and amygdaloidal. They are regularly interstratified with the sandstone, shale, and ironstone of the lower Coal-measures, and, on the East Lomond; with Mountain Limestone.

I examined these trap rocks in 1838, in the cliffs south of St. Andrew's, where they consist in great part of stratified tuffs, which are curved, vertical, and contorted, like the associated coal-measures. In the tuff I found fragments of carboniferous shale and limestone, and intersecting reins of greenstone. At one spot, about two miles from St. Andrew's, the encroachment of the sea on the cliffs has isolated several masses of trap, one of which (fig. 731) is aptly called the " rock and spindle," * for it consists of a pinnacle

Fig. 732.

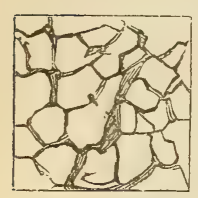

Columns of Greenstone, seen endwise at 6 , fig. 731 . of tuff, which may be compared to a distaff, and near the base is a mass of columnar greenstone, in which the pillars radiate from a centre and appear at a distance like the spolkes of a wheel. The largest diameter of this wheel is about twelve feet, and the polygonal terminations of the columns are seen round the circumference (or tire, as it were, of the wheel), as in the accompanying figure. I conceive this mass to be the extremity of a string or vein of greenstone, which penetrated the tuff. The prisms point in every direction, because they were surrounded on all sides by cooling surfaces, to which they always arrange themselves at right angles, as before explained (p. 617).

A trap dike was pointed out to me by Dr. Fleming, in the parish of Flisk, in the northern part of Fifeshire, which cuts through the gray sandstone and shale, forming the lowest part of the Old Red Sandstone, but which may probably be of carboniferous date. It may be traced for many miles, passing through the amygdaloidal

- and other traps of the hill called Norman's Law. In its course it affords a good exemplification of the passage from the trappean into the plutonic, or highly crystalline texture. Professor Gustavus Rose, to whom I submitted specimens of this dike, finds the rock, which he calls dolerite, to consist of greenish black augite and Labrador felspar, the latter being the most abundant ingredient. A small quantity of magnetic iron, perhaps titaniferous, is also present. The result of this analysis is interesting, because both the ancient and modern lavas of Etna consist in like manner of augite, Labradorite, and titaniferous iron.

Trap of the Old Red Sandstone Period.-By referring to the sec-•

* "The Rock," as English readers of Burns" poems may remember, is a Scotch term for a distaff. 
tion explanatory of the structure of Forfarshire, already giren (p. 48), the reader will perceive that beds of conglomerate, No. 3, occur in the middle of the Old Red Sandstone system, 1, 2, 3, 4. The pebbles in these conglomerates are sometimes composed of granitic and quartzose rocks, sometimes exclusirely of different varieties of trap, which last, although purposely omitted in the section referred to, is often found either intruding itself in amorphous masses and dikes into the old fossiliferous tilestones, No. 4, or alternating mith them in conformable beds. All the different divisions of the red sandstone, $1,2,3,4$, are occasionally intersected by dikes; but they are very rare in Nos. 1 and 2, the upper members of the group consisting of red shale and red sandstone. These phenomena, which occur at the foot of the Grampians, are repeated in the. Sidlaw Hills; and it appears that in this part of Scotland volcanic eruptions were most frequent in the earlier part of the Old Red Sandstone period.

The trap rocks alluded to consist chiefly of felspathic porphyry and amrgdaloid, the kernels of the latter being sometimes calcareous, often chalcedonic, and forming beautiful agates. We meet also with claystone, clinkstone, greenstone, compact felspar, and tuff. Some of these rocks flowed as lavas over the bottom of the sea, and enveloped quartz pebbles which were lying there, so as to form conglomerates with a base of greenstone, as is seen in Lumley Den, in the Sidlaw Hills. On either side of the axis of this chain of hills (see section, p. 48), the beds of massire trap, and the tuffs composed of volcanic sand and ashes, dip regularly to the southeast or northwest, conformably with the shales and sandstones. But the geological structure of the Pentland Hills, near Edinburgh, shows that igneous rocks were there formed during the newer part of the Deronian or "Old Red" period. These hills are 1900 feet high above the sea, and consist of conglomerates and sandstcnes of Upper Deronian age, resting on the inclined edges of grits and slates of Lower Deronian and Upper Silurian date. The contemporaneous volcanic rocks intercalated in this Upper Old Red consist of felspathic lavas, or felstones, with associated tuffs or ashy beds. The lavas were some of them originally compact, others vesicular, and these last have been converted into amygdaloids. They consist chiefly of felstone or compact felspar. The Pentland Hills, say Messrs. Maclaren and Geikie, afford evidence that at the time of the Tpper Old Red Sandstone, the district to the southirest of Edinburgh was for a long while the seat of a powerful volcano, which sent out massive streams of lava and showers of ash, and continued active until mell-nigh the dawn of the Carboniferous period.*

Silurian Period.-It appears, from the investigations of Sir R. Murchison in Shropshire, that when the lower Silurian strata of

* Maclaren, Geology of Fife and Lothians. Geikie, Trans. Royal Soc. Edinburgh, 1860-1861. 
that country were accumulating, there were frequent volcanic eruptions beneath the sea; and the aśhes and scoriæ then ejected gave rise to a peculiar kind of tufaceous sandstone or grit, dissimilar to the other rocks of the Silurian series, and only observable in places where syenitic and other trap rocks protrude. These tuffs occur on the flanks of the Wrekin and Caer Caradoc, and contain Silurian fossils, such as casts of encrinites, trilobites, and mollusca. Although fossiliferous, the stone resembles a sandy claystone of the trap family.*

Thin layers of trap, only a few inches thick, alternate in some parts of Shropshire and Montgomeryshire with sedimentary strata of the lower Silurian system. This trap consists of slaty porphyry and granular felspar rock, the beds being traversed by joints like those in the associated sandstone, limestone, and shale, and having the same strike and dip. $\dagger$

In Radnorshire there is an example of twelve bands of stratified trap, alternating with Silurian schists and flagstones, in a thickness of 350 feet. The bedded traps consist of felspar porphyry, clinkstone, and other varieties; and the interposed Llandeilo flags are of sandstone and shale, with trilobites and graptolites.

The Snowdonian hills in Caernarvonshire consist in great part of volcanic tuffs, the oldest of which are interstratified with the Bala limestone and slate. There are some contemporaneous felspathic lavas of this era, which, says Professor Ramsay, alter the slates on which they repose, having doubtless been poured out over them in a melted state, whereas the slates which overlie them having been subsequently deposited after the lava had cooled and consolidated, have entirely escaped alteration. But there are greenstones associated with the same formation, which, although they are often conformable to the slates, are in reality intrusive rocks. They alter the stratified deposits both above and below them, and when traced to great distances, are sometimes seen to cut through the slates, and to send off branches. Nevertheless, these greenstones appear to belong, like the lavas, to the Lower Silurian period.

Cambrian Volcanic Rocks.-The Lingula beds in North 'Wales have been described as 7000 feet in thickness. In the upper portion of these deposits, volcanic tuffs or ashy materials are interstratified with ordinary muddy sediment, and here and there associated with thick beds of felspathic lava. These rocks form the mountains called the Arans and the Arenigs; numerous greenstones are associated with them, which are intrusive, although they often run in the lines of bedding for a space. "Much of the ash," says Professor Ramsay, "seems to have been subaërial. Islands, like Graham's Island, may have sometimes raised their craters for various periods above the

* Murchison, Silurian System, \&c., p. 230.

† Ibid., p. 212.

† Ibid., p. 325 . 
water, and by the waste of such islands some of the ashy matter became waterworn, whence the ashy conglomerate. Viscous matter seems also to have been shot into the air as volcanic bombs, which fell among the dust and broken crystals (that often form the ashes) before perfect cooling and consolidation had taken place." *

Laurentian Volcanic Rocks.-The Laurentian rocks in Canada, especially in Ottawa and Argenteuil, are the oldest irtrusive masses ret known. They form a set of dikes of a fine-grained dark greenstone or dolerite, composed of felspar and pyroxene, with occasional scales of mica and grains of pyrites. Their width varies from a few feet to a hundred yards, and they have a columnar structure, the columns being truly at right angles to the plane of the dike. Some of the dikes send off branches. These dolerites are cut through by intrusive syenite, and this syenite, in its turn, is again cut and penetrated by felspar porphyry, the base of which consists of petrosilex, or a mixture of orthoclase and quartz. All these trap rocks appear to be of Laurentian date, for the lowest fossiliferous rocks, such as the Cambrian or Potsdam sandstone, overlie eroded portions of them.t Whether some of the various conformable crystalline rocks of the Laurentian series, such as the coarse-grained granitoid and porphyritic rarieties of gneiss, exhibiting scarcely any signs of stratification, some of the serpentines, may not also be of volcanic origin, is a point rery difficult to determine in a region which has undergone so much metamorphic action.

* Geol, Quart. Journ., vol, ix. p. 170, 1853.

† Logan, Geology of Canada, 1862. 


\title{
CHAPTER XXXIII.
}

\author{
PLUTONIC ROCKS- GRANITE.
}

General aspect of granite-Decomposing into spherical masses-Rude columnar structure-Analogy and difference of volcanic and plutonic formations-Minerals in granite, and their arrangemen 2 -Graphic and porphyritic granite-Mutual penetration of crystals of quartz and felspar-0ccasional minerals-SyeniteSyenitic, talcose, and schorly granites-Eurite-Passage of granite into trapExamples near Christiania and in Aberdeenshire-Analogy in composition of trachyte and granite-Granite veins in Glen Tilt, Cornwall, the Valorsine, and other countries-Different composition of veins from main body of graniteMetalliferous veins in strata near their junction with granite-Apparent isolation of nodules of granite-Quartz veins-Whether plutonic rocks are ever overlying -Their exposure at the surface due to denudation.

THE plutonic rocks may be treated of next in order, as they are most nearly allied to the volcanic class already considered. I have described, in the first chapter, these plutonic rocks as the unstratified division of the crystalline or hypogene formations, and have stated that they differ from the volcanic rocks, not only by their more crystalline texture, bnt also by the absence of tuffs and breccias, which are the products of eruptions at the earth's surface, or beneath seas of inconsiderable depth. They differ also by the absence of pores or cellular cavities, to which the expansion of the entangled gases gives rise in ordinary lava. From these and other peculiarities it has been inferred, that the granites have been formed at considerable depths in the earth, and have cooled and crystallized slowly under great pressure, where the contained gases could not expand. The volcanic rocks, on the contrary, although they also have risen up from below, have cooled from a melted state more rapidly upon or near the surface. From this hypothesis of the great depth at which the granites originated, has been derived the name of "Plutonic rocks." The beginner will easily conceive that the influence of subterranean heat may extend downwards from the crater of every active volcano to a great depth below, perhaps several miles or leagues, and the effects which are produced deep in the bowels of the earth may, or rather must, be distinct; so that volcanic and plutonic rocks, each different in texture, and sometimes even in composition, may originate simultaneously, the one at the surface, the other far beneath it.

By sôme writers, all the rocks now under consideration have been 
comprehended under the name of granite, which is, then, understood to embrace a large family of crystalline and compound rocks, usually found underlying all other formations; whereas we have seen that trap very commonly overlies strata of different ages. Granite often preserves a very uniform character throughout a wide range of territory, forming hills of a peculiar rounded form, usually clad with a scanty vegetation. The surface of the rock is for the most part in a crumbling state, and the hills are often surmounted by piles of stones like the remains of a stratified mass, as in the annexed figure, and

Fig. 789.

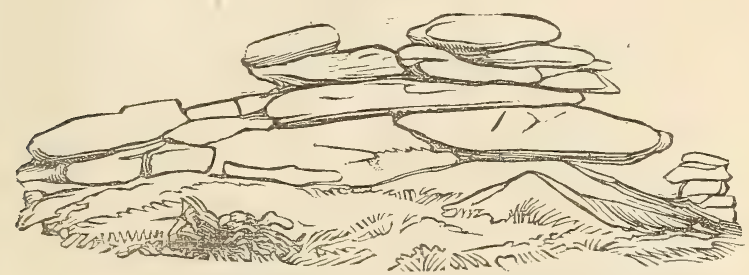

Mass of granite near the Sharp Tor, Cornwall.

sometimes like heaps of boulders, for which they have been mistaken. The exterior of these stones, originally quadrangular, acquires a rounded form by the action of air and water, for the edges and angles waste away more rapidly than the sides. A similar spherical structure has already been described as characteristic of basalt and other volcanic formations, and it must be referred to analogous causes, as yet but imperfectly understood.

Although it is the general peculiarity of granite to assume no definite shapes, it is nerertheless occasionally subdivided by fissures, so as to assume a cuboidal, and even a columnar structure. Examples of these appearances may be seen near the Land's End, in Cornwall. (See fig. 734.)

The plutonic formations also agree with the volcanic in having veins or ramifications proceeding from central masses into the adjoining rocks, and causing alterations in these last, which will be presently described. They also resemble trap in containing no organic remains; but they differ in being more uniform in texture, whole mountain masses of indefinite extent appearing to have originated under conditions precisely similar. They also differ in never being scoriaceous or anygdaloidal, and never forming a porphyry with an uncrystalline base, or alternating with tuffs. Nor do they form conglomerates, although there is sometimes an insensible passage from a fine to a coarse-grained granite, and occasionally patches of a fine texture are imbedded in a coarser variety.

Felspar, quartz, and mica are usually considered as the minerals essential to granite, the felspar being most abundant in quantity, and the proportion of quartz exceeding that of mica. These minerals are 
Fig. 734 .

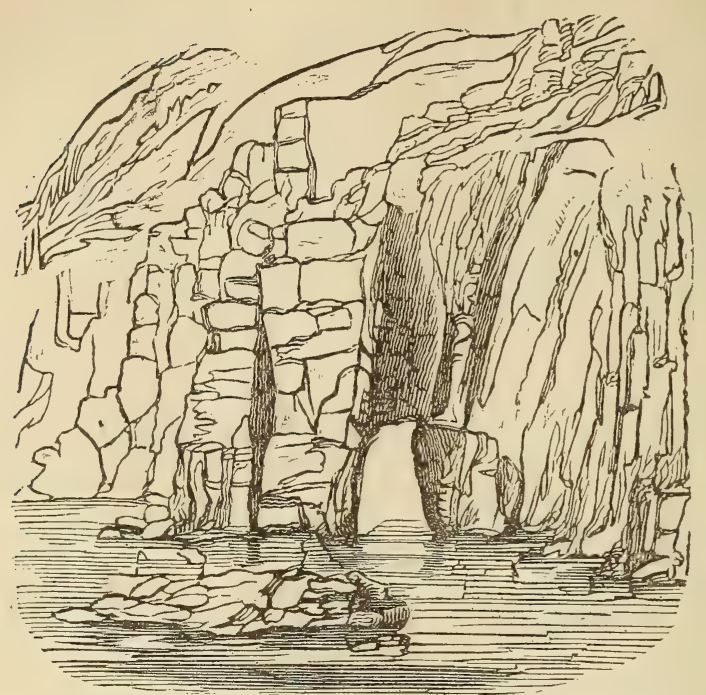

Granite having a cuboidal and rude columnar structure, Land's End, Cornwail.

united in what is termed a confused crystallization; that is to say, there is no regular arrangement of the crystals in granite, as in gneiss (see fig. 756, p. 733), except in the variety termed graphic granite, which occurs mostly in granitic veins. This variety is a compound of felspar and quartz, so arranged as to produce an imperfect laminar structure. The crystals of felspar appear to have been first formed, leaving between them the space now occupied by the darker-colored quartz. This mineral, when a section is made at right angles to the

Fig. 735.

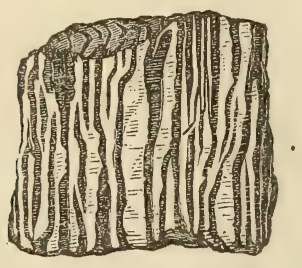

Fig. 736.

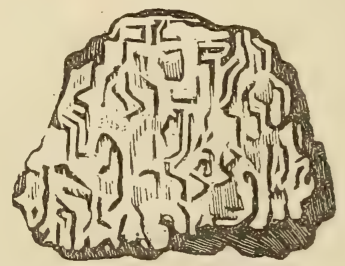

- Graphic granite.

Fig. 735. Section parallel to the laminx.

Fig. 736. Section transverse to the laminæ.

alternate plates of felspar and quartz, presents broken lines, which have been compared to Hebrew characters. The variety of granite called by the French Pegmatite, which is a mixture of quartz and common felspar, usually with some small admixture of white silvery

- mica, often passes into graphic granite. 
Ordinary granite, as well as syenite and eurite, usually contains two kinds of felspar: 1st, the common, or orthoclase, in which potash is the prevailing alkali, and this generally occurs in large crystals of a white or flesh color; and 2dly, felspar in smaller crystals, in which soda predominates, usually of a dead white or spotted, and striated like albite, but not the same in composition.*

As a general rule, quartz, in a compact or amorphous state, forms a ritreous mass, serving as the base in which felspar and mica have crsstallized; for although these minerals are much more fusible than silex, they have often imprinted their shapes upon the quartz. This fact, apparently so paradoxical, has given rise to much ingenious speculation. We should naturally have anticipated that, during the cooling of the mass, the flinty portion would be the first to consolidate; and that the different varieties of felspar, as well as garnets and tourmalines, being more easily liquefied by heat, would be the last. Precisely the rererse has taken place in the passage of most granite aggregates from a fluid to a solid state, crystals of the more fusible minerals being found enreloped in hard, transparent, glassy quartz, which has often taken very faithful casts of each, so as to preserve eren the microscopically minute striations on the surface of prisms of tourmaline. Tarious explanations of this phenomenon have been proposed by MLI. de Beaumont, Fournet, and Durocher. They refer to M. Gaudin's experiments on the fusion of quartz, which shows that silex, as it cools, has the property of remaining in a viscous state, whereas alumina never does. This "gelatinous flint" is supposed to retain a considerable degree of plasticity long after the granitic mixture bas acquired a low temperature; and M. E. de Beaumont suggests that electric action may prolong the duration of the viscosity of silex. Occasionally, howerer, we find the quartz and felspar mutually imprinting their forms on each other, affording eridence of the simultaneous crystallization of both. $\uparrow$

According to the experiments and observations of Gustave Rose, the quartz of granite has the specific gravity of $2 \cdot 6$, which characterizes silica when it is precipitated from a liquid solvent, and not that inferior density, namely, $2 \cdot 3$, which belongs to it when it cools in the laboratory, in what is called the dry war, or from a state of fusion. It has been, therefore, inferred, perhaps somewhat rashly, that the manner in which the consolidation of granite takes place is exceedingly different from the cooling of lavas, eren of those which are the most crystalline. It has also been still more hastily inferred, that the intense heat formerly supposed to be necessary for the production of mountain masses of plutonic rocks may be dispensed with. The first question to be decided is, whother or not silica can be ob-

* Delesse, Ann. des Mines, 1852, t. iii. p. 409, and 1848, t. xiii. p. 675.

† Bulletin, 2e série, iv. 1304; and D'Archiac, Hist. des Progrès de la Géol., i. 38 . 
tained even in the laboratory in a crystalline state by fusion. $\mathrm{Mr}$. Sorby, who has devoted much time and talent to the solution of this and kindred problems, has come to the conclusion that it can be so obtained. He informs me that he is convinced, by the examination of quartz fused by Mr. David Forbes, that silica can crystallize in the dry way, and he has found in quartz forming a constituent part of some trachytes, both from Guadaloupe and Iceland, glass-cavities * quite similar to those met with in genuine volcanic minerals, which prove most conclusively that this quartz crystallized out from a fused material like obsidian.

By "glass-cavities" are meant those in which a liquid, on cooling, has become first viscous and then solid without crystallizing or undergoing a definite change in its physical structure. Other cavities which, like those just mentioned, are frequently discernible under the microscope in the minerals composing granitic rocks, are filled some of them with gas or vapor, others with liquid, and by the movements of the bubbles thus included the distinctness of such cavities from those filled with a glassy substance can be tested.

Mr. Sorby admits that the frequent occurrence of fluid cavities in the quartz of granite implies that water was almost always present in the formation of this rock; but the same may be said of almost all lavas, and it is now more than forty years since Mr. Scrope insisted on the important part which water plays in volcanic eruptions, being so intimately mixed up with the materials of the lava that he supposed it to aid it in giving mobility to the fluid mass. It is well known that steam escapes for months, sometimes for years, from the cavities of lava when it is cooling and consolidating.

As to the result of Mr. Sorby's experiments and speculations on this difficult subject, they may be stated in a few words. He concludes that the physical conditions under which the volcanic and granitic rocks originate are so far similar that in both cases they combine igneous fusion, aqueous solution, and gaseous sublimation-the proof, he says, of the operation of water in the formation of granite being quite as strong as that of heat. $\dagger$

When rocks are melted at great depths water must be present, for two reasons: First, because in a state of solid combination water enters largely into the composition of some of the most common minerals, especially those of the aluminous class; and, secondly, because rain-water and sea-water are always descending through fissured and porous rocks, and must at length find their way into the regions of subterranean heat. But the existence of water under great pressure affords no argument against our attributing an excessively high temperature to the mass with which it is mixed up.

Bunsen, indeed, imagines that in Iceland it attains a white heat at

* See Quart. Geol. Journ., vol, xiv. p. 465.

† Ibid., p. 488. 
a very moderate depth. Still less does the point to which the materials of granite or lara must be cooled down before they crystallize or consolidate afford any test of the degree of heat which the same materials acquired before they could be made to form lakes and seas of molten rock in the interior of the earth's crust.

To what extent some of the metamorphic rocks containing the same minerals as the granites may have been formed by hydrothermal action without the interrention of intense heat comparable to that brought into play in a rolcanic eruption, will be considered when we treat of the metamorphic rocks, in the thirty-fifth chapter, p. 736.

Porphyritic Granite.-This name has been sometimes giren to that variety in which large crystals of common felspar, sometimes more than 3 inches in length, are scattered through an ordinary base of granite. An example of this texture may be seen in the granite of the Land's End, in Cornwall (fig. $73 \%$ ). The two larger prismatic crystals in this draw-

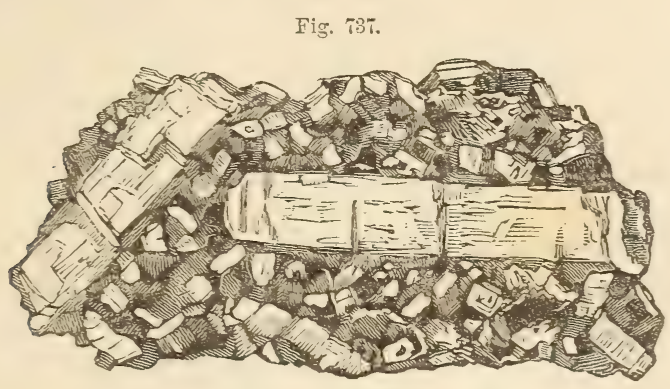

Porphyritic granite. Land's End, Cornmall.

ing represent felspar, smaller crystals of which are also seen, similar in form, scattered through the base. In this base also appear black specks of mica, the crystals of which have a more or less perfect hexagonal outline. The remainder of the mass is quartz, the translucency of mhich is strongly contrasted to the opaqueness of the white felspar and black mica. But neither the transparency of the quartz nor the silvery lustre of the mica can be expressed in the engraving.

The uniform mineral character of large masses of granite seems to indicate that large quantities of the component elements were thoroughly mixed up together, and then crystallized under precisely similar conditions. There are, howerer, many accidental, or "occasional," minerals, as ther are termed, which belong to granite. Among these, black schorl or tourmaline, actinolite, zircon, garnet, and fluor spar are not uncommon; but they are too sparingly dispersed to modify the general aspect of the rock. Ther show, nerertheless, that the ingredients were not ererywhere exactly the same; and a still greater variation may be traced in the ever-varying proportions of the felspar, quartz, and mica. 
Syenite.-When hornblende is the substitute for mica, which is very commonly the case, the rock becomes Syenite; so called from the celebrated ancient quarries of Syene in Egypt. It has all the appearance of ordinary granite, except when mineralogically examined in hand specimens, and is fully entitled to rank as a geological member of the same plutonic family as granite. Syenite, however, after maintaining the granitic character throughout extensive regions, is not uncommonly found to lose its quartz, and to pass insensibly into syenitic greenstone, a rock of the trap family. Werner considered syenite as a binary compound of felspar and hornblende, and regarded quartz as merely one of its occasional minerals.

Syenitic Granite.-The quadruple compound of quartz, felspar, mica, and hornblende, may be so termed. This rock occurs in Scotland and in Guernsey.

Talcose Granite, or Protogine of the French, is a mixture of felspar, quartz, and talc. It abounds in the Alps, and in some parts of Cornwall, producing by its decomposition the China clay, more than 12,000 tons of which are annually exported from that country for the potteries.*

Schorl-Rock, and Schorly Granite.-The former of these is an aggregate of schorl, or tourmaline, and quartz. When felspar and mica are also present, it may be called schorly granite. This kind of granite is comparatively rare.

Eurite.-A rock in which all the ingredients of granite are blended into a finely granular mass. When crystalline, it is seen to contain crystals of quartz, mica, common felspar, and soda felspar. When there is no mica, and when common felspar predominates, so as to give it a white color, it becomes a felspathic granite, called. "whitestone" (Weisstein) by Werner, or Leptynite by the French, in which microscopic crystals of garnet are often present.

All these and other varieties of granite pass into certain kinds of trap-a circumstance which affords one of many arguments in favor of what is now the prevailing opinion, that the granites are also of igneous origin. The contrast of the most crystalline form of granite to that of the most common and earthy trap is undoubtedly great; but each member of the volcanic class is capable of becoming porphyritic, and the base of the porphyry may be more and more crystalline, until the mass passes to the kind of granite most nearly allied in mineral composition.

The minerals which constitute alike the granitic and volcanic rocks consist, almost exclusively, of seven elements, namely, silica, alumina, magnesia, lime, soda, potash, and iron (see Table, p. 608); and these may sometimes exist in about the same proportions in a porous lava, a compact trap, or a crystalline granite. It may perhaps be found, on further examination-for on this subject we have yet much to

* Boase on Primary Geology, p. 16. 
learn-that the presence of these elements in certain proportions is more farorable than in others to their assuming a crystalline or true granitic structure; but it is also ascertained by experiment, that the same materials may, under different circumstances, form very different rocks. The same lava, for example, may be glassy, or scoriaceous, or stony, or porphyritic, according to the more or less rapid rate at which it cools; and some trachytes and syenitic-greenstones may doubtless form granite and syenite, if the crystallization take place slowly.

It has also been suggested that the peculiar nature and structure of granite may be due to its retaining in it that water which is seen to escape from lavas when they cool slowly, and consolidate in the atmosphere. Boutigny's experiments have shown that melted matter, at a white heat, requires to have its temperature lowered before it can vaporize water; and such discoveries, if they fail to explain the manner in which granites have been formed, serve at least to remind us of the entire distinctness of the conditions under which plutonic and voleanic rocks must be produced.*

It would be easy to multiply examples and authorities to prove the gradation of the granitic into the trap rocks. On the western side of the fiord of Christiania, in Norway, there is a large district of trap, chiefly greenstone-porphyry and syenitic greenstone, resting on fossiliferous strata. To this, on its southern limit, succeeds a region equally extensive of syenite, the passage from the volcanic to the plutonic rock being so gradual that it is impossible to draw a line of demarcation between them.

"The ordinar'y granite of Aberdeenshire," says Dr. MacCulloch, "is the usual ternary compound of quartz, felspar, and mica; but sometimes hornblende is substituted for the mica. But in many places a variety occurs which is composed simply of felspar and hornblende; and in examining more minutely this duplicate compound, it is observed in some places to assume a fine grain, and at length to become undistinguishable from the greenstones of the trap family. It also passes in the same uninterrupted manner into a basalt, and at length into a soft claystone, with a schistose tendency on exposure, in no respect differing from those of the trap islands of the western coast." The same author mentions, that in Shetland a granite composed of hornblende, mica, felspar, and quartz graduates in an equally perfect manner into basalt. $\uparrow$

In Hungary, there are varieties of trachyte, which, geologically speaking, are of modern origin, in which crystals, not only of mica, but of quartz, are common, together with felspar and hornblende. It is easy to conceive how such volcanic masses may, at a certain depth from the surface, pass downwards into granite.

* E. de Beaumont, Bulletin, vol. iv., 2e sér., pp. 1318 and 1320.

+ Syst. of Geol., vol. i. pp. 157 and 158 . 
I have already hinted at the close analogy in the forms of certain granitic and trappean veins; and it will be found that strata penetrated by plutonic rocks have suffered changes very similar to those exhibited near the contact of volcanic dikes. Thus, in Glen Tilt, in Scotland, alternating strata of limestone and argillaceous schist come in contact with a mass of granite. The contact does not take place as might have been looked for, if the granite had been formed there before the strata were deposited, in which case the section would have appeared as in fig. 738 ; but the union is as represented in fig. 739 ,

Fig. 738.

Fig. 739.

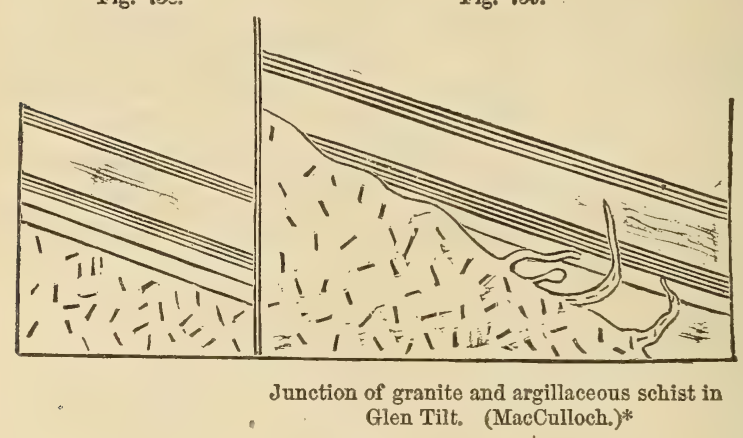

Fig. 740 .

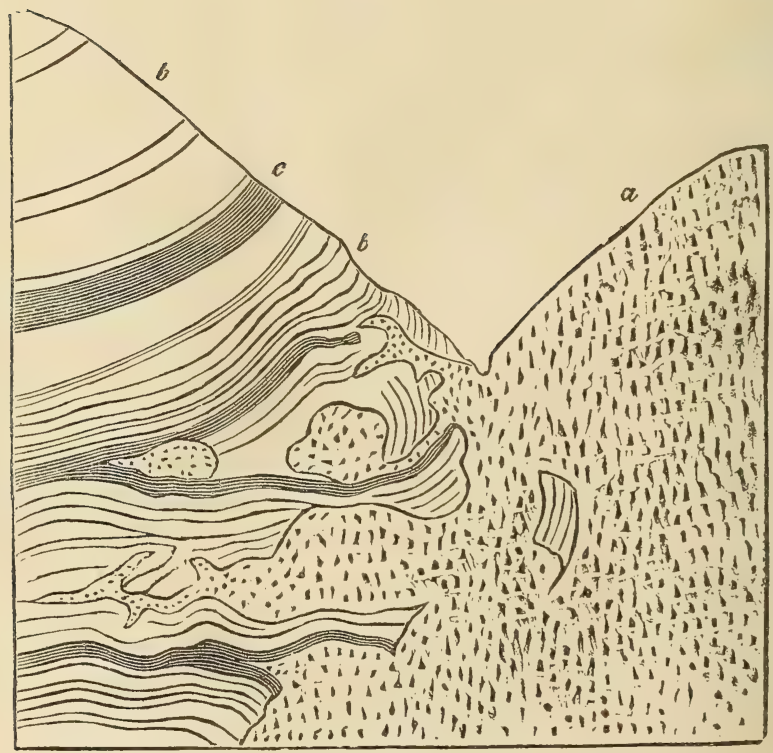

Junction of granite and limestone in Glen Tilt. (MacCulloch.)
a. Granite.
b. Limestone.
c. Blue argillaceous schist.

* Geol. Trans., First Series, vol. iii. pl. 21. 
the undulating outline of the granite intersecting different strata, and occasionally intruding itself in tortuous reins into the beds of clayslate and limestone, from which it differs so remarkably in composition. The limestone is sometimes changed in character by the proximity of the granitic mass or its reins, and acquires a more compact texture, like that of hornstone or chert, with a splintery fracture, and effervescing freely with acids.

The foregoing diagram (fig. 740 ) represents another junction, in the same district, where the granite sends forth so many veins as to reticulate the limestone and schist, the veins diminishing towards their termination to the thickness of a leaf of paper or a thread. In some places fragments of granite appear entangled, as it wcre, in the limestone, and are not visibly connected with any larger mass; while sometimes, on the other hand, a lump of the limestone is found in the midst of the granite. The ordinary color of the limestone of Glen Tilt is lead blue, and its texture large-grained and highly crystalline; but where it approximates to the granite, particularly where it is penetrated by the smaller reins, the crystalline texture disappears, and it assumes an appearance exactly resembling that of hornstone. The associated argillaceous schist often passes into hornblende slate, where it approaches very near to the granite.*

The conversion of the limestone in these and many other instances into a siliceous rock, efferrescing slowly with acids, would be difficult of explanation, were it not ascertained that such limestones are always impure, containing grains of quartz, mica, or felspar disseminated through them. The elements of these minerals, when the rock has been subjected to great heat, may have been fused, and so spread more uniformly through the whole mass.

Fig. 741 .

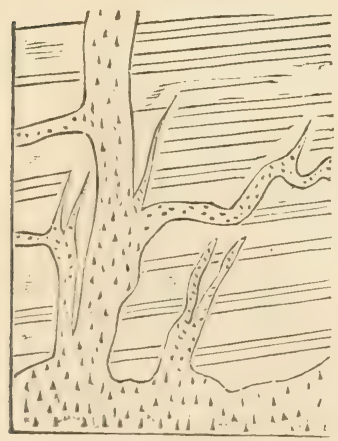

Granite veins traversing clay slate, Table Mountain, Cape of Good Hope.t
Fig. 742

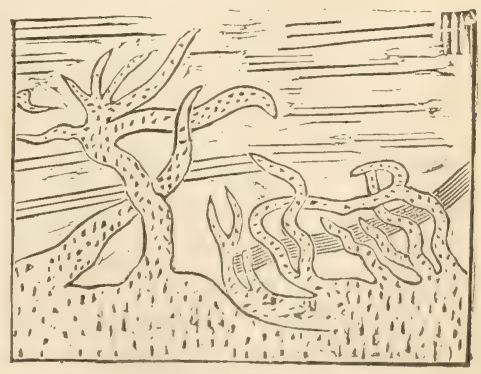

Granite veins traversing gneiss, Cape Wrath. (MacCallocb.) $\ddagger$

* MacCulloch, Geol. Trans, vol. iii. p. 259.

† Capt. B. Hall, Trans. Roy. Soc. Edinburgh, vol. vii.

$\ddagger$ Western Islands, pl. 31. 
In the plutonic, as in the volcanic rocks, there is every gradation from a tortuous vein to the most regular form of a dike, such as intersect the tuffs and lavas of Vesuvius and Etna. Dikes of granite may be seen, among other places, on the southern flank of Mount Battock, one of the Grampians, the opposite wall sometimes preserving an exact parallelism for a considerable distance.

As a general rule, however, granite veins in all quarters of the globe are more sinuous in their course than those of trap. They present similar shapes at the most northern point of Scotland, and the southernmost extremity of Africa, as the foregoing drawings (figs. 741 and 742) will show.

It is not uncommon for one set of granite veins to intersect another; and sometimes there are three sets, as in the environs of Heidelberg, where the granite on the banks of the river Necker is seen to consist of three varieties, differing in color, grain, and various peculiarities of mineral composition. One of these, which is evidently the second in age, is seen to cut through an older granite; and another, still newer, traverses both the second and the first.

In Shetland there are two kinds of granite. One of them, composed of hornblende, mica, felspar, and quartz, is of a dark color, and is seen underlying gneiss. The other is a red granite, which penetrates the dark variety everywhere in veins.*

The accompanying sketches will explain the manner in which granite veins often ramify and cut each other (figs. 743 and 744). They

Fig. 743 .

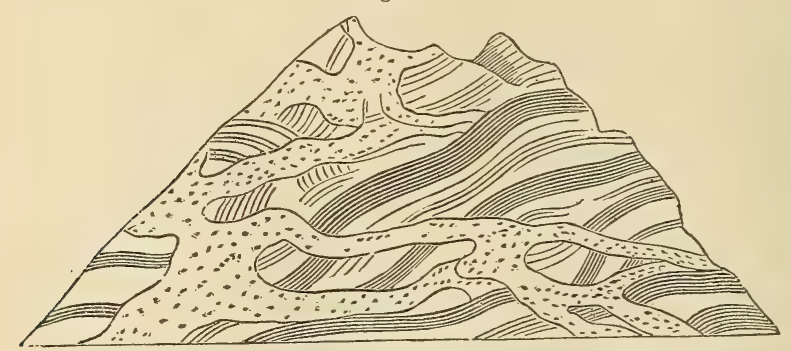

Granite veins traversing gneiss at Cape Wrath, in Scotland. (MacCulloch.)

represent the manner in which the gneiss at Cape Wrath, in Sutherlandshire, is intersected by veins. The light color strongly contrasted with that of the hornblende-schist, here associated with the gneiss, renders them very conspicuous.

Granite very generally assumes a finer grain, and undergoes a change in mineral composition, in the veins which it sends into contiguous rocks. Thus, according to Professor Sedgwick, the main body of the Cornish granite is an aggregate of mica, quartz, and 
felspar; but the veins are sometimes without mica, being a granular aggregate of quartz and felspar. In other varieties quartz prevails to the almost entire exclusion both of felspar and mica; in others, the mica and quartz both disappear; and the vein is simply composed of white granular felspar.*

Fig. 744 is a sketch of a group of granite veins in Cornwall, given by Messrs. Von Oeynhausen and Von Dechen.t The main body of the granite here is of a porphyritic appearance, with large crystals of felspar; but in the veins it is fine-grained, and without these large crystals. The general height of the veins is from 16 to 20 feet, but some are much higher.

Fig. 744 .

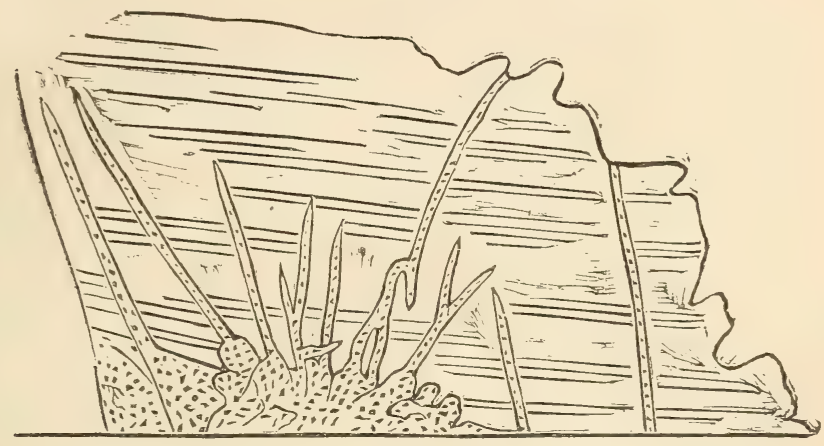

Granite veins passing through hornblende slate, Carnsilver Cove, Cornwall.

In the Valorsine, a valley not far from Mont Blanc in Savoy, an ordinary granite, consisting of felspar, quartz, and mica, sends forth veins into a talcose gneiss (or stratified protogine), and in some

Fig. 745 .

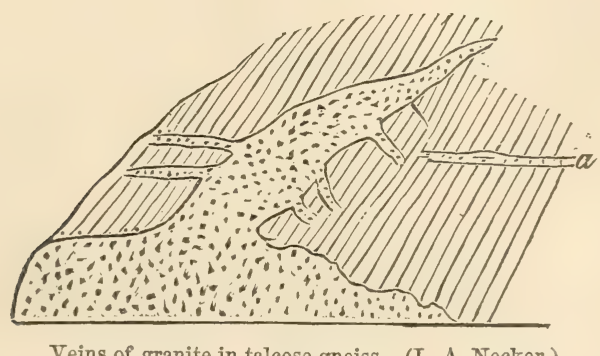

Veins of granite in talcose gneiss. (L. A. Necker.)

places lateral ramifications are thrown off from the principal veins at right angles (see fig. 745), the veins, especially the minute ones, being finer grained than the granite in mass.

* On Geol, of Cornwall, Camb. Trans, vol. i. p. 124.

† Phil. Mag. and Annals, No. 27, new series, March, 1829. 
It is here remarked, that the schist and granite, as they approach, seem to exercise a reciprocal influence on each other, for both undergo a modification of mineral character. The granite, still remaining unstratified, becomes charged with green particles; and the talcose gneiss assumes a granitiform structure without losing its stratification.*

Professor Keilhau drew my attention to several localities in the country near Christiania, where the mineral character of gneiss appears to have been affected by a granite of much newer origin, for some distance from the point of contact. The gneiss, without losing its laminated structure, seems to have become charged with a larger quantity of felspar, and that of a redder color, than the felspar usually belonging to the gneiss of Norway.

Granite, syenite, and those porphyries which have a granitiform structure, in short all plutonic rocks, are frequently observed to contain metals, at or near their junction with stratified formations. On the other hand, the veins which traverse stratified rocks are, as a general law, more metalliferous near such junctions than in other positions. Hence it has been inferred that these metals may have been spread in a gaseous form through the fused mass, and that the contact of another rock, in a different state of temperature, or sometimes the existence of rents in other rocks in the vicinity, may have caused the sublimation of the metals.t

There are many instances, as at Markerud, near Christiania, in Norway, where the strike of the beds has not been deranged throughout a large area by the intrusion of granite, both in large masses and in veins. This fact is considered by some geologists to militate against the theory of the forcible injection of granite in a fluid state. But it may be stated in reply, that ramifying dikes of trap also, which almost all now admit to have been once fluid, pass through the same fossiliferous strata, near Christiania, without deranging their strike or dip.

Fig. 746.

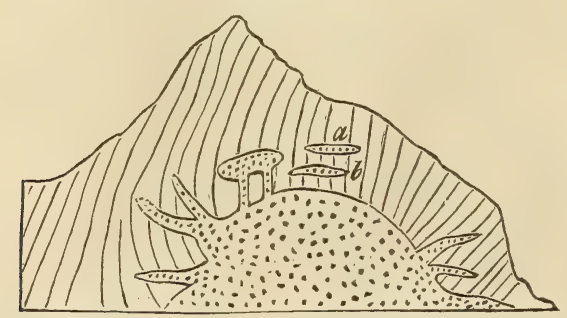

General view of junction of granite and schist of the Valorsine. (L. A. Necker.)

* Necker, Sur la Val de Valorsine, Mém. de la Soc. de Phys. de Genève, 1828

I visited, in 1832, the spot referred to in fig. 745.

+ Necker, Proceedings of Geol. Soc., No. 26, p. 392.

‡ See Keilhau's Gæa Norvegica; Christiania, 1838. 
The real or apparent isolation of large or small masses of granite detached from the main body, as at $a, b$, fig. 746 , and above, fig. 739 , and $\alpha$, fig. 745 , has been thought by some writers to be irreconcilable with the doctrine usually taught respecting veins; but many of them may, in fact, be sections of root-shaped prolongations of granite; while, in other cases, they may in reality be detached portions of rock having the plutonic structure. For there may have been spots in the midst of the invaded strata, in which there was an assemblage of materials more fusible than the rest, or more fitted to combine readily into some form of granite.

Veins of pure quartz are often found in granite as in many stratified rocks, but they are not traceable, like veins of granite or trap, to large bodies of rock of similar composition. They appear to have been cracks, into which siliceous matter was infiltered. Such segregation, as it is called, can sometimes be shown to have clearly taken place long subsequently to the original consolidation of the containing rock. Thus, for example, I observed in the gneiss of Tronstad Strand, near Drammen, in Norway, the annexed section on the beach. It appears that the alternating strata of whitish granitiform gneiss and black hornblendeschist were first cut through by a greenstone dike, about $2 \frac{1}{2}$ feet wide; then the crack $a b$ passed through all these rocks, and was filled up with quartz. The opposite walls of the vein are in some parts incrusted with transparent

Fig. 747 .

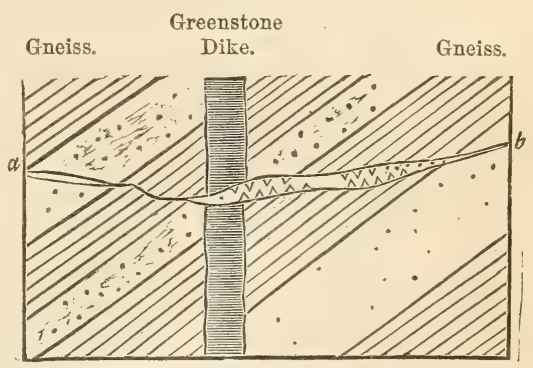

$a, b$. Quartz vein passing through gneiss and greenstone, Tronstad Strand, near Christiania. crystals of quartz, the middle of the vein being filled up with common opaque white quartz.

We have seen that the volcanic formations have becn called overlying, because they not only penetrate others, but spread over them. II. Necker has proposed to call the granites the underlying igneous rocks, and the distinction here indicated is highly characteristic. It was indeed supposed by some of the earlier observers, that the granite of Christiania, in Norway, was intercalated in mountain masses betrreen the primary or palæozoic strata of that country, so as to overlie fossiliferous shale and limestone. But although the granite sends veins into these fossiliferous rocks, and is decidedly posterior in origin, its actual superposition in mass has been disprored by Professor Keilhau, whose observations on this controverted point I had opportunities in 1837 of verifying. There are, however, on a smaller scale, certain beds of euritic porphyry, some a few feet, others many yards in thickness, which pass into granite, and deserve perhaps to be 
classed as plutonic rather than trappean rocks, which may truly be described as interposed conformably between fossiliferous strata, as the porphyries ( $a, c$, fig. 748), which divide the bituminous shales

Fig. 748

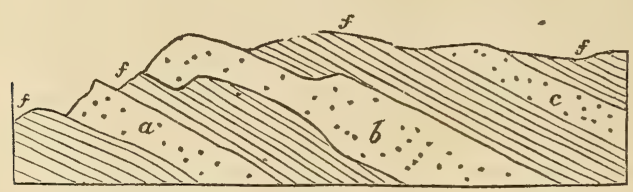

Euritic porphyry alternating with primary fossiliferous strata, near Christiania.

and argillaceous limestones, $f f$. But some of these same porphyries are partially unconformable, as $b$, and may lead us to suspect that the others also, notwithstanding their appearance of interstratification, have been forcibly injected. Some of the porphyritic rocks above mentioned are highly quartzose, others very felspathic. In proportion as the masses are more voluminous, they become more granitic in their texture, less conformable, and even begin to send forth veins into contiguous strata. In a word, we have here a beautiful illustration of the intermediate gradations between volcanic and plutonic rocks, not only in their mineralogical composition and structure, but also in their relations of position to associated formations. If the term "overlying" can in this instance be applied to a plutonic rock, it is only in proportion as that rock begins to acquire a trappean aspect.

It has been already hinted that the heat, which in every active volcano extends downwards to indefinite depths, must produce simultaneously very different effects near the surface and far below it; and we cannot suppose that rocks resulting from the crystallizing of fused matter under a pressure of several thousand feet, much less miles, of the earth's crust can resemble those formed at or near the surface. Hence the production at great depths of a class of rocks analogous to the volcanic, and yet differing in many particulars, might also have been predicted, even had we no plutonic formations to account for. How well these agree, both in their positive and negative characters, with the theory of their deep subterranean origin, the student will be able to judge by considering the descriptions already given.

It has, however, been objected, that if the granitic and volcanic rocks were simply different parts of one great series, we ought to find in mountain chains volcanic dikes passing upwards into lava and downwards into granite. But we may answer that our vertical sections are usually of small extent; and if we find in certain places a transition from trap to porous lava, and in others a passage from granite to trap, it is as much as could be expected of this evidence.

The prodigious extent of denudation which has been already demonstrated to have occurred at former periods, will reconcile the 
student to the belief that crystalline rocks of high antiquity, although deep in the earth's crust when originally formed, may have become uncorered and exposed. at the surface. Their actual eleration abore the sea may be referred to the same causes to which we hare attributed the upheaval of marine strata, even to the summits of some mountain chains. But to these and other topics I shall rerert when speaking, in the next chapter, of the relative ages of different masses of granite.

\section{CHAPTER XXXIV.}

ON THE DIFFERENT AGES OF THE PLUTONIC ROCKS.

Difficulty in ascertaining the precise age of a plutonic rock-Test of age by relative position-Test by intrusion and alteration-Test by mineral composition-Test br included fragments-Recent and Pliocene plutonic rocks, why invisible-Tertiary plutonic rocks in the Andes-Granite altering Cretaceous rocks-Granite altering Lias in the Alps and in Skye-Granite of Dartmoor altering Carboniferous strata-Granite of the Old Red Sandstone period-Syenite altering Silurian strata in Norway-Blending of the same with gneiss-Most ancient plutonic rocks-Granite protruded in a solid form-On the probable age of the granites of Arran, in Scotland.

Whes we adopt the igneous theory of granite, as explained in the last chapter, and beliere that different plutonic rocks have originated at successire periods beneath the surface of the planet, we must be prepared to encounter greater difficulty in ascertaining the precise age of such rocks, than in the case of volcanic and fossiliferous formations. We must bear in mind, that the eridence of the age of each contemporaneous rolcanic rock was derived, either from lavas poured out upon the ancient surface, whether in the sea or in the atmosphere, or from tuffs and conglomerates, also deposited at the surface, and either containing organic remains themselres, or intercalated between strata containing fossils. But all these tests fail when we endearor to fix the chronology of a rock which has crystallized from a state of fusion in the bowels of the earth. In that case, we are reduced to the following tests: 1st, relatire position; 2 dly, irtrusion, and alteration of the rocks in contact; $3 \mathrm{dly}$, mineral characters ; 4thly, included fragments.

Test of Age by Relative Position.-Unaltered fossiliferous strata of every age are met with reposing immediately on plutonic rocks; as at Christiania, in Norway, where the Post-pliocene deposit rests on granite; in Aurergne, where the freshwater Niocene strata, and at 
Heidelberg, on the Rhine, where the New Red Sandstone occupy a similar place. In all these, and similar instances, inferiority in position is connected with the superior antiquity of granite. The crystalline rock was solid before the sedimentary beds were superimposed, and the latter usually contain in them rounded pebbles of the subjacent granite.

Test by Intrusion and Alteration.-But when plutonic rocks send veins into strata, and alter them near the point of contact, in the manner before described (p. 709), it is clear that, like intrusive traps, they are newer than the strata which they invade and alter. Examples of the application of this test will be given in the sequel.

Test by Mineral Composition.-Notwithstanding a general uniformity in the aspect of plutonic rocks, we have seen in the last chapter that there are many varieties, such as Syenite, Talcose granite, and others. One of these varieties is sometimes found exclusively prevailing throughout an extensive region, where it preserves a homogeneous character; so that, having ascertained its relative age in one place, we can easily recognize its identity in others, and thus determine from a single section the chronological relations of large mountain masses. Having observed, for example, that the syenitic granite of Norway, in which the mineral called zircon abounds, has altered the Silurian strata wherever it is in contact, we do not hesitate to refer other masses of the same zircon-syenite in the south of Norway to the same era.

Some have imagined that the age of different granites might, to a great extent, be determined by their mineral characters alone; syenite, for instance, or granite with hornblende, being more modern than common or micaceous granite. But modern investigations have proved these generalizations to have been premature. The syenitic granite of Norway already alluded to may be of the same age as the Silurian strata, which it traverses and alters, or may belong to the Old Red Sandstone period; whereas the granite of Dartmoor, although consisting of mica, quartz, and felspar, is newer than the coal. (See p. 725.)

Test by Inchuded Fragments.-This criterion can rarely be of much importance, because the fragments involved in granite are usually so much altered, that they cannot be referred with certainty to the rocks whence they were derived. In the White Mountains, in North America, according to Professor Hubbard, a granite vein, traversing granite, contains fragments of slate and trap which must have fallen into the fissure when the fused materials of the vein were injected from below,* and thus the granite is shown to be newer than certain superficial slaty and trappean formations.

Recent and Pliocene Plutonic Rocks, why Invisible.-The explanations already given in the 29th and in the last chapter of the probable

* Silliman's Journ., No. 69, p. 123. 
relation of the plutonic to the volcanic formations, will naturally lead the reader to infer, that rocks of the one class can never be produced at or near the surface without some members of the other being formed below simultaneously, or soon afterwards. It is not uncommon for lava-streams to require more than ten years to cool in the open air; and when they are of great depth, a much longer period. The melted matter poured from Jorullo, in Mexico, in the year 1759, which accumulated in some places to the height of 550 feet, was found to retain a high temperature half a century after the eruption.* We may conceire, therefore, that great masses of subterranean lava may remain in a red-hot or incandescent state in the volcanic foci for immense periods, and the process of refrigeration may be extremely gradual. Sometimes, indeed, this process may be retarded for an indefinite period, by the accession of fresh supplies of heat; for we find that the lava in the crater of Stromboli, one of the Lipari Islands, has been in a state of constant ebullition for the last two thousand years; and we may suppose this fluid mass to communicate with some caldron or reservoir of fused matter below. In the Isle of Bourbon, also, where there has been an emission of lava once in every two years for a long period, the lava below can scarcely fail to have been permanently in a state of liquefaction. If then it be a reasonable conjecture, that about 2000 rolcanic eruptions occur in the course of every century, either above the waters of the sea or beneath them, $\uparrow$ it will follow, that the quantity of plutonic rock generated, or in progress during the Recent epoch, must already have been considerable.

But as the plutonic rocks originate at some depth in the earth's crust, they can only be rendered accessible to human observation by subsequent upheaval and denudation. Between the period when a plutonic rock crystallizes in the subterranean regions and the era of its protrusion at any single point of the surface, one or two geological periods must usually interrene. Hence, we must not expect to find the Recent or eren the Pliocene granites laid open to view, unless we are prepared to assume that sufficient time has elapsed since the commencement of the Pliocene period for great upheaval and denudation. A plutonic rock, therefore, must, in general, be of considerable antiquity relatively to the fossiliferous and volcanic formations, before it becomes extensirely visible. As we know that the uphearal of land has been sometimes accompanied in South America by rolcanic eruptions and the emission of lava, we may conceive the more ancient plutonic rocks to be forced upwards to the surface by the newer rocks of the same class formed successirely below-subterposition in the plutonic, like superposition in the sedimentary rocks, being usually characteristic of a newer origin.

\footnotetext{
* See "Principles," Index, "Jorullo."

+ Ibid., "Volcanic Eruptions."
} 
[Сн. XXXIV.

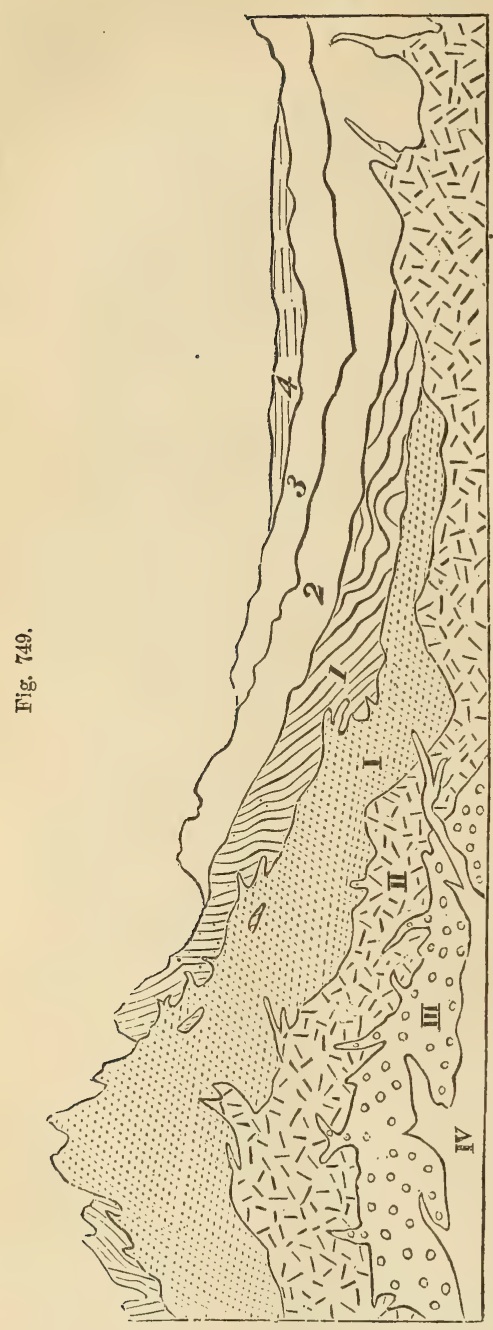

|c

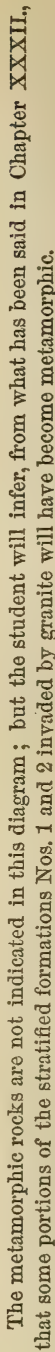

In the accompanying diagram (fig. 749) an attempt is made to show the inverted order in which sedimentary and plutonic formations may occur in the earth's crust.

The oldest plutonic rock, No. I., has been upheaved at successive periods until it has become exposed to view in a mountain-chain. This protrusion of No. I. has been caused by the igneous agency which produced the newer plutonic rocks Nos. II., III., and IV. Part of the primary fossiliferous strata, No. 1, have also been raised to the surface by the same gradual process. It will be observed that the Recent strata No. 4 and the Recent granite or plutonic rock No 
IV. are the most remote from each other in position, althongh of contemporaneous date. According to this hypothesis, the convulsions of many periods will be required before Recent or Post-tertiary granite will be upraised so as to form the highest ridges and central axes of mountain-chains. During that time the Recent strata No. 4 might be covered by a great many newer sedimentary formations.

Eocene Granite and Plutonic Rocks. - In a former part of this volume (p. 307), the great nummulitic formation of the Alps and Pyrenees was referred to the Eocene period, and it follows that those vast movements which have raised fossiliferous rocks from the level of the sea to the height of more than 10,000 feet above its level have taken place since the commencement of the tertiary epoch. Here, therefore, if anywhere, we might expect to find hypogene formations of Eocene date breaking out in the central axis or most disturbed region of the loftiest chain in Europe. Accordingly, in the Swiss Alps, even the fysch, or upper portion of the nummulitic series, has been occasionally invaded by plutonic rocks, and converted into crystalline schists of the hypogene class. There can be little doubt that even the talcose granite or gneiss of Mont Blanc itself has been in a fused or pasty state since the flysch was deposited at the bottom of the sea; and the question as to its age is not so much whether it be a secondary or tertiary granite or gneiss, as whether it should be assigned to the Eocene or Miocene epoch.

Great upheaving movements have been experienced in the region of the Andes, during the Post-tertiary period. In some part, therefore, of this chain, we may expect to discover tertiary plutonic rocks laid open to view. What we already know of the structure of the Chilian Andes seems to realize this expectation. In a transverse section, examined by Mr. Darwin, between Valparaiso and Mendoza, the Cordillera was found to consist of two separate and parallel chains, formed of sedimentary rocks of different ages, the strata in both resting on plutonic rocks, by which they have been altered. In the western or oldest range, called the Peuquenes, are black calcareous clayslates, rising to the height of nearly 14,000 feet above the sea, in which are shells of the genera Gryphcea, Turritells, Terebratula, and Ammonite. These rocks are supposed to be of the age of the central parts of the secondary series of Europe. They are penetrated and altered by dilzes and mountain masses of a plutonic rock, which has the texture of ordinary granite, but rarely contains quartz, being a compound of albite and hornblende.

The second or eastern chain consists chiefly of sandstones and conglomerates, of vast thickness, the materials of which are derived from the ruins of the western chain. The pebbles of the conglomerates are, for the most part, rounded fragments of the fossiliferous slates before mentioned. The resemblance of the whole series to certain tertiary deposits on the shores of the Pacific, not only in mineral character, but in the imbedded lignite and silicified woods, leads to the conjec- 
ture that they also are tertiary. Yet these strata are not only associated with trap rocks and volcanic tuffs, but are also altered by a granite consisting of quartz, felspar, and talc. They are traversed, moreover, by dikes of the same granite, and by numerous veins of iron, copper, arsenic, silver, and gold; all of which can be traced to the underlying granite.* We have, therefore, strong ground to presume that the plutonic rock here exposed on a large scale in the Chilian Andes is of later date than certain tertiary formations.

But the theory adopted in this work of the subterranean origin of the hypogene formations would be untenable, if the supposed fact here alluded to, of the appearance of tertiary granite at the surface, was not a rare exception to the general rule. A considerable lapse of time must intervene between the formation of plutonic and metamorphic rocks in the nether regions, and their emergence at the surface. For a long series of subterranean movements must occur before such rock can be uplifted into the atmosphere or the ocean; and, before they can be rendered visible to man, some strata which previously covered them must usually have been stripped off by denudation.

We know that in the Bay of Baiæ in 1538, in Cutch in 1819, and on several occasions in Peru and Chili, since the commencement of the present century, the permanent upheaval or subsidence of land has been accompanied by the simultaneous emission of lava at one or more points in the same volcanic region. From these and other examples it may be inferred that the rising or sinking of the earth's crust, operations by which sea is converted into land, and land into sea, are a part only of the consequences of subterranean igneous action. It can scarcely be doubted that this action consists, in a great degree, of the baking, and occasionally the liquefaction of rocks, causing them to assume, in some cases a larger, in others a smaller volume than before the application of heat. It consists also in the generation of gases, and their expansion by heat, and the injection of liquid matter into rents formed in superincumbent rocks. The prodigious scale on which these subterranean causes have operated in Sicily since the deposition of the Newer Pliocene strata will be appreciated, when we remember that throughout half the surface of that island such strata are met with, raised to the height of from 50 to that of 2000 and even 3000 feet above the level of the sea. In the same island also the older rocks which are contiguous to these marine tertiary strata must have undergone, within the same period, a similar amount of upheaval.

The like observations may be extended to nearly the whole of Europe, for, since the commencement of the Eocene period, the entire European area, including some of the central and very lofty portions of the Alps themselves, as I have elsewhere shown, $\nmid$ has, with the ex-

* Darwin, pp. 390, 406 ; second edition, p. 319.

† See map of Europe and explanation, in "Principles," book $\mathbf{i}$. 
ception of a few districts, emerged from the deep to its present altitude; and even those tracts which were already dry land before the Eocene era, have, in many cases, acquired additional hsight. A large amount of subsidence has also occurred during the same period, so that the extent of the subterianean spaces which have either become the receptacles of sunken fragments of the earth's crust, or have been rendered capable of supporting other fragments at a much greater height than before, must be so great that they probably equal, if not exceed in volume, the entire continent of Europe. We are entitled, therefore, to ask what amount of change of equivalent importance can be prored to hare occurred in the earth's crust within an equal quantity of time anterior to the Eocene epoch. They who contend for the more intense energy of subterranean causes in the remoter eras of the earth's history may find it more difficult to give an answer to this question than they anticipated.

The principal effect of volcanic action in the nether regions during the tertiary period seems to have consisted in the upheaval to the surface of hypogene formations of an age anterior to the carboniferous. The repetition of another series of movements, of equal violence, might upraise the plutonic and metamorphic rocks of many secondary periods; and, if the same force should still continue to act, the next convulsions might bring up to the day the tertiary and recent hypogene rocks. In the course of such changes many of the existing sedimentary strata would suffer greatly by denudation, others might assume a metamorphic structure, or become melted down into plutonic and volcanic rocks. Meanwhile the deposition of a vast thickness of new strata would not fail to take place during the upheaval and partial destruction of the older rocks. But I must refer the reader to the last chapter but one of this volume for a fuller explanation of these views.

Cretaceous Period.-It will be seen in the next chapter that chalk, as well as lias, has been altered by granite in the eastern Pyrenees. Whether such granite be cretaceous or tertiary cannot easily be decided. Suppose $b, c, d$, fig. 750 , to be three members of the Cretaceous series, the lowest of which, $b$, has been altered by the granite $\mathrm{A}$, the modifying influence not having extended so far as $c$, or having but slightly affected its lowest beds. Now it can rarely be possible for the geologist to decide whether the beds

$d$ existed at the time of the intrusion of $\mathrm{A}$, and alteration of $b$ and $c$, or whether they were subsequently thrown down upon $c$.

But as some Cretaceous and even tertiary rocks have been raised to the height of more than 9000 feet in the Pyrenees, we must not assume that plutonic formations of the same periods may not have been brought up and exposed by denudation, at the height of 2000 or 3000 feet on the flanks of that chain. 
Period of Oolite and Lias.-In the Department of the Hautes Alpes, in France, M. Elie de Beaumont traced a black argillaceous limestone, charged with belemnites, to within a few yards of a mass of granite. Here the limestone begins to put on a granular texture, but is extremely fine-grained. When nearer the junction it becomes gray, and has a saccharoid structure. In another locality, near Champoleon, a granite composed of quartz, black mica, and rose-colored felspar is observed partly to overlfe the secondary rocks, producing

Fig. 751.

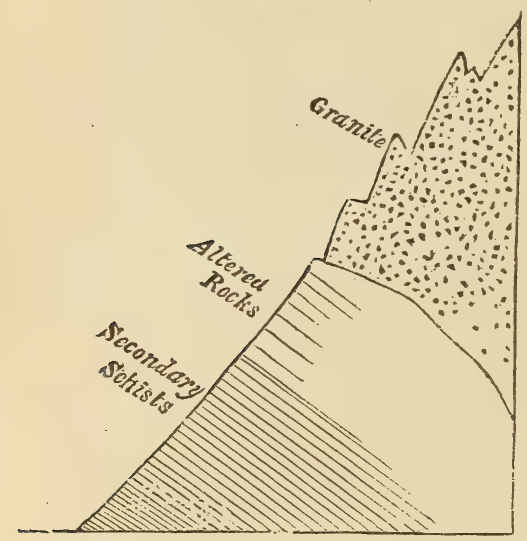

Junction of granite with Jurassic or Oolite strata in the Alps, near Champoleon. an alteration which extends for about 30 feet downwards, diminishing in the beds which lie farthest from the granite. (See fig. 751.) In the altered mass the argillaceous beds are hardened, the limestone is saccharoid, the grits quartzose, and in the midst of them is a thin layer of an imperfect granite. It is also an important circumstance, that near the point of contact, both the granite and the secondary rocks become metalliferous, and contain nests and small veins of blende, galena,

uron, and copper pyrites. The stratified rocks become harder and more crystalline, but the granite, on the contrary, softer and less perfectly crystallized near the junction.*

Although the granite is incumbent in the above section (fig. 751), we cannot assume that it overflowed the strata, for the disturbances of the rocks are so great in this part of the Alps that their original position is often inverted.

A considerable mass of syenite, in the Isle of Skye, is described by Dr. MacCulloch as intersecting limestone and shale, which are of the age of the lias. $\uparrow$ The limestone, which at a greater distance from the granite contains shells, exhibits no traces of them near its junction, where it has been converted into a pure crystalline marble.\$

At Predazzo, in the Tyrol, secondary strata, some of which are limestones of the Oolitic period, have been traversed and altered by plutonic rocks, one portion of which is an augitic porphyry, which

* Elie de Beaumont, sur les Montagnes de l'Oisans, \&c. Mém. de la Soc. d'Hist. Nat. de Paris, tom. v.

† Murchison, Geol. Trans., Second Series, vol. ii. part ii. pp. 311-321.

₹ Western Islands, vol, i. p. 330, plate 18, figs. 3, 4 . 
passes insensibly into granite. The limestone is changed into granular marble, with a band of serpentine at the junction.*

Carboniferous Period.-The granite of Dartmoor, in Devonshire, was formerly supposed to be one of the most ancient of the plutonic rocks, but is now ascertained to be posterior in date to the culmmeasures of that country, which from their position, and as containing true coal-plants, are regarded by Professor Sedg'wick and Sir R. Murchison as members of the true carboniferous series. This granite, like the syenitic granite of Christiania, has broken through the stratified formations without much changing their strike. Hence, on the northwest side of Dartmoor, the successive members of the culmmeasures abut against the granite, and become metamorphic as they approach. These strata are also penetrated by granite veins, and plutonic dikes, called "elvans." $\dagger$ The granite of Cornwall is probably of the same date, and, therefore, as modern as the Carboniferous strata, if not newer.

Silurian Period.-It has long been known that the granite near Christiania, in Norway, is of newer origin than the Silurian strata of that region. Von Buch first announced, in 1813, the discovery of its posteriority in date to limestones containing orthocerata and trilobites. The proofs consist in the penetration of granite veins into the shale and limestone, and the alteration of the strata, for a considerable distance from the point of contact both of these veins and the central mass from which they emanate. (See p. 715.) Von Buch supposed that the plutonic rock alternated with the fossiliferous strata, and that large masses of granite were sometimes incumbent upon the strata; but this idea was erroneous, and arose from the fact that the beds of shale and limestone often dip towards the granite up to the point of contact, appearing as if they would pass under it in mass, as at $a$, fig. 752 , and then again on the opposite side of the same mountain, as at $b$,

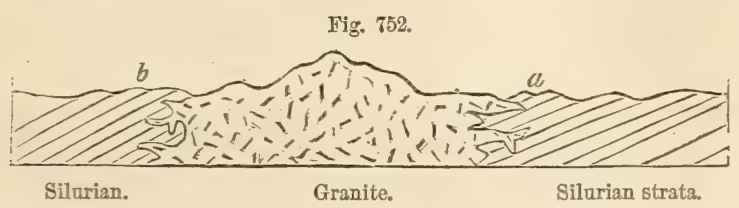

dip away from the same granite. When the junctions, however, are carefully examined, it is found that the plutonic rock intrudes itself in reins, and nowhere covers the fossiliferous strata in large overlying masses, as is so commonly the case with trappean formations. $\downarrow$

Now this granite, which is more modern than the Silurian strata of Norray, also sends reins in the same country into an ancient formar

* Von Buch, Annales de Chimie, \&c.

† Proceed. Geol. Soc., vol. ii. p. 562 ; and Trans., Second Series, vol. v. p. 686.

$\ddagger$ See the Gra Norvegica and other works of Keilhau, with whom I examined this country. 
tion of gneiss; and the relations of the plutonic rock and the gneiss, at their junction, are full of interest when we duly consider the wide difference of epoch which must have separated their origin.

The length of this interval of time is attested by the following facts: The fossiliferous or Silurian beds rest unconformably upon the truncated edges of the gneiss, the inclined strata of which had been denuded before the sedimentary beds were superimposed (see fig. 753).

Fig. 753.

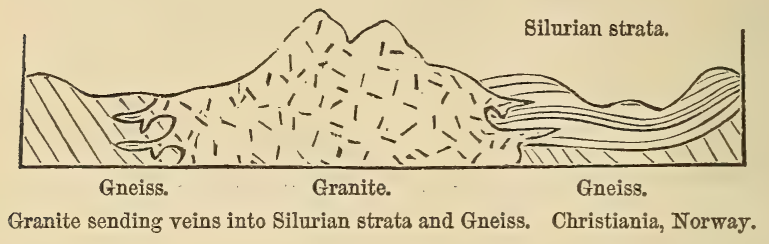

The signs of denudation are twofold; first, the surface of the gneiss is seen occasionally, on the removal of the newer beds, containing organic remains, to be worn and smoothed; secondly, pebbles of gneiss have been found in some of these Silurian strata. Between the origin, therefore, of the gneiss and the granite there intervened, first, the period when the strata of gneiss were denuded; secondly, the period of the deposition of the Silurian deposits. Yet the granite produced after this long interval is often so intimately blended with the ancient gneiss, at the point of junction, that it is impossible to draw any other than en arbitrary line of separation between them; and where this is not the case, tortuous veins of granite pass freely through gneiss, ending sometimes in threads, as if the older rock had offered no resistance to their passage. These appearances may probably be due to hydrothermal action (see below, p. 740). I shall merely observe in this place, that had such junctions alone been visible, and had we not learned, from other sections, how long a period elapsed between the consolidation of the gneiss and the injection of this granite, we might have suspected that the gneiss was scarcely solidified, or had not yet assumed its complete metamorphic character when invaded by the plutonic rock. From this example we may learn how impossible it is to conjecture whether certain granites in Scotland, and other countries, which send veins into gneiss and other metamorphic rocks, are primary, or whether they may not belong to some secondary or tertiary period.

Oldest Granites.-It is not half a century since the doctrine was very general that all granitic rocks were primitive, that is to say, that they originated before the deposition of the first sedimentary strata, and before the creation of organic beings (see above, p. 9). But so greatly are our views now changed, that we find it no easy task to point out a single mass of granite demonstrably more ancient than all the known fossiliferous deposits. Could we discover some Lower 
Cambrian strata resting immediately on granite, there being no alterations at the point of contact, nor any intersecting granitic veins, we might then affirm the plutonic rock to have originated before the oldest known fossiliferous strata. Still it would be presumptuous, as we have already pointed out (p. 587), to suppose that when a small part only of the globe has been investigated, we are acquainted with the oldest fossiliferous strata in the crust of our planet. Even when these are found, we cannot assume that there never were any antecedent strata containing organic remains, which may have become metamorphic. If we find pebbles of granite in a conglomerate of the Lower Cambrian system, we may then feel assured that the parent granite was formed before the Lower Cambrian formation. But if the incumbent strata be merely Silurian or Upper Cambrian, the fundamental granite, although of high antiquity, may be posterior in date to known fossiliferous formations.

Protrusion of Solid Granite.-In part of Sutherlandshire, near Brora, common granite, composed of felspar, quartz, and mica, is in immediate contact with Oolitic strata, and has clearly been elevated to the surface at a period subsequent to the deposition of those strata。* Professor Sedgrwick and Sir R. Murchison conceive that this granite has been upheaved in a solid form; and that in breaking through the submarine deposits, with which it was not perhaps originally in contact, it has fractured them so as to form a breccia along the line of junction. This breccia consists of fragments of shale, sandstone, and limestone, with fossils of the oolite, all united together by a calcareous cement. The secondary strata, at some distance from the granite, are but slightly disturbed, but in proportion to their proximity the amount of dislocation becomes greater.

If we admit that solid hypogene rocks, whether stratified or unstratified, have in such cases been driven upwards so as to pierce through yielding sedimentary deposits, we shall be enabled to account for many geological appearances otherwise inexplicable. Thus, for example, at Weinböhla and Hohnstein, near Meissen, in Saxony, a mass of granite has been observed covering strata of the Cretaceous and Oolitic periods for the space of between 300 and 400 yards square. It appears clearly from a memoir of Dr. B. Cotta on this subject, $\uparrow$ that the granite was thrust into its actual position when solid. There are no intersecting veins at the junction-no alteration as if by heat, but evident signs of rubbing, and a breccia in some places, in which pieces of granite are mingled with broken fragments of the secondary rocks. As the granite orerhangs both the lias and chalk, so the lias is in some places bent over strata of the cretaceous era.

Relative Age of the Granites of Arran.-In this island, the largest in the Firth of Clyde, being twenty miles in length from north to

* Murchison, Geol. Trans., Second Series, vol. ii. p. 307.

† Geognostische Wanderungen, Leipzig, 1838. 
south, the four great classes of rocks, the fossiliferous, volcanic, plutonic, and metamorphic, are all conspicuously displayed within a very small area, and with their peculiar characters strongly contrasted. In the north of the island the granite rises to the height of nearly 3000 feet above the sea, terminating in mountainous peaks. (See section, fig. 754.) On the flanks of the same mountains are chloriticschists, blue roofing-slate, and other rocks of the metamorphic order (No. 1), into which the granite (No. 2) sends veins. This granite, therefore, is newer than the hypogene schists (No. 1), which it penetrates.

These schists are highly inclined. Upon them rest beds of conglomerate and sandstone (No. 3), which are referable to the Old Red formation, to which succeed various shales and limestones (No. 4) containing the fossils of the Carboniferous period, upon which are other strata of sandstone and conglomerate (the higher beds of No. 4 ), in which no fossils have been met with. These are perhaps carboniferous, though it has been conjectured that they may belong to the New Red Sandstone, or at least to some part of the Poikilitic period. All the preceding formations are cut through by the volcanic rocks (No. 6), which consist of greenstone, basalt, pitchstone, felstone, and other varieties. These appear either in the form of dikes, or in dense masses from 50 to 700 feet in thickness, overlying the strata (No. 4). In one region, at Ploverfield, in Glen Cloy, a fine-grained granite $(5 a)$ is seen to send veins through the sandstone or the upper strata of No. 4. This interesting discovery of granite in the southern region of Arran, at a point where it is separated from the northern mass of the same rock by a great thickness of secondary strata, was made by M. L. A. Necker of Geneya, during his survey of Arran in 1839. Dr. MacCulloch had long before pointed out that in the granitic nucleus of the north there were two distinct varieties of granite (see diagram, p. 730) occupying separate tracts, both consisting of quartz, felspar, and mica, but the crystalline grains in the fine variety being so small as often to impart to it an arenaceous aspect and sandy feel. Prof. Ramsay afterwards traced out the geographical limits of both varieties, and these have since been more precisely defined and laid down on a map by Dr. Bryce, author of a valuable work on the geology of Arran. The last-mentioned observer remarks that the fine-grained kind never reaches so great an elevation above the level of the sea as does the coarse-grained. He also discovered, in 1864, that the fine-grained variety is not entirely isolated, as formerly supposed, within a boundary of the coarse, but that, on the south side of the nucleus, it comes into contact with the slates, which it penetrates and alters. The same geologist also found that, besides the outlier of fine-grained granite at Ploverfield, there is another smaller outbreak of the same rock to the westward, a quarter of a mile long and from 250 to 300 yards broad. It is called the CraigDhu granite, and seems to rise at the junction of the Old Red sandstone with the Carboniferous strata. 
At and near the point of contact the base of the conglomerate of the Old Red consisting of sandstone is rendered crystalline, and fragments of granite of an elliptical form and of the same mineral structure as the adjoining mass of fine granite are included in the sandstone or conglomerate. It has been already stated that no pieces of granite, rounded or angular, occur elsewhere in the Old Red, and as they are only found here in close proximity to the crystalline and intrusive rock, Dr. Bryce supposes that they were injected into the strata in a fluid or semi-fluid state. I have seen a similar junction in Caithness, of which Sir R. Murchison in 1827, and again in 1828 jointly with Professor Sedg'wick, has given a faithful description. Close to the point of contact of certain oolitic sandstones, shales, and limestones in the Caithness cliffs, a breccia occurs containing granite fragments mixed with those of the invaded rock. The granite, they say, appears as if it had been mechanically driven in among the shattered and altered strata.* In the coarse-grained granite of the northern nucleus trap-dikes of pitchstone and basalt are numerous, but dikes are comparatively rare in the fine-grained granite, and were even supposed to be entirely wanting until three or four, consisting of basalt and greenstone, were discovered by Dr. Bryce, running north and northwest. It seems therefore fair to infer, as Prof. Ramsay has done, that many of the dikes penetrating the older granite are cut off at the junction of the newer or fine-grained variety in the manner expressed at $b, c, d$, fig. 754, though no such cutting off has been actually observed. We may also feel assured that some of the dikes traversing the fine must also penetrate the coarse-grained granite, as Dr. Bryce infers, although, as yet, he has not observed the actual passage of any one from the newer to the older rock. There can be scarcely a doubt that the fine-grained variety of nucleus and the similar rocks of Ploverfield and Craig-Dhu are of contemporaneous date, and they seem to be more modern than all the formations of Arran, except the overlying trap (No. 6) and its associated dikes. But the coarser granite (No. 2) may be the oldest rock in Arran, with the exception of the hypogene slates (No. 1), into which it sends veins, and which it alters at the point of contact.

An objection may perhaps at first be started to this conclusion, derived from the curious and striking fact, the importance of which was first emphatically pointed out by Dr. MacCulloch, that no pebbles of granite occur in the conglomerates of the red sandstone in Arran, although these conglomerates are several hundred feet in thickness, and lie at the foot of lofty granite mountains, which tower above them. As a general rule, all such aggregates of pebbles and sand are mainly composed of the wreck of preëxisting rocks occurring in the immediate vicinity. The total absence therefore of granitic pebbles has justly been a theme of wonder to those geologists who have

* Geol. Trans., Second Series, vol. ii. p. 353, and vol. iii. p. 132 


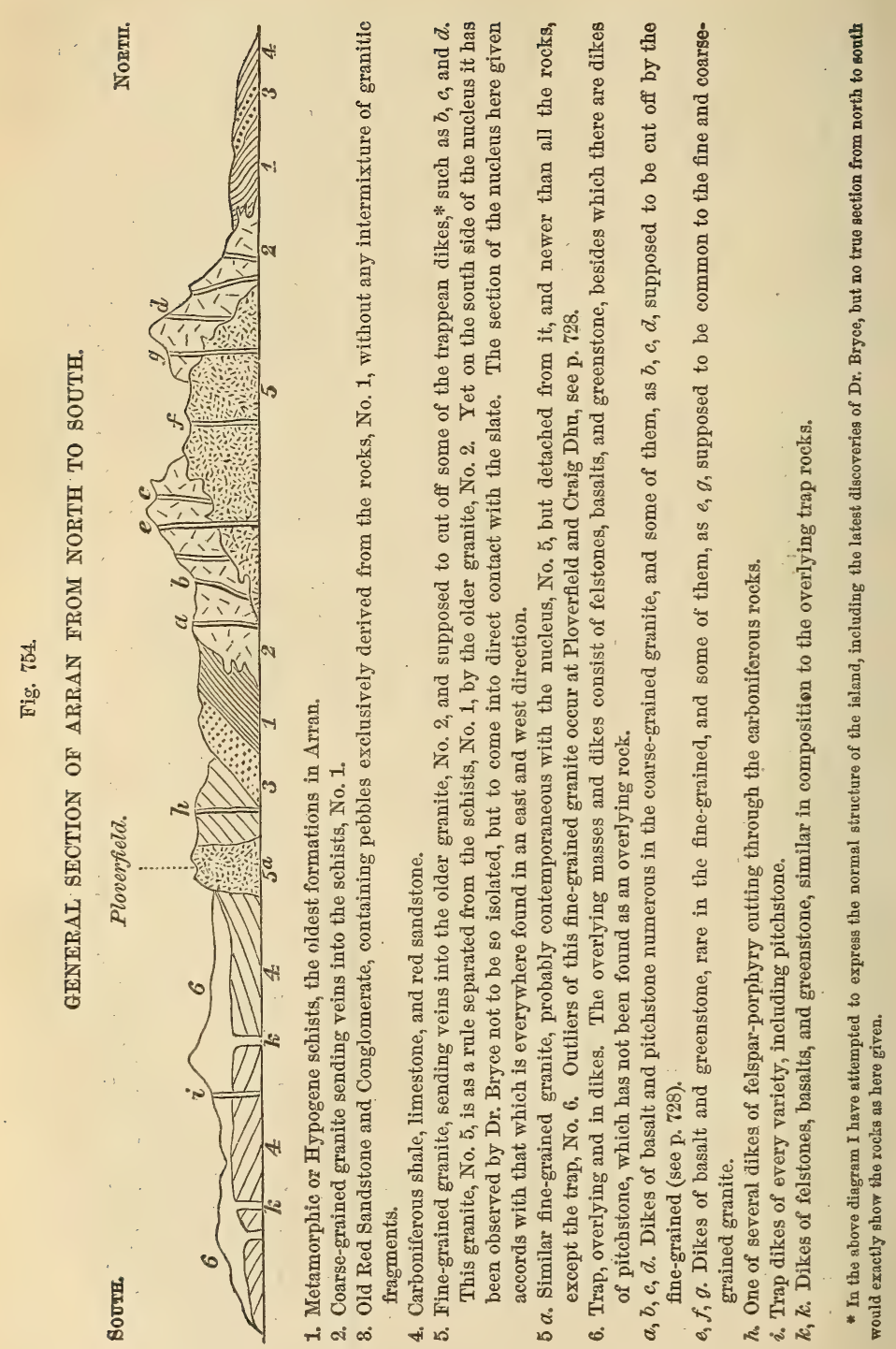


successively visited Arran, and they have carefully searched there, as I have done myself, to find an exception, but in vain. The rounded masses consist exclusively of quartz, chlorite-schist, and other members of the metamorphic series; nor in the newer conglomerates of No. 3 have any granitic fragments been discovered. Are we then entitled to affirm that the coarse-grained granite (No. 2), like the finegrained variety (No. 5), is more modern than all the other rocks of the island? This we cannot assume, but we may confidently infer that when the various beds of sandstone and conglomerate were formed, no granite had reached the surface, or had been exposed to denudation in Arran. It is clear that the crystalline schists were ground into sand and shingle when the strata No. 3 were deposited, and at that time the waves had never acted upon the granite, which now sends its veins into the schist. May we then conclude, that the schists suffered denudation before they were invaded by granite? The opinion, although not inadmissible, is by no means fully borne out by the evidence. For at that time when the Old Red Sandstone originated, the metamorphic strata may have formed islands in the sea, as in fig. 755 , over which the breakers rolled, or from which

Fig. 755 .

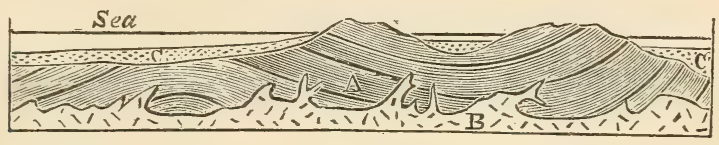

torrents and rivers descended, carrying down gravel and sand. The plutonic rock or granite (в) may even then have been previously injected at a certain depth below, and yet may never have been exposed to denudation.

As to the time and manner of the subsequent protrusion of the coarse-grained granite (No. 2), this rock may have been thrust up bodily in a solid form, during that long series of igneous operations which produced the plutonic formations (No. 5), and some of the trap dikes of the same age.

We have shown that these eruptions, whatever their date, were posterior to the deposition of all the fossiliferous strata of Arran. We can also prove that subsequently both the granitic and trappean rocks underwent great aqueous denudation, which they probably suffered during their emergence from the sea. The fact is demonstrated by the abrupt truncation of numerous dikes, such as those at $b, c, d$, which are cut off on the surface of the granite and trap.

The theory of the protrusion in a solid form of the northern nucleus of granite is confirmed by the manner in which the hypogene slates (No. 1) and the beds of conglomerate (No. 3) dip away from it on all sides. In some places indeed the slates are inclined towards the granite, but this exception might have been looked for, because th`se hypogene strata have undergone disturbances at more than one geo- 
logical epoch, and may at some points, perhaps, have their original order of position inverted. The high inclination, therefore, and the quâquâversal dip of the beds around the borders of the granitic boss, and the comparative horizontality of the fossiliferous strata in the southern part of the island, are facts which all accord with the hypothesis of a great amount of movement at that point where the granite is supposed to have been thrust up bodily, and where we may conceive it to have been distended laterally by the repeated injection of fresh supplies of melted materials.*

\section{CHAPTER XXXV.}

M E T M O R P I C R O K S

General character of metamorphic rocks-Gneiss-Hornblende-schist-Mica-schistClay-slate-Quartzite-Chlorite-schist-Metamorphic limestone-Alphabetical list and explanation of the more abundant rocks of this family-Origin of the metamorphic strata-Their stratification-Fossiliferous strata near intrusive masses of granite converted into rocks identical with different members of the metamorphic series-Arguments hence derived as to the nature of plutonic action-Time may enable this action to pervade denser masses-From what kinds of sedimentary rock each variety of the metamorphic class may be derived-Certain objections to the metamorphic theory considered-Partial conversion of Eocene slate into gneiss.

WE have now considered three distinct classes of rocks: first, the aqueous or fossiliferous; secondly, the volcanic; and, thirdly, the plutonic, or granitic; and it remains for us to examine those crystalline (or hypogene) strata to which the name of metamorphic has been assigned. The last-mentioned term expresses, as before explained, a theoretical opinion that such strata, after having been deposited from water, acquired, by the influence of heat and other causes, a highly crystalline texture. They who still question this opinion, may call the rocks under consideration the stratified hypogene, or schistose hypogene formations.

These rocks, when in their most characteristic or normal state, are wholly devoid of organic remains, and contain no distinct fragments

* For the geology of Arran, which I examined myself in 1836, consult the works of Drs. Hutton and MacCulloch, the Memoirs of Messrs. Von Dechen and Oeynhausen, that of Professor Sedgwick and Sir R. Murchison (Geol. Trans., Second Series), Mr. L. A. Necker's Memoir, read to the Royal Soc. of Edin., 20th April, 1840, and Prof. Ramsay's Geol. of Arran, 1841, and lastly, Mr. Bryce's Geol. of Arran and Clydesdale, 3d ed., 1864. 
of other rocks, whether rounded or angular. They sometimes break out in the central parts of narrow mountain chains, but in other cases extend over areas of vast dimensions, occupying, for example, nearly the whole of Norway and Sweden, where, as in Brazil, they appear alike in the lower and higher grounds. In Great Britain, those members of the series which approach most nearly to granite in their composition, as gneiss, mica-schist, and hornblende-schist, are confined to the country north of the rivers Forth and Clyde.

However crystalline these rocks may become in certain regions, they never, like granite or trap, send veins into contiguous formations, whether into an older schist or granite or into a set of newer fossiliferous strata.

Many attempts have been made to trace a general order of succession or superposition in the members of this family; clay-slate, for example, having been often supposed to hold invariably a higher geological position than mica-schist, and mica-schist always to overlie gneiss. But although such an order may prevail throughout limited districts, it is by no means universal. To this subject, however, I shall again revert, in the 37 th chapter, when the chronological relations of the metamorphic rocks are pointed out.

The following may be enumerated as the principal members of the metamorphic class: gneiss, mica-schist, hornblende-schist, clay-slate, chlorite-schist, hypogene or metamorphic limestone, and certain kinds of quartz-rock or quartzite.

Gneiss.-The first of these, gneiss, may be called stratified, or, by those who object to that term, foliated granite, being formed of the same materials as granite, namely, felspar, quartz, and mica. In the specimen here figured, the white layers consist almost exclusively of granular felspar, with here and there a speck of mica and grain of quartz. The dark layers are composed of gray quartz and black mica,

Fig. 756 .

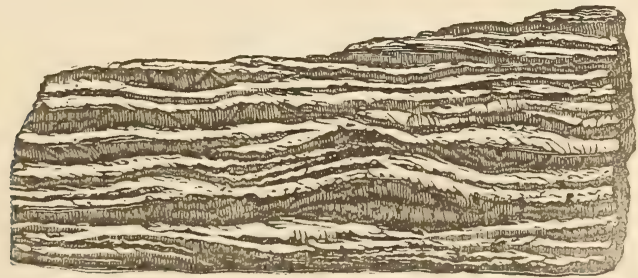

Fragment of gneiss, natural size; section made at right angles to the planes of foliation.

with occasionally a grain of felspar intermixed. The rock splits most easily in the plane of these darker layers, and the surface thus exposed is almost entirely corered with shining spangles of mica. The accompanying quartz, however, greatly predominates in quantity, but the most ready clearage is determined by the abundance of mica in certain parts of the dark layer. 
Instead of consisting of these thin laminæ, gneiss is sometimes simply divided into thick beds, in which the mica has only a slight degree of parallelism to the planes of stratification.

The term "gneiss," however, in geology is commonly used in a wider sense, to designate the formation in which the above-mentioned rock prevails, but with which any one of the other metamorphic rocks, and more especially hornblende-schist, may alternate. These other members of the metamorphic series are, in this case, considered as subordinate to the true gneiss.

The different varieties of rock allied to gneiss, into which felspar enters as an essential ingredient, will be underistood by referring to what was said of granite. Thus, for example, hornblende may be superadded to mica, quartz, and felspar, forming a syenitic gneiss; or talc may be substituted for mica, constituting talcose-gneiss, a rock composed of felspar, quartz, and talc, in distinct crystals or grains (stratified protogine of the French).

Hornblende-schist is usually black, and composed principally of hornblende, with a variable quantity of felspar, and sometimes grains of quartz. When the hornblende and felspar are nearly in equal quantities, and the rock is not slaty, it corresponds in character with the greenstones of the trap family, and has been called "primitive greenstone." It may be termed hornblende rock. Some of these hornblendic masses may really have been volcanic rocks, which have since assumed a more crystalline or metamorphic texture.

Mica-schist, or Micaceous Schist, is, next to gneiss, one of the most abundant rocks of the metamorphic series. It is, slaty, essentially composed of mica and quartz, the mica sometimes appearing to constitute the whole mass. Beds of pure quartz also occur in this formation. In some districts, garnets in regular twelve-sided crystals form an integrant part of mica-schist. This rock passes by insensible gradations into clay-slate.

Clay-slate, or Argillaceous Schist.-This rock sometimes resembles an indurated clay or shale. It is for the most part extremely fissile, often affording good roofing-slate. Occasionally it derives a shining and silky lustre from the minute particles of mica or talc which it contains. It varies from greenish or bluish-gray to a lead color; and it may be said of this, more than of any other schist, that it is common to the metamorphic and fossiliferous series, for some clay-slates taken from each division would not be distinguishable by mineral characters alone.

Quartzite, or Quartz Rock, is an aggregate of grains of quartz which are either in minute crystals, or in many cases slightly rounded, occurring in regular strata, associated with gneiss or other metamorphic rocks. Compact quartz, like that so frequently found in veins, is also found together with granular quartzite. Both of these alternate with gneiss or mica-schist, or pass into those rocks by the addition of mica, or of felspar and mica. 
Chlorite-schist is a green slaty rock, in which chlorite is abundant in foliated plates, usually blended with minute grains of quartz, or sometimes with felspar or mica; often associated with, and graduating into, gneiss and clay-slate.

Ciystalline or Metamorphic Limestone.-This hypogene rock, called by the earlier geologists primary limestone, is sometimes a white crystalline granular marble, which when in thick beds can be used in sculpture; but more frequently it occurs in thin beds, forming a foliated schist much resembling in color and appearance certain varieties of gneiss and mica-schist. When it alternates with these rocks, it often contains some crystals of mica, and occasionally quartz, felspar, hornblende, talc, chlorite, garnet, and other minerals. It enters sparingly into the structure of the hypogene districts of Norway, Sweden, and Scotland, but is largely developed in the Alps.

Before offering any farther observations on the probable origin of the metamorphic rocks, I subjoin, in the form of a glossary, a brief explanation of some of the principal varieties and their synonyms.

\section{Explanation of the Names, Synonyms, and Mineral Composition of the more abundant Metamorphic Rocks.}

ActrNolite-SCHIST. A slaty foliated rock, composed chiefly of actinolite (an emerald-green mineral, allied to hornblende), with some admixture of garnet, mica, and quartz.

AyPELtTE. Aluminous slate (Brongniart); occurs both in the metamorphic and fossiliferous series.

A мrpeibol.tтe. Hornblende rock, which see.

ARgillaCenous-schist, or Clay-Slate. See p. 734.

Arkose. Name given by Brongniart to a compound of the same materials as granite, which it often resembles closely. It is found at the junction of granite with formations of different ages, and consists of crystals of felspar, quartz, and sometimes mica, which, after separation from their original matrix by disintegration, have been reunited by a siliceous or quartzose cement. It is often penetrated by quartz veins.

Chiastolite-sLate scarcely differs from clay-slate, but includes numerous crystals of Chiastolite: in considerable thickness in Cumberland. Chiastolite occurs in long slender rhomboidal crystals. For composition, see Table, p. 608.

Celorite-schist. A green slaty rock, in which chlorite, a green scaly mineral, is abundant. See p. 735 .

Clay-slate, or Argillaceods-schist. See p. 734.

Ecrite has been already mentioned as a plutonic rock (p. 708), but occurs also with precisely the same composition in beds subordinate to gneiss or mica. slate.

GNEIss. A stratified or foliated rock; has the same composition as granite. See p. 733.

Hornblende Rock, or Assphibolite. See above, p. 605. A member both of the 
voleanic and metamorphic series. Agrees in composition with hornblendeschist, but is not fissile.

Hornblende-SCHist, or Slate. Composed of hornblende and felspar. See p. 734. HoRnblendic or Syenitic Gneiss. Composed of felspar, quartz, and hornblende. HYPOGENe LiMESTONE. See p. 735.

Marble. See pp. 12 and 735.

MICA-SCHIST, or MICACEOUS-SCHIST. A slaty rock, composed of mica and quartz, in variable proportions. See p. 734.

MiCa-Slate. See Mica-SCHIST, p. 734.

Phyllade. D'Aubuisson's term for clay-slate, from $\phi v \lambda \lambda \alpha \varsigma$, a heap of leaves.

Primary Limestone. See Hypogene Limestone, p. 735.

Protogrne. See TaLcose-gneiss, p. 734 ; when unstratified, it is Talcose-granite.

QUARTz Rock, or QUARTzite. A stratified rock; an aggregate of grains of quartz. See p. 734.

Serpentine has already been described (p. 606), because it occurs in both divisions of the hypogene series, as a stratified or unstratified rock.

TALCOSE-GNEISS. Same composition as talcose-granite or protogine, but stratified or foliated. See p. 734.

TALCOSE-SCHIST consists chiefly of talc, or of tale and quartz, or of talc and felspar, and has a texture something like that of clay-slate.

\section{Origin of the Metamorphic Strata.}

Having said thus much of the mineral composition of the metamorphic rocks, I may combine what remains to be said of their structure and history with an account of the opinions entertained of their probable origin. At the same time, it may be well to forewarn the reader that we are here entering upon ground of controversy, and soon reach the limits where positive induction ends, and beyond which we can only indulge in speculations. It was once a favorite doctrine, and is still maintained by many, that these rocks owe their crystalline texture, their want of all signs of a mechanical origin, or of fossil contents, to a peculiar and nascent condition of the planet at the period of their formation. The arguments in refutation of this hypothesis will be more fully considered when I show, in the thirtyseventh chapter, to how many different ages the metamorphic formations are referable, and how gneiss, mica-schist, clay-slate, and hypogene limestone (that of Carrara for example) have been formed, not only since the first introduction of organic beings into this planet, but even long after many distinct races of plants and animals had passed away in succession.

The doctrine respecting the crystalline strata, implied in the name metamorphic, may properly be treated of in this place; and we must first inquire whether these rocks are really entitled to be called stratified in the strict sense of having been originally deposited as sediment from water. The general adoption by geologists of the term 
stratified, as applied to these rocks, sufficiently attests their division into beds rery analogous, at least in form, to ordinary fossiliferous strata. This resemblance is by no means confined to the existence in both occasionally of a laminated structure, but extends to every kind of arrangement which is compatible with the absence of fossils, and of sand, pebbles, ripple-mark, and other characters which the metamorphic theory supposes to have been obliterated by plutonic action. Thus, for example, we behold alike in the crystalline and fossiliferous formations an alteration of beds varying greatly in composition, color, and thickness. We observe, for instance, gneiss alternating with layers of black hornblende-schist, or of green chlorite-schist, or with granular quartz, or limestone; and the interchange of these different strata may be repeated for an indefinite number of times. In the like manner, mica-schist alternates with chlorite-schist, and with beds of pure quartz or of granular limestone.

We have already seen that, near the immediate contact of granitic veins and volcanic dikes, very extraordinary alterations in rocks have taken place, more especially in the neighborhood of granite. It will be useful here to add other illustrations, showing that a texture undistinguishable from that which characterizes the more crystalline metamorphic formations has actually been superinduced in strata once fossiliferous.

In the southern extremity of Norway there is a large district, on the west side of the fiord of Christiania, in which granite or syenite protrudes in mountain masses through fossiliferous strata, and usually sends veins into them at the point of contact. The stratified rocks, replete with shells and zoophytes, consist chiefly of shale, limestone, and some sandstone, and all these are invariably altered near the granite for a distance of from 50 to 400 yards. The aluminous shales are hardened and have become flinty. Sometimes they resemble jasper. Ribboned jasper is produced by the hardening of alternate layers of green and chocolate-colored schist, each stripe faithfully representing the original lines of stratification. Nearer the granite the schist often contains crystals of hornblende, which are even met with in some places for a distance of sereral hundred yards from the junction; and this black hornblende is so abundant that eminent geologists, when passing through the country, have confounded it with the ancient hornblende-schist, subordinate to the great gneiss formation of Norway. Frequently, between the granite and the hornblende slate above-mentioned, grains of mica and crystalline felspar appear in the schist, so that rocks resembling gneiss and micaschist are produced. Fossils can rarely be detected in these schists, and they are more completely effaced in proportion to the more crystalline texture of the beds, and their vicinity to the granite. In some places the siliceous matter of the schist becomes a granular quartz; and when hornblende and mica are added, the altered rock loses its stratification, and passes into a kind of granitc. The limestone, 
[Сн. XXXV.

which at points remote from the granite is of an earthy texture and blue color, and often abounds in corals, becomes a white granular marble near the granite, sometimes siliceous, the granular structure extending occasionally upwards of 400 yards from the junction; the corals being for the most part obliterated, though sometimes preserved, even in the white marble. Both the altered limestone and

Fig. 757.

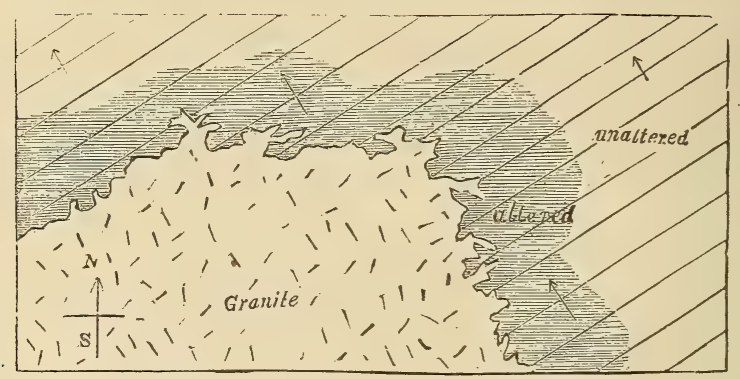

Altered zone of fossiliferous slate and limestone near granite. Christiania. The arrows indicate the dip, and the straight lines the strike, of the beds.

hardened slate contain garnets in many places, also ores of iron, lead, and copper, with some silver. These alterations occur equally, whether the granite invades the strata in a line parallel to the general strike of the fossiliferous beds, or in a line at right angles to their strike, as will be seen by the accompanying ground plan.*

The indurated and ribboned schists above mentioned bear a strong resemblance to certain shales of the coal found at Russell's Hall, near Dudley, where coal-mines have been on fire for ages. Beds of shale of considerable thickness, lying over the burning coal, have been baked and hardened so as to acquire a flinty fracture, the layers being alternately green and brick-colored.

The granite of Cornwall, in like manner, sends forth veins into a coarse argillaceous-schist, provincially termed killas. This killas is converted into hornblende-schist near the contact with the veins. These appearances are well seen at the junction of the granite and killas, in St. Michael's Mount, a small island nearly 300 feet high, situated in the bay, at a distance of about three miles from Penzance.

The granite of Dartmoor, in Devonshire, says Sir H. De la Beche, has intruded itself into the slate and slaty sandstone called graywacke, twisting and contorting the strata, and sending veins into them. Hence some of the slate rocks have become "micaceous; others more indurated, and with the characters of mica-slate and gneiss; while others again appear converted into a hard-zoned rock strongly imvregnated with felspar." $\dagger$

* Keilhau, Gæa Norvegica, pp. 61-63.

† Geol. Manual, p. 479. 
We learn from the inrestigations of M. Dufrénoy, that in the eastern Pyrenees there are mountain masses of granite posterior in date to the formations called lias and chalk of that district, and that these fossiliferous rocks are greatly altered in texture, and often charged with iron-ore, in the neighborhood of the granite. Thus in the environs of St. Martin, near St. Paul de Fénouillet, the chalky limestone becomes more crystalline and saccharoid as it approaches the granite, and loses all trace of the fossils which it previously contained in abundance. At some points, also, it becomes dolomitic, and filled with small veins of carbonate of iron, and spots of red iron-ore. At Rancie the lias nearest the granite is not only filled with iron-ore, but charged with prrites, tremolite, garnet, and a new mineral somewhat allied to felspar, called, from the place in the Pyrenees where it occurs, " couzeranite."

Now the alterations above described, as superinduced in rocks by volcanic dikes and granite veins prove incontestably that powers exist in nature capable of transforming fossiliferous into crystalline strata-powers capable of generating in them a new mineral character, similar to, nav, often absolutely identical with that of gneiss, mica-schist, and other stratified members of the hypogene series. The precise nature of these altering causes, which may prorisionally be termed plutonic, is in a great degree obscure and doubtful ; but their reality is no less clear, and we must suppose the influence of heat to be in some way connected with the transmutation, if, for reasons before explained, we concede the igneous origin of granite.

The experiments of Gregory Watt, in fusing rocks in the laboratory, and allowing them to consolidato by slow cooling, prore distinctly that a rock need not be perfectly melted in order that a rearrangement of its component particles should take place, and a partial crystallization ensue." Te mar easily suppose, therefore, that all traces of shells and other organic remains may be destroyed; and that new chemical combinations may arise, without the mass being so fused as that the lines of stratification should be wholly obliterated.

We must not, however, imagine that heat alone, such as may be applied to a stone in the open air, can constitute all that is comprised in plutonic action. We know that rolcanoes in eruption not ouly emit fluid lara, but gire off steam and other heated gases, which rush out in enormous rolume, for days, weeks, or years continuously, and are even disengaged from lava during its consolidation.

TTe also know that long aiter rolcanoes have spent their foree, hot springs continue for ages to flow out at rarious points in the same area. In regions also subject to riolent earthquakes such springs are frequently observed issuing from rents, usually along lines of fault or displacement of the rocks. These thermal waters are most commonly charged with a rariety of mineral ingredients, and they retain a 
remarkable uniformity of temperature from century to century. A like uniformity is also persistent in the nature of the earthy, metallic, and gaseous substances with which they are impregnated. It is well ascertained that springs, whether hot or cold, charged with carbonic acid, and especially with hydrofluoric acid, which is often present in small quantities, are powerful causes of decomposition and chemical reaction in rocks through which they percolate.

The changes which Daubrée has shown to have been produced by the alkaline waters of Plombières in the Vosges, are more especially instructive.* These waters have a heat of $160^{\circ} \mathrm{F}$., or an excess of $109^{\circ}$ above the average temperature of ordinary springs in that district. They were conveyed by the Romans to baths through long conduits or aqueducts. The foundations of some of their works consisted of a bed of concrete made of lime, fragments of brick, and sandstone. Through this and other masonry the hot waters have been percolating for centuries, and have given rise to various zeolites-apophyllite and chabazite among others; also to calcareous spar, arragonite, and fluor spar, together with siliceous minerals, such as opal-all found in the interspaces of the bricks and mortar, or constituting part of their rearranged materials. The quantity of heat brought into action in this instance in the course of 2000 years has, no doubt, been enormous, but the intensity of it developed at any one moment has been always inconsiderable.

From these facts and from the experiments and observations of Sénarmont, Daubrée, Delesse, Scheerer, Sorby, Sterry, Hunt, and others, we are led to infer that when in the bowels of the earth there are large volumes of molten matter, containing heated water and various acids under enormous pressure, these subterranean fluid masses will gradually part with their heat by the escape of steam and various gases through fissures, producing hot springs; or by the passage of the same through the pores of the overlying and injected rocks. Even the most compact rocks may be regarded, before they have been exposed to the air and dried, in the light of sponges filled with water. According to the experiments of Henry, water, under an hydrostatic pressure of 96 feet, will absorb three times as much carbonic acid gas as it can under the ordinary pressure of the atmosphere. There are other gases, as well as the carbonic acid, which water absorbs, and more rapidly in proportion to the amount of pressure. Although the gaseous matter first absorbed would soon be condensed, and part with its heat, yet the continual arrival of fresh supplies from below might, in the course of ages, cause the temperature of the water, and with it that of the containing rock, to be materially raised, the water acts not only as a vehicle of heat, but also by its affinity for various silicates, which, when some of the materials of the invaded rocks are decomposed, form quartz, felspar, mica, and other minerals. As for quartz, it can be produced

* Daubrée, Sur le Métamorphisme; Paris, 1860. 
under the influence of heat by water holding alkaline silicates in solution, as in the case of the Plombières springs, without any chemical reaction. The quantity of water required, according to Daubrée, to produce great transformations in the mineral structure of rocks, is very small. As to the heat required, silicates may be produced in the moist way at about incipient red heat, whereas to form the same in the dry way would require a much higher temperature.

M. Fournet, in his description of the metalliferous gneiss near Clermont, in Auvergne, states that all the minute fissures of the rock are quite saturated with free carbonic acid gas; which gas rises plentifully from the soil there and in many parts of the surrounding country. The various elements of the gneiss, with the exception of the quartz, are all softened; and new combinations of the acid with lime, iron, and manganese are continually in progress.*

Another illustration of the power of subterranean gases is afforded by the Stufas of St. Calogero, situated in the largest of the Lipari Islands. Here, according to the description published by Hoffmann, horizontal strata of tuff, extending for four miles along the coast, and forming cliffs more than 200 feet high, have been discolored in various places, and strangely altered by the "all-penetrating vapors." Dark clays have become yellow, or often snow-white; or have assumed a chequered or brecciated appearance, being crossed with ferruginous red stripes. In some places the fumeroles have been found by analysis to consist partly of sublimations of oxide of iron; but it also appears that veins of chalcedony and opal, and others of fibrous gypsum, have resulted from these volcanic exhalations. $\nmid$

The reader may also refer to M. Virlet's account of the corrosion of hard, flinty, and jaspideous rocks near Corinth by the prolonged agency of subterranean gases; $\$$ and to Dr. Daubeny's description of the decomposition of trachytic rocks in the Solfatara, near Naples, by sulphuretted hydrogen and muriatic acid gases. $\$$

Although in all these instances we can only study the phenomena as exhibited at the surface, it is clear that the gaseous fluids must have made their way through the whole thickness of porous or fissured rock, which intervene between the subterranean reservoirs of gas and the external air. The extent, therefore, of the earth's crust which the vapors have permeated and are now permeating may be thousands of fathoms in thickness, and their heating and modifying influence may be spread throughout the whole of this solid mass.

We learn from Professor Bischoff that the steam of a hot spring at Aix-la-Chapelle, although its temperature is only from $133^{\circ}$ to $167^{\circ} \mathrm{F}$., has converted the surface of some blocks of black marble into a

* See "Principles," Index, "Carbonated Springs," \&c.

† Hoffmann's Liparischen Inseln, p. 38. Leipzig, 1832.

$\ddagger$ See Princ. of Geol. ; and Bulletin de la Soc. Géol. de France, tom. ii. p. 230.

$\S$ See Princ. of Geol. ; and Daubeny's Volcanoes, p. 167. 
doughy mass. He conceives, therefore, that steam in the bowels of the earth having a temperature equal or even greater than the melting point of lava, and having an elasticity of which even Papin's digester can give but a faint idea, may convert rocks into liquid matter.*

The above observations are calculated to meet some of the objections which have been urged against the metamorphic theory on the ground of the small power of rocks to conduct heat; for it is well known that rocks, when dry and in the air, differ remarkably from metals in this respect. It has been asked how the changes which extend merely for a few fect from the contact of a dike could have penetrated through mountain masses of crystalline strata several miles in thickness. Now it has been stated that the plutonic influence of the syenite of Norway has sometimes altered fossiliferous strata for a distance of a quarter of a mile, both in the direction of their dip and of their strike. (See fig. 757, p. 738.) This is undoubtedly an extreme case; but it is natural to suppose that analogous causes may, under favorable circumstances, affect masses of greater volume. The metamorphic theory does not require us to affirm that some contiguous mass of granite has been the altering power; but merely that an action, existing in the interior of the earth at an unknown depth, whether thermal, hydrothermal, or other, analogous to that exerted near intruding masses of granite, has, in the course of vast and indefinite periods, and when rising perhaps from a large heated surface, reduced strata thousands of yards thick to a state of semifusion, so that on cooling they have become crystalline, like gneiss.

The prominent part which water has played in distributing the heat of the interior through mountain masses of incumbent strata, and in conveying various mineral elements in a fluid or gaseous state into the same masses, so as to give rise in the course of long geological periods to vast chemical changes, enables us to dispense with the intense heat formerly thought necessary for the production of the metamorphic rocks. But, on the other hand, the length of time which must have been consumed during the escape of so much heat from molten matter underlying the solid crust, at the depth of many miles, raises our conception of the great original intensity of temperature required to bring those subterranean sheets of lava into a liquid state. That they are sometimes of vast horizontal extent, even hundreds of miles in length, seems proved by facts observed during eruptions in the volcanic region of the Andes.

The scorching heat radiated by lava in a volcanic crater, when it is white and glowing like the sun, prepares us to believe that the temperature of the same fluid thousands of fathoms below, must far exceed any heat which can ever be witnessed at the surface. The uniform composition, the absence of stratification, and the great vol-

* Jam. Ed. New Phil. Journ., No. 51, p. 43. 
ume of the plutonic rocks, is in perfect aceordance with the Huttonian hypothesis of the intense heat to which this class of rocks has owed its origin.

In considering, then, the various data already enumerated, the forms of stratification and lamination in metamorphic rocks, their passage on the one hand into the fossiliferous, and on the other into the plutonic formations, and the conversions which can be ascertained to have occurred in the vicinity of granite, we may conclude that gneiss and mica-schist may be nothing more than altered micaceous and argillaceous sandstones, that granular quartz may have been derired from siliceous sandstone, and compact quartz from the same materials. Clay-slate may be altered shale, and granular marble may have originated in the form of ordinary limestone, replete with shells and corals, which have since been obliterated; and, lastly, calcareous sands and marls may have been changed into impure crystalline limestones.

"Hornblende-schist," says Dr. MacCulloch, "may at first have been mere clay; for clay or shale is found altered by trap into Lydian stone, a substance differing from hornblende-schist almost solely in compactness and uniformity of texture." * "In Shetland," remarks the same author, "argillaceous-schist (or clay-slate), when in contact with granite, is sometimes converted into hornblende-schist, the schist becoming first siliceous, and ultimately, at the contact, hornblendeschist." $\uparrow$

The anthracite and plumbago associated with hypogene rocks may have been coal; for not only is coal converted into anthracite in the vicinity of some trap dikes, but we have seen that a like change has taken place generally even far from the contact of igneous rocks, in the disturbed region of the Appalachians. $\$$ At Worcester, in the State of Massachusetts, 45 miles due west of Boston, a bed of plumbago and impure anthracite occurs, interstratified with mica-schist. It is about 2 feet in thickness, and has been made use of both as fuel and in the manufacture of lead pencils. At the distance of 30 miles from the plumbago, there occurs, on the borders of Rhode Island, an impure anthracite in slates containing impressions of coal-plants of the genera Pecopteris, Neuropteris, Calamites, \&c. This anthracite is intermediate in character between that of Pennsylvania and the plumbago of Worcester, in which last the gaseous or volatile matter (hydrogen, oxygen, and nitrogen) is to the carbon only in the proportion of 3 per cent. After traversing the country in various directions, I came to the conclusion that the carboniferous shales or slates with anthracite and plants, which in Rhode Island often pass into mica-schist, have at Worcester assumed a perfectly crystalline and

\footnotetext{
* Syst. of Geol., vol. i. p. 210

+ Ibid., p. 211.

$\ddagger$ See above, pp. 497, 503.
} 
metamorphic texture; the anthracite having been nearly transmuted into that state of pure carbon which is called plumbago or graphite.*

It has been remarked by M. Delesse that the minerals developed in hypogene limestone vary according to the degree of metamorphism which the rock has undergone. Thus, for example, where the structure is but slightly crystalline, talc, chlorite, serpentine, andalusite, and kyanite are commonly present; where it is more highly crystallized, garnet, hornblende, wallastonite, dipyre, couzeranite, and some others appear; and, lastly, where the crystallization is complete, there are found, in addition to many of the above minerals, felspar, especially those kinds which are richest in alkali, together with mica. The same author observes that, as calcareous deposits usually contain some aluminous clay, so we may naturally expect to meet with silicates of alumina in crystalline limestone; such silicates, accordingly, are frequent, and occasionally even pure alumina crystallized in the form of corundum. $\uparrow$

Mr. Dana has suggested that the phosphoric acid of phosphate of lime, and the fluor of fluor-spar, so often met with in crystalline limestones, may have been derived from the remains of mollusca and other animals; also that graphite (which is pure carbon in a crystalline form, with or without admixture of alumina, lime, or iron) may have been derived from vegetable remains imbedded in the original matrix.

The total absence of any trace of fossils has inclined many geologists to attribute the origin of the crystalline strata to a period antecedent to the existence of organic beings. Admitting, they say, the obliteration, in some cases, of fossils by plutonic action, we might still expect that traces of them would oftener occur in certain ancient systems of slate, in which, as in Cumberland, some conglomerates occur. But in urging this argument, it seems to have been forgotten that there are stratified formations of enormous thickness, and of various ages, and some of them very modern, all formed after the earth had become the abode of living creatures, which are, nevertheless, in certain districts, entirely destitute of all vestiges of organic bodies. In some, the traces of fossils may have been effaced by water and acids, at many successive periods; and it is clear, that the older the stratum, the greater is the chance of its being nonfossiliferous, even if it has escaped all metamorphic action.

It has been also objected to the metamorphic theory, that the chemical composition of the secondary strata differs essentially from that of the crystalline schists, into which they are supposed to be convertible.† The "primary" schists, it is said, usually contain a considerable proportion of potash, or of soda, which the secondary clays,

* See Lyell, Quart. Geol. Journ., vol. i. p. 199

† Delesse, Bulletin Soc. Géol. France, 2e série, tom. ix. p. 126, 1851.

$\ddagger$ Dr. Boase, Primary Geology, p. 319. 
shales, and slates do not, these last being the result of the decomposition of felspathic rocks, from which the alkaline matter has been abstracted during the process of decomposition. But this reasoning proceeds on insufficient and apparently mistaken data; for a large portion of what is usually called clay, marl, shale, and slate, does actually contain a certain, and often a considerable proportion of alkali; so that it is difficult, in many countries, to obtain clay or shale sufficiently free from alkaline ingredients to allow of their being burnt into bricks or used for pottery.

Thus the argillaceous shales and slates of the Old Red sandstone, in Forfarshire and other parts of Scotland, are so much charged with alkali, derived from triturated felspar, that, instead of hardening when exposed to fire, they sometimes melt into a glass. They contain no lime, but appear to consist of extremely minute grains of the various ingredients of granite, which are distinctly visible in the coarsergrained varieties, and in almost all the interposed sandstones. These laminated clays and shales might certainly, if crystallized, resemble in composition many of the primary strata.

There is also potash in fossil vegetable remains, and soda in the salts by which strata are sometimes so largely impregnated, as in Patagonia. But recent analysis may be said to have settled the point at issue, by demonstrating that the carboniferous strata in England,* the Upper and Lower Silurian in East Canada, $\nmid$ and the clay-slates (of Cambrian or Laurentian date?) in Norway, $\$$ all contain as much alkali as is generally present in metamorphic rocks.

Another objection has been derived from the alternation of highly crystalline strata with others having a less crystalline texture. The heat, it is said, in its ascent from below must have traversed the less altered schists before it reached a higher and more crystalline bed. In answer to this, it may be observed, that if a number of strata differing greatly in composition from each other be subjected to equal quantities of heat, or hydrothermal action, there is every probability that some will be much more fusible or soluble than others. Some, for example, will contain soda, potash, lime, or some other ingredient capable of acting as a flux or solvent; while others may be destitute of the same elements, and so refractory as to be very slightly affected by the same causes. Nor should it be forgotten that, as a general rule, the less crystalline rocks do really occur in the upper, and the more crystalline in the lower part of each metamorphic series.

Moreover, metamorphism must often begin to exert its force long after the strata have assumed a vertical position, and it may then act locally or within limited areas, and will be as likely to affect the

* H. Taylor, Edin. New Phil. Journ., vol. 1., 1851, p. 140.

$\dagger$ Hunt, Phil. Mag., 4th ser., vol. vii. p. 237.

$\ddagger$ Kyersly, Norsk, Mag. for Naturvidenp., vol. viii. p. 172 . 
newer as the older beds. As an illustration of such partial conversion into gneiss of portions of a highly inclined set of beds, I may cite Sir R. Murchison's memoir on the structure of the Alps. Slates provincially termed "flysch" (see above, p. 307), overlying the nummulitic limestone of Eocene date, and comprising some arenaceous and some calcareous layers, are seen to alternate several times with bands of anitoid rock, answering in character to gneiss.* In this case heat, vapor, or water at a high temperature may have traversed the more permeable beds, and altered them so far as to admit of an internal movement and rearrangement of the molecules, while the adjoining strata did not give passage to the same heated gases or water, or, if so, remained unchanged because they were composed of less fusible or decomposable materials. Whatever hypothesis we adopt, the phenomena establish beyond a doubt the possibility of the development of the metamorphic structure in a tertiary deposit in planes parallel to those of stratification.

Whether such parallelism be the rule or the exception in gneiss, mica-schist, and other formations of the same family, is a question which I shall discuss at length in the next chapter.

\section{CHAPTER XXXVI.}

METAMORPHIC ROCKs, continued.

Definition of joints, slaty cleavage, and foliation-Supposed causes of these structures-Mechanical theory of cleavage-Condensation and elongation of slate rocks by lateral pressure-Supposed combination of crystalline and mechanical forces-Lamination of some volcanic rocks due to motion-Whether the foliation of the crystalline schists be usually parallel with the original planes of stratification--Examples in Norway and Scotland-Foliation in homogeneous rocks may coincide with planes of cleavage, and in uncleaved rocks with those of stratification-Causes of irregularity in the planes of foliation.

Ww have already seen that chemical forces of great intensity have frequently acted upon sedimentary and fossiliferous strata long subsequently to their consolidation, and we may next inquire whether the component minerals of the altered rocks usually arrange themselves in planes parallel to the original planes of stratification, or whether, after crystallization, they more commonly take up a different position.

In order to estimate fairly the merits of this question, we must first define what is meant by the terms cleavage and foliation. There

* Geol. Quart. Journ., vol. v. p. 211, 1848. 
are four distinct forms of structure exhibited in rocks, namely, strati-fication, joints, slaty clearage, and foliation; and all these must have different names, even though there be cases where it is impossible, after carefully studying the appearances, to decide upon the class to which they belong.

Professor Sedo'wick, whose essay "On the Structure of large Mineral Masses" first cleared the way towards a better understanding of this difficult subject, obserres, that joints are distinguishable from lines of slaty clearage in this, that the rock interrening between two joints has no tendency to cleave in a direction parallel to the planes of the joints, whereas a rock is capable of indefinite subdivision in the direction of its slaty cleavage. In cases where the strata are curred, the planes of clearage are still perfectly parallel. This has been observed in the slate rocks of part of Wales (see fig. 758),

Fig. 758.

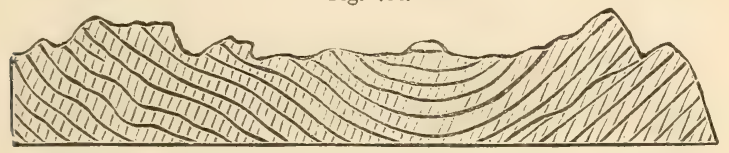

Parallel planes of clearage intersecting curved strata. (Seảgwrick.)

which consist of a hard greenish slate. The true bedding is there indicated by a number of parallel stripes, some of a lighter and some of a darker color than the general mass. Such stripes are found to be parallel to the true planes of stratification, wherever these are manifested by ripple-mark, or by beds containing peculiar organic remains. Some of the contorted strata are of a coarse mechanical structure, alternating with fine-grained crystalline chloritic slates, in which case the same slaty cleavage extends through the coarser and finer beds, though it is brought out in greater perfection in proportion as the materials of the rock are fine and homogeneous. It is only when these are rery coarse that the clearage planes entirely vanish. These planes are usually inclined at a very considerable angle to the planes of the strata. In the Welsh hills, for example, the average angle is as much as from $30^{\circ}$ to $40^{\circ}$. Sometimes the clearage planes dip towards the same point of the compass as those of stratification, but more frequently to opposite points. It may be stated as a general rule, that when beds of coarser materials alternate with those composed of finer particles, the slaty clearage is either entirely confined to the fine-grained rock, or is rery imperfectly exhibited in that of coarser texture. This rule holds, whether the clearage is parallel to the planes of stratification or not.*

In regard to joints, they are natural fissures which often traverse rocks in straight and well-determined lines. They afford to the 
quarryman, as Sir R. Murchison observes, when speaking of the phenomena, as exhibited in Shropshire and the neighboring counties, the greatest aid in the extraction of blocks of stone; and, if a sufficient number cross each other, the whole mass of rock is split into symmetrical blocks. The faces of the joints are for the most part smoother and more regular than the surfaces of true strata. The joints are straight-cut chinks, often slightly open, often passing, not only through layers of successive deposition, but also through balls of limestone or other matter which have been formed by concretionary action, since the original accumulation of the strata. Such joints, therefore, must often have resulted from one of the last changes superinduced upon sedimentary deposits.*

In the annexed diagram (fig. 759), the flat surfaces of rock A, B, c,

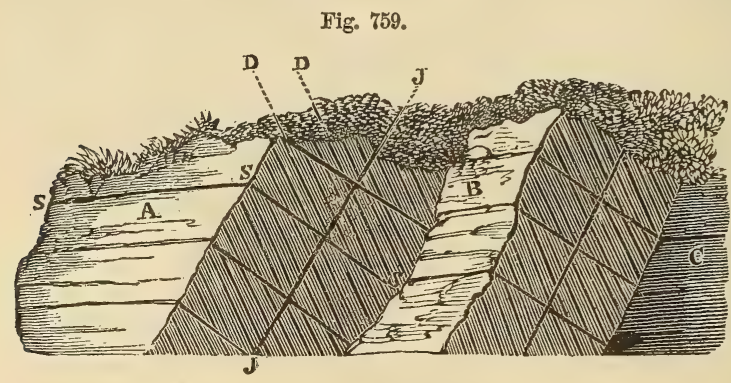

Stratification, joints, and cleavage.

(From Murchison's Silurian System, p. 245.)

represent exposed faces of joints, to which the walls of other joints, $\mathrm{J} \mathrm{J}$, are parallel. s s are the lines of stratification; D D are lines of slaty cleavage, which intersect the rock at a considerable angle to the planes of stratification.

In the Swiss and Savoy Alps, as Mr. Bakewell has remarked, enormous masses of limestone are cut through so regularly by nearly vertical partings, and these joints are often so much more conspicuous than the seams of stratification, that an inexperienced observer will almost inevitably confound them, and suppose the strata to be perpendicular in places where in fact they are almost horizontal. $\dagger$

Now such joints are supposed to be analogous to the partings which separate volcanic and plutonic rocks into cuboidal and prismatic masses. On a small scale we see clay and starch when dry split into similar shapes; this is often caused by simple contraction, whether the shrinking be due to the evaporation of water, or to a change of temperature. It is well known that many sandstones and other rocks expand by the application of moderate degrees of heat, and thèn contract again on cooling; and there can be no doubt that 
large portions of the earth's crust have, in the course of past ages, been subjected again and again to very different degrees of heat and cold. These alternations of temperature have probably contributed largely to the production of joints in rocks.

In some countries, as in Saxony, where masses of basalt rest on sandstone, the aqueous rock has for the distance of several feet from the point of junction assumed a columnar structure similar to that of the trap. In like manner some hearthstones, after exposure to the heat of a furnace without being melted, have become prismatic. Certain crystals also acquire by the application of heat a new internal arrangement, so as to break in a new direction, their external form remaining unaltered.

Professor Sedgrick, speaking of the planes of slaty cleavage, where they are decidedly distinct from those of sedimentary deposition, declared, in the essay before alluded to, his opinion that no retreat of parts, no contraction in the dimensions of rocks in passing to a solid state, can account for the phenomenon. He accordingly referred it to crystalline or polar forces acting simultaneously, and somewhat uniformly, in given directions, on large masses having a homogeneous composition.

Sir John Herschel, in allusion to slaty cleavage, has suggested, "that if rocks have been so heated as to allow a commencement of crystallization-that is to say, if they have been heated to a point at which the particles can begin to move amongst themselves, or at least on their own axes, some general law must then determine the position in which these particles will rest on cooling. Probably that position will have some relation to the direction in which the heat escapes. Now, when all, or a majority of particles of the same nature have a general tendency to one position, that must of course determine a cleavage-plane. Thus we see the infinitesimal crystals of fresh precipitated sulphate of barytes, and some other such bodies, arrange themselves alike in the fluid in which they float; so as, when stirred, all to glance with one light, and give the appearance of silky filaments. Some sorts of soap, in which insoluble margarates * exist, exhibit the same phenomenon when mixed with water; and what occurs in our experiments on a minute scale may occur in nature on a great one." $\dagger$

Professor Phillips has remarked that in some slaty rocks the form of the outline of fossil shells and trilobites has been much changed by distortion, which has taken place in a longitudinal, transverse, or oblique direction. This change, he adds, seems to be the result of a "creeping movement" of the particles of the rock along the planes of cleavage, its direction being always uniform orer the same tract of country, and its amount in space being sometimes measurable, and

* Margaric acid is an oleaginous acid, formed from different animal and vegetable fatty substances. A margarate is a compound of this acid with soda, potash, or some other base, and is so named from its pearly lustre.

† Letter to the author, dated Cape of Good Hope, Feb. 20, 1836. 
being as much as a quarter or even half an inch. The hard shells are not affected, but only those which are thin.* Mr. D. Sharpe, following up the same line of inquiry, came to the conclusion that the present distorted forms of the shells in certain British slate rocks may be accounted for by supposing that the rocks in which they are imbedded have undergone compression in a direction perpendicular to the planes of cleavage, and a corresponding expansion in the direction

Fig. 760 .

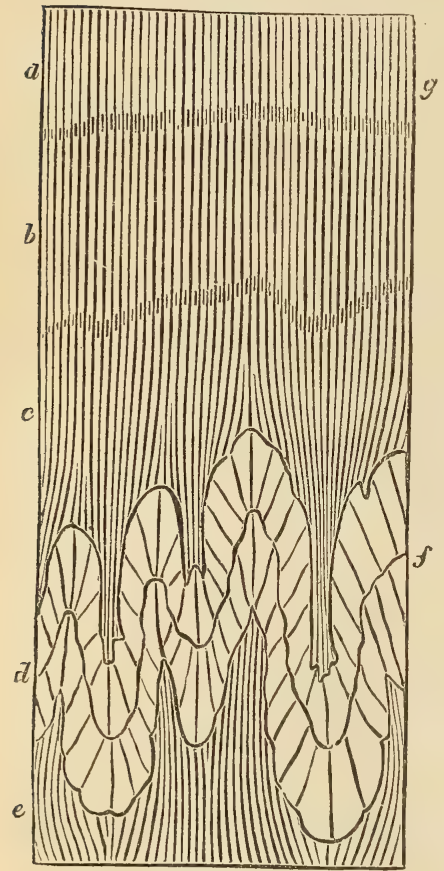

(Drawn by H. C. Sorby.)

Vertical section of slate rock in the cliffs near Ilfracombe, North Devon.

Scale one inch to one foot.

$a, b, c, e$. Fine-grained slates, the stratification being shown partly by lighter, or darker colors, and partly by different degrees of fineness in the grain.

$d, f$. A coarser-grained light-colored sandy slate with less perfect cleavage. direction of the flexures than in a plane perpendicular to them; and the same bed exhibits cleavage-planes in the direction of the greatest

* Report, Brit. Assoc., Cork, 1843, Sect. p. 60.

$\uparrow$ Quart. Geol. Journ., vol. iii. p. 87, 1847.

$\ddagger$ On the Origin of Slaty Cleavage, by H. C. Sorby, Edinb. New Phil. Journ, 1853, vol. lv. p. 137. 
morement, although they are much fewer than in the slaty strata above and below.

Abore the sandy bed $d f$, the stratum $c$ is somewhat disturbed, while the next bed $b$ is much less so, and $a$ not at all; yet all these beds $c, b$, and $a$, must have undergone an equal amount of pressure with $d$, the points $a$ and $g$ haring approximated as much towards each other as have $d$ and $f$. The same phenomena are also repeated in the beds below $d$, and might hare been shown, had the section been extended downwards. Hence it appears that the finer beds hare been squeezed into a fourth of the space they previously occupicd, partly by condensation, or the closer packing of their ultimate particles (which has given rise to the great specific gravity of such slates), and partly by elongation in the line of the dip of the cleavage, of which the general direction is perpendicular to that of the pressure. "These and numerous other cases in North Devon are analogous," says Mr. Sorby, "to what would occur if a strip of paper were included in a mass of some soft plastic material which would readily change its dimensions. If the whole were then compressed in the direction of the length of the strip of paper, it would be bent and puckered up into contortions, whilst the plastic material would readily change its dimensions without undergoing such contortions; and the difference in distance of the ends of the paper, as measured in a direct line or along it, would indicate the change in the dimensions of the plastic material."

The student will readily conceive that, when the shape of a fossil or of a crystal of some mineral, or of a spheroidal concretion, has been altered by lateral pressure, the new forms which they assume respectively will rary according to whether they have yielded in one or more directions. They may have been drawn out solely in the direction of the dip of the cleavage, or they may have yielded in a plane perpendicular to that dip, or they may hare undergone both these movements. By micruscopic examination of minute crystals, and by other observations too minute to be detailed here, Mr. Sorby comes to the conclusion that the absolute condensation of the slate rocks amounts upon an arerage to about one-half their original rolume. This must hare resulted chiefly from the forcing of the particles more closely together, so as to fill up the spaces left between them, when they only touched each other. The rest of the change has been due to elongation which has produced slaty cleavage.

Most of the scales of mica occurring in certain slates examined by Mr. Sorby lie in the plane of clearare; whereas in a similar rock not exhibiting clearage they lie with their longer axes in all directions. May not their position in the slates have been determined by the morement of elongation lefore alluded to? To illustrate this theory some scales of oxide of iron were mixed with soft pipe-clay in such a mammer that they inclined in all directions. The dimensions of the mass were then changed artificially to a similar extent to what has occurred in slate rocks, and the pipe-clay was then dried and baked. 
When it was afterwards rubbed to a flat surface perpendicular to the pressure and in the line of elongation, or in a plane corresponding to that of the dip of cleavage, the particles were found to have become arranged in the same manner as in natural slates, and the mass admitted of easy fracture into thin flat pieces in the plane alluded to, whereas it would not yield in that perpendicular to the cleavage.**

Dr. Tyndall, when commenting in 1856 on Mr. Sorby's experiments, observed that pressure alone is sufficient to produce cleavage, and that the intervention of plates of mica or scales of oxide of iron, or any other substances having flat surfaces, is quite unnecessary. In proof of this he showed experimentally that a mass of "pure white wax after having been submitted to great pressure, exhibited a cleavage more clean than that of any slate-rock, splitting into laminæ of surpassing tenuity." $\dagger \mathrm{He}$ remarks that every mass of clay or mud is divided and subdivided by surfaces among which the cohesion is comparatively small. On being subjected to pressure, such masses yield and spread out in the direction of least resistance, small nodules become converted into laminæ separated from each other by surfaces of weak cohesion, and the result is that the mass cleaves at right angles to the line in which the pressure is exerted. The experiments of Mr. Sorby in reference to the manner in which scales of mica and oxide of iron arrange themselves in soft pipe-clay under compression have been supposed to lend countenance to the opinion that the lamination of basalt and trachyte, and even of some kinds of gneiss, and the grain of certain granites, may all have been determined by a mechanical cause, a movement having taken place after the development of crystals in the pasty mass.

Mr. Scrope, in his description of the Ponza Islands, ascribed the zoned structure of the Hungarian perlite (a semi-vitreous trachyte) to its having subsided, in obedience to the impulse of its own gravity, down a slightly inclined plane, while possessed of an imperfect fluidity. In the Islands of Ponza and Palmarolo, the direction of the zones is more frequently vertical than horizontal, because the mass was impelled from below upwards." $\$$ In like manner, Mr. Darwin attributes the lamination and fissile structure of volcanic rocks of the trachytic series, including some obsidians in Ascension, Mexico, and elsewhere, to their having moved when liquid in the direction of the laminæ. The zones consist sometimes of layers of air-cells drawn out and lengthened in the supposed direction of the moving mass. This division into parallel zones, thus caused by the stretching of a pasty mass as it flowed slowly onwards, he compares to the zoned or ribboned structure of ice, which Professor James Forbes has endeav

\footnotetext{
* Sorby, as cited above, p. 750, note.

+ Tyndall, View of the Cleavage of Crystals and Slate Rocks.

¥ Geol. Trans., Second Series, vol. ii. p. 227.
} 
ored to explain by referring to the fissuring of a viscous body in motion.*

Whaterer be the cause, the result, observes Darwin, is well worthy the attention of geologists; for, in a volcanic rock of the trachytic series in Ascension, layers are seen often of extreme tenuity, even as thin as hairs, and of different colors, alternating again and again, some of them composed of crystals of quartz and diopside (a kind of augite), others of black augitic specks with granules of oxide of iron, and lastly, others of crystalline felspar. It is supposed in this case that the crystallizing force acted more freely in the direction of the planes of clearage, produced when the pasty mass was stretched, whether because confined rapors were enabled to spread themselves through the minute fissures, or because the ultimate molecules had more freedom of motion along the planes of less tension, or for some other reasons not yet understood.

After studying, in 1835, the crystalline rocks of South America, Mr. Darwin proposed the term foliation for the laminæ or plates into which gneiss, mica-schist, and other crystalline rocks are divided. Cleavage, he observes, may be applied to those divisional planes which render a rock fissile, although it may appear to the eye quite or nearly homogeneous. Foliation may be used for those alternating layers or plates of different mineralogical nature of which gneiss and other metamorphic schists are composed. The cleavage planes of the clayslate in Terra del Fuego and Chili preserve a uniform strike for hundreds of miles in regions where these planes are quite distinct from stratification. In the same country the planes of foliation of the micaschist and gneiss are parallel to the cleavage of the clay-slate. Hence we are tempted, at first sight, to infer that some common cause or process, and that cause not connected with sedimentary deposition, has impressed clearage on the one set of rocks and foliation on the other. But such an inference can only be legitimately drawn in those rare cases where we are able, by a continuous section, to prove that not only the strike, but the dip of the slaty cleavage on the one hand, and of the foliation on the other, preciscly coincide; the cleavage at the same time not being parallel to the stratification in the slate rock. In some examples cited by Mr. Darwin, in Terra del Fuego, the Chonos Islands, and La Plata, this uniformity of dip seems to have been traced in a manner as satisfactory as the nature of such evidence will allow. But we must be on our guard against a source of deception which may mislead us in this chain of reasoning. Te are informed that in South America, as in other countries, the strike of the cleavage in clay-slate conforms to the axis of elevation of the rocks in the same districts. Hence it must follow that the folia of gneiss, micaschist, limestone, and other crystalline rocks, even if they strictly coincide with the planes of original stratification, will run in the same 
direction as the strike of the slaty cleavage; for the true strata always dip at right angles to the axis of elevation, and are parallel to it in their strike. No argument, therefore, can be drawn in favor of a common origin from uniformity of strike in the slaty and foliated rocks; for we require, in addition, coincidence of dip; and such is the variability of the dip both of the slates and folia as to render this kind of proof very difficult to obtain.

That the planes of foliation of the crystalline schists in Norway accord very generally with those of original stratification is a conclusion long since espoused by Keilhau.* Numerous observations made by Mr. David Forbes in the same country (the best probably in Europe for studying such phenomena on a grand scale) confirm Keilhau's opinion. In Scotland, also, Mr. D. Forbes has pointed out a striking case where the foliation is identical with the lines of stratification in rocks well seen near Crianlorich on the road to Tyndrum, about 8 miles from Inverarnon in Perthshire. There is in that locality a blue limestone foliated by the intercalation of small plates of white mica, so that the rock is often scarcely distinguishable in aspect from gneiss or mica-schist. The stratification is shown by the large beds and colored bands of limestone all dipping, like the folia, at an angle of 32 degrees N.E. $†$

In stratified formations of every age we see layers of siliceous sand with or without mica, alternating with clay, with fragments of shells or corals, or with seams of vegetable matter, and we should expect the mutual attraction of like particles to favor the crystallization of the quartz; or mica, or felspar, or carbonate of lime along the planes of original deposition, rather than in planes placed at angles of 20 or 40 degrees to those of stratification.

In Patagonia, a series of thin sedimentary layers of tuff were observed by Mr. Darwin to have become porphyritic, first where least altered, by a process of aggregation, small patches of clay appearing to be shortened into almond-shaped concretions, which in those places where they were more changed had become crystals of felspar, having their longer axes parallel to each other. In other associated strata, grains of quartz had in like manner aggregated into nodules of crystalline quartz.\$.

May we not, then, presume that in rocks where no cleavage has intervened, foliation and the planes of stratification will usually coincide, as in all cases where cleavage happens (as in the writing-slates of the Niesen on the Lake of Thun in Switzerland, containing fucoids) to agree with the original planes of sedimentary deposition? Mr. Darwin conceives that "foliation may be the extreme result of the process of which cleavage is the first effect ;" or, at any rate, that the

* Norske Mag. Naturvidsk., vol, i. p. 71.

† Memoir read before the Geol. Soc. London, Jan. 31, 1855.

$\ddagger$ South America, p. 149. 
crystalline force may have been most energetic in the direction of clearage. As bearing on this view, he says, "I was particularly struck in the eastern parts of Terra del Fuego with the fact that the fine laminæ of clay-slate, where they cut straight through the bands of stratification, and therefore indisputably true clearage-planes, differ slightly from one another in their grayish and greenish tints of color, as also in their compactness, and in some laminæ haring a more jaspery appearance than others. This fact shors that the same cause which has produced the lighly fissile structure has altered in a slight degree the mineralogical character of the rock in the same planes." * As one step farther towards tracing a passage from planes of clearage to those of foliation, Professor Sedgwick observes that in North Wales the surfaces of slates are sometimes coated over with chlorite, "the crystals of which have not only defined the cleavage planes but struck through the whole mass of the rock." $\dagger$ So also, says Mr. Darmin, in some places in South America crystals of epidote and of mica coat the planes of cleavage.

There seems to be no difficulty in imagining that in rocks of homogeneous composition the foliation may take place along planes previously caused by the elongation of the materials along the dip of the clearage ; for experienced geologists hare been at a loss to decide in many countries which of two sets of divisional planes were referable to clearage, and which to stratification; and, after much doubt, have discorered that they had at first mistaken the lines of cleavage for those of deposition, because the former were by far the most marked of the two. Now if such slaty masses should become highly crystalline, and be converted into gneiss, hornblende-schist, or any other member of the hypogene class, the cleavage planes might possibly remain more visible than those of stratification. Professor Henslow had noticed, so long ago as the year 1821, that the lamination of the chloritic and other crystalline schists in Anglesea was approximately in the planes of bedding; and Professor Ramsay, in 1841, observed the same in regard to the gneiss and mica-schist of Arran. The lastcited geologist says, in reference to Anglesea, that the metamorphism probably took place when the Lower Silurian volcanoes were in activity, and therefore long before the cleavage of the Welsh rocks; for the clearage of the latter affects in common the Lower Silurian and the Cambrian strata. In the same memoir he adds, when referring to Mr. Darwin's theory of foliation, "that if the rocks be uncleared when metamorphism occurs, the foliation planes will be apt to coincide with those of bedding; but if intense clearage has preceded, then we may expect that the planes of foliation will lie in the planes of cleavage." †

\footnotetext{
* Geol. Observ. on South America, p. 155.

† Sedgwick, Geol. Trans., Second Series, vol. iii. p. 471.

‡ Geol. Quart. Journ., 1853, vol. ix. p. 172.
} 
From what I have myself seen in the Grampians, both in Forfarshire and Perthshire, I have always concluded that MacCulloch was correct in the opinion that gneiss and mica-schist may be considered as stratified rocks, and that certain beds of pure quartz; one or two feet thick, which run for miles in the strike of their foliation, as well as the intercalation of masses of limestone, and of chloritic, actinolitic, and hornblende schists, all indicate the planes of original stratification. At the same time, I fully admit that the alternate layers of quartz, or of mica and quartz, of felspar, or of mica and felspar, or of carbonate of lime, are more distinct, in certain metamorphic rocks, than the ingredients composing alternate layers in most sedimentary deposits, so that similar particles must be supposed to have exerted a molecular attraction for each other, and to have congregated. together in layers more distinct in mineral composition than before they were crystallized.

We have seen how much the original planes of stratification may be interfered with or even obliterated by concretionary action in deposits still retaining their fossils, as in the case of the magnesian limestone (see p. 37). Hence we must expect to be frequently baffled when we attempt to decide whether the foliation does or does not accord with that arrangement which gravitation, combined with current-action, imparted to a deposit from water. Moreover, when we look for stratification in crystalline rocks, we must be on our guard not to expect too much regularity. The occurrence of wedge-shaped masses, such as belong to coarse sand and pebbles-diagonal lamination (see p. 16)-ripple-marked-unconformable stratification (p. 16), the fantastic folds produced by lateral pressure-faults of various width-intrusive dikes of trap-organic bodies of diversified shapes -and other causes of unevenness in the planes of deposition, both on the small and on the large scale, will interfere with parallelism. If complex and enigmatical appearances did not present themselves, it would be a serious objection to the metamorphic theory.

Fig. 761 .

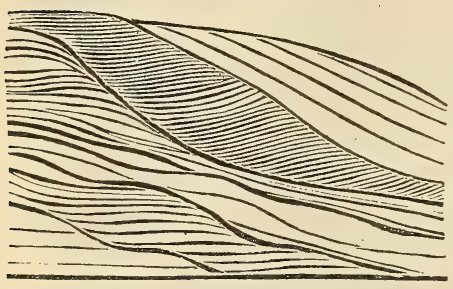

Lamination of clay-slate, Montagne de Seguinat, near Gavarnie, in the Pyrenees.

Mr. Sorby has shown that the peculiar structure belonging to ripple-marked sands, or that which is generated when ripples are formed during the deposition of the materials, is distinctly recognizable in many varieties of micaschists in Scotland.*

In the accompanying diagram I have represented carefully the lamination of a coarse argillaceous schist which I examined in 1830 in the Pyrenees. In part it approaches in character to a green and 
blue roofing-slate, while part is extremely quartzose, the whole mass passing downwards into micaceous schist. The vertical section here exhibited is about three feet in height, and the layers are sometimes so thin that fifty may be counted in the thickness of an inch. Some of them consist of pure quartz.

There is a resemblance in such cases to the diagonal lamination which we see in sedimentary rocks, even though the layers of quartz and of mica, or of felspar and other minerals, may be more distinct in alternating folia than they were originally.

M. Elie de Beaumont, while he regards the greater part of the gneiss and mica-schist of the Alps as sedimentary strata altered by plutonic action, still conceives that some of the Alpine gneiss may have been erupted, or, in other words, may be granite drawn out into parallel laminæ in the manner of trachyte, as above alluded to.*

If the mass were squeezed and elongated in a certain direction after crystals of mica, talc, or other scaly minerals were developed, these may perhaps have arranged themselves in planes parallel to those of movement, and a similar process may account for what the quarrymen call "the grain" in some granites, or a tendency to split in one direction more freely than in another. But, as a general rule, the fusion of the crystalline schists does not appear to have gone so far as to allow of motion analogous to that of lava or granite, and for this reason rocks of this class do not send veins into surrounding rocks. In the next chapter we may inquire at how many distinct periods the hypogene or metamorphic schists can be proved to have originated, and why for so long a time the earlier geologists regarded them as entitled to the name of "primitive."

* Bulletin Soc. Géol. de France, 2e série, vol. iv. p. 1301. 


\title{
CHAPTER XXXVII.
}

\author{
ON THE DIFFERENT AGES OF THE METAMORPHIC ROCKS.
}

\begin{abstract}
Age of each set of metamorphic strata twofold-Test of age by fossils and mineral character not available-Test by superposition ambiguous-Conversion of dense masses of fossiliferous strata into metamorphic rocks-Limestone and shale of Carrara-Metamorphic strata of older date than the Cambrian rocks-0thers of Lower Silurian origin-Others of the Jurassic and Eocene periods in the Alps of Switzerland and Savoy-Why scarcely any of the visible crystalline strata are very modern-Order of succession in metamorphic rocks-Uniformity of mineral character-Why the metamorphic strata are less calcareous than the fossiliferous.
\end{abstract}

According to the theory adopted in the last chapter, the age of each set of metamorphic strata is twofold-they have been deposited at one period, they have become crystalline at another. We can rarely hope to define with exactness the date of both these periods, the fossils having been destroyed by plutonic action, and the mineral characters being the same, whatever the age. Superposition itself is an ambiguous test, especially when we desire to determine the period of crystallization. Suppose, for example, we are convinced that certain metamorphic strata in the Alps, which are covered by cretaceous beds, are altered lias; this lias may have assumed its crystalline texture in the cretaceous or in some tertiary period, the Eocene for example. If in the latter, it should be called Eocene when regarded as a metamorphic rock, although it be liassic when considered in reference to the era of its deposition. According to this view, the superposition of chalk does not prevent the subjacent metamorphic rock from being Eocene.

When discussing the ages of the plutonic rocks, we have seen that examples occur of various primary, secondary, and tertiary deposits converted into metamorphic strata, near their contact with granite. There can be no doubt in these cases that strata, once composed of mud, sand, and gravel, or of clay, marl, and shelly limestone, have for the distance of several yards, and in some instances several hundred feet, been turned into gneiss, mica-schist, hornblende-schist, chloriteschist, quartz rock, statuary marble, and the rest. (See the two preceding chapters.)

But when the metamorphic action has operated on a grander scale, it tends entirely to destroy all monuments of the date of its development. It may be easy to prove the identity of two difierent parts of 
the same stratum; one, where the rock has been in contact with a volcanic or plutonic mass, and has been changed into marble or hornblende-schist, and another not far distant, where the same bed remains unaltered and fossiliferous; but when we have to compare two portions of a mountain chain-the one metamorphic, and the other unaltered-all the labor and skill of the most practised observers are required, and may sometimes be at fault. I shall mention one or two examples of alteration on a grand scale, in order to explain to the student the kind of reasoning by which we are led to infer that dense masses of fossiliferous strata have been converted into crystalline rocks.

Northern Apennines-Carrara.-The celebrated marble of Carrara, used in sculpture, was once regarded as a type of primitive limestone. It abounds in the mountains of Massa Carrara, or the "Apuan Alps," as they have been called, the highest peaks of which are nearly 6000 feet high. Its great antiquity was inferred from its mineral texture, from the absence of fossils, and its passage downwards into talc-schist and garnetiferous mica-schist; these rocks again graduating downwards into gneiss, which is penetrated, at Forno, by granite veins. Now the researches of MM. Savi, Boué, Pareto, Guidoni, De la Beche, Hoffmann, and Pilla have demonstrated that this marble, once supposed to be formed before the existence of organic beings, is, in fact, an altered limestone of the oolitic period, and the underlying crystalline schists are secondary sandstones and shales, modified by plutonic action. In order to establish these conclusions, it was first pointed out, that the calcareous rocks bordering the Gulf of Spezia, and abounding in oolitic fossils, assume a texture like that of Carrara marble, in proportion as they are more and more invaded by certain trappean and plutonic rocks, such as diorite, euphotide, serpentine, and granite, occurring in the same country.

It was then abserved that, in places where the secondary formations are unaltered, the uppermost consist of common Apennine limestone with nodules of flint, below which are shales, and at the base of all, argillaceous and siliceous sandstones. In the limestone fossils are frequent, but very rare in the underlying shale and sandstone. Then a gradation was traced laterally from these rocks into another and corresponding series, which is completely metamorphic; for at the top of this we find a white granular marble, wholly devoid of fossils, and almost without stratification, in which there are no nodules of flint, but in its place siliceous matter disseminated through the mass in the form of prisms of quartz. Below this, and in place of the shales, are talc-schists, jasper, and hornstone; and at the bottom, instead of the siliceous and argillaceous sandstones, are quartzite and gneiss.* Had

* See notices of Savi, Hoffmann, and others, referred to by Boué, Bull. de la Soc. Géol. de France, tom. v. p. 317 ; and tom. iii. p. 44 ; also Pilla, cited by Murchison, Quart. Geol. Journ., vol. v. p. 266. 
these secondary strata of the Apennines undergone universally as great an amount of transmutation, it would have been impossible to form a conjecture respecting their true age; and then, according to the method of classification adopted by the earlier geologists they would have ranked as primary rocks. In that case the date of their origin would have been thrown back to an era antecedent to the deposition of the Lower Silurian or Cambrian strata, although in reality they were formed in the Oolitic period, and altered at some subsequent and perhaps much later epoch.

Alps of Switzerland.-In the Alps, analogous conclusions have been drawn respecting the alteration of strata on a still more extended scale. In the eastern part of that chain, some of the primary fossiiferous strata, as well as the older secondary formations, together with the oolitic and cretaceous rocks, are distinctly recognizable. Tertiary deposits also appear in a less elevated position on the flanks of the Eastern Alps; but in the Central or Swiss Alps, the primary fossiliferous and older secondary formations disappear, and the Cretaceous, Oolitic, Liassic, and at some points even the Eocene strata, graduate insensibly into metamorphic rocks, consisting of granular limestone, talc-schist, talcose-gneiss, micaceous schist, and other varieties. In regard to the age of this vast assemblage of crystalline strat;, we can merely affirm that some of the upper portions are altered newer secondary, and some of them even Eocene deposits; but we cannot aroid suspecting that the disappearance both of the older secondary and primary fossiliferous rocks may be owing to their having been all converted in the same region into crystalline schist.

It is difficult to convey to those who have never visited the Alps a just idea of the various proofs which concur to produce this conviction. In the first place there are certain regions where Oolitic, Cretaceous, and Eocene strata have been turned into granular marble, gneiss, and other metamorphic schists, near their contact with granite. This fact shows undeniably that plutonic causes continued to be in operation in the Alps down to a late period, even after the deposition of some of the nummulitic or middle Eocene formations. Having established this point, we are the more willing to believe that many inferior fossiliferous rocks, probably exposed for longer periods to a similar action, may have become metamorphic to a still greater extent.

We also discover in parts of the Swiss Alps dense masses of secondary and even tertiary strata which have assumed that semi-crystalline texture which Werner called transition, and which naturally led his followers, who attached great importance to mineral characters taken alone, to class them as transition formations, or as groups older than the lowest secondary rocks. (See p. 88.) Now, it is probable that these strata have been affected, although in a less intense degree, by that same plutonic action which has entirely altered and rendered metamorphic so many of the subjacent formations; for in the Alps, 
this action has by no means been confined to the immediate vicinity of granite. Granite, indeed, and other plutonic rocks, rarely make their appearance at the surface, notwithstanding the deep ravines which lay open to view the internal structure of these mountains. That they exist below at no great depth we cannot doubt, and we have already seen (p. 713) that at some points, as in the Valorsine, near Mont Blanc, granite and granitic veins are observable, piercing through talcose gneiss, which passes insensibly upwards into secondary strata.

It is certainly in the Alps of Switzerland and Savoy, more than in any other district in Europe, that the geologist is prepared to meet with the signs of an intense development of plutonic action; for here we find the most stupendous monuments of mechanical violence, by which strata thousands of feet thick have been bent, folded, and overturned. (See p. 58.) It is here that marine secondary formations of a comparatively modern date, such as the Oolitic and Cretaceous, have been upheaved to the height of 12,000, and some Eocene strata to elevations of 10,000 feet above the level of the sea; and even deposits of the Miocene era have been raised 4000 or 5000 feet, so as to rival in height the loftiest mountains in Great Britain.

If the reader will consult the works of many eminent geologists who have explored the Alps, especially those of MM. de Beaumont, Studer, Necker, Boué, and Murchison, he will learn that they all share, more or less fully, in the opinions above expressed. It has, indeed, been stated by MN. Studer and Hugi, that there are complete alternations on a large scale of secondary strata, containing fossils, with gneiss and other rocks of a perfectly metamorphic structure. I have visited some of the most remarkable localities referred to by these authors; but, although agreeing with them that there are passages from the fossiliferous to the metamorphic series far from the contact of granite or other plutonic rocks, I was unable to convince myself that the distinct alternations of highly crystalline, with unaltered strata above alluded to, might not admit of a different explanation. In one of the sections described by M. Studer in the highest of the Bernese Alps, namely in the Roththal, a valley bordering the line of perpetual snow on the northern side of the Jungfrau, there occurs a mass of gneiss 1000 feet thick and 15,000 feet long, which I examined, not only resting upon, but also again covered by strata containing oolitic fossils. These anomalous appearances may partly be explained by supposing great solid wedges of intrusive gneiss to have been forced in laterally between strata to which I found them to be in many sections unconformable. The superposition, also, of the gneiss to the oolite may, in some cases, be due to a reversal of the original position of the beds in a region where the convulsions have been on so stupendous a scale.

On the Sattel also, at the base of the Gestellihorn, above Enzen, in the valley of Urbach, near Meyringen, some of the intercalations of 
gneiss between fossiliferous strata may, I conceive, be ascribed to mechanical derangement. Almost any hypothesis of repeated changes of position may be resorted to in a region of such extraordinary confusion. The secondary strata having first become vertical, may then In certain portions have become metamorphic (the plutonic influence ascending from below), while intervening strata remained unchanged. The whole series of beds may then again have been thrown into a nearly horizontal position, giving rise to the superposition of crystalline upon fossiliferous formations.

It was remarked, in Chap. XXXIV., that as the hypogene rocks, both stratified and unstratified, crystallize originally at a certain depth beneath the surface, they must always, before they are upraised and exposed at the surface, be of considerable antiquity, relatively to a large portion of the fossiliferous and volcanic rocks. They may be forming at all periods; but before any of them can become visible, they must be raised above the level of the sea, and some of the rocks which previously concealed them must have been removed by denudation.

In Canada, as we have seen (p. 583), the Lower Laurentian gneiss, quartzite, and limestone, may be regarded as metamorphic, because organic remains (Eozoon Canadense) have been detected in a part of one of the calcareous masses. Nor can we doubt that the Upper Laurentian, or Labrador series, consisting of gneiss, with Labradorfelspar and felstones, in all 10,000 feet thick, have assumed their crystalline structure by metamorphic action, since they lie in unconformable stratification on the Lower Laurentian. The remote date of the period when some of these old Laurentian strata of Canada were converted into gneiss, may be inferred from the fact that pebbles of that rock are found in the overlying Huronian formation, which is of Lower Cambrian age, if not older (p. 583). The oldest stratified rock of Scotland is the hornblendic gneiss of Lewis, in the Hebrides, and that of the northwest coast of Rossshire, represented at the base of the section given at p. 67 , fig. 90 . It is the same as that intersected by numerous granite veins, which forms the cliffs of Cape Wrath, in Sutherlandshire (see fig. 743, p. 712), and is conjectured to be of Laurentian age. Above it, as shown in MacCulloch's section (fig. 90, p. 67), lie unconformable beds of a reddish or purplish sandstone and conglomerate, nearly horizontal, and between 2000 and 3000 feet thick. In these ancient grits no fossils have been found, but they are supposed to be of Lower Cambrian date, and they certainly do not belong to the Old Red, as was formerly supposed, for they have been shown. by Sir Roderick Murchison to pass in the North Highlands or in the three northern counties of Scotland, under quartz rocks, which, with a subordinate limestone, rest unconformably upon them. In this limestone, in 1854, Mr. Charles Peach found some obscure organic remains, which led Sir R. Murchison to institute a searching inquiry, and eventually to establish beyond all doubt 
that the calcareous formation in question was of Lower Silurian age. This was one of the most important steps made of late years in the progress of British Geology, for it led to a very unexpected conclusion, namely, that all the Scotch crystalline strata to the eastward, once called primitive, which orerlie the limestone and quartzite in question, are referable to some part of the Silurian series. The most abundant and best preserved, shells of the limestone are those obtained from Durness and Assynt. They comprise, among others, three or four species of Orthocercas, also the genera Cyrtoceras and Lituites, two species of Murchisonia, a Pleurotomaria, a species of Maclurea, one of Eumphalus, and an Orthis. Several of the species are beliered by Mr. Salter to be identical with Lower Silurian fossils of Canada and the United States. The mere occurrence of Cephalopoda in such numbers is strongly against the supposition of their being Cambrian, and the large siphuncles of some of the Orthocerata point distinctly to a Lower Silurian date, for this division of the genus, both in Europe and North America (see p. 565), is eminently characteristic of the inferior members of the Silurian system (see above, p. 565). To the fossiliferous rock above mentioned, with its accompanying quartzites, succeed in conformable stratification a dense series of gneiss, mica-schists, and clay-slates, this younger gneiss being very different in mineral character from the fundamental gneiss before mentioned. There can be no question that these crystalline formations, which are similar to those of the Central and Southern Highlands, comprising the metamorphic rocks of Aberdeenshire, Perthshire, and Forfarshire, for example, are altered Silurian strata; * the inferences of Sir R. Murchison on this subject having been confirmed by the subsequent observations of three able geologists, Messrs. Ramsay, Harkness, and Geikie. The newest of the series is a clay-slate, on which, along the southern borders of the Grampians, the Lower Old Red, containing Cephalaspis Lyelli, Pterygotus Anglicus, and Parka decipiens, rests unconformably.

In Anglesea, as was before remarked, the metamorphism of the schists, according to the observations of Professor Ramsay, took place during the Lower Silurian period. Coupling these conclusions with the fact that a hypogene texture has been superinduced in the Alps on Middle Eocene deposits (see p. 746), we cannot doubt that, hereafter, geologists will succeed in detecting crystalline schists of almost every age in the chronological series, although the quantity of metamorphic rocks visible at the surface must, for reasons above explained, diminish rapidly in proportion as the monuments of newer eras are investigated.

Order of Succession in Metamorphic Rocks.-There is no universal and invariable order of superposition in metamorphic rocks, although

* Quart. Geol. Journ., vol. xv. p. 353, 1859. Siluria, 3d ed., Appendix, p. ธ̌ร3. 
a particular arrangement may prevail throughout countries of great extent, for the same reason that it is traceable in those sedimentary formations from which crystalline strata are derived. Thus, for example, we have seen that in the Apennines, near Carrara, the descending series, where it is metamorphic, consists of, 1st, saccharine marble; 2dly, talcose-schist; and 3dly, of quartz-rock and gneiss: where unaltered, of 1st, fossiliferous limestone; $2 \mathrm{dly}$, shale; and $3 \mathrm{dly}$, sandstone.

But if we investigate different mountain chains, we find gneiss, mica-schist, hornblende-schist, chlorite-schist, hypogene limestone, and other rocks, succeeding each other, and alternating with each other in every possible order. It is, indeed, more common to meet with some variety of clay-slate forming the uppermost member of a metamorphic series than any other rock; but this fact by no means implies, as some have imagined, that all clay-slates were formed at the close of an imaginary period, when the deposition of the crystalline strata gave way to that of ordinary sedimentary deposits. Such clay-slates, in fact, are variable in composition, and sometimes alternate with fossiliferous strata, so that they may be said to belong: almost equally to the sedimentary and metamorphic order of rocks. It is probable that had they been subjected to more intense piutonic action, they would have been trạnsformed into hornblende-schist, foliated chlorite-schist, scaly talcose-schist, mica-schist, or other more perfectly crystalline rocks, such as are usually associated with gneiss.

Uniformity of Mineral Character in Hypogene Rocks. - It is most true, as Humboldt has happily remarked, that when we pass to another hemisphere, we see new forms of animals and plants, and even new constellations in the heavens; but in the rocks we still recognize our old acquaintances-the same granite, the same gneiss, the same micaceous schist, quartz-rock, and the rest. There is certainly a great and striking general resemblance in the principal kinds of hypogene rocks in all countries, however different their ages; but each of them, as we have before seen, must be regarded as geological families of rocks, and not as definite mineral compounds. They are more uniform in aspect than sedimentary strata, because these last are often composed of fragments varying greatly in form, size, and color, and contain fossils of different shapes and mineral composition, and acquire a variety of tints from the mixture of various kinds of sediment. The materials of such strata, if melted and made to crystallize, would be subject to chemical laws, simple and uniform in their action, the same in every climate, and wholly undisturbed by mechanical and organic causes.

It would, however, be a great error to assume, as some have done, that the hypogene rocks, considered as aggregates of simple minerals, are really more homogeneous in their composition than the several members of the sedimentary series. In the first place, different as- 
semblages of hypogene rocks occur in different countries; and, secondly, in any one district, the rocks which pass under the same name are often extremely rariable in their component ingredients, or at least in the proportions in which each of these are present. Thus, for example, gneiss and mica-schist, so abundant in the Grampians, are wanting in Cumberland, Wales, and Cornwall; in parts of the Swiss and Italian Alps, the gneiss and granite are talcose, and not micaceous, as in Scotland; hornblende prevails in the granite of Scotland - schorl in that of Cornwall-albite in thə plutonic rocks of the Andes - common felspar in those of Europe. In one part of Scotland, the mica-schist is full of garnets; in another it is wholly devoid of them; while in South America, according to Mr. Darwin, it is the gneiss, and not the mica-schist, which is most commonly garnetiferous. And not only do the proportional quantities of felspar, quartz, mica, hornblende, and other minerals, vary in hypogene rocks bearing the same name; but, what is still more important, the ingredients, as we have seen, of the same simple mineral are not always constant (see p. 595, and Table, p. 102).

The Me:amorphic Strata, why less Calcareous than the Fossiliferous. - It has been remarked, that the quantity of calcareous matter in metamorphic strata, or, indeed, in the hypogene formations generally, is far less than in fossiliferous deposits. Thus the crystalline schists of the Eastern and Southern Grampians in Scotland, consisting of gneiss, mica-schist, hornblende-schist, and other rocks, many thousands of yards in thickness, contain an exceedingly small proportion of interstratified calcareous beds, although these have been the sbjects of careful search for economical purposes. Yet limestone is not wanting even in the Southern Grampians, in Perthshire and Forfarshire, for example, and it is associated sometimes with gneiss, sometimes with mica-schist, and in other places with other members of the metamorphic series. Where limestone occurs abundantly, as at Carrara, and in parts of the Alps, in connection with hypogene rocks, it usually forms one of the superior members of the crystalline group. The limestones of the Lorrer Laurentian in Canada, consisting of several distinct bands, one of them containing Eozoon Canadense, and of great thickness (from 700 to 1500 feet), afford a remarkable exception to the general rule. In this instance, however, augite, serpentine, and various other minerals are largely intermixed with the carbonate of lime.

The general scarcity of carbonate of lime in the plutonic and metamorphic rocks seems to be the result of some general cause. So long as the hrpogene rocks were believed to have originated antecedently to the creation of organic beings, it was easy to impute the absence of lime to the non-existence of those mollusca and zoophytes by which shells and corals are secreted; but when we ascribe the crystalline formations to plutonic action, it is natural to inquire whether this action itself may not tend to expel carbonic acid and lime from the 
materials which it reduces to fusion or semi-fusion. Although we cannot descend into the subterranean regions where volcanic heat is developed, we can observe in regions of spent volcanoes, such as $\mathrm{Au}$ vergne and Tuscany, hundreds of springs, both cold and thermal, flowing out from granite and other rocks, and having their waters plentifully charged with carbonate of lime. The quantity of calcareous matter which these springs transfer, in the course of ages, from the lower parts of the earth's crust to the superior or newly formed parts of the same, must be considerable.*

If the quantity of siliceous and aluminous ingredients brought up by such springs were great, instead of being utterly insignificant, it might be contended that the mineral matter thus expelled implies simply the decomposition of ordinary subterranean rocks; but the prodigious excess of carbonate of lime over every other substance must, in the course of time, cause the crust of the earth below to be almost entirely deprived of its calcareous constituents, while we know that the same action imparts to newer deposits, ever forming in seas and lakes, an excess of carbonate of lime. Calcareous matter is poured into these lakes and the ocean by a thousand springs and rivers; so that part of almost every new calcareous rock chemically precipitated, and of many reefs of shelly and coralline stone, must be derived from mineral matter subtracted by plutonic agency, and driven up by gas and steam from fused and heated rocks in the bowels of the earth.

Not only carbonate of lime, but also free carbonic acid gas, is given off plentifully from the soil and crevices of rocks in regions of active and spent volcanoes, as near Naples and in Auvergne. By this process, fossil shells or corals may often lose their carbonic acid, and the residual lime may enter into the composition of augite, hornblende, garnet, and other hypogene minerals. That the removal of the calcareous matter of fossil shells is of frequent occurrence, is proved by the fact of such organic remains being often replaced by silex or other minerals, and sometimes by the space once occupied by the fossil being left empty, or only marked by a faint impression. We ought not indeed to marvel at the general absence of organic remains from the crystalline strata, when we bear in mind how often fossils are obliterated, wholly or in part, even in tertiary formations-how often vast masses of sandstone and shale, of different ages, and thousands of feet thick, are devoid of fossils-how certain strata may first have been deprived of a portion of their fossils when they became semicrystalline, or assumed the transition state of Werner-and how the remaining portion may have been effaced when they were rendered metamorphic. Rocks of the last-mentioned class, moreover, have sometimes been exposed again and again to renewed plutonic action.

* See Principles of Geology, by the Author, Index, "Calcareous Springs." 


\title{
CHAPTER XXXVIII.
}

\author{
MINERAL VEINS.
}

Werner's doctrine that mineral veins were fissures filled from above-Veins of segregation-Ordinary metalliferous veins or lodes-Their frequent coincidence with faults-Proofs that they originated in fissures in solid rock-Veins shifting other veins-Polishing of their walls or "slicken-sides"-Shells and pebbles in lodes-Evidence of the successive enlargement and reopening of veins-Fournet's observations in Auvergne-Dimensions of veins-Why some alternately swell out and contract-Filling of lodes by sublimation from below-Chemical and electrical action-Relative age of the precious metals-Copper and lead veins in Ireland older than Cornish tin-Lead rein in lias, GlamorganshireGold in Russia, California, and Australia-Connection of hot springs and mineral veins-Concluding remarks.

Tre manner in which metallic substances are distributed through the earth's crust, and more especially the phenomena of those nearly vertical and tabular masses of ore called mineral veins, from which the larger part of the precious metals used by man are obtainedthese are subjects of the highest practical importance to the miner, and of no less theoretical interest to the geologist.

The views entertained respecting metalliferous veins have been modified, or, rather, have undergone an almost complete revolution, since the middle of the last century, when Werner, as director of the School of Mines at Freiburg, in Saxony, first attempted to generalize the facts then known. He taught that mineral veins had originally been open fissures which were gradually filled up with crystalline and metallic matter, and that many of them, after being once filled, had been again enlarged or reopened. He also pointed out that veins thus formed are not all referable to one era, but are of various geological dates.

Such opinions, although slightly hinted at by earlier writers, had nerer before been generally received, and their announcement by one of high authority and great experience constituted an era in the science. Nerertheless, I have shown, when tracing, in another work, the history and progress of geology, that Werner was far behind some of his predecessors in his theory of the volcanic rocks, and less enlightened than his contemporary, Dr. Hutton, in his speculations as to the origin of granite." According to him, the plutonic formations, as well as the crystalline schists, were substances precipitated from a

* Principles of Geology, chap. iv. 
chaotic fluid in some primeval or nascent condition of the planet; and the metals, therefore, being closely connected with them, had partaken, according to him, of a like mysterious origin. He also held that the trap rocks were aqueous deposits, and that dikes of porphyry, greenstone, and basalt, were fissures filled with their several contents from above. Hence he naturally inferred that mineral veins had derived their component materials from an incumbent ocean, rather than from a subterranean source; that these materials had been first dissolved in the waters above, instead of having risen up by sublimation from lakes and seas of igneous matter below.

In proportion as the hypothesis of a primeval fluid, or "chaotic menstruum," was abandoned, in reference to the plutonic formations, and when all geologists had come to be of one mind as to the true relation of the volcanic and trappean rocks, reasonable hopes began to be entertained that the phenomena of mineral veins might be explained by known causes, or by chemical, thermal, and electrical agency still at work in the interior of the earth. The grounds of this conclusion will be better understood when the geological facts brought to light by mining operations have been described and ex- . plained.

On Different Kinds of Mineral Veins.-Every geologist is familiarly acquainted with those veins of quartz which abound in hypogene strata, forming lenticular masses of limited extent. They are sometimes observed, also, in sandstones and shales. Veins of carbonate of lime are equally common in fossiliferous rocks, especially in limestones. Such veins appear to have once been chinks or small cavities, caused, like cracks in clay, by the shrinking of the mass, which has consolidated from a fluid state, or has simply contracted its dimensions in passing from a higher to a lower temperature. Silicenus, calcareous, and occasionally metallic matters have sometimes found their way simultaneously into such empty spaces, by infiltration from the surrounding rocks, or by segregation, as it is often termed. Mixed with hot water and steam, metallic ores may have permeated a pasty matrix until they reached those receptacles formed by shrinkage, and thus gave rise to that irregular assemblage of veins, called by the Germans a "stockwerk," in allusion to the different floors on which the mining operations are in such cases carried on.

The more ordinary or regular veins are usually worked in vertical shafts, and have evidently been fissures produced by mechanical violence. They traverse all kinds of rocks, both hypogene and fossilifer ous, and extend downwards to indefinite or unknown depths. We may assume that they correspond with such rents as we see caused from time to time by the shock of an earthquake. Metalliferous veins, referable to such agency, are occasionally a few inches wide, but more commonly three or four feet. They hold their course continuously in a certain prevailing direction for miles or leagues, passing through rocks varying in mineral composition. 
That Metalliferous Veins were Fissures.-As some intelligent miners, after an attentive study of metalliferous veins, have been unable to reconcile many of their characteristics with the hypothesis of fissures, I shall begin by stating the evidence in its favor. The most striking fact, perhaps, which can be adduced in its support, is the coincidence of a considerable proportion of mineral veins with faults, or those dislocations of rocks which are indisputably due to mechanical force, as above explained (p. 61). There are even proofs in almost every mining district of a succession of faults, by which the opposite walls of rents, now the receptacles of metallic substances, have suffered displacement. Thus, for example, suppose $a a$, fig. 762 , to be a tin lode in Cornwall, the term lode being applied to veins containing metallic ores. This lode, running east and west, is a yard wide, and is shifted by a copper lode $(b b)$, of similar width.

The first fissure $(a \quad a)$ has been filled with various materials, partly of chemical origin, such as quartz, fluor-spar, peroxide

Fig. 762.

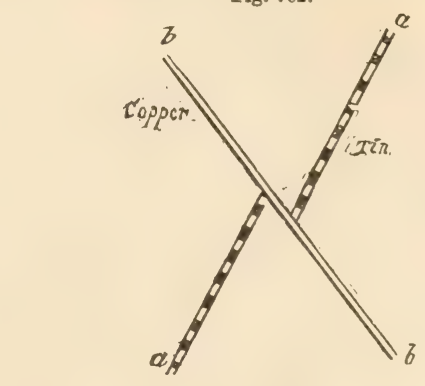

Fig. 763.

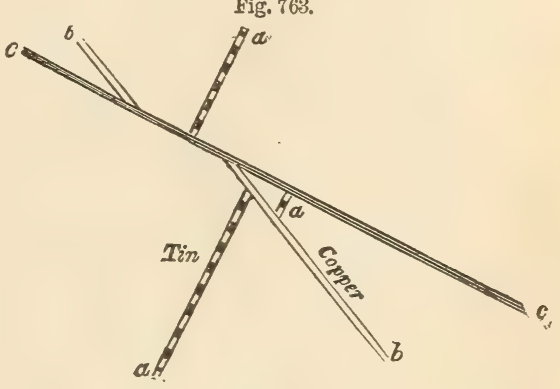

Fig. 764.

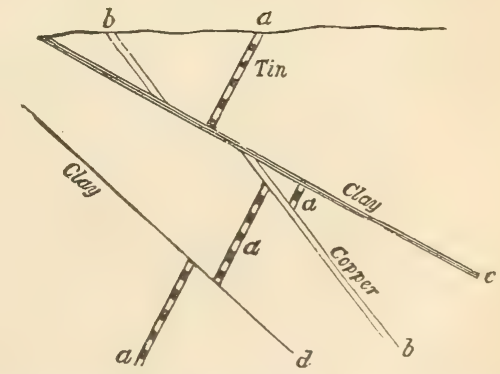

Vertical sections of the mine of Huel Peever, Redruth, Cornwall.

of tin, sulphuret of copper, arsenical pyrites, bismuth, and sulphuret of nickel, and partly of mechanical origin, comprising clay and angular fragments or detritus of the intersected rocks. The plates of quartz and the ores are, in some places, parallel to the vertical sides or walls of the vein, being divided from each other by alternating layers of clay, or other earthy matter. Occasionally the metallic ores are disseminated in detached masses among the veinstones.

It is clear that, after the gradual introduction of the tin and other substances, the second rent $(b b)$ was produced by another fracture 
accompanied by a displacement of the rocks along the plane of $b b$. This new opening was then filled with minerals, some of them resembling those in $a$ a, as fluor-spar (or fluate of lime) and quartz; others different, the copper being plentiful and the tin wanting or very scarce.

We must next suppose the shock of a third earthquake to occur, breaking asunder all the rocks along the line $c c$, fig. 763 ; the fissure, in this instance, being only 6 inches wide, and simply filled with clay, derived, probably, from the friction of the walls of the rent, or partly, perhaps, washed in from above. This new movement has heaved the rock in such a manner as to interrupt the continuity of the copper vein $(b b)$, and, at the same time, to shift or heave laterally in the same direction a portion of the tin vein which had not previously been broken.

Again, in fig. 764 , we see evidence of a fourth fissure $(d d)$, also filled with clay, which has cut through the tin vein $(a a)$, and has lifted it slightly upwards towards the south. The various changes here represented are not ideal, but are exhibited in a section obtained in working an old Cornish mine, long since abandoned, in the parish of Redruth, called Huel Peever, and described both by Mr. Williams and Mr. Carne.* The principal movement here referred to, or that of $c c$, fig. 764, extends through a space of no less than 84 feet; but in this; as in the case of the other three, it will be seen that the outline of the country above, $d, c, b, a, \& c$., or the geographical features of Cornwall, are not affected by any of the dislocations, a powerful denuding force having clearly been exerted subsequently to all the fauits. (See above, p. 69.) It is commonly said in Cornwall, that there are eight distinct systems of veins which can in like manner be referred to as many successive movements or fractures; and the German miners of the Hartz Mountains speak also of eight systems of veins, referable to as many periods.

Besides the proofs of mechanical action already explained, the opposite walls of veins are often beautifully polished, as if glazed, and are not unfrequently striated or scored with parallel furrows and ridges, such as would be produced by the continued rubbing together of surfaces of unequal hardness. These smoothed surfaces resemble the rocky floor over which a glacier has passed (see fig., p. 140). They are common even in cases where there has been no shift, and occur equally in non-metalliferous fissures. They are called by miners "slicken-sides," from the German schlichten, to plane, and seite, side. It is supposed that the lines of the striæ indicate the direction in which the rocks were moved. During one of the minor earthquakes in Chili, which happened about the year 1840, and was described to me by an eye-witness, the brick walls of a building were rent vertically. in several places, and made to vibrate for several minutes during each

\footnotetext{
* Geol. Trans., vol. iv. p. 139 ; Trans. Roy. Geol. Soc., Cornwall, vol. ii, p. 90.
} 
shock, after which they remained uninjured, and without any opening, although the line of each crack was still visible. When all movement had ceased, there were seen on the floor of the house, at the bottom of each rent, small heaps of fine brickdust, evidently produced by trituration.

In some of the veins in the mountain limestone of Derbyshire, containing lead, the vein-stuff, which is nearly compact, is occasionally traversed by what may be called a vertical crack passing down the middle of the rein. The two faces in contact are slicken-sides, well polished and fluted, and sometimes covered by a thin coating of leadore. When one side of the vein-stuff is removed, the other, side cracks, especially if small holes be made in it, and fragments fly off with loud explosions, and continue to do so for some days. The miner, availing himself of this circumstance, makes with his pick small holes about 6 inches apart and 4 inches deep, and on his return in a few hours finds every part ready broken to his hand.* These phenomena and their causes (probably connected with electrical action) seem scarcely to have attracted the notice which they deserve.

That a great many veins communicated originally with the surface of the country above, or with the bed of the sea, is proved by the occurrence in them of well-rounded pebbles, agreeing with those in supericial alluviums, as in Auvergne and Saxony. In Bohemia, such pebbles have been met with at the depth of 180 fathoms. In Cornwall, Mr. Carne mentions true pebbles of quartz and slate in a tin lode of the Relistran Mine, at the depth of 600 feet below. the surface. They were cemented by oxide of tin and bisulphuret of copper, and were traced over a space more than 12 feet long and as many wide. $\nmid$ Marine fossil shells, also, have been found at great depths, having probably been engulfed during submarine earthquakes. Thus, a gryphæa is stated by M. Virlet to have been met with in a lead-mine near Démur, in France, and a madrepore in a compact vein of cinnabar in Hungary.

When different sets or systems of veins occur in the same country, those which are supposed to be of contemporaneous origin, and which are filled with the same kind of metals, often maintain a general parallelism of direction. Thus, for example, both the tin and copper veins in Cornwall run nearly east and west, while the lead-veins run north and south; but there is no general law of direction common to different mining districts. The parallelism of the veins is another reason for regarding them as ordinary fissures, for we observe that contemporaneous trap dikes, admitted by all to be masses of melted matter which have filled rents, are often parallel. Assuming, then, that veins are simply fissures in which chemical and mechanical do-

* Conyb. and Phil. Geol, p. 401 ; and Farey's Derbysh., p. 243.

† Carne, Trans. of Geol. Soc. Cornwall, vol. iii. p. 238.

$\ddagger$ Fournet, Études sur les Dépôts Métallifères. 
posits have accumulated, we may next consider the proofs of their having been filled gradually and often during successive enlargements. I have already spoken of parallel layers of clay, quartz, and ore. Werner himself observed, in a vein near Gersdorff, in Saxony, no less than thirteen beds of different minerals, arranged with the utmost regularity on each side of the central layer. This layer was formed of two plates of calcareous spar, which had evidently lined the opposite walls of a vertical cavity. The thirteen beds followed each other in corresponding order, consisting of fluor-spar, heavy spar, galena, \&c. In these cases the central mass has been last formed, and the two plates which coat the walls of the rent on each side are the oldest of all. If they consist of crystalline precipitates, they may be explained by supposing the fissure to have remained unaltered in its dimensions, while a series of changes occurred in the nature of the solutions which rose up from below; but such a mode of deposition, in the case of many successive and parallel layers, appears to be exceptional.

If a veinstone consist of crystalline matter, the points of the crystals are always turned inwards, or towards the centre of the vein; in other words, they point in the direction where there was space for the development of the crystals. Thus each new layer receives ithe impression of the crystals of the preceding layer, and imprints its crystals on the one which follows, until at length the whole of the vein is filled; the two layers which meet dovetail the points of their crystals the one into the other. But in Cornwall, some lodes occur where the vertical plates, or combs, as they are there called, exhibit crystals so dovetailed as to prove that the same fissure has been often enlarged. Sir H. De la Beche gives the following curious and instructive example (fig. 765)

Fig. 765 .

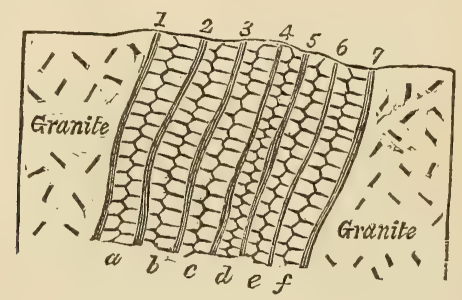

Copper lode, near Redruth, enlarged at six successive periods.

from a copper-mine in granite, near Redruth.* Each of the plates or combs $(a, b, c, d, e, f)$ is double, having the points of their crystals turned inwards along the axis of the comb. The sides or walls $(2,3$, 4,5 , and 6 ) are parted by a thin covering of ochreous clay, so that each comb is readily separable from another by a moderate blow of

* Geol. Rep. on Cornwall, p. 340. 
the hammer. The breadth of each represents the whole width of the fissure at six successive periods, and the outer walls of the vein, where the first narrow rent was formed, consisted of the granitic surfaces 1 and 7 .

A somewhat analogous interpretation is applicable to many other cases, where clay, sand, or angular detritus, alternate with ores and veinstones. Thus, we may imagine the sides of a fissure to be encrusted with siliceous matter, as Von Buch observed, in Lancerote, the walls of a volcanic crater formed in 1731 to be traversed by an open rent in which hot rapors had deposited hydrate of silica, the incrustation nearly extending to the middle.* Such a vein may then be filled with clay or sand, and afterwards reopened, the new rent dividing the argillaceous deposit, and allowing a quantity of rubbish to fall down. Various metals and spars may then be precipitated from aqueous solutions among the interstices of this heterogeneous mass.

That such changes have repeatedly occurred, is demonstrated by occasional cross-veins, implying the oblique fracture of previously formed chemical and mechanical deposits. Thus, for example, M. Fournet, in his description of some mines in Auvergne worked under his superintendence, obserres that the granite of that country was first penetrated by reins of granite, and then dislocated, so that open rents crossed both the granite and the granitic veins. Into such openings, quartz, accompanied by sulphurets of iron and arsenical pyrites, was introduced. Another convulsion then burst open the rocks along the old line of fracture, and the first set of deposits were cracked and often shattered, so that the new rent was filled, not only with angular fragments of the adjoining rocks, but with pieces of the older veinstones. Polished and striated surfaces on the sides or in the contents of the vein also attest the reality of these movements. A new period of repose then ensued, during which various sulphurets were introduced, together with hornstone quarta, by which angular fragments of the older quartz before mentioned were cemented into a breccia. This period was followed by other dilatations of the same veins, and other sets of mineral deposits, until, at last, pebbles of the basaltic lavas of Auvergne, derived from superficial alluviums, probably of Miocene or older Pliocene date, were swept into the veins. I have not space to enumerate all the changes minutely detailed by M. Fournet, but they are valuable, both to the miner and geologist, as showing how the supposed signs of riolent catastrophes may be the monuments, not of one paroxysmal shock, but of reiterated movements.

Such repeated enlargement and reopening of veins might have been anticipated, if we adopt the theory of fissures, and reflect how few of them have ever been sealed up entirely, and that a country with fis sures only partially filled must naturally offer much feebler resistance along the old lines of fracture than anywhere else. It is quite other 
wise in the case of dikes, where each opening has been the receptacle of one continuous and homogeneous mass of melted matter, the consolidation of which has taken place under considerable pressure. Trappean dikes can rarely fail to strengthen the rocks at the points where before they were weakest; and if the upheaving force is again exerted in the same direction, the crust of the earth will give way anywhere rather than at the precise points where the first rents were produced.

A large proportion of metalliferous veins have their opposite walls nearly parallel, and sometimes over a wide extent of country. There is a fine example of this in the celebrated vein of Andreasburg in the Hartz, which has been worked for a depth of 500 yards perpendicularly, and 200 horizontally, retaining almost everywhere a width of 3 feet. But many lodes in Cornwall and elsewhere are extremely variable in size, being 1 or 2 inches in one part, and then 8 or 10 feet in another, at the distance of a few fathoms, and then again narrowing as before. Such alternate swelling and contraction is so often characteristic as to require explanation. The walls of fissures in general, observes Sir H. De la Beche, are rarely perfect planes throughout their entire course, nor could we well expect them to be so, since they commonly pass through rocks of unequal hardness, and different mineral composition. If, therefore, the opposite sides of such irregular fissures slide upon each other, that is to say, if there be a fault, as in the case of so many mineral veins, the parallelism of the opposite walls is at once entirely destroyed, as will be readily seen by studying the annexed diagrams.

Fig. 766 .

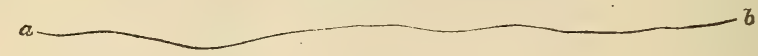

Fig. 767.

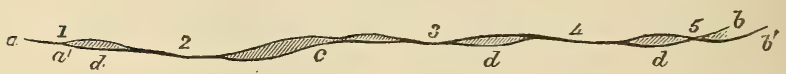

Fig. 768.

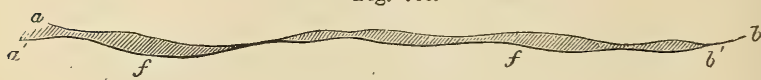

Let $a b$, fig. 766 , be a line of fracture traversing a rock, and let $a b$, fig. 767 , represent the same line. Now, if we cut in two a piece of paper representing this line, and then move the lower portion of this cut paper sideways from $a$ to $a^{\prime}$, taking care that the two pieces of paper still touch each other at the points $1,2,3,4,5$, we obtain an irregular aperture at $c$, and isolated cavities at $d d d$; and when we compare such figures with nature we find that, with certain modifications, they represent the interior of faults and mineral veins. If, instead of sliding the cut paper to the right hand, we move the lower part towards the left, about the same distance that it was previously 
slid to the right, we obtain considerable variation in the cavities so produced, two long irregular open spaces, $f f$, fig. 768 , being then formed. This will serve to show to what slight circumstances considerable variations in the character of the openings between unevenly fractured surfaces may be due, such surfaces being moved upon each other, so as to have numerous points of contact.

Most lodes are perpendicular to the horizon, or nearly so ; but some of them have a considerable inclination or "hade," as it is termed, the angles of dip varving from $15^{\circ}$ to $45^{\circ}$. The course of a vein is frequently very straight; but if tortuous, it is found to be choked up with clay, stones, and pebbles, at points where it departs most widely from verticality. Hence at places, such as $a$, fig. 769 , the miner complains that the ores are "nipped," or greatly reduced in quantity, the space for their free deposition having been interfered with in consequence of the preoccupancy of the lode by earthy materials. When lodes are many fathoms wide, they are usually filled for the most part with earthy matter, and fragments of rock, through which the ores are much disseminated. The metallic substances frequently coat or encircle detached pieces of rock, which our miners call "horses" or "riders." That we should find some mineral veins which split into branches is also natural, for we observe the same in regard to open fissures.

Chemical Deposits in Veins.-If we now turn from the mechanical to the chemical agencies which have been instrumental in the production of mineral veins, it may be remarked that those parts of fissures which were not choked up with the ruins of fractured rocks must always have been filled with water; and almost every vein has probably been the channel by which hot springs, so common in countries of volcanoes and earthquakes, have made their way to the surface. For we know that the rents in which ores abound extend downwards to rast depths, where the temperature of the interior of the earth is more elevated. We also know that mineral veins are most metalliferous near the contact of plutonic and stratified formations, especially where the former send veins into the latter, a circumstance which indicates an original proximity of veins at their inferior extremity to igneous and heated rocks. It is moreover acknowledged that even those mineral and thermal springs which, in the present state of the globe, are far from volcanoes, are nevertheless observed to burst out along great lines of upheaval and dislocation of rocks.* It is also ascertained that all the substances with which hot springs are impregnated agree with those discharged in a gaseous form from volcanoes. Many of these bodies occur as veinstones; such as silex, carbonate of lime, sulphur, fluor-spar, sulphate of barytes, magnesia, oxide of iron, 
and others. I may add that, if veins have been filled with gaseous emanations from masses of melted matter, slowly cooling in the subterranean regions, the contraction of such masses as they pass from a plastic to a solid state would, according to the experiments of Deville on granite (a rock which may be taken as a standard), produce a reduction in volume amounting to 10 per cent. The slow crystallization, therefore, of such plutonic rocks supplies us with a force not only capable of rending open the incumbent rocks by causing a failure of support, but also of giving rise to faults whenever one portion of the earth's crust subsides slowly while another contiguous to it happens to rest on a different foundation, so as to remain unmoved.

Although we are led to infer, from the foregoing reasoning, that there has often been an intimate connection between metalliferous veins and hot springs holding mineral matter in solution, yet we must not on that account expect that the contents of hot springs and mineral veins would be identical. On the contrary, M. E. de Beaumont has judiciously observed that we ought to find in veins those substances which, being least soluble, are not discharged by hot springs - or that class of simple and compound bodies which the thermal waters ascending from below would first precipitate on the walls of a fissure, as soon as their temperature began slightly to diminish. The higher they mount towards the surface, the more will they cool, till they acquire the average temperature of springs, being in that case chiefly charged with the most soluble substances, such as the alkalis, soda and potash. These are not met with in veins, although they enter so largely into the composition of granitic rocks.*

To a certain extent, therefore, the arrangement and distribution of metallic matter in veins may be referred to ordinary chemical action, or to those variations in temperature which waters holding the ores in solution must undergo, as they rise upwards from great depths in the earth. But there are other phenomena which do not admit of the same simple explanation. Thus, for example, in Derbyshire, veins containing ores of lead, zinc, and copper, but chiefly lead, traverse alternate beds of limestone and greenstone. The ore is plentiful where the walls of the rent consist of limestone, but is reduced to a mere string when they are formed of greenstone, or "toadstone," as it is called provincially. Not that the original fissure is narrower where the greenstone occurs, but because more of the space is there filled with veinstones, and the waters at such points have not parted so freely with their metallic contents.

"Lodes in Cornwall," says Mr. Robert.W. Fox, "are very much influenced in their metallic riches by the nature of the rock which they traverse, and they often change in this respect very suddenly, in passing from one rock to another. Thus many lodes which yield abundance of ore in granite, are unproductive in clay-slate, or killas, 
and vice versâ. The same observation applies to killas and the granitic porphyry called elvan. Sometimes, in the same continuous vein, the granite will contain copper, and the killas tin, or vice versa.". * Mr. Fox, after ascertaining the existence at present of electric currents in some of the metalliferous veins in Cornwall, has speculated on the probability of the same cause, having acted originally on the sulphurets and muriates of copper, tin, iron, and zine, dissolved in the hot water of fissures, so as to determine the peculiar mode of their distribution. After instituting experiments on this subject, he even endeavored to account for the prevalence of an east and west direction in the principal Cornish lodes by their position at right angles to the earth's magnetism; but Mr. Henwood and other experienced miners have pointed out objections to the theory; and it must be orned that the direction of veins in different minng districts varies so entirely that it seems to depend on lines of fracture, rather than on the laws of voltaic electricity. Nevertheless, as different kinds of rock would be often in different electrical conditions, we may readily believe that electricity must often govern the arrangement of metallic precipitates in a rent.

"I have observed," says Mr. R. Fox, "that when the chloride of tin in solution is placed in the voltaic circuit, part of the tin is deposited in a metallic state at the negative pole, and part at the positive one in the state of a peroxide, such as it occurs in our Cornish mines. This experiment may serve to explain why tin is found contiguous to, and intermixed with, copper ore, and likewise separated from it, in other parts of the same lode." $\dagger$

Relative Age of the Different Metals.-After duly reflecting on the facts above described, we cannot doubt that mineral veins, like eruptions of granite or trap, are referable to many distinct periods of the earth's history, although it may be more difficult to determine the precise age of reins; because they have often remained open for ages, and because, as we have seen, the same fissure, after having been once filled, has frequently been reopened oi enlarged. But besides this diversity of age, it has been supposed by some geologists that certain metals have been produced exclusively in earlier, others in more modern times-that tin, for example, is of higher antiquity than copper, copper than lead or silver, and all of them more ancient than gold. I shall first point out that the facts once relied upon in support of some of these views are contradicted by later experience, and then consider how far any chronological order of arrangement can be recognized in the position of the precious and other metals in the earth's crust.

In the first place, it is not true that veins in which tin abounds are the oldest lodes worked in Great Britain. The Government survey of reland has demonstrated, that in Wexford veins of copper and lead 
(the latter as usual being argentiferous) are much older than the tin of Cornwall. In each of the two countries a very similar series of geological changes has occurred at two distinct epochs-in Wexford, before the Devonian strata were deposited; in Cornwall, after the carboniferous epoch. To begin with the Irish mining district: We have granite in Wexford, traversed by granite veins, which veins also intrude themselves into the Silurian strata, the same Silurian rocks as well as the veins having been denuded before the Devonian beds were superimposed. Next we find, in the same county, that elvans, or straight dikes of porphyritic granite, have cut through the granite and the veins before mentioned, but have not penetrated the Devonian rocks. Subsequently to these elvans, veins of copper and lead were produced, being of a date certainly posterior to the Silurian, and anterior to the Devonian; for they do not enter the latter, and, what is still more decisive, streaks or layers of derivative copper have been found near Wexford in the Devonian, not far from points where mines of copper are worked in the Silurian strata.*

Although the precise age of such copper lodes, cannot be defined, we may safely affirm that they were either filled at the close of the Silurian or commencement of the Devonian period. Besides copper, lead, and silver, there is some gold in these ancient or primary metalliferous veins. A few fragments also of tin found in Wicklow in the drift are supposed to have been derived from veins of the same age. $\dagger$

Next, if we turn to Cornwall, we find there also the monuments of a very analogous sequence of events. First the granite was formed; then, about the same period, veins of fine-grained granite, often tortuous (see fig. 744, p. 713), penetrating both the outer crust of granite and the adjoining fossiliferous or primary rocks, including the coalmeasures ; thirdly, elvans, holding their course straight through granite, granitic veins, and fossiliferous slates; fourthly, veins of tin also containing copper, the first of those eight systems of fissures of different ages already alluded to, p. 769 . Here, then, the tin lodes are newer than the elvans. It has indeed been stated by some Cornish miners that the elvans are in some few instances posterior to the oldest tin-bearing lodes, but the observation of Sir H. De la Beche during the survey led him to an opposite conclusion, and he has shown how the cases referred to in corroboration can be otherwise interpreted.\$. We may, therefore, assert that the most ancient Cornish lodes are younger than the coal-measures of that part of England, and it follows that they are of a much later date than the Irish copper and lead of Wexford and some adjoining counties. How much later it is not so easy to declare, although probably they are not newer than the beginning of the Permian period, as no tin lodes have been discovered in

* I am indebted to Sir H. De la Beche for this information. See also maps and sections of Irish Survey.

† Sir H. De la Beche, MS. notes on Irish Survey.

$\ddagger$ Report on Geology of Cornwall, p. 310 . 
any red sandstone of the Poikilitic group, which overlies the coal in the southwest of England.

There are lead veins in the Mendip hills which extend through the mountain limestone into the Permian or Dolomitic conglomerate, and others in Glamorganshire which enter the lias. Those worked near Frome, in Somersetshire, have been traced into the Inferior Oolite. In Bohemia, the rich veins of silver of Joachimsthal cut through basalt containing olivine, which overlies tertiary lignite, in which are leaves of dicotyledonous trees. This silver, therefore, is decidedly a tertiary formation. In regard to the age of the gold of the Ural Mountains, in Russia, which, like that of California, is obtained chiefly from auriferous alluvium, it occurs in veins of quartz in the schistose and granitic rocks of that chain, and is supposed by MM. Murchison, De Verneuil, and Keyserling to be newer than the syenitic granite of the Uralperhaps of tertiary date. They observe, that no gold has yet been found in the Permian conglomerates which lie at the base of the Ural Mountains, although large quantities of iron and copper detritus are mixed with the pebbles of those Permian strata. Hence it seems that the Uralian quartz veins, containing gold and platinum, were not formed, or certainly not exposed to aqueous denudation, during the Permian era.

In the auriferous alluvium of Russia, California, and Australia, the bones of extinct land-quadrupeds have been met with, those of the mammoth being common in the gravel at the foot of the Ural Mountains, while in Australia they consist of huge marsupials, some of them of the size of the rhinoceros and allied to the living wombat. They belong to the genera Diprotodon and Nototherium of Professor Owen. The gold of Northern Chili is associated in the mines of Los Hornos with copper pyrites, in veins traversing the cretaceo-oolitic formations, so called because its fossils have the character partly of the cretaceous and partly of the oolitic fauna of Europe.* The gold found in the United States, in the mountainous parts of Virginia, North and South Carolina, and Georgia, occurs in metamorphic Silurian strata, as well as in auriferous gravel derived from the same.

Gold has now been detected in almost every kind of rock, in slate, quartzite, sandstone, limestone, granite, and serpentine, both in veins and in the rocks themselves at short distances from the veins. In Australia it has been worked successfully not only in alluvium, but in reinstones in the native rock, generally consisting of Silurian shales and slates. It has been traced on that continent over more than nine degrees of latitude (between the parallels of $30^{\circ}$ and $39^{\circ} \mathrm{S}$.), and over twelve of longitude, and yielded in 1853 an annual supply equal, if not superior, to that of California; nor is there any apparent prospect of this supply diminishing, still less of the exhaustion of the gold-fields.

It has been remarked by M. de Beaumont, that lead and some 
other metals are found in dikes of basalt and greenstone, as well as in mineral veins connected with trap rocks, whereas tin is met with in granite and in veins associated with the granitic series. If this rule hold true generally, the geological position of tin in localities accessible to the miners will belong, for the most part, to rocks older than those bearing lead. The tin veins will be of higher relative antiquity for the same reason that the "underlying" igneous formations or granites which are visible to man are older, on the whole, than the overlying or trappean formations.

If different sets of fissures, originating simultaneously at different levels in the earth's crust, and communicating, some of them with volcanic, others with heated plutonic masses, be filled with different metals, it will follow that those formed farthest from the surface will usually require the longest time before they can be exposed superficially. In order to bring them into view, or within reach of the miner, a greater amount of upheaval and denudation must take place in proportion as they have lain deeper when first moved. A considerable series of geological revolutions must intervene before any part of the fissure, which has been for ages in the proximity of the plutonic rocks, so as to receive the gases discharged from it when it was cooling, can emerge into the atmosphere. But I need not enlarge on this subject, as the reader will remember what was said in the 30th, 34th, and 37th chapters, on the chronology of the volcanic and hypogene formations.

Concluding Remarks. - The theory of the origin of the hypogene rocks, at a variety of successive periods, as expounded in two of the chapters just cited, and still more the doctrine that such rocks may be now in the daily course of formation, has made and still makes its way, but slowly, into favor. The disinclination to embrace it has arisen partly from an inherent obscurity in the very nature of the evidence of plutonic action when developed on a great scale, at particular periods. It has also sprung, in some degree, from extrinsic considerations ; many geologists having been unwilling to believe the doctrine of transformation of fossiliferous into crystalline rocks, because they were desirous of finding proofs of a beginning, and of tracing back the history of our terraqueous system to times anterior to the creation of organic beings. But if these expectations have been disappointed, if we have found it impossible to assign a limit to that time throughout which it has pleased an Omnipotent and Eternal Being to manifest his creative power, we have at least succeeded beyond all hope in carrying back our researches to times antecedent to the existence of man. We can prove that man had a beginning, and that all the species now contemporary with man, and many others which preceded, had also a beginning.

It can be shown that the earth's surface has been remodelled again and again; mountain chains have been raised or sunk; valleys formed, filled up, and then reëxcavated; sea and land have changed places; 
jet throughout all these rerolutions, and the consequent alternations of local and general climate, animal and regetable life has been sustained. This has been accomplished without riolation of the laws now gorerning the organic creation, whether the succession of living being's has been brought about by the transmutation of species, or, as some contend, by the abrupt introduction into the earth from time to time of ner plants and animals, each assembiage of new species must hare been admirably fitted for the new states of the globe as they arose, or they would not have increased and multiplied and endured for indefinite periods.

Astronomy has been unable to establish the plurality of habitable worlds throughout space, however favorite a subject of conjecture and speculation; but geology, although it cannot prore that other planets are peopled with appropriate races of liring beings, has demonstrated the truth of conclusions scarcely less wonderful-the existence on our own planet of so many habitable surfaces, or worlds as they have been called, each distinct in time, and peopled with its peculiar races of aquatic and terrestrial beings.

The proofs now accumulated of the close analogy between extinct and recent species are such as to leare no doubt on the mind that the same harmony of parts and beauty of contrivance which we admire in the liring creation has equally characterized the organic world at remote periods. Thus as we increase our knowledge of the inexhaustible rariety displayed in living nature, and admire the infinite wisdom and power which it displays, our admiration is multiplied by the reflection, that it is only the last of a great series of preëxisting creations, of which we cannot estimate the number or limit in times past.*

* See the Author's Anniv. Address to the Geol. Soc., 1837. Proceedings G. S., rol. ii. p. 520 . 


\section{N D E X.}

[The Fossits, the names of which are printed in Italics, are figured in the Text.]

A Bbeville, Post-pliocene, flint tools of, 116. Aberdeenshire, granite of, 709 .

Abich, M., on trachytic rocks, 599.

Abridged table of fossiliferous strata, 101. Acer rubmum, EEningen, 253.

- trilobatum, Eningen, 252, 253.

leaf of, Eningen, 266.

Acrodus nobilis, Lias, 421.

Acrogens, term explained, 333.

Acrolepis Sedgroickii, scale of, 462.

Actreon acutus, Great Oolite, 405.

Actinocyclas in Atlantic mud, 320.

Actinolite-schist, 735 .

Adams, Dr., on Nile river-terraces, 118.

Eichmodus Leachii, Lias, 421.

Egean sea, mud of, 35 .

Epiornis of Madagascar, 45 .

Africa, South, Devonian strata of, 546.

Agrassiz, M., on carboniferous reptiles, 505.

- on fish of Brown-coal, 679.

- - on fish of Lias, 420,421 .

- ou fish of Sheppey, 294.

- on footprints, 455 .

- on glaciers, 141, 142.

- on Monte Bolca fish, 694.

- on Old Red fossil fish, 532.

_ on Permian fish, 461.

on Placodus, 440.

on Pterygotus, 526.

Agglomerate, 603.

Agnostus integer, A. Rex, 580.

Air-breathers in Coal, 510. - rarity of, 518.

Aix-la-Chapelle, cretaceous flora of, 333. hot springs at, 741 .

Alabama, cretaceous shingle of, 339. river-section near, 310 .

Alabaster defined, 13.

Alberti, on Keuper, 434

Alkali present in Silurian and Cambrian strata, 745 .

Allwvial deposits, Recent and Post-pliocene, 114.

Alluvium, term explained, 79 .

formation of, 81.

in Auvergne, 80 .

Alpine erratics, 142

glaciers, colossal size of ancient, 142

blocks on the Jura, 142

Alps, age of metamorphic rocks in, 760 .

Austrian, infra-liassic strata of, 435. curved strata of, 58.

elevated fossiliferons rocks in, 4

nummulitic limestone of, 307 .

Swiss and Savoy, cleavage of, 748 .

Alteration of metamorphic rocks, 743 .

Alternations of different rocks, 14.

- of marine and freshwater formations, 32.
Alum Bay, flora of, 291.

Alum schists of Sweden and Norway, 581.

Alumina in rocks, 11

Amblyrhynchus cristatus, living, 425.

Armentacer of Swiss Miocene flora, 264.

Amer, volcanic formations near, 667 .

America, North. See United States, Canada and Nova Scotia.

America, South, cleavage of clay-slate in, 753 . Cretaceous strata of, 340 .

- gradual rise of parts of, 46 .

American forms in Swiss Miocene flora, 268.

Amiens, Post-pliocene flint tools of, 116.

Ammonites Bucklandi (bisculatus), 419 .

- bifrons (Walcotii), Lias, 418

- Braikenridgii, Oolite, 413.

- Humphresianus, Inferior Oolite, 412.

- Jason (A. Elizabetho), 400.

- macrocephalus, Oolite, 414

- margaritatus (Stokesii), Middle Lias, 419.

- Nodotianus (striatulus), Lias, 418.

- planorbis, Lower Lias, 419.

- Rhotomagensis, 331.

- striatuTus, Upper Lias, 419.

Ampelite, or aluminous slate, 735 .

Amphibole, 597.

Amphibolite, 598, 604, 735.

Amphistegina Hauerina, 244.

Amphitherium Broderipii, 407 .

Prevostii, Stonesfield slate, 407 .

Ampullaria glavea (recent), 30.

Amsterdam, or St, Paul Island, 644.

Amygdaloid, 601, 604

Analysis of volcanic minerals, 608 .

Ananchytes ovata, White chalk, 325.

Ancillaria subulata, Eocene, 31.

Ancyloceras gigas, 343.

- spinigerum, 332.

Ancylus elegans, Pleistocene, 29.

Andelys, chalk cliff's at, 354

Andernach, strata near, 679 .

volcanic sand and loess at, 679 .

Andes, plutonic rocks of, 721 .

— volcanic eruptions of, 742 .

Andesite, 599.

Andreasburg, vein of, 774 .

Angiosperms in the coal, 479 .

- term explained, 333

Anodonta Cordierii, A. latimarginatus (rocent), 28.

Anoplotherium commune, Binstead, 283.

- gracile, 300.

Antholithes, Coal, 479.

Anthophyllum lineatum, 279

Anthracite, conversion of coal into, 743 .

- in Rhode Island, 743.

Anticlinal line, 48, 57.

Antiquity of living \&pecies, 195. 
Antiquity of man, 132.

Antrim, basalt, age of, 242 .

— rocks altered by dikes in, 613 .

Ants, winged; of CEningen, 252.

Antwerp Crag, fossils of, 207.

Apateon pedestris, a carboniferous reptile, 505 .

Apennines, Northern, metamorphic rocks of, 759 .

Aphanite, or cornean, 604.

Apiocrinites rotundus, Great Oolite, 403.

Appalachian coal-field, 497, 501.

Appalachians, conversion of coal into anthracite in, 743 .

Apteryx of New Zealand, 129.

Aptychus latus, 395.

Apuan Alps, marble of, 759

Apus (?) dubius, Coal, 493 .

Aquapendente, Older Pliocene volcanic rocks of, 673 .

Aqueous deposits, superposition and chronology of, 92.

- erosion in Palma, 637.

— rocks defined, 2.

- rocks, mineral character of, 94 .

Aquitanien, term explained, 258.

Aralo-Caspian formations, 211.

Arans, volcanic formations, 700 .

Araucaria, cone of fossil, Inferior Oolite, 410.

Arbroath paving-stone, 526

section from, to the Grampians, 48

Archceopteryx macrura, Solenhofen, 397.

Archegosaurus minor, Coal; A, medius, skin of, 506.

Archiac, M. d', on fossils of Chalk, 336.

- on nummulites, 307

- on Nerita conoidea, 305.

- on pisolitic limestone, 313

- on Touraine faluns, 218.

Arctic icebergs, size and weight of, 146.

Ardèche, lava in, 617

Area of the Wealden, 351.

Arenaceous rocks described in, 11.

Arenig, or Lower Llandeilo, formation. 567.

Arenigs, volcanic formations of, 700 .

Argile plastique, 305 .

Argillaceous rocks, 11.

- schist, 734

Argyle, Duke of, on Isle of Mull Leaf-beds, 242.

Argyleshire, trap vein in cliff, 610 .

Arkose, 735.

Arran, age of granite in, 727

- amygdaloid filled with brown spar near, 622

- greenstone dike in, 610 .

- section of, 722 .

Arthur's seat, altered strata of, 615

Arvicola, teeth of, 136

Asaphus caudatus, Silurian, 559

tyrannus, Silurian, 566; A. Buchii, 566.

Ascension, larnination of volcanic rocks in, 752

Ashby-de-la-Zouch, fault in coal-field of, 69.

Aspidura loricata, Muschelkalk, 439.

Astarte bipartita (A. Omalii), 204.

- borealis, Clyde drift, 153.

- compressa, 164

Asterolepis, size of, 533

Asterophyllites foliosus, Coal, 473.

Asterias limestone, fossils of, 232.

Asti, formations at, 209.

Astrangia lineata, Virginia, 279

Astroea basaltiformis, 516 .

Astropecten crispatus, Sheppey, 294.

Atherfield beds, Isle of Wight, 342

Athyris navicula, Ludlow, 553 .

Atlantic mud composed of organic bodies, 320 .

- Islands, 277.

- flora of, compared to American, 271.

Atlantis, Miocene, theory of, 267-275.

Atmosphere of Coal period, 490.

Atrium of a volcano, $636^{\circ}$

Aturia ziczac (Nautilus zigzag), Sheppey and

Porto Santo, 293, 675.

Atrypa reticularis, Aymestry, 554.

Augite, 595, 598, 604.

Augitic porphyry, 604 .
Aulopora serpens, Devorian, 539.

Aurillac, freshwater strata of, 230.

Austen, Mr., on Upper Greensand, 331.

Australia, auriferous gravel of, 7 .

- cave-breccias of, 126 .

- gold of, 779

- mammalia of, 127

Auvergne, alluvium in, 80

- age of trachytic rocks in, 657 .

- extinct volcanoes of, 684 .

- granite veins, 773 .

- indusial limestone in, 226.

- lacustrine strata of, $222-228$.

Lower Miocene, freshwater formations of,

227.

mineral veins of, 773

- springs from spent volcanoes, 766

succession of changes in, 220

Avicula cygnipes, Lias, 416.

- contorta, Trias, 441.

- incequivalvis, Lias, 416.

- papyracea, Coal, 495.

- socialis, Muschelkalk, 439

Aviculopecten sublobatus, 518

Aymestry limestone, fossils of, 553.

Azores, Upper Miocene, shells of, 676 .

Bacillaria anceps, White Chalk, 326.

Baculites anceps, Chloritic Marl, 326

Faujasii, White Chalk, 326.

vulgaris (?) in Tripoli, 25

Baffin's Bay, drift of, described, 144

Bagshot beds, fossils of, 288 .

Baise, Bay of, tufaceous strata. containing $\mathrm{Im}$ plements, 661

- subterranean igneous action in, 722 .

Bakewell, Mr., on cleavage in Swiss .4lps, 748.

Bala beds, thickness and fossils of, 564 .

Balona emarginata, tympanic bone of, 202.

Balgray, near Glasgow, stumps of trees in coal, 480.

Balistid $\propto$, defensive spine of, 289 .

Bangor group, 578.

Barcelona, marine tertiary strata of, 673.

Barmouth sandstones, 578 .

Barranco, section through the, 638 .

- de las Angustias, 638 .

Barrande, M. Joachim, on primordial zone, $574-579$.

- on trilobites, 574, 580

Barrett, M. Louis, on bird in Blackdown beds, 332.

Barton clay, shells of, 287.

Basalt, 598, 604

- columnar, in the Vicentin, 618.

- columnar, of Giant's Causeway, 6 .

- columnar in the Eifel, 618.

- specific gravity of minerals in, 657

Basanite, 604 .

Basilosaurus, 311.

Basset, term explained, 56.

Basterot, M. de, on Bordeaux tertiary strata, 183.

Batemian, Mr. J. F., on Blackpool shells, 160 .

Batrachian (?), eggs of, in Old Red, Scotland, 529.

Bats, molars of insectivorous, Kyson, 294.

Bay of Fundy, impressions in red mud of, 453. denudation of coal-field in, 488 .

Bayfield, on inland cliffs in Gulf of St. Lawrence, 78.

Bean, Mr., on fossil shells from Oolite, 411.

Beaumont, M. E. de, on line between Miocene and Eocene, 218.

- on pisolitic limestone, 313

on Chalk, 386.

on island in Eocene sea, 367.

on Lias, 417

on formation of granite, 705 .

on chemical deposits in veins, 775 .

on Jurassic plutonic rocks, 724 .

on plutonic action in Alps, 757 .

Beauport, near Quebec, glacial drift at, 163.

Bèche, Sir H. de la, on marine lizards, 427

on Oolite, 429. 
Bèche, Sir H. de la, on teeth of saurians, 447 . on trap of Now Red, 696.

on Redruth copper mine, 772

Beck, Dr., on graptolites, 565 . on Jutland seaweed, 324 on Phryganea, 227.

Beckles, Mr. S. H., on mammalia of Purbeck, 381.

on upper jaw of mammals, 385 .

on footprints in Hastings Sands, 388 .

Belemnites Puzosianus, Oxiord Clay, 401.

- mucronatus (Belemnitella mucronata), 325.

hastatus, Oxford Clay, 400.

Belgian fossils, 238 .

- Miocene formations, 234

Belgium, Limburg beds of, 23 T.

Miocene strata of, 236 .

Bellerophon costatus, 520.

Belosepia sepioidea, Sheppey, 293.

Bembridge beds, 281 .

Bentham, Mr., on Miocene Atlantis, 269.

Berger, Dr., on rocks altered by dikes, 614 .

Berlin, Tertiary strata near, 237.

Bermuda Islands, rocks of 78 .

Bernese Alps, gneiss in, 761 .

Berthier, M., on augite and hornblende, 596 .

Bertrich-Baden, basaltic pillars at, 619 .

Beudant, Mr., on voleanic rocks of Hungary, 653.

Beyrich, MI., on German Miocene strata, 236 246.

Biaritz, calcareous cliffs of 72 .

Bilin tripoli, composed of Diatomaceæ, 25.

Binney, on Stigmaria, 475 .

Bird, in Argile plastique, 306.

- footprints of, 454 .

Bischoff, Prof., on Nile mud, 112

on Aix-la-Chapelle spring, 741 .

Black erag, recent species in, 200.

Blackdown beds, $33 \%$

Black River, limestone fossils of, 572

Blackwood, Capt., on Island of St. Paul, 612.

Blainville, M. de, on quadrupeds of Gers, 233

Boblave, M., on inland cliffs, 78

- cited. 696

Bog-iron-ore, 26

Bohemia, Cambrian rocks of, 579

Bolderberg in Belgium, Upper Miocene of, 235.

Bone of reptile, Great Oolite, Woodstock, 406.

Bone-bed of fish remains, Armagh, 521 . of Upper Ludlow, 552.

Bone-beds, triassic, in Würtemberg, 438.

Bonelli, Praf,, cited, 188.

on Italian Tertiary strata, 183

Boom and Rupelmonde, 237

Bordeaux, Miocene strata of, 231.

Borrowdale, black lead of, 39 .

Bosquet, M., on chalk fossils, 334

- on Maestricht beds, 315 .

Boston, U. S., contorted strata near, 157 .

Boncher de Perthes, M., on Abbeville alluvium, 116.

Boné, M. Ami, on human skeleton of Rbine, 117 .

- on Hangarian shells, 684 on arrangement of rocks, 91

Bonlder clay, described, 137

formation in Canada, 163

formation in England, 15s.

fauna of 161.

Bournemonth, vegetation of, 290

Boutigny, on evaporation of water from granite, 709 .

Bovey Tracey, lignites of, 240

Bowen, Lieut. A., R.N., drawings of rocks in Gulf of St. Lawrence, 78.

Bowerbank, Mr., on plants of Sheppey, 292

Bowman, Mr. on coal-seams, 500 .

Brachiopoda, Devonian, 542 .

Brachycephalous skull, 113.

Brackish-water and marine strata in coal, 492

Bracklesham beds, fossils of, 288.

Bradford Encrinites, 402.

Brash, term explained, 81.
Bravard, M., on fossils of Mount Perrier, 687. Brazil, ossiferous caves of, 128 .

Breccia on ancient waste-lines, 73 .

Breccias of the Caldera of Palma, 633

Brecciated limestone, 459 .

Brick-earth, or fluviatile loam, 117.

Bridlington beds, fossils of, 199.

Brighton, elephant-bed of, 373.

Bristol, Dolomitic conglomerate of, 446 . section of strata near, 98 .

British Miocene formations, 233.

Brixham caye, near Torquay, 124.

Brocchi, on Italian Tertiary strata, 183. on Subapennine strata, 209.

Brockedon, Mr., on black-lead, 38

Brockenhurst, shells of, 286 .

Brodie, Mr., on Purbeck mammalia, 381. Rev. P. B., on Lias insects, 427.

Brongniart, M, Adolphe, on groups of fossi plants, 335 .

- on ferns, 468,469

on botanical nomenclature, 338 .

on erect fossil trees, 482 .

on flora of Bunter, 440.

on age of acrogens, 479 .

on Lias plants, 428 .

on Eocene flora, 29

on calamites, 472

Bronyniart, M. Alex., on Tertiary series, 182 on Eocene strata of France, 298. on shells of nummulitic formation, 307 .

on coal-mine near Lyons. 482

Bronn on St. Cassian fossils, 437.

Brontes flabellifer, 510

Bronze implements found at Pompeii, 112.

at Herculaneum, 112

- utensils at Nidau, 111.

Brora, Oolitic coal formation, 411.

Brown, Mr. R., on Stigmariæ, 475.

on Cape Breton coal-field, 488.

- on carboniferous rain-prints, 489

Brown-coal of the Eifel, 679.

Brownsville, view of coal at, 502.

Bryce, on two granites of Arran, 728.

Bryozoum, term explained, 203.

Buch, Von. See Von Buch.

Buckley, Dr., on Eocene, U. S., 310.

Buckland, Dr., on violent death of saurians 426.

- on preservation of lower jaws, 385.

on dirt-bed at Thame, 392.

on spines of fish, 422 .

on Bristol conglomerate, 447 .

on chalk flints, 322

Bridgewater Treatise, cited, 404, 406

on footprints of Trias, 444

on term Poikilitic, 432

on Antrim chalk, 323

on Eocene oysters, 295 .

on coal-plants, 450 .

on Kirkdale cave, 125

Buddle, Mr. on ancient river-channel of Coal period, 504

on creeps in coal-mines, 50

Bufadors of Olot, 672 .

Buist, Dr. G., on saltness of Red Sea, 450.

Bulimus ellipticus, Bembridge, 282. lubricus, 30.

Bunbury, Sir C., on Virginian fossil plants, 452

- on Madeiran fossil plants, 649 .

Bunsen, Prof., on Palagonite, 603.

Bunter sandstein, thickness of, 410 . Labyrinthodon of, 440 .

Buprestis? Elytron of, 406 .

Burmeister, on trilobites, 563 .

Burnes, Sir A., on Runn of Cutch, 449.

CanNozorc, term explained, 91.

Cajro, excarations at, 3 .

Caithness, fish-beds of, 581 .

Calamary in Lias, 427.

Calamite, structure of, $4 \pi 2$.

root of, 471 .

Calamites cannoformis, Casl, 471 Sucoroii, Coal, 471 . 
Calamodendron, 472.

Calamophyllia radiata, 402.

Calcaire grossier, 303.

- lower, 304.

- silicieux, 302

Calcareous rocks, 11 .

- formation, Maestricht, 315

Calcarina rarispina, Eocene, 303.

Calceola sandalina, 540.

Calceola-schiefer, term explained, 540 .

Caldera, the, 631 .

- of Palma, section through the, 631

Calderas of Java, 626 .

of the Sandwich Isles, 623.

California, auriferous gravel of, $\pi \tau 9$.

Calymene Blumenbachii, 559.

Cambrian group, table of, 575,576 .

- rocks of Bohemia, 579 .

— strata of Norway and Sweden, 581.

- strata of U. S. and Canada, 581 .

volcanic rocks, 700 .

Campania, volcanic region of, 661 .

Campophy7lum flexuosum, Devonian, 515.

Campophyllum flexuosum, 515 ; C. turbinatum, 557.

Canada, Cambrian strata of, 581.

- Devonian strata of, 546 .

lakes of, 169.

Labradorite series of, 584.

Canadian drift, 163 .

Canary, Grand, shelly tuffs of, 675 .

- Islands, volcanoes of, 627 .

Cantal, lacustrine strata of the, 229.

- Plomb du, igneous rocks of, 691.

Cape Breton, coal-measures of, $4 \mathrm{~S} 8$.

Wrath, granite veins at, 711,762

Caradoc and Bala beds, nomenclåture of, 562 .

Carbonate of lime in rocks, how tested, 12.

Carboniferous flora, $467-479$.

— formation, divisions of, 465 .

- limestone, 514.

— limestone of North America, 522

—- period, plutonic rocks of, 725 .

- reptiles, 505 .

- volcanic rocks, 697 .

Carcharodon heterodon, tooth of, 290.

Cardiocarpon Ottonis, Permian, 464.

Cardita planicosta (Venericardia planicosta), 298

- sulcata, 287.

Cardium dissimile, Portland-stone, 395.

- porulosum, 305 .

_rhoticum, Trias, 441.

striatulum, Kimmeridge clay, 395

Carne, Mr. N., on Cornish lodes, 769.

- on pebbles in the lode, 771 .

Carpenter, Dr., on Orbitoides, 309.

Carrara, hypogene limestone of, 736.

- marble of, 759 .

Caryophyllia caspitosa, 193

Cashmere, recent formations in, 108

Cassian, St., beds, position and fossils of, 434 436.

Cassiterides (Cornwall), tin obtained from, 112. Castell Follit, section of lava at, 671 .

Castrogiovanni, bent strata near, 58.

Catalonia, volcanic rocks of, 666 .

Catania, tertiary beds of, 192 .

Catenipora escharoides, Silurian, 557.

Catillus Lamarckii, Chalk, 328.

Cauldrons, Giant, of Sweden, 141

Caulopteris primseva, carboniferous, 469 .

Cave breccias of Australia, 126.

Caverns with human and animal deposits, 122.

Caves at Engihoul and Brixham, 124

- at Kirkdale and Brixham, 125.

in Sicily, 195.

of Wellington Valley, 126.

Cellent and Olot, section of volcanic matter between, 669 .

Celts described, 116

Cephalaspis Lyelli, 526

Ceratites nodosus, Muschelkalk, 438

Cerithium concavum, Headon series, 284.

- elegans, Hempstead, 240.
Cerithium melanoides, 296.

- plicatum, Hempstead, 240.

Cervus alces, molar of, 135 .

Cestracion Philippi, recent, 330.

Chalk, differing in N. and S. of Europe, 336.

- escarpments, 360

of Normandy, 356

pebbles in, 323.

white, section of, 317.

white, extent and origin of, 318 .

white, fossils of, 26 .

white, animal origin of, 318

needles of, in Normandy, 356 .

of Faxoe, 316.

cliffs on Seine, 354

flints, 321.

Chalk pinnacle at Senneville, 355 .

Chalk-pit with potstones, view of, 322.

Chaluzet, lava of, 690 .

Chama squamosa, 287.

Chamerops Helvetica, Lower Miocene, 259.

Chambers, Mr. R., on ice in Scotland, 151.

Champoleon, junction of granite with jurassic strata, 724

Champradelle, vertical strata of marl at, 225 .

Chara elastica (recent), C. medicaginula, 32.

in freshwater strata, 31.

in flints of Cantal, 230

tuberculata, Bembridge, 282.

Charlesworth, Mr. E., on Suffolk strata, 196, 200.

- on Stereognathus, 409.

Charpentier, M., on Alpine glaciers, 142.

Chatham coal-field, 457.

Cheirotherium, footsteps of, 443. 507.

Chemical and mechanical deposits, 33.

- deposits in veins, 775 .

Chiapa, fall of volcanic dust at, 657 .

Chiastolite slate, 735 .

Chili, gold with copper pyrites in, 779 . earthquake in, 770 .

Chillesford beds, fossils of, 199 .

Chimara monstrosa, Lias, 422.

Chlorite-schist, 8, 735.

Christiania, metamorphic rocks of, 737.

quartz veins in gneiss in, 715 .

granite veins in Silurian gneiss of, 726 .

— trap and syenite of, 709.

Chronology of deposits, clue to, 185.

Test of, in rocks, $97,98$.

Cidaris coronata, Coral-rag, 399.

Cinder-bed, Purbeck, 380.

Cinnamomum polymorphum, Eningen, 254. Rossmässteri, 264.

Cladocora stellaria, 194

Claiborne, Eocene strata at, 311.

Clarke County, Eocene section in, 310.

Classification of Hastings strata, 348. of Silurian rocks, 562, 568 .

of T'ertiary formations, 178

of Old Red Sandstone fish, 531.

of rocks and strata, $2,10$.

of Lower Cretaceous rocks, 341.

of Cretaceous rocks, 314.

- remarks on, 217.

Clausen, M., on mammalia of Brazil, 128.

Clausitia bidens, Rhine valley, 30.

Clavulina corrugata, Eocene, 301

Clay, defined, 11.

- slate, 8, 734, 735.

Weald, 346.

- ironstone, 495

Clays, plastic, 295.

Claystone and Claystone Porphycy, 604.

Cleavage of metamorphic rocks, 747.

Clermont, metalliferous gneiss near, 741 .

Cliff-limestone, corals of, 545 .

Cliffs, lines of inland, 355 .

Climate, causes of change in, 175 .

- of Coal period, 504.

effects of fluctuations on quadrupeds, 130.

Clinkstone, 599, 604 .

Clinton group, U. S., fossils of, 571

Clyde, northern shells in drift of, 153

Clymenia linearis, Devonian, 537.

Clymenien-kalk, term explained, 537 
Coal, air-breathers in, 510.

- causes of purity of, 490

conversion into anthracite, 743 .

- conversion of lignite into, 503 .

continuity of seams of, 503 .

zigzag flexures of, near Mons, 53.

formation at Brora, 411

- at Brownsville, Pennsyl vania, view of, 502.

- how formed, 479 .

- period, climate of, 501

rain-prints in, 489 .

rain-prints in, 489.

slow accumulation of, 49 :

Coal-bearing strata, thickness of, 465

Coal-field of Ashby-de-la-Zouch, 69.

- of Virginia, 451

Coal-fields of United States, 493

Coal-measures, 466 .

- thickness of, in Wales, 466.

Coal-mine near Lyons, 452 .

Coal-pipes, danger of, 451.

Coalbrook Dale, coal-measures of, 493. fossil beetles in, 494 . faults in, 62

Coan, Mr., on crater of Kilauea, 624

Cochtiodus contortus, 521.

Cockfield rocks altered by dikes, 614 .

Colacanthus granulatus, marl slate, 462 .

Coleoptera of CEningen beds, 257.

Collyrites ringens, Inferior Oolite, 412

Columbia, vinegar river of, 299.

Columnar basalt in the Vicentin, 618 .

- structure of volcanic rocks, 616 .

Côme, ravine in lava of, 689

Composition of volcanic rocks, 594 .

Compact felspar, 605

Concretionary structure, 37

Condensation of rock-material, 38 .

- of slate-rock, 751 .

Cone of a pine, Purbeck, 394. of Tartaret, 688 of Catalonia, 66 .

Cones and eraters, 593. absence of, in England, 6.

Conformable stratification, 13 .

Conglomerate, or pudding-stone, $11,47$. dolomitic of Bristol, 146

Conifer: of Coal period, 476.

Connecticut, New Red Sandstone of, 453 beds, antiquity of, 456 .

Conocephalus striatus, 580 .

Conocoryphe striata, 580.

Consolidation of strata, 33.

Contorted strata in drift, Forfarshire, 156.

Conularia ornata, 540 .

Conus deperditus, 290.

Conybeare. Mr., on term Poikilitic, 432

- on Plesiosaurus, 424 on Bristol conglomerate, 447.

on Oolite and Lias, 429 .

Coomb, the, near Lewes, 363.

Coprolites of fish, 319.

Coral islands and reefs, 34,46

Cural-rag, fossils of, 398 .

Coralline crag, white or, 202

Corals of Deronian strata in United States, 54 . of mountain limestone, 514 .

of Sicily, 194.

neozoic type of, 515

palacozoic type of, 515

Corbula pisum, Hempstead beds, 239 alata, 350 .

Corinth, corrosion of rocks by gases near, 741 . Cornbrash, composition of, 401.

Corneas, 605

Cornwall, granite veins of, 738 .

- granite veins in hornblende slate in, 713 . Deronian series of $53 \%$.

lodes of, 772,776 .

tin obtained by ancients from, 112. clay in, 12.

- vertical section of veins in mines, 769 .

Coryphodon eocænus, of Sheppey, 292.

Coseguina, volcano of, 650 .

Costa, Prof, cited, 133.
Crag, Norwich, 197.

- of Antwerp, 207.

coralline, fossils in, 203

of Suffolk, red and coralline, 200-202.

tables of marine testacea in, 205.

Crag and tail, term described, 152.

Craig-Dhu, granite, 728

Craigleith quarry, slanting tree in, 483 .

- fossil trees, 40.

Crania Parisiensis, White Chalk, 327.

- attached to Echinus, 23.

Crassatella sulcata, 287.

Crater of the Island of St. Paul, 642.

Craters and cones, 593.

of Lagoa, Madeira, 650.

of the Sandwich Islands, 623 .

Credneria in quader-sandstein, 335 .

Creeps in coal-mines described, 52.

Cretaceous fossils, 325

- rocks, classification of, 314.

— volcanic rocks, 696

- plutonic rocks, 723

- formation of U. S., 338 .

flora. 332

- derivation of term, 312.

Crinoids, Silurian, 55s.

Cristellaria rotulata, Chalk, 26.

Croatia, Lower Miocene of, 245 .

Croizet, M., on Auvergne fossil mammalia, 229

Cromer, Norfolk drift at, 160

Crop out, term explained, 55.

Crossopterigidæ, or fringe-finned fish, 532.

Crust of earth defined, 2.

Crustaceans of Old Red Sandstone, 526

Cryptodon angulatum, Hornsea, 294.

Crystalline rocks, cleavage of, 754

- limestone, 459.

- rocks, foliation of, 753 .

- or metamorphic limestone, 735 .

erroneously termed primitive, 9

schists defined, 7

Cumbrecito, Pass of, 640

Cuming, Mr., collection of, 190 .

Cunningham, Mr. J., on rain-marks, 444

Cup-and-star corals, 515 .

Curral, the, in Madeira, 651 .

Curved strata, 48, 49

Cutch, Runn of, 449 .

Cuvier, M., on tertiary series, 182.

- on Amphitherium, 408.

on Eocene formation, 298

on fossils of Montmartre, 298.

Cyathea glauca, Carboniferous, 469 .

Cyathina Bowerbankii, Gault, 515.

Cyathocrinites planus, 517.

Cyathocrinus caryocrinoides, 517.

Cyathophyllum coespitosum, 538.

Cycadeoidea (Mantellia) megalophylla, 390

Cycadites comptus, Gristhorpe, 411.

Cyclas obovata, 28.

Cycloidal scaled fish, 533.

Cyclopian Islands, beds of clay and tuff at, 659 .

Cyclostoma elegans, Pleistocene, 30 .

Cyclopteris Hibernica, 524

Cylindrites acutus, Great Oolite, 405.

Cурroe a europoea, Red Crag, 202.

Cypress swamps of Mississippi, 491.

Cypris fasciculata, 380 .

- granulata, 380 .

gibbosa, Purbeck, 379

spinigera, Weald, 348 .

punctata, Lower Purbeck, 389.

tuberculata, Purbeck, 379.

Zeguminella, Purbeck 379.

Valdensis (C. faba), 348.

(?) inflata, Coal, 493.

striato-punctata, 380 .

Purbeckensis, Lower Purbeck, 389.

Cyprides in Weald, 348.

Cypridina serrato-striata, 537.

Cypridinien-schiefer, term explained, 537.

Cyrena fluminalis, 23.

- consobrina, 28.

cuneiformis, 296.

semistriata, Hempstead beds, 239. 
Cystider in Silurian rocks, 564. Cythere (?) inflata, Coal, 493.

Cytherella, Chalk, 26

Oytherina, Chalk, 26.

DachSTEIN beds, composition of, 435.

Dadoxylon, coal-plant, 476.

Dana, Mr., on Sandwich Islands volcanoes, 623 , 625,664 .

- on Kamschatka soundings, 321.

on slope of lavas, 685 .

on zoantharia and bryozoa, 214

on minerals of metamorphic rock, 744 .

on coral-reef of Sandwich Islands, 319 .

Dapedius monilifer, Lias, 421.

Daphnogene cinnamomifolia, 264.

Darbishire, Mr. R. D., on Moel Tryfaen shells,

Dartmoor, intrusive granite of, 738.

carboniferous granite of, 725 .

Darwin, Mr., on plutonic rocks of Andes, 721. on corals of Pacific, 319.

on mammalia of South America, 129.

on Welsh glacial drift, 159 .

on gravel-beds of South America, 640 .

on sinking of coral-reefs, 46 .

on gradual rise of part of S. America, 46 .

on pre-glacial migration of plants, 273 .

on transportation of pebbles, 323.

on dikes of St. Helena, 664

on marine saurian, 426 .

on South American ostrich, 456 .

on foliation and cleavage, $753-755$

Date of rocks ascertained by organic remains, 180.

Dates of discovery of fossil vertebrata, 589.

Daubeny, Dr., on basalt, 598 .

- on decomposition of trachytic rocks, 741 . on age of Auvergne volcanoes, 691 .

Daubrée, on alkaline waters of Plombières, 740 .

Davidson, Mr., on fossils of Lias, 418 .

Dawes, Mr. J. S. on calamites, 472 .

Dawkins, Mr. W. Boyd, on Trias quadrupeds, 388.

- on Triassic mammifer, 442

Dawson, Dr., on Eozoon Canadense, 584

- on Pupa vetusta, 511.

- on position of calamite, 472.

- on Devonian flora, 547.

Dax, inland cliff at; 72 .

Dean, forest of, coal in, 504 .

Deane, Dr., on footprints in Trias, 454

Debey, Dr., on flora of Aix-la-Chapelle, 333.

Dechen, M. von, on Cornish granite veins, 713 .

- on reptiles in Saarbrück coal-field, 506 . - on remains in brown-coal, 678 .

Delesse, M., on minerals of hypogene limestone, 744

_ on augite and basalt, 598 .

- on globular structure of voleanic rock, 619.

- on felspathic rock of Madeira, 653

Deltas of Switzerland, 120.

Deluge, 4.

Dendrerpeton found in Coal, 510.

Dennis, Rev. J. P., on Stereognathus, 409.

Denudation explained, 66.

— terraces of, in sicily, 75 .

of the Weald valley, 357-376.

- of chalk, 364.

- of Palma fluviatile or marine? 639

Deposition, proofs of gradual, 231.

Derbyshire, veins in rnountain limestone, 771.

Deshayes, M., on recent and fossil shells, 188.

- on pisolitic limestone, 313

- on shells of Etna, 190 .

- on Hungarian shells, 683.

- on Soissonnais shells, 305.

Desmarest, on trappean rocks, 87 .

Desnoyers, M., on Eocene fossil footprints, 301.

on faluns of the Loire, 183 .

Desor, M., on shells of the Sahara, 176.

- on Celtic coins, 111.

Devonian period, vegetation of, 546 .

- Brachiopoda, 542 .
Devonian fossils of the Eifel, 679 . fossils of, $537-543$.

series of North Devon, 536.

of Russia, 542 .

of United States, 543 .

series, table of 536 .

- system, term explained, 535.

Devonshire, cleavage of slate rocks in, 750 .

Diablerets, shells from the, 307.

Diagonal, or cross-stratification, 16

Diagram of plutonic and sedimentary formations, 720 .

Diallage rock, 605 .

Diastopora diluviana, 403

Diatomacea in tripoli, 25.

Diceras arietina, Coral-rag, 399. Lonsdalii, 344.

Limestone, term explained, 399.

Dicotyledonous leaves in chalk, 333.

Didelphys Azarce, Oolite, 408.

Didymograpsus geminus, Silurian, 567.

- Murchisonii, Llandeilo, 565.

Diest sands, 234

Dikelocephalous skull, 113.

Dikelocephatus minnesotensis, 582.

Dikes, trap and volcanic, 609.

- in Sicily, 665 .

- of coarse and fine-grained granite, 730.

- of Monte Somma, 662 .

- defined, 6 .

— rocks altered by, 613 .

- volcanic, of St. Helena, 617.

- of Vesuvius, 663.

Diluvium, origin of term, 137.

Dinornis, skeleton of, 455 .

Dinotherium giganteum, 213.

Diorite, 599, 605 .

Dip, term explained, 53.

Diplograpsus folium, Silurian, 565.

pristis, Silurian, 565.

Dirt-bed of Lower Purbeck, 389.

Distribution of fossil quadrupeds, 128.

Dolerite, 598,605 .

Dolomite defined, 13.

- of cone of Monte Somma, 661 .

Domite, 605 .

Downs, South, chalk escarpment of, $360,361$.

Downton Sazdstone, fossils of, 551.

Drew, Mr., on Hastings sand, 348.

Dritt of Scandinavia, North Germany, and Russia, 149.

- shells in Canada, 165.

contorted, 156 .

in Ireland, 160

- northern, of Scotland, 151.

- North Wales, 158.

- Norfolk, 160.

- transported by icebergs, 144

- meteorites in, 176.

Dromatherium sylvestre of N. Carolina, 457.

Dryandra Schrankii, Lower Miocene, 262.

Dryandroides Hakecefolia, near Lausanne, 262

Dudley limestone, 557.

- burning coal-mines at, 738 .

Dufrénoy, M., on line between Miocene and Eocene, 218.

- on granite of Pyrenees, 739 .

Dumont, Prof., on Belgian Lower Eocene, 313.

Duncan, Dr., on West Indian corals, 274.

Dundry Hill, near Bristol, section of, 98.

Dunker, Dr., on Weald of Germany, 351

Dura Den, yellow sandstone, 524.

Durham, intrusion of trap between beds near, 616.

EARThQUAKe in Olot, 672 .

Echinoderms in coralline crag, 205.

Echinosphorites balticus, Silurian, 564.

Echinus, with crania attached, 23.

Edeghem beds, fossils of, 233.

Edwards, Mr., on Brockenhurst shells, 286.

Egerton, Mr., on fossils of Southern India, 340.

Egerton, Sir P., on fish of Penarth beds, 442

- on old Red fish, 532. 
Egerton, Sir P., on fish of Permian, 462 , on fish of Headon series, 285. on Ichthyosaurus, 423 on Ischypterus, 456.

Egg-like bodies in Old Red Sandstone, 529.

Ehrenberg, Prof, on bog-iron-ore, 26. on infusoria, 25 . on term Bryozoum, 203. on Silurian foraminifera 570.

Eifel, age of trachytic rocks in, 655 .

- basaltic pillars of the Kïsegrotte in the, 619. lake-craters of, 679 .

- Lower Miocene, volcanic rocks of, 677 Lower, trass of, $65^{3}$

Elephant-bed, Brighton, 373.

Elephas meridionatis, molar of, 134. antiquus molar of, 133 primigenius, molar of, 133

Elevation craters, 634

Elvans of Ireland and Cornwall, $7 \mathrm{ts}$

- term explained, 725 . in granite, 778 .

Elytron of Buprestis, 406.

Emarginula clathrata, Great Oolite, 405.

Embothrium, or Hakea saligna, Eningen, 256.

Emmons. Prof., on jaws of Triassic quadruped, 399.

on Dromatherium, 457

Enerinite with serpulae attached, 403.

Encrinites of Bradford, 402.

Encrinus liliiformis (moniliformis), 439.

Endogens, term explained, 333.

Engihoul cave, 124.

England, Lower Miocene strata of, 239.

Newer Pliocene strata of, 196.

Upper Eocene formations of, 2 s1.

Eocene formations, map of, 280.

- foraminifera, 303,304

formations of England, 281

strata of France, table of, 297

granite and plutonie rocks, 721

and Miocene, line between, 217, 247.

strata, France, fossil footprints in, 292.

volcanic rocks of Monte Bolca, 694

strata in the United States, 309 .

term explained, 183 .

Eosaurus found in Coal, 511.

Eozoon Canadense, in Lanrentian rocks, 765. oldest known fossil, 584.

Eppelsheim, Dinotherium of, 243.

Equisetacer of the Coal, 471 .

Equisetites columnaris, 434

Equus caballus, molar of, 134

Erman, M., on finding of meteoric iron, 177. Erratic blocks, actions of, 140 . near Chichester, 374.

Erratics of Canada, 163. of Greenland, 141 of Victoria Land, 146 . Alpine, 142

Erosion, aqueous, in Palma, 637.

Escarpments of the Weald, 360.

Eschara disticha, Chalk, 329.

Escharina oceani, Chalk, 329.

Escher von der Linth, on submergence of Sahara, 176.

Estheria minuta, Muschelkalk, 439. Beckeri, 522.

ovata, Richmond, 452

Etheridge, Mr., tables of Oolitic fossils, 413. on fossils of Middle Oolite, 401. on cretaceous fossils, 314 on fossils of Upper Oolite, 39S.

Etna, Mt., 652.

lavas of, 191.

age of lavas of, 658

Eunomia radiata, Great Oolite, 402.

Eunotia bidens, Atlantic mud, 320.

Euomphalus pentagulatus, 519.

Euphotide, 605 .

Eurite, 708, 735 .

Euritic porphyry near Christiania, 716.

Europe, divisions of Tertiary strata in, 157

- extinct quadrupeds of, $115,116$.
Excavation through lava by rivers, 670 .

Exogens, term explained, 333.

Exogyra virgula, Kimmeridge clay, 395.

Extracrinus Briareus, Lias, 420.

Falconer, Mr, A, H, on Dichodon, 285.

Falconer, Dr., on Purbeck mammalia, 382.

on flint knives of Brixham cave, 124.

on Mastodon arvernensis, 198.

on Siwâlik Hills, 276.

on cave and drift fossils, 129.

on Plagiaulax, 384.

Faluns of the Loire, 183

of Touraine, 213.

Farnham, phosphate of lime near, 332.

Fascicularia aurantium, Coralline crag, 204

Fault, term explained, 62 .

in Chalk near Lewes, 363 .

Faults, origin of, 64

Fauna of Nebraska, 278.

of Keuper, 432 .

of Weald elay, 346

and flora of Upper Val d'Arno, 196.

of Montmartre, 298

of Vienna basin, 245 .

of Headon series, 285

of Galapagos Islands, 425

fluctuations in 186

Favosites Gothlandica, $55 \%$. - polymorpha, 538

Faxoe, chalk of, 316 .

Felis tigris, molar of 135

Felixstow, remains of cetacea near, 202.

Felspar porphyry, 605,

Felspathic lava, specific gravity of minerals of 658.

Felstone, 605 .

Fenestella retiformis, 460 .

Ferns of Carboniferous period, 468 .

Ferruginous sands, sand-pipes in, 235.

Fife, altered rock in, 615 .

Fifeshire, carboniferous trap of, 697.

Filling up of veins, 772 .

Fisb, Eocene, of Monte Bolea, 694

- fossil, of mountain limestone, 521.

number of living, 534 .

of the Upper Ludlow, 551 .

of Lias, 420.

fossil of Old Red Sandstone, 525-534.

of Permian marl-slate, 461

of the Brown Coal, 678 .

oldest known, not of low grade, 555 .

Fisher, Mr.. on dirt-bed at Ridgway, 392.

Fissures filled with metallic matter, 767 .

in metalliferous veins, 769 .

Fitton, Dr., on Lower Cretaceous, 341.

on Hastings sand, 346 .

on dirt-bed of Boulonnais, 392.

on corals of Oolite, 399 .

Fleming, Dr., on Parka decipiens, 523. on carboniferous trap, 696.

on scales of fish in Old Red, 525

Flint-breccias, angular, 372 .

Flints in chalk, 321

Flora, Miocene, of Switzerland, richness of 267.

of Carboniferous period, 467,478

of Great Oolite, 410

grade of Carboniferous, 478 .

Miocene, of Switzerland, 251-267.

Upper Cretaceous, 332

of Subapennine beds, 210

Recent and Miocene relations of, 269

fluctuations in, 186.

of the Permian, 463

Miocene, of EEningen, 251.

of Wealden, 352.

Devonian, compared to Carboniferous, 518

- of Vienna basin, 245 .

Flötz, term explained, 87.

Fluctuations in conformation of Weald, 369371.

Fluvia, the, cutting through lavas of Olot, 669 .

Flysch, term explained, 307

invaded by plutonic rocks, 721 . 
Foliated gneiss, 733 .

Foliation, irregularities in, 756

of crystalline rocks, 758 .

Fontainebleau, grès de, 217.

Footprints of reptiles, 507,508

fossil, in Now Red. 443.

of a bird, Connecticut, 454

in Connecticut Valley, 453

fossil; on Potsdam sandstone, 582.

Foraminifera, Chalk, 26.

Cretaceous, 321.

of Mountain Limestone, 522

Eocene, 303, 304.

Forbes, late $\mathrm{E}_{\text {, }}$ on term Pleistocene, 107.

on Post-glacial fauna, 129

on westward extension of Europe, 269

on depth of animal life in Agean Sea, 35.

on corals of Devonian strata, 545 .

on subdivisions of Bembridge beds, 282.

on Older Pliocene shells, 205.

- on Touraine fossil testacea, 213.

Forbes, Mr. D., on planes of foliation, 754

Forbes, Prof. J. D., on Alpine glaciers, 142.

Forest marble, 401 .

Forests, fossil, in Coal, 484-488.

- fossil, of Isle of Portland, 391.

Forfarshire, Cephalaspis beds of, 531 .

Formation of the Weald, 345 .

- of the Caldera of Palma 634 term defined, 3.

Formations, Belgian and British Miocene, 233. intermediate between Eocene and Cretaceous? 313.

Formica lignitum, OEningen, 251.

Fossil plants of Lias, 428

_ forest near Wolverhampton, 482

- footprints, Eocene, 301.

- trees erect in Coal, 482,483

- plants of Lower Miocene, Switzerland, 259.

- plants of Bovey Tracey, 240.

- term defined. 4

- wood, perforated by Teredina, 24.

- - petrifaction of, 39 .

- shells in Coal, Nova Scotia, 488.

quadrupeds, distribution of, 128.

- shells, 'Tertiary, 188.

- plants of Monte Bolca, 695.

Fossiliferous strata, general table of, 101. groups of, 99, 100

- table of, 102

Fossils of Portland-stone and Kimmeridge elay, 394,395

- of hippurite limestone, 338.

- of mountain limestone, 516 .

- of mountain limestone, 516.

- common to Upper and Middle Oolite, 398.

- common to Middle and Lower Oolite, 401.

- of the Lias, 418 .

- petrifaction of, 39-43.

- test of the age of formations, 98 .

- arrangement of, in strata, 21.

- freshwater and marine, 27.

- of Liandovery formation, 561.

of the Muschelkalk. 438.

— of Old Red Sandstone, 524-534.

- proportions of, in divisions of Oolite, 413.

- of primordial zone, 580 .

- of Lower Greensand, 343

of Coal, 493-495

of Wealden group, 348 .

- of Bolderberg beds, 236

number of, in Hallstadt beds, 436.

of Permian strata, 460 .

- of CEningen molasse, 249.

- of nummulitic formations, 307.

- of the Upper Ludlow, 551 .

of Red Crag, 201

— of Upper Greensand, 331

— of the Upper Cretaceous rocks, 325.

- of Devonian, 537-543.

Fournet, on Auvergne metalliferous gneiss, 741.

- on quartz, 705 .

- on veins in granite, 773

Fox, Rev. D. on Isle of Wight mammalia, 293.
Fox, $\mathrm{Mr}_{\mathrm{r}}$ on canse of electric currents in veins, 776

Fracture, lines of, in the Wealden, 366.

- lines of, in rock, 774

Fragments, included, test of age of plutonio rocks, 717 .

- test of age of volcanic rocks, 658 .

France, Lower Miocene strata of, 217-222.

- map of Lower Miocene of, 221.

Miocene strata of, 212 .

French divisions of cretaceous series, 314 .

Freshwater formations in Auvergne, 227.

- how distinguished from marine, 27, 28,

$30,32$.

bedis, land-shells numerous in, 27.

- shells in brown-coal near Bonn, 679 .

Fulgur canaliculatus, Maryland, 278.

Fuller's earth, shells of, 412 .

Fundy, Bay of, impressions of red mud in, 453.

Fungi on fossil leaves, 266.

Fungia patellaris (recent), 515.

Fusion of quartz, 705

Fusalina cylindrica, 522 .

Fusus contrarius, Red Crag, 202.

- quadricostatus, Maryland, 278.

GABBR0, or Diallage rock, 605 .

Gaillonella distans, G. ferruginea, 25.

Galapagos Islands, living marine saurian in, 425.

Galeocerdo latidens, tooth of, 290 .

Galerites albogalemis, White Chalk, 325.

Galestes in Middle Purbeck, 385.

Ganges, buried soil in delta of, 492.

Ganoids of Wealden, 349.

- preponderance of, in Old Red strata, 538.

- of Trias, 452

Gap in time between Eocene and Cretaceous periods, 312 .

Gaps, numerous, in the transitions of strata, 179.

Gases, subterranean, rocks altered br, 740 .

Gaudin, M. on Subapennine flora, 210.

- on Swiss Miocene, 248, 261.

Gault of Upper Cretaceous, 331

- thickness of, 332

Gavarnic, flexures of strata near, 59.

Geikie, Mrr., on ice-action on land, 15̄3, 155 .

— on Pentland Old Red voleanic rocks, 699

Gemunder Maar, view of, 680 .

Genera of Hallstadt and St. Cassian mollusea, 437.

Geneva, Lower Molasse of, 259, 260.

Geographical relationship between fossil and living vertebrata, 128, 129 .

Geography, physical, of Cretaceous and Wealden districts, 353.

Geology defined, 1.

Gergovia, associated tuffs and lacustrine strata of, 693 .

Germany, Triassic fauna of, 432

Gers, Upper Miocene strata of, 232

Gervillia anceps, 344.

Giant cauldrons of Sweden, 141.

Giant's Causeway, columnar basalt of, 616

- basalt, age of, 242.

Gibbes, R. W., on Eocene cetacean, U. S., 310.

Girgenti, limestone of, 194.

Glacial formations of North America, 162.

- erosion, theory of, 173 .

- epoch, 136-177.

Glaciation of Russia, 149 - of Scotland, 151 .

- of Scandinavia, 149 .

Glaciers, abrading action of, 138 .

Glasgow, marine strata near, 109.

Glass-cavities in quartz, 705 .

Glauconie grossière, 304

Glen Tilt, granite and argillaceons schist of 710.

Globigerina bulloides, Atlantic mud, 320.

Globular structure of volcanic rocks, 616 .

Glyphea (?) dubia, Coal, 493.

Glyptostrobus Europaus, OEningen, 256.

Gneiss, foliated, 733-735. 
Gneiss, fundamental, of Scotland, 5\$5. granite veins traversing, 711

Gold, age of, in Ireland, 778 .

- in Ural Mountains, 779 .

Gold mines of Australia and Chili, 779 .

Goldenberg, Mr. Fr., on Saarbrück insects, 494.

Goldfuss, Prof., on reptiles in Coal, 506.

Goniatites erenistria, 520.

Listeri, Coal, 495 .

evolutus, 520 .

Güppert, M., on petrifaction, 40.

on plants of coal-measures, $46 \mathrm{~s}$.

- on Swiss Miocene, 248, 256 .

Gorgonia infundibuliformis, 460 .

Graham's Island, 621.

Grampians, Old Red eonglomerates in, 47. Old Red of, こ̌30.

gneiss and erystalline schists of, 765 .

Grateloup, M. de, on Dax fossils, 338 . on fossils of Chalk. 338.

Grand Canary, shelly tuff's of, 675 .

Granite, dikes in coarse and fine-grained, 729.

- described, 7

— fine-grained, of Ploverficld, 728, 729.

- schorly, 708 .

- porphyritic, 707.

- veins, structure of, 712 .

- formation of, 702 .

- protrusion of solid, 727,781 .

- veins in talcose gneiss, 713 .

- composition of, 705 .

- hydrothermal action in formation of, 707 .

- passage of, into trap, 708 .

Granites, Arran, age of, 727 .

- oldest, 726 .

Graphic granite, 704

Graphite, powder of, consolidated by pressure, 39.

Graptolites, 565 .

Graptolites Murchisonii, Llandeilo, 56.

Graptolithus Ludensis, Silurian, 559.

Grasshopper, wing of, in coal-meusures, 494.

Grauwacke, term explained, 549.

Gray, Dr. Asa, on Miocene Atlantis, 269, 271.

Gray's Thurrock. Essex, pachyderms found at, 130.

Graystone, 605.

Graystone, volcanic rock, 605 .

Great Oolite, 402.

- fossils of 402

Greece, Upper Miocene of, 247

Greensburg, Penn., reptile footprints of, 509 .

Greenland, sinking of coast of, 46 .

- continual ice of, 144,145 .

Greensand, Lower, 341.

- Upper, 331.

Greenstone, 599, 605

- dike, Christiania, 612.

colnmns of 698

Grès de Beauchamp, 302.

Grès de Fontainebleau, Miocene or Eocene? 217.

Greywacke, Older Rhenish, equivalents of, 511. Griffiths, Sir R., on Coal strata of Ireland, 466 . Grignon, fossil shells near, 303.

Grit defined, 11.

Gryllacris lithanthraca, Coal, 494

Gryphoea coated with Serpuloe, 22

Grypheata, $G$. incurva, 29.

- incurva, Lias, 417.

- virgula, Kimmeridge clay, $39 \varepsilon$

- columba, Chalk, 328 .

- globosa, Chalk, 328.

Gryphite limestone, 417.

Guadaloupe, glass-cavities in quartz of, 706 .

Guidotti, Prot., cited, 188.

Guiscardi, Signor, on shells of Vesuvius, 190.

Gümbel, M., on Hallstadt beds, 434.

Gunn, Mr., on Norfolk drift fauna, 160.

- Mrs., on Norwich flints, 322.

Gutbier, Col, von, on Permian flora, 463.

Guttenstein beds, thickness of, 436 .

Gymnogens, term explained, 333.

Gypseous marls of Auvergne, 227

Gypsum defined, 13
Gyrotepis tenuistriatus, 442

Hanme, M., on Bryozoa, 214.

Hakea exulata, Switzerland, 262 salicina, CEningen, 255, saligna, OEningen, 255

Hall, Capt, on Cyclopian Isles, 659

Prof,, on exogen in Devonian strata, 547.

Sir James, on curved strata, 48.

on crag and tail, 152.

on cooling of metals, 663 .

Hallstadt beds, position and fossils of, 431-436.

Halysites catenularius, Silurian, 557.

Hamites spiniger, 332.

Hamilton, Sir W., on dikes of Vesuvius, 663.

Hampshire, Old Harry rocks of, 372

Harlech Grits, fossils of, 578 .

Harpactor maculipes, EEningen, 257.

Harris, Major, on salt lakes, 450.

Hartung, M., on aqueous erosion in Palma, 642

— on Madeiran tossil plants, 649.

- on Teneriffe, 645 .

- on lava at Port Moniz, 654.

on shells of Azores, 676

on geology of Madeira, 628.

on Madeira and Canary Miocene fossils, 674

Hartz Monntains, mineral veins of, 770 .

- bunter sandstein of, 440 .

Hastings, Marchioness of, on Headon beds, 285. sands, 348.

Hauer, M. von, on age of Werien sandstone, 436.

Hautes Alpes, rocks of, 724 .

Hawkshaw, on fossil trees in Coal, 480.

Hayden, Mr., on Nebraska plants, 340 .

Headon series, Isle of Wight, 284

Heat, intense, not required for metamorphic rocks, 739 .

Hébert, M., on pisolitic limestone, 313.

- on Sables de Bracheux, 306.

on fossil shells of Étampes, 218

on French Eocene mammalia, 387.

Tebrides, dikes in trap in, 611 .

Heer, M., on Superga fossil plants, 247. on Lower Miocene plants, 243.

on North American Sequoia, 263.

on beds of Croatia, 246 .

on Miocene Atlantis, 269

on Virginian fossils, 451.

on fossil plants of Switzerland, 248-267.

on Monte Bolea Eocene plants, 695 .

on Madeiran fossil plants, 650 .

- on Swiss Miocene insects, 267

Heidelberg, varieties of granite near, 712

Heliolites porosa, Devonian, 539.

Helix labyrinthica, Headon Hill, 284.

- occlusa, Bembridge, 282

- plebeia, Rhine, 119.

Turonensis, 30

Hemicidaris Purbeckensis, 380

Hemipneustes radiatus, Chalk, 316.

Hemitelites Brownii, Lower Oolite, 411.

Hempstead beds, subdivisions of, 239.

Henirey, Mr. A., on New Jersey Mastodon, 167

Henslow, Prof, on altered rock near Plas-

Newydd, 613 .

- on trunks in dirt-bed, 391.

Herculaneum, bronze instruments found at, 112.

Herodotus on lake-dwellings, 110.

Herschel, Sir J., on slaty cleavage, 749.

Hertfordshire pudding-stone, 35.

Heterocercal tail of fish, 461 .

- tails characteristic of fish of primary period, 534.

Hibbert, Dr., on coal-field at Burdiehouse, 495.

Hill of Gergovia, strata of, 693.

Himalaya, elevated fossiliferous rocks in, 4 .

- Tertiary mammalia of, 276.

Hippurite limestone, 336.

Hippurite organisans, Chalk, 337.

Hippopodium ponderosum, Lias, 418.

Hippopotames, molar of, 134

Hister coprolithorum, Eningen, 251. 
Hitchcock, Prof,, on Trias footprints, 453. Hoffmann, on stufas of St. Calogero, 741. Holoptychius nobilissimus, tooth of, 525 .

\section{- Hibberti, tooth of, 505 .}

Homalonotus armatus, 541 .

delphinocephalus, 559.

Homocercal tail of fish, 461 . 534

Hooghly River, analysis of water of, 41 .

Hooker, Dr., on seaweed, 324

- on sporangia of Silurian plant, 552.

on P. Richardi, 266.

on Sigillariæ, 475 ; on Coniferæ, 477.

on Carboniferous flora, 478 .

- on Arctic ice, 146

Hopkins, Mr., on fractures of Weald, 366.

Horizontal strata, upheaval of, 45 .

Horizontality of strata, 15 .

Hornblende rock, 598, 605, 735 .

- schist, 734, 736

- composition of, 595

Horner, Mr., on Holoptyehius, 505 .

Hörnes, Dr., on mollusea of Vienna basin, 244

Hornstone porphyry, 605.

Horstead, potstones at, 323 .

Howell, Mr., on Oolitic strata, 415

Hubbard, Prof., on granite veins of White Mountains, 718 .

Hudson River group, fossils of, 571.

Hugi, M., on Swiss Alps, 761 .

Human remains of Recent period, 109-112.

- in Post-pliocene deposits, 117.

deposits in caverns, 122, 124.

Humboldt, on uniform character of rocks, 764 . Hungary, trachyte of, 709.

- volcanic rocks of 633 .

Hunt, Mr., experiments on clay-iron-stone, 495. Huronian series, 583 .

Hutton, opinions of, 60 .

Huttonian theory, 87.

Huxley, Prof., on tish of Old Red, 532.

- on Atlantic mud, 320.

- on Pteraspis, 555.

IIycena Spelcea, molar and lower jaw of, 135.

Hybodus plicatilis, 442

Hybodus reticulatus, Lias, 421.

irydrothermal action, 739 .

in formation of granite, 707.

— producing granite veins, 726 .

— cause of metamorphism, 739 .

Hylerpeton, reptile found in Coal, 511

Hylonomus, reptile found in Coal, 511.

Hymenocaris vermicauda, 577.

Hypersthene rock, 606

Hypogene limestone, 736 .

rocks, mineral character of, 764

— term defined, 9

Hyracotherium, molar of, 294.

IbBetson, Mr., on Stonesfield slate, 410

Ice, rocks drifted by, 138.

Icebergs of Labrador, 148.

- mediums of transportation, 145.

- abrading power of 148 .

Iceland, flow of lava in, 657 .

- glass-cavities in quartz of, 706.

Ichthyodorulite of Lias, 421

Ichthyolites of Old Red Sandstone, 534

Ichthyosaurus communis, Lias, 423.

— hind fin or paddle of, 423 .

Identification of fossil plants, 266.

Igneous rocks, 6 .

of Siebengebirge and Westerwald, 679.

- of Val di Noto, 621.

Iguanodon Mantelli, Wealden, 347.

Ilfracombe group, fossils of, 538 .

India, cretaceous system in, 340 .

- Upper Miocene formations of, 276 .

Indusial limestone in Auvergne, 226.

Inferior Oolite, fossils of, 412

Infusoria in tripoli, 24.

Inland sea-cliffs in South of England, 71.

Inoceramus Lamarckii, Chalk, 328.

Insect-bed of Eningen, 251.
Insect limestone of Lias, 428 .

Insect, wing of neuropterous, 428

Insects of Coal, 494

- Miocene, of Croatia, 245.

of Swiss Miocene strata, 267.

Intercalation of strata, difficulties of, 184

Intrusion, test of age of plutonic rocks, 718 .

- test of age of volcanic rocks, 655 .

Inundation mud, 117.

Ipswich, section near, 201.

Ireland, Old Red Sandstone of, 524.

- Devonian plants of, 524

drift in, 160 .

- an archipelago, 160.

Iron weapons at Neufchatel, 111.

- sands of England, 234.

Invertebrate animals, period of, 582

Isastrae oblonga, Portland sand, 394.

Ischia, age of volcanoes of, 658,661 .

- Newer Pliocene of, 189.

Ischypterus of 'Trias, 456 .

Islands in Eocene sea, 367.

Isle of Mull, Miocene leaf-bed of, 242.

- Wight Hempstead beds, 239.

Isornorphism, theory of, 596 .

Issoire, section of volcanic formations at, 686 .

Italian Pliocene fossils, agreement with Brit-

ish, 674 .

Italy, Miocene strata of, 247.

Older Pliocene volcanic rocks of, 673 .

Older Pliocene formations of, 208.

JAOKson, Dr. C. T., analysis of fossil bones, 167.

Jamieson, Mr. T. F., on Scotch glacial drift, 152.

Japan, flora of, compared to American, 271.

Java, volcanoes of:, 626 .

- - stream of sulphureons water, 299.

Jaws of mammalia in Purbeck, 381.

Johnson, Mr. J. Yate, on Madeira Miocene shells, 675 .

Jointed structure of metamorphic rocks, 748 .

Jorullo, lava stream of, 719 .

Jukes, Mr., on origin of lakes, 170.

Jukes, Prof., on erosion of the Weald, 374

Junghuhn on crater-walls, 639 .

- on Javanese volcanoes, 626

Jura, blocks on, 142

- structure of, 55 .

KANGAROO, jaws of, 127.

Kaup, Prof., on Cheirotherium, 443.

Kaye, Mr., on fossils of Southern India, 340.

Keeling Island, fragment of greenstone in, 324.

Keilhau, Prof., on granite veins in gneiss, 714, 715 .

- on planes of foliation, 754 .

Keller, Dr. F., on lake-dwellings, 110.

Kelloway rock, 34 .

- fossils of, 400 .

Kentish chalk, sandgalls in, 82.

- rag, 341.

Keuper, or Upper Trias, 432.

plants of, 434.

- marine fauna of, 434

Keyserling, Count, on Russian glacial drift, 150

Kiesel-gerölle of the Eifel, 679 .

Kilauea, volcanic crater of, 623 .

Kilkenny yellow sandstone, fossil plants of, 524.

Killas in granite in Cornwall, 738.

Kimmeridge clay, composition and fossils of, 394.

King, Mr, on fauna of Norfolk drift, 161.

- on Permian fossils, 458.

on footprints of reptile, 507 .

Kirkdale cave, hyrna's den of, 125.

Kitchen-middens, Danish, 109 .

- of Denmark, 109

Kleyn Spawen, Lower Miocene of, 238.

Könen, Baron von, on Brockenhurst shells, $2 S 6$.

Köninck, M. de, on Kleyn Spawen beds, 243. 
Köninck, M, de, on mountain limestone fish, 521.

on shells of Mayence basin, 243 .

Koninckia Leonhardi, Hallstadt, 436.

Kyson, in Suffolk, strata of, 294.

LAACH, lake-crater of, 681 .

Labrador, icebergs of, 148 .

Labrador, iceber.

Labradorite, 598 .

- or Labrador felspar, 595.

Labyrinthodon, tooth of, 445

Jaegeri, section of tooth, 445 .

Labyrinthodonts of Coal, 511.

Lacustrine strata of Auvergne, 222, 228,

Lagoa, view of crater of, 650 .

Lagoons at mouth of rivers, 33 .

of Bermuda Islands, 319

Lake-crater of Laach, 681 .

craters of the Eifel, 679 .

Lake-dwellings of Switzeriund, 110.

Lake-terraces, Post-pliocene, in Switzerland, 120

Lakes, deposits in, 3.

- how formed, 171

- Post-pliocene, of Switzerland, 173.

how far connected with glacial action, 169-171.

Lamarck, on bivalve mollusea, 29.

Lamination of clay-slate, Pyrenees, 757.

Lamna elegans, tooth of, 290.

Lancerote, rent in volcanic crater, 773

Land, rising and sinking, 45 .

Landenian, or Lower Eocene beds, 313.

Land-ice, action of, 152 .

Land's End, columnar granite of, 701

porphyritic granite of, 707 .

Lanidifieation of fossils, 43 .

La Roche, estuary of, 14 .

Lartet, M., on French Eocene mammalia, 387.

- on Gastornis Parisiensis, 306.

- on quadrumana of Gers, 233.

on reindeer period, 125 .

on Calcaire de la Beauce, 219.

Las Nieves, Santa Cruz, ravine of, 641

Palmas, raised beach north of, 676 .

Cañadas, 645 .

Lastrcea stiriaca, Switzerland, 264.

Laterite of Giant's Causeway and Madeira, 603,604 .

Laurent, M., on submergence of Sahara, 176.

Laurentian rocks, upper and lower, 584

- volcanic rocks, 701.

group, table ô, 575,576 .

Laurels of Miocene flora, 261

Lava, 601.

— of La Coupe d'Ayzac, 617.

streams, effects of, 6 .

relation to trap, 620 .

stream of Jorullo, 719

of Stromboli, 719 .

forming beds on a declivity, 637. of Chaluzet, 690 .

Lava-currents of Auvergne, 688.

Lavas of Catalonia, 668.

- of Madeira, 648,654

Lavini, Signor Spada, on Pliocene strata, Ischia, 190.

Lea, Mr., reptile footprints found by, 509.

Lead veins in Permian rocks, 779 .

Leaf-bed of Madeira, 649 .

- Miocene, of Isle of Mull, 242.

Leda truncata, Scotch drift, 154

- oblonga, Clyde drift, 153.

- Deshayesiana (Syn. Nucula Deshayesiana), 237.

- amygdaloides. Highgate, 294

Lee, Mr. J. E., on Pteraspis of L. Ludlow, 555. Lehman, on classification of rocks, 86 .

Leibnitz, theory of, 89 .

Leidy, Dr., on Pliocene mammalia, 272.

- on Titanotherium, 279.

on Triassic reptiles, 455

- on bone in chalk, U. S., 339 .

Lepidodendron Sternbergii, Coal, 470.
Lepidodendron, stem of, 524 .

Lepidostrobus ornatus, 471 .

Lepidotus gigas, Lias, 420

- Mantelli, 349 .

Leptona Moorei, Upper Lias, 418. depressa, Silurian, 558.

I.eptynite, or white stone, 708

Lesguereux, on Vancouver's Island fossils, 272

Lewes, Coomb near, 363.

Lias, volcanic rocks of, 696 .

- fossils of 418,419

- plutonic rocks of, 723

reptiles of, 422

formation described, 415 .

fish of, 420 .

origin of, 429 .

fossil plants of, 428

Liebig, Prof., on stalactite, 123.

- on conversion of lignite into coal, 503.

Liège, limestone caverns at, 123.

Lightbody, Mr., on Aymestry limestone, 555.

Lignite, conversion of, into coal, 503.

of Madeira, 649 .

Lima giganteum, 417

- spinosa, Chalk, 327. Hoperi; White Chalk, 327.

Limagne d'Auvergne, 222.

Limburg beds, table of, 237.

- fossils, 238 .

Lime, scarcity of, in metamorphic rocks, 765 .

- in solution, source of, 42

Limestone, brecciated, 459 .

- caverns described, 122

- compact, 461.

crystalline, 459 .

fossiliferous, 460

hippurite, 336 .

- indusial, Auvergne, 226

- mountain or carboniferous, 514.

magnesian, 458.

primary or metamorphic, 735 .

of Jura, 399.

- Devonian, of Germany, 537.

striated, 139.

Limulus rotundatus, 493.

Eindley, Dr., on botanical nomenclature, 333.

Lingula Dumortieri, Antwerp crag, 207. Davisii, Lingula flags, 577 .

Lewisii, Silurian, 554

Crednerii, 460 .

beds, voleanic tuffs of, 700 .

- flags, fossils of 577 .

Link, M., on footprints of Trias, 444.

Linton group, equivalents of, 541 .

Lipari Isles, stufas in, 741 .

Liquidamber europaum, Eningen, 210.

Liriodendron Procaccinii, 258.

Lithodomi in beaches of North America, 78. in inland cliffs, 73.

Lithostrotion basaltiforme (striatum), L. floriforme, 516.

Lits coquilliers, 304

Lituites giganters, Silurian, 555.

Llanberis slates, 578

Llandeilo flags, composition and fossils of, 565 .

Lower, or Arenig formation, 567.

Llandovery, Upper, formation, 560.

- Lower, rocks, thickness of, 561 .

Loa, Mount, craters of, 623 .

Loam defined, 13, 117.

Lodes. See Mineral Veins. filled with earthy matter, 775 .

Loess, or fluviatile loam, described, 117

- fossil shells of 119 .

Logan, Sir W., on Stigmaria in underclays, 467.

— on Eozoon Canadense, 584.

- on Potsdam sandstone, 582

- on thickness of coal-beds, 485 .

Loire, faluns of the, 183

London clay, relative position to Red crag, 201.

- clay proper, 291.

Longevity, relative, of mammalia and testacea, $13 \%$

Longmynd group, 578. 
Lonsdale, Mr., on fossils in White Chalk, 26. - on corals, 279 .

- on Stonesfield slate, 405.

on corals of Sicily, 194.

Lowe, Rev. R. T., on shells of Mogadore, 675 . Lower Oolite, 401-413.

- Miocene of Belgium, 238.

Lucerne, thickness of shingle beds near, 259.

Lucina serrato, 290.

Ludlow formation, fossils of, 55̃1-556.

- Lower, 553-556.

Lulworth Cove, dirt-bed of, 391

Lund, M., on mammalia of Brazils, 128.

Lycett, Mr., on Great Oolite shells, 404.

Lycopodium densum, 470 .

Lyme Regis, lias at, 427.

Lym-Fiord invaded by the sea, 33 .

- kelp in, 324.

Lymnea longiseata, 29, 252.

- caudata, Headon beds, 284.

Lyons, coal-mine near, 4S2.

$M^{*}$ ANDREW, on scarcity of fish on sea-bottoms, 587.

Maclaren, Mr., on Portland Old Red volcanic rocks, 699 .

Maclure, Dr., on Olot volcanic rocks, 666.

Maclurea Logani, Silurian, 572.

M'Clintock, Sir Leopold, on Globigerina, 320. - on depth of North Atlantic, 273.

Macropus atlas, 127.

incisor of, 127.

- major, 127.

$\mathrm{M}^{\circ} \mathrm{C}$ ulloch, Dr., on foliation in Scotland, 756 .

on absence of pebbles in granite, 729 .

- on basaltic columns in Skye, 616 .

- on denudation, 67 .

_ on formation of hornblende schist, 743 .

- on Glen Tilt granite, 710

_

- on overlying rocks, 7 .

- - on relations of trap, lava, and scorix, 622.

- on rocks altered by trap, 615 .

- on two granites of Arran, 728 .

on trap-veins, 610 .

M.Culloch, Mr. J., on Lanrentian fossil, 584.

Madeira, Upper Miocene shells of, 674.

- dike in valley in, 610 .

- Island of, formation and length of, 646

- lavas, absence of waterworn pebbles in, 652 .

- section of, 648

Maestricht beds, 315 .

Maftiote, Don Pedro, on shells of raised beach, 676.

Magas pumila, White Chalk, 327.

Magnesian limestone, concretionary structure of, 37 .

- limestone defined, 13

- limestone group, 458 .

Maidstone, fossils in White Chalk of, 330

Malaise, Prof., on Engihoul cave, 124.

Mammalia anterior to Paris gypsum, Table of, 387.

- extinct, coeval with man, 115.

— fossil, of Middle Purbeck, 381

- in Auvergne alluvium, 688.

— of Bembridge beds, 283.

—_ of Great Oolite, 406 .

— of Siwâlik Hills, 276 .

Mammalian fauna, ancient, of North America, 166.

Mamamat, Mr., cited, 69.

Mammoth. See Elephas primigenius, 133

Man coeval with extinct mammalia, 115.

Mantell, Dr., on fossils of Weald, 349.

- on belemnites in Oxford clay, 400.

- on Brighton Elephant-bed, 373.

- on freshwater beds, Isle of Wight, 283.

- on Iguanodon, 347.

- on Wealden formation, 345 .

- on the Coomb, 362

Mantellia megalophylla, 390.

Map of Palma, 628 .
Map of Caldera of Palma, 629.

of Eifel volcanic region, 678.

of Eocene tertiary basins, 280

to illustrate denudation of Weald, 357

of Lower Miocene of France, 221.

showing chalk formation in France, 336.

of 'St. Paul's Island, 642 .

of volcanic district of Catalonia, 667 .

Marble of Carrara, 759 .

defined 12.

Marine and brackish-water strata in Coal, 492

Marl, red, of Auvergne, 224.

- defined, 13.

- in Lake Superior, 36.

- red, white, and green, in England, 442.

Marls, green and white, of Auvergne, 223.

Marl-slate defined, 13.

Marsupites Milleri, White Chalk, 326.

Martin, Mr., on chalk fractures, 360 .

- on fractures of Weald, 366

Martins, M., on shells of Sahara, 176.

Massachusetts, plumbago of, 743 .

Mastodon arvernensis, Norwich crag, 198. giganteus, United States, 167.

Mayence basin, tertiaries, 243.

Mayencien, term explained, 258.

May-Hill, bone-beds of, 552 . sandstone, thickness and fossils of, 560 . Silurian strata of 550

Mediterranean, deposits forming in, 96.

Meek, Mr., on Nebraska plants, 340 .

Meerfelder Maar, Lake of', 681

Megalodon cucullatus, 540.

DTegatherium, molar of, 136 .

Melania turritissima, Bembridge, 282

inquinata (Cerithium melanoides), 296.

Melanopsis buccinoidea (recent), 29.

Melaphyre, 606 .

Menai strait, marine shells in drift, 158.

Mendip Hills, lead veins in, 779.

Mendips, denudation in, 67 .

Mesozoic, term explained, 91 .

Metalliferous veins. See Mineral Veins.

Metals, relative age of 777 .

Metamorphic or Crystalline Limestone, 735, 736.

- rocks, defined, 8

- rocks, cleavage of, 747 .

— rocks, order of succession, 764 .

rocks, 732 .

- rocks, age of, 758 .

— rocks, scarcity of lime in, 765 .

strata, origin of, 736 .

strata, why less calcareous than fossiliferous strata, 765 .

- structure, origin of, 743 .

Metamorphism not requiring intense heat, 739.

by hydrothermal action, 739.

Metamorphosis of trilobites, 563. See Trilobites.

Meteorites in drift, 176.

Meyer, M. H. von, on reptile of Coal, 506. - on specimens of Archegosaurus, 514 - on Weald of Germany, 351.

Mexico, melted matter from Jorullo in, 719.

Micaceous sandstone, origin of, 14 .

Mica-schist, 734, 736 .

Micraster cor-anguinum, White Chalk, 325.

Microconchus carbonarius, 493.

Microlestes antiquus, molars of, 433.

Middendorf, on Siberian ice-drift, 157 .

Middle crag, recent species in, 208 .

Middle Oolite, 398-401.

Migration of Miocene plants, theory of, 269. of quadrupeds, 131.

Miliolite limestone, 304

Miller, Hugh, on salt lakes, 449.

- on fossil trees in coal near Edinburgh, 484.

on Old Red Sandstone, 530.

Milne Edwards, M, on bryozos, 214.

Minchinhampton, fossil shells at, 404.

Mineral composition, test of age of plutonic rocks, 717.

composition considered as test of age, 96 . 
Mineral composition, test of age of rolcanic rocks, 657 .

composition of volcanic rocks, 594

character of hypogene rocks, 764

character of aqueous rocks, $10,9 \mathrm{~s}$ $\pi 68$

veins and faults, $767-769$

veins of different ages, 767 .

veins, pebbles in, 771 .

veins near granite, 773

Mineralization of organic remains, 38

Minerals, table of analysis of, 608 .

Miocene, Lower, fossils at Mont Perrier, 687.

and Eocene, line between, 217, 247.

Atlantis, theory of, 26s-275.

Upper, of the Bolderberg, 235.

Upper, volcanic rocks, 674 .

Upper, Madeira and Porto Santo shelly tuffs, 674 .

- Lower, rocks of Eifel, 677.

period, 212

- plants and shells, whether distinct genera

or varieties of living, 267.

term explained, 188.

Mississippi, accumulation of sediment in, 491. fluviatile strata and delta of, 3 .

Mitcbell, Sir T., on Wellington caves, 126.

Mitra scabra, Barton clay, 287.

Mitscherlich, on Monte Somma cone, 661. on augite and hornblende, 596.

Modiola acuminata, Permian, 459.

Modon, lithodomi in cliff at, 73 .

Moel Tryfaen, marine shells found at, 158.

Molasse, Middle, of Switzerland, 258.

freshwater of Switzerland, 249.

Lower of Switzerland 258 .

Mollusca of Hallstadt beds, 437.

common to Upper and Middle Oolite, 398.

Mona Loa, 652 .

Mons, flexures of coal at, 53 .

Mont Blane, talcose granite of, 721

Dor, volcano of, $6 \varsigma 5$.

Perrier, breccias of, with bones, 685 .

Monte Bolca, Middle Eocene, fossil fish of, 694 Mario, age of volcanic deposits of, 674 .

Montlosier, M., on cones of the Vivarais, 689 .

Montmartre, gypseous series of, 298.

Montsacopa, crater of, 669 .

Monts Dome, Auvergne, extinct volcanoes of, 594.

Moore, Mr. Charles, on San Domingo shells, 274

- on teeth of mammalia, 442

on Upper Trias quadrupeds, 388.

Moraine, term explained, 133.

Moraines of glaciers, 140 .

- terminal, 140

Morea, inland sea-cliffs of 43.

Morlot, M., on lake-dwellings, 110. on Swiss deltas, 120

Morris, Mr., on Stonesfield slate, 410

Mortillet, M. de, theory of lake-excavation, 173.

DLosasaume Camperi, 316

Mottled clays and sand 295.

Mountain limestone, 514

- strata contemporanoous with, 522

Mountains, volcanic, form, structure, and origin of, 625 .

Mull, Isle of, leaf-bed, 242.

Münster, Count, on fossils of Solenhofen, 396. on Placodus, 440

Murat, freshwater limestone near, 692

Murchison, Sir R. I., on granite of Caithness, 729.

on flints in Dover cliffs, 374.

on Silurian strata, 551 .

on Swiss molasse, 250 .

on carboniferous plutonic rocks, 725

on Silurian volcanic rock, 699

on cleavage, 747 .

on conversion into gneiss, 746

- on Devonian series, 536.

- _ on fossil fish of Monte Bolea, 694.
Murchison, Sir R. I., on metamorphic rocks of North Highlands, 762

on name Permian, 458

on Permian rocks, 462

on Posidonia minuta, 443

on protrusion of solid granite, 727 .

on Russian glacial drift 149.

- on schists of Old Red, 531.

on the Cantal, 231.

- on thickness of White Chalk, 318.

Murchisonia gracilis, Silurian, 572.

Murex vaginatus, Ischia. 190.

Muschelkalk, fossils of, 438 .

Myliobates Edwardsi, 289.

Myrmecobius described, 409.

Mytilus septifer, Permian, 459 .

NAples, Post-pliocene volcanic formations of 661.

Nassa granulata, Red Crag, 202.

Natica, spawn of, 528 .

- clausa, Clyde drift, 153.

helicoides, Norwich crag, 197.

Nautilus ziczac, 293.

Danicus, Faxoe, 316

centralis, Highgate, 293.

plicatus, 343.

- truncatus, Lias, 418.

Navarino, lithodomi found in cliff at, 73

Nebraska, Miocene strata of, 279.

Necker, M. L. A., on dikes of Vesuvius, 663.

on Arran granite, 728

terms granite "underlying," 7

Needles of chalk, size and position of, 355 .

Nelson, Capt., on Bermuda corals, 319.

- drawing of Bermuda, 79.

Neocomian, term explained, 341.

Neozoic type of corals, 515.

Neptunian theory, 87.

Nerinac hieroglyphica, 399.

- Goodhallii, Coral-rag, 399.

Nerinæan limestone, 399

Nerita conoidea (Schmidelliana), 305.

- costulata, Great Oolite, 405.

granulosa, 30

- globulus, 30.

Neritina concava, Headon series, 284.

Newberry, Dr., on Spenophyllum, 474.

on New Jersey flora, 340.

Newcastle coal-field, great faults in, 63.

New Red Sandstone of Connecticut valley, 453.

Red Sandstone period, trap of, 696 .

Red Sandstone formation, 431.

New York, Devonian strata of, 543 .

Cambrian strata of, 583.

Laurentian strata of, 584 .

- Silurian strata of, 570 .

New Jersey, Mastodon at, 167

New Zealand, sudden rise of land in, 172

Newer Pliocene volcanic rocks, 658 .

Niagara Limestone, fossils of, 571.

Nile, deposits of, 118 .

- mud, 118

Nipadites ellipticus, Sheppey, 292

Nodosania, Ctalk, 26 .

Noeggerathia cuneifolia, 464.

Nomenclature of volcanic minerals, 594. changes of, 89

of Trias, 432.

Norfolk, buried forest, $\mathfrak{i} 60$.

- drift, composition of, 160.

Normandy, chalk of, 354 . shells in, 208.

needles and cha

North America, glacial formations of, 163. carboniferous limestone of, 522 .

North Germany, fossil fauna of, 236.

North Wales, cleavage of slate rocks in, 750 , 755 .

Northwich, beds of salt at, 448 .

Norway, granite veins in gneiss of, 714 Cambrian of, $5 S 1$.

Silurian plutonic rocks of, 725

Norwich crag, shells of, 197.

- sand-pipes near, 82. 
Nova Scotia fossil forests of 484 .

period of coal accumulation in, 491. Nucula Cobboldice, Norwich crag, 197. Nummulites (Nummularia) Zoevigata, 259 exponens, Europe and Asia, 308. Puschi, Pyrenees, 308. Nummulitic formations, 308.

Nyst, Mr., on testacea in Antwerp crag, 207. on Edeghem shells, 234.

OBoLUs grit of Russia, 569 . Apollinis, Silurian, 569. Obsidian, 606

Ocellaria radiata, 329.

CEningen, Upper Miocene beds of, 248.

Oeynhausen, M, von, on Cornish granite veins, 713.

Ogygia Buchii, Silurian, 566

Ohio, Falls of, Devonian coral-reef of, 544.

Old Red, supposed reptilian remains of, 530 .

Old Red Sandstone, subdivisions of, 524 . thickness of, 524

- trap of, 698 .

Oldest granites, 726 .

Oldhamia radiata, 0 antiqua, 579

Olenus micrumus, Lingula flags, 577.

Oligoclase, composition of, 595 .

Oliva Dufresnii, Bolderberg, Belgium, 236.

Oliver, Prof., on Miocene Atlantis, 270

Olivine, 598.

Olot, volcanic rocks of, 666 .

Omphyma turbinatum. Wenlock, 557.

Onchus tenuistriatus, Silurian, 552

Oolite, origin of, 429 .

- divisions of, compared, 414.

- Great, fossils of, 402

_ Great, fossil plants of, 411.

- Inferior, fossils of, 412

- plutonic rocks of, 723 .

- physical geography of, 378 .

- table of divisions of, 377,378 .

- term defined, 12

— upper, middle, and lower, 378.

Oolitic strata of England and France, 378

- voleanic rocks, 696 .

Ophioderma Egertoni, Middle Lias, 420 .

Ophite, Ophiolite, 606.

Opossum, molar tooth and part of jaw of, 294.

Oppel, M., on zones of Lias, 416.

Orbigny, A. d', on Orbitoides, 309, 311.

- on cretaceous series, 314.

- on distinction of species, 215 .

- on Vienna basin, 244.

Orbigny, M. C. d', on pisolitic limestone, 314.

Oreodaphne Heerii, 210.

Organic remains, criterion of age of formation of, 93 .

tests of age of rolcanic rock, 656

Oriskany sandstone, classification of, 544

Ormerod, Mr., on thickness of Trias, 44.

Orthis elegantula, Upper Ludlow, 553.

tricenaria, O. vespertilio, O. grandis, Silurian, 563.

Orthoceras in St. Cassian beds, 437.

Orthoceras ventricosum, 554.

- laterale, 520.

- duplex, Silurian, 566.

- Iudense, fragment of, 555 .

Orthoclase, composition of, 595 .

Osborne, or St. Helen's series, 284

Osteolepis, old Red Sandstone, 533.

Ostrea gregarea, Coral-rag, 399

- acuminata, Fuller's earth, 412.

— carinata, Chalk, 328.

- columba, Chalk, 328.

- deltoidea, Upper Oolite, 395.

- distorta, Purbeck, 380.

- expansa, Portland-stone, 395.

vesicularis, Chalk, 328.

Otodus obliquus, tooth of, 290 .

Overlying, term applied to volcanic rocks, 7 .

Owen, Prof., on Eocene mammalia, 387

- on carboniferous limestone, 523.

on cave-breccia fossils, 126.

- on fauna of Sheppey, 292.
Owen, Prof,, on footsteps on Potsdam sand. stone, 582 .

- on footprints of Trias, 445, 455 .

- on Gastornis Parisiensis, 306

- on Ichthyosaurus, 424.

- on Palæophis typhœus, 239.

- on Plagiaulax, 384.

- on Purbeck mammalia, 382.

- on reptile of Coal, 506.

on Triconodon, 385.

- on Stonesfield mammalia, 407-409.

- on Zeuglodon, 310, 311.

Ox common molar of 135 .

Oxford clay, fossils of, 400 .

PAorfic, corals and chalk of, 318.

Palachinus gigas, Mountain Limestone, 517. Palceoniscus (Palcothrissum), 461.

- comptus, $P$. elegans, $P$. glaphyrus, 462.

Palæontology of cretaiceous rocks, 344.

- term explained, 100.

Paloeophis typhoeus, Bracklesham, 289.

Palceosaurus platyodon, tooth of, 447.

Palootherium magnum, 283.

Palæozoic type of corals, 515.

Palagonite tuff, 603, 606 .

Palermo, caves near, 74.

Palma, aqueous erosion in, 637.

- denudation of fluviatile or marine, 640 . caldera of, 629

structure of, 628-631.

Paludina, fossil, of Auvergne, 226

- lenta, Hempstead, 29, 240 .

Mayence, 243.

orbicularis, Bembridge, 282.

Paradoxides Bohemicus, 580.

Parasmilia centralis, Chalk, 515.

Paris basin, tertiaries of, 298.

Parka decipiens, 528.

Parkinson, Mr., on Suffolk crag, 183.

Parrot, Dr. F., on salt-lakes of Asia, 449.

Patagonia, sedimentary layers of, 754 .

ground-plan of dikes near, 666 .

Patella rugosa, Great Oolite, 405.

Peach, Mr. C. Scotch Devonian fossils found by, 531 .

Peak of Teneriffe, view of, 644 .

Pearlstone, 606.

Peat of Denmark, 109

Pebble-beds of Lower Miocene, Switzerland, 259.

Pebbles, absence of, in granite, 729.

— in Chalk, 323.

Pecopteris lonchitica, Carboniferous, 468.

Pecten istandicus, Clyde drift, 153.

- Beaveri, White Chalk, 327.

- papyraceus, Coal, 495.

_- quinque costatus, White Chalk, 327.

- jacobaus, Sicily, 194.

Taloniensis, Trias, 441.

Pegmatite, 704.

Penarth beds, 442

Pengelly, Dr., on flint-knives of Brixham cave 124.

Pengelly, Mr., on Bovey Tracey lignite, 241.

Pentacrinus Briareus, Lias, 420.

Pentamerus beds, 560.

Pentamerus Knightii, Aymestry, 554.

$\longrightarrow$ lovis, 561

- oblongus, 561.

Pentland Hills, volcanic rocks of, 699 .

Pentuan, human skulls at, 109.

Peperino, 606.

Peperinus of Gergovia, 693.

Pepys, Mr., cited, 41.

Period of Weald denudation, 369.

Permian group, 458.

- flora, 463 .

Perna Mulleti, 343.

Petherwyn group, fossils of, 537.

Petrifaction of fossil wood, 39 .

process of, 43

Petrosilex, 606 .

Phacops latifrons, Devonian, 587

— caudatus, Silurian, 559. 
Phaseolotherintm Bucklandi, Stonesfield, 409. Phasianella Heddingtonensis, Coral-rag, 39. Philippi, on tertiary shells of Sicily, 192.

Phillips, Prof,, on coal-bearing strata, 465.

- on Wenlock shale, 559

on slaty cleavage, 749

Phillips, Mr. W., on kaolin of China, 11

Phlebopteris contigua, Lower Oolite, 411.

Pholadomya fidicula, Inferior Oolite, 412

Phonolite, 599, 606.

Phome extensus, Highgate, 293.

Phosphate of lime, 332

Phragmoceras ventricosum, 5 ã

Phryganea, larva of recent, 226.

Phyllade, 736.

Physa columnaris, P. hypnorum (recent), 29.

- Bristorii, Middle Purbeck, 381.

Pico Torres, \&c., of Madeira, 648.

Pictou, calamites near, 491.

Pile-dwellings of stone and bronze age, 111.

- of Switzerland 110.

Pilton group, fossils of: 586

Pinnularia, Atlantic mud, 320 .

Pinus sylvestris in pent, 109.

Pisolitic limestone, France. 313.

Pitchstone, 606

Placodus gigas, teeth of, 439 .

Placoids of Wealden, 319

- scarcity of, in Old Red strata, 532.

Plagiaulax Becklesii, jaw of, Middle Purbeck. 383.

- minor, jaw of, Middle Purbeck, 381.

Plagiostoma giganteum, 417.

- Hoperi, White Chalk, 327.

Planera Richardi, Eningen, 266.

Planitz, tripoli of, 26.

Planorbis discus, Bembridge, $2 \lesssim 2$. euomphalus, $29,254$.

Plants common to Eocene and Miocene, 295.

fossil, of Madeira, 619

fossil, of Switzerland, 260.

of Purbeck Deds, 394

- of the Keuper, 434.

Plas Newydd, rock altered by dike near, 613 .

Plastic clays and sand, 295.

Platanus aceroides, CEningen, 254.

Platystoma Suessii, Hallstadt, 436.

Playlair, cited, 45,88 .

on faults, 61 .

on Huttonian theory of stratification, 60 .

Plectrodus mirabitis, Üpper Ludiow, 552

Pleistocene, term, why abandoned, 107.

Plesiosaums dolichodeirus, Lias, 423.

Pleurodictyum problematicum, 541.

Pleurotoma attenuata, 290.

- rotata, 31.

Pleurotomaria carinata (flammigera), 518. Anglica, 39 . granulata, Inferior Oolite, 412

- ornata, Inferior Oolite, 412.

Plieninger, Prof., on triassic mammifer, 432

Pliocene, term explained, 158.

- Older, volcanic rocks, 673.

strata in Ischia 189.

period, 178

voleanic rocks, why invisible, 718 .

Plomb du Cantal, igneous rocks of, 691 .

Plombieres, alkaline waters of, 740 .

Ploverfield, fine-grained granite of, 728,729 .

Plumbago of Massachusetts, 743 .

Plutonic rocks, 7.

- action, 740 .

- carboniferons, 725 .

- cretaceous, oolitic and liassic, 727.

of the Andes, 721 .

rocks, origin of name, 702

Silurian, 725 .

- test of age of 717 .

Pluvial action on chalk, 365 .

Podocarya, portion of fruit, 410 .

Podogonium Knorrii, CEningen, 221.

Poikilitic, term explained, 432

Polycalia profunda, Permian, 515.

Polyptemes, living, in the Nile, 532.

Pomel, M., on fossil of Mont Perrier, 657.
Pompeii, bronze instruments found at, 112

Ponza Islands in Mediterranean, 619 zoned structure of trachyte in, 752 .

Ponza, Isle of, globular pitchstone in, 619.

Ponzi, Prof., on Subapennine strata, 209.

Porphyritic granite, 707.

Porphyry, 600.

Portland, Isle of, fossil forests in, 391

- stone and sind, 394

Port Moniz, surface of lava at, 654

Porto da Cruz, trachytic tuifs of, 652 .

Porto Santo, Madeira, Upper Miocene shells of, 674 .

Posidonia minuta, Muscbelkalk, 439.

Posidonomya Becheri, 522.

Post-pliocene period, human remains of, 113.

- mammalia, teeth of, 133.

- lakes of Switzerland, 173 .

- valley drifts of, 114 .

- volcanic rocks, 661

- strata, 107, 113

Potamides cinctus, 30.

Potsdam sandstone, 581.

Potstones at Horstead. 323.

Pottery in upraised strata, 121.

Pottsville, coal-seams near, 499

- footprints of reptiles near, 509.

Powrie, Mr., on Cephalaspis beds, 531.

Pozzolana, 36.

Prasias, Lake, lake-dwellings in, 110.

Pratt, Mr., on fossils of Oxford elay, 400. on Isle of Wight mammalia, 283.

Precipitation of mineral matter, 41.

Predazzo, altered rocks at, 724

Prestwich, Mr., on island in Eocene sea, 367.

- on Barton clay shells, 287.

on Blackheath shingle, 296 .

on Eocene strata, 369

— on shells of London clay, 292.

on Weald denudation, 367.

- on iron-sands, 235 .

- on Calais flint-breccia, 374

- on cave and drift fossils, 129

on coal-measures of Coalbrook Dale, 62. on Sables de Bracheux, 387.

Prévost, M. Constant, on fauna of Montmartre, 299.

Prérost, M., on Paris basin, 299.

Primary Limestone, 736.

"Primary" schists, composition of, 744

Primordial zone of Barrande, 573, 579.

Productus horridus, 460.

- semireticulatus (antiquatus), 517.

Progressive development and oldest fossil fish, 585.

Proteaceæ, species in Lower Molasse, Switzer-

land, 261.

Protogine, 708, 736.

Protrusion of solid granite, 727, 731.

Psammodus porosus, 521.

Psaronius in Permian of Saxony, 464

Pseudocrinites bifasciatus, Wenlock, 558.

Psilophyton princeps, Devonian, 548.

Pteraspis in Lower Ludlow shale, 555.

Pterichthys, Old Red Sandstone, 534.

Pterodactyl, gigantic size of, 331 .

Pterodactylus crassirostris, Solenhofen, 396.

Pterophyllum comptum, Gristhorpe, 411.

Pterygotus anglicus, 523.

Ptychodus decurrens, Chalk, 330.

Puggaard, M., on strata of Ischia, 190.

Pulvermaar of Gillenfeld, lake of, 681 .

Pumice, 602, 606.

Pupa muscorum, Rhine, 119.

vetusta, Coal, 512 . tridens, 30.

Purbeck, Lower, shells of, 389 .

- beds, 377, 379-394.

fossil mammalia of, 381 .

marble, 380

Middle, shells of, 380 .

Upper, shells of, 379 .

Purity of coal, causes of 490 .

Purpura tetragona, Ped crag, 202.

Purpuroidea nodulata, Great Oolite, 405. 
Pay de Côme, volcano of, 659.

- de Pariou, crater of, 691.

- de Tartaret, eruptions of, 638.

Pyrenees, curvatures of strata in, 58.

— altered fossiliferous rocks of, 739

- lamination of clay-slate in, 756 .

Pyroxene, 597.

Pyroxenic porphyry, 606

Puzzuoli, elevation and depression of land at, 661.

Pymila reticulata, Coralline crag, 204.

QUADRUMANA of Upper Miocene strata, Gers, 233.

Quadrupeds, extinct, in alluvium, 11.

Quartz, fusion of, 705 .

- veins in gneiss of Norway, 715 .

Quartzite, quartz rock, 734,736 .

Quebec groun, fossils of, 583 .

Quekett, Prof., on Pupa vetusta, 512

Quenstedt, M., on zones of Lias, 416.

RADABOJ, fossils of, 245.

Radicofani, Older Pliocene volcanic rocks of, 673.

Radiolites foliaceus, Chalk, 337.

- Mortoni, Chalk, 328.

- radiosa, Chalk, 337

Radnorshire, stratified trap of, 700 .

Rain-prints with worm-tracks, 489.

- carboniferous, 489

Raised beach of San Catalina, 676 .

Ramsay, Prof., on Welsh glaciers, 159

_ - on causes of Weald denudation. 374.

- on cretaceous fossils, 341.

on denudation, 67 .

on Devonian Brachiopoda, 542.

518.

518.

- on relations of Oolitic fossils, 413 .

- on St. Cassian fossils, 437.

- on Tremadoc slates, \&sc., 577.

- on Trias of England, 440

- on two granites of Arran, 72S.

on volcanic tuffs of Snowdon, 700 .

- on zones of Lias, 416.

Rastrites peregrinus, Silurian, 565.

Raulin, M. V., on Diest sands, 235.

Ravine of Barranco de las Angustias, 638.

Recent strata, defined. 107.

- strata near Naples, 108.

- volcanic rocks, why invisible, 718 .

Record, imperfection of, in the earth's history, 150.

Red crag of Suffolk, 200.

Red Sandstone, origin of, 447 .

Red Sea, saltness of, 450 .

- and Mediterranean, distinct species in, 96

Reindeer period in South of France, 125.

Relation of trap, lava, and scorix, 620 .

Relistran mine, pebbles in tin, 771 .

Reptile of the Kupferschiefer, 463.

Reptiles of coal-measures, 511.

- carboniferous, 504

— of the Lias, 422.

- supposed remains of, in Old Red, 529.

Retepora flustracea, 460 .

Rhrtic beds, 442

Rhine, fossils of, 120

- valley, human skeleton of, 117

Rhinoceros leptorhinus, molar of, 134

- tichorhinus, molar of 134

Rhomboidal scaled fish, 533.

Rhynchonella Wilsoni, Aymestry, 554.

- navicula, Ludlow, 553

- octoplicata. White Chalk, 327.

- spinosa, Inferior Oolite, 412

Rhytisma insuratum, Eningen, 267.

Richardson, Sir John, on fossil Sequoia, 262.

Richmond, Va., triassic coal-field of, 451.

Rimula clathrata, Great Oolite, 405.

Rink, Mr., on ice of Greenland, 144 .

Ripple-mark, formation of, 19 .

Rise and fall of land, 108, 114

— in Wealden period, 352.
Rissoa Chastelii, Hempstead, 240.

Ritter, M., on submergence of Sahara, 176

River terraces, ancient, of Nile, 118.

- channels, ancient, 504

Roche de Pignon, Seine, 356

Roche moutonnée described, 141.

Roches d'Orival, Elbœuf, 355.

Rock, term defined, 2 - cretaceous, 340 .

and Spindle, St. Andrew's, 697. salt, origin of, $447-450$.

Rocks, four classes of, contemporaneous, 8 . altered by subterranean gases, 741 . classification of, 86 .

14

glacial scorings on, 143.

metamorphic, 732 .

metamorphic, age of, 758 .

trachytic, of Madeira, 653

trappean, 88.

Silurian, table of, 550, 551 .

smoothed and striated, 139

volcanic eocene, 694 .

Eocene, granite, and plutonic, 721 .

altered by subterranean gases, 615 .

tests of age of, 655 .

voleanic, structure of, 616

Roderberg, volcano of, 682 .

Rogers, Prof, on Devonian rocks, U. S., 544.

on coal-field, United States, $498,501$.

on reptile footprints, 509 .

on Richmond coal-field, 451

Roman relics in Swiss strata 121

Rome, formations at, 209, 673 .

Römer, F., on chalk of Texas, 340.

- on Aix-la-Chapelle beds, 334.

Rose, Gustar, on fusion of quartz, 705 .

on Fifeshire dike, 698

- on hornblende, 596 .

Ross, Capt., on greenstone at Keeling Island, 324.

Ross-shire, denudation in, 67 .

Rosso antico, red porphyry of Egypt, 601.

Rostellaria ampla, 293.

Roth, M., on Miocene formations of Greece, 247

Roxalina, Chalk, 26

Rubble, term explained, 81.

Runn of Cutch, salt of, 449 .

Rupelian of Dumont, 237.

Rupelmonde, Upper Eocene beds, 238.

Russia, glaciation of, 149.

- Devonian of, 542 .

fossil meteoric iron in, 177.

Rütimeyer, M., on Eocene monkey, 294.

SABLes de Bracheux, 306

moyens, 302

Saarbrück coal-field, 506

Sabal major, Vevay, 259.

Sahara, submergence of, 175 .

St. Abb's Head, unconformable stratification at, 60 .

- curved strata near. 49

St. Andrew's, Rock and Spindle in, 697 .

St. Helena, voleanic dike of horizontal prisms, 617.

St. Lawrence, Gulf of, inland beaches and cliffs, 78 .

St. Mary's, shells of, 676 .

St. Mihiel, France, inland cliffs near, 77.

St. Pàul's or Amsterdam Island, 643.

St. Peter's Mount, near Maestricht, sandpipes in, 83.

S. Vicente, tuffs and limestones of, 646 .

Salisbury Craig, altered strata near, 615 .

Salt rock, origin of, 448 .

lakes of Asia, 449 .

Salter, Mr., on fossils of Lower Llandeilo, 567.

San Catalina, raised beach of, 676 .

Sandberger, Dr. F., on Mayence Tertiary, 243.

Sandpipes of North Downs, 861.

- in Norwich, 82

or sandgalls, term explained, 82 . 
Sands of Hastings, 349.

— of Diest, 234 .

Sandstone, Gray, of Upper Ludlow, 552.

and conglomerate of Auvergne, 223.

New Red, of Connecticut, 452 .

slab, with cracks, 350 .

Sandwich Islands, craters and calderas of, 623 .

- volcanoes of, 623 .

Sao hirsuta, 550.

Sattel, intercalations of gneiss in the, 761.

Saucats, near Bordeaux, taluns of, 232.

Saurians of Lias, 422-42S.

- sudden destruction of, 426

Saurichthys apicalis, 442 .

Sanssure, on erraties, 142

- on vertical conglomerates, 47.

Saxicava rugosa, Clyde drift, 153.

Saxony, protrusion of solid granite in, 727 .

- beds of minerals, 772 .

Scandinavia, glaciation of, 149

Scaphites cequalis, Dorsetshire, 326.

Scarborough, oolitic plants of, 411 .

Sehist, micaceous, $73 \pm, 736$.

- argillaceous, 734 , 73 .

Schizodus Schlotheimi, Permian, 459.

truncatus, Permian, 459 .

Schmerling, Dr., on Liège caverns, 124, 125.

Schorl rock, 708 .

Schwab, M, on Celtic coins, 111.

Scoliostoma, St. Cassian, 436 .

Scoresby, on Arctic icebergs, 146.

Scoriaceous lava in part amygdaloid, 600 .

Scoriæ, 602, 606 .

- formation of, 594

Scotland, fundamental gneiss of, 535 . Old Red Sandstone of, 521 . - glaciation of, 151 .

Scrope, Mr., on zoned structure of Ponza Islands, 752

- on globular structure of traps, 619 . on globiform pitchstone, 610 . on tuff and peperino, 602

Sea-beds, scored by icebergs, $14 \mathrm{~S}$

- cliff's, inland, 71 .

Section through part of Teneriffe, 645 .

— at Champradelle, near Clermont, 225.

- between Atlantic and Mississippi, 497.

310 .

- in Isle of Portland, 391.

of Arran, 730

of central region of Madeira, 651

of contorted strata, Forfarshire, 156

of Dundry Hill, near Bristol, 48, 98 .

of escarpments of Weald Valley, 358.

of Foriarshire, 48.

of Isle of Arran, 730.

of lava at Castell Follit, $6 \pi 1$.

of Madeira 648.

of Palma, 631

of South Joggins cliffs, 485

of Chalk and Greensand, 317.

of Elephant-bed, Brighton, 373.

of Lulworth Cove dirt-bed, 391.

of Old and New Rerl Sandstene, 431

of the Weald, $346,358,368$.

showing chalk in Seine Valley, 354

showing erect fossil trees in Coal, 483

vertical, of slate-rock, Devon, 750 .

Sedgwick, Prof., on concretionary magnesian

limestone, 37

- on brecciated limestone, 459 .

on Cambrian, 575 .

on carboniferuns platonic rocks, 725

on Coal strata, 466.

on Cornish granite, 712.

on Devonian series, 536 .

on garnets in altered rock, 613 .

on granite of Caithness, 729 .

on Silurian strata, 560,567 .

on structure of mineral masses, 746 .

Segregation of mineral veins, 768 .

Semi-crystalline strata of Alps, 760 .

Semi-opal, Diatomacere in, 26.

Senneville, chalk pinnacle at, 355 .
Senonian, term explained, 315

Sequoia Langsdorfii, Switzerland, 263.

- Mackenzie River, 263.

Seraphs convolutum, 287.

Serapis imbedded, 108 .

Serpentine, 606, 736 .

Serpulæ on voleanic rocks in Sicily, 192.

attached to Encrinite, 403.

attached to Gryphoea, 22

- attached to Spatangus, 23.

Shale, Lower Lualow, 555 .

- defined, 11.

Sharks, teeth of, 290.

Sharp Tor, Cornwall, granite of, 703 .

Sharpe, Mr. D., on shells in slaty cleavage, 60.

- on Silurian fossils, 571 .

- on Upper Canada, 331.

Shell-mounds of Denmark, 109.

Shells, proportion of Northern and Southern, in crag, 206

- Aretic, in Scotch drift, 154

fossil, of Virginia, U. S., 278

fossil, of London clay, 293.

fossil, of mountain limestone, 516-529.

of Barton clay, 287.

of Edeghem, 234.

of faluns compared to those of crag, 214

of Faxoe, 316

of Gergovia formation, 693 .

of Great Oolite, 40 .

- of Míayence basin, 243

of Norwich crag, 197.

of Sicily, 190, 194.

of Subapennine beds, 208.

- of Upper and Middle Purbeck, 379, 380.

preserving their color, 518.

proportion found in different strata, 189. recent, $28,29,30$.

- valuable in classification, 187

Sheppey, fauna and flora of, 292

Shetland, granite of 709

hornblende schist of, 743 .

Sicily, volcanic dikes of, 192.

corals of, 194.

- dikes in, 665 .

- inland clift's in, 74 .

newer Pliocene beds of, 192

- terraces of denudation in, 75 .

Sidlaw Hills, trap of, 699

Siebengebirge, igneous rocks of, 679 .

Sigillaria, structure and size of, 474, 481 . lavigata, Coal, 474

Siliceous limestone defined, 12

- rocks defined, 11

Silurian plutonic rocks, 725 .

derivation of name, 551

fossils, 552-570.

- lower metamorphic, in Scotch Highlands,

rocks, table of, 550,551 .

562

rocks, Upper, 551; Middle, 560 ; Lower,

rocks, whether of deep-water origin, 573 .

strata of Europe, 569.

strata of United States, table of, 570 .

- volcanic rocks, 699 .

Siphonia pyriformis, Blackdown beds, 329

Siphonotreta unguiculata, Silurian, 569.

Siwâlik Hills, freshwater deposits of, 276 .

Skaptar Jokul, flow of lava from, 657 .

Skye, plutonic rocks of Lias in, 724 . decomposed trap of, 610 .

sandstone in, 36.

Stcull of stone age, Denmark, 113

of iron age, Denmark, 113.

Skulls, brachy cephalous, 113.

dolichocephalous, 113

Slaty cleavage, 749

Slicken-sides, term defined, 770

Smilex obtusifolia, CEuingen, 255. sagittifer a, Eningen, 255.

Smith, Mr., of Jordanhill, on Madeira fossil plants, 649

Snags, fossil, $4 \$ 3$. 
Snowdon, volcanic tuffs of, 700 .

Soissonnais sands, 304 .

Solenhofen, fossils in lithographic stone of, 395.

Solfatara, decomposition of rocks in the, 741.

Somma, sahlband at, 612 .

cone and dikes of, 662 .

Sopwith, Mr. T., models by, 57.

Sorby, Mr., on ripple-marks in mica-schist, 756.

on hydrothermal action, 706 .

- on slate cleavage, 751

South Devon, Old Red of, 535

South Downs, transverse valley, 362.

- view of, 360 .

South Joggins, stigmaria and sigillaria at, 475.

- section of cliffs at, 485 .

Spaccoforno inland cliffs, 76 .

Spain, volcanoes in, 6

Spalacotherium, Purbeck, 406.

Spanish volcanoes, age of, 672 .

Spatangus radiatus, Chalk, 316.

with Serpula attached, 23.

Species, antiquity of living, 195.

- of Upper and Lower Cretaceous, 344.

- of plants common to Older Miocene and

flora of Eningen, 260.

- variations of, 215 .

Specific gravity of basalt and trachyte, 599 .

Spezia, Gulf of, calcareous rocks, 759 .

Sphocerexochus mirus, Silurian, 559.

Sphcerulites agariciformis, Chalk, 337.

Sphenopteris gracilis, Wealden, 351.

- crenata, Carboniferous, 468 .

Spicula of sponge, Atlantic mud, 320.

Spirifer trigonalis, S. glaber, Mountain Limestone, 518.

- disjunctus, Devonian, 537.

- mucronatus, 541.

Walcotti, Lower Lias, 418

- undulatus, 460.

Spirolina stenostoma, Eocene, 303.

Spirorbis carbonarius, 493.

Spondylus spinosus, Chalk, 327.

Sponge in flint (Chalk), 330

Spongilla, spicula of, in tripoli, 25.

Springs, mineral. See Mineral Springs.

Staffa, columanar basalt of, 616 .

Stalactite, origin of, 123 .

starfish of Lower Ludlow, 555 .

Stauria astraceformis, Silurian, 515.

Steuo, on classification of rocks, 86 .

Stereognathus described, 409.

Sternbergia, structure of, 477 .

Stigmaria in coal-measures, 468.

- ficoides, Coal, 476.

- and Sigillaria, 475 .

Stirling Castle, rock of, altered by dike, 615 .

Stiper-stones group, 567.

Stockwerk, assemblage of veins, 768 .

Stokes, Mr., on petritaction, 43.

Stone weapons at Geneva, 111.

Stonesfield slate, composition and fossils, 405 .

Strata of Kyson, 294 $\frac{1}{22}$ arrangement of, determined by fossils, 21 ,

- consolidation of 34

- contortions of, in Cyclopian Isles, 659.

- contorted, in drift, 156.

- curved and vertical, 47, 58.

- elevation of, above the sea, 44 .

- fossiliferous, tabular view of, 102.

- horizontality of, 15,45 .

- infraliassic, of Austrian Alps, 435.

- Lacustrine, of the Cantal, 229

- Lower Miocene, of England, 239.

- Lower Miocene, of France, 217.

metamorphic, origin of, 736 .

- mineral composition of, 10 .

- Miocene, of Italy, 247.

- Miocene, of Belgium, 236.

- Miocene, of Bordeaux, 231.

- Miocene, of France, 212.
Strata, Miocene, of Switzerland, 248.

Newer Pliocene, of England, 196

Older Pliocene, of England, 200.

outcrop of, 56 .

Post-pliocene, 107

prominence of harder, $\delta 64$

Recent, 107.

Silurian, of Europe, 569.

Subapennine, 208.

table of New York Devonian, 543.

term defined, 2 .

Upper Miocene, of Gers, 232

Stratification, unconformable, 60 .

forms of, $13,16,47$.

unconformable, 59.

Striæ, production of, 139

Striation of rocks, 139.

Strickland, Mr., on Posidonia minuta, 443.

Strike, term explained, 53.

Stringocephatus Burtini, 539.

Stromboli, lava of, 719 .

Strophomena grandis, Silurian, 563.

- depressa, Silurian, 558 .

Strozzi, Marquis, on Upper Miocene flora 210.

Structure, columnar and globular, of volcanic rocks, 616 .

- jointed, of metamorphic rocks, 747 . metamorphic origin of, 743 .

Studer, M., on gneiss of Jungfrau, 761.

- on boulders of Jura, 143.

Subapennine strata, 208.

Subdivisions of Bembridge beds, 282.

Submergence of North America, 165.

- and reëlevation of land in scotland, 152.

Succession, order of, in metamorphic rocks, 764.

Succinea amphibia, 29.

- elongata, Rhine, 119.

Suess, M., on Hallstadt fossils, 436.

- on Koessen beds, 435 .

- on Vienna basin, 244.

Suffolk, crag of, 196,200 .

Superga, near Turin, tertiaries of hill of, 209.

Superior, Lake, marl in, 36 .

Superposition of aqueous deposits, 96.

of Catalonian rocks, 673 .

- test of age of 'volcanic rucks, 655 .

Supracretaceous, term defined, 99.

Sus scrofa, molar of, 134

Sussex marble, 348 .

Swanage, fossil mammalia found at, 381

Swansea, coal-measures at, 467.

Sweden, Cambrian of, 581.

Swiss pile-dwellings, 110, 111.

- Jura, structure of, 55 .

Switzerland, age of metamorphic rocks in, 760.

lake-terraces of, 120 .

lake-dwellings, 110.

- Miocene strata of, $248,266$.

fossil plants of Lower Miocene of, 260.

Sydney coal-field, Cape Breton, 489.

Syenite, formation of, 708.

Syenitic granite, 708.

gneiss, 736.

Symonds, Rev. W. S., on Moel Tryfaen shells, 158.

Synclinal line, term defined, 48.

Table Mountate, strata horizontal in, 45. granite veins in 711 .

Table of fossil vertebrata, 588 .

from Portland-stone to Lower Greensand, 392.

of Devonian series, 536.

of French Eocene strata, 297, 298.

of Limburg beds, 237, 238.

of New York Devonian strata, 543.

of Silurian rocks, 550,551 .

of minerals analyzed, 608 .

of Cambrian and Laurentian strata, 575 .

576. of Eocene formations, England, 281. 
Table of fossil mammalia older than Paris gypsum, 387.

of fossiliferous strata, 101.

of Permian strata, 458 .

Tabular view of fossiliferous strata, 102

Tails of homocercal and heterocercal fish, 461.

Talcose granite, 708 .

- gneiss, 736 .

gneiss granite veins, 713 .

schist, 786.

Tarannon shale, thickness of, 560 .

Tartaret, cone and lava-current of, 688.

Teeth of extinct mammalia, 133-135.

Teleostei, term explained, 534 .

Tellina obliqua, Norwich crag, 197. proxima, Scotch drift, 154

Temnechinus excavatus, Coralline crag, 204.

Temnopleurus excavatus, 204.

Teneriffe, view of Peak of, 644 .

Tentaculites annulatus, Silurian, 561.

Tephrine, 607.

Terebellum sopita (Seraphs convolutum), 287.

- fusiforme, Barton, 287.

Terebratula porrecta, 539.

2- digona, Bradford clay, 405.

sella, 344 .

- carnea, White Chalk, 327.

fimbria, Inferior Oolite, 412.

hastata, 518.

Wilsoni, Aymestry, 554

Terebratula biplicata, Cretaceous, 327.

Terebratulina striata, White Chalk, 327.

Terebrirostra lyra, 331.

Teredina personata, fossil wood bored by, 24

Teresto navalis boring wood, 24.

Tertiary formations, classification of, 178 .

- term defined, 182. of Paris, 297.

- volcanic rocks of Auvergne, 687.

Termites of Eningen, 257.

Terra del Fuego, clay slates of, 755 .

Testacea of plastic clays, $295,296$.

Tête d'Homme, Andelys, 354, 355.

Texas, chalk in, 340 .

Thallogens, term explained, 333.

Thamnastroea, Coral-rag, 398.

Thanet sands, 297.

Thecodontosaurus, tooth of, 447.

Thecosmilia annularis, Coral-rag, 398.

Thelodus, shagreen seales of placoid fish, 5วั2.

Thickness of Laurentian rocks, 583.

Thirria, M., on Oolitic group, 429.

Thompson, Dr., on nummulites of Thibet, 308.

Thurmann, M., on anticlinal ridges of Jura, 366.

- cited, 55 .

on Bernese Jura Oolite, 404

Thylacotherium Prevostii, Valenc., 407.

Tilestones of Silurian strata, 551.

Tilgate Forest, remains in, 349 .

Tili, described, 137.

Tin, whence obtained by ancients, 112 .

- veins, age of, 780 .

Toadstone, 607 .

Tongrian of Dumont, 237, 238.

Torell, Dr, Otto, on icebergs, 144 .

Touraine, faluns of 213 .

Tournouer, M., on Lower Miocene shells, 232.

Trachyte, 599, 607 .

- porphyry, 599 .

Trachytic lava, age of, 657

- tuff's of Madeira, 653 .

Transition, term explained, 88.

Transverso valleys, 362.

Trap, term explained, 592. between limestone and shale, Durham,

alluvium, interce
Trap dikes, 609

intrusion of, between strata, 616 .

of New Red Sandstone period, 696 . passage of granite into, 708 .

620.

rocks, name and origin of, 592

spheroidal, of Madeira, 655 .

tuff, 602,607 .

- veins in Airdnamurchan, 610.

Trappean rocks, 88 .

relation to lava, 620 .

Trass of Lower Eifel, 652.

- term explained, 607.

Travertin, how deposited, 34.

- inférieur, 302.

Tree-fern from Brazil. 469

- from Isle of Bourbon, 469.

Tree, fossil, oblique in Coal, $483,486$.

Trees, erect, in Coal, 479,482 .

Tremadoc slates, fossils of, 776 .

Trenton limestone, fossils of, 571

Trezza, beds of clay and lava at, 658

Trias of United States, 451.

- nomenclature of, 432.

- in Cheshire and Lancashire, 443.

subdivisions of 432 .

Triassic group in England, 440.

Triconodon in Middle Purbeck, 385.

Trigonellites latus, Kimmeridge clay, 395.

Trigonia caudata, 344.

gibbosa, Portland-stone, 394.

Trigonocarpum ovatum, 477; T. olivaforme, 477.

Trigonotreta undulata, 460.

Trilobites of primordial zone, 580 .

- in Devonian strata, 537.

- in Cambrian, 574.

- metamorphosis of, 580

Triloculina inflata, Eocene, 304

Trimmer, Mr., on shells of Moel Tryfaen, 158.

- on contorted strata, 157

on sand-galls, 82

Trinucleus concentricus ( $T$. ornatus), Trinucleus Caractaci, 563.

Trionyx, carapace of Bembridge, 282

Tripoli composed of Diatomaceæ, 24.

Tristram, M., on submergence of Sahara, 176.

Trochoceras giganteus, Silurian, 555 .

Trophon clathratum, Clyde drift, 153.

Tuffs of Ischia, 189.

- volcanic and trap, 6, 602

- of Lower Llandeilo, 567.

- described, 607.

Tuomey, Mr., on burr-stone strata, 312.

Tupaia Tana, Oolite, 408

Turner, Dr., on chemical decomposition, 41. 42.

Turrilites costatus, Chalk, 326

Turritella multisulcata, 290.

Tuscany, springs from spent volcanoes, 766.

- Older Pliocene volcanic rocks of 673 .

Tyndall, Dr., on slate cleavage, 752 .

Tynedale fault, 64

Tynemouth cliff, limestone at, 459 .

Tyrol, junction of plutonic rocks with Oolitic strata, 724

Typhis pungens, Barton clay, 287.

UNCONFORMABLE stratification, 60,61 .

Underlying, term applied to granite, 7

Unger, Prof., on Planera Richardi, 266.

- on Miocene Atlantis, 269.

- on Miocene plants of Croatia, 245.

on Swiss Miocene, 248, 256

Ungulite or Obolus grit of Russia, 569.

Unio littoralis (recent), 28.

- Valdensis, 350 .

United States, Eocene strata in, 309.

- Cambrian strata of, 581 .

cretaceons rocks of, 338 .

coal-fields of, 496 . 
United States, Devonian strata of, 543 .

- Lower Miocene of, 279.

Older Pliocene and Miocene formations in, 277 .

- section of geological structure of, 497 .

Silurian strata of, 570 .

Trias of, 451.

Unstratification of Nile deposits, 118.

Upheaval, theory of violent, considered, 723. of calderas, theory of, 635 . of the Weald, 366 .

Upper Greensand, 331.

Miocene sea in area of Downs, 371.

Val d'Arno, newer Pliocene strata of, 196

Upraised marine strata in Sardinia, 121

Upsala, erratics on modern marine drift near, 150.

Ural Mountains, quartz veins of, 779 .

— gold of, 779 .

Ursus speloeus, molar of, 135.

Urville, Capt, d', on size of icebergs, 146.

VAL DI Nото, inland cliffs in, 76

voleanic formations of, 665 .

igneous rock of, 621 .

Valleys, origin of, 70 .

- transverse, of Weald, 362.

Valorsine granite, 713 .

Valvata, Pleistocene, 29.

Vanessa Pluto, Croatia, 245.

Vegetation of Middle Eocene period, 290.

- of Devonian period, 546.

Veins, granite, rocks altered by, 709

- mineral. See Mineral Veins. chemical deposits in, 775 .

Veinstones in parallel layers, 772 .

Velay, volcanic formations of, 692

Venericardia planicosta (cardita planicosta), 288.

Venetz, M., on Alpine glaciers, 142.

Ventricutites radiatus, Chalk, 329.

Verneuil, M. de, on Permian flora, 462

- on glacial drift of Russia, 149 . on Lower Silurian, United States, 571.

Vertebrata, absence of, in oldest fossiliferous rocks, 585 .

absence of, in lower rocks, 585 .

- fossil, progress of discovery of, 588 .

Vesuvius, Newer Pliocene beds of, 189 .

- age of lavas of, 658.

dikes of, 663 .

depth of crater of, 645

Vicentin, columnar basalt in, 618 .

Vicenza, basaltic column near, 618 .

Victoria Land, erratics of, 146.

Vienna basin, Upper Miocene of, 244.

View of volcanoes of Olot, 668.

of lava-current of Chaluzet, 690.

of Isle of Cyclops, 659.

of Gemunder Maar, 680

Virginia, coal-field of, 451. Miocene strata of, 278 .

Virlet, M., on corrosion of rocks near Corinth, 741

- on cretaceous traps of Greece, 696 .

on inland cliffs, 73

volcanic dikes, 6

- mountains, form of, 5 .

Viterbo, Older Pliocene volcanic rocks of, 673.

Vitreous lava, 607 .

Volcanic rocks of Olot, 666 .

- breccia, 602, 603 .

_ carboniferous rocks, 698 .

dike at St. Helena, 617 .

- dikes of Sicily, 192

- Eocene rock, 694

- formation of Val di Noto, 665

- mountains, form, structure, and origin of, 623.

- mountains, form of, 623.

rocks, synonyms and mineral composition
Volcanic rocks, 592

- rocks of Auvergne, 684

rocks, Cambrian, 700 .

rocks, Cretaceous, Oolitic, and Lias, 696.

columnar and globular siructure of, 616

rocks, Laurentian, 701.

rocks, structure of, 616-619.

rocks, Silurian, 700

tuff, $6,602,607$.

Volcano of Puy de Côme, 689.

of Verigojo, height of, 642.

Volcanoes, extinct, 6.

- of Auvergne, 684

of Canaries, 627.

of Java, 626 .

of Sandwich Isles, 623

Voltria heterophylla (brevifolia), 439.

Volume of hidden plutonic rocks, 722 .

Voluta Lamberti, Touraine Faluns, 215.

- ambigua, Barton clay, 287.

athleta, Barton, 287.

Lamberti, Coralline and Red Crag, 204. nodosa, Highgate, 293.

- Selseïensis, 290.

Von Buch, on Caldera of Palma, 634.

- on land rising, 45 .

- on Silurian plutonic rocks, 725 .

WAOKE, 607.

Wael, M. de, on testacea in Antwerp crag, 207.

Wagner, M., on Miocene of Greece, 247.

Walchia piniformis, Permian, 463.

Wales, glaciation of, 158 .

Walker, Dr., on Sequoia, 262

Waller, quoted, 88

Wallich, Dr., on Atlantic mud, 320.

Water, action of, in distributing heat, 742 .

Waterhouse, Mr., on Tupaia Tana, 408 .

Watt, Mr. Gregory, on cooling of metals, 663.

- on fusion, 739

Waves, action of, on limestone, 78 .

Weald, map to illustrate denudation of, 357.

- valley, denudation of, 357,367 .

Wealden formations, 345 .

- term explained, 365 .

- area of the, 351 .

- plants and animals of, 333,349 .

- theory of fracture and upheaval of, 366

Webster, Mr. T., on tertiary strata, 182

- on Headon series, 284.

Weisstein, term explained, 708.

Wellington Valley caves, 126.

Wenlock formation, fossils of, $557-560$.

- limestone, 557 .

- shale, fossils of, 559

Werfen beds, composition of, 435.

Werner, on classification of rocks, 87 .

on plutonic formations, 767 .

Westerwald, igneous rocks of, 679

Westwood, Mr., on Lias beetles, 428 .

Wexford, veins of copper at, 777

Whinstone, 607.

White Chalk, 12

- Mountains, centres of erratic dispersion, 166.

- sand of Alum Bay, 12.

- sands and Barton clay, 287.

Wigham, Mr., on jaw of Mastodon, 198.

Williamson, Prof., on calamites, 472

Wood, fossil and recent, perforated by mollusca, 24 .

fragment of, in Lias, 428

Wood, Mr. Searles, on fish of Headon series, 285.

Ooluta Lamberti 215 .

Woodstock, bone of reptile found at, 406 .

Woodward, Dr. S. P., tables on marine testacea, $205,206$.

- on Bridlington fossils, 199.

- on Hallstadt fossils, 436 . 676 . 
Wooducardia Rössneriana, Lower Miocene, Yorkshire Oolite, plants of, 411.

258.

Woolhope limestone and grit, 560 .

Wrekin, trap of, 70 .

Wright, Dr., on zones of Lias, 416.

- on Headon series, 255 .

TrPHODON GRACTLE (Anoplotherium gracile), 300.

Xylobius Sigillarice, Coal, 512.

YELLOW CRAG, recent species in, 208.

ZaMTA SPIratis, Australia, 390.

Zechstein, 458 .

Zeuglodon cetoides, Owen, 311.

Ziegler, M., on Mastodon angustidens, 256.

Zoantharia aporosa, 515 .

Zones, successive, of Lias, 416

Zoophytes, fossil, 22, 192, 279, 399, 515, 538

Zarich, lake-dwellings in Lake of, 110. 



\section{RECENT PUBLICATIONS}

OF

\section{APPLETON \& COIMPANY,}

90, 92 \& 94 Grand Street, New York.

Any of the following Books will be forwarded by mail to any address on receipt of the price.

\section{THE HUMAN ELEMENT IN THE INSPIRATION OF THE SCRIPTURES.}

By T. F. CURTIS, D. D. 1 vol., 12mo. Cloth, $\$ 2.00$.

\section{THE PHYSIOLOGY OF MAN;}

Designed to represent the existing state of Physiological science, as applied to the Functions of the Human Body. By AUSTIN FLINT, JR., M. D. Alimentation; Digestion; Absorption; Lraph and Chrle. 1 vol,, 8vo. Cloth. Price, $\$ 4.50$.

FIrst series.-The Blood; the Circulation; Respiration. 1 vol, 8vo. $\$ 4.50$.

\section{THE WIT AND WISDOM OF DON QUIXOTE.}

1 vol., 12mo. Cloth, $\$ 1.25$.

\section{THE PRINCIPLES OF BIOLOGY.}

By HERBERT SPENCER. 2 vols., 12mo. Price, $\$ 5.00$. (Vol. II. just published.)

\section{SYBIL'S SECOND LOVE.}

By JULIA KAVANAGH, author of "Adele," "Nathalie," \&c. 1 vol. 12mo. Cloth. 432 pages. Price, $\$ 2.00$.

\section{A JOURNEY IN ASHANGO-LAND:}

and Further Penetration into Equatorial Africa. By PaUL B. DU CHAILU, author of "Explorations in Equatorial Africa." 1 rol., 8ro with Map and 30 Mlustrations. $\$ 5.00$ 
D. APPLETON \& CO.'S PUBLICATIONS.

HOME LIFE: A JOURNAL.

By ELIZABETH M. SEWELL. 1 vol., 12mo. \$2.00.

A NEW SYSTEM OF INFANTRY TACTICS.

Dodble and Single RANK. Adapted to American Topography and Im. proved Fire-Arms. By Brevet Major-Gen. EMORY UPTON, U. S. Army One thick volume, $16 \mathrm{mo}$. Price, $\$ 2.00$.

THE COMPARATIVE GEOGRAPHY OF PALESTINE AN'D THE SINAITIC PENINSULA.

By CARL RITTER. Translated by Rev. W. L. GAGE. 4 vols., 8 ro. $\$ 14.00$.

THE POLITICAL WRITINGS OF RICHARD COBDEN.

2 vols., 8vo. Cloth, $\$ 6.00$.

HAND-BOOK OF PRACTICAL COOKERY, FOR LADIES AND PROFESSIONAL COOKS.

Containing the whole Science and Art of Preparing Human Food. By PIERRE BLOT, Professor of Gastronomy and Founder of the Now York Cooking Academy. 1 vol., $12 \mathrm{mo}$. $\$ 2.00$.

EZEKIEL AND DANIEL;

With Notes, Critical, Explanatory, and Practical. Designed for both Pastors and People. By Rev. HENRY COWLES, D. D. 1 rol, 12mo, $\$ 2.25$.

\section{BIBLE TEACHINGS IN NATURE.}

By REv. HUGH MoMILLAN. 1 vol., 12mo. \$2.00。

PHYSIOLOGY AND PATHOLOGY OF THE MIND.

By HENRY MAUDSLEY, M. D. 1 vol., 8vo. $\$ 4.00$.

HENRY VIII. AND CATHARINE PARR.

An Historical Novel. By L. MÜHLBACH. 1 vol., 12mo. Cloth, $\$ 2.00$.

THE MANAGEMENT OF STEEL.

By GEORGE EDE, employed at the Royal Gun Factories Department WOOLWICH ARSENAL. From the Fourth London Edition. 1 vol., $12 \mathrm{mo}$. Cloth, $\$ 1.50$.

JOSEPH II. AND HIS COURT.

An Historical Novel. Translated from the German by ADELAIDE DE $V$ CHAODRON. 1 vol., 8vo. Cloth, $\$ 2.00$. 


\section{NAPOLEON AND THE QUEEN OF PRUSSIA.}

An Historical Novel. By L. MÜHLBACH. Translated by F. JoRdAN. 1 vol., 8vo. Paper covers, $\$ 1.50$; Cloth, $\$ 2.00$.

\section{COUSIN ALICE:}

A Memoir of ALICE B. HAVEN. With Portrait. 392 pages. Beautifully printed. 1 vol., $12 \mathrm{mo}$. Cloth, $\$ 1.75$.

\section{THE ORIGIN OF THE STARS,}

And the Causes of their Motions and their Light. By JaCOB ENNIS, Principal of the Scientific and Classical Institute, Philadelphị. 1 vol., $12 \mathrm{mo}$. Cloth. Price, $\$ 2.25$.

\section{HALF HINTS.}

Table D'Hôte and Drawing-Room. 1 vol., 12mo. Cloth, \$1.25.

\section{THE DAUGHTER OF AN EMPRESS.}

An Historical Novel. By LOUISA MÜHLBACH. Translated by NAthaniel Greene. 1 vol., 8vo. Mlustrated. Paper covers, $\$ 1.50$; Cloth, $\$ 2.00$.

\section{IRON MANUFACTURE OF GREAT BRITAIN,}

Theoretically and practically considered, including descriptive details of the Ores, Fuels, and Fluxes employed, the preliminary operation of Calcination, the Blast, Refining, the Puddling Furnaces, Engines and Machinery, and the various processes in union, etc., etc. By W. TRURAN. Second Edition. Revised from the Manuscripts of the late Mr. TRURAN by J. ARthUr Philitrs, author of "A Manual of Metallurgy," and William H. Dorman, C. E. 1 vol., large 8vo. Illustrated with 84 Plates. Price, $\$ 10$.

\section{A COMPREHENSIVE DICTIONARY OF THE BIBLE.}

Mainly abridged from Dr. WM. SMITH'S Dictionary of the Bible. With important Additions and Improvements, and 500 Illustrations. Price of each Number, in a neat paper cover, Thirty Cents.

\section{THE COMBINED SPANISH METHOD.}

A New, Practical, and Theoretical System of Learning the Castilian Language, embracing the most advantageous features of the Best Known Methods. With a Pronouncing Vocabulary, containing all the Words used in the course of the work, and References to the Lessons in which each one is explained, thus enabling any one to be his own instructor. By ALBERT DE TORNOS. 1 vol., $12 \mathrm{mo}, 470$ pages. Price, $\$ 2.00$. 
D. APPLETON \& CO'S PUBLICATIONS.

\section{THE NEW FRENCH MANUAL.}

A New, Simple, Concise, and Easy Method of acquiring a Conversational Knowledge of the French Language, including a Dictionary of over Ten Thousand Words. By M. ALFRED HAVET. 1 vol., $12 \mathrm{mo}, 332$ pages. Half bound, $\$ 1.75$.

\section{THE ANNUAI CYCLOP EDIA.}

Commenced in 1861. Six volumes now out. The same price per volume, and uniform with the New American Cyclopædia. One volume. Published annually. Registering all the important events of each year-valuable as a work of reference. Price and style of binding: In extra cloth, per vol., $\$ 5.00$; in library leather, $\$ 6.00$; in half turkey morocco, $\$ 6.50$; in half russia, extra gilt, $\$ 7.50$; in full morocco antique, gilt edges, $\$ 9.00$; in full russia, $\$ 9.00$.

\section{THE HOUSEHOLD BOOK OF POETRY.}

Collected and Edited by CHARLES A, DANA. Eleventh Edition. Revised and Enlarged. 1 vol., royal 8vo, half bound, gilt top, $\$ 7$; half calf extra, $\$ 9$; morocco antique, $\$ 10$. Elegant Mlustrated edition, roval 8 vo.

\section{IOUISA OF PRUSSIA AND HER TIMES.}

An Historical Novel. By L. MÜHLBACH, 1-vol,, 8ं். Illustrated. Paper covers, $\$ 1.50$; cloth, $\$ 2.00$.

\section{MARIE ANTOINETTE AND HER SON.}

An Historical Novel. By L. MÜHLBACH. Trans ated by Rev. W. L. GAGE. 1 vol., 8vo. Containing eight Mlustrations. Paper covers, $\$ 1: 50$; cloth, $\$ 2.00$.

\section{APPLETONS' HAND-BOOKS :}

HAND-BOOK OF TRAVEL THROUGHOUT THE UNITED STATES AND CANADAS.

1 vol., $12 \mathrm{mo}$, with Maps. $\$ 4.00$.

HAND-BOOK OF NORTHERN TRAVEL. $\$ 3.00$.

FAND-BOOK OF SOUTHERN TRAVEL, $\$ 2.00$.

\section{CHRISTIANITY AND ITS CONFLICTS,}

ANcrent ANd Modern. By E. E. MARCY, A. M. 1 vol., 12mo. $\$ 2.00$.

\section{THE ROMANCE OF THE AGE;}

or, The Discovery of Gold in California, By EDWARD E. DUNBaR. 1 vol., 12mo. Illustrated. $\$ 1.25$. 





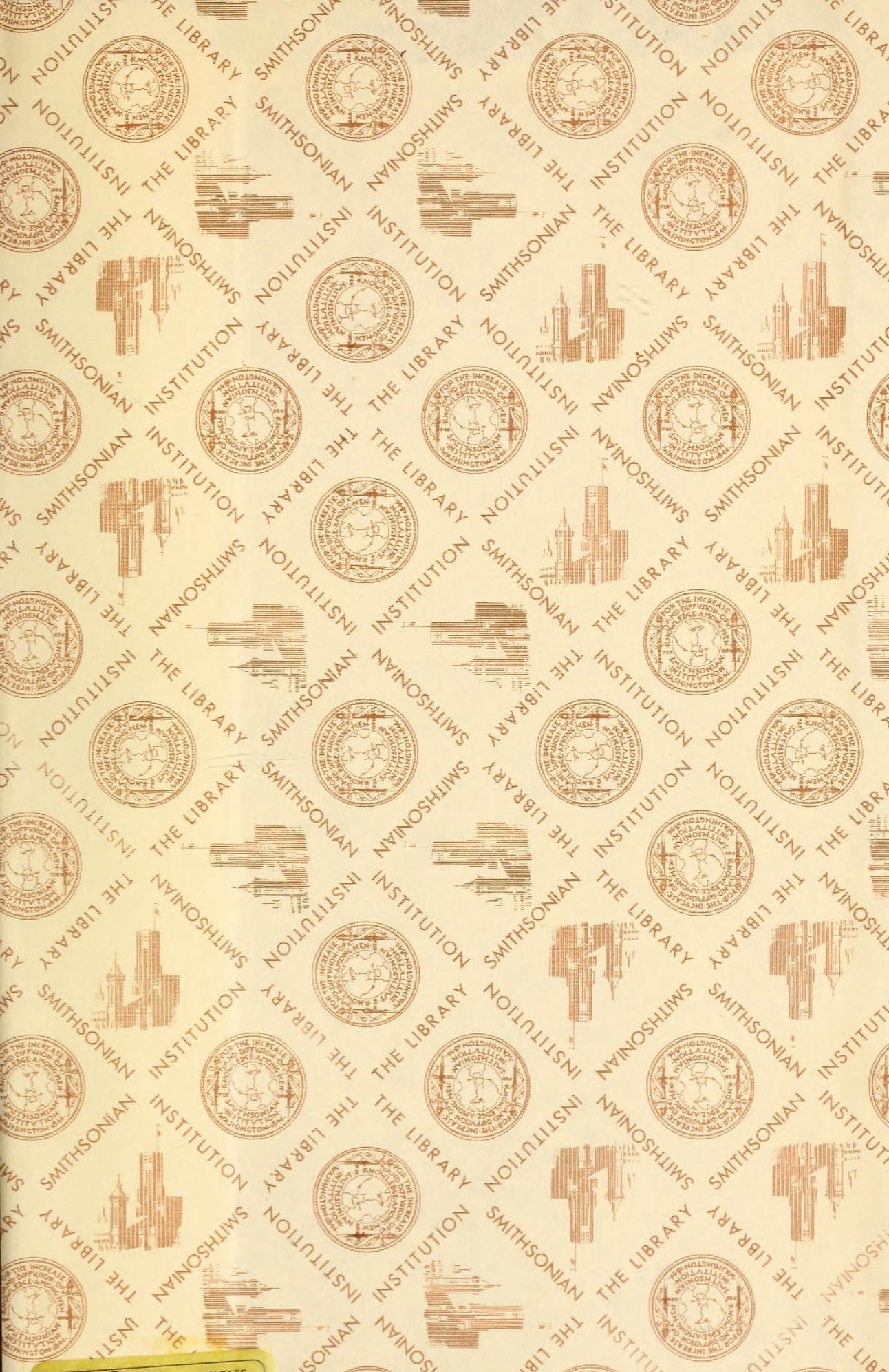


